3. 35 18

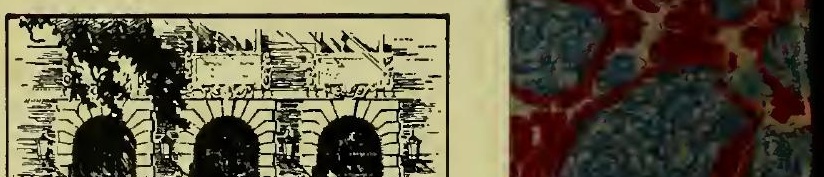

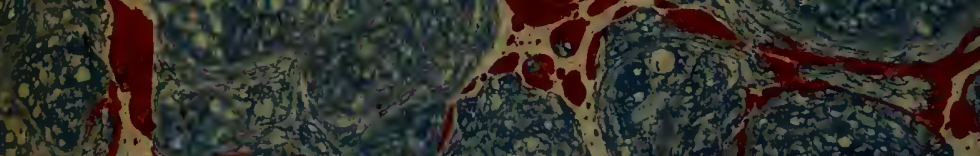

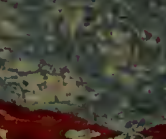

ints 1 ?

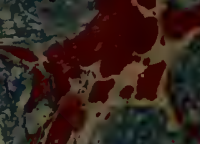

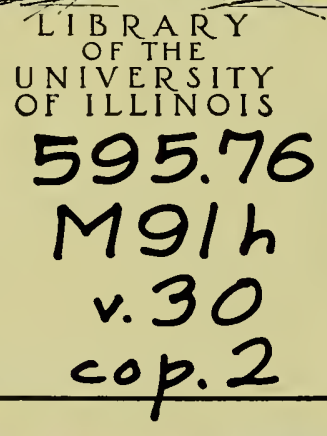

BIOLOGY

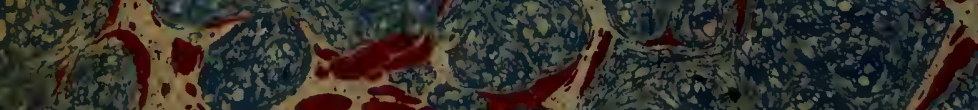

$10^{3}$ -

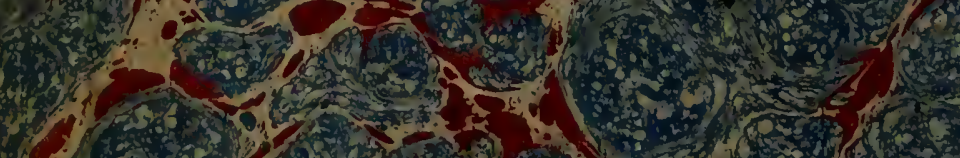

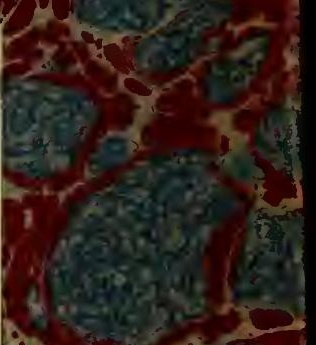

.

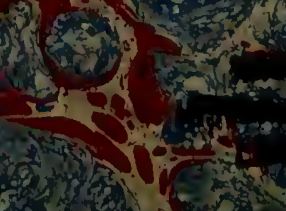






$x$ ate Sy

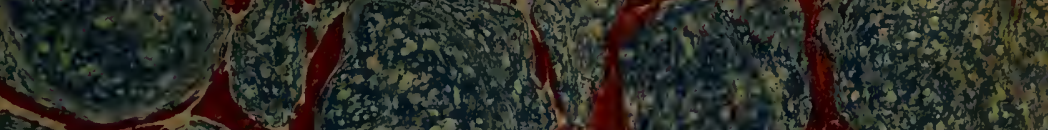

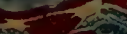

(3) (3)

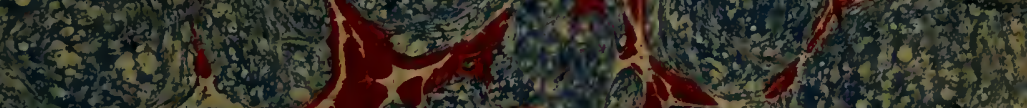
3.

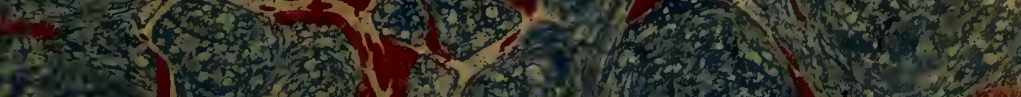
to $x=-10+2$

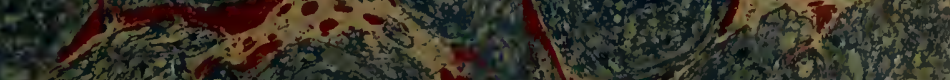


Digitized by the Internet Archive in 2011 with funding from University of Illinois Urbana-Champaign 
by

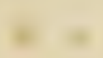

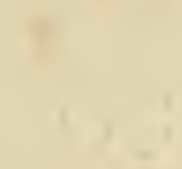

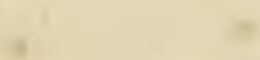

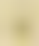

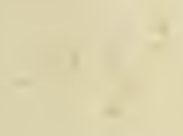

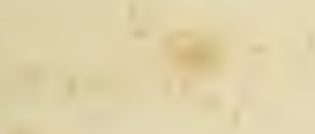

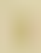

$\cdot$

*

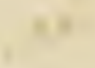

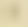

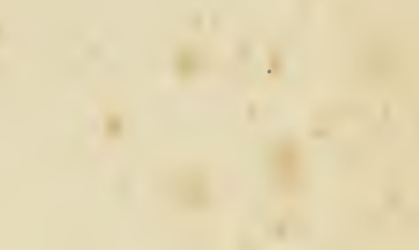<smiles>CCCCC</smiles>

(n)

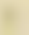

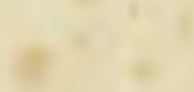

4
.

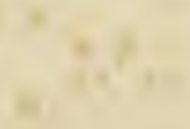

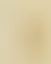





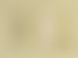

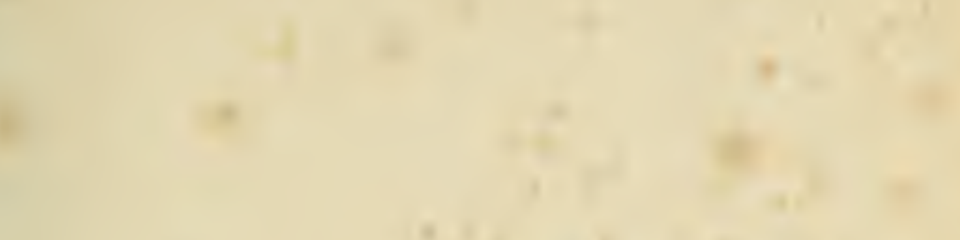

+

$+2+2$

.

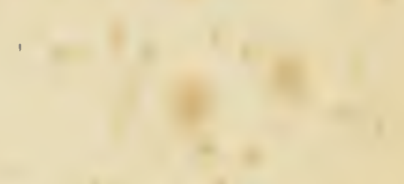$$
\text { (n) }
$$

+

(n)

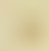

$$
\begin{aligned}
& \text { (2) }
\end{aligned}
$$

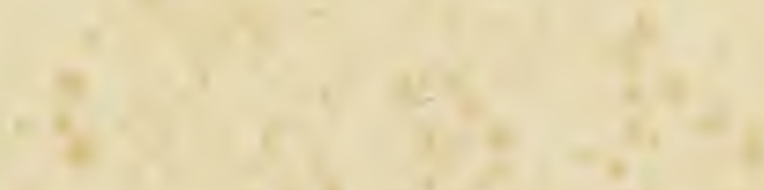

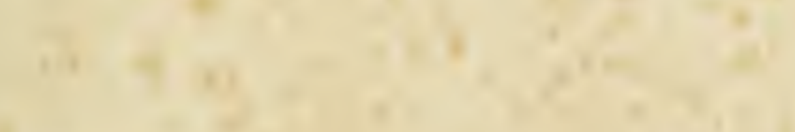

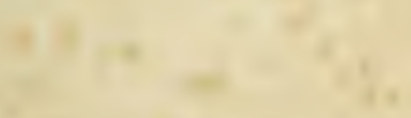

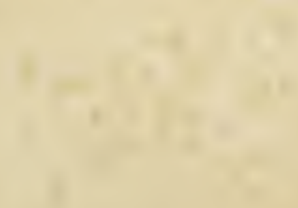



HISTOIRE IATCRELLE

\section{DES \\ COLÉOPTÈRS}

DE FRANCE 


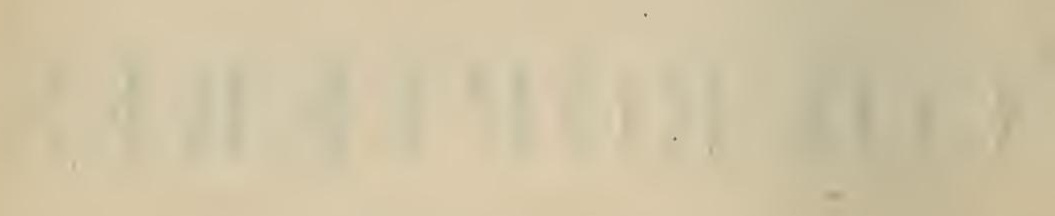




\title{
A IONSIEUR
}

\section{A B EILLE DE PERR I N}

\author{
UEMBRE DE R.A SOCIÉTÉ ENTOMOLOGIQUE DE FRANGE \\ ETC.. ETC.
}

\section{Monsicur.}

Vos travaux consciencieux sur diverses parties de l'Entomologie vous ont fait, depuis longtemps, un nom glorieux parmi les amis de cette science.

Vous êtes le dénicheur le plus intrépide des insectes amis des cavernes, et les grottes les plus obscures et les plus profondes n'ont pu vous cacher les Coléoptères aveugles qu'elles recèlen'. 
moins saillantes. Palpes maxillaires de 4 articles, le dernier souvent petit ou subulé. Palpes labiaux courts, ordinairement de 3 articles, quelquefois de 2, rarement comme inarticulés. Mâchoires à 2 lobes plus ou moins membraneux, l'ex'erne le plus souvent bifide, cilié ou lacinié intérieurement ou vers le sommet. Languette membraneuse, rarement cornée. Paraglosses souvent distinctes. Menton presque toujours corné, en trapèze généralement transverse. Yeux la plupart du temps apparents (1). Antennes tantôt filiformes, tantôt plus ou moins épaissies ou parfois en massue vers leur extrémilé ; ordinairement de 11 articles, rarement de 10 ou de 9. Prothorax très -variable dans sa forme. Abdomen avec les 2 premiers segments rudimentaires et le plus souvent cachés : celui de l'armure parfois enfoui, parfois apparent. Hanches généralement grandes ou assez grandes, affectant diverses formes et dispositions. Pieds rarement courts. Tarses variant quant au nombre de leurs arlicles.

Ons. La tribu dont ions entreprenons l'étude est la plus ardue et en mème temps une des plus naturelles de l'ordre des Coléoptères.

Eile se distingue de toute autre par la brièveté de ses élytres, ce qui lui a valu la dénomination de Brévipennes, déjà indiquée par quelques naturalistes, et qui n'est autre chose que la traduction à étymologie latine du nom de Brachélytres imposé par Lalreille (Règn. anim. Cuvier, I, p. 179), et de celui de Microptères, donné par Gravenhorst (Mon. Micr.) a la famille des Staphylinides ou Stapleyliniens de la plupart des auteurs.

Quoique bien tranchée et reconnaissable au premier coup d'œil, cette tribu ne laisse pas d'offrir qucl jue affinité avec plusieurs autres. Ainsi, par exemple, les Autalia et les Falagria ressemblent un peu aux Psélaphiens qui ont également l'abdomen entièrement découvert, mais avec les segments de celui-ci immobiles et seulement au nombre de cinq. Les Hypocyptus simulent assez bien le genre Scaphisoma. Les Conurus, les Tachyporils, les Olophrum, etc. se rapprochent un peu, par le fucies, de certains Silphides ct surtout des Catops et des Agyrtes. Les Olisthaerus et les Prognata présentent quelque analogie avac les Laemophlaeus, nonseulement quant à leur forme, mais aussi relativement à leurs mœurs

(1) Nous noterons, en passant, que quelques Brévipennes hypogées, la plupart étrangers à la France, sont dépourvus d'yeux : tels sont les genres Glyptomerus, Müller, Cylindrogaster, Perris, Anillosthetus, Saulcy, Thermocharis, Fauvel, Leptotyphlus, Fauvel, etc. 
xylophages. Les Glyptoma ont l'aspect d'un Monotoma ou encore de quelque Térédile ou Colydite. Les Lesteva, les Anthoplıagus et surtout les Trigonurus donnent un air de famille avec certains Carabiques, les deux premiers avecles Dromies, le dernier avec les Argutors. Les genres Anthobium, Proteinus, Megarthrus et Phloeobium nous rappellent la forme et parfois les habitudes de quelques-uns de nos Nitiduliens, tels que les Brachyptères, les Epurcées et les Méligèthes. Mais celui de tous les genres de Brévipennes qui se rapproche le plus des Clavicornes que nous venons de citer, est sans contredit le genre Micropeplus, qui a figuré longtemps parmi eux dans les anciens catalogues.

\section{Étude des Parties extérIEURES DU CORPS}

Le Corps, malgré les affinités qui lient entre eux tous nos Brévipennes, affecte dans sa forme des modifications diverses et notables. Il est le plus souvent allongé, linéaire ou sublinéaire, tantôt convexe ou subdéprimé, lantôt plan ou tout à fait déprimé (Hygronoma, Achenium, Prognatha, quelques Homalotates, etc.). Chez les Stènes, chez les Glyptomes et quelques Blédies, il est épais, cylindrique ou subcylindrique. Chez d'autres, il est court et plus ou moins ramassé, ainsi qu'on en trouve l'exemple dans les Gyrophénates, les Hypocyptes, les Syntomies, les Anthobies, les Proteiniens et les Micropéplides. Chez ces derniers, chez les Syntomies et quelques autres, il est en même temps plus ou moins épais. Quand il est allongé ou oblong, il n'est pas toujours linéaire ou parallèle sur ses côtés, nais il est aussi fusiforme ou plus ou moins rétréci aux deux extrémités, tels que dans les genres Oxypoda, Trigonurus, Pseudopsis, Phloeocharis, etc., et dans la plupart des Tachiniens. La surface du corps est tantôt lisse ou tantôt ponctuée, tantôt pubescente ou sétosellée ou tantôt glabre (Oxyporus); mais, par une exception unique et remarquable (Pholidus), elle est recouverte d'une cuirasse composée d'écailles déprimées. Rarement, elle est chargée sur toute sa longueur (Psendopsis) de côtes longitudinales saillantes qui, d'autres fois, ne surmontent qu'un ou deux des grands segments qui composent le corps.

La Tête, plus ou moins grande, plus ou moins large, plus ou moins saillante, est presque toujours visible, vue de dessus. Elle est parfois fortement resserrée en arrière et portée sur un cou plus ou moins grêle(Aulalia, Falagria, Xantholinus, Stilicus, etc.) ; d'autres fois, au contraire, nulle- 
ment étranglée à sa base, elle est plus ou moins engagée ou enfoncée dans le prothorax, comme cela peut se voir chez les Gymnusaires, les Aléocharaires, les Oxypodes, les Tachiniens, etc., et, dans ce dernier caś, elle est souvent un peu saillante et d'autres fois plus ou moins infléchie, comme on le remarque dans le genre Aleochara. Tantôt moins, tantôt plus, tantót aussi large que le prothorax, la tête est parfois obtuse, parfois angulée ou même prolongée en rostre à sa partie antérieure.

Le Front est toujours plus ou moins large, plus ou moins convexe, plus ou moins déprimé, avec son milieu parfois noté d'une petite fossette ou d'un petit sillon longitudinal, ou même, chez quelques mâles, d'une impression ou excavation plus ou moins prononcée et plus ou moins étendue. En outre, son bord antérieur est quelquefois armé, chez le sexe masculin, de fortes dents (Bledius) ou de simples épines (Platystethus, Prognata et quelques Anthophagus). Sa surface est parfois très-inégale (Pholidus) ou fovéolée-réticulée (Micropeplus), ou mème chargée de côtes longitudinales irrégulières (Glyptoma). Chez la plupart des Oxytéliens, elle offre deux sillons longitudinaux, situés un de chaque côté, près et un peu en dedans de l'insertion des antennes, et réunis quelquefois en arrière (Platystethus) par une ligne enfoncée transversale. D'autres fois ces mêmes sillons, au lieu de s'étendre en arrière, n'existeut qu'en avant, comme dans les Xantholins, par exemple. Plus rarement, ils se transforment. s'oblitèrent ou se réduisent à une fossetle arrondie, située près du bord antérieur (Prognatha). A ant de passer à un autre organe, on ne doit pas oublier de rappeler que le front ou du moins sa partie postérieure ou vertex devient quelquefois le siége d'ocelles, au nombre d'un seul chez les Phléobies, et de 2 , disposés sur une ligne transversale, chez les Omaliens. Très-rarement, ce même vertex offre en arrière un rebord fin le long de sa base; d'autres fois, il est plus ou moins sillonné sur sa ligne médiane, ce qui le fait parfois paraître comme échancré postérieurement.

Les Joues, situées sur les côtés de la tête au devant des yeux, sont presque insignifiantes et ne méritent pas même une mention spéciale, envahies, pour la plupart du temps, par la fossette antenriaire ou refoulées par la base des mandibules qui, souvent, prennent naissance presque contre le bord antérieur des yeux. 'Toutefois (Staphyliniens), elles présentent rarement, en dehors et en devant du bord antéro-externe des yeux, une surface assez sensible, transversale, subinfléchie ou subverticale, parfois gibbeuse, et séparée ell arrière, des tempes, par une fine suture oblique (Emus, Creophilus, etc.). 
Il n'en est pas de même des Tempes qui prennent quelquefois, derrière les yeux, un développoment dautant plus considérable que ceux-ci sont plus éloignés du bord antérizur du prothorax. Elles touchent en dessus au vertex et retourneat toujours en dessous, où clles sont séparées par un intervalle quelquefois assez large, d'autres fois plus ou moins étroit, ou parallèle, ou évasé seulement en avant, ou étranglé dans son milieu et élargi en avant et en arrière ; et même il arrive souvent qu'elles se réunissent inférieurement, au point d'annihiler presque complétement les pièces basilaire et prébasilaire (certains Pédériens et Oxytéliens, etc,), qui se trouvent alors représentẻcs par une suture fine (Stilicus, Sinius, etc.) ou une ligne enfoncée. Mais, dans d'autres cas, elles ne se touchent en dessous que dans leur milieu ou après celui-ci(Philonthus, quelques Omaliens, etc.), ou seulement à leur base (Othius, Stenus, etc.). Généralement chez les Omaliens, elles sont chacune en dessous individuellement convexes et comme mamelonnées. Enfin, elles sont ou rebordées, ou simples sur leurs côtés

L'Épistome, tantôt soudé au front et confondu avec lui, tantôt séparé. de celui-ci par une suture plus ou moins prononcée, rectiligne, arquée ou angulée, se trouve quelquefois sur un plan inférieur à celui de la partie antérieure de la tête. Généralement convexe ou subconvexe, surtout dans le sens de sa longueur, il est souvent rétréci dans son milieu par le plus ou moins grand développement des fossettes antennaires, qui empiètent alors tant sur sa surface que sur celle des joues. Son bord antérieur, généralement tronqué. se lie parfois au labre au moyen d'une lisière membraneuse ou submembraneuse et plus ou moins rétractile ; d'autres fois, il est obtusément arrondi, comme dans plusieurs Oxytéliens, Omaliens, Proteiniens, etc., et même un peu rebordé (Glyptoma), et, par une singularité remarquable, dans le genre Phloeobinm ce même bord antéricur se relève en forme de chaperon largement échancré.

Le Labre parait jouer un rôle plus important que les autres organes que nous venons de décrire et peut servir de caractère accessoire pour la délimitation des genres. Le plus souvent transverse, il s'allonge davantage chez les Myllènes, chez quelques Bolitobies et surtout chez les Pronomées où la partie antérieure de la tête semble alors se prolonger en manière de rostre, en même temps que les autres parties buccales. Au contraire, chez les Stiliques et chez les Sténides, il atteint en largeur un tel développement qu'il recouvre presque entièrement tous les autres organes de la mastication. Entier ou simplement sinué ì son bord apical dans la plupart des Aléchariens el des Tachiniens, il offre d'autres fois deux lub)ss distincts, 
lesquels sont arrondis dans les Staphylins, les Ocypes, les Philonthes, les Scimbalies, etc. ; aigus et divergents dans les Oxypores, assez courts et subdivergents dans les Lathrobies, allongés et subdivergents dans les Achénies; avec leur sommet généralement garni de longs cils mélangés parfois de soies assez raides et subspiniformes. Quelquefois, au lieu d'ètre bilobé, le labre présente, au milieu de son bord antérieur une échancrure plus ou moins profonde, limitée, de chaque côté, soil par une dent obtuse mais distincte (Dolicaon), soit par une dent saillante et aiguë ou même subspiniforme (Lithocharis, Scopaeus, Stilicus, Sunius). Très-rarement membraneux ou submembraneux (Tanygnathus), le labre est le plus souvent entièrement de consistance cornée; mais quelquefois il offre une bordure membraneuse ou submembraneuse plus ou moins distincte qui occupe tout son bord antérieur, comme dans la plupart des Staphyliniens, les Phléochares, les Micralymmes, quelques Omaliens, etc., ou seulement les côtés, comme dans les Xantholins, les Stiliques, etc. Tandis que les membranes dont nous venons de parler se réduisent la plupart du temps à une espèce de bordure, il est nécessaire ici de fuire remarquer que dans les Oxytéliens, ou du moins dans le plus grand nombre des genres qui composent cette famille, ces mêmes membranes affectent la forme de lobes plus ou moins triangulaires, ou même de lanières plus ou moins allongées et acuminées, et dont l'intervalle est densement cilié. Dans d'autres cas, la membrane terminale est seulement échancrée dans son milieu, au point de représenter de chaque côté comme un lobe plus ou moins court (Arpedium, Deliphrum, Olophrum, Omalium, Proteinus, Phloeobium). Enfin, nous terminerons cet article en indiquant que le labre est quelquefois peu apparent et caché en dessus par l'épistome, principalement quand celui-ci est avancé en forme de chaperon comme chez les Phléobies, ou de pointe comme chez certains Jicropeples.

Quoique les Mandibules, toujours cornées, généralement peu saillantes, ne présentent pas beaucoup de valeur comme base de classification, elles subissent cependant des nodifications servant à corroborer les caractères de certains genres. Ainsi, par exemple, ordinairement peu développées, arquées et simples, soit à leur sommet, soit à leur bord interne, chez la plupart des Aléochariens, chez les Tachiniens, les Astrapées, les Syntomies, les Micralymmes, les Anthobies, la plupart des Proteiniens, etc. elles sont d'autres fois bifides ou bidentées à leur pointe (Schistoglossa, Dasyglossa, Nicropeplus, etc.). Dans plusieurs autres cas, inermes à lenr extrémité, elles sont plus on moins grêles, saillantes, falciformes (Planeus- 
tomus, quelques Ocypus, etc.), ou bien assez robustes, proéminentes (Oxyporus) et croisées seulement près de leur sommet. Quant aux armures dont les mandibul's sont souvent munies, nous dirons qu'elles offrent dans bien des cas, vers le milieu ou après le milieu de leur bord interne une dent plus ou moins obtuse, plus ou moins sensible (Platystethus, Oxytelus, Bledius, Coprophilus, Phloeocharis, la plupart des Staphyliniens, etc.), $\mathrm{l}_{\mathrm{aquelle}}$ dent devient quelquefois très-saillante et très aiguë (Cryptobium, Dolicaon, Achenium, Lathrobium, Evaestethus, etc.) et même grêle ou subspiniforme (Sunius), ou rarement bifide (Paederus). D'autres fois ces dents sont au nombre de 2 (Anthophagns, Geodromicus) et même de 3 ou de 4 (Scimbalium, Lithocharis, Scopaeus, Stilicus), et d'ailleurs, quel que soit leur nombre, les mandibules peuvent être à la fois falciformes (Sunius). De plus, dans ce dernier genre (Sunius), outre la dent du milieu, on remarque intérieurement, vers la base, deux ou trois petites dentelures, et nous ferons observer en passant que les dents terminales peuvent même exister indépendamment de celles du bord interne, ainsi que l'atteste le genre Trogophloeus. Il existe une particularité qui concerne les mandibules, c'est de présenter quelquefois vers la base de leur bord interne une espèce de lobe membraneux plus ou moins distinct et du reste sans importance, ainsi qu'on peut le remarquer chez certains Staphyliniens, Pédériens et Oxytéliens. Par une exception unique (Phloecbium) le bord externe des mandibules est lui-même garni d'une espèce de membrane terminée antérieurement par un petit pinceau de poils libre et qui dépasse un peu la pointe de la mandibule. Nous ne pouvons terminer la définition de ces mêmes organes sans altirer l'attention sur une singularité remarquable, c'est que les mandibules ne sont pas toujours toutes les deux identiques. Ainsi, par exemple, dans le genre Eugnatuis, elles sont fortement croisées au bout, mais la droite est falciforme et la gauche coudée en dedans vers le sommet, et d'autres fois, au contraire, c'est la droite qui est coudée (Pseudopsis). Dans plusieurs genres de la famille des Omaliens (Arpedium, Acidota, Deliphrum, Omalium, etc.) ainsi que dans le genre Deleaster, la mandibule gauche est simple et la droite munie à son bord interne d'une petite dent plus ou moins obsolète. D'autres fois, elles sont chacune armées d'une forte dent, mais celle-ci est située plus près du sommet dans l'une que dans l'autre. Enfin, dans le genre Prognatha, les différences deviennent sexuelles, c'est-à-dire que les mandibules sont simples ou presque simples chez les femelles et armées extérieurement et en dessus chez les mâles, d'une corne subhorizontale arquée en faux, plus longue que, 
la mandibule et simulant celle-ci qui est peu saillante. Dans quelques Anthophages, c'est au contraire la pointe terminale des mandibules cqui se redresse elle-même plus ou moins en l'air, chez les mâles, au point de simuler une corne. Quant à leur côté externe, il est souvent sillonné, au moins vers la base, comme dans les Staphyliniens.

Nous ne nous étendrons guère sur les Mâchoires qui ne nous seront d'aucun secours, vu la difficulté de leur examen. Nous nous bornerons seulement à constater qu'elles sont composées de 2 lobes, dont l'interne est généralement plus court que l'externe, qui est quelquefois comme bifide. Plus ou moins membraneux (l'interne surtout), tantôt libres, tantôt accolés, ces lobes sont le plus souvent tous deux garnis, ou vers leur sommet ou le long de leur bord intérieur, de poils ou de cils plus ou moins serrés qui se changent quelquefois, surtout an lobe interne, en épines (Platystethus) ou en dents de scie(Gymnusaires). L'externe, souvent beaucoup plus long que l'interne, est parfois plus ou moins élargi vers son extrémité (Lathrimaeum, Phloeobium, etc.) Il est lui-même rarement terminé par un crochet corné, tandis que l'interne en est presque toujours pourvu. En outre, tanlôt tous deux épais, tantôt d'épaisseur inégale, ils sont parfois tous deux très-grêles, ainsi que les Gymnusaires nous en offrent l'exemple. Avant d'en finir avec les mâchoires, nous pourrons faire observer un caractère plus facile à distinguer que leur structure elle-même, c'est que leur tige forme souvent à sa base un angle plus ou moins prononcé et méme quelquefois rectanguiaire, ce que l'on peut remarquer surtout chez les Aléochariens et chez les Omaliens.

Les Palpes maxillaires, auxquels on a accordé une trop grande imporlance comme base de classification, ne doivent jouer sclon nous qu'un rôle secondaire (1). lls sont insérés sur le côlé externe de la tige des mâchoires. Ils sont tous évidemment de 4 articles, avec le 1 er très-court ou presque rudimentaire; excepté toutefois chez les Sténides oùil est allongé et grêle.

(1) On nous dira que les formes des grands segments du corps sont trop variables pour pouvoir servir à asseoir une classification. Nous répondrons que les caractères tirés des palpes ne reposent le plus sourent aussi que sur la forme respective de leurs différentes pièces ct n'offrent par conséquent pas plus de constance. Ajoutez à cela que les organes de la bouche sont souvent de consistance molle et à la fois d'une exiguité qui échappe la plupart du temps à l'examen. D'après ces considerations, on peut dowe conclure qu'il vaut mieux prendre pour point de départ un caractère tiré d'un grand organe, qui a trait à la vie de relation et auquel on adjoint d'antres signes secondaires, quie de se placer. suus le point de vuc exclusif d'un petit organe le plus souvent de uature tuembianeuse et qui a rapport sculement a la vie de nutrition. 
Le $2^{c}$ est toujours plus grand que le $1^{\mathrm{er}}$, souvent arqué et en massue plus ou moins allongée. Le 3 , graduellement épaissi de la base à son extrémité, ou subcylindrique, ou même parfois fusiforme (Gymnusa), est tantôt plus, tantôt moins long que le précédent et quelquefois même très-court relativement à celui-ci, ainsi qu'on peut le constater dans les genres Prognatha, Micralymma, Glyptoma, quelques Omaliens et Proteiniens, les Micropeplides, etc. Il varie, en outre, dans son volume transversal; ainsi, par exemple, généralement épaissi vers son extrémité en massue plus ou moins graduée, il est parfois fortement renflé en ovale court (Callicerus).

Considérés dans leur ensemble, les Palpes maxillaires sont en général filiformes ou légèrement épaissis vers leur sommet. Quelquefois courts et un peu épais, d'autres fois assez développés, ils se montrent dans d'autres circonstances très-allongés et grêles (Diglossaires, Gymnusaires, Sténides, Pronomaea). Mais leur aspect général subit parfois, surtout dans leur extrémité, de grandes modifications, suivant la forme et le volume qu'affecte l'article terminal. En effet, celui-ci joue un rôle assez important par les différentes variations qu'il nous présente. Il est subulé ou en alène dans tous les Aléchariens, plusieurs Tachiniens, les Pédériens, les genres Leptacinus et Heterothops, la plupart des Oxytéliens, etc. Il devient même d'autres fois si petit qu'on a de la peine à le distinguer, quelques Gymnusaires, les genres Stilicus et Sunius, le's Sténides, etc., et tout en se montrant subulé, il peut être plus ou moins grêle, plus ou moins atténué, sauf quelques cas rares (Dolicaon, Paederus) où il est court, assez épais et obtus. Par une exception singulière (Aleochara, Baryodma), ce même article terminal subulé cffre à son sommet un petit lobe urliculé, parfois à peine distinct. Toutes les fois qu'il esı subulé, le quatrième article des palpes maxillaires est plus court ou même beaucoup plus court que celui qui le précede; mais, dans les autres cas, il est parfois aussi long, plus long ou mème beaucoup plus long que le troisième, et il est alors ou conique ou faiblement atténué vers son sommet, ou fusiforme ou linéaire, tantôt acuminé, tantôt mousse ou tronqué au bout (Deliphrum, etc.), quelquefois même subsécuriforme ou sécuriforme (Astrapaeus). Enfin, il est à noter que les $2 \mathrm{e}$ et $3^{\mathrm{e}}$ articles des palpes maxillaires portent généralement quelques poils ou cils à leur sommet; d'autres fois, le pénultième est sẹul entièrcment cilié ou poilu; quelquefois même les $2 \mathrm{e}$ et 3̉e participent à la fois à ce. caractère et rarement les trois derniers. 
La Languette est d'une si minime importance qu'il est presque inutile d'insister sur son étude. Nous ferons seulement remarquer qu'elle est le plus souvent membraneuse, rarement cornée. Elle est étroite, linéaire, le plus souvent bifide, allongée chez la plupart des Aléochariens; petite et courte chez la plupart des Staphyliniens; d'autres fois large, rarement tronquée au bout, mais le plus souvent échancrée ou même profondément incisée, ce qui la fait paraitre comme bilobée ainsi que dans plusieurs Pédériens, et elle paraît même aigument tridentée dans le genre Scopaeus. N'oublions pas, en parlant de la languette, de signaler la faculté particulière dont elle jouit chez les Stènes, de se retirer et de s'allonger d'une manière notable au moyen d'une membrane rétractile qui lie le menton à l'hypoglotte; elle simule alors une espèce de trompe à peu près semblable à celle des Diptères (1).

Quant aux Paraglosses, nous nous bornerons à dire qu'elles sont parfois peu distinctes, d'autres fois plus apparentes. Tantôt égales à la languette, tantôt plus courtes que celle-ci, elles la dépassent dans quelques cas d'une manière notable.

Les Palpes labiaux varient quant au nombre de leurs articles qui est généralement de $\delta$ et plusieurs fois de 2 (Autalia, Silusa, Placusa. Gyrophaena, Pronomaea, Diglossa, Myllaena, Trichophya, etc.). Ils sont généralement petits et peu développés, subfiliformes ou avec leurs articles graduellement un peu moins épais (Aléochariens). Du reste, ceux-ci varient dans leur forme et leurs proportions relatives autant que ceux des palpes marillaires. Cependant, celui du milieu est presque toujours plus court que les autrcs, mais dans le genre Evaesthetus, il est beaucoup plus long, tandis que le dernier est ici presque imperceptible. Celui-ci est aussi bien inconstant dans sa forme. Très-souvent subulé, conique ou fusiforme, il est parfois plus ou moins en fer de hache ainsi qu'on peut l'observer chez certains Ocypus, les genres Astrapaeus, Euryporus, etc., ou même en forme de croissant ou demi-lune comme dans le genre Oxyporus. Dans quelques autres, au contraire, les palpes labiaux comme inarticulés ou composés de 2 articles très-fortement soudés (Silusa, Pronomaea, Diglossa, Gymnusaires) sort très-allongés, très-grêles et presque sétiformes ou tout à fait sétiformes. Enfin, dans les Aléochares et Baryodmes,

(1) Voyez à ce sujet : Description des organes de la manducation chez les Stènes, par le Dr Thirion, d'Orléans (Ann. Soc. Ent. Fr. IV, 1835, p. 153), oll plutGt Jacquelin du Val (Staphylinides, p. 52, note 2), etc. 
l'article terminal, comme dans les maxillaires, présente à son extrémité un petit lobe articulé.

Le Menton n'est pas très-variable darns sa forme. Il est ordinairement grand, corné ou rarement avec une légère membrane à son bord antérieur ; transverse ou trapéziforme, rarement triangulaire, tronqué ou bien trèsrarement à peine arrondi à son sommet; d'autrefois échancré ou même profondément (Pronomaea, Myiloena) incisé à celui-ci. Tantôt plan, tantôt à peine convexe, il est exceptionnellement longitudinalement carinulé sur son disque (Stenus), avec la carène formant une pointe avancée dans le milieu du bord antérieur. Les pièces basilaire et prébasilaire, le plus souvent très-distinctes, sont parfois plus ou moins réduites par le développement des tempes qui se retournent plus ou moins fortement en dessous ainsi que nous l'avons déjà dit.

Les Yeux sont situés sur les côtés de la tête, tantôt loin (Xantholiniens, Pédériens, .etc.) du bord antérieur du prothorax, tantôt à une passable ou à une légère distance de celui-ci, auquel ils touchent ou paraissent toucher quelquefois (Aleochara, Oxypoda, Gymnusaires, etc.). Leur forme est généralement arrondie, subarrondie, subovalairement arrondie ou ovalaire, avec le bord postérieur parfois un peu plus aplati. Quelquefois très-grands, ordinairement de grandeur médiocre et peu saillants, ils sont, dans certains cas, gros et très-proéminents (Dianoüs, Stenus, etc.) ; dans certains autres, beaucoup moin grands, mais assez saillants (Gyrophaena, Deleaster), la plupart des Omaliens), etc., et entin, dans quelques autres, très-petits ou même obsolètes (Sipalia), mais presque toujours distincts, du moins quant aux espèces françaises connuesjusqu’à ce jour (1). Leur surface, généralement mate, est parfois micacée, souvent glabre, quelquefois légèrement pubescente ou hérissée de quelques poils. Les facettes qui les composent sont le plus souvent petites, subdéprimées et hexagonales, d'autres fois plus grossières (Oxytéliens, ctc.) et presque hémisphériques.

Les Ocelles existent quelquefois, au nombre de 1 (Phlocobium) ou de 2 (Omaliens) situés sur le vertex.

L'étude des Antennes, comme dans la plupart des Cioléoptères, mérite une attention particulière, soit à cause de leur disposition, soit à cause des variations de structure qu'elles peuvent présenter. Elles sont libres, excepté dans le genre Micropeplus où elles sont, à l'état de repos, logées dans urie fossette profonde destinée à les recevoir. Leur mode d'insertion a servi de

(1) Les exceptions sont très-rares (Thermocharis). 
base å Erichson pour établir ses grandes divisions, et malgré les changements qu'on chercherait pour déranger ce système, il nous semble encore un des meilleurs, pour peu qu'on l'accompagne de considérations accessoires. En effet, elles sont insérées tantôt entre les yeux, dans une fossette plus ou moins profonde située vers le bord antéro-interne de ceux-ci (Aléochariens) et destinée à faciliter les mouvements de l'antenne dans sa base; tantôt sur les côtés de la tête, plus (Pédériens) ou moins (Tachiniens, Oxytéliens, Omaliens, etc.) en avant de la ligne idéale tangente au bord antérieur de chaque œil. Quelquefois, elles sont implantées sur le milieu du front (Stenus, Dianoüs), d'autres fois sur le bord antérieur de celui-ci (Staphyliniens), en dedans de la base des mandibules, et, dans ce dernier cas, elles sont ou écartées (Staphyliniens) ou rapprochées entre elles à leur naissance (Xaniholiniens). Dans quelques familles, comme dans les $0 x y$ téliens et les Omaliens, par exemple, le point d'insertion est surmonté en dessus d'une saillie plus ou moins prononcée.

Les Antennes sont composées de 11 articles, quelquefois de 10 (Oligota, Hypocyptus), rarement de 9 (Micropeplus). Très-rarement coudées, elles sont, considérées dans leur ensemble. ordinairement filiformes ou un peu épaissies vers leur extrémité ; parfois elles se terminent par une massue allongée et plus on moins graduée (Hypocyptus, Pseudopsis, quelques Oxytéliens et Omaliens, Dianoïs, etc.) ou oblóngue et plus ou moins brusque (Oligota, Stenus, Evcesthetus, Pholidus, etc.), formée de 3 ou de 4 articles, ou bien, très-rarement, par un bouton court et presque solide (Micropeplus). D'autres fois elles sont grêles (quelques Pédériens, Prognatha) et même capillaires (Trichophya, Habrocentus). Les articles dont elles sont formées, pris isolément, affectent des formes et des dimensions qu'il est bon de signaler. Ainsi, le $1^{\text {er }}$ est généralement grand, plus ou moins allongé, plus ou moins renflé en massue et même rarement très-grand, très-épais et dilaté intérieurement (Pholidus). Les deux suivants, ordinairement un peu moins longs et moins épais que le 1er, sont le plus souvent en cône renversé plus ou moins allongé oll oblong et, en tous cas, presque toujours plus développés que les suivants; cependant, le $3^{\mathrm{e}}$ est parfois notablement plus court que le $2^{\mathrm{e}}$ et à peine plus long que le $4^{\mathrm{e}}$. Celui-ci et ceux qui suivent sont trop variables pour pouvoir être décrits en détail, et nous nous contenterons de dire qu'ils sont souvent subégaux, parfois inégaux, tantôt obconiques ou subcylindriques, tantôt submoniliformes, tantôt allongés ou oblongs, tantôt carrés, taniôt courts et transverses et parfois mềme présque perfoliês. Si les aniè- 
pénultièmes sont généralement un peu plus courts que les autres, il n'en est pas de même du dernier qui est toujours plus développé que le précédent, le plus souvent ovalaire ou oblong, parfois suborbiculaire, d'autres fois conique, tantôt subcylindrique, tantôt fusiforme ou subelliptique et, en tous cas, généralement plus ou moins acuminé au somme', ou même obliquement tronqué ou subéchancré au bout ou intérieurement et submucroné en dessous (Staphylinus, etc.). S'agit-il du développement des antennes, nous nous contenterons de dire qu'elles sont quelquefois à peine plus longues que la tête, souvent un peu moins longues que la tête et le prothorax réunis; que d'autres fois elles atteignent ou dépassent la base de ce dernier, mais que rarement elles sont presque aussi prolongées que le corps (Prognatha).

Les Antennes peuvent fournir non-seulement des caractères génériques, mais encore des caractèr's sexuels, ainsi que nous en fournissent l'exemple le Callicerus obscurus, dont les deux derniers articles șont beaucoup plus allongés dans le $\sigma$ que dans la $\$$; la Baryodma inconspicua, dont le dernier article seul est plus long dans le premier sexe que dans le second; le genre Discerota, chez lequel quelques-uns des articles intermédiaires présentent, du $\sigma^{\prime}$ à la $q$, une conformation toute différente. Dans certains autres cas, les antennes sont un peu plus développées dans le sexe masculin, et par conséquent leurs articles sont à la fois un peu plus longs. Enfin, les antennes, généralement duveteuses ou finement pubescentes, présfntent ordinairement, surtout vers le sommet de chaque article, des poils plus ou moins apparents, plus ou moins longs, souvent géminés, et parfuis même verticillés (Habrocerus, Trichophya), lesquels poils, chez certains mâles (quelques Homalotates), se condensent sur le bord interne

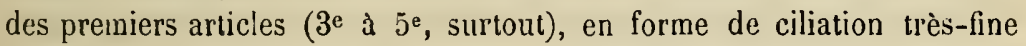
mais plus ou moins longue. Il est bon d'ajouter que l'article terminal est souvent pilosellé sur toute sa surface.

Le Prothorax varie considérablement pour sa forme et dans ses proportions, non-seulement selon les familles, mais encore suivant les différentes coupes et même les différentes espèces du même genre. II serait difficile d'énumèrer toutes les modifications qu'il subit; nous généraliserons, tout en indiquant les conformalions qui nous sembleront particulières et dignes de mention. Il est iantôt carré ou oblong gantôt court ou fortement transverse; d'autres fois subarrondi ou subglobuleus, ou bien encore subcordiforme ou cordiforme (Cardiola, Falagria, Deleaster, etc.). Ordinairement pluṣ étroit, du moins à sa base, que les élytres, il se montre; dans 
plusieur's antres cas, plus large (Homoeusa, Dinarda, Euryusa, etc,), ou aussi large à celle-ci que les mèmes organes (les Gymmusaires, la plupart des Oxypoda el des Tachiniens, Phlococharis, Phloeobium, Micropleplus, etc.) Souvent rétréci dans sa partie postéricure, il est d'autres fois plus ou moins atténué en avant (Tachiniens, Oxypoda, Acylophorus, elc.), el même quelquefois assez. brusquement (Autalia, Stilicus, Sunius, etc.).

Son bord antérieur est tantôt tronqué ou obtusément arrondi, tantôt subéchancré ou èchancré (Tachiniens), ou mème bissinué (Phloeobium). Ses côtés sont plus ou moins arrondis, d'autres fois subrectilignes ou rectilignes (quelques Stapinyliniens, Xantholiniens et Pédériens, etc.), ou rarement flexueux (Ochthephilus, Megarthrus) ou sinueux avec ou sans dent qui limite le sinus. Le plus souvent, ces mêmes côtés sont finement rebordés ou du moins ils présentent une arête plus ou moins distincte qui sépare la page supérieure du repli inférieur, arête parfois tranchante (Dinarda, etc.) ou méme plus ou moins relevée en forme de gouttièrc (Lomechusa, Phlocobium, Micropeplus). D'autres fois, au contraire, ils sont tout à fait mousses ou sans arête, el alors la surface supérieure se confond insensiblement avec le repli inférieur, comme on peut le voir daus le geure Cardiola, dans certains Pédéricns et surtout dans les Stènes où le prothorax est souvent conıme subcylindriquc. Dans les Blédics, ce segment est toujour's assez épais, et chez quelques mâles de certaines espèces de ce genre, il projette, du milieu de son bord antéricur, unc corne plus ou moins saillantc et souvent pubescente à sa pointe. Dans le genre Pholidus, il est dilaté de chaque côté en forme de larges oreillelles, ce qui lui donnc à peu près la forme d'un trèfle très-imparfait.

Ses angles antérieurs, le plus souvent infléchis, sont presque toujours obtus ct peu prononcés; cependant quelquefois ils sout saillants et asse\% aigus, surtout quand le bord antérieur est échancré. Les postérieurs: quoique souvent obtus ou même arrondis, se montrent asscz fréquemment droits ou presque droits, el quelquefois meme ils sont saillants, plus ou moins aigus et plus ou moins prolongés en arrièrc (Lomechusa, Dinarda, etc.).

Le bord postérieur, généralement fimement rebordé, le plus souvent tronqué ou arrondi, est quelquelois subbissinué, principalement lorsque les angles sont marqués ou déjetés en arrière. D'autres fois la base, lout en restant subarrondic dans son ensemble, parait subtronquée ou subsinuée daus son milicu, avec ses cores plus ou moins obliquement coupés. Parfois libre el dégagée, cette méme base vient s’appliquer sou- 
vent sur celle des élytres qu'elle embrasse, pour ainsi dire, dans certains cas (Gymnusaires, la plupart des Tachiniens, etc.), d'une manière étroite.

Eu égard à sa surface, le prothorax est tantòt uni, tantôt creusé dans son milieu d'un sillon longitudinal plus ou moins prononcé, qui se rédnit souvent à une simple fossette basilaire, et qui se transforme d'autres fois en une forte impression ou large excavation, surtout chez le $\sigma$ de ccrtaines espèces (Drusilla, etc.). Rarement, il est marqué à sa base de plusieurs fossettes transversalement disposées (Autalia), et il rappelle ainsi celui des Bryaxis. Dans un cas exceptionnel, chez l'Anthobium robustum ơ, l'excavation du prothorax, ainsi que celle de la tête, est limitée, de chaque côté, par une crête ou saillie comprimée. Rarernent, il est inégal oul mamelonné (Pholidus); dans d'autres circonstances, il est chargé de côtes plus ou moins saillantes, plus ou moins régulières et longitudinales(Glyptoma, Pseudopsis, Micropeplus).

Généralement peu convexe, quelquefois beancoup plus fortement, il se montre, dans d'autres cas, subdéprimé ou inême tout à fait déprimé, comme on peut le voir dans les genres Hygronoma, certains Homalotates et quelques Omaliens. Il est le plus souvent convert d'une ponctuation plus ou moins variable et quelquefois rugueuse, tantôt uniforme, tantôt inégale ou entremêlée d'inlervalles lisses on de cicatrices (certains Bledius, Haploderus, etc.); souvent serrée, parfois très-parcimoniense et même affectant une disposition particulière ou en crosse (certains Xantholinus) ou en séries longitudinales (Gyrophaena, Philonthus). Il est, rarement, lisse ou presque lisse (Oxyporus, Tachyporus, Bolitobius, etc.), ou avec quelques rares points, (Mycetoporus, Quedius, Othins, etc.). Quant à sa pubes cence, elle est de plusieurs natures, tantôt serrée, tantôt parcimonieuse, tantỏt très-fine, tantôt plus grossière, tantôt soyeuse et très-condensée (Emus, etc.), tantôt nulle ou presque nulle (Philonthus, Oxyporus, la plupart des Tachiniens, etc.), ou avec seulement de rares soies redressées, disposées soit sur la surface, soit plıs fráquemment sur les côtés ou mème sur le bord antérieur.

Le Repli du prothorax, tantồ lisse, tantôt ponctué ou rugueux, tantôt plan, tantôt subexcavé, est, ainsi que nous l'avons déjà dit, la plupart du temps séparé de la page supérieure par une arête plus ou moins apparente; mais il varie lui-mẻme aussi dans sa forme, dans son développement et dans sa disposition. En effet, généralement visible quand on examine l'insecte de profil, il est d'autres fois fortement retoüné en dessous (Oxypoda. Alcochara, Baryodma, Gymnasaires, etc.) ou mẻme 
au point de venir se coller au tégument de la surface supérieure (Tachiniens), ce qui le rend le plus souvent invisible, vu de côté et aussi de dessous, et parfois même tout à fait inappréciable. Dans ce dernier cas, il est bon de remarquer qu'en même temps les côtés du prothorax s'abaissent et deviennent plus ou moins tranchants. Ce repli, plus ou moins développé, représente souvent la forme d'un triangle, dont le sommet interne, très-ouvert et plus ou moins émoussé, est appuyé contre ou un peu derrière la base externe des hanches aniérieures (Aléochariens, quelques Staphyliniens, etc.). Tantôt graduellement rétréci (Lathrobium): tantôt subparallèle et assez large (la plupart des Oxytélens et des Omaliens, etc.) dans sa partie antérieure, il se dilate fortement en arrière, derrière les hanches, en forme d'angle plus ou moins prononcé, plus ou moins aigu, au point d'absorber complétement la région des épisternums et des épimères de l'antépectus; et généralement alors il présente en son milieu une échancrure ou sinus plus ou moins profond pour rccevoir la noix des hanches antérieures, ainsi qu'on peut l'observer dans les genres Bledius, Coprophilus, Anthophagus, etc.). Dans le genre Platystethus, il émet antérieurement, au devant des hanches, un liseré étroit et transversal qui longe le bord postéro-inférieur de la tête jusqu'à la rencontre du prosternum ; mais, dans le genre 0xytelus, c'est tout autre chose, car, en ce même endroit, il est très-développé, trapéziforme, à bord interne subrectiligne et subparallèle au bord externe. Chez les Acrognathes et les Ochthéphiles, quoique très-développé, il forme simplement, en dedans, un angle mousse ou subtronqué dont le sommet vient s'appliquer exactement contre le condyle ou base externe des hanches antérieures. $\mathrm{Si}$, comme on vient de le voir, le repli du prothorax est parfois trèsétendu dans son diamètre transversal, il n'en est pas de même dans certains cas (Xantholiniens, quelques Staphyliniens), où il est plus ou moins étroit dans loute sa longueur et borné à un liseré ou atténué à ses deux extrémités (Othius, Xantholinus, etc.), ou subparallèle (Dianoüs) Le plus souvent, son bord interne est parfaitement distinct d'un bout à l'autre, mais, par exception (Deleaster, Stenus), il est effacé et confondu avec les pièces prosternales de l'antépectus. Enfin, négligeant les autres détails relatifs au repli du prothorax, nous ajouterons que, dans le genre Micropeplus, subparallèle dans toute sa longueur, il est longé en dedans par la fosselte oblongue destinée à loger les antennes à l'état de repos et qui l'isole complétement du contact des hanches, et que, dans quelques Stapluyliniens, où il cst assez étroit et subangulé, il projette en arrière des 
hanches antérieures une espèce d'opercule triangulaire, subcorné ou submembraneux, qui recouvre le stigmate prothoracique, et qui, selon Thomson, n'est autre chose que l'épimère de l'antépectus.

L'Écusson, sans importance, ne peut guère être utilisé que pour séparer les espèces. Il est, le plus souvent, de forme triangulaire ou subogival, d'autres fois semicirculaire. Généralement bien distinct, il est souvent petit, et même parfois à peine visible (Stenus, Oxytéliens, etc.), ou recouvert par le bord postérieur du prothorax (Hypocyptus, etc.). Sa surface est tantôt ponctuée ou tantôt lisse, tantôt pubescente ou tantôt glabre. Dans sa sculpture, il n'a rien de saillant, si ce n'est d'offrir très-rarement, sur son milieu (Falagria), deux lignes élevées enclosant un silion longitudinal.

Les Élytres, au contraire, vont nous présenter un intérêt majeur, à cause des modifications nombreuses qui s'opèrent dans leur développement, leurs contours et leur texture. Toujours plus ou moins tronquées au sommet et ne recouvrant jamais en enticr. le dos de l'abdomen, elles sont néanmoins susceptibles de varier infiniment, sous le rapport de leur longueur. Ainsi, par exemple, ou moins longues, ou aussi longues, ou plus longues que le prothorax, le plus souvent elles ne dépassent pas le bord postérieur de la poitrine; quelquefois elles sont plus courtes que celle-ci (Micralymma, quelques Aléochariens, etc.), et, au contraire, dans des cas assez nombreux, elles sont évidemment ou même notablement plus prolongées en arrière que ce même segment, ainsi qu'on peut le remarquer chez beaucoup de Tachiniens, quelques Oxytéliens, la plupart des Omaliens et les Proteiniens. Bien entendu, à mesure qu'elles s'allongent, elles passent successivement de la forme transverse à la forme, ou carrée, ou oblongue ou allongée. Considérées dans leurs contours, nous avons déjà dit qu'elles étaient tronquées à leur sommet ; mais cette troncature n'est pas toujours franche ou rectiligne, et nous dirons même qu'elle l'est rarement, car leur bord apical est souvent plus ou moins sinué ou même incisć (Silusa, Dinarda, Oxypoda, Tanygnathus, etc.) sur ses côtés, au point de faire paraitte aigu l'angle postéro-externe qui se prolonge parfois en arrière. D'autres fois, prises ensemble, elles sont simultanément plus ou moins échancrées à leur bord postérieur, avec l'angle sutural ou droit, ou obtus et émoussé, ou même fortement et obliquement tronqué (Thinobius, quelques Anthobies), au point de les faire paraitre comme déhiscentes ou séparées à leur sommet par un angle renitrant plus ou moins prononcé. Dans certains cas, au contraire, obtusément tronquées ou mêne subarquées à leur extrémité (Omaliens), elles 
olfrent leur angle postéro-externe plus ou moins laryement arrondi, avec le sutural un peu prolongẻ ou même acuminé en arrière (quelques Anthobium $\$$ ). Comme le prothorax est souvent arrondi à son bord postérieur qui recouvre plus ou moins la base des élytres, et que celles-ci sont alors, en cet endroit, un peu impressionnées pour faciliter les mouvements du segment qui vient s'appliquer sur elles, il s'ensuit naturellement que ces dernières paraissent, dans bien des cas, simultanément plus ou moins échancrées antérieurement (la plupart des Aléochariens, Staphyliniens,etc.) Quand, au contraire, leur base est libre, celle-ci parait coupée en ligne ou à peu près droite ou mème à peine arquée en dehors (Pédériens, quelques Oxytéliens, etc.).

Les élytres ne sont pas toujours parallèles sur leurs côtés, car ceux-ci divergent quelquefois postérieurement, ce qui fait paraitre ces premières un peu plus larges en arrière qu'en avant. Ces côtés d'ailleurs, souvent subrectilignes, sont parfois subarrondis ou du moins dans leur partie pastérieure. Ils sont toujours plus ou moins déclives ou infléchis, souvent rebordés ou munis d'unc arête parfois tranchante, qui sépare la page supérieure du repli latéral, avec celui-ci plus ou moins réfléchi, plus ou moins large et à bord interne subrectiligne ou subarqué. Elles sont rarement rebordées à leur sommet, moins rarement à la suture qui, généralement simple est, par exception, imbriquée chez plusieurs Xantholiniens.

Tantôt convexes ou subconvexes, tantôt déprimées ou subdéprimées, parfois subimpressionnées, les élytres, considérées dans leur texture, sont couvertes d'une ponctuation plus ou moins variable, plus ou moins serrée ou parfois très-parcimonieuse, plus ou moins rugueuse ou même râpeuse ou réticulée, plus ou moins fine ou même obsolète ou presque nulle, et, rarement, rangée en stries ou séries longitudinales. Dans quelques circonstances (Glyptoma, Psendopsis, Pholidus, Nicropeplus), de même que le prothorax, elles sont chargées de côtes longitudinales plus ou moins saillantes.

Enfin, les élytres peuvent, en certains cas, devenir le siége de divers signes caractéristiques des sexes, tels que des tubercules (Brachida) ou des plis (Bolitochara, Sipalia, etc.), ou bien encore le prolongement de l'angle sutural (certains Anthobium).

Les Ailes sont le plus souvent très-développées chez les Brévipennes, et atteignent au moins la longueur de l'abdomen. Elles sont ordinairement pâles et diaphanes, quelquefois irisées ou enfumées, et elles se replient 
complétement sous les élytres. Dans des cas assez rares, elles sont rudimentaires, ou bien elles manquent totalement.

L'Abdomen, qui est presque toujours plus ou moins découvert (1), joue naturellement ici un plus grand rôle que dans toutes les autres familles de Coléoplères. Ainši que l'a consłaté feu Jacquelin Du Val, il est composẻ de 9 segments, tous cornés (2), savoir : 102 segnments courts, quelquefois rudimentaires, le plus souvent recouverts en dessus par les élytres et néanmoins parfois, ou au moins le $2^{\mathrm{c}}$, découverts et apparents (3) ; 2०5 aulres plus développés, transverses, généralement tous découverts ou quelquefois pour la plupart recouveris (certains Omaliens), parfois subégaux, souvent inégaux, avec le $5^{\text {e }}$ et plus rarement le $4^{\mathrm{e}}$ plus grands; $3^{\circ}$ un $6^{\circ}$ plus étroil, ordinairement moins saillant, le plus souvent rétractile ou susceptible de se retirer dedans ou dessous le précédent, quelquefois triangulaire ou semilunaire; $4^{\circ}$ enfin, un $7^{\mathrm{e}}$ souvent caché ou enfoui, et qui laisse parfois saillir 2 espèces de styles plus ou moins grèles et plus ou moins apparenıs. Lors même que la plupart des segments sont nus et que l'abdomen déborde notablement les élytres, celui-là peut être plus ou moins allongé, plus ou moins raccourci, au point de représenter 4 ou 5 fois ou seulement 2 ou 3 fois la longueur des étuis protecteurs des organes du vol. Dans les cas, au colıtraire, où il est, en majeure partie, recouvert (plusieurs Omaliens, Proteiniens), il est court et large. Il esı, quant à sa forme, soit subparallèle, soit plus ou moins arqué latéralement, soit étranglé vers sa base (Tachyusa), soit subélargi postérieurement (Actosus, Sipalia, etc.), soit même, assez souveul, atténué en arrière (Oxypoda, Dinarda, Homoeusa, Deinopsis, Pseudopsis, les Tachiniens, etc.) d'une manière plus ou moins accentuée. Parfois déprimé ou subdéprimé en dessus diıns tout son développement, quelquefois il ne l'est que vers la base, avec le reste

(1) Excepté chez quelques Anthobies.

(2) La nature, ayant dénudé !'abdomen de tout étui protecteur, a dú, dans sa sage prévoyance, le douer d'une cuirasse solide.

(3) Comme on n'est pas d'accord sur le segment qui doit être considéré comme le 1er, pour éviter toute confusion, nous ferons abstraction des 2 segments rudimentaires que nous nommerons segments basilaires, et nous ne compteruns que les suivants, qui sont de grandeur raisonnable et normale. Nous désignerons le dernier (neuvième réel, scptième apparent) du nom de Segment de l'arnure ainsi que l'a fait avec raison Jacquelin du Val. Nous ferons observer en passant que le 2 e basilaire, bien que souvent caché en dessous, est quelquefois bien distinct et découvert en dessus, et que néanmoins nous n'ell tiendrons pas compte, parce que le plus souvent il est invisible ou inappréciable, si ce n'est par la dissection. Chez plusieurs Oxytéliens, il est apparent en dessous comme en dessus, mais le cas est exceptionnel. 
de sa longueur plus ou moins convexe, mais, plus rarement, il est convexe d'un bont à l'autre. Le plus souvent ses bords latéraux sont plus ou moins forlement relevés en forme de bourrelet, ou même de tranche quelquefois (Encephalus) très-saillante et comprimée; d'autres fois, au contraire, les côtés sont mutiques et n'offrent aucune espèce de rebord, comme on peut le voir dans quelques genres, et alors il affecte la forme conique (Conurus), ou cylindrique (Glyptoma, quelques Stenus).

Comme la Nature, en découvrant l'abdomen de la plupart des Brévipennes, l'avait délivré de toute entrave, elle l'a en même temps doué d'une grande faculté de se mouvoir en tous les sens, au point qu'ils s'en servent souvent pour faire rentrer, après le vol, les ailes sous les étuis qui doivent les protéger. La plupart des Aléochariens peuvent, soit le redresser verticalement, soit le recourber en l'air en forme d'arc, même jusqu'à cacher le corps en cntier ou le recouvrir étroitement comme d'un capuchon (Encephalus), et, dans ce jeu, naturellement les arceaux du ventre sont appelés à s'allonger et les segments du dos à se contracter; de là la faculté qui leur a élé dévolue de pouvoir se retirer ou de rentrer sans peine l'un dans l'autre, et qui, par exception, a élé refusée au genre Micropeplus, chez lequel les segments abdominaux paraissent plus ou moins immobiles ou comme soudés, ainsi que dans les insectes de la tribu des Psélaphiens. Les Staphyliniens ou du moins un grand nombre des espèces de cette famille se contentent de tenir, en courant, leur abdomen droit comme un élendard. Plusieurs autres, au contraire, ont l'habitude de le ramasser cn dessous en arc (Bolitobius, Mycetoporis, etc.), ou en cercle ou même en spirale (Xantholinus); et quelques autres (Omaliens), surtout celles à abdomen entièrement ou presque entièrement (Anthobium) caché, se bornent seulement à infléchir son extrémité postérieure.

Il est inutile de faire l'étude isolée de chaque segment, et nous nous contenterons de dire que les 2 ou 3 premiers segments, rarement le $4^{\mathrm{c}}$, toujours absiraction faite des deux basilaires, sont souvent (Aléochariens, etc.) creusés à leur base d'une impression ou sillon transversal plus ou moins prononcé ; et de plus, Irès-rarement (Lomechusa), garnis de chaque côté d'un pinceau de poils serrés. Le $5^{\mathrm{e}}$, souvent plus grand que le précédent, est presque toujours largement tronqué ou parfois échancré à son bord postérieur qui est souvent muni d'une étroite membrane pâle. Le $6^{\mathrm{c}}$, ainsi que nous l'avons dit, est plus étroit que le précédent, ordinairement moins saillant, plus ou moins rétractile, et du reste trè́s-variable dans sa forme, mème d'un sexe la l'autre, 
car il est souvent chez les $\sigma$ (Aléochariens) ou simplement crénelé ou échancré, ou armé à son sommet de dents, d'épines ou de tubercules. D'ailleurs, il n'est pas seul à offrir des signes masculins, et le précédent est parfois surmonté sur le dos, soit d'une saillie de forme variable, soit de 1 ou de 2 ou même de plusieurs (Gyrophoena) plis longitudinaux. Mais il est rare, quoique cela existe, de voir les segments précédents, ou seulement l'un d'eux, chargés de quelque tubercule, de quelque protubérance ou de tout autre signe distinctif des $\sigma^{*}$. Dans le genre Thectura, le $6^{\text {e }}$ segment de l'abdomen est ar'mé, à son sommet, de 3 forts aiguillons, et cela dans les deux sexes, ce qui constitue une exception unique et remarquable. Le segment de l'armure qui est, ainsi qu'il a été dit, le plus souvent caché ou enfoui et rétractile, devient, au contraire, en d'autres cas, très-apparent et même assez saillant (Oxytéliens, etc.). Il parait alors composé de plusieurs valves qui laissent sortir parfois 2 appendices courts ou bien styliformes.

La ponctuation de l'abdomen est très-variable, suivant les espèces qu'elle aide à déterminer. 'Tantôt plus ou inoins fine, tantôt plus ou moins forte, quelquefois très-serrée, d'autres fois moins serrée et même parcimonieuse, elle est souvent plus écartée sur les derniers que sur les premiers segments, rarement granulée sur les $5^{\mathrm{e}}$ ou $6^{\mathrm{e}}$ ou $5^{\mathrm{e}}$ et $b^{\mathrm{e}}$, quelquefois nulle ou obsolète, ou du moins en partie.

Nous n'entrerons pas dans de grands détails relativement à la pubescence du dos de l'abdomen, sinon qu'elle varie également suivaut les espèces, c'est-à-dire qu'elie est plus ou moins fine et plus ou moins légère, plus ou moins serrèe, plus ou moins longue, plus ou moins couchée, parfois parcimonieuse, d'autres fois condensée, soit en un duvet très-fourni et uniforme, soit en taches ou lignes soyeuses (Emus, Staphylinus, etc.) formant des dessins divers. Souvent, outre la pubescence ordinaire, les côtés et surtout l'extrémité de l'abdomen, plus rarement le dos, sont hérissés de soies redressées, plus ou moins longues, mais généralement éparses ou clair-semées.

Nous allons passer maintenant à la Page inférieure du corps, qui est plus ou moins convexe, plus ou moins ponctuée, plus ou moins pubescente et qui offre sarıs contredit un intérêt majeur.

Nous n'aurons rien de remarquable à dire du Dessous de la tête, occupé d'ailleurs en grande parlie par les organes de la bouche et surtout par les tempes, qui sont très-développées et retournent fortement en dessous au point de se réunir parfois sur une plus ou moins grande étendue et de 
refouler ou d'annihiler les pièces basilaire et prébasilaire, ainsi que no:ss en avons déjà fait mention. Alors ces mêmes tempes, souvent glabres et rarement pubescentes ou pilosellées, ponctuées ou rugueuses et rarement lisses, offrent quelquefois des points enfoncés et des poils très-distancés, mais bien apparents.

L'Antépectus est toujours distinct, largement tronqué ou subéchancré à son bord antérieur, avec celui-ci offrant souvent de chaque côté comme une petite oreillette avancée(1), et quelquefois plus fortement échancré, avec l'échancrure remplie par une pièce antésternale cornée (Ẍantholiniens) en forme de semi-disque ou d'ellipse transverse.

Le Prosternum, qui forme la partie médiane de l'antépectus, est le plus souvent peu, d'autres fois plus ou moins fortement développé (Autalia, Pédériens, Coprophilus, Prognatha, Stenus, etc.) an devant des hanches antérieures. Généralement, il se prolonge un peu en arrière entre celles-ci, en angle le plus souvent peu prononcé et très-ouvert, quelquefois plus ou moins saillant et plus ou moins aigu. Rarement, son bord postérieur est presque en ligne droite (Bledius) ou avec une dilatation angulaire presque insensible dans son milien. Quant à sa surface, l'angle prosternal est tantôt plan, tantôt convexe, tantôt parcouru sur sa ligne médiane par une carène, plus prononcée surtout en arrière. Les Épisternums et les Épimères de l'antépectus sont cachés ou soudés avec les pièces du milieu. Mais quelquefois, ainsi que nous l'avons dit plus haut, les Épimères sont distinctes el deviennent les Opercules prothoraciques.

Le Médipectus, quoique généralement peu développé, est néanmoins souvent plus grand que le segment précédent. Il présente, selon nous, une importance qu'on a trop longtemps négligée, faute d'examiner la page inférieure du corps qui, ainsi que nous l'avons dit en d'autres occasions, reproduit des pièces cardinales.

Le Mésosternum, qui occupe le milieu du médipectus, est susceptible de formes si variées que, forcés de renoncer à toutes les signaler, nous nous bornerons à en indiquer les principales. En effet, comme le prosternum, il se prolonge plus ou moins en arrière entre les hanches intermédiaires en forme d'angle; mais cet angle lui-même subit de nombreuses variations, soit dans ses dimensions, soit dans sa forme, soit dans sa sculpture. Rarement court, tronqué ou obtus, il se rétrécit d'autres fois postérieurement en pointe plus ou moins aiguë et même effilée ou aciculée,

(1) Ces oreillettes représentent, selon Thomson, les clavicules. 
prolongée tantôt jusqu'au milieu, tantôt même jusqu'au sommet des hanches intermédiaires. Quelquefois il forme entre celles-ci comme un filet étroit et même tranchant, d'autres fois il y représente une lame horizontale, plane, plus ou moins large, ou subparallèle, ou graduellement rétrécie en arrière, avec son extrémité plus ou moins largement tronquée (Gyrophcena, etc.). La surface du mésosternum, tantôt ponetuée, tantôt rugueuse, tantôt presque lisse, offre parfois en outre une carène longitudinale, ou fine et réduite à une simple ligne élevée, ou tranchante et comprimée, et, dans ce dernier cas, il arrive que la partie située de chaque côté en dehors de la carène est plus ou moins creusée ou excavée, comme cela se voit dans quelques Baryodmes. D'autres fois, cette surface présente une suture ou arête transverse, en forme d'arc ou de chevron plus ou moins ouvert et dont l'ouverture est en avant (Philonthus); et rarement, cet arc est indiqué par une chaînette de gros points enfoncés (Trichoderma). Eufin, pour abréger, nous constaterons que souvent le mésosternum, de même que le prosternum, offre sur les côtés un rebord plus ou moins accusé.

Les Médiépisternums ou Épisternums du médipectus sont généralement grands et soudés, dans bien des cas, au mésosternum avec lequel ils semblent comme confondus. Cependant, dans plusieurs autres circonstances, il en est séparé par une suture ou arête plus ou moirıs fine et parfois bien saillante, ainsi qu'on peut l'observer dans quelques Aléochariens, quelques Pédériens, quelques Staphyliniens, et notamment le genre Quedius.

Les Médièpimères ou Épimères du médipectus, ordinairement moins grandes que les médiépisternums, ne laissent pas d'être souvent assez développées. Leur forme générale est celle d'un trapèze ou d'un triangle irrégulier, subtransversalement ou obliquement disposé. Cependant, cette règle présente des exceptions; ainsi, par exemple, chez quelques Staphyliniens (Staphylinus, Philonthus; etc.), elles deviennent allongées, prennent en même temps une disposition longitudinale et s'étendent assez loin en arrière le long du repli latéral des élytres. Nous ajouterons même que, chez quelques espèces linéaires (Xantholiniens), elles sont très-étroites et réduites à une espèce de liseré, refoulées qu'elles sont par les hanches intermédiaires, qui sont implantées tout près du bord externe des étuis.

Le Métasternum, quoique ordinairement grand et plus ou moins développé dans son diamètre antéro-postérieur, devient quelquefois très-court, et cela se comprend lorsqu'on considère qu'en même temps les hanches intermédiaires et postérieures se rapprochent entre elles au point de paraître 
se toucher presque. Borné alors à un très-étroit ruban transversal, il n'offre qu'une légère dilatation angulaire dans ses pointes antéro et postéro médiaires. En général, il est transversalement ou subobliquement coupé sur les côtés de son bord postérieur, avec ceux-ci souvent sinués ou échancrés et parfois d'une manière sensible (Staphyliniens, Pédériens, Bledius, etc.) au devant de l'insertion des hanches postérieures. Sa pointe antéromédiaire est avancée tantôt en un angle peu senti, tantôt en un angleplus ou moins aigu, avec celui-ci ou prolongé jusqu'à la rencontre de la pointe mésosternale, ou s'arrêtant plus ou moins loin de celle-ci, avec laquelle elle se lie alors au moyen d'une pièce intermédiaire visible. Il est bon cependant de noter ici que, lorsque les hanches intermédiaires sont tout à fait contiguës, les pointes mésosternales et métasternales, loin de se toucher, restent passablement distantes l'une de l'autre par leur sommet, et que, lorsque la lame mésosternale est tronquée, celle que projette le métasternum dans son milieu offre aussi la même particularité ; et, dans ce caslà, les hanches intermédiaires sont nécessairement plus cu moins écartées entre elles. La pointe postéro-médiaire du métasternum est presque toujours courte, mais elle présente des caractères qui ne se retrouvent jamais dans la précédente. En effet, bien que souvent simple et entier, l'angle qu'elle forme, d'ailleurs peu prononcé, est assez souvent fendu ou échancré à son sommet, lequel est muni dans quelques cas d'un lobe triangulaire, submembraneux et bifide (Philonthus), ou bien terminé par deux lobes assez grands, assez. larges et cornés (Dianoüs, Stenus).

Quant à la surface du métasternum, elle est ordinairement peu convexe, avec la ligne médiane rarement et à peine sillonnée ou impressionnée. Sa ponctuation ét sa pubescence sont variables et son milieu est rxceptionnellement (Pcederus) creusé d'un gros point enfoncé.

Les Postépisternums ou Épisternums du postpectus, généralement assez grands, sont allongés en forme de languette plus ou moins étroite, dont le sommet est acuminé ou parfois mousse ou subtronqué. Il a une direction ou longitudinale ou oblique, avec son bord interne, dans le premier cas, subparallèle au repli des élytres et, daus le second, divergent plus ou moins postérieurement de celui-ci; dans un troisième cas, très-rare, il se rapproche en arrière (Discerota, Sunius) du même repli. Dans certaines circonstances, principalement chez les espèces linéaires, les postépisternums deviennent très-étroits, refoulés et parfois comme annihilés par les hanches, qui ont de la preine à trouver une place dans unc poitrine à diamètre transversal insuffis.nt. 
Les Postépimères ou Épimères du postpectus doivent forcément se plier aux diverses modifications que leur fait subir le postépisternım. Généralement de forme subtriangulaire, elles sont plus ou moins développées suivant que l'extrémité des épisternums s'écarte plus ou moins du repli des élytres. Elles finissent même par devenir très -petites ou par disparaître complétement sous celıi-ci (Discerota, Sunius, etc.), surtout quand elles sont refoulées par la pointe postérieure de la pièce voisine.

Si le Ventre, toujours plus convexe que le dos de l'abdomen, suit naturellement dans son ensemble le même dévoloppement et la même forme que celui-ci, dont il est la page inférieure, il n'en est pas de même, comme on pourrait le croire, des différents arceaux qui le composent. En effet, chacun de ceux-ci, dans sa dimension et sa struclure, ne répond pas toujours exactement à chaque segment dorsal correspondant. Ainsi, par exemple, le $1^{\text {er }}$ (sans compter bien entendu les basilaires) est ici souvent plus grand et même notablement plus grand que le $2^{\bullet}$, tandis que le segment correspondant du dos de l'abdomen est égal ou subégal au $2^{\mathbf{e}}$, ou rarcment plus court que celui-ci. Le $5^{\circ}$ n'est pas toujours plus grand que les précédents; le $6 \bullet$, au contraire, est assez souvent plus développé que le segment abdominal correspondant, et, comme ce dernier, il devient, par la diversité de sa structure, un caractère de différence sexuelle. En parlant du $1^{\text {er }}$ arceau, nous avons omis de signaler une singularité qui le concerne, celle de présenter sur le milieu de sa base, surtout chez plusieurs Pédériens et Sténides, une crête ou carène longitudinale plus ou moins prononcée et qui semble parfois se continuer sur les arceaux rudimentaires.

Quant à la ponctuation et à la pubescence du ventre, elles sont à peu près les mêmes que celles du dos de l'abdomen; cependant, il arrive que, dans certains cas, elles sont l'une et l'autre moins serrées ou moins condensées que sur la page supérieure, et, notamment dans quelques espèces de Staphylins ou genres voisins, la pubescence du dessous du ventre n'offre pas toujours, comme en dessus, ni d'aussi grandes ni d'aussi nombreuses plaques de soies très-serrées. Enfin il est, en outre, souvent parsemé de soies redressées el plus ou moins distinctes.

Les Pieds sont plus ou moins allongés, rarement courts, rarement subégaux. Les antérieurs sont le plus souvent moins longs, mais plus robustes que les autres; les intermédiaires sont généralement plus dévcloppés que les antérieurs et les postérieur's plus que les intermédiaires.

Les Hanches offrent toujours un assez grand développenent pour qu'il soit facile de bien préciser leur forme et leur disposition. Les antérieures 
sont grandes, coniques et la plupart du temps saillantes; mais quelquefois elles sont moindres et en même temps elles ne ressortent que légèrement (Prognatha, Glyptoma, Phloeocharis, etc.); el, d'autres fois, tout en se montrant un peu proéminentes, elles sont petites, faiblement oblongues ou à peine coniques (Dianoüs, Stenus). Dans des cas plus rares (Proteiniens), elles sont allongées, subcylindriques, et alors elles sont transversalement et un peu obliquement couchées. Le plus souvent écartées à leur base, elles sc rapprochent l'une de l'autre vers leur sommet, où elles sont contiguës on subcontiguës, tout en se renversant plus ou moins en arrière. D'autres fois, au contraire, leur position est moins oblique ou plus parallèle; alors, tantót très-proéminentes (Xantholiniens, Pédériens), tantôt moins saillantes (Oxytéliens), elles sont légèrement (Xantholiniens, Pédériens) ou non (Oxytéliens) renversées en arrière, et il est à remarquer que, dans ce dernier cas, elles sont plutôt cylindrico-coniques et un peu distantes que coniques et contiguës. Les Hanches antérieures sont généralement convexes en avant, planes et parfois subexcavées en dessous. Elles sont reçues à leur base dans une cavité transversale plus ou moins étendue latéral ement, et on aperçoit souvent, en dehors et au devant de cette même base, une espèce d'opercule ou de pièce triangulaire ou semidiscoïdale, subcornée, souvent rudimentaire, parfois assez développée(Xantholiniens, quelques Pédériens, etc.), et qui recouvre plus ou moins la noix ou condyle articulaire.

Les Hanches intermédiaires, bien que moins développées et beaucoup moins saillantes en général que les antérieures, sont néanmoins quelquefois aussi grandes ou presque aussi grandes (Xantholinus, Pédériens, etc.) que celles-ci, mais moins proéminentes. Elles en sont généralement rapprochées au point parfois de se toucher, mais d'autres fois elles en sont passablement éloignées (Acrognathus, Coprophilus, Glyptoma, Stenus, etc.) suivant le développement antéro-postérieur dı mésosternum. Parfois uniformément subconvexes, elles sont d'autres fois subdéprimées, déprimées ou même subexcavées dans la partie extérieure de leur surface, avec la partie intérieure de celle-ci plus ou moins convexe et formant comme un bourrelet arqué, plus ou moins large, en tous cas souvent plus étroit que le reste du disque, et qui doit servir de borne intérieurement au monvement des cuisses. Elles ne sont pas toujours coniques, mais elles sont dans bien des circonstances, subovalaires ou conico-ovalaires, parfois subréniformes ou même subarrondies. Elles sont le plus souvent obliquement disposées; seulement, lorsque les antérieures affectent la direction 
longitudinale et subparallèle, elles tendent aussi plus ou moins à la prendre elles-mêmes. Quant à l'intervalle qui les sépare l'une de l'autre, il nous suffira de dire qu'il varie suivant le développement de la lame mésosternale et de la pointe antéro-médiaire du métasternum, c'est-à-dire qu'il est tantôt nul, tanlôt très-étroit, tantôt plus ou moins iarge.

Les. Hanches postérieures jouent encore un plus grand s'ôle que les antérieures et les intermédiaires. Elles sont grandes et généralement transverses, et le plus souvent, dans ce cas, elles sont composées de deux lames dislincles : l'une supérieure, parfois (Aléochariens, Tachiniens, etc.) nulle ou très-étroite en dehors, mais brusquement dilatée intérieurement en cône plus ou moins saillant, ou rarement en carré ou trapèze (Hypocyptus, Conurus): l'autre, située sur un plan inférieur, horizontale, découverte, plus on moins large, parfois très-grande (Bolitobius, Iycetoporus), subparallèle ou un peu atténuée de dedans en dehors. Toutefois, ceite règle souffre des exceptions : ainsi, par exeniple, dans le genre Habrocerus, la lame supérieure es! très-grande et s'étend en forme de triangle transverse jusque près du repli des élytres au point de recouvrir presque entièrement la lame inférieure; assez. souvent encore celle-ci, affectant une position verticale, est plus ou moins refoulée en dessous du bord postérieur du métasternum, ce qui la rend presque annihilée ou peu apparente, et alors, la lame supérieure est simplement conique et réduite seulement à sa dilatation interne. Le cône formé par celle-ci est lui-même susceptible de modifications assez nombreuses; en effet, tantôt court et large, tantôt allongé et étroit, il est parfois subdéprimé, peu convexe et subhorizontal, et d'autres fois convexe, subcylindrique et plus ou moins saillant. Presque toujours il est échancré, entaillé ou seulement sinueusement tronqué à son sommet pour recevoir la noix des trochanters. Dans d'autres cas, il offre vers ou avant son milieu un rétrécissement ou étranglement transversal plus ou moins prononcé, ainsi qu'on peut le voir dans plusieurs Staphyliniens, Xantholiniens el Pédériens.

Dans leurs rapports avec les hanches intermédiaires, nous avons déjà dit que les postérieures en étaient parfois rapprochẻes au point de les toucher presque (Actosus, Sipalia). Dans leurs rapports entre elles, nous aurons peu d'observations à faire, car généralement elles sont contiguës ou subcontiguës en dedans à leur base et plus ou moins divergentes à leur sommet, excepté dans certains cas où elles sont légèrement (Philonthus, etc.) ou même notablement (Dianoüs, Stenus) écartées l'une de l'autre intérieurement à leur naissance. 
Les Trochanters, qui isolent complétement ou presque complétement les cuisses des hanches, tout en leur servant d'attache, sont toujours bien apparents. Les antérieurs et intermédiaires sont en général petits et subcunéiformes. Les postérieurs offrent un plus grand développernent; ils sont allongés, oblongs ou subelliptiques, a vec leur sommet tantôt acuminé, tantôt subarrondi, ou libre et détaché de la cuisse, ou parfois appliqué contre celle-ci, qui est obliquement coupée à l'endroit de son insertion. Par une exception unique et remarquable, les trochanters postérieurs deviennent le siége d'un caractère sexuel, car chez le $\sigma$ ' de l'Emus hirtus, ils sont chacun armés d'un fort crochet dilaté à son extrénité.

Les Cuisses, inplantées de côté et un peu obliquement sur les trochanters, débordent plus ou moins les côtés du corps. Elles sont, la plupart du temps, comprimées ou subcomprimées, et légèrement cintrées sur leur face interne, ou au moins les intermédiaires et postérieures, comme pour embrasser la courbure du corps, afin de n'être pas gênées dans leur mouvement ascensionnel. Elles sont généralement élargies ou subélargies, les antérieures souvent, les intermédiaires rarement avant leur milieu, les autres vers leur milieu, avec leur extrémité parfois plus ou moins atténuée. Cependant, quelquefois elles sont comme linéaires et subcylindriques, ou à peine renflées dans leur partie médiane. En dessous, elles sont rarement ou faiblement rainurées vers leur sommet. Chez certains Laihrobies, les antérieures surtout sont ćpaissies d'une manière notable. Enfin, il arrive parfois qu'elles offrent inférieurement, surtout vers leur extrémité, ou une série de petites épines (Quedius), ou quelques soies distinctes (Bolitobius) et assez raides, ou une épine longue et grêle (Conurus), et rarement, vers la base des antérieures, une frange de cils fins, mous et assez serrés.

De toutes les parties des pieds, les Tibias sont sans doute celles qui présentent le plus d'intérêt, et ils sont le siége de caractères d'une importance principale. Ils sont droits ou presque droits, ou parfois un peu arqués à leur base; d'autres fois, les postérieurs surtout sont faiblement recourbés en dedans vers leur extrémité et quelquefois aussi en arrière, vers le sommet de leur arête supérieure. Plus ou moins allongés, ils sont généralement grêles à leur base et graduellement élargis vers leur extrémité, parfois inême d'une manière notable (Xnntholinus); d'autres fois, ils sont larges et comprimés (plusieurs Oxytéliens), à l'exception des postérieurs, et, chez certains $\sigma$ (Amphichroum), les antérieurs et même les intermédiaires sont assez brusquement épaissis dans leur dernière moitié 
ou dans leur dernier tiers; dans d'autres cas, les antérieurs seuls sont subitement élargis soit dès leur tiers basilaire (Lathrobium, Achenium, etc.), soit dès leur base elle-même (Emus, Creophilus, étc.). Rarement, ils sont tous très-grêles et presque linéaires (Stilicus, Sunius, Micropeplus, Stenus, etc.); d'autres fois, ils sont même subatténués vers leur sommet (Lomechusa, Oxytelus (les postérieurs), Trogophloeus, etc.). Les antérieurs et souvent les interíédiaires sont un peu moins longs ou même sensiblement moins long; (Bolitobius, Mycetoporus, etc.) que les cuisses, mais les postérieurs sont presque toujours aussi longs ou au moins aussi longs que la pièce à laquelle ils sont attachés.

Les Tibias sont le plus souvent entiers, mais cependant les antérieurs sont quelquefois sinués vers leur tiers basilaire. avant leur dilatation (Lathrobium, Achenium); rarement, les intermédiaires présentent en dessous, vers leur milieu, une échancrure assez profonde qui les oblige à se fléchir assez brusquement en dedans à cet endroii (Amphichroum canaliculatum $\sigma^{\prime \prime}$ ). Dans certains cas, les antérieurs et rarement les intermédiaires sont plus on moins obliqnement coupés ou entaillés avant l'extrémité de leur arête externe (quelques Oxytéliens). Quint an soınmet lui-mème, il est généralement tronqué, parfois d'une façon un peu oblique, d'autres fois subéchancré.

Mais ce qui distingue principalement les tibias, c'est l'armure de leur tranche supérieure, car ce genre de conformation annonce des espèces fouisseuses et par consėquent nous révèle un caractère de mœurs. En effet, les tibias, le plus souvent simplement pubescents ou ciliss sur leurs deux arètes, sont d'autres tois plus ou inoins épineux, avec les épines ou nombreuses el disposées sans ordre sur toute la périphèrie (Philonthus, Xantholinus, etc.) ou moins nombreuses et réduites aux tranches supérieure et inférieure, ou le plıs souvent à la supérieure seule. Ainsi, les antérieurs et les internédiaires, surtout dans les cspèces véritablement fouisscuses, offrent, sur leur tranche supérieure, une sćrie régulière d'épines plus ou moins redressées, tantôt petites ou assez petites (Phytosus, Actosus, Oxylelus, Haploderus, etc.), tantôt plus fortes ct plus longues (Platystethus, Bledius, Coprophilus, etc.), tantôt assez serrées (Bledius, etc.), tantôt plus écartées (Haploderus, Acrognathus, etc.). Notons ici que dans les gentes Microglossa, Aleochata, etc, , ces épines existent aussi, mais d'une manière moins visible, parce qu'elles sont moins forles on réduites à des soies spinifornes, couché: s et mêlées à une épaisse pubescence. Généralement, ces épines n'existent pas sur la tranche externe 
des tibias postérieurs, ou bien elles y sont remplacées par une fine ciliation régulière, plus ou moins longue et plus ou moins serrẻe (Bledius, Oxytelus, etc); il fuut toutefois en excepter quelques genres (Platystetlus, Coprophilus) où elles se montrent, mais d'une manière moins accusée que dans les antérieurs et intermédiaires. Dans certaines circonstances, ces épines sont assez longuts, très-rares et assez fortes (Gymnusaires) ou clair-semées (la plupart des Tachiniens) sur l'une et l'autre trancl.e; dans d'autres, elles sont courtes, médiocrement ou peu strrées, et alors elles forment comme une espèce de dentelure aiguë (Prognatha, Lathrimaeum: Deliphrum, etc.) qui parfois n'est bien apparente que vers l'extrémité de la tranche externe (Omalium). Quelquefois, quand ces diverses arnure; existent sur les 4 tibias antérieurs, elles sont obsolètes ou nulles dans les deux postérieurs ; ou bien, quand elles se remarưuent sur les tibias intermédiaires et postérieurs, elles sont nulles ou s'aperçoivent à peine dans les antérieurs (Conurus, Amphichroum, Deliphrum) oì elles sont remplacées par une frange de cils fins, courts et serrés (Conurus) régnánt sur toute la longucur de la tranche supérieure. Pour eil finir avec ces épines, nous ferons observer que, lorsqu'elles sont éparses et sans ordre, elles sont répandues généralement sur les deux tranches et même sur toute la périphérie du tibia, et que, lorsqu'elles sont disposées en série régulière, elles parent ordinairement la tranche supérieure et rarement l'inféricure. Enfin, dans tout autre cas, les tibias sont mutiques ou inermes, simplement ciliés ou finement pubescents (la plupart des Aléochariens, quelques Pédériens, les Trogophlées, quelques Omaliens, les Proteiniens, les Micropeplides, les Stinides, etc.).

Les tibias sont presque toujours munis, au bout de leur tranche inférieure de deux éperons généralement divergents, rarement subparallèles, le plus souvent petits et grêles et même parfois obsolètes ou à peine distincts, tantôt plus grands et subégaux (Aleochara, la plupart des Tachiniens, etc.), tantôt robustes et inégaux (Staphyliniens, Xantholiniens) avec l'interne plus long. Quelquefois aussi, la tranche supérieure semble offrir 2 ou 3 petits éperons, mais ceux-ci solıvent, dans ce cas-là, paraissent plutôt être les épines terminales de la série d'armures qui pare cette même tranche. Nous avons dit que le sommet des tibias était ou tronqué ou obliquement coupé, mais nous ne devous pas omettre d'ajouter que dans l'un (Conurus) et l'autre cas (quelques Pédéricns) il est comme pectiné (Conurus) ou finement frangé (Lathrobium, Achenium, Dianoüs, Stenus, etc.); et que, daus les espèces à tibias épineux, cette même tron- 
cature, outre les deux éperons ordinaires, est souvent pius on moins complétement entourée d'épines plus longues (la plupart des Tachiniens, les Staphyliniens, les Xantholiniens), parfois plus courtes mais robustes, (Bledius, Coprophilus).

Comme on vient de le voir, les tibias doivent jouter un grand rôle dans la classification des genres et même des rameaux et des branches, parce que leurs diverses modifications répondent d'une manière manifeste a des différences de mœurs et d'habitudes. Il n’en est pas tout à fait de même des Tarses qui n'offrent de caractères principaux qu'eu égard au nombre, à la forme et aux proportions de leurs articles. Ils sont le plus souvent pentamères, quelquefois tétramères (Hygronoma, Oligota, Diglossa. Hypocyptus, Tanygnatus, Evaesthetus), d'autres fois trimères (Deinopsis, la plupart des Oxytéliens, Glyptoma, Pholidus, Micropeplus). Dans tous les autres cas, ils sont hétéromères, avec les antérieurs et intermédiaires de 4 articles et les postérieurs seuls de 5 (Bolitocharaires), ou avec les antérieurs seuls de 4 articles et les intermédiaires et postérienrs de 5 (Myrmedoniaires). Tantôt tous plus courts, tantôt tous aussi longs ou même plus longs (Conurus, Bolitobius, Mycetoportus), tantôt les postérieurs seuls aussi longs ou à peine moins longs que les tibıas, les tarses sont soit filiformes ou subfiliformes, soit sétiformez ou subattėnués vers leur cxtrémité, le plus souvent étroits et subcomprimés, d'autres fois élargis et déprimés (Emus), à l'exception toutefois du dernier article; mais la plupart du temps, cc sont les tarses antérieurs seuls qui offrent leurs 3 ou 4 premiers articles dilatés soit dans les deux sexes (la plupart des Staphyliniens), soit dans les mâles seulement (la plupart des Tachiniens, quelques F'hilonthus et une partie des Pidériens); et, plus rarement, le fer $^{\text {article des mêmes }}$ tarses est seul un peu élargi (Hypocyptus). Les 4 premiers articles varient passablement quantà leur furm:; ainsi, par exemple, ils sont ou allongés, ou oblongs, ou triangulaires, ou subnoueux, ou même subcordiformes ou cnrdiformes, principalement lorsqu'ils sont dilatés; et quelquefois (Sunius (1), certains Stenus) le $4^{\mathrm{e}}$ et mème le $3^{\mathrm{e}}$ (quelques Stenus) sont plus ou moins fortement bilobés, avec les premiers simples et étroits. Quand on considère les articles des tarses dans leurs dimensions relatives, on trouve qu'ordinairement les 3 ou 4 premiers vont graduellement et parfois presque insensiblement en diminuant de longueur; que, dans un grand nombre de cas, ils sont égaux ou subégaux; que, dans d'autres, le: 1 er seul est un peu plus grand, ou sensiblement ou même beaucoup plus

(1) Dans les Sunius, les lobes sont membraneux en dessous. 
grand que les 3 suivants, pris isolément, parfois égal à eux trois réunis ; mais cet excédant, quand il existe, cst rare et minime dans les tarses antérieurs, ordinairement moins rare et plus sensible dans les intermédiaires, assez fréquent et notable dans les postérieurs (Tachyusida, Falagria, Tachyusa, Conurus, Bolitobius, Mycetoporus, etc.). Dans quelques circonstances qui se représentent rarement, le $1^{\text {er }}$ article est à peine aussi long (Lathrobium, Achenium), quelquefois même un peu plus court que le suivant; mais ce dernier cas ne se rencontre principalement que pour les tarses intermédiaires (Earoia) ou aussi les postérieurs (Kraatzia, etc.). Le dernier article qui porte les ongles est presque toujours plus ou moins allongé en massue et beaucoup plus long que chacun de ceux qui le précèdent, quelquefois même aussi long que tous les précédents réunis. Toutefois, dans des cas exceptionnels, il est assez court, subépaissi ou èlargi.

Quand on envisage les tares au point de vue des poils dont ils sont garnis, on trouve qu'ils sont tantôt simplement pubescents, lantôt plus ou moins densement et plus ou moins longuement ciliés en dessous, soit sétosellés, soit épineux surtout vers le sommet de chaque article, à l'exception pourtant du dernier qui offre souvent à son exirémité quelques cils fins, mais rarement des soies et jamais des épines. Ordinairement les articles dilatés sont garnis à leur page inférieure d'un épais duvet cotonneux qui y forme comme une espèce de brosse à poils ras et serrés, ordinairement de couleur blonde ou fauve. Enfin, dans quelques cas rares, par exemple dans les genres Eusphalerum et Anthobium, dont les 4 premiers articles des tarses sont subdéprimés et plus ou moins dilatés, la pubescence qui garnit cenx-ci en dessous, s`étend et s'allunge sur les côtés où elle se redresse un peu pour former une frange subhorizontale bien saillante et composée de cils fins, mous, serrés et assez longs.

Les Ongles ne sont pas d'une grande ressource pour l'étude. Ils sont au nombre de 2, égaux ou subégaux, généralement entiers et subarqués, parfois tendus, d'autres fois brusquement infléchis, le plus souvent tenant. le milieu entre ces deux extrêmes, mais, du reste, assez mobiles dans leur insertion pour prendre quelquefois l'une ou l'autre de ces trois positions. Quoique ordinairement simples et falciformes, ils paraissent parfois comne subdilatés, subangulés ou obtusément dentés intérieurement it leur base (quelques Staphyliniens, Pédériens, Oxytéliens, etc.). Dans le genre Anthophagus, chacun d'eux est muni en dessous, vers son insertion, d'un appendicc nembraneux, linéaire et libre. Contigus à leur naissance, 
ils divergent d'une plus ou moins grande quantité à leur sommet, surtout quand ils sont fortement ou médiocrement infléchis; mais il n'en est pas toujours de mème lorsqu'ils sont tendus ou qu'ils se relèvent pour continuer plus ou moins directement l'axe du tarse lui-mème, car alors ils semblent parfois se rapprocher l'un de l'autre et affecter une position respective moins divergente (quelques Gymnusaires), sans cependant jamais ètre parallèle.

Les stigmates sont au nombre de 10 de chaque cóté du corps. Lies prothoraciques. sont quelquefois visibles, les autres toujours cachés.

\section{VIE ÉvoLUTIVE}

Lorsque les femelles des Brévipennes ont accompli le mystèrc de leur destinée conforınément aux lois générales de la nature, leur unique soin est de chercher à déposer leurs œufs dans un endroit qui réunisse les conditions favorables au développement de leur postérité, comme, par exemple, dans les fumiers, les matières animales, les détritus végétaux, la vase des rivières et des étangs, sous les pierres, autour des nids de fourmis, on en tout autre lieu où la jeune progéniture puisse trouver une subsistance facile, suivant la mission dévolue à chaque espèce, à chaque genre. Ces œufs sont ordinairement oblongs, assez gros, mais généralement en groupes peu nombreux. Leur éclosion, pour la plupart, a lieu deux fois par an, lorsque le printemps nous envoie ses zéphirs attiédis, et lorsque l'été, près de nons quitter, semble, par un dernier effort, vouloir faire reverdir les arbres et les champs, comme pour nous procurer une jouissance, hélas ! trop éphémère. De chacun de ces œufs sort une larve qui, dès sa naissance à la lumière, se livre aux habitudes carnassières que nous signalerons encore dans l'âge adulte ou l'insecte parfait.

Les larves des différentes familles de Brévipennes ont assez d'analogie entre elles et ne se distinguent que par des caractères de peu ou de médiocre importance. Elles sont généralement allongées et quelquefois même linéaires; clles ont beaucoup de ressemblance, les unes avec les larves des Carabiques, le; autres avec les larves de certains Hydrocanthares. D'autres, cependant, à forme plus courte et plus large, semblent se rapprocher davantage des larves des Silphides, des Nitidulaires el des Histérides. On est loin de connaître toutes les larves des Brivipennes, et nous dirons même qu'il en est très-peu de connues com- 
parativement au nombre immense d'espèces qui existent. Frisch, le premier, en a décrit d'une manière succincle une ou deux ; mais on ignore, ou du moins on ne sait pas d'une manière positive à quelle espèce l'une ou l'autre se rapporte. Plus tard, Bouché a publié la description des larves des Quedius fulgidus, Philonthus aeneus et Xantholinus punctulatus. Plus récemment, M. Heer a tracé l'histoire des métamorphoses de l'Ocypus olens, et MM. Blanchard et Ratzeburg ont donné un dessin exact de la larve du même insecte. M. Waterhouse a aussi fait connaîlre celle du Quedius fuliginosus. Ensuite Erichson en a signalé quelques autres, celle du Syntomium aeneum, par exemple. Mais après ces auteurs, on s'appliqua avec plus d'attention à l'étude des mœurs et de la vie évolutive, el l'on découvrit un certain nombre de larves de Brévipennes, dont nous devons la description à des observateurs patients et habiles, tels quc MM. Perris, Chapuis et Candèze, Westwood, Heeger, Schioedte, etc, que nous ne négligerons pas de citer, quand l'occasion s'en présentera. Nous allons, en attendant, pour donner une idée des larves des Brévipennes, décrire aussi complétement que possible, à son état le plus avancé, celle d'une grande espèce, celle de l'Ocypus olens, déjà signalée par Heer (Obs. Ent. 16, 5, pl. III, A) et figurée avec soin par MM. Blanchard (Guérin, Mag. Zool. VI, pl. 165), Ratzeburg (Forstins, I, p. 30, pl.1, fig. 14) et Jacquelin Du Val (Gen. Col. Eur. I, pl. XII, fig. 8), nous réservant d'indiquer les autres larves connues, après la description de l'espèce à laquelle se rapporte chacune d'elles.

Long., 24 à 26 mill. (11 à 12 l.).

Corps allongé, graduellement atténué vers son extrémité, d'un brun un peu roussátre et livide, avec les antennes, les palpes, les pieds, les appendices terminaux et une ligne dorsale de l'abdomen plus pâles.

Tête grande, presque carrée, à peine plus étroite en arrière, avec les angles postérieurs arrondis; un peu ou même sensiblement plus large que le prothorax; faiblement convexe; presque lisse, avec quelques rides obsolètes el parfois des plaques chagrinées à peine distinctes dans la partie antéro-médiane qui est subdéprimée; parseniée çà et là de quelques longues soies fauves ou brunâtres, toul à fait redressées, entremêlées de quelques autres moins longues, toutes très-distinctes, naissant chacune d'un petit point subombiliqué et peu distinct; entièrement d'un brun roussátre et très-brillant, quelquefois plus clair sur les côtés. Front 
très-large, oftranı, entre les tubercules antennilères, 2 impressions suboblongues, obliques et subarquées, et, sur son milieu, une ligne longitudinale très-fiue, obsolète, plus visible en avant, où elle rcuconıre, à lì hauteur des yeux, une ligne également trés-fine, transversale, ar quée, à ouverturc en devant. Épistome denticulé à son bord antérieur, à dentelures au nombre de 7, émoussées, inégales : celle du milieu pctite, pell sensible, refoulée et comme effacéc par deux plus épaisses. Labre nul ou caché. Mandibules grandes et robustes, falciformes, de la même couleur que la tête. Mâchoires en forme de tige épaisse et simple, armées à leur sommet interne d'un éperon ou épine robuste dirigée obliquement en dedans. Palpes maxillaires d'un testacé livide, avec la tige parfois un peu plus foncée; de 4 articles : les 2 premiers allongés, subcylindriques (1), presque subégaux, très-parcimonieusement sétosellés : le $3^{\mathrm{e}}$ plus grêle, moins long, subatténué vers son extrémité : le dernier petit, assez étroit, presque 4 fois plus court que le $3^{\mathrm{e}}$, en forme de lobe conique, allongé et continuant assez bien le rétrécissement gradué du précédent. Lèvre inférieure d'un brun roussâtre; offrant, dans le milieu de son bord antérieur, une dent épaisse, conique, subémoussée ct dirigée en bas. Palpes labiaux testacés, de 3 articles graduellement moins épais : le $1^{\text {er }}$ allongé, subcylindrique : le $2^{\mathfrak{c}}$ à peine moins long, subatténué vers son extrémité : le dernier petit, plus grêle, subsubulé, subcylindrique ou à peine plus étroit vers son sommet. Mlenton transverse, subélargi en avant, bissinué à. son bord antérieur, assez convexe, généralement d'une couleur plus claire que la lèvre inférieure.

Yellx formés de 4 ocelles lisses, obscurs, disposés ell quadrille et souvent plus ou moins réunis.

Antennes très-écartées, insérées sous une saillie sensible ; assez courtes;

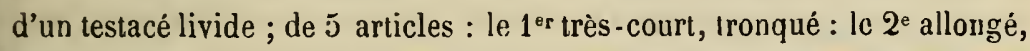
subcylindrique, subélargi vers son extrémité : le $3 \mathrm{e}$ formant un coude à son insertion avec le précédent, un peu moins long que celui-ci, de même forme, plus étroit vers sa base, obliquement coupé au sommet; offrant en dedans, avant celui-ci, un petit lobe articulé et redressé; paré, près de son extrémité, de 3 soies divergentes : le $4^{\mathrm{e}}$ formant aussi un coude à son insertion avec le $3 e$, beaucoup plns grêle et beaucoup moins long que celui-ci, subcylindrique, portant au bout 2 ou 3 soies divergentes : le

(I) Le premier articte semble emboité dans un article rudimentaire très-courl, reu distinct, que nous ne comptons pas. 
deruier très-petit, courı, subulé, submembraneux, terminé par 1 ou 2 cils ou soies légères.

Prothorax presque carré, subrétréci en avant, à peine arqué sur les côtés, tronqué au sommet et à la base, avec celle-ci assez largement rebordée; parfois obsolètement sillonné sur son miiieu, qui est parcourú par une ligne longitudinale très-fine; convexe sur son disque; creusé sur les côtés de 2 ou 3 impreșsions; lisse, avec quelques rares et longues soies redressées; d'un brun de poix très-brillant, à côtés parfois un peu roussâtres.

Mésothorax une fois plus court que le prothorax, aussi large en avant que celui-ci, un peu plus large en arrière, subarqué sur les côtés; tronqué au sommet et à la base, avec celle-ci longée par un large repli ou bourrelet déprimé, subarqué en avant, chagriné ou finement ridé en travers; convexe sur son disque, qui offre une fine ligne longitudinale, subimpressionnée en avant, mais obsolète en arrière; lisse, avec quelques rares soies redressées et 2 ou 3 impressions subobsolètes sur les côtés; d'un roux de poix brillant et livide, a vec le bourrelet postérieur plus obscur et mal.

Mélathorax à peu près de même que le mésothorax, mais seulement un peu plus sensiblement arqué sur les côtés, avec ceux-ci plus élargis postérieurement.

Abdomen aussi large à sa base que le métathorax, graduellement et même subarcuément atténué en arrière ; composé de 9 segments; longitudinalement subconvexe; finement chagriné; garni de soies nombreuses, assez raides et redressées; d'un brun ou d'un gris de poix livide et mat, avec la ligne médiane parcourue, excepté sur les $1^{\text {er }}$ et 9 e segnients, par une bande longitudinale pâle, étroite ch: $\mathrm{z}$ les jeunes et devenan: plus large avec l'âge: Chacun des segments muni de chaque côté d'un stigmate bien apparent et un peu ressorti : le $1^{\text {er }}$ plus court, plus lisse et plus brillant que les suivants, creusé sur sa ligne médiane d'un sillon assez profond qui se poursuit parfois sur ceux-ci, mais en s'affaiblissant; marqué près des côtés d'une forte fossette subarrondie : les $2^{\mathrm{e}}$ à $8^{\mathrm{e}}$ généralcment subégaux, subarqués latéralement, offrant en arrière un repli, et, sur les côlés, des cicatrices arquées, sinuées ou subcirculaires, enclosant une espèce de mamelon peu élevé : le 9 e plus étroit que le précédent, cn forme de carré ou de trapèze sultransverse, un peu atténuć en arrière, tronqué au sommet, avec celui-ci muiai de 2 app ıdices d'un testacé livide, articulés à leur insertion, gaınis surtout en dehors de quelques lorgues 
soies raides: ces appendices en forme de lanières assez étroites, subarquées en dehors, atténuées ver's leur extrémité, plus longues que le segment qui les porte, écartées entre elles à leur naissance et terminées elles-mêmes par un style plus grêle, un peu déjeté en dehors, également sétosellé, formé de 2 articles, dont le $1^{\text {er }}$ court, le 2 e beaucoup plus long, mais les 2 réunis égalant environ la moitié de la pièce qui précède.

Dessous de la tête faiblement convexe, lisse et brillant, avec quelques rides transversales dans la partie antérieure; d'un brun de poix un peu roussâtre.

Prosternum subruguleux, de même couleur, suhconvexe, en forme de triangle arrondi au sommet, finement et longitudinalement canaliculé en avant sur sa ligne médiane, traversé dans son milieu par une arête brisée en trois.

Ventre déprimé ou subexcavé, fortement sétosellé, d'une couleur encore moins obscure que le dos de l'abdomen; inégal ou mamelonné; à $9^{e}$ arceau plus pâle et terminé par un lobe épais, beaucoup plus étroit, subcylindrique, articulé à son insertion, tronqué au bout, sétosellé, d'un roux livide et un peu moins prolongí que les lanières supérieures.

Pieds courts, d'un testacé livide. Hanches très-développées, subcylindrico-coniques, toutes rassemblées les unes contre les autres et contiguës à leur sommet, occupant et cachant en entier la poitrine et ses diverses pièces moins le prosternum. Cuisses allongées, étroites, un péu en massue, un peu plus longues que les hanches, fortement épineuses en dessous. Tibias beaucoup plus courts que les cuisses, subcylindriques ou à peine en massue, fortement épineux dans tout leur pourtour, terminés par un fort crochet subarqué, acéré, représen'ant le tarse, armé vers son milieu de 2 ou 3 épines divergentes, insérées autour d'une espèce de nœud presque insensible et qui semble simuler l'articulation de 2 pièces intimement soudées.

Quand les la'ves des Brévipennes, comme celles de tous les autres insectes, sont parvenues à l'apogée de leur développement, elles s'épaississent et s'engourdissent pour s'immobiliser et se métamorphoser en nymphe, espèce d'état transitoire et léthargique pendant lequel l'être verra se consolider les organes qu'll va montrer dans l'àge adulte, où il pourra réaliser la destinée et la mission auxquelles l'a appelé la Providence.

Les nymphes des Coléoptères Brévipennes font pressentir d'une manière très-recennairsable l'image de l'insecte parfait. Elles ne sont pas toujours 
complétement recouvertes d'une membrane qui, pareille à un lincenl, enveloppe à la fois tous les organes; mais les antennes et les pieds, repliés contre les parois du corps, bien que libres, paraissent revêtus d'une légère pellicule. Du reste, pour faire connaitre la position des diverses parties dans l'état de momie, nous allons donner la description de la nymphe d'un Brévipenne en général.

Corps plus ou moins allongé, plus ou moins atténué en arrière.

Tète grande, infléchie ou repliée en dessous, ce qui fait ressortir un pea le cou. Mandibules libres, plus ou moins saillantes. Palpes maxillaires repliés en dessous des mandibules, mais reconverts d'une membrane. Les autres parties de la bouche peu distincles, ou enveloppées en un seul paquet.

Yeux représentés par une bosse légère.

Antennes recouvertes par une membrane, repliées contre et sous les côtés de la tête et du prothorax.

Prothorax incliné d'arrière en avant, à bord postérieur libre.

Écusson relativement grand, à côlés solidés aux étuis, à sommet libre.

Élytres déhiscentes, libres, obliquement repliées sur les côtés du corps. Ailes recouvertes d'une membrane, libres dans leur pourtour.

Mésothorax en grande partie découvert en dessus. Métathorax nu, plus développé que le $1^{\text {er }}$ segment abdominal, avec ses stigmates situés tout à fait sur les côtés.

Abdomen nu, subdéprimé, composé de 8 segments apparents : les 7 premiers largement rebordés latéralement, offrant de chaque côté un stigmate ombiliqué bien distinct : le $8^{\mathrm{e}}$ assez saillant : celui de l'armure caché.

Métasternum représcnté par une pièce assez grande, carrée ou oblongue.

Ventre convexe, à arceaux apparents subégaux : le $8^{\mathrm{e}}$ comme soudé au segment supérieur correspondant.

Pieds enveloppés d'une membrane sensible, obliquement repliés contre les côtés du corps, de sorte que les genoux s'élèvent presque jusqu'au niveau supéricur. Tibias intermédiaires laissant distinctement, les postérieurs à peine, apercevoir les épines dont ils doivent être armés. Tarses déjetés en dehors ; les antérieurs et intermédiaires légèrement, les postérieurs plus fortement : ceux-ci libres, laissant un pen distinguer leurs articles.

Les nymphes des Brévipennes se rencontrent généralement dans la terre, dans la crie ou le tan des vieux arbres el dans les vieux fumiers. 


\section{VIE DE RELATION ET ÉTUDE DES MOEURS}

A peine dégagés de l'enveloppe de leur jeune âge, la plupart des insectes se hâtent d'étaler au grand jour leur nouvelle parure. On ne peut pas précisément en dire autant des Brévipennes qui, en général, ne brillent pas par l'éclat de leur robe, et même celle-ci, plus ou moins obscure, semble le plus souvent revêtir la livrée du deuil et de la tristesse Comme plusieurs mènent une existence cachée, la nature les a dotés d'un manteau sombre, plus ou moins en harmonie avec leur manière de vivre, et la couleur qui domine chez eux est une teinte uniforme d'un noir mat et brillant, d'un brun de poix, d'un roux châtain ou ferrugineux, d'un fauve ochracé ou testacé. Cependant quelques espèces font reluire à nos yeux une parure d'un rouge éclatant, rehaussée par des taches ou dessins d'un noir profond; d'autres joignent à des étuis et à une tête plus sombres que l'ébène, un corsage et un abdomen qui reproduisent toutes les diverses nuances entre l'écarlate et le jaune pâle. Quelques-unes, revêtues de l'une ou de l'autre de ces deux dernières livrées, offrent sur la base de leurs élytres et avant le sommet de leur abdomen une ceinture transversale, brune ou noire, qui sert à faire ressortir la couleur foncière; et, d'autres fois, cette ceinture est tantôt réduite à une tache tranchée, arrondie ou oblongue et située sur le milieu des étuis, tantôt transformée en une lisière plus ou moins large qui couvre entièrement ou en partie la suture. Quelquefois, sur un fond d'un roux testacé vif, la tête, l'exirémité de l'abdomen et les élytres nous présentent une teinte du plus bel ébène, rehaussée sur ces dernières par une tache humérale ou apicale blanchâtre ou d'un jaune paille. Dans d'autres cas, au contraire, la couleur générale est d'un noir brillant, avec les éluis et même parfois l'extrémité de l'abdomen d'un rouge de feu, ou bien encore avec les élytres seules d'un bleu clair ou violacé. Plusieurs autres font reluire sur leur tête, sur leur prothorax et priucipalement sur leurs étuis des couleurs métalliques qui passent d'une manière graduée du bronzé obscur au vert bronzé.

Plus rarement, quelques espèces d'un certain genre revêtent une teinte générale obscure, avec les élytres parées sur leur disque d'une petite tache arrondie, rougeâtre ou d'un roux testacé. D'autres enfin, sur un 
fond plus ou moins rembruni, sont recouvertes, comme d'une riche fourrure, d'un épais duvet d'un jaune doré, et qui tantôt s'étend sur toute la tête, le prothorax et une parlie de l'abdomen, tantôt est réduit par plaques ou linéoles qui forment des dessins variés sur l'un ou l'autre de ces segments ; et quelquefois, cette pubescence, serrée et cotonneuse, passe de la couleur d'ocre à la teinte grise ou blanchâtre, pour reproduire, sur tout le dessus du corps ou sur l'nne de ses parties, des bigarrures qui raprellent le damas ou la marqueterie.

Bien que tous les Brèvipennes soient liés entre eux de manière que l'œil le moins exercé puisse les reconnaître à première vue, ils sonınéanmoins susceptibles de modifications importantes qui ont servi à établir parmi enx plusieurs familles tranchées. Avec cette diversité de formes, on rencontre bien diversité d'habitudes, mais relativement pen de mœurs bien différentes. En effet, les uns se trouvent dans les cadavres, les fumiers et les champignons, sous les détritus végétaux, les mousses et les vieux fagots ; les autres au bord des marais ou dans la vase des rivières ; ceux-ci sous les écorces, dans les troncs cariés des arbres et sous les pierres enfoncées, ceux-là en compagnie des fourmis ou autres Hyménoptères; d'autres enfin, sur les rameaux des arbres, sur les plantes et sur les fleurs, etc. Ma'gré les résidences diverses que semble préférer chaque famille, chaque branche, cha que rameau, chaque genre, nous regardons tous les Brévipennes, ou pour la plupart, comme des iusectes plus ou moins carnassiers. Nous disons plus ou moins, parce que ceux qui scmblent n'avoir pas des guûts aussi voraces ne se contentent pas toujours d'une nourriture purement végétale; mais, véritables maraudeurs ou larrons en miniature, ils cherchent çà et là à dérober les débris plus ou moins ténus de substances animales que d'autres insectes ont accumulées à grand'peine pour leur approvisionnement.

Dès que le soleil de mars commence à nous faire sentir ses feux bienfaisants, on voit déjà de tous côtés voltiger el courir des essaims de Brívipennes; car ceux -ci sont, comme les Carabiques, des premiers à saluer le retour de la belle saison; mais, comme eux, ce n'est pas non plus pour jouir, dans la paix de l'innocence, des avantages sars nombre que Flore vient nous offrir. En eff cl, loin d'a voir abjuré les instincts cruels de leur premier âge, à peine arrivés à l'état parfait, les insectes dont nous retraçons ici l'histoire continuent à faire une guerre acharnée aux autres petils êtres vivants qui n'ont pas le bonheur ou l'agilité d'échapper à leur poursuite. Les uns, plus hardis que les autres, surtout les espèces de grande 
aille, ne craignent pas de s'attaquer aux chenilles, aux lombrics, aux hélices et autres mollusques, et de disputer souvent une pareille proie aux plus grandes espèces de Carabiques. Quelques autres, encore plus audacieux, osent même s'introduire dans les nids des grandes guêpes (Vespa crabo) et de certains bourdons, pour y dévorer leur progéniture. D'autres, plus timides et peu délicats, ne dédaignent pas de pénétrer au sein des fumiers, des champignons décomposés, des substances végétales ou animales en putréfaction et même jusque dans les matières les plus immondes, pour aller y détruire les-œufs ou les larves de certains Diptères, qui croyaient trouver parmi ces substances un refuge assuré et y jouir en paix de l'abondance qu'elles leur procuraient. Mais tous n'ont pas des gouts aussi sordides, tels sont, par exemple, les Bolitochares, les Bolitobies, les Gyrophènes, etc., qui ont soin de se faufiler, soit entre les lamelles des champignons encore frais, soit dans les trous multipliés des polypores, moins pour se nourrir de ces cryptogames, que pour y dénicher, sans doute, les larves microscopiques qui en font leur séjour et leur subsistance. Un grand nombre passent la plus grande partie de leur vie cachés sous les mousses, sous les feuilles mortes, sous les fagots et sous les pierres, où ils se tiennent en embuscade pour surprendre les petits imprudents qui viendraient y chercher une retraite. Plusieurs Brévipennes, même parmi les petites espèces, osent s'introduire dans les grandes fourmilières de nos forêts, sans crainte d'être décimés ou exterminés par la population innombrable qui habite ces demeures coniques. Ils y viennent vivre aux dépens des provisions animales ou végétales que ces industrieuses y ont entassées comme dans un vaste grenier d'abondance, et sans doute aussi faire la guerre aux différentes larves qui fréquentent ces mémes habitations où rien ne leur manque. Les espèces qui vivent de la sorte sont assez nombreuses, parfois de grande taille, et de diverses familles. Elles sont probablement, il faut le croire, utiles à toute cette république de fourmis, qui, loin de leur faire du mal, semblent prendre plaisir à les retenir en leur société. On voit même ces dernières courir sur les fugitifs, les entourer et les contraindre à regagner la demeure commune. Sans doute, ces espèces parasites sont appelées à remplir auprès de leurs hôtes une mission bienfaisante qui doit dédommager ceux-ci des dégâts qu'elles peuvent leur occasionner ; et M. Lespès a eu l'occasion de constater que les Loméchuses, par exemple, sont appelées à rendre à cenx qui les logent les mêmes services que les Clavigères et qu'elles sont aussi. pour ainsi dire, les vaches laitières des fourmis qui viennent sucer 
la liqueur sucrée que laissent transsuder les faisceaux de poils de leur abdomen (1).

D'autres Myrmécophiles se contentent de fréquenter les petites fourmis qui établissent leur colonie soit sous les pierres, soit sous les mousses, soit dans les troncs caverneux des arbres, et, là aussi, ils sont souvent forcément retenus prisonniers par leurs hôtes (2).

Plusieurs autres espèces de Brévipennes se tiennent sous les écorces où elles rampent et semblent mener une vie cachée et tout à fait innocente, mais, en réalité, elles ne sont guère moins cruelles que les autres, car elles s'attachent à dévorer les larves de certains insectes xylophages.

Un grand nombre d'insectes de cette tribu sont essentiellenient riverains. On les voit -courir avec vitesse, à l'ardeur du soleil, sur le sable desséché des ruisseaux et des fleuves, ou sur la vase limoneuse des mares et des étangs, en redressant leur abdomen en forme d'étendard, soit verticalement, soit d'une manière cintrée, et poursuivre avec acharnement la proie qui doit leur servir de pâture. D'autres espèces, qu'on reconnaît principalement à leurs tibias armés d'une série régulière d'épines ou garnis d'une simple frang= de cils serrés, sont naturellement fouisseuses et se creusen', dans le sable humide ou dans la vase, des galeries plus ou moiıs profondes où les petits infusoires et les molucelles doivent leur fournir une nourriture abondante. Il suffit, pour les faire sortir de leur retraite, de presser la vase et le sable avec les pieds, et quelquefois la Nature parvient à les déloger, en envoyant des inondations. D'autres s'enterrent assez profondément et cherchent leur asile et leur aliment parmi les tiges serrées et même parmi lẹs racines des plantes aquatiques, où elles se nourrissent, à l'instar des Bryaxis, de certains résidus végétaux ou animaux. Quelques-unes mènent, on peut le dire, une existence presque aquatique (Thinobils, Ochthephilus, Lesleva, etc.); elles ne se contentent pas d'habiter le voisinage des lieux humides, mais elles se tiennent, à la manière des Parnes, ou sous les pierres à moitié submergées, uu sous celles dont la place est envahie par l'eau quand on les soulève, ou bien encore, elles restent cachèes parmi les mousses des roches ou murailles inondées par des cascades.

(1) Voyez : Sur les mours de la Lomechusa paradoxa, par M. Lespès (Ann. Soc. Ent. Fr. 185\%, III, LI).

(2) Nous indiquerons les espèces Myrmécophiles en leur lieu, après la description de chacune d'elles. 
Tous les insectes riverains de notre tribu ne fréquentent pas également et indifféremment le bord des eaux douces; mais plusieurs semblent préférer exclusivement le voisinage des eaux saumâtres ou bien le littoral de la mer, qui peut seul leur fournir les conditions nécessaires à leur subsistance, tant il est vrai que la Providence a pris soin de placer chaque espèce dans le milieu qui lui convient. Il en est même, parmi les espèces marines, quelques-unes qui osent affronter les flots de l'Océan et établir leur's pénates sur la plage humide alternativement submergée par le flux et le reflux de l'onde amère (Diglossa, Micralymma).

La plupart des Brévipennes, ainsi que nous venons de le voir, semblen $n_{t}$ mencr une existence presque toute terrestre, sans beaucoup s'éloigner des lieux et des retraites cachées où se sont écoulés les jours de leur premier âge. Plusieurs cependant sc plaisent à se promener ou à voltiger en sens divers, surtout vers le crépuscule d'une belle journée, soit pour aller chercher ailleurs une alimentation devenue insuffisante, soit pour rejoindre la femelle que le ciel leur a désignée. Quelques autres, à mœurs apparemment plus douces, à l'instar des Nitidulaires dont ils ont souvent les habitudes et même quelque peu le facies, semblent avoir complétement renoncé aux instincts sanguinaires de leur enfance. On ne les rencontre le plus souvent (Homalota brunnea, Anthophagus, Anthobium, etc.) que sur les rameaux des arbres élevés, ou bien encole sur les herbes, et même au sein de la corolle des fleurs ou tout à fait dans le fond du lube des Primulacées où ils trouvent en leur nectar une nourriture succulente, mais où aussi leur naturel les pousse parfois à dévorer les Thrips de différentes esfèces qui y ont également établi leur demeure. D'autres enfin, moins voraces, paraissent se contenter de sucer les plaies des arbres, comme pour en hâter la cicatrisation.

Les Brévipennes se montrent dès le premier printemps jusqu'à la fin de l'aulomne, mais ils se rencontrent en plus grande abondance dans ces deux saisons tempérées que durant les grandes chaleurs de l'été. Cependani, quelques-uns ont leurs époques particulières d'apparition, telles sont certaines espèces follisseuses qui ne craignent pas de braver les feux embrasés des jours caniculaires. D'autres, au contraire, encore plus retardalaires, n'apparaissent que vers la fin de l'automne, prennent leur quartier d'hiver (Orochares, Boreaphilus), profitent, pour se promener oll voltiger, des moindres et rares rayons de soleil de cette saison gllaciale, et, dès les premiers beaux jours, se mettent décidément en campagne, pour disparaitre ensuite avec l'arrivée des chaleurs. Parmi ceux-ci, les uns 
établissent leur résidence hivernale sous les mousses et les feuilles mortes, les autres, entre la terre et les murailles ou les troncs des arbres (1).

Tous n'affectionnent pas ron plus les mêmes zones et les mêmes natures de localités. Ainsi, les uns se plaisent principalement dans les pays entrecoupés de collines, d'autres dans nos plaines; ceux-ci dans les régions élevées et froides de nos montagnes, ceux-là dans les contrées chaudes et méridionales où l'aquilon fait rarement sentir ses rigueurs; quelques-uns dans les prairies émaillées et les champs découverts, quelques autres dans la profondeur des forêts; tels sur les bords humides des rivières ou des marais, tels sur les cotenux secs et arides. Ainsi la Providence a assigné à chaque être sa place respective suivant la mission qu'il doit accomplir et la destinée qui lui est réservée.

Tous les Brachélytres ne profitent pas de la lumière du jour pour errer çà et là à la recherche de leur nourriture. Quelques-uns restent cachés durant l'apparition du soleil, et attendent que la nuit vienne leur prêter son ombre favorable, pour sortir de leur gîte et aller exercer leurs déprédations ou surprendre dans leur sommeil les petites espèces qui doivent leur servir de pâture (Paederus, Oxytelus, Heterothops, etc.). D'autres enfin ne sortent qu'au crépuscule ou vers le coucher du soleil, ou bien encore dès l'aurore inatinale.

Quelques Brachélytres sont privés d'ailes et sont forcément condamnés à une existence toute terrestre. Mais parmi ceux que la Nature a pourvus des organes du vol, il en est qui en font rarement usage et passent leur vie dans une espèce de retraite, où leur instinct carnassier les pousse à se tenir incessamment en embuscade pour surprendre leur proie. Cependant, quelques-uns d'entre eux, oubliant un moment leur solitude, se plaisent à utiliser les heures do beau temps pour se livrer à des excursions aériennes, soit dans la journée, soit souvent dins cet instant tranquille et radieux où le soleil se prépare à cacher son disque enflammé derrière l'horizon.

Lorsqu'on veut saisir certains Brévipennes, ils se relèvent sur leurs pieds, prennent un air menaçant, écartent leurs mandibules, rel èvent leur abdomen qu'ils agitent en tous sens et du bout duquel ils font sortir deux lanières ou vésicules blanches, d'ou s'émane une odeur forle qui fait lâcher prise à l'innocent qui a osé porter la main sur eux, et qui

(1) Nous avons trouvé plusieurs fois les Orochares voltigeant et les Boreaphilus se promenant, dans les mois décembre et janvier, par plusieur's degrés de conızélation. 
ignore que toutes ces menaccs sont vaines: que cis insectes n'ofirent d'autres armes dangereuses que les pointes acérées de leurs mandibules, tout au plus capables de lui faire une piquure d'épingle.

Plusieurs autres, quand on les capture, exhalent une odeur nauséabonde et répugnante; quelques-uns même laissent couler de leur bouche une humeur brune ou bien jaunâtre comme le fiel, légèrement corrosive mais jamais aussi active que celle de certains Carabes. Sans doute que tous ces moyens, petits moyens à nos yeux, deviennent, quant à leur conservation, d'un effel puissant pour éloigner leurs ennemis. Eh! qui sait d'ailleurs si ces sucs, si ces effluves particulières qui affectent désagréablement nos organes ne sont pas des propriétés ou du moins l'indice de propriétés médicales dont l'analyse est appelée plus tard à dénontrer l'efficacité ! En cffet, la Providence doit avoir placé dans les insectes, de même que dans les plantes et les minéraux, des remèdes ou d'autres agents cachés, qu'll appartient au génie de l'homme de découvrir et d'approprier à son usage et à son bien-être.

D'autres Brévipennes, au contraire, au moindre bruit, à la moindre atteinte à leur liberté, au lieu de hâter lc pas, de s'agiter et de redresser l'abdomen, recourbent celui-ci en dessous (Tuchinus, Bolitobius, Mycetoporus, Xantholinus), replient leurs pattes, affectent l'immobilité la plus complète et ne reprennent leurs mouvements que lorsque toute apparence de danger a disparu. Quelques-uns même peuvent se contonrner en spirale.

Tous soutt loin de jouir de la même agilité; ainsi, par exemple, les Tachines, dont rous venons de parler, de même que la plupart des Oxytéliens et Proleiniens, et surtout les Micropéplides, ont la démarche plus ou moins lente, qui du reste convient parfaitement à leur vie casanière et sédentaire.

L'S nombreux insfctes qui composent la tribu des Brévipennes, malgré l'aversion que pourraient nous inspirer leurs gouts sanguinaires, loin de mériter notre mépris, doivent, al contraire, exciter notre admiration. Cct instinct cruel qui les porte à assouvir leur appétit vorace, cette guerre acharnée qu'ils font aux autres créatures, les embûches qu'ils dressent à leur proie, tout cela révèle aux yeux de l'observateur los bifrfaits d'une Providence surnaturelle qui a voulu, par une admirable loi d'équilibre, tout en procmrant à certains êtres unc nourriture facile, les faire servir en même temps, à son gré, d'instruments utiles pour décimer d'autres espèces qui nous caus"nt des dégâts souvent cousidérables. Ainsi, par exemple, 
nous devrions garder reconnaissance aux grandes espèces de Staphyliniens (Velleius, Staphylinus, Ocypus, etc.), qui concnurent, avec d'autres destructeurs, à débarrasser nos jardins des guçnes, des chenilles, des vers, des limaces, des escargots, etc., qui sont des fléaux trop connus pour nos plantes potagères. Qui ne reconnaîtrait pas aussi l'utilité des espèces fimicoles et carnivores, qui vont rechercher jusque dans les fumiers, dans les cadavres et autres matières putrides, les larves de certains Diptères, hôtes parfois très-incommodes de nos habitations et de nos étables? Peuton ne pas voir le doigl de Dieu et du moins sa prévoyance dans ces petites espèces qui, s'insinuant sous les écorces des végétaux ligneux, y vont dénicher les larves des Bostrichides (1) ou autres insectes xylophages parfois si nuisibles à nos bosquets, à nos forêts, à nos arbres abattus destinés à nos charpentes.

Telle est l'histoire abrégée des mœur's et des habitudes de nos Brévipennes. Il serait trop long d'entrer dans de plus amples détails à cet égard, et nous nous réservons de rapporter, après la description de chaque espèce, ce que nous saurons de leur manière de vivre. Mais, en terminant, n'oublions pas de reconnaitre, au milieu de cette variation infinie, une loi immuable d'harmonie qui établit parmi tous les êtres vivants un équilibre aussi nécessaire pour eux que la pesanteur et la pondération pour les corps inanimés, loi qui émane de Celui qui a tout créé, qui conserve et régit tout par une vertu invisible, auteur de toutes ces merveilles qui, d'elles-mêmes, nous enseignent à le révérer et à lui rendre un éternel homminge de reconnaissance.

\section{HISTORIQUE}

Il nous reste maintenant à esquisser l'histoire des divisions génériques successivement créées dans notre tribu des Brévipennes.

1758. Le législateur des sciences naturelles, Linné, dans la $10^{\mathrm{e}}$ édition

(1) Ces observations sur les mœurs des espèces Brévipcnnes vivant sous les écorces ont été faites et publiées par M. E. Perris, dans son beau travail sur les Insectes $d u$ Pin maritime. Ces espèces sont : Phloepora reptans et corticalis, Gr., Homalota cclata et cuspidata, Er., Oxypoda analis, Gyl., Placusa pumilio, Gr., Xautholinus collaris, Er., Quedius scintillans, Gr., Macropalpus pallipes, Cuss., Omalium vile, Er., et pusillum, Gr. (Ann. Soc. Ent. Fr. 1853, p. 557 et suiv., pl. 17.) 
de son Systema Naturae et dans ses ouvrages suivants, comprit tous les Coléoptères, objet de celte Monographie, dans le genre Staphylinus.

Poda (1), Geoffroy (2), Scopoli (3), Müller (4), De Geer (5), Fabricius (6), Schrank (7) et les divers autres entomologistes de cette époque jusqu'en 1781, marchèrent sur les pas du père de la science.

1781. Fabricius, dans son Species (8), créa, aux dépens du genre linnéen, deux coupes nouvelles : Oxyporus et Paederus.

Dans ses ouvrages postérieurs, il adopta le genre Stenus de Latreille, mais il ne proposa aucun démembrement nouveau dans la tribu qui nous occupe.

Rossi (9), Panzer (10), Olivier (11), Lamarck (12) el d'autres f́crivains de la fin du xvin ${ }^{\mathrm{e}}$ siècle, se borrièrent à suivre les traces dı professeur danois, tandis que divers entomologistes attardés ou trop exclusivement admirateurs de Linné, tels que Gmelin (13), de Villers (14), Paykull (15), Marsham (16), Walkenaer (17), restèrent fidèles à la classification du grand homme, l'honneur de la Suède.

1777. Latreille, qui débutait dans la carrière entomologique où il devait, plus tard, laissñ une lrace si lumincuse, créa, dans son Précis (18), trois coupes nouvelles qui ont pris rang parmi nos BrívipenNes, savoir : Proteinus, Lesteva et Stenus.

1802. Les Coléoptères de celte tribu n’avaient, jusquà cc jour, inspiré

(1) Insecta Musaci Graecensis (Insectes du Musẻun de Gratz). 1761, in-12.

(2) Histoire abrégée des Insectes des environs de Paris. 1762, 2 vol. in-4.

(3) Entomologia carniolica. 1763, in-8.

(4) Müller (0. F.) Fauna Insectorum Fridrichsdalina. 1764, in-8. - Id. Zoologiae Danicae Prodromus. 1776, in-8.

(5) Mémoires pour servir à l'Histoire des Insectes (t. IV). 1774, in-4.

(6) Systema Entomologiae. 1775, in-8.

(7) Enumeratio Insectorum Austriac. 1781, in-8.

(8) Species Insectorum. 1781, 2 vol. in-8.

(9) Fauna etrusca. 1790, 2 vol. in-4.

(10) Fauna Insectorum Gernaniac initia, in-8 obl. 1793 et suiv. - Id. Entomologia Germanica. 1795, pet. in-8.

(1i) Entomologie (t. III). 1795, in-4.

(12) Système des Animaux sans vertèbres. 1801, in-8

(13) Systema Naturae. 13 e édit. 1788 et suiv., in-8.

(14) Caroli Linnaei Entomologia. 1789, 4 vol. in-8.

(15) Monographia Staphylinorum Sueciae. 1789, in-8.

(16) Entomologia britannica. 180\%, in-8.

(17) Faune parisienne. 1802,2 vol. in -8.

(18) Précis des caractères génériques des Insectes. Brives, an V de la Rép., in-8. 
qu'un médiocre intérêt aux entomologistes, lorsque Gravenhorst, se livrant à leur recherche avec plus de soins, éveilla l'attention des naturalistes sur ces insectes, remarquables par la brièveté de leurs étuis, et auxquels il donna le nom de Microptères. Il publia, dans l'intervalle de quelques années, deux ouvrages remarquables (1), dans lesquels il fractionna le grand genre linnéen en un assez grand nombre de coupes nouvelles, ajoutées au petit nombre de celles créées par Fabricius et Latreille:

Aleochara, Callicerus (2), Tachinus, Astrapaeus, Oxytelus, Anthophagus, Omalium, puis Lomechusa, Gymnusa, Lathrobium, Evaesthetus, Piestus.

1804. Latreille, dont le génie se révélait tout à coup dans son Histoire naturelle des Crustacés et des Insectes (3), adoptait dans sa famille des Staphyliniens tous les genres, à sa connaissance, créés avant lui.

1806. Dans le premier volume de son Genera (4), cet illustre auteur n'ajoutait que le genre Micropeplus (5) aux coupes admises dans son précédent travail, mais il établissait, dans ses genres, des divisions particulières qui, plus tard, ont servi à divers auteurs à fractionner encore le grand genre linnéen.

1806. Duméril, dans sa Zoologie analytique (6), essayait de faire pour les animaux ce qui avait été exécuté pour les plantes, c'est-à-dire de les diviser en familles naturelles, et les insectes qui nous occupent constituen t sa fatmille des BrÉvipennes ou BrachéLytres.

1810. Gyllenhal, dont les descriptions feront toujours l'adıniration des entomologistes, secontenta, dans le tome II de ses Insecta suecica (7), de composer sa famille des Brachélytres, des genres a loptés par Gravenhorst, en les caractérisant à sa manière.

1810. Latreille, dans ses Considérations (8) ajouta peu de documents nouveaux à son ouvrage précédent.

1817. Lamarck, dans le tome IV de ses Animaux sans vertèbres, réduisit ses STAPHyLiniess à un petit nombre de genres (9), en offrarıt, dans leurs

(1) Colcoptera Microptera Brunsvic encia. Brunsvigac. 1802, in-8. el Monographia Colcoptcrorum Microptcrorum. Göttingen. 1806, in-8.

(2) Genre abandonné dans son second ouvrage.

(3) 1802-1803. 14 vol. in-S.

(4) Genera Crustaccorum et Insectorum. 1806 a 1809, 4 vol. in-8.

(5) Id. t. IV, p. 377. I! plaçait ce genre parmi les Nitidulaircs.

(6) 1806 , in. 8 .

(7) Insecta succica, t. If (1810), in-8.

(8) Considérations sur l'ordre naturel des animaux. 1810, in-8.

(9) Genres Staphylin, Oxyporc, Pédère, Oxytèle, Aléochare, Loméchuse, Tachine: 
divisions, des caractères faciles pour arriver aux coupes adoptées par lui.

1817. Dans la première édition du Règne animal (1), du au génie de Cuvier, Latreille, chargé, par l'illustre zoologiste, de la partie entomologique de cet ouvrage,substitua aux. Coléoptères microptères de Gravenhorst le nom de Brachélytres, créé par Duméril, et les divisa en quatre sections :

10 Les Fissilabres (2); 20 les Longipalpes (3); 30 les Aplatis (4); $4^{\circ}$ los MiCrocéphiLes (5).

1825. Dans ses Familles naturelles (6), l'illustre auteur suivit le même ordre d'idées; seulement il ajouta aux Fissilabres le genre Xantholinus, déjà séparé des Staphyliniens dans les calalogues de Dahl (7) et Dejean (8), et celui de Stilicus, démembré de celui de Paederus.

1825. La même année, dans le tome $\mathrm{X}$ de l'Encyclopédie méthodique, Saint-Fargeau et A. Serville publièrent quelques articles sur nos BréviPENNES.

1829. Latreille, dans la $2^{\mathrm{c}}$ édition du Règne animal, ajoutait une seclion à sa division des Brachélytres, savoir : $1^{\circ}$ Fissilabres (9); $2^{\circ}$ Longipalpes (10); $3^{\circ}$ Denticrures (11); $4^{\circ}$ Aplatis (12); $5^{\circ}$ Microct́phales (13).

1830. Le comte Mannerheim présente au mois de juin 1830 à l'Académie des sciences de Saint-Pétersbourg un mémoire imprimé dans le $1^{\text {er }}$ volume des Savants étranger's, intitulé : Précis d'un nouvel arrangement de la famille des Brachélytres.

Il divisait ces insectes de la manière suivante :

(1) 1817,4 rol. in 8 . (Le $3^{\text {e }}$ volume forme la parlie entomologique).

(2) Genres Oxyporus, Astrapacus, Staphylinus, Pinophilus, Lathrobium.

(3) Genres Paederus, Evaesthetus, Stenus.

(4) Genres Oxytelus, Omalium, Proteinus, Lesteva (Anthophagus de Gravenhorsi), Alcochara.

(5) Genres Lomechusa, Tachinus, Tachyporus.

(6) Familles raturelles du règne animal. 1825, 1 rol. in-8.

(7) Colcoptera et Lepidoptera. Wien, 1823, in-8.

(8) Catalogue des Coléoptères. 1821, in $=8$.

(9) Genres Oxyporus, Astrapaeus, Staphylinus, Pinophilus, Lathrobium.

(10) Genres Paederus, Evaesthetus, Stenus.

(I) Genre Oxytclus, auquel il ajoutait Prognatha et Coprophilus.

(12) Geıres Omalium, Lesteva (auquel étaient réunis les Anthophayus de Grarenhorst), Micropeplus, Proteinus Alcochara.

(13) Genres Lomechusa, Tuchinus, Tachyporis.

BR. 
A Labre échancré. . . . . . . . . . . . 1. Staphylinides.

AA Labre entier.

B Tarses de 5 articles.

C Palpes à articles tous distincts.

D Antennes insérées au devant des yeux.

E Pieds inermes. . . . . . . . . 4. Omalides.

EE Pieds épineux. . . . . . . . . . . 3. Tachinides.

DD Antennes joignant le bord interne des yeux. . 6. Aleocharides.

CC Palpes à dernier article caché. . . . . . 2. Stenides.

EB Tarses de 3 ou 4 articles. . . . . . . . . 3. Oxylelides.

Dans ce mémoire, qui était un perfectionnement des travaux de Latreille, le savant entomologiste ajoutait a la plupart des genres nouveaux indiqués par Leach, Kirby, Knock, etc., un certain nombre de coupes créées par lui, savoir :

Staphylinides : Physetops, Eulissus, Platyprosopus, Gryptobium.

Oxytelides : Platystethus, Trogophloeus.

Onalides : Taenosoma.

TACIINIDES : Mycetoporus.

Aleocharides : Sphenoma, Oxypoda, Miciocera, Oligola, Trichophya, Homalota, Gyrophaena, Bolitochara, Calodera.

1832. Les calalogues de Curtis el de Stephens, publiés en 1829, en dèlaissant le système tarsal, avaient déjà annoncé un p'us grand fractionnoment du genre Staphylinus de Linné, lorsque le second de ces entomologistes publia, dans le tome $\mathrm{V}$ de ses Illustrations, la section des Brachélytres, dans laquelle il comprenait les Pś́laphides.

Les insectes qui nous occupent y furent partagés en cinq familles : Tachyporides (1), Staphiylinides (2), Stenides (3), Oxytelides (4) el OmaLIDEs (5), comprenant un grand nombre de genres nouveaux.

(1) Autulia (LEACH). - Falagria (LeACI). - Astilbus (Dillwyn). - Encephalus (Kindy). - Megacromus (SteriI). - Iseltnosoma (Stepn). - Bolilobius (LEACH). Cypha (KiRBY). - Comerus (STEPII).

(2) Velleius (Leach). - Creophilus (linby). - Emus (Leach). - Gocrius (LeaCu). - Ocypus (KırBY). - Tasgius (Leacil). - Philonthus (Leacil). - Bisnius (LEACH). - Gabrius (Leacu). - Othius (LeaCu). - Hetcrothops (KIRDY).

(3) Medon, StePrI. - Sunius, Leach. - Astenus (DeJean). - Rugilus, Leach. - Dianoïs, Samouelle.

(4) Singonium. KirBy. - Bledius, Leacil. - Hesperophilus, StepH. - Aploderus, Stepr. - Carpolimus, Kirby.

(5) Syntomium, CURTis, Brit. Ent. tome V (1828), pl. 228. - Megarlhrus, KirgY. - Anthobium, LeACH. - Acidola, KinBY. 
1833. Dans la $2^{\circ}$ édition de son Catalogue (1833), édition restée inachevée, et réimprimée en 1836 , Dejean rejetait une grande partie des coupes fournies de l'autre côté du détroit, et en signalait de nouvelles à introduire dans notre tribu, savoir : Microsaurus, Microphius, Lithocharis, Astenus (déjà indiqué dans l'ouvrage de Stephens), Phloeobium.

1834. M. Wesmaël, dans le Journal de l'Institut (1), - 1835. MM. Lacordaire et Boisduval, dans leur Faune entomologique (2), et de Castelnau (3) introduisaient dans la tribu des Brachélytres les genras Lithocharis et Phloeobium indiqués par Dejean, et celui de Lithocharis créé par cux.

Newman, dans son Entomol: Magaz., t. II, p. 313, créait le genre Pseudopsis.

1837. Erichson, déjà connu par ses œuvres estimées, publie sur les Coléoptères de la Marche de Brandebourg (4), un travail dans lequel nos Brévipennes ou les Staphylen de cet auteur furent traités avec un talent qui élevait ce naturaliste au rang des premiers entomologistes del'Europe.

Dans celte étude remarquable par la nouveauté des aperçus, la précision des caractères, l'établissement d'un grand nombre de coupes nouvelles, la réforme de celles précédemment établies, les insectes qui nous occupent furent partagés en neuf groupes dont le premier, celui des Aleocharini, parut seul dans la première partie de l'ouvrage précité. Il comprenait les genres suivants (5).

1838. M. Heer, dans sa Fauna Coleopterorum helvetica distribuait la famille des Br.schéLytres de la manière suivante :

(1) Genre Harpognalhus, Recueil Encycl. belge, I, p. 119, et Journal de l'Institut (1834), p. 76.

(2) Faune entomologique des environs de Paris, 1838.

(3) Études entomologiques (i834), in-8.

(4) Dic Kacfer der Mark Brandenburg. Berlin, 1 re part., in-8.

(5) Myrmedonia (Er.) - Autalia (Lac.). - Falagria (Lac.). - Ocalea (Er.). Calodera (IIsNн.). - Tachyasa (Er.), - Phleopora (ER.). - Hygronoma (Еr.). -

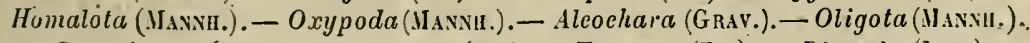
- Gyrophaena (Мansh.) - Placusa (Er.). - Euryusa (En.). - Dinarda (LaG.). Lomechusa (Grav.). - Silusa (Er.). - Pronomaca (Er.). - Gymnusa (Grav.). Myllacna (Er.).

La même année, M. Holme indiquait, près des Philontluus, le G. Remuus (Tr:ans. of the Ent. Soc. t. II, p. 01). 
A Prosternum totum corneum; stigma prothoracicum obtectum.

B Tarsi triarticulati.

C Antennae 9 articulatae. . . . . . . . 1. Micropeplida.

CC Antennae 11 articulatae. . . . . . . . 3. Oxytelida.

BB Tarsi $\ddot{b}$ articulati.

D Antennae in fronte vel sub frontis margine, non elevato, insertae, coxae posticae conicae.

E Antennae sub frontis margine insertae. . . 5. Pacderida.

EE Antennae in fronte insertae. . . . . . . 4. Stenida.

DD Antennae sub frontis margine elevato insertae. . . 2. Omalida.

AA Prosternum basi membranaceum; stigma prothoracicum inde conspicuum.

F Antennae in fronte insertae. . . . . . . 8. Aleocharida.

FF Antennae in frontis margine insertae.

G Antennae in frontis margine anteriori insertae. - 6. Staphylinida.

GG Antennue sub frontis margine laterali insertae. . 7. Tachyporida.

AI. II:e:, dans ce truvail, introduisait les genres nouveaux suivants : Oralida : Olisthaerus (Dejedn.) - Xylodromus (Heer). - Phloeonomus (H.). - Chevrieria (H.). - Geobius (H.).

AlEOCH:ARIDA : Semiris (H.).

1839. Mfenlionnons, en passant, les travaux du même auteur, dans les nouveaux Mémoirej de la Société Suisse (1); - ceux de MM. Matthews (2), - Huliday (3), - Westwood (4), - Gravenhorst (5), Shackard (6), - Curtis (7), - Stephens (8).

1839. Dans la 2e partie des Coléoptères de la Marche de Brandebourg parurent les huit derniers groupes des Staphyliniens, savoir : 2० Tachyporini, $-3^{\circ}$ Staphylinini, $-4^{\circ}$ Paederini, $-5^{\circ}$ Stenini, $-6^{\circ}$ Oxytelini.-

(1) Nıı: Denkschrift. allgem. Schweiz. Gesellschaft. 1838-1841, 5 vol. in-8.

(2) Entom. Mag. t. V, p. 188 et suiv. (G. Deinupsis.)

(3) Id. t. V, p. 252. (G. Diglossa).

(4) May. of Zool. and Botan. p. 129. (G. Micralymma). - Introduct. to the modern c!assif. of Inscets. 2 vol. in-8.

(5) In Germal's, Zeitschr. t. It, p. 210 et suiv.

(6) The Elements of brit. Ent. 1839. In-8. - Id. The Brit. Coleopt. delineated by W. S. Spry. 1840, in-8, pl.

(7) Brit. Entom. t. XIV, pl. 718. (G. Phytosics.)

(8) A Manual of brit. Coleoptera. 1839, in-8. 
7. Phloeocharini, $-8^{\circ}$ Omalini, - 90 Proteini et avec eux plusieurs genres nouveaux (1).

1840. L'ouvrage dont nous venons de parler n'était que le prélude ct la base d'un travail plıs général et plus étendu de l'illustre entomologiste de Berlin, travail qui devait ajouter beaucoup à sa gloire.

Il eut pour titre : Genera et species Staphylinorum (2). Les groupes du premier ouvrage prirent le nom de Tribus et furent port's à 11, savoir :

A Stigmata prothoracica conspicua.

B Antennae in fronte ad oculorum marginem interiorem insertae.

1. Alcorharini.

BB Antennae sub frontis margine laterali inscrtac. . 2. Tachyporini.

BBB Antennae in frontis marginc anteriore insertac. 3. Staphyluini (3).

AA Stignata prothoracica occulta.

C Coxae posticae conicae.

D Prothorax spatio pone coxas anticas membranaceo.

4. Paederini.

DD Prothorax spatio pone coxas anticas corneo.

E Antennac sub frontis margine latcrali insertae. . . . . . . . . . . 3. Pinophilini.

EE Antennae in fronte insertae. . . . . 6. Stcnini.

CC Coxae posticae transversae

F Trochanteres postici simplices.

G Coxae anticae conicae, prominentes. . 7. Oxylelini (4).

C. Coxae anticae globosae, haud prominentes. 8. Picstini.

FF Trochanteres postici fulcrantes.

H Coxae anticae conicae, exsertae.

I Ocelli nulli. . . . . . . . . . 9. Pllococharini.

II Ocelli duo. . . . . . . . . . . 10. Omalini.

HH Coxae anticae subcylindricae, haud exsertae. 11. Proleinini.

Ce Iravail, dans lequel les insectes exotiques occupaient unc ass z large place offrit, pour les cspèces européennes, un certain nombre de coupes

(1) T.chyporinı : Hubrocerus, ER.- Trichophyus, Er. - Taly.jnalhis, Er. Staphylinisi : Leptacinus, Er. - Acylophorus, Nordu. - Eur!uporus, Er. - OxyreL'Nı : Acrognathus, ER. - Delcasler, ER. - On.lins : Arpedlum, Eil. - Olophrum, E?. - Lathrimacum, ER. - Deliphrum, ER.

(2) Berolini. 1840, gr. in 8.

(3) Subtribus : Xantholinini; - Staphylinini; - Oxyporini.

(4) Subtribus : Megalopini; - Osorini; - Oxytelini; - Coprophilini. 
nouvelles qui n'avaient pas tiguré dans les Coléoptères de la Marche de Brandebourg, savoir :

Aleocharini : Phytosus (1), CurT. - Peliusa, Er., - Diglossa, HaliDAY (2). - TACHYPORINi : Conurus (3), STEPH,- StaPhylinini : Platyprosopus, Ek., Astrapaeus, Grav.-Paederini: Dolicaon (4) Casteln. - Scimbalium, Er., Scopaeus, Er. - Pinophilini : Pinophilus, Grav., - Oedichirus, Er., - Procirrus (5), Latr. - Oxytelini : Micralymma, Westw., - Syntomium (6), Curt. - Poteinini : Piestus, Grav. - Prognatha, Latr. Phloeocharini : Olisthaerus (7), Dẹjean.- Omalini, Boreaphilus (8), SahlBerg.- Proteinini : Phloeobium (9), Dejean. Glyptoma (10), ER.

1840-1844. Le Genera d'Erichson avait attiré l'attention des entomologistes sur les insectes dont nous essayons la monographie, et bientôt parurent un assez grand nombre d'articles et de mémoires fournissant de nouveaux matériaux pour l'ètude de nos Brévipennes (11).

1844. Parmi ces travaux, celui de M. Kiesenwetter, publié śous le titre de: Revue des Staphyliniens des environs de Leipzig (12) mérite un intérêt particulier. Il est plein d'observations judicieuses, de descriptions d'espèces nouvelles et de la création d'un genre nouveau.

1845. M. Nordmann, dans ses Symbolae ad Monographiam Staphylinorum (13) éclaire d'un nouveau jour la tribu des Brachélytres fissilabres de Latreille. Il y établissait des divisions et des genres nouveaux, formait des sections dans les coupes trop nombreuses en espèces, pour faciliter l'étude de ces dernières.

Dans cette étude remarquable, consacrée également aux insectes exoti-

(1) Curtis, Brit, Ent. t, XV, pl. 718.- (2) IIALIDAY, Ent. Mag. t. IV, p. 252. - (3) Stephens, Illustr. t. V, p. 186. - (4) DE Casteln. Etudes Eut. p. 119. - (5) Latreille, Règn. anim. 2e édit. t. IV, p. 436. - (6) Curtis, Brit. Entom. t. V, p. 218. - (7) DeJEAN, Catal. (1833), p. 69. - (8) SAHLBERG, Insect. fenn. I, p. 433. - (9) Dejean, Catal. p. 69. - (10) Thoraxophorals de M. Motschulsky, Bullet. de Mosc. 1837, nº 5, p. 98.

(11) Voy. Westwood, Ann. of Nat. Hist. t. VII, p. 149. - HaLiday, Entomologist, 1841, p. 186. - Ericuson, Germar's Zeitsch. t. III, p. 407. - MaERKL, Gerara's Zeitsch. t. III. - Id. Ent. Zeit. (1842), p. 142. - Acbé, Ann. Soc. Entom. t. XI. - Id. $2^{\text {e }}$ série, t. I. - Kísenwet. (1843), Ent. Zeit. p. 306. - Manvern. Bullet. de Mosc. (1843), p. 77. - Id. p. 224.-Id. (184.4), p. 176. - Chevrol. Ann. Soc. Ent. 2 e série, t. 1. - Kellner, Ent, Zeit. (1843), p. 31. - Id. (1844), p. 412 . - Motschulsky. Bullet. de Mosc. (1844), p. 812.

(12) Stct. Ent. Zeit. (1844), p. 307-320. - 340-356. - 372-378.

(13) Mémoires présentés à l'Académie de Saint-Pétersbourg par divers savants, tome IV (1845), p. 1-167 et pl: 33. 
ques, les Fissilabres européens s'enrichirent de quatre genres non mentionnés dans Erichson, savoir : Anodus (NoRdu.),- Gyrohypnus (Kirby), - Acylophorus et Trichopygus (Nordw.).

1845-48. Chaque année apportait de nouveaux matériaux pour l'élude de nos Brévipennes (1).

1849. M. L. Redtenbacher, qui avait publié, en 1845, une table analytique des genres des Coléoptères, tenta, dans sa Faune d'Autriche, d'imiter ce qu'avait fait Lamarck, pour la Flore française, c'cst-à-dirc d: conduire, par une méthode dichotomique, jusqu’ł la connaissance des espèces (2).

1849-54. Chaque annéc fournissait de nouveaux matériaux (3) pour l'histoire de nos Brévipennes, lorsque parut le tome II du Genera de Lacordaire (4).

L'illustre professeur adoptait les bases du travail d'Erichson, mais dis tribuait les genres d'après un ordre qui lui était particulier et reformait à sa manière les genres créés avant lui.

1854. La même année, MM. Fairmaire et Laboulbène publiaient le commencement de leur Faune entomologique française dans laquelle its créaient deux genres nouveaux Stichoglossa et Leptusa (5), ce dernier indiqué par Kraalz.

(1) Voy. С гим. Stelt. Ent. Zcit. (1845), p. 123-136. - Kolenatr, Yclet. Fusc. 3.-Kusteik, Kref. Europ. - MaEKLIN, Bullet. de Blosc. (1845), 54\}. - Il. (1846), 166-176. - KIESENw. Stett. Ent. Zeit. (1845'), p. 222.-IU. (1846), p. 20. - Scunidt-Goeber, Slett. Ent. Zeit. (1846), p. 2 ís. - Letzen: Arbcit. Sch'. Gesell. (1816), p. 73-85. - Maeklix, Bullel de Mosc. (1846), t. XIX, p. 1956. 187. - Id. Symbolae ad Cogn. Gen. Mycctopori. (1847), in S. - Kiesenw. Kust. Kuef. - Id. Stett. Ent. Zeitt. (1847), p. 74-78. - Jd. (1848), r. 210 et stiv. Gravennonst, Airb. Schl. Gesell. (1846), p. 94-100.-IU. Stelt. Eut. Zeit. (18\{7), p. 211-224. - 226-237. - lioseNli. Bestr. (1817). in-S. - Ba.d, Studi Eulomol.

(2) Fauna Austriaca, 1849, gr. in-8.

(3) Ericus. Stelt. Ent. Zeit. (1849), p. 184. - AubÉ, Soc. Eut. de Fr. (18̈̈0), p. 302. - Kra.tтz, Ent. Zeit. (1849), p. 124. - (1831), p. 166. - Id. p. 292. - Id. (183̈2), p. 446. - Id. (1833), p. 287-273327 - (1854), p. 124-17j. DE KILSExw. Stctt. Ent. Zeit. (1845), [1. 328. - (18:0), p. 217. - Id. p. 31 3̈. - (1851), p. 403-440. - JaCQLelin du Val, Soc. Eut. (1850), p. 4S. - (18334),

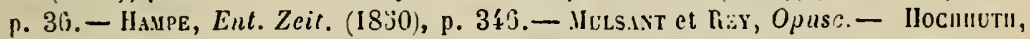
Bullet. de Mose. (1851), no 3, p. 3. - Norscilleskr, Etudes Eutumol. - Luster, Kaef. Eur.. - Rovget, Catalogue des Colëoptères de la Cóte-d Or.

(4) Voy. Fuss. Vurhandl. d. Sisbenb. ver Naturw. (1854), t V, p. 16.-Luc.ss, Mag. Zool., etc.

(B) Leur genre Euphanias avait été décrit préalablement sous un autre noin. 
1855-56. Nous nous bornerons à signaler quelques écrits (1) publiés Jans ces années, pour arriver à un ouvrage plus important.

1856. Dans le tome II de l'Histoire naturelle des Insectes d'Allemagn', entreprise par MM. Schaum, de Kiesenwetter et Kraatz, ce dernier, l'un des entomologistes de l'Europe les plus familiarisés avec la connaissance des insectes microptères, chargé de la famille des Staphyliniens, a pris aussi poul base de la classification de ces insectes les onze tribus de l'ouvrage d'Erichson; mais en les subdivisant à sa manière (2).

Dans ce travail remarquable sous beaucoup de rapports, surtout par le soin apporté à la distinction des espèces, il a employé souvent des caractères difticiles à constater et reposant sur des parties, telles que la languette, dont la forme est si variable suivant l'insecte vivant ou desséché, et il a été amené par là à créer une foule de genres nouveaux (3). Mais malgré les imperfections reprochées à cet ouvrage, il n'en est pas moins d'un mérite incontestable (4).

1837. Jacquelin du Val, dans le tome II de son beau Genera, illustré par M. Migneaux et édité par M. Deyrolle, admit aussi les onze groupes des auteurs précédents ; mais il ne suivit aucun de ceux-ci pour leur disposition.

Dans cette étude remarquable par la justesse des observations, l'exactitude et la précision des caractères, la fidélité des figures accompagnant le

(1) KRAATZ, Stett. Ent. Z. (1855), p. 20-165. - Id. Linn. Ent. t. XI, p. 1, p. 44. - Id. Berlin. Ent. Zeit. (1855), p. 45-49.-Waterhouse et Janson, Trans. Eıt. Soc. Lond. (1855), t. II, p. 136-143. - Scriba, Stett. Ent. Z . (1855), p. 29.3. - Dietrich, Ent. Zeit. (1856), p. 201. - Rosenhaule, Th. Andal. (1856), in-8. - Tuomson, Ofuersigt (1855 et 1856). - Mulsant et Rey, Ann. Soc. limn. (1855), p. 161-190, etc.

(2) Naturgeschchte der insecten Deufschlands, t. II (1856), in-8.

(3) Aleocharint : Stenusa, Stenoglossa, Ischnoglossa, Leptusa, Thiasoplita, Homoeusa, Haploglossa, Dasyglossa, Hygropora, Ilyobates, Chilopora, Ocyusa, Phlo?odioma, Tomoglossa, Schisloglossa. - TAGHyporını : Leucoparyphus, Brioporus. - Staphylinini : Leistotrophus, Metoponcus, Baptolinus. - Oxytelint: Thinodromus, Ancyrophorus, Compsochilus. - OnALINI : Amphichroum, Orochares, Porrhodites, Philorinum, Eusphalerum.

(4) Voy. aussi Motschulsky, Etud. Ent. t. VI, p. 44 ct suiv. - Page 54, il charge le nom de Conurus en Conosomus (Conosoma, Krastz). - Id. p. 59. - Thonsos, Ofversigt, t. XIV, p. 219. - DieTrich, Stett. Ent. Zeit (1857), p. 136. - Allard, Reicue, fairmaire, Merkel, líaatz et Perris. (Hist. des Insectes du Pin maritime), etc. 
texte, Jacquelin du Val, discutant la valeur de chaque genre, rejeta une partie de ceux créés avant lui et il en admit de nouveaux (1).

1858. M. Redtenbacher, dans la seconde édition de sa Faune d'Autriche, changea de place sa famille des Staphyuinides, reconstitua la classification qu'il en avait donnée et se rapprocha, dans son travail, des idées de Jacquelin du Val.

185̆8-60. Nous nous bornerons à signaler la Faune des Coléoptères du nord et du milieu de l'Allemagne (2) et divers mémoires particuliers publiés à parlir de celte époque (3).

1858. Dans le tome XV des Comptes rendus de l'Académie de Stockholm (4), M. Thomson publia une classification nouvelle des StaphyLiniens, dont nous allons reproduire les caractères :

A Prothorax inflectendus; mesosternum brevissimum, apice medio excisum.

1 Elytra immarginata; thorax marginatus ; metasternum postice utrinque pro coxis inserendis excisum: coxae anticae magnae, femorum longitudine, posticae intus conicoglobosae, extus margine inflexo haud deplanato.

a Prosternum claviculis liberis; antennae inter se magis quam ab oculis distantes. . . . . . . . 1. Staphylinini. aa Prosternum processu antico claviculis connexo ; anten-

nae inter se non magis quam ab oculis distantes. . 2. Xantholinini.

2 Elytra immarginata; metasternum postice truncatum; coxae posticae extus margine deplanato.

$b$ Antennae articulis 2 primis tumidis : caeteris tenuibus, verticillato-pilosis. . . . . . . . . 3. Trichophyini.

$b b$ Antennae haud verticillatorfilosac.

$c$ Abdomen sursum curvatum.

4. Aleocharini.

cc Abdomen segmentis retractis; antennae sub frontis maryine laterali insertae, articulis 3 ultimis crassioribus. . 3. Hypocyptini.

(1) Tagilyonites : Cilea (J. D. v.). -- Sraphylinires : Atrecus (J. D. v.). - Vuld. (J D. v.). - Oxytelites : Planeustomus (J. D. v.). - Pilleocisnites : Euphanias F.sin.s. et L.ıoulb. - Omalites : Hadrognalhus (J. D. v.).

(2) Kaefer funna. Nord und Mitteldeutschland, Coblenz. 1860, in-8.

(3) Laboulbène, Su?. Ent. 3e série VI, p. 73-10J. -- Krattz, Berlin. Ent. Z. (1858), p. 37 et suiv. - Fairmaire, Soc. Ent. t. VII (1859), p. 35, etc. - Brisour de Barneville, t. VII (1859), p. ccxvil. - Boleldieu, t. VII (1859), p. 464,

(4) Ofversigt, t. XV, ए. 28. 
3 Thorax immarginatus; elytra infra marginem lateralem linea impressa; coxae internediac valde distantes; antennae compressu-clavatae. . . . . . . . 6. Oxyporini.

4 Elytra linea marginali impressa. . . . . . . . 7. Tuchyporini. AA Prothorax porrectus; mesosternum produclum, apice truncatum, medio haud excisum.

1 Antennae capitulatae.

8. Micropeplini.

2 Antennae haud capitulatae.

$d$ Elytra intra marginem lateralem (acutum) lines impressa.

c Abdomen margine tenui deplanato. . . . . . 9. Omalini.

ce Abdomen crasse marginatum. . . . . . . . . 10. Olistaerini.

dd Elytra infra marginem lateralem linea impressa; abiomen crasse marginatum. . . . . . . . . 11. Oxytclini.

ddd Elytra immarginata.

$f$ Palpi maxillares articulo ultimo vis conspicuo, penultimo subclavato.

g Thorax immarginatus; antennae clavatae. . . . 12. Stenini.

gg Coxae anticae magnae, conicae; oculi parvi. . . . 13. Paederini.

If Palpi maxillares articulo ultimo distincto; tarsi anteriores dilatati. . . . . . . . . . . 14. Phloeocharini.

Dans cette classification, l'auteur, s'éloignant de la manière de voir de ses prédécesseurs, donnait moins d'attention aux organes de la vie de nutrition qu'd ceux de la vie de relation, supprimait un certain nombre de genres et en créait de nouveaux.

1860-67. Dans les tomes II, III et IV de ses Skandinaviens Coleoplera, l'auteur modifie cette classification, augmenle le nombre des tribus et multiplie les coupes génériques; en voici le tableau :

10 Staphylinina : $1^{\mathrm{e}}$ sous-tribu Staphylinides $(1) ;-2^{2}$ sous-iribu Philonthides (2); $-3^{\mathrm{e}}$ sous-Iribu Quediides (3).

$2^{\circ}$ Xantholinisa (4) : $1^{\text {e }}$ sous-tribu Oihiides $(4) ;-2$ sous-trib!1 Xantholinides (5).

(I) Genres Emus, Crcophilus, Schizochilus, Trichoderina, P'alydracus, Staphylinus, Uoerius, Ocypus, Tasgius, Anodus.

(2) G. Cafius, Philonthus, Gefyrobius, Remus, Bisnius, Gabrius.

(3) G. Velleius, Quedius, Hicrosaurus, Raphirus, Euryporus, Heterothops, Acylophorus, Tanygnathus.

(4.) G. Othius, Gyrohypnus.

(3) G. Gubiopterus, Nudobius, Nantholinus, Leptacinus. 
30 Paederina : 1 e sous-tribu Paederides (1); - $2^{\mathrm{e}}$ sous-tribu Lathrobiides (2).

$4^{\circ}$ Stenina (3).

$5^{\circ}$ Aleociarina : sons-tribus : $1^{\mathrm{e}}$ Autalides (4);-2c Hygronomides (5); - $3^{\mathrm{e}}$ Oligotides (6); - $4^{\mathrm{e}}$ Gymnusides (7); - $5^{\mathrm{e}}$ Phytosides (8); $6^{\mathrm{e}}$ Lomechusides (9); $-7^{\mathrm{e}}$ IIyrmedoniides (10); $-8^{\mathrm{e}}$ Aleocharides (11); - $9^{\mathrm{e}}$ Euryusides (12);-10 $0^{\mathrm{e}}$ Bolitocharides $(13) ;-11^{\mathrm{e}}$ Gyrophaenides (14); $-12^{\mathrm{e}}$ Tachyusides (15); $-13^{\circ}$ Oxypodides (16); $-14^{\mathrm{e}}$ Homalotides (17).

$5^{\circ}$ Hrpocyptind, G. Hypocyptus.

$6^{\circ}$ Trichopilyina. G. Trichophyia.

7o Pilloeocharina, G. Phloeocharis.

80 Euassthetina, G. Euaesthetus.

90 Oxytelina, $1^{\text {a }}$ sous-tribu, Oxytelides $(18) ;-2^{\mathrm{e}}$ sous-tribu, Coprophilides (19).

$10^{\circ}$ Oxyporina, G. Oxyporus.

(1) G. Paederus.

(2) G. Lathrobium, Cryptobium, Stilicus, Lithocharis, Medon, Scopaeus Sunius.

(3) G. Dianous, Stenus.

(4) G. Autalia.

(J) G. Hygronoma.

(6) G. Oligota, Miciocera.

(7) G. Gymnusa.

(8) G. Phytosus.

(9) G. Lomechusa, Alemeles.

(10) G. Myrmedonia, Zyras, Astilbus.

(11) G. Aleochara, Baryodma, Polystoma, Microglotta.

(12) G. Dinarda, Thiasophila, Notothecta, Lyprocorrhe.

(13) G. Bolithochara, Phloeopora, Leptusa, Pachygluta, Dexiogyia, Thamiosoma, Silusa, Crataraea.

(14) G. Encephalus, Gyrophaena,

(15) G. Falagria, Semiris, Calodera, Amarochara, Chilopora, Ilyobates, Ityochara, Tashyusa, Ischnopoda, Thinonoma, Gnypeta, Aloconota, Dilacra, Ocyusa, Acrostiba, Hydrosmecta.

(10) G. Myllaena, Oxypoda, Thliboptera, Baeoglena, Bessopora, Mycctodrepa. Pycuriraea, Disochara, Demosoma, Coprothassa, Acrotona.

(17) G. Ocalea, Placusa, Homalota, Thectura, Dadobia, Dinaraca, Amischa, Amilobia, Bessobia, Aliunta. Plataraea, IIalobrchta, Enalodroma, Alcvonota, Disopora, Liogluta, Thinobaena, Alaobia, Thamiaraea, Schistoglossa, Atheta, Dochmonota, Geostiba, Sipalia.

(18) G. Bledius, Hesperophilus, Astycops, Platystethus, Pyclocraerus, Oxytelus, Caccoporus, Epomotylus, Tanycraerus, Anotylus, Aploderus, Carpalimus, Tras: gophlocus, Taenosoma, Ancyrophorus

(19) G Syntomium, Acrognathus, Planeustomus, Coprophilus, 
110 Tachyporina : Sous-tribus : $1^{\mathrm{e}}$ Tachyporides $(1) ;-2^{\mathrm{e}}$ Iy porides (2).

$12^{\circ}$ Olisthaerina, G. Olisthaerus.

$13^{\circ}$ Omalinina : sous-tribus : $1^{\mathrm{e}}$ Anthophagides $(3) ;-2^{\mathrm{e}}$ Omaliides (4) ; - $3^{e}$ Proteinides (5).

1862-1868. Depuis la publication de cet ouvrage jusqu’à sa terminaison, il n'a pas paru de monographie sur nos Brévipennes; mais une foule de documents ont été produits se rattachant à l'histoire de ces insectes.

Nous nous bornerons à citer un des articles se rattachant de plus ou moins près à nos Coléoptères de France.

1869-71. Divers travaux plus ou moins importants, publiés dans Ics dernières années, méritent d'être signalés: Rye, Ent. Monath. Mag. (1869). - Pandellé, Soc. Ent. de Fr. t. IX, p. 261 (Tachyporides). - Scharp. (Homalotides), Trans. Soc. Ent. Lond. (1869). - De Marseul, Brachélytres d'Europe (Abeille), 1871. - Baudi, etc. (6).

En 1872, nous avons présenté à la Société linnéenne de Lyon le commencement de l'histoire des Brévipennes destinée à faire partie de nos

(1) G. Habrocerus, Conosoma, Tachyporus, Lamprinus, Cilea, Tachinus , Drymoporus.

(2) G. Mycctoporus, Ischnosoma, Megacronus, Bryocharis, Bryoporus, Bolitobius, Lordithon.

(3) G. Anthophagus, Gcodromicus, Lestcva, Boreaphilus, Eudcctus, Coryphium.

(4) G. Micralymma, Arpedium, Cylletron, Olophrum, Lathrimaeum, Porrhodites, Deliphrum, Pycnoglypta, Acrulia, Hapalaraea, Acrolocha, Anthobium, Acidota, Etheotassa, Phlocostiba, Xylodromus, Phloconomus, Omalium, Phyllodrepa.

(J) G. Proteinus, Megarthrus.

(6) Voyez Fairmaire, Ann. Soc. Ent. de Fr. (1859), p. 272. - (1861), p. 580. - Scriba, Berlin. Ent. Zeit. (1859), p. 413.-(1862), p. 273.-(1864), p. 125, elc. - De Matilan, Soc. linn. de Normand. (1861), p. 101. - Id. Soc. Ent. de Fr. (I862), p. 244. - Fauver, Soc. linn. de Normand. (1861), p. 248. - Id. Soc. Ent. dc Fr. (1861), p. 230. - (1861), p. 81 - P. 292 (genre Arena). - 1863, p. 293, elc. - Reiche, loc. cit. (1864), p. 375, etc. - De Saulcy, Soc. Eut. (1862), p. 69, 71, etc. - Waterhouse, Trans. Soc. linn. Lond. (1863); p. 160, 211, 233 et suiv. - Kiesenwerter, Berlin. Ent. Zeit. (1861), p. 373 et suiv. Kr.atz, loc. cit. (1862), p 404 (et Fuss) (g. Borboropora) et ann. suiv. - Tiromson, Ofucrsigt, elc. (18ð6) et ann. suiv. - SchIOed Te, Kroyer's, Nat. Tirlskr. (1842) et ann. suiv. - Baudi, divers mémoires. - Kuster, Kaef. Europ. - Ajoutez les catalogues publiés par iIM. Schaum, Stein, Grenier, de Marseul, Leconte, Kraatz, HAROLD el GEMMINGER, etc. 
Coléoptères de France, et, vers le mème temps paraissait aussi la première partie des Stapisulinides de la faune gallo-rhénane, par M. Fauvel, dont le beau talent nous promet, sur ces insectes, un bon ouvrage de plus.

Nous partagerons la tribu des BrévipenNes en trois groupes principaux :

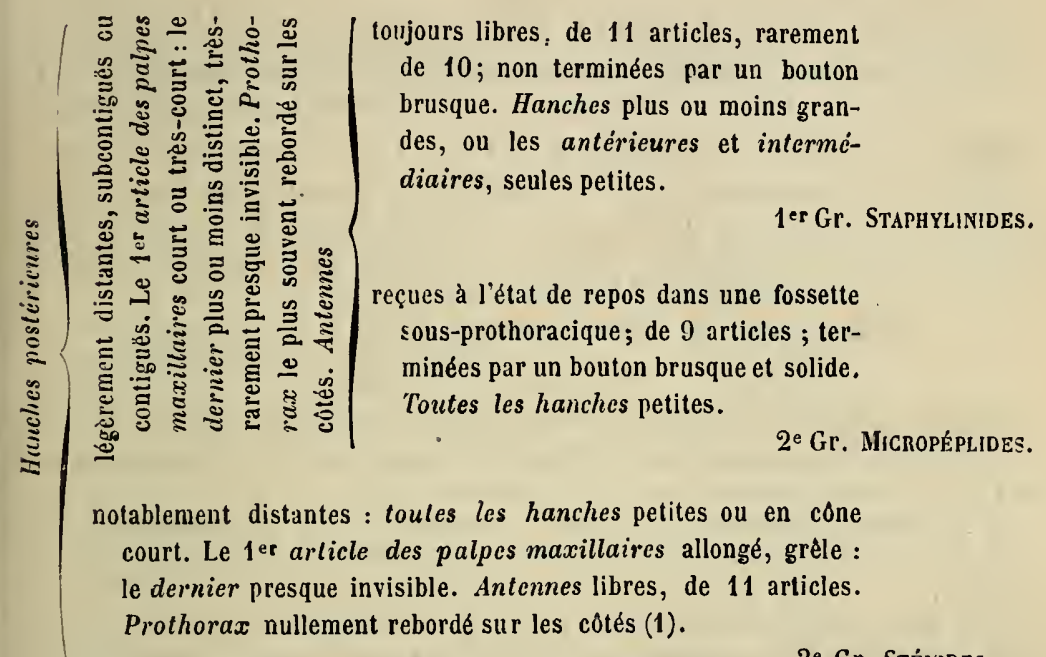

$3^{3}$ Gr. STÉNides.

(1) On peut ajouter à ces caractères : $1^{\circ}$ antennes terminées par une massue de 3 articles : $2^{\circ}$ mésosternum fortement prolongé au devant des hanches intermédiaires, au point que celles-ci sont fortement distantes des antérieures. Chez les Staphylinides, il est vrai, les antennes sont parfois exceptionnellement terminées en massue, comme, par exemple, dans les gemes Oligota, Syntomium et Phloeobium, mais alors les hanches postérieures sont transverses et les autres plus ou moins grandes; comme aussl dans le genre Pholidus, mais alors le corps est recouvert d'écailles déprimées. Chez la plupart des Pédériens et chez quelques Oxytéliens, le mésosternum est assez dẻveloppé au devant des hanches intermédiaires, mais alors les lianches sont toutes, ou au moins les postérieures, plus ou moins grandes, et les autrunes ne sont pas terminécs en massue.

Nous cxcluons de nos Sténill's le genre Evaesthetus que nous transporlons parmi les $P e ́ d e ́-$ riens. 


\section{PREMIER GROUPE}

\section{STAPHYLINIDES}

Caractères. Antennes toujours libres; composées de 11 articles ou rarement de 10 ; nun terminées par un bouton brusque et solide. $1^{\text {er }}$ article des palpes maxillaires court ou très-court, souvent en massue arquée, toujours moins long que la moitié du suivant (1): le dernier plus ou moins distinct, très-rarement presque invisible (2). Hanches plus ou moins grandes, ou quelquefois les antérieures ou intermédiaires petites, mais les postérieures assez grandes et transverses.

Nous subdiviserons ce premier groupe en 15 familles distinctes (3),

(1) Dans certaines espèces du genre Ocypus de la famille des Staphyliniens, le 1 er article des palpes maxillaires parait assez développé, mais alors il est épais, et, en tous cas, moins long que la moitié du précédent.

(2) Par exemple, chez quelques Pédlériens, le dernier article des palpes maxillaires est à peine distinct, mais alors les hanches sont toutes plus ou moins grandes ou saillantes.

(3) Il existe plusieurs classifications des Brévipennes, basées soit sur le plus ou moins d'apparence des stigmates prothoraciques, soit sur le mode d'insertion des antennes, soit sur la présence ou l'absence d'ocelles sur le vertex, soit sur la forme et la disposition des hanches, surtout des postérieures, soit sur le développement dı mésosternum, soit sur la direction du prothorax, etc. Conıme les stigmates prothoraciques ne peuvent le plus souvent ètre découverts qu'à l'aide d'une anatomie minutieuse, étant situés dans l'intervalle membraneux de derrière les hanches antérieures, et que cet intervalle est plus ou moins refoulé selon que le mésosternum se prolonge plus ou moins en avant pour s'emboiter plus ou moins fortenient, dans le prothorax, nous avons dú rejeter tout système auquel ces stigmates serviraient de point de départ. Quant aux hanches antérieures, leur forme trop variable ne leur assigne qu'un rang accessoire. Nous en dirons autant du mésosternunı, qui varie de développement dans une mème famille, et qui offre son bord antérieur plus ou moins ćchancrè à mesure qu'il devient plus court. La direction du prothorax tantot incliné darrière en avant et recouviunt un peu la base des élytres, taniôt prolongé horizontalement et séparé des élytres par un léger intervalle, ne nous parait pas un caractère absolu, car, chez plusieurs Omaliens, chez quelques Oxytéliens et mème chez quelques Pédériens, le prothorax semble s'abaisscr en avant et il est à noter qu'en mème temps sa base tend à s'appnyer sur celle des élytres. Reste donc le caractère des hanches postérieures qui, pour nous, est dominateur coinme révélant des mœurs diffirentes; puis viendraient celui du mode d'insertion des antennes et celui des ocelles, que nous placerons en deuxième et troisième lignes. Mais comme le caractère des antennes, pour être bien apprécié, exige 
répondant à 4 sections principales, dont voici les caractères les plus saillants :

un examen attentif, nous avons cru devoir le corroborer par diverses modifications essentielles, que nous ont présentées quelques autres organes, tels que le front, le prosternum, les élytres, les tibias, etc. Bref, n'ayant pu trouver un signe exclusif bien tranclić, nous avons ètabli nos grandes coupes sur un ensemble de caractères, dont nous discuterons la valeur après la description de chaque famille.

Après a voir fait abstraction de tout systeme antérie ur afin de nous dégager de toute prévention, nous avons essayé de créel une classification à nous. Un travail patient, plusieurs fois abandonné et repris, nous a donné les trois résultats suivants, quant à la Uisposition des familles :

$\begin{array}{lll}\text { Aléochariens. } & \text { Staphyliniens. } & \text { Staphyliniens. } \\ \text { Trichophyens. } & \text { Tantholiniens. } & \text { Xantholiniens, } \\ \text { Tachyporiens. } & \text { Pédériens. } & \text { Pédériens. } \\ \text { Habrocériens } & \text { Aléochariens. } & \text { Oxyporiens. } \\ \text { Staphyliniens, } & \text { Trichophyens. } & \text { Oxytéliens. } \\ \text { Tantholiniens. } & \text { Tachyporicns. } & \text { Phléochariens. } \\ \text { Pédiricns. } & \text { Habrocériens. } & \text { Trigonuriens. } \\ \text { Oxyporiens. } & \text { Oxyporiens. } & \text { Proteiniens. } \\ \text { Oxytéliens. } & \text { Oxytéliens. } & \text { Phléobiens. } \\ \text { Phliochariens. } & \text { Phléochriens. } & \text { Omaliens. } \\ \text { Trigonuriens. } & \text { Trigonuriens. } & \text { Pholidiens. } \\ \text { Proteiniens. } & \text { Proteiniens. } & \text { Habrocériens. } \\ \text { Phléobiens. } & \text { Phlíobiens. } & \text { Tachyporiens. } \\ \text { Omaliens. } & \text { Omalicns. } & \text { Trichophyens. } \\ \text { Pholidiens. } & \text { Pholidiens. } & \text { Aléochariens. }\end{array}$

Comme on le voit, la première disposition rappelle un peu celle d'Erichson, de Jacquelin du Val, de Kraatz et de la plupart de nos catalogues récents. Mais, au lieu de commencer par les grandes espèces les plus carnassières, elle place en tête les Aliochariens et les Tachyporiens, la plupart mycétophages comme les Omaliens, arec lesquels les derniers semblent du reste se lier par le développement des élytres. La deuxieme se rapproche un peu de l'ordre suivi par Thomson, qui nous semble mettre une trop grande dista:ce entre les Pédériens et les Oxyléliens d'une part et les Tachyporiens et les Omalicns d'uutrc part. Quant aux Pidériens que Thomson place prosque a la fin, ils nous semblent suivre naturellement les Xantholiniens, dont avec raison cet autcur a fait une famille distincte. La troisièmedisposition sc trouve d'accord avec celle ¿ce Dejean, qui possédait au plus haut degré le coup d'œil entomologique. Elle passe des grandes espèces carnas ières aux espèces riveraines (les Pédériens), de celles-ci aux fouisseuses (Oxytéliens), de ces dernières aux floricoles et mycétophages (Omaliens, Tachyporiens, Alćochariens), et ces familles, ainsi disposées, se trouvent enchainées non-seulement par les mœurs, mais encorc par des caractères organiques plus importants et plus réels. Après avoir jugé et mûri ces trois plans, nous nous sommes arrêtés à ce dernier, qui nous a paru classer les familles d'une manière plus naturelle. 
I. Hanches postérieures à lame supérieure plus ou moins conique (1); a lame inférieure verticale ou enfouie, rarement subexplanée. Élytres non rebordées sur les côtés, dépassant peu ou non la poitrine. Métasternum le plus souvent échancré pour recevoir la lame supérieure des hanches postérieures.

a Autennes iusérées sur le devant du front, en dedans de la base externe des mandibules, sous une saillie peu prononcéc. 1 Mésosternum court, échancré en avant. Hanches antérieures de la longueur des cuisses. Tibias, all moins les intermédiaires et postérieurs, épineux.

b Prosternum peu développé au devant des hanches antérieures, sans pièce antésternale cornée entre les clavicules. Antennes écartées.

STAPHYLINIENS.

b) Prosternum passablement développé au devant des hanclies antérieures, avec une pièce antésternale cornée (2) entre les clavicules. Antennes rapprochées.

Xantholiniens.

aa Antennes insérées à l'angle antéro-externe du front, sous une saillie sensible. Mésosternum plus ou moins développé au devant des hanches intermédiaires, tronqué ou subarqué en avant. Tibias simplement pubescents.

PÉdénIENs.

II Hanches postérieures à lame supérieure transverse ou en cônc court; à lame inféricure verticale ou déclive, parfois subexplanée en dehors mais étroite (3). Antennes insérées sous une saillie plus ou moins sensible des bords latéraux du front, en dehors de la base externe des mandibules. Métasternum légèrement ou uon sinué au devant des hanches postérieures : les antérieures moins longues que les cuisses.

c Front largement tronqué, à peine prolongé au devant de l'insertion des antennes. Dernier article des palpes labiaux grand, semi-lunaire. Hanches intermédiaires largement distantes. Prosternum assez court.

OXYPORIENS.

cc Front plus ou moins prolongé au devant de l'insertion des antennes. Dernier article des palpes labiaux normal, subcylindrique ou subovalaire. Hanches intermédiaires médio crement distantes, rapprochées ou contiguës.

d Corps non recouvert d'écailles déprimées. Le premier

(1) Celte lame csl généralement plus ou moins élranglèe avant ou ver's son milieu.

(2) Celte pièce, plus ou moins développée, occupe toute l'ćchancirure antćrieure du proslcrnum, rnlre 2 saillies ou clavicules plus ou moins apparenles, situées, chacune, all devant du bord iuteruc du repli prollıoracique, el plus ou moius obliquement dirigées en dedans.

(3) Il est a remarquer quc, loisque la lane inférieure parail parfois un peu cxplanéc, elle ne l'est qu'en dehors oủ elle s’élève jresque jusqüan nivcau de la lane supérieure; de plus, elle ne cesse de rester élroile. Les genres Coprophilus et Deleaster nous en offrent des exemples. 
article des antenıes médiocre, non dilaté intérieurement, simplement en massue.

e Vertex sans ocelle.

f Prosternum plus ou moins développé au devant des hanches antérieures : celles-ci coniques ou cylindriques, parfois peu saillantes, petites ou subglobuleuses.

g Élytres prolongées, au plus, jusqu'au sommet des hanches postérieures, laissant à découvert au moins 5 segments de l'abdomen, sans compter celui de l'armure.

h Tiochanters postérieurs petits, atteignant à peine le 5ैe de la longueur des cuisses, Tête plus ou moins dégagée, à cou distinct. Tempes plus ou moins contiguës en dessous.

Oxytéliens.

hh Trochanter's postérieurs grands, atteignant environ le tiers de la longueur des cuisses. Téte plus ou moins engagée sous le prothorax, sans cou distinct. Tempes séparées en dessous par un intervalle assez grand. PhlÉochariens.

gg Élytres prolongées bien au delà du sommet des hanches postérieures, laissant à découvert, au plus, les 4 derniers segments de l'abdomen, sans compter celui de l'armure. Tête saillante, beaucoup plus étroite que le prothorax. Corps scaphidiforme,

Trigonuriens.

If Prosternum peu développé au devant des hanches antérieures : celles-ci sublinéaires, non saillantes, transversalement et subobliquement couchées. Élytres recouvrant en majeure partie l'abdomen, rebordées sur les côtés. Proteiniens.

ee Vertex avec un seul ocelle. Épistome relevé et subéchancré en avant. Hanches antérieures sublinéaires, non saillantes, transversalement et obliquement couchées. Elytres dépassant un peu la poitrine, fortement rehordées-subexplanées sur les côtés.

Phléobiens.

eee Vertex avec deux ocelles. Ėlytres dépassant presque toujours (1) la poitrine, constamment rebordées sur les côtés. Onaliens.

dd Corps recouvert d'écailles déprimées. Le 1 er article des an-

tennes très-gros, dilaté intérieurement, les 3 ou 4 derniers

formant unes massue allongée. Toutes les hanches petites.

Tar ses de 3 articles (2).

Pholidiens.

III. Hanches postérieures réduites à une seule lame supérieure,

(1) Exceptè le genre Micralymma.

(2) Jacquelin du Val, qui souvent semble tenir beaucoup an nombre des articles soit des antennes, soit des tarses, a cru devoir avec raison, dans son tableau des Staphylinides, rejeter un système qui eủt abouti à réunir les Deinopsis, Pholidus et Micropeplus au groupe des Oxytélites, où les premier et dernier de ces trois genres eussent étẻ tout à fait dẻclassés.

BR. 
grande, transverse, triangulaire : les antciricures coniques, aussi longues que les cuisses. Antennes capillaires, verticillées-pilosellées, insérées vers le bord antérieur des yeux. Ėlytres rebordées sur les côtés. Tibias intermédiaires et postérieurs éparsement épineux.

HABROCÉRIENS.

IV. Hanches postérieures à lame supéricure conique ou en carré long; à lame inférieure plus ou moins large, fortement explanée: les antéricures coniques. Tête sans saillie antennaire distincte. Mésosternum et Prosternum généralenent peu(1) développés. Métasternum non ou peu sinué pour l'insertion des hanches postérieures (2).

i Elytres rebordées sur les côtés, dépassant sensiblement ou notablement la poitrine. Téte engagée dans le prothorax. Antennes insérées sous les bords latéraux $d u$ front, en dehors de la base externe des mandibules. Abdomen se recourbant généralement en dessous. Hanches antérieures aussi longues ou un peu moins longues que les cuisses. Tibias le plus souvent épineux. Tachyporiens,

ij Elytres non rebordécs (3) sur les côtés. Tête généralement assez dégagée. Hanches antéricures ordinairament moins longues que les cuisses.

k Antennes insérées assez loin des yeux, capillaires, verticillées-pilosellées, avec les 2 premiers articles renflés. Élytres dépassant un peu la poitrine. Tibias pubescents.

TRICHOPHYENS.

kk Antennes insérées sur le front, vers le bord antérointerne des yeux, un peu en dedans ou sur la ligne de la base externe des maniiibules. Élytres dépassant à peine ou non la poitrine. Abdomen se recourbant en l'air. Tibias pubescents, rarement épineux.

AlÉochariens.

(1) Excepté les genres Cardiota, Falagria et Autalix. Il est à noter quordinairement le nisosternum suit dans son développement la mème loi que le prosternum.

(2) Excepté le geure Tachinus, cliez lequel le sinus ou échancrure est sensible. En outre, dans ce genre, la lame inféricure des hanclıes postérieures, bien que explanée dans presque tout son développement, est assez étroite; mais elle est parallẻle, horizontale et sur un plan inférieur, beaueoúp plus prolongée en delırs que la lame supérieure qui est conique, tandis que, dans le genre Coprophilus, eelle-ci est transver'sale et aussi étendue extérieurement que l'inférieure. D'alleurs, e dernier genre offe une saillic antennaire dislinete, qui n'existe pas dans le genre Tachinus.

(3) A l'exception du genre Dinarda, oủ les eótés forment une arçte trancliante séparant le repli de la page supérieure. 


\title{
PREMIÈRE FAMILLE
}

\author{
STAPHYLINIENS (1)
}

Caractères. Corps plus ou moins allongé. Tête saillante, dégagée, le plus souvent portée sur un col court et épais. Front non ou peu prolongé au devant de l'insertion des antennes; vertex sans ocelle. Tempes séparées en dessous par un inlervalle nul ou étroit, rarement assez sensible. Palpes maxillaires de 4 articles, les labiaux de 3. Antennes de 11 articles; écartées à leur base, plus distantes entre elles que des yeux; insérées sur le devant du front, en avant du niveau anlérieur des yeux, en dedans de la base externe des mandibules (2), sous une saillie peu prononcée. Prothorax de forme variable, loujours rebordé sur les côtés. Élytres non rebordées latéralement, dépassant à peine ou non la poitrine, ou laissant l'abdomen presque en entier à découvert. Abdomen plus ou moins rebordé sur les côtés, possédant la faculté de se redresser en l'air; le segment de l'arınure souvent distincl, avec 2 ou 3 lanières ou appendices. Prosternum peu développé au devant des hanches antérieures, sans pièce antésternale cornée entre les clavicules. Mésosternum peu prolongé au devant des hanches intermédiaires, échancré en avant. Métasternum plus ou moins échancré au devant des hanches postérieures. Hanches antérieures grandes, coniques, très-saillantes, de la longueur des cuisses (3): les intermédiaires conico-ovalaires, peu saillantes, obliquement disposées (4) :

(1) Lorsque a paru la 5e livraison de la Faune gallo-rhénane, notre manuscrit sur les Staphyliniens était tout prêt. Nous avons dú retarder la publication de ce dernier, afin de pouvoir citer et mettre à profit l'excellent travail de notre collègue de Caen, travail où abondent les critiques les plus judicieuses.

(2) C'est-à-dire en dedans des parallèles tangentes à la base externe de chaque mandibule.

(3) Elles sont coniques dans leur configuration; elles sont toujours convexes en avant, planes ou subexcavées en dessous, subobliques, un peu renversées en arrière. Cela dit, une fois pour toutes.

(4) Quoique peu saillantes, elles sont plus ou moins convexes intérleurement, mais plus ou moins creusées ou déprimées et lisses en dehors pour faciliter le jeu des cuisses. Elles sont plus ou moins obliquement disposées. Nous n'en reparleronspas. 
les postérieures (1) à lame supérieure plus ou moins conique, plus ou moins étranglée ou sillonnée en travers; à lame inférieure verticale ou enfouie, rarement apparente ou subexplanée. Tibias, au moins les intermédiaires, et postérieur's épineux. Tarses de 5 articles.

Nous partagerons la famille des Staphyliniens en 2 branches :

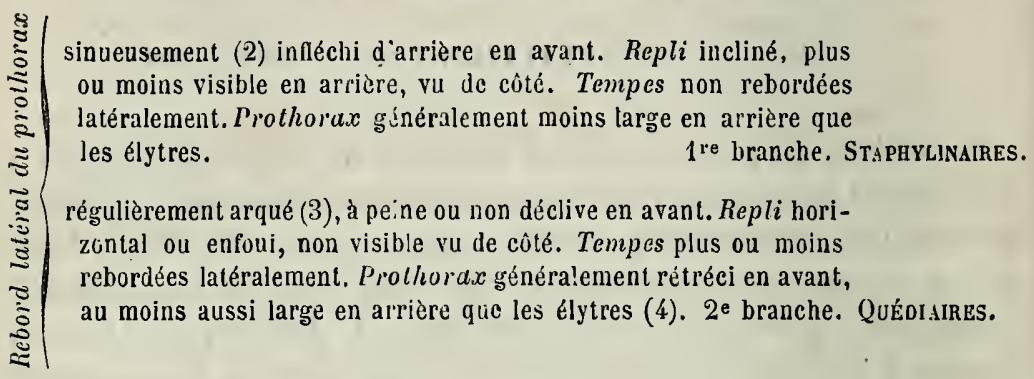

\section{PREMIÉRE BRANCHE}

\section{STAPHYLINAIRES}

Caractères. Corps allongé, plus ou moins parallèle. Tête saillante, très-grande, surtout ch $+\mathrm{z}$ la plupart des $\sigma^{\star}$, portée sur un col court, épais, moins large que le virtex. Tempes sans rebord latéral distinct. Antennes plus ou moins développées, souvent courtes ou assez courtes. Prothorax transverse, carré ou suboblong, parfois rétréci en arrière, rarement en avant, généralement moins large que les élytres; à rebord latéral plus ou moins infléchi d'arrière en avant (5) et le plus souvent d'une

(1) Elles sont munies en dessous, vors leur sommet, de 2 ou 3 épines ou soies spiniformes, rarement réduites à de simples cils.

(2) Dans les exceptions, qui sont très-rares, le repli reste visible vu de côté et les tempes ne sont pas rebordées, etc.

(3) Les exceptions sont très-rares, mais le repli n'est jamais visible vu de côté.

(4) Les exceptions en sont rares.

(5) De ce que le bord latéral du prothorax s'infléchit, il résulte que celui-ci offre, sur les cótés, une surface verticale ou subverticale étroite et graduellement élargie d’arrière en avant, limitée supérieurement par les côtés du disque qui sont mousses, et infésieurement par le rebord latéral lui-mêıne ou bord supérieur du repli, de telle sorte que la marge latérale paraît comme doublée, surtout antérieurement. Mais cette disposition est loin d’ètre absolue. Elle est bien accusée dans les genres Leistotrophus, Trichoderma el Abemus, moins sentie dans les Creophilus, Staphylinus, Platydracus et Ocypus, etc., faible dans la plupart des Philonthates, presque nulle, surtout chez les espèces de ce rameau à tete plus étroite que le prothorax ( $P$. politus, cruentatus, varians, etc.), et mème chez quelques autres (P. cyınipennis). 
manière sinuée ; à repli incliné, plus ou moins visible en arrière. vu de côté. Élytres ordinairement courtes, mousses latéralement. Abdomen subparallèle, quelquefois subatténué en arrière. Pieds généralement assez courts. Tarses antérieurs plus ou moins dilatés, surtout chez les $\sigma^{\prime \prime}$, parfois simples dans les 2 sexes.

La branche des Staphylinaires peut se partager en 3 rameaux, ainsi qu'il suit :
\begin{tabular}{c|c} 
terminé, entre les hanches postérieures, par un lobe peu \\
saillant, échancré ou verticalementinfléchi.Mésosternum \\
sans arête transvers ale arquée ou angulée. Opercule
\end{tabular} prothoracique distinct ou non.
1 er rameau. Staphylinates.
terminé, entre les hanches postéricures, par un lobe saillant, profondément incisé, explané ou subhorizontal. Mésosternum à arête transver'sale le plus souvent arquée ou angulée (1). Opercule prothoracique nul.
$2^{\mathrm{e}}$ rameau. Philonthates.
Triangulairement renflé, plus ćpais que le suivant.Métasternum à lobe postérieur peu saillant, échancré. Mésosternum sans arête trans- versale. Opercule prothoracique distinct. 3e rameau. Rémates.

\section{PREMIER RAMEAU}

\section{STAPHYLINATES}

Caractères. Corps plus ou moins ponctué ou pubescent en dessus. Tète grosse, en carré transverse, suborbiculaire ou subtriangulaire; offrant de chaque côté un pore sétifère, situé vers le bord interne des yeux (2). Labre b!lobé, présentant souvent sur les côtés une expansion cornée oll submembraneuse (3). Le $2^{e}$ article des antennes normal, non renflé, non plus épais que le suivant. Prothorax transverse ou subcarré, souvent rétréci en arrière, rarement lisse. Mésosternum variable, sans arête transversale arquée ou angulée. Métasternum offrant entre les hanches posté-

(1) Excepté le genre Orthidus oi l'ardte transversale est nulle.

(2) Presque loujours, dans la famille des Staphyliniens, les côtés de la tête, du prothorax et des élytres, et souvent l'abdomen et le ventre sont parés de pores sétiferes très-distincts. Nous ne mentionnerons ici que ceux situés entre les yeux, parce qu'ils offrent quelque importance par leur nombre (2 oul 4 ) et leur disposition, ainsi que nous le verrons quant aux autrcs rameaux.

(3) La languette, sans importance, peu appréciable mème chez les plus grandes espèces, souvent membraneuse au sommet, est tantôt bilobée, tantôt simplement échancrée ou sinuée en avant. 
rieıres un lobe peu saillant, échancré ou verticalement infléchi : celles-ci très-légèrement distantes ou rapprochées à leur base. Opercules prothoraciques distincts ou non.

OBs. Ce rameau, qui renferme les plus grandes espèce; de la tribu des Brévipennes, peut se diviser en plusieurs genres, d'un faciès analogue, mais bien différents par les caractères constitutifs. Nous en donnons ciaprès le tableau :

non caréné, courı, en hémicycle. Hanches intermédiaires notablement distantes. Antennes assez fortement épaissies. Opercule prothoracique distinet. Prothorax transverse. Tarses intermédiaires el postérieurs

subélargis. Tèle en trapèze subtransverse. Tête et prothorax trèsdensement soyeux ou pubescents. EMus.

non élargis. Tête en carré fortement irausverse. Téte et prothorax glabres et lisses sur leur disque.

Crbophilus.

caréné sur sa ligne médiane; en triangle arrondi au sommet. Hanches intermédiaires passablement distantes. Antennes subfiliformes. Opercule prothoracique distinct. Prothorax subcarrè, à angles antérieurs saillants et aigus. Dessus $d u$ corps pubescent, marqueté de taches obscures.

Leistothophus.

subarrondi au sommet, traversé par une chainetle arquée de gros points enfoncės. Antennes subépaissies. Opercule prothoracique distinct. Corps pubescent, marqueté en dessus de taches nébuleuses.

TRICHO OERMA.

( aiguë. Hanches intermédiaires subcontiguës. Élytres faiblement varièes.

ABEMUS.

nul. Pointe mésosternale émoussẻe. Hanches intermédiaires lègèremen! distantes. Elytres unicolores.

STAPHYLIXES.

trapéziforme ou subtriangulaire, étıoitement arrondie aux angles postérleurs. Opercule prothoracique dis. tinct. Elytres unicolores.

Platydaces.

$\cong$ ( au bout. Le dernier article des 记范 mxxillaives subfusiforme ou subcylindrique. Opercule prothoracique nul. A odomen unicolorc ou peu tacliè en dessus.

Ocypus.

subsécuriforme dans les 2 sexes. Le dernier article des maxillaires parfois subsécuriforme chez le mảle. Opercule prothoracique nul ou rudimentaire. Abdomen unicolore. TAsgios

assez grčles, subfalciformes, non dentèes intérieurement. Le dernier article des palpes labiaux sécuriforne. Opercule prothoracique nul ou rudimentaire. Abdomen unlcolore. 


\section{Genre Emus, Ème, Curtis.}

Curtis. Brit, Ent. XII, pl. 534. 1825.

Etymologie ? żน̀̀ร, mien?

Caractéres. Corps allongé, subdéprimé, ailé, revêtu en dessus d'une puhescence soyeuse et très-serrée.

Tête grande, saillante, trapéziforme, subtransverse, portée sur un col très-court, épais, moins large que le vertex. Tempes non rebordées sur les côtés, contiguës en dessous dans leur milieu. Épistome très-court (1), tronqué ou à peine échancré au sommet. Labre court, bilobé. Mandibules robustes, saillantes, subsillonnées en dehors, fortement et inégalement unidentées intérieurement vers leur milieu, aiguës, arquées, croisées au repos. Palpes maxillaires assez développés, subfiliformes; à $1^{\mathrm{er}}$ article court : les $2^{\mathrm{e}}$ et $3^{\text {e }}$ suballongés, en massue : le dernier plus étroit et presque aussi long que le précédent, subfusiforme, mousse au bout. Palpes labiaux assez courls; à $2^{\mathrm{e}}$ et $3^{\mathrm{e}}$ articles suballongés, subégaux : le dernier un peu plus long, un peu plus grêle, subfusiforme, mousse au bout. Menton transverse, trapéziforme, plus étroit en avant, submembraneux et tronqué au sommet.

Yeux grands, peu saillants, irrégulièrement ovalaires, subverticalement disposés, séparés du prothorax par un intervalle assez grand.

Antennes courtes, assez fortement épaissies; à $1^{\text {er }}$ a ticle en massue allongée : les $2^{\text {e }}$ et $3^{\mathrm{e}}$ beaucoup plus courts, obconiques : les suivants non contigus ou pédicellés, plus ou moins transverses : le dernier court, comprimé et à peine èchancré au bout.

Prothorax transverse, rétréci en arrière, un peu moins large que les élytres; largement tronqué au sommet; arrondi à la base ; finement rebordé sur celle-ci et sur les côtis ; à bord latéral sinueusement infléchi d'arrière en avant. Repli assez. large, incliné, visible vu de côté, muri d'un opercule subtriangulaire et submembraneux (2).

(1) Dans ce genre et les suivants, l'épistome offre en avant une bordure membraneuse ou suhmembraneuse, assez. large, inclinée ou subverticale, non ou peu rétractile. Nous omettrons d'en parler ultérieurement.

(2) Cet opercu'e, qui représente l'épimère du prothorax, est situé derrière la base des hanches antérieures et recouvre les stigmates prothoraciques. 
Écusson assez grand, subogival, mousse au bout.

Élytres courtes, transverses; simultanément subéchancrées à leur bord apical; arrondies à leur angle postéro-externe; subrectilignes sur leurs côtés; rebordées sur la suture. Repli étroit, subvertical, subparallèle. Épaules peu saillantes.

Prosternum très-peu développé au devant des hanches antérieures; offrant entre celles-ci un angle court, très-ouvert et mousse au sommet. Mésosternum à lame médiane courte, en hémicycle, à peine prolongée jusqu'au tiers des hanches intermédiaires. Médiépisternums très-grands, séparés du mésosternum par une arête transversale, obtuse. Médiépimères assez grandes, en losange ou en carré suboblong. Jétasternum court, fortement transverse, échancré au devant des hanches postérieures, prolongé entre celles-ci en' un lobe très-court et angulairement entaillé au sommet; avancé entre les intermédiaires en une lame large, presque plane et entière. Postépisternums assez grands, postérieurement rétrécis en languette, divergeant à peine en arrière du repli des élytres. Postépimères étroites; en onglet allongé.

Abdomen suballongé, subparallèle ou faiblement arqué latéralement, fortement rebordé sur les côtés; à $2^{\mathrm{e}}$ segment basilaire rarement découvert, presque lisse : les suivants subégaux : le $5^{\mathrm{e}}$ un peu plus grand(1): le 6 e plus ou moins saillant, rétractile : celui de l'armure le plus souvent caché. Ventre à $5^{\mathrm{e}}$ arceau un peu plus grand que les précédents : le $6^{\text {e }}$ plus ou moins saillant, rétractile.

Hanches antérieures très-grandes, environ de la longueur des cuisses, très-saillantes, coniques, contiguës au sommet. Les intermédiaires un peu moindres, conico-ovalaires, peu saillantes, notablement distantes. Les postérieures médiocres, rapprochées à leur base, divergentes au sommet; à lame supérieure conique, transversalement sillonnée ou subétranglée dans son milieu ; à lame inférieure nulle ou enfouie.

Pieds assez courts, robustes. Trochanters antérieurs et intermédiaires en forme d'onglet; les postérieurs un peu plus grands, ovales-oblongs. Cuisses subcomprimées, attínuéəs vers leur extrémité, surtout les antérieur's et intermédiaires. Tibias environ de la longueur des cuisses, graduellement élargis de la base au sommet, plus ou moins fortement

(1) Ce $5^{e}$ segment, surtout dans les premiers genres, cst muni le long de son bord apical d'une fine membrane pale ou parfois d'un gris obscur. Nous n'en reparlerons pas. 
épinetix sur leur tranche externe, munis au bout de leur tranche inférieure de 2 éperons assez forts, dont l'interne plus long; les antérieurs plus courts et plus robustes; les intermédiaires à peine arqués. Tarses antérieurs courts, déprimés, fortement dilatés dans les 2 sexes (1); les intermédiaires et postérieurs moins courts, subdéprimés, subélargis, à $1^{\text {er }}$ article plus long que les suivants : ceux-ci courts, cordiformes, subégaux : le dernier de tous les tarses suballongé, en massue subdéprimée, subégal aux 2 précédents réunis. Ongles assez grêles, assez fortement arqués.

OBs. La seule espèce de ce genre, dont le vol est très-agile, vit dans les matières fécales.

L'épaisse pubescence soyense el veloutée du dessus du corps suffirait à elle seule pour caractériser le genre Emus. Il répond à la famille d'Erichson.

\section{Emus hirtus LiNné.}

Allongé, subdéprimé, densement et rugueusement pointillé, d'un noir velouté peu brillant, avec le dessous du corps violattre, la tête, la majeure partie du prothorax, les 3 derniers segments de l'abdomen, les côtés du $4^{\mathrm{e}}$ arceau du ventre et la plus grande partie du $5^{\mathrm{e}}$, revètus d'une trèsépaisse pubescence dorée, et la partie postérieure des élytres variée d'une pubescence cendrée.

$\sigma^{*}$ Tétc à peine plus large que le prothorax. Le $5^{\mathrm{e}}$ arceau ventral subsinué à son bord postérieur, paré vers sa base d'une espèce de sulure transversale, arquée ou bissinuée, à ouverture en arrière (2). Le $6^{e}$ fortenent et subangulairement sinué dans le milieu de son bord apical. Trochanters postérieurs armés d'un crochet comprimé, robuste, dichotome. Tibias postérieur's sinués intérieurement avant leur sommet.

q Tète à peine aussi large que le prothorax. Le $5^{\mathrm{e}}$ arceau ventral à

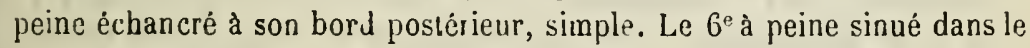
milicu de son bord apical. Trochanters postérieurs inermes. Tibias postérieurs simples.

(1) Celte dilatation est graduellement plus :aible du $2^{c}$ au q́ $^{\mathrm{e}}$ article, et cela dans plusieurs des genres oi elle existe.

(2) L'épaisse pubescence dorée du 5e arccau est plus redressée sur cẹtte sulure. 
Staphylinus hirtus, LiNNÉ, Faun. Suec. no 839 ; - Syst. Nat. I, II, 589, 2. -Fabricios, Syst. Ent. 264, 1 ; - Spec. Ins. I, 334, 1. - Fourcroy, Ent. Par. I, 165, 7. - De Villers, Ent. I, 409, 1. - Paykull, Mon. Staph. I, 1. - Olivier, Ent. III, 42, 7, 2, pl. 1, fig. 6. - Gravenhorst, Micr. 159, 1 ; - IIon. 125, 148. - Latreille, Hist. Nat. Crust. et Ins. IX, 292, 1, pl. 79. fig. 4; - Gen. Crust. et Ins. I, 286, 1. - Gyldenhal, Ins. Suec. II, 281, 2. - Erichson, Col. March. I, 431, 1 ; - Gen. et Spec. Staph. 346, 1, - Redtenbacher, Faun. Austr. 694, 4. - IIeer, Faun. CoI. Helv. I, 249, 2. - Fairmaire et Laboulbène, Faun. Ent. Fr. I, 505, 1. - JacQuelin Du Val, Gen. Col. Eur. Staph. 1858, pl. 13, fig. 61 .

Staphylinus bombylius, DE GEER, Ins. IV, 20,5 .

Le Staphylin bourdon, Geofrnoy, Hist. Ins. I, 363, 7.

Emus hirtus, Mannerielin, Brach. 20, 1. - Curtis, Brit. Ent. XII, pl. 534. Boisduval et Lacordare, Faun. Ent. Par. I, 360, 2. - Kraatz, Ins. Deut. II, 531. 1. - Thomson, Skand. Col. 140, 1, 1860. - Fauvel, Faun. Gallo-Rhén. III, $395,2$.

$$
\text { Long., } 0^{\mathrm{m}}, 026 \text { (12 l.); - larg., } 0^{\mathrm{m}}, 0075 \text { (3 1/2 1.). }
$$

Corps allongé, subdéprimé, d'un noir velouté, avec la tète, la majeure partie du prothorax, l'extrémité de l'abdomen et du ventre revêtues d'une pubescence dorèe et très-serrée, et les élytres en majeure partie grisâtres ou cendrées.

Tête densement et rugueusement pointillée, d'un noir submétallique, recouverte d'une très-épaisse pubescence veloutée, soyeuse et dorée. Front très-large, subdéprimé, paré sur les côtés de longues soies obscures. Epistome submembraneux en avant. Labre grossièrement ponctué, cilié à son sommet de longues soies obscures. Parties de la bouche noires.

Yeux obscur:, parfois d'un gris livide.

Antennes à peine plus longues que la lète; assez fortement épaissies; rugueusement ponctuées et ciliées-sétosellées vers leur base; entièrement noires; à $1^{\text {er }}$ article en massue allongée, lisse et glabre en dessous, paré vers le milicu de son cốé interne et vers le sommet de l'externe d'une soie beacoup plus longue, obscurs et redressée : les $2^{\mathrm{e}}$ et $3^{\mathrm{e}}$ à peine moins épais que le $1^{\mathrm{er}}$, obconiques : le $3^{\mathrm{e}}$ à peine plus long que le $2^{\mathrm{e}}$ : les $4^{\mathrm{e}}$ et $5^{\mathrm{e}}$ moniliformes : le $4^{\mathrm{e}}$ légèrement, le $5^{\mathrm{e}}$ sensiblement transverses : les $6^{\mathrm{e}} \mathrm{a} 10^{\mathrm{e}}$ plus épais que les précédents, très-fortement transverses, avec le $6^{\text {e }}$ néanmoins un peu moins court : le dernier brièvement ovalaire, un peu plus étroit que les pénultièmes, latéralement comprimé ou subexcavé de chaque côté vers son sommet, ce qui le fait parâttre, vu de côté, comme à peine échancré au bout. 
Prothorax transverse, subsinueusement rétréci en arrière, oủ il est un peu moins large que les élytres; largement tronqué en avant, avec les angles antérieurs bien prononcés, vus de dessus, mais subarrondis à leur sommet; arrondi à la base simultanément avec les angles postérieurs, celle-là parfois subtronquée dans son milieu; à peine convexe; densement et rugueusement pointillé, avec la ligne médiane subélevée, plus lisse et plus brillante, surtout en arrière; sétosellé sur les côtés; recouvert d'une pubescence veloutée, très-serrée, soyeuse et dorée, avec la partie postérieure veloutéc de noir. Repli noir, glabre et lisse.

Écusson velouté de noir.

Élytres transverses, is pcine plus longues que le prothorax, un peu plus larges postérieurement; déprimées; tinement et densement ponctuées. avec quelques points plus forts; d'un noir assez brillant et subplombé; distinciement sétosellées; veloutées de noir sur leur tiers antérieur, et, sur le reste de leur surface, de gris cendré, varié de quelques taches ou points nóbuleux. Épaules subarrondies.

Abdomen suballongé, un peu moins large que les élytres, subparallele ou faiblement arqué sur les côtés; subconvexe sur le dos; densement et rugueusement pointillé; assez fortement sétosellé; velouté de noir sur les 3 premiers segments, de doré soyeux sur les suivants.

Dessous du corps finement pointillé, brillant, violâtre; pubescent et sétosellé, avec les $4^{\circ}$ ut $5^{\mathrm{e}}$ arccaux du ventre parés à leur base d'une bande transversale arquée, d'un velouté soyeux et doré : celle du $\mathbf{4}^{\mathrm{e}}$ plus étroite el plus ou moins interrompue dans son milieu, celle du $5^{\text {e }}$ plus large et entière.

Pieds robustes, d'un noir brillant, ruguensement ponctués, avec la face antérieure des cuisses antérieures et la face postérieure des intermédiaires et postérieures glabres et lisses; recouverı d'une épaisse pubescence noire, qui devient un peu roussâtre sur les tibias antérieurs, et parfois sur tous les tarses. Tibias antérieurs plus élargis que les autres. Turses antérieurs fortement et graduellement dilatés du sommet à la base, dans les 2 sexes.

Patrie. Celle espèce, sans être très -commune, se r'encontre dans presque toute la France, dans les bouses fraiches. 
Genre Creophilus, Créophile Mannerheim.

Jannerhelm, Brach., 20, 1830. - Kraatz, Ins. Deut. II, 528.

Étymologie : xpśxs, chair; ̣̂ìos, ami.

CARactères. Corps allongé, subdéprimá, ailé, plus ou moins pubescent en dessus.

Tête grande, saillante, en carré fortement transverse, portée sur un col très-court, épais, moins large que le vertex. Témpes non rebordées sur leurs côtés, subcontiguës en dessous. Épistome très-court, à peine échancré aı sommet. Labre court, bilobé. IIandibules assez robustes, saillantes, aiguës, sillonnéès en dehors, grossièrement unidentées intérieurement vers leur milieu, arquées, croisées à l'état de repos. Palpes maxillaires assez développés, subfiliformes; à $1^{\text {er }}$ article court : les $2^{\text {e }}$ el $3^{\text {e }}$ suballongés, en massue : le dernier à peine aussi long, subfusiforme, mousse au bout. Palpes labiaux assez courts; à $2^{\text {e }}$ et $3^{\text {e }}$ articles suballongés, subégaux : le dernier plus long, subfusiforme, subtronqué au bout. Menton transverse, trapéziforme, plus étroit en avant, submembraneux, tronqué au sommet.

Yeux très-grands, peu saill:ınts, ovales-oblongs, obliquement disposés : séparés du prothorax par un intervalle assez grand.

Antennes courtes, assez fortement épaissies, à $1^{{ }^{\mathrm{e}}}$ article épaissi en massue suballongée : les $2^{\text {e }}$ et $3^{\text {e }}$ p'us courts, obconiques : les suivants nou contigus ou pédicellés, plus ou moins transverses : le dernier court, comprimé et à peine échancré au bout.

Prothorax transverse, rétréci en alrière, un peu moins large que les élytres; bissinué au sommet, subarrondi à la base; rebordé sur celle-ci et sur les côtés; à rebord latéral subsinueusement infléchi d'arrière en avant. Repli assez large, incliné, visible vu de côtó, muni d'un opercule prothoracique submembraneux.

Écusson grand, ogival.

Elytris courtes, transverses, simultanément à peine ćchancrćes à leur bord apical ; arrondies à leur angle postéro-externe; rebordées sur la suture; à repli étroit, subvertical. Épanle; peu saillante's.

Prostermum psu développé au devant des hanches antéricures; offrant entre celles-ci un angle court, ouvert, émoussé au sommet, à disque gib- 
beux. Mésosternuin à lame médiane courte, en hémicycle, pro!ongée jusqu'au tiers des hanches internédiaires. Médiépisternums très-développés, séparés du mćsosternum par une arête transversale, obtuse. Médiépimères grandes, presque carrées. Métasternum très-court, échancré au devant de linsertion des hanches postérieures, prolongé entre celles-ci en un lobe court, entaillé et subverticalement infléchi au sommet; avancé entre les intermédiaires en une lame large, presque plane et entière. Postépisternums assez grands, postérieurement rétrécis en languette, divergeant un peu en arrière du repli des élytres. Postépimères assez étroites en onglet allongé.

Abdomen suballongé, subparallèle ou faiblement arqué latéralement; fortement rebordé sur les côtés; à $9^{\mathrm{e}}$ segment basilaire rarement découvert, presque lisse : les suivants subégaux : le う̌ un peu plus grand : le $6^{\mathrm{C}}$ plus ou moins saillant, rétractile : celui de l'armure, rarement distinct, laissant saillir 2 fascicules de longues soies. Ventre à $5^{\mathrm{e}}$ arceau à peine p'us grand que les précédents : le $6^{\ominus}$ plus ou moins saillant, rétractile.

IIanches antérieures très-grandes, environ de la longueur des cuisses, très-saillantes, coniques, contiguës au sommet. Les intermédiaires moindres, conico-ovalaires, peu saillantes, notablement distantes. Les postérieures médiocres, rapprochées à leur base, divergentes au sommet; à lame supérieure conique, transversalement subétranglée vers son milieu ; à lame inférieure nulle ou enfouie.

Pieds assez courts, robustes. Trochanters anterieurs et intermédiaires subcunéiformes; les postérieurs un peu plus grands, ovales-oblongs. Cuisses subcomprimées, subatténuées vers leur extrémité. Tibias presque droits, graduellement élargis de la base au sommet, plus ou moins épineux sur leur tranche externe, munis au bout de leur tranche inférieure de 2 éperons assez forts, dont l'interne plus long (1); les antérieurs robustes, un peu moins longs, les autres aussi longs que les cuisses. Tarses antérieurs courts, à 4 premiers articles déprimés et fortement dilatés dans les 2 sexes; les intermédiaires et postérieurs moins courts, subcomprimés, à $1^{\text {er }}$ article suballongé, subégal au moins aux deux suivants réunis : les $2^{\mathrm{e}}$ à $4^{\mathrm{e}}$ triangulaires, graduellement un peu plus courts et plus étroits : le dernier assez allongé, en massue, subégal aux 2 précédents réınis. Ongles assez grêles, arqués, subdentés en dessous à leur base.

(1) Les éperons des tibias antérieurs sont plus courts, et il en es! ainsi dans les autres genres. 
OBs. La seule espèce de ce genre semble préférer les cadavres. Elle est assez agile.

La tête est plus fortement transverse que dans le genre Emus; les tarses intermédiaires et postérieurs sont plus étroits, subcomprimés au lieu d'être subdéprimés. Le disque de la tête et du prothorax est glabre, presque lisse.

Ce genre répond à la famille II d'Erichson.

\section{Creophilug maxillogus LINNÉ.}

Allongé, subdéprimé, d'un noir brillant, avec une bande transversale cendrée sur les élytres et un épais duvet cendré couvrant les $2^{\mathrm{e}} \dot{a} 4^{\mathrm{e}}$ arceaux du ventre et réduit à des taches sur le dos de l'abdomen. Tête et prothorax presque lisses et glabres sur leur disque.

$\sigma$ Tête généralement un peu plus large que le prothorax. Le $6^{\mathrm{e}}$ arceau ventral profondément et subaigument entaillé dans le milieu de son bórd apical. Cuisses antérieures dentées ou angulées en dessous à leur base.

$q$ Tête généralement un peu moins large que le prothorax. Le $6^{\mathrm{e}}$ arceau ventral entier à son bord apical. Cuisses antérieures simples à leur base.

Staphylinus maxillosus, LinNÉ, Faun. Suec. no 841, 1761. - Syst. Nat. I, II, 683, 3. - Fabricius, Syst. Ent. 2605, 3. - De Villers, Ent. I, 410, 3.- Pa yKulu, Mon. Staph. 5, 2. - Olivier, Ent. III, 42, 9, 5, pl. 1, fig. 5. - Gravenhorst, Nicr. 2, 1; - Mon. 126, 50. - Latreille, Hist. Nat. Crusi. et Ins. IX, 293, 2. - Grllenhal, Ins. Suec. II, 279, 1. - Erichson, Col. March. I, 432, 2 ; Gen. et Spec. Staph. 348, 2. - Redtenbacher, Faun. Austr. 694, 2. - Heer, Faun. Col. Helv. I, 249, 1.- Fairmaire et Laboulbène, Faun. Ent. Fr. I, 505, 2. - JacQuelin Du VAL, Gen. Col. Eur. Staph. pl. 13, fig. 62.

Staphylinus nebulosus, FочRскоу, Ent. Par. 165, 5.

Le Staphylin nébuleux, Geoprroy, Hist. Ins. I, 362, 5.

Emus maxillosus, Boisduval et Lacordare, Faun. Ent. Parl I, 33̈8, 1. - Fauvel, Faun. Gallo-Rhén. III, 395, 1.

Creophilus maxillosus, ManNerHeim, Brach. 20, 1. - Kratz, Ins. Deut. II, 529, 1.

- Thomson, Skand. Col. 141, 1. 1860.

$$
\text { Long., } 0^{\mathrm{m}}, 0020 \text { (9 l.); - larg., } 0^{\mathrm{m}}, 0065 \text { (3 l.). }
$$

Corps allongé, subdéprimé, noir, avec une bande d'un velouté cendré 
sur. les élytres, des taches grises sur le dos de l'abdomen, et un épais duvet de même couleur sur les $2^{\circ}$ à $4^{\mathrm{e}}$ arceaux du ventre.

Tête éparsement sétosellée sur les côtés, éparsement ponctuée en avant et autour des yeux, glabre et presque lisse sur son milieu, d'un noir brillant, Front très-large, subdéprimé. Col ronctué sur les côtés, lisse sur son milieu. Épistome submembraneux dans sa partie antérieure. Labre fortement cilié-sétosellé à son sommet. Bouche en partie noire.

Yeux obscurs, parfois livides.

Antennes à peine plus longues que la tête, fortement et graduellement épaissies; médiocrement pilosellées vers leur base, avec les poils pàles ; entièrement noires : les 6 premiers articles brillants, ponctués en dessus, les suivants mats et finement chagrinés (1) : le $1^{\text {cr }}$ épaissi en massue suballongée, paré après le milieu de son côté interne d'une soie plus longue et redressée : les $2^{\mathrm{e}}$ et $3^{\mathrm{e}}$ un peu moins épais que le $1^{\mathrm{er}}$, obconiques, subégaux : les $4^{\mathrm{e}} \mathrm{a} 6^{\mathrm{e}}$ moniliformes : le $4^{\mathrm{e}}$ légèrement, les $5^{\mathrm{e}}$ et $6^{\mathrm{e}}$ sensiblement, les $7^{\mathrm{e}}$ à $10^{\mathrm{e}}$ très-fortement transverses : le dernier brièvement ovalaire, un peu plus étroit que les précédents, subexcavé de chaque côté vers son sommet, et paraissant, vı de côté, comme à peine échancré au bout.

Prothorax transverse, subsinueusement rétréci en arrière, où il est un peu moins large que les élytres; bissinué en avant, avec les angles antérieurs prononcés mais subarrondis à leur sommet; largement arrondi à la base ainsi qu'aux angles postérieur's, celle-là parfois subsinueusement tronquée dans son milieu; à peine convexe; paré sur le bord antérieur et sur les côtés d'une pubescence obscure et redressée, et, en outre, de 2 pores sétifères; grossièrement ponctué dans tout son pourtour; glabre et lisse sur la majeure partie de son disque; entièrement d'un noir brillant. Repli noir, glabre, lisse.

Écusson rugueusement ponctué, velouté de noir.

Elytres transversis, un peu plus longues que le prothorax, un peu plus larges en arrière qu'en avant, subdéprimées; finement et densement pointillées, avec 4 ou 5 pores sétifères bien distincts, disposés en long sur les parties latérales du disque, et quelques autres, sans ordre, sur les côtés; d'un noir brillant; traversées dans leur milieu par une bande

(1) Ce caractère existant plus ou moins dans les espèces des genres suivants, nous nous dispenserons d'en parler désormais. 
transversale de poils cendrés, inégale ou festonnée en avant et en arrière. Epaules étroitement arrondies, à calus plus lisse.

Abdomen suballongé, un peu moins lorge que les élytres; subparallèle ou faiblement arqué sur les côtés ; subconvexe sur le dos ; densement et rugueusement pointillé; d'un noir peu brillant; revêtu d'une épaisse pubescence obscure, avec 2 grandes taches d'un duvet cendré, sur les côtés des $3^{\mathrm{e}}$ et $4^{\mathrm{e}} \mathrm{segments,}$ et des mouchetures semblables, disposées sur 2 lignes longitudinales, au bord apical des 4 premiers segments, et denx autres, sur le dos du $5^{\mathrm{e}}$; paré en outre de 4 séries de pores sélifères.

Dessous du corps finement et densement pointillé, d'un noir assez brillant, éparsement sétosellé ; revêtu d'une pubescencc obscure et serrée, avec un épais duvet cendré couvrant les $2^{\mathrm{e}}, 3^{\mathrm{e}}$ et $4^{\mathrm{e}}$ arceaux du ventre et souvent la partie postérieure du $1^{\mathrm{er}}$, parfois étendu sur la base du $5^{\mathrm{e}}$ pour y former 2 taches grises : la partie cendrée laissant souvent à nu, de chaque côté, 2 ou 3 taches obscures, et, sur le reste de sa surface, des points noirs, indiqués par les pores sétifères.

Pieds robustes, d'un noir brillant, rugueusement ponctués, densement pubescents. Cuisses antérieures glabres et lisses à leur face antérieure, les autres à leur face postérieure. Tibias antérieurs plus élargis que les autres. Tarses antérieurs fortement dilatés dians les 2 -sexes, à pubescence inférieure épaisse et roussâtre.

PAtrie. Cette espèce est commune, dans presque loute la France, sous les cadavres ou autres matières animales. Elle s’introduit jusque dans les basses-cours et les celliers.

OBs. Quelques mâles efféminés ont la tête à peine aussi large que le prothorax, et les cuisses antérieures presque semblables à celles des femelles.

Chez les exemplaires épilés tout le dessus du corps est dun noir brillant.

Quelquefois, chez les $\sigma "$, la pubescence du sommet di ventre tourne au roussâtre.

Le Creophilus ciliaris de Stephens (III. V. 202) a la pubescence cendrée variée de poils dorés.

\section{LARVE}

La larve du Creophilus maxillosus est peu allongée, épaissē; d'un brun de poix brillant, avec l'abdomen mat, longuement et éparsement séto- 
sellé. La lête est grosse, plus large que le prothorax; celui-ci, subrétréci en avant, est un peu plus long que les 2 segments suivants réunis. Le dernier segment abdominal offre à son sommet 2 lanières étroites, subarquées ell dehors, subatténuées et terminées à leur extrémité par un article plus grêle, 4 fois moins long et subcylindrique. On aperçoit en dessous, entre ces lanières, un lube allongé, subcylindrique, tronqué au bout, presque aussi prolongé qu'elles.

Les antennes, les pâlpes et les pieds sont testacés.

Nous ne décrirons pas davantage cette larve, que MM. Chapuis et Candèze (Mém. Liége, 1853, 399, pl. 2, fig. 1) ont fait connaitre dans tous ses détails.

Henri Kroyer (Nat. Tids. in Schiödte) lui a aussi consacré quelques lignes (p. 195), ainsi que sur sa nymphe (p. 206), dont il a donné le dessin (pl. X, fig. 8).

La larve indiquée par Westwood (Intr. I, 168, 16) appartient peut-être aussi au Creophilus maxillosus?

\section{Genre Leistotrophus, Leistorrophe Perty. PeRTy, Deleet. An. 30. 1830. \\ Étymologie : خr.}

Caractères, Corps allongé, subdéprimé, ailé, densement pubescent et marqueté en dessus de taches obscures.

Tête grande, saillante, suborbiculaire; portée sur un col très-court, moins large que le vertex. Tempes non rebordées sur les côtés, contiguës el: dessous. Épistome très-court, subéchancré au sommet. Labre court, bilobé. Mandibules robustes, saillantes, aiguës, subsillonnées en dehors, grossièrement dentées intérieurement vers leur milieu, arquées, croisées au repos. Palpes maxillaires assez développés; à $1^{\mathrm{e}_{\mathrm{r}}}$ article très-court : les $2^{\mathrm{e}}$ et $3^{\mathrm{e}}$ suballongés, en massue : le dernier sensiblement plus court et plus grêle que le précédent, subfusiforme, subtronqué au bout. Palpes labiaux courts, à articles suballongés : le dernier un peu moins long et plus étroit que le précédent, subfusiforme, mousse au bout. Menton trapéziforme, plus étroit en avant, submembraneux, tronqué au sommet.

Yeux grands, peu saillants, subovales, obliquement disposés, séparés du prothorax par un intervalle grand.

BR. 
Antennes médiocres, subfiliformes; à $1^{\text {cr }}$ artiule allongé, subarqué : le $2^{\mathrm{e}}$ oblong : le $3^{\mathrm{e}}$ allongé, plus long que le précédent : les $4^{\mathrm{e}}$ à $10^{\mathrm{e}}$ graduellement plus courts et à peine plus épais, non contigus : le dernier court, obliquement subéchancré au bout.

Prothorax subcarré, sinueusement rétréci en arrière, moins large que les élytres; bissinueusement tronqué au sommet, à angles antérieurs saillants et aigus; arrondi à sa base; finement rebordé sur celle-ci et sur les côtés, à rebord latéral sinueusement infléchi d'arrière en avant. Repli assez large, incliné, visible en arrière vu de côté, muni d'un opercule prothoracique submembraneux.

Écusson grand, ogival.

Élytres assez courtes, transverses, simultanément subéchancrées à lcur bord apical ; arrondies à leur bord postéro-externe; très-finement rebordées sur la suture; à repli assez étroit, subvertical, parfois subarqué. Épaul's peu saillantes.

Prosternum peu développé au devant des hanches antérieures, offrant entre celles-ci un angle court, mais à sommet subaigu et relevé en carène obtuse. Mésosternum à lame médiane triangulaire, arrondie au sommet, carénée sur sa ligne médiane, prolongée presque jusqu'au milieu des hanches intermédiaires. Médiépisternums très-grands, séparés du mésosternum par une arête transversale, obsolète ou interrompue. Mlédiépimères grandes, presque carrées. Hétasternum court, échancré au devant des hauches postérieures, prolongé entre celles-ci en un lobe court et subéchancré ; avancé entre les intermédiaires en une lame plane, triangulaire, arrondie au sommet, liée à la pointe mésosternale par un intermède oblong, plus ou moins en dos d'âne. Postépisternums assez étroits, postérieurement rétrécis en languette, divergeant à peine en arrière du repli des élytres. Postépimères médiocres, triangulaires.

Abdomen peu allongé, subatténué en arrière, fortement rebordé sur les cô'ès; à 4 premiers segments subégaux, le $5^{\mathrm{e}}$ un peu plus grand : le $6^{\mathrm{e}}$ médiocrement saillant, rétractile : celui de l'armure rarement distinct, ćmettant 2 fascicules de longues soies. Ventre à $5^{\mathrm{e}}$ arceau un peu plus grand que les précédents : le $6^{\circ}$ plus ou moins saillant, rétractile.

Hanches antérieures très-grandes, environ de la longueur des cuisses, très-saillantes, coniques, contiguës au sommet. Les intermédiaires moindres, conico-ovalaires, peu saillantes, passablement distantes. Les postéricur's médiocres, très-légèrement écartées à leur base, divergentes au sommet, terminées en dessous par de simples cils, au lieu d'épines ; à 
lame supérieure conique, subsillonnée en travers sur son milieu; à lame inférieure nulle ou enfouic.

Fieds médiocres, assez grêles. Trochanters antérieurs petits, cunéiformes; les intermédiaires et postérieurs un peu plus grands, ovalesoblongs. Cuisses subcomprimées, plus ou moins épaissies vers leur base. Tibias subélargis vers leur extrémité, épineux sur leurs tranches, munis au bout de leur tranche inférieure de 2 éperons spiniformes : les antérieurs plus robustes et plus courts, épineux seulement au sommet de leur tranche externe : les intermédiaires subarqués. Tarses antérieurs courts, à 4 premiers articles déprimés et fortement dilatés dans les 2 sexes ; les intermédiaires et postérieurs suballongés, subcomprimés, subatténués vers leur extrémité, à $1^{\mathrm{er}}$ article allongé, un peu plus long que les deux suivants réunis : les $2^{\mathrm{e}} \mathfrak{a} 4^{\mathrm{e}}$ triangulaires, graduellement plus courts : le dernier assez grêle, assez allongé, en massue, subégal aux 2 précédents réunis. Ongles assez grêles, arqués.

OBs. Les espèces de ce genre sont agiles. Elles vivent parmi les fumiers et les champignons décomposés.

Les antennes et les pieds sont plus grêles et plus allongés que dans les genres précédents. La lame mésosternale, moins courte, est carénće sur son milieu. Les hanches intermédiaires sont moins distantes entre elles. Les angles antérieurs du prothorax sont plus saillants et plus aigus, etc. Cette coupe générique répond au genre Schizophilus de Gray et à la famille VI d'Erichson.

Deux espèces françaises rentrent dans le genre Leistotrophus, savoir :

a Palpes testacés, ainsi que la majeure partie des pieds. Élylres un peu plus longues que le prothorax.

NEBULOSUS.

aa Palpes et pieds noirs. Élytres de la longueur du prothorax. Taille moindre.

MURINUS.

\section{Leigtotrophus nebulomus, Fabricius.}

Allongé, subdéprimé, densement pointillé, noir, revêtu d'une épaisse pubescence grise; variée de taches obscures, avec les palpes, la base des antennes et les pieds testacés, la base des cuisses et parfois les tarses plus ou moins rembrunis.

$\checkmark *$ Le 6e orceau ventral angulairement entaillë dans le milieu de son 
bord apical, a vec le sommet de l'angle rempli par une membrane cintrée, formant gouttière (1).

$\subsetneq$ Le 6 arceau ventral simple.

Staphylinus nebulosus, Fabricius, Ent. Syst. I, II, 520, $3 ;-$ Syst. El. II, 590, 3. - Gravenhorst, Micr. 13, 14; - Mon. 121, 139.- Latrzille. Hist. Nat. Crust. et Ins. IX, 295, 5. - Gyllenhal, Ins. Suec. II, 282, 3. - ERICIIson, Col. March. II, 432, 3; - Gen. et Spec. Staph. 360, 22.- Redtenbacier, Faun. Austr. 69ö, 6. - Heer, Faun. Col. Helv. I, 250, 3. - Fairmaire et Laboul.B. Faun. Ent. Fr. I, 505, 3.

Emus nebulosus, Manneriejm, Brach. 20, 2.- Boisduval et Lacordaire, Faun. Ent. Par. I, 361, 3.

Staphylinus tessellatus, Fotrcnoy, Ent. Par. I, $165,6$.

Le Staphylin velouté, GeoffroY, IIist. Ins. I, 362, 6.

Leistotrophus nebulosus, KraAtz, Ins. Devit. II, 534, 1.- Thonson, Skand. Col. II, 142, 1. 1860. - Fauvel, Faun. Gallo-Rhén. III, 396, 1.

$$
\text { Long., } 0^{\mathrm{m}}, 0165 \text { (7 1/2 l.); - larg., } 0^{\mathrm{m}}, 0050 \text { (2 1/3 l.). }
$$

Corps allongé, subdéprimé, noir, revêtu en dessus d'une pubescence d'un gris verdâtre, serrée et variče de taches obscures.

Tête un peu ou à peine plus large que le prothorax; densement et rugueusement pointillée; d'un noir métallique ; revêtue d'un velouté grisâtre, avec 4 taches nébuleuses sur le vertex. Front très-large, déprimé, éparsement sétosellé sur les côtés; offrant parfois en arrière, sur son milieu, une ligne longitudinale, subélevée, plus lisse et raccourcie. Col densement pointillé, d'un gris velouté. Épistome membraneux dans -sa partie antérieure. Labre fortement cilié-sétosellé à son sommet. Palpes testacés.

Yeux obscurs, souvent d'un gris livide.

Antennes sensiblement plus longues que la tête; subfiliformes ou à peine ćpaissies ; pubescentes et pilosellées, surtout vers lur base, avec les poils gris ; testacées à leur base, plus ou moins obscurcies en dehors; à $1^{{ }^{\mathrm{e}}}$ article allongé, subarqué, paré vers le milieu de son côté interne d'une longue soie redressée : le $2^{\circ}$ oblong, obconique, aussi épais que le précédent : le $3^{\mathrm{e}}$ allongé, d'un tiers plus long que le $2^{\mathrm{e}}$ : les $4^{\mathrm{e}}$ et $5^{\mathrm{c}}$ oblongs :

(I) Quand le rebord membraneux ou submembraneux' est sur un plan inféricur, il forme alors comme une gouttière. 
le $6^{\mathrm{e}}$ non, les $7^{\mathrm{e}}$ à $10^{\circ}$ légèrement transverses, avec les pénultièmes plus . sensiblement : le dernier brièvement ovalaire, comprimé vers son sommet, paraissant, vu de côté, obliquement subéchancré au bout et acuminé inférieurement.

Prothorax subcarré, mais sensiblement et sinueusement rétréci en arrière, où il est moins large que les élytres; bissinueusement tronqué au sommet, avec les angles antérieurs, vus de dessus, saillants et aigus; plus ou moins arrondi à sa base, ainsi qu'aux angles postérieurs qui, vus de dessus, sont pourtant légèrement prononcés ; faiblement convexe et inégal sur son disque; densement et rugueusement pointillé ; éparsement sétosellé sur les côtés; d'un noir métallique; revêtu d'une épaisse pubescence grise, variée de taches nébuleuses. Repli noir, glabre, lisse.

Écusson rugueux, velouté de noir, avec la base, les angles antérieurs, une ligne médiane et l'extrême pointe garnis d'une pubescence fauve.

Elytres subtransverses, un peu plus longues que le prothorax; subparallèles ou à peine plus larges en arrière qu'en avant; subdéprimées; densement et rugueusement pointillées; éparsement sétosellées sur les côtés ; d'un noir métallique; revêtues d'un épais duvet grisâtre, entremêlé de taches obscures; ciliées en outre, à leur bord postérieur, de poils tirant sur le fauve. Épaules étroitement arrondies, à calus plus ou moins prononcé.

Abdomen suballongé, moins larre que les élytres, subatténué vers son extrémité ; subconvexe sur le dos ; rugueusement pointillé ; d'un noir peu brillant; éparsement sétosellé ; revêtu d'une pubescence obscure, variée de gris et de fauve brillant sur les 3 premiers segments, avec ordinairement 2 séries longitudinales de grandes taches en carrí long et plus ou moins veloutées de noir, obsolètes ou plus confuses sur les $4^{\mathrm{e}}$ et $5^{\mathrm{e}} \mathrm{seg}-$ ments.

Dessous du corps densement pointillé, d'un noir assez brillant, avec la poitrine recouverte d'une épaisse jubescence d'un gris fauve. Ventre convexe, íparsement sétosellé, à pubescence d'un gris obscur, passant souvent au fauve sur les côtés des premiers arceaux.

Pieds assez grêles, garnis d'une pubescence ou fauve, ou d'un gris obscur; rugueusement pointillés; testacés, avec les hanches, les trochanters et les cuisses noirs, le dernier ticrs de celles-ci testacé, et les tarses, surtout les intermédiaires et postérieurs, parfois un peu rembrunis, ainsi que, rarement, les tibias postérieurs.

Patrie. Cette espèce se prend principalement parmi los champignons en 
diliquescence, dans les forêts et lieux élevés : les environs de Paris, les Alpes, l'Auvergne, le Beaujolais, les Pyrénées, etc.

OBs. Quelquefois les cuisses sont presque entièrement testacées, avec un anneau plus obscur vers leur milieu. Les médiépisternums et la base des hanches intermédiaires sont parfois un peu roussâtres.

Lạ fig. $51, \mathrm{~b}$, d'Olivier répond peut-être au nebulosus?

Entre cette espèce et la suivante, nous décrirons,',en abrégé, une espèce non encore trouvée dans la France continentale :

Leistotrophus marginalis, GÉNÉ.

Allongé, subdéprimé, rugueusement pointillé, d'un noir bronzé, revếtu d'un duvet grisâtre, varié de fauve et de taches nébuleuses, la majeure partie des antennes, le repli latéral des élytres et les pieds testacés, la base des cuisses noire et les palpes brunâtres.

${ }^{\prime}$ Le $6^{\mathrm{e}}$ arceau ventral angulairement sinué dans le milieu de son bord apical.

L Le $6^{\ominus}$ arceau ventral simple.

Emus marginalis, GÉNÉ, Act. Reg. Sc. Ac. Taur. Xxxix.

Staphylinus marginalis, Erichson, Gen. et Spec. Staph. 361, 23.

$$
\text { Long., } 0^{\mathrm{m}}, 011 \text { (5 l.); - larg., } 0^{\mathrm{m}}, 0033 \text { (1 1/2 l.). }
$$

Patrie. La Corse, la Sardaigne, le Portugal.

OBs. Cette espèce est remarquable par la couleur testacée du repli latéral des élytres. Elle est de la taille des petits exemplaires du murinus. Les antennes ne sont rembrunies que tout à fait vers le sommet. L'Ecchancrure du $\sigma$ est plus angulée que dans les 2 autres espèces.

\section{Leistotrophus murinus', LINNÉ.}

Allongé, subdéprimé, rugueusement pointillé, obscur, revêtu d'un épais duvet grisâtre, varié de fauve et de taches nébuleuses, la base des antennes testacée, les palpes et les pieds noirs. 
$\sigma^{*}$ Le $6^{\mathrm{e}}$ arceau ventral profondément et angulairement entaillé au milieu de son bord apical, avec le sommet de l'angle rempli par un espace subcorné, cintré, non en gouttière. Téte à peine plus large que le prothorax.

† Le $6^{\mathrm{e}}$ arceau ventral simple. Tête de la largeur du prothorax.

Staphylinus murinus, LiNNÉ, Faun. Suec. n. 840 ; - Syst. Nat. I, II, 683, 2. Fabricius, Syst. Ent. 265, 2 ;-Spec. Ins. I, 334, 2.- De Villers, Ent. I, 409, 2. - Paykull, Mon. Staph. 14, 8.-Olivier, Ent. III, $\mathrm{n}^{\circ}$ 42, 15, 14, pl. 6, fig. 51, a. - Gravenhorst. Micr. 14, 15 ; - Mon. 122, 142. - Latreille, Hist. Nat. Crust. et Ins. IX, 294, 4.- Gyllenhal, Ins. Suec. II, 283, 4. - Erichson, Col. March. I, 433, 4; - Gen. et Spec. Staph. 361, 24.- Redtenbacuer, Faun. Austr. 695, 6. - Heer, Faun. Col. Helv. I, 250, 4. - Falrm. et Labuulb. Faun. Ent. Fr. I, 506,4 .

Emus murinus, Mannerheim, Brach. 21, 7. - Boisduval et Lacordaire, Faun. Ent. Par. I, 363, 6.

Leistotrophus murinus, KraAtz, Ins. Deut. II, 535, 2. - Thomson, Skand. Col. II, 142, 2, 1860. - Fauvel, Faun. Gallo-Rhén. III, 397, 2.

$$
\text { Long., } 0^{\mathrm{m}}, 013 \text { (6 l.) ; - larg., } 0^{\mathrm{m}}, 0035 \text { (1 1/2 l.). }
$$

Corps allongé, subdéprimé, obscur, revêtu en dessus d'un épais duvet grisâtre, avec des taches nébuleuses.

Tête rugueusement pointillée, d'un noir métallique parfois assez clair; revêtue d'une fine pubescence grisâtre. Front très-large, subdéprimé, paré sur les côtés de quelques pores sétifères à soie très-longue. Col pointillé, à duvet un peu doré. Épistome membraneux dans sa partie antérieure. Labre fortement sétosellé au sommet. Mandibules et palpes d'un noir de poix (1).

Yeux obscurs, parfois à taches livides.

Antennes un peu plus longues que la tête; subfiliformes ou à peine épaissies; pubescentes et éparsement pilosellées, surtout vers leur base, avec les poils obscurs; testacées, puis peu à peu rembrunies dès le $6^{\mathrm{e}}$ article; le $1^{\text {er }}$ allongé, subarqué, paré après le milieu de son còté interne d'une longue soie redressée : le $2^{\circ}$ oblong, obconique, à peine moins épais que le précédent: le $3^{\mathrm{e}}$ assez allongé, presque d'un tiers plus long

(1) Les mâchoires et la languette sont généralement tcstacées, ainsi quc le menton qui est submembraneux, et cela, dans la plupart des cspèces de Staphylinates. 
que le $2^{\mathrm{e}}:$ les $4^{\mathrm{e}}$ el $5^{\mathrm{e}}$ à peine plus longs que larges : le $6^{\mathrm{e}}$ à peine, les suivants plus sensiblement transverses : le dernier brièvement ovalaire, comprimé vers son sommet, paraissant, vu de côté, obliquement subéchancré au bout et subacuminé inférieurement.

Prothorax en carré subtransverse et légèrement rétréci en arrière, où il est un peu moins large que les élytres ; bissinueusement tronqué au sommet, avec les angles antérieurs, vus de dessus, saillants et subaigus; largement arrondi à sa base, ainsi qu'aux angles postérieurs ; à côtés paraissant, de dessus, subrectilignes ; faiblement convexe et subinégal sur son disque ; rugueusement pointillé ; plus ou moins métallique ; paré sur les côtés de 2 ou 3 pores sétifères; revêtu d'un duvet d'un gris obscur, varié de poils d'un fauve doré, avec quelques taches nébuleuses. Repli noir, lisse, glabre.

Écusson rugueux, velouté de noir, avec la base, les ang'es antérieurs, un fine ligne médiane et l'extrême pointe couverts d'une pubescence d'un gris doré.

Élytres transverses, de la longueur du prothorax; à peine ou non plus larges en arrière qu'en avant; subdéprimées; assez densement pointillées ; éparsement sétosellées sur les côtés ; plus ou moins métalliques; revêtu es d'un duvet serré et grisâtre, varié de fauve, avec plusieurs taches nébuleuses ou veloutées de noir; ciliées en outre, à leur bord postérieur, de poils d'un fauve pâle et brillant. Épaules subarrondies, à calus assez prononcé.

Abdomen suballongé, moins large que les élytres, subatténué vers son extrémité ; subconvexe sur le dos; rugueusement pointillé ; obscur ; éparsement sétosellé; revêtu d'une pubescence noire, assẹ serrée, variée de poils dorés ou cendrés, surtout sur les 3 premiers segments, avec ceux-ci parés, sur le milieu de leur base, d'une tache fauve, formée de poils plus condensés, et, de chaque côté de celle-ci, d'une tache d'un noir velouté, reparaissant sur le $4^{\mathrm{e}}$ segment, mais nulle ou obsolète sur le $5^{\mathrm{e}}$ : le $6^{\mathrm{e}}$ parfois d'un gris argenté à sa base.

Dessous du corps densement et rugueusement pointillé, d'un noir assez brillant, avec une pubescence cendrée recouvrant la poitrine et la base des arceaux du ventre : celui-ci convexe, éparsement sétosellé.

Pieds peu robustes, garnis d'une pubescence d'un fauve ou d'un gris obscur, finement et rugueusement pointillés ; entièrement noirs.

Patrie. Cette espèce se rencontre dans les bouses, les crottins ct les fumiers, dans presque toute la France. Elle est commune. 
OBs. Chez quelques mâles de petite taille, la tête n'est pas plus large que chez les femelles.

Dans les échantillons bien frais, on aperçoit des taches d'un duvet gris, sur les côtés non-seulement des premiers segments de l'abdomen, mais encore des suivants, ainsi qu'une large bande de même couleur sur la base du 6 e, surtout quand celui-ci est tendu.

La larve du Leistotrophus murinus a été décrite par Stroëm (Nogl. Ins. Larv. II, 375).

Genre Trichoderma T'richoderne, Thomson (1).

Thомson, Skand. Col. II, 1860, 142.

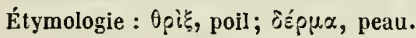

Caractères. Corps allongé, subdéprimé, ailé, densement pubescent et marqueté en dessus de taches nébuleuses,

Tête grande, saillante, suborbiculaire; portée sur un cou très-court, moins large que le vertex. Tempes non rebordées sır les côtés, contiguës en dessous dans leur milieu. Épistome très-court, à peine échancré au sommet. Labre court, bilobé. Mandibules robustes, saillantes, aiguës, à peine sillonnées en dehors, grossièrement dentées intérieurement vers leur milieu, arquées, croisées au repos. Palpes maxillaires assez développés, à $4^{\text {er }}$ article court : les $2^{\mathrm{e}}$ et $3^{\mathrm{e}}$ suballongés, en massue : le dernier subégal au précédent, subfúsiforme. Palpes labiaux courts, à d rnier article plus long, subfusiforme, mousse au bout. Menton trapéziforme, plus é!roit en avant, membraneux, tronqué au sommet.

Yeux médiocres, faiblement saillants, ovales, obliquement disposés, séparés du prothorax par un intervalle grand.

Antennes assez courtes, subépaissies; à $1^{\mathrm{er}}$ article allongé, en massue : le $2^{\mathrm{e}}$ oblong, obconique : le $3^{\mathrm{e}}$ un peu plus long, suballongé : les $4^{\mathrm{e}}$

(1) Erichson (p. 404) dit que le genre Trichoderma de Stephens a été établi sur I'Ocypus picipennis. Kratz (p. \$32) et le catalogue Gimminger le font synonyme du Leistotrophus de Perty. Thomson (II, p. 142) le rapporte au Staphylinus pubescens, après aroir créé pour cette même espèce son genre Dinothenarus (Vet. Ac. 1858, 29, ee), qu'il a rejeté plus tard pour adopter le nom de Trichoderma, qui lui convient parfaitement. Nous suirrons donc l'exemple de l'auteur suédois, qui, sans doute, a eu des raisons pour se corriger lui-même. 
à $10^{\mathrm{e}}$ graduellement plus courts et un peu plus épais, non contigus : le dernier court, échancré au bout.

Prothorax subcarré, subsinueusement et faiblement rétréci en arrière, moins large que les élytres ; tronqué au sommet ; à angles antérieurs non saillants ; subarrondi à sa base ; très-finement rebordé sur celle-ci et sur les côtés; à rebord latéral subsinueusement infléchi d'arrière en avanıt. Repli assez large, incliné, visible en arrière vu de côté, muni d'un opercule prothoracique submembraneux, en triangle court.

Ecusson grand, ogival.

Élytres subtransverses, simultanément subéchancrées à leur bord apical; arrondies à leur angle postéro-externe; finement rebordées sur la sulure; à repli médiocrement infléchi. Épaules peu saillantes.

Prosternum très-peu développé au devant des hanches antérieures, offrant entre celles-ci un angle court, très-ouvert, à sonımet mousse. Mésosternum à lame médiane triangulaire, subarrondie au sommet, à peine prolongée jusqu'au milieu des hanches intermédiaires; traversée, vers son tiers postérieur, par une chaînette de gros points enfoncés, arquée en arrière، Médiépisternums très-développés, séparés du mésosternum par une suture transversale très-fine. Ifédiépimères assez grandes, trapéziformes ou en carré long. Métasternum court, fortement échancré au devant des hanches postérieures, prolongé entre celles-ci en un lobe court et subéchancré, a vancé entre les intermédiaires en une lame assez large, antérieurement subarrondie en dos d'âne. Postépisternums assez étroits, subparallèles ou à peine rétrécis en arrière et subarrondis au sommet. Postépimères assez réduites, triangulaires, plus prolongées que les postépisternums.

Abdomen peu allongé, subatténué en arrière, fortement rebordé sur les côtés; à 4 premiers segments subégaux, le $5^{\mathrm{e}}$ un peu plus grand, muni à son bord apical d'une très-fine membrane pâle : le $6^{\text {e }}$ plus ou moins saillant, rétractile : celui de l'armure enfoui, émettant 2 fascicules de soies. Ventre à $5^{\mathrm{e}}$ arceau parfois un peu plus grand que les précédents : le $6^{\mathrm{e}}$ plus ou moins saillant, rétractile.

HIanches antérieures très-grandes, environ de la longueur des cuisses, très-saillantes, coniques, contiguës au sommet. Les intermédiaires moindres, subovales, peu saillantes, médiocrement distantes. Les postérieures médiocres, très-faiblement écartées intérieurement à leur base: divergentes au sommet : à lame supérieure en cône moısse, étranglé vers son milicu; à lame inférieure nulle ou enfouie. 
Pieds médiocre;, assez robustes. Trochanters antérieurs petits, cunéiformes, les autres un peu plus grands: les intermédiaires subcunéiformes, les postérieurs ovales-oblongs. Cuisses subcomprimées, plus ou moins atténuées vers leur extrémité. Tibias élargis de la base au sommet, épineux, surtout sur leur tranche externe, munis au bout de leur tranche inférieure de 2 éperons assez grêles : les antérieurs plus courts et plus robustes, les intermédiaires subarqués. Tarses antérieurs courts, à 4 premiers articles déprimés et fortement dilatés dans les 2 sexes; les intermédiaires et postérieur's suballongés, subcomprimés, à $1^{\text {er }}$ article subégal aux deux suivants réunis : les $2^{\circ}$ à $4^{e}$ triangulaires, graduellement plus courts et à peine plus étroits : le dernier en massue, subégal aux 2 précédents réunis. Ongles asse z grêles, arqués.

OBs. Les espèces de ce genre sont agiles. Elles fréquentent les matièrestercoraires.

Cette coupe générique, qui répond à la famille VIII d'Erichson, est assez distincte par la chainette de gros points enfoncés de la lame mésosternale. Celle-ci, sans carène, est moins arrondie au sommet que dans le genre Leistotrophus. Les yeux sont moins grands, les antennes moins grêles, les hanches intermédiaires moins distantes, les angles antérieurs du prothorax non saillants. Le dernier article des palpes est plus long relativement au précédent.

Voici les caractères des 2 espèces françaises qui appartiennent à ce genre :

a Téte testacée. . . . . . . . . . . . . . . . chrysocephalum.

aa Tète d’un noir bronzé. . . . . . . . . . . . . puBEscens.

\section{Trichoderma chrysocephalum FourCroy.}

Ailongé, subdéprimé, rugueusement pointillé, noir, revêtu d'un duvet d'un gris obscur, varié de fauve et de taches nébuleuses, avec la tête, la base des antennes, le dessous des épaules et un annean des cuisses testacis, une transparence fauve aux bords antérieur et postérieur du prothorax, des taches de même couleur sur le disque de celui-ci, et le ventre d'un velouté argenté.

$\sigma$ Le $6^{\text {e }}$ arceau ventral profondément et angulairement entaillé dans 
le milieu de son bord apical, avec le fond de l'entaille submembraneux, formant gouttière, et le sommet de l'angle mousse. Tête un peu plus large que le prothorax.

o Le $6^{\mathrm{e}}$ arceau ventral simple. Tête de la lirgeur du prothorax.

Staphylinus chrysocephalus, Fourcroy, Ent. Par. I, 165, 8. - Latreille, Hist. Nat. Crust. et Ins. IX, 296, 7. - Gravenionst, Mon. 124, 146. - Ekichson, Gen. et Sprc. Staph. 371 42. - Fatrmaire et Laboulbène, Faun. Ent. Fr. I, 506, 5. - Fauvel, Faun. Gallo-Rhén. III, 402, 1.

Staphylinus pubescens, Rossi, Mant. 97, 217.- Olivier, Ent. III, no 42, 16, 15, pl. 2, fig. 15 .

Le Staphylin à tête jaune, Geofrroy, Hist. Nat. Ins. I, 363, 8.

Emus chrysocephalus, Mannerheim, Brach. 21, 4.- Boisduval et Lacordaire, Faun. Ent. Par. I, 362, 3 .

$$
\text { Long., } 0^{\mathrm{m}}, 015 \text { (6 2/3 l.); - larg., 0 }{ }^{\mathrm{m}}, 004 \text { (1 2/3 l.). }
$$

Corps allongé, subdéprimé, noir, revêtu en dessus d'un duvet varié de gris obscur et de taches nébuleuses, avec la tête jaune et le ventre argenté.

Tête densement et rugueusement pointillée, presque mate, testacée, avec 2 points noirs entre les yeux; épar:ement et longuement sétosellée sur les côtés; revêtue d'un épais duvet fauve, varié, ça et là, de taches d'une pubescence brillante et d'un blond pâle. Front très-large, subdéprimé (1). Col pointillé, testacé, à duvet fauve. Épistome membraneux dans sa partie antérieure. Labre testacé, fortement cilié et sétosellé à.son sommet. Mandibules et palpes d'un noir de poix, avec la base de celles-là largement, et le $1^{\text {er }}$ article de ceux-ci, testacés.

Yeux obscurs, uvec des taches d'un roux livide.

Antennes un peu plus longues que la tête; graduellement subépaissics; pubescentes et pilosellées, surtout vers leur base; testacées, avec les 6 derniers articles obscurs : le $1^{\text {er }}$ subépaissi en massue allongée : les $2^{\circ}$ et $3^{\text {e }}$ plus étroits, obconiques : le $2^{\mathrm{e}}$ oblong, le $3^{\mathrm{e}}$ plus long, suballongé : le $4^{\mathrm{e}}$ subglobuleux : le $5^{\mathrm{e}}$ légèrement, les $6^{\mathrm{e}}$ à $10^{\mathrm{e}}$ fortement transverses : le dernier co:ırt, paraissant, vu de côté, échancré au bout et acuminé inférieurement.

(1) Quand la pubescence a été enlevée, on aperçoit en arrière, sur le front, une pctite ligne longitu !inale lisse, peu distincte. 
Prothorax subcarré, friblement rétréci en arrière; scnsiblement moins large que les élytres; tronqué au sommet; à angles antérieurs non saillants, subémoussés; subarrondi à sa base, avec les angles postérieurs très-obtus ; légèrement convexe et subinégal sur son disque (1); rugueusement pointillé ; noir, avec une transparence fauve aux bords antérieur et postérieur, quelques taches confuses, de même couleur, sur les côtés, et quelques autres semblables, disposées transversalement sur le milieu; éparsement et longuement sétosellé vers les côtés; revêtu d'un duvet obscur, varié de velouté noir, et transformé en duvet fauve sur les parties fauves. Repli noir, lisse, glabre.

Écusson ruguleux, velouté de noir.

Élytres subtransverses, un peu plus longues que le prothorax; subdéprimées ; rugueusement pointillées; éparsement sétosellées; ciliées de fauve à leur bord apical; noires, avec un duvet obscur, varié ou réticulé de velouté noir, quelques mouchetures de poils gris ou fauves, presque indistinctes, et la marge inférieure des épaules testacée. Celles-ci subarrondies.

Abdomen suballongé, un peu moins large que les élytres, subatténué vers son sommet; convexe sur le dos; densement et rugueusement pointillé; éparsement sétosellé; noir, avec une pubescence plus ou moins variée, cendrée sur les côtés des 4 premiers segments et sur la majeure partie des 2 premiers (2), ferrugineuse sur le milieu du bord postérieur des 4 premiers et sur le dos du $5^{\mathrm{e}}$, avec un velouté noir sur le milieu de la base des $1^{\mathrm{er}}, 2^{\mathrm{e}}$ et $4^{\mathrm{e}}$, et occupant presque tout le milieu du dos du $3^{\mathrm{e}}$.

Dessous du corps ruguleux, noir, pubescent, avec le mélasteruum et surtout le ventre recouverts d'un épais duvet d'un cendré argenté, formant des festons au bord apical des \& premiers arceaux, avec les pores sétifères simulant des points noirs.

Pieds médiocres, à pubescence variée d'obscur, de gris et de fauve; rugueusement ponctués; noirs, avec les cuisses ornées a vant leur sommet l'un large anneau testacé.

Patrie. Celte espèce est rare partout. Elle se trouve dans les excréments, aux environs de Paris, dans certaines parties de la France cen-

(1) Quelquefois le prothorax paraît finement et obsoletement carinulé, en avant et cn arrière, sur sa ligne médianc.

(2) Au milieu de la pubescence, les pores sétiferes, qui sont assez nombreux, surtout sur les côtés, apparaissent comme des points noirs. 
trale, dans le Languedoc, la Provence, etc. Elle attaque quelquefois les chenilles.

OBs. Quand l'abdomen est épilé, le bord postérieur des 4 premiers segments devient roussâtre, et le $5^{\mathrm{e}}$ est paré sur son milieu d'une étroite bande transversale de même couleur.

Le $5^{\text {e }}$ arceau ventral parait plus ( $\sigma^{\circ}$ ) ou moins ( 9 ) angulairement sinué dans le milieu de son bord postérieur, plus sensiblement que dans les espèces des genres précédents.

2. Trichoderma pubescens, DE GEER.

Allongé, subdéprimé, rugueusement pointillé, noir, revêtu d'un duvet d'un gris obscur, varié de blond et de taches nébuleuses, avec la tête d'un noir bronzé, la base des antennes, le dessous des épaules et un anneau des cuisses testacés, et le dessous du corps d'un gris argenté.

$\sigma$ Le $6^{\text {e }}$ arceau ventral circulairement sinué dans le milieu de son bord apical avec le sinus précédé d'un espace triangulaire lisse et nu, ne formant pas gouttière. Téte un peu plus large que le prothorax.

$\subsetneq$ Le $6^{\mathrm{e}}$ arceau ventral simple. Tête aussi large ou à peine aussi large que le prothorax.

Staphylinus pubescens, de GEER, Ins. IV, 17, 2. - Fabricius, Ent. Syst. I, II, 520, 5. - Paykull, Mon. Staph. 16, 9. - Gravenhorst, Micr. 12, 13; - Mon. 123, 144.- Latreille, Hist. Nat. Crust. et Ins. IX, 295, 6. - Gylenhal, Ins. Suec. Il, 284, 5. - Erichson, Col. March. I, 434, 5 ; - Gen. et Spec. Staph. 372, 43.- Redtenbacher, Faun. Austr. 695. - Heer, Faun. Col. Helv. I, 250, 5. Fairmaire et Laboulbène, Faun. Ent. Fr. I, 506, 6.- KraATZ, Ins. Deut. II, 546, 7. Fauvel, Faun. Gallo-Rhén. III. 402, 2.

Emus pubescens, MannerHein, Brach. 21, 5.-Boisduval et LaCORdaire, Faun. Ent. Par. J, 361, 4.

Trichoderma pubescens, Tномson, Skand. Col. II, 1860, 142, 1.

$$
\text { Long., 0m,013 (6 l.) ; - larg., } 0^{\mathrm{m}}, 0035 \text { (1 1/2 l.). }
$$

Corps allongé, subdéprimé, noir, revêtu d'un duvet varié de gris obscur et de taches nébuleuses, avec la tête d'un noir bronzé et le dessous du corps d'un gris argenté.

Tête rugueusement ponctuée; d'un noir bronzé; variée d'une pubes- 
cence blonde, subredressée et disposée par fascicules, avèc une petite plaque médiane et quelques pores épars, nus, lisses et très-brillants (1). Front très-large, subdéprimé, éparsement et longuement sétosellé sur les còtés. Col rugueux, d'un noir bronzé, à pubescence variée de blond et d'obscur. Épistome submembraneux dans sa partie antérieure. Labre d'un roux de poix, sétosellé et fortement cilié à son sommet, Mardibules et palpes d'un noir de poix : celles-là ferrugineuses à leur base.

Yeux obscurs, parfois à taches livides.

Antennes un peu plus longues que la tête, graduellement subépaissies; pubescentes et pilosellées, surtout vers leur base; obscures, avec les '4 premiers articles testacés, plus ou moins rembrunis en dessus; le $1^{\text {er }}$ subépaissi en massue allongée : les $2^{\mathrm{e}}$ et $3^{\mathrm{e}}$ un peu plus étroits, obconiques : li: $2^{\mathrm{e}}$ oblong, le $3^{\mathrm{e}}$ un peu plus long : le $4^{\mathrm{e}}$ subglobuleux : le $5^{\mathrm{e}}$ sensiblement, les $6^{\circ}$ à $10^{\mathrm{e}}$ assez fortement ou fortement transverses : le dernier court, échancré au bout et acuminé inférieurement.

Prothorax subcarré, subrétréci en arrière; moins large que les élytres; tronqué au sommet; à angles antérieurs non saillants, subémoussés; subarqué à sa base, avec les angles postérieurs obtus et arrondis; faiblement convexe et subinégal sur son disque; densement et rugueusement pointillé (2); paré sur les côtés de quelques longues soies redressées, et, sur le disque, de points enfoncés ou pores non sétifères nus, plus nombreux sur les parties latérales; noir; revêtu d'une pubescence obscure, disposée par fascicules, entremêlée de taches confusément blondes, avec le rebord postérieur parfois obscurément ferrugineux, à pubescence fauve. Repli noir, lisse, glabre.

Écusson ruguleux, d'un noir bronzé, avec 2 grandes taches oblongues ou d'un noir velouté.

Élytres subtransverses, un peu plus longues que le prothorax, subdéprimées ; densement et rugueusement pointillées ; très-éparsement sétosellées; noires, avec le rebord sutural ferrugineux, et la marge inférieure des épaules testacée; variées de fascicules de poils obscurs, entremêlés, sur le disque, de taches moins sombres et subdénudées, et sur les côtés, de quelques mouchetures de poils d'un gris blond, avec le bord apical cilié de fauve. Epaules subarrondies.

(1) Ces pores, assez nombreux sur les côtés, ne sont pas tous sétiferes.

(2) Quand le prothorax est épilé, il présente sur son milieu une étroite ligne lisse, plus ou moins interrompue sur le dos. 
Abdomen suballongé, moins large que les élytres, subatténué vers son sommet; convexe sur le dos ; finement et ruguleusement pointillé ; éparsement sétosellé; noir, avec le bord apical des 4 premiers segments ciliéfasciculé de fauve, avec les fascicules des côtés d'un blond pâle; recouvert d'un duvet varié de blond et de gris obscur, avec une série de taches obliques d'un noir velouté, disposées de chaque côté de la ligne médiane, enclosant des taches triangulaires d'un duvet d'un blond pâle, s'effaçant généralement; les unes et les autres, sur le $5^{\mathrm{e}}$ segment.

Dessous du corps rugueusement ponctué, noir, pubescent, avec la pubescence d'un gris cendré, très-serrée et transformée sur la poitrine et surtout sur le ventre en velours argenté, festonné au bord apical des 4 premiers arceaux et parfois du $5^{\mathrm{e}}$, avec des points noirs indiqués par des pores sétifères ou non, tant sur les côtés de la poitrine que sur le ventre.

Pieds médiocres, à pubescence blonde ; rugueusement pointillés; noirs, avec les cuisses ornées avant leur sommet d'un large anneau testacé.

Patrie. Cette espèce se prend parmi les fumiers, mais peu communément, dans diverses parties de la France: les environs de Paris et de Lyon, le Beaujolais, le Bugey, les Alpes, la Savoie, les Pyrénées, etc.

OBs. Quand l'abdomen est épilé, le bord apical des segments paraît légèrement ferrugineux.

Ghez certains $\sigma^{\prime}$ de petite taille, la tête est à "peine aussi large qu」 le prothorax.

\section{LARVE}

Nous donnerons ici la description de la larve du Trichoderma pubescens :

Corps suballongé, épais, fortement alténué en arrière, sétosellé, d'un roux de poix livide, brillant sur la tête et le thorax, mat sur l'abdomen, avec la tête plus ou moins rembrunie.

Tête grande, suborbiculaire ou en carré arrondi aux angles, plus large que le prothorax, subdéprimée, brunâtre, lisse, parfois ridée sur le milieu du front. Épistome aigument quadridenté. Mandibules d'un brun de poix, arquées. Les autres parties de la bouche d'un testacé de poix. Mâchoires allongées, subcylindriques, terminées en dedans par un appendice spiniforme. Palpes maxillaires de 4 articles : le $1^{\mathrm{er}}$ très-court, par 
fois retiré dans le sommet des mâchoires : le $2^{\circ}$ suballongé, le $3^{\text {e }}$ allongé, subcylindrique: le dernier plus grêle, conique, un peu moins long. Palpes iabiaux courts, ne paraissant que de 2 articles : le $1^{\text {er }}$ allongé, subcylindrique : le dernier plus grêle et plus court, conique.

Yeux peu distincts, lisses.

Antennes courtes, testacées, de 4 articles : le $1^{\text {er }}$ très-court : les $2^{\mathrm{e}}$ à $4^{\mathrm{e}}$ graduellement plus courts et plus étroits : les $2^{\mathrm{e}}$ et $3^{\mathrm{e}}$ allongés, un peu en massue : le dernier grêle, subcylindrique, terminé par un petit lobe articulé, bicilié au bout.

Prothorax transverse, subrétréci en avant, subconvexe, brillant, d'un roux de poix plus foncé antérieurement, lisse, rebordé en arrière. Mésothorax court, subégal à la moitié du prothorax, subarqué latéralement, subconvexe, brillant, d'un roux livide, lisse, très-finement rebordé en arrière. Métathorax encore plus court, arqué sur les côtés, subconvexe, d'un roux livide et brillant, lissè, très-finement rebordé en arrière.

Abdomen fortement et graduellement atténué postérieurement, longuement sétosellé, d'un roux livide et mat, plus ou moins sillonné sur sa ligne médiane, composé de 8 ou 9 segments apparents, très-courts, pourvus chacun, sur les côtés, d'un stigmate : le dernier largement tronqué ou subéchancré au sommet, muni de 2 longs appendices subcylindriques, écartés à leur base, recourbés en dedans à leur extrémité, qui émet en dehors une lanière grêle, un peu moins longue, obliquemeņt ou subtransversalement dirigée, subatténuée vers son sommet et terminée par urıe longue soie redressée.

Dessous du corps déprimé, de même couleur que le dessus, Ventre fortement sétosellé, à dernier arceau terminé par un appendice épais, apparaissant entre les lanières du segment supérieur comme un tube court, tronqué, subcylindrique.

Pieds courts, épineux, d'un testacé livide. Hanches couchées, trèsdéveloppées. Cuisses subcylindriques. Tibias plus courts, subélargis vers leur sommet, terminés par un crochet solide, acéré, subarqué vers sa pointe.

Patrie. Cette larve se trouve avec l'insecte parfait, dans les crottins et les fumiers.

OBs. Elle a la forme de la larve du Creophilus maxillosus; mais elle est d'une couleur plus claire; les épines des pieds sont moins longues et moins nombreuses; l'article terminal des appendices du dernier segment 
abdominal est beaucoup plus long; l'appendice du dernier arceau du ventre est bien plus court et plus épais, etc.

\section{Genre Abemus, AbĖme, Mulsant et Rey.} Étymologie : $\alpha$ privatif $\beta \tilde{\eta} \mu \alpha$, pas, distance.

Caractères. Corps allongé, subdéprimé, ailé, pubescent, à élytres faiblement variées.

Tête grande, saillante, suborbiculaire ou subcarrée, portée sur un col court, épais, moins large que le vertex. Tempes non rebordées sur les côtés, très-rapprochées en arrière mais non contiguës en dessous. Épistome très-court, à peine échancré au sommet. Labre transverse, bilobé. Mandibules robustes, saillantes, aiguës, subsillonnées en dehors, grossièrement dentées intérieurement vers leur milieu, arquées, croisées au repos. Palpes maxillaires assez développés, à $1^{\mathrm{cr}}$ article court : les $2^{\mathrm{c}}$ et $3^{\mathrm{e}}$ suballongés, en massue : le dernier subfusiforme, subégal au prècédent ou à peine plus long. Palpes labiaux courts, à dernier article plus long, subfusiforme, mousse ou subtronqué au bout. Menton trapéziforme, plus étroit en avant, membraneux, tronqué au sommet.

Yeux médiocres ou assez grands, peu ou assez saillants, ovales, obliquement disposés, séparés du prothorax par un intervalle plus ou moins grand.

Antennes médiocres, faiblement épaissies; à $1^{\text {er }}$ article allongé, sub¿paissi en massue subarquée : le $2^{\mathrm{c}}$ oblong, obconique : le $3^{\mathrm{e}}$ plus long, suballongé : les $4^{\mathrm{e}}$ à $10^{\mathrm{e}}$ graduellement un peu plus courıs et un peu plus ¿́pais, non ou peu contigus : le dernier court, subéchancré au bout.

Prothorax subcarré, à peine rétréci en arrière; moins large que les élytres ; tronqué au sommet; à angles antérieurs non saillants; arrondi à sa base; très-finement rebordé sur celle-ci et sur les côtés; à rebord latéral sinueusemeut infléchi d'arrière en avant. Repli assez large, incliné, visible vu de côté, muni d'un opercule prothoracique submembraneux, triangulaire.

Écusson grand, ogival.

Élytres transverses ou subtransverses, simultanément subéchancrées à leur bord apical; arrondies à leur angle postéro-externe ; finement rebor- 
dées sur la suture (1); à repli assez étroit, subvertical. Épaules peu saillantes.

Prosternum très-peu développé au devant des hanches antérieures, offrant entre celles-ci un angle assez court, gibbeux, à sommet droit. Mésosternum à lame médiane simple, triangulaire, à sommet très-aigu, prolongée jusques ou presque jưsques au milieu des hanches intermédiaires. Médiépisternums très-grands, séparés du mésosternum par une arête transversale. Médiépimères assez grandes, trapéziformes, oblongues. Métasternum très-coult, fortement échancré au devant des hanches postélieures, prolongé entre celles-ci en un lobe court et entaillé; avancé entre les intermédiaires en angle assez aigu (2). Postépisternums assez. étroits, rétrécis au sommet en languette mousse, à bord interne subparallèle au repli des illytres. Postépimères réduites à un onglet allongé, dépassant un peu les postépisternums.

Abdomen suballongé, subatténué en arrière, fortement rebordé sur les côtés; à $2^{e}$ segment basilaire parfois découvert, glabre : les 4 premiers subégaux : le $5^{\mathrm{c}}$ un peu plus grand ; le $6^{\mathrm{e}}$ plus ou moins saillant, rétractile : celui de l'armure enfoui, émettant 2 fascicules de soies. Ventre à $5^{\mathrm{e}}$ arceau un peu plus grand : le $6^{\mathrm{e}}$ plus ou moins saillant, rétractile.

Hanches antérieures grandes, de la longueur des cuisses, très-saillantes, coniques, contiguës au sommet. Les intermédiaires moindres, conico-subovales, peu saillantes, subcontiguës en arrière. Les postérieures assez grandes, rapprochées à leur base, divergentes au sommet; à lame supérieure conique, étranglée vers son milieu; à lame inférieure nulle ou unfouie.

Pieds médiocres, assez robustes. Trochanters antérieurs petits, cunéiformes; les intermédiaires et postérieurs un peu plus grands : ceux-là subcunéiformes, ceux-ci ovalaires. Cuisses subcomprimées, subatténuées vers leur extrémité. Tibias plus ou moins élargis de la base au sommet, plus ou moins épineux, munis au bout de leur tranche inférieure de 2 éperons grêles, dont l'interne plus long: les intermédiaires à peine arqués : les antérieurs plus courts et plus robustes, simplement pubescents ou à peine épineux sur leur tranche externe. Tarses antéricurs courts, à 4 premiers articles déprimés et dilatés dans les 2 sexes; les

(1) Leur couleur est faiblement variée.

(2) Le sommet de cet angle ne s'avance pas jusquä la pointe mésosternale, el ie filet qui l'en sépare est très-mince et enfoui. 
intermédiaires et postérieurs suballongés, subdéprimés, subatténués vers leur extrérnité, à $1^{\text {er }}$ article subégal aux 2 suivants réunis : les $2^{\mathrm{e}}$ à $4^{\mathrm{e}}$ triangulaires, graduellement plus courts : le dernier en massue, subégal aux 2 précédents réunis. Ongles assez grêles, arqués.

Obs. Les espèces de ce genre vivent sous les pierres et parmi les champignons. Elles sont médiocrement agiles.

Cette coupe générique lie les Trichoderma aux Staphylinus. Elle se distingue du premier de ces genres par sa lame mésosternale sans chainette de points enfoncés et à pointe plus aiguë; par ses hanches intermédiaires moins distantes; par ses tibias antérieurs non visiblement épineux en dehors; par la pubescence du prothorax et des élytres plus uniforme ou moins variée, etc.

Deux espèces, bien disparates, rentrent dans notre genre Abemus. En voici les différences :

a Tête et prothorax cuivreux. Elytres vertes. Pieds testacés, avec une tache noire sur les cuisses. . . . . . . . . crloropterus.

aa Tête, prothorax et élytres d'un rouge brunâtre, avec l'extrémité de celles-ci plus claire. Pieds testacés, avec les cuisses entièrement noires. . . . . . . . . . . Fossor.

\section{Abemus chloropterus, Panzer.}

Allongé, subdéprimé, densement ponctué, pubescent, avec la tête et le prothorax cuivreux, les élytres vertes, l'abdomen d'un ferrugineux obscur, l'écusson et la poitrine noirs, les palpes, les antennes et les pieds testacís et une tache noire sur les cuisses. Abdomen subvarié.

$\sigma^{7}$ Le $6^{e}$ arceau ventral sinué dans le milieu de son bord apical, avec le sinus précédé d'un espace angulaire, lisse, nu, subimpressionné.

\& Le $6^{\mathrm{e}}$ arceau ventral simple.

Staphylinus chloropterus, Panzer. Faun. Germ. 36, 20. - Gravenhorst, Micr 166, 15 ; - Mon. 121, 141. - Fabricius, Syst. El. II, 590, 5. - Latreille, Hist. Nat. Crust. et Ins. IX, 306, 22. - Nordman, Symb. 33, 14.- ERicason, Gen. et Spec. Staph. 372, 44. - Redrenbacher, Faun. Austr. 694, 4. - Falrmaire et Labouldène, Faun. Ent. Fr. I, 506, 7. - Kraatz, Ins. Deut. II, 546, 6. - Fauvel, Faun. Gallo-Rhén. III, 403, 3.

Emus chloroplerus, Bolsduval et Lacondalie, Faun. Ent. Far. I, 364, 7. 
Long., $0^{\mathrm{m}}, 010$ (4 1/2 l.); - larg., $0^{\mathrm{m}}, 0030$ (1 1/3 1.).

Ciorps allongé, subdéprimé, pubescent, avec la tête et le prothorax cuivreux, l'écusson noir, les élytres vertes, et l'abdomen varié d'obscur et de ferrugineux.

Tête de la largeur du prothorax, rugueusement ponctuée; revêtue d'une jubescence grise ou blonde, peu serrée; éparsement et longuement sétnsellée sur les côtés; d'un bronzẻ cuivreux et brillant. Front très-large, à peine convexe. Col ponctué, pubescent, cuivreux. Épistome submembraneux dans sa partie antérieure. Labre fortement sétosellé et cilié à son sommet. Parties de la bouche testacées, avec les mandibules rembrunies.

Yeux grands, assez saillants, obscurs, à taches livides.

Antennes sensiblement plus longues que la tête, à peine épaissies; pubescentes et pilosellées, surtout vers leur base; d'un roux testacé; à $1^{\text {er }}$ articlc subépaissi en massue allongée el subarquée : les $2^{\mathrm{c}}$ et $3^{\mathrm{e}}$ un peu plus étroits, obconiques : le $2^{\mathrm{e}}$ oblong, le $3^{\mathrm{e}}$ plus allongé : les $4^{\mathrm{e}}$ et $5^{\mathrm{e}}$ oblongs, subcylindriques : les $6^{\mathrm{e}}$ à $10^{\circ}$ subobconiques, graduellement un peu plus courts, avec lés pénultièmes substranverses, vus de côté : le dernier court, subéchancré au bout et subacuminé inférieurement.

Prothorax subcarré, à peine rétréci en arrière; moins large que les élytres; tronqué au sommet; à angles antérieurs presque droits mais subémoussés; arqué à sa base, avec les angles postérieurs très-obtus et subarrondis ; très-peu convexe; densement et subrugueusement ponctué, avec un trait longitudinal subélevé, lisse, sur le milieu de la base; d'un bronzé cuivreux brillant; paré sur les côtés de deux ou trois longues soies flavescentes, et sur le disque d'une pubescence grise ou blonde plus ou moins brillante, asscz serrée. Repli noir, lisse, glabre.

Écusson rugueux, velouté de noir.

Élytres transverses, de la longueur du prothorax ou à peine plus longues; subdéprimées; denscment et rugueusement pointillées; à peine sétosellées sur les côtés; d'un vert peu brillant, avec les bords latéraux, la marge apicalc et parfois le rebord sutural étroitement ou à peine roussâtres ou subtestacés; ciliées de blond à leur sommet; revêtues sur leur disque d'une pubescence faiblement variée de blond el de gris obscur. Épaules étroitement arrondies.

Abdomen suballongé, moins large que les élytres, subatı́nué vers son 
exlrémité; convexe sur le dos; rugueusement pointillé; d'un brun ferrugineux, presque mat, avec la base des premiers segments plus obscurs; recouvert d'une épaisse pubescence fauve ou blonde, variée de gris obscur près des côtés, avec les 4 premiers segments parés sur le dos d'une grande tache veloutée de noir, interrompue à sa base par une autre tache médiane soyeuse el semi-dorée.

Dessous du corps rugueusement ponclué, à pubescence grise ou blonde; noir, avec le ventre ferrugineux et la base des premiers segments rembrunie.

Pieds médiocres, revêtus d'une pubescence d'un gris blond; subrugucusement ponctués; testacés, avec les hanches et les trochanters noirs, les cuisses antérieures ornées dans leur milieu d'un large anneau obscur, et les autres parées d'une tache de même couleur, sur leur face antérieure :eulement.

P.trie. Cette espèce est rare. Elle se rencontre dans les grandes forêts de nos contrées septentrionales, sous les mousses et parmi les feuilles mortes, dans les environs de Paris, à Fontainebleau, à Compiègne, dans la basse Bourgogne, dans le Bourbonnais, etc.

Ors. Par son faciès et par sa teinte faiblemen! variée, elle fait le passage au geure plécédent.

II. Laboulbène a fait connaitre la larve et les métamorphoses de cette espèce (Ann. Soc. Ent. Fr. 1862, 559, pl. 13, fig. 1-7).

\section{จ. Alomus fogsor, Scopolr.}

Allongé, subdéprimé, rugueusement pointillé, pubescent, noir, av'c la iite, le prothorax et les élytres d'un roux brunâtre, le tiers postéricur de celles-ci, les tibias et les tarses testacés. Abdomen varié.

$\sigma$ Le $6^{c}$ arceau ventral angulairement entaillé dans le milieu de son bord apical, avec les bords de l'entaille subinembraneux. Lo $5^{\mathrm{c}}$ creusé à sa base d'une grande fossette veloutée de noir.

\& Le $6^{\circ}$ arceau ventral simple ainsi que le $5^{\circ}$.

Stupliylinus fossor, Scorol., Aut. Hist. Nat. V, 109, 10:3. - Fabricius, Ent. Syst. I, II, 523, 16. - Gravenhorst, Micr. 10, 109; - Moll. 117, 136. - Latreille, Hist. Nat. Crust. et Ins. IX, 299, 12. - Nondman. Symb. 60, 43.- Erichson, Gen. 
cl Spec. Staph. 377, 52. - ledtenbacier, laun. Austr. 69.5, 7. - Heer, Faun. Col. Helv. I, 252, 12. - Fairmaire et Laboulbène, Faun. Ent. Fi. I, 507, 8. KraAtz, Ins. Deut. II, 519, 10. - Jagquelin du Val, Gen. Staph. pl. 13, tig. 63.

- Fauver, Faun. Gallo-Rhén. III, 406, 10.

Staphylinus erytropterus, var. 2, Scop. Ent. Carn. 101, 306.

Slaphylinus fodiens, Gravenhorst, Mon. 116, 134.

Eimus fossor, Boisduval et Lacordaire, Faun. Ent. Par. I, 367, 11.

$$
\text { Long., } 0^{\mathrm{m}}, 0165 \text { (7 1/2 1.); - larg., } 0^{\mathrm{m}}, 0038 \text { (1 1. 2/3). }
$$

Corps allongé, subdéprimé, pubescent, d'un roux brun mat, avec l'abdomen obscur, varié de taches soyeuses ou veloutees, et la partie postėrieure des élytres testacée.

Tête de la largeur du prothorax; densement et rugueusement pointillée; d'un roux très-obscur et mat, devenant presque noir en avant; recouverte d'une légère pubescence fauve et, de plus, longuement et éparsement sétoscllèe sur les côtés. Front très-large, à peine convexe. Col rugueusement pubcscent, d'un roux brun. Épistome submembraneux dans sa parlie antérieurc. Labre fortement sétosellé et cilié à son sormmet. Mandibules e! palpes d'un noir de poix, avec le dernier article de ceux-ci testacé.

Yeux médiocres, peu saillants, brunâtres.

Antennes un peu moins longues que la tête et le prothorax réunis; faiblement et subgraduellement épaissies; légèrement pubescentes et éparsement sétosellées vers leur base; obscures, avec leur extrémité parfois grraduellement moins foncée; à $1^{\mathrm{er}}$ article subépaissi en massue allongẻe ct subarquée : les $2^{\text {e }}$ et $3^{\mathrm{c}}$ un peu plus étroits, obconiques : le $2^{\mathrm{c}}$ oblong, le $3^{\text {e }}$ plus allongé : les suivants graduellement un peu plus courts, avec les pénultièmes à peine transver'ses : le dernier court, subéchancré au bout ct subacuminé inférieurement.

Prothorax subcarré ou à peine plus long que large; subrétréci en arrière; un peu moins large que les élytres ; tronqué au sommet; à angles antérieurs presque droits mais émoussés; arrondi à sa base ainsi qu'aux angles postéricurs ; peu convexe ; densement et rugueusement pointillé ; finement el obsolètement carinulé en arrière sur sa ligne médiane; d'un roux foncé et presque mat ; éparsement sétosellé ; recouvert d'unc légère pubcscence fauve, plus obscure vers les côtés. Repli noir, lisse, glabre.

Écusson rugueux, velouté de noir.

Elytres subtransverses, à peine plus longucs que le prothorax; subdéprimées; densement et rugucusement pointillées; trìs-éparsement séto- 
sellées; d'un roux brun et mat, avec le tiers postérieur plus clair ou testacé et cette partie plus claire irrégulière, oblique et remontant davantage sur les côtés; légèrement ciliées à leur bord apical; revêtues d'une épaisse pubescence, obscure sur la base, d'un blond doré et brillant sur la partie testacée. Épaules subarrondies.

Abdomen plus ou moins allongé, un peu moins large que les élytres, subalténué vers son extrémité; convexe sur le dos ; finement et rugueusement pointillé ; éparsement sétosellé; d'un noir presque mat; recouvert d'une fine pubescence obscure, avec une tache triangulaire, médiane, formée d'une pubescence d'un blond doré, vers la base des 5 premiers segments (1), 3 mouchetures de mème couleur, au bord postérieur du $5^{\mathrm{e}}$, parfois quelques autres insignifiantes sur la tranche latérale et une bande basilaire sur le $6^{\text {e. }}$

Dessous du corps rugueusement pointillé; d'un noir assez brillant; recouvert d'une pubescence obscure. Ventre distinctement sétosellé, avec les arceaux ornés à leur base d'une étroite bande transversale, formée d'un duvet d'un blond cendré et brillant, obsolète ou interrompue sur les 4 premiers, plus large et plus entière sur les 2 suivants.

Pieds médiocres, à pubescence grise ou blonde; rugueusement pointillés ; noirs, avec les tibias et les tarses d'un roux testacé, ceux-ci souvent un peu plus foncés.

P.trie. Celte espèce préfère les lieux élevés ou les forêts. Elle est peu commune et elle se trouve sous les pierres ou parmi les champignons : les environs de Paris, l'Auvergne, le mont Pilat, les montagnes du Beaujolais, les Alpes, la Savoie, les parties orientales de la France, etc.

OBs. Les $\sigma^{\prime}$ diffèrent encore des $q$ par les $4^{\mathrm{e}}$ et $5^{\mathrm{e}}$ arceaux du ventre, qui sont faiblement sinués dans le milieu de leur bord apical et un peu plus lisses au devant du sinus. Chez la $\$$, néanmoins, le bord postérieur dı $4^{\mathrm{e}}$ est à peine subsinué dans son milieu.

Chez l'Abemus fossor, les yeux sont moins gros et moins saillants et les antennes plus longues que chez l'A. chloropterits.

Cette espèce, par son aspect général, fait la transition aux vrais Stıphy. linus.

(1) Ché les sujets bicn frais, ces taches blondes sont rehaussées de chaque cóté par une petite tache d'un velours noir. 


\section{Genre Staphylinus, Staphylin, Linné.}

LiNnė, SysL. nat. II, 767,683. - JACQ. DU VAL, Gen. Staph. 33.

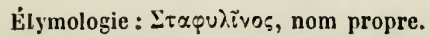

Caractères. Corps allongé, subdéprimé, ailé, pubescent, à élytres unicolores.

Tète grande, saillante, suborbiculaire, portée sur un col court, épais, moins large que le vertex. Tempes non rebordées sur les côtés, Irèsrapprochées ou subcontiguës en arrière en dessous. Épistome trés-court, tronqué au sommet. Labre transverse, fortement bilobé. Mandibules robustes, saillantes, aiguës, sillonnées en dehors, grossièrement dentées intérieurement vers leur milieu, arquées, croisées au repos. Palpes maxillaires assez développés, à 1er article court : les $2^{\text {c }}$ et $3^{\text {e }}$ suballongés, en massue : le dernier plus grêle et plus court que le précédent, subfusiforme, subtronqué au bout. Palpes labiaux assez courts, à dernier article plus long, tronqué au bout. Menton trapéziforme, plus étroit en avant, menbraneux, tronqué au sommet.

Yeux assez grands, peu saillants, ovales, obliquement disposés, séparés du prothorax par un intervalle grand.

Antennes assez courtes, à peine épaissies; à $1^{\text {cr }}$ article allongé, en massue subarquée : le $2^{\mathrm{e}}$ oblong, obeonique : le $3^{\mathrm{e}}$ plus long, suballongé : les $4^{\circ}$ à $10^{\circ}$ graduellement un peu plus courts et un peu plus épais, non contigus : le dernier court, subéchancré au bout.

Prothorax subcarré, parfois subrétréci en arrière, un peu moins large. que les élytres; bissinueusement tronqué au sommet; à angles antérieurs non saillants; subarrondi à sa base; finement rebordé sur celle-ci et sur les còtés; á rebord latéral sinueusement infléchi d'arrière en avant. Repli assez large, incliné, visible vu de côté, sans opercule prothoracique.

Écusson grand, ogival.

Élytres transverses, simultanément subéchancrées à leur bord apical ; arrondies à leur angle postéro-exterue; très-finement rebordées sur la suture (1); à repli médiocre, subvertical. Epaules peu saillantes.

Prosternum peu développé au devant des hanches antérieures, oflrant

(1) Elles sont unicolores. 
entre celles-ci un angle assez court, à sommet droit mais submucroné. Mésosternum à lame médiane simple, triangulaire, émousséc au bout, prolongée environ jusqu'à la moitié des hanches intermédiaires. Hédiépisternums grands, séparés du mésosternum par une suture transversale et sinueuse. Médiépimères assez grandes, en losange ou carré oblong. Métas ternum très-court, fortement échancré au devant des hanches postérieures, prolongé entre celles-ci en un lobe court et subéchancré; avancé entre les intermédiaires en une lame allongée, angulaire, aiguë, liée à la pointe mésosternale par un intermède sensible et ridé en travers. Postépistermums assez étroits, subogivalement arrondis au sommet, subparallèles au repli des élytres. Postépimères réduites, triangulaires.

Abdomen suballongé, subarqué sur les côtés, fortement rebordé latéralement; à $2^{\mathrm{e}}$ segment basilaire parfois découvert : les 3 premiers subégaux : le $5^{\text {e }}$ souvent un peu plus grand : le $6^{\text {e }}$ plus ou moins saillant, rétractile : celui de l'armure enfoui, avec 3 appendices. Ventre à $5^{\text {e arceau }}$ parfois un peu plus grand : le $6^{\mathrm{e}}$ plus ou moins saillant, rélractile.

Hanches antérieures grandes, de la longueur des cuisses, très-saillan'es, coniques, contiguës au sommet. Les intermédiaires presque aussi grandes, peu saillantes, conico-subovales, légèrement distantes. Les postérieures médiocres, rapprochées à leur base, divergentes au sommet (1); à lame supérieure en cône court, sillonné en travers dans son milieu; à lami inférieure nulle ou enfouie.

Pieds médiocres, assez robustes. Trocluanters antérieurs pelits, cunci-iformes; les intermédiaires et postérieurs un peu plus grands : ceus-lii subcunéiformes, ceux-ci elliptiques. Cuisses subcomprimées, subatténuée: vers leur extrémité, surtout les antérieurs et intermédiaires. Tibias sub). élargis de la base au sommet, éparsement épineux, munis au bout de len: tranche inférieure de 2 éperons grêles, dont l'interne plus long ; les intermédiaires subarqués; les antérieurs plus courts et plus robustes (2), sim plement pubescents sur leur tranche externe. Tarses antéricurs courls, $-i$ 4 premiers articles subdéprimés et dilatés dans los 2 sexes; les inte'midiaires et postérieurs moins courts, à peine atténués vers leur ex!rémité, ì $1^{\text {cr }}$ article subégal aux 2 suivants réunis : les $2^{\circ}$ à $4^{\circ}$ Iriangulaires, gri

(1) Les soies qui les terminent en dessous sont réduites presque à de simples ci's. a! licu d'épines.

(2) Ils sont semsiblenent moins longro que les cuisses, tandis que les intermédiatter sont seutement tii peu moins longs que les cuisses, et les posterieurs de la longuetir de celtes-ci. 
duellement plus courts : le dernier en massue, subégal aux 2 précédents réunis. Ongles assez grêles, arqués.

OBs. Les espèces de ce genre, peu nombreuses el médiocrement agiles, se tiennent cachés sous les pierres.

L'opercule prothoracique nul, la pointe mésosternale émoussée, les hanches intermédiaires légèrement distantes, le dernier article des palpes maxillaires plus court que le pénultième, les élytres concolores : tels sont les caractères principaux qui séparent le genre Staphylinus de notre genic Abemus.

Nous donnons ici les diffërences des 2 espèces françaises de Stuphylinus :

a Prothorax de la largeur de la tête, subcarré, nullement rétréci cn arrière; paré d'une bordure postérieure et de 2 taches antérieures, d'un soycux doré. Écusson velouté de noir. Segments de l'abdomen, tous avec une tache d'un soyeux 'doré, sur les côtés.

aa Prothorax moins large que la tète, suboblong, subrétréci en arrière, sans taches. Écusson velouté de blond. Les 3 premiers segments de labdomen sans taches soyeuses sur les côttís.

CAESAREUS.

\section{Staphylinus cuegarens, CEDERHILL.}

Allongé, subdéprimé, rugueusement ponctué, pubescent, d'un noir mat. avec les palpes, la base des antennes, les élytr's et les pieds roux, le devant de la tête et le cou d'un soyeux doré, deux taches antérieures sur le prothorax, la marge postéricure de celui-ci, dis taches sur les côtés de chaque srgment abdominal, de semblable couleur. Ecusson velouté de noir.

$\sigma$ Le $6^{\text {e }}$ arceau ventral fortement sinué dans le milieu de son bord apical. Le $5^{\mathrm{e}}$ faiblement sinué dans le milieu de son bord postérieur.

q Les $5^{\mathrm{e}}$ et $6^{\mathrm{e}}$ arceaux du ventre simples.

Stuphylinus caesareus, CEDïrulels, Faun. Ingr. 105\%, pl 3, fig. c (179s). - ERICHson, Col. March. I, 43.5, 7 ; - Gen. et Spec. Staph. 378, 34. - Redrenbacher, Faun. Austr. 696, 10. - Heer, laun. Col. Helv. I, 2̌̈0, 6. - Fatratke et Laboulbène, Faln. Ent. Fr. 1, 507, 9. - Kilatz, Ins. Deui. II, 3448, ?. Thousov, Skand. Col. II, If́t 6, 2.- Faures, Faun. Gallo-fihén. III, 408, 12.

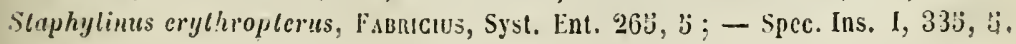


- Fourcroy, Ent. Par. I, 166, 9.- Paykull, Mon. Staph. 7, 3.- Olivier, Ent. III, no 42, 12, 10, pl. 1, f. 14.- Gravenhorst, Micr. 10, 11 ; - Mon. 116, 33. - Latreille, Hist. Nat. Crust. el Ins. IX, 297, 9. - Gyllenhal, Ins. Suec. II, 293, 13.- ManNerheim, Brach. 22, 2.

Le Staphylin à étuis couleur de rouille, GEofrnoy, Hist. Ins. I, 364, 9.

Emus erythropterus, Boisduval et Lacordaire, Faun. Ent, Par. I, $365,8$.

$$
\text { Long., } 0^{\mathrm{m}}, 020 \text { (9l.); - larg., } 0^{\mathrm{m}}, 0050 \text { (2 1/3 l.). }
$$

Corps allongé, subdéprimé, pubescent, d'un noir mat, avec les élytres rousses, la marge postérieure du prothorax et 2 séries de taches-abdominales d'un soyeux doré.

Tête de la largeur du prothorax; densement et rugueusement ponctuée ; éparsement sétoseilée sur les côtés; d'un noir presque mat et à peine métallique; à pubescence courte, assez serrée, noire, devenant d'un blond doré et soyeux au dessus des saillies antennaires, et parfois sur les côtés des tempes. Front très-large, subdéprimé, avec une petite carène postérieure lisse. Col rugueux, à pubescence soyeuse et dorée. Épistome submembraneux antérieurement. Labre cilié et fortement sétosellé à son sommet. Mandibules d'un noir de poix. Palpes d'un roux testacé.

Yeux noirs, parfois à taches livides.

Antennes moins longues que la tête et le prothorax réunis; à peine épaissies; pubescentes et éparsement sétosellées, surtout vers leur base ; d'un roux testacé, avec leur extrémité plus ou moins largement rembrunic; à $1^{\text {er }}$ article allongé, en massue subarquée: les $2^{\mathrm{e}}$ et $3^{\mathrm{e}}$ un peu plus étroits, obconiques: le $2^{\mathrm{e}}$ oblong, le $3^{\mathrm{e}}$ suballongé : les suivants graduellement un peu plus courts : le $8^{\mathrm{e}}$ légèrement, les $9^{\mathrm{e}}$ et $10^{\mathrm{e}}$ sensiblement transverses : le dernier court, subéchancré au bout et subacuminé inférieurement.

Prothorax subcarré, nullement rétréci en arrière, parfois même à peine atténué en avant; un peu moins large que les élytres; bissinueusement tronqué au sommet; à angles antérieurs peu saillants, subarrondis; arrondi à sa base ainsi qu'aux angles postérieurs; légèrement convexe; densement et rugueusement ponctué ; obsolètement caréné sur sa liguc médiane; d'un noir presque mat et à peine métallique ; éparsenent séto sellé sur les còtés ; revêtu d'une courte pubescence noire, avec une étroilc: bordure postérieure et 2 taches près des angles antéricurs, d'un soyeux doré : celles-ci souvent peu distinctes ou effacées. Repli noir: lisse, glabre. 
Écusson velouté de noir, parfois de soyeux doré ver's ses angles latéraux.

Elytres transverses, de la longueur du prothorax ou à peine plus lonģues ; subdéprimées; densement et rugueusement ponctuées; trèsépar'sement sélosellées; ciliées de fauve à leur sommet; revêtues d'une pulescence obscure sur le disque, d'un roux fauve sur le repli ; entièrement d'un roux mat. Épaules étroitement arrondies.

Abdomen plus ou moins allongé, à peine moins large à sa base que les éytres, subarqué sur les côtés ; subconvexe sur le dos ; finement, densen.ent et rugueusernent pointillé, éparsement sétosellé, densement pubescent; d'un noir mat et velouté, avec le bord postérieur du $1^{\text {er }}$ segment, et des taches basilaires obliques, d'un soyeux doré, sur les côtés de tous les segments : celles des $4^{\mathrm{e}}$ et $5^{\mathrm{e}}$ plus larges, triangulaires : celles du $6^{\mathrm{e}}$ souvent enfouies.

Dessous $d u$ corps rugueusement pointillé; d'un noir assez brillant. Poitrine à pubescence soyeuse et mi-dorée, surtout en arrière, avec une tache semblable mais plus marquée, couvrant les médiépimères, et une autre voilant les postépimères et l'extrémité des postépisternums. Ventre convexe, éparsement sétosellé, à pubescence obscure, avec une tache d'un soyeux doré, plus ou moins réduite, sur les côtés de la base des 5 premiers arceaux.

Pieds médiocres, à pubescence blonde; rugueusement pointillés ; d'un roux subtestacé, avec les hanches noires.

Patrie. Celte espèce est commune dans presque toute la France, sous les pierres, dans les champs.

OBs. Quelquefois les cuisses postérieures sont un peu rembrunies dans leur milieu.

Nous avons vu plusieurs exemplaires à antennes entièrement testacées (Emus flavicornis, Dejean, Cat., 3, 68, 1837). Il est à remarquer que, dans cette variélé, la pubescence des élytres est entièrement d'un blond ou d'un roux fauve.

Nous donnerons une description abrégée de l'espèce suivante, étrangère i) la France : 
Strengylinus nuedioximens, FaIRMAIRE.

Allongé, subdéprimé, rugueusement pointillé, pubescent, d'un noir mat, avec les palpes, les antennes, les élytres et les pieds roux, le devant de la tête, les tempes et le cou d'un soyeux doré, le bord apical du $1^{\mathrm{er}}$ segment abdominal, des taches latérales sur les $2^{\mathrm{e}} \mathrm{e} i 3^{\mathrm{e}}$ et une bande basilaire sur le $4^{\mathrm{e}}$, de même coulẹur.

Staphylinus medioximus, Fairmaire, Ann. Soc. Ent. Fr. 1852, 73.

$$
\text { Long., } 0^{\mathrm{m}}, 018 \text { (8 1/3 1.); - larg., } 0^{\mathrm{m}}, 0045 \text { (2 l.). }
$$

PAtrie. Cette espèce habite l'Afrique, ainsi que les contrées les plus méridionales de l'Europe.

OBs. Elle ressemble, à s'y tromper, à la précédente. Néanmoins elle en est distincte par ses antennes entièrement d'un roux testacé; par ses tempes d'un soyeux doré; par son prothorax non ou à peine bordé, vers les angles postérieurs, de poils blonds; par le $4^{\text {e }}$ segment dorsal de l'abdomen et les $3^{\mathrm{e}}$ et $4^{\mathrm{e}}$ arceaux du ventre plus largement maculés de soyeux doré, etc.

La pubescence des élytres est d'un roux fauve.

\section{Staphylinas erythropterus, LINÉ.}

Allongé, subdeprimé, rugueusement pointille, pubescent, d'un noir mat, les palpes, la base et le sommet des antennes, les élytres et les pieds roux, le devant de la tête, le cou et l'écusson d'un soyeux dor'é, et des taches basilaires, de même couleur, sur les côtés des $4^{\mathrm{e}}, 5^{\mathrm{e}}$ et $6^{\mathrm{e}}$ segments de l'abdomen et arceaux du ventre.

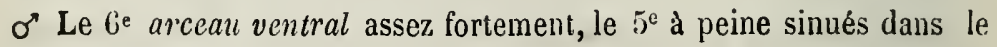
milieu de leur bord apical.

ㅇ Les $5^{\mathrm{e}}$ et $6^{\mathrm{e}}$ arceaux du ventre simples.

Staphylinus erythropterus, Lisné, Faun. Suec. no 842 ; - Syst. Nat. I, II, 683, 4.

- De Villers, Ent. I, 411,4.- Olivier, Ent. III, no 42, 12, 10, pl. 2, fig. 14 ? - 
Eruchson, Col. March. I, 434, 6 ; - Gen. et Spec. Staph. 377, 53. - Redtenbaclier, Faun. Austr. 696, 11.- Heer, Faun. Col. Helv. I, 251, 7.- Fairmaire et Laboulbène, Faun. Ent. Fr. I, 507, 10. - KraAtz, Ins. Deut. II, 547, 8. Trouson, Skand. Col. II, 143, 1. - Fauvel, Faun. Gallo-Rhén. III, 407, 11.

Staphylinus castanopterus, Gravexhonst, Micr.10;-Mon. 116, 132.-Latreille. Ifist. Nat Crust. et Ins. IX, 298, 10. - GyllenhıL, Ins. Suec. II, 298, 14. MaxNermein, Brach. 22, 3.

$$
\text { Long., } 0^{\mathrm{m}}, 016 \text { (7 1/3 l.); - larg., } 0^{\mathrm{m}}, 0034 \text { (1 1/2 l.). }
$$

Corps allongé, subdéprimé, pubescent, d'un noir mat, avec les élytres rousses, et des taches d'un soyeux doré sur les côtés des $4^{\mathrm{e}}$ à $6^{\mathrm{e}}$ segments de l'abdomen.

Tête un peu plus large que le prothorax; densement et rugueusement poinlillée ; éparsement sétosellée sur les côtés ; d'un noir mat; à pubescence courte, assez serrée, noire, devenant d'un soyeux doré au dessus des saillies antennaires. Front très-large, subdéprimé, avec une petite c.rrène postérieure lisse. Col rugueux, à pubescence soyeuse et dorée. Eistome presque subcorné en avant. Labre cilié et fortement sétosellé à son sommet. Mandibules noires. Palpes roux.

Yeux noirs, à taches livides.

Antennes moins longues que la tête êt le prothorax rémnis ; pubescentes rt éparsement sétosellées, surtout vers leur base; rousses, avec leurs articles intermédiaires (4-8) plus ou moins rembrunis : le $1^{\text {er }}$ en massue allongée et subarquée : les $2^{\circ}$ et $3^{\circ}$ à peine plıs étroits, obconiques : le $2^{2}$ oblong : le $3^{\mathrm{e}}$ plus allongé : les suivants graduellement un peu plus courts, avec les $9^{\mathrm{e}}$ et $10^{\mathrm{e}}$ subtransverses : le dernier court, subéchancré au bout et subacuminé infériẹrement.

Prothorax en carré suboblong, subrétréci en arrière, où il est sensiblement moirs large que les élytres; subbissinueusement tronqué au sommet; ¿̀ angles antérieurs peu saillants, presque droits mais émoussés; arrondi i sa base ainsi qu'aux angles postérieurs ; légèrement convexe; densement et rugueusement pointillé ; obsolètement carinulé sur sa ligne méliane; d'un noir mat; très-éparsement sétosellé sur les côtés ; revêtu d'une courte pubescence noire, assez serrée, uniforme. Repli noir, lisse, slabre.

Écusson ruguleux, velouté de soyeux doré.

Élytres transverses, à peine aussi longues que le prothorax ; subdéprinées; finement, densement et rugueusement pointillées; à pcine sétosellées; 
ciliées de fauve à leur sommet; revêtues d'une fine pubescence d'un roux fauve; entièrement d'un roux mat. Épaules étroitement arrondies.

Abdomen plus ou moins allongé, un peu moins large à sa base que les élytres ; subarqué sur les côtés ; assez convexe sur le dos ; très-finement, densement et rugueusement pointillé; d'un noir mat ; éparsement sétosellé; à pubescence noire et serrée, avec une tache basilaire subtriangulaire et d'un soyeux doré, de chaque côté des $4^{\mathrm{e} a ̀ ~} 6^{\mathrm{e}}$ segments, et parfois une petite tache, semblable mais confuse, vers chacun des côtés du bord postérieur du $\mathbf{1}^{\mathrm{er}}$.

Dessous $d u$ corps finement et rugueusement pointillé, d'un noir assez brillant. Poitrine à pubescence soyeuse, plus condensée, plus apparente et plus dorée sur les postépimères et l'extrémité des postépisternums. Ventre convexe, très-éparsement sétosellé; à pubescence obscure ; paré, sur les $4^{\circ}$ à $6^{\circ}$ arceaux, d'une bande transversale, basilaire, d'un soyeux doré, et parfois de quelques soies de même couleur, vers les côtés, sur la base du 3 .

Pieds médiocres, à pubescence d'un blond fauve; finement ponctués ; d'un roux à peine testacé, avec les hanches noires.

Patrie. Cette espèce, moins répandue que le caesareus, préfère les lieux élevés ou les contrées septentrionales. Elle se prend sous les pierres, dans la Flandre, la Picardie, la Normandie, l'Alsace, la Lorraine, l'Auvergne, les Alpes, etc.

OBs. Quelquefois les antennes sont rembrunies jusqu'à leur extrémité, comme chez le S. caesareus. Mais l'erythropterus se distingue toujours facilement de cette dernière espèce, par son prothorax unicolore, un peu plus oblong, plus étroit, rétréci en arrière; par son écusson d'un velouté soyeux et doré; par les 3 premiers segments abdominaux sans taches, etc. La taille est constamment moindre.

A l'exemple des auteurs, nous avons rapporté ici la synonymie d'Olivier, bien que la description et la figure semblent convenir autant au caesareus qu'à l'erythropterus. 
Genre Platydracus, Platydraque, Thomson.

Thowson, Ofv. af Kongl. Vet. Ac. Förh., 1858, p. 29, ff; - Skand, Col. III, 143, 1860.

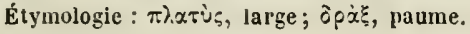

Caractères. Corps plus ou moins allongé, suhdéprimé, ailé, pubescent, à élytres unicolores.

Tête grande, saillante, trapéziforme ou subtriangulaire, subélargic et étroitement arrondie aux angles postérieurs; portée sur un col court, épais, moins large que le vertex. Tempes non rebordées sur les côtés, contiguës en arrière en dessous. Épistome subéchancré au sommet. Labre court, bilobé. Mandibules robustes, assez saillantes, subsillonnées en dehors, dentées intérieurement vers leur milieu, aiģuës, arquées, croisées all repos. Palpes maxillaires médiocres, à $1^{\text {er }}$ article court, les $2^{\mathrm{e}}$ et $3^{6}$ suballongés, obconiques : le dernier plus grêle et un peu plus long, subfusiforme, mousse au bout. Palpes labiaux courts, à dernier article un peu plus long, subfusiforme, subtronqué au bout. Menton transverse, t'apéziforme, plus étroit en avant, membraneux, tronqué au sommet.

Yeux grands ou médiocres, peu saillants, irrégulièrement ovales, obliques, séparés du prothorax par un intervalle plus ou moins grand.

Antennes courtes ou assez courtes, subfiliformes ou à peine épaissies; à $1^{\text {er }}$ article en massue allongée et subarquée : les $2^{\mathrm{e}}$ et $3^{\mathrm{e}}$ obconiques : le $3^{\mathrm{e}}$ souvent plus long que le $2^{\mathrm{e}}$ : les $4^{\mathrm{e}}$ à $10^{\mathrm{e}}$ graduellement un peu plus courts, non uu peu contigus : le dernier court ou assez court, subéchancré au bout.

Prothorax en carré subtransverse, aussi large ou presque aussi large que les élytres; tronqué au sommel (1); à angles antérieurs peu saillants ; arrondi à sa basc ; à peine rebordé sur celle-ci, plus distinctement sur les côtés; à rebord latéral sinueusement infléchi d'arrière en avant. Repli assez large, incliné, visible vu de côté, muni d'un opercule prothoracique triangulaire, submembraneux.

Ecusson grand, ogival.

Elytres transverses; simultanément subéchancrées à leur bord apical;

(1) Parfois d'une manière bissinueuse.

BR. 
arrondies à leur angle postéro-externe; très-finement rebordées sur la suture. Repli assez étroit, subvertical. Épaules peu saillantes.

Prosternum peu développé au devant des hanches antérieures, formant entre celles-ci un angle assez ouvert, gibbeux ou obtusément caréné, à sommet émoussé. Mésosternum à lame médiane simple, triangulaire, prolongée environ jusqu'à la moitié des hanches intermédiaires. Médiépisternums grands, séparés du mésosternum par une arête obsolète, arquée ou sinueuse. Médiépimères médiocres, en losange ou en carré long. Jítas ternum court, fortement échancré au devant des hanches postérieures, prolongé entre celles-ci en un lobe court et subentaillé; avancé entre les intermédiaires en une lame triangulaire, liée à la pointe mésosternale par un intermède étroit, plus ou moins sensible, parfois linéaire et enfoui. Postépisternums médiocres, postérieurement rétrécis en languette mousse, divergeant un peu ou à peine en arrière du repli des élytres. Postépimères variables, subtriangulaires ou en onglet, dépassant parfois les postépisternums.

Abdomen plus ou moins allongé, subatténué en arrière, fortement rebordé sur les côtés; à $2^{\mathrm{e}}$ segment basilaire rarement découvert : les suivants subégaux : le $5^{\mathrm{e}}$ un peu plus grand : le $6^{\mathrm{e}}$ plus ou moins saillant, rétractile : celui de l'armure enfoui, avec 2 fascicules de longues soies. Ventre à $5^{\mathrm{e}}$ arceau un peu plus grand : le $b^{\mathrm{e}}$ plus ou moins saillant, rétractile.

Hanches antérieures grandes, environ de la longueur des cuisses, trèssaillantes, coniques, contiguës au sommet. Les intermédiaires un peu moindres, peu saillantes, conico-subovales, légèrement écartées ou subcontiguës. Les postérieures médiocres, rapprochées à leur base, divergentes au sommet; à lame supérieure conique, sillonnée en travers ou subétranglée vers son milieu; à lame inférienre nulle ou enfouie.

Pieds médiocres, assez robustes. Trochanter's antérieurs petits, cunéiformes : les intermédiaires et postérieur's un peu plus grands : ceux-là subcunéiformes, ceux-ci ovales-oblongs ou subelliptiques. Cuisses subcomprimées, subatténuées vers leur extrémité; les postérieures parfois subélargies dans leur milieu. Tibias subdilatés de la base au sommet; plus ou moins épinenx, surtout sur leur tranche externe; munis au bout de leur tranche inférieure de 2 éperons assez grêles, dont l'interne plus long; les intermédiaires souvent subarqués; les antérieurs plus courts et plus robustes, parfois simplement pubescents ou à peine épineux. Tarses antérieurs courts, à 4 premiers articles subdéprimés et dilatés dans les 2 sexes : les intermédiaires et postérieurs moins courts, à peine atténués vers leur 
extrémité, à $1^{\text {er }}$ arlicle suballongé ou allongé, subég $1 \mathrm{l}$ au moins aux 2 suivants réunis : les $2^{\mathrm{e}} \mathrm{a} 4^{\circ}$ triangulaires, graduellement plus courts : le dernier en massue, subégal aux 2 précédents réunis. Ongles assez grêles, arqués.

OBs. Les espèces de ce genre sont assez agiles. Elles ont des mœurs variées; elles se trouvent sous les pierres, sous les mousses, sous les fumiers et sous les petits cadavres.

Cette coupc générique, créée avec raison par Thomson, est remarquable par la forme de la tête subélargie en arrière et plus ou moins atténuée en avant. La présence de l'opercule prothoracique et le développement du dernier article des palpes maxillaires, toujours un peu plus long que le pénultième, séparent suffisamment le genre Platydracus du genre Staphylinus.

Un petit nombre d'espèces représentent le genre Platydracus. En voici es principaux caractères :

a Hainches intermédiaires légèrement distantes. Pointe mésostcrnale mousse. Antcnnes courtes, assez épaisses, à $3^{e}$ article subégal au $2 \mathrm{e}$ (sous-genre Bemasus; de $\beta \tilde{n} \mu x$, pas, distance),

b Téte et prothorax bronzés, à pubescence fauve et soyeuse.

Elytres, antenncs, tibias et tarses d'un roux fauve.

Abdomen avec tous les segments tachés. . . . . . Lutakius.

bb Téte et prothorax noirs, à pubescence obscure. Étytres,

tibias et tarses diun rouge ferrugineux. Abdomen avec les

2 segments intermédiaires inmaculés. . . . . . .

MERIDIONALIS.

aa Hanehes intermédiaires subcontiguës. Pointe mísosternale plus ou moins aiguë (1). Antenncs moins courtes, à $3^{\mathrm{e}}$ article plus long que le $2^{e}$ (soussgenre Plalydracus).

c Antennes assez courtes, faiblement épaissies. Yeux médiocres. Elytres fauves ou rousses. Dos de l'abdomen taché, au moins sur 4 segments. Vontre taché, au moins sur les cotés.

d Tóte évidemment plus large en arrière qu'au niveau des yeux, à angles postćrieurs très-étroitenent arrondis. Tćte et prothorax bronzés. Antennes et cuisses obscures.

CHALCOCEPIIALS.

(1) L'intermède on pièce qui réunit la pointe antéro-médiane du métasternum à la pointe mésosternale est réduit ici à un filet très-mince et plus ou moins enfoui, tandis que, dans la section $a$, il représente une lame allongée, découverte, à surface sensible et arrondie en dos d'àne. 
dd Téte à peine plus large en arrière qu'au niveau des yeux, à angles postérieur.s moins étroitement arrondis (1). Pieds rour.

e Antennes rousses, au moins à leur base. Tête et prothorax noirs. . . . . . . . . . STERCorarius.

ee Antennes d'un noir de poix à leur base. Téte et pro-

thorax bronzés. . . . . . . . . . LATEBRICOLA.

cc Antennes un peu plus longues, subfiliformes. Yeux grands.

Élytres d'un vert ou d'un bleu sombre, ainsi que la tête et le prothorax. Dos de l'abdomen taché, seulement sur les $5^{\mathrm{e}}$ et $6^{\mathrm{e}}$ segments. Ventre sans taches.

FULVIPES.

\section{1.'Platydracus (Bemasus) Iutarius, Gravenhorst.}

Allongé, subdéprimé, rugueusement ponctué, pubescent, noir, avec la tête et le prothorax bronzés, les palpes, les antennes, les élytres, les tibias et les tarses d'un roux fauve, des taches ou bandes d'un blond soyeux sur tous les segments de l'abdomen.

$\sigma$ Le $6^{\text {e }}$ arceau ventral circulairement et sensiblement sinué dans le milieu de son bord apical, avec un espace à peine impressionné, triangulaire, lisse, au devant du sinus. Tête de la largeur du prothorax.

? Le $6^{\mathrm{e}}$ arceau ventral simple. T'ête un peu moins large que le prothorax.

Staphylinus tutarius, Gravenhorst, Mon. 115, 131. - Mannerhets, Brach. 23, 8.

- Erichson, Gen. et Spec. Staph. 381, 59.- Redtenbacher, Faun. Austr. 695, 8.

- Heer, Faun. Col. Helv, I, 251, 9. - Fairmaire et Laboulbène, Faun. Ent. Fr. 508, 14. - Krattz, Ins. Deut. II, 543, 1. - Fauvel, Faun. Gallo-Rhén. III, $403,7$.

Staphylinus favopunctatus, LAtreille, Hist. Nat. Crust. et Ins. IX, 297, 8.

$$
\text { Long., 0m,0180 (8 1/3 l.); - larg., } 0^{\mathrm{m}}, 0044 \text { (2 l.). }
$$

Corps allongé, subdéprimé, pubescent, noir, avec la tête et le prothorax

(1) Les deux especces Stercorarius et Latebricola, qui représentent cette section $d d$, semblent séloigner des autres par leur tête plus carrée, à peine subtriangulaire ou à peine alténuée ell avant et à angles postérieurs moins étroitement arrondis; mais la présence des opercules prothoraciques et le développement du dernier article des palpes maxillaires relativement au pénultième, nous ont paru des caractères suffisants pour les séparer des Staphylinus et les maintenir dans le genre Platydracus. 
bronzés, les élytres d'un roux fauve et l'abdomen taché de blond soyeux.

Tête rugueusement ponctuée, très-épar'sement sétosellée sur les côtés ; d'un bronzé assez obscur; revêtue d'une pubescence serrée, d'un blond soyeux et semi-dorée. Front très-large, subdéprimé. Col de ia même conleur que la tête. Épistome submembraneux en avint. Labre cilié ct fortement sétosellé à son sommet. Mandibules noires. Palpes d'un roux subtestacé.

Yeux obscurs, parfois à taches livides.

Antennes à peine plus longues que la tête; légèrement épaissies; pubescentes et éparsement pilosellées, surtout vers leur base; rousses, avec le $1^{\text {er }}$ article plus ou moins rembruni dans son milieu : celui-ci en massue allongée et subarquée : les $2^{\text {e }}$ et $3^{\mathrm{e}}$ à peine moins épais, assez courts, obconiques, subégaux : les suivants graduellement un peu plus courts : le $4^{\mathrm{e}}$ subglobuleux, subtransverse : le $5^{\mathrm{e}}$ sensiblement, les $6^{\mathrm{e}}$ â $10^{\mathrm{e}}$ plus fortement transverses : le dernier assez court, subéchancré au bout et subacuminé inférieurement,

Prothorax en carré subtransverse, presque aussi large que les élytres; Ironqué au sommet; à angles antérieurs presque droits, subémoussés ; arrondi à sa base ainsi qu'aux angles postérieurs; peu convexe; densement et rugueusement ponctué, avec une carène obsolète lisse, située en arrière sur la ligne médiane et parfois peu distincte ; d'un noir bronzé peu brillant; très-éparsement sétosellé sur les côtés; revêtu d'une pubescence serrée, d'un blond fauve et mi-doré (1). Repli noir, lisse, glabre.

Écusson ruguleux, velouté de noir.

Élytres transverses, un peu plus longues que le prothorax; subdéprimées ; finement, densement et rugueusement ponctuées; à peine sétosellée.s sur les côtés; revêtues d'unc pubescence assez serrée, d'un roux fauve ou blond, soyeuse et mi-dorée. Epaules subarrondies.

Abdomen plus ou moins allongé ; à peine moins large que les élytres; parfois subatténué vers son extrémité ; assez convexe sur le dos ; finemen ‘ et densement pointillé ; éparsement et longuement sétosellé ; pubescent ; d'un noir mat et velouté, avec 3 taches d'un blond soyeux sur la base des 3 premiers segments, et une bande transversale, sinueuse ou dentée, de même couleur, sur la hase des $4^{\mathrm{e}}$ à $6^{\mathrm{e}}$.

Dessous du corps finement et rugueusement pointillé, d'un noir assez brillant. Poitrine à pubescence soyeuse et blonde. Ventre convexe, épar-

(1) La partie infléchie des côtśs, vers les angles antérieurs, est noire et glabre. 
sement sétosellé; à pubescence obscure, avec les $2^{\mathrm{e}}$ à $6^{\mathrm{e}}$ arceaux parés a leur base d'une bande transversale d'un blond soyeux et subargenté, assez étroite, plus ou moins inlerrompue, souvent peu apparente.

Pieds médiocres, à pubescence blonde ou fauve; rugueusèment pointillés; noirs, avec l'extrémité des cuisses, les tibias et les tarses d'un roux subtestacé, ceux-ci souvent un peu plus foncés.

Patrie. Cette espèce est peu commune. Elle se capture sous les pierres ou dans les bouses mi-desséchées, dans les environs de Lyon, la Savoie, le Languedoc, la Provence, etc. Elle est très-rare dans les provinces du nord.

OBs. Souvent les cuisses postérieures sont largement, parfois presque complétement d'un roux testacé.

Chez les $\sigma^{\circ}$ de taille inférieur', la tête est, comme chez les $q$, un peu moins large que le prothorax.

\section{Platydracus (Bemasus) meridionalis, RosengAUER.}

Allongé, subdéprimé, densement ponctué, pubescent, noir, avec les palpes et les antennes brunâtres, les élytres, les tibias et les tarses d'un rouge ferrugineux, les segments intermédiaires de l'abdomen sans taches latérales.

$\sigma^{*}$ Le $6^{\text {e }}$ arceau ventral légèrement sinué dans le milieu de son bord apical, avec un espace à peine impressionné, triangulaire, lisse, au devant du sinus.

$\uparrow$ Le $6^{\mathrm{e}}$ arceau $\boldsymbol{v}$ entral simple.

Staphylinus meridionalis, Rosenhauer, Beitr. Ins. Eur. I, 12. - Fairmaire et Laboulbène, Faun. Ent. Fr. I, :308, 16. - FajNel, Faun. Gallo-Rhén. III, 404, 5. Staphylinus Mulsanti, Godat, Ann. Sce. Linn. Lyon, 1850-52, 1, 219.

$$
\text { Long., } 0^{\mathrm{m}}, 0160 \text { (7 1/2 l.); - lat'g., 0m,0036 (1 2/3 l.). }
$$

Corps allongé, subdéprimé, pubescent, noir, avec les élytres d'un rouge ferrugineux, et l'abdomen taché de soyelx argenté sur les côtés des 2 premiers segments et à la base des $5^{\mathrm{e}}$ et $6^{\mathrm{e}}$.

Tête à peine aussi large que le prothorax, subrugueusement ponctuée, 
éparsement et longuement sétosellée sur les côtés; d'un noir assez brillant; à pubescence obscure. Front très-large, à peine convexe, avec une petite ligne longitudinale lisse sur sa partie postérieure. Col pointillé, noir. Existome submembraneux en avant. Labre cilié et fortement sétosellé au sommet. Mardibules noires. Palpes brunâtres ou d'un roux de poix foncé.

Yeux obscurs, tachés de livide.

Antennes à peine plus longues que la tête; faiblement épaissies; pubescentes et éparsement pilosellées, surtout vers leırr base; d'un brun un peu ronssátre, avec les 3 premiers articles noirs, sauf l'articulation du $2^{e}$ : le $1^{\mathrm{er}}$ en massue allongée et subarquée : les $2^{\mathrm{e}}$ et $3^{\mathrm{e}}$ à peine moins épais, assez courts, obconiques, subégaux : les suivants presque subcontigus : les $4^{\mathrm{e}}$ et $5^{\mathrm{e}}$ sensiblement, les $6^{\mathrm{e}}$ à $10^{\mathrm{e}}$ fortement transverses : le dernier assez court, subéchancré au sommet et subacuminé inférieurement.

Prothorax en carré subtransverse, parfois à peine rétréci en arrière; de la largeur des élytres; tronqué au sommet; à angles antérieurs presque droits, à peine émoussés; arrondi à sa base ainsi qu'aux angles postérieurs ; peu convexe; subrugueusement ponctué, avec une ligne longitudinale lisse, obsolète, souvent visible seulement en arrière; d'un noir assez brillant; éparsement et longuement sétosellé sur les côtés; revêtu d'une pubescence obscure et médiocrement serrée. Repli noir, lisse, glabre.

Écusson ruguleux, velouté de noir.

Elytres subtransverses, un peu plus longues que le prothorax; subdéprimées; finement, densement et rugueusement pointillées; éparsement sétosellées sur les côtés; revêtues d'une pubescence assez serrée, obscure à reflets roussâtres, entremêlée de poils plus courts, déprimés et d'un gris blond; plus longuement ciliées à leur bord apical; entièrement d'un rouge ferrugineux peu brillant. Épaules subarrondies.

Abdomen suballongé, un peu moins large à sa base que les élytres; subparallèle ou à peine atténué vers son extrémité; subconvexe sur le dos; finement et densement pointillé ; éparsement et longuement sétosellé; recouvert d'une pubescence obscure; d'un noir velouté, avec une tache triangulaire, d'un soyeux argenté, sur les côtés des 2 premiers segments, une bande transversale de même nature sur la base des $5^{\mathrm{e}}$ et $6^{\mathrm{e}}$, et une petite tache basilaire sur le milieu des $2^{\mathrm{e}}, 3^{\mathrm{e}}$ et $4^{\mathrm{e}}$.

Dessous du corps aspèrement pointillé, d'un noir brillant, à pubescence obscure. Ventre convexe, éparsement sétosellé, avec des taches soyeuses et pâles à la base et sur les côtés des $2^{\mathrm{e}}$ à $6^{\mathrm{e}}$ arceaux.

Pieds médiocres, à pubescence obscure, mais à reflets gris ou fauves; 
rugueusement ponctués; noirs, avec les tibias et les tarses d'un roux ferrugineux, ainsi que parfois une transparence de même couleur sur la face postérieure des cuisses antérieures.

Patris. Cette espèce, peu répandue, se prend dans les Basses-Alpes, le Languedoc et les Pyrénées-Orientales.

Ons. Elle est un peu moindre que le lutarius. Sa couleur génėrale est plus obscure. La tête et le prothorax ne sont pas bronzés et leur pubescence est noire et pen apparente. Les antennes, plus sombres, ont leurs $4^{\mathrm{e}} \mathrm{à} 10^{\mathrm{e}}$ articles plus fortement transverses. Lns $3^{\mathrm{e}}$ et $4^{\mathrm{e}}$ segments de l'abdomen sont sans taches, au moiıs sur leurs côtés, etc.

\section{Lasydracus chalcocephalus, FABRICIUS.}

Allongé, subdéprimé, densement ponctué, pubescent. noir, avec la tête et le prothorax bronzés, les palpes, les élytres, les tibias et les tarses d'un roux fauve, les segments de l'abdomen plus ou moins tachés de soyeux subargenté.

$\sigma^{*}$ Le $6^{\mathrm{e}}$ arceau ventral sensiblement et subangulairement sinué dans le milieu de son bord apical, avec un léger espace subimpressionné, lisse, au devant du sinus (1).

\& Le $6^{\mathrm{e}}$ arceau ventral simple.

Staphylinus chalcocephalus, Fabricius, Syst. El. II, 593, 17. - Erichson, Col. March. I, 436, 9.- Gen. et Spec. Staph. 381, 60.- Redtenbacher, Faun. Austr. 695, 9. - HeEr, Faun. Col. Helv. I, 252, 10. - Fairmairf. et Laboulbène, Faun. Ent. Fr. I, 508, 13. - KraAtz, Ins. Deut: II, 544, 3. - Fauvel, Faun. GalloRhén. III, 405, 8.

Straphylinus aeneocephalus. Fabricius, Ent. Syst. I, II, E22, 17. - PANZER, Ent Germ. 353, 11.

Staphylinus ochropterus, Germar, Spec. Ins. 34, 57. - Faun. Ins. Eur. viI, 14. Emus carinthiacus, Boisduval et Lacordaire, Faun. Ent. Par. I, 365, 9.

$$
\text { Long., } 0^{\mathrm{m}}, 0153 \text { (7 l.) ; - larg.. } 0^{\mathrm{m}}, 0033(11 / 2 \text { l.). }
$$

(1) Le $\breve{J}^{\ominus}$ arceau est souvent à peine et subangulairement sinué dans le milieu de son bord postérieur. 
Corps allongé, subdéprimé, pubescent, noir, avec la tête et le prothorax bronzés, les élytres d'un roux fauve et tous les segments de l'abdomen tachés de soyeux subargenté.

Tête un pen moins large en arrière que le prothorax; évidemment subrétrécie en avant; densement et assez fortement ponctuée, à points ombiliqués ; éparsement sétosellẻe sur lez côtés ; d'un bronzé assez brillant ; à pubescence fauve et modérément serrée. Front très-large, ả peine convexe, parfois avec un étroit espace lisse, en arrière. Col ponctué, bronzé, pubescent. Épistome membraneux en avant. Labre cilié et sétosellé vers son sommet. Mandibules noires. Palpes roux.

Yeux médiocres, obscurs ou grisâtres.

Antennes sensiblement plus longues que la tête; faiblement épaissies; pubescentes et éparsement pilosellées, surtout vers leur base; noires, avec l'extrémité parfois moins obscure; à $1^{\text {er }}$ article en massuc allongée et subarquée : les $2^{\mathrm{e}}$ et $3^{\mathrm{e}}$ un peu moins épais, obconiques : le $3^{\mathrm{e}}$ plus long que le $2^{\mathrm{e}}$ : les sujvants graduellement un peu plus courts : le $4^{\mathrm{e}}$ subglobuleux :

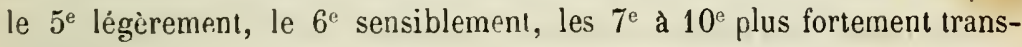
verses : le dernier assez court, subéchancré au sommet et subacuminé inférieurement.

Prothorax presque carré, parfois subcomprimé et subatténué en avant; aussi large ou à peine moins large en arrière que les élytres; tronqué au sommet; à angles antérieurs presque droits et à peine émoussés; arrondi a sa hase ainsi qu’aux angles postérieurs; peu convexe; densement et assez fortement ponctué, à points ombiliqués; offrant vers sa base une ligne longitudinale subélevée, lisse ; éparsement et longuement sétosellé sur les côtés; d'un bronzé assez brillant; avec une pubescence assez serrée et fauve (1). Repli noir, lisse, glabre.

Écusson ruguleux, velouté de noir.

Élytres transverses, à peine plıs longues que le prothorax; subdéprimées; assez finement et deñsement ponctuées; à peine sétoseilées sur les côtés; revêtues d'une pubescence fauve, assez serrée, avec le bord apical plus longuement cilié; entièrement d'un roux fauve et peu brillant. Épaules subarrondies.

Abdomen suballongé, un peu moins large que les élytres; parfois assez sensiblement atténué en arrière; subconvexe sur le dos ; densement poin-

(1) Comme dans le $P l$. lularius, la parlie inféchie du prothorax, vers les angles antérieurs, est noire et glabre. 
illlé; éparsement sétosellé ; recouvert d'une pubescence obscure; d'un noir subvelouté, avec 3 petiles taches subtriangulaires, d'un soyeux blond et subargenté, sur la base des 4 premiers, et une bande de même nature, plus ou moins sinueuse ou dentée, sur la base des $5^{\text {e }}$ et $6^{\text {e }}$, plus confuse sur ce dernier.

Dessous du corps aspèrement ponctué, d'un noir brillant, à pubescence d'un gris obscur. Ventre convexe, très-éparsement sćtosellé, avec une légère bande transversale d'un soyeux cendré sur la base de chaque arceau, souvent peu distincte, effacée ou subinterrompue sur les premiers.

Pieds médiocres, à pubescence fauve; aspèrement pointillés; noirs, avec les tibias et les tarses roux, ceux-ci souvent plus foncés.

Patrie. Cette espèce est médiocrement commune. Elle se prend de diverses manières, mais principalement sous les cadavres de serpents, dans les pays boisés : les environs de Paris et de Lyon, la Bretagne, la Normandie, le Bourbonnais, la Bourgogne, le Beaujolais, les Alpes, etc.

Obs. La tête est généralement plus large chez les $\sigma^{7}$ que chez les $\$$. Toutefois, chez quelques petits exemplaires du premier sexe, elle n'est pas plus grosse que chez le dernier.

LARVE

La larve du Platydracus chalcocephalus ressemble beaucoup à celle du Creophilus maxillosus. Toutefois, elle est d'une couleur plus claire, surtout sur le mésothorax et le métathorax. L'épistome est plus obtusément denté en avant. Le dernier article des palpes maxillaires, avec son lobe terminal, est plus aciculé. L'abdomen est plus fortement sillonné sur sa ligne médiane. L'article terminal des lanières du dernier segment est plus long, plus grêle, moins cylindrique, subatténué et subincourbé en dedans vers son extrémité. Les épines des tibias sont plus grêles ei moins nombreuses, etc. (1).

\section{Platydracus stercorarius, OLIVIER.}

Allongé, subdéprimé, densement ponctué, pubescent, noir, avec les pal-

(1) La taille des larves variant suivant l'àge, nous nous dispenserons de l'indiquer. 
pes, la base des antennes, les élytres el les pieds roux. les segments de l'abdomen tachés de soyeux subargents.

$\sigma$ Le $6^{e}$ arcean ventral largement sinué dans le milieu de son bord apical, avec un espace subimpressionné, lisse, au devant du sinus.

Le $6^{\mathrm{e}}$ arceau ventral simple.

Staphylinus stercorarius, OLIvler, Ent. III, nos $42,18,18$, pl. III, fig. 23. latreille, Hist. Nat. Crust. et Ins. IX, 299, 11. - Gravenhorst, Micr. 11, 12; - Mon. 115, 130. - Gyllenhal, Ins. Suec. II, 296, 15. - ManNerheis, Brach. 22, 4. - Ericnson, Col. March. I, 4:36, 8. - Gen. et Spec. Staph. 380, 58. Redtenbacier, Faun. Austr. 696, 11. - Heer, Paun. Col. Helv. I, 251, 8. Fairmaire et Laboulbène, Faun. Fnt. Fr. I, 507, 11 - Kraatz, Ins. Deut. II, 343 3, 2.

- Fautel, Faun. Gallo-Pihén. III, 404, 6 (1).

Emus stercorarius, Boisduval et Lacordatre, Faun. Ent. Par. I, 366, 10. Platydracus stercorarius, Tномson, Skand. Col. II, 143, 1, 1860.

$$
\text { Long., 0m,0142 (6 1/2 l.); - larg., } 0^{\mathrm{m}}, 0029 \text { (1 } 1 / 3 \text { l.). }
$$

Corps allongé, subdéprimé, pubescent, noir, avec les élytres rousses $\mathrm{e}^{\mathrm{t}}$ lous les segments de l'abdomen tachés de soyeux subargenté, au moin ${ }^{\mathrm{S}}$ sur les côtés.

Tête de la largeur du prothorax, presque carrée ou à peine atténuée en avant; assez densement ponctuée, à points ombiliqués ; éparsement sétosellée sur les côtés; d'un noir un peu brillant; à pubescence obscure et assez serrée. Front très-large, subdéprimé ou à peine convexe, avec une léger espace longitudinal, lisse, en arrière. Col pointillé, noir. Épistome submembraneux en avant. Labre cilié et sétosellé à son sommet. Mandibules noires. Palpes roux.

Yeux médiocres, obscurs, à taches livides.

Antennes un peu plus longues qua la têle; légèrement épaissies; pubescentes et éparsement pilosellées vers leur base; obscures, avec les 3 ou 4 premiers articles roux; le $1^{\text {er }}$ en massue allongée et subarquée: les $2^{\mathrm{e}}$ et $3^{\mathrm{e}}$ un peu moins épais, obconiqces : le $3^{\mathrm{e}}$ plus long que le $2^{\mathrm{e}}$ : les suivants graduellement un peu pius courts : le $4^{\mathrm{e}}$ légèrement, le $5^{\mathrm{e}}$ sensiblement, le $6^{\mathrm{e}}$ assez fortement, les $7^{\mathrm{e}} \mathrm{a} 10^{\mathrm{e}}$ fortement transverses : le dernier court, subéchancré au sommet et subacuminé inférieurement.

(1) Dans la synonymie de Fauvel, au lieu de: Er. Gen. 543 , il faut lire: Er. Gen. 380. 
Prothorax presque carré, subtransverse, parfois à peine rétréci en arrière; presque aussi large que les élytres; tronque au sonımet; à angles antérieurs droits et à peine émoussés; arrondi à sa base ainsi qu'aux angles postérieurs; pell convexe; densement ponctué, à points ombiliqués; offrant sur sa ligne médiaue une carène très-obsolète, souvent nulle en avant, mais plus prononcée, plus large, lisse ct déprimée en arrière; éparsement sétosellé sur les cótés; d'un noir peu brillant, avec une pubescence obscure et assez serrée. Repli noir, lisse, glabre.

Écusson ruguleux, d'un noir velouté.

Elytres transverses, de la longuenr du prothorax ; subdéprimées; assez. finement, densement et subrugueusement ponctuées; à peine sẻtosellées sur les côtés; revêtues d'une pubescence fauve, assez serrée, avec le bord apical plus longuement cilié ; entièrement d'un roux peu brillant. Épaules étroitement arrondies.

Abdomøn suballongé, à peine moins large que les élytres: subparallèle ou à peine atténué vers son extrémité; subconvexe sur le dos; finement ponctué; éparsement sétosellé; recouvert d'une pubescence obscure; d'un noir velouté, avec une tache oblique, d'un soyeux subargenté, sur les côtés des 4 premiers segments et une bande de même nature, plus ou moins dentée, sur la base des $5^{\mathrm{e}}$ et $6^{\mathrm{e}}$, et de plus, une petite moucheture senblable, peu tranchée, sur le milieu de la base des 4 premiers.

Dessous du corps aspèrement ponctué, d'un noir brillant. Poitrine à pubescence blonde, soyeuse, plus distincte sur les côtés. Ventre convexe, éparsement sétosellé; à pubescence d'un gris obscur, avec une bande transversale, assez étroite, d'un soyeux subargenté, plus ou moins apparente, sur la base des $2^{\mathrm{c}}$ a $6^{\mathrm{e}}$ arceaux.

Pieds médiocres, à pubescence fauve; aspèrement ponctués ; roux, a vec les hanches noires, les antérieures parfois moins foncées ou même d'un roux de poix.

Patrie. Cette espèce est assez commune dans presque toute la France. E!le se prend sous les pierres et, le plus souvent, dans les croutins et les bouses.

OBs. La forme générale est plus parallèle et la tête moins triangulaire que dans les espèces précédentes, avec les angles postérieurs de celle-ci plus largement arrondis. La taille est moindre, etc.

Souvent les antennes sont entièrement rousses. Rarement les cuisses sout plus ou moins rembrunirs. Cette dernière variété est des montagnes. 
On peut rapporter au sterco:arius le crebrepunctatus, Motsch. (Bull. Mosc. 1850, II, 570).

\section{Platydracus latebricola, Gravenhorst.}

Allongé, subdéprimé, densement ponctué, pubescent, noir, avec la tête et le prothorax d'un bronzé obscur, les palpes et l'extrémité des antennes d'un roux brunâtre, les élytres et les pieds roux, les segments de l'abdomen légèrement tachés de soyeux cendré.

$\sigma^{*}$ Le $6^{e}$ arceau ventral largement et angulairement échancré dans le milieu de son bord apical, avec un espace à peine impressionné, triangulaire, lisse, au devant de l'échancrure.

ㄴ Le $6^{\mathrm{e}}$ arceau ventral simple.

Staphylinus latebricola, Gravenhorst, Mon. 113, 129. - Erichson, Col. March. I, 437, 10 ; - Gen. et Spec. Staph. 382, 61.- Redtenbacuer, Faun. Austr. 693, 9. - Heer, Faun. Col. Helv. I, 252, 11. - Fairmaire et Laboulbène, Faun Ent. Fr. I, 508, 12. - KinatTz. Ins. Deut. II, 545, 4. - Fauvel, Faun. Gallo-Rhén. III, 406,9 .

Staphylinus rupicola, Kiesenwetter, Stett. Ent. Zeit. XI, 219 ; - Ann. Soc. Ent.

Fr. IX, 413.- Fairmaire et Larotilbène, Faun. Ent. Fr. I, 508, 13. Platydracus latebricola, Tuomson, Skand. Col II, 143, 2, 1860.

$$
\text { Long., } 0^{\mathrm{m}}, 0120 \text { (5 1/2 l.); - larg., } 0^{\mathrm{m}}, 0026 \text { (1 1/4 l.). }
$$

Corps allongé, subdéprimé, pubescent, noir, avec ha tète et le prothorax d'un bronzé obscur, les élytres rousses et les segments' de l'abdomen légèrement tachés de soyeux cendré.

Téte à peine moins large que le prothorax, presque carrée ou à peine atténuée en avant; assez fortement et assez densement ponctuée, à points ombiliqués ; très-éparsement sétosellée sur les côtés; d'un bronzé assez sombre et assez brillant; à pubescence légère el d'un gris fauve. Front très-large, à peine convexe, avec un étroit espace lisse, en arrière. Col peu sensible, pointillé, pubescent, d'un bro ızé obscur. Épistome submembraneux en avant. Labre cilié et sétosellé à son sommet. Mandibules noires. Palpes d'un roux foncé.

Yeux médiocres, obscurs, à tache : grises.

Antennes sensiblement plus longues que la tête; faiblement épaissies; 
pubescentes et éparsement pilosellées vers leur base ; d'un noir de poix avec leur extrémité graduellement moins obscure et parfois même un peu roussâtre; à $1^{\mathrm{er}}$ article en massue allongée et subarquée : les $2^{\mathrm{e}}$ et $3^{\mathrm{e}}$ à peine moins épais, obconiques : le $3^{\mathrm{e}}$ plus long que le $2^{\mathrm{e}}$ : les $4^{\mathrm{e}} \mathrm{a} 10^{\mathrm{e}}$ subgraduellement et à peine plus épais : le $4^{\mathrm{e}}$ subglobuleux, à peine, les $5^{\mathrm{e}} \mathrm{ct}$ $6^{\mathrm{e}}$ sensiblement, les $7^{\mathrm{e}} \mathrm{a} 10^{\mathrm{c}}$ plus fortement transverses : le dernier court, subéchancré au bout et subacuminé inférieurement.

Prothorax presque carré, subtransverse, parfois à peine rétréci en avant, à peine moins large que les élytres ; tronqué au sommet; à angles antérieurs droits et à peine émoussés; arrondi à la base ainsi qu'aux angles postérieurs ; faiblement convexe; assez fortement et densement ponctué, à points ombiliqués; offrant en arrière, sur sa ligne médiane, une carène lisse, déprimée; éparsement et longuement sétosellé sur les côtés; d'un bronzé plus ou moins sombre et assez brillant; à pubescence d'un gris fauve et modérément serrée. Repli noir, lisse, glabre.

Ecusson ruguleux, velouté de noir.

Élytres transverses, de la longueur du prothorax ou à peine plus longues; subdéprimées; finement, densement et subrugueusement ponctuées; trèséparsement sétosellées sur les côtés ; entièrement d'un roux peu brillant; revêtues d'une pubescence fauve, assez serrée, avec le bord apical plus longuement cilié. Épaules, étroitement arrondies.

Abdomen suballongé, moins large que les élytres; subatténué vers son extrémité; subconvexe sur le dos ; finement ponctué ; éparsement et longuement sétosellé; recouvert d'une pubescence obscure; d'un noir un peli brillant, avec 3 léè̀res taches d'un soyeux cendré et plus ou moins effacées, sur la base des 4 premiers segments, et une étroite bande de même nature, parfois peu apparente, sur la base des $5^{\mathrm{e}}$ et $6^{\mathrm{e}}$.

Dessous du corps subaspèrement ponctué, d'un noir brillant. Poitrine à pubescence d'un blond soyeux. Ventre convexe, subirisé, Irès-éparsemen $\mathbf{t}_{\mathbf{t}}$ sétosellé; à pubescence d'un gris obscur, avec une bande d'un soyeux cendré, plus ou moins obsolète ou subinterrompue, sur la base des arceaux.

Pieds médiocres, à pubescence fauve; aspèrement ponctués; roux, avec toutes les hanches et les trochanters antérieurs noirs, les tarses souvent d'un roux foncé.

Patrie. Cette espèce est rare. Elle habite les nids de la Formica rufa ; les environs de Paris et de Lille, la Normandie, la Lorraine, la Bourgogne, le Bourbonnais, la Savoie, les Pyrénées, etc. 
Quelquefois les cuisses antérieures sont plus on moins rembrunies ou a'l moins à leur base.

Les taches soyeuses de l'abdomen et du ventre sont généralement peu tranchées.

Kraatz et le catalogue Gimminger réunissent au latebricola le rupicola de Kiesenwelter. Cette dernière espèce, d'après MM. Fairınaire et Laboul. bène, diffërerait de la précédente par une taille un peu plus avantageuse, par ses anternes un peu plus longues et plus épaisses; par sa tête et son prothorax d'un bronzé moins obscur et plus finement pointillés, etc. Nous n'avons pas vu en nature des échantillons qui répondent au rupicola. Nous n'avons donc pu constater son identité.

Peut-être doit-on rapporter au latebricola l'aericeps de Stephens (Ill.v, 206)?

\section{Platydracus fulvipes, Scopolr.}

Allongé, subdéprimé, densement ponctué, pubescent, noir, avec la tête, le prothorax et les élytres d'un vert ou d'un bleu obscur, les palpes, la base et le sommet des antennes et les pieds roux, les $5^{\mathrm{e}}$ et $6^{\mathrm{C}}$ segments de l'abdomen à bande basilaire d'un soyeux argenté. Ventre sans taches.

$\sigma^{\circ}$ Le $6^{\text {e }}$ arceau ventral largement et angulairement échancré dans le milieu de son bord apical, avec les lobes latẻraux largement tronqués.

Le $6^{\circ}$ arceau ventral simple.

Staphylinus fulvipes, Scopol', Ent. Carn. 99, 30t. - Ericason, Col. March. I, 438, 11 ; - Gen. el Spec. Staph. 382, 62.-Redtenbacher, Faun. Aust. 699, 1. - Heer, Faun. Col. Helv. 1, 523, 13. - Fatraatre et laboulbène, Faun. Ent. Fr. I, 509, 17. - KraAtz, Ins. Deut. II, 545, 5. - FaUvel, Faun. Gallo-Rhén. III. 403, 4 .

Staphylinus bicinctus, Rossi, Faun. Etr. I, Mant. 96, 216.

Staphylinus cingulus, CoxolLt, Col. Nov. 1837, 13.

Stcplyylinus erythropus, PAYKUiL, Faun. Suec. III, 372, 7.- GyllenusL, Ins. Suec. II, 290, 11. - MANNERHEIM, Brach. 24, 22.

Staphylinus tricolor, Gravenuonst, Micr. 7, 6; - Mon. 110, 113. - Latreille, Uist. Nat. Crust. et Ins. IX, 305, 20 .

Staphylinus azureus, Gebler in Ledebour, Reise, App. III, 70, 4. Platydracis fulvipes, Thosson. Skand. Col. II, 144, 3, 1860. 


$$
\text { Long., } 0^{\mathrm{m}}, 0146 \text { (6 2/3 l.); - larg., } 0^{\mathrm{m}}, 0033 \text { ( } 1 \text { 1/2 l.). }
$$

Corps allongé, subdéprimé, pubescent, noir, avec la tête, le prothorax et les élytres d'un vert ou d'un bleu obscur, et les $5^{\text {e }}$ et $6^{\mathrm{e}}$ segments de l'abdomen parés à leur base d'une bande d'un soyeux argenté.

Tête à peine ou un peu moins large que le prothorax, subatténuée en avant; densement et assez fortement ponctuée, à points subombiliqués ; éparsement sétosellée sur les côtés; d'un noir bleuâtre ou verdâtre, un peu brillant; à pubescence obscure. Front très-large, à peine convexe. Col finement ponctué, noirâtre. Épistome submenbraneux on avant. Labre légèrement cilié et fortement sétosellé ver's son sommet. Mandibules noires. Palpes roux.

Yeux grands, obscurs, à taches grisâtres.

Antennes un peu moins longues que la tête etle prothorax réunis; subtiliformes ou à peine épaissies; pubescentes et éparsement pilosellées vers leur base; obscures, avec les 2 ou 3 premiers aricles roux ainsi que le dernier ou parfois les 2 derniers; le $1^{\text {er }}$ en masscue allongée et subarquée : les $2^{\mathrm{e}}$ et $3^{\mathrm{e}}$ un peu plus grêles, obconiques : le $3^{\mathrm{e}} \mathrm{un}$ peu plus long que le $2^{\mathrm{e}}$ : les $4^{\mathrm{e}} \mathrm{a} 10^{\mathrm{e}}$ graduellement un peu plus courts, avec les $9^{\mathrm{e}}$ et $10^{\mathrm{e}}$, seuls subtransverses : le dernier assez couri, subéchancré au bout et subacuminé inférieureınent.

Prothorax en carré à peine iransverse; de la largeur des élytres; tronqué au sommet; à angles antérieur's presque droits et subénoussés; arrondi à la base ainsi qu'aux angles postérieurs ; peu convexe; densement et assez fortement ponctué et à points subombiliqués, avec un trait longitudinal lisse, peu distinct, vers la base ; éparsement sélosellé sur les côtés ; d'un noir bleu ou verdâtre, peu brillant; reconvert d'une fine pubescence d'un gris obscur. Repli noir, lisse, glabre.

Écusson ruguleux, d'un noir velouté.

Élytres transverses, de la longueur du prothorax; subuéprimées; finement, densement et subrugueusement ponctuées; éparsement sétosellées sur les côtés; d'un noir bleu ou verdâtre, presque mat, avec une pubescence d'un gris obscar et assez serrée. Epaules étroitement arrondies.

Abdomen suballongé, un peil noins large que les ćlyues; subatténué vers son extrénité ; assez convexe sur le dos; finement ponctué ; éparsement sétosellé; revêtu d'une pubscence obscure; c'un noir mat et velouté, 
avec une bande transversale, assez large et d'un soyeux argenté, sur la base des $5^{\mathrm{e}}$ et $6^{\mathrm{e}}$ segments.

Dessous du corps densement et aspèrement ponctué, d'un noir brillant. Poitrine à pubescence blonde ou fauve. Ventre convexe, éparsement sétosellè, à pubescence d'un gris obscur; sans tache.

Pieds inédiocres, à pubescence fauve; aspèrement ponctués; roux, avẹc les hanches noires.

Patrie. Cette espèce, assez rare, se rencontre, en été el en automne, sous les pierres et sous les mousses des grandes forêts : les environs de Paris, la Flandre, la Normandie, la Bretagne, l'Alsace, la Lorraine, la Bourgogne, la Savoie, les Alpes, les Pyrénées, etc. Nous en avons trouvé, I. Rizaucourt et nous, en avril, parmi le détritus des marais des environs d'Hyères, plusieurs exemplaires identiques à ceux des hautes montagnes.

OBs. Cette espèce intéressante se distingue suffisamment des précédentes par sa coloration et surtout par ses antennes plus grêles et plus allongées. A part la forme subtriangulaire de la tête, elle fait naturellement le passage aux Ocypus par sa teinte obscure et par son abdomen peu taché (1).

La couleur de la tête, du prothorax et des élytres, est tantôt bleuâtre, tantôt d'un vert obscur. Les antennes sont souvent entierement rousses.

On doil peut-être rapporter au fulvipes l'aureofasciatus Moı̀sch. (Étud. Ent. 1860, 40).

(1) II. Abeille de Perrin nous a communiqué un exemplaire, provenant des Apennins, à forme un peti plus large et plus robuste, à pruthorax moins rétréci en arrière, à élytres un peu moins courtes, à ponctuation de la tête el, dı prothorax un peu plus forte et plus rugueuse. C'est un individu o o, dont le 6 e arceau ventral est a peine, et le కe larzement et subangulairement, sinués à leur sommet. A part la forme de la tête, est-ce là peut-être le Staphylinus cingulus de Villa, cité par Comolli (Col. Nov. 1837, 14, 20), ou bien une variété "locale du fulvipes? Toutefois, le caractère féminin, qui rappelle faiblement celui du $\sigma$ de certaines espèces, nous a paru une particularité remarquable. 
Genre Ocypus, Ocype, Stephens.

Stephens, 11]. Brit. V, 211.

Ètymologie : $\dot{\omega} x \grave{u} \varsigma$, agile; $\pi 0$ $\varsigma$, pied.

Caractères. Corps allongé, subdéprimé, ailé ol parfois aplère, fubescent.

Tête grande, saillante, suborbiculaire ou en carré traisverse, portée sur un col très-court, moins large que le vertex. Tempes non rebordées sur les côtés, fortement co!ıtiguës en dessous. Épistome lurgement tronqué au sommet (1). Labre transverse, bilobé. Mandibules assez saillantes, sillonnées en dehors, grossièrement bidentées intérieurenient vers leur milieu (2), aiguës, arquées, croisées au repos. Palpes maxillaires médiocrss, à $1^{\text {er }}$ article court ou assez court, les $2^{e}$ el $3^{\mathrm{e}}$ subaliongés, obconiques : le dernier assez variable, environ de la longueur du précédent, subcylindrique ou subfusiforme (3), mousse ou subtronqué au bout. Palpes labiaux courts, à dernier article plus long, oblong ou ovalaireoblong, mousse ou tronqué au bout. Menton transverse, trapéziforme, beaucoup plus étroit en avant, tronqué au sommet, plus ou moins largement membraneux ou submembraneux dans sa partie antérieure.

Yeux de grosseur variable, peu saillants, irrégulièrement ovales, obliques, séparés du prothorax par un intervalle grand ou très-grand.

Antennes peu ou médiocrement allongées, subfiliformes (4); à $1^{\mathrm{er}}$ article en massue grêle, allongée et subarquée : le $3^{\mathrm{e}}$ un peu plus long que le $2^{\mathrm{e}}$, parfois suballongé : les $4^{\mathrm{e}}$ à $10^{\circ}$ graduellement un peu plus courts, peu ou non contigus, avec les 2 pénultièmes ou le pénultième seul, subtransverses : le dernier assez court, subéchancré au bout.

Prothorax en carré transverse ou suboblong; aussi large ou presque aussi large que les élytres; Ironqué au sommet; à angles antérieurs peu

(1) La bordure antérieure de l'épistone est toujours plus étroite que dans les genres précédents, subverticale, souvent subcornée, rarement submembraneuse.

(2) L'une des deux est parfois unidentée seulement, surtout la droite.

(3) Ce dernier article est tanlôt aussi long, tantôt à peine plus long, tuntôt à peine moins long que le pénultième, parfois plus ou moins épais suivant les sexes.

(4) Comme elles sont subcomprimées vers leur extrémité, elles paraissent parfois subattėnuées, vues de dessus. 
saillants (1); plus ou moins arrondi à sa base ; très-finement rebordé sur celle-ci et sur les côtés; à rebord latéral subsinueusement infléchi d'arrière en avant. Repli assez large, incliné, visible vu de côté, sans opercule prothoracique apparent.

Écusson grand, ogival ou triangulaire.

Élytres transverses ou subtransverses; simultanément subéchancrées à leur bord apical; arrondies à leur angle postérn-externe ; à peine rebordées sur la suture. Repli assez étroit, subparallèle, subvertical. Épaules à peine saillantes.

Prosternum peu développé au devant des hanches antérieures, formant cntre celles-ci un angle plus ou moins ouvert, à sommet droit ou subaigu et parfois mousse, à disque relevé postérieurement en carène souvent tranchante. Mésosternum à lame médiane assez courte, en triangle à sommet brusquement rétréci en pointe acérée, prolongée environ jusqu’au tiers des hanches internıediaires. Médiépisternums très-grands, séparés du mésosternum par une fine suture transversale et subsinueuse. Médiépimère plus ou moins étroites; allongées, parfois linéaires. Métasternum trèscourt, fortement échancré au devant des hanches postérieures, prolongé cntre celles-ci en un lobe court et subentaillé; avancé entre les intermédiaires en angle obtus, court, émeltant un intermède lanciforme, enfoui. Postépisternums p!us ou moins étroits, subparallèles ou divergeant à peine du repli des élytres. Postépimères petites, triangulaires.

Abdomen plus ou moins allongé, subparallèle ou parfois subatténué en arrière, fortement rebordé sur les cótés; à $2^{\mathrm{c}}$ segment basilaire quelquefois un peu découvert : les suivants subégaux : le $5^{\mathrm{e}}$ un peu plus grand : le $6^{\mathrm{e}}$ plus ou moins saillant, rétractile : celui de l'armure enfoui, avec un lobe médian et 2 lanières latérales. Ventre à $5^{\text {e }}$ arceau un peu plus grand que les précédents : le $6^{\text {e }}$ lus ou moins saillant, rétractile.

Hanches antérieures grandes, environ de la longueur des cuisses, trèssaillantes, coniques, contiguës au sommet. Les intermédiaires moindres, peu saillantes, conico-ovales, fortement contiguës. L's postérieures médiucres, rapprochécs à leur base, divergentes au sommet; à lame supérieure conique, subétranglée ou sillonnée en travers dans son milieu; à lame inférieure nulle ou enfouie.

Pieds suballongés, assez robustes. Trochanters antéricurs petits, cunéiformes; les intermédiaires et postérieurs plus grands : ceux-là subcunéi-

(1) Ils sont plus infléchis que dans les genres précédents. 
formes, ceux-ci ovales-oblongs. Cuisses subcomprimées, subatténuées vers leur extrémité. Tibias subélargis de la base au sommet, plus ou moins épineux, munis au bout de leur tranche inférieure de 2 éperons grêles dont l'interne plus long; les antérieur's plus courts et plus robustes, souvent simplement pubescents sur leur tranche externe. Tar'ses antérieurs courts, à 4 premiers articles subdéprimés et dilatés dans les 2 sexes; les intermédiaires et postérieurs plus développés, subatténués vers leur extrémité, à $1^{\text {er }}$ article allongé, égal au moins aux 2 suivants réunis : les $2^{\mathrm{e}}$ a $4^{\mathrm{e}}$ triangulaires, graduellement plus courts : le dernier en massue, subégal aux 2 précédents réunis. Ongles peu grêles, arqués, subdentés en dessous à leur base.

OBs. Les espèces de ce genre, d'une démarche agile, vivent sous les pierres, les mousses, au pied des arbres. Elles sortent souvent de leur retraite pour courir et chasser au gros soleil; toutefois elles sont la plupart nocturnes.

La pointe mésosternale, brusquement atténuée en pointe acérée, est moins prolongée que dans les genres précédents, avec les hanches intermédiaires toujours contiguës. Les antennes sont plus grêles et moins courtes. L'abdomen est généralement plus allongé, peu taché ou immaculé; les médiépimères sont plus étroites et parfois sublinéaires; les postépimères plus réduites, etc.

Les espèces du genre Ocypus sont nombreuses. Leurs caraclères peuvent se résumer ainsi quant à la $1^{\text {re }}$ section, qui répond au sous-genre Goerius :

a Tibias antérieurs plus ou moinsépineux sur leur tranche externe (1).

Yeux relativement petits (2), séparés du cou par un intervalle beaucoup plus long que leur plus grand diamètre. Tête au moins aussi large que le prothorax, en carré plus ou moins arrondi aux angles. Antennes assez allongées, paraissant, vues de dessus, subatténuées vers leur extrémité (3) (sous-genre Goerius Leach in Stephens, 1835, Ill. Brit. Ent, V, 208).

(1) L'unique caractère des tibias antérieurs épineux ou non, indiqué par Thomson pour le genre Goerius (Skand. Col. IX, 139, 1867), ne nous a pas paru suffisant. Nous n'adopterons donc cette coupe que comme sous-genre, en l'appuyant de caractères accessoires.

(2) Les yeux, vus de dessus, paraissent souvent subangulés à leur côté interne.

(3) Dans celte section, le dernier article des palpes maxillaires est généralement subcylindrique et subtronqué au bout, parfois plus épais et plus largement tronqué chéz les $\sigma$. 
b Dessus du corps tout à fait mat. Cuisses postérieures beaucoup plus longues que les intermédiaires. Taille trèsgrande.

c Prothorax étroit, allongé, fortement rétréci en arrière. BaCDII.

cc Prothorax large, assez court, subparallele.

d Ailes complètes. Pubescence obscure. Elytres de la longueur du prothorax ou à peine plus longues. . . . OLENs.

dd Ailes nulles ou rudimentaires. Pubescence ferrugineuse. e Ėytres noires, un peu plus courtes que le prothorax. BRACHYptenus. ee Elytres roussátres, sensiblement plus courtes que le prothorax. Taille un peu moindre. . . . . Italicus.

bb Dessus du corps un peu brillant sur la tête et sur le protho. rax. Cuisses postérieures un peu plus longues que les intermédiaires. Taille moindre.

f Têt.e, prothorax et élytres bleuâtres : celles-ci de la longueur du prothorax. Ailes complètes.

CYANEUS.

ff Tête, prothorax at élytres noirs. Ailes nulles ou rudimentaires.

g Prothorax subcarré. Elytres un peu plus courtes que celui-ci. Antennes et pieds obscurs. . . . . .

gg Prothorax oblong. Elytres d'un tiers plus courtes que celui.ci. Antennes et pieds d'un brun ferrugineux.

SIMILIS.

DECURTatus.

\section{Ocypug (Goerius) Baudil, FaUvel.}

Staphylinus Baudii, Fuvvel, Ann. Soc. Ent. Fr. 1867, Bull. 5ॐ. - Mars. l’Aboille, 1871, vili, 289 (nec Peyron).

Extrêmement distinct de l'olens par sa taille, sa forme étranglée au milieu, moitié plus é:roite, allongée ; tête plus large que le corselet; celui-ci ètroit, trapézoi lal, non sinué latéralement, Ironqué subcarrément à la base; angles postérieurs plus marqués; élytres plus petites, plus courles, passant all brun foncé; $\sigma^{7} \tau^{\mathrm{e}}$ segment à peine sinué-échancré au sonmet. Long., 20 à 21 millim.

Sous les pierres, dans les haules montagnes (TR).

Mont Bernina (Ch. Brisout de Barneville); Alpes lépontiennes, mont Rosa, Vavallo (Balidi).

Nous n'avons pas vu celte espèce. Nous en rapportons la description d'après M. Fauvel. 


\section{ஐ. Deypus (Coerius) olens, Muller.}

Allongé, subdéprimé, ailé, finement et subrugueusement ponclué, d'un noir tout à fait mat, à pubescence obscure. Antennes moins fonceies ì leur sommet. Élytres aussi longues ou à peine plus longues que le prothorax.

$\sigma^{*}$ Le $6^{\mathrm{e}}$ arceau ventral faiblement, le to très-faiblement sinués à leur bord apical.

q Les $5^{\mathrm{e}}$ et $6^{\mathrm{e}}$ arceaux du ventre simples.

Staphylinus olens, IUuler, Faun. Fridr. 23, 228; - Prodr. 97, 1090. - Fabricius, Mant. Ins. I, 219, 1.-- Ent. Syst. I, II, 520, 6 ; Syst. El. II, 391, 8. - DE VII LERS, Ent. 1, 421, 66. - P.үкull, Mon. Staph. 9, 4. - Olivier, Ent. III, no 42, 9, 4 , pl. 1, fig. 1. - Gravenhorst, Nicr. 4, 2 ; - Mon. 111, 117. - Latreille, Hist. Nat Crust. et Ins. IX, 302, 16.- Gyleenia:, Ins. Succ. II, 28ð, 6. - Mannerheim, - Brach. 23, 15. - lievr, Faun. Col. Helv. I, 2J3, 14.-Fairiaire et Laboulbène,

Faun. Ent. Fr. I, 509, 1S. - Fauves, Faun. Gallo-Rhén. III, 409, 14.

Le grand Staphylin noir lisse, Geoffroy, Hist. Ins. 300, I, pl. 7, fig. 1.

Emus olens, Boisduval et Lacordane, Faun. Ent. Par. I, 367, 12.

Ocypus olens, Ericnson, Col. Iarch, I, 439, 1; - Gen. et Spec. Staph. 403, 1. -Redtenbacher, Faun. Austr. 698. - Kraatz, Ins. Deut. II, 5ร3, 1.

Goerius olens, Thouson, Skand. Col. II, 147, 1, 1860.

Variété a (immature). Élytres et parfois prothorax d'un brun ferruyine'x $x$.

$$
\text { Long., } 0^{\mathrm{m}}, 0305 \text { (14 l.); - larg., } 0^{\mathrm{m}}, 0060 \text { (2 2/3 l.). }
$$

Corps allongé, subdéprimé, ailé, d'un noir tout à fait mat, avec une pribescence courte, serrée et plus ou moins obscure.

Tête subtransverse, de la largeur du prothorax ou à peine plus large, finement et densement ponctué noir mal, avec une pubesc nce obscure. Front très-large, à peine convexe, parfois subimpressionné en avant; offrant en arrière, sur sa ligne médiane, une très-fine carène obsolèt... Col rugueusement pointillé, d'un noir mat, pubescent. Expistome à bord antéricur subcorné, obscur. Labre cilié et fortement sétosellé en avant. Mandibules et palpes d'un noir de poix.

Yeux assez petits, noirs, parfois lavés de gris.

Antennes sensibltment plus longues que la tête; ‘̀ peine atténuées vers 
leur extrémité; pubescentes et éparsement sétosellées vers leur base; noires, avec leur sommet graduellement moins foncé et parfois d'un brun ferrugineux; à $1^{\text {er }}$ artiele allongé en massue grêle et subarquée : le $2^{\circ}$ obconique : le $3^{\circ}$ suballongé, plus lo.g que le $2^{\mathrm{e}}$ : les $4^{\mathrm{e}}$ à $10^{\mathrm{e}}$ graduellement plus courts : les $4^{\mathrm{e}}$ à $6^{\circ}$ oblongs, conico-subcylindriques : les suivants obconi jues, avec le pénultième seul paraissant parfois subtransverse vu de côté : le dernier assez court, obliquement subéchancré au bout et acuminé inférieurement.

Prothorax en carré transverse; de la largeur des élytres; tronqué au somnet; à angles antérieurs peu saillants, subobtus et émoussés; à peine arqué sur les côtés; arrondi à sa base ainsi qu'aux angles postérieurs, qui sont très-obtus; légèrement convexe ; finement, très-densement et subrugueusement ponctué, avec une très-fine carène longitudinale obsolète, effacée antérieurement; éparsement sétosellé sur les côtés; d'un noir tout à fait mat, avec une fine pubescence obscure. Repli noir, lisse, glabre.

Écusson ruguleux, velouté de noir.

Élytres transverses; de la longueur du prothorax ou à peine plus longues; subdéprimées; finement, très-densement et rugueusement ponctuées; très-éparsement sétosel ées; d'un noir tout ‘ fait mat, avec une fine pubescence obscure. Epaules subarrondies.

Abdomen plus ou moins allongé; à peine moins large à sa base que les élytres; subarqué sur les côtés; subconvexe sur le dos; à peine sétosellẻ ; tinement, densement et subaspèrement pointillé; d'un noir mat, avec une fine pubescence obscure. Le $6^{\mathrm{e}}$ segment subarrondi au sommet.

Dessous du corps densement et subaspèrement pointillé, d'un noir brillant, à pubescence ubscure. Dessous de la tête plus lisse, éparsement ponctué. Jétastermum avec une ligne longitudinale lisse. Ventre convexe, éparsement sétosellé.

Pieds médiocres, aspèrement pointillés, noirs, à pubescence obscure. Cuisses postérieures allongées. Tibias antérieur's distinctenent épineux sur leur tranche externe.

Patrie. L'Ocypus olens est très-conınıun daus presque toute la France. On le rencontre principalement en automne, dès le mois d'août, sous les pierres, les détritus, et sourent courant dans les champs ou les chemins, prenant un air menaçant à l'approche du moindre péril.

Chcz les sujcis immatures, les élytres et parfois le pruthorix sont d'un brun ferrugineux. 
La larve de l'Ocypus olens, signalèe par Heer (Obs. Ent. 16, 5, pl. III, fig. A), a ćté décrite ou figurée par Blanchard (in Guérin, Mag. Zool. VI, pl. 165), Ralzeburg (Forst. I, Käf. 1839, 31, pl. I, fiğ. 14), Jacquelin du Val (Gen. Col. Eur. I, 30, pl. 1, fig. 14), et Kroyer (in Schiödte, Nat. Tidss. 1864, 197, pl. IX, fig. 1), qui en a donné les mólamorphoses.

3. Deypus (Goerius) brachypterns, Falrmaire el Laboulbìne.

Allongé, subdéprimé, subaptère, finement et subrugueusement ponctué, d'un noir tout $\dot{a}$ frit mat, à pubescence ferrugineuse. Antennes moins foncées à leur sommet. Elytres un peu plus courtes que le prothorax.

$\sigma^{*}$ Le $6^{\mathrm{e}}$ arceau ventral faiblement, le $5^{\mathrm{e}}$ à peine sinués dans le milieu de leur bord apical.

$\subsetneq$ Les $5^{\mathrm{e}}$ et $6^{\mathrm{e}}$ arceaux du ventre simples.

Staphylinus brachypterus, Fatraaire et Laboulbène, Faun. Ent. Fr. I, 509, 19. Ocypus micropterus, Redtenbacher, Faun. Austr. I, 697, 7.

Ocypus brachypterus, Krastz, Ins. Deut. II, 553, 2.

$$
\text { Long., } 0^{\mathrm{m}}, 0295 \text { (13 1/2 l.); - larg., } 0^{\mathrm{m}}, 0055 \text { (2 1/2 l.). }
$$

Patrie. Cetle espèce se prend dans les Hautes-Pyrénées.

OBs. Elle ressemble tellement à la précédente, qu'elle pourrait bien en être une variété et que nous nous dispenserons d'en donner une plus ample description. Nous constaterons seulement que les ailes sont nulles ou rudimentaires, la pubescence ferrugineuse au lieu d'être noire ou d'un gris obscur, les élytres toujours un peu plus courtes que le prothorax. Nous n'avons pas observé d'intermédiaires.

Le curtipennis Motsch. s'applique peut-êtra à cette espèce?

\section{Deypus (Goerius) Halicus, Aragona.}

Allongé, subdéprimé, aptère, finement et subruguersement ponctué, d'un noir mat, à pubescence ferrugineuse, avec les èlytres d'un brun roussâtre. 
dutennes obscures, moins foncies à leur sommet. Elytres sensiblement plus courtes que le prothorax.

$\sigma^{*}$ Le $6^{*}$ arceau ventral subsinué à son bord apical.

ㄴ Le $6^{\mathrm{e}}$ arceau ventral simple.

Staphylinus Italicus Aragona, DE Quib. Col. 1830, 10, 406. - Erichson, Gen. et Spec. Staph. 400̉, 3. - Fauvel. Faun. Gallo-Rhén. III, 409 (note).

$$
\text { Long., } 0^{\mathrm{m}}, 022(101 .) \text {; - larg., } 0^{\mathrm{m}}, 0028 \text { (1 2/31). }
$$

Corps allongé, subdéprimé, aptère, d'un noir ma!, aves une pubescence courtre, serrée et ferrugineus".

Téte sublransverse. à peine plus large que le prothorax, finement et densement poncluée, éparsement sétosellée sur les côtés; d'un noir mat, avcc une pubescence d'un rouillé obscur. Front Irès-large, subdéprimé ou à peine convexe. Col pointillé, noir, à pubescence ferrugineuse. Épistome à bord antérieur subcorné, noirâtre. Labre presque lisse, cilié et fortemont sétosellé en avant (1). Mandibules et palpes d'un noir de poix, le pénultième article de ceux-ci souvent moins foncé.

Yeux assez petits, noirs, lavés de livide.

Antennes un peu plus longues que la tête; à peine atténuées vers leur extrémité ; pubescentes et éparsement pilosellées vers leur base; noires, avec leur sommet gradueltement moins foncé el parfois roussátre; à $1^{\mathrm{e}}$ article allongé en massue grêle et subarquée : le $2^{\mathrm{e}}$ obconique : le $3^{\text {e }}$ plus long que le $2^{e}$, suballongé : les suivants gradueilement un peu plus courls, subobconiques: les $4^{\mathrm{e}} \mathrm{à} \mathbf{7}^{\mathrm{e}}$ oblongs ou suboblongs : le pénultième seul subıransverse : le dérnier court, excavé à son sommet et acuminé inférie urement.

Prothorax en carré subtransverse; de la largeur des élytres; tronqué au sommel; à angles antérieurs peu saillants, presque droits mais subarrondis; à peine arqué ou presque subrectiligne sur les côtés; subarrondi à sa base ainsi qu'aux angles postérieur's, qui sont très-obtus; faiblement convexe; finement, densement et subrugneusement ponctué; très-éparsement sétosellé sur lés còtés; d'un noir mal, avec une tỉne pubescence d'un brun ferrugineux. Repli noir, lisse, glabre.

(1) Les cils, généralement fauves ou páles, garnissent le bord apical liri-mìme. Les soies, plus ou moins obscures, sont implantées immédiatement au dessus. Cette remarque sंapplique à la plupart des espèces, même des genres précédents et suivants. 
Écusson pointillé, noir, à pubescence obscure et à reflets ferrugineux. Elytres transvirses, environ d'un tiers plus courtes que le prothorax; subdéprimées; finement, très-densement et rugueusement ponctućes; à peine sétosellées; d'un brun roussâtru ct toul à fail mat, avec une fi:.e pubescence ferrugineuse. Épaules subarrondies.

Abdomen allongé, un peu moins large à sa base que les élytres; subparallèle ou à peine aryué sur les côtés, parfois suballénué tout à fait vers son sommet; convexe sur le dos; à peine sétosellé; finement, densement et subaspèrement ponctué; d'un noir mat, avec une pubescence plus ou moins ferrugineuse. Le $6^{\circ}$ segment subarrondi au sommet.

Dessous du corps assez densenent et subaspèrement ponctué, d'un noir assez brillant, à pubescence obscurément ferrugineuse ou grisâtre. Dessous de la tête plus lisse, éparsemen! ponctué. Ventre convexe, à peine sétosellé.

Pieds médiocres, aspèrement pointillés, noirs, à pubescence grise ou fauve. Cuisses postéricures allongées. Tibias antérieurs plus ou moins épineux sur leur tranche externe (1).

Patrie. Celte espècr, qui nous vient de feu M. Truqui, se prend dars les Apennins. Elie est indiquée de France dans quelques calalogues.

Oвs. Quely'refois on aperçoit vers la base du prothorax une fine ligne longitudinale lisse et subélevée, peu apparente.

L'Ocypus Italicus est distinct du Brachypterus par sa taille moindre, par ses antennes un peu moins allongées, et par ses élytres sensiblement plus courtes et toujours plus ou moins roussât'es. Lit taille, l'absence des ailes, la brièveté des élytres et la couleur de la pubescence, le séparent évidemment de la variété a de l'Ocypus olens (2).

\section{Deypus (Goenins) eyaneus, PaYkull.}

Allonyé, subdéprimé, ailé, densement ponctué, finement pubescent, d'un noir brillant en dessous, d'un noir mat sur l'abdomen, d'un bleu un peu

(1) Chez cette espèce, les épines des tibias, étant couchécs, sont peu spparentes.

(2) A la suite de l'Ocypus Italicus, on pourrait colloquer l'espèce suivante, également aptère, et dont nous ne ferons que citer le nom, avec l'auteur, attendu qu'elle est étrangère à la France :

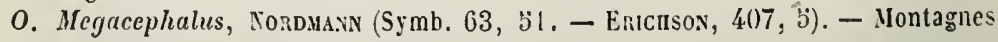
de la Carinthie.

Cette espèce a la t'te et le prothorax d'un bronzé obscar, et les élytres d'un roux lestacé, 
brillant sur la tôte et le prothorax, mat sur les èlytres. Antennes obscures, moins foncées à leur sommet. Elytres de la longucur du prothorax: celui-ci à carène raccourcie en avant.

o* Le $6^{2}$ arcéau ventral distinctement et largem nı, le $5^{\mathrm{e}}$ à peine sinués à leur bord apical.

o Le $6^{\mathrm{e}}$ arceau ventral sinple, ainsi que le $5^{e}$.

Staphylinus cyancus, Paykcl., Mon. Staph. 13, 7. - Faun. Suec. III, 370, 4. Fabricius, Ent. Syst. I, II, ̈̈21、I1 ; - Syst. Lil. II, 392, 13.- Olivier, Ent. III, no $\{2,14,13, \mu$. I, f. 4. - Gravivinnsr. Micr. 6, 5; - Ion. 110, 114. latreille, Hist. Nat. Crust. et Ins. IX, 30' , 19. - Gyllevilal, Ins. Suec. II, 286, 7. - Manne:H:I, Brach 2k, 10. - Ilezr, Faun. Col. Helv. II, 253, 13.-Fairmar: et laboulabèxe, ,Falun. Ent. Fr. I, J09, 20.

Le Staphylia bleu, Geoffroy, I:Is. I, 361, 2.

Staphylinus coerulescens, Fourcr.y, Ent. Par. I, 164, 2.

Staphylinus azurescens, Mans nuEIn, Brach. 23, 15.

Enus cyaneus, Bolsduvil, et Lacord.hre, Faun. Ent. Par. I, 3j8, 13.

Ocypus cyaneus, Encusov, Col. March. I, 440, 2; - Gen. et Spec. Staph. 403, 2.

- Redtexbacher. Faun. Austr. 698. - Krastz, Ins. Deut. II, 555, 6.

Goerius cyancus, Thouson, Skand Col. II, 147, 2, 1860.

Staphylinus alrocyaueus, Falrascie, Ann. Soc. Ent. Fr. 1860, 157.

Staphylinus ophthalmicus, Fayvec, Faun. Gallo-Rhén III, 411, 17 (1).

Variétśs. Tête, prothorax el élytres d'un noir verdâtre.

$$
\text { Long., } 0^{\mathrm{m}}, 020 \text { (9 l.) ; - larg., } 0^{\mathrm{m}}, 0036 \text { (1 2/3 !.). }
$$

Corps all ungé, subdéprimé, ailé, noir, avec la tête, le prothorax et les élyıres d'un bleu plus o' moins foncé; revêtu d'une fine pubescence assez serrée et d'un gris obscur.

Téte subcarrie, a peine plus large que le prothorax, densement ponctuée: éparsement sétosellée sur les côtés; d'un bleu plus ou noins fones et assez brillant, avec un tine pubescence d'un gris obscur. Front trèslarge, à peine convexe, souvent moins densement ponctué vers l'épistome ; olfrant sur sa ligne nıédiane une fine carène, plas ou moins obsolète surtout antérieurement. Col poirtillé, bleuâtre, lègèrement pubescent.

(1) Il nous semble quon doit almettre le nom de cyancus conacri par l'usage plutót que celui d'ophthalmicus Scop. qui peut induire en erreur, les yeux ne dcvenant blancs que par la dessication. 
Épistome à bord antérieur subcorné, obscur. Labre presque lisse, cilié et fortement sétosellé en avant. Mandibules et palpes d'un noir de poix, avec le dernier article des maxillaires purfois moins foncé.

Yeux assez petits, obscurs, lavés de livide.

Antennes beaucoup plus longues que la tête; subfiliformes ou à peine atténuées vers leur extrémité; pubescentes et éparsement pilosellées vers leur base; noires, avec leur sommet soluvent moins foncé; à $1^{\text {er }}$ article allongé en massue grêle et subarquée : le $2^{\mathrm{e}}$ obconique : le $3^{\mathrm{e}}$ asscz allongé, sensiblement plus long que le $2^{\circ}$ : les $4^{\mathrm{e}}$ à $10^{\mathrm{e}}$ graduellement un peu plus courts : les $4^{\mathrm{e}}$ à $6^{\mathrm{c}}$ oblongs, conico-subcylindriques : les suivants subobconiques : les $7^{\mathrm{e}}$ et $8^{\mathrm{e}}$ suboblongs : le $9^{\mathrm{e}}$ non, le $10^{\mathrm{e}}$ faiblement transverses, vus de côté : le dernier assez cour', obliquement subéchancré au bout et acuminé inférieurement.

Prothorax subcarré, à peine moins large à sa base que les élytres; tronqué au sommet; à angles antérieurs non saillants, subobtus et émoussés ou subarrondis; à peine arqué ou presque droit sur les côtés; subarrondi à sa base ainsi qu'aıx angles poslérieurs qui sont très-obtus; filiblemert convexe; densement ponctué ; souvent finement et obsolètement carinulé en arrière, sur sa ligne médiane; très-éparsement et longuement sétosellé sur les côtés; d'un bleu plus ou moins foncé, peu ou même assez brillant, avec une fine pubescence d'un gris obscur ou azuré. Repli noir, lisse, glabre.

Écusson ruguleux, d'un noir velouté.

Élytres transverses, environ de la longueur du prothorax; subdéprimées ; finement, très-densement et rugueusement ponctuées ; éparsement et longuement sétosellées; d'un bleu plus ou moins foncé, mat, avec une fine pubescence d'un gris obscur ou bleuâtre. Épaules subarrondies.

Abdomen plus ou moins allongé, à pein moins large à sa base que les élytres; subparallèle ou à peine arqué sur les côtés; assez convexe sur le dos ; éparsement sétosellé ; finement, densement et subaspèrement pointillé; d'un noir mat ou presque mal, avec une fine pubescence d'un gris obscur. Le $6^{\mathrm{e}}$ segment subtronqué au sommet.

Dessous du corps densement et subaspèrement pointillé, d'un noir brillant, à pubescence d'un gris obscur. Dessous de la tête plus lisse, éparsement ponctué. Poitrine avec une fine ligne longitudinale lisse. Ventre convexe, éparsement sétosellé.

Pieds médiocres, éparsement ponctués, noir's, à pubescence d'un grris obscur. Cuisses postérieures sıballongées. Tibias antérieurs dis- 
tinctement épineux sur leur tranche externe. Ongles souvent d'un roux de poix.

Patrie. Cette espèce est commune dans presque toate la France, sous les pierres, dans les champs et les chemins.

Oвs. Sa couleur bleuâtre la distingue suffisamment de tous ses congénères.

Quelquefois (var. a), la couleur bleue est remplacée par une teinte verdâtre; d'autres fois, elle se montre presque noire.

Cette espèce varie beaucoup pour la taille, et passablement pour la ponctuation de la tête et du prothorax, laquelle est plus ou moins fine, plus ou moins serrée, et parfois rugneuse.

Les angles antéricur's du prothorax, plus ou moins infléchis ainsi que dans les autres espèces, le sont parfois au point de faire paraitre ce segment subatténué en avant, vu de dessus. Nous avons vu un exemplaire, de couleur verdâtre, dont le prothorax, outre cetle dernière particularité, est plus convexe, avec la carène médiane plus sensible et presque entière, et dont la tête, moins large, présente en avant une légère impression lisse.

Le cyanochloris, Fairmaire et Hochhuth, se rapporte à une variété du cyaneus.

\section{LARVE}

Voici la'description de la larve de l'Ocypus cyaneus trouvée sous les pierres avec l'insecte parfait.

Corps suballongé, assez épais, éparsement sétosellé, d'un roux de poix brillant, avec la tête un peu plıs foncée, la bouche, les a itennes et les pieds testacés, l'abdomen obscur et mat avec une bande dorsale livide.

Tète grande, en carré suborbiculairè, subrétrécic en arriere, plus large que le prothorax, à peine convexe, presque lisse ou obsolètement ridée en travers, d'un roux de poix brunâtre et brillant. Mandibules obscures. Palpes testacés.

Yenx petits, faiblement saillauts, presugue lisses, bruns, entourés d'un cercle pâle.

Antennes courtes, testacées, de 3 articles sans compter le tubercule antennifêre : le $1^{\text {er }}$ allungé, subcylindrique : le $2^{\mathrm{e}}$ plus étroit mais presque aussi long que le $1^{\mathrm{er}}$, obtusément angulé en dessous, paré de quelques soies spiniformes : le dernier plus court que le précédent, un peu plus grêle, subcylindrique, terminé par une longue soie. 
Prothorax en carré subarcuément rétréci en avant, rebordé à sa bise. convexe, lisse, d'un roux de poix brillant.

Mésothorax court, égalant à peine le tiers du prothorax, un peu plus large en arrière que celui-ci, convexe, lisse, d'un roux de poix brilIant.

Métathorax un peu plus court et un peu plus large que le segment précédent, arqué sur les cótés, subconvexe, lisse, d'un roux do poix brillant. Abdomen presque aussi large à sa base que le mitathorax, un peu moins long que le reste du corps; subarqué sur les côtés et subatténué en arrière; plus fortement et moins parcimonieusement sétosellé que la tête et le thorax; subdéprimé; d'un brun obscur et mat, avec les bourrelets latéraux plus pâles et une bande longitudinale livide, assez étroite, sur le milieu du dos; composé de 9 segments : les 8 premiers très-courts, subégaux, munis chacun sur les côtés d'un stigmate plus distinct que ceux du thorax : le $9^{\text {e }}$ plus étroit, transverse, d'un brun livide, subéchancré au sommet, émetiant 2 lanières 3 fois plus longues que lui, rapprochées à leur base, subatténuées et un peu recourbées en dedans vers leur extrémité, longuement sétosellées sur les côtés, terminées par un style grêle, linéaire, sétifère, une fois moins long.

Dessous de la tête presque lisse, d'un roux de poix foncé et très-brillant. Dessous du thorax testacé. Ventre déprimé, fortement sétosellé, obscur, avec une étroite bande longitudinale pâle sur son milieu; à dernier arceau très-court, subéchancré à son sommet, qui émet un appendice épais, subcylindrique, en forme de tube, un peu plus court que les lanières supérieures.

Pieds testacés, avec les hanches plus pâles : celles-ci très-allongées. Cuisses sublinéaires, épineuses en dessous. Tibias plus courts, subcylindriques, épineux de tous côtés, terminés par un fort crochet, solide, subarqué vers le bout.

Obs. Cette larve est remarquable par la brièveté du lobe terminal des lanières.

\section{Deypus (Goerius) simuilis, Fabricius.}

Allongé, subdéprimé, aptère, densement ponctué, finement pubescent, d'un noir mat sur les élytress et l'abdomen, un peu brillant sur la tète et le. 
prothor ix. Antennes obscures, à sommet plus ou moins ferruginenx. Elytres plus courtes que le prothorax, celui-ci subcarré, à carène entière.

$\sigma^{\prime \prime}$ Le $6^{e}$ arceau ventral fortement et angulairement entaillé, le $5^{e}$ à peine sinué, dans le milieu de leur bord apical. Le dernier article des palpes maxillaires épais, de la largeur du sommet du précédent.

\& Le $6^{\text {e }}$ arcean ventral subarrondi, le $5^{\mathrm{e}}$ simple, à leur bord apical. Le dernier article des palpes maxillaires moins épais, plus grêle que le sommet du précédent.

Staphylinus similis, F.dricius, Ent. Syst. I, II, 52l, 7 ; - Syst. El. II, 591, 9. Gravenhorst, Micr. 5, 3 ; - Mon. 111, 119. - Latreille, Hist. Nat. Crust. et Inst IX, 302, 17.- Gyllenilat, Ius. Suec. II, '287, 8. - Mannemein, Brach. 24, 17. - Ileer, Faun. Col. Helv. I, 233, 16. - Fal maire et Laboulbène, Faun. Ent. li. $\overline{1}, 510,21$.

Staphylinus globulifer, Fourcroy, Ent. Par. I, 1034, 3.

Emus similis, Botsduval et Lacordatre, Faun. Ent. Par. I, 368, 14.

Ocypus similis, Entcuson, Col. March. I, 440, 3; - Gen. et Spec. Staph. 403, 7.

- Redtenbscher, Faun. Austr. 697, 7. - Kratz, Ins. Deut. II, 5כ06, 7.

Staphylinus nitens, FaUvel, Faun. Gallo-Rhén. III, 411, 18 (1).

$$
\text { Long., } 0^{\mathrm{m}}, 018 \text { (8 1/4 1.); - larg., } 0^{\mathrm{m}}, 0032 \text { (1 1/2 l.). }
$$

Corps allongé, subdéprimé, aptère, noir, mat sur les Łlyıtres et l'abdomen, plus brillant sur le reste ; revèlu d'une légère pubescence d'un gris obscur.

Téte subcarréc, un peu ou à peine plus larye que le prothorax, densement ponctuée, éparsenent sétose'líe sur les côtés, d'un noir parfois assez brillant, légèrement pubescente. Fron: tris-large, subdéprimé ou à peine convexe, offrant sur son milieu une étroite ligne longitıdinale, lisse, raccourcie en avant. Cou ponctué, noir, pubescent. Épistome à bord antérieur submembraneux, pâle. Labre presque lisse, cilié et forlement sétosellé vers son sommet. Mandibules et palpes d'un noir de poix.

Yeux assez petits, obscurs ou grisâtres.

Antennes sensiblement plus longues đ̦ue la tète; subfiliformes ou à peine atténuées vers leur extrémité; plilusscentes et éparseuent pilosellées vers

(1) Le nom de nitens Schr. ne convient nullement à cet insecte, qui est un dəs plus mats du genre. Nous lui préférons le nom consacré de similis. 
leur base ; noires, avec leur sommet ou seulement le dernier article ferrugineux; le $1^{\text {er }}$ allongé en massue très-grê!e et subarquée : le $2^{e}$ obconique, suboblong : le $3^{\mathrm{c}}$ assez allongé, plus long que le $2^{\mathrm{e}}$ : les suivants graduellement plus courts, subobconiques, oblongs ou suboblongs, avec les 2 pénultièmes au moins aussi longs que larges et nullement transverses : le dernier assez court, obliquement et à peine subéchancré au bout, acuminé inférieurement.

Prothorax subcarré, à peine rétréci en arrière; de la largeur des élytres; tronqué au sommet; à angles antérieurs non saillanıs, presque droits mais émoussés ou subarrondis; presque rectiligne sur les côtés; subarrondi à sa base ainsi qu'aux angles postérieurs qui sont tris-obtus, souvent subtronqué sur le milieu de celle-là ; légèrement convexe; densement ponctué, avec une très-fine ligne longitudinale subélevée, lisse, entière ; éparsement sétosellé sur les côtés; d'un noir un peu ou parfois assez brillant; légèrement pubescent. Repli noir, lisse, glabre.

Écusson pointillé, noir, pubescent.

Élytres transverses, visiblement plus courtes que le prothorax ; subdéprimées; finement, très-densement et rugueusement pointillées ; éparsement sétosellés; d'un noir mat, avec une fine pubescence d'un gris obscur. Épaules étroitement arrondies.

Abdomen plus ou moins allongé, un peu ou à peine moins large à sa base que les élytres; subparallèle ou à peine arqué sur les côtés; subconvexe sur le dos ; éparsement sétosellé sur les côtés; finement, densement et subaspèrement pointillé; d'un noir mat, avec une fine pubescence assez serrée et d'un gris obscur. Le $6^{\text {e }}$ segment obtusément tronqué ail sommet.

Dessous du corps densement et aspèrement pointillé; d'un noir assez brillant, à fine pubescence d'un gris obscur. Dessous de la tète plus brillant, plus fortement et moins densement ponctué. Métasternum déprimé. Ventre convexe, éparsement sétosellé.

Pieds médiocres, aspèrement ponclués, noirs, à pubescence d'un gris obscur. Cuisses postérieures suballongées. Tibias antérieurs plus ou moins distinctement épineux sur leur tranche externe, avec leur pubescence souvent blonde ou fauve, ainsi que celle du dessous de tous les tarses.

Patrie. Celle espèce se prend sous les pierres et au pied des arbres, dans presque toute la France. Elle n'est pas très-commune.

OBs. Elle diffère de la précédente par sa couleur, des autres par sa taille moindre, par sa tête encore plus carrée el par son prothorax plus droit 
sur les côtés. Mais ce qui distingue principalement cette espèce, c'est l'échancrure triangulaire profonde $d u 6^{\mathrm{e}}$ arceau ventral chez les $\sigma^{\prime \prime}$.

Elle varie beaucoup pour la taille. Les exemplaires des montagnes sont moindres et relativement plus étroits. La ponctuation de la tête et du prothorax est tantôt assez forte et plus ou moins serrée, tantôt plus fine, plıs dense et plus rugueuse, ce qui leur donne une teirite plus mate.

Les antennes, parfois entièrement obscures, sont souvent moins foncćes vers leur sommet, avec le dernier article quelquefois d'un roux ferrugineux assez tranché.

Les exemplaires immatures sont parfois brunâtres, avec le dessous du corps, les antennes et les pieds plus ou moins ferrugineux.

L'Ocypus similis de Thomson (Skand. Col. II, 148, 2) nous semble différent du nôtre, car il le place dans son genre Ocypus, à tête suborbiculaire, à tibias antérieurs inermes, ce qui n'a pas lieu dans notre espèce, dont la tête est plus carrée que dans toute autre, avec les tibias antérieurs distinctement épineux.

On rapporte au similis l'abbreviatipennis d'Aubé (Ann. Ent. Fr. 1850, $315)$.

C'est avec doute aussi qu'on doit rapporter la synonymie d'Olivier (Ent. no 42, 13, 12, pl. V, fig. 42), qui dit : noir, sans taches; tête et corselet lisses, luisants; tandis que dans la figure les élytres sont d'un roux brunâtre.

\section{\%. Deypus (Goeriug) decurtatus, Mulsant et Rey.}

Allongé, étroit, subdéprimé, aptère, densement ponctué,finement pubescent, d'un noir mat sur les élytres, moins mat sur l'abdomen, brillant sur' la tête et le prothorax, avec les antennes et les pieds d'un brun ferrugigineux. Élytres d'un tiers plus courtes que le prothorax: celui-cioblong, à carène entière.

$\sigma^{7}$ Le $6^{\circ}$ arceau ventral fortement, largement et angulairement entaillé. Le $5^{\mathrm{e}}$ subsinué dans le milieu de son bord apical. Le dernier article des palpes maxillaires aussi épais que le sommet du précédent.

L Les $5^{\mathrm{e}}$ et $6^{\mathrm{e}}$ arceaux du ventre simples. Le dernier article des palpes maxillaires plus étroit que le sommet du précédent.

$$
\text { Long., } 0^{\mathrm{m}}, 012 \text { (5 1/2 1.); - larg., } 0^{\mathrm{m}}, 0022 \text { (1 l.). }
$$

BR. 
Patrie. Celte espève esı assez rare. Elle se prend sous les pierrej, dans les Hautes-Alpes, les montagnes de la Lozère et de la Provence.

OBs. Nous ne la décrirons pas davantage, car elle est très-voisine de l'Ocypus similis, dont elle est peut-être une variété. Mais tlle est d'une taille bien moindre et proportionnellement plus étroite. La tête et le prothorax sont un peu plus brillants, avec ce dernier un peu plus oblong et plus parallèle. Les élytres sont encore plus courtes, moins déprimées. L'abdomen est un peu moins mat. Les tibias antérieurs sont moins épineux en dehors. Enfin, les antennes, les palpes et les pieds sont d'une couleur moins obscure.

Quelquefois les pieds et les antennes sont entièrement ferrugineux, avec le premier article de celles-ci à peine ou non rembruni.

Souvent les intersections ventrales sont un peu roussâtres, et, chez les sujets immatures, tout le dessous du corps se montre d'un roux de poix plus ou moins foncé.

Comme nous l'avons vu, dans cette espèce et la précédente, le dernier article des palpes maxillaires est plus épais chez les $\sigma^{\prime}(1)$. Nous ajouterons que le même article est visiblement un peu plus long que le pénultième, dans les deux sexes.

L'entaille du $6^{\mathrm{e}}$ arceau ventral des $\sigma$ nous a paru plus large dans le decurtatus que dans le similis.

Suit le tableau de la $2^{\mathrm{e}}$ section des Ocypus, laquelle comprend les.Ocypus vrais et le sous-genre Pseudocypus :

2a Tibias antéricurs simplement pubescents sur leur tranche externe.

h Yeux relativement petits, séparés du cou par un intervalle beaucoup plus long que leur plus grand diamètre. Ailes nulles. Téte plus large que le prothorax. Antennes suballongées, testacées vers leur extrémité. (Sous-genre Ocypus.)

1 Tête et prothorax presque mats. Tête suborbiculaire, à angles antérieurs effacés. . . . . .

li Tête et prothorax assez brillants. Téte en carré transverse, à angles antérieurs prononcés. . . . . MaCrocephalus.

(1) Comme il est plus épais, il parait plus largement tronqué au bout. 
hh Yeux assez grands, séparés du cou par un intervalle un peu plus grand que leur plus grand diamètre. Téte de la largeur du prothorax. Antennes rousses ou ferrugineuses à leur sommet.

k Dessus du corps brillant sur la tête et le prothorax. Antennes assez allongées. Ailes nulles. Abdomen sans taches. Pieds roux. . . . . . . . . .

BRUNNIPES.

kk Dessus du corps entièrement mat. Autennes assez courtes. Ailes complètes. Abdomen à série dorsale de taches cendrées. Pieds obscurs. . . . . . AETHIOPS.

hhh Yeux grands, séparés du cou par un intervalle aussi long ou moins long que leur plus grand diamètre. Antennes assez courtes, subfiliformes. Ailes complètes. (Sousgenre Pseudocypus, de $\uparrow \varepsilon v \tilde{\delta}$ os, faux, et Ocypus, Ocype(1). p Tête subcarrée ou en carré transverse, de la largeur du prothorax : celui-ci un peu brillant, sans ligne lisse bien apparente. Abdomen à série dorsale de taches cendrées. . . . . . . . . .

pp Tête suborbiculaire ou courtement ovalaire, souvent un peu moins large que le prothorax.

m Prothorax éparsement ponctué, avec un espace médian lisse, assez large. Téte et prothoraxd'un noir bronzé très-brillant. Élytres obscures. $A b$ domen sans taches. . . . . . . .

mm Prothorax densement ponctué, avec une étroite ligne lisse entre deux séries de points plus forts. Téte et prothorax bronzés.

n Abdomen à lignes longitudinales d'un soyeux cendré.

- Prothorax subcarré, brillant, uniformément pointillé. Elytres un peu plus courtes que le prothorax, obscures ou ferrugineuses. . . . . . .

oo Prothorax suboblong, assez brillant, plus densement pointillé et impressionnéle long de la ligne médiane (2). Élytres de la longueur du prothorax, bronzées ou d'un bronzé roussâtre. . . . . . .

FUSCATUS.

PICIPENNIS.

AENEOCEPHALUS,

(1) Chez les Pseudocypus, le dernier article des palpes maxillaires est ordinairement plus grẻle que le pénultième, subfusiforme, mousse ou subtronqué au bout, dans les deux sexes. Les Ocypus vrais commencent à montrer une conformation analogue.

(2) Ce qui fait paraitre cette ligne comme subélevée ou subcarinulée. 
Abdomen à pubescence obscure, mélangée de poils cendrés.

p Tête et prothorax peu brillants. Élytres obscures, de la largeur du prothorax. Pieds brunatres. . . . . . .

OBSCUROAENEUS.

pp Tête et prothorax brillants. Élytres rousses, un peu plus courtes que le prothorax. Pieds roux.

FULVIPENNIS.

8. Deypus alpestris, ErichSoN.

Allongé, subdéprimé, aptère, finement ponctué, finement pubescent, d'un noir presque mat, avec l'extrémité des antennes testacée, la bouche et les tarses d'un roux de poix. Elytres d'un tiers plus courtes que le prothorax: celui-ci subcarré, à carène effacée en avant. Téte à peine plus large que le prothorax.

$\sigma$ Le $6^{\mathrm{e}}$ arceau ventral légèrement et subangulairement, le $5^{\mathrm{e}} a \mathrm{a}$ peinc échancrés dans le milieu de leur bord apical.

Les $5^{\mathrm{e}}$ et $6^{\mathrm{e}}$ arceaux du ventre simples.

Ocypus alpestris, Erichson, Gen. et Spec. Staph. 408, 6. - Redtenbaceer, Faun. Austr. 698. - Kratz, Ins. Deut. II, 554, 4.

Staphylinus brevipennis, HeER, Faun. Col. Helv. I, $254,17$.

Staphylinus alpestris, FaUvel, Faun. Gallo-Rhén. III, 410, 15.

$$
\text { Long., } 0^{\mathrm{m}}, 015 \text { (7 1.); - larg., } 0^{\mathrm{m}}, 0028 \text { (1 1/4 l.). }
$$

Corps allongé, subdéprimé, aptère, d'un noir presque mal, revêtu d'une fine pubescence d'un gris obscur.

Tête subtransversalement orbiculaire, un peu plus large que le prothorax, densement ponctuée, très-éparsement sétosellée sur les côtés, d'un noir presque mat ou peu brillant, finement pubescente. Front très-large, à peine convexe, avec une ligne longitudinale lisse, peu distincte, raccourcie en avant. Cou pointillé, noir. Epistome infléchi, livide. Labre lisse, fortement sétosellé à son sommet. Mandibules noires. Palpes d'un roux de poix.

Yeux petits, obscurs, souvent grisâtres et micacés.

Antennes un peu plus longues que la tête; subfiliformes; finement duve. 
teuses ; éparsement sėtosellées surtout vers leur base; obscures, a vec les 3 ou 4 derniers articles testacés : le $1^{\text {er }}$ en massue allongée et subarquée : les $2^{\text {e }}$ et $3^{\mathrm{e}}$ obconiques : le $2^{\mathrm{e}}$ oblong : le $3^{\circ}$ suballongé, sensiblement plus long que le $2^{\mathrm{e}}$ : les suivants graduellement un peu plus courts : les $4^{\circ} \mathrm{a}$ $7^{\mathrm{e}}$ oblongs, subcylindriques : le $8^{\mathrm{e}}$ suboblong : les $9^{\mathrm{e}}$ et $10^{\mathrm{e}}$ subobconıques, à peine plus longs que larges : le dernier subovalaire, obliquement subéchancré au bout et acuminé inférieurement.

Prothorax subcarré, subparallèle; de la largeur des élytres; tronqué au sommet; à angles antérieurs infléchis et à peine arrondis; largement arrondi à sa base, avec celle-ci subtronquée dans son milieu et les angles postérieurs très-obtus; subconvexe; finement et densement ponctué, avec une fine carène longitudinale lisse, obsolète, effacée en avant; éparsement sétosellé sur les côtés; d'un noir presque mat ou peu brillant; finement pubescent. Repli noir, lisse, glabre.

Ecusson ruguleux, pubescent, noir.

Elytres fortement transverses, d'un tiers plus courtes que le prothorax; déprimées ; finement, très-densement et rugueusement ponctuées, trèséparsement sétosellées; d'un noir mat ; finement et assez densement pubescentes. Épaules cachées.

Abdomen allongé, à peine moins large à sa base que les élytres; à peine arqué sur les côtés et subatténué vers son extrémité; subconvexe sur le dos ; éparsement sétosellé; très-finement et densement pointillé, moins densement en arrière; d'un noir mat, avec une fine pubescence modérément serrée. Le $6^{\circ}$ segment subtronqué au sommet.

Dessous du corps subaspèrement ponclué, finement pubescent, d'un noir assez brillant. Dessous de la tête éparsement ponctué. Métasternum subdéprimé. Ventre convexe, très-éparsement sétosellé.

Pieds médiocres, aspèrement pointillés, finement pubescents, noirs, avec les tarses d'un roux de poix. Cuisses postérieures suballongées. Tibias antérieurs simplement pubescen!s sur leur tranche externe, seukment a vec 2 ou 3 épines à leur face inférieure.

Patrie. Celte espèce es! rare. Elle se prend sous les pierres, dans les Alpes du Dauphiné et de la Savoie.

OBs. Elle est plus étroite et moins paralièle que l'Oc. similis, et ordinairement moins noire. La pubescence e:t moins obscure, la poncluation moins serrée, surtout sur la partie postérieure de l'abdomen. La tètc est plus arrondie aux angles, surtout aux antérieurs, au devant 
des yeux, ce qui la rend moins carrée. Le prothorax, moins rétréci en arrière, a sa ligne élevée moins prononcée. Les élytres, plus courtes, sont moins densement ponctuées, plus pubescentes. L'échancrure du $6^{\circ}$ arceau ventral des $\sigma^{7}$ est beaucoup moins profonde. Enfin, l'extrémité des antennes et les tarses sont d'une couleur plus claire, et les tibias antérieurs non épineux en dehors, etc.

Chez les exemplaires immatures, le dessus du corps est brunâtre, et les pieds d'un brun roussâtre.

\section{Deypus macrocephalus, Gravenhorst.}

Allongé, subdéprimé, aptère, finement ponctué, finement pubescent, d'un noir asses brillant et submétallique sur la tête et le prothorax, presque mat sur les élytres et l'abdomen, avec l'extrémité des antennes testacée et les tarses d'un brun de poix. Élytres d'un tiers plus courtes que le prothorax: celui-ci à peine oblong, à carène effacée en avant. Tête plus large que le prothorax.

$\sigma^{*}$ Le $6^{\mathrm{e}}$ arceau ventral légèrement, le $5^{\mathrm{e}}$ à peine sinués dans le milieu de leur bord apical.

오 Les $5^{\mathrm{e}}$ et $6^{\mathrm{e}}$ arceanx du ventre simples à leur bord apical.

Staphylinus macrocephalus, Gravenhorst, Micr. 160, 3 ; - Mon. 111, 116. -

Latreille, Hist. Nat. Crust. et Ins. IX, 305, 21.- Nordiann, Symb. 64, 52.

Ocypus macrocephalus, Erichson, Gen. et Spec. Staph. 407, 4. - RedtenbaCher, .

Faun. Austr. 697, 8. - KraATz, Ins. Deut. II, 554, 3.

Ocypus Chevrolati, Baudi, Stud. Ent. I. 121.

$$
\text { Long., } 0^{\mathrm{m}}, 0190\left(8 \text { 2/3 l.); - larg., } 0^{\mathrm{m}}, 0033\right. \text { (1 1/2 l.). }
$$

Corps allongé, subdéprimé, aptère, d'un noir assez brillant et submétallique sur la lête et lle prothorax, presque mat sur les élytres et l'abdomen; revêtu d'une fine pubescence d'un gris obscur ou fauve.

Tête en carré subtransverse et subarrondi aux angles, visiblement plus large que le prothorax, assez densement ponctuice, très-éparsement sétosellée sur les côtés, d'un noir assez brillant et submétallique, à peine pubescente. Front très-large, peu convexe, a vec une étroite ligne longitudinale lisse, effacée en avant. Cou pointillé, noir, à peine pubescent. Épistome à 
bord antérieur submembraneux, livide. Labre presque lisse, cilié et fortement sétosellé à son sommet. Mandibules noires. Palpes d'un roux de poix.

Yeux petits, obscurs, parfois avec un cercle gris.

Antennes sensiblement plus longues que la tête; subfiliformes; pubescentes et éparsement sétosellées vers leur base; d'un noir de poix, avec leur extrémité graduellement plus claire et les 3 ou 4 derniers articles testacés; le $1^{\text {er }}$ en massue allongée, très-grêle et subarquée : les $2^{\circ}$ et $3^{\circ}$ obconiques : le $2^{\mathrm{e}}$ oblong : le $3^{\mathrm{e}}$ allongé, sensiblement plus long que le $2^{\circ}$ : les suivants graduellement un peu plus courts : les $4^{\mathrm{e}}$ à $8^{\mathrm{e}}$ oblongs, subcylindriques : les $9^{\circ}$ et $10^{\circ}$ subobconiques, au moins aussi longs que larges : le dernicr assez court, obliquement et à peine échancré au bout, subacuminé inférieurement.

Prothorax en carré à peine oblong ou suboblong; de la largeur des élytres; tronqué au sommet; à angles antérieurs non saillants, presque droits mais subarrondis; presque subrectiligne sur les cótés ; subarrondi à sa base, avec celle-ci subtronquée dans son milieu, et les angles postérieurs très-obtus ; légèrement convexe; assez finement et assez densement ponctué, avec une fine carène longitudinale lisse, déprimée, plus ou moins effacée en avant, parfois subsillonnée en arrière; éparsement sétosellé sur les côtés; d'un noir assez brillant et submétallique; à peine pubescent. Repli noir, lisse, glabre.

Écusson ruguleux, noir, pubescent.

Elytres Iransverses, environ dun tiers plus courtes que le prothorax; déprimées; finement, très-densement et rugueusement ponctuécs; ̀̀ peine sétosellées ; d'un noir mat ou presque mat. avec une fine pubescence d'un gris obscur et médiocrement serrée. Épaules effacées.

Abdomen allongé, à peine moins large à sa base que les élytrcs, subparallèle ou à peine arqué sur les côtés et parfois subatténué en arrière ; assez convexe sur le dos; éparsement sétosellé; fincment, densement et subaspèrement pointillé; d'un noir presque mat vers la base, un peu plus brillant vers l'extrémité, avec une fine pubescence d'un gris obscur. Le $6^{\circ} \mathrm{seg}$ ment subtronqué au sommet.

Dessous du corps densement et aspèrement pointillé, d'un noir brillant, à fine pubescence grisâtıe. Dessous de la tête grossièrement et éparsement ponctué. Métasternum subdéprimé. Ventre convexe, éparsement sétosellé à intersections parfois couleur de poix.

Pieds médiocres, aspèrement ponctués, d'un noir de poix, avec les 
tarses et parfois le sommet des tibias moins foncés; recouverts d'une pubescence grise ou d'un blond fauve. Cuisses postérieures suballongées. Tibias antérieur's simplement pubescents sur leur tranche externe, seulement avec 2 ou 3 épines à leur face inférieure.

Patrie. Celte espèce, peu commune, nous a été envoyée des Alpes du Piémont par feu M. Truqui, sous le nom de Chevrolati. Elle se trouve aussi en Savoie et au mont Pilat, sous les mousses des forêts.

OBs. La taille est plus grande et la tête plus large que dans l'Ocypus alpestris, avec les côtés de celle--ci plus droits, et ses angles antérieurs, au devant des yeux, plus prononcés, ce qui lui donne la forme d'un carré subtransverse. La ponctuation, surtout du prothorax, est un peu moins serrée et moins rugueuse. La tête et le prothorax sont plus brillants, submétalliques. L'abdomen est aussi moins mat. Les antennes, plus longues, ont leurs articles un peu plus allongés, etc.

Celte espèce varie beaucoup pour la taille. La ponctuation du prothorax est plus ou moins fine, plus ou moins serrée.

Quelquefois, surtout chez les sujets moins adultes, les pieds, moins les hanches, sont d'un roux de poix, ainsi que l'extrémité du ventre. Les élytres sont parfois d'un brun rougeâtre.

Le dernier article des palpes maxillaires est à peine plus épais chez le $\sigma^{\prime}$ que chez la $q$, et subtronqué au bout.

Les exemplaires de France, tout à fait conformes au Chevrolati, ont une forme un peu moins épaisse que le macrocephalus type, avec la tête, le prothorax et l'abdomen un peu plus brillants et moins pubescents.

\section{Deypus brumnipes, Fabricius.}

Allongé, subdéprimé, aptère, assez finement et densement ponctué, finement pubescent, d'un noir brillant sur la tête et le prothorax, presque mat sur les élytres et l'abdomen, avec les palpes, la base et l'extrémité des antennes, et les piels d'un roux testacé. Elytres d'un tiers plus courtes que le prothorax : celui-ci à peine oblong, à ligne lisse. Téte de la largeur du prothorax. Antennes assez allongées.

$\sigma$ Le $6^{e}$ arceau ventral légèrement sinué dans le milieu de son bord apical. Le dernier article des palpes maxillaires aussi épais que le pénultième, tronqué au bout. 
Le 6 arceau ventral simple. Le dernier article des palpes maxillaires un peu moins épais que le précédent, subtronqué au bout.

Staphylinus brunnipes, Fabricius, Spec. Ins. I, 336, 8; - Syst. El. II, 595, 26. - De Villers, Ent. I, 419, 27. - Olivier, Ent. III, no 42, 15, 11, pl. 1, fig. 7. - Latreille, Hist. Nat. Crust. et Ins. IX, 326, 75 - Gravenhorst, Mon. 112, 124. - Grllenhal, Ins. Suec. II, 289, 10. - Mannerieim, Brach. 24, 23. HeEr, Faun. Col. Helv. I, 254, 18. - Fairsaire et Laboulbène, Faun. Ent. Fr. I, 510, 23. - Fauvel, Faun. Gallo-Rhén. III, 410, 16.

Staphylinus erythropus, Paykull, Faun. Suec. III, 372, 7.- Gyllenhal, Ins. Suec.

II, 290, 11. - MaNNerhfiм, Trach. 24, 22.

Emus brumipes, Bolsduval ei LaCordare, Faun. Ent. Par. I, 371, 20.

Ocypus brunnipes, Erichson. Col. March. I, 411, 4 ; - Gen. et Spec. Staph. 410. 10.- Redtenbacher, Faun. Austr. 698, 13.- Kradtz, Ins. Deut. II, 557, 9. Thомson. Skand. Col. II, 148, 1, 1860.

Ocypus alpicola, Erichson, Gen. et Spec. Staph. 411, 11.

Staphylinus alpicola, HeEr, Faun. Col. Helv. I, 582, 18.

$$
\text { Long., } 0^{\mathrm{m}}: 013 \text { (6 l.); - larg., } 0^{\mathrm{m}}, 0027 \text { (1 1/4l.). }
$$

Corps allongé, subdéprimé, aptère, d'un noir brillant sur la tềte et le prothorax, presque mat sur les élytres et l'abdomen; revêtu d'une légère pubescence d'un gris obscur.

Tête suborbiculaire ou en carré arrondi aux angles; de la largeur du prothorax; densement ponctuée en arrière, plus parcimonieusement en avant; éparsement sélosellée sur les côtés; d'un noir brillant, avec une légère pubescence. Front très-large, faiblement convexe, offrant sur son milieu une ligne longitudinale lisse, raccourcie en avant. Cou pointillé, pubescent, d'un noir brillant, subcarinulé sur sa ligne médiane. Épistome à bord antérieur submembraneux, livide. Labre presque lisse, couleur de poix, cilié et sétosellé vers son sommet. Mandibules brunâtres. Palpes roux.

Yeux assez grands, obscurs, tachés de gris livide.

Antennes sensiblement plus longues que la tête; subfiliformes; éparsement sétosellées à leur base; pubescentes jusque près de leur extrémité ; obscures, avec le $1^{\text {er }}$ article et l'insertion des 2 ou 3 suivants roux, et les 2 ou 3 derniers testacés ou d'un roux lestacé ; le $1^{\text {er }}$ en massue :.: ongée, assez grêle et subarquée : les $2^{\mathrm{e}}$ et $3^{\mathrm{e}}$ suballongés, obconiques : :e $3^{\mathrm{e}}$ un peu plus long que le $2^{\mathrm{e}}$ : les $4^{\circ}$ à $7^{\mathrm{e}}$ oblongs, subégaux, su' yli.driques : les suivants obeoniques : le $8^{\mathrm{e}}$ suboblong : les $9^{\mathrm{e}}$ et $10^{\mathrm{e}}$.. : noins aussi 
longs que larges : le dernier assez courı, obliquement subéchancré au bout et acuminé inférieurement.

Prothorax en carré à peine oblong et parfois subrétréci en avant, de la largeur des élytres; subtronqué au sommet; à angles antérieurs subobtıs et subarrondis ; presque droit ou à peine arqué sur les côtés; subarrondi à sa base ainsi qu'aux angles postérieurs; médiocrement convexe; assez finement et densement ponctué, avec une fine ligne longitudinale lisse, entière ; à peine sétosellé sur les côtés; d'un noir brillant et parfois submétallique, avec une légère pubescence peu apparente. Repli noir, lisse, glabre.

Écusson pointillé, pubescent, d'un noir peu brillant.

Élytres transverses, environ d'un tiers plus courles que le prothorax; déprimées ou subdéprimées; finement, très-densement et rugueusement ponctuées; à peine sétosellées; d'un noir presque mat, avec une fine pubescence d'un gris obscur et modérément serrée. Épaules effacées.

Abdomen allongé, à peine moins large à sa base que les élytres, subparallèle ou à peine arqué sur les côtés ; assez convexe sur le dos ; très éparsement sétosellé; finement, densement et aspèrement pointillé; d'un noir presque mat, avec une fine pubescence d'un gris obscur. Le $6^{\mathrm{e}} \mathrm{seg}$ ment subsinueusement tronqué au bout.

Dessous du corps densement et aspèrement pointillé, d'un noir brillant, finement pubescent. Dessous de la tête plus lisse, éparsement ponclué. Métasternum subdéprimé. Ventre convexe, éparsement sétosellé.

Pieds médiocres, aspèrement ponctués, à pubescence blonde ou fauve: roux, avec les hanches rembrunies. Cuisses postérieures suballongées Tibias antérieurs simplement pubescents sur leur tranche externe, ou épineux seulement vers le sommet de celle-ci et en dessous.

Patrie. Cette espèce, peu commune, se trouve sous les pierres, sous les mousses, au pied des arbres, dans diverses provinces de la France: les environs de Paris et de Lyon, la Normandie, la Picardie, le Bourbonnais, la Bourgogne, le Jura, la Savoie, les Alpes, les Pyrénées, etc.

OBs. Elle se distingue suffisamment des précédentes par ses yeux plus grands, par sa tête plus arrondie, par la couleur des pieds et de la base des antennes, etc.

L'Ocypus alpicola d'Erichson est d'une taille $\mu$ lus forte, avec le prothorax à peine plus court et un peu. moins densement ponctué. De semblables 
modifications se remarquent, à mesure qu'on approche d'une altitude plus grande.

Quelquefois la tète et le prothorax ont un léger reflet submétallique.

Peut-être le cartianus de Stephens (Ill. Brit. V, 207) doit-il ètre regardśs comme synonyme du brunnipes, ainsi que l'abbreviatus de Motschulsky (Bull. Mlosc. 1858, II, 669).

\section{Oeypus aethiops: IValth.}

Allongé, subdéprimé, ailé, finement et densement ponctué, à pubescence obscure et serrie; d'un noir tout à fait mat, avec le sommet des palpes, des antinnes et des tarses roussâtres et une série dorsale de taches soyeuses sur l'abdomen. Elytres à peine plus courtes que le prothorax : celui-ci subcarri, sans ligne lisse. Tête de la largeur du prothorax. Antennes assez courtes.

$\sigma^{7}$ Le $6^{e}$ arceau ventral légèrement et subangulairement, le $5^{\circ}$ à peine, sinués à leur bord apical.

I Les $5^{\mathrm{e}}$ et $6^{\mathrm{e}}$ arceaux du ventre simples.

Staphylinus aethiops. Walth, Reis. Span. II, 56, 1835.-Fairmaire et LaboulbèNe, Faun, Ent. Fr. I, 5ั10, 22.- Fauvel, Faun. Gallo-Rhén. III, 412, 19. Stapliylinus masculus, Nordmann, Symb. 67, 55. - Jacquelin du Val, Gen. Col.

Eur. Staph. pl. 13, tig. 64.

Ocypus masculus, Erichson, Gen. et Spec. Staph. 409, 8.

$$
\text { Long., } 0^{\mathrm{m}}, 015 \text { (6 3/4 l.); - larg., } 0^{\mathrm{m}}, 0030 \text { (1 } 1 / 3 \mathrm{l} \text {.). }
$$

Corps allongé, subdéprimé, ailé, d'un noir tout à fait mat, avec une pubescence serrèe et d'un gris très-obscur.

Tête subcarrée, de la largeur du prothorax, assez finement et densement ponctuće, éparsernent sétosellée sur les côtés; d'un noir mat, densement pubescente. Front très-large, à peine convexe. Cou ponctué, noir, pubescent. Epistome à bord antérieur submembraneux, livide. Lal: is lisse, cilié et fortement sétosellé en avant. Mandibules noires. Palpes bscurs, a vec leur extrémité roussâtre.

Yeux médiocres, noirs, tachés de gris. 
Antennes peu allongées, un peu plus longues que la tête; subfiliformes; pubescentes et éparsement pilosellées vers leur base; noires, avec leur extrémité graduellement moins foncée ou d'un roux ferrugineux; à $1^{\mathrm{e}_{\mathbf{r}}}$ article en massue allongée, grêle et subarquée : les $2^{\mathrm{e}}$ et $3^{\mathrm{e}}$ obconiques : le $2^{\mathrm{e}}$ oblong, le $3^{\mathrm{e}}$ un peu plus long que le $2^{\mathrm{e}}$ : les suivants subobconiques, graduellement un peu plus courts, avec les pénultièmes à peine transverses, vus de côté : le dernier assez court, obliquement subéchancré au bout et subacuminé inférieurement.

Prothorax subcarré, parfois subatténué en arrière, de la largeur des élytres; tronqué au sommet; à angles antérieurs presque droits mais émoussés ; presque subrectiligne sur ses cỏtés; arrondi à sa base, ainsi qu'aux angles postérieurs ; à peine convexe ou subdéprimé sur son milieu; finement et densement ponctué; à peine sétosellé sur les côtés; d'un noir mat ; densement pubescent. Repli noir, lisse, glabre.

Écusson ruguleux, velouté de noir.

Elytres transverses, à peine ou un peu plus courtes que le prothorax; déprimées ou subdéprimées; finement, très-densement et rugueusement pointillées; à peine sétosellées; d'un noir tout à fait mat, avec une fine pubescence assez serrée, d'un gris très-obscur. Épaules étroitement arrondies.

Abdomen plus ou moins allongé, à peine moins large à sa base que les élytres, subparallèle ou à peine arqué sur les côtés et parfois subatténué en arrière ; subconvexe sur le dos; à peine sétosellé; finement, très-densement et aspèrement pointillé; d'un noir mat, avec une pubescence obscure et serrée, et chaque segment paré sur le milieu de sa base d'une moucheture ou petite tache subtriangulaire et d'un blond soyeux. Le $6^{\text {e }}$ tronqué au sommet.

Dessous du corps densement et aspèrement pointillé, tinement chagriné dans l'intervalle des points, d'un noir assez brillant, tinement pubescent. Dessous de la tête plus lisse, subéparsement ponctué. Métasternum subdéprimé. Ventre convexe, éparsement sétosellé.

Pieds médiocres, aspèrement ponctués, à pubescence grise ou blonde; noirs, avec les tarses parfois moins foncés ou d'un roux de poix à leur sommet, Cuisses postérieures peu allongées. Tibias antérieurs simplement pubescents sur leur tranche externe, seulement avec 2 ou 3 épines en dessous.

Patrie. Cette espèce est peu commune. On la trouve dans des localités 
bien opposées : en Bretagne, à Fontainebleau, dans la Bourgogne, les environs de Tarbes et d'Arcachon, la Provence, etc.

OBs. La forme de la tête, la couleur mate de tout le dessus du corps, la couleur des pieds, et les taches dorsales de l'abdomen, tels sont les caractères qui distinguent cette espèce du brunnipes, et, en partie, de la plupart des espèces précédentes.

Parfois les taches de l'abdomen sont effacées.

Dans cette espèce, le dernier article des palpes maxillaires n'est pas plus long, mais plus étroit que le pénultième dans les 2 sexes. Il est étroitement tronqué au bout.

On doit rapporter à l'aethiops l'hesperus Crotch. (Proc. Zool. Soc. Lond. 1867, 391).

\section{Deypus (Pgendocypus) mus, Brullé.}

Allongé, subdéprimé, ailé, finement et densement ponctué, finement pubescent, d'un noir assez brillant sur la tête et le prothorax, presque mat sur les élytres et l'abdomen, avec les palpes, les antennes et les pieds d'un roux de poids, et une série dorsale de taches soyeuses sur l'abdomen. Élytres de la longueur du prothorax : celui-ci subcarré, sans ligne lisse bien apparente. Tête de la largeur du prothorax.

$\sigma$ Le 6 e arceau ventral subangulairement sinué dans le milieu de son bord apical.

우 Le $6^{\mathrm{e}}$ arceau ventral simple.

Staphylinus mus, Brullé, Exp. Mor. 1832, III, 130. - Fauvel, Faun. Gallo-Rhén. III, 413 (note.)

Staphylinus picipes, Nordyann, Symb. $68,58$.

Staphylinus fuscipes, HeER, Faun. Col. Helv. I, 254, 20 ?

Ocypus picipes, Erichson, Gen. et Spec. Staph. 409, 9. - Kraatz, Ins. Deut. II. $557,8$.

$$
\text { Long., } 0^{\mathrm{m}}, 015 \text { (6 3/4 l.); - larg., } 0^{\mathrm{m}}, 0030 \text { (1 1/8 l.). }
$$

Corps allongé, subdéprimé, ailé, d'un noir assez brillant sur la tête et le prothorax, presque mat ou peu brillant sur les élytres et l'abdomen; recouvert d'une fine pubescence assez serrée et d'un gris obscur. 
Téte subcarrée, de la largeur du prothorax, finement et densement ponctuée, éparsement et longuement sétosellée sur les côtés, d'un noir assez brillant, légèrement pubescente. Front très-large, peu convexe, parfois avec, une ligne longitudinale lisse, presque imperceptible. Cou pointillé, à peine pubescent, d'un noir assez brillant. Épistome à bord antérieur submembraneux, pâle. Labre lisse, cilié et fortement sétosellé en arant. Mandibules noires, la gauche bidentée en dedans. Palpes roux.

Yeux grands, obscurs, lavés de gris.

Antennes peu allongées, un peu plus longues que la tête, subfiliformes; pubescentes et éparsement pilosellées vers leur base ; d'un roux de poix, un peu rembrunies dans leur milieu, avec leur extrémité plus ou moins ferrugineuse ; à $1^{\text {er }}$ article en massue allongée et subarquée : les $2^{\mathrm{e}}$ et $3^{\mathrm{e}}$ obconiques, oblongs : le $3^{\mathrm{e}}$ un peu plus long que le $2^{\mathrm{e}}$ : les suivants subobconiques, graduellement un peu plus courts, avec les 2 ou 3 pénultièmes subtransverses, vus de côté : le dernier assez court, obliquement subéchancré au bout et subacuminé inférieurement.

Prothorax subcarré, environ de la largeur des élytres; tronqué au som met; à angles antérieurs presque droits mais émoussés; presque parallèle sur les côtés; arrondi à sa base ainsi qu'aux angles postérieurs qui sont très-obtus; subconvexe; finement et densement ou même très-densement ponctué, avec 2 séries dorsales de points plus forts, et parfois une fine carène, lisse, peu distincte, en arrière sur la ligne médiane; éparsement et longuement sétosellé sur les côtés; d'un noir assez brillant et à peine métallique; légèrement pubescent. Repli noir, lisse, glabre.

Écusson finement ruguleux, d'un noir velouté dans sa partie postérieure.

Élytres transverses, de la longueur du prothorax ; subdéprimées ; finement, très-densement et rugueusement pointillées; à peine sétosellées; d'un noir presque mat ; finement pubescentes. Épaules subarrondies.

Abdomen plus ou moins allongé, un peu moins large à sa base que les élytres; à peine arqué sur les côtés et un peu atténué en arrière; assez convexe sur le dos; à peine sétosellé ; finement, très-densement et aspèrement pointillé; d'un noir presque mat ; revètu d'une pubescence obscure, avec une petite tache triangulaire, d'un soyeux fauve, sur le milieu de la base de chaque segment. Le $6^{\mathrm{e}}$ obtusément tronqué au sominet.

Dessous du corps densement et aspèrement pointillé, d'un noir brillant, finement pubescent. Dessous de la tête plus lisse, éparsement et assez grossièrement ponctué. Métasternum à peine convexe. Ventre convexe, aprésement sétosellé. 
Pieds médiocres, aspèrement ponctués, à pubescence d'un gris blond; d'un roux de poix, avec les hanches et parfois les cuisses rembrunies, les trochanters restant roussâtres. Cuisses postérieures suballongées. Tibias unterieurs simplement pubescents sur leur tranche extrerne, avec seuleinent 2 ou 3 épines en dessous.

Patrịe. Nous avons reçu cette espèce de Grèce. Elle se prendrait aussi en Suisse? Quelques catalogues l'indiquent aussi de France, mais ces deux derniers habitats sont très-douteux.

OBs. Elle ressemble beaucoup à l'aethiops par son abdomen à série dorsale de taches soyeuses. Mais les yeux, plus grands, sont plus prolongés en arrière, et par conséquent plus rapprochés du cou. La tête et le prothorax sont plus brillants et plus finement ponctués. Les palpes, la base des antennes et les pieds sont d'une couleur moins obscure, etc.

Chez les exemplaires bien frais, la tête et le prothorax sont moins brillants, et les élytres plus mates.

Dans cette espèce, le dernier article des palpes maxillaires est subfusiforme, aussi long et à peine plus étroit que le précédent, subtronqué ou mousse au bout.

Elle lie notre sous-genre Pseudocypus aux vrais Ocypus; elle a la tête de ceux-ci, mais les yeux sont plus grands, et le prothorax présente deux séries dorsales de points plus gros, ainsi que dans la plupart des espèces suivantes.

\section{Deypug (Pseudocypus) fuscatus, Gravenhorst.}

Allongé, subconvexe, ailé, finement pubescent, éparsement ponctué, d'un noir bronzé très-brillant sur la tête et le prothorax, densement pointillé, obscur et mat sur les élytres et l'abdomen, avec les palpes et les tarses d'un roux de poix. Elytres de la longneur du prothorax : celui-ci subcarré, à espace longitudinal lisse, assez large. Tête un peu plus étroite que le prothorax.

$\sigma^{*}$ Le $6^{e}$ arceau ventral subsinué dans le milieu de son bord apical.

\& Le $6^{\text {e }}$ arceau ventral simple à son bord apical.

Staphylinus fuscatus, Gravengorst, Micr. 161, 10; - Mon. 112, 123. - Heer. 
Faun. Col. Helv. I, 254, 21. - Fairmaire et Laboulbène, Faun. Ent. Fr. I, 510, 24.- Fauvel, Faun. Gallo-Rhén. III, 414, 21.

Staphylinus crassicollis, Gravenhorst, Micr. 7, 7.- Latreille, Hist. Nat. Crust. et Ins. IX, 302, 15.

Staphylinus bipunctatus, Gyllenhal, Ins. Suec. IV, 474, 9.- ManNerheim, Brach. 24, 19.

Staphylinus morio, Gyllenhal, Ins. Suec. II, 288, 9.

Ocypus fuscatus, Ericrson, Col. March. I, 441, 5; - Gen. et Spec. Staph. \$11, 12.

- Redtenbacier, Faun. Austr. 698, 11. - Kraatz, Ins. Deut. II, 558, 10. Thomson, Skand. Col. II, 148, 3, 1860.

$$
\text { Long., } 0^{\mathrm{m}}, 013\left(6 \text { l.); - larg., } 0^{\mathrm{m}}, 0026\right. \text { (1 1. 1/4). }
$$

Corps allongé, subconvexe, ailé, obscur et mat sur les élytres et l'abdomen, d'un noir bronzé très-brillant sur la tête et le prothorax; revêtu d'une fine pubescence d'un gris très-obscur.

Téte suborbiculaire, un peu moins large que le prothorax; éparsement ponctuée sur son disque, plus densement sur les côtés, surtout derrière les yeux ; éparsement sétosellée ; d'un noir bronzé très-brillant; légèrement pubescente. Front très-large, peu convexe. Cou ponctué, légèrement pubescent, d'un noir brillant. Épistome à bord antérieur à peine sensible, subcorné, lisse, noir. Labre cilié et fortement sétosellé en avant. Mandibules noires. Palpes d'un roux de poix.

Yeux grands, noirs, avec un cercle pâle.

Antennes assez courtes, sensiblement plus longues que la tête; subfiliformes; pubescentes et éparsement pilosellées vers leur base; noires, avec leur extrémité souvent moins obscure; à $1^{\mathrm{er}}$ article en massue allongée, grêle et subarquée : les $2^{e}$ et $3^{e}$ obconiques : le $3^{e}$ suballongé, plus long que le $2^{\mathrm{e}}$ : les suivants graduellement un peu plus courts : les $4^{\mathrm{e}}$ à $7^{\mathrm{e}}$ subcarrés : les $8^{\mathrm{e}} \mathrm{a} 10^{\mathrm{e}}$ subobconiques, subtransver'ses, vus de côté : le dernier assez court, obliquement tronqué ou subéchancré au bout, subacuminé inférieurement.

Prothorax subcarré ou à peine plus long que large; de la largeur des élytres; tronqué au sommet; à angles antérieurs subobtus et arrondis; presque droit ou à peine arquè sur les côtés; subarrondi à sa base ainsi qu'aux angles postérieurs, qui sont très-obtus; assez convexe ; éparsement et assez fortement ponctué, plus densement sur les côtés, avec un espace longitudinal lisse, assez large, sur son milieu; éparsement et longuement 
sétosellé !atéralement ; d'un noir bronzé très-brillant; presque glabre ou à peine pubescent. Repli noir, lisse, glabre.

Ecusson pointillé, obscur, densement pubescent.

Elytres subiransverses, environ de la longueur du prothorax; subdéprimées; finement, très-densement et rugueusement pointillées; éparsement sétosellées; d'un noir un peu bronzé, mat ou presque mat; finement et assez densement pubescentes. Épaules étroitement arrondies.

Abdomen plus ou moins allongé, presque aussi large à sa base que les élytres; subparallèle ou à peine arqué sur les côtés; assez fortement convexe sur le dos; Irès-éparsernent sétosellé; finement, très-densement et aspèrement pointillé (1); d'un noir mat, avec une pubescence obscure et serrée. Le $6^{\text {e }}$ segment subtronqué au sommet.

Dessous du corps finement, densement et aspèrenent pointillé, avec l'intervalle des points très-finement chagriné; d'un noir assez brillant; finement pubescent. Dessous de la tête presque lisse, très-éparsement ponctué. Métasternum subdéprimé. Ventre convexe, éparsement et longueınent sétosellé, à pores sétifères bien distincts, plus nombreux en arrière.

Pieds médiocres, aspèrement ponctués; pubescents; noirs, avec les larses et parfois les tibias d'un roux de poix plus ou moins foncé. Cuisses postéricures peu allongées. Tibias antérieurs simplement pubescents sur leur tranche externe, seulement avec 2 ou 3 épines en dessous, à pubescence blonde.

Patrie. Cetle espèce, peu commune, se prend sous les bouses semidesséchées, sous les pierres et sous les mousses des forêts et des montagnes, dans les environs de Paris, la Normandie, la Bourgogne, l'Auvergne, les Alpes, etc.

OBs. Elle est remarquable par l'espace lisse assez large qui s'étend longitudinalement sur le milieu du prothorax, avec celui-ci plus éparsement ponctué sur son disque que dans tous ses congẻnères. La tête est également peu ponctuée sur le front; elle est plus orbiculaire et moins large que dans les espèces précédentes, etc.

(1) Ici les séries dorsales de pores sétiferes sont bien marquées et indiquées par des points enfoncés beaucoup plus gros, et it en est ainsi chez toutes les espèces suivantes. Dans les précédentes, à part les alpestris, brunnipes et mus, ces points sont peu apparents.

BR. 
Le dernier article des palpes maxillaires est subfusiforme, aussi long et plus étroit que le précédent, chez les deux sexes, subtronqué chez le $\sigma$, mousse au bout chez la $\$$.

\section{Deypus (Pseudoeypus) pieipennis, Fabriclus.}

Allongé, peu convexe, ailé, finement et densement ponctué, finement pubescent, d'un bronzé brillant sur la tête et le prothorax, obscur et mat sur les élytres et l'abdomen, avec l'extrémité des antennes et les palpes d'un roux de poix. Élytres un peu plus courtes que le prothorax: celui-ci subcarré, à fine ligne lisse. Tète un peu moins large que le prothorax. Abdomen avec des lignes longitudinales grises.

$\sigma^{*}$ Le $6^{\text {e }}$ arceau ventral faiblement sinué dans le milieu de on bord apical, avec un étroit espace lisse au devant du sinus.

ㅇ Le $6^{\text {e }}$ arceau ventral simple.

Staphylinus picipennis, Fabricius, Ent. Syst. I, II, 521, 8 ; - Syst. El. II, 591, 10. - Panzer, Ent. Germ. 333, 7. - Fauved, Faun. Gallo-Rinén. III, 414, 20. Staphylinus aeneocephahlus, PAYkuLl, Mon. Staph. II, 6 ; - Faun. Suec. III, 374, 10.- Gravenhorst, Micr. 8, 8; - Mon. 113, 126. - Gyllenhal, Ins. Suec. II, 291, 12.- Mannerieim, Brach. 23, 11.- Heer, Faun. Col. Helv. I, 255, 22. Fairmaire et Laboulbène, Faun. Ent. Fr. I, $510,23$.

Enus aeneocephalus, Bolsduval el Lacordaire, Faun. Ent. Par. I, 373, 22. Ocypus picipennis, Erichson, Col. March. I, 442, 6; - Ger. et Spec. Staph. 412, 13.- Redtenbacher, Faun. Austr. 698, 12.- Kraatz, Ins. Deut. II, 559, 11.Thomson, Skand. Col. II, 148, 4, 1860.

Variété $a$. Elyjtres d'un noir de poix.

Staphylinus tristis, Fabricius, Lint. Syst. I, II, 524, 21 ; - Syst. El. II, 594, 23. Staphylinus chalcocephalus, ManNerheis, Brach. 23, 12.

Emus chalcocephalıs. Boisduval et Lacondaise, Faun. Ent. Par. I, 374, 23.

Variẹté $b$. Élytres d'un brun ferrugineux.

$$
\text { Long., } 0^{\mathrm{m}}, 0175 \text { (8 l.); - larg., } 0^{\mathrm{m}}, 0030 \text { (1 1/3 l.). }
$$

Corps allongé, peu convexe, ailé, d'un bronzé brillant sur la tête et le prothorax, plus obscur et mat sur les élytres et l'abdomen; recouvert 
d'une fine pubescence grise, condensée sur celui-ci en lignes longitudinales cendrées.

Tête suborbiculaire, un peu ou à peine moins large que le prothorax; fiuement et densement ponctuée ; éparsement et longuement sétosellée ; d'un bronzé brillant ; légèrement pubesente. Front très-large, peu convexe, un peu moins densement pointillé sur son milieu. Cou pointillé, pubescent, d'un bronzé brillant. Epistome à bord antérieur submembraneux, livide. Labre cilié et fortement sétosellé en avant. Mandibules noires. Pulpes d'un roux de poix.

Yeux grands, obscurs, parfois lavés de gris.

Antennes assez courtes, un peu plus longues que la lête; subfiliformes ou à peine épaissies (1); pubescentcs et éparsement pilosellées vers leur base; obscures et souvent graduellement roussâtres vers leur extrémité ; à $1^{\mathrm{er}}$ article en massue allongée, grêle et subarquée : les $2^{\mathrm{c}}$ at $3^{\mathrm{e}}$ obconiques : le $3^{e}$ un peu plus long que le $2^{i}$ : les suivants graduellement un peu plus courts, subobconiqunes : les $4^{\mathrm{e}}$ à $7^{\circ}$ aussi longs ou à peine plus longs que larges : le $8^{\mathrm{e}}$ non, les $9^{\text {" }}$ ct $10^{\mathrm{e}}$ faiblement transverses, vus dic côté : le derniel court $\left(\sigma^{*}\right)$ on assez court $(q)$, subtronqué ou à peine échancré au bout, subacuminé inférieurement.

Prothorax subcarré ou à peine plus long que large, de la largeur des élytres; tronque au sommet; à angles antérieurs subobtus et arrondis; presque droit ou à peine arqué sur les còtés; arrondi à sa base ainsi qu'aux angles postérieurs ; asse\% convexe ; finement, densement et uniformément pointillé, avec une étroite ligue longitudinale lisse entre 2 séries dorsales de points plus forts ; éparsement et longuement sétosellé sur le $\mathbf{e}_{\mathbf{S}}$ côtés; d'un bronzé brillant; légèrèment pubesceut. Repli d'un noir métallique, lisse, glabre.

Ecusson pointillé, d'un noir bronzé, pubescent, avec une grande tache postérieure d'un noir velouté.

Élytres transverses, un peu plus courtes que le prothorax; subdéprimées; finement, très-densement et rugueusement pointillées; à peine sétosellées; d'un bronzé plus ou moins obscur et mat ; à pubescence serrée et d'un gris blond, avec des taches subdénudées ou rembrunies. Épaules efiacées.

(1) It est à remarquer que, dans toutes les espèces répondant à notre sous-genre l'seudocypus, les antennes, assez courtes, sont subtiliformes, souvent mème subépaissies plutat que subatténuées ver's leur extrénité, surtout vues de coté. 
Abdomen allongé, un peu moins large à sa base que les élyires ; subparallèle ou à peine arqué sur les côtés et parfois subatlénué en arrière; assez fortement convexe sur le dos ; éparsement sétosellé, à pores sétifères très-distincts ; finement, très-densement et aspèrement pointillé ; d'un noir bronzé, obscur et mat, avec 5 lignes longitudinales d'un soyeux cendré, la médiane plus tranchée et continue, les autres plus on moins interrompues. Le $6^{\mathrm{e}}$ segment à peine arrondi au sommet.

Dessous $d u$ corps densement et aspèrement pointillé, avec l'intervalle des points très-finement chagriné; d'un noir submétallique assez brillant ; finement pubescent. Dessous de la tête plus lisse, grossièrement et éparsesement ponctué. Métasternum subdéprimé. Ventre convexe, à pores sétifères très-distincts, plus nombreux en arrière sur les côtés.

Pieds médiocres, aspèrement pointillés, pubescents; noirs, avec les lirses et parfois les tibias d'une couleur de poix souvent un peu roussâtre. Cuisses postérieures suballongées. Tibias antérieur's simplement pubesccnts, seulement avec 2 ou 3 épines en dessous, à pubescence blonde et assez brillante.

Patrie. Cette espèce est médiocrement commune, sous les pierres, surtuut sur les coteaux élevés et exposés au soleil, dans une grande partie de la France: les environs de Paris et de Lyon, la Bretagne, la Normandie, l'Alsace, la Bourgogne, l'Auvergne, le Beaujolais, les Alpes, la Savoie, la Lozère, la Provence, les Pyrénées, etc.

OBs. La ponctuation serrée de la tête et du prothorax, et les lignes d'un soyeux cendré de l'abdomen, la distinguent amplement de l'o. fuscatus. La couleur générale est moins obscure, la ligne lisse du prothorax moins large, la taille est plus grande, etc. Les palpes ont ì peu près la même conformation.

Les petits exemplaires atteignent à peine 13 millimètres.

\section{Deypus (Pseudoeypus) acneocephalus, DE GeER.}

Allongé, peu convexe, ailé: finement et densement ponctué, finement pubescent, d'un bronze brillant sur la tete et le prothorax. mat sur les élytres, obscur sur l'abdomen, avec les antennes et les palpes roux, les tibias et les tarses d'un roux de poix. Élytres de la longueur du prothorax: celui-ci suboblong, $\dot{a}$ fine carène lisse. Tête moins large que le prothorax. Abdomen avec des lignes longiludinales grises ou blondes. 
$\sigma$ Le 6e arceau ventral à peine sinué dans le milieu de son bord apicil, avec un léger espace angulaire lisse au devant du sinus.

ㄴ. Le 6 e arceau ventral simple.

Staphylinus aeneocephalus, DE GEER, Ins. IV, 22, 8. - DE Villers, Ent. I, 423, 584.-Latreille, Hist. Nat. Crust. et Ins. IX, 300, 13. - Fauvel, Faun. Gall1)Rhén. III, 417, 24.

Staphylinus cupreus, Rossı, Faun. Etr. 1, 248, 612, pl. 7, fig. 13.- Ouvier, Ent. no 42, 16, 16, pl. II, fig. 16. - Fourcroy, Ent. Par. I, 173, 33. - HeEr, Fall I. Col. Helv. I, 25̋, 24. - Fairmaire et Laboulbène, Faun. Ent. Fr. I, 511, 26. Staphylinus aeneicollis, - Gydlenhal, Ins. Suec. IV, 475, 12-13. - Mannerheim, Brach. 23, 13.

Emus aeneicollis, Boisduval et LaCordalre, Faun. Ent. Far. I, 24, 74.

Ocypus cupreus, ERICason, Col. Marcl. I, 443, 7 ; - Gen. et Spec Staph. 41.2, 14. - Redtenbacher, Faun. Austr. 698, 12. - Kraatz, Ins. Deut. II, J60, 12. - Thомsоn, Skand. Col. II, 14?, 5.

Variété $a$. Élytres d'un brun ferrugineux. Antennes et pieds entièr. ment d'un roux testacé.

$$
\text { Long., } 0^{\mathrm{m}}, 0153 \text { (7 l.); - larg., } 0^{\mathrm{m}}, 0030 \text { (1 1/3 l.). }
$$

Corps allongé, peu convexe, ailé, d'un bronzé brillant sur la tête et le prothorax, mat sur les élytres, obscur sur l'abdomen; recouvert d'une fine pubescence grise, condensée sur celui-ci en lignes longitudinales cendrées ou blondes.

Tête suborbiculaire ou brièvement subovalaire, moins large que le prothorax, finement et densement ponctuée, éparsement et longuement sétusellée; d'uu bronzé brillant, légèrement pubescente. Front Irès-large, peu convexe, offrant en arrière une étroite ligne longitudinale lisse. Cou pointillé, pubescent, d'un bronzé brillant. Épistome à bord antérieur étroitement submembraneux, livide. Labre cilié et fortement sétosellé en avant. Mandibules d'un noir de poix. Palpes roux.

Yeux grands, obtus, à taches grises.

Antennes assez courtes, plus longues que la têle, subfiliformes ou à peine épaissies ; pubescentes jusque près de leur extrémité et éparsement sétosellées vers leur base ; rousses, avec leur milieu parfois un peu rembruni; à $1^{\text {er }}$ article en massue allongẻe, grêle et subarquée : les $2^{\mathrm{e}}$ et $3^{\mathrm{e}}$ obconiques : le $2^{\circ}$ oblong : le $3^{\mathrm{e}}$ suballongé, un peu plus long que le $2^{\mathrm{e}}$ : les suivants graduellement un peu plus courts : les $4^{\circ}$ à $7^{\circ}$ obconico-sub- 
cylindriques, à peine ou non plus longs que larges : les $8^{e}$ à $10^{e}$ subobconiques : le $8^{\mathrm{e}}$ à peine ou non, les $9^{\mathrm{e}}$ et $10^{\mathrm{e}}$ faiblrment transverses, vus de côté : le dernier assez court, obliquement subéchancré au bout et acuminé inférieurement.

Prothorax en carré suboblong; à peine aussi large que les élytres; parfois subcomprimé et subrétréci en avant; tronqué au sommet; à angles antérieurs subobtus et arrondis : presque droit sur les côtés; arrondi à sa base, ainsi qu'aux angles postérieurs ; assez. convexe; finement et densement ponctué, avec une ligne subélevée lisse entrc 2 séries dorsales de points plus forts; plus densement pointillé et souvent longitudinalement subimpressionné, surtout en arrière, de chaque côté de la ligne médiane; éparsement et longuement sétosellé sur les côtés; d'un bronzé brillant ; finement pubescent, avec la pubescence plus distiucte et divergente sur les impressions. Repli noir, lisse, glabre.

Écusson pointillé, d'un noir submétallique; à pubescence grise, avec une grande tache postérieure, veloutée de noir.

Élytres subtransverses, de la longueur du prothorax; subdéprimées; tinement, très-denseınent et rugueusement pointillées ; éparsement sétosollées; d'un bronzé un peu obscur et mat; à pubescence serrée, grise ou hlonde, parfois plus obscure et mélangée de poils pâles. Épaules étroitement arrondies.

Abdomen allongé ou suballongé, un peu moins large à sa base que les elytres, subparallèle sur ses côtés et souvent subatténué en arrière; assez f. rrtement convexe sur le dos; à pores sétifères bien marqués; finement, Irès-densement et aspèrement pointillé; d'un noir submétallique et mat; it pubescence obscure, avec 5 lignes longitudinales d'un soyeux gris ou blond, la médiane plus tranchée, plus large, continue, les autres obsolètes vu interrompues. Le $6^{\mathrm{e}}$ segment obtusément tronqué au sommet.

Dessous du corps densement et aspèrement pointillé, avec l'intervalle les points très-finement chagriné ; d'un noir submétallique un peu brill.ınt; tinement pubescent. Dessous de la tête plus lisse, éparsement et lortement ponctué. Métasternum subdéprimé, parfois avec une très-fine ligne longitudinale lisse. Ventre convexe, à pores sétifères bien marquiés.

Pieds médiocres, aspèrement pointillés; à pubescence ģrise ou blonde ; noirs, avec les tibias et les tarses d'un roux de poix. Cuisses postérieures peu allongées. Tibias antérieurs simplement pubescents, seulement avec 2 ou 3 épines en dessous. 
STAPHYLINIENS.

Patrie. Cette espèce est assez commune sous les pierres et les mousses, sur les collines chaudes, dans presque toute la France.

OBs. Elle se distingue facilement de l'O. picipennis par sa taille un peu moindre, moins parallèle, et surtout par son prothorax un peu plus oblong, subimpressionné et plus densement pointillé sur les côtés de la ligne médiane, qui est subélevée en arrière. Les élytres sont un pou moins courtes, les antennes et les pieds moins obscurs, etc.

Les exemplaires du nord de la France et des montagnes, généralement moindres (10 à 12 millimètres), ont les élytres un peu plus courtes.

La variété $a$, capturée en Provence, est remarquable par ses élytres ferrugineuses, par ses antennes et ses pieds d'un roux testacé. Le velouté de l'écusson est parfois comme roussi.

Les confinis et angustatus de Stephens (Ill. Br. V, 211 et 212) ne sont probablement que des variétés du cupreus?

Le dernier article des palpes maxillaires, à peine plus long mais plus grêle que le pénultième, est subfusiforme, parfois subatténué vers son sommet, mousse au bout dans les 2 sexes.

Nous donnerons ici une espèce voisine, non encore signalée en France:

\section{Deypug (Pseudocypus) confusus, Baudi.}

Allongé, peu convexe, ailé, finement ponctué, finement pubescent, d'un bronzé brillant sur la tête et le prothorax, obscur et mat sur les élytres et l'abdomen, avec les palpes, la base et le sommet des antennes, les tibias et les tarses roux. Elytres de la longueur du prothorax: celui-ci oblong, à ligne lisse entière et moins fine. Tête un peu moins large que le prothorax. Abdomen à pubescence obscure, presque uniforme ou avec quelques poils pâles.

Ocypus confusus, Baudi, Stud. Ent. I, 122. - Kraatz, Ins. Deut. II, 560, note. Staphylinus confusus, Fairmaire et Laboulbène, Faun. Ent. Fr. I, 511, 27.

Variété $a$. Élytres un pel roussâtres.

$$
\text { Long., } 0^{\mathrm{m}}, 013 \text { (6 l.); - larg., } 0^{\mathrm{m}}, 0027 \text { (1 1/4 l.). }
$$

Patrie. Les Alpes du Piémont.

Oвs. Cette espèce, que nous avons jadis reçue de feu Truqui, diffère de 
l'O. cupreus par sa tête et son prothorax un peu plus brillants, avec celui-ci surtont moins densement pointillé sur les côtés de la ligne médiane lisse, qui est un peu plus large et moins élevée. De plus, la pubescence de l'abdomen est presque uniformément abscure, avec quelques rares poils cendrés.

Pent-être est-ell: une variété à prothorax épilé de l'espèce suivante?

Toutefois, la ligne lisse du prothorax, plus élevée, est obsolètement prolongée sur le cou et le vertex, etc.

Nous avons reçu 4 inscctes différents, sous le nom de confusus; le $1^{\mathrm{er}}$, venant de feu Truqui, est. pour nous, le vrai confusus; le $2^{\ominus}$ était un mus; le $3^{\mathrm{e}}$ un aeneocephalus; le $4^{\mathrm{e}}$, un fulvipennis.

\section{Deypus (Pseudocypus) ohseuroaeneus, Farrmaire.}

Allongé, peu convexe, ailé, finement et très-densement ponclué, finement pubescent, d'un bronwi obscur et peubrillant, avec les palpes, les antennes et les tarses d'un roux de poix. Élytres de la longneur du prothorax: celui-ci suboblong, à carène lisse, obsolète en avant. Tête un peu moins large que le prothorax. Abdomen à pubescence obscure, variée de poils cendrés.

$\sigma$ Le $6^{\text {e }}$ arceau ventral assez fortement sinué dans le milieu de son bold apical avec un rebord lisse sensible, formant presque gouttière au devant du sinus.

\& Le $6^{\mathrm{e}}$ arceau ventral simple.

Slaphylinus obscuroaeneus, FalRmalae, Aun. Soc. Ent. Fr. 1852, 73; 1860, 157.Fauvel, Faun. Gallo-Rhén. III, 416, 23.

$$
\text { Long., } 0^{\mathrm{m}}: 016 \text { (7 1/3 l.) ; - larg., } 0^{\mathrm{m}}, 0030 \text { (1 1/3 l.). }
$$

Corps allongé, peu convexe. ailé, d'un bronzé obscur et peu brillant, avec l'abdomen à pubescence noire, variée de poils d'un cendré pâle.

Tête suborbiculaire, un peu moins large que le prothorax; finement et très-densement ponctuée; un peu moins densement en avant; éparsement et longuement sétosellée; d'un bronzé obscur et un peu brillant; médio . crement pubescente. Front très-large, peu convexe, avec les 2 pores séti- 
fères antérieurs bien marqués (1). Cou pointillé, pubescent, d'un bronzė assez foncé et un peu brillant. Épistome à bord antérieur étroit, subcorné, obscurément livide. Labre cilié et fortement sétosellé en avant. Mandibules noires. Palpes d'un roux de poix.

Yeux grands, obscurs, lavés de cendré

Antennes assez courtes, plus longues que la tète; subfiliformes; pubescentes jusque près de leur extrémité et éparsement pilosellées vers leur base; d'un roux de poix ferrugineux, avec les articles intermédiaires parfois un pen rembrunis; le $\mathbf{1}^{\mathrm{er}}$ en massue allongée, grêle el subarquée : les $2^{\mathrm{e}}$ et $3^{\mathrm{e}}$ obconiques : le $2^{\mathrm{e}}$ oblong, le $3^{\mathrm{e}}$ assez allongé, évidemment plus long que le $2^{\mathrm{e}}$ : les suivants graduellement un peu plus courts : les $4^{\mathrm{e}}$ à $7^{\mathrm{e}}$ oblongs ou suboblongs, obconico-subcylindriques : les $8^{\mathrm{e}} \mathrm{à} 10^{\mathrm{e}}$ subobconiques : les $8^{\mathrm{e}}$ et $9^{\mathrm{e}}$ non, le $10^{\mathrm{e}}$ à peine tranverses, vus de côté : le dernier court ou assez court, subtronqué au bout et subacuminé infériellrement.

Prothorax en carrè suboblong, à peine aussi large que les élytres; parfois subcomprimé et subrétréci en avant; tronqué au sommet; à angles antérieurs subobtus et émoussés; presque droit ou à peine arqué sur les côtés ; arrondi à sa base ainsi qu'aux angles postérieurs qui sont trèsobtus; subconvexe; finement et très-densement ponctué, avec 2 -séries dorsales de points plus forts, entre lesquels une étroite carène lisse, confuse ou seulement visible en arrière; éparsement et longuement sétosellé sur les côtés; d'un bronzé obscur et peu brillant, avec une fine pubescence serrée et d'un gris sombre. Repli noir, lisṡe, glabre.

Écusson pointillé, d'un bronzé obscur, velouté de noir.

Elytres subtransverses, environ de la longueur du prothorax; subdéprimées ; finement, très-densement et rugueusement pointillées; éparsement sétosellées; d'un bronzé sombre, mat ou presque mat; à pubescence obscure, mélangée de poils lisses et brillants. Épaules effacées.

Abdomen allongé ou suballongé, un peu moins large à sa base que les élytres, subatténué en arrière ; assnz fortement convexe sur le dos ; à pores sétifères très-marqués ; finement, Irès-densement et aspèrement pointillé ; d'un noir presque mat et subvelouté; à pubescence obscure, mélangée de poils pâles et brillants, avec quelques cils fauves au bord apical des 4 premiers segments, Le $6^{\mathrm{e}}$ obtusément tronqué au sommet.

(1) Dans les espèces précédentes, ces pores, peu ou à peine sensibles, sont à la fois un peu plus écartés. 
Dessous du corps densement et aspèrement ponctué, avec l'intervalle des points très-finement chagriné; d'un noir brillant; à pubescence fine et d'un gris obscur. Dessous de la tête plus lisse, éparsement ponctué. Métasternum subdéprimé, avec une très-fine ligne longitudinale lisse. Ventre convexe, à pores sétifères bien marqués; paré çà et là, surtout vers les côtés, de quelques poils pâles et brillants.

Pieds médiocres, aspèrement pointillés ; à pubescence grisâtre; noirs, avec les tarses d'un roux de poix. Cuisses postérieures suballongées. Tibias antérieurs simplement pubescents ou seulement avec 2 ou 3 épines en dessous, à pubescence blonde et brillante vers son extrémité.

Patrie. Cette espèce, peu commune, se trouve sous les pierres, dans les lieux sablonneux et exposés au midi des montagnes des environs de Lyon et du Beaujolais. Elle se prend aussi dans le Limousin et la Guienne.

OBs. Elle est de la taille des plus grands exemplaires du cupreus, mais d'une couleur plus sombre et moins brillante. La tête et le prothorax sont plus densement pointillés, avec celui-ci nullement subimpressionnẻ de chaque côté de la ligne lisse, qui est plus obsolète. L'abdomen, sans bandes longitudinales grises, est obscur, avec quelques poils épars, pâles ou fauves, etc. Les palpes sont à peu près de même.

Elle ne diffère de l'0. confusus que par une taille un peu plus forte, par sa tête et son prothorax plus obscurs, moins brillants, plus pubescents et plus densement pointillés, avec ce dernier à ligne lisse plus fine et plus effacée. Les antennes, moins rembrunies dans leur milieu, sont un peu plus longues, avec leurs pénultièmes articles moins courts, etc.

\section{Deypus (Pseudocypus) fulvipennis, ERICHSON.}

Allongé, peu convexe, ailé, finement et densement ponctué, finement pubescent, d'un bronzé obscur et brillant sur la tête et le prothorax, avec les palpes, les antennes, les élytres et les pieds roux, ct l'abdomen d'un noir mat. Elytres à peine moins longues que le prothorax : celui-ci suboblong. à étroite ligne lisse. Tête un peu moins large que le prothorax. Abdomen à pubescence obscure, variée de poils pâles.

$\sigma$ Le 6 e arceau ventral à peine sinué dans le milieu de son bord apical, 
avec un espace triangulaire subimpressionné, lisse et submembraneux, all devant du sinus.

q Le $6^{\text {c }}$ arcean ventral simple.

Staphylinus chalcocephalus, Norduavs, Symb. 70,62.

Emus picipennis, Borsduval et Lacordare, Fainn. Ent. Par. I, 374, 25.

Ocypus fulvipennis Ericusox, Gen. et Spec. Staph.413, I5.- Redtenbacher, Faun. Austr. 699. - Kratı, Ins. Deut. II, 501, 13.

Staphylinus vagaus, HeEr, Faun. Cot. Helv, I, 25\%̀, 23.

Stuphylinus fulvipenuis, Fairaaire et Laboulbène, Faun. Ent. Fr. I, 511, 28. Fauvel, Faun. Gallo-Phhén. IIJ, 415, 22.

$$
\text { Long., } 0^{\mathrm{m}}, 0142 \text { (6 1/21.); - larg., } 0^{\mathrm{m}}, 0027 \text { (1 1/4 l.). }
$$

Corps allongé, peu convexe, ailé, d'un bronzé foncé et brillant sur la tête et le prothorax, avec les élytres rousses et l'abdomen noir, celui-ci à pubescence obscure, variée de poils pâles.

Tête suborbiculaire, un peu moins large que le prothorax; finement et densement ponctuée, un peu moins densement sur son disque et en avallt; éparsement et longuemcut sétosellée; d'un bronzé obscur et brillant; lègèrement pubescente. Front très-large, peu convexe. Cou pointillé, lèzèrement pubescent, d'un bronzé sombre et brillant. Épistome à bord antérieur étroit, à peine submembraneux, livide. Labre cilié et fortement sétosellé en avant. Mandibules d'un noir de poix. Palpes roux.

Yeux grands, noirs, lavés de, gris.

Antennes assez courtes, plus longues que la tête; subfiliformes ou à pcine épaissies; pubescentes et éparsement pilosellées vers leur base ; ruusses, parfois à peine rembrunies dans leur milieu; à $1^{\text {er }}$ article en massue allongée, grêle et subarquée: les $2^{\mathrm{e}}$ et $3^{\mathrm{e}}$ obconiquues : le $2^{\mathrm{e}}$ oblong, le $3^{\mathrm{e}}$ un peu plus lorig que le $2^{\mathrm{e}}$ : les suivants graduellement plus courts, subobconique.s: les $4^{\mathrm{e}}$ et $5^{\mathrm{e}}$ un peu, les $6^{\mathrm{e}}$ et $7^{\mathrm{e}}$ à peine ou non plus longs que larges : le $8^{e}$ à peine ou non, les $9^{\text {e }}$ et $10^{\circ}$ faiblement transvorses : le dernier assez court, obliquement tron fué ou subéchancré au bjut et subacuminé inférieurement.

Prothorax en carrà suboblong, presque aussi large.que les élytres; souvent subrétréci en avant; tronqué au sommet; à angles antérieurs presque droits mais subarrondis; à peine arqué sur les côtés; arrondi à sa base ainsi qu'aux angles postérieurs qui sont très-obtus; médiocrement convexe; finement et densement ponctué, avec un espace longitudinal 
lisse, sensible, entre 2 séries dorsales de points plus forts ; éparsenent et longuement sétosellé sur les côtés; d'un bronzé sombre et brillant, avec une légère pubescence grisâtre. Repli noir, lisse, glabre.

Écusson pointillé, à pubescence grise, velouté de noir dans sa parti postérieure.

Élytres subtransverses, à peine ou un peu plus courtes que le prothorax, subdéprimées ; finement, très-densement et rugueusement pointillées; ćparsement et longuement sétosellées; entièrement d'un roux mat, avec une fine pubescence serrée, d'un gris blond ou fauve. Épaules effacées.

Abdomen plus ou moins allongé, un peu moins large que les élytres, subatlénué en arrière; assez convexe sur le dos; à pores sétifères bien marqués ; finement, très-densement et aspèrement pointillé ; d'un noir mat et subvelouté; à pubescence d'un gris très-obscur, mélangée de poils pâles et brillants, avec quelques cils fauves au bord apical des 4 premiers segments. Le $6^{\mathrm{e}}$ obtusément tronqué au sommet.

Dessous $d u$ corps densement et aspèrement pointillé, d'un noir brillant, finement pubescent. Dessous de la tête plus lisse, éparsement ponctué. Métasternum subdéprimé. Ventre convexe, à pubescence d'un gris obscur, variée, surtout sur les côtés, de quelques rares poils pâles et brillants.

Pieds médiocres, aspèrement pointillés, à pubescence blonde; roux, avec les hanches d'un noir de poix. Cuisses postérieures peu allongées. Tibias antérieurs simplement pubescents ou seulement avec 2 ou 3 épines en dessous, à pubescence devenant soyeuse et brillante vers leur extrémité.

Patrie. Cette espèce, peu commune, habite sous les pierres et sous les mousses, surtout dans les endroits humides, dans diverses provinces de la France : les environs de Paris et de Lyon, l'Alsace, la Bourgogne, le Bugey, la Savoie, les montagnes du Beaujolais, les Alpes, les Pyrénées, la Provence, elc.

Oвs. Elle se distingue aisément des précédentes par la couleur des élytres et des pieds. L'abdomen est à peu près semblable à celui de l'O. obscuroaeneus.

Le dernier article des palpes est peut-être un peu moins atténué et plus distinctement subtronqué au bout. 


\section{Genre Tasgius, TASGIE, Leach.}

Leach in Stephens, III. Brit. Ent. v, 213, 1835.

Étymoiogie incertaine.

Caractères. Corps allongé, subdéprimé, ailé, légèrement pubescent.

Tête grande, saillante, suborbiculaire, portée sur un col court, beaucoup moins large que le vertex. Tempes non rebordées sur les côtés, contiguës en dessous. Épistome tronqué an sommet, à bordure submemhraneuse très-étroite. Labre court, bilobé. Mandibules saillantes, assez rnbustes, unidentées intérieurement vers leur milieu, aiguës, arquées, croisées au repos. Palpes maxillaires médiocres, à $1^{\text {er }}$ article court : le $2^{\circ}$ suballongé, en massue subarquée : le $3^{e}$ plus court, oblong, obconique : le dernier de la longueur du précédent, subsécuriforme chez les $\sigma^{\circ}$, subcylindrique ou subfusitorme chez les $\$$. Palpes labiaux courts, à dernier aricle grand, épais, subsécuriforme dans les 2 sexes. Menton transverse, Irapéziforme, beaucoup plus étroit en avant, membraneux, avec sa base cornée ou subcornée.

Yeux assez grands, peu saillants, subovales, obliques, séparés du cou par un intervalle aussi long que leur plus grand diamètre.

Antennes suballongées, subfiliformes; à $1^{\text {er }}$ article en massue allongée, grêle et subarquée : le $3^{\mathrm{e}}$ plus ou moins allongé, plus long que le $2^{\mathrm{e}}$ : les $4^{\mathrm{c}}$ a $10^{\circ}$ graduellernent un peu plus courls, peu ou non contigus, avec le p'úultième, seul à peine ou non transverse : le dernier assez court, obliquement tronqué ou subéchancré au bout.

Prothorax en carré à peine oblonġ; aussi large ou un peu moins large que les élytres ; tronqué au sommet; à angles antérieurs peu saillants; iırrondi à sa base; finement rebordé sur celle-ci et sur les côtés; à rebord Lhiéral sinueusement infléchi d'arrière en avant. Repli large, incliné, visible vu de côté: avec ou sans opercule prothoracique.

Eccusson grand, ogival ou subtriangulaire.

Elytres subcarrées ou à peine transverses, simultanément subéchancrées à leur bord apical; subarrondies à lcur angle postéro-externe; finement 1. Lurdées sur la suture. Repli médiocre ou assez étroit, subvertical. Epaules à peine saillantes. 
Prosternum peu développé au devant des hanches antérieures; offrant entre celles-ci un angle à sommet subaigu, à disque postérieurement relevé en carène. Mésosternum à lame médiane triangulaire, assez courte, à sommet brusquement rétréci en pointe acérée, prolongée environ jusqu'au tiers des hanches intermédiaires. Médiépisternums très-grands, séparés du mésoternum par une très-fine suture transversale et subsinueuse. Médiépimères étroites, plus ou moins linéaires. Métasternum court, fortement échancré au devant des hanches postérieures, prolongé entre celles-ci en un lobe court et subentaillé ; avaucé entre les intermédiaires en saillie à peine sensible et subarrondie, au devant de laquelle un intermède court, triangulaire, lisse. Postépisternums étroits, terminés en languette mousse, divergeant à peine du repli des élytres. Postépimères plus ou moins réduites : parfois peu distinctes, en onglet.

Abdomen allongé, subparallèle ou parfois subatténué en arrière, fortement rebordé sur les côtés; à $2^{\text {e }}$ segment basilaire quelquefois un peu découvert : les suivants subégaux : le $5^{\mathrm{e}}$ un peu plus grand: le $6^{\mathrm{e}}$ plus ou moins saillant, rétractile : celui de l'armure enfoui, avec 2 lanières sétosellées. Ventre à $5^{\mathrm{e}}$ arceau un peu plus grand que les précédents : le $6^{e}$ plus ou moins saillant, rétractile.

Hanches antérieures grandes, de la longueur des cuisses, saillantes, coniques, contiguës au sommet. Les intermédiaires moindres, peu saillantes, conico-ovalaires, fortement contiguës dans leur milieu. Les postérieures médiocres, rapprochées à leur base, divergentes au sommet; à lame supérieure conique, subétranglée ou sillonnée en travers dans son premier tiers; à lame inférieure nulle ou enfonie.

Pieds suballongés, médiocrement robustes. Trochanters antérieur's petits, cunéiformes; les intermédiaires et postérieurs plus grands, ovalesoblongs. Cuisses subcomprimées, subatténuées vers leur extrémité : les antérieures sensiblement renflées ou élargies dans leur milieu. Tibias graduellement élargis de la base au sommet, plus ou moins épineux, munis au bout de leur tranche inférieure de 2 éperons assez grêles, dont l'interne pius long ; les antérieur's plus courts et plus robustes, simplement pubescents sur leur tranche externe. Tarses antérieurs courts, à 4 premiers articles subdéprimés et dilatés dạns les 2 sexes; les intermédiaires et postérieurs plus développés, subcomprimés, subatténués vers leur extrémité ; à $1^{\text {er }}$ article allongé, plus long que les deux suivants réunis : les $2^{\circ}$ à $4^{\mathrm{e}}$ triangulaires, graduellement plus courts : le dernier légèrement en massue, subégal aux 2 précédents réınis. Ongles assez grêles, arqués. 
OBs. Les espèces de ce genre, médiocrement agiles, vivent cachées sous les pierres et parfois dans les écuries.

Cette coupe générique, peu tranchée, ne diffère organiquement de la précédente que par la structure des palpes labiaux, dont le dernier article est grand, plus ou moins sécuriforme dans les $\cdot 2$ sexes. L'aspect général est plus brillant, la tête et le prothorax moins pubescents. L'abdomen est unicolore.

Le genre Tasgins est réduit à 2 espèces françaises bien caractérisées et dont voici les différences :

a Opercule prothoracique nul. Tête et prothorax assez densement ponctués. Elytres d'un noir bleuâtre. Antennes et pieds roux. .

aa Opercule prothoracique apparent. Tète et prothorax éparsement ponctués. Elytres noires, Base des antennes et pieds obscurs. . ATER.

\section{Taggius pedator, GravenhoRst.}

Allongé, peu convexe, ailé, ponctué, légèrement pubescent, d'un noir asse: brillant, avec les élytres bleuâtres, les palpes, les antennes et les pieds roux. Tête et prothorax brillants, assez densement ponctués. Opercule prothoracique nul.

$\sigma$ Le $\dot{o}^{e}$ arceau ventral à peine sinué dans le milieu de son bord apical. Le dernier article des palpes maxillaires épais, subsécuriforme.

ㅇ Le $6^{\mathrm{e}}$ arceau ventral arrondi à son bord apical. Le dernier article des palpes maxillaires normal, subatténué au bout.

Staphylinus pedalor, Gravengonst, Micr. 163, 9; - Mon. 113, 125.-HEer, Faun.

Col. Helv. I, 254, 19. - Fairmaire et Laboulb. Faun. Ent. Fr. I, 511, 29. JACQuelin du VaL, Gen. Col. Eur. Staph. pl. 13, fig. 65.-Fauvel, Faun. GalloRhén. III, 417, 23 (I).

Astrapaeus rufipes, Latreille, Gen. Crust. et Ins. I, 285, 2.

Emus rufipes, Boisduval et LaCordaire, Faun. Ent. Par. I, 371, 19.

Tasgius rufipes, CURTIs, Brit. Ent. X, pl. 438.

Ocypus pedator, Ehichson, Gen. et Spec. Staph. 415, 17. - Kraatz, Ins. Deut. II, $\cdot 561,14$.

Tasgius pedator, Tromson, Skand. Col. II, 149, 2, 1860.

(1) Dans la synouymie de Fauvel, au lieu de Er. Gen. 561, lisez: Er. Gen. 415. 


$$
\text { Long., } 0^{\mathrm{m}}, 020 \text { (9 l.); - larg., } 0^{\mathrm{m}}, 0034(1 \text { l/2 l.). }
$$

Corps allongé, peu convexe, ailé, d'un noir assez brillant, avec les èlytres bleuâtres; revêtu d'une fine pubescence grisâtre, à peine distincte sur la tête et le prothorax, médiocrement serrée sur les élytres et l'abdomen.

Tête suborbiculaire, à peine moins large que le prothorax ; assez fortement et assez densement ponctuée, avec des points plus petits dans les intervalles; éparsement sétosellée; d'un noir brillant ; à peine pubescente sur son disque. Fronl très-large, faiblement convexe, parfois avec une carène lisse, obsolète, peu visible. Cou pointillé, plus lisse sur son milieu, presque glabre, d'un noir brillant. Expistome à bord antérieur submembraneux, nul ou très-éiroit. Labre cilié et fortement sétosellé en avant, Mandibules d'un noir de poix. la droite parfois avec une dent obsolète derrière celle du milieu. Palpes roux, souvent plus ou moins rembrunis.

Yeux assez grands, obscurs, lavés de gris.

Antennes à peine aussi longues que la tête et le prothorax réunis; subfiliformes; pubescentes et éparsement pilosellées vers leur base; rousses, souvent rembrunies vers leur milieu; à $1^{\text {er }}$ article allongé, en massue grêle et subarquée : les $2^{\text {e }}$ et $3^{\text {e }}$ obconiques : le $2^{\mathrm{e}}$ oblong, le $3^{\mathrm{s}}$ suballongé, plus longs que le $2^{\mathrm{e}}$ : les suivants graduellement plus courts : les $4^{\mathrm{e}} \mathrm{a} 8^{\mathrm{e}}$ oblongs, subcylindriques: les $9^{\mathrm{e}}$ et $10^{\mathrm{e}}$ subobconiques: le $9^{\mathrm{e}} \mathrm{a}$ peine, le $10^{\mathrm{e}}$ non plus longs que large, vu de côté : le dernier assez court, obliquement tronqué ou à peine échancré au bout, acuminé inférieurement.

Prothorax en carré à peine oblong; à peine moins large que les élytres ; rarement à peine rétréci en arrière; tronqué au sommet; à angles antérieurs presque droits mais subarrondis; subrectiligne ou à peine arqué sur les côtés; subarrondi à sa base, avec celle-ci parfois subtronquée dans son milieu; à angles postérieurs très-obtus et arrondis; assez convexe, assez fortement et assez densement ponctué, avec un point plus petit dans les intervalles et une fine carène longitudinale lisse, obsolète, souvent tout à fait effacée en avant; éparsement et longuement sétosellé sur les côtés; d'un noir brillant; à peine pubescent ou presque glabre. Repli noir, lisse, glabre.

Écusson assez fortement ponclué, noil, pubescent. 
Elytres subtransverses, elıviron de la longueur du prothorax; subdéprimées; très-densement et rugueısement ponctuées; éparsement sétosellées; d'un noir assez brillant et plus ou moins bleuâtre, avec une fine pubescence d'un gris azuré . Épaules effacées.

Abdomen allongé, à peine moins large que les élytres; subparallèle ou un peu alténué en arrière; assez convexe sur le dos ; distinctement sétosellé ; assez finement, densement et aspèrement ponctué; d'un noir un peu brillant, arec une fine pubescence grisàtre. Le $6^{\mathrm{e}}$ segiment subtronqué $\left(\sigma^{*}\right)$ ou subarrondi ( $q$ ) au sommet.

Dessous du corps densement et subaspèrement ponctué, d'un noir brillant, finement pubescent. Dessous de la tête éparsement et fortement ponctué. Métasternum subdéprimé, a vec un sillon longitudinal lisse, visible seulement en arrière. Ventre convexe, distinctement sétosellé.

Pieds médiocres, aspèrement ponctués, pubescents, d'un roux plus ou moins foncé, avec les hanches, et rarement les cuisses, d'un noir de poix. Cuisses postérieures peu allongées. Tibias antérieurs simplement pubescents ou seulement avec 2 ou 3 épines en dessous, à pubescence fauve $a$ brillante sur leurs arêtes externe et interne, ainsi que sur la tranche inférieure des cuisses antérieures, et au dessous de tous les tırses.

Patrie. Cetle espèce est assez commune, au priutemps eb en été, sous les pierres, dans les expositions chaudes : les environs de Paris et de Lyon, la Normandie, la Bretagne, le Bourbonnais, la Bourgogne, le Beaujolais, les Alpes, les Pyrénées, le Languedoc, la Provence, etc.

OBs. Elle varie un peu pour la taille el pour la couleur des palpes, des antennes et des pieds. Ces deux derniers organes sont quelquefois presque entièrement rembrunis, excepté leur extrémité.

Parfois le prothorax parait subatténué vers son sommet.

Le $5^{\circ}$ arceau ventral est souvent à peine sinué dans le milieu de son bord apical, et la même remarque s'applique à l'espèce suivante.

On doit rapporter au pedator le Siculus d'Aubé (Ann. Fr. 1842, 234).

LARVE

Nous avons trouvé plusieurs larves du Tasgius pedator en compagnie de l'insecte parfait. Nous en donnerons ici la description :

Corps allongé, peu épais, atténué en arrière, sétosellé, d'un roux de BR. 
poix très-brillant sur la tète et le thorax, mat sur.l'abdomen, avec une ligne longitudinale plus pâle et très-étroite sur le milieu de celui-ci.

Tête grande, subcarrée, rétrécie en arrière, plus large que le thorax, peu convexe, presque lisse ou à peine ridée en travers, obsolètement biimpressionnée entre les antennes, d'un roux de poix très-foncé et trèsbrillant. Épistome à 8 dents, les 2 intermédiaires plus grossières, obtuses. Mandibules falciformes, d'un roux de poix. Palpes testacées, à dernier article allongé, assez grêle, subatténué vers son extrémité et terminé par un petit lobe subsubulé (1).

Yeux peu distincts, lisses, indiqués par 2 ou 3 points obscurs.

Antennes courtes, testacées, à $1^{\mathrm{er}}$ article très-court, épais : le $2^{\mathrm{e}}$ allongé, en massue subcylindrique : le $3^{\mathrm{e}}$ plus court, un peu plus étroit, avec 2 ou 3 soies avant son extrémilé, et un petit lobe conique à son sommet interne: le dernier grêle, plus court, subcylindrique, terminé par 3 soies et un petit lobe conique.

Prothorax en carré plus ou moins rétréci en avant, largement rebordé en arrière, convexe, presque lisse ou à peine ridé en travers, subimpressionné sur les côtés, d'un roux de poix foncé et très-brillant.

Mésothorax et métathorax courts, subégaux, égalant à peine ensemble la longueur du prothorax, assez convexes, presque lisses, subimpressionnés sur les côtés, d'un roux de poix assez foncé et très-brillant. Le métathorax arcuément subélargi en arrière, un peu plus large que le segment précédent.

Abdomen égalant environ le reste du corps, un peu ou à peine moins large à sa base que le métathorax, graduellement subatténué en arrière, subdéprimé ou peu convexe, plus densement sétosellé que la tête et le thorax: d'un roux mat, avec une ligne pâle, très-étroite, le long du dos; composé de 9 segments apparents, munis chacun, sur les côtés, d'un bourrelet et d'un stigmate plus distinct que ceux du thorax : les 8 premiers courts, subégaux : le $1^{\text {er }}$ plus brillant, plus ou moins retiré sous le métathorax : le dernier plus étroit et plus pâle que le précédent, armé de 2 longues lanières étroites, un peu recourbées en dedans, éparsement sétosellées, terminées par 2 soies beaucoup plıs longues et divergentes et par un article beaucoup plus grêle, mais une fois moins long, subcylindrique, un peu déjeté en dehors et terminé lui-même par une longue soie.

(1) Les mâchoires, en forme de tige épaisse et subcylindrique, sont terminées en dedans par un appendice allongé, subfusiforme et transversalement dirigé. 


$$
\text { staphyliniess. - Tasgius }
$$

Dessous du cor'ps brunâtre, avec la poitrine enfouic, testacée, et le ventr's subexcavé, sétosellé, d'un roux livide. Dessous de la téte très-brillant. Le dernier arceau ventral terminé par un appendice assez épais, subcylindrique, tubulaire, un peu moins long que le $1^{\mathrm{er}}$ article des lanières supérieures.

Pieds testacés. Hanches très-longues. Cuisses sublinéaires, épineuses en dessous. Tibias plus courts, fortement épineux de tous côtés, terminés par un crochet fort, solide, subarqué.

\section{Tasgius ater, Gravenhorst.}

Aliongé, subdéprimé, ailé, ponctué, légèrement pubescent, d'un noir brillant, avec le sommet des antennes d'un ferrugineux obscur. Tête et prothorax très-brillants, éparsement ponctués. Opercule prothoracique apparent.

$\sigma^{7}$ Le $6^{c}$ arceau ventral largement et sensiblement sinué dans le milieu de son bord apical. Le dernier article des palpes maxillaires assez épais, subsécuriforme.

$\uparrow$ Le $6^{\mathrm{e}}$ arceau ventral simple. Le dernier article des palpes maxillaires subcylindrico-fusiforme, subtronqué au bout.

Staphylinus ater, Gravenhorst, Micr. 161, 5; - Mon. 112, 120. - Heer, Faun.

Col. Helv. 1, 236, 23. - Fairmaire et Laboulbène, Faun. Ent. Fr. I, 512, 30. FaUvel, Faun. Gallo-Rhén. III, 418, 26.

Staphylinus fuscatus, Gyllenhal, Ins. Suec. IV, 479, 9-10.

Emus nigripes, Boisduval et Lacordaine, Faun. Ent, Par. I, 370, 18.

Tasgius confinis, Curris, Brit. Ent. X, f. 438, 4, 2.

Ocypus ater, Erichson, Col. March. I, 444, 8;-Gen. et Spec. Staph. 416, 18.-

- Redtenbacher, Faun. Austr. 697, 3. - Kraatz, Ins. Deut. II, 562, 15.

Tasgius ater, Thovsos, Skand. Col. II, 1ł́9, 1.

$$
\text { Long., } 0^{\mathrm{m}}, 0185 \text { (8 1. 1/2); - larg., } 0^{\mathrm{m}}, 0033 \text { (1 1/2 1.). }
$$

Corps allongé, subdéprimé: ailé, presque glabre et d'un noir trèsbrillant sur la tête et le prothorax, pubescent et inoins brillant sur les élytres et l'abdomen, avec cette pubescence grisâtre et médiocrement serrée.

Tête suborbiculaire, environ de la largeur du prothorax; assez fortement mais éparsement ponctuée, avec quelques points plus petits; éparsenent 
sétosellée; d'un noir très-brillant; à peine pubescente. Front très-large, peu convexe, avec une ligne longitudinale, lisse. Cou ponctué sur les côtés, lisse sur son milieu, presque glabre, d'un noir très-brillant. Épistome à bord antérieur submembraneux, très-étroit, livide. Labre cilié et fortement sétosellé en avant. Mandibules noirâtres, obtusément dentées ou simplement angulées vers le milieu de leur còté interne. Palpes couleur de poix, avec le dernier article des maxillaires souvent roussâtre.

Yeux assez grands, obscurs ou gris.

Antennes un peu moins longues que la tête et le prothorax rẻunis; subfiliformes; pubescentes et éparsemen pilosellées vers leur base; noires, avec leur sommet obscurément ferrugineux; à $1^{\text {er }}$ article en massue allongée, grêle et subarquée : les $2^{ }$et $3^{\mathrm{e}}$ obconiques : le $2^{e}$ oblong : le $3^{\mathrm{e}}$ allongé, sensiblement plus long que le $2^{\mathrm{e}}$ : les suivants graduellement un peu plus courts : les $4^{\mathrm{e}}$ à $8^{\mathrm{e}}$ oblongs ou suboblongs, subcylindriques : les $9^{\mathrm{c}}$ et $10^{\mathrm{e}}$ subobconiques : le $9^{\mathrm{e}}$ non, le $10^{\mathrm{e}}$ parfuis à peine subtransverse, vu de côté : le dernier assez court, obliquement tronqué au bout, subacuminé inférieurement.

Prothorax en carré suboblong et subrétréci en arrière; un peu moins large que les élytres; tronqué au sommet; à angles antérieurs presque droits mais émoussés; presque rectiligne sur ses côtés; subarrondi à sa base ainsi qu'aux angles postérieurs, qui sont très-obtus; peu convexe; assez fortement ponctué sur les côtés, plus finement et éparsement sur le disque, avec des points plus petits et un étroit espace longitudinal lisse sur la ligne médiane; éparsement et longuement sétosellé sur les côtés; d'un noir très-brillant; presque glabre. Repli noir, glabre, lisse, avec un opercule court, triangulaire, subcorné, obscur.

Écusson rugueusement ponctué, pubescent, noir.

Élytres subcarrées ou subtransverses, environ de la longueur du prothorax ou à peine plus longues ; subdéprimées; très-densement et rugueusement ponctuées ; éparsement et longuement sélosellées; d'un noir assez brillant; finement pubescentes. Épaules subarrondies.

Abdomen allongé, un peu moins large que les élytres; subparallèle ou un peu atténué en arrière ; assez convexe sur le dos ; distinctement sétosellẻ ; densement et subaspèrement ponctué ; d'un noir assez brillant, avec une fine pubescence d'un gris obscur. Le $6^{\mathrm{e}}$ segment obtusément ariondi an sommet.

Dessous du corps densement et subaspèrement ponctué, d'un noir brillant, finement pubescent. Dessous de la tête fortement et subéparsement 
ponctué. Métastermum subdéprimé, subsillonné sur son milieu. Ventre convexe, distinctement sétosellé.

Pieds médiocres, aspèrement ponctués, pubescents, d'un noir de poix, avec les tarses et parfois les tibias moins foncés. Cuisses postérieures suballongées. Tibias antérieur's simplement pubescents ou seulement avec 2 ou 3 épines en dessous, à pubescence souvent blonde ou fauve, plus ou moins brillante, plus serrée sur leur arête interne ainsi que sur la tranche inférieure des cuisses antérieures et au dessous de tous les tarses.

Patrie. Cette espèce, peu commune, se rencontre sous les pierres et parfois sous les excréments de lièvres et dans les écuries de lapins. Elle a un habitat étendu : les environs de Paris et de Lyon, la Picardie, la Normandie, la Bretagne, l'Alsace, la Bourgogne, la Guyenne, le Languedoc, etc.

OBs. La couleur plus obscure des antennes et des pieds, la ponctuation moins serrée de la tête et du prothorax et la présence d'un opercule prothoracique, tels sont les caractères qui séparent le Tasgius ater du pedator. En outre, la taille est un peu moindre, la forme plus déprimée, la teinte générale plus brillante, le prothorax plus étroit et plus rétréci en arrière; les élytres sont sans reflet bleuâtre, etc.

Le dernier article des palpes maxillaires des $\sigma$ est relativement un peu moins épais, moins sensiblement sécuriforme, moins atténué, mais subtronqué au bout chez la $q$.

Par ses mandibules plus obtusément dentées en dedans et par son prothorax subrétréci en arrière, cette espèce lie le genre Tasgius au genre Anodus.

Peut-ètre doit-on lui appliquer le punctulatus de Stephens (IIll. Br. V, 209)?

Genre Anodus, Avode, Nordmann.

Tordmann, Symb. Mon. Staph. 11, pl. I, 1. 1, 1837.

Étym. : $\alpha$ privatif; v euphonique; ójoùs, dent.

Cakactères, Corps allongé, subdéprimé, ailé, pubescent.

Tête grande, saillante, subcarrée ou suborbiculaire; portée sur un col court, beaucoup moins large que le vertex. Tempes non rebordées sur les côtés, subcontiguës en arrière, en dessous. Épistome tronqué au sommet, à bordure submembraneuse trìs-étroite. Labrè court, bilobé. Mandibules 
saillantes, asseź grêles, simples ou à peine angulées en dedans, subfalciformes, acérées. Palpes maxillaires assez courts; à $1^{\mathrm{e}_{\mathrm{r}}}$ article court : le $2^{c}$ suballongé, en massue subarquée : le $3^{\text {e }}$ plus court, obconique : le dernier subégal all précédent, subsécuriforme chez le $\sigma^{*}$, ovale-oblong chez la ㅇ. Palpes labiaux courts, à 2 premiers articles très-courts : le dernier grand, sécuriforme. Menton transverse, trapéziforme, plus étroit en avant, tronqué au sommet, submembraneux.

Yeux assez grands, peu saillants, subovales, obliques, séparćs du cou par un intervalle aussi long que leur plus grand diamètre.

Antennes suballongées, subfiliformes; à $1^{\mathrm{e}} \stackrel{\mathrm{r}}{\mathrm{r}}$ article en massue allongée , grêle et subarquée : le $3^{\mathrm{e}}$ allongé, plus long que le $2^{\mathrm{e}}$ : les $4^{\mathrm{e}}$ à $10^{\mathrm{e}}$ graduellement un peu plus courts, peu ou non contigus, avec les pénultièmes nullement transverses : le dernier court, tronqué ou creusé au bout.

Prothorax en carré suboblong et subrétréci en arrière, un peu ou à peine moins large que les élytres; tronqué au sommet; à angles antérieurs peu saillants; subarrondi à sa base; très-finement rebordé sur celle-ci et sur les côtés; à rebord latéral subsinueusement infléchi d'arrière en avant. Repli assez large, incliné, visible vu de côté, à opercule prothoracique nul ou rudimentaire.

Écusson grand, ogival.

Élytres subcarrées ou subtransverses, simultanément subéchancrées à leur bord apical; subarrondies à leur angle postéro-externe; très-finement rebordées sur la suture. Repli médiocre, subvertical. Epaules peu saillantes.

Prosternum peu développé au devant des hanches antérieures, offrant entre celles-ci un angle à sommet subaigu mais émoussé, à disque post'́rieurement relevé el carène. Mésosternum à lame médiane assez courte, triangulaire, à sommet rétréci en pointe plus ou moins acérée et prolongée environ jusqu'au tiers des hanches intermédiaires. Médiépistermums très-grands, séparés du mésosternum par une fine suture transversale et subsinueuse. Médiépimères étroites, chagrinées. Métasternum court, fortement échancré au devant des hanches postérieures, prolongé entre celles-ci en un lobe court et subentaillé ; avancé entre les intermédiaires en angle très-court et arrondi au devant duquel un intermède court, subtriangulairc, chagriné. Postépistermums étroits, terminés en languette mousse, divergeant à peine du repli des ilytres. Postépimères peu développées, subtriangulaires.

Abdomen allongé, subparallèle ou parfois subatténué en arrière, for- 
tement rebordé sur les côtés; à $2^{e}$ segment basilaire parfois découvert, presque lisse : les suivants subégaux : le $5^{\mathrm{e}}$ un peu plus grand ; le $6^{\mathrm{e}}$ plus ou moins saillant, rétractile : celui de l'armure enfoui, avec 3 lanières sétosellées. Ventre à $5^{\mathrm{c}}$ arceau un peu plus grand que les précédents : le $6^{\mathrm{e}}$ plus ou moins saillant, rétractile.

Hanches antérieures grandes, de la longueur des cuisses, saillantes, coniques, contiguës au sommet. Les intermédiaires moindres, peu saillantes, conico-subovales, fortement contiguës dans leur milieu. Les postérieures médiocres, rapprochées à leur base, divergentes au sommet; à lame supérieure conique, subétranglée ou sillonnée en travers dans son premier tiers; à lame inférieure nulle ou enfouie.

Pieds suballongés, peu ou médiocrement robustes. Trochanters antérieurs petits, cunéiformes; les intermédiaires et postérieurs plus grands, ovales-oblongs. Cuisses subcomprimées, subatténuées vers leur extrémité ; les antérieures sensiblement renflées dans leur milieu. Tibias subélargis de la base au sommet, plus ou moins épineux, munis au bout de leur tranche inférieure de 2 éperons grêles, dont l'interne plus long: les antérieurs plus courts et un peu plus robustes, simplement pubescents sur leur tranche externe. Tarses antérieurs courts, à 4 premiers articles subdéprimés et dilatés dans les 2 sexes; les intermédiaires et postérieurs suballongés, subcomprimés, subatténués vers leur extrémité, à $1^{\text {er }}$ article allongé, à peine moins long que les 3 suivants réunis : les $2^{\mathrm{e}}$ à $4^{\mathrm{e}}$ triangulaires, graduellement plus courts (1) : le dernier en massue, subégal aux 2 précédents réunis. Ongles assez grêles, arqués.

Obs. Les espèces de ce genre yivent sous les pierres, les mousses et les fagots. Elles sont assez agiles.

Les mandibules sont plus grêles que dans la coupe précédente, presque simples en dedans, subfalciformes, rétrécies vers leur base, très-acérèes à leur pointe. Les antenues sont à peine plus grêles, avec leur $3^{\mathrm{e}}$ article plus allongé, le dernier article des palpes labiaux est plus fortement sécuriforme. Le prothorax est généralement plus rétréci en arrière. Le corps est ordinairement moins brillant, plus pubescent, etc.

Les espèces du genre Anodus sont peu nombreuses. En voici le tableau :

a Tête, prothorax et élytres noirs.

b Buse des antenmes ct pieds obscurs. Tète et prothorax densement et subrugueusement ponctués.

MORI0.

(1) Ils sont néanmoins plus longs que larges, oblongs ou suboblongs. 
bb Base des antennes et pieds roux.

c Tête et prothorax finement,très-densement et ruguleusement ponctués, tout à fait mats : celui-ci à ligne lisse très-fine, obsolète et racconrcie.

COMPRESSUS.

ce Téle et prothorax assez finement, assez densement et non ruguleusement ponctués, très-brillants, celui-ci à ligne lisse moins fine, bien marquée et presque entière . . . MiNax.

Tête, prothorax et élytres bleuàtres. Base des antennes et pieds roux.

FALCIFER.

\section{Amodung morio, Gravenhorst.}

Allongé, subdéprimé, ailé, densement ponctué, finement pubescent, d'un noir presque mat, avec l'extrémité des antennes ferrugineuse, et les tarses d'un roux de poix foncé. Elytres de la longueur du prothorax : celui-ci finement caréné sur sa ligne médiane. Opercule prothoracique plus ou moins apparent, rudimentaire.

$\sigma^{*}$ Le $6^{\mathrm{e}}$ arceau ventral sensiblement el angulairement sinué dans le milieu de son bord apical, avec un léger espace lisse et submembraneux

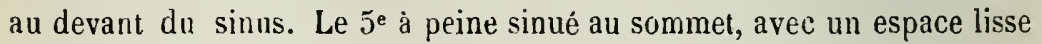
au devant du sinus.

\section{\& Le $6^{\mathrm{e}}$ arceau ventral simplè.}

Slaphylinus morio, Gravenhorst, Micr. 6, 4; - Mon. 112, 121. - Latreille,

Hist. Nat. Crust. et Ins. IX, 303, 18. - Gylienhal, Ins. Suec. IV, 373, 8-9. -

Manneraeim, Brach. 24, 18. - Heer, Faun. Col. Helv. I, 256, 26.- Fairmaire et L.soulbènl:, Faun. Ent. Fr. I, 312, 31 .

Anodus morio, Norimane,Symb. 13, 3. - Thomson, Skand. Col. II, 150, 1. 1860. Emus morio, Bolsduval et Lacordaine, Faun. Ent. Par. I, 369, 15.

Emus fuscalus, Boisduval et Lacordaire, Faun. Ent. Par. I, 372, 21:

Ocypus morio, Erichson, Col. March. I, 444, 9;- Gen. et Spec. Staph. 47, 19.

- Redtenbacher, Faun. Austr. 696, 2. - Krastz, Ins. Deut. II, 563, 16.

Slophylinus edenlulus, Fauvel, Faun. Gallo-Rhén. IIr, 419, 28.

Variété $a$. Tête et prothorax moins rugueusement ponctués, plus brillants, submétalliques.

Emus angustalus, Borsovv.ll et Lacondare, Faun. Ent. Par. I, 3ิ69, 16.

Slaphylinus melanarius, Heer, laun. Col. Helv. I, 2ü6, 28. - Falnsu!ne et

Laboulbène, Faun. Ent. Fr. I, 512, 32.

$$
\text { Long., } 0^{\mathrm{m}}, 016 \text { (7 1/3 1.); - larg., } 0^{\mathrm{m}}, 0032 \text { (1 1/2 l.). }
$$


Corps allongé, subdéprimé, ailé, d'un noir presque mat, revêtu d'une fine pubescence assez serrée et d'un gris obscur.

Téte suborbiculaire ou en carré subarrondi, un peu plus large que le: prothorax; assez fortement et densement ponctuée, un peu moins densement en avant, avec les points subombiliqués; éparsement sétosellée; d'ur. noir plus oı moins mat; légèrement pubescente. Front très-large, à peine convexe, avec une ligne médiane lisse, raccourcie en avant. Cou rugueusement ponctué, noir, pubescent, avec une ligne médiane lisse. Épistomi a bord antérieur submembraneux, très-étroit, livide. Labre presque lisse . cilié et fortement sétosellé vers son sommet. Mandibules noires. Palpes d'un noir de poix, avec le dernier article des maxillaires parfois roussâtre.

Yeux assez grands, obscurs, lavés de gris.

Antennes moins longues que la tête et le prothorax réunis; subfiliformes ou à peine subatténuées vers leur extrémité ; pubescentes; éparsement pilosellées vers leur base; noires, graduellement moins foncées et ferrugineuses vers leur sommet; à $1^{\mathrm{er}}$ article en massue allongée, grêle et subarquée : le $2^{\mathrm{e}}$ oblong, obconique : le $3^{\mathrm{e}}$ allongé, beaucoup plus long que le $2^{\mathrm{e}}$ : les suivants graduellement un peu plus courts, obçonico-subcylindriques. oblongs ou subob!ongs, avec les pénultièmes nullement transrerses : le dernier assez court, obliquement tronqué au bout et subacuminé iıférieurement.

Prothorax en carré suboblong et subrétréci en arrière, où il est un peu moins large que les élytres; tronqué au sommet; à angles antérieurs presque droits mais émoussés ; subrectiligne sur ses côtés ; subarrondi à sa base, avec les angles posiérieurs obtus ; peu convexe ; densement el subrugueusement ponctué, avec les points subombiliqués; paré sur sa ligne médiane d'une fine carène lisse, plus ou moins effacée antérieurement; éparsement sétosellé sur les côtés; d'un noir plus ou moins mat, ì pubescence légère. Repli noir, glabre, lisse, avec un opercule prothoracique court, submembraneux ou subcorné, parfois nul ou rudimentaire.

Écusson rugueusement pointillé. pubescent, noir.

Élytres subcarrés ou subtransverses, environ de la longueur du prolhorax; subdéprimées; très-densement et rugueusement pointillées; éparsement sétosellées; d'un noir mat, avec une fine pubescence d'un gris obscur. Épaules étroitement arrondies.

Abdomen allongé, un peu moins large à sa base que les élytres; subparallèle ou parfois subatténué vers son sommet; assez convexe sur le dos ; éparsement sétusellé; finement, très-densement et aspèrement pointillé ; 
d'un noir mat ou presque mat, avec une fine pubescence d'un gris trèsobscur. Le $6^{\mathrm{e}}$ segment obtusément tronqué ou à peine arrondi au sommet.

Dessous du corps densement et aspèrement ponctué, d'un noir brillant, finement pubescent. Dessous de la tête plus lisse, éparsement ponctué. Métasternum subdéprimé, subsillonné sur son milieu. Ventre convexe, éparsement sétosellé.

Pieds médiocres, aspèrement ponctués, finement pubescents, noirs, avec les tarses et parfois les tibias d'un roux de poix foncé. Cuisses postérieures assez allongées. Tibias antérieurs simplement pubescents ou seulement avec 1 ou 2 épines peu distinctes en dessous; à pubescence blonde ou fauve et plus ou moins brillante, ainsi que celle du dessous des cuisses antérieures et de tous les tarses.

Patrie. Cette espèce est commune sous les pierres et les mousses, dans presque toute la France.

OBs. Elle varie beaucoup pour la taille (de 11 à 17 millimètres) et pour la ponctuation, surtout de la tête et du prothorax. Quand cette ponctuation devient moins serrée et moins rugueuse, ces deux segments prennent une teinte plus brillante et souvent submétallique (melanarius, Heer), avec la carène prothoracique plus prononcée et plus entière, parfois subélargie et déprimée vers sa base. Sur un certain nombre d'exemplaires, nous avons rencontré tous les passages, et il est à noter que ces modifications sont plus accentuées à mesure que les échantillons diminuent de grandeur.

Nous avons vu un exeinplaire provenant de la Provence et dont la forme est plus parallèle et les angles postérieur's du prothorax plus prononcés. Peut-être est-ce là le Siculus de Stierlin (Berl. Ent. Zeits. 1864, 146)? Sa taille est des moindres.

Le Kirbyi de Stephens (Ill. Br. V, 210) est peut-être un morio? Il en serait de même des erosicollis et Saulcyi de Reiche (Ann. Ent. Fr. 1856, 364 , et 1857, Bull. 9)?

\section{Anodus compressus, Marsham.}

Allongé, subdéprimé, ailé, très-densement et ruguleusement pointillé, finement pubescent, d'un noir mat, avec les palpes, la base et le sommet des antennes et les pieds roux. Élytres de la longueur du prothorax; celui-ci presque sans carène. Opercule prothoracique rudimentaire ou nul. 
$\sigma^{*}$ Le $6^{e}$ arceau ventral légèrement et subangulairement sinué dans le milieu de son bord apical, avec un léger espace lisse au devant du sinus. Le $5^{\mathrm{e}}$ à peine sinté dans le milieu de son bord postérieur.

\& Le 6e arceau ventral simple.

Staphylinus compressus, .Harsham, Ent. Brit. 503, 15. - Fatrmatre et Laboulbène,

Faun. Ent. Fr. I, 312, 34. - Jacquelin Di VaL, Gen. Staph. pl. 15, fig. 66. -

- Fautel, Faun. Gallo-Rhén. III, 420, 29 (1).

Emus rufipalpis, Borsdutal et Lacordaire, Faun. Ent. Par. I, 370, 17.

Ocypus compressus, Erichson, Gen. et Spec. Staph. 418, 21. - KraAtz, Ins. Deut. II, $564,18$.

Anudus compressus, Тномsos, Skand. Col. II, 150, 2.

Variété $a$. Pieds obscurs, avec les tarses et parfois les tibias roussâtres.

Ocypus cerdo, Ericison, Gen. et Spec. Staph. 417, 20. - Rosenhauer, Beitr, Ins. 90. - Kraatz, Ins. Deut. II, 564, 17.

Staphylinus luganensis, HeER, Faun. Col. Helv. I, 256, 27.

Staphylinus cerdo, FairMatre, et Laboulbène, Faun. Ent. Fr. I, 512, 33.

$$
\text { Long., } 0^{\mathrm{m}}, 0153\left(7 \mathrm{l} \text {.); - } \operatorname{larg} ., 0^{\mathrm{m}}, 0028\right. \text { (1 1/4 1.). }
$$

Corps allongé, subdéprimé, ailé, d'un noir mat, avec une fine pubescence assez serrée et d'un gris obscur.

Tête suborbiculaire ou en carré subarrondi ; de la largeur du prothorax ou à peine plus large; assez finement, très-densement et ruguleusement ponctuée, presque lisse vers l'épistome; éparsement et longuement sétosellée; d'un noir presque mat, plus brillant en avant ; légèrement pubescente. Front très-large, subdéprimé ou à peine convexe, parfois avec une fine ligne lorgitudinale lisse el presque imperceptible. Cou rugueusement pointillé, pubescent, noir. Epistome à bord antérieur submembraneux, très-étroit et testacé. Labre d'un roux de poix, cilié et fortement sétosellé à son sommet. Mandibules brunâtres. Palpes roux, le dernier article des labiaux fortement sécuriforme.

Yeux assez grands, obscurs, parfois tachés de gris.

Antennes un peu moins longues que la tête et le prothorax réunis; subfiliformes; pubescentes ; éparsement pilosellées vers leur base; obscures, avec les 2 ou 3 premiers articles et les 2 ou 3 derniers roux; le $1^{\text {er }}$ en

(1) Dans la synonymie de Fauvel, au lieu de Kraatz, Nat. 654, lisez Kraatz, Nat. 564 . 
massue allongée, très-grêle et subarquée : le $2^{e}$ oblong, obconique : le $3^{\text {e }}$ allongé, plus long que le $2^{\mathrm{e}}$ : les suivants graduellement un peu moins longs: les $4^{\mathrm{e}}$ à $8^{\mathrm{e}}$ plus ou moins oblongs, subcylindriques : les $9^{\mathrm{e}}$ et $10^{\mathrm{e}}$ subobconiques: le $9^{\mathrm{e}}$ un peu, le $10^{\mathrm{e}}$ non ou à peine plus longs que larges : le der nier assez court, creusé en cuiller à son sommet et acuminé inférieurement.

Prothorax en carré suboblong ou à peine oblong; à peine rétréci en arrière, où il est un peu moins large que les élytres; tronqué au sommet; à angles antérieurs presque droits et à peine émoussés; subrectiligne sur les côtés; subarrondi à sa base, avec les angles postérieurs obtus; peu convexe; finement, très-densement et ruguleusement pointillé, avec une très-fine carène longitudinale postérieure et souvent effacée ; éparsement et longuement sétosellé sur les côtés; d'un noir mat; finement et assez densement pubescent. Repli noir, glabre, lisse, opercule prothoracique submembraneux, rudimentaire ou parfois nul.

Écusson ruguleux, pubescent, noir.

Élytres subtransverses, de la longueur du prothorax ou à peine plus courtes ; déprimées; finement, très-densement et rugueusement pointillées ; éparsement et longuement sétosellées ; d'un noir mat ; finement et assez. densement pubescentes. Épaules effacées.

Abdomen plus ou inoins allongé, un peu moins large à sa base que les élytres; subparallèle ou parfois à peine atténué en arrière ; assez convexe sur le dos; éparsement sétosellé ; finement, très-densement et aspèrement pointillé; d'un uoir mat; finement et assez densement pubescent. Le $6^{\mathrm{e}} \mathrm{seg}$ ment obtusément tronqué à son sommet.

Dessous $d u$ corps densement et aspèrement pointillé, d'un noir brillant, finement pubescent. Dessous de la tête plus lisse, éparsement ponctué. Métasternum subdéprimé, subsillonné en arrière sur sa ligne médiane. Ventre convexe, éparsement sétosèllé.

Pieds médiocres, aspèrement pointillés, à pubescence blonde; d'un roux parfois subtestacé, a vec les hanches d'un noir de poix et parfois roussâtres à leur sommet ou en dedans. Cuisses postérieures suballongées. Tibias antérieurs simplement pubescents ou seulement avec 2 ou 3 épines peu distinctes, en dessous.

Patrie. Cette espèce vit dans les lieux humides, sons les pierres. les mousses et les fagots, en automne, dans diverses localités de la France : les environs de Paris e! de Lyon, la Normandie, la Bourgogne, le Bealljolais, les Alpes, etc. 
OBs. La ponctuation de la tête et du prothorax est plus fine et plus serrée que chez l'o. morio; la carène prothoracique, très-fine, est souvent nulle ou très-réduite; les palpes et les pieds sont roux ainsi que la base des antennes, etc.

Le catalogue Gimminger et les auteurs récents s'accordent à regarder l'O. cerdo d'Erichson comme une variété du compressus, variété dont la tête el le prothorax sont moins finement ponctués, dont les cuisses et parfois les tibias sont rembrunis. Elle est du nord de l'Italie et de la Provence.

Quelquefois les antennes sont entièrement rousses, d'autres fois les 2 premiers et le dernier articles sont seuls de cette couleur.

On doit attribuer au compressus le phoeopus de Stephens (Ill. Br. V, 212), et le fulvipes de Motschulsky (Bull. Mosc. 1858, 11, 669).

3. Amodus minax, Mulsant et Rey.

Allongé, subdéprimé, ailé, ponctué, légèrement pubescent, d'un noir très-brillant sur la tête et le prothorax, pen brillant sur les élytres et l'abdomen, avec les palpes, la base et le sommet des antennes et les pieds roux. Élytres de la longueur du prothorax: celui-ci à ligne lisse, bien marque. Opercule prothoracique rudimentaire.

$\sigma$ Le 6e arceau ventral angulairement échancré dans le milieu de son bord apical.

ㅇ Le $6^{\mathrm{e}}$ arceau ventral simple.

Ocypus minax, Mulsant et Rey, Ann. Soc. Lin. Lyon, 1861, VIII, 123; - 0p. Ent. XII, 139, 1861.

Staphylinus minax, Fauvel, Faun. Gallo-Rhén. III, 419, 27.

$$
\text { Long., } 0^{\mathrm{m}}, 0142\left(6 \text { 1/2 l.) ; - larg., } 0^{\mathrm{n}}, 0027\right. \text { (1 1/4 l.). }
$$

Corps allongé, subdéprimé, ailé, d'un noir très-brillant sur la tête et lc prothorax, peu brillant sur les élytres et l'abdomen; revêtu d'un très-fine pubescence peu serrée et d'un gris obscur.

Tête subcarrément orbiculaire, visiblement plus large que le prothorax, assez finement et assez densement ponctueje, plus éparsement en avant, ivec des points plus petits dans les interstices ; éparsement sétosellée; d'un noir luisant; légèrement pubescente. Front très-large, à peine convexe, avec une ligne longitudinale lisse. Col ponctué, pubescent, d'un noir lui- 
sant. Épistome à bord submembraneux nul ou retiré. Labre légèrement cilié et fortement sétosellé en avant. Mandibules d'un noir de poix. Palpes roux.

Yeux assez grands, obscurs.

Antennes un peu moins longues que la tête et le prothorax réunis; grêles ; subfiliformes; pubescentes; éparsement pilosellées vers leur base ; obscures, avec le $1^{\text {er }}$ article roux ainsi que l'articulation des 2 suivants, et l'extrémité un peu ferrugineuse; à $1^{\mathrm{er}}$ article en massue très-allongée, très-grêle et subarquée : le $2^{\mathrm{e}}$ oblong, obconique : le $3^{\mathrm{e}}$ allongé, beaucoup plus long que le $2^{\mathrm{e}}$ : les suivants graduellement un peu moins longs, subcylindriques, tous plus ou moins oblongs : le dernier aussi long ou à peine plus long que le pénultième, obliquement tronqué au bout et subacuminé inférieurement.

Prothorax en carré suboblong, visiblement rétréci en arrière où il est un peu moins large que les élytres; tronqué au sommet; à angles antérieurs presque droits mais émoussés ; subrectiligne sur les côtés ; subarrondi à sa base, avec celle-ci subtronquée dans son milieu, et les angles postérieurs obtus ; très-peu convexe; assez finement et assez densement ponctué, avec quelques points plus fins ; offrant sur sa ligne médiane un espace lisse, étroit mais bien marqué, subélargi et subélevé en arrière, de chaque côté duquel la ponctuation paraît un peu plus serrée (1) ; éparsement sétosellé sur les côtés; d'un noir luisant; à peine pubescent. Repli noir, glabre, lisse, avec un opercule prothoracique membraneux, rudimentaire.

Ecusson ruguleux, pubescent, d'un noir peu brillant.

Élytres subtransverses, aussi longues ou à peine aussi longues que le prothorax ; déprimées ; finement, très-densement et rugueusement pointillées; éparsement sétosellées; d'un noir peu brillant, avec la suture étroitement ferrugineuse; finement et modérément pubescentes. Épaules étroitement arrondies.

Abdomen assez allongé, un peu moins large à sa base que les élytres ; subparallèle ou à peine arqué sur les côtés; subconvexe sur le dos; à peine sétosellé; finement, densement et subaspèrement pointillé; d'un noir peu ou un peu brillant; finement et modérément pubescent. Le 6e segment à peine arrondi au sommet.

Dessous du corps assez densement et subaspèrement pointillé; d'un

(1) On aperçoit, en outre, vers le milieu des côtés du disque, une place lisse ou moins ponctuée, peu apparente. 
noir brillant; finement pubescent. Dessous de la tête plus lisse, éparsement ponctué. Métasternum subdéprimé, subsillonné sur sa ligne médiane. Ventre convexe, à peine sétosellé.

Pieds médiocres, aspèrement pointillés, pubescents; roux, ainsi que les hanches, moins la base des postérieures qui est rembrunie. Cuisses postérieures suballongées. Tibias antérieur's simplement pubescents.

Patrie. Celte espèce a été rapportée de la vallée du Champsaur (HautesAlpes) par feus MM. Célestin Maurel et Émile Millon, qui l'avaient capturée en septembre. Elle se prend aussi en Normandie, dans la Champagne, la Lozère, les Basses-Alpes.

OBs. Elle diffère de l'O. compressus par sa tête et son prothorax moins finement, moins densement et non rugueusement ponctués, et surtout très-brillants. La tête est relativement plus large ; la ligne lisse du prothorax moins fine, plus marquée et plus entière. Les antennes, plus grêles, ont leurs pénultièmes articles plus longs, plus cylindriques, etc.

\section{Anodus falcifer, NordunN.}

Allongé, subdéprimé, ailé, ponctué, légèrement pubescent, noir, avec la tête, le prothorax et les élytres bleuâtres, les palpes, la base et l'extrémité des antennes el les pieds roux. Élytres de lalongueur du prothorax : celui-ci à carène lisse entière. Opercule prothoracique distinct.

$\sigma$ Le $6^{\text {e }}$ arceau ventral subsinué dans le milieu de son bord apical.

o Le $6^{\mathrm{e}}$ arceau ventral simple.

Anodus falcifer, Norduan, Symb. 12, 2.

O Anodus messor, Nonduan, Symb. 11, 1.

Ocypus falcifer, Erichson, Gen. et Spec. Staph. 418, 22. - Redtenbacher, Faun.

Austr. 646, 2. - KraAtz, Ins. Deut. II, 565, 19.

Staphylinus falcifer, Fauvel, Faun. Gallo-Rhén. III, 419, note.

$$
\text { Long., } 0^{\mathrm{m}}, 013 \text { (6 l.); - larg., } 0^{\mathrm{m}}, 0027 \text { (1 1/4 l.). }
$$

Corps allongé, subdéprimé, ailé, d'un noir peu brillant sur' l'abdomen, d'un bleu foncé irès-brillant sur la tête et le prothorax, mat sur les élytres; revêtu d'une très-fine pubescence peu serrée et d'un gris obscur. 
Téte subcarrément orbiculair., un peu plus large que le prothorax; assez fortement et peu densernent ponctuée, avec des points plus petits dans les interstices; éparsement sétosellée ; d'un bleu foncé très-brillant ; lègèrement pubescente. Front très-large, à peine convexe, avec une ligne longitudinale lisse. Cou ponctué, légèrement pubescent, brillant, bleuâtre. Epistome à bord submembraneux nul. Labre fortement sétosellé en avant. Mandibules noires. Palpes roux, avec le dernier article des labiaux parfois rembruni.

Yeux assez grands, obscurs.

Antennes moins longues que la tête et le prothorax réunis; grêles, subfiliformes; pubescentes ; éparsement pilosellées vers leur base ; obscures, avec la base et l'extrémité rousses; à $1^{\text {er }}$ article en massue trèsallongée, très-grèle et subarquée : le $2^{\mathrm{e}}$ oblong, obconique : le $3^{\mathrm{e}}$ allongé, beaucoup plus long que le $2^{\mathrm{e}}$ : les suivants graduellement un peu moins longs, subcylindriques, plus ou moins oblongs: le dernier subovalaire, acuminé au bout inférieurement.

Prothorax en carié suboblong; légèrement rétréci en arrière où il est un pcu moins large ụue les élytres; tronqué au sommet; à angles antérieurs presque droits mais émoussés; subrectiligne sur ses côté ; subarrondi à sa base, avec les angles postérieurs obtus; peu convexe ; assez fortement mais peu densement ponclué, avec quelques points plus petits dans les interstices ; surmonté, sur sa ligne médiane, d'une carène lisse, obsolète en avant, plus prononcée en arrière; éparsement sétosellé sur les côtés; d'un bleu foncé très-brillant; à peine pubescent. Repli noir, glabre, lisse, à opercule prothoracique distinct, court, subtriangulaire, membraneux.

Écusson pointillí, noir, pubescent.

Élytres subtransverses, environ de la longueur du prothorix ; subdéprimées ; finement, très-densement et rugueusement ponctuées; trèséparsement sétosellées; d'un bleu foncé mat ; finenent et modérément pubescentes. Épaules effacées.

Abdomen allongé, un peu moins large à sa base que les élytres; sub-. parallèle ou à peine arqué sur les côtés; assez forlement convexe ; éparsement sétosellé; assez fortement, densement et aspèrement ponctué; d'un noir un peu brillant; finement et médiocrement pubescent. Le $6^{c}$ segment obtusément tronqué au sommet.

Dessous du corps ass z fortement, assez densement et subaspèrement ponctué; d'un noir brillant; légèrement pubescent. Dessous de la têté plus 
lisse, éparsement ponctué. Métusternum subdéprimé. Ventre convexe, éparsement sétosellé.

Pieds médiocres, aspèrement ponctués, à pubescence blonde; d'un roux subtestacé, avec les hanches intermédiaires et postérieures d'un noir de poix. Cuisses postérieures suballongées. Tibias antérieurs simplement pubescents ou seulement avec 1 ou 2 épines peu distinctes, en dessous; avec la pubescence plus serrée et plus brillante sur leurs tranches externe et interne, ainsi qu'au dessous des cuisses antérieures.

Patrie. Cette espèce, qui habite le nord de l'Italie et le midi de l'Autriche, est indiquée de France dans quelques catalogues récents.

OBs. Sa couleur bleuatre la distingue suffisamment de ses congénères.

Peut-être doit-on lui rapporter le Staph. morsitans de Rossi (Faun. Etr. I, 249, 614; Ed. Hellw. I, 308, 614)?

\section{DEUXIÈME RAMEAU}

PHILONTHATES

Caractères. Corps plus ou moins ponctué et pubescent sur les élytres et l'abdomen, le plus souvent lisse et glabre sur la tête et le prothorax. Tête grosse, subcarrée ou suborbiculaire, parfois suboblongue ou subovalaire, offrant généralement, entre les yeux, 4 pores sétifères transversalement disposés (1). Labre très-court, entaillé dans son milieu, membraneux ou submembraneux sur ses bords (2). Le $2^{\mathrm{e}}$ article des antennes normal, non renflé, non ou à peine plus épais que le suivant. Prothorax subtransverse, subcarré ou oblong, souvent subatténué en avant. Mésosternum triangulaire, le plus souvent avec une arête transversale arquée ou angulée, plus ou moins accusée. Métasternum offrant entre les hanches postérieures un lobe saillant, profondément incisé, explané ou subhorizontal : celles-ci légèrement écartées à leur base. Opercules prothoraciques nuls.

OBs. Ce rameau, qui renferme des espèces à prothorax presque toujours

(1) Les externes sont situés vers ou contre le bord interne même des yeux, les autres sur le front, ordinairement plus distants entre eux que des premiers.

(2) La languette, peu appréciable, est le plus souvent arrondie.

BR. 
lisse et glabre, peut se partager en plusieurs genres bien variés, et dont nous allons essayer d'esquisser les différences, dans le tableau suivant :

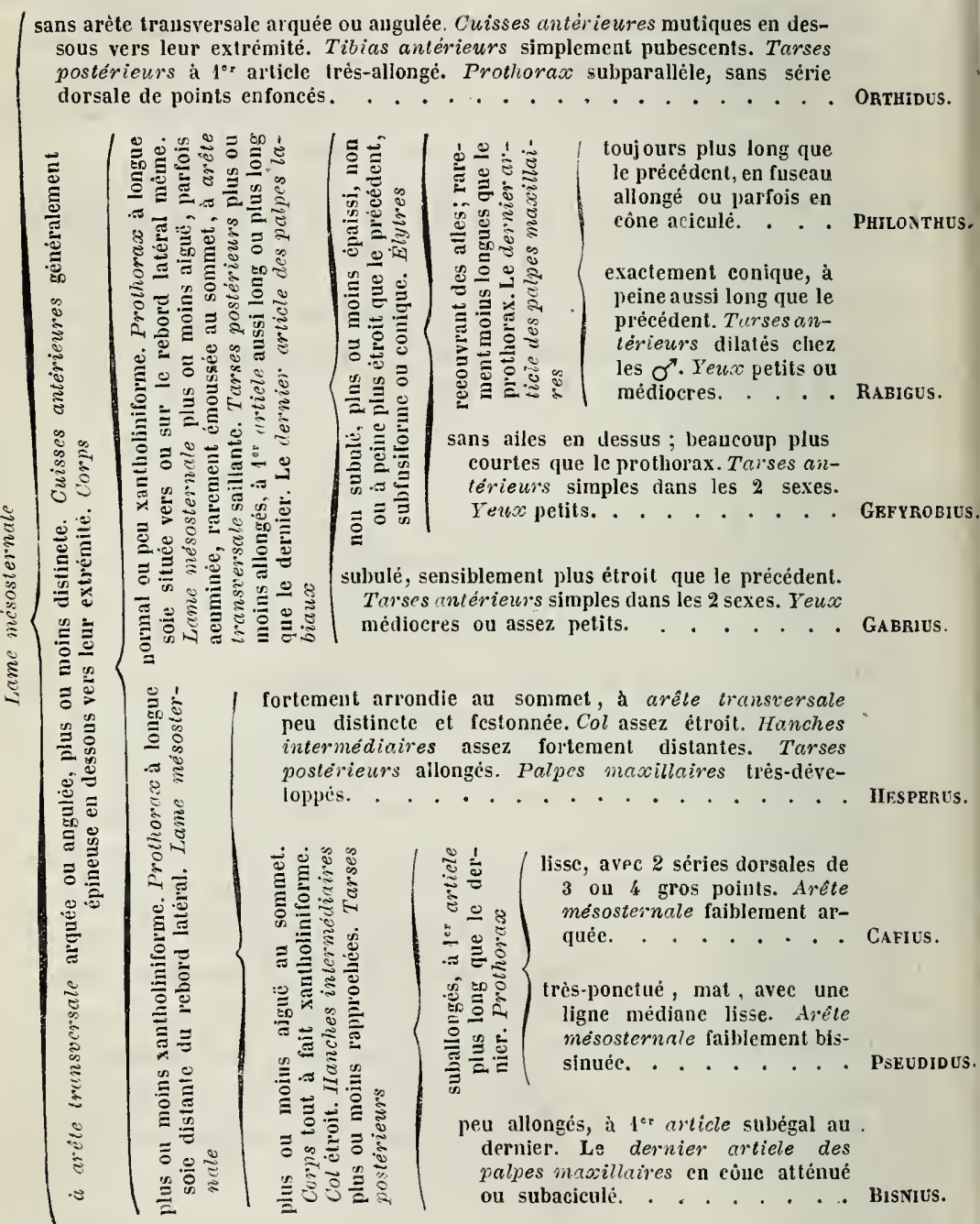


Genre Orthidus, Othide, Mulsant et Rey.

Élymologie : opfos, droite; siòos, forme.

CARACtĖREs. Corps allongé, subparallèle, subdéprimé, ailé, légèrement pubescent, avec la tête et le prothorax glabres tt lisses.

Téte grande, saillante, suborbiculaire; portée ś ur un col court, assez étroit, beancoup moins large que le vertex. Tempes à peine rebordées en avant sır les côtés, fortement contiguës en dessous sur la majeure partic de leur longueur. Épistome rebordé à son bord antérieur, subsinué dans le milieu de celui-ci. Labre très-conrt, bilobé. Mandibules saillantes, falciformes, acérées, finement sillonnées en dessus vers leur base, fortrement dentées en dedans vers leur milieu (1), croisées au repos. Palpes maxillaires assez développés, à $L^{\mathrm{e}}$ article court : le $2^{\mathrm{e}}$ suballongé, cu massue subarquée : le $3^{e}$ plus court, obconique : le dernier à peine plus long que le $3^{\circ}$, subfusiforme, mousse ou subtron flé au boul. Palpes labiaux assez courts, à $1^{\mathrm{er}}$ article oblong, subcylindrique : le $2^{\mathrm{e}}$ un peu plus long : le dernier sensiblement plus long que le $2^{\mathrm{e}}$, à peine en mas sue. Menton transverse, träpéziforme, plus étroit eil avant, subarrondi an sommet, corné à sa base, membraneux dans sa partie antérieure.

Yeux médiocres, peu saillants, subovales, obliques, séparés du con par un intervalle aussi long ou à peine plus long que leur plus grand diamètre.

Antennes peu allongées, subfiliformes ou à peine épaissies; à $L^{e_{r}}$ article en massue allongée, grêle et subarquée : le $3^{\mathrm{e}}$ plus long que le $2^{\circ}$ : le; suivants graduellement plus courts, non ou peu contigus, avec le pénul tième subtransverse : le dernier courr, subéchancré au bout.

Prothorax en carré suboblong, subparallèle, moins large que les élytres; tronqué au sommet, à angles antérieurs peu saillants; arrondi à sa base ; finement rebordé sur celle-ci et sur les côtés; à rebord latéral subsinueusement infléchi d'arrière en avant (2). Repli large, incliné, visible vu de côté, sans opercule prothoracique.

(1) Cette dent, assez grẻle, est obliquement prolongée en avant, subcylindrique tt tronquée au bout.

(2) La longue soie latérale, située un peu tin avant, est légèrement ścartée du rebord. 
Écusson grand, ogival.

Elytres subcarrées, simultanément subéchancrées à leur bord apical; subarrondies à leur angle postéro-externe; finement rebordées sur la suture. Repli médiocre, subvertical. Épaules effacées.

Prosternum assez peu développé au devant des hanches antérieures, formant entre celles-ci un angle prononcé, subaigu, relevé sur sa ligne médiane en carène obtuse. Mésosternum à lame médiane triangulaire, presque plane, non traversée par une arête arquée ou angulée (1), sinueusement rétrécie en pointe acérée et prolongée jusqu'au milieu des hanches intermédiaires. Médiépisternums très-grands, séparés du mésosternum par une suture transversale très-distincte. Médiépimères étroites, rétrécies d'avant en arrière. Métasternum court, assez fortement échancré au devant des hanches postérieures, prolongé entre celles-ci en un lobe prononcé, corné, presque lisse, subhorizontal et profondénent incisé; avancé entre les: intermédiaires en angle prononcé et assez aigu. Postépisternums trèsétroits, linéaires. Postépimères petites, triangulaires.

Abdomen allongé, subparallèle, fortement rebordé sur les côtés, à $2^{\text {c }}$ segment basilaire souvent découvert, lisse sur le dos : les suivants subégaux : le $5^{\mathrm{e}}$ un peu plus grand: le $6^{\mathrm{e}}$ plus ou moins saillant, rétractile : celui de l'armure enfoui, émettant 3 appendices, dont l'intermémédiaire plus court. Ventre un peu relevé en faite à sa base, à $2^{\mathrm{e}}$ arceau basılaire distinct, prolongé en angle dans le milieu de son bord postérieur : le $1^{\text {er }}$ plus grand sur les côtés que les suivants : le $5^{\mathrm{e}}$ à peine plus léveloppé que les précédents : le $6^{\mathrm{e}}$ plus ou moins saillant, rétractile.

Hanches antérieures grandes, de la longueur des cuisses, très-saillantes, couiques, contiguës au sommet (2). Les intermédiaires un peu moindres, pcu saillantes, subovales, rapprochées mais non contiguës dans leur nilieu. Les postérieures. médiocres, légèrement ècartées à leur base, divergentes au sommet, parées en dessous, vers celui-ci, de 1 ou 2 épines; á lame supérieure en cône court et mousse, subétranglé vers son premier tiers; à lame inférieure nulle ou enfouie.

Pieds peu allongés, peu robustes. Trochanters antérieurs petits, cunéi-

(1) Elle est bordée sur les côtés, surtout en arrière, de gros points enfoncés sétipères.

(2) Les hanches antérieures offrent à leur base, au devant de leur insertion, un petit opercule subcorné, plus ou moins distinct clez les Philonthates, assez apparent chez les Anodus, Tasgius et Pseudocypus, peu visible ou rudimentaire chez les prewiers Staphylinates. 
formes; les intermédiaires et postérieurs plus grands : ceux-là subcunéiformes, ceux-ci ovales-oblongs. Cuisses subcomprimées, subatténuées vers leur extrémité; les antérieur'es subépaissies dans leur milieu, non épineuses en dessous vers leur sommet. Tibias subélargis de la base au sommet, fortement épineux surtout en dehors, munis au bout de l? tranche inférieure de 2 éperons grêles, dont l'interne plus long; les antérieurs plus courts, simplement pubescents ou avec 2 petites épines al bout de leur tranche supérieure, et les éperons courts. Tarses antérieurs courts, à 4 premiers articles déprimés, fortement et subégalement dilatés dans les 2 sexes; les intermédiaires et postérieurs allongés, à peiw: atténués vers leur extrémité, à $\mathbf{1}^{{ }^{\mathrm{e}} \mathrm{r}}$ article très-allongé, au moins aussi long que les 3 suivants réunis : les $2^{\mathrm{e}}$ à $4^{\mathrm{e}}$ triangulaires, graduellement plu: courts : le dernier en massue, subégal aux 2 précédents réunis. Ongles grêles, arqués.

OBs. La seule espèce de ce genre est médiocrement agile. Elle vit sous les débris végétaux, au bord des eaux saumâtres.

OBs. Cette conpe générique est bien tranchée. Elle se distingue de toutes les autres du même rameau, par son mésosternum sans arête transversalt?, par ses cuisses toutes inermes en dessous, par ses tibias antérieurs simplement pubescents, par les 4 premiers articles des tarses antérieurs fortement et presque également dilatés dans les 2 sexes, et par le $2^{\text {e }}$ segment basilaire du ventre angulé dans le milieu de son bord postérieur. De plus, l'épistome est subsinué antérieurement; le prothorax est subparallèle, ;ans séries dorsales de points enfoncés. Les tempes commencent à présenter en avant un rudiment de rebord latéral obsolète qui disparaì somplétement derrière les yeux, etc.

Ce genre lie les Philonthates aux Staphylinates.

\section{Drthidus cribratus, ERICHSON.}

Allongé, subparallèle, subdéprimé, éparsement pubescent, d'un noir rillant, avec l'extrémité des antennes ferrugineuse et les pieds brunâtres. rète et prothorax d'un noir bronzé luisant, lisse et glabre : celui-ci subblong, sans série dorsale de points enfoncés. Élytres profondément, bdomen assez finement ponctués.

$\sigma^{*}$ Le 6e arcean ventral assen fi,rtement et subogivalement sinué dans 
la milieu de son bord apical, avec le fond du sinus bordé d'une légère membrane lisse, formant gouttière. Le $5^{\mathrm{e}}$ à peine et subangulairement sinué dans le milieu de son bord postérieur.

$q$ Le $6^{\text {e }}$ arceau ventral subsinueusement tronqué, le $5^{\mathrm{e}}$ presque simphe, à leur bord apical.

Philonthus cribratus, Erichson, Gen. et Spec. Staph. 431, 4.- Fairmaire et Laboul bène, Faun. Ent. Fr. I, 514, 4. - Redtenbacher, Faun. Austr. 3e éd. 208. C'afius cribratus, FaUvel, Faun. Gallo-Rhén. III, 422, 1.

$$
\text { Long., } 0^{\mathrm{m}}, 011 \text { (5 1.); - larg., } 0^{\mathrm{m}}, 0022(1 \mathrm{l} .) \text {. }
$$

Corps allongé, subparallèle, subdéprimé, d'un noir brillant, bronzé, li-se et luisant sur la tête et le prothorax ; revêlu sur les élytres et l'abdomen d'une fine pubescence grisâtre et peu serrée.

T'ête suborbiculaire, environ de la largeur du prothorax, lisse et glabre, iparsement sétosellée sur les côtés, d'un noir bronzé très-brillant. Front tiès-large, à peine convexe, avec 4 pores sétifères transversalement lli iposés entre les yeux. Cou presque lisse, glabre, d'un noir bronzé irrillant. Épistome subsinué à son bord antérieur. Labre fortenent sétosellé en avant, Mandibules d'un noir de poix. Palpes brunâtres, avec le $1^{\text {er }}$ et le dernier article des maxillaires parfois plus clairs.

Yeux médiocres, obscurs, à taches grisâtres.

Antennes moins longues que la tête et le prothorax réunis; subfiliformes ou à peine épaissies; légèrement pubescentes; éparsement pilosellées ver's leur base; noires, avec leur extrémité graduellement moins foncée ou firrugineuse; à $1^{\text {er }}$ article allongé, en massue grêle et subarquée: les $2^{\mathrm{e}}$ rt $3^{\mathrm{e}}$ obconiques : le $2^{\mathrm{e}}$ oblong : le $3^{\mathrm{e}}$ suballongé, plus long que le $2^{\circ}$ : les s uivants graduellement moins longs, subobconiques : les $4^{e}$ à $7^{\mathrm{e}}$ suboblongs: $l_{\text {es }} 8^{\text {e et }} 9^{\mathrm{e}}$ aussi longs ou presque aussi longs que larges : le $10^{\mathrm{e}}$, seul, subtransverse, vu de côté : le dernier court, obliquement tronqué ou subéchancré au bout, subacuminé inférieurement.

Prothorax en carré suboblong; moins large que les élytres; bissinueusement tronqué au sommet; à angles antérieur's presque droits mais subarrondis; subparallèle sur ses côtés; arrondi à sa base, avec les angles postérieur's obtus ; subconvexe; lisse et glabre, avec quelques pores sétifères vers le bord antérieur, le long du rebord latéral et dans l'ouverture des angles antérieurs ; d'un noir bronzé brillant. Repli noir, glabre, lisse. 
Écusson d'un noir assez brillant, rugueusement ponctué et pubescent dans sa partie antérieure.

Élytres subcarrées, à peine plus longues que le prothorax; subdéprimées ; assez densement et profondément ponctuees; d'un noir assez bril ant, à peine métallique, avec une pubescence blonde, soyeuse et peu serrée, des cils plus pâles au bord apical, et 2 ou 3 soies obscures et redressées sur les côtés. Épaules effacées.

Abdomen allongé, moins large que les élytres; subparallèle ou à peine arqué sur les côtés; assez convexe sur le dos; éparsement sétosellé et à pores sétifères bien marqués; assez finement el assez densement ponctué; d'un noir brillant, avec une fine pubscence grisâtre et peu serrée. Le $6^{\mathrm{e}}$ segment subtronqué au sommet.

Dessous du corps assez densement et subaspèrement ponctué, d'un noir brillant, à pubescence blonde et assez serrée. Dessous de la tête presque entièrement lisse, glabre ou à peine pubescent et sur les côtés seulement. Jétasternum subdéprimé, subsillonné sur sa ligne médiane. Ventre convexe, un peu subélevé en faîte à sa base, éparsement sétosellé, avec les pores sétifères bien marqués.

Pieds peu allongés, aspèrement ponctués, à pubescence blonde; d'un noir de poix, avec les tarses et parfois les tibias un peu moins foncés. Cuisses postérieures assez grêles. Tibits antérieur's simplement pubescents ou seulement avec 2 courtes épines au sommet de leur tranche supérieure, et les éperons inférieur peu distincts. Turses postérieurs à $1^{\text {er }}$ article beaucoup plus long que le dernier.

P.trriz. Cette espèce est commune, sur presque tout le littoral de la Iéditerranée, sous les pierres et les débris végétaux, au bord des eaux saumâtres. Elle se trouve aussi sur les côtes do l'Océan, depuis la Bretagñe jusqu'à l'Espagne.

Obs. Elle est remarquable par sa forme subparallèle.

Accidentellement, le prothorax, ontre les pores sétifêres, présente, sur les côtés de son disque, 1 ou 2 gros points enfoncés obsolètes ou impressions ponciformes (1).

(1) Outre les 4 pores sétifères du front, la tête présente en arrière, de chaque côté, sur chaque tempe, un très-gros pore sétifère, situé loin des yeux; 2 autres moindres, subcontigus ou conligus au bord postéro-interne de l'œil; 2 autres transversalement rapprochés, dont l'externe plus gros, de chaque côté du vertex.

Le prothorax, outre les pores de sa surface, est paré, le long des cútés, d'une série 


\section{Genre Philonthus, Philonthe, Curtis.}

Curtis. Brit. Ent. XIII, pl.610. 1825.

Étymologie :

Caractères. Corps plus ou moins allongé, subdéprimé, ailé, légèrement pubescent, avec la tête et le prothorax glabres et presqué lisses (1).

Tête plus ou moins grande, transverse, carrée, suborbiculaire ou ovalaire; portée sur un col court, sensiblement moins large que le vertex. Tempes non visiblement rebordées sur les côtés. Épistome souvent submembraneux, tronqué à son bord antérieur. Labre court, bilobé. Mandibules saillantes, assez robustes, subfalciformes, acérées, plus ou moins sillonnées en dehors vers leur base, dentées intérieurement vers leur milieu, croisées au repos. Palpes maxillaires assez développés, à $1^{\text {er }}$ article court mais bien apparent: le $2^{e}$ suballongé, en massue plus ou moins arquée : le $3^{e}$ ardinairement plus court, obconique le dernier généralement plus long et parfois plus grêle que le ${ }^{3 e}$, plus ou moins. allongé, subfnsiforme ou en cône atténué, souvent mousse au bout. Palpes labiaux médiocres, de 3 articles graduellement plus courts : le dernier subfusiforme ou en cône atténué, parfois beaucoup. plus long que le $2^{2}$, rarement subtronqué au bout. Menton grand, trapéziforme, plus ou moins rétréci et membraneux en avant, subtronqué au sommet.

Yeux médiocres ou assez grands, séparés du prothorax par un intervalle plus ou moins grand.

Antennes plus ou moins allongées, ordinairement peu épaissies; à $1^{\text {er }}$ arlicle en massue allongée et subarquée : le $3^{e}$ généralement plus long que le $2^{\mathrm{e}}$ : les suivants graduellement plus courts, non uu peu contigus : le dernier plus ou moins ovalaire, obliquement tronqué ou subéchancré au bout.

Prothorax carré, transverse ou rarement oblong; le plus souvent moins large que les élytres, quelquefois rétréci en avant; tronqué an sommet; à angles antérieurs infléchis et plus ou moins arrondis, et les postérieurs

de points enfoncés, avec celui des angles postérieurs plus fort et sétifere, et un autre semblable de chaque côté du bord antérieur.

(1) Quelquefois la tète ot le prothorax sont parsemés de quelques gros points enfoncés, mais la texture foncière est généralement lisse et glabre. 
obtus; subarrondi à sa base; finement rebordé sur celle-ci et sur les côtés ; à rebord latéral infléchi d'arrière en avant (1). Repli large, incliné: visible vu de côté, sans opercule prothoracique.

Écusson grand, ogival ou triangulaire.

Élytres transverses; carrées ou suboblongues; souvent simultanément subéchancrées à leur bord apical ; à peine arrondies ou presque reclangulaires à leur angle postéro-externe; finement rebordées sur la suture. Repli assez étroit, subvertical. Épaules peu saillantes.

Prosternum peu développé au devant des hanches antérieures, formant entre celles-ci un angle plus ou moins ouvert, à disque élevé, à pointe généralement mousse. Mésosternum à lame médiane triangulaire, plus ou moins prolongée, plus ou moins aiguë, parfois acuminée, rarement émoussée au sommet, traversée par une arête plus ou moins saillante, arquée on angulée(2). Médiépisternums très-grands, séparés du mésosternum par une suture distincte. Médiépimères assez étroites, allongées, parfois subrétrécies dans leur milieu. Jétasternum assez grand, fortement échancré au devant des hanches postérieures, prolongé entre celles-ci en un lobe prononcé, corné, explané, subhorizontal, incisé; avancé entre les intermédiaires en angle plus ou moins obtus et arrondi, peu saillant, séparé de l'intermède par une fine suture : celui-ci lanciforme on en dos d'âne. Postépistermums assez étroits, subparallèles. Postépimères grandes, triangulaires.

Abdomen plus ou moins allongé, subparallèle ou subatténué en arrière, fortement rebordé sur les côtés; à $2^{\mathrm{e}}$ segment basilaire parfois découvert : les suivants subégaux : les 3 premiers souvent avec un repli basilaire sensible : le $6^{\mathrm{e}}$ plus ou moins saillant, rétractile : celui de l'armure enfoui, émettant généralement 4 appendices ciliés, dont les intermédiaires plıs petits. Ventre à arceaux subégaux : le $b^{\ominus}$ plus ou moins saillant, rétractile.

Hanches antérieures grandes, de la longueur des cuisses, très-saillantes, coniques, contiguës au sommet. Les intermédiaires un peu moindres, peu saillantes, ovales-oblongues, obliquement disposées, rapprochées ou peu distantes. Les postérieures médiocres, légèrement écartées à leur base, divergentes au sommet, parées en dessous à celui-ci de 2 ou 3 épines; à lame supérieure en cône inousse, étringlé vers son milieu; à lame inférienre nulle ou enfouie:

(1) Ce rebord est infléchi d’une manière sinuée, sauf quelques rares exceptions. La longue soie latẻrale est située rers ou sur le rebord uneme.

(2) La partie du disque située au devant de cette arête est souvent déclive. 
Pieds peu ou médiocrement allongés, peu robustes. Trochanters antérieurs et intermédiaires petits, cunéiformes : les antérieurs assez grands, ovales-oblongs. Cuisses plus ou moins comprimées, plus ou moins atténuées vers leur extrémité; les antérieures plus ou moins épineuses en dessous vers leur sommet. Tibias subélargis de la base au sommet; plus ou moins épineux, munis au bout de leur tranche inférieure de 2 éperons assez développés, grêles, dont l'interne plus long; les antérieurs plus courts, parfois simplement pubescents sur leur tranche externe. Tarses antérieurs courts, à 4 premiers articles subégaux, triangulaires ou cordiformes, les 3 premiers souvent dilatés : les intermédiaires et postérieurs allongés, à peine atténués vers leur extrémité, à $1^{\text {er }}$ article plus ou moins allongé, aussi long ou plus long que le dernier (1) : les $2^{\mathrm{e}}$ à $4^{\mathrm{e}}$ oblongs ou suboblongs, graduellement plus courts : le dernier en massue allongée. Ongles grêles, arqués.

Ors. Les espèces de ce genre nombreux, de taille diverse, ont des mours et des habitudes variées.

Elles se reconnaissent à leur tête et prothorax luisants (2).

Tout varie dans le genre Philonthus, même jusqu'aux organes dont on pourrait le plus tirer parti pour une subdivision, tels que les palpes et les anlennes, la tête et le prothorax, les tibias et les tarses antérieurs, l'écartement des hanches intermédiaires, les tarses postérieurs, et surtout la lame mésosternale qui est rarement la même dans plusieurs espèces de suite. Nous nous servirons donc, pour distribuer les espèces, de la méthode d'Erichson, c'est-à-dire du nombre de points des séries dorsales du prothorax, en lui assujétissant les modifications tirées d'autre part.

(1) Rien n'est plus variable, dans ses proportions, que le $1^{\text {er }}$ article des tarses postérieurs, auquel on a accordé trop d'importance. Il est le plus souvent beaucoup, d'autres fois sensiblement, rarement à peine plus long que le dernier; et l'on peut. dire qu'il ne lui est subégal que dans un nombre restreint d'espèces, telles que : umbratilis, fuscus, ventralis, quisquiliarius, punctus, dimitiatipennis et quelques antres. Bien entendu, nous faisons abstraction des ongles qui, mobiles et articulés, sont susceptibles de s'étendre ou de s'infléchir.

(2) Outre les points enfoncés normaux du front, les plus constants sont : 1 sur chaque tempe, 1 ou 2 derrière le bord postéro-interne de chaque oil; 1 de chaque côté du vertex.

Quant au prothorax, il présente, outre les points du disque et le gros pore sétifere latéral, une série de points sur le rebord latéral mème, une autre de chaque côté des bords antérieur et postérieur. 
Iro SECTION. - Séries dorsales du prolhorax nulies ou avec le seul point antérieur submarginal.

OBs. Dans celte section, le dernier article des palpes maxillaires est pilıs grêle et sensiblement plus long que le précédent, allongé, fusiforme, mousse au bout. Le dernier article des palpes labianx est à peine moins cpais mais beancoup plus long que le $2^{c}$, subtronqué au bout. La pointe misosternale est très-aiguë, souvent brusquement rétrécie ou submucronée, et l'arête transversale, fortement arquée en arrière, descend jusqu'au milieu. Los hanches intermédiaires sont assez sensiblement distantes, et les tibias antérieurs fortement épineux. Le $1^{\text {er }}$ article des tarses postérieurs.est plus long que le dernier. La tête est plus grande chez los $\sigma$.

Cette section ne comprend que a espèces, dont voici les différences :

a Tibias anléricur's subarqués. Téte et prothorax d'un noir bronzé. Tête suborbiculaire, au moins aussi large que le prothorax chez les $\sigma^{*}$. Abdomen assez densement ponctué. . . . . . splendens.

at Tibias antérieurs droits ou presque droits. Têle et prothorax d'un vert bronzé. Le $4^{\mathrm{e}}$ arceau ventral des $\sigma^{\prime}$ jrolongé en lame sur le $5^{\mathrm{e}}$.

b Tête suborbiculaire, au moins aussi large que le prothorax chez les $\sigma^{\prime}$ : celui-ci non ou à peine rétréci en avant.'Elytres subéparsement ponctuées, abdomen peu densement. Tarses antérieurs plus $\left(\sigma^{\top}\right)$ ou moins $(Q)$ dilatés. . . . . " intermedius.

bb Tête subovalaire, moins large que le prothorax dans les 2 sexes: celui-ci subrétréci en avant. Élylres densement ponctuées, abdomen un peu moins. Tarses antérieurs légèrement et subégalement dilatés $\sigma$. . . . . . . . . Laninatus (1).

\section{Philonthus splendeng, Fabricius.}

Allongé, subdéprimé, éparsement pubescent, d'un noir brillant, avec les clytres d'un bronzé verdâtre. Tête et prothorax d'un noir bronzé luisant, lisse et glabre : celui-ci subcarré, sans série dorsale de points enfoncés.

(1) On ne pouvait éloigner le laminatus de l'intermedius, les $\subsetneq$ de ces 2 espèces ayant la plus grande affinité. 
Élytres assez fortement, abdomen plus finement, ponctués. Tibias antérieurs subarqués.

$\sigma^{\circ}$ Le $6^{e}$ arceau ventral profondément et très-aigument entaillé dans le milieu de son bord apical, avec l'entaille munie, en dedans, sur les côtés, d'une gouttière bien accusée. Le $5^{\text {e }}$ faiblement et subangulairement sinué dans le milieu de son bord postérieur, avec un espace lisse, au devant du sinus. Tarses antérieurs très-faiblement dilatés. Tête un peu plus large que le prothorax.

† Le $6^{\mathrm{e}}$ arceau ventral subarrondi à son sommet. Le $5^{\mathrm{e}}$ simple. Tarses antérieurs à peine dilatés. Tête aussi large ou à peine aussi large que le prothorax.

Staphylinus politus, LinnÉ, Syst. Nat. I, II, 683, (pars.)

Staphylinus splendens, Fabricius, Syst. Ent. I, II, 523, 19; - Syst. El. II, 594, 21.

- Gravenhorst. Mier. 16, 16; - Mon. 87, 82. - Latreille, Hist. Nat. Crust. et Ins. IX, 306, 23. - Gyllenhal, Ins. Suec. II, 297, 16. - Mannerheim, Brach. 25, 24. - Boisduval et LaCordaire, Faun. Ent. Par. I, 387, 3, pl. 2, fig. 16. Staphylinus sextus, SchaEfFer, Icon. I, pl. 30, f. 12.

Philonthus splendens, ERICHson, Col. IIarch. I, 447, 3; - Gen. et Spec. Staph. 429, 1. - Fairmaire et Laboulbène, Faun. Ent. Fr. I, 513, 1. - Kratutz, Ins. Deut. II, 569, 1.- Thомson, Skand. Col. II, 155, 1, 1860.- Fauvel, Faun. Gallo-Rhén. III, 439,1 .

$$
\text { Long., } 0^{\mathrm{m}}, 014 \text { (6 1/3 l.); - larg., } 0^{\mathrm{m}}, 0030 \text { (1 } 1 / 3 \text { l.). }
$$

Corps allongé, subdéprimé, d'un noir brillant, avec la tête et le prothorax un peu bronzės, luisants, lisses, et les élytres d'un bronzé un peu verdâtre; revêtu sur celles-ci et l'abdomen d'une fine pubescence d'un gris obscur et peu serrée.

Tête suborbiculaire ou en carré subtransverse et subarrondi; lisse et glabre sur son disque; éparsement et fortement ponctuée derrière les yeux; plus finement et plus densement de chaque côté au devant du cou ; éparsement sétosellée latẻralement; d'un noir bronzé luisant. Front trèslarge, peu convexe, avec 4 pores sétifères transversalement disposés entre les yeux, et une petite fossette obsolète entre les $2 \mathrm{du}$ milieu : ceux-ci plus écartés entre eux : les extérieurs situés un peu plus en avant, à une légère distance du bord interne des ycux. Cou d'un noir bronzé très-brillant, glabre, lisse, avec quelques points sur lés còtés. Existome avec un rebord 
subcorné, sensible. Labre fortement sétosellé en avant. Mandibules d'un noir de poix. Palpes brunâtres, avec le dernier article souvent moins foncé.

Yeux assez grands, obscurs, parfois lavés de gris.

Antennes peu allongées. plus longues que la tête; subfiliformes ou à peine épaissies; pubescentes et éparsement pilosellées vers leur base; entièrement obscures ; à $1^{\mathrm{er}}$ article en massue allongée, grèle et subarquée : les $2^{\mathrm{c}}$ et $3^{\mathrm{e}}$ obconiques : le $2^{\mathrm{e}}$ oblong : le $3^{\mathrm{e}}$ suballongé, plus long que le $2^{\mathrm{e}}$ : les suivants graduellement un peu plus courts, avec les intermédiaires (6-8) à peine plus épais : les $4^{\mathrm{e}}$ et $5^{\mathrm{e}}$ non, le $6^{\mathrm{e}}$ légèrement, les $7^{\mathrm{e}} \mathrm{a} 10$ o plus fortement transverses : le dernier ovalaire, subéchancré au bout.

Prothorax subcarré ou à peine transverse, subsinueusement subrétréc $\mathrm{i}$ en arrière dès après son milieu; un peu moins large que les élytres; Ironqué au sommet; à angles antérieurs presque droits mais arrondis; arı̣né à sa base, avec les angles postérieurs ubtus ; médiocrement convexe; lisse et glabre, avec quelques pores sétifères sur les côtés, le long du bord antérieur et dans l'ouverture des angles antérieurs, et la longue soie latérale située contre le rebord lui-même; d'un noir bronzé luisant. Repli d'un brun de poix, glabre, lisse.

Ecusson subaspérement ponctué, pubescent, noir.

Elytres subcarrées ou subtransverses, un peu plus longues que le prothorax; subdéprimées ; assez fortement, assez densement et subaspèrement ponctuées; d'un bronzé brillant et un peu verdâtre, avec une pubescence grisatre et peu serrée, et les côtés parés d'une série de soies obscures et horizontales, dont 2 ou 3 beaucoup plus longues. Épaules effacées. Ailes eutumées (1).

Abdomen plus ou moins allongẻ, un peu. moins large que les élytres; - ubparallèle ou parfois un peu atténué en arrière ; assez convexe sur le dus; éparsement sétosellé, avec quelques soies beancoup plus longues que les autres ; assez finement et assez densement ponctué ; d'un noir brillant; finement et subéparsement pubescent. Le $6^{\text {e }}$ segment à peine arrondi au sommet.

Dessous du corps assez densement et subaspèrement ponctué, d'un noir billant, à pubescence d'un gris obscur. Dessous de la tête plus lisse, éparsement ponctué et pubescent en arrière seulement. Métasternum à peine

(1) Yous négligerons souvent de parler des ailes, exceplé lorsqu'elles pourront curruborer les caractères spẻcifiques. 
convexe, très-finement canaliculé sur sa ligne médiane. Ventre convexe, éparsement sétosellé.

Pieds peu allongés, aspèrement ponctués; finement pubescent, noirs, avec les tarses souvent couleur de poix. Cuisses postérieures assez grêles, les antérieures fortement épineuses en dessous à leur sommet. Tibias antérieurs subarqués, fortement épineux en dehors, densement pubescents en dessous, avec cette pubescence d'un blond fauve, reparaissant parfois au dessous des cuisses (1). Tarses postérieurs à $1^{\mathrm{cr}}$ article un peu moins long que les 3 suivants réunis, sensiblement plus long que le dernier.

Patrie. Cette espèce est assez commune, dans les excréments et dans les champignons décomposés, dans presque toute la France, principalement dans les forêts ou lieux élevés. Elle s'envole rapidement.

Ons. Rarement, les élytres se montrent d'un bronzé un peu bleuâtre.

Quelques mâles, de taille moindre, ont la tête aussi large ou d̀ peine aussi large que le prothorax.

2. Philonthus intermedius, BOISDUVAL et LACORDAIRE.

Allongé, subdéprimé, éparsement pubescent, d'un noir brillant, avec la tête, le prothorax et les élytres d'un vert bronż. Tête et prothorax luisants, glabres et presque lisses : celui-ci subcarré. Élytres et abdomen assez finement et peu densement ponctués. Tibias antérieurs droits.

ơ Le 6 arceau ventral profondément sinué dans le milieu de son bo:d apical. Le $4^{\mathrm{e}}$ prolongé en forme de lame large, recouvrant la majeure partie du $4^{\mathrm{e}}$, qui est parfois sinué dans le milieu de son bord postérieur. Tarses antérieurs assez fortement dilatés, densement et longuement ciliés sur les côtés des 4 premiers articles. Téte aussi large ou un peu plus large que le prothorax.

₹ Les $4^{\mathrm{e}}$ à $6^{\mathrm{e}}$ arceaux du ventre simples. Tarses antérieurs médiocrement dilatés, légèrement ciliés sur les côtés des 4 premiers articles. Tête à peine moins large que le prothorax.

(1) Ce caractère d'avoir le dessous des tibias et souvent des cuisses garni d'une pubescence plus serrée et plus påle se rencontre d'une manière assez générate. Nous omettrons parfois d'en parler. 
Staphylinus intermedius, Bolsduval et Lacordalre, Faun. Ent. Par. I, 388, 4. Philonthus intermedius, Erichson, Col. March. I, 447, 2 ; - Gen. et Spec. Staph. 429, 2. - Redtenbacher, Faun. Aust. 700, 5.- Heer, Faun. Col. Helv. 1, 257, 2. - Farmaire et Laboulbène, Faun. Ent. Fr. I, 513, 2, - Kraatz, Ins. Deut. II, 570, 2. - Thomson. Skand. Col. II, 155, 3, 1860.- Fauvel, Faun. Galio-Rhén. III. $439,2$.

Philonthus laminalus, Nordmann, Symb. 74, 3 .

$$
\text { Long., } 0^{\mathrm{m}}, 009 \text { (4 2/3 1.); - larg., } 0^{\mathrm{m}}, 0024 \text { (1 1. forte). }
$$

Corps allongé: subdéprimé, d'un noir brillant, avec la tête, le prothorax et les élytres d'un vert bronzé ; revêtu sur celles-ci et l'abdomen d'une fine pubescence d'un gris obscur et peu serrée.

Tête suborbiculaire ou en carré subarrondi ; très-finement, obsolètement et éparsement pointillée sur son disque; éparsement et grossièremęn $n_{t}$ ponctuée derrière les yeux, plus finement, plus densement et subrugueusement le long du cou, excepté dans le milieu; éparsement sétosellée dans son pourtour, et mêne pubescente sur les côtés des tempes; d'un bronzé luisant et verdâtre. Front très-large, pen convexe, avec 4 pores sétifères transversalement disposés entre les yeux : les 2 intermédiaires plus écartés, les 2 extérieurs situés non ou à peine plus en avant, contre ou presque contre le bord interne des yeux. Cou d'un bronzé verdâtre et très-brillant, glabre, lisse avec quelques points sur les côtés. Épistome avec une marge antérieure subcornée, sensible. Labre fortement sétosellé en avant. Mandibules noires. Palpes d'un noir de poix, avec le dernier article des maxillaires parfois moins foncé.

Yeux assez grands, obscurs, striés de gris.

Antennes peu allongẻes, sensiblement plus longues que la tête; légèment épaissies ; pubescentes et éparsement pilosellées vers leur base; entièrement noires; à $1^{\mathrm{er}}$ article en massue allongée, grêle et subarquée : les $2^{\mathrm{e}}$ et $3^{\mathrm{e}}$ obconiques : le $3^{\mathrm{e}}$ suballongé, un peu plus long que le $2^{\mathrm{e}}$ : les suivants graduellement un per plus courts : les $4^{\mathrm{e}}$ et $5^{\mathrm{e}}$ non, le $6^{\mathrm{e}}$ légèrement, les $\tau^{\mathrm{e}} \mathrm{a} 10^{\circ}$ plus sensiblement transverses : le dernier assez court, échancré au boul.

Prothorax subcarré, un peu moins large que les élytres; tronqué au sonmet; à angles antérieurs presque droits mais arrondis; à peine arqué sur les côtés, vu de dessus, avec ceux-ci, vus latéralement, distinctement sinués en arrièr.: ; arrondi à sa basc, avec les angles postérieurs obtus; 
peu convexe; presque lisse ou à peine visiblement poinillé ; glabre, avec quelques pores sétifères sur les côtés, le long du bord antérieur, sur le rebord latéral, et 3 ou 4, écartés, dans l'ouverture des angles antérieurs, et la longue soie latérale située sur le bord même; d'un bronzé verdâtre et luisant. Repli noir, glabre, lisse.

Écusson ponctué, pubescent, d'un noir bronzé.

Élytres subtransverses, à peine plus longues que le prothorax; subdéprimées; assez finement et peu densement ponctuées; d'un bronzé verdâtre et brillant, éparsement pubescentes, avec 1 ou 2 longues soies sur les côtés, parmi d'autres plus courtes et plus fines. Épaules effacées. Ailes enfumées.

Abdomen suballongé, un peu moins large que les élytres; subparallèle ou parfois un peu atténué en arrière; assez convexe sur le dos ; distinctement sétosellé, avec des soies beaucoup plus longues que les autres; assez finement et peu densement ponctué ; d'un noir brillant et parfois submétallique; finement et éparsement pubescent. Le $6^{\mathrm{e}}$ segment subtronqué ou à peine arrondi au sonmet.

Dessous du corps subaspèrement ponctué, d'un noir brillant, finement pubescent. Dessous de la tête plus lisse, éparsement ponctué et pubescent en arrière seulement. Métasternum subdéprimé, éparsement sétosellé, finement canaliculé sur sa ligne médiane. Ventre convexe, éparsement sétosellé, avec quelques soies beaucoup plus longues; à ponctuation moins fine et un peu moins serrée que celle du métasternum.

Pieds peu allongés, aspèrement pointillés, finement pubescents, noirs. Cuisses postérieures un peu renflées avant leur milieu, les antérieures fortement épineuses en dessous à leur sommet inierne. Tibias antérieurs droits, fortement épineux en dehors, à pubescence serrée en dessous et tirant parfois sur le fauve. Tarses postéricurs à $1^{\text {er }}$ article un peu moins long que les 3 suivants réunis, sensiblement plus long que le dernier.

Patrie. Cette espèce se trouve de la même manière et dans les mêmes localités que la précédente.

OBs. Elle s'en distingue par une taille moindre, par la couleur verdâtre de la tête et du prothorax, par les tibias antérieurs plus droits, et surtout par le prolongement du $4^{\mathrm{c}}$ arceau ventral des $\sigma^{\prime}$ et la dilatation des tarses antérieurs dans ce même sexe, etc. 
Dans le $P h$. splendens l'arête transversale est très-saillante, prolongée jusqu'all milieu de la lame mésosternale en angle subarrondi. Dans le $p h$. intermedius, elle est plus légère, également prolongée mais plus largement arrondic au sommet. Dans l'un et dans l'autre, la pointe mésosternale est plus ou moins aiguë, parfois plus ou moins brusquement rétrécie, précédée d'une série arquée de pores sétitères.

Dans l'une et dans l'autre espèce, le dernier article des palpes maxillaires est subfusiforme, plus grêle et sensiblement plus long que le précédent.

Quelques mâles dégénérés ont la tête un peu moins large que le prothorax.

On rapporte au Ph. intermedius l'aeratus de Stephens(Ill. Brit. V, 228).

\section{Philonthus Iaminatus, CReutzer.}

Allongé, peu convexe, finement pubescent, d'un noir brillant, avec la tête et le prothorax d'un vert bronsé, et les élytres vertes ou bleuâtres. Tête et prothoraxluisants, glabres et presque lisses. Tête plus étroite que le prothorax; celui-ci subrétréci en avant. Élytres densement, abdomen moins densement ponctués. Tibias antérieurs presque droits.

$\sigma^{7}$ Le $6^{\mathrm{e}}$ arceau ventral profondément sinué dans lé milieu de son bord apical. Le $4^{\mathrm{e}}$ prolongé en furme de lame large, recouviant la majeure partie du $5^{\mathrm{e}}$, qui est faiblement et subangulairement simué dans le milieu de son bord postérieur.

\section{\& Les $4^{\mathrm{e}}$ à $6^{\mathrm{e}}$ arceaux du ventre simples.}

Staphylimus laminatus, Creutzer, Ent. Vers. 128,9, pl. 3, fig. 31. - Gravenhorst, Mier. 16, 17 ; - Mon. 86, 81. - Latreille, Hist. Nat. Crust. et Ins. IX, 307, 24. - Gyllenhdl, Ins. Suec. II, 298, 17. - Mannerheim, Brach., 25, 25. - Bolsdival et Lacordaire, Faun. Ent. Par. 1, 389, 5.

Staphylinus aeneus, MaRsham, Ent. Brit. 311, 37.

Philonthus viridanus, Nordmann, Symb. 74, 3.

Philonthus laminctus, Erichson, Col. March. 1, 446, 1. - Gen. et Spec. Staph. 430, 3. - Redtenbacher, Faun. Austr. 700, 5. - Heer, Faun. Col. Helv. I, 257, 1. - Fairmaire et Laboulbène, Faun. Ent. Fr. I, 514, 3. - Kratiz, Ins. Deut. II, 570, 3. - Thomson, Skand. Col. II, 155, 2, 1860. - FaUver, Faun. GalloRhén. III, 455, 22. 


$$
\text { Long., } 0^{\mathrm{m}}, 009 \text { (4 2/3 l.); - larg., } 0^{\mathrm{m}}, 0026 \text { (1 } 1 / 5 \text { l.). }
$$

Corps allongé, peu convexe, d'un noir brillant, avecla tête et le prothorax d'un vert bronzé, et les élytres verdâtres ou bleuâtres; revêtu sur celles-ci et l'abdomen d'une fine pubescence d'un gris obscur et pell serrée.

Tête suborbiculaire ou courtement ovalaire, plus étroite que le prothorax dans les 2 sexes; très-finement, obsolètement et à peine pointillée sur son disque ; fortement et inégalement ponctuée derrière les yeux ; éparsement et longuement sétosellée dans son pourtour, et même pubescente sur les côtés des tempes ; d'un vert bronzé luisant. Front très-large, faiblement convexe, avec les 2 pores sétifères intermédiaires plus écartés, et les 2 extérieurs situés à peine plus en avant, presque contre le bord interne des yeux. Cou d'un vert bronzé luisant, glabre, presque lisse. Épistome à bordure subcornée, sensible. Labre fortement sétosellé au sommet. Mandibules et palpes d'un noir de poix, avec l'extrémité de ceux-ci parfois moins foncée.

Yeux assez grands, obscurs ou livides.

Antennes suballongées, beaucoup plus longues que la tête; faiblement épaissies; pubescentes et éparsement pilosellées vers leur base; entièrement obscures; à $1^{\text {er }}$ article en massue assez allongée, assez grêle et subarquée : les $2^{\mathrm{e}}$ et $3^{\mathrm{e}}$ obconiques : le $3^{\mathrm{e}}$ suballongé, un peu plus long que le $2^{\mathrm{e}}$ : les suivants graduellement un peu plus courts : les $4^{\mathrm{e}}$ à $7^{\mathrm{c}}$ non, les $8^{\mathrm{e}}$ à $10^{\mathrm{e}}$ à peine transverses, vus de côté : le dernier ovalaire, échancré au sommet.

Prothorax en carré subrétréci en avant; un peu moins large en arrière que les élytres ; tronqué ou à peine échancré au sommet; à angles antérieurs presque droits mais subarrondis; subarqué sur les côtés, vu de dessus, avec ceux-ci, vus latéralcment, visiblement sinués en arrière ; arrondi à sa base, avec les angles postérieurs obtus; légèrement convexe; presque lisse; glabre, avec quelques pores sétifères épars, sur les côtés et dans l'ouverture des angles postéricurs, et la longue soie latérale située sur le rebord même; d'un vert bronzé luisant. Repli noir, glabre, lisse.

Écusson ponctué, pubescent, d'un noir submétallique.

Elytres subtransverses, à peine plus longues que le prothorax; subdéprimées ou à peine convexes; assez finement, densement et subaspère- 
ment ponctuées; d'un vert brillant plus ou moins foncé ou parfois bleuâtre ; modérément pubescentes, avec 1 ou 2 longues soies sur les côtés, parmi d'autres plus courtes et plus droites. Exaules effacées.

Abdomen suballongé, un peu moius large que les élytres: subparallèle ou un peu atténué en arrière; assez convexe sur le dos; éparsement et longuement sétosellé; un peu moins densement ponctué que les élytres ; d'un noir brillant; finement et peu densement pubescent. Le $6^{\mathrm{e}}$ segment subtronqué au sommet.

Dessous du corps subaspèrement ponctué, d'un noir brillant, finement pubescent. Dessous de la tête presque lisse ou un peu ponctué en arrière dans son milieu. Mésosternum à arête transversale saillante, arquée, situce un peu avant le milieu, à pointe presque aciculée, prolongée au dessis de l'intermède, au delà de la moitié des hanches intermédiaires. Métaster'num subdéprimé, éparsement sétosellé, finement canaliculé en arrière sur sa ligne médiane. Ventre convexe, éparsement sétosellé, à ponctuation un peu moins serrée que celle de la poitrine.

Pieds peu allongés, aspèrement pointillés, finement pubescents, noirs. Cuisses postérieures assez grêles, les antérieures fortement épineuses en dessous à leur sommet. Tibias antérieurs presque droits, fortement épineux en dehors, à pubescence assez serrée et blonde en dessous. Tarșes antérieurs légèrement et presque également dilatés dans les 2 sexes. Les postérieurs à $1^{\mathrm{er}}$ article subégal aux 3 suivants réunis, beaucoup plus long que le dernier.

Patrie. Cette espèce, peu commune, se prend dans les bouses et les crottins, surtout dans les lieuxélevés : les environs de Paris, la Normandie, l'Alsace, la Lorraine, la Bourgogne, le Bugey, les montagnes du Lyonnais, l'Auvergne, les Alpes, les Pyrénées, etc.

OBs. Elle est de la même taille et à peu près de la même couleur que le Ph. intermedius. Nais elle s'en distingue aisément par' sa tête plus petite, moins large que le prothorax dans les 2 sexes, avec celui-ci subatténué antérieurement. Les antennes sont un peu plus longues et plus grêle;, avec leurs pénultièmes articles un peu moins transverses. Les élytres, plus densement ponctuées, sont un peu plus larges en arrière, moins droites sur leurs côtés. Les tarses antérieurs sont moins dilatés, etc.

La structure des palpes est à peu près la même.

Parfois les antennes sont d'un roux brunâtre à leur sommet. 
II SECTION. - Séries dorsales du prolhorax de 3 points (1)

OBS. Les espèces decette section sont d'une taille moins forte que celles de la précédente. Le dernier article des palpes est proportionnellement moins allongé : celui des maxillaires est un peu moins grêle et un peu moins long relativement au précédent, en fuseau plus longuement atténué vers son extrémité, à partie renflée un peu plus près de la base. La lame mésosternale est déprimée, avec sa pointe moins aiguë et parfois subémoussée; son arête transversale est plus ou moins saillante, fortement arquée ou obtusément angulée, et descendue jusque vers le milieu. Les hanches intermédiaires sont rapprochées dans leur milieu. Les tibias antérieurs sont fortement épineux. Les tarses antérieurs sont fortement dilatés ch $\mathrm{z}$ les $\sigma$, assez fortement ou médiocrement chez les $q$. Les côtés $d u$ prothorax, vus laléralement, sont à peine sinués en arrière au devant des angles postérieurs. La tête est suborbiculaire ou courtement ovalaire.

Trois espèces, seulement, se rangent dans celte section. En voici les caractères :

a Elytres très-finem nt chagrinées, peu brillantes, éparsement et subégalement ponctuées.

aa Élytres presque lisses, brillantes, obsolètement et inégalement ponctuées, avee une série de points plus gros sur les eôtés. . . montivagus. aaa Ėlytres à fond lisse, grossièrement ponctuées, a vec 2 séries de points plus gros. . . . . . . . . . . . . . . NimBicola.

\section{Philonthus Iaevicollis, Boisduval et Lacordaire}

Allongé, subdéprimé, légèrement pubescent, d'un noir brillant, avec la tete. le prothorax et les élytres d'un bronzé obscure, et les tarses d'un roux de poix. Tète et prothorax brillants, glabres et à peine chagrinés. Tète un peu moins large que le prothorax: celui-ci à peine rétréci en avant. Elytres très-finement chagrinées, peu brillantes, éparsement et subégalement, abdomen assez finement et densement ponctué.

$\sigma$. Le $6^{\text {e }}$ arceau ventral fortenent et aigument entaillé dans le milieu

(1) Le point antérieur est soluvent, dans cette section comme dans les suivantes, silué plus ou moins en dehors des autres. Toutefois, conıme il n'est jamais sur le reburd antérieur mème dont il est parfois assez distant, il ne saurait appartenir à ceux de ta marge. Nous le considérons donc, ainsi qu'krichson, comme faisant partie des séıies dorsales. 
de son bord apical, avec les bords de l'entaille garnis en dedans d'une étroite gouttière subpellucide. Le $5^{\mathrm{e}}$ à peine sinué dans le milieu de son bord postérieur. Tarses antérieurs fortement et arcuément dilatés (1).

ㅇ Le $6^{\circ}$ arceau ventral subtronqué, le $5^{\mathrm{e}}$ simpli', à leur sommet. Tarses ariterieur's médiocrement dilatés (2).

Staphylinus laevicollis, Borsduval et Lacordare, Faun. Ent. Par. I, 397, 21.

Philonthus adscitus, Kiesenwetter, Stett. Ent. Zeit. IX, 322.

Philonthus laevicollis, Fairmaire et Larouldène, Faun. Ent. Fr. I, 514, 6.- KraAtz, Ins. Deut. II, 571, 4. - Seiduitz, Faun. Balt. 272. - FauveL, Faun. Gallo-Rhén. III, 458, 27.

$$
\text { Long., } 0^{\mathrm{m}}, 0082\left(33 / 4 \text { l.); - larg., } 0^{\mathrm{m}}, 0019\right. \text { (4/5 l.). }
$$

Corps allongé, subdéprimé, d'un noir brillant, avec la tête, le prothorax et les élytres d'un bronzé obscur : celles-ci moins brillantes, revêtues, ainsi que l'abdomen, d'une légère pubescence gris âtre.

Tête courtement ovalaire, un peu moins large que le prothorax, trèséparsement et longuement sétosellée; d'un bronzé obscur et brillant; à peine chagrinée, avec 3 points assez forts de chaque côté du disque, et quelques autres épars, en arrière et sur les tempes. Front très-large, faiblement convexe, marqué en avant de 4 pores sétifères assez gros, les externes situés tout près du bord interne des yeux, les intermédiaires un peu moindres, beaucoup plus écartés entre eux et plus en arrière. Cou glabre, à peine chagriné, d'un bronzé obscur et brillant. Epistome à bordure subcornée, sensible et étroitement subsinuée dans le inllieu de son bord antérieur. Labre noir, fortement sétosellé en avant. Mandibules et palpes d'un noir ou d'un brun de poix, avec la base de ces derniers souvent plus claire.

Yeux médiocres, obscurs, parfois tachés de livide.

Antennes suballongées, un peu moins longues que ia tête et le prothorax réunis; à peine épaissies; légèrement pubescentes ; épar'sement pilosellées vers leur base; noires, avec le $2^{\mathrm{e}}$ article souvent d'un roux de poix vers

(2: Il est bien entendu que le dernier article n'est jamais dilaté. Ici les 1 er et $3^{\text {e }}$ le sont un peu moins que le $2^{e}$, et le $4^{e}$ sensiblement noins que le $3^{e}$, de sorte que la dilatation de l'ensemble des articles dilatés se montre arquée en dehors. Ceux-ci, en outre, sont plus finemeut, plus lunguement et plus densement ciliés sur les côtés que

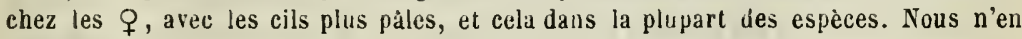
reparlerons pas.

(2) Les 3 premier's articles sulbégalement, le qe plus légèrement. 
son insertion; le $1^{\mathrm{er}}$ en massue allongée et subarquée : les $2^{\mathrm{e}}$ et $3^{\mathrm{e}}$ obconiques : le $3^{\mathrm{e}}$ suballongé, à peine plus long que le $2^{\mathrm{e}}$ : les suivants graduellement un peu plus courts et à peine plus épais, subobconiques : les $4^{\mathrm{e}}$ a $6^{\mathrm{e}}$ oblongs : le $7^{\mathrm{e}}$ à peine oblong : le $8^{\mathrm{e}}$ non, les $9^{\mathrm{e}}$ et $10^{\mathrm{e}}$ à peine transverses, vus de côté : le dernier subovalaire, subéchancré au bout et à peine acuminé inférieurement.

Prothorax subcarré, à peine rétréci en avant; à peine moins large en arrière que les élytres; tronqué au sommet, avec les angles antérieurs obtus et subarrondis ; légèrement arqué sur les côtés, vu de dessus, avec ceux-ci, vus latéralement, à peine sinués en arrière; subarrondi à sa base, avec les angles postérieurs obtus; faiblement convexe; très-éparsement sétosellé, avec la longue soie des côtés située sur le rebord latéral même; à peine ou excessivement finement chagriné, avec 2 séries dorsales composées de 3 points médiocres, subégalement distants; marqué de plus, outre ceux de la marge, de 5 points semblables, épars en avant, vers les côtés; entièrement d'un bronzé obscur et brillant. Repli noir, glabre, lisse.

Écusson éparsement ponctué et pubescent, d'un noir brillant et submélallique.

Élytres subtransver:es, à peine plus longues que le prothorax; subdéprimées; très-finement chagrinées et en outre éparsement ct subégalement ponctuées; d'un bronzé obscur et peu brillant; finement et subéparsement fubescentes, avec une longue soie redressée sur les côtés derrière les ipaules et une autre de chaque côté de l'écusson. Épaules effacées.

Abdomen suballongé, un peu moins large que les élytres; subparallèle ou à peine arqué sur les côtés; assez convexe sur le dos; éparsement sétosellé vers son sommet; assez finement et densement ponctué; d'un noir brillant, à pubescence plus fine et un peu plus serıée que celle des c̀lytres. Le $6^{\mathrm{e}}$ segment obtusément tronqué à son bord postérieur.

Dessous du corps subaspèrement ponctué, finement pubescent, d'un noir brillant, avec la marge apicale des arceaux du ventre souvent d'un brun té poix. Dessous de la tête éparsement ponctué et éparsement pubescent. Lame mésosternale distinctement ponctuée au devant de l'arête transversale, qui est saillante et obtusément angulée; à pointe subémoussée. Métasternum subdéprimé, finement canaliculé sur sa ligne médiane. Ventre convexe, éparsement et longuement sétosellé cn arrière.

Pieds médiocres, aspèrement ponctués, finement pubescents, d'un noir ou d'un brun de poix, avec les tarses plus ou moins roussâtres. Cuisses cintérieures fortement épineuses en dessous vers leur sommet. Tibias anté- 
rieurs fortement épineux. Tarses postérieurs à $1^{\mathrm{er}}$ article sensiblement plus long que le dernier', à peine aussi long que les 3 suivants réunis.

Patrie. Cette espèce est assez rare, parmi les mousses et sous les bouses sèches, dans les Alpes, au mont Pilat et autres points élevés de la France.

OBs. Elle est remarquable par son prothorax à séries de 3 points distants, et par ses élytres peu brillantes et très-finement chagrinées.

Parfois les tibias et les trochanters paraissent d'un roux de poix.

\section{Philonthus montivagus, HeER.}

Allongé, subdéprimé, légèrement pubescent, d'un noir brillant, avec la tête, le prothorax et les élytres d'un noir bronzé brillant, et les tarses d'un roux de poix. Tête et prothorax glabres et lisses. Tête un peu moins large que le prothorax: celui-ci à peine rétréci en avant. Élytres presque lisses, obsolètement et inégalement ponctuées, avec une série de points plus gros sur les côtés. Abdomen assez finement et assez densement ponctué.

$\sigma$ Le $6^{\text {c }}$ arceau ventral fortement et aigument entaillé dans le milieu de son bord apical, avec les bords de l'entaille garnis en dedans, d'une assez étroite gouttière subpellucide. Le $5^{\mathrm{e}}$ à peine et subangulairement sinué dans le milieu de son bord postérieur. Tarses fortement et subarcuément dilatés (1).

ㅇ Le $6^{\text {e }}$ arceau ventral subarrondi, le $5^{\mathrm{e}}$ simple, à leur sommet. Tarses cuntérieurs assez fortement dilatés.

Staphylinus nigrita, HEER, Mittheil. I, 75 .

Philonthus laevicollis, Erichsov, Gen. et Spec. Staph. 433, 8 ?

Philonthus montivagus, Heer, Faun. Col. Helv. I, 275,64. - Fairmatre et Laboulbène, Faun. Ent. Fr. I, 514, 5.- KraAtz, Ins. Deut. II, 572, 5.-Fauvel, Faun. Gallo-Rhén. III, 4357, 26.

$$
\text { Long., 0 }{ }^{\mathrm{m}}, 0077 \text { (3 1/2 l.); - larg., } 0^{\mathrm{m}}, 0012 \text { (1/2 l.). }
$$

Corps allongé, subdéprimé, d'un noir brillant, avec la tête, le prothorax et les élytres d'un noir bronzé également brillant; revêtu sur celles-ci et sur l'abdomen d'une fine pubescence grisâtre et peu serrée.

Tête suborbiculaire, un peu noins large que le prothorax; éparsement et longnement sétosellée; d'un noir bronzé brillant ou très-brillant; pres-

(1) Ici le $4^{\mathrm{e}}$ article est seulement un peu moins dilaté que le $3 \mathrm{e}$. 
que lisse, avec 2 points forts ou assez forts de chaque côté du disque et quelques autres épars derrière les yeux. Front très-large, subconvexe, marqué en avant de 4 pores sétifères médiocres, les externes situés tout près $d u$ bord interne des yeux, les intermćdiaires plus fins, un peu plus écartés entre eux et un peu plus en arrière. Cou glabre, presque lisse, d'un noir bronzé brillant. Épistome à bordure subcornée ou submembraneuse, érroite, à peine subsinuée dans le milieu de son bord antérieur. Labre d'un noir brillant, fortement sétosellé en avant. Murdibules et palpes d'un brun de poix, avec l'extrémité de ceux-ci souvent un peu roussâtre.

Yeux médiocres, obscur's.

Antennes suballongées, à peine moins longues que la tête et le prothorax réunis; à peine épaissies; légèrement pubescentes et éparsement pilosellées vers leur base; noires; à $1^{\mathrm{e}}$ article en massue allongée et subarquée : les $2^{\mathrm{e}}$ et $3^{\mathrm{e}}$ obconiqces : le $3^{\mathrm{e}}$ suballongé, à peine plus long que le $2^{\mathrm{e}}$ : les suivants graduellement un peu pius courts et à peine plus épais, subobconiques: les $4^{\mathrm{e}} \mathrm{a} 6^{\mathrm{e}}$ suboblongs, le $7^{\mathrm{e}}$ à peine oblong : le $8^{\mathrm{e}}$ non, les $9^{\mathrm{e}}$ et $10^{\mathrm{e}}$ subtransverses, vus de côté : le dernier subovalaire, subéchancré au bout et à peine acuminé inférieurement.

Prothorax subcarré, à peine rétréci en avan! ; un peu moins large en arrière que les élytres; tronqué au sommet, avec les angles antérieurs obtus et subarrondis; à peine arqué sur les côtés, vu de dessus, avec ceux-ci, vus latéralement, à peine sinués en arrière; subarrondi à $\leqslant n$ base, avec les angles postérieurs obtus; légèrement convexe; éparsement sétosellé, avec la longue soie des côtés située sur le rebord latéral même; presque lisse, avec 2 séries dorsales de 3 points médiocres et subégalement distants ; marqué de plus, outre ceux de la marge, de 3 ou 4 autres points semblables, épars, dans l'ouverture des angles antérieurs; entièrement d'un noir bronzé brillant ou très-brillant. Repli noir, glabre, lisse.

Écusson épàrsement ponctué et pubescent, d'un noir brillant.

Elytres subtransverses, à peire plus longues que le prothorax ; subdéprimées; lisses ou presque lisses, mais éparsement, obsolètement et inégalement ponctuées, avec les points intérieurs souvent effacés, it ure série longitudinale et irrégulière de points plus grossiers, sur les côtés; d'un noir bronzé brillant; finement et éparsement pubescentes, avec 1 soie redressée derrière les épaules et de chaque côté de l'écusson. Epaulis étroitement arrondies.

Abdomen assez allongé, un peu moins large que hs ćlytres; ì $p$ inc arq̣ué sur les côtés et subatténué en arrière; assez convexe sur le dus; 
assez fortement sétosellé; assez finement et assez densement ponctué ; d'un noir brillant; à pubescence plus longue et un peu plus serrée que celle des élytres. Le $6^{\mathbf{e}}$ segment à peine arrondi au sommet.

Dessous du corps subaspèrement ponctué, finement pubescent, d'un noir brillant, avec les intersections ventrales parfois moins foncées. Dessous de la tête presque lisse et presque glabre. Lame mésosternale presque lisse au devant de l'arête transversale, qui est assez saillante et arquée; à pointe très-aiguë. Métasternum subdéprimé, obsolètement canaliculé sur sa ligne médiane. Ventre convexe, éparsement et fortement sétosellé en arrière.

Pieds médiocres, aspèrement ponctués, finement pubescents, d'un noir ou d'un brun de poix, avec les tarses moins foncés et un peu plus roussâtres. Cuisses antérieures fortement épineuses en dessous vers leur sommet. Tibias antérieurs fortemtnt épineux, surtout en dehors. Tarses postérieurs à $1^{\mathrm{e}}$ article sensiblement plus long que le dernier, à peine aussi long que les 3 suivants réunis.

Patrie. Cette espèce, aussi rare que la précédente, se trouve sous les nousses et les feuilles tombées, dans les champignons, les bouses et le bois carié. Elle est exclusive aux lieux élevés : la Savoie, les Alpes, l’Auvergne, les Pyrénées, etc.

OBs. Bien voisine de la précédente, elle en est distincte par ses élytres plus brillantes, à fond plus lisse, plus obsolètement et plus irrégulièrerement ponctuées, avec 1 série de points plus gros sur les côtés. La taille est moindre. La tête, moins ovale, est plus lisse en dessous. L'abdomen est un peu moins densement ponctué. La lame mésosternale est plus lisse en avant, avec sa pointe plus aiguë, etc.

Les tibias et les trochanters sont parfois d'un roux de poix foncé.

On rapporte au montivagus le laevicollis d'Erichsolı. Cet auteur nous semble avoir eu en vue les 2 espèces à la fois. Car cette phrase : E/ytra... subtiliter alutacea » s'applique évidemment à l'espèce précéden:e.

Ici se placerait sans doute l'espèce suivante que nous n'ârons pas vue en nature, et dont nous donnons la descriplion d'après M. Fauvel :

\section{Philonthus nimbicola, Fauvel.}

FAuVeL, Faun. Gallo-Rhén. 1II. 437, 25, pl. v, fig. 17.

Voisin du montivagus; distinct par son corselet bien plus étroil, plus 
long; élytres plus brillantes, non chagrinées, à ponctuation 3 fois plus grosse, serrée comme chez la laevicollis, avec deux séries chacune de 3 ou 4 points plus gros sur le disque et un très-petit espace imponctué vers la suture; ponctuation de l'abdomen bien plus éparse, surtout vers le sommet : celui-ci à pubescence plus rare; $\sigma^{*} 6^{\mathrm{e}}$ segment simplement sinué; $7^{\mathrm{e}}$ à incision moins profonde, un peu moins large.

$$
\text { Long., } 6 \text { 1/2 à } 7 \text { 1/2 mill. }
$$

Comme montivagus ; juillet (TR).

Mont-Rosa, Macugnaga !

OBs. Sous un certain jour, le fond de la tête paraît très-obsolètement pointillé chez certains exemplaires.

III ${ }^{\bullet}$ SECTION. - Séries dorsales du prothorax de 4 points.

OBs. Cette section comprend des espèces variables pour la taille et la forme. Le dernier article des palpes est toujours plus long que le pénultième, plus ou moins fusiforme. Le dernier des maxillaires, ordinairement allongé et assez grêle, est rarement en fuseau atténué et à partie renflée plus près de la base que du sommet. La lame mésosternale varie quant à son arête transversale et sa pointe terminale. Les hanches intermédiaires sont médiocrement ou légèrement distantes, ou assez souvent rapprochées dans leur milieu. Les tarses antérieurs, généralement plus ou moins dilatés, sont parfois simples dans les 2 sexes. Le $1^{{ }^{\mathrm{e}_{r}}}$ article des tarses postérieurs est quelquefois sensiblement plus long, d'autres fois à peine ou non plus long que le dernier. Lá tête est transverse, suborbiculaire ou subovalaire, tantôt aussi large, tantôt moins large que le prothorax.

Cette section renferme un certain nombre d'espèces dont voici le tableau pour la première partie :

a Le $1^{\text {er }}$ article des tarses postérieurs sensiblement plus long que le dernier, subégal aux 3 suivants réunis.

b Tête transverse ou suborbiculaire, au moins aussi large que le prothorax chez les $\sigma^{\prime}$ : celui-ci non ou peu rétréci en avant.

c Elytres densement ponctuées. Hanches intermédiaires médiocrement distantes. Taille grande ou assez grande.

d Elytres rousses. Tarses antérieurs presque simples dans les

2 sexes. Prothorax sinué en arrière, vu de côtè. . . . Nitidus. 
dd Elytres bleues. Tarses antérieurs presque simples dans les 2 sexes. Prothorax non visiblement sinué en arrière, vu de côtè.

ddd Elytres plus ou moins bronzées. Prothorax sensiblement sinué en arrière, vu de côté.

e Repli basilaire des $2^{\mathrm{e}}$ ct $3^{\mathrm{e}}$ segments de l'abdomen en accolade. Antennes subépaissies, à pénultièmes articles $(7-10)$ transverses.

I Abdomen densement ponctué. Antennes unicolores. Tarses antérieurs fortement dilatés chez les $\sigma^{\circ}$. ff Abdomen subéparsement ponctué. Tarses antérieurs presque simples dans les 2 sexes.

g Tempes éparsement ponctuées. Antennes sensiblement épaissies, à dernier article ferrugineux. Prothorax subimpressionné sur ses cotés. Corps d'un bronzé obscur. . . . . . . . . . .

gg Tempes assez densement ponctućes. Antennes faiblement épaissies, unicolores. Prothorax non ou à peine impressionné sur ses cotés. Corps d'un bronzé assez clair. . . . . . . .

ee Repli basilaire des $2 \mathrm{e}$ et $3 \mathrm{e}$ segments de l'abdomen en ligne droite. Antennes unicolores. Prothorax à peine ou non impressionné sur les côtés. Tarses antérieurs presque simples dans les 2 sexes. Taille assez grande.

h Tempes assez densement et rugueusement ponctuées. Antennes à pénultièmes articles (7-10) visiblement transverses. Abdomen modérément et assez densement ponctué.

CYANIPENN IS.

AENEUS.

CARBONARIUS.

ADDENDUS.

TEMPORALIS.

hh Tempes éparsement ponctuées. Antennes à pénultièmes articles $(8-10)$ non ou à peine transverses. Abdomen éparsement ponctué.

TENUICORNIS.

cc Élytres éparsement ponctuées, d'un bronzé verdâtre ou bleų́ !se.

Hanehes intermédiaires assez rapprochées. Tarses antériexrs dilatés dans les 2 sexes. Taille moindre. . . . . . .

hb Téte subovalaire ou ovalaire, moins large que le prothorax dans les 2 sexes : celui-ci visiblement rétréci en avant.

i Pieds plus ou moins obscurs.

k Élytres bleuàtres, très-finement et densement ponctuées, mates. Palpes et pieds noirs. Taille assez grande. . .

kk Élytres bronzées, noires ou rousses.

1 Le $4^{\mathrm{e}}$ arceau ventral des $\sigma$ prolongé sur le 弓̆e. Tarses antérieurs légèrement dilatés dans les 2 sexes. Corps d'un bronzé assez clair.

Il Le $4^{\mathrm{e}}$ arccau ventral des $\sigma^{\prime}$ normal.

m Ėlytres finement chagrinées, d'un bronzé mat. Téte et prothorax plus clairs. Tarses antérieurs presque 
simples dans les 2 sexes. Palpes, tibias et tarses roussátres. . . . . . . . . . . .

DECORUS

$\mathrm{mm}$ Elytres plus ou moins brillantes, d'un bronzé obscur.

n Le ier article des antennes testacé en dessous.

Tarses antérieurs médiocrement dilatés chez les $\checkmark$. Élytres très-finement ponctuées. Taille assez grande.

nn Le $1^{\mathrm{er}}$ article des antennes concolore.

- Elytres très-densement ponctuées. Tarses antérieurs presque simples dans les 2 sexes. Taille assez grande. . . . . . . . . .

oo Élytres assez densement ponctuées, bronzées, parfois à disque rouge. Tarses antérieurs plus ( $\left.\sigma^{\prime}\right)$ ou moins ( $\$$ ) dilatés. Taille assez petite.

p Elytres d'un bronzé un peu verdâtre, parfois à disque rouge, de la longueur du prothorax. Pénultièmes articles des antennes (8-10) non transverses. . . . . . . . . . .

pp Élytres presque noires, à peine plus longues que le prothorax. Pénultièmes articles des antennes (8-10) faiblement transverses. . POLITUS.

LUCENS.

varius.

MELANARIUS.

000 Elytres éparsement ponctuées, ainsi que l'abdomen. Tarses antérieurs plus ( $\left.\sigma^{\top}\right)$ ou moins ( $(+)$ dilatés.

q Elytres dun noir submétallique, assez finement ponctuées. Taille assez petite. . . .

qq Élytres d'un noir de jais, finement ponctuées. Taille petite.

PYRENAEUS

FRIGIDUS.

ii Pieds testacés ou d'un roux testacé.

r Prothorax à marge latérale largement testacée. Élytres submétalliques, un peu plus longues que le prothorax. Tarses antérieurs dilatés $\sigma \circ$.
$\sigma r$ Prothorax concolore. Tarses antérieurs des $\sigma^{\circ}$ plus ou moins dilatés.

s Antennes suballongées, à base d'un roux testacé. Élytres plus courtes que le prothorax, bronzées ou d'un rouge de brique. Taille assez petile. . . . . . . . . .

ss Antemnes assez courtes, à base brunatre. Elytres de la lon. gueur du prothorax, d'un noir de poix. Taille petite.

MARGINATUS.

LEPIDUS.

ALBIPES.

\section{\%. Philonthes mitidug, Fabriclus.}

Allongé, subdéprimé, légèrement pubescent, d'un noir brillant, avec les élytre; rousses. Tête et prothorax glabres, lisses et luisants : celui-ci sub- 
transverse. Elytres assez finement et densement, abdomen assez finement et assez densement ponctués. Tar'ses antérieurs presque simples.

$\sigma^{*}$ Le $6^{e}$ arceau ventral assez fortement et angulairement entaillé dans le milieu de son bord apical, avec les bords de l'entaille garnis en dedans d'une étroite membrane pellucide. Le $5^{\mathrm{e}}$ à peine sinué dans le milieu de son bord postérieur. Tête en carré transverse, un peu plus large que le prothorax.

$\subsetneq$ Le $6^{\text {e }}$ arceau ventral subarrondi, le $5^{\text {e }}$ simple, à leur bord apical. Tête suborbiculaire, à peine aussi large que le prothorax.

Staphylinus nitidus, Fabricius, Mant. Ins. I, 220, 13; - Ent. Syst. I, II, 524, 24 ; - Syst. El. II, 596, 30. - Paykull, Mon. Staph. 40, 30. - Gyllenhal, Ins. Suec. II, 315, 31. - Mannerheim, Brach. 27, 42.

Staphylinus coenosus, Gravenhorst, Mon. 51, 15. - Boisduval et Lacordaire, Faun. Ent. Par. I, 386, 1.

Philonthus nitidus, Nordmann, Symb. 90, 52, - Erichson, Col. March. I, 448, 4; Gen. et Spec. Staph. 435, 13. - Redtenbacher. Faun. Austr. 700, 8. - Heer, Faun. Col. Helv. I, 258, 4. - Fairmaire et Laboul bène, Faun. Ent. Fr. I, 515, 9. - KraAtz, Ins. Deut. II, 576, 7. - Thomson, Skand. Col. II, 156, 5, 1860. Fauvel, Faun. Gallo-Rhén. III, 440, 3.

$$
\text { Long., 0m,0133 (6 l.); - larg., } 0^{\mathrm{m}}, 0029 \text { (1 1/3 l.). }
$$

Corps allongé, subdéprimé, d'un noir brillant, avec les élytres rousses; revêtu sur celles-ci et sur l'abdomen d'une légère pubescence blonde ou grisâtre et modérément serrée.

Tête plus ou moins large; éparsement sétosellée ; légèrement pubescente ct assez densement poncluée en arrière sur les côtés; d'un noir trèsbiillant (1). Front très-large, subconvexe, marqué latéralement de 3 ou 4 gros points encore plus forts que ceux des tempes et, entre les yeux, di 4 ; ores sétifères, gros et subtransversalement disposés, les intermédiaires néanmoins un peu plus en arrière, plus écartés entre eux. Cou glabre, presque lisse, d'un noir très-brillant. Epistome à bo rảure submembraneuse assez large, obscurément livide. Labre foriement sétosellé ell avant. Mandibules et palpes d'un noir de poix.

(1) Le fond, presque lisse, parait, à un très-fort grossissement, comme très-finemen chagriné. 
Yeux assez grands, subovales-oblongs, obscurs, lavés de gris sombre.

Antennes assez courtes, sensiblement moins longues que la tête et le prothorax réunis; visiblement épaissies; pubescentes et éparsement pilosellées vers leur base; noires; à $1^{\text {er }}$ article allongé en massue subarquée : les $2^{\mathrm{e}}$ et $3^{\mathrm{e}}$ obconiques : le $3^{\mathrm{e}}$ suballongé, un peu plus long que le $2^{\mathrm{e}}$ : les suivants graduellement un peu plus courts, suboconiques : le $4^{\mathrm{e}}$ non, le $5^{\mathrm{e}}$ à peine plus larges que longs : les $6^{\mathrm{e}}$ à $10^{\mathrm{e}}$ subégalement épaissis, légèrement transverses, avec les pénultièmes néanmoins un peu plus fortement : le dernier subovalaire, échancré au bout et subacuminé inférieurement.

Prothorax subtransverse; un peu moins large que les élytres; tronqué au sommet, avec les angles antérieurs infléchis, obtus et subarrondis; subarqué sur les côtés, vu de dessus, avec ceux-ci, vus latéralement, sinués en arrière ; médiocrement arrondi à sa base, avec les angles postérieurs obtus; subconvexe; éparsement sétosellé, avec la longue soie des côtés située contre le rebord latéral même; d'un noir luisant; presque lisse, avec deux séries dorsales composées de 4 points assez forts et subégalement distants; marqué de plus, outre ceux des marges antérieure et latérale, de 9 ou 10 autres points semblables et disposés sans ordre en avant sur les côtés. Repli d'un noir de poix, glabre, lisse.

Écusson assez densement ponctué, d'un noir assez brillant, à pubescence obscure.

Elytres transverses, un peu plus longues que le prothorax; subdépriprimées; assez finement et densement ponctuées; d'un roux brillant, avec une légère pubescence blonde et modérément serrée; éparsement sétosellées, avec 1 ou 2 soies plus longues sur les côtés. Épaules subarrondies.

Abdomen allongé, moins large que les élytres; subparallèle ou à peine arque sur les côtés et subatténué tout à fait en arrière; subconvexe sur le dos ; assez fortement sétosellé; assez finement et assez densement ponctué ; d'un noir assez brillant; à pubescence grisâtre et modérément serrée. Le 6 e segment subarrondi au sommet.

Dessous du corps aspèrement ponctué, finement pubescent, d'un noir brillant. Dessous de la tête plus éparsement ponctué. Lame mésosternale presque lisse en avant, rugueusement ponctuée en arrière de l'arête transversale, qui est saillante, subangulée et descendue jusqu'au milieu; à pointe acérée. Métasternum subdéprimé, finement canaliculé sur sa ligne 
médiane. Ventre convexe, éparsement sétosellé, plus longuement en arrière.

Pieds médiocres, aspèrement ponctués, finement pubescents, noirs, avec es tarses, surtout les antérieurs, parfois d'un roux de poix. Cuisses antérieures fortement épineuses en dessous vers leur sommet. Tibias antérieurs fortement épineux en dehors, densement pubescents en dedans, avec la pubescence d'un blond fauve et brillant. Tarses antérieurs presque simples. Les postérieurs à $1^{\mathrm{er}}$ article sensiblement plus long que le dernier, presque égal aux 3 suivants réunis.

Patrie. Cette espèce est assez commune dans les bouses, dans les forêts, ou lieux élevés : la France orientale, l'Alsace, la Lorraine, l'Auvergne, les mont Pilat, les montaønes lyonnaises, les Alpes, la Savoie, les Pyrénées, etc.

OBs. Elle a la taille et la tournure du Ph. splendens; mais les élytres sont rousses et le prothorax est paré de 2 séries dorsales de 4 points. Accidentellement, ces mêmes séries sont de 5 points ou l'une d'elles seulement.

Les $\sigma$ à petite taille ont souvent la tête à peine aussi large que le prothorax.

Les tarses antérieurs sont presque aussi simples chez les $\sigma$ que chez les ㅇ.

La larve du $P$. nitidus a été décrite par Henri Kroyer (in Schiödte, Nat. Tidsskr. 1864, 199, pl. IX, fig. 6-17)

\section{Philonthus cyanipennis, Fabricius.}

Allongé, subdéprimé, légèrement pubescent, d'un noir brillant, avec les élytres d'un bleu violace. Téte et prothorax glabres, lisses et luisants : celui-ci subtransverse, subrétréci en avant. Élytres assez finement et densement, abdomen assez finement et peu densement, ponctués. Tarses antérieurs presque simples.

$\sigma$ Le $6^{\mathrm{e}}$ arceau ventral profondément et angulairement entaillé, le $5^{\mathrm{e}}$ à peine sinué dans le milieu de leur bord apical. Téte transverse, presque aussi large que le prothorax.

ㄴ. Les $5^{\mathrm{e}}$ et $6^{\mathrm{e}}$ arceaux du ventre presque simples ou à peine subsinués 
dans le milieu de leur bord apical. Téte courtement ovalaire, sensiblement moins large que le prothorax.

Staphylinus cyanipennis, Fabricius, Ent. Syst. I, II, 525, 29; - Syst. El. II, 597, 37. - TWalkenaer, Faun. Par. I, 271, 12. - Gravenhorst, Micr. 168, 17; Mon. 86, 78. - Boisduval et Lacorbaire, Faun. Ent. Par. I, 387, 2.

Staphylinus amoenus, Olivier, Ent. III, no 42, 26, 32, pl. IV, fig. 36. - Latreille, Hist. Nat. Crust. et Ins. IX, 308, 27.

Staphylinus coeruleipennis, NANNER日EIM, Brach. 27, 43.

Philonthus coeruleipennis, Nоврмамs, Symb. 80, 25.

Philonthus cyanipennis, Erichson, 433, 9, - Redtenbacher, Faun. Aust. 700,9. -

Heer, Faun. Col. Helv. I, 260, 12. - Fairmarre et Labulbène, Faun. Ent. Fr. I, 518, 17. - Kratz, ins. Deut. II, 573, 6. - Jacquelin du Val, Gen. Col. Eur. Staph. pl. 14, tig. 67. - Favvel, Faun. Gallo-Rhén. III, 441, 4.

$$
\text { Long., 0ª } 0130 \text { (6 l.); - larg., } 0^{\mathrm{m}}, 0029 \text { (1 1/3 l.). }
$$

Corps allongí, subdéprimé, d'un noir brillant, avec les élytres d'un bleu violacé ou parfois verdâtre; revêtu sur celles-ci et sur l'abdomen d'une légère pubescence ogrisâtre et peu serrée.

Téte plus ou moins large; éparsement et longuement sétosellée; à peine pubescente et assez densement et rugueusement ponctuée sur les tempes; d'un noir très-brillant. Front très-large, subdéprimé ou à peine convexe, marqué en arrière, de chaque côté, de 3 ou 4 gros points, et entre les yeux, de 4 pores sétifères subtransversalement disposés, les extérieurs gros et situés contre le bord interne des yeux, les intermédiaires beaucoup plus écartés entre eux, un peu plus en arrière, très-fins et le plus souvent nuls ou effacés; offrant de plus, entre ces derniers, une fossette légère ou obsolète, rarement oblitérée (1). Cou glabre, d'un noir brillant, presque lisse ou avec quelques rares points sur les côtés. Expistome à bordure submembraneuse ass $\mathrm{z}$ large, d'un livide obscur. Labre fortement sétosellé en avant. Mandibules et palpes d'un noir de poix, avec le sommet de ceux-ci parfois moins foncé.

Yeux assez grands, subovales, obscurs, striés de gris.

Antennes assez courtes, un peu moins longues que la tête et le prothorax réunis ; subépaissies; légèrement pubescentes et ćparsement sétosellées ; noires, avec le dernier article brunâtre; le ${ }^{\text {er }}$ allongé, en massue grêle et subarquée; les $2^{\mathrm{e}}$ et $3^{\mathrm{e}}$ obconiques : le $2^{\mathrm{e}}$ suballongé : le $3^{\mathrm{e}}$ allongé, sen-

(1) Et parfois une autre de chaque côté vers l'insertion des antennes. 
siblement plus long que le $2^{\mathrm{e}}$ : les suivants graduellement un peu plus courts et un peu plus épais : le $4^{\mathrm{e}}$ oblong, subcylindrique : les $5^{\mathrm{e}}$ à $10^{\circ}$ subobconiques : le $5^{\mathrm{e}}$ suboblong : le $6^{\mathrm{e}}$ non, les $7^{\mathrm{e}}$ à $10^{\mathrm{c}}$ lćgèrement transverses, vus de côté, avec les deux pénultièmes un peu plus sensiblement: le dernier subovalaire, obliquement subéchancré au bout et acuminé inférieurement.

Prothorax subtransverse, subcomprimé et subatténué en avant, à peine moins large en arrière que les élytres; tronqué ou à peine échancré aut sommet: avec les angles antérieurs infléchis et subobtıs ; subarqué sur les côtés, avec ceux-ci, vus latéralement, non sinués en arrière (1); arrondi à la base ainsi qu'aux angles postérieurs ; assez convexe; ćparsement sétosellé, avec la longue soie des côtés située sur le rebord latéral même; d'un noir luisant; lisse, avec 2 séries dorsales composées de 4 points médiocrès et égalemont distants; marqué de plus, outre ceux de la marge, de 5 autres points semblables, épars, en avant sur les côtés. Repli noir, glabre, lisse.

Écusson assez densement ponctué, d'un noir brillant, à pubescence obscure.

Élytres transverses, un peu plus longues que le prothorax; subdéprimées; assez finement et densement ponctuées; d'un beau bleu brillant, violacé ou parfois un peu verdâtre, avec une fine pubescence d'un gris sombre et modérément serrée, et quelques soies redressées légères, dont 2 notamment plus longues sur les côtés (2). Épaules subarrondies.

Abdomen suballongé, moins large que les élytres ; visiblem`nt atténué ell arrière; subconvexe sur le dos; distinctement sétosellé; assez finement et peu densement ponctué; d'un noir brillant et subirisé ; à pubescence d'un gris obscur, un peu plus longue et moins serrée que celle des élytres. Le $6^{\text {e }}$ segment moins ponctué, subarrondi au sommet.

Dessous du corps ponctué, finement pubescent, d'un noir brillant et sub irisé. Dessous de la téte glabre, presque lisse. Lame mésosternale obsolè tement ponctuce à la base de son aire antérieure; à arête transversalc assez saillante, fortement arquée et descendue jusqu'au milieu, suivie d'une chaînette arquée de pores sétifères (3); à pointe lisse, plus ou moins

(1) Contrairement à la plupart des espèces, le prothorax n'est pas visiblement sinué en arrière, vulu de côté.

(2) Celle des côtés de l'écusson est souvent caduque.

(3) Ces pores sétiferes existent plus ou moins chez la plupart des espèces. Nous n'y revicndrons pas.

BR. 
émoussée au bout. Métasternum à peine convexe, à peine canaliculé sur sa ligne médiane. Ventre convexe, éparsement sétosellé, plus longuement en arrière.

Pieds assez allongés, aspèrement ponctués, finement pubescents, noirs, avec les tarses un peu moins foncés. Cuisses antérieures finement épineuses en dessous vers leur sommet; les postérieures assez allongées, assez grêles. Tibias antérieurs presque aussi fortement épineux que les autres. Tarses antérieurs presque simples (1); les postérieurs allongés, à $1^{\mathrm{er}}$ article un peu plus long que le dernier, égal aux 3 suivants réunis.

Patrie. Cette belle espèce se prend au pied des arbres, dans les agarics décomposés. Elle préfère les forêts et les montagnes : les environs de Paris et de Lyon, la Normandie, l'Alsace, la Bourgogne, le Beaujolais, la Bresse, les Alpes, la Savoie, les Pyrénées, etc. Elle est peu commune.

OBs. Les tarses postérieurs sont plus grêles que dans les espèces précédentes, avec leurs articles plus longs. Le prothorax est plus rétréci en avant, l'abdomen plus atténué en arrière. La pointe mésosternale est plus émoussée.

Les élytres sont parfois un peu verdatres.

\section{Philonthus aeneus, Rossi,}

Allongé, subdéprimé, finement pubescent, d'un noir brillant, avec les élytres bronzées. T'éte et prothorax d'un noir bronzé, glabres, lisses et luisants : celui-ci subtransverse, à peine rétréci en avant. Élytres et abdomen assez finement et densement ponctués.

$\sigma^{7}$ Le $6^{\text {e }}$ arceau ventral assez fortement et angulairement entaillé dans le milieu de son bord apical, avec les bords de l'entaille garnis en dedans d'une étroite gouttière pellucide. Le $5^{\circ}$ subéchancré dans le milieu de son bord postérieur. Tarses antérieurs à 3 premiers articles fortement, le $4^{e} \mathbf{a}$ peine dilatés. Tête transverse, plus large que le prothorax.

ㅇ Le $6^{\mathrm{e}}$ arceau ventral arrondi, le $5^{\mathrm{e}}$ simple, à leur bord apical. Tarses antérieurs à peine dilatés. Tête suborbiculaire, moins large que le prothorax.

(1) Ils sont pourtant à peine dilatés chez les $\sigma^{*}$ et surtout plus longuement et plus densement cillés sur les cơtés. 
Staphylinus aeneus, Rossi, Faun. Etr. I, 249,613. - Gravenhorst, Micr. 17, 18 ; - Mon. 86, 80.- Latreille, Hist. Nat. Crust. et Ins. IX, 307, 23. - Gyllenhal. Ins. Suec. II, 314, 30.- MaNNERHEIM, Brach. 27, 48.

Staphylinus laticeps, Zetrenstedt, Faun. Lapp. 73, 15; - Ins. Lapp. 62, 21.

Staphylinus cyanicornis, MaNNERHEIM, Brach. 27, 45 .

Staphylinus metallicus, Boisduval et LaGordalRe, Faun. Ent. Par, I, 390, 7.

Staphylinus similis, Marsham, Ent. Brit. 497, 3.

Philonthus aeneus, Nordana, Symb. 81, 26. - Erichsor, Col. March. I, 449, 6 , - Gen. et Spec. Staph. 437, 16. - Redtenhacher, Faun. Austr. 701, 11. Heer, Faun. Col. Helv. I, 258, 5. - Fairmaire et Laboulbène, Faun. Ent. Fr. I, 316, 13. - Krastz, Ins. Deut. II, 578, 11. - Thouson, Skand. Col. 156, 6. Fauvel, Yaun. Gallo-Rhén. III, 442, 6.

Variété $a$. Pieds d'un roux de poix.

Staphylinus atratus, Boisduval et Lacordatre, Faun. Ent. Par. I, 392, 11.

$$
\text { Long., } 0^{\mathrm{m}}, 0133\left(6 \text { l.) ; - } \operatorname{larg.,~} 0^{\mathrm{m}}, 0026 \text { (1 } 1 / 4\right. \text { l.). }
$$

Corps allongé, subdéprimé, d'un noir brillant, avec les élytres bronzẻes ; revêtu d'une fine pubescence grisâtre et modérément serrée.

Tête plus ou moins large; éparsement sétosellée ; d'un noir bronzé luisant; presque lisse, mais inégalement et vaguement ponctuée en arrière sur les tempes. Front très-large, subconvexe, marqué entre les yeux de 4 pores sélifères subtransversalement disposés, les extérieurs situés contre le bord interne des dils organes, les intermédiaires un peu moindres, beaucoup plus distants entre eux ct à peine plus en arrière. Cou glabre, d'un noir bronzé brillant, presque lisse ou à peine ponctué sur les côtés. Epistome à bordure antérieure assez large, submembraneuse ou subcornée, obscure ou d'un roux livide. Labre fortement sétosellé en avant, noir. Mandibules et palpes d'un noir de poix, avec leur sommet parfois un peu roussâtre.

Yeux assez grands, ovales-oblungs, obscurs, striés de gris.

Antennes peu allongées, un peu moins longues que la tête et le prothorax réunis; visiblement subépaissies ; légèrement pubescentes et éparsement pilosellées vers leur base; noires; à $1^{\text {er }}$ article allongé, en massue subarquée : les $2^{\mathrm{e}}$ et $3^{\mathrm{e}}$ suballongés, obconiques : le $3^{\mathrm{e}}$ un peu plus long que le $2^{\mathrm{e}}$ : les suivants graduellement un peu plus courts et un peu plus épais, subobconiques, parfois brièvement pédicellés : le $4^{\mathrm{C}}$ à peine, le $5^{\mathrm{e}}$ non plus longs que larges : les $6^{\circ}$ à $10^{\mathrm{e}}$ transverses, avec les pénul- 
tièmes un peu plus fortement, vus de côté : le dernicr subovalaire, échancré au bout et acuminé inférieurement.

Prothorax subtransverse, subcomprimé et à peine rétréci en avant; un peu moins large en arrière que les élytres; tronqué au sommet, avec les angles antérieurs infléchis et subarrondis; arcuément subdilaté, vu de dessus, dans le milieu de ses côtés, avec ceux-ci, vus latéralement, sinués en arrière; subarrondi à sa base, avec les angles postérieurs obtus; peu convexe; subimpressionné sur les côtés; éparsement sétosellé, avec la longue soie latérale située contre le bord même; d'un noir bronzé luisant ; presque lisse, avec 2 séries dorsales composées de 4 points médiocres et également distants; marqué de plus, outre ceux des marges, de 3 ou 4 autres points semblables, disposés en triangle ou en losange dans l'ouverture des angles antérieurs. Repli noir, glabre, lisse.

Écusson finement pointillé, à pubescence obscure; d'un, noir assez brillant el submétallique.

Élytres transverses, un peu ou à peine plus longues que le prothorax; subdéprimées ; assez finement, densement et subrâpeusement ponctuées ; d'un bronzé brillant, parfois assez clair, avec une fine pubescence grisâtre et modérément serrée, et quelques soies obscures et redressées, dont 1 ou 2 plus longues sur la marge latérale et 1 autre de chaque côté de l'écusson. Épaules effacées. Ailes enfumées.

Abdomen suballongé, moins large que les élytres; subarqué et un peu atténué tout à fait en arrière; assez convexe sur le dos, avec le repli des $2^{\mathrm{e}}$ et $3^{\mathrm{e}}$ segments en accolade prononcée ; longuement sétosellé ; assez finement et densement ponctué; d'un noir assez brillant, avec une fine pubescence grisâtre, un peu plus longue et non moins serrée que celle des élylres. Le $6^{\mathrm{e}}$ segment subarrondi au sommet.

Dessous du corps aspèrement ponctué, finement pubescent, d'un noir brillant. Dessous de la tête glabre, éparsement ponctué. Lame mésosternale presque lisse en avant, rugueuse en arrière de l'arêtc transversale, qui est saillante, fortement arrondie ou subangulée; à pointe trèsaiguë. Métasternum subdéprimé, très-fine ment canaliculé sur sa ligne médiane. Ventre convexe, épar'scment sétosellé, plus longuernent en arrière.

Pieds médiocres, aspèrement ponctués, finement pubescents, noirs, avec les tarses, surtout les antérieurs, parfois d'un roux de poix. Cuisses antérieures assez fortement épineuses en dessous vers leur sommet; les posterieures suballongées, assez grêles. Tibias antérieurs assez fortement 
épineux en dehors. Tarses postérieurs à ler article sensiblement plus long que le dernier, subégal aux 3 suivants réunis.

Patrie. Cette espèce est très-commune dans presque toute la France, dans les fumiers, les cadavres, les champignons, sous les détritus, etc.

Obs. Souvent les premiers articles des antennes son! un peu roussâtres vers leur insertion.

Chez les exemplaires immatures, les palpes, la base des antennes et les pieds sont d'un roux de poix. Le's élytres même présentent parfois une transparence de celte couleur.

Les $\sigma^{*}$, à taille inférieure, ont la tête moins large que le prothorax.

On peut rapporter à l'aeneus le puncticoilis de Stephens (Ill. Br. V, 439), et en partie le politus de Linné (Syst. Nat. I, 2, p. 683), et peutêtre aussi l'angulicollis de Motschulsky (Schrenk. Reis. 1860, 121, pl, 8, fig. 15).

\section{LARVE}

La larve du Ph. aeneus a été décrite pour la première fois par Bouché (Naturg. Ins. I, 179, pl. VII, fig. 29). Depuis, Henri Kroyer (in Schiödte, Naturh. Tids. 1864, p, 206, pl.12, fig. 1) a donné l'histoire de ses métamorphoses,

Cette larve est d'un roux testacé brillant sur la tête et les segments thoraciques, livide et mat sur l'abdomen. La tête est oblongue, le prothorax suboblong; le mésothorax et le métathorax sont courts et subélargis en arrière. L'abdomen, d'un livide parfois assez obscur, offre une ligne pâle sur les côtés et une autre sur la liģne médiane, qui est sillonnée sur presque toute sa longueur. Le dernier segment est oblong, tronqué au sommet, avec 2 appendices pâles et biarticulés : le $1^{\text {er }}$ article trèslong, le $2^{e}$ beaucoup moindre tt plus grèle, sétifère. Le tube de dessous est plıs long que les appendices supérieurs, souvent fortement replié au coudé à son insertion, etc.

\section{Philonthug carbonarius, ERichsoN.}

Allongé, subdéprimé, légèrement pubescent, d'un noir brillant, avec les élytres bronzées. Têle et prothorax d'un noir bronzé, glabres, lisses et luisants : celui-ci subtransverse, subrétréci en avant: celle-là éparsement ponctuée derriere les yeux. Elytres asser funement et densement, 
abdomen assez finement et peu densement, ponctués. Tarses antérieurs presque simples.

$\sigma$ Le $6^{\mathrm{e}}$ arceau ventral profondément et aigument entaillé dans le milieu de son bord apical, avec les bords de l'entaille garnis en dedans d'une gouttière assez large et subpellucide. Le $5^{\text {e }}$ largement subsinué dans le milieu de son bord postérieur. Tête en carré transverse, un peu plus large que le prothorax.

$q \cdot$ Le $6^{\text {e }}$ arceau ventral subarrondi, le $5^{\mathrm{e}}$ simple, à leur bord apical. Téte suborbiculaire, moins large que le prothorax.

Staphylinus nigritus, Runde, Brach. Hal. 7, 33.

Philonthus carbonarius, ERICHson, Col. March. I, 448, 5; - Gen. et Spec. Staph. 437, 15.- Redtenbacher, Faun. Austr. 824.- Heer, Faun. Col. Helv. I, $2599,6$. - Fairmaire et Laboulbène, Faun. Ent. Fr. I, 516, 11. - Kratiz, Ins. Deut. If, $577,9$.

Philonthus proximus, Kratiz, Wiegm. Arch. 1859, I, 80.-Fauvet, Faun. GalloRhén. III, 441, 5 .

Philonthus succicola, Thomson, Skanu. Col. II, 1860, 157, 7. - Rye, Ent. Ann. 1864, 55.

$$
\text { Long., } 0^{\mathrm{m}}, 0122\left(51 / 2 \text { l.); - larg., } 0^{\mathrm{m}}, 0026 \text { (1 } 1 / 4 \mathrm{l}\right. \text { l.). }
$$

Corps allongé, subdéprimé, d'un noir brillant, avec les élytres bronzées; recouvert sur celles-ci et sur l'abdomen d'une légère pubescence d'un gris obscur et peu serrẻe.

Tête plus ou moins large, éparsement sétosellée; d'un noir bronzé luisant; presque lisse, éparsement et assez fortement ponctuée derrière les yeux. Front très-large, à peine convexe, marqué en avant de 4 pores sétifères subtransversalement disposés, les extérieurs situés tout près du bord interne des yeux, les intermédiaires moindres, plus distants entre eux et à peine plus en arrière; offrant en outre, entre ceux-ci ( $q$ ) ou plus en avant $\left(\sigma^{*}\right)$, une fossette plus ou moins légère, parfois effacée. Cou glabre, presque lisse, d'un noir bronzé brillant. Épistome à bordure submembraneuse assez lar.e, d'un livide plus ou moins obscur. Labre noir, fortement sétosellé en avant. Mandibules et palpes d'un noir de poix, avec leur sommet parfois moins foncé.

Yeux assez grands, ovales-oblongs, noirs ou lavés de gris.

Antennes peu allongées, moins longues que la tête et le prothorax réunis ; sensiblement épaissies; légèrement pubescentes et éparsement 
pilosellées; noires, avec le dernier article souvent ferrugineux; le 1 er allongé en massue grêle et subarquée : les $2^{\mathrm{e}}$ et $3^{\mathrm{e}}$ obconiques : le $2^{\mathrm{e}}$ suballongé : le $3^{\mathrm{e}}$ allongé, sensiblement plus long que le $2^{\mathrm{e}}$ : les suivants graduellement un peu plus courts et plus épais, subobconiques: le $4^{\circ}$ presque aussi large que long : le $5^{\mathrm{e}}$ à peine, le $6^{\mathrm{c}}$ médiocrement, les pénultièmes plus fortement transverses : le dernier subovalaire, échancré au bout et subacuminé inférieurement.

Prothorax subtransverse, subcomprimé et subrétréci en avant ; à peine moins large en arrière que les élytres ; tronqué au sommet, avec les angles antérieurs infléchis et arrondis; arcuément subélargi, vu de dessus, vers le milieu de ses côtés, avec ceux-ci, vus latéralement, sinués en arrière ; subarrondi à sa base ainsi qu'aux angles postérieurs ; légèrement convexe ; obliquement subimpressionné de chaque côté ; éparsement sétosellé, avec la longue soie latérale située contre le rebord mênı ; d'un noir bronzé luisant; presque lisse, avec 2 séries dorsales composćes de 4 points médiocres et subégalement distants; marqué de plus, outre ceux des marges, de 4 ou 5 points semblables, écartés et situés dans l'ouverture des angles antérieurs. Repli noir, glabre, lisse.

Écusson densement ponctué, pubescent, d'un noir assez brillant.

Élytres transverses, un peu plis longues que le prothorax; subdéprimées; assez finement, densement et subràpeusement ponctuées; d'un bronzé brillant, souvent un peu ioncé, rarement un peu verdâtre, avec une fine pubescence d'un gris obscur et modérément serrée, et quelques légères soies redressées, dont 2, notamment plus longues, sur les côtés, et 1-autre de chaque côté de l'écusson. Épaules effacées. Ailes enfumées.

Abdomen suballongé, moins large que les élytres; à peine arqué sur les côtés et un peu atténué en arrière; subconvexe sur le dos, avec le repli des $2^{\mathrm{c}}$ et $3^{\circ}$ segments en accolade prononcée; fortement sétosellé; assez finement, mais un peu moins densement ponctué que les élytres; d'un noir brillant et parfois à peine irisé ; à pubescence peu serrée. Le $6^{\ominus}$ segment subarrondi au sommet.

Dessous du corps aspèrement ponctué, finement pubescent, d'un noir brillant. Dessous de la tête glabre et presque lisse. Lame mésosternale presque lisse en avant, rugueuse en arrière; à pointe très-aiguë et submucronée; à arête transversale peu saillante, angulée, descendue jusqu'au milieu ou à peine au delà. Métasternum subdéprimé, très-finement canaliculé sur sa ligne médiane. Ventre convexe, éparsement sétosellé.

Pieds médiocres, aspèrement ponctués, légèrement pubescents, noirs, 
avec les tarses antérieurs parfois moins foncés. Cuisses postérieures assez fortement épineuses en dessous ver's leur sommet ; les postérieures suballongées, assez grêles. Tibias antérieurs à peine arqués, fortement épineux en dehors, densement pubescents en dessous. Tarses antérieur's presque simples; les postérieurs à $1^{\text {er }}$ article beaucoup plus long que le dernier, subégal aux 3 suivants réunis.

Patrie. Celte espèce, moins commune que la précédente, se prend au pied des arbres, parmi les champignons, dans les forêts, dans presque toute la France : les environs de Paris et de Lyon, l'Alsace, la Lorraine, la Bourgogne, le Bourbonnais, le Beaujolais, le Bugey, les Alpes, les Pyrénées, etc.

OBs. Elle diffère de l'aeneus par sa forme à peine plus large et par sa teinte d'un bronzé plus foncé. L'abdomen est moins densement ponctué, etc.

Chez les $\sigma^{\circ}$ de petite taille, la tête ressemble à celle des $q$.

Nous avons conservé le nom de carbonarius d'Erichson, qui, le premier, a bien décrit cette espèce. Le carbonarius de Gravenhorst est un autre insecte; et, si l'on tient à lui restituer son premier nom, il faudrait l'appeler nigritus, Runde.

\section{Philonthus addendus, SHARP.}

Allongé, peu convexe, finement pubescent, d'un noir brillant, avec les élytres bronzées. Tète et prothorax d'un noir métallique, glabres, presque lisses, luisants : celui-ci presque aussi long que large, à peine rétréci en avant : celle-là densement ponctuée derrière les yeux. Élytres assez finement et densement, abdomen assez finement et peu densement ponctués. Tarses untérieur's prisque simples.

$\sigma$ Le $6^{\text {e }}$ arceau ventral assez largement sinué dans le milieu de son bord apical, avec un espace triangulaire lisse, corné, au devant du sinus. Tête subtransverse, de la largeur du prothorax.

ㅇ Le $6^{\mathrm{e}}$ arceau ventral à peine arrondi à son bord apicıl. Tête suborbiculaire, moins large que le prothorax.

Philonthus addendus, Smarp, Proc. Ent. Soc. Lond. $1867 ; \rightarrow$ Ent. An!. 1867, 48. 
- Kratuz, Berl. Ent. Zeit. 1868, 351. - Rye. Ent. Ann. 1869, 30. - Marseul, Ab. 1809, VI, 118.-- Fauvel, Faun. Gallo-Rhén. III, 443, 7.

$$
\text { Long., } 0^{\mathrm{m}}, 0110 \text { (5l.); - larg., } 0^{\mathrm{m}}, 0024 \text { ( } 1 \text { l. fort). }
$$

Corps allongé, peu convexe, d'un noir brillant, avec les élytres d'un bronzé cuivreux ; recouvert sur celles-ci et sur l'abdomen d'une fine pubescence grise et modérément serrée.

Tête éparsement sétosellée sur les côtés; d'un noir métallique luisant ; presque lisse ou à peine chagrinée; assez fortement et assez densement ponctuée derrière les yeux. Front très-large, à peine convexe, marqué en avant de 4 pores sétifères subtransversalement disposés, rapprochés 2 a 2 , les intermédiaires très-distants, beaucoup moindres et à soie courte. Cou glabre, d'un noir mélallique brillant, presque lisse ou avec 2 ou 3 points sur les côtés. Épistome à bordure submembraneuse assez large, livide. Labre noir, fortement sétosellé en avant. Mandibules et palpes noirs.

Yeux assez grands, ovales-oblongs, obscurs, tachés de gris.

Antennes assez courtes, moins longues que la tête et le prothorax réunis; légèrement épaissies; finement duveteuses et éparsement pilosellées ; noires; à $1^{\mathrm{er}}$ article allongé, en massue à peine arquée : les $2^{\mathrm{e}}$ et $3^{\mathrm{e}}$ obconiques : le $2^{\mathrm{e}}$ oblong : le $3^{\mathrm{e}}$ suballongé, sensiblement plus long que le $2^{\mathrm{e}}$ : les suivants graduellement un peu plus courts et un peu plus épais, subobconiques : les $4^{\mathrm{e}}$ et $5^{\mathrm{e}}$ suboblongs : le $6^{\mathrm{e}}$ à peine ou non, le $7^{\mathrm{e}}$ légèrement Iransverses, les pénultièmes plus fortement : le dernier courtement ovalaire, subéchancré au bout.

Prothorax presque aussi long que large; à peine rẻtréci en avant; à peine moins large en arrière que les élytres ; tronqué au sommet, avec les angles antérieurs infléchis et arrondis ; subangulairement subarqué derrière le milieu de ses côtés, avec ceux-ci, vus latéralement, sinués en arrière ; largement arrondi à sa base, avec les angles postérieurs très-obtus et subarrondis; non ou à peine impressionné de chaque côté ; éparsement sétosellé, à soie latérale située contre le rebord même; d'un noir métallique luisant; presque lisse, avec 2 séries dorsales composées de 4 points médiocres, dont les intermédiaires un peu plus rapprochés; marqué de plus, sur les còtés, outre ceux de la marge, de 4 à 6 points semblables, mais épars. Repli noir, glabre, lisse.

Écusson assez densement ponctué, pubescent, d'un noir assez brillant. Élytres transverses; à peine plus longues que le prothorax; subdépri- 
mées; assez finement, densement et subrâpeusement ponctuées; d'un bronzé brillant, assez clair et un peu cuivreux, avec une fine pubescence grise et modérément serrée, et quelques légères soies redressées, dont 2 notamment plus longues sur les côtés et 1 autre vers l'écusson. Épaules presque effacées.

Abdomen assez allongé, un peu moins large que les élytres; à peine arqué sur les côtés et un peu atténué en arrière; assez convexe sur le dos, avec le repli des premiers segments en accolade prononcée; assez finement et peu densement ponctué; d'un noir brillant à peine azuré; à pubescence un peu plus longue $\in$ t un peu moins serrée que celle des élytres. Le 6 e segment à peine arrondi au sommet.

Dessous du corps aspèrement ponctué, finement pubescent, d'un noir brillant. Dessous de la tète presque glabre, presque lisse ou éparsement ponctué en arrière. Lame mésosternale à pointe très-aiguë; à arête transversale saillante, en angle arrondi, descendue jusqu'au milieu. Métasternum subdéprimé, obsolètement canaliculé sur sa ligne médiane. Ventre convexe, éparsement sétosellé.

Pieds médiocres, aspèrement ponctués, finement pubescents, noirs, avec les tarses antérieurs un peu moins foncés. Cuisses antérieures assez fortement épineuses en dessous vers leur sommet; les postérieures un peu plus allongées et un peu plus grêles. Tibias antérieurs assez fortement épineux en dehors, densement pubescents en dessous. Tarses antérieurs presque simples; les postérieurs à $1^{\mathrm{er}}$ article plus long que le dernier, presque égal aux 3 suivants réunis.

Patrie. Cette rare espèce a été capturée, sous les tas d'herbes et parmi les agarics, dans les montagnes des environs de Tarbes, par M. Pandellé, qui nous l'a généreusement communiquée, et à qui la science doit tant de découvertes précieuses.

Obs. Elle diffère du P. carbonarius, Er. par sa couleur d'un bronzé plus clair sur les élytres. Celles-ci sont un peu plus longues. La tête, moins large chez les $\sigma^{\circ}$, est plus densement ponctuée derrière les yeux, avec les points situés entre ceux-ci rapprochés deux à deux, de sorte que les intermédiaires sont plus largement distants. Les antennes sont plus grêles, avec leurs pénultièmes articles moins fortement transverses. Le prothorax, un peu moins court, est moins visiblement impressionné sur les côtés. Le $6^{\mathrm{e}}$ arceau ventral des $\sigma^{\prime \prime}$ est moins profondément et moins aigument entaillé, et le $5^{\mathrm{e}}$ moins fortement sinué, etc. 
Le $\sigma$ présente, en outre, sur le devant du front, une fossette à peine : ensible.

12. Philonthus teamporalis, Mulsant et Rey.

Allonge, peu convexe, finement pubescent, d'un noir brillant, un peu bronzé sur la tête, le prothorax et les élytres. Tête et prothorax presque lisses, brillants : celui-ci subtransverse, subrítréci en avant. Élytres finement et densement, abdomen finement et modérément, ponctués. Tempes grossièrement ponctuées. Tarses presque simples.

$\sigma^{*} \mathrm{l}_{2} \mathrm{e} 6^{\mathrm{e}}$ arceau ventral modérément et an śllairement entaillé dans le nilieu de son bord apical.

i lue $6^{e}$ arceau ventral subarrondi à son bord apical.

Philonthus temporalis, Julsant et Rey, Ann. Soc. Lin. Lyon, 1853, 61; - Op. Ent. II, 74, 2, 1833. - Fairmaire et Laboulbène, Faun. Ent. F. I, 516. - Rye, Ent. Ann. 1870, 82.-Fauvel, Faun. Gallo-Rhén. III, 444, 9.

$$
\text { Long., } 0^{\mathrm{m}}, 0100 \text { (4 1/2 l.); - lar. }
$$

Corps allongé, peu convexe, d'un noir brillant, avec la tête, le prothorax et les élytres un peu bronzés; recouvert sur celles-ci et l'abdomen d'une fine pubescence d'un gris obscur et peu serrée.

Tète subcarrée $\left(\sigma^{\prime}\right)$ ou suborbiculaire $(q)$, à peine ou un peu moins large que le prothorax; légèrement sétosellée ; d'un noir brillant et un peu bronzé; presque lisse, pubescente sur les tempes, avec celles-ci grossièrement, assez densement et rugueusement ponctuées. Front large, à peine convexe, marqué de chaque côté entre les yeux de 2 pores sétifêres assez gros, rapprochés et subtransversalement disposés, les internes néanmoins parfois moins forts et un peu plus en arrière. Cou glabre, presque lisse, d'un noir un peu bronzé. Labre noir, fortement sétosellé en avant. Mandibules et palpes d'un noir de poix, parfois moins foncé.

Yeux assez grands, subovales, obscurs, lavés de gris.

Antennes peu allongées, un peu plus courtes que la tête et le prothorax réunis; légèrement épaissies; pubescentes ịt éparsement pilosellées vers leur base; noires, avec l'insertion des premiers articles parfois un peu roussâtre $; l_{0} 1^{\mathrm{er}}$ allongé, en massue subarquée : les $2^{\mathrm{e}}$ et $3^{\mathrm{e}}$ suballongés, 
obconiques, subégaux : les suivants graduelleınent un peu plus courts $e_{t}$ un peu plus épais, subobconiques : le $4^{\mathrm{e}}$ à peine oblong : les $5^{\mathrm{e}}$ et $6^{\mathrm{e}}$ non, les $7^{\circ}$ à $10^{\circ}$ visiblement transverses, vus de cỏté : le dernier subova laire, subéchancré au bout et à peine acuminé inférieurement.

Prothorax subtransverse, subrétréci en avant; à peine moins large en arrière que les élytres; tronqué au sommet, avec les angles antérieurs infléchis et arrondis ; subarqué sur les côtés, qui, vus latéralement, sont sinués en arrière; subarrondi à la base, avec les angles postérieurs obtus; subconvexe; éparsement sétosellé, avec la longue soie latérale située contre le rebord même ; d'un noir brillant et un peu bronzé; presque lisse, avec 2 séries dorsales composées de 4 points assez forts, dont l'antérieur souvent plus écarté; marqué de plus vers les côtés, outre ceux de la marge, de 5 ou 6 autres points semblables et épars. Repli noir, glabre, lisse.

Écusson densement pointillé, pubescent, noir.

Élytres subtransverses, un peu plus longues que le prothorax; subdéprimées; finement, densement et rápeusement ponctuées; d'un noir un peu bronzé et assez brillant ; finement et modérément pubescentes; brièvement et éparsement sétosellées, a vec une soie beaucoup plus longue vers l'écusson, et 2 sur les côtés : celles-ci souvent cadıques. Épaules effacées. Ailes enfumées.

Abdomen peu allongé, moins large que les élytres; à peine arqué sur les côtés et à peine atténué tout à fait en arrière; subconvexe sur le dos ; éparsement et longuement sétosellé; finement et modérément ou même assez densement ponctué; d'un noir brillant, parfois subazuré; à pubescence assez longue, moins serrée que celle des élytres. Le $6^{\mathrm{e}}$ segment à peine arrondi au sommet.

Dessous du corps aspèrement porictué, tinement pubescent, d'un noir brillant. Dessous de la tête glabre, presque lisse. Lame mésosternale presque lisse en avant, subrugueuse en arrière; à arête transversale peu saillante, obtusément angulée ou subarrondie, descendue jusqu'au milieu ; à pointe souvent brusque et acérée. Métasternum subdéprimé sur son milieu, finement canaliculé sur sa ligne médiane. Ventre convexe, éparsement sétosellé, plus longuement en arrière, souvent subirisé.

Pieds médiocres, aspèrement ponctués, finement pubescents, d'un noir de poix, avec les tarses antérieurs parfois moins foncés. Cuisses antérieures assez fortement épincuses en dessous vers leur sommet; les postérieures peu allongées. Tarses antérieur's presque simples; les postérieurs 
à $1^{\text {er }}$ article sensiblement plus long que le dernier, presque égal aux 3 suivants réunis.

Patkie. Cette espèce est rare. Elle se prend parmi les mousses, dans les hautes mo ntagnes du Bugey et de la Savoie. Elle est assez commune en Suisse.

Oвs. La tête est un peu moi ns large relativement au prothorax que chez le Ph. tenuicornis, plus grossièrement et plus densement ponctuée en arrière sur les côtés. Les antennes, un peu moins longues, ont leur $2^{a}$ et $3^{\mathrm{e}}$ articles moins inégaux, avec les pénultièmes plus sensiblement transverses. Les élytres et l'abdomen sont un peu plus densement et un peu plus fine ment ponctués. La forme générale, plus large et plus ramassée, est à peu près celle du Ph. lucens, décrit plus loin ; mais celui-ci a la tête moins large et ovalaire, avec les côtés du prothorax à peine visiblement sinués en arrière.

Notre $P$. temporalis répond sans doute au punctiventris de Kraatz (Ins. Deut. II, 578, 10; Berl. Ent. Zeit. 1858, 351).

\section{Philonthas temaicorrais, Mulsant et Rey.}

Allongé, peu convexe, légèrement pubescent, d'un noir brillant, avec les élytres d'un bronzé obscur. Tête et prothorax d'un noir bronzé, presque lisses et assez luisants : cellii-ci subtransverse, à peine rétréci en avant. Elytres assez finement et densement, abdomen assez finement et éparsement, ponctués. Tarses antérieurs presque simples.

$\sigma^{\circ}$ Le $6^{\mathrm{e}}$ arceau ventral médiocrement et subangulairement entaillé dans le milieu de son bord apical. Le $5^{\text {e }}$ entier. Tête transversalement orbiculaire, de la largeur du prothorax.

\& Le $6^{e}$ arceau ventral arrondi à son bord apical. Tète suborbiculaire, moins large que le prothorax.

Philonthus tenuicornis, Mulsant et Rey, Ann. Soc. Lin. Lyon, 1853, 58, pl. 2, fig. 5, a. - Op. Ent. II, 1853, 71, 1. - Fairmaire et Laboulbène, Faun. Ent.

Fr. I, 516, 12.- Scriba, Berl. Ent. Zeit. 1866, 293.

Philonthus punctiventris, Jans on, Ent. Ann. 1863, 82.

Philonthus carbonarius, Fauvel, Faun. Galto-Rhén. III, $443,8$.

$$
\text { Long., } 0^{\mathrm{m}}, 0110 \text { (51.); - larg., } 0^{\mathrm{m}}, 0022 \text { (11.). }
$$


Corps allongé, peu convexe, d'un noir brillant, avec les élytres d'un bronzé obscur ; revêtu sur celles-ci et sur l'abdomen d'une légère pubescence d'un gris obscur et peu serrée.

Téte plus ou moins orbiculaire; éparsement sétosellée; d'un noir blonzé assez luisant ; presque lisse, fortement et éparsement ponctuée en arrière vers les tempes. Front très-large, subconvexe, marqué en avant de 4 pores sétifères transversalement disposés, les extérieurs situés tout près du bord interne des yeux, les intermédiaires moindres, beaucoup plus distants entre eux. Cou glabre, presque lisse, d'un noir bronzé brillant. Épistome à bordure submembraneuse obscure. Labre noir, fortement sétosellé en avant. Mandibules et palpes d'un noir de poix, avec leur summet parfois moins foncé.

Yeux assez grands, ovales-oblongs, obscurs.

Antennes peu allongées, un peu moins longues que la tête et le prothorax réunis; faiblement épaissies; légèrement pubescentes et éparsement pilosellées; noires, avec le dernier article parfois brunâtre; le $1^{\mathrm{er}}$ allongé, en massue grêle et subarquée : les $2^{\mathrm{e}}$ et $3^{\mathrm{e}}$ obconiques : le $2^{\mathrm{e}}$ suballongé : le $3^{\mathrm{e}}$ allongé, plus long que le $2^{\mathrm{e}}$ : les suivants graduellement un peu plus courts et à peine plus épais, subobconiques : les $4^{\mathrm{e}}$ à $6^{\mathrm{e}}$ suboblongs : le $7^{\mathrm{e}}$ à peine aussi large que long: les $8^{\mathrm{e}}$ à $10^{\mathrm{e}}$ non ou à peine transverses, vus de côté : le dernier subovalaire, subéchancré au bout et subacuminé inférieurement.

Prothorax subtransverse, à peine comprimé et à peine rétréci en avan!; un peu moins large en arrière que les élytres; tronqué au sommet, avec les angles antérieurs inflèchis et arrondis; subarqué, vu de dessus, sur les côtés, avec ceux-ci, vus latéralement, subsinués en arrière; subarrondi à sa base ainsi qu'aux angles postérieurs; assez convexe; à peine impressionné de chaque côté ; éparsement sétosellé, avec la longue soie latérale située sur le rebord même; d'un noir bronzé assez luisant ; presque lisse, avec 2 séries dorsales composées de 4 points assez forts et subégalement distants ; marqué de plus, outre ceux de la marge, de 4 ou 5 autres points semblables, en avant vers les côtés. Repli noir, glabre, lisse.

Écusson assez densement ponctué, pubescent, d'un noir assez brillant.

Élytres transverses, à peine plus longues que le prothorax; subdéprimées; assez finement, densement et aspèrement ponctuées; d'un bronzé brillant et plus ou moins foncé, avec une légère pubesceuce d'un gris obscur et modérément serrée; ei quelques soies redressées, dont 2 notam- 
ment plus longues sur les côtés et une autre de chaque côté de l'écusson. Épaules effacées. Ailes enfumées.

Abdomen suballongé, moins large que les élytres; à peine arqué sur les côtés el parfois subatténué en arrière; subconvexe sur le dos; assez fortement sétosellé; assez finement et éparsement ponctué; d'un noir brillant et souvent subirisé; à pubescence très-peu serrée. Le $6^{c}$ segment moins ponctué, à peine arrondi au sommet.

Dessous du corps aspèrement et peu densement ponctué, finement pubescent, d'un noir brillant. Dessous de la tête presque glabre, à peine ponctué en arrière. Lame mésosternale presque lisse en avant, subrugueuse en arrière; à pointe très-aiguë; à arête peu saillante, angulée, descendue jusqu'au milieu. Métasternum subdéprimé. Ventre convexe, parfois subirisé, éparsement sélosellé, plus longuement en arrière.

Pieds médiocres, aspèrement ponctués, légèrement pubescents, d'un noir de poix, avec les tarses antérieurs parfois moins foncés. Cuisses antérieures sensiblement épineuses en dessous vers leur sommet; les postérieures suballongées, assez grêles. Tibias antérieurs presque droits, fortement épineux en dehors, à pubescence fauve. Tarses antérieurs presque simples ou avec les 3 premiers articles à peine dilatés chez les $\sigma$; les postérieurs à $1^{\mathrm{er}}$ article sensiblement plus long que le dernier, à peine égal aux 3 suivants réunis.

Patrie. Cette espèce se trouve dans les bouses, dans les champignons décomposés et parmi les détritus. Elle est médiocrement commune. Elle habite certaines régions de la France : la Normandie, la Bourgogne, le Beaujolais, les environs de Lyon, le Dauphiné, les Pyrénées, etc.

OBs. Bien voisine de la précédente, elle s'en distingue par sa taille moindre et proportionnellement moins large; par ses antennes plus grêles, à pénultièmes articles non ou à peine transverses et par les points de la tête et du prothorax un peu plus forts. Chez les $\sigma^{\circ}$, l'entaille du $6^{\mathrm{e}}$ arceau ventral est moins profonde et moins aiguë, presque sans membrane; le $5^{\text {e }}$ n'est pas échancré ou sinué ; la tête est moins grosse, etc.

Le carbonarius de Gyllenhal (Ins. Suec. II. 319, 35) est sans doute un insecte immature, qui, du reste, ne peut s'appliquer à notre espèce, car l'auteur suédois le fait synonyme de politus, Payk. var. $b$. et lui donne la taille de l'atratus, Grav. ei la tête subovale. 
Nous avons parfois rencontré la larve supposée du Ph. tenuicornis. En voici la description:

Corps allongé, assez convexe, d'un roux de poix brillant sur la tête et sur le thorax, obscur et mat sur l'abdomen.

Tête suboblongue, de la largeur de la base du prothorax, presque droite sur les côtés, subdéprimée, bissillonnée en avant, éparsement sétosellée; d'un roux de poix brillant, avec le disque plus forcé ; presque lisse ou avec quelques rides obsolètes. Épistome fortement sexdenté. Mandibules fortes, ferrugineuses, falciformes. Palpes grêles, pâles : le dernier article des maxillaires eı cône étroit et allongé : celui des labiaux court, subsubulé.

Yeux petits, peu distincts, lisses.

Antennes testacées, à $1^{\mathrm{er}}$ article court, épais : le $2^{\mathrm{e}}$ allongé, subcylindrique, brusquement renflé au bout en tête d'os : le $3^{\mathrm{e}}$ plus court que le précédent, plus grêle à sa base, subépaissi et paré de 3 soies ve:ss son sommet : le dernier moins long et plus grêle que le $3^{\mathrm{e}}$, à peine épaissi et paré vers le bout de 2 soies légères.

Prothorax suboblong, graduellement rétréci en avant où il est beaucoup moins large que la tête, largement rebordé en arrière, convexe, éparsement sétosellé; d'un roux de poix brillant, avec le disque plus foncé; presque lisse, avec 2 légères fosietles sur le dos, et 3 sillons transversaux sur les côtés.

Mésothorax et métathorax courts, subégaux, rebordès postérieurement, arcuément subélargis en arrière, convexes, éparsement sétosellés; d'un roux de poix livide et brillant; presque lisses, avac 1 ou 2 légères impressions sur les côtés.

Abdomen allongé, graduellement rétréci en arrière, pœu convexe, à peine sillonné sur sa ligne médiane, fortement sétosellé; d'un brun livide et mat, avec le sillon à peine plus pâle sur les $3^{\mathrm{e}}$ et $4^{\mathrm{e}}$ segments; le $1^{\mathrm{er}}$ très-couıt, plus lisse el plus brillant : les $2^{\mathrm{e}}$ à $8^{\mathrm{e}}$ courts, subégaux, finement chagrinés, marqués chacun sur les côtés de cicatrices et bourrelets indiquant les stigmates : le dernier très-court, tronqué et muni au sommet de 2 appendi ces très-longs, subcylindriques ou à peine atténués vers leur extrémité, un peu recourbés en derlans, assez pâles, à soies de la base 
semi-couchées et celles de la seconde moitié beaucoup plus longues et redressées.

Dessous du corps excavé, d'un roux de poix subtestacé. Prosternum subconvexe, lisse. Ventre fortement sétosellé, mat, à dernier arceau terminé par un tube allongé, subcylindrique, subinfléchi, sétosellé, plus court que les appendices supérieurs.

Pieds courts, d'un testacé de poix brillant. Hanches très-grandes, subépineuses. Cuisses grêles, sublinéaires, fortement épineuses en dessous. Tibias plus courts, fortement épineux tout autour, terminés par un crochet solide, assez long, subarqué et très-acéré.

OBs. Cette larve, qu'on rencontre avec l'insecte parfait, diffère de celle du $P h$. aeneus par une couleur plus obscure; par son abdomen à ligne médiané moins pâle et moins fortement sillonnée, avec le dernier segment plus court mais armé d'appendices beaucoup plus longs. Le tube terminal du ventre, un peu moins long, est moins prolongé que les dits appendices. Le dernier article des palpes maxillaires est un peu plus court; le $2^{\mathrm{e}}$ article des antennes est plus brusquement épaissi vers le bout, etc.

\section{Philonthus atratus, Gravenhorst.}

Allongé, peu convexe, éparsement pubescent, dun noir brillant, avec les élytres d'un bron๖é verdâtre. Tête et prothorax submétalliques, lisses et luisants : celui-ci subcarré, à peine rétréci en avant. Élytres et abdomen assez finement et éparsement ponctués. Tarses antérieurs fortement dilatés.

$\sigma$ Le $6^{c}$ arceau ventral assez profondément et angulairement entaillé dans le miliell de son bord apical, avec le fond de l'entaille garni d'une membrane subpellucide, assez large et formant gouttière. Tête en carré subarrondi, à peine moins large que le prothorax.

\& Le $6^{c}$ arceau ventral simple ou subsinueusement tronqué au sommet. Tête suborbiculaire, un peu moins large que le prothorax.

Slaphylinus atratus, Grivenhorst, Micr. 21, 23; - Mon. 84, 74. - Latreille, Hist. Nat. Crust. et Ins. IX, 310, 29. - Gyllendal, Ins. Suec. If, 319, 34. ManNerneim, Brach. 28, 29.

Staphylinus metallicus, Gravenhorst, Hicr. 168, 78. - Latreille, Hist. Nat. Crust. et ins. IX, 323, 64 .

Philonthus atratus, Nordman,, Symb. 82, 30. - Erichson, Col. March. I, 450, 7; BR. 
-Gen. el Spec. Staph. 439, 18. - Redtenbacher, Faun. Austr. 700, 10.-Heer, Faun. Col. Helv. I, 259, 7.- Fairmaire et Laboulbène, Faun. Ent. Fr. I, 517, 15.

- Krastz, Ins. Deut. II, 586, 19. - Thomson, Skand. Col. II, 158, 10, 1860. Fauvel, Faun. Gallo-Rhén. III, 456, 24.

Variété $a$. Ellytres d'un vert bleuâtre, ou bleues.

Staphylinus caemulescens, Boisduval et Lacordaire, Faun. Ent. Par. I, 393, 13. Philonthus janthinipennis, Kolenatı, Melet. Ent. III, 19, 72.

$$
\text { Long., } 0^{\mathrm{m}}, 008 \text { (3 2/3 1.); - larg., } 0^{\mathrm{m}}, 0017 \text { (3/4 l.). }
$$

Corps allongé, peu convexe, d'un noir brillant, avec les élytres d'un bronzé verdâtre ou bleuâtre; revêtu sur celles-ci et l'abdomen d'une légère pubescence grisâtre et très-peu serrée.

Tête plus ou moins orbiculaire ; éparsement sétosellée; d'un noir submétallique et luisant; lisse, avec quelques forts points en arrière vers les tempes qui sont légèrement pubescentes. Front très-large, à peine convexe, marqué entre les yeux de 4 pores sétifères assez gros et subtransversalement disposés, les intermédiaires un peu moindres, beaucoup plus distants entre eux. Cou glabre, presque lisse, d'un noir submétallique et brillant. Labre noir, sétosellé en avant. Mandibules et palpes d'un noir de poix.

Yeux assez grands, subovales, obscurs, lavés de gris.

Antennes peu allongées, un peu plus courtes que la tête et le prothorax rẻunis; subfiliformes ou à peine épaissies; légèrement pubescentes et éparsement pilosellées vers leur base; entièrement noires; à $1^{\mathrm{er}}$ article allongé, en massue grêle et subarquée : les $2^{\mathrm{e}}$ et $3^{\mathrm{e}}$ obconiques : le $3^{\mathrm{e}}$ suballongé, un peu plus long que le $2^{\mathrm{e}}$ : les suivants graduellement un peu plus courts, subobconiques : les $4^{\mathrm{e}}$ à $6^{\mathrm{e}}$ oblongs, le $7^{\mathrm{e}}$ suboblong et les pénultièmes nullement transverses : le dernier subovalaire, subéchancré ou subtronqué au bout et subacuminé inférieurement.

Prothorax subcarré, à peine rétréci en avant; à peine moins large en arrière que les élytres; tronqué au sommeh avec les angles antérieurs infléchis et arrondis; subarqué sur les côtés, qui, vus latéralement, sont subsinués en arrière; subarrondi à sa base, avec les angles postérieurs. obtus; légèrement convexe; éparsement sétosellé, avec la longue soie latérale située sur le rebord même; d'un noir submétallique et luisant; lisse, avec 2 séries dorsales composées de 4 points assez forts et subégalement distants, l'antérieur plus en dehors; marqué de plus, outre 
ceux de la marge, de 5 autres points semblables, épars en avant vers les côtés. Repli noir, glabre, lisse.

Écusson densement pointillé, pubescent, d'un noir assez brillant et submétallique.

Élytres subtransverses, de la longueur du prothorax ou à peine plus longues ; subdéprimées; assez finement et éparsement ponctuées ; d'un bronzé brillant, verdâtre ou bleuâtre ; éparsement pubescentes, avec quelques légères soies redressées, dont 1 ou 2, notamment plus longues, sur les côtés, et une autre de chaque côté de l'écusson. Épaules cachées.Ailes blanches.

Abdomen suballongé, moins large que les élytres, subparallèle ou un peu atténué en arrière; subconvexe sur le dos, avec les 3 premiers segments subimpressionnés en travers à leur base, et leur repli en accolade émoussée; éparsement sétosellé; assez finement et éparsement ponctué; d'un noir brillant ; éparsement pubescent. Le $6^{e}$ segment subtronqué ou à peine arrondi au sommet.

Dessous du corps aspèrement ponctué, finement pubescent, d'un noir brillant. Dessous de la tête presque glabre, presque lisse ou très-éparsement ponctué. Lame mésosternale subconvexe, presque lisse ou avec la seule chaînette de pores sétifères; à pointe prolongée et émoussée au bout; à arête assez saillante, arquée, s'arrêtant vers le premier tiers. Métasternum subdéprimé, à peine canaliculé sur sa ligne médiane. Ventre convexe, éparsement sétosellé, plus fortement en arrière.

Pieds médiocres, aspèrement ponctués, finement pubescents, 'd'un noir de poix. Cuisses antérieures finement épineuses en dessous vers leur sommet; les postérieures assez grêles. Tarses antérieurs à 3 premiers articles subégalement et plus $\left(\sigma^{\prime}\right)$ ou moins $(q)$ fortement dilatés; les postérieurs à $1^{\mathrm{er}}$ article beaucoup plus long que le dernier, égal aux 3 suivants réunis.

Patrie. Cette espèce se trouve sous les pierres et sous les mousses, au bord des ruisseaux d'eau courante. Elle est peu commune : les environs de Paris et de Lyon, la Normandie, l'Auvergne, le Beaujolais, les Alpes, la Savoie, les Pyrénées, etc.

OBs. La taille est moindre que dans toutes les espèces précédentes, avec les élytres moins densement ponctuées, et les hanches intermédiaires un peu moins distantes.

La variété à élytres bleues (caerulescens) a celles-ci en mẻme temps à 
peine plus longues, plus déprimées et un peu plus densement ponctuées, avec la suture subimpressionnée de chaque côté. Elle est exclusive aux régions alpines, et elle doit constituer au moins une race à part.

Parfois les tibias et les tarses sont d'un roux de poix funcé. Rarement les $4^{\mathrm{e}}$ et $5^{\mathrm{e}}$ segments de l'abdomen sont plus densement ponctués à leur base, tant en dessus qu'en dessous. Quelquefois, une des séries dorsales est de 5 points.

On peut rapporter à l'atratus le picipes de Stephens (Ill. Brit. V, 221).

Henri Kroyer in Schiödte, Nat. Tids, p. 200) a parlẻ de la larve de l'atratus.

\section{Philonthug Ghilianii, Kratz.}

Allongé, subdéprimé, peu pubescent, d'un noir brillant, avec la tête et le prothorax d'un bronzé cuivreux et très-brillant et les élytres d'un bleu obscur et mat. Téte et prothorax à peine chagrinés, luisants : celui-ci subrétréci en avant. Ellytres très-finement chagrinécs, très-finement et densement ponctuées. Abdomen assez finement et modérément ponctué. Tarses antérieur's simples.

$\sigma^{7}$ Le $6^{e}$ arceau ventral profondément et très-aigument entaillé, avec le fond de l'entaille garni d'une étroite gouttière.

\& Le $6^{\mathrm{e}}$ arceau ventral simple.

Philonthus laetus, HeER, Faun. Col. Helv. I, 259, 8. - FaUvel, Faun. Gallo-Rhén. III, 472, 40 (1).

Philonthus Ghilianii, KraAtz, Ins. Deut. II, 574, 13-14 (note).

$$
\text { Long., } 0^{\mathrm{m}}, 010 \text { (4 1/2 l.); - larg., } 0^{\mathrm{m}}, 0026 \text { (1 } 1 / 5 \text { l.). }
$$

Patrie. Cette espèce se prend dans les Alpes du Piémont et du Valais, ainsi que dans les Alpes maritimes. Elle nous a été communiquée par M. Abeille de Perrin, qui la tenait du mont Cenis. Elle est rare dans les collections.

OBs. Nous nous dispensons de la décrire complétement, tant elle res-

(1) M. Kraatz a dủ changer le nom de laetus, qui cxistait déjà dans Erichson (Gen. et Spec. Staph. 477, 81). 
semble au Ph. decorus décrit ci-après. Toutefois, l'abdomen, la bouche et les pieds sont d'une couleur plus noire; la tête et le prothorax sont d'un bronzé plus clair, plus éclatant et plus ou moins cuivreux ; les élytres sont encore plus mates, d'un bleu obscur et parfois un peu verdâtre; leur poncluation paraît plus fine et à peine moins serrée. L'abdomen, plus convexe et surtout plus brillant, est un peu moins finement et moins densement ponctué, etc.

Avec le Ghilianii commence une série d'espèces à tête non plus grande chez le $\sigma$ que chez la $q$, subovalaire et sensiblement moins large que le prothorax, avec celui-ci plus ou moins rétréci en avant. Les hanches intermédiaires sont plus ou moins rapprochées dans leur milieu.

\section{Philonthus seutatus, ERICHSON.}

Allongé, peu convexe, finement pubescent, d'un noir brillant, avec la tête, le protinorax et les élytres d'un bronzé un peu verdâtre. Tête et prothorax lisses et luisants : celui-ci subtransverse, un peu rétréci en avant. Elytres et abdomen finement et densement ponctuls. Tarses antérieurs légèrement dilatés.

ơ Le $4^{\mathrm{e}}$ arceau ventral prolongé en forme de lame large, recouvrant le $5^{\circ}$.

으 Le 6 arceau ventral simple.

Philonthus scutatus, Erichson, Gen. et Spec. Staph. 438, 17. - Redtenbicher,

Faun. Austr. 701, 13. - Fatrmairr et Labouldène, Faun. Ent. Fr. I, 317, 14. -

Krustz, Ins. Deut. II, 580, 12. - Thosson, Skand. Col. If, 156, 4, 1860.

Philonthus rotundicollis, Fauvel, Faun. Gallo-Rhén. III, 456, 23.

$$
\text { Long., } 0^{\mathrm{m}}, 011 \text { (5 l.); - larg., } 0^{\mathrm{m}}, 0022 \text { (1 l.). }
$$

Corps allongé, peu convexe, d'un noir brillant, avec la tête, le prothorax et ies élytres d'un bronzé un peu verdâtre; revêtu sur celles-ci et l'abdomen d'une fine pubescence grisâtre et modérément serrée.

Tête subovale, moirıs large que le prothorax; éparsement sétosellée; d'un bronzé obscur et à peine verdâtre, très-luisant ; lisse, très-finement et éparsement pointillée sur son disque; légèrement pubescente et plus fortement poncluée sur les tempes. Front très-large, subconvexe, marqué 
entre les yeux de 4 pores sétifères subtransversalement disposés, les intermédiaires moindres et beaucoup plus distants entre eux. Cou glabre, éparsement pointillé sur les côtés, d'un bronzé très-brillant. Labre noir, fortement sétoselle en avant. Mandibules et palpes couleur de poix.

Yeux assez grands, subovales, plus ou moins obscurs.

Antennes peu allongées, un peu plus courtes que la tête et le prothorax réunis; à peine épaissies; pubescentes et éparsement pilosellées vers leur base; noirâtres; à $1^{\mathrm{er}}$ article allongé, en massue subarquée : les $2^{\mathrm{e}}$ et $3^{\mathrm{e}}$ obconiques : le $3^{\mathrm{e}}$ allongé, un peu plus long que le $2^{\mathrm{e}}$ : les suivants graduellement un peu plus courts : les $4^{\mathrm{e}}$ à $6^{\mathrm{e}}$ suboblongs, subcylindriques : les $7^{\mathrm{e}} \mathrm{a} 10^{\mathrm{e}}$ subobconiques : le $7^{\mathrm{e}}$ à peine oblong : le $8^{\mathrm{e}}$ non, les $9^{\mathrm{e}}$ et $10^{\mathrm{c}}$ à peine ou non transverses, vus de côté : le dernier subovalaire, obliquement subéchancré au bout et acuminé inférieurement.

Prothorax subtransverse, un peu rétréci en avant; un peu moins large en arrière que les élytres; tronqué au sommet, avec les angles antérieurs infléchis et subarrondis; légèrement arqué sur les côlés, qui, vus latéralement, sont subsinués en arrière; subarrondi à sa base, avec les angles postérieurs obtus ; médiocrement convexe ; éparsement sétosellé, avec la longue soie latérale située sur le rebord même; d'un bronzé obs cur, à peine verdâtre et très-luisant; lisse, très-finement et éparsement pointillé, avec 2 séries dorsales composées de 4 points médiocres et subégalement distants; marqué, de plus, outre ceux de la marge, de 4 ou 5 points semblables, écartés, en avant vers les côtés. Repli noir. glabre, lisse.

Écusson densement pointillé, pubescent, d'un noir brillant.

Élytres transverses, un peu plus longues que le prothorax; subdéprimées ; finement, densement et subrâpeusement ponctuées ; d'un bronzé brillant et un peu verdâtre; modérément pubescentes, avec 2 longues soies redressées sur les côtés et une autre ver's l'écusson. Épaules étroitement arrondies.

Abdomen suballongé, moins large que les élytres; à pcine arqué sur les côtés et à peine atténué tout à fait en arrière; assez convexe sur le dos ; éparsement sétosellé ; finement et densement ponctué ; d'un noir brillant ; à pubescence modérément serrée, plus longue que celle des élytres. Le $6^{\circ}$ segment à peine arrondi au sommet.

Dessous du corps subaspèrement ponctué, finement pubescent, d'un noir brillant. Dessous de la tête presque glabre, presque lisse ou à peine ponctué en arrière. Pointe mésosternale aiguë; arête assez saillante, ar- 
quée. Métasternum subdéprimé sur son milieu. Ventre convexe, éparsement sétosellé.

Pieds médiocres, aspèrement ponclués, finement pubescents, d'un noir de poix, avec les tarses et parfois les tibias moins foncés. Cuisses antérieures fortement épineuses en dessous vers leur sommet. Tibias antérieurs à 3 premiers articles légèrement dilatés; les postérieurs à $1^{\mathrm{er}}$ article sensiblement plus long que le dernier, égal aux 3 suivants réunis.

Patrie. Cette espèce, particulière à l'Autriche, à la Silésie el à la Hongrie, est très-rare en France : les environs de Paris, les BassesAlpes, etc.

OBs. Elle ne diffère du Ph. laminatus que par sa couleur un peu moins verdâtre; par la ponctuation des élytres et de l'abdomen un peu plus fine et un peu plus serrée, et surtout par son prothorax paré de 2 séries dorsales de 4 points. Comme lui, elle a le $4^{\mathrm{e}}$ arceau du ventre prolongé sur le $\check{\jmath}^{\mathrm{e}}$, chez les $\sigma$.

Les tarses sont parfois d'un roux de poix, et rarement les tibias.

Contrairement à la plupart des autres espèces, la tête et le prothorax sont parsemés d'une ponctuation éparse, très-fine et souvent peu apparente.

C'est avec doute qu'on doit rapporter au scutatus le rotundicollis de Ménétriès (Cat. Rais., 145,581), qui, sous la même dénomination, a mêlé plusieurs espèces. Nous avons donc préféré le nom doriné par Erichson.

On doit peut-être aussi appliquer au scutatus le sinuatocollis de Motschulsky (Schrenk Reis., 1860, 121, pl. 8, fig. 16) et le duplopunctatus du même auteur (Bul. Mosc., 1860, II, 567).

\section{Philonthus decorus, Gravenhorst.}

Allongé, subdéprimé, très-finement pubescent, d'un noir assez brillant, avec la tête et le prothorax d'un noir verdâtre, les élytres d'un bronzé obscur et mat, les palpes, les intersections ventrales, les tibias et les tarses d'un roux de poix. Tête et prothorax à peine chagrinés, brillants : celui-ci subrétréci en avant. Élytres très-finement chagrinées, finement et densement, abdomen finement et assez densement, ponctués. Tarses antérieurs simples.

$\sigma$ Le $6^{\text {e }}$ arceau ventral fortement et très-aigument entaillé dans le mi- 
lieu de son bord apical, avec les bords de l'entaille garnis en dedans d'une large membrane subpellucide. Le $5^{\mathrm{e}}$ à peine sinué dans le milieu de son bord postérieur.

․ Le $6^{\mathrm{e}}$ arceau ventral subarrondi, le $5^{\circ}$ sïmple, à leur bord apical.

Staphylinus decorus, Gravenhorst, Micr. 19, 20 ; - Mon: 85, 77. - Grllenhal, Ins. Suec. II, 316, 32.- MaNNERBEim, Brach. 27, 14.- Boisduval et Lacordaire, Faun. Ent. Par. I, 391, 9.

Philonthus decurus, NordmanN, Symb. 82, 31. - Erichson, Col. Narch. I, 451, 8 ; - Gen. et Spec. Staph. 442, 24. - Redtenbacrer, Faun. Austr. 701, 12. Heer, Faun. Col. Helv. I, 260, 9. - Fairmaire et Laboulbène, Faun. Ent. Fr. I, 517, 16. - KraAtz, Ins. Deut. II, 580. 13. - Thomson, Skand. Col. II, 163, 26, 1860. - Fauvel, Faun. Gallo-Rhén. III, 472, 41.

$$
\text { Long., } 0^{\mathrm{m}}, 012\left(5 \text { 1/2 1.); - larg., } 0^{\mathrm{m}}, 0028(1 / / 41 .)\right. \text {. }
$$

Corps allongé, subdéprimé, d'un noir assez brillant, avec la tête et le prothorax un peu verdâtres et brillants, et les élytres d'un bronzé obscur et mat; revêtu sur celles-ci et sur l'abdomen d'une très-fine pubescence d'un gris foncé, assez ou médiocrement serrée.

Tête subovale, moins large que le prothorax; éparsement et longuement sétosellée; d'un noir bronzé souvent un - peu verdâtre, brillant ; à peine chagrinée, avec quelques assez gros points en arrière sur les côtés, et les tempes légèrement pubescentes, plus finement et plus densement ponctuées vers leur base. Front très-large, subconvexe, marqué entre les yeux de 4 pores sétifères subtransversalement disposés, les intermédiaires moindres, beaucoup plus distants entre eux et un peu plus en arrière. Cou glabre, presque lisse, à peine ponctué sur les côtés, d'un bronzé brillant. Labre noir, fortement sétosellé en avant. Mandibules d'un noir de poix. Palpes roussatres.

Yeux assez grands, subovales, obscurs, lavés de gris.

Antennes suballongées, environ de la longueur de la tête/et du prothorax réunis; subfiliformes ou à peine épaissies; légèrement pubescentes et éparsement pilosellées vers leur base; noires, avec l'insertion des premiers articles souvent d'un roux de poix; le $1^{\text {er }}$ allongé, en massue grêle et subarquée : les $2^{\mathrm{e}}$ et $3^{\mathrm{e}}$ obconiques : le $2^{\mathrm{e}}$ suballongé : le $3^{\mathrm{e}}$ allongé, sensiblement plus long que le $2^{\circ}$ : les suivants graduellement un peu plus courts, subobconiques : les $4^{\mathrm{e}}$ à $7^{\mathrm{e}}$ oblongs, le $8^{\mathrm{e}}$ suboblong : les $9^{\mathrm{e}}$ et 
$10^{\circ}$ nullement transverses, même| vus de côté : le dernicr subovale, subtronqué ou à peine échancré au bout, subacuminé inférieurement.

Prothorax à peine oblong, subrétréci en avant; moins large en arrière que les èlytres; tronqué ou à peine échancré au sommet, avec les angles antérieurs infléchis et subarrondis ; légèrement arqué sur les côtés ; médiocrement arrondi à sa base, avec les angles postérieurs obtus; subconvexe; à peine sétosellè, avec la longue soie latérale située contre le rebord mème ; d'un noir bronzé brillant, souvent un peu verdâtre ; à peine chagriné, avec 2 séries dorsales composées de 4 points assez fins, dont l'antérieur un peu plus écarté ; marqué de plus, outre ceux de la marge, de 4 ou 5 autres points semblables, épars, en avant, vers les côtés. Repli noir, glabre, lisse.

Ecusson densement pointillé, pubescent, d'un noir assez brillant.

Élytres transverses, un peu ou à peine plus longues que le prothorax; déprimées; très-finement et visiblement chagrinées, et en outre finement, densement et subaspèrement ponctuées ; d'un bronzé obscur et mat ; trèsfinement et modérément pubescentes, avec une longue soie redressée derrière les épaules et une autre vers l'écusson. Épaules arrondies.

Abdomen peu allongé, moins large que les élytres; subarqué sur les côtés et sensiblement atténué en arrière, subconvexe sur le dos ; éparsement sétosellé; finement et assez densement ponctué; d'un noir assez brillant; à pubescence à peine moins serrée que celle des élytres. Le $6^{\circ}$ segmert subarrondi ou obtusément angulé au sommet.

Dessous $d u$ corps aspèrement ponctué, finement pubescent, d'un noir brillant, avec les intersections ventrales d'un roux de poix plus ou moins foncé. Dessous de la tête presque glabre, presque lisse. Lame mésosternale presque lisse ; à arête peu saillante, arquée et descendue jusqu'au milieu environ; à pointe aiguë, terminée par un petit lobe lisse, qui la lie à l'intermède (1). Métasternum subdéprimé sur son milieu. Ventre convexe, éparsement et longuement sétosellé en arrière.

Pieds assez allongés, aspèrement ponctués, finement pubescents ; d'un noir de poix, avec les tibias et les tarses un peu roussâtres. Cuisses antérieures fortement épineuses en dessous vers leur sommet; les postérieures suballongées, assez grêles. Tarses antérieurs simples; les postérieurs à $1^{\text {er }}$ article beaucoup plus long que le dernier, égal aux 3 suivants réunis.

(1) Cet intermède, assez étroit, est sinué en avant, sur le dos. 
Patrie. Celte espèce, médiocrement commune, babite les forêts et les montagnes, sous les pierres et les mousses : les environs de Paris, la Normandie, l'A uvergne, le Bugey, le mont Pilat, les Alpes, les Pyrénées, etc.

OBs. Elle est remarquable par ses élytres mates et densement ponctuées. Elles sont parfois d'un bronzé un peu bleuâtre, d'autres fois presque noires.

Sa tête assez petite, son prothorax subrétréci en avant, son abdomen atténué en arrière, concourent à lui donner un ensemble fusiforme, encore plus accusé dans les espèces suivantes.

\section{Philonthus politus, Fabricius.}

Allonge, subfusiforme, peu convexe, finement pubescent, d'un noir brillant, avec la tête, le prothorax et les élytres d'un bronzé: obscur et à peine verdâtre, et le dessous du $1^{\mathrm{er}}$ article des antennes testacé. Tête et prothorax presque lisses, luisants : celui-ci subcarré, rétréci en avant. Élytres finement et très-densement, abdomen finement et densement, ponctués.

$\sigma^{*}$ Le $6^{\mathrm{e}}$ arcean ventral assez profondément et angulairement entaillé dans le milieu de son bord apical. Tarses antérieurs à 4 premiers articles assez fortement dilatés.

$\subsetneq$ Le $6^{\mathrm{e}}$ arceau ventral subtronqué ou à peine arrondi, le $5^{\mathrm{e}}$ presque simple, à leur bord apical. Tarses antérieurs à 4 premiers articles à peine dilatés.

Staphylinus politus, Syst. El. 266, 7 ; - Ent. Syst. I, II, 524, 20 - OLIvier, Ent. III, no 42, 25, 31, pl. II, fig. 10. - Gravenhorst, Micr. 17, 19; - Mon. 85, 76. - Latrellee, Hist. Nat. Crust. et Ins. IX, 308, 26; - Gen. Crust. et Ins. I, 287, 3.- Gyylleneal, Ins. Suec. II, 317, 33. - ManNerheim, Brach. 28, 46. - Boisnuval et Lacordaire, Faun. Ent. Par. I, 392, 10.

Philonthus politus, Nordmann. Symb. 8t, 27. - Erichson, Col. March. I, 432, 10 ; - Gen. et Spec. Staph. 443, 26.-Reptenbacher, Faun. Austr. 701, 13. - HeEr, Faun. Col. Helv. I, 260, 11. - Fairmaire et Laboulbève, Faun. Ent. Fr. I, s18, 19.- Kraatz, Ins. Deut. II, 581, 14. - Thouson, Skand. Col. II, 162, 25, 1860. - Fauvel, Faun. Gallo-Rhén. III, 473, 42.

$$
\text { Long., } 0^{\mathrm{m}}, 011 \text { (5 l.); - larg., } 0^{\mathrm{m}}, 0010 \text { (1 l.). }
$$

Corps allongé, subfusiforme, peu convexe, d'un noir brillant, avec la 
'têle, le prothorax et les élytres d'un bronzé plus ou moins foncé; recouvert sur celle-ci et l'abdomen d'une fine pubescence grisâtre et médiocrement serrée.

Tête subovale, sensiblement moins large que le prothorax, éparsement et longuement sétosellée; d'un noir bronzė très-brillant; presque lisse, légèrement pubescente et éparsement ponctuée en arrière sur les tempes. Front large, subconvexe, marqué entre les yeux de 4 pores sétifères subtransversalement disposés, les intermédiaires bien moindres, beaucoup plus distants entre eux et un peu plus en arrière. Cou glabre, presque lisse, d'un bronzé obscur et brillant. Labre noir, fortement sétosellé en avant. Mandibules et palpes d'un noir de poix, avec le sommet des premières parfois ferrugineux.

Yeux assez grands, ovales-oblongs, obscurs, lavés de gris.

Antennes suballongées, de la longueur de la tête et du prothorax réunis; subfiliformes ou à peine épaissies; légèrement pubescentes et éparsement pilosellées vers leur base; noires, avec le $1^{\mathrm{e}_{\mathbf{r}}}$ article testacé mais rembruni en dessus ; celui-ci allongé, en massue subarquée : les $2^{\circ}$ et $3^{\text {e }}$ obconiques : le $3^{\mathrm{e}}$-allongé, plus long que le $2^{\mathrm{e}}$ : les suivants graduellement un peu plus courts : les $4^{\mathrm{e}}$ à $6^{\mathrm{e}}$ oblongs, subcylindriques : les pénultièmes subobconiques, oblongs ou suboblongs : le dernier subovale, obliquemen t subéchancré au bout.

Prothorax presque aussi large que long, médiocrement rétréci en avant, à peine moins large en arrière que les élytres; à peine échancré au sommet, a vec les angles antérieurs subinfléchis et subarrondis ; subarqué sur les côtés; arrondi à sa base, avec les angles postérieurs obtus; assez convexe; légèrement sétosellé sur le rebord même; d'un noir bronzė brillant et parfois à peine verdâtre; presque lisse, avec 2 séries dorsales composées de 4 points assez fins et subégalement distants; marqué de plus, outre ceux de la marge, de 4 ou 5 autres points semblables, écartés et épars, en avant, vers les côtés. Repli noir, glabre, lisse.

Écusson densement pointillé, pubescent, d'un noir assez brillant et métallique.

Élytres transverses, un peu ou à peine plus longues que le prothorax ; subdéprimées ; finement, très-densement et subrâpeusement ponctuées ; d'un bronzé obscur, assez brillant et parfois à peine verdâtre ; briève ment et modérément pubescentes, avec une longue soie redressée derrière les épaules, et une autre vers l'écusson. Épaules subarrondies. Ailes enfumées. 
Abdomen suballongé, un peu moins large que les élytres, à peine arqué sur les côtés et visiblement atténué en arrière ; subconvexe sur le dos.; éparsement sétosellé; finement et densement ponctué; d'un noir brillant; à pubescence plus longue mais á peine aussi serrée que celle des élytres. Le $6^{\text {e }}$ segnent subarrondi au sommet.

Dessous du corps aspèrement ponctué, finement pubescent, d'un noir brillant. Dessous de la tête presque glabre et presque lisse. Lame mésosternale lisse en avant, rugueuse en arrière ; à arête transversale assez saillante, arquée, non descerıdue jusqu’au milieu; à pointe très-acérée. Métasternum subdéprimé sur son milieu. Ventre convexe, éparsement sétosellé en arrière, souvent subirisé.

Pieds assez longs, aspèrement pointillés, aspèrement pubescents, noirs. Cuisses antérieures assez fortement épineuses en dessous vers leur sommet; les postérieures suballongées, assez grêles. Tarses postérieurs à $1^{\text {er }}$ article beaucoup plus long que le dernier, subégal aux 3 suivants réunis.

Patrie. Cette espèce est très-commune, sous les pierres, les mousses, les feuilles mortes, etc., dans presque toute la France et à toutes les altitudes.

Obs. Elle se distingue de toutes ses voisines par la couleur du $1^{\text {er }}$ article des antennes.

Les exemplaires des montagnes sont un peu plus robustes et d'un bronzé un peu plus clair. .

Les articles des antennes (4-11) sont parfois brièvement pédicellés, avec le pédicelle roussâtre.

Le Philonthus politus de Linné, de Paykull et autres auteurs, se rapporte à plusieurs espèces. On en peut dire autant de l'aeneus de Degeer et du Staphỵlin à étuis bronzés de Geoffroy.

On doit appliquer au politus les cognatus, maculicornis, microcephalus et melanopterus de Stephens (Ill. Brit., V, 229).

La larve du Ph. politus a été décrite par Westwood (Zool. Journ., 1826-27, p. 56).

\section{Philonthus Iucens, ErICHSON.}

Allongé, subfusiforme, peu convexe, finement pubescent, d'un noir assez brillant et ì peine bronzé. Tête et prothorax presque lisses, brillants : 
celui-ci subtransverse, rétréci en avant. Elytres finement et très-densement, abdomen assez finement et assez densement, ponctués.

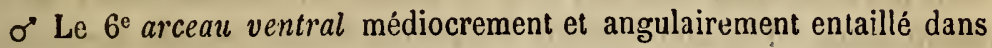
le milieu de son bord apical. Tarses antérieurs à 3 premiers articles à peine dilatés.

\& Le $6^{\mathrm{e}}$ arcean ventral subarrondi à son bord apical. Tarses anté. rieurs simples.

Philonthus lucens, Enichson, Col. March. I, 452, 9; - Gen. et Spec. Staph. 443, 25.- Redtenb.cher, Faun. Austr. 701, 13.- HeEr, Faun. Col. Helv. I, 260,10. - Fairmaire et L.boulbène, Faun. Ent. Fr. I. 518, 18. - Kraatz, Ins, Deut. II, 582, 15. - Rye, Ent. Ann. 18599, 129. - Thoмson, Op. Ent. 1870, II, 126.

Philonthus Mannerheimi, FavVEL, Faun. Gallo-Rhén. III, 473, 42.

$$
\text { Long., } 0^{\mathrm{m}}, 0105(43 / 41 .) ;- \text { larg., } 0^{\mathrm{m}}, 0023 \text { (1 l.). }
$$

Corps allongé, subfiliforme, peu convexe, d'un noir assez brillant, avec la tête, le prothorax et les élytres à peine bronzés; revêtu sur celles-ci ct l'abdomen d'une fine pubescence d'un gris obscur et peu serrée.

Tête subovalaire, beaucoup moins large que le prothorax; éparsement sétosellée; d'un noir brillant et à peine bronzé; presque lisse, à peine pubescente et assez finement et subéparsement ponctuce en arrière sur les tempes. Front large, subconvexe, paré de chaque côté entre les yeux de 2 pores sétifères rapprochés et transversalement disposés, les internes beaucoup moindres. Cou glabre, presque lisse, d'un noir brillant. Labre d'un noir brillant, sétosellé en avant. Mandibules et palpes d'un noir de poix, parfois moins foncé.

Yeux assez grands, subovales, plus ou moins obscurs.

Antennes peu allongées, un peu plus courtes que la tête et le prothorax réunis, faiblement épaissies ; légèrement pubescentes et éparsement pilosellées vers leur base; noires; à $1^{\mathrm{er}}$ article allongé, en massue subarquée : les $2^{\mathrm{e}}$ et $3^{\mathrm{e}}$ suballongés, obconiques, subégaux ou avec le $3^{\mathrm{e}}$ à peine plus grand : les suivants graduellement un peu plus courts et à peine plus épais, subobconiques : les $4^{\mathrm{e}}$ à $6^{\mathrm{e}}$ suboblongs : le $7^{\mathrm{e}}$ non, les pénultièmes légèrement transverses, vus de cỏté : le dernier subovale, subtronqué au bout et subacuminé inférieurement.

Prothorax à peine transverse, rétréci ell avant; un peu moins large en arrière que les élytres; tronqué ou à peine échancré au sommet, avec les 
angles antérieurs subinfléchis et arrondis; sensiblement arqué sur les côtés ; arrondi à sa base, avec les angles postérieurs obtus; médiocrement convexe; légèrement sétosellé, avec la longue soie latérale située sur le rebord même; d'un noir brillant et à peine bronzé ; presque lisse, avec 2 séries dorsales.composées de 4 points assez fins et également distants, l'antérieur un peu plus en dehors; marque de plus, vers les côtés, outre ceux de la marge, de 5 points semblables et écartés. Repli noir, glabre, lisse.

Écusson densement pointillé, pubescent, noir.

Élytres fortement transverses, à peine plus longues que le prothorax; subdéprimées; finement, très-densement et subrâpeusement ponctuées ; d'un noir à peine bronzé, peu ou parfois assez brillant; finement et modérément pubescentes, avec une soie redressée vers l'écusson, celles des côtés souvent caduques. Epaules effacées. Ailes enfumées.

Abdomen suballongé, un peu moins large que les élytres, graduellement atténué en arrière; assez convexe sur le dos ; éparsement sétosellé postérieurement; assez finement et assez densement ponctué; d'un noir brillant, parfois subirisé; à pubescence évidemment moins serrée que celle des élytres. Le $6^{\mathrm{e}}$ segment subarrondi au sommet.

Dessous du corps subaspèrement et peu densement ponctué, légèrement pubescent, d'un noir brillant. Dessous de la tête glabre; éparsement ponctué vers sa base. Lame mésosternale obsolètement ponctuée en avant, rugueuse en arrière; à arête transversale assez saillante, angulée, à peine descendue jusqu'au milieu; à pointe très-aiguë. Métasternum à peine convexe, à peine canaliculé sur sa ligne médiane. Ventre convexe, éparsement sétosellé, plus longuement en arrière, souvent subirisé.

Pieds médiocres, aspèrement ponctués, finement pubescents, d'un noir de poix, avec les tarses parfois moins foncés.: Guisses antérieures fọtement épineuses en dessous vers leur sommet; les postérieures assez allongées, assez grêles. Tarses postérieurs à $1^{\mathrm{er}}$ article beaucoup plus long que le dernier, subégal aux 3 suivants réunis.

Patrie. Cette espèce, peu commune, se prend dans les forèts, sous les mousses, dans les environs de Paris, la Normandie, les Vosges, le mont Pilat, les Alpes, la Savoie, les Pyrénées, etc. Elle est commune en Suisse.

OBs. Outre la coloration du $1^{\text {er }}$ article des antennes, elle est proportionnellement moins allongée et un peu plus large que l'espèce précédente. Elle est d'un bronzé plus obscur, avec la ponctuation de l'abdomnen 
un peu moins serrée. Les antennes sont moins grêles, à pénultièmes articles plus courts, etc.

D'après Motschulsky, le lucens de Mannerheim serait l'atratus. Mais notre espèce est réellement le lucens d'Erichson. Il n'y a donc pas d'inconvénient à conserver cette dénomination, puisqu'elle ne prime pas ailleurs, l'espèce désignée ainsi par Mannerheim et peut-être aussi par Nordmann étant synonyme d'une autre et, par conséquent, devant être regardée comme non avenue.

\section{Philonthus variug, Gyllennal.}

Allongé, subfusiforme, peu convexe, légèrement pubesceint, d'un noir brillant, avec les élytres d'un bronzé un peu verdâtre. Tête et prothorax lisses, luisants : celui-ci presque aussi large que long, rétréci en avant. Elytres et abdomen finement et assez densement ponctués.

$\sigma$ Le $6^{\text {e }}$ arceau ventral assez fortement et subogivalement entaillé dans le milieu de son bord apical, avec le fond de l'entaille garni d'une gouttière subpellucide. Tarses antérieurs à $1^{\mathrm{er}}$ et $3^{\mathrm{e}}$ articles fortement, le $2^{e}$ plus fortement, dilatés.

q Le $6^{e}$ arceau ventral subarrondi à son bord apical. Tarses antérieurs à 3 premiers articles légèrement dilatés.

Staphylinus varius, Gyllenhal, Ins. Suec. II, 321, 37. - ManNerheiM, Brach. 28, ö3. - Boisduval et lacondaire, Faun. Fint. Par. I, 395, 17.

Staphylinus varians, Gravenhonst, Micr. 20, 21.

Philonthus varius, Nondmank Symb. 84, 37. - ERichson, Col. March. I, 455, 14 ;

- Gen. et Spec. Staph. 447, 31. - Redtenbacher, Faun. Austr. 702, 21. Heer, Faun. Col. Helv. I, 261, 16. - Falrmaire et Laboulbèie, Faun. Ent. Fr. I, 519, 21, - Kratiz, Ins. Deut. II, 583, 17.-Thouson, Skand. Col. II, 163, 27, 1860. - Faụvel, Faun. Gallo-Rhén. III, 476, 46.

Variété $a$. Élytres d'un noir bronzé à leur base, rouges à leur extrémité.

Staphylinus bimaculatus, Gravenhorst, Micr. 38, 55; - Mon. 63, 32.-Latreille,

Hist. Nat. Crust. et Ins. IX, 321, 60. - Bolsduval et Lacordalre, Faun. Ent. Par. I, 400, 26.

Philonthus bimaculatus, Norduann, Symb. 92, 59.- Ericuson, Col. March, I, 454, 13 ; - Gen. et Spec. Staph., 448, 33. 
Variété $b$. Élytres presque entièrement rouges.

Staphylinus nitidicollis, Borsduval et Lacordatre, Faun. Ent. Par. I, 40t, 28. Staphylinus dubius, GravenhoRst, Mon. 74, 63 ?

$$
\text { Long., } 0^{\mathrm{m}}, 0077 \text { (3 1/2 l.); - larg., } 0^{\mathrm{m}}, 0014 \text { (2/3 l.). }
$$

Corps allongé, subfusiforme, peu convexe, d'un noir brillant, avec les élytres plus ou moins bronzées; revêtu sur celles-ci et l'abdomen d'une fine pubescence grisâtre et peu serrée.

Tête subovalaire, beaucoup moins large que le prothorax; distinctement sétosellée; d'un noir luisant, lisse, éparsement et assez fortement ponctuée derrière les yeux. Front large, subconvexe, paré de chaque côté de 2 pores sétifères assez gros, rapprochés et transversalement disposés, les extérieurs joignant le bord interne de l'œil. Cou glabre, lisse, d'un noir luisant. Labre noir, sétosellé en avant. Mandibules et palpes noirs.

Yeux médiocres, subovales, noirs, souvent lavés de gris.

Antennes suballongées, de la longueur de la tête et du prothorax réunis ; faiblement épaissies; pubescentes et éparsement pilosellées vers leur base ; noires; à $1^{\mathrm{er}}$ article allongé, en massue subarquée : les $2^{\mathrm{e}}$ et $3^{\mathrm{e}}$ obconiques : le $3^{\mathrm{e}}$ suballongé, un peu plus long que le $2^{\mathrm{e}}$ : les suivants graduellement un peu plus courts, subcylindriques, avec les pénultièmes subobconiques: les $4^{\mathrm{e}}$ à $7^{\mathrm{e}}$ oblongs ou suboblongs : les $8^{\mathrm{e}}$ à $10^{\mathrm{e}}$ à peine plus longs ou au moins aussi longs que larges, vus de côtć : le dernier ovale-oblong, subobliquement tronqué au bout, subacuminé inférieurement.

Prothorax presque aussi long que large, évidemment rétréci en avant; presque aussi large en arrière que les élytres; tronqué ou à peine échancrè au sommet, avec les angles antérieurs infléchis ou arrondis; presque droit ou à peine arqué sur les côtés; arrondi à sa base ainsi qu'aux angles postérieurs; assez convexe; légèrement sétosellé, a vec la longue soie latérale située sur le rebord même; d'un noir luisant; lisse, avec 2 séries dorsales composées de 4 points (1) assez forts et subégalement distants; marqué de plus, sur les côtés et en avant, outre ceux de la marge, de 5 autres points semblables el épars. Repli noir, glabre, lisse.

Écusson assez densement pointillé, pubescent, d'un noir brillant et submétallique.

(1) Accidentellement, une des séries présente š points. 
Elytres transverses ; de la longueur du prothorax ; subdéprimées ; finement, subaspèrement et assez densement ponctuées; d'un bronzé brillant, souvent un peu. verdâtre; brièvement et subéparsement pubescentes; légèrement et éparsement pilosellécs, avec une soie, notamment plus longue, vers l'écusson, et une autre derrière les épaules. Celles-ci effacées. Ailes blanchâtres.

Abdomen suballongé, un peu moins large que les élytres ; à peine arqué sur les côtés et un peu atténué en arrière; subconvexe sur le dos, avec le repli des $2^{\mathrm{e}}$ et $3^{\mathrm{e}}$ segments en accolade peu sentie ; distinctement sétosellé; finement et assez densement ponctué, avec la base des segments à peine plus densement ; d'un noir brillant, à pubescence un peu plus longue et à peine plus serrée que celle des élytres. Le $6^{\text {e }}$ segment moins ponctué, moins pubescent, à peine arrondi au sommet.

Dessous du cor'ps aspèrement ponctué, finement pubescent, d'un noir brillant. Dessous de la tête glabre, presque lisse, avec le côté des tempes légèrement pubescent. Lame mésosternale presque lisse; à pointe aciculée, ciliée au bout; à arête transversale assez saillante, à peine arquée, descendue seulement jusque vers.le premier tiers. Métasternum à peine convexe. Ventre convexe, éparsement sétosellé, avec des soies plus longues en arrière.

Pịeds médiocres, aspèrement pointillés; finement pubescents, noirs, avec les tarses antérieur's parfois moins foncés. Cuisses antérieures assez finement épineuses en dessous vers leur sommet; les postérieures assez grèles. Tarses postérieurs à $1^{\mathrm{e}}$ article beaucoup plus long que le dernier, égal aux 3 suivants réunis.

Patrie. Celle espèce se trouve communément dans les fumiers, sous les détritus, les mousses, elc., dans presque toute la France.

OBs. Elle est d'une taille beancoup moindre que les précédentes. Les élytres sont un peu moins densement ponctuées que dans les $P h$. politus et lucens.

La variété $a$, plus répandue dans le Midi, a les élytres rouges, avec la base et les côtés flus ou moins largement rembrunis; et la variété $b$ a les mêmes organes presque entièrement rougeatres. On trouve des-individus intermédiaires, dont les élytres sont d'un rouge brun, ou bronzées avec une transparence apicale rousse.

Prarfois les séries dorsales du prothorax sont de 5 points. 
Le picimanus de Menetriès est une variété à pieds d'un brun plus ou moins roussâtre.

\section{LARVE}

Nous donnons ici la description de la larve du Ph. varius :

Corps allongé, assez étroit, subconvexe, éparsement sétosellé, d'un testacé livide et brillant sur la tête et le thorax, mat sur l'abdomen.

Tête grande, en carré suboblong et subarrondi aux angles, sensiblement plus large que le prothorax, subdéprimée, éparsement sétosellée, lisse, à peine ridée et obliquement biimpressionnée en avant, d'un testacé luisant. Épistome multidenté, avec les 2 dents intermédiaires plus saillantes, aiguës et séparées entre elles par une autre très-petite dent. Mandibules grandes, assez grêles, falciformes, acérées, testacées. Palpes pâles, à dernier article. assez long, grêle, subulé.

Yeux petits, lisses, indiqués par 4 points noirs, subréunis.

Antennes courtes, pâles, à $1^{\mathrm{er}}$ article nodiforme : le $2^{\mathrm{e}}$ allongé, subcylindrique ou a peine épaissi : le $3^{\mathrm{e}}$ plus court, un peu renflé et tricilié avant son sommet, lobé au bout de son côté interne : le $4^{\mathrm{e}}$ beaucoup moins long, beaucoup plus grêle, terminé par un petit lobe brièvemen $\mathbf{t}_{\mathrm{t}}$ bicilié et 3 soies divergentes.

Prothorax oblong, convexe, tronqué au sommet, sensiblement atténué en avant, largement rebordé à la base, éparsement sétosellé; presque lisse, marqué de chaque côté d'un sillon oblique, partant des angles antérieurs et s'arrêtant vers le $1^{\text {er }}$ tiers ; d'un testacé luisant.

Mésothorax el métathorax assez courts, subégaux, aussi longs réunis que le prothorax, subarqués sur les côtés, rebordés à leur base, assez convexes, éparsement sétosellés; lisses, avec des replis ou cicatrices de chaque côté; d'un testacé livide et brillant.

Abdomen allongé, plus long que la tête et le thorax réunis; subparallèle ou à peine arqué sur les côtés et assez brusquement atténué tout à fait en arrière, peu convexe sur le dos et parfois subsillonné sur sa ligne médiane, assez fortement sétosellé, d'un testacélivide et mat; à $1^{\mathrm{er}} \mathbf{s e g -}$ ment très-court, plus brillant: les suivants courts, subégaux, plus ou moins mamelonnés et sillonnés sur le dos, avec des bourrelets ou cicatrices sur les côtés : le dernier assez étroit, en cône court et largement tronqué, muni au sommet de 2 longs appendices subcylindriques, presque droits, éparsement ciliés, très-éparsement et longuement sétosellés avant 
leur extrémité, terminés par un lobe très-court, presque imperceptible, sétifère, à soie très-longue, un peu déjetée en dehors, biarticulée, épaisse à sa base, à $2^{\mathrm{e}}$ article très-fin, capillaire.

Dessous de la tête presque lisse, testacé, brillant, excavé dans sa partie antérieure. Prosternum triangulaire, subconvese, lisse, d'un testacé brillant. Ventre longitudinalement bissillonné, assez fortement sétosellé, d'un testacé livide et mat, très-inégal et plus ou moins mamelonné ou cicatrisé, à tube terminal spinosule surtout en dessous, subcylindrique, subinfléchi, sensiblement plus long que les appendices supérieurs.

Pieds médiocres, d'un testacé très-pàle. Hanches très-grandes. Cuisses très-allongées, sublinéaires, épineuses en dessous sur 2 rangées. Tibias beaucoup plus courts que les cuisses, à peine atténués vers leur extrémité, épineux tout autour, terminés par un fort crochet solide, très-acéré. presque droit.

Oвs. Celte larve diffère de celle du $P h$. fumigatus par le tube terminal du ventre plus long que les appendices supérieur's, et par ses pieds: plus allongés.

21. Philonthus melanarius, Mulsant et Rey.

Allongé, subfusiforme, peu convexe, légèrement pubescent, d'un noir très-brillant, avec les palpes et les pieds d'un brun de poix. Tête et prothorax lisses, luisants : celui-ci presque aussi large que long, rétréci en avant. Élytres et abdomen finement et assez densement ponctués.

$\sigma$ Le $6^{\mathrm{e}}$ arceau ventral sensiblement et angulairement entaillé dans le milieu de son bord apical, a vec le fond de l'entaille garni d'une membrane subpellucide. Tarses antérieurs à $2^{\mathrm{e}}$ article fortement, les $1^{\mathrm{er}}$ et $3^{\mathrm{e}}$ assez fortement, dilatés.

을 Le $6^{e}$ arceau ventral subarrondi à son bord apical. Tarses antérieurs à 3 premiers articles faiblement dilatés.

Staphylinus carbonatius, Gravengonst, Micr. 23, 31 ;-Mon, 67, 42. - Latreille, Hist. Nat. Crust. et Ins. IX, 313, 36.

Philonthus varius, var. a, ERICHSon, Gen. et Spec. Staph. 447. - KraATz, Ins. Deut. II, ǒ84.

Long. $0^{\mathrm{m}}, 0074\left(3 \mathrm{1} / 3 \mathrm{l}\right.$.; - larg., $0^{\mathrm{m}}, 0012$ (1/2 l.). 
Corps allongé, subfusiforme, peu convexe, d'un noir très-brillant; revêtu sur les élytres et l'abdomen d'une fine pubescence grisâtre et peu. serrée.

Tête subovalaire, sensiblement moins large que le prothorax ; fortement sétosellée: d'un noir très-luisant; lisse, avec les tempes légèrement pubescentes, éparsement et fortement ponctuées. Front large, subconvexe, marqué de chaque côté, entre les yeux, de 2 pores sétifères assez gros, rapprochés et subtransversalement disposés, dont l'interne un peu moindre. Cou glabre, lisse, d'un noir luisant. Labre noir, fortement sétosellé en avant. Mandibules noires. Palpes d'un brun de poix.

Yeux médiocres, subovales, plus ou moins obscurs.

Antennes suballongées, presque aussi longues que la tête et le prothorax réunis ; faiblement épaissies ; légèrement pubescentes et éparsement pilosellées vers leur base ; noires; à $1^{\text {er }}$ article allongé, en massue subarquée : les $2^{\mathrm{e}}$ et $3^{\mathrm{e}}$ obconiques : le $3^{\mathrm{e}}$ suballongé, à peine plus long que le $2^{\mathrm{e}}$ : les suivants graduellement un peu plus courts, subobconiques : les $4^{\mathrm{e}}$ à $6^{\mathrm{e}}$ à peine oblongs : les $7^{\mathrm{e}}$ non, les $8^{\mathrm{e}}$ à $10^{\mathrm{e}}$ faiblement transverses, vus de côté : le dernier subovalaire, subtronqué au bout et subacuminé inférieurement.

Prothorax presque aussi large que long, sensiblement rétréci en avant; présque aussi large en arrière que les élytres; tronqué ou à peine échancré au sommet, avec les angles antérieurs infléchis et arrondis ; presque droit ou à peine arqué sur les côtés; arrondi à sa base ainsi qu'aux angles postérieurs; assez convexe; éparsement sétosellé, avec la longue soie latérale située sur le rebord même; d'un noir très-luisant; lisse, avec 2 séries dorsales composées de points assez forts et subégalement distants; marqué de plus, un peu en avant vers les côtés, outre ceux de la marge, de 4 ou 5 autres points semblables et épars. Repli noir, glabre, lisse.

Écusson ponctué, pubescent, d'un noir brillant.

Elytres transverses, à peine plus longues que le prothorax ; subdéprimées; finement, subaspèrement et assez densement ponctuécs ; d'un noir de jais brillant, parfois à peine métallique; légèrement et subaspèrement pubescentes ; éparsement sétosellées sur les côtés, avec 1 soie, notamment plus longue, vers l'écusson, et 1 autre près des épaules. Celles-ci effacées. Ailes blanchâtres.

Abdomen suballongé, un peu moins large que les élytres; à peine arqué sur les côtés et un peu alténué en arrière; subconvexe sur le dos, avec 
le repli des $2^{\mathrm{e}}$ et $3^{\mathrm{e}}$ segments en accolade peu sentie; assez fortement sétosellé ; finement et assez densement ponctué ; d'un noir brillant; à pubescence plus longue et à peine plus serrée que celle des élytres. Le $6^{\text {e }}$ segment à peine arrondi au sommet.

Dessous du corps aspèrement ponctué, finement pubescent, d'un noir brillant. Dessous de la téte glabre et lisse. Lame mésosternale presque lisse ; à pointe très-aiguë; à arête transversale assez saillante, arquée, descendue à peine au delà du premier tiers. Métasternum à peine convexe, à peine canaliculé sur sa ligne nıédiane. Ventre convexe, éparsement sétosellé, avec des soies plus longues en arrière.

Pieds médiocres, aspèrement pointillés, finement pubescents, d'un brun de poix, avec les tarses et parfois les tibias moins foncés. Cuisses antérieures assez fortement épineuses en dessous vers leur sommet; les postérieures assez grêles. Tarses postérieurs à $1^{\text {er }}$ article beaucoup plus long que le dernier, égal aux 3 suivants réunis.

Patrie. On trouve, mais peu communément, cette espèce, sous les mousses et feuilles mortes, dans les Alpes et les inontagnes du Lyonnais.

Oss. On l'a considérée jusqu'à présent comme une variété noire du Ph.varius. Mais il nous a été permis de constater, sur un certain nombre d'exemplaires, qu'elle doit constituer une espèce distincte. Elle est généralement d'une taille un peu moindre. Les élytres, plus noires, sont à la fois un peu moirs courtes et à peine plus finement ponctuées. La ponctuation de l'abdomen n'est pas sensiblement plus serrée à la base des segments. Les pieds sont d'une couleur moins foncée..'Enfin, les antennes, à peine moins longues, ont constamment leurs articles intermédiaires un peu plus courts, et les pénultièmes faiblement mais visiblement transverses.

Quelquefois les pieds, avec les hanches, sont entièrement d'un roux de poix sublestacé.

Nous avons du changer le nom de carbonarius déjà employé pour une autre espèce.

\section{Philonthus Pyrenaens, KIEsenwetter.}

Allongé, subfusiforme, peu convexe, à peine pubescent, d'un noir trèsbrillant, avec les élytres submétalliques. Tête et prothorax lisses, luisants: 
celui-ci presque aussi large que long, subatténué en avant. Élytres asse -fortement et éparsement, abdomen assez finement et éparsement, ponctués.

$\sigma^{7}$ Le $6^{\circ}$ arceau ventral assez fortement et angulairement entaillé dans le milieu de son bord apical. Tarses antérieurs à 3 premiers articles asse $z$ fortement dilatés.

o Le $6^{\mathrm{e}}$ arceau ventral subarrondi à son bord apical. Tarses antérieurs à 3 premiers articles à peine dilatés.

Philonthus pyrenaeus, Kiesenwetrer, Stett. Ent. Zeit. 1850, 219 ; - Ann. Soc.

Ent. Fr. 1851, 414- Fairmaire et Labouldìne, Faun. Ent. Fr. I, 519, 22. philonthus frigielus, Fauvel, Faun. Gallo-Rhén. III, 461, 29.

$$
\text { Long., } 0^{\mathrm{m}}, 074 \text { (3 1/3 l.) ; - larg., } 0^{\mathrm{n}}, 0012 \text { (1/2 l.). }
$$

Corps allongé, subfusiforme, peu convexe, d'un noir très-brillant, avec les élytres submétalliques; revêtu sur celles-ci et sur l'abdomen d'une légère pubescence d'un gris obscur, éparse et peu apparente.

Tête subovalaire, sensiblement moins large que le prothorax; fortement sétosellée; d'un noir luisant; lisse, avec les tempes à peine pubescentes, éparsement et assez fortement ponctuées. Front large, subconver e, marqué de chaque côté, entre les yeux, de 2 pores sétifêres, rapprochés et transversalement disposés, dont l'interne un peu ınoindre. Cou glabre, presque lisse, d'un noir brillant. Labre noir, brillant, sétosellè en avant. Mandibules et palpes d'un noir de poix, les premières souvent ferrugineuses à leur pointe.

Yeux médiocres, subovales, obscurs, lavés de gris.

Antennes suballongées, environ de la longueur de la tête et du prothorax réunis ; à peine épaissies ; légèrement pubescentes et éparsement pilosellées vers leur base; noires; à $1^{\text {er }}$ article allongé, en massue subarquée : les $2^{\mathrm{e}}$ et $3^{\mathrm{e}}$ obconiques : le $3^{\mathrm{e}}$ suballongé, un peu plus long que le $2^{\mathrm{c}}$ : les suivants graduellement un peu plus courts, subobconiques : les $4^{\mathrm{e}} \mathrm{a} 6^{\mathrm{e}} \mathrm{a}$ peine oblongs : le $7^{\mathrm{e}}$ non, les $8^{\mathrm{e}} \mathrm{a} 10^{\mathrm{e}}$ à peine ou non transverses, vus de côté : le dernier subovalaire, à peine échancré au bout et subacuminé inférieurement.

Prothorax presque aussi large que long, un peu rétréci en avant; presque aussi large en arrière que les élytres; tronqué ou à peine échancré au sommet, avec les angles antérieurs infléchis et subarrondis; 
presque droit ou à peine arqué sur les côtés; subarrondi à sa base ainsi qu'aux angles postérieurs ; légèrement convexe ; éparsemeni sétosellé, avec la longue soie latérale située contre le rebord môme; d'un noir trèsluisant ;lisse, avec 2 séries dorsales composées de 4 points assez forts et subégalement distants ; marqué de plus, sur les còtés et en avant, outre ceux de la marge, de 5 autres points semblables et épars, les 2 internes souvent rapprochés. Repli noir, glabre, lisse.

Écusson éparsement ponctué, légèrement pubescent, d'un noir "brillant.

Élytres transverses, à peine plus longues que le prothorax; subdéprimées; assez fortement et éparsement ponctuées; d'un noir três-brillant et souvent submétallique; éparsement et à peine pubescentes, avec une longue soie redressée vers l'écusson et une autre sur le côté des épaụles. Celles-ci effacées. Ailes à peine enfumées.

Abdomen suljallongé, moins large que les élytres; à peine arqué sur les côtés et un peu atténué en arrière ; assez convexe sur le dos; éparsement sétosellé; assez finement et éparsement ponctué; d'un noir brillant; légèrement et éparsement pubescent. Le $6^{\mathrm{e}}$ segment moins ponctué, moins pubescent, subarrondi au sommet.

Dessous du corps aspèrement ponctué, légèrement pubescent, d'un noir brillant. Dessous de la tête glabre, lisse ou éparsement ponctué en arrière. Pointe mésosternale très-aiguë. Métasternum à peine convexe. Ventre convexc, éparsement sétosellé, avec des soies plus longues vers l'extrémité.

Pieds médiocres, aspèrement ponctués, finement pubescents, d'un noir de poix. Cåisses antérieures assez tinement épineuses en dessous, vers leur sommet; les postérieures assez grêles. Tarses postérieurs à $1^{\mathrm{er}}$ article beaucoup plus long que le dernier, subégal aux 3 suivants réunis.

Patrie. Cette espèce est assez commune, au bord des neiges, dans les Alpes, en Savoie, dans les Pyrénées, etc. Nous l'avons reçue de cette der nière localité, de M. de Kiesenwetter lui-même.

Obs. Elle est plus noire que le $P h$. varius. Les élytres sont plus fortement et moins densement ponctuées que dans celui-ci et que dans le melanarius, auquel elle ressemble beaucoup. La pubescence est moins apparente et encore moins serrée que dans l'un et l'autre, etc.

Peut-être doit-on lui rapporter le janthinipennis (Hochh. Bull. Mosc., 1849, I, 137 ; 1851, III, 17)? 
23. Philontlus frigidus, KIESENwetTER.

Allongé, à peine fusiforme, peu convexe, à peine pubescent, d'un noir brillant. Tête et prothorax lisses, luisants : celui-ci presque aussi large que long, subrétréci en avant. Elytres et abdomen finement et éparsement ponctués.

$\sigma^{7}$ Le $6^{\text {e }}$ arceau ventral profondément et angulairement entaillé dans le milieu de son bord apical, avec l'entaille presque complétement remplie par une membrane subpellucide. Le $5^{\mathrm{e}}$ à peine et subangulairement échancré dans le milieu de son bord postérieur. Tarses antérieurs à 3 premiers articles assez fortement dilatés.

ㅇ Le $6^{\mathrm{e}}$ arceau ventral subarrondi, le $5^{\mathrm{e}}$ simple, à leur bord apical. Tarses antérieurs presque simples.

Philonthus frigidus, KiesenweTter, Stett. Ent. Zeit. 1848, IX, 324.

Philonthus consputus, BAUDI, Stud. Ent. I, 127.

$$
\text { Long., } 0^{\mathrm{m}}, 0062 \text { (2 3/4 l.); - larg., } 0^{\mathrm{m}}, 0008 \text { (1/3 l.). }
$$

Corps allongé, à peine fusifornce, peu convexe, d'un noir brillant, avec les élytres concolores; revêtu sur celles-ci et l'abdomen d'une légère pubescence grisâtre, éparse et à peine apparente.

Téte courtement ovalaire, sensiblement moins large que le prothorax; éparsement sétosellée, d'un noir luisant; lisse, avec les tempes à peine pubescentes, éparsement et assez fortement ponctuées. Front large, subconvexe, marqué de chaque côté, entre les yeux, de 2 pores sétifères sapprochés et subtransversalement disposés, l'interne beaucoup moindre et parfois un peu plus en arrière. Cou glabre, presque lisse, d'un noir luisant. Labre noir, sétosellé en avant. Mandibules ferrugineuses à leur extrémité. Palpes d'un noir de poix.

Yeux médiocres, subovales, obscurs ou lavés de gris.

Antennes peu allengées, un peu plus courtes que la tête et le prothorax réunis; subfiliformes ou à peine épaissies; légèrement pubescentes et éparsement sétosellées vers leur base; obscures; à $1^{\text {er }}$ article allongé, en massıe subarquée : les $2^{\mathrm{e}}$ et $3^{\mathrm{e}}$ suballongés, obconiques, subégaux : les 
suivants graduellement un peu plus courts, subcylindrico-coniques : les $4^{\mathrm{e}} \mathrm{a}^{\mathrm{e}}$ à peine oblongs : le $7^{\mathrm{e}}$ non, les $8^{\mathrm{e}}$ à $10^{\mathrm{e}}$ à peine transverses; vus de côté : le dernier subovalaire, tronqué au bout et obtusément acuminé inférieurement.

Prothorax presque aussi large que long, subrétréci en avant ; presque aussi large en arrière que les élytres; tronqué ou à peine échancré au sommet, avec les angles antérieurs infléchis et subarrondis ; presque droit sur les côtés ; arrondi à sa base ainsi qu'aux angles postérieurs ; légèrement convexe; éparsement sétosellé, avec la longue soie latérale située contre le rebord même; d'un noir luisant; lisse, avec 2 séries dorsales composées de 4 points assez fins et subégalement distants; marqué de plus, vers les côtés et en avant, outre ceux de la marge, de 5 autres points semblables et épars, les 2 internes plus rapprochés. Repli noir, glabre, lisse.

Écusson éparsement ponctué, éparsement pubescent, d'un noir brillant.

Élytres transverses, de la longueur du prothorax ou à peine plus longues; subdéprimées ; finement et éparsement ponctuées; d'un noir de jais brillant; éparsement et à peine visiblement pubescentes, avec 1 soie redressée vers l'écusson et 1 autre sur le côté des épaules. Celles-ci effacées.

Abdomen suballongé, moins large que les élytres; à peine arqué sur les côtés et un peu atténué en arrière ; assez convexe sur le dos ; éparsement sétosellé; finement et é,arsement ponctué; d'un noir brillant; éparsement et à peine pubescent. Le $6^{\mathrm{e}}$ segment noins ponctué, subarrondi au sommet.

Dessous du corps aspèrement pointillé, légèrement pubescent, d'un noir brillant. Dessous de la tête glabre, presque lisse. Pointe mésosternale aiguë. Métasternum obsolètement ponctué et subdéprimé sur son milieu. Ventre convexe, à peine sétosellé.

Pieds médiocres, aspèrement pointillés, légèrement pubescents, d'un noir de poix, avec les tarses, surtout les antérieurs, parfois moins foncés. Cuisses antérieures assez finement épineuses en dessous vers leur sommet ; les postérieurs à peine plus allongés et à peine plus grêles que les autres. Tarses postérieur's à $1^{\text {er }}$ article beaucoup plus long que le dernier, subégal aux 3 suivants réunis.

Patrie. Cette espèce se rencontre, assez rarement, sous les pierres et 
les mousses, sur les sommités les plus élevées de la Grande-Chartreuse et du mont Dore (Auvergne).

OBs. Elle est un peu moindre que le Ph. pyrenaeus, auquel elle ressemble beaucoup. Mais les élytres sont d'un noir de jais et nullement métalliques, et surtout plus finement ponctuées. La tête est relativemen $t$ moins étroite, brièvement ovalaire. Les $2^{\mathrm{e}}$ et $3^{\mathrm{e}}$ articles des antennes sont moins inégaux, etc.

Le Ph. frigidus de Kraatz (Ins. Deut. II, 590, 24), par ses élytres bronzées et fortement ponctuées, nous semble plutôt devoir appartenir au pyrenaeus?

Les Philonthus varius, melanarius, pyrenaeus et frigidus forment, par rapport aux espèces précédentes, un petit groupe à part, remarquable par leur taille inférieure et par la structure du dernier article des palpes maxillaires. En effet, celui-ci est un peu moins allongé et moins régulièrement fusiforme, à fuseau un peu plus longuement atténué en avant et à partie renflée un peu plus près de la base.

\section{Philonthus marginatus, FaBricius.}

Allongé, subfusiforme, peu conxexe, finement pubescent, d'un noir brillant, avec les élytres submétalliques, la base des palpes, le dessous du $1^{\mathrm{e}_{\mathrm{r}}}$ article des antennes, les côtés du prothorax, et les pieds testacés, les genoux et les tarses rembrunis. Tête et prothorax lisses, assez luiisants : celui-ci presque aussi large que long, rétréci en avant. Élytres finement et assez densement, abdomen finement et éparsement, ponctués. Tarses antérieurs fortement dilatés.

$\sigma^{7}$ Le $6^{\text {e }}$ arceau ventral médiocrement et angulairement sinus dans le milieu de son bord apical, avec un étroit espace triangulaire lisse, au devant du sinus.

Q Le $6^{\mathrm{e}}$ arceau ventral à peine arrondi à son bord apical.

Staphylinus marginatus, Fabricius, Syst. Ent. 266, 8 ; - Ent. Syst. I, II, 526, 30 ; - Syst. El. II, 597, 38. - Paykull, Mon. Staph. 4 4, 32. - Olivier, Ent. III, no $42,26,33$, pl. III, fig. 29.- Gravenhorst, Miur. 24, 32 ; - Mon. 71, 56.Latreille, Hist. Nat. Crust. et Ins. IX, 313, 37.-Gyllenhal, Ins. Suec. II, 32\%, 38. - Vinnerheim Brach. 28, 54. - Boisduval et Lacordaire, Faun. Ent. Par. I, $397,22$. 
Philonthus märginatus, Curtis, Brit. Ent. XIII, pl. 610. - Nordannv, Symb. 84, 38. - Enicuson, Col. March. I, 453, 11 ; - Gen. et Spec Staph. 444, 27. Redtenbacher, Faun. Austr. 702, 18. - Heer, Faun. Col. Helv. I, 261, 13. Fairmaire et Laboulbène, Faun. Ent. Fr, I, 515, 10. - Kratiz, Ins. Deut. II, 587; 21.- Thomson, Skand. Col. II, 163, 30, 1860.. - Fauver, Faun. Gallo-Rhén. III, 478,49 .

$$
\text { Long., } 0^{\mathrm{m}}: 0088 \text { (4 l.); - larg., } 0^{\mathrm{m}} .0018 \text { (3/4 1.). }
$$

Corps allongé, subfusiforme, peu convexe, d'un noir brillant et à peine métallique avec les côtés du prothorax testacés ; revêtu sur les élytres et l'abdomen d'une fine pubescence grisâtre, moins serrée sur ce dernier.

Tête ovalaire, moins large que le prothorax ; fortement sétosellée; d'un noir assez luisant et à peine métallique; lisse, avec les tempes à peine pubescentes, très-éparsement et fortement ponctuées. Front large, subconvexe, marqué de chaque côté, entre les yeux, de 2 pores sétifères très-rapprochès, l'interne beaucoup moindre, souvent un peu plus en avant. Cou glabre, lisse, d'un noir brillant. Labre noir, fortement sétosellé en avant. Mandibules ferrugineuses à leur extrémité. Palpes obscurs avec leur base plus ou moins testacér.

Yeux assez grands, subovales, noirs ou lavés de gris.

Antennes suballongées, presque aussi longues que la tête et le prothorax réunis ; assez grêles, subfiliformes ; pubescentes et éparsement pilosellées vers leur base; noires, avec le $1^{\text {er }}$ article d'un flave testacé mais rembruni en dessus; celui-ci allongé, cn massue : les $2^{\mathrm{e}}$ et $3^{\mathrm{e}}$ obconiques : le $2^{\mathrm{e}}$ suballongé : le $3^{\mathrm{e}}$ allongé, un peu plus long que le $2^{\mathrm{e}}$ : les suivants graduellement un peu plus courts, subobconique : $\operatorname{les} 4^{\mathrm{e}}$ à $6^{\mathrm{e}}$ oblongs, le $7^{\mathrm{e}}$ suboblong : les $8^{\mathrm{e}}$ à $10^{\mathrm{e}}$ à peine plus longs que larges, vus de côté : le dernier ovale-oblong, obliquement subéchancré au bout et subacuminé inférieurement.

Prothorax presque aussi large que long, sensiblement rétréci en avant; presque aussi large en arrière que les élytres : tronqué au sommet, avec les angles antérieurs subinfléchis et arrondis; presque droit ou à peine arqué sur les côtés; subarrondi à sa base, avec les angles postérieurs très-obtus; légèrement convexe ; éparsement sétosellé, avec la longue soie latérale située contre le rebord même; d'un noir assez brillant et à peine métallique, avec une large bordure d'un flave testacé et embrassant les côtés ; lisse, avec 2 séries dorsales composées de 4 points assez fins et subégalement distants; marqué de plus, vers les côtés, outre ceux de 
la marge, de 4 ou 5 autres points semblables et épars. Repli d'un flave testacé, glabre, lisse.

Écusson ponctué, pubescent, d'un noir submétallique.

Élytres subtransverses, un peu plus longues que le prothorax; subdéprimées ; finement, assez densement et subaspèrement ponctuées; d'un noir brillant et à peine bronzé; finement et modérément pubescentes, avec 1 longue soie redressée vers l'écusson, 1 autre derrière les épaules et des cils obscurs au bord apical. Épaules effacées. Ailes cnfumées.

Abdomen suballongé, moins large que les élytres; à peine arqué sur les côtés et subatténué en arrière ; subconvexe sur le dos, avec les 3 premiers segments subimpressionnés en travers à leur base, et le repli des $2^{\mathrm{e}}$ et $3^{\ominus}$ en accolade à lobe médian court, largement arrondi ou subtronqué; fortement sétosellé; finement et éparsement ponctué ; d'un noir brillant; à pubescence plus longue mais moins serrée et moins apparente que celle des élytres. Le $6^{\text {e }}$ segment subtronqué ou à peine arrondi au sommet.

Dessous du corps aspèrement ponctué ; finement pubescent, d'un noir brillant, avec l'antépectus testacé et le bord apical des arceaux du ventre d'un roux ferrugineux. Dessous de la tête glabre, lisse. Lame mésosternale presque lisse; à arête transversale assez saillante, à peine arquée, descendue jusqu'au premier tiers; à pointe subaiguë, peu prolongée, avec la chainette de pores sétifères située près de celle-ci. Métasternum à peine convexe, à peine canaliculé "sur sa ligne médiane. Ventre convexe, éparsement sétosellé.

Pieds médiocres, aspèrement ponctués, tinement pubescents, d'un flave testacé, avec les hanches et trochanters postérieurs, les genoux et les tarses, surtout les intermé liaires et postérieurs, plus ou moins renblunis. Cuisses antérieures assez finement épineuses en dessous vers leur sommet; les postérieures un peu plus grèles. Tarses antérieurs. à 3 premiers articles fortement, le $4^{\mathrm{e}}$ faiblement, dilatés, avec les 3 premiers garnis sur les côtés, dans les 2 sexes, d'une brosse de cils mous, pâles et serrés; les posterieurs grêles, presque aussi longs que les tibias, à $1^{\text {er }}$ article sensiblement plus long que le dernier, subégal aux 3 suivants réunis, ceux-ci suballongés ou oblongs.

Patrie. Cette espèce est médiocrement comınune dans les bouses et les crottins, dans les lieux boisés ou élevés : les environs de Paris et de Lyon, la Normandie, l'Alsace, la Lorraine, la Bourgogne, le Beaujolais, le Bugey, les Alpes, la Guienne, les Pyrénées, etc. 
OBs. Outre la coloralion, elle est remarquable par ses antennes assez grêles et par ses tarses postérieurs très-allongés.

Souvent les tibias, ou au moins leurs épines, sont d'une couleur plus sombre.

Contrairement à ce que dit Erichson, nous avons vu les tarses antérieur's des $q$ aussi fortement dilatés que ceux des $\sigma$.

\section{Philonthus lepidus, Gravenhorst.}

Allonge, aptère, subfusiforme, peu convexe, finement pubescent, d'un noir brillant, avec les élytres d'un bronzé verdatre, la bouche, la base des antennes etles pieds d'un roux testacé. Tête et prothorax lisses, luisants : celui-ci aussi large que long, rétréci en avant. Elytres et abdomen finement et densement ponctués. Elytres plus courtes que le prothorax.

$\sigma$ Le $6^{\mathrm{e}}$ arceau ventral assez fortement et subangulairement sinué dans le milieu de son bord apical, avec un léger espace triangulaire lisse au devant du sinus. Tarses antérieurs à 3 premiers articles assez fortement dilatés.

ㅇ Le $6^{\mathrm{e}}$ arceau ventral simple. Tarses antérieurs presque simples.

Philonthus gilvipes, Ericrson, Col. March. I, 456, 13̈; - Gen. et Spec. Staph. 448, 32. - Redtenbacher, Faun. Austr. 702, 18.

Variété $a$. Elytres d'un rouge de brique.

Staphylinus lepidus, Gravenhorst, Micr. 31,45 ; - Mon. 74, 64. - Latreille. Hist. Nat. Crust. et Ins. IX, 318, 30.- Gyilenand, Ins. Suec. II, 328, 44. Boisduyal et L.scordare, Faun. Ent. Par. I, 401, 29.

Staphylinus Ravopterus, Gravenhorst, Mon. 74, 63.

Staphylinus fulvipes, RuvDE, Brach. Hal. 10, 52 .

Philonthus favopterus, Nordanan, Symb. 89, 31 .

Philonthus lepidus, Erichson, Col. March. I, 457, 17; -- Gen. et Spec. Staph. 450, 35. - Rbdtendacher, Faun. Austr.701, 16.- Heer, Faun. Helv. I, 262, 18. - Fatrisaire et Laboulbène, Faun. Ent. Fr. I, 515, 7. - Krastz, Ins Deut. II, 588, 22. - Thouson, Skand. Col. II, 163, 29, 1860.- Fauvel, Faun. Gallo-Rhén. III, 474,44 .

$$
\text { Long., } 0^{\mathrm{m}}, 0066 \text { (31.); - larg., } 0^{\mathrm{m}}, 0011 \text { (1/21.). }
$$


Corps allongé, aptère, subfusiforme, peu convexe, d'un noir brillant, avec les élytres d'un bronzé verdâtre; revêtu sur celles-ci et l'abdomen d'une fine pubescence grise et peu serrée.

Tête ovalaire, beaucoup moins large que le prothorax; éparsement sétosellée; d'un noir luisant; lisse, avec quelques rares points sur les tempes. Front large, subconvexe, marqué de chaque côté de 2 pores sétifères rapprochés et transversalement disposés, l'extérieur situé sur le hord interne même de l'ceil, l'intérieur beaucoup moindre. Cou glabre, presque lisse, d'un noir luisant. Labre noir, sétosellé en avant. Mandibules et palpes d'un roux de poix, ces derniers souvent subtestacés.

Yeux médiocres, subovales, obscurs.

Antennes suballongées, presque aussi longues que la tête et le prothorax réunis; à peine épaissies; légèrement pubescentes et éparsement pilosellées vers leur base; brunâtres, avec les 2 premiers articles d'un roux testacé : le $1^{\mathrm{er}}$ allongé, en massue subarquée : les $2^{\mathrm{e}}$ et $3^{\mathrm{e}}$ suballongés, obconiques : le $3^{\mathrm{e}}$ à peine plus long que le $2^{\mathrm{e}}$ : les suivants graduellement un peu plus courts et à peine plus épais, subobconiques : les $4^{\mathrm{e}}$ à $7^{\mathrm{e}}$ suboblongs, le $8^{\mathrm{e}}$ à peine oblong : les $9^{\mathrm{e}}$ et $10^{\mathrm{e}}$ non ou à peine transverses, vus de côté : le dernier subovalaire, subtronqué au bout et subacuminé inférieurement.

Prothorax aussi large que long, sensiblement rétréci en avant; aussi large en arrière que les élytres ; tronqué au sommet, avec les angles antérieurs infléchis et subarrondis ; à peine arqué sur les côtés; arrondi à sa base ainsi qu'aux angles postérieurs ; assez convexe ; à peine sétosellé, avec la longue soie latérale située sur le rebord même ; d'un noir luisant ; lisse, avec 2 séries dorsales composées de 4 points assez fins et écartés ; marqué de plus, vers les côtés, outre ceux de la marge, de 4 autres points semblables et épars. Repli d'un roux de poix, glabre, lisse.

Écusson pointillé, pubescent, d'un noir de poix.

Élytres fortement transverses, plus courtes que le prothorax ; subdéprimées ; finement, densement et subaspèrement ponctuées; d'un bronzé brillant et un peu verdâtre; brièvement et subéparsement pubescentes ; brièvement et obsolètement sétosellées vers leur base, avec 1 soie plus longue de chaque côté de l'écusson. Epaules cachées.

Abdomen peu allongé, à peine moins large que les élytres; à peine arqué sur les côtés et un peu atténué tout à fait en arrière; assez convexe sur le dos; distinctement sétosellé; finement, densement et subécailleusement pointillé ; d'un noir brillant; à pubescence plus longue et à peine 
plus serrée que celle des élytres. Le $6^{e}$ segment moins ponctué, moins pubescent, subtronqué ou à peine arrondi au sommet.

Dessous du corps aspèrement pointillé, finement pubescent, d'un noir brillant, avec l'antépectus roussâtre et les intersections ventrales étroitement ferrugineuses. Dessous de la tête glabre, presque lisse. Lame mésosternale lisse en avant; à arête transversale saillante, subarquée, descen due jusqu'au $1^{\text {er }}$ tiers; à pointe aiguë, peu prolongée. Métasternum subdéprimé sur son milieu. Ventre convexe, distinctement sétosellé.

Pieds peu allongés, aspèrement pointillés, finement pubescents, d'un roux testacé, avec les hanches postérieures un peu rembrunies. Cuisses antérieures finement épineuses en dessous vers leur sommet; les postérieures plus longues et un peu plus grêles. Tarses postérieurs à $1 \mathrm{er}$ article beaucoup plus long que le dernier, subégal aux 3 suivants réunis.

Patrie. Cette espèce est rare. Elle se prend sous les pierres et les détritus, au bord des rivières, principalement dans les régions froides ou scptentrionales : les environs de Paris, la Picardie, la Normandie, la Champagne, l'Alsace, les montagnes du Lyonnais, les Alpes, les Pyrénées, etc.

OBs. Avec la forme du Ph. varius, elle s'en distingue par la couleur des antennes et des pieds.

La variété $a$, dont les élytres sont entièrement d'un rouge de brique, est plus répandue que le type.

Quelquefois les antennes sont d'un testacé obscur, avecla base plus claire.

Le Staphylinus flavopterus d'Olivier (t. III, $\mathrm{n}^{\circ} 42,36$, pl. IV, fig. 40) ressemble à un Quedius plutôt qu'à un Philonthus.

26. Philonthus albipes, Gravenhorst.

Allongé, ailé, subfusiforme, peu convexe, finement pubescent, d'un noir brillant, avec les élytres d'un noir de poix, la bouche et la base des antennes brunâtres, les intersections ventrales et les pieds d'un roux testacé. Tête et prothorax lisses, luisants : celui-ci à peine oblong, subrétréci en avant. Elytres assez finement et densement, abdomen fincment et assez densement, ponctués. Elytres de la longueur du prothorax.

$\sigma^{\top}$ Le $6^{\mathrm{e}}$ arceau ventral légèrement sinué dans le milieu de son bord apical. Tarses antérieurs à 3 premiers articles médiocrement dilatés. 
† Le $6^{\mathrm{c}}$ arceau ventral subarrondi à son hord apical. Tarses antérieurs presque simples.

Staphylinus albipes, Gravenhorst, Micr. 28, 40;-Mon. 76, 68. - Latreille, Hist. Nat. Crust. et Ins. IX, 316, 43. - Gyllenhal, Ins. Suec. II. 327, 43. ManNerheim, Brach. 29, 58. - Bolsduval et Lacordaire, Faun. Ent. Par. I, 405, 37.

Philonthus albipes, Erichson, Col. March. 1, 457, 16; - Gen. et Spec. Staph. 449, 34.- Redtenbacaer, Faun. Austr. 702, 20.- Heer, Faun. Col. Helv. 262, 17. - Falrmaire et Laboulbène, Faun. Ent. Fr. I, 520, 26. - Kraatz, Ins. Deut. II, 585, 18. - Thomson, Skand. Col. II. 163, 28, 1860. - Fauvel, Faun. GalloRhèn. III, 482, 3̌5.

Variẻté a (immature). Base des antennes et élytres testacées.

$$
\text { Long., } 0^{\mathrm{m}}, 0050 \text { (2 1/4 1.); - larg., } 0^{\mathrm{m}}, 00075 \text { (1/3 l.). }
$$

Corps allongé, ailé, subfusiforme, peu convexe, d'un noir brillant, avec les élytres à peine moins foncées; revêtı sur celles-ci et l'abdomen d'une fine pubescence grise et modérément serrée.

Tête ovalaire, moins large que le prothorax; fortement sétosellée; d'un noir luisant ; lisse, avec quelques points assez forts vers les tempes. Front large, subconvexe, marqué de chaque côté, entre les yeux, de 2 pores sétifères rapprochés et subtransversalement disposés, l'interne moindre et parfois un peu plus en arrière. Cou glabre, lisse, d'un noir luisant. Labre noir, sétosellé en avant. Mandibules et palpes d'un brun de poix.

Yeux assez petits ou médiocres, brièvement ovales, obscurs ou lavés de gris.

Antennes assez courtes, un peu moins longues que la tête et le prolhorax réunis; à peine épaissies ; légèrement pubescentes et éparsement pilosellées vers leur base; obscures, avec les 2 premiers articles d'un brun de poix parfois un peu roussâtre; le $1^{\text {er }}$ allongé, en massuc subarquée : les $2^{\mathrm{c}}$ et $3^{\mathrm{e}}$ obconiques : le $3^{\mathrm{e}}$ à peine plus long que le $2^{\mathrm{e}}$ : les suivants graduellement un peu plus courts, subcylindrico-coniques : les $4^{\mathrm{c}}$ et $5^{\mathrm{e}}$ à peine oblongs : le $6^{\mathrm{e}}$ et $7^{\mathrm{e}}$ non, les $8^{\mathrm{e}}$ à $10^{\mathrm{e}}$ faiblement transverses, vus de côté $:$ le dernier ovalaire, suboblong, subéchancré au bout et obtusément acuminé inférieurement.

Prothorax à peine plus long que large, subrétréci en avant; presque aussi large en arrière que les élytres; tronqué au sommet, avec les angles antérieurs infléchis, subobtus et subarrondis; presque droit ou à 
peine arqué sur ses côtés; arrondi à s. base ainsi qu'au $x$ angles postérieurs; médiocrement convexe; fortement sétosellé, avec la longue soie latérale située contre le rebord mème; d'un noir luisant; lisse, avec 2 séries dorsales composées de 4 points (1) médiocres et assez écartés; inarqué de plus, de chaque côté, outre ceux de la marge, de 5 autres points semblables, épars et distants. Repli noir, glabre, lisse.

Écusson pointillé, pubescent, noir.

Élytres transverses, de la longueur du prothorax ou à peine plus longues ; subdéprimées ; assez finement, densement et subaspèrement ponctuées; d'un noir de poix assez brillant ; finement et modérément pubescentes; distinctement sétosellées, avec 1 soie, notamment plus longue, vers l'écusson, et 2 autres sur les côtés. Épaules effacées. Ailes blanchâtres.

Abdomen peu allongé, un peu moins large que les élytres; à peine arqué sur les côtés et visiblement atténué en arrière; assez convexe sur le dos ; fortement sétosellé; finement et assez densement ponctué, avec la ponctuation un peu plus serrée vers la base des 4 premiers segments; d'un noir brillant; à pubescence moins apparente mais presque aussi serrée que celle des élytres. Le $6^{\mathrm{e}}$ segment subtronqué ou à peine arrondi au sommet.

Dessous du corps aspèrement pointillé, assez longuement pubescent, d'un noir brillant, avec le sommet du ventre et les intersections ventrales d'un roux testacé. Dessous de la tête glabre et lisse. Lame mésosternale à peine rugucuse en arrière; à arête transversale assez saillante, subarquée ou à peine angulée, descendue jusqu'au $l^{\text {er }}$ tiers; à pointe aiguë, prolongée. Nétasternum à peine convexe sul son milieu, à peine canaliculé sur sa ligne médiane. Ventre convexe, distincternent sétosellé.

Pieds peu allongés, aspèrement pointillés, finement pubescents; d'un roux testacé, avec les hanches postérieures rembrunies. Cuisses antérieures très-finement spinosules en dessous vers leur sommet; les postérieures un peu plus longues et un peu plus grêles. Tar'ses postérieurs à $1^{\text {er }}$ article sensiblement pilus long que le dernier, un peu moins long que les 3 suivants réunis.

Patrie. Cette espèce, peu commune, habite sous les pierres, les feuilles morles et les détritus, dans les lieux boisés et humides, dans les environs

(1) Accidentellement une des séries est composée de 5 points. 
de Paris et de Lyon, la Flandre, la Normandie, la Lorraine, la Bourgogne, l'Auvergne, le Beaujolais, les Alpes, les Pyrénées, etc.

OBs. Elle est plus petite, plus fortement sétosellée que le $\mathrm{Ph}$. lepidus. Les antennes, un peu moins allongées, ont leur base d'une couleur moins claire et leurs pénultièmes articles à peine plus courts. Les élytres, un peu plus longues, couvrent des ailes, etc.

Quelquefois la bouche et la base des antennes sont d'un roux testacé, et les pieds plus pâles.

Chez les exemplaires immatures, le prothorax est d'un roux de poix, et les élylres sont testacées, ainsi que les intersections abdominales et ventrales, avec les pieds d'une covleur encore plus claire.

Nous avons vu un échantillon'à pieds d'un testacé obscur, et dont le $2^{\text {e }}$ article des antennes, clairement testacé à sa base, paraît au moins aussi long que le $3^{\mathrm{e}}$.

Le dernier article des palpes maxillaires est en fuseau atténué, comme dans les $P h$. varius, melanarius et autres.

Le $P h$. albipes, par le $1^{\mathrm{er}}$ article des tarses postérieurs un peu moins allongé que dans les espèces précédentes, conduit naturellement ces dernières aux suivantes.

Elle répond peut-être au simplex de Marsham (Ent. Brit. 505, 20), et aux hirtipennis et nitescens de Stephens (IIl. Br. V, 221 et 222), ainsi qu'au microcephalus Grav. (Ion. 70, 52); Er. (Gen. et Spec. 459, 52)?

Suit le tableau de la $2^{\mathrm{e}}$ partie de la IIIe section.

aa Le 1er article des tarses postérieurs non ou à peine plus long que le dernier, moins long que les trois suivants réunis. Hanches intermédiaires légèrement distantes (1).

b Tarses antérieurs plus ou moins dilatés chez les $\sigma^{*}$. Èlytres d'un noir bronzé. . . . . . . . . . . . . . UMBRATILIS.

bb Tarses antérieurs simples ou presque simples chez les deux sexes (2).

c Tête en carré suboblong. Ėlytres à peine bleuatres. d Elytres à ponctuation non rugueuse, concolores. . . . ANGuINus.

(1) Pour éviter un tableau trop long, nous avons transporté ici la $2^{\circ}$ partie de celui des especes à séries dorsales de 4 points.

(2) Nous n'avons pas vu les $\sigma$ des anguinus et subrugosus, que nous plaçons arec doute dans cette subdivision. 
dd Elytres à ponctuation rugueuse, à bord apical roussatre. subrugosus.

cc Tête suborbiculaire ou en carré transverse et subarrondi.

e Prothorax noir; élytres plus ou moins bronzées, rarement rousses.

f Élytres assez densement ponctuées.

g Pieds d'un brun de poix avec les tarses un peu roussâtres. Taille assez petite.

h Téte éparsement ponctuée à sa base . . . . CEPHALOTEs.

bh Téte assez densement ponctuée à sa base . . MEgacephalus

gg Pieds testacés. Taille petite. . . . . . . Fimetarius.

ff Elytres éparsement ponctuées. Pieds brunâtres. . sordidus.

ffi Elytres très-éparsement ponctuées. Pieds d'un roux

de poix. . . . . . . . . . . . . sparsus.

ee Prothorax et élytres d'un noir de poix parfois roussatre.

Élytres densement ponctuées. Antennes et pieds roux. puscus.

Nous plaçons ici une espèce étrangère à la France et dont nous donnons une simple phrase diagnostique :

\section{Philonthus heterodoxus, MuLsant et REY.}

Allongé, peu convexe, légèrement pubescent, d'un noir brillant, avec les élytres bronzées, la bouche et les pieds d'un brun roussâtre. Tête ế prothorax lisses, luisants, submétalliques. Celui-ci un peu plus long que large, subparallèle. Elytres assez finement et assez densement, abdomen plus eparsement, ponctués. Ailes fortement enfumées.

$\sigma$ Le 6e arceau ventral profondément el angulairement entaillé, avec le sommet de l'angle émoussé et ses côtés garnis d'une étroite gouttière. Tarses antérieurs à 3 premiers articles assez fortement dilatés. Téte en carrẻ transverse, de la largeur du prothorax.

q Nous est inconnue.

$$
\text { Long., 0m,0080 (3 2/3 l.); - larg., } 0^{\mathrm{m}}, 0015 \text { (2/3 1.). }
$$

Patrie. Biguglia en Corse (collection Revelière).

OBs. Cette espèce remarquable tient de l'umbratilis et du cephalotes, par sa forme générale. Elle diffère de l'un el de l'autre par ses antennes plus longues et à articles intermédiaires et pérıultièmes plus allongés, $\mathrm{par}$ 
se's turses postérieurs à $1^{\text {er }}$ artic'c un pen plus long que le dernier, par son prothorax un peu plus oblongr et un peu plus parallèle. La taille est plus grande que daus l'umbratilis; les élytres sont plus longues et plus finement ponctuées que dans le cephalotes. Enfin, le dernier article des palpes est plus allongé et plus grêle que chez la plupart des espèces voisines; il est à peu près comme dans le genre Hesperus.

\section{2\%. Philonthus umbratilis, Gravenhorst.}

Allongé, subdéprimé, finement pubescent, d'un noir brillant, avec les élytres d'un noir bronzé, la bouche d'un roux de poix et les pieds d'un testacé obscur. Tête et prothorax lisses, luisants: celui-ci subcarré. Élytres finement et densement, abdomen légèrement et assez densèment, ponctués.

$\sigma^{7}$ Le $6^{\theta}$ arceau ventral profondément et aigument entaillé dans le milieu de son bord apical, avec l'entaille bordée en dedans d'une gouttière subpellucide assez large. Le $5^{\mathrm{e}}$ largement subéchancré. Tarses antérieurs à 3 premiers articles fortement dilatés. Tête presque aussi large que le prothorax.

Q Le 6 arceau ventral subsinueusement tronqué à son bord apical. Tarses antérieurs presque simples. Tête un peu moins large que le prothorax.

Staphylinus umbratilis, Gravenhorst, Mier. 170, 21 ; - Mon. 69, 46.

Staphylinus subfuscus, Grulenhal, Ins. Suec. II, 326, 42. - ManNerheim, Brach. 29, 57. - Boisduval et Lacordatre, Faun. Ent. Par, I, 395, 18.

Plilonthus subfuscus, Nordmann, Symb. 84, 41 .

Philonthus umbratilis, Nordmann, Symb. 84, 47. - Erichson, Col. March. I, 454, 12 ; - Gen. et Spec. Staph. 443, 28. - Redtenbacher, Faun. Austr. 824. Heer, Faun. Col. Helv. I, 262, 14. - Fatrmatre et Laboulbène, Faun. Ent. Fr. İ, 518, 20. - Krastz, Ins. Deut. II, 583, 16. - Thomson, Skand. Col. II, 1388, 9, 1860.- FAUVEL, Faun. Gallo-Rhén. III, 447, 13.

$$
\text { Long., } 0^{\mathrm{m}}, 0066 \text { (3 l.); - larg., } 0^{\mathrm{m}}, 0010 \text { (1/2 l.). }
$$

Corps allongé, subdéprimé, d'un noir brillant, avec les élytres à peine bronzées; revêtu sur celles-ci et l'abdomen d'une fine pubescence grise et modérément serrée. 
Tête orbiculaire, fortement sétosellée ; d'un noir luisant ; lisse, éparsement et fortement ponctuée en arrière, vers les côtés, plus finement, plus densement et subruguleusement sur les tempes qui sont légèrement pubescentes. Front très-large, à peine convexe, marqué de chaque côté, entre les yeux, de 2 pores sétifères rapprochés et subtransversalement disposés, dont l'interne un peu moiudre. Cou glabre, lisse, d'un noir luisant. Labre noir (1), fortement sétosellé en avant. Mandibules et palpes d'un roux de poix plus ou moins foncé.

Yeux grands, ovales-oblongs (2); obscurs, lavés de gris.

Antennes suballongées, de la longueur de la tête et du prothorax réunis ou à peine plus longues; à peine épaissies ; pubescentes et distinctement pilosellées vers leur base; obscures, avec les 2 premiers articles souvent d'un brun de poix; le $1^{e_{\mathbf{r}}}$ allongé, en massue assez grêle $e_{t}$ subarquée : les $2^{\mathrm{e}}$ et $3^{\mathrm{e}}$ obconiques : le $3^{\mathrm{e}}$ suballongé, à peine plus long que le $2^{\mathrm{e}}$ : les suivants graduellement un peu plus courts, subobconiques : les $4^{\mathrm{e}} \mathrm{a} 7 \mathrm{e}$ oblongs, les pénultièmes à peine plus longs que larges: le dernier ovale-oblong, obliquement tronqué au sommet et subacuminé inférieurement.

Prothorax subcarré, un peu moins large que les élytres; tronqué au sommet, avec les angles antérieurs infléchis et subarrondis ; presque droit sur les côtés ; subarrondi à sa base ainsi qu'aux angles postérieurs ; peu convexe; dislinctement sétosellé, avec la longue soie latérale située sur le rebord même; d'un noir luisant; lisse, avec 2 séries dorsales composées de 4 points assez gros et assez profonds, dont les 2 antérieurs souvent plus rapprochés; marqué de plus, de chaque côté, de 4 ou 5 autres points semblables et épars. Repli noir, glabre, lisse.

Écusson densement pointillé, finement pubescent, d'un noir assez brillant.

Élytres subcarrées ou à peine transverses, à peine plus longues que le prothorax; sulıdéprimées ; finement, densement et subaspèreme $n_{t}$ ponctuées; d'un noir brillant et un peu bronzé ; modérément pubescentes ; éparsement sétosellées, avec 1 soie, notamment plus longue, vers l'écusson et 1 autre derrière les épaules. Celles-ci subarrondies. Ailes légèrement enfumées.

(1) La bordure submembraneuse est hien distincte, large, explanée, livide.

(2) Les yeux, étant plus grands, sont séparés du c ù p Ir un intervalle moindre quıe leur plus grand diamètre. 
Abdomen peu allongé, moins large que les élytres; subparallèle ou à peine arqué sur les côtés; parfois subatténué tout à fait en arrière; subconvexe sur le dos; assez fortement sétosellé ; finement, légèrement et un peu moins densement ponctué que les élytres; d'un uoir brillant; à pubescence assez longue et modérément serrée. Le $6^{\mathrm{e}}$ segment moins ponctué, moins pubescent, subarrondi au sommet.

Dessous $d u$ corps aspèrement pointillé, pubescent, d'un noir brillant, avec le sornmet du ventre parfois moins foncé. Dessous de la tête glabre, lisse. Lame mésosternale presque lisse en avant, subruguleuse et pbescente en arrière ; à arête transversale saillante, subangulée, ne dépassant pas le $1^{\text {er }}$ tiers; à pointe aiguë mais émoussée au bout. Métasternum à peine convexe sur son milieu. Ventre convexe, distinctement sétosellé.

Pieds médiocres, aspèrement pointillés, finement pubescents; d'un testảcé plus ou moins obscur, avec les hanches, surtout les postérieures, plus foncées. Cuisses antérieures finement épineuses en dessous vers leur sommet ; les postérieures un peu plus grêles. Tarses postérieurs à 1 er article aussi long ou à peine plus long que le dernier, moins long que les 3 suivants réursis.

Patrie. Cette espèce, médiocrement commune, se prend au printemps, sous les détritus et les feuilles mortes, sur divers points de la France : la Normandie, le Maine: le Bugey, le Beaujolais, les environs de Lyon, les Alpes, la Savoie, la Guienne, les Pyrénées, etc.

OBs. Elle diffère des e̊spèces précédentes par sa forme moins allénuée en avant, par sa tête plus large et plus orbiculaire, et surtout par le $1^{\text {er }}$ article des tarses postérieurs moins long relativement au dernier, etc.

Parfois la base des antennes et la bouche sont d'un roux de poix, et les pieds d'un testacé assez pâle.

\section{Philonthus anguinus, FAUVEL.}

Allongé, subdéprimé, légèrement pubescent, d'un noir de poix brillant, avec les élytres à reflet à peine bleuâtre, les antennes et la marge des segments abdominaux brunâtres, la bouche et les pieds roux. Tête et prothorax lisses, luisants : celui-ci suboblong, celle-là en carré à peine oblong. Elytres assez fortement, abdomen finement et peu densement, ponctués ( 9 ). 
Philonthus anguinus, FAUver. Faun. Gallo-Rhén. III, 464, 32, pl. V, fig. 18.

$$
\text { Long., } 0^{\mathrm{m}}, 0070 \text { (3 1/4 l.); - larg., } 0^{\mathrm{m}}, 0012(1 / 2 \text { l.), }
$$

Corps allongé, subdéprimé, d'un noir de poix brillant, avec les elytres à peine bleuâtres; revêtu sur celles-ci et l'abdomen d'un fine pubescence blonde et peu serrée.

Téte en carré à peine plus long que large, de la largeur du prothorax, à peine sétosellée, très-éparsement et assez finement ponctuée sur les tempes; d'un noir luisant. Front très-large, subdéprimé, subimpressionné en avant; offrant entre les yeux 4 pores sétifères, rapprochés 2 à 2 sur les côtés, l'interne beaucoup plus petit et plus ell avant; présentant, en outre, de chaque côté et en arrière de son disque, 3 petits points disposés en triangle. Cou glabre, lisse. Labre d'un roux brunatre, éparsenuent sétosellé en avant. Mandibules d'un noir de poix. Palpes roux.

Yeux relativement petits, ovales, brunâtres, séparés du prothorax par un intervalle très-grand.

Antennes assez robustes, moins longues que la tête et le prothorax réunis; subépaissies; finement duveteuses et légèrement pilosellées ; brunatres ou d'un roux obscur, avec lc dernier article moins foncé : le $\mathbf{1}^{\text {er }}$ en massue allongée et subarquée : les $2^{\mathrm{e}}$ et $3^{\mathrm{e}}$ oblongs, obconiques, un peu renflós et subnoueux vers leur soinmet : le $3^{\circ}$ à peine plus long que le $2^{\mathrm{e}}$ : les suivants graduellement un peu plus épais, non contigus, transverses, les pénultièmes plus fortement: le dernier subovalaire, obliquement subéchancré au bout.

Prothorax suboblong, moins large que les élytres; tronqué au sommet, avec les angles antérieurs infléchis èt arrondis; presque droit ou à peine arqué sur les côtés; subtronqué à sa base ; à angles postérieurs ôbtus et subarrondis; peu convexe; à peine sétosellé, à longue soie latérale située sur le rebord même; d'un noir de poix luisant; lisse, avec 2 séries dorsales composées de 4 points assez fins, dont les 2 intermédiaires plus rapprochés ; marqué de plus, de chaque côté, de 5 points semblables, mais épar's. Repli d'un noir de poix, glabre, lisse.

Écusson à peine pubescent, ponctué, noir.

Élytres subcarrées, environ de la longueur du prothorax; subdéprimées ; assez fortement mais peu densement ponctuées; d'un noir brillant, à reflet à peine bleuâtre; éparsement pubescentes, avec une courte soie sur l'angle huméral. Épaules peu arrondies. 
Abdomen suballongé, un peu moins large que les élytres; subparallèle ou à peine arqué sur les côtés jusqu'aux deux tiers, puis atténué en arrière; subconvexe sur le dos, avec le repli basilaire des $2^{\mathrm{e}}$ et $3^{\mathrm{e}} \mathrm{seg}$ ments à peine angulé à son bord postérieur; à peine sétosellé ; finement et peu densement ponctué et encore moins vers son extrémité ; d'un noir de poix brillant, avec la marge apicale des segments et le sommet moins foncés ; à pubescence fine, à peine plus serrée que celle des élytres. Le $6^{\mathrm{e}}$ segment obtuséinent tronqué.

Dessous $d u$ corps aspèrement ponctué, finement pubescent; d'un noir brillant, avec la marge apicale des arceaux du ventre moins foncée ou même un peu roussâtre. Dessous de la tête glabre, presque lisse. Ventre convexe, très-éparsement et longuement sétosellé en arrière.

Pieds assez courts, aspèrement ponctués, finement pubescents, roux. Cuisses antérieures assez fortement épineuses en dessous vers leur som-. met. Tarses postérieurs à $1^{\text {cr }}$ article subégal au dernier, moins long que les 3 suivants réunis.

Patrie. Cette espèce intéressante a été prise, en juillet, à Arrens (Hautes-Pyrénées), par M. Pandellé, qui nous l'a communiquée. Elle est très-rare.

. OBs. Elle semblerait former un genre voisin de notre genre Gabrius, tel que nous l'avons restreint; mais la conformation des palpes est celle des Philonthus. D'ailleurs, nous n'en avons vu qu'un seul exemplaire.

Elle simule un peu un Othius. A part la taille, elle a la forme du Gabrius nigritulus, mais, comme nous venons de le dire, elle ne peut rentrer dans le même genre.

Nous la rangeons à côté du Philonthus umbratilis, dont elle a un peu le port. Elle a la tête plus longue et plus parallèle, avec les antennes plus courtes et plus épaissies. Le prothorax est un peu plus long, plus parallèle, à points en série moins gros, plus inégalement distants ; la ponctuation des élytres est ṕlus forte et moins serrée, et celles-ci sont moins longues, etc.

Elle diffère du Phil. sordidus par sa tête plus oblongue et par ses élytres plus obscures et un peu plus densement ponctuées, etc.

29. Philonthus subrugosus, Mulsant et Rey.

Allongé, subdéprimé, éparsement pubescent, d'un noir de poix brillant 
et à peine métallique, avec les palpes, le bord apical des élytres et les pieds d'un roux de poix, les tarses et la marge des arceaux du ventre un peu plus clairs. Téte et prothorax lisses, luisants, à peine oblongs. Élytres assez fortement et rugueusement, abdomen plus finement et peu densement ponctués.

$$
\text { Long., } 0^{\mathrm{m}}, 0060 \text { (2 3/4 l.); - larg., } 0^{\mathrm{m}}, 0010 \text { (1/2 l.). }
$$

Corps allongé, subdéprimé, d'un noir de poix brillant et à peine métallique; revêtu sur les élytres et l'abdomen d'une fine pubescence blonde et peu serrée.

Tête à peine oblongue, à peine moins large que le prothorax, éparsement sétosellée, éparsement ponctuée sur les tempes, d'un noir luisant et à peine métallique. Front très-large, peu convexe, offrant de chaque côté, entre les yeux, 2 pores sétifères rapprochés et obliquement disposés, dont l'interne plus en avant; présentant en outre, de chaque côté en arrière, 3 points assez forts, dont les 2 antérieurs vers le bord postérointerne des yeux et le 3 e sur le vertex. Cou glabre, presque lisse. Labre obscur, sétosellé en avant. Mandibules noires. Palpes d'un roux de poix.

Yeux médiocres, ovales, brunâtres, séparés du prothorax par un intervalle assez grand.

Antennes médiocres, plus courtes que ia tête et le prothorax réunis; à peine épaissies ; finement duveteuses et légèrement pilosellées; obscures ; à $1^{\text {er }}$ article en massue suballongée : les $2^{\circ}$ et $3^{\mathrm{e}}$ oblongs, obconiques : le $3^{\mathrm{e}}$ un peu plus grêle et un peu plus long que le $2^{e}$ : les suivants graduellement à peine plus épais et un peu plus courts, non contigus, obconiques, avec les pénultièmes faiblement transverses : le dernier subovalaire, obliquement subéchancré au bout.

Prothorax en carré à peine oblong, sensiblement moins large que les élytres; tronqué au sommet; à angles antérieurs infléchis et arrondis؛ presque droit sur les côtés, avec ceux-ci, vus latéralement, subsinués au devant des angles postćrieurs, qui sont très-obtus; légèrement arrondi à sa base; peu convexe ; éparsement sétosellé; à longue soie latérale située contre le rebord même; d'un noir de poix luisant et à peine métallique;

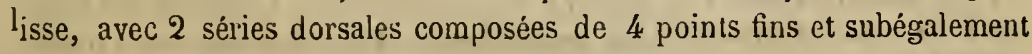
distants; marqué de plus, de chaque côté, outre ceux de la marge, de 4 points semblables, disposés en losange. Repli brunâtre, lisse. 
Écusson presque glabre, épar'sement ponctué, d'un noir de poix.

Elytres subcarrées, un peu plus larges en arrière; à peine plus lon. gues que le prothorax ; subdéprimées; assez fortement mais peu densement ponctuées, avec la ponctuation, vue de côté, formant comme des rugosités transversales; d'un noir de poix brillant et à peine bleuâtre, avec le bord apical légèrement roussâtre ; très-éparsement pubescentes, avec 1 courte soie sur l'angle humẹral, et 1 autre, un peu plus longue, vers l'écusson. Épaules subarrondies.

Abdomen peu allongé, un peu moins large à sa base que les élytres; à peine atténué en arrière ; subconvexe sur le dos, avec le repli basilaire du 2 e segment très-étroit, formant un angle rentrant dans son milieu; éparsement sétosellè ; finement et éparsement ponctué, un peu plus densement à la base des 3 premiers segments; d'un noir de poix brillant; à pubescence tine et peu serrée.

Dessous $d u$ corps éparsement et subaspèrement ponctué, finement pubescent, d'un noir de poix brillant, avec le sommet du ventre et la marge apicale des derniers arceaux plus ou moins largement d'un roux testacé. Dessous de la têté glabre, presque lisse. Mésosternum subconvexe, à pointe acérée, à arête transversale arquée et descendue jusqu'au milieu, à aire postérieure longuement ciliée. Ventre convexe, à pubescence éparse.

Pieds assez courts, aspèrement ponctués, légèrement pubescents, d'un roux de poix assez foncé, avec les tarses plus clairs. Cuisses antérieures peu renflées. Tarses postérieurs à $1^{\mathrm{er}}$ article subégal an dernier, moins long que les 3 suivants réunis.

Patrie. Cette espèce, dont nous n'avons vu qu'un seul exemplaire $q$ a été capturée en Provence.

OBs, Elle est voisine de l'anguinus pour la forme de la tête et du prothorax ; mais elle est moins grande, moins parallèle. Les antennes sont moins robustes, à pénultièmes articles moins transverses. Les élytres, un peu moins courtes, ont leur bord apical étroitement roussâtre (1), leur ponctuation aussi forte mais plus rugueuse, etc.

Elle ressemble beaucoup au $P h$. ventralis décrit plus loin. La base des

(1) La suture tend aussi à se montrer d'une teinte roussâtre. Les élytres sont crellsées à leur sommet, près de l'angle postéro-externe, d'une impression assez grande et sensible, qu'on remarque quelquefois, mais d'une manière si faible, chez plusieurs autres especes. 
antennes est plus obscure, les cuisses et les tibias sont d'un roux plus foncé. La tête est un peu plus ablongue. Les points des séries dorsales du prothorax, au nombre de 4, sont beaucoup plus fins. Les élytres sont un peu plus fortement et un peu plus lâchement ponctuées, etc.

Elle est moins parallèle que le $\mathrm{Ph}$. sordidus, avec la tête plus oblongue et les élytres un peu plus densement et plus rugueusement ponctuées, etc.

\section{Philonthus cephalotes, Gravenhorst.}

Allongé, subdéprimé, finement pubescent, d'un noir brillant, avec les élytres bronzées, la bouche et les pieds d'un brun de poix. Téte et prothorax presque lisses, luisants : celui-ci à peine plus long que large, subparallèle. Élytres assez fortement et assez densement, abdomen finement et assez densement, ponctués. Tarses antérieurs simples.

$\sigma$ Le $6^{\circ}$ arceau ventral assez profondément et angulairement entaillé, le $5^{\text {e }}$ subéchancré, dans le milieu de leur bord apical. Tête en carré transverse, un peu ou sensiblement plus large que le prothorax.

ㄴ Les $5^{\mathrm{e}}$ et $6^{\mathrm{e}}$ arceaux du ventre simples. Tête suborbiculaire, aussi large ou un peu moins large que le prothorax.

Siaphylinus cephalotes, Gravenhorst, Micr. 22, 27 ;-Mon. 71, 55.-Latreille, Hist. Nat. Crust. et Ins. IX, 311, 32. - GrLlennial, Ins. Suec. II, 320, 36. - MaNnerheim, Brach. 28, 52.- Boisduval et Lacordatre, Faun. Ent. Par. I, 90, 8.

Philonthus cephalotes, Nordmann, Symb. 82, 35. - Ericrson, Col. March, I, 439, 19 ; - Gen. et Spec. Staph. 455, 45. - Redtenbacaer, Faun. Austr. 701. Heer, Faun. Col. Helv. I, 263, 21. - Fairuaire et Laboulbène, Faun. Ent. Fr. I, 519, 23. - KraAtz, Ins. Deut. II, 592, 37. - Tromson, Skand. Col. II, 158, 11 , 1860. - Fauvel, Faun. Gallo-Rhén. III, 446, 12.

$$
\text { Long., } 0^{\mathrm{m}}, 0080 \text { (3 2/3 l.); - larg., } 0^{\mathrm{m}}, 0014 \text { (2/3 l.). }
$$

Corps allongé, subdéprimé, d'un noir brillant,avec les élytres bronzées ; revêtu sur celles-ci et l'abdomon d'une fine pubescence grise, plus serrée sur ce dernier.

Tête plus ou moins grosse, éparsement sétosellée; d'un noir luisant, presque lisse, avec quelques points assez gros, épars, distants, en arrière sur le disque, sur le vertex et sur les tempes. Front très-large, faiblement 
convexe, marqué entre les yeux de 4 pores sétifères subtransversalement disposés : les intermédiaires un peu moindres, un peu plus écartés entre eux et parfois un peu plus en arrière, offrant souvent dans leur intervalle une fossette légère et obsolète. Cou glabre, presque lisse, d'un noir luisant. Labre d'un noir brillant, fortement sétosellé en avant, Mardibules et palpes d'un brun de poix, avec ces derniers parfois un peu roussâtres.

Yeux médiocres, subovales, obscurs ou livides.

Antennes peu allongées, un peu plus courtes que la tête et le prothorax réunis; faiblement épaissies; légèrement pubescentes et éparsement pilosellées, surtout vers leur base ; d'un noir de poix, avec l'extrémité souvent moins foncée; à $1^{\text {er }}$ article allongé, en massue subarquée : les $2^{\mathrm{e}}$ et. $3^{\mathrm{e}}$ obconiques : le $3^{\mathrm{e}}$ assez allongé, plus long que le $2^{\mathrm{e}}$ : les suivants graduellement un peu plus courts, subobconiques: les $4^{\mathrm{e}}$ et $5^{\mathrm{e}}$ suboblongs : les $6^{\mathrm{e}}$ et $7^{\mathrm{e}}$ non, les $8^{\mathrm{e}}$ à $10^{\mathrm{e}}$ faiblement transverses, vus de côté : le dernier subovalaire, subéchancré au bout et subacuminé inférieurement.

Prothorax à peine plus long que large, subparallèle ou parfois à peine visiblement rétréci en arrière; un peu moins large que les élytres; tronqué au sommet, avec les angles antérieurs subinfléchis et arrondis; presque droit ou à peine arqué sur les côtés, qui, vus latéralement, sont sinués en arrière; subarrondi à sa base, avec les angles postérieurs obtus; peu convexe; fortement sétosellé, avec la longue soie latérale située contre le rebord même; d'un noir luisant; presque (1) lisse, avec 2 séries dorsales composées de 4 points assez gros (2) et subégalement distants; marqué de plus, de chaque còté, outre ceux de la marge, de 5 autres points semblables et épars. Repli noir, glabre, lisse.

Écusson pointillé, pubescent, d'un noir brillant.

Élytres subtransverses, un peu plus longues que le prothorax; subdéprimées; assez fortement, assez densement et subaspèrement ponctuées; d'un bronzé brillant et assez foncé ; assez longuement et subéparsement pubescentes; distinctement sétosellées, avec 1 soie, beaucoup plus longue vers l'écusson, et 1 autre derrière les épaules. Celles-ci arrondies. Ailes enfumées.

Abdomen suballongé, un peu moins large que les élytres; à peine arqué sur les côtés et subatténué tout à fait en arrière; assez convexe sur le

(1) Nous disons presque, parce que le fond parait, à un fort grossissement, à peine chagriné, comme dans plusieurs autres especes.

(2) Aecilentellement les séries sont formées de :i points au lieu de 4 . 
dos (1); distinctement sélosellé; finement et assez denscinent ponctué ; d'un noir brillant, avec une pubescence ercore plus longue et un peu plus serrée que celle des élytres. Le 6 e segment moins ponctué, moins pubescent, subtronqué au sommet.

Dessous du corps aspèrement ponctué, pubescent, d'un noir brillant, avec les intersections ventrales souvent ferrugineuses. Dessous de la tête pubescent sur les côtés, glabre sur le milieu, à peine ponctué en arrière. Lame mésosternale chagrinée en avant, lugueuse postérieurement. Métasternum à peine convexe sur son milieu, finement canaliculé sur sa ligne médiane. Ventre convexe, assez fortement sétosellé.

Pieds médiocres, aspèrement ponctués, finement pubescents, d'un brun de poix, avec les tarses moins foncés. Cuisses antérieures assez fortement épineuses en dessous vers leur sommet; les postérieures un peu plus grêles. Tarses antérieurs simples; les postérieur's à $1^{\text {er }}$ article à peine plus long que le dernier, moins long que les 3 suivants réunis.

Patrie. Cette espèce est médiocrement commune, sous les détritus et les fumiers secs, dans plusieurs localités de la France : les environs de Paris et de Lyon, la Normandie, le Maine, le Beaujolais, le Bugey, la Savoie, les Alpes, les Pyrénées, etc.

OBs. Elle commence une série de petites espèces remarquables à la fois par leurs tarses antérieurs simples dans les 2 sexes, et par les postérieurs, dont le $1^{\mathrm{er}}$ article est moins développé relativement au dernier et aux $2^{\mathrm{e}} \dot{\mathrm{a}}$ $4^{\circ}$ réunis.

La tête est plus large que le prothorax chez les $\sigma^{\prime}$, mais chez ceux a taille inférieure, elle est comme chez les $q$.

Quelquefois les antennes el les pieds sont presque entièrement d'un roux de poix.

Rarement, les séries dorsales du prothorax, ou l'une ou l'autre, sont de 5 points (2).

Nous placerons ici une espèce jusqu'alor's étrangère à la France ct que nous n'avons pas vue. Nous en traduisons la description :

(1) Les 3 premiers segments sont à peine impressionnés en travers à leur base, ainsi que dans quelques autres espèces suivantes.

(2) Nous n'indiquons pas toujours cette variation, qui n'est qu'accidentelle. 


\section{Philonthus megacephalus, HEER.}

Noir, brillant. Élytres d'un noir bronzé, densement et assez profondément ponctuées. Marge des segments ventraux de l'abdomen et pieds d'un brun de poix.

Philonthus megacephalus, HeER, Faun. Col. Helv. II, 263, 22.

Long., 3 1/2 lignes.

Antennes de la longueur du pronotum.

Tète plus large que le pronotum, dans le $\sigma^{\circ}$, marquée à sa base de quelques points profonds. Mandibules rousses.

Pronotum un peu plus large que long, à côtés presque droits.

Élytres un peu plus larges et un peu plus longues que le pronotum, densement et assez profondément ponctuées.

Patrie. La Suisse.

OBs. Cette espèce a beaucoup d'affinité avec la précédente, dont elle est peut-être une variété. Mais elle s'en distingue par une forme plus longue, par la tête encore plus grande, subcarrée, plus profondément et plus densement ponctuée à sa base; par ses antennes un peu plus épaisses et plus longues, à $1^{\text {er }}$ et $2^{e}$ articles (1) roux à leur base.

31. Philonthus fimetarius, Gravenhorst.

Allongé, subdéprimé, assez finement pubescent, d'un noir brillant, avec les élytres bronzées, et les pieds d'un testacé de poix. Tête et prothorax lisses, luisants : celui-ci suboblong, subparallele. Elytres assez finement et assez densement, abdomen finement et assez densement, ponctués. Tarses antérieurs simples.

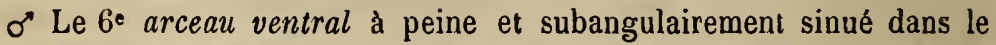
milieu de son bord apical, avec le sinus souvent rempli par une membrane. Tête aussi large ou un peu plus large que le prothorax.

(1) Ce caractère se rotrouve souvent dans les autres especes. 
$\$$ Le $6^{\text {e }}$ arceau ventral simple, subarrondi au sommet. Téte à peine aussi large que le prothorax.

Staphylinus fimetarius, Gravenilorst, Nicr. 175, 32;-Mon. 80,72.- LATReILle, Hist. Nat. Crust. et Ins. IX, 325, 72. - Gyllenbal, Ins. Suec. II, 342, 40. MannehHeIs, Brach. 29, 55. - Botsduval et LacordalRe, Faun. Ent. Par. I, 406, 38.

Staphylinus rigidicornis, GravenHORST, Micr. 23, 29 ;-Mon. 69, 49. - LATREILLE, Hist. Nat. Crust. et Inst. IX, 312, 34.

Philonthus rigidicornis, NORDMAN, Symb. 82, 33.

Philonthus fimetarius, Erichson, Col. March. I, 460, 21 ; - -Gen. et Spec. Staph. 456, 40. - Redrenbacher. Faun. Austr. 703. - Heer, Faun. Col. Helv. I, 263, 23. - Fatraaire et Laboulbène, Faun. Ent. Fr. I, 521, 27. - Kratz, Ins. Deut. II, 592, 26. - FAUVEL, Faun. Gallo-Rhén. III, 406, 34.

$$
\text { Long., } 0^{\mathrm{m}}, 0065 \text { (3 1.); - larg., } 0^{\mathrm{m}}, 0012 \text { (1/2 l.). }
$$

Corps allongé, subdéprimé, d'un noir brillant, avec les élytres bronzées; revêtu sur celles-ci et l'abdomen d'une assez fine pubescence d'un gris flave, assez longue et peu serrée.

Tête suborbiculaire, assez fortement sétosellée ; d'un noir luisant ; lisse, íparsement et fortement ponctuée en arrière. Front très-large, subconvexe, marqué de chaque côté, entre les yeux, de 2 pores sétifères assez gros, très-rapprochés et subtransversalemen disposés, et, sur le milieu, d'une impression assez large mais peu profonde. Cou glabre, presque lisse, d'un noir brillant. Labre noir, éparsement sétosellé en avant. Mandibules et palpes d'un brun de poix.

Yeux médiocres, brièvement ovales.

Antennes peu allongées, un peu plus courtes que la têle et le prothorax réunis ; faiblement épaissies ; légèrement pubescentes et éparsement pilosellées vers leur base; noires, avec l'insertion des premiers articles souvent d'un roux de poix; le $1^{\mathrm{er}}$ allongé, en massue subarquée : les $2^{\mathrm{e}}$ et $3^{\mathrm{e}}$ obconiques : le $3^{\mathrm{e}}$ suballongé, plus long que le $2^{\mathrm{e}}$ : les suivants graduellement un peu plus courts, subobconiques : les $4^{\mathrm{e}}$ et $5^{\mathrm{e}}$ suboblongs : les $6^{e}$ et $7^{e}$ presque aussi larges que longs : les $8^{e}$ à $10^{e}$ à peine ou non transverses, vus de côti: le dernier subovalaire, obliquement subéchancré au bout et subacuminé inférieurement.

Prothorax suboblong, subparallèle, évidemment moins large que les élytres; Ironqué au sommet, avec les angles antérieurs infléchis et arrondis ; presque droit sur les côtés, qui, vus latéralement, sont sensiblement 
sinués en arrière ; subarrondi à si base, a vec les angles postérieurs ubtus; peu convexe; assez fortement sélosellé, avec la longue soie latérale insérée tout près du rebord ; d'un noir luisant ; lisse, avec 2 séries dorsales composées de 4 points assez gros et assez profonds, inégalement distants (1); marque de plus, de chaque côté, outre ceux de la marge, de 5 points semblables et épars. Repli noir, glabre, lisse.

Écusson pointillé, pubescent, d'un noir brillant.

Élytres subcarrées, subélargies ell arrière, évidemment plus longues que le prothorax ; subdéprimées; assez finement, assez densement et subaspèrement ponctuées; d'un bronzé brillant, souvent assez clair et parfois un peu verdâtre; assez longuement ct subéparsement pubescentes; assez fortement sétosellées, avec 1 soie beaucoup plus longue vers l'écusson, et 1 autre vers les épaules. Celles-ci arrondies. Ailes légèrement enfumées.

Abdomen suballongé, moins large que les élytres; subarqué sur les côtés et subatténué en arrière ; assez convexe sur le dos; assez fortement sétosellé; finement et assez densement ponctué, un peu moins postérieurement; d'un noir brillant, avec une pubescence un reu plus longue, un peu plus fine et non ou à peine plus serrée que celle des élytres. Le $6^{\mathrm{e}}$ segment à peine arrondi au sommet.

Dessous du corps aspèrement pointillé, finement pubescent, d'un noir briliant, avec le bord apical des arceaux du ventre souvent d'un roux de poix. Dessous de la tête pubescent sur les côtés, glabre et presque lisse ou à peine ponctué sur le reste de sa surface. Lame mésosternale presque lisse en avant, ruguleuse en arrière; à arête transversale saillante, sub-

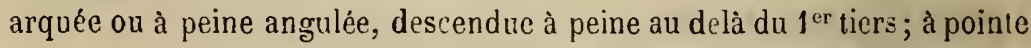
aiguë, mais souvent émoussée au bout. Métasternum légèrement ponctué et à peine convexe sur son milieu, ì peine canaliculé sur sa ligne médiane. Ventre convexe, éparsement sétosellé.

Pieds médiocres, aspèrement ponclués, finement pubescents, d'un testacé de poix, avec les hanches, surtout les postéricures, plus foncées. Cuisses antérieures assez fortement épineuses en dessous vers leur sommet; les postérieures un peu plus grêles. Tarses antérieurs simples; les postérieurs à $\mathbf{1}^{\mathrm{er}}$ article à peine plus long que le dernier, moins long que les 3 suivants réunis.

(1) Quelquefisis ils sont tous également distants ; d'autres fois les 2 antérieurs sont plus lapprochés, "arement le postérieur est plus écarté, elc. 
Patrie. Cetle espèce est commune dans presque toute la France, dans les bouses, les crottins, les fumiers et les matières végétales en putréfaction.

OBs. La taille est moindre que dans le cephalotes; la tête est moins carrée, avec les pores intermédiaires du front beaucoup plus écartés entre eux; les élytres sont plus longues, les pieds d'une couleur plus claire; la pointe mésosternale est moins prolongée, moins acérée; la couleur bronzée des élytres est moins sombre, etc.

La tête varie de grosseur comme dans l'espèce précédente. La ponctuation des élytres est tantôt assez fine, tantôt un peu plus forte. Les pieds sont d'un testacé parfois assez pâle, plus rarement assez obscur.

Accidentellement, les séries dorsales sont de 5 ou même de 6 points.

Le stenoderus de Reiche (Ann. Ent. Fr. 1861, 204; - Marseul, l'Abeille, 1871, VIII, 302) ne nous a paru qu'une variété du fimetarius. La taille est à peine plus grande ; les pieds sont plus obscurs, et l'impression antérieure du front est généralement plus profonde, plus fovéiforme (Corse).

\section{LAR VE}

Voici la description de la larve présumée du Philonthus fimetarius:

Corps allongé, étroit, subatténué en arxière, plus ou moins sétosellé, presque lisse, d'un testacé pâle, livide et brillant, avec la tête et le prothorax plus foncés.

Téte grande, en carré suboblong et arrondi aux angles, plus large que le prothorax, subdéprimée, éparsement sétosellée, d'un roux de poix brillant et subtestacé; presque lisse, mais offrant en avant quelques rides obsolètes, et, sur sa ligne médiane, une très-fine ligne longitudinale, subsinueuse, antérieurement dichotome. Épistome grossièrement 4-denté, a dents émoussées au bout. Mlandibules très-développées, grêles, falciformes ferrugineuses. Palpes courts, testacés, sétacés, à dernier article grêle, subulé.

Yeux petits, obscurs, lisses.

Antennes courtes, à $1^{\mathrm{e}} \mathrm{r}$ article nodiforme : les $2^{\ominus}$ et $3^{\mathrm{e}}$ subcylindriques : le $2^{\mathrm{e}}$ allongé : le $3^{\mathrm{e}}$ plus court, suballongé, paré, après son milieu, de 2 soies : le dernier oblong, plus étroit et plus court que le $3^{e}$, paré d'une légère soie vers sa base, terminé par une petite pointe ou lobe sétifère et par 3 longurs soies divergentes.

Prothorax oblong, subrétréci en arrière; presque droit sur les côtés, qui, BR. 
vus latéralement, sont verticalement inflechis et largement arrondis en avant ainsi qu'aux angles antérieurs; tronqué au sommet et à la base, avec celle-ci légèrement rebordée; subdéprimé ou à peine convexe sur le dos et très-finement canaliculé sur sa ligne médiane; offrant, de chaque côté du disque, une suture ou fine arête subarquée en dedans, raccourcie en arrière et qui sépare celui-ci de la partie infléchie ; éparsement sétosellé, presque lisse, d'un roux de poix testacé et brillant.

Mésothorax et métathorax graduellement et simultanément rétrécis en arrière, transverses; à peine plus longs, réunis, que le prothorax; assez convexes; à peine rebordés à leur base; impressionnés sur les côtés; éparsement sétosellés; presque lisses; d'un testacé brillant, pâle et livide.

Abdomen allongé, un peu plus long que la tête et le thorax réunis; à peine moins large à sa base que le métathorax et puis graduellement subatténué en arrière ; subconvexe ; fortement sétosellé ; presque lisse, avec une impression ou cicatrice sur les côtés de chaque segment; d'un testacé pâle, livide et brillant; à $1^{\text {er }}$ segment très-court, les suivants graduellement moins courts : le dernier oblong, muni de 2 appendices ou lanières articulées, à $1^{\mathrm{er}}$ article allongé, en massue, paré vers son sommet de 2 ou 3 soies : le $2^{e}$ presque aussi long mais plus grêle, subcylindrique ou à peine épaissi, terminé par une longue soie.

Dessous de la tête d'un roux ferrugineux, lisse, avec le menton et la pièce prébasilaire ridés. Prosternum triangulaire, d'un roux testacé, finement chagriné sur son milieu. Poitrine et ventre excavés, pâles : celui-ci à tube terminal épais, un peu plus long que le $1^{\text {er }}$ article des lanières supérieures.

Pieds courts, pâles. Cuisses subcomprimées, fortement épineuses en dessous. Tibias plus courts, épineux en dedans et en dehors, terminés par un fort crochet, presque droit, subinfléchi.

OBs. Cette larve ressemble un peu à celle d'un Xantholin, comme, sans doute, la plupart de celles de Philonthes xantholiniformes ou bien à prothorax subparallèle.

\section{Philonthius sordidus, GravenhoRst.}

Allongé, subdéprimé, éparsement pubescent, d'un noir brillant, aveć les élytres d'un bronvé obscur et les pieds d'un brun de poix. Tête et 
prothorax lisses, luisants : celui-ci suboblong, subparallèle. Élytres fortement ét éparsement, abdomen finement et assez densement, ponctués. Tarses antérieurs simples.

$\sigma^{\prime \prime}$ Le $6^{\circ}$ arcean ventral sensiblement entaillé dans le milieu de son bord apical, avec le fond de l'entaille garni d'une membrane subpellucide, étroite et formanı légèrement gouttière. Le $5^{\text {e }}$ à peine échancré dans le milieu de son bord postérieur. Tête suborbiculaire, de la largeur du prothorax.

\& Le $6^{\circ}$ arceau ventral subarrondi, le $5^{\mathrm{e}}$ simple, à leur bord apical. Téte courtement ovalaire, à peine moins large que le prothorax.

Slaphylinus sordidus, Gratenhorst, Micr. 176, 33. - Gylleneal, Ins. Suec. II, 326, 41. - M ANNeraeim, Brach. 29, 53. - Boisduval ei Lacordaire, Faun. Ent. Par. I, 396, 19.

Philonthus pachycephalus, Nordmane, Symb. $82,33, \sigma^{\circ}$.

Philonthus sordidus, Norduasx, Symb. 84, 40.- ERichsox, Col. March. I, 459, 20;

- Gen. et Spec. Staph. 4506. 47. - Redrenbacaer, Faun. Austr. 825. - Heer, Faun. Col. Helv. I, 262, 20. - Fairmaire et Laboulbène, Faun. Ent. Fr. I, 24, 519. - Krastz, Ins. Deut. II, 391, 25. - Tzumson. Skand. Col. II, 159, 12. -Fauver, Faun. Gallo-Rhén. III, 448, 14.

Variété a. Élytres d'un roux de poix, ainsi que les pieds.

Long., $0^{\mathrm{m}}, 0060$ (2 3/4 l.); - larg., $0^{\mathrm{m}}, 0009$ (1/2 l. à peine).

Corps allongé, subdéprimé, d'un noir brillant, avec les élytres d'un bronzé obscur'; recouvert sur celles-ci et l'abdomen d'une fine pubescence grise et très-peu serrée.

Tête suborbiculaire ou courtement ovale, éparsement sétosellée; d'un noir luisant; lisse, très-éparjement et assez fortement ponctuée en arrière et sur les tempes. Front très-large, à peine convexe, paré entre les yeux de 4 pores sétifères subtransversalement disposés : les intermédiaires à peine moindres, à peine plus écarlés entre eux, parfois à peine plus en arrière, offrant souvent dans leur intervalle une légère fossette plus ou moins obsolète. Cou glabre, lisse, d'un noir luisant. Labre d'un noir brillant, sétosellé en avant. Mandibules et palpes d'un noir ou d'un brun de poix.

Yeux médiocres, subovales, obscurs, lavés de gris.

Antennes peu.allongées, un peu plus courtes que la tête et le prothorax 
réunis ; faiblement épaissies ; légèrement pubescentes et éparsement pilosellées vers leur base; noires, avec l'insertion des premiers articles parfois roussâtre; le $1^{\text {er }}$ allongé, en massue subarquée : les $2^{\mathrm{e}}$ et $3^{\mathrm{e}}$ obconiques : le $3^{\mathrm{e}}$ suballongé, plus long que le $2^{\mathrm{e}}$ : les suivants graduellement un peu plus courts, subobconiques : les $4^{\mathrm{e}}$ et $5^{\mathrm{e}}$ suboblongs : les $6^{\mathrm{e}}$ et $7^{\mathrm{e}}$ presque aussi larges que longs : les $8^{\mathrm{e}}$ à $10^{\circ}$ à peine tranverses, vus de côté : le dernier subovale, obliquement subtronqué au bout et acuminé inférieurement.

Prothorax suboblong, subparallèle, un peu moins large que les élytres; tronqué au sommet, avec les angles antérieurs subinfléchis et subarrondis; presque droit sur les côtés qui, vus latéralement, sont faiblement sinués en arrière; subarrondi à la base ainsi qu'aux angles postérieurs; peu convexe; éparsement sétosellé, avec la longue soie latérale situéc presque contre le rebord mêmé d'un noir luisant; lisse, avec 2 séries dorsales composées de 3 points assez forts et subégalement distarts; marqué de plus, de chaque côté, outre ceux de la marge, de 5 points semblables et épars. Repli noir, glabre, lisse.

Écusson très-finement chagriné, ponctué, légèrement pubescent, d'un noir assez brillant.

Elytres subtransverses, à peine plus longues que le prothorax; subdéprimées ; fortement, profondément et éparsement ponctuées, avec la poncIuation à peine plus serrée le long du bord postérieur; d'un bronzé brillant; mais sombre; très-éparsement pubescentes, avec la pubescence assez redressée; éparsement sétosellées, avec 1 soie beaucoup plus longue vers l'écusson et 1 autre derrière les épaules. Celles-ci subarrondies. Ailes blanches.

Abdomen allongé, moins large que les élytres, subparallèle ou faiblement arqué sur les côtés et à peine atténué tout à fait en arrière; subconvexe sur le dos; assez fortement sétosellé ; finement et assez densement ponctué, plus lâchement ou presque lisse vers le sommet des $3^{\mathrm{e}}, 4^{\circ}$ et $5^{\mathrm{e}}$ segments ; d'un noir brillant; à pubescence déprimée, plus fine et un peu plus serrée que celle des élytres. Le $6^{\text {e }}$ segment moins ponctué, moins pubescent: subtronqué au sommet.

Dessous du corps subaspèrement ponctué, finement pubescent, d'un noir brillant, avec lo bord apical des arceaux du ventre souvent ferrugineux. Dessous de la tête légèrement pubescent sur les côtés, glabre et presque lisse sur le reste de sa surface ou à peine ponctué vers sa base. Lame mésosternale presque lisse en avant, subruguleuse en arrière; à arête 
transversale assez saillante, fortement arquée, descendue presque jusque vers le milieu; à pointe assez prolongée, acérée, pubescente. Métasternum à peine convexe sur son milieu, très-finement canaliculé sur sa ligne médiane. Ventre convexe, distinctement sétosellé, plus longuement en arrière.

Pieds médiocres, aspèrement ponctués, finement pubescents, d'un noir ou d'un brun de poix, avec les tarses et parfois les tibias un peu moins foncés. Cuisses antérieures assez fortement épineuses en dessous vers leur sommet; les postérieures suballongées, assez grêles. Tarses antérieurs simples; les postérieurs à $1^{\mathrm{er}}$ article à peine plus long que le dernier, moins long que les 3 suivants réunis.

Patrie. Cette espèce est assez commune dans les fumiers et parmi les détritus, dans les basses-cours et non loin des habitations, dans les environs de Paris et de Lyon, la Picardie, la Normandie, la Lorraine, le Bugey, le Beaujolais, les Alpes, la Provence, les Pyrénées, etc.

OBs. Sa forme est plus parallèle que celle du Ph. fimetarius. Les pores intermédiaires du front sont moins écartés entre eux. Les élytres, moins élargies en arrière, sont un peu plus courtes, plus fortement et surtout moins densement ponctuées et d'une teinte plus foncée. Les pieds sont généralement plus obscurs. La pointe mésosternale est plus prolongée et plus acérée, etc.

Quelquefois les élytres, moins leur extrême base, sont roussâtres, avec les pieds d'un roux de poix ainsi que les intersections de l'abdomen tant en dessus qu'en dessous.

La grosseur de la tête varie suivant la taille, et c'est sans doute aux éclıatillons à grosse tête qu'il faut rapporter le pachycephalus de Nordmann.

\section{LARVE}

Suit la description de la larve supposée du Ph. sordidus.

Corps allongé, étroit, subconvexe, plus ou moins sétosellé, d'un testacé brillant sur la tête et le thorax, livide et presque mat sur l'abdomen.

Tête grande, oblongue, subparallèle sur ses côtés, plus large que le sommet du prothorax, de la largeur de la base de celui-ci; à peine convexe, éparsement sétosellée; presque lisse, à peine chagrinée ou ridée et longitudinalement et subobliquement sillonnée en ivant; d'un testacé 
brillant. Epistome aigument denticulé à son bord antérieur. Mandibules assez grandes, falciformes, acérées, d'un testacé ferrugineux. Palpes d'un testacé pâle, à dernier article assez, court, assez grêle, subulé.

Yeux petits, lisses, indiqués par une tache noire.

Antennes très-courtes, pâles, à $1^{\mathrm{er}}$ article épais, nodiforme $:$ les $2^{\circ}$ et $3^{\mathrm{e}}$ assez épais : le $2^{\mathrm{e}}$ oblong, subcylindrique : le $3^{\mathrm{e}}$ un peu plus long, subépaissi et bicilié avant.son extrémité, à peine lobé au bout de son côté interne : le dernier beaucoup plus court et plus grêle que le $3^{\mathrm{e}}$, terminé par un petit lobe presque indistinct et par 3 soies divergentes.

Prothọax à peine oblong et sensiblement atténué en avant, convexe, tronqué au sommet, rebordé à la base, éparsement sétesellé, lisse, obliquement sillonné-impressionné en avant sur les côtés, d'un testacé brillant.

Mésothorax et métathorax courts, subégaux, environ aussi longs réunis que le prothorax, subarqués sur les côtés et à peine élargis en arrière, finement rebordés à leur base, assez convexes, éparsement sétosellés; lisses, avec des cicatrices de chaque côté; d'un testacé livide et brillant.

Abdomen allongé, environ de la longueur du reste du corps, un peu atténué tout à fait en arrière, subdéprimé et inégal sur le dos, subsillonné sur sa ligne médiane; assez fortement sétosellé, avecles soies subépaissies et bifurquées ou trifurquées au bout; d'un testacé livide et presque mat; à $1^{\mathrm{er}}$ segment très-court : les suivants courts, subégaux, plus ou moins sillonnés ou mamelonnés sur les côtés : le dernier assez étroit, subıransverse, subrétréci en arrière, subarqué au sommet, muni à celui-ci de 2 lanières écartées à leur base, subcylindriques, assez longues, éparsement sétosellées, terminées par un lobe oblong, assez grêle, un peu déjeté en dehors et portant au bout une asșez longue soie.

Dessous de la tête presque lisse, testacé, brillant, subexcavé antérieurement. Prosternum triangulaire, subconvexe, lisse, d'un testacé pâle et brillant. Ventre d'un testacé pâle et assez brillant, longitudinalement tri_ sillonné, très-inégal et plus ou moins mamelonné, sétosellé comme en dessus; à tube terminal éparsement cilié-spinosulé surtout en dessous, subcylindrique, inflèchi, beaucoup plus long que les lanières supérieures.

Pieds assez courts, d'un testacé pâle. Hanches grandes. Cuisses allongées, subépaissies en massue, éparsement épineuses en dessous. Tibias plus courts que les cuisses, subatténués vers leur extrémité, éparsement épineux dans leur pourtour, terminés par un fort crochet solide, assez long, très-acéré, à peine arqué. 


\section{Philonthus sparsus, LUCAS.}

Allongé, subdéprimé, très-éparsement pubescent, d'un noir brillant, avec les élytres d'un noir bronzé, la bouche et les pieds d'un roux de poix. Tète et prothorax lisses et luisants: celui-ci suboblong, subparallèle. Elytres assez fortement et lâchement, abdomen finement et subépar'sement, ponctués. Tarses antérieurs simples.

$\sigma^{*}$ Le $6^{\text {e }}$ arceau ventral légèrement et angulairement entaillé dans le milieu de son hord apical, avec l'entaille bordée d'une étroite membrane subpellucide. Le $b^{\text {a }}$ à peine échancré dans le milieu de son bord postérieur. Tête de la largeur du prothorax.

ㅇ Le $6^{\circ}$ arceau ventral subarrondi, le $5^{\text {e }}$ simple, à leur bord apical. Tête à peine aussi large que le prothorax.

Variété $a$. Elytres rousses ou rougeâtres. Pieds d'un roux testacé.

Philonthus sparsus, Lucas, Expl. alg. Ent. 112, pl. 12, fig. 4. - Falrmatre et Liboulbène, Faun. Ent. Fr. I, 520, obs. - KraAtz, Ins. Deut. II, 574, 24-25, note.

$$
\text { Long., } 0^{\mathrm{m}}, 0060 \text { (2 3/4 1.); - larg., } 0^{\mathrm{m}}, 0009 \text { (1/2 1. à peine). }
$$

Patrie. Cette espèce se prend dans les bouses et les crottins, dans les environs de Lyon, où elle est assez rare. Elle est plus commune en Provence et dans le Languedoc.

OBs. Elle ressemble tellement à la précédente que nous nous dispensons d'en donner une description détaillée, et elle pourrait bien en être une simple variété locale. Toutefois, nous ferons observer que les pores sétifères du front sont moins inégaux, également distants et tout à fait diśpósés en ligne transversale; que les points des séries dorsales du prothorax sont un peu moins forts, avec les 2 des extrémités un peu plus rapprochés; que les élytres sont encore plus éparsement ponctuées, avec la ponctuation non plus serrée vers le bord postérieur ; que l'abdomen est moins densement pointillé, à pubescence plus longue, moins déprimée et un peu moins serrée; que les parties de la bouche et les pieds sont généralement d'une couleur moins foncée, etc. 
La couleur des élytres ne signifie rien, car on trouve tous les passages, et c'est aux variétés à élytres claires que doit s'appliquer la description de Lucas.

A cause de celte phrase : Elytra... crebrius subtiliusque punctata, nous pensons que le Ph. placidus d'Erichson (Gen. et Spec. Staph. 458, 49) doit être une espèce distincte.

Dans les Ph. sordidus et sparsus le dernier article des palpes maxillaires, est un peu moins allongé et un peu moins grèle.

\section{Philonthus fuscus, Gravenhorst.}

Allongé, subdéprimé, finement pubescent, d'un noir de poix brillant, avec la bouche, les antennes, le sommet de l'abdomen, les intersections ventrales et les pieds roux. Tète et prothorax lisses, luisants : celui-ci à peine plus long que large, subparallèle. Élytres et abdomen finement ponctués. Tarses antérieurs simples.

$\sigma$ Le 6e arceau ventral sensiblement sinué au sommet, avec un espace triangulaire lisse, au devant du sinus. Tête de la largeur du prothorax.

$\uparrow$ Le $6^{\circ}$ arceau ventral subarrondi au sommet. Tête un peu moins large que le prothorax.

Staphylinus fuscus, Gravenhorst, Micr. 29, 41; - Mon. 59, 26. - LATReIlle, Hist. Nat. Crust. et Ins. IX, 317, 46. - Gyllenkal, Ins. Suec. II, 329, 45. Manneraeis, Brach. 29, 50.

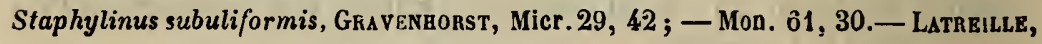
Hist. Nat. et Crust. et Ins. 1X, 317, 47.

Staphylinus terminatus, Gravengorst, Micr. 30, 43.- Latreille, Hist. Nat. Crust. et Ins. IX, 317, 48.

Staphylinus fragilis, Gravenhorst, Micr. 30, 44. - LATreille, Hist. Nat. Crust. et Ins. IX, 317, 49.

Philonthus fuscus, Nordmann, Symb. 90, 54. - Erichson. Col. March. I, 461, 22 ; - Gen. et Spec. Staph. 457, 48. - RedtengaCher, Faun. Austr. 702. - HeEr. Faun. Col. Helv. I, 264, 24. - KraATz, Ins. Deut. II, 593, 28. - Thonson, Skand. Col. II, 159, 14, 1860. - Rye, Ent. Ann. 1860, 106. - Fauver, Faun. Gallo-Rhén. III, 450, 16.

$$
\text { Long., } 0^{\mathrm{m}}, 0065 \text { (3 I.); - larg., } 0^{\mathrm{m}}, 0011 \text { (1/2 l.). }
$$

- Corps allongé, subdéprimé, d'un noir brillant, avec le prothorax et les 
élytres moins foncés, le sommet de l'abdomen et les intersections ventrales d'un roux de poix ; revêtu sur les élytres et l'abdomen d'une fine pubescence grise.

Tête subcarrée ou suborbiculaire, d'un noir luisant; éparsement sétosellée; lisse, avec quelques rares points en arrière vers les tempes. Front très-large, légèrement convexe, marqué entre les yeux de 4 points assez forts, transversalement disposés et subégalement distants. Cou lisse, glabre, d'un noir luisant. Labre roux, -sétosellé en avant. Mandibules d'un roux de poix. Palpes roux.

Yeux subovales, plus ou moins obscurs.

Antennes assez courtes, un peu plus longues que la tête; assez robustes, subépaissies; rousses, avec le milieu parfois un peu rembruni et lesommet ferrugineux; à $1^{\text {er }}$ article allongé, en massue : les $2^{\mathrm{e}}$ et $3^{\mathrm{e}}$ obconiques : le $3^{\mathrm{e}}$ un peu plus long que le $2^{\circ}$ : les suivants graduellement un peu plus courts et un peu plus épais : les $5^{\mathrm{e}}$ à $10^{\mathrm{e}}$ obconiques, transverses : le dernier subovale, obliquement échancré au bout et acuminé inférieurement.

Prothorax à peine plus long que large, subparallèle, un peu plus étroit que les élytres; tronqué au sommet, avecles angles antérieurs subinfléchis et arrondis; presque droit sur les cotés; arrondi à sa base, avec les angles postérieurs obtus; peu convexe; d'un noir ou d'un brun de poix luisant ; éparsement sétosellé ; lisse, avec 2 séries dorsales composées de 4 points assez fins, dont le postérieur plus en dehors; marqué de plus, de chaque côté, outre ceux de la marge, d'environ 5 points semblables et épars. Repli roux, glabre, lisse.

Écusson densement et finement pointillé, noirátre, à pubescence grise. Elytres peu plus longues que le prothorax; subdéprimées ; finement et densement ponctnées; d'un noir ou d'un brun de poix brillant, avec une fine pubescence grise, 1 fine et longue soie sur le còté des épaules et 1 autre vers l'écusson. Épaules subarrondies.

Abdomen suballongé, éparsement sétosellé, finement et assez densement pointillé, d'un noir brillant, avec le sommet d'un roux de poix; revêtu d'une fine pubescence grise. Le $6^{\text {e }}$ segment à peine arrondi à son bord postérieur.

Dessous du corps ponctué, finement pubescent, d'un noir brillant, avec le dessous du prothorax roux, ainsi que le sommet du ventre et les intersections ventrales. Dessous de la tête presque glabre et presque lisse. Ventre convexe, éparsement et longuement sétosellé.

Pieds médiocres, ponclués, finement pubescents, roux, avec les hanchès 
postérieures rembrunies. Tarses antérieurs simples; les postérieurs à $1^{\text {er }}$ article subégal au dernier, moins long que les 3 suivants réunis.

Patrie. Cette espèce est très-rare. Elle se trouve dans le nord de a France et quelquefois aussi dans la région des Pyrénées. Elle habite parfois, même en hiver, les nids de frelons.

OBs. Qutre sa coloration, elle diffère des Ph. fimetarius et sordidus par ses antennes, dont les pénultièmes articles sont plus sensiblement transverses.

La couleur du prothorax et des élytres varie du noir de poix au roux de poix. Quelquefois le premier est d'un rouge assez clair, avec sa partie antérieure plus ou moins rembrunie. La description d'Erichson et de quelques autres auteurs a été faite sur des exemplaires semblables, qui sont immatures, quoique le cas se représente assez souvent. Le prothorax est même parfois entièrement rouge et les élytres se montrent alors d'un rouge brun. Nous réduirons ces diverses variations de couleur à 3 principales, savoir :

a Corps d'un noir de poix, avec le sommet de l'abdomen roux.

$b$ Base du prothorax et sommet de l'abdomen d'un rouge testacé.

c Pourtour du prothorax, élytres et sommet de l'abdomen l'un rouge testacé ou d'un rouge acajou.

Les antennes sont parfois d'un roux assez obscur, d'autres fois rousses avec le $1^{\text {er }}$ article rembruni dans son milieu.

Les séries dorsales du prothorax sont quelquefois composées de 5 points au lieu de 4, exception accidentelle qui se remarque également cheż d'autres espèces.

IV• SECTION. - Séries dorsales du prothorax de 5 polnts.

OBs. Cette section renferme des espèces à taille médiocre ou petite. Le dernier article des palpes labiaux est plus long que le pénultième, plus ou moins fusiforme. Celui des maxillaires, plus ou moins allongé et fusiforme, est parfois sensiblement atténué vers son extrémité. La lame mésosternale varie dans son arête et dans sa pointe. Les hanches intermédiaires sont ou légèrement distantes ou rapprochées dans leur milieu. Les tarses antérieurs, plus ou moins fortement dilatés dans les $\sigma^{\prime \prime}$, le sont parfois faiblement ou à peine dans ce même sexe. Le $1^{\text {or }}$ article des tarses postérieurs 
est lantôt beaucoup plus long, tantôt aussi long ou à peine plus long que le dernier. La tête, suborbiculaire ou subovalaire, est tantôt aussi large, Iantôt moins large que le prothorax, avec celui-ci généralement rétréci en avant.

Cette section répond à un certain nombre d'espèces dont voici le tableau :

Le 1 er article des tarses postericurs beaucoup ou sensiblement plus long que le dernier, subégal aux 3 suivants réunis. Tarses antérieurs plus ou moins dilatés, au moins chez les $\sigma$. Hanches intermédiaires plus ou moins rapprochées:

b Têtc en carré subarrondi, suborbiculaire ou courtement ovalaire, non ou à peine plus étroite que le prothorax chez les $\sigma$; celui-ci ordinairement peu rétréci en avant. L: dernier article des palpes maxillaires presque exactement fusiforme.

c Elytres unicolores, bronzées, noires, parfois rousses à base noire.

d Tibias antérieurs plus ou moins fortement épineux en dehors. Élytres bronzées, d'un noir bronzé ou rouges.

e Abdomen modérément ou peu densement ponctué. Pieds obscurs. Taille moyenne.

f Élytres bronzées. Têtc des $\sigma$ en carré subarrondi, de la largeur du prothorax. Repli des premiers segments de l'abdomen en accolade obtuse. Ailes blanches. .

ff Elytres rouges. Tête des $\sigma$ suborbiculaire, un peu moins large que le prothorax. Repli des premiers segments de labdomen en accolade prononcée. Ailes à peine enfumées. . . . . . . . . . . . ee Abdomen assez densement ponctué. Elytres submétalli ques. Téte des $\sigma$ suborbiculaire, à peine moins large que le prothorax. Pieds brunâtres. Ailes blanchàtres. Taille petite.

EBERINUS.

corruscus.

dd Tibias antérieurs à peine ou peu épineux en debors. Pieds obscurs ou d'un roux brunatre.

g Elytres d'un noir de jais. Abdomen densement ponctué, plus éparsement à la base et au sommet. Téte des $\sigma^{*}$ en carré subarrondi. Ailes enfumées. Pieds obscurs.

gg Élytres d'un noir ou d'un brun de poix. Abdomen finement et densement pointillé. Téte suborbiculaire. Pieds d'un roux plus ou moins obscur.

h Antennes médiocres, à pénultièmes articles (8-10)à peine transverses. Taille un peu moindre. Ailes enfumées. . . . . . . . . . . .

hh Antennes assez courtes, à pénultièmes articles (7-10) visiblement transverses. Taille petite. Ailes blanches.

pumigatus.

GAGATES.

DEBILIS. 
ce Élytres noires, avec la suture et une tache posthumérale rouges. Abdomen très-finement et très-densement pointillé. Ailes blanchâtres. . . . . . . . . . . sanguinolentus.

ccc Élytres d'un roux testacé, avec une large bande suturale noire. Abdomen assez finement et assez densement ponctué. - stragulatus.

cccc Élytres noires, a vec une tache rouge à l'angle sutural; éparsement ponctuées. . . . . . . . . . . . Fenestratus.

bb Tête subovalaire, plus étroite que le prothorax dans les 2 sexes: cclui-ci visiblement rétréci en avant. Le dernier article des palpes maxillaires plus aminci vers son extrémité qu'à la base. i Élytres noires, avec 1 tache discoïdale postérieure, noire. Abdomen peu densement ponctué. Hanches antérieures concolores. Ailes blanchătres. . . . . . : cruentatus.

ii Ellytres noires ou brunâtres, parfois à transparence rouge. Ailes blanches ou blanchâtres.

1 Hanches antérieures testacées, ainsi que souvent le dessous du 1er article des antennes : celles-ci suballongées. Abdomen densement ponctué. . . . scrbalarius.

II Hanches antérieures rembrunies, au moins en dehors.

m Antennes peu allongées, à articles $4-10$ plus ou moins oblongs. Elytres et abdomen finement et densement ponctués. Hanches antérieures testacées en dedans. . . . . . . . . .

mm Antennes assez courtes, à articles 7-10 subcarrés ou à peine oblongs. Elytres et abdomen moins finement et moins densement ponctués. Hanches antérieures obscures. . . . . . . . AGILIS.

\section{Le 1er article des tarses postérieurs aussi long ou à peine plus} long que le dernier, moins long que les 3 suivants réunis. Tibias antérieurs distinctement épineux. Le dernier article des palpes maxillaires plus ou moins atténué vers son extrémité.

n Antennes assez courtes, subépaissies, à pénultièmes articles subtransverses. Hanches intermédiaires légèrement distantes. Téte en carré subarrondi ou suborbiculaire (1).

- Tarses antérieurs presque simples dans les 2 sexes. Élytres d'un noir de poix. Base des antenne, pieds et intersections ventrales d'un roux testacé. . . . . ventralis.

00 Tarses antérieurs fortement dilatés chez les $\sigma$. Marge des élytres, antennes et pieds d'un roux testacé (2). DISCOIDEus.

(l) Chez les ventralis et discoideus, la pointe mésosternale, médiocrement prolongée, est parfois subémoussée au bout.

(2) Chez le discoideus, le dernier article des palpes maxillaires est moins allonge et un peu moins grele que chez le ventralis. 
Antennes suballongées, subfiliformes, à pénultièmes articles nullement transverses. Hanches intermédiaires plus rapprochécs. Téte subovalaire. Tarses antérieurs des $\sigma^{\prime}$ fortement dilatés (1).

p Elytres bleues. Hanches et cuisses antérieures et intermédiaires testacées. . . . . . . . . . Rufinanus.

pp Élytres d'un noir bronzé, ou rouges à hase rembrunie. Pieds testacés, avec toutes les hanches et les cuisses postérieures rembrunies, . . . . . . . . QuisquiLIarius.

\section{Philonthus ebeninus, Gravenhorst.}

Allongé, subdéprimé, épar'sement pubescent, d'un noir brillant, avec les élytres bronzées. Tête et prothorax lisses, luisants : celui-ci aussi long que large, plus ou moins rétréci en avant. Élytres et abdomen assez fortement et modérément ponctués. Ailes blanches. Repli des premiers segments de l'abdomen en accolade obtuse.

$\sigma^{*}$ Le $6^{e}$ arceau ventral assez profondément et subaigument entaillé dans le milieu de son bord apical, avec le fond de l'entaille garni d'une gouttière subpellucide. Tarses antérieurs à 3 premiers arlicles fortement dilatés. Tête en carré subarrondi, de la largeur du prothorax.

ㄴ $6^{\circ}$ arceau ventral subarrondi à son bord apical. Tarses antérieurs à 3 premiers articles médiocrement dilatés. Tête suborbiculaire, moins large que le prothorax.

Staphylinus ebeninus, Gravenhorst, Micr. 170, 22 ; - Mon. 67, 21.- LATREILle, Hist. Nat. Crust. et Ins. IX, 323, 66. - GrleEnhal, Ins. Suec. II, 326, 52. Mannerheis. Brach. 30, 66.-Boisduyal et Lacordatre, Faun. Ent. Par. I, 394, 15. Staphylinus brevicornis, Gravenhorst, Micr. 22, 28; - Mon. 69, 50.- Latreille, Hist. Nat. Crust. et Ins. IX, 312, 33.

Philonthus ebeninus, Nordyans, Symb. 93, 63. - Erichson, Gen. et Spec. Staph. 461, 56. - Redtenbacher, Faun. Austr. 703, 25. - Fairmalre et Laboulbène, Faun, Ent. Fr. I, 5̌23, 36.- Krastz, Ins. Dcut. II, 596, 30.-Thомson, Skand. Col. II, 159, 15, 1860.- Fauvel, Faun. Gallo-Rhén. III, 459, 28.

Philonthus brevicornis, Nordmann, Symb. 94, 69.

Philonthus varians, Erichson, Col. March. I, 461, 23. - HeEr, Faun. Col. Helv. I, 264,25 .

(1) Chez les rufimanus et quisquiliarius, la pointe mésosternale est généralement plus prolongée et plus aiguë que chez les ventralis et discoideus. 


$$
\text { Long., } 0^{\mathrm{m}}, 0080 \text { (3 2/3 l.); - larg., } 0^{\mathrm{m}}, 0014 \text { (2/3 1.). }
$$

Corps allongé, subdéprimé, d'un noir brillant, avec les élytres bronzées; revêtu sur celles-ci et l'abdomen d'une fine pubescence grise et peu serrée.

Tête subcarrée ou suborbiculaire, éparsement sétosellée; d'un noir luisant; lisse, avec quelques gros points épars en arrière et sur les tempes. Front très-large, faiblement convexe, marqué de chaque côté, entre les yeux, de 2 pores sétifères rapprochés et subtransversalement disposés, dont l'interne moindre. Cou glabre, lisse, d'un noir luisant. Labre d'un noir brillant, fortement sétosellé en avant. Mandibules et palpes d'un noir ou d'un brun de poix.

Yeux grands, subovales, obscurs ou tachés de livide.

Antennes suballongées, à peine aussi longues que la tête et le prothorax réunis; à peine épaissies; légèrement pubescentes et éparsement pilosellées vers leur base; noires; à $1^{\mathrm{er}}$ article allongé, en massue subarquée : les $2^{\mathrm{e}}$ et $3^{\mathrm{e}}$ obconiques, suballongés, subégaux : les suivants graduellement un peu plus courts, subobconiques : les $4^{\mathrm{e}} \mathrm{a} 6^{\mathrm{e}}$ à peine aussi larges que longs, souvent brièvement pédicellés avec le pied roux : le $7^{\mathrm{e}}$ non, les

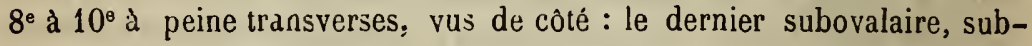
échancré au bout et subacuminé inférieurement.

Prothorax environ aussi large que long; plus ou moins rétréci en avant ; à peine moins large en arrière que les élytres; tronqué au sommet, avec les angles antérieurs infléchis et subarrondis; presque droit ou à peine arqué sur les côtés; subarrondi à sa base ainsi qu'aux angles postérieurs ; subconvexe; éparsement sétosellé, avec la longue soie latérale située contre le rebord même; d'un noir luisant; lisse, avec 2 séries dorsales composées de 5 points assez gros et assez profonds, dont l'antérieur plus écarté ; marqué de plus, de chaque côté, outre ceux de la marge, de 4 ou 5 autres points semblables et épars, dont les 2 internes assez rapprochés. Repli noir, glabre, lisse.

Écusson ponctué, pubescent, d'un noir brillant.

Élytres transverses, de la longueur du prothorax; subdéprimées; assez fortement, modérément et subaspèrement ponctuées; d'un bronzé brillant, parfois assez foncé ; éparsement pubescentes; ciliées à leur bord apical; éparsement sétosellées, avec 1 soie beaucoup plus longue, vers l'écusson, et 1 autre derrière les épaules. Celles-ci subarrondies. Ailes blanchâtres.

Abdomen suballongè ou allongé, moins large que les élytres; à peinc 
arqué sur les côtés et un peu atténué en arrière; subconvexe sur le dos, avec le repli des $2^{\circ}$ et $3^{\text {e }}$ segments en accolade obluse; assez fortement sétosellé (1); modérément et presque aussi fortement ponctué que les élytres, avec la ponctuation un peu plus légère et à peine moins serrée vers l'extrémité; d'un noir brillant; subéparsement pubescent. Le $6^{\mathrm{e}} \mathrm{seg}$ ment moins ponctué, moins pubescent, subtronqué au sommet.

Dessous du corps peu densement et subaspèrement ponctué, finement pubescent, d'un noir brillant. Dessous de la tête presque glabre, lisse. Lame mésosternale presque lisse, à arête transversale saillante, obtusément angulée, s'arrêtant vers le $1^{\text {er }}$ tiers ; à pointe subconvexe, assez prolongée, très-aiguë ou subacérée, parfois roussâtre vers le bout. Métasternum à peine convexe sur son milieu. Ventre convexe, distinctement sétosellé, plus longuement en arrière.

Pieds médiocres, aspèrement ponctués, légèrement pubescents, d'un noir de poix, avec les tarses souvent moins foncés. Cuisses antérieures assez finement épineuses ell dessous vers leur sommet; les postérieures plus grêles, suballongées. Tibias antérieurs fortement épineux en dehors. Tarses postérieurs à $1^{\mathrm{er}}$ article beaucoup plus long que le dernier, égal aux 3 suivants réunis.

Patrie. Celte espèce est assez commune, dans presque toute la France, dans les bouses, sous les détritus et les vieux fagots, etc.

OBs. La taille varie beaucoup, ainsi que la grosseur de la tête, qui est quelquefois moins large que le prothorax, même chez les $\sigma$.

Les pieds sont parfois d'un roux de poix plus ou moins foncé. Le lobe postérieur du métasternum est souvent roussâtre.

Rarement, une des séries dorsales du prothorax ne prẻsente que 4 points au lieu de 5. Plus rarement encore, ce sont les 2 séries qui sont dépour-vues du point postérieur, et c'est sans doute à cet accident qu'on doit altribuer le lhesgicus Kolenati (Melet. Ent. III, 1846, 19).

36. Philonthus corruscug, Gravenhorst.

Allongé, peu convexe, épursement pubescent, d'un noir brillant, avec les élytres rouges. Tête et prothorax lisses, luisants : celui.ci à peine pluslong

(1) On aperçoit sur les cotés une série de soies plus longues, et cela chez plusieurs especes suivantes. 
que large, subrétréci en avant. Elytres et abdomen assez fortement et modérément ponctués. Ailes faiblement enfumées. Repli des premiers segments de l'abdomen en accolade prononcée.

$\sigma^{*}$ Le $6^{e}$ arceau ventral assez profondément et aigument entaillé dans le milieu de son bord apical, avec le fond de l'entaille garni d'une goutlière subpellucide. Tarses antérieurs à 3 premiers articles assez fortement dilatés. Tête suborbiculaire, un peu moins large que le prothorax.

९ Le $6^{\mathrm{e}}$ arceau ventral subarrondi à son bord apical. Tarses antérieur's à 3 premiers articles médiocrement dilatés. Tête brièvement ovalaire, moins large que le prothorax.

Staphylinus corruscus, Gravenhorst, Micr. 33, 47; - Mon. 31, 14. - Latreille,

Hist. Nat. Crust. et Ins. IX, 319, 52 .

Staphylinus 'nitidus, Marshas, Ent. Brit. 511,38.

Staphylinus planus, Boisduval et LacordalRe, Faun. Ent. Par. I, 401, 27.

Philonthus corruscus, Nordanan, Symb. 98, 81. - ERichson, Col. March. I, 704,

26; - Gen. et Spec. Staph. 465, 61.- Redtenbacher, Faun. Austr. 704, 26. -

HeEr, Faun. Col. Helv. I, 265, 27. - Falrmaire et Laboulbène, Faun. Ent. Fr. I, 525,44 .

Philonthus ebeninus, var. KвaAтz, Ins. Deut. 597. - Fauvel, Faun. Gallo-Rhén. III, 460 .

$$
\text { Long., } 0^{\mathrm{m}}, 0080 \text { (3 2/3 l.); - larg., } 0^{\mathrm{m}}, 0015 \text { (2/3 l.). }
$$

Patrie. Cette espèce, assez commune dans presque toute la France, se prend de la même manière que la précédente.

Obs. Comme elle ressemble infiniment à l'ebeninus, sauf la couleur des élytres, nous nous dispenserons de la décrire plus amplement. Elle a, depuis quelque temps, étí considérée comme une variété de cette deruière. Toutefois, nous ferons observer que, dans le corruscus, la tête est un peu moins grande que dans l'ebeninus, le prothorax un peu moins court et un peu plus rétréci en avant; que les élytres sont à peine moins fortement ponctuées et que le repli des premiers segments abdominaux est en accolade toujours plus nette. Les $2^{\mathrm{e}} \mathrm{et} 3^{\mathrm{e}}$ articles des antennes sont un peu plus inégaux et les ailes un peu moins blanches, etc.

Parfois les élytres sont un peu moins rembrunies sur la région scutellaire, et la couleur des pieds varie comme chez l'ebeninus.

Le turbatus, Er. (466) se rapporte peut-être au corruscus? 
On peut rapporter ici le

\section{Philonthus disuidiatus, Sahlberg.}

Suballongé, subdéprimé, éparsement pubescent, d'un noir brillant, avec une grande tache ronge occupant la moitie postirieure des élytres, la bouche et les pieds d'un roux obscur. Téte et prothorax lisses, luisants : celui-ci suboblony, moins large queles élytres, subattinué en avant. Élylres subéparsement, abdoinen plus finement et plus densement ponctués.

$\sigma^{7}$ Le $6^{\circ}$ arceau ventral assez profondément et subaigument entaillé dans le milieu de son bord apical, avec l'entaille rebordée d'une étroite membrane. Téte de la largeur du prothorax.

$\uparrow$ Nous est inconnue.

Staphylinus dimidiatus, Sahlberg, Ins. Fenn. I, 326, 51. - ManNerheim, Brach. 30,69 .

Philonthus dimidiatus, Nondman, Symb. 97, 77. - Eвrchson, Gen. et Spec. Staph. 480, 86.- Fauvel, Faun. Gallo-Rhẻn. III, 459, 28, note.

Plilonthus caucasicus, Nordmanr, Symb. 99, 82. - Ericason, Gen. et Spec. Staph. $46 \dot{0}, 63$.

$$
\text { Long., } 0^{\mathrm{m}}, 0056 \text { (2 1/2 1.); - larg., } 0^{\mathrm{m}}, 0012 \text { (1/2 l.). }
$$

Patrie. La Finlande, la Prusse, l'Autriche, la Russie méridionale, etc.

OBs. Elle ressemble aux petits exemplaires du corruscus. Le prothorax est plus étroit, plus oblong; les élytres, plus éparsement ponctuées, paraissent un peu plus courtes; elles sont plus largement lavées de noir à leur base, et cette dernière couleur descend presque jusqu'au sommet sur la suture. La tête et le prothorax ont un reflet submétallique à peine sensible.

\section{3\%. Philonthus comeinmus, Gravenhorst.}

Allongé, à peine fusiforme, peu convexe, éparsement pubescent, d'un noir brillant, avec les élytres submétalliques et les pieds brunâtres. Tête et prothorax lisses, luisants : celui-ci subcarré, subatténué en avant. Élytres Br. 
assez finement et modérement, abdomen finement et assez densement, ponctués. Ailes blanchâtres.

$\sigma^{7}$ Le $6^{e}$ arceau ventral profondément et subogivalement entaillé au milieu de son bord apical, avec les côtés de l'entaille garnis en dedans

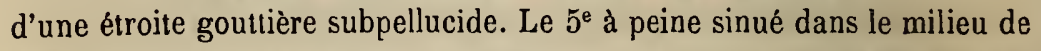
son bord postérieur. Tarses antérieurs à 3 premiers articles'fortement dilatés, le $2^{\mathrm{e}}$ à peine plus fortement. Tête suborbiculaire, à peine moins large que le prothorax.

으 Le $6^{\mathrm{e}}$ arceau ventral à peine arrondi, le $5^{\mathrm{e}}$ simple, à leur bord apical. Tarses antérieurs à 3 premiers articles légèrement dilatés. Tête brièvement ovalaire, un peu ou sensiblement moins large que le prothorax.

Staphylinus varians, Gravennorst, Mon. 82, 73.-Gyllenkal, Ins. Suec. II, 342, 58. - ManNerheim, Brach. 30, 73. - Boisduval et Lacordaire, Faun. Ent. Par. I, $394,16$.

Staphylinus concinnus, Gravenhorst, Micr. 21, 25.

Philonthus varians, Nondmans. Symb. 93, 65 - Thomson, Skand. Col. II, 159, 16. Philonthus ebeninus, var. minor, Erichson, Gen. et Spec. Staph. 461. - KraATZ, Ins. Deut. II, 597.

Variété $a$. Élytres rousses ou d'un rouge brunâtre. Pieds d'un roux de poix.

Variété $b$. Élytres d'un noir bronzé. Bouche et pieds d'un testacé obscur. Ventre moins densement ponctué. Taille moindre.

Staphylinus ochropus, GraveNhoRst, Micr. 39, 57 ; - Mon. 67, 39. - LATREILle,

Hist. Nat. Crust. et Inst. IX, 322, 62. - Gyllenhal, Ins. Suec. II, 336, 51.Mannerheim, Brach. 29, 65.

Philonthus ochropus, NoRdans, Symb. 93, 62.

Philonthus ebeninus, var. Erichson, Gen, et Spec. Staph. 462. - KraAtz, Ins. Deut. II, 597.

Philonthus ebeninus, var. $c$, Fairmaire et Laboulbène, Faun. Ent. Fr. I, 524.

Philonthus varians, var. HeEr,Faun. Col. Helv, 203.- Thomson, Skand. Col. II, 160.

$$
\text { Long., } 0^{\mathrm{m}}, 0070 \text { (3 1/5 l.); - larg., } 0^{\mathrm{m}}, 0012 \text { (1/2 l.). }
$$

Corps allongé, peu fusiforme, peu convexe, d'un noir brillant, avec les élytres submétalliques ; revêtu sur celles-ci et l'abdomen d'une fine pubescence grisâtre et peu serréc.

Tête suborbiculaire ou brièvement ovalaire; éparsement sétosellée; d'un noir luisant; lisse, avec quelques points médiocres et épars sur les tempes, Front large, à peine convexe, marqué de chaque cỏté, entre les yeux de. 
2 pores sétifères rapprochés et subtransversalement disposés, l'interne un peu moindre, parfois un peu plus en arrière. Cou glabre, lisse, d'un noir luisant. Labre d'un noir brillant, fortement sétosellé en avant. Mandibules et palpes d'un noir de poix, parfois brunâtre.

Yeux assez grands, subovales, plus ou moins obscurs.

Antennes suballongées, à peine moins longues que la tête et le prothorax réunis; à peine épaissies; légèrement pubescentes et éparsement pilosellées surtout vers leur base; noires; à $1^{\mathrm{e}_{\mathbf{r}}}$ article allongé, en massue subarquée: les $2^{\circ}$ et $3^{\mathrm{e}}$ suballongés, obconiques : le $3^{\mathrm{e}}$ non ou à peine plus long que le $2^{\mathrm{e}}$ : les suivants graduellement un peu plus courts, subobconiques : les $4^{\mathrm{e}}$ à $7^{\circ}$ à peine oblongs : le $8^{\mathrm{e}}$ non, les $9^{\mathrm{e}}$ et $10^{\mathrm{e}}$ à peine transverses, vus de côté : le dernier subovalaire, subéchancré au bout et subacuminé inférieurement.

Prothorax en carré subatténué en avant; à peine moins large en arrière que les élytres; tronquė au sommet, avec les angles antérieurs infléchis et arrondis; à peine arqué ou presque droit sur les côtés; subarrondi à sa base, avec les angles postérieurs obtus ; assez convexe: éparsement sétosellé, avec la longue soie latérale insérée contre le rebord même; d'un noir uisant; lisse, avec 2 séries dorsales composées de 5 points médiocres, dont l'antérieur et le postérieur plus écartés; marqué de plus, de chaque côté, outre ceux de la marge, de 5 autres points semblables et épars. Repli noir, glabre, lisse.

Écusson ponctué, pubescent, d'un noir submétallique.

Élytres transverses, à peine aussi longues que le prothorax; subdéprimées; assez finement et modérément ponctuées, avec la ponctuation subrâpeuse, vue de côté; d'un noir bronzé brillant ; éparsement pubescentes; à peine sétosellées, avec une soie beaucoup plus longue vers l'écusson et une autre derrière les épaules, celle-ci souvent caduque. Épaules presque effacées. Ailes blanchâtres, à peine irisées.

Abdomen assez allongé, moins large que les élytres; à peine arqué sur les côtés, mais visiblement atténué en arrière; subconvexe sur le dos, avec le repli des $2^{e}$ et $3^{e}$ segments presque en ligne droite; distinctenuent sétosellé ; finement et assez densement ponctué, un peu plus densement sur la base, surtout des $3^{\mathrm{e}}$ et $\dot{4}^{\mathrm{e}}$ segments; d'un noir brillant; à pubescence un peu plus serrée que celle des élytres. Le $6^{\circ}$ segment moins ponctué, moins pubescent, parfois subazuré, subtronqué au sommet.

Dessous $d u$ corps aspèrement pointillé, finement pubescent, d'un noir brillant. Dessous de la tête presque glabre, presque lisse, avec les côtés 
des tempes légèrement pubescents. Pointe mésosternale assez prolongée, très-aiguë ou subacérée. Métasternum à peine convexe sur son milieu. Ventre, convexe, éparsement sétosellé, plus longuement en arrière, parfois subazuré.

Pieds médiocres, aspèrement pointillés, finement pubescents, d'un noir de poix souvent brunâtre, avec les trochanters antérieurs et parfois les tarses d'un roux de poix. Cuisses antérieures assez finement épineuses en dessous vers leur sommet; les postérieures un peu plus grêles. Tibias antérieurs plus ( $q$ ) ou moins ( $\sigma^{\prime}$ ) fortement épineux en dehors (1). Tarses postérieurs à $1^{\text {er }}$ article beaucoup plus long que le dernier, égal aux 3 suivants réunis.

Patrie. Celte espèce se rencontre, en automne, parmi les végétaux en décomposition, dans les courges et les melons pourris. Elle est médiocrement commune : la Flandre, la Normandie, le Beaujolais, les environs de Lyon, les Alpes, la Provence, le Languedoc, les Pyrénées, etc.

Oss. Elle ressemble beaucoup au $P h$. ebeninus. Elle est moindre, un peu plus fusiforme, avec la tête un peu moins grosse, le prothorax un peu plus rétréci en avant et l'abdomen plus atténué en arrière. Les élytres, un peu plus courtes, sont un peu moins fortement ponctuées. La ponctuation de l'abdomen est plus fine et plus serrée, et le repli des $2^{\mathrm{e}}$ et $3^{\mathrm{e}}$ segments est peu ou non en accolade.

Thomson a décrit cette espèce sous le nom de varians, dẹjà employé par Paykull pour une espèce décrite plus loin. Nous avons dû, pour éviter loute équivoque, adopter la dénomination synonyme de concinnus, imposée par Gravenhorst.

Cette espèce varie beaucoup. Les pieds sont parfois brunâtres ou d'un roux obscur. Les élytres passent du noir bronzé au roux de poix ou au rouge brun (variété $a$ ).

La variété $b$ (ochropus, Gravenhorst) pourrait bien être une espèce distincte, rare aux environs de Lyon et plutôt propre aux provinces méridionales. La taille est un peu moindre. Les élytres sont généralement d'un bronzé moins sombre. Le dessus de l'abdomen et surtout le ventre sont un peu moins densement ponctués. Les parties de la bouche et les pieds sont d'un testacé plus ou moins obscur.

Nous avons vu même un exemplaire à élytres rouges, à abdomen moins

(1) Souvent les épines des tibias antérieurs, chez les $\sigma^{\circ}$, sont plus courtes et moins apparentes que chez les $\$$, et cela dans plusieurs especes. 
densement ponctué, à pieds obscurs, à :nt:nnes moins allongées avec 1 's $5^{\mathrm{e}}$ à $10^{\circ}$ articles plus courts et subtransverse; et qui semblerait se ri!nporter au caucasicus d'Erichson $(466,63)$.

Toutes les nuances qui séparent ces diverses variétés sont si peu tranchées, que nous les regarderons toutes, jusqu'à nouvel ordre, comme devant se rapporter à une seule et même espèce.

\section{LARVE}

Voici la description de la larve du Ph. concinnus :

Corps allongé, subconvexe, éparsement sétosellé, d'un testacé livide et brillant, avec l'abdomen plus mat.

Tête grande, en catré oblong et subarrondi aux angles, un peu plus large que le prothorax, subdéprimée, éparsement sétosellée, presque lisse, bissillonnée en avant, d'un testacé luisant. Epistome quadridenté. MIandibules grandes, falciformes, acérées, testacées. Palpes pâles, à dernier article long, grêle, aciculé.

Yeux petits, lisses, indiqués par un point irrégulier noir.

Antennes courtes, testacées, à $1^{\mathrm{er}}$ article nodiforme : les $2^{\mathrm{e}}$ et $3^{\mathrm{e}}$ oblongs, obconiques, subégaux : le $3^{\ominus}$ bicilié au sommet, lobé au bout de son côté interne : le $4^{\mathrm{e}}$ beaucoup moins long, beaucoup plus grêle, terminẻ par un petit lobe membraneux et 3 soies divergentes.

Prothorax à peine oblong, convexe, sıbulténué en avant, subtronqué an sommet, éparsement sétosellé, preique lisse; marqué en avant, sur les côtés, d'un sillon oblique; d'un testacé luisant.

.Ié:othorax et métathorax moins longs réunis que le prothorax, assez convexes, éparsement sétosellćs ; lisses, avec 2 cicatrices de chaque côté ; d'un testacé livide et brillant; le premier arcuément dilaté en arrière, un peu moins court que le deuxième : celui-ci subdilaté en avant sur les côtés et sensiblement rétréci postérieurement.

Abdomen suballongé, un peu moins long que le reste du corps; subrétréci dans son dernier tiers; subdéprimé et très-inégal sur le dos; longitudinalement sillonné sur sa ligne médiane; furtement sétosellé, a vec les soies subhispides, tronquėes, subépaissies et parfois fourchues au bout ; d'un testacé livide, un peu obscur et presque mat; à $1^{\text {er }}$ segment trèscourt : les suivants courts, subégaux, plus ou moins mamelonnés et cicatrisés sur les côtés de leur dis jue : le dernier plus étroit, transverse, tra péziforme, pâle, largement tronqué, muni au sommet de 2 appendices 
écartés et subdivergents, subépaissis vers leur milieu, éparsement hispidosétosellés, terminés par un lobe assez étroit, assez court, déjeté en dehors, sétifère, à soie longue et comme biarticulée.

Dessous de la tête testacé, brillant, presque lisse, subexcavé et finement ridé en travers dans sa moitié antérieure. Prosternum triangulaire, subconvexe, lisse, brillant, testacé. Ventre longitudinalement sillonné-excavé, hispido-sétosellé, d'un testacé livide; à tube terminal sétosellé, en cylindre subdéprimé, subhorizontal, plus long que les appendices supérieurs.

Pieds assez courts, d'un testacé pâle. Hanches grandes, allongées. Cuisses très-allongées, à peine épaissies vers leur sommet, épineuseș en dessous. Tibias plus courts, sublinéaires, fortement épineux, terminés par un crochet assez long, assez grêle, acéré, à peine arqué.

QBs. Cette larve ressemble à celle du Ph. varius. Elle en diffère par le dernier article des palpes plus long; par le $3^{\mathrm{e}}$ article des antennes plus allongê; par son abdomen plus déprimé, à soies plus raides et tronquées, à appendices du dernier segment terminés yar un lobe moins court et à soie moins longue, etc.

\section{Philonthus gagates, Mulsant et Rey.}

Allongé, subdéprimé, éparsement pubescent, d'un noir brillant. Tête et prothorax lisses, luisants : celui-ci subcarré, à peine rétréci en avant. Élytres modérément, abdomen finement et densement ponctués, celui-ci surtout dans son milieu. Ailes enfumées.

$\sigma^{*}$ Le $6^{\mathrm{e}}$ arceau ventral profondément et aigument entaillé dans le milieu de son bord apical, avec les côtés de l'entaille garnis d'une assez large gouttière submembraneuse et pellucide. Tarses antérieurs à 3 premiers articles fortement dilatés. Tête de la largeur du prothorax.

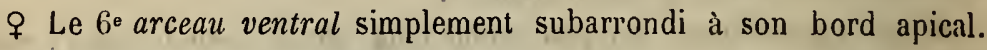
Tarses antérieurs à 3 premiers articles légèrement dilatés. Tête un peu moins large que le prothorax.

$$
\text { Long., } 0^{\mathrm{m}}, 0081 \text { (3 2/3 l.); - larg., } 0^{\mathrm{m}}, 0014(2 / 3 \text { l.). }
$$

Corps allongé, subdéprimé, d'un noir brillant; revêtu sur les élytres et l'abdomen d'une fine pubescence d'un gris obscur et peu serrée. 
Tête ell carré subarrondi ou suborbiculaire, fortement sétosellée ; d'ún noir luisant ; lisse ; éparsement et fortement ponctuée en arriêre sur les còtés ; plus finement, plus densement et subrugueusement sur les tempes. Front très-large, à peine convexe, marqué de chaque côté, entre les yeux, de 2 pores sétifères très-rapprochés et subtransversalement disposés, dont l'interne un peu moindre. Cou glabre, presque lisse, d'un noir luisant. Labre d'un noir brillant, fortement sétosellé en avant. Mandibules et palpes d'un noir de poix.

Yeux assez grands, subovales, obscurs.

Antennes suballongées, environ de la longueur de la tête et dı prothorax réunis; faiblement épaissies; légèrement pubescentes et éparsement pilosellées vers leur base; noires, avec le dernier article parfois d'un ferrugineux obscur; le $1^{\text {er }}$ allongé, en massue subarquée : les $2^{\circ}$ et $3^{\circ}$ subobconiques : le $2^{\mathrm{e}}$ suballongé, le $3^{\mathrm{e}}$ allongé, un peu plus long que le $2^{\circ}$ : les suivants graduellement un peu plus courts, subobconiques : les $4^{\circ}$ à $6^{\mathrm{e}}$ suboblongs : le $7^{\mathrm{e}}$ non, les $8^{\mathrm{e}}$ à $10^{\mathrm{e}}$ à peine transverses, vus de côté : le dernier ovale-oblong, subéchancré au bout et subacuminé inférieurement.

Prothorax subcarré on aussi long que large ; à peine rétréci en avant ; à peine moins large en arrière que les élytres; tronqué au sommet, avec les angles antérieurs subinfléchis et subarrondis; presque droit ou à peine angulé vers le milieu de ses côtés, vu de dessus, avec ceux-ci, vus latéralement, visiblement sinués en arrière; subarrondi à sa base; avec les angles postérieurs obtus; assez convexe ; médiocrement sétosellé, avec la longue soie latérale située contre le rebord même ; d'un noir luisant, lisse, avec 2 séries dorsales composées de 5 points assez forts, dont l'antérieur plus écarté ; marqué de plus, de chaque côté, outre ceux de la marge, de 5 autres points semblables et épars. Repli noir, glabre, lisse.

Écusson pointillé, pubescent, noir.

Élytres transverses, de la longueur du prothorax; subdéprimées ; assez finement, modérément et subaspèrement ponctuées; d'un noir de jais brillant; éparsement pubescentes; garnies de cils obscurs à leur bord apical; brièvement et à peine sétosellées, avec 1 soie plus longue vers l'écusson, et 1 autre derrière les épaules. Celles-ci subarrondies. Ailes enfumées.

Abdomen plus ou moins allongé, moins large que les élytres; à peine arqué sur les còtés et subatténué en arrière; subconvexe sur le dos; brièvement sétosellé, avec quelques soies plus longues sur les côtés; 
finement, et densement ponctué, plus lâchement sur les $1^{\text {er }}$ et $2^{\mathrm{e}}$, et les $5^{\ominus}$ et surtout $6^{\text {e }}$ segments (1); d'un noir briilan; à pubescence un peu plus serrée que celle des élytres. Le $6^{\circ}$ segment subarrondi au sommet.

Dessous $d u$ corps aspèrement pointillé, finement pubescent, d'un noir brillant. Dessous de la tête presque glabre, lisse. Lame mésosternale presque lisse, à arête transversale saillante, arquée, s'arrêtant vers le $1^{\text {er }}$ tiers; à pointe assez prolongée, très-aiguë, subacérée. Métasternum subdéprimé sur son milieu, très-finement cilié sur sa ligne médiane, à lobe postérieur d'un roux de poix. Ventre convexe, éparsement sétoselle.

Pieds médiocres, aspèrement pointillés, finement pubescents; d'un noir de poix, avec les tarses et parfois les tibias moins foncés. Cuisses antérieures finement épineuses en dessous vers leur sommet; les postérieures plus grêles. Tibias antérieurs peu épineux en dehors. Tarses postérieurs à $1^{\text {er }}$ article sensiblement plus long que le dernier, subégal aux 3 suivants réunis.

Patrie. Cette espèce est rare. Elle se prend sous les détritus, en Provence et dans le Languedoc.

UBs. On la prendrait volontiers pour une variété du Ph. ebeninus. Elle s'en distingue néanmoins par plusieurs caractères, par exemple : les élytres sont d'un noir de jais et nullement bronzées, à ponctuation plus fine, avec la soie de l'écusson et des épaules moins longue; les ailes sont enfumées; le prothorax est un peu moins rétréci en avant; les cuisses antérieures sont un peu plus finement épineuses en dessous vers leur sommet; les tibias antérieurs sont moins épineux en dehors; les tarses an!érieurs des $\sigma$ sont un peu moins dilatés, etc.

Souvent les tarses et parfois les tibias sont d'un roux de poix.

Elle est en quelque sorte intermédiaire entre les $P h$. ebeninus et fumigatus.

Elle doit ressembler beaucoup au Ph. corvinus, Er. Mais elle a les tibias antérieurs moins épineux en dehors, l'abdomen plus densement ponctué, etles antennes moins allongées, à pénultièmes articles plus courts.

A propos du corvinus, espèce d'Allemagne, Erichson dit: Caput thoracis latitudine... abdomen parcius subtiliusque punctatum, è 'Thomson : Capite prothorace angustiore...; abdomine minus crebre, subtiliter punctato. Ces

(1) Les $3^{e}, 4^{e}$ et $5^{e}$ segments sont généralement plus finement et plus densement ponclués sur leur base qu'à leur extrémité. 
caractères concordent peu, et les descriptions de Kraatz et de Fauvel semblent encore un pell différer. Quant à notre insecte, il convient aux descriptions pour la tête et le prothorax, mais non pour l'abdomen et les tibias antérieurs : ce qui nous a obligés à le regarder comme une espèce distincte du corvinus.

\section{Philonthus fumigatus, ERICHSON.}

Allongé, subdéprimé, finement pubescent, d'un noir brillant, avec la bouche, les tibias et les tarses d'un roux de poix. Tête et prothorax lisses, luisnnts : celuii-ci subcarré, à peine rétréci en avant. Élytres assez fortement et assez densement, abdomen finement et très.densement, ponctués. Ailes irisées, subenfumées.

$\sigma^{\circ}$ Le $6^{\circ}$ arceau ventral très-profondément et aigument entaillé dans le milieu de son bord apical, avec l'entaille garnie, sur les côtés, d'une assez étroite gouttière subpellucide. Le $5^{\mathrm{e}}$ à peine et subangulairement échancré au milieu de son bord postérieur. Tar'ses antérieurs à 2 premiers arlicles très-fortement, le $3^{3}$ fortement, dilatés. Tête à peine moins large que le prothorax.

\& Le $6^{\circ}$ arceau ventral subarrondi, le $5^{\circ}$ simple, à leur bord apical. Tarses antérieurs à 3 premiers articles assez fortement dilatés. Tête un peu moins large que le prothorax.

Staphylinus atratus, var. Gravenhorst, Mon. 85.

Philonthus fumigatus, Ericnson, Col. March. I, 463, 25 ; - Gen. et Spec. Staph. 463, 58. - Redtenbacher, Faun. Austr. 703, 25. - Heer, Faun. Col. Helv. I, 582, 22. - Fairmatre et Laboulbène, Faun. Ent. Fr. I, 524, 38.- KraAtz, Ins. Deut. II, 599, 32.- Tномson, Skand. Col. II, 161, 21, 1860.

Variété a (immature). Élytres et dessous du corps d'un roux de poix. Antennes et pieds d'un roux ferrugineux.

$$
\text { Long., } 0^{\mathrm{m}}, 0070 \text { (3 1/5 l.); - larg., } 0^{\mathrm{m}}, 0013 \text { (2/3 1.). }
$$

Corps allongé, subdéprimé, d'un noir luisant; revêtu d'une fine pubescence grisâtre, éparse sur les élytres, plus serrée sur l'abdomen.

Tète suborbiculaire, éparsement sétosellée, d'uı noir luisant, lisse, avec 
quelques points médiocres, épars en arrière sur les côtés. Front très-large, à peine convexe, paré de chaque côté, entre les yeux, de 2 pores sétifères rapprochés et subtransversalement disposés, dont l'interne moindre. Cou glabre, presque lisse, d'un noir luisant. Labre d'un noir brillant, fortement sétosellé en avant. Mandibules et palpes d'un brun de poix plus ou moins roussâtre.

Yeux assez grands, subovales, obscurs, avec des taches livides.

Antennes peu allongées, un peu plus courtes que la tête et le prothorax réunis ; à peine épaissies, légèrement pubescentes et éparsement pilosellées vers leur base ; noires ou noirâtres; à $1^{\text {er }}$ article allongé, en massue subarquée : les $2^{\circ}$ et $3^{\circ}$ obconiques, parfois roussâtres à leur insertion : le $3^{\mathrm{e}}$ suballongé, plus long que le $2^{\mathrm{e}}$ : les suivants graduellement un peu plus courts : les $4^{\mathrm{e}} \mathrm{a}^{\mathrm{e}}$ subcylindriques, suboblongs, souvent brièvement pédicellés, avec le pédicelle roux : le $7^{\mathrm{e}}$ non, les $8^{\mathrm{e}}$ et $10^{\mathrm{e}}$ à peine transverses, vus de côté : le dernier subovale, subtronqué au bout el subacuminé inférieurement.

Prothorax subcarré, à peine rétréci en avant; aussi large ou presque aussi large que les élytres ; tronqué au sommet,' a vec les angles antérieur's subinfléchis et subarrondis ; presque droit sur les côtés ; arrondi à la base, avec les angles postérieurs obtus; légèrement convexé ; éparsement sétosellé, avec la longue soie latérale située contre le rebord même; d'un noir luisant; lisse, avec 2 séries dorsales composées de 5 points assez forts et assez profonds, dont l'antérieur un peu plus écarté; marqué de plus, de chaque côté, outre cenx de la marge, de 5 autres points semblables et épars, dont les 2 internes rapprochés. Repli brunâtre, glabre, lisse.

Écusson densement pointillé, finement pubescent, noir.

Élytres transverses, de la longueur du prothorax ; subdéprimées; assez fortement, assez densement et subaspèrement ponctuées ; d'un noir brillant, parfois à peine métallique ; éparsement pubescentes; garnies de cils obscurs à leur bord apical; très-brièvement ou à peine sétosellées, avec 1 soie, beaucoup plus longue, vers l'écusson, et 1 autre derrière les épaules. Celles-ci subarrondies. Ailes subenfumées, fortement irisées de vert et de rouge violacé.

Abdomen suballongé, moins large que les élytres; à peine arqué sur les côtés et subatténué en arrière; subconvexe sur le dos, avec le repli du $2^{\text {e }}$ segment en accolade obsolète; plus ou moins sétosellé; finement et très-densement pointillé, un peu moins finement et moins densement sur le $1^{\text {er }}$ segment et surtout sur le $6^{\bullet}$; d'un noir assez brillant ; à pubescence 
déprimée, plus fine et sensiblement plus serrée que celle des élytres. Le oe segment subarrondi au sommet.

Dessous du corps aspèrement pointillé, finement pubescent, d'un noir brillant. Dessous de la tète à peine pubescent, très-éparsement ponctué. Lame mésosternale presque lisse, à arête transversale saillante, arquée, s'arrêtant vers le $1^{\text {er }}$ tiers; à pointe assez prolongée, très-aiguë ou subacérée. Métasternum subdéprimé sur son milieu, très-finement canaliculé sur sa ligne médiane, à lobe postérieur souvent roussâtre. Ventre convexe, distinctement sétosellé, à arceaux intermédiaires plus densement pointillés.

Pieds médiocres, aspèrement ponctués; finement pubescents; d'un noir ou d'un brun de poix, avec les tibias et les tarses plus ou moins roussâtres. Cuisses antérieures finement épineuses en dessous vers leur sommet; les postérieures plus grèles. Tibias antérieurs non ou à peine épineux en dehors. Tarses postérieurs aussi longs que les tibias; à $1^{\text {er }}$ article beaucoup plus long que le dernier, presque égal aux 3 suivants réunis, ceux-ci suballongés ou oblongs.

Patrie. Cette espèce est commune sous les détritus, dans presque toute la France.

OBs. L’abdomen est plus finement et plus densement pointillé que dans le $P h$. gagates, avec sa pubescence plus serrée et plus déprimée. Les tarses antérieurs des $q$ sont plus dilatés; les postérieurs sont un peu plus grêles et un peu plus longs dans les 2 sexes, avec le $1^{\text {er }}$ article plus allongé. Les pieds sont généralement d'une couleur moins foncée.

Chez les individus immatures, les pieds, la bouche et les antennes sont d'un roux lestacé, avec la base de celles-ci rembrunie ; et, en outre, les èlytres sont parfois d'un roux de poix, ainsi que l'abdomen, surtout en dessous.

Chez les petits $\sigma "$, la tête est moins large que le prothorax, comme chez les ․

\section{LARVE}

Nous donnons ici la description de la larve supposée du Ph. fumigatus. Corps allongé, assez étroit, subconvexe, plus ou moins sétosellé d'un testacé livide, brillant sur la tête et le prothorax, mat sur l'abdomen.

Tête en carré à peine oblong et arrondi aux angles, plus large que le 
prothorax, subdéprimée, éparsement sétosellée; presque lisse en arrière finement ridée et chagrinée en avant; d'un testacé brillant. Epistome 4-denté, à dents assez aiguës, les intermédiaires plus fortes. Mandibule s grandes, falciformes, rousses. Palpes pâles, à dernier article très-court, subsubulé.

Yeux très-petits, lisses, indiqués par un point nébuleux.

Antennés courtes,pâles, à $1^{\mathrm{er}}$ article rudimentaire : le $2^{\mathrm{e}}$ allongé, subélargi au sommet : le $3^{\mathrm{e}}$ un peu plus court, à peine épaissi, composé de 3 soies avant son extrémité et légèrement lobé au bout de son côté interne : le $3^{\text {e }}$ moins long, beaucoup plus grêle, subcylindrique, terminé par un très-petit lobe bicilié et par 3 soies divergentes.

Prothorax oblong, convexe, subtronqué au sommet, subparallèle sur les cồtés, largenıent rebordé à la base, éparsement sétosellé; presque lisse, paré de chaque côté de 2 impressions sulciformes; d'un testacé livide et brillant.

Mésothorax et métathorax courts, subégaux, un peu moins longs réunis que le prothorax, subélargis en arrière, assez convexes, éparsement sétosellés; presque lisses, parés de chaque côté d'une cicatrice sensible; d'un testacé livide et brillant.

Abdomen allongé, un peu plus long que la tête et le thorax réunis; subatténué en arrière, subdéprimé sur le dos, sillonné sur sa ligne médiane, fortement sétosellé, d'un testacé livide et mat; à $1^{\mathrm{e}_{\mathbf{r}}}$ segment trèscourt, un peu plus brillant : les suivants courts, subégaux, plus ou moins fortement sillonnés ou ridés en travers sur les côtés, avec les stigmates assez distincts : le dernier plus étroit, court, tronqué et armé au sommet de 2 longs appendices subcylindriques, à peine recourbés en dedans, éparsement ciliés, parés sur les côtés après leur milieu d'une longue soie subhorizontale, et, vers le bout, en dessous, d'une soie semblable dirigét: en bas, terminés en outre par un lobe très-court, très-petit, fortement soudé.

Dessous de la tête presque lisse, testacé, brillant. Prosternum triangulaire, subconvexe, presque lisse, d'un testacé livide et brillant. Ventre subexcavé, fortement sétosellé, d'un testacé livide et mat, très-inégal avec 3 rangées de fossettes grossières et profondes; à tube terminal spinosule, subcylindrique, sensiblement moins long que les appendices supérieurs.

Pieds assez cour'ts, d'un testacé pâle. Cuisses sublinéaires, éparsement épineuses en dessoas. Tibias plus courts que les cuisses, subatténués vers 
eur extrẻmité, fortement épineux tout autour, terminės par un fort crochet solide, acéré, subarqué.

OBs. Cette larve se trouve avec l'insecte parfait, sous les détritus végétaux.

\section{Plailonthus debilis, Gravenhorst.}

Allongé, ì peine fusiforme, peu convexe, finement pubescent, d'un noir brillant, avec les élytres souvent moins foncées, la bouche et le $1^{\mathrm{er}}$ article des antennes d'un brun de poix, et les pieds d'un roux obscur. Tète et prothorax lisses, luisants : celui-ci subcarré, subatténué en avant. Élytres assez finement et assez densement, abdomen finement et densement ponctués. Ailes blanchatres.

$\sigma^{*}$ Le $6^{\circ}$ arceau ventral profondément et aigument entaillé dans le milieu de son bord apical, avec les bords de l'entaille garnis d'une assez large gouttière subpellucide. Le $5^{\mathrm{e}}$ à peine et subangulairement échancré à son bord postérieur, avec un espace triangulaire lisse, au devant de l'échancrure. Tarses antérieurs à 3 premiers articles fortement dilatés.

ㄴ Le $6^{\mathrm{e}}$ arceau ventral subarrondi, le $5^{\mathrm{e}}$ simple, à leur bord apical. Tarses antérieurs à 3 premiers articles médiocrement dilatés.

Staphylinus debilis, Gravenhorst, Micr. 35, 52. - Latreille, Hist. Nat. Crust. et Ins. IX, 329, 57.

Staphylinus lucidus, Gravenhorst, Micr. 21, 24. - Latreille, Hist. Nat. Crust. et Ins. IX, 311, 30.

Staphylinus fimetarius, var. Gravenhorst, Mon. 82.

Staphylinus agilis, Boisduval et Lacordare, Faun. Ent. Par. 1, 407, 42.

Philonthus debilis, Ericuson, Col. March. I, 467, 31 ; - Gen. et Spec. Staph. 472, 73.- Redtenb.cher, Faun. Austr. 705, 32.- Heer. Faun. Col. Helv. I, 266, 32. - Fairmaire et Laboulbène, Faun. Ent. Fr. I, 524, 39. - KraATz, Ins. Deut. II, 604, 38.- Fauvel, Faun. Gallo-Rhén. III, 454, 20.

Variété $a$. Elytres brunâtres. Bouche, base des antennes, sommet du ventre et pieds d'un roux testacé.

$$
\text { Long., } 0^{\mathrm{m}}, 0055 \text { (2 1/2 l.); - larg., } 0^{\mathrm{m}}, 00075 \text { (1)3 l.). }
$$

Corps allongé, à jeine fusiforme, peu convexe, d'un noir brillant, avec 
les élytres un peu moins foncées; recouvert sur celles-ci et l'abdomen d'une fine pubescence grise, plus serrée sur ce dernier.

Tète suborbiculaire ou très-brièvement ovalaire, à peine $\left(\sigma^{\prime \prime}\right)$ ou un peu ( $q$ ) moins large que le prothorax; éparsement sétosellee ; d'un noir luisant ; lisse, avec quelques points médiocres en arrière sur les côtés. Front large, à peine convexe, marqué de chaque côté entre les yeux de 2 pores sétifères assez rapprochés et subtransversalement disposés, dont l'jnterne moindre et parfois plus en arrière. Cou glabre, lisse, d'un noir luisant. Labre noir, sétosellé en avant. Mandibules et palpes d'un brun de poix.

Yeux médiocres, courtement ovales, plus ou moins obscurs.

Antennes assez courtes, un peu moins longues que la tête et le prothorax réunis; à peine épaissies; légèrement pubescentes et éparsement pilosellées vers leur base; obscures, avec le $1^{\text {er }}$ article d'un brun ou souvent d'un roux de poix : celui-ci allongé, en massue subarquée : les $2^{\mathrm{e}}$ et $3^{\mathrm{e}}$ obconiques : le $3^{e}$ à peine plus long que le $2^{e}$ : les suivants graduellement plus courts : le $4^{\mathrm{e}}$ à $6^{\mathrm{e}}$ subc:arrés : les pénultièmes visiblement transverses, vus de côté : le dernier subovale, tronqué au bout et subacuminé inférieurement.

Prothorax subcarré, subrétréci en avant, un peu moins large en arrière que les élytres; tronqué au sommet, avec les angles antérieurs infléchis et arrondis; presque droitsur les côtés, subarrondi à la base, avec les angles postérieurs obtus ; légèrement convexe; brièvement sétosellé, avec la longue soie latérale située sur le rebord même; d'un noir luisant; lisse, avec 2 séries dorsales composées de 5 points assez fins, dont les extrêmes à peine plus distants; marqué de plus, de chaque côté, outre ceux de la marge, de 4 ou 5 autres points semblables et épars. Repli brunâtre, glabre, lisse.

Écusson finement po intillé, légèrement pubescent, noir.

Élytres subtransverses, un peu ou à peine plus longues que le prothorax; subdéprimées ; assez finement, assez densement et subrâpeusement ponctuées; d'un noir de poix brillant; éparsement pubescentes; à peine sétosellées, avec 1 longue soie vers l'écusson et 1 autre vers les épaules. Celles-ci subarrondies. Ailes blanchâtres, parfois irisées.

Abdomen suballongé, moins large que les élytres; à peine arqué sur les côtés et subatténué e: arrière; subconvexe sur le dos; éparsement sétosellé; plus longuement sur les côtés ; finement et densement ponctué; d'un noir assez" brillant ; à pubescence un peu plus longue et plus serrée 
que celle des élytres. Le $6^{\text {e }}$ segment beaucoup moins ponctué, bien moins pubescent, subtronqué ou à peine arrondi au sommet.

Dessous $d u$ corps densement et aspèrement pointillé, finement pubescent, d'un noir brillant. Dessous de la téte à peine pubescent, à peine ponctué. Lame mésosternale presque lisse, à arête transversale assez saillante, presque droite ou à peine arquée, située vers le $1^{\text {er }}$ tiers; à pointe assez prolongée, très-aiguë, subacérée, pubescente. Métasternum subdéprimé sur son milieu, très-finement ou à peine canaliculé sur sa ligne médiane. Ventre convexe, à peine sétosellé.

Pieds médiocres, aspèrenuent pointillés, aspèrement pubescents, d'un roux de poix plus ou moins foncé, avec les tarses ordinairement plus clairs, et les hanches postérieures rembrunies. Cuisses antérieures finement spinosules en dessous vers leur sommet; les postérieures suballongées, grêles. Tibias antérieurs à peine $\left(\sigma^{*}\right)$ ou brièvement ( $q$ ) épineux en dehors. Tarses postérieurs à $1^{\text {er }}$ article sensiblement plus long que le dernier, presque égal aux 3 suivants réunis.

Patrie. Cette espèce est très-commune dans les environs de Lỵon, au printemps, parmi les détritus et sous les feuilles mortes. Elle se prend aussi dans les environs de Paris, dans la Flandre, la Normandie, le Beaujolais, le Bugey, les Alpes, les Pyrénées, etc.

OBs. Elle ressemble aux petits exemplaires de la variété ochropus du $P h$. concinnus. Les ćlytres ne sont nullensent méralliques, et elles sont un peu plus densement ponctuées. La ponctuation de l'abdomen est un peu plus serrée. Les antennes, un peu plus courtes, ont leurs pénultièmes articles un peu plus transverses. Les tibias antérieurs sont moins épineux en dehors, avec leurs tarses un peu plus dilatés chez les $q$ que chez celles du concinnus, etc.

Dans les sujets immatures (variété $a$ ), les élytres sont parfois brunes ou roussâtres, avec la bouche, la base des antennes, les pieds, le sommet du ventre et parfois les intersections ventrales d'un roux de poix plus ou moins clair. Quelquefois les antennes sont ferrugineuses, avec la base et le sommet plus pales.

Rarement, les séries dorsales du prothorax ne présentent que 4 points. Le celer d'Heer est peut-être un debilis très-adulıe. 


\section{Philonthus sanguindlentus, Gravenhorst.}

Allongé, subdéprimé, finement pubescent, d'un noir brillant, avec la sutnre et une tache humérale rouges, les tibias et les tarses brunâtres, et les hanches antérieures testacées. Tête et prothorax lisses, huisants, celui-ci subcarré, subparallele. Elytres finement et densement, abdomen trèsfinement et très-densement, ponctués : ce dernier peubrillant. Ailes blanchâtres. Turses antérieurs dilatés.

$\sigma^{*}$ Le $6^{e}$ arceau ventral très-profondément et aigument entaillé au milieu de son bord apical, avec le fond de l'entaille garni d'une gouttière subpellucide. Le $5^{\mathrm{e}}$ à peine visibl-‘ment échancré dans le milieu de son bord postérieur.

ㅇ Le 6e arceau ventral à peine arrondi à son bord apical, souvent subsinué dans le milieu de celui-ci. Le $5^{e}$ simple.

Staphylinus sanguinolentus, Gr.venhonst, Mier. 36, 53; - Mon. 64, 34. LAtreille, Hist. Nat. Crust. et Ins. IX, 320, 58.- Gyllenhal, Ins. Suec. II, 338, 54.- Nan.verheis, Brach. 30,68. - Bolsduval et Lagordare, Faun. Ent. Par. I, $399,24$.

Philonthus sanguinolentus, Noвdмanv, Symb. 97, 76. - ERichson, Col. March. I, 464, 27 ; - Gen. et Spec. Staph. 467, 65:- Redtenb.cher, Faun. Austr. 70f. 28. - Heer, Faun. Col. Helv. I, 265, 28.- Fairmatre el Laboulbène, Faun. Ent. Fr. I, 525, 41. - Kratiz, Ins. Deut. II, 600, 33. - Thurson, Skand. Col. II 161, 22, 1860. - FaUvel, Faun. Gallo-Rhén. III, 451, 17.

Variété a. Taches des élytres séunies.

Staphylinus contaminatus, Gravenhorst, Micl. 174, 31. - Latreille, Hist. Nat. Crust. et Ins. IX. 325, 71.- SElduitz, Faun. Balt. 276.

$$
\text { Long., } 0^{\mathrm{m}}, 0078\left(31 / 2 \text { l.); - larg., } 0^{\mathrm{m}}, 0015\right. \text { (2/3 l.). }
$$

Corps allongé, subdéprimé, d'un noir brillant, avec les élytres paréesd'une tache suturale et d'une tache humérale d'un rouge de sang; revêtu sur celles-ci et l'abdomen d'une fine pubescence d'un gris obscur, dépriInée et beaucoup plus serrée sur ce dernier.

Tête suborbiculaire, à peine $\left(\sigma^{\prime \prime}\right)$ ou un peu (Q) moins large que le prothorax ; forlemeıt sélosellėe ; d'un noir luisant; lisse, avec quelques 
gros points en arrière vers les côtés, et les tempes légèrement pubescentes, plus finement, plus densernent et subrugueusement ponctuées. Front trèslarge, à peine convexe, marqué de chaque côté, entre les yeux, de 2 pores sétifères rapprochés et subtransversalement disposés, dont l'interne moindre et parfois un peu plus en arrière. Cou glabre, presque lisse, d'un noir luisant. Labre d'un noir brillant, fortement sétosellé en avant. Mandibules et palpes. d'un noir de poix, avec l'extrémité des premières et le dernier article des maxillaires souvent d'un brun ferrugineux.

Yeux grands, subovales, plus ou moins obscurs.

Antennes peu allongées, plus courtes que la tête et le prothorax réunis ; assez grêles, subfiliformes; pubescentes et éparsement pilosellées, surtout vers leur base; obscures, avec l'insertion des premiers articles souvent d'un roux de poix ; le $1^{\text {er }}$ allongé, en massue subarquée : les $2^{\mathrm{e}}$ et $3^{\mathrm{e}}$ obconiques : le $3^{\mathrm{e}}$ suballongé, un peu plus long que le $2^{\mathrm{e}}$ : les suivants oblongs ou suboblongs, subobconiques, subégaux ou graduellement à peine plus courts : le dernier subovalaire, tronqué au bout et subacuminé inférieurement.

Prothorax subcarré, subparallèle ou parfois à peine plus étroit en avant; à peine moins large que les élytres; tronqué au sommet, avec les angles antérieurs subinfléchis et subarrondis ; presque droit sur les côtés, qui, vus latéralement, sont à peine sinués en arrière ; arrondi à sa base ainsi qu'aux angles postérieurs ; assez convexe ; distinctement sétosellé, avec la longue soie latérale située sur le rebord même; d'un noir luisant; lisse, avec 2 séries dorsales composées de 5 points assez gros et assez profonds, dont les 3 du milieu plus rapprochés; marqué de plus, de chaque côté, de 5 autres points semblables et épars, les internes moins écartés. Repli brunâtre, glabre, lisse.

\section{Écusson densement pointillé, pubescent, noir.}

Elytres transverses, environ de la longueur du prothorax; subdéprimées ; finement, densement et aspèrement ponctuées ; d'un noir brillant, avec la suture assez largement d'un rouge de sang et une tache posthumérale oblongue, de même couleur ; modérément pubescentes ; éparsement et brièvement sétoseilées, avec 1 soie beaucoup plus longue vers l'écusson et 1 autre derrière les épaules. Celles-ci subarrondies. Ailes blanchâtres.

Abdomen suballongé, un peu moins large que les élytres; à peine arqué sur les côtés et un pau atténué tout à fait en arrière; subconvexe sur le dos ; fortement sétosellé; très-finement et très-densement pointillé ou 
comme chagriné; d'un noir presque mat; à pubescence très-fine, déprimée, comme duveteuse, beaucoup plus serrée que celle des élytres. Le $6^{\mathrm{e}} \mathrm{seg}$ ment moins ponctué et moins pubescent vers son extrémité, subarrondi au sommet.

Dessous du corps d'un noir brillant, avec le ventre presque mat. Dessous de la tête glabre et lissę. Lame mésosternale subconvexe, à peine ponctuée;

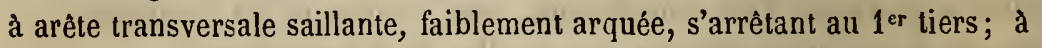
pointe émoussée ou subarrondie. Métasternum à peine convexe, aspèrement ponctué, finement pubescent. Ventre convexe, distinctement sétosellé, finement duveteux, très-finement et très-densement pointillé ou comme chagriné.

Pieds médiocres, aspèrement ponctués, finement pubescents, obscurs, avec les tibias et les tarses d'un brun souvent un peu roussâtre, les hanches antérieures testacées et les intermédiaires d'un roux de poix plus ou moins foncé. Cuisses antérieures assez finement épineuses en dessous vers leur sommet; les postérieures un peu plıs grêles, suballongées. Tibias antérieur's à peine épineux en dehors. Tarses antérieurs à 2 premiers articles fortement, le $3^{\mathrm{e}}$ moins fortement, dilatés dans les 2 sexes ; les postérieurs à $1^{\text {er }}$ article beaucoup plus long que le dernier, égal aux 3 suivants réunis.

Patrie. Cette espèce est assez commune dans les fumiers, les bouses et les crottins, dans presque toute la France.

OBs. Outre la couleur des élytres, elle diffère des précédentes par la ponctuation et la pubescence de l'abdomen, qui sont très-fines et trèsserrées.

La variété $a$, particulière aux sujets moins adultes, est remarquable par la tache humérale des élytres réunie postérieurement à la suturale, au point que parfois la couleur rouge devient dominante.

On doit peut-être rapporter au sanguinolentus l'aciculatus de Stephens (Ill. Brit. V, 238)?

\section{Philonthus stragulatus, ERicilson.}

Allongé, subdéprimé, légèrement pubescent, d'un noir brillant, avec les élytres d'un roux testacé, parées sur la suture d'une large bande noire, commune, les antennes et les pieds brunâtres. Téte et prothorax lisses, 
luisants : celui-ci subcarré, subrétréci en avant. Elytres et abdomen assez finement et assez densement ponctués. Ailes blanchâtres.

$\sigma^{*}$ Le $6^{e}$ arceau ventral angulairement échancré au sommet. Tarses antérieurs légèrement dilatés.

ㄴ Le $6^{\circ}$ arceau ventral simple.

Philonthus stragulatus, ERICHSon, Gen. et Spec. Staph. I, 468, 66. - FatrmalRe et Laboulbène, Faun. Ent. Fr. I, 525, 43.-Fauver, Faun. Gallo-Rhén. III, 480, 32.

Long., $0^{\mathrm{n}}, 0060$ (2 3/4 l.); - larg., $0^{\mathrm{m}}, 0014$ (2/3 l.).

Corps allongé, subdéprimé, d'un noir brillant, avec les élytres testacées, parées d'une large bande suturale noire, commune; revêtu sur celles-ci et l'abdomen d'une légère pubescence d'un gris obscur.

Tête subovalaire, un peu moins large que le prothorax; éparsement sétosellée; d'un noir luisant et submétallique, lisse, éparsement ponctuée derrière les yeux. Front large, subconvexe, à pores sétifères rapprochés, l'interne à peine plus en arrière. Cou glabre et lisse, d'un noir luisant. Labr'e noir, sétosellé en avant. Parties de la bouche brunâtres.

Yeux grands, subovales, obscurs.

Antennes de la longueur de la tête et du prothorax réunis; à peine subépaissies ; très-finement duveteuses; éparsement pilosellées ; obscures ou brunâtres; à $1^{\mathrm{er}}$ article en massue allongée et subarquée : les $2^{\mathrm{e}}$ et $3^{\mathrm{e}}$ suballongés, obconiques, subégaux : les suivants obconiques, subégaux, à peine oblongs, nullement transverses : le dernier ovale-oblong, subtronqué au sommet et subacuminé inférieurement.

Prothorax à peine aussi large que long; subrétréci en avant; un peu ou à peine moins large en arrière que les élytres; tronqué au sommet, avec les angles antérieurs infléchis et arrondis ; presque droit sur les côtés, qui, vus latéralement, sont faiblement sinués en arriere; subarrondi à sa base, avec les angles postérieurs très-obtus et arrondis ; assez convexe; distinctement sétosellé; à longue soie latérale située tout près du rebord même; d'un noir luisant et submétallique; lisse, avec 2 séries dorsales composées de 5 points médiocres, dont le postérieur plus écarté ; marqué de plus, sur les côtés, de 4 points semblables, épars, les deux internes plus rapprochés. Repli brunâtre, glabre et lisse.

Écusson pointille, pubescent, d'un noir assez brillant. 
Elytres subtransverses, de la longueur du prothorax; subdéprimées; assez finement, assez densement et aspèrement ponctuées; d'un roux testacé brillant, avec une large bande suturale noire, commune aux deux étuis et prolongée jusqu'au sommet où elle est un peu plus étroite; légèrement pubescentes; à peine sétosellées, avec 1 soie plus longue vers l'écusson et 1 autre derrière les épaules. Celles-ci presque effacées. Ailes blanchâtres.

Abdomen peu allongé, un peu moins large que les élytres; subparallèle ou à peine arqué sur les côtés ; subconvexe sur le dos ; éparsement sélosellé ; assez finement et assez densement ponctué; d'un noir assez brillant, avec le sommet parfois moins foncé; à pubescence fine, assez longue et peu serrée. Le 6 e segment moins ponctué, plus fortement sétosellé, à peine arrondi au sommet.

Dessous du corps aspèrement ponctué, légèrement pubescent, d'un noir brillant, avec le sommet du ventre parfois moins foncé. Dessous de la tête presque lisse. Ventre convexe, éparsement sétosellé, à pubescence assez longue.

Pieds médiocres, éparsement ponctués, légèrement pubescents, brunâtres, avec les hanches antérieures et les cuisses parfois plus claires ou d'un roux subtestacé. Tarses postérieurs à $1^{\mathrm{er}}$ article beaucoup plus long que le dernier, subégal aux 3 suivants réunis.

Patrie. Cette espèce est très-rare en France. Elle a été trouvée dans les environs de Marseille.

OBs. La coloration des élytres ne permet de la confondre avec aucune de ses congénères.

Parfois les antennes, les pieds, le sommet de l'abdomen et la marge des segments sont d'un roux plus ou moins brunâtre.

Nous avons vu un exemplaire tout à fait semblable au stragulatus quant à la forme générale et quant à la coloration des élytres. Mais il a la tête moins ovalaire, plus orbiculaire ; les antennes un peu moins longues, entièrement rousses, à articles intermédiaires et pénultièmes plus courts, le dernier moins oblong, plus visiblement échancré au bout. Les pieds, l'extrémité de l'abdomen, la marge des segments abdominaux et ventraux sont d'un rouge assez clair. Les points des séries dorsales du prothorax sont un peu plus petits(1), etc.

(1) L'exemplaire que nous avons vu avait accidentellement une série de 5 et l'autre de 6 points. 
Cette variété remarquable a été capturée dans les environs de Naples et elle nous a été communiquée par M. E. Revelière. Elle pourrait bien constituer une espèce distincte (ruficornis, nobis).

Nous rapportons ici la description d'une espèce que nous n'avons pas vue en nature :

\section{Philonthus renestratus, Favver.}

Fauvel, Mém. Soc. Linn. Norm. 1869, XV, 35.-MARSeul, l'Abeille, 1871, vili, 299. - Reiche et Lallemant, Cat.' Col. Alg. Esp. nouv. 1872, 35, 15 (note). - Bipustulatus, WOLlastoN, Ins. Mad. 585.

\section{Long., 7 à 7 1/2 millim.}

Forme et couleurs du cruentatus; plus brillant, plus parallèle; distinct par la ponctuation plus forte, bien plus écartée des élytres et la position de la tache de celles-ci, qui est petite, arrondie et non pas discoïdale, mais placée dans l'angle apical de la suture; tête bien plus grosse, plus large, suborbiculaire, tronquée plus brusquement à la base ; corselet bien moins rétréci en avant; angles postérieurs moins effacés; élytres plus convexes, plus brillantes, déprimées vers l'écusson, à pubescence plus rare; $\sigma 7^{\mathrm{e}}$ segment profondément incisé en triangle obtus, large, l'incision bordée d'une gouttière prolongée en arrière en triangle très-aigu.

Patrie. France méridionale.

OBs. C'est avec doute que nous colloquons ici cette espèce, que nous n'avons pas vue en nature.

\section{Philonthus cruentatus, Gueun.}

Allongé, subfusiforme, peu convexe, finement pubescent, d'un noir brillant, avec les élytres parées d'une tache subapicale rouge. Tête et prothorax lisses, luisants : celui-ci à peine oblong, subrétréci en avant. Élytres assez finement et densement, abdomen assez finement et peu densement, ponctués. Ailes blanchâtres.

$\sigma^{*}$ Le $6^{e}$ arceau ventral profondément et aigument entaillé dans le milieu 
de son bord apical, avec l'entaille en majeure partie remplie par une membrane subpellucide. Tarses antérieurs à 3 premiers articles fortement dilatés. le $3^{\circ}$ toutefois un peu moins.

\& L $6^{\mathrm{e}}$ arceau ventral subtronqué ou à peine arrondi, :parfois mème subsinué à son bord apical. Tarses antérieurs à 3 premiers articles légèrement, mais sensiblement dilatés.

Staphylinus cruentatus, GmeLiN, Linn. Syst. Nat. Ed. 13, I, IV, 2035.

Staphylinus bipustulatus, PAnzer, Faun. Germ. 27, 10. - LATREIlle, Hist. Nat. Crust. et Ins. IX, 321, 59, pl. 79, fig. 5. - Gravenhorst, Mion. 63, 33. - GrLleneal. Ins. Suec. II, 339, 55. - Mannerhein, Brach. 30, 70. - Boisduval et Lacordaire, Faun. Ent. Par. I, 399, 25.

Staphylinus bipustulatus, var. 3, Gravenhorst, Micr. 37, 54.

Philonthus bipustulatus, Nordann, Symb. 98, 78. - Erichson, Col. March. I, 464. 28 ; - Gen. et Spec. Staph. 468; 67. - Redtenbacher, Faun. Austr. 704, 28,

- Heer, Faun. Col. Helv. I, 265, 29. - Fairmatre et Labouldéne, Faun. Ent. Fr. I, 525, 42. - Kraatz, Ins. Deut. II, 601, 34. - Thomson, Skand. Col. 164, 31.

Philonthus cruentatus, Fauver, Faun. Gallo-Rhén. III, 479, 51 (1).

Variété $a$. Élytres noireś, sans tache.

$$
\text { Long., } 0^{\mathrm{m}}, 0077 \text { (3 1/2 l.); - larg., 0m:0015 (2/3 l.). }
$$

Corps allongé, subfusiforme, peu convexe, d'un noir brillant, avec les élytres parées d'une tache subapicale rouge; revètu sur celles-ci et l'abdomen d'une fine pubescence obscure et modérément serrée.

Tête subovalaire, évidemment moins large que le prothorax; fortement sétosellée; d'un noir luisant; lisse, avec quelques gros points épars en arrière sur les côtés. Front large, subconvexe, marqué de chaque côté, entre les yeux, de 2 pores sétifères assez forts, rapprochés et transversalement disposés. Cou glabre, lisse, d'un noir luisant. Labre d'un noir brillant, sètosellé en avant. Mandibules et palpes d'un noir de poix.

Yeux assez grands, subovales, plus ou moins obscurs.

Antennes peu allongées, un peu pluscourtes que la lête et le prothorax réunis; à peine épaissies; légèrement pubescentes et éparsement sétosellées surtout vers leur base; noirâtres; à $1^{\text {er }}$ article allongé, en massue à peine arquée : les $2^{\circ}$ et $3^{e}$ obconiques : le $3^{\mathrm{e}}$ suballongé, un peu plus

(1) Dans la citation Latreille, lisez 321 au lieu de 231, chez Fauvel. 
long que le $2^{\circ}$ : les suivants graduellement un peu plus cour's, subobconiques, suboblongs, avec les pénultièmes néanmoins à peine plus longs que larges, vus de côté : le dernier subovale, subéchancré au bout et subacuminé inférieurement.

Prothorax à peine plus long que large à sa base; subrétréci en avant ; presque aussi large en arrière que les élytres; tronqué au summet, avec les angles antérieurs infléchis et arrondis; presque droit ou à peine arqué sur les côtés; subarrondi à sa base ainsi qu'aux angles postérieurs; médiocrement convexe; éparsement sétosellé, avec la ıongue soie latérale située contre le rebord même; d'un noir luisant; lisse, avec 2 séries dorsales composées de 5 points assez fins ou médiocres, dont les extrêmes plus écartés des autres; marqué de plus, de chaque côté, outre ceux de la marge (1), de 5 autres points semblables et épars, dont les 2 internes plus rapprochés. Repli noir, glabre, lisse.

Écusson densement pointillé, pubescent, noir.

Elytres transverses, non ou à peine plus longues que le prothorax; subdéprimées; assez finement, densement et subaspèrement ponctuées; d'un noir assez brillant; parées après leur milieu d'une tache ovale-oblongue, assez grande et rougeâtre; modérément pubescentes ; éparsement et brièvemeut sétosellées, avec 1 soie notamment plus longue vers l'écusson et 1 autre derrière les épaules. Celles-ci étroitement arrondies. Ailes blanchâtres.

Abdomen suballongé, moins large que les élytres; à peine arqué sur les côtés et visiblement atténué en arrière; subconvexe sur le dos; assez fortement sétosellé; assez finement, mais un peu moins densement ponctué que les élytres; d'un noir brillant; à pubescence assez longue et médiocrement serrée. Le $6^{\mathrm{e}}$ segment un peu moins ponctué, moins pubescent, subtronqué au sommet.

Dessous $d u$ corps aspèrement ponctué, finement pubescent, d'un noir brillant. Dessous de la tête glabre et lisse. Lame mésosternale presque lisse ou à peine ponctuée; à arête transversale assez saillante, angulée, descendue jusqu'au milieu; à pointe peu prolongée, aiguë. Métastermum subdéprimé sur son milieu, à lobe postérieur souvent d'un roux de poix. Ventre convexe, distinctement sétosellé.

Pieds médiocres, aspèrement ponctués, finement pubescents, d'un noir

(1) Les points postérieurs de la marge latérale sont parfois situés assez loin du rebord, et cela dans quelques autres especes suivantes. 
de poix. Cuisses antérieures assez fortement épineuses en dessous vers leur sommet; les postérieures suballongées, assez grêles. Tibias antérieurs fortement épineux en dehors. Tarses postérieurs à $1^{\mathrm{er}}$ article beaucoup plus long que le dernier, subégal aux 3 suivants réunis.

Patrie. Cette espèce se prend dans les bouses et les crottins à moitié desséchés, dans presque toute la France. Elle n'est pas rare.

OBs. Avec à peu près la couleur du Ph. sanguinolentus, elle en diffère abondamment par sa forme plus atténuée aux 2 extrémités; par sa tête plus petite et plus ovalaire; par son prothorax moins parallèle, à points moins gros; par ses élytres sans tache suturale; par son abdomen beaucoup moins finement et moins densement ponctué, plus brillant; par ses tibias antérieurs fortement épineux en dehors ; par ses pieds plus noirs, avec les hanches antérieures concolores; par sa pointe mésosternale plus aiguë, etc.

La taille varie beaucoup. Les élytres sont parfois en majeure partie d'un rouge brun, d'autres fois seulement vers leur bord postérieur, plus rarement entièrement noires.

\section{Philonthus seybalarius, Nordann.}

Allongé, subfusiforme, peu convexe, finement pubescent. d'un noir brillant, avec les hanches et la base des cuisses anterieures testacées. Tête et prothorax lisses, luisants : celui-ci à peine oblong, rétréci en avant. Élytres assez finement et densement, abdomen finement et densement, ponctués. Ailes blanches.

$\sigma^{\circ}$ Le $6^{\circ}$ arceau ventral sensiblement et angulairement sinué dans le milieu de son bord apical, avec un espace triangulaire allongé, lisse, au devant du sinus. Tarses antérieurs à 2 preniers articles fortement, le $3^{\ominus}$ assez fortement, dilatés.

Q Le $6^{e}$ arceau ventral à peine arrondi ou subsinueusement tronqué au sommet. Tarses antérieurs à 3 premiers articles légèrement dilatés.

Philonthus scybalarius, Nordnan, Symb. 94, 70. - Krastz, Ins. Deut. II, 601, 35.

- Trouson, Skand. Col. II, 164, 32.

Philonthus fuscicornis, NoRDManN, Symb. 96, 72. 
Philonthus varians, var. $b$, Erichson, Col. March. 1, 466 ; - Gen. et Spec. Staph. 470. - Fairmaire et Laboulbène, Faun. Ent. Fr. I, 525.

Philonthus longicornis, Fauvec, Faun. Gatlo-Rhén. III, 480, 53.

Variété $a$. Le $1^{\mathrm{er}}$ article des antennes testacé en dessous.

Variété $b$. Le $1^{\text {er }}$ article des antennes entièrement testacé. Pieds antérieurs et intermédiaires d'un roux ferrugineux, avec les hanches plus pâles.

Staphylinus immundus, Grulendal, lns. Suec. II, 337, 53.

Philonthus immundus, Nordmans, Symb. 93, 64 .

$$
\text { Long., } 0^{\mathrm{m}}, 0078 \text { (3 1/2 l.); - larg., } 0^{\mathrm{m}}, 0015 \text { (2/3 l.). }
$$

Corps allongé, subfusiforme, peu convexe, d'un noir brillant; revêtu sur les élytres et l'abdomen d'une fine pubescence d'un gris obscur et modérément serrée.

Tête ovalaire, beaucoup moins large que le prothorax ; fortement sétosellée; d'un noir luisant; lisse, avec quelques points assez forts et épars sur les tempes. Front large, subdéprimé ou à peine convexe, marqué de chaque côté, entre les yeux, de 2 pores sétifères assez fins, subégaux, rapprochés et transversalement disposés. Cou glabre, lisse, d'un noir luisant. Labre d'un noir brillant, fortement sélosellé en avant. Mandibules et palpes d'un noir de poix.

Yeux grands, subovales, obscurs, souvent lavés de gris.

Antennes suballongées, assez grêles, à peine moins longues que la tête et le prothorax réunis; subfiliformes; légèrement pubescentes et éparsement pilosellées, surtout vers leur base; d'un noir de poix, avec l'insertion du $2^{\mathrm{e}}$ article souvent d'un roux de poix; le $1^{\mathrm{er}}$ allongé, en massue à peine arquée : les $2^{\mathrm{e}}$ et $3^{\mathrm{e}}$ obconiques : le $3^{\mathrm{e}}$ suballongé, à peine plus long que le $2^{\circ}$ : les suivants subobconiques, subégaux, tous plus longs que larges ou suboblongs : le dernier ovale-oblong: obliquement subtronqué au bout, subacuminé inférieurement.

Prothorax à peine oblong, sensiblement rétréci en avant; presque aussi large en arrière que les élytres ; tronqué au sommet, avec les angles antérieurs infléchis et arrondis; presque droit sur les côtés; subarrondi à sa base ainsi qu'aux angles postérieurs; subconvexe; éparsement sétosellé, avec la longue soie latérale située sur le rebord même; d'un noir luisant; lisse, avec 2 séries dorsales composées de 5 points assez fins, dont les extrêmes plus écartés des autres; marqué de plus, de chaque côté, outre 
ceux de la marge, de 5 antres points semblables et épars, dont les 2 internes plus rapprochés. Repli noir, glabre, lisse.

Écusson densement pointillé, pubescent, noir.

Élytres transverses, à peine plus longues que le prothorax; subdéprimées; assez finement, densement et aspèrement ponctuées; d'un noir brillant; modérément pubescentes; éparsement sétosellées, avec 1 soie notamment plus longue vers l'écusson et 1 autre derrière les épaules. Celles-ci presque effacées. Ailes blanches.

Abdomen suballongé, moins large que les élytres; à peine arqué sur les côtés et visiblement atténué en arrière; subconvexe sur le dos; assez fortement sétosellé; finement et densement ponctué; d'un noir brillant, subazuré; à pubescence un peu plus longue et à peine plus serrée que celle des élytres. Le 6 e segment moins ponctué, moins pubescent, à peine arrondi au sommet.

Dessous du corps aspèrement pointillé, finement pubescent, d'un noir brillant. Dessous de la tête glabre et lisse. Lame mésosternale presque lisse; à arête transversale saillante, fortement arquée ou à peine angulée, descendue à peine au delà du $1^{\text {er }}$ tiers; à pointe peu prolongée, aiguë ou à peine émoussée. Métasternum à peine convexe sur son milieu, très-fine: ment canaliculé sur sa ligne médiane. Ventre convexe, fortement sétosellé, souvent subazuré.

Pieds médiocres, aspèrement ponctués, finement pubescents, d'un noir de poix, avec les hanches antérieures testacées ainsi que les trochanters et plus ou moins la base des cuisses, et les hanches intermédiaires souvent d'un roux de poix. Cuisses antérieures assez fortement épineuses en dessous vers leur sommel; les postérieures suballongées, assez grêles. Tibias antérieurs fortement épineux en dehors. Tarses postérieurs à $1^{\mathrm{er}}$ article beaucoup plus long que le dernier, à peine égal aux 3 suivants réunis : le $2^{\mathrm{e}}$ suballongé, les $3^{\mathrm{e}}$ et $4^{\mathrm{e}}$ oblongs.

Patrie. Cette espèce se trouve sous les mousses et les détritus dans les environs de Lyon, la Normandie, le Beaujolais, les Alpes, le Languedoc, la Provence, les Pyrénées, etc. Elle est médiocrement commune.

OBs. Elle ressemble à la variété sans tache du Ph. cruentatus. Mais la tête est un peu moindre, le prothorax plus rétréci en avant, l'abdomen plus finement et plus densement ponctué. Les antennes sont un peu plus allongées et un peu plus grêles. Les hanches antérieures sont toujours testacées, avec la base des cuisses souvent de cette même couleur, elc. 
Parfois le dessous du $1^{\mathrm{er}}$ article des antennes est testacé; plus rarement, ces mêmcs organes sont d'un roux brunâtre, avec ce même $1^{\text {er }}$ article entièrement d'un testacé pâle (immundus, Gyl.). Dans ces 2 variétés, les pieds antérieurs et intermédiaires se montrent d'un roux plus ou moins ferrugineux, avec leurs hanches plus claires. Les exemplaires immatures ont parfois les élytres rouges et les pieds entièrement testacés.

Le longicornis de Stephens (Ill. Br. V, 237) répond peut-être au Ph. scybalarius? Il en serait de même du perplexus de Fairmaire (Ann. Ent. Fr. 1861, 431) et du peregrinus de Fauvel (Ann. Ent. Fr. 1866, 315)

\section{Philonthus varians, PAYKulL.}

Allongé, subfusiforme, peu convexe, finement pubescent, d'un noir brillant, avec une tache ou transparence rouge sur le milieu des élytres et les hanches intermédiaires plus ou moins testacées en dedans. Téte et prothorax lisses, luisants: celui-ci à peine oblong, rétréci en avant. Élytres assez finement et densement, abdomen finement et densement, ponctués. Ailes blanchâtres.

$\sigma^{*}$ Le $6^{\mathrm{e}}$ arceau ventral profondément et aigument entaillé au milieu de son bord apical, ayec les côtés de l'entaille garnis d'une étroite gouttière subpellucide. Tarses antérieurs à $1^{\mathrm{er}}$ et $3^{\mathrm{e}}$ articles fortement, le $2^{\mathrm{e}}$ très-fortement, dilatés.

ㅇ Le $6^{\text {e }}$ arceau ventral subsinueusement tronqué à son bord apical. Tarses antérieur's à 3 premiers articles faiblement dilatés.

Slaphylinus varians, PAYkulL, Mon. 45, 33; - Faun. Suec. III, 393, 33.

Staphylinus bipustulatus, var. 1, 2, 4-7, Gravenhorst, Micr. 37, 51 .

Staphylinus opacus, Gravenhorst, Mon. 64, 33. - Gyllenhal, Ins. Suec. II, 340, 56. - Manneraeim, Brach. 30, 71. - Bolsduyal et Lacordaike, Faun. Ent. Far. I, 404,31 .

Staphylinus bimaculatus, MarshaM, Ent. Brit. 525, 78.

Philonthus opacus, Norbuann, Symb. 98, 79. - ERicuson, Col. March. I, 465, 29, - Hetr, Faun. Col. Helv. I, 265, 30. - Tromson, Skand. Col. II, 164, 33.

Philonthus varians, Ericuson, Gen. et Spec Staph. 470, 70.- Redtenbacher, Faun. Austr. 703. - Fairmaire et Laboulbìne, Faun. Ent. Fr. I, 524, 40. - Kratiz, Ins. Deut. II, 602, 36. - Fauver, Faun. Gallo-Rhén. III, 481, 54.

Variété $a$. Élytres uniformément d'un rouge brun.

Variété $b$. Élytres noires, sans taches. 
Staphylinus varians, Fabricius, Ent. Syst. I, II, 524, 22 ; - Syst. El. II, 594, 25. - Olivier, Ent. III, n० 42, 27, 3̈, pl. V, tig. 46.

Staphylinus opucus, Gravenhorst, Micr. 26, 25. - Latreille, Hist. Nat. Crust. et Ins. IX, 315, 40.

Staphylinus aterrimus, MarsyaM, Ent. Brit. $513,44$.

$$
\text { Long., } 0^{\mathrm{m}}, 0078\left(31 / 2 \text { l.); - larg., } 0^{\mathrm{m}}, 0014\right. \text { (2/3 l.). }
$$

Corps allongé, subfusiforme, peu convexe, d'un noir brillant, avec une transparence ou tache rouge sur le milieu des élytres; revêtu sur celles-ci et sur l'abdomen d'une fine pubescence d'un gris obscur et modérément serrée.

Tête subovalaire, beaucoup moins large que le prothorax; fortement sétosellée; d'un noir luisant, lisse, avec quelques points assez forts et épars sur les tempes. Front très-large, à peine convexe, marqué de chaque côté, entre les yeux, de 2 pores sétifères très-rapprochés et subtransversalement disposés, dont l'interne souvent un peu moindre. Cou glabre, lisse, d'un noir luisant. Labre d'un noir brillant, fortement sétosellé en avant. Mandibules et palpes d'un nọir de poix, parfois brunâtre.

Yeux grands, subovales, obscurs, souvent lavés de gris.

Antennes peu allongées, un peu plus courtes que la tête et le prothorax réunis; à peine épaissies; légèrement pubescentes, éparsement pilosellées, surtout vers leur base; noires, avec l'insertion du $2^{\mathrm{e}}$ article souvent d'un roux de poix; le $1^{\mathrm{er}}$ allongé en massue à peine arquée : les $2^{\mathrm{e}}$ et $3^{\mathrm{e}}$ obconiques : le $2^{\mathrm{e}}$ suballongé : à peine plus long que le $2^{\mathrm{e}}$ : les suivants graduellement à peine plus courts, subobconiques, un peu, les pénultièmes à peine, plus longs que larges: le dernier ovale-oblong, obliquement subéchancré au bout et subacuminé inférieurement.

Prothorax à peine oblong, seusiblement rétréci en avant; à peine moins large en arrière que les élytres ; tronqué au sommet, avec les angles antérieurs infléchis el arrondis; à peine arqué ou presque droit sur les côtés, subarrondi à sa base ainsi qu'aux angles postérieurs ; légèrement convexe; éparsement sétosellé, avec la longue soie latérale située contre le rebord mêne; d'un noir luisant; lisse, avec 2 séries dorsales composées de 5 points assez fins, dont le $1^{\text {er }}$ et le dernier plus écartés; marqué de plus, de chaque côté, outre ceux de la marge, de 5 autres points semblables et épars, dont l'antérieur plus distant. Repli noir, glabre, lisse.

Écusson densement pointillé, pubescent, noir. 
Élytres transverses, à peine plus longues que le prothorax; subdéprimées; assez finement, densement et aspèrement ponctuées; d'un noir assez brillant; finement et modérément pubescentes ; distinctement ciliées à leur bord apical (1); brièvement sétosellées, avec 1 soie, beaucoup plus longue vers l'écusson et 1 autre derrière les épaules. Celles-ci presque effacées. Ailes blanchâtres.

Abdomen suballongé, moins large que les élytres; à peine arqué sur les còtés et sensiblement atténué en arrière; convexe sur le dos; fortement sétosellé ; finement et densement ponctué, un peu moins densement vers l'extrémité; d'un noir brillant; à pubescence déprimée, un peu plus fine, plus longue et à peine plus serrée que celle des élytres. Le $6^{\mathrm{e}}$ segment moins pubescent, subtronqué ou à peine arrondi au sommet.

Dessous du corps aspèrement pointillé, finement pubescent, d'un noir brillant, avec les intersections ventrales à peine roussâtres. Dessous de la tête glabre, presque lisse. Pointe mésosternale très-aiguë (2). Métasternum subdéprimé sur son milieu. Ventre convexe, parfois subazuré, distinctement sétosellé, plus longuement en arrière.

Pieds médiocres, aspèrement pointillés, finement pubescents, d'un noir de poix, avec les hanches antérieures plus ou moins testacées en dedans, ainsi que leurs trochanters. Cuisses antérieures assez finement mais longuement épineuses en dessous; les postérieures allongées, assez grêles. Tibias antérieurs plus $(q)$ ou moins $\left(\sigma^{*}\right)$ épineux en dehors. Tarses postérieurs à $1^{\mathrm{er}}$ article beaucoup plus long que le dernier, subégal aux 3 suivants réunis, ceux-ci suballongés ou oblongs.

Patrie. Celte espèce est très-commune dans les bouses, les fumiers, parmi les détritus, etc., dans presque toute la France.

OBs. Les antennes sont un peu plus longues et un peu moins grêles que dans le Ph. scybalarius, avec les pieds plus noirs et les hanches antérieures rarement entièrement testacées. L'abdomen est plus finement et plus densement ponctué que dans la $P h$. cruentatus, avec la tache des élytres située moins en arrière.

Celle-ci, généralement assez réduite, s'étend parfois sur la majeure

(1) Cette ciliation, ordinairement obscure, existe dans la plupart des espèces. Nous ne l'indiquons que lorsqu'elle est bien apparente.

(2) La lame mésosternale est à peu près comme dans le scybalarius, avec sa pointe un peu plus prolongée et p̣lus aiguë. 
partie des élytres qu'elle envahit d'autres fois entièrement. Les hanches antérieures sont rarement concolores. Dans les sujets immatures, les pieds, la bouche el parfois les antennes sont plus ou moins roussatres.

La variété $b$, à élytres noires et sans tache, est la plus répandue. Elle est facile à confondre avec le Ph. scybalarius; mais, chez celui-ci, les hanches antérieures et parfois la base des cuisses et le $1^{\text {er }}$ article des antennes sont d'une couleur plus claire; le $2^{\mathrm{c}}$ article des tarses antérieurs des $\sigma^{7}$ n'est pas sensiblement plus dilaté que les $1^{\text {er }}$ et $3^{\mathrm{e}}$; l'échancrure du $6^{\circ}$ segment abdominal $\sigma^{7}$ est plus profonde et plus aiguë.

D'après le catalogue de Harold et Gemminger, les unicolor, intaminatus et lituratus de Stephens (Ill. Brit. 224, 235 et 238) répondraient au varians, et le costatus de Baudi (Stud. Ent. I, 128) en serait une monstruosité.

D’après Fauvel, le punctiventris, Steph. (Ill. Brit. V, 235) serait aussi la même espèce.

4\%. Philonthus agilis, GravenHORST.

Allongé, subfusiforme, peu convexe, finement pubescent, d'un noir brillant, avec le bord apical des élytres subferrugineux et les hanches antérieures plus ou moins testacées en dedans. Tête et prothorax lisses, luisants : celui-ci à peine plus long que large, rétréci en avant. Élytres et abdomen assez finement et assez densement ponctués, celui-ci moins densement sur le dos des derniers segments. Ailes blanches.

$\sigma$ Le $6^{c}$ arceau ventral profondément et aigument entaillé à son bord apical, avec le fond de l'entaille garni d'une membrane subpellucide. Tarses antérieurs à 3 premiers articles fortement et subégalement dilatés.

ㅇ Le $6^{\circ}$ arceau ventral subsinueusement tronqué au sommet. Tarses antérieurs presque simples.

Staphylinus agilis, Gravenhorst, Mon. 77, 70. - Grllenhal, Ins. Suec. II, 341, 57. - MaNNERIIEIM, Brach., 30, 72.

Staphylinus parvicornis, GravenhoRst, Micr. 23, 30; - Mon. 69, 18.

Philonthus agilis, Nordmann, Symb. 98, 80. - Kraatz, Ins. Deut. II, 603, 37. Thomson, Skand. Col. II, 165, 34.

Philonthus opacus, var. e, HeER, Faun. Col. Helv. I, 266.

Philonthus varians, var. $d$, Erichson, Gen. et Spec. Staph. 470. - Var. c, FalRMaIRE et Laboulbène, Faun. Ent. Fr. I, 325. 
Variété $a$. Élytres noires, unicolores.

$$
\text { Long., } 0^{\mathrm{m}}, 0054 \text { (2 1/2 1.); - larg., } 0^{\mathrm{m}}, 0011 \text { (1/2 1.). }
$$

Corps allongé, subfusiforme, peu convexe, d'un noir brillant, avec le bord apical des élytres subferrugineux; revêtu sur celles-ci et l'abdomen d'une fine pubescence d'un gris obscur et modérément serrée.

Téte ovalaire, beaucoup moins large que le prothorax ; assez fortement sétosellée ; d'un noir luisant; lisse, avec quelques points assez forts et épars sur les tempes. Front large, à peine convexe, marqué de chaque côté, entre les yeux, de 2 pores sétifères assez fins, très-rapprochés et transversalement disposés. Cou glabre, lisse, d'un noir luisant. Labre d'un noir brillant, éparsement sétosellé en avant. Mandibules et palpes d'un noir de poix, parfois brunâtre.

Yeux assez grands, subovales, plus ou moins obscurs.

Antennes peu allongées, un peu plus courtes que la tête et le prothorax réunis ; à peine épaissies ; légèrement pubescentes ; éparsement pilosellées, surtout vers leur base; noires; à $1^{\text {er }}$ article allongé, en massue à peine arquée : les $2^{\mathrm{e}}$ et $3^{\mathrm{e}}$ obconiques, subégaux : les suivants subcarrés ou à peine oblongs, 'subobconiq'es, subégaux : le dernier ovale-oblong, subtronqué au bout et subacuminé inférieurement.

Prothorax à peine plus long que large à sa base; rétréci en avant ; presque aussi large en arrière que les élytres; tronqué au sommet, avec les angles antérieurs infléchis et arrondis ; à peine arqué ou presque droit sur les côtés; subarrondi à sa base ainsi qu'aux angles postérieurs; assez convexe ; éparsement sétosellé, avec la longue soie latérale située sur le rebord même; d'un noir luisant; lisse, avec 2 séries dorsales composées de 5 points assez fins, dont l'antérieur et parfois le postérienr plus écartés; marqué de plus, de chaque côtè, outre ceux de la marge, de 5 autres points semblables. Repli noir, glabre, lisse.

Écusson densement pointillé, pubescent, d'un noir bronzé.

Ellytres transverses, de la longueur du prothorax; subdéprimées; assez finement, assez densement et aspèrement ponctuées'; d'un noir brillant, avec le bord apical un peu ferrugineux ; finement et modérément pubescentes ; ciliées à leur bord apical; brièvement et éparsement sélosellées, avec 1 soie plus longue vers l'écusson et 1 autre derrière les épaules. Celles-ci presque effacées. Ailes blanches ou blanchâtres.

Abdomen suballongé, moins large que les élytres; à peine arqué sur les 
côtés et sensiblement atténué en arrière ; convexe sur le dos; fortement sétosellé; assez finement et assez densement ponctué, moins densement sur le dos du $3^{\mathrm{e}}$ segment et sur les suivants; d'un noir brillant ; à pubescence déprimée, plus longue et aussi serrée que celle des élytres. Le $6^{\mathrm{e}}$ segment moins pubescent, subtronqué ou à peine arrondi au sommet.

Dessous du corps aspèrement pointillé, finement pubescent, d'un noir brillant. Dessous de la tête glabre et lisse, avec les côtés des tempes légèrement pubescents. Pointe mésosternale très-aiguë. Métasternum à peine convexe sur son milieu. Ventre convexe, parfois subazuré, distinctement sétosellé.

Pieds médiocres, aspèrement pointillés; finement pubescents ; d'un noir de poix, avec les hanches antérieures plus ou moins testacées en dedans, ainsi que leurs trochanters. Cuisses antérieures assez, finement épineuses en dessous vers leur sommet; les postérieures plus grêles. Tibias antérieurs plus ou moins épineux en dehors. Tarses postérieurs à $1^{\mathrm{er}}$ article très-allongé, beaucoup plus long que le dernier, égal aux 3 suivants réunis.

Patrie. Celte espèce se trouve sous les mousses, les vieux fagots, les détritus, dans la Normandie, la Bourgogne, le Beaujolais, les environs de Lyon, le mont Pilat, les Alpes, le Languedoc, les Pyrénées, etc. Elle est moins commune que le $P h$. varians.

OBs. On la prendrait pour une variété moindre de cette dernière espèce, dont elle est peu distincte. Cependant, les antennes sont à peine plus courtes, avec les $2^{\mathrm{e}}$ et $3^{\mathrm{e}}$ articles moins inégaux, les $4^{\mathrm{e}}$ et les suivants à peine plus courts. La ponctuation des élytres est un peu moins fine et un peu moins dense et celle de l'abdomen un peu plus forte. Les $3^{\mathrm{e}}$ à $5^{\mathrm{e}} \mathrm{seg}-$ ments de l'abdomen sont plus éparsement ponctués, surtout sur le dos. Les 3 premiers articles des tarses antérieurs des $\sigma$ sont plus également dilatés, et ceux des $q$ tout à fait simples, etc.

La variété à élytres noires est la plus répandue. Quelquefois les pieds et les intersections ventrales sont d'un roux de poix.

Nous avons vu une variété à taille un peu plus forte et surtout plus large, à tête encore plus étroite et à prothorax plus rétréci en avant et plus larga en arrière, où il est de la largeur des élytres. Celles-ci paraissent à peine plus longues et un peu moins brillantes. Les tarses antérieurs des $\sigma^{\prime \prime}$ sont un peu plus fortement dilatés et ceux des $\subsetneq$ sont moins simples. Le veniru plus ou moins irisé, est un peu moins densement ponctué, etc. Cette variéti 
remarquable et qui pourrait bien être une espèce distincte (Philonthus alpigradus, nobis) a été capturée sous les mousses et sous les pierres, au bord des ruisseaux, à la Grande-Chartreuse et au mont Dore (Auvergne). Elle répond peut-être au véritable opacus de Gravenhorst (Micr., 26, 35) et à l'opacis var. $d$, de Heer (Faun. Helv. I, 226)? Elle fait, pour ainsi dire, le passage entre le varians et l'agilis. Elle ressemble plus à la première pour la taille et la forme ainsi que pour la couleur et la structure des antennes; mais l'abdomen paraît moins densement pointillé. Le $6^{\text {e }}$ arceau ventral des $\sigma$ est plus profondément et plus aigument entaillé que dans l'une et l'autre de ces deux espèces.

\section{Philonthus ventralis, GRAVENHORST.}

Allongé, subdéprimé, légèrement pubescent, d'un noir de poix brillant, avec la bouche, la base des antennes, les pieds et la marge posteirieure des arceaux du ventre d'un roux testacé. Tète et prothorax lisses, luisants : celui-ci à peine oblong, subparallèle. Ėlytres assez fortement et assez densement, abdomen finement et modérément, ponctués, ce dernier plus éparsement en arrière. Tarses presque simples.

$\sigma$ Le $6^{\mathrm{e}}$ arceau ventral à peine sinué dans le milieu de son bord apical, avec un espace triangulaire lisse au devant du sinus. Tête orbiculaire, à peine moins large que le prothorax.

† Le $6^{\mathrm{e}}$ arceau ventral simplement subarrondi à son bord apical. Tête brièvement ovalaire, un peu moins large que le prothorax.

Staphylinus ventralis, Grayenhorst, Micr.174, 29; - Mon. 60, 28. - Gyllenhal, Ins. Suec. II, 334, 49.- ManNerheim, Brach. 29, 63. - Boisdural et LaCordaire, Faun. Ent. Par. 1, 437, 41.

Staphylinus immundus, Gravenhorst, Mon. 66, 36.

Staphylinus anthrax, Gravengorst, Micr. 176, 34; - Mon. 97, 38.

Philonthus anthrax, NoRoyan,, Symb. 97, 74.

Philonthus ventralis, NordmanN, Symb. 93, 60. - Erichson, Col. March. I, 468, 32 ; - Gen. et Spec. Staph. 473, 74. - Redtendacher, Faun. Austr. 705,32. Heer, Faun. Col. Helv. I, 267, 36. - Fairmaire et Laboulbène, Faun. Ent. Fr. I. 523, 33. - Kratiz, Ins. Deut. II, 605, 39. - Thomson, Skand. Col. II, 160, 18,

- Fauver, Faun. Gallo-Rhén. III, 453, 19.

Long., $0^{\mathrm{m}}, 0058$ (2 2/3 l.); - larg., $0^{\mathrm{m}}, 0009$ (1/2 l. a peine). 
Corps allongé, subdéprimé, d'un noir de poix brillant en dessus; revêtu sur les élytres et l'abdomen d'une fine pubescence grise et peu serrée.

Téte orbiculaire ou courtement ovalaire, éparsement sétosellée, d'un noir luisant; lisse ou presque imperceptiblement chagrinée, avec quelques gros points épars en arrière sur les côtés. Front large, à peine convexe, marqué entre les yeux de 2 pores sétifères assez forts, très-rapprochés et subtransversalement disposés, l'interne néanmoins un peu plus petit et un peu plus en arrière. Cou glabre, presque lisse, d'un noir luisant. Labre d'un noir de poix, fortement sétosellé en avant. Mandibules et palpes d'un roux de poix, avec ces derniers parfois moins foncés.

Yeux assez grands, subovales, plus ou moins obscurs.

Antennes peu allongées, plus courtes que la tête et le prothorax réunis; à peine épaissies ; légèrement pubescentes et éparsement pilosellées, surtout vers leur base; noires, avec le $1^{\text {er }}$ article d'un roux testacé ; celui-ci allongé, en massue subarquée : les $2^{\mathrm{e}}$ et $3^{\mathrm{e}}$ obconiques : le $3^{\mathrm{e}}$ suballongé, un peu plus long que le $2^{\mathrm{e}}$ : les suivants assez épais, graduellement un peu plus courts : le $4^{\mathrm{e}}$ subcarré : les $5^{\mathrm{e}}$ et $6^{\mathrm{e}}$ non oll à peine, les $7^{\mathrm{e}}$ à $10^{\mathrm{e}}$ légèrement transverses : le dernier subovalaire, étroitement subéchancré au bout et subacuminé inférieurement.

Prothorax à peine oblong, subparallèle $\left(\sigma^{*}\right)$ ou parfois å peine rétréci en avant ( $q$ ); un peu moins large que les élytres; tronqué au sommet, avec les angles antérieurs infléchis et arrondis ; presque droit sur les côtés, vus de dessus, avec ceux-ci, vus latéralement, assez largement sinués en arrière; subarrondi à sa base, avec les angles postérieurs obtus ; légèrement convexe ; éparsement sétosellé, avec la longue soie latérale située contre le rebord même ; d'un noir de poix luisant; lisse ou presque invisiblement chagriné, avec 2 séries dorsales composées de 5 points assez gros et assez profonds, dont l'antérieur' et le postérieur plus écartés ; marqué de plus, de chaque côté. outre ceux de la marge, de 5 autres points semblables et épars, dont l'antérieur plus isolé. Repli d'un roux de poix, glabre, lisse.

Écusson finement pointillé, légèrement pubescent, d'un noir de poix brillant.

Elytres subtransverses, à peine plus longues que le prothorax; subdéprimées ; assez fortemeilt, assez densement et subaspèrement ponctuées ; d'un noir de poix brillant; éparsement pubescentes; éparsement sétosellées, avec 1 soie beaucoup plus longue vers l'écussonet 1 autre vers les épaules. Celles-ci arrondies. Ailes blanchâtres.

Abdomen suballongé, moins large que les élytres; subarqué sur les côtés 
et un peu atténué tout ả fait en arrière; assez convexe sur le dos ; éparsement sétosellé; finement et modérément ponctué sur les 3 premiers segments, plus éparsement sur la partie postérieure du dos de ceux-ci et sur les 3 suivants; d'un noir brillant; à pubescence plus'fine, plus longue et à peine plus serrée que celle des élytres. Le $6^{\mathrm{e}}$ segment subarrondi au sommet.

Dessous $d u$ corps aspèrement pointillé, finement pubescent, d'un noir brillant, avec le sommet du ventre et le bord postérieur de chaque arceau d'un roux testacé. Dessons de la tête presque glabre et presque lisse, avec le côté des tempes légèrement pubescent. Lame mésosternale presque lisse, parfois roussâtre en avant; à arête transversale fortement saillante, à peine arquée, s'arrêtant vers le $1^{\text {er }}$ tiers ; à pointe aiguë, mais nullement acérée, parfois émoussée. Métasternum à peine convexe sur son milieu, très-finement canaliculé sur sa ligne médiane, à lobe postérieur souvent d'un roux de poix. Ventre convexe, éparsement sétosellé.

Pieds médiocres, éparsement et subaspèrement ponctués, finement pubescents, d'un roux testacé, avec les hanches postérieures rembrunies. Cuisses antérieures assez finement épineuses en dessous vers leur sommet; les postérieures plus grêles. Tibias antérieur's distinctement épineux en dehors. Tarses antérieurs simples ( $q$ ) ou presque simples $\left(\sigma^{\prime}\right)$. Les postérieurs à $1^{\text {er }}$ article subégal au dernier, plus court que les 3 suivants réunis.

Patrie. Cette espèce est assez commune, surtout au printemps, parmi les détritus végétaux et les fumiers secs, dans plusieurs provinces de la France : les environs de Paris et de Lyon, la Normandie, la Lorraine, le Beaujolais, les Alpes, le Languedoc, la Provence, les Pyrénées, etc.

OsB. Cette espèce, outre la couleur des antennes, du ventre et des pieds, se distingue de toutes les précédentes à séries dorsales de 5 points par ses tarses postérieurs à $1^{\mathrm{er}}$ article plus court relativement au dernier. Elle comnience une petite phalange d'espèces caractérisées par ce même signe organique.

Chez les exemplaires immatures, la têté et le prothorax sont souvent d'un roux de poix, avec les antennes ferrugineuses, la base de celles-ci, la bouche, les pieds et les intersections ventrales testacés.

On doit peut-être rapporter au ventralis les picicollis et rotundiceps de Stephens (Ill. Brit. V, 224, 248) et le celer de Gravenhorst (Mon.66,37)? 


\section{LARVE}

Suit la description de la larve du $\mathrm{Ph}$. ventralis :

Corps allongé, étroit, subconvexe, plus ou moins sétosellé, brillant, testacé sur la tête et le thorax, brunâtre sur l'abdomen, avec le dernier segment de celui-ci livide et pâle.

Tête grande, suboblongue, un peu plus large que le prothorax, subdéprimée, éparsement sétosellée, presque lisse, à peine chagrinée et lungitudinalement bissillonnée en avant, d'un testacé brillant. Épistome denticulé antérieurement, avec 2 dents médianes plus saillantes et aiguës. Mandibules assez grandes, falciformes, acérées, d'un roux testacé. Palpes páles, à dernier article court, peu distinct, formant avec l'avant-dernier comme un seul article sétiforme.

Yeux petits, lisses, indiqués par 4 points très-noirs et réunis.

Antennes courtes, pâles, à $1^{\text {er }}$ article rudimentaire : les $2^{\mathrm{e}}$ et $3^{\mathrm{e}}$ suballongés, subcylindriques, assez épais, subégaux : le $3^{\mathrm{e}}$ paré de 3 soies avant son extrémité, lobé au bout de son côté interne : le dernier petit, court, beaucoup plus étroit que le $3^{\mathrm{e}}$, terminé par un lobe à peine distinct et brièvement cilié et par 3 soies divergentes.

Prothorax oblong, subparallèle ou à peine arqué sur les côtés, convexe, tronqué au sommet, légèrement rebordé à la base, très-éparsement sétosellé, lisse, biimpressionné de chaque côté, d'un testacé brillant.

Mésothorax et métathorax assez courts, subégaux, aussi longs réunis que le prothorax, subarcuément subélargis en arrière, finement rebordés à leur base, assez convexes, éparsement sétosellés antérieurement et postérieurement; lisses, avec des cicatrices de chaque côté; d'un testacé livide et brillant.

Abdomen allongé, un peu plus long que le reste du corps, graduellement subatténué en arrière, subdéprimé sur le dos; sillonné sur sa ligne médiane, avec le fond du sillon parfois pâle.; fortement sétosellé, avec les soies raides, tronquées ou même subépaissies au bout; d'un brun livide et brillant; à $1^{\text {er }}$ segment très-court : les suivants courts, subégaux, plus ou moins mamelonnés et fovéolés sur le dos et sur les côtés : le dernier plus ou moins pâle et livide, trapézitorme, plus étroit en arrière, tronqué au sommet, muni de 2 appendices assez longs, presque droits, subatténués vers leur extrémité, très-éparsement sétosellés, terminés par un lobe assez allongé, assez grêle, portant au bout une longue soie. 
Dessous de la tête d'un testacé brillant, lisse et convexe à la base, subexcavẻ et à peine ridé en avant. Prosternum triangulaire, subconvexe, lisse, d'un testacé pâle et brillant. Ventre plus ou moins excavé, trèsinégal, sétosellé comme dessus le dos, d'un brun testacé et assez brillant; à tube terminal très-long, cilié-sétosellé en dessous, subcylindrique, beaucoup plus long que les appendices supérieurs.

Pieds médiocres, pâles. Hanches très-grandes. Cuisses allongées, subépaissies en massue, éparsement épineuses en dessous. Tibias plus courts que les cuisses, subcylindriques, éparsement épineux dans leur pourtour, terminés par un crochet médiocre, solide, acéré, presque droit.

OBS. Celte larve est remarquable par la longueur du tube terminal du ventre.

49. Philonthus discoideng, GravenHorst.

Allongé, subdéprimé, finement pubescent, d'un noir brillant, avec les antennes, les pieds, les intersections ventrales, la suture et le repli des élytres d'un roux testacé. Tête et prothorax lisses, luisants ; celui-ci subcarré, subparallèle. Élytres assez fortement et asscz densement, abdomen fincment et modérément, ponctués.

$\sigma^{*}$ Le $6^{\mathrm{e}}$ arceau ventral lègèrement sinué dans le milieu de son bord apical, avec un étroit espace lisse aı devant du sinus. Tarses antérieurs à ô premiers articles fortement dilatés.

$\uparrow$ Le $6^{\mathrm{e}}$ arceau ventral à peine arrondi à son bord apical, parfois subsinué dans le milieu de celui-ci.Tarses antérieul's à 3 premiers articles légèrement dilatés.

Staphylinus discoideus, Gravenmorst, Nicr. 38,56 ; - Mon. 38 , 24. - Latreille. Hist. Nat. Crust. et Ins. IX, 322, 61. - Gyllenhal, Ins. Suec. 331, 47. - MaNNenueis, Brach. 29, 61.

Staphylinus conformis, Borsduvil et Lacordare, Faun. Ent. Par. I, 398, 33. Philonthus discoideus, Nornaas , Symb. 97, 75. - ERicnson, Col. March. I, 469, 33 ; - Gen. et Spec. Staph. 474, 78. - Kedtënbacher, Faun. Austr. 703, 22.Heer, Faun. Col. Helv. 1, 268, 39. - Fatrasire et Laboulbène, Faun. Ent. Fr. I, 5:26, 45. - Kraatz, Ins. Deut. II, 605, 40.- Thomson. Skand. Col. II, 160, 19. - Fauvel, Faun. Gallo-Thén. III. 404, 21.

Variété $a$. Élytres noires, avec le repli seul d'un roux testacé. 
Variété b. Elytres entièrement d'un roux testacé.

Staphylinus testaceus, GravenHorST, Mop. 60, 27.

$$
\text { Long., } 0^{\mathrm{m}}, 0050 \text { (2 1/4 1.); - larg., } 0^{\mathrm{m}}, 0007 \text { (1/3 l.). }
$$

Corps allongé, subdéprimé, d'un noir brillant, avec les intersections ventrales, la suture et le repli des élytres d'un roux testacé; revêtu sur celles-ci et sur l'abdomen d'une fine pubescence, grise et peu serrée.

T'ête subcarrée, presque aussi large que le prothorax; éparsement sétosellée; d'un noir luisant; lisse, avec quelques points assez forts, épars, en arrièrc sur les côtés. Front très-large, marqué de chaque côté, entrc les yeux, de 2 porcs sétifères rapprochés et transversalement disposés, dont l'interne un peu plus fin. Cou glabre, presque lisse, d'un noir luisant. Labre noir, brillant, fortement sétosellé en avant. Mandibules et palpes d'un roux de poix.

Yeux assez grands, subovales, obscurs, souvent lavés de gris et submicacès.

Anlennes assez courtes, beaucoup moins longues que la tête et le prothorax réunis; à peine épaissies; légèrement pubescentes et éparsement pilosellées vers leur base; d'un roux testacé, avec les $2^{\circ}$ et $3^{\mathrm{e}}$ articles souvent un peu plus foncés; le $1^{\text {er }}$ allongé, en massue subarquée; les $2^{\mathrm{e}}$ et $3^{\mathrm{e}} \mathrm{ob}-$ coniques, subégaux : les suivants graduellement à peine plus courts : los $4^{\mathrm{e}}$ et $5^{\mathrm{e}}$ à peine ou non, les $6^{\mathrm{e}}$ à $10^{\mathrm{e}}$ légèrcment transverses, avec les pénultièmes un peu plus sensiblement : le dernier courtement ovalaire, sllbéchancré au bout et subacuminé inférieurement.

Prothorax subcarré, subparallèle $\left(\sigma^{*}\right)$ ou à peine rétréci en avant ( $q$ ); presque aussi large que les élytres; tronqué au sommet, avec les angles antérieurs infléchis et subarrondis; presque droit sur les côtés, vu de dessus ; subarrondi à sa base ainsi qu'aux angles postérieurs ; légèrement convexe; éparsement sétosellé, avec la longue soie latérale située contre le rebord même; d'un noir luisant; lisse, àvec 2 séries dorsales composées de 5 points assez forts, dont l'antérieur et le postérieur un peu plus écartés ; marqué de plus, outre ceux de la marge, de 5 autres points semblables et épars. Repli roux, glabre, lisse.

Écusson finement pointillé,"pubescent, d'un noir brillant, souvent lisse vers son extrémité.

Élytres subtransverses, de la longueur du prothorax; subdéprimées; 
assez fortement, assez densement et subaspèrement ponctuées; d'un noir brillant, avec la suture, le repli et parfois le bord apical $d$ un roux testacé; éparsement pubescentes; à peine sétosellées, avec 1 longue soie vers l'écusson et 1 autre derrière les épaules. Celles-ci presque effacées.

Abdomen suballongé, un peu moins large que les élytres; subarqué sur les côtés et un peu atténué tout à fait en arrière; subconvexe sur le dos; éparsement sétosellé; plus longuement sur les côtés; finement et modérément ponctué, un peu plus làchement en arrière ; d'un noir brillant; à pubescence plus fine, un peu plus longrue tt plus serrée que celle des élytres. Le $6^{e}$ segment subtronqué ou à peine arrondi au sommet.

Dessous du corps subașèrement pointillé, finement pubescent, avec le prosteruum d'un roux de poix, le sommet du ventre et les intersections ventrales d'un roux plus ou moins testacé. Dessous de la tête presque glabre et presque lisse. Lame mésosternale souvent d'un roux de poix, presque lisse; à arête transversale saillante, à peine arquée, située vers le $1^{\text {er }}$ tiers; à pointe peu aiguë, parfois subémoussée au bout. Mrétasternum à peine convexe sur son milieu, très-finement canaliculé sur sa ligne médiane, à lobe terminal souvent d'un roux de poix. Ventre convexe, éparsement sćtosellé, plus longuement en arrière.

Pieds médiocres, aspèrement pointillés, finement pubescents, d'un roux testacé, avec les hanches postérieures rembrunies. Cuisses antérieures assez finement spinosules en dessous vers leur sommet; les postérieures plus grêles. Tibias antérieurs assez fortement épineux en dehors. Hanches intermédiaires parfois sensiblement distantes. Tarses postérieur's à $1^{\mathrm{er}}$ article à peine plus long que le dernier, moins long que les 3 suivants réunis.

Patrie. Celte espèce est assez commune dans les fumiers des bassescours et des écuries, surtout au printemps, dans les environs de Lyon. Elle se prend aussi dans ceux de Paris, dans le Beaujolais, Ic Bugey, la Bresse, les Alpes, la Provence, les Pyrénćes, etc.

OBs. Outre la coulcur des élytres et des antennes, celles-ci sont plus courtes que dans le Pll. ventralis. La taille est un peu moindre; les tarses antérieurs sont plus ou moins dilatés, etc.

Quelquefois la suture est concolore, avec la marge inférieurc du repli, seule testacée. D'autres fois (variété $b$ ), les élytres sont entièrement rousses ou rougeâtres. Lcur ponctuation, variable, cst parfois assez fine.

Cctte espèce et les suivantes ont !e dernier article des palpes maxillaires 
en fuseau atténué vers le sommet, mais un peu moins allongé que dans la précédente.

Elle répond peut-être aux lepidulus et suturalis de Stephens (Ill. Brit. $\mathrm{V}, 223$ et 224)?

\section{Philonthus rufimanus, ERICBSON.}

Allongé, subdéprimé, éparsement pubescent, d'un noir brillant, avec les élytres bleues, les hanches et les cuisses antèrieures et intermédiaires d'un roux testacé. Tête et prothorax lisses, luisants : celui-ci suboblong, subparallèle. Élytres assez finement et assez densement, abdomen finement et éparsement ponctués.

$\sigma$ Le $6^{\circ}$ arceau ventral assez profondément et subaigument entaillé au milieu de son bord apical, avec l'entaille parfois subémousséc au sommet, en majeure partie remplie par une membrane subpellucide. Le $5^{\text {a }}$ largement et subangulairement échancré dans le milieu de son bord postérieur. Tarses antérieurs à $1^{\text {er }}$ et $3^{\mathrm{e}}$ articles assez fortement, le $2^{\circ}$ fortement transverses.

ㄴ Le $6^{\mathrm{e}}$ arceau ventral subarrondi, le $5^{\mathrm{e}}$ simple, à leur bord apical. Tarses antérieurs à 3 premiers articles légèrement dilatés.

Philonthus rufimanus, Erichson, Gen. et Spec. Staph. 476, 80. - Redtenbacher, Faun. Aust. 703, 23. - HeEr, Faun. Col. Helv. I, 266, 34. - Fairmaire et LAвoulbène, Faun. Ent. Fr. I, 526, 46. - KrAATz, Ins. Deut. II, 609, 45. FaUvel, Faun. Gallo-Rhén. III, 449, 15.

$$
\text { Long., } 0^{\mathrm{m}}, 0067 \text { (3 l.); - larg., } 0^{\mathrm{m}}, 0011 \text { (1/2 l.). }
$$

Corps allongé, assez étroit, subdéprimé, d'un noir brillant, avec les élytres bleues; revêtu sur celles-ci et l'abdomen, d'une fine pubescence cendrée et éparse.

Tête subcarrée ou suborbiculaire, aussi large ou presque aussi large que le prothorax ; fortement sétosellée; d'un noir luisant; lisse, avec quelques points assez forts sur les tempes, et 2 autres, écartés et transversalement disposés sur le verlex. Front très-large, faiblement convexe, marqué de chaque côté, entre les yeux, de 2 pores sétifères assez forts, très-rapprochés et obliquement disposés, dont l'interne plus en arrière. 
Cou glabre, presque lisse, d'un noir luisant. Labre noir, brillant, fortement sétosellẻ en avant. Mandibules et palpes d'un noir de poix.

Yeux assez grands, subovales, obscurs, lavés de livide.

Antennes suballongées, à peine moins longues que la tête et le prothorax réunis; subfiliformes; légèrement pubescentes et éparsement pilosellées vers leur base; noires, avec le $1^{\mathrm{er}}$ article et la base du $2^{\circ}$ souvent roux : le $1^{\text {er }}$ allongé,en massue subarquée : les $2^{\mathrm{e}}$ et $3^{\mathrm{e}}$ suballongés, obconiques : le $3^{\circ}$ à peine plus long que le $2^{\mathrm{e}}$ : les suivants graduellement un peu plus courts : les $4^{\circ}$ à $7^{e}$ oblongs : les $8^{\circ}$ à $10^{\circ}$ à peine plus longs que larges, vus de côté : le dernier subovalaire, étroitement subéchancré au bout et subacuminé inférieurement.

Prothorax suboblong, subparallele, sensiblement moins large que les élytres ; tronqué au sommet, avec les angles antérieurs infléchis et arrondis ; presque droit sur les côtés, vu de dessus ; subarrondi à sa base, ainsi qu'aux angles postérieurs ; légèrement convexe ; distinctement sétosellé, avec la longue soie latérale située contre le rebord même; d'un noir luisant; lisse, avec 2 séries dorsales composées de 5 points assez gros, dont l'antérieur un peu plus écarté; marqué de plus, de chaque côté, outre ceux de la marge, de 5 autres points semblables et épars. Repli d'un noir ou parfois d'un brun de poix, glabre, lisse.

Écusson pointillé, légèrement pubescent, noir.

Élytres subcarrées, un peu plus longues que le prothorax; subdéprimées; assez densement et assez finement bie qu'assez profondément ponctuées; d'un bleu brillant, assez clair et parfois un peu verdâtre; éparsement pubescentes, éparsement sétosellées, avec 1 soie plus longue vers l'écusson et 1 autre sur les épaules. Celles-ci arrondies. Ailes blanches.

Abdomen allongé, moins large que les élytres; subparallèle ou à peine arqué sur les cótés; assez convexe sur le dos; visiblement sillonné en travers à la base des 4 premiers segments; assez fortement sétosellé; finement, légèrement et éparsement ponctué ; parfois plus sensiblement sur la base des $4^{\mathrm{e}}$ et $5^{\mathrm{e}}$ segments; d'un noir brillant; éparsement pubescent. Le $6^{\text {e }}$ segment à peine arrondi, quelquefois même subsinueusement tronqué au sommet.

Dessous du corps éparsement ponctué et pubescent, d'un noir brillant. Dessous de la tête presque glabre, presque lisse, légèrement pubescent sur le côté des tempes. Lame mésosternale lisse en avant; à arête trans-

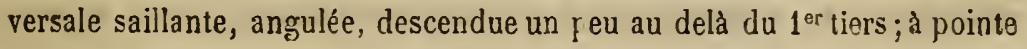


p rolongée, subacérée, ciliée ou pubescente. Métasternum subdéprimé sur sın milieu, obsolètement canaliculé en arrière sur sa ligne médiane. V:itre convexe, éparsement sétosellé, à soies mélangées de longues et de courtes.

Pieds médiocres, éparsement et subaspèrement ponctués, noirs, avec les hanches et les cuisses antérieures et intermédiaires d'un roux testacé ainsi que les trochanters. Cuisses antérieures assez finement epineuses en dessous vers leur sommet; les postérieures suballongėes. Tibias antérieurs assez fortement épineux en dehors. Hanches intermédiaires plus ou moins rapprochées. Tarses postérieurs à $1^{\mathrm{er}}$ article à peine plus long que le dernier, un peu moins long que les 3 suivants réunis.

Patrie. Celle espèce se rencontre assez souvent, aux environs de Lyon, cn ćté, courant sur le lit desséché de la rivière d'Izeron, l'abdomen relevé en forme d'étendard. On la prend aussi dans les régions orientales ou méridionales de la France, telles que l'Alsace, la Lorraine, la Bourgogne, la Savoie, les Alpes, la Provence, la Guyenne, les Fyrénées, etc.

Obs. Elle est remarquable par la couleur bleue de ses élytres. Erichson, Kraatz, Fairmaire et Laboulbène donnent à cet insecte des antennes entièr'cment noires. Quant aux exemplaires de nos localités, ils offrent le $1^{\mathrm{er}}$ article de ces organes plus ou moins roux, ainsi que l'indique Heer. Rarement, il est d'un r'oux de poix foncé. C'est une des espèces les plus gracieuses du genre Philonthus.

Près du Ph. rufimanus se placerait l'espèce suivante, non encore trouvée dans la France continentale :

philonthus alcyoneu, ERICHSON.

Allongé, subdéprimé, éparsement pubescent, d'un noir brillant, avec la tête et le prothorax submétalliques et les élytres bleuâtres. Tête et protloorax lisses, très-luisants : celui-ci suboblong, subparallèle ou à peine rétréci en arrière. Élytres assez finement et assez densement, abdomen finement et éparsement, ponctués.

$\sigma^{*}$ Le $6^{\text {e }}$ arceau ventral peu profondément et angulairement entaillé à son bord apical, avec le fond de l'entaille garni d'une étroite membrane subpellucide. Le $5^{\mathrm{e}}$ largement et à peine échancré dans le milieu de son 
bord postérieur. Tarses antérieurs à 3 premiers articles médiocrement dilatés.

† Le 6e arceau ventral subarrondi, le $5^{\circ}$ simple, à leur bord apical. Tarses antérieur's à 3 premiers articles légèrement dilatés.

Philonthus alcyoneus, Ericison, Gen. et Spec. Staph. 476, 79. - Fauvec, Faun. Gallo-Rhén. III, 449, note.

$$
\text { Long., } 0^{\mathrm{m}}, 0066 \text { (3 l.); - larg., 0m,0011 (1/2 l.). }
$$

Patrie. Celte espèce nous a été donnée de Corse, par M. Revelière; de Sardaigne, par M. Bauduer.

OBs. Elle diffère du rufimanus par ses pieds antérieurs et intermédiaires, concolores, ainsi que le $1^{\mathrm{er}}$ article des antennes. Les points enfoncés de la tête et du prothorax sont un peu plus gros, et ces deux segments sont toujours submétalliques, etc.

Près du rufimanus marche une espèce encore bien voisine :

Philonthus sunvis, Brisout.

Allongé, subdéprimé, très-éparsement pubescent, d'un noir brillant, avec les élytres bleuâtres, la base des antennes d'un roux de poix, les luanches et les cuisses antérieures d'un roux testacé. Téte et prothorax lisses, luisants : celui-ci suboblong, subparallèle. Elytres assez fortement et modérément, abdomen finement et éparsement, ponctués.

$\sigma$ Le $6^{\mathrm{e}}$ arceau ventral angulairement entaillé dans le milieu de son bord apical. Tarses antérieurs à 3 premiers articles sensiblement dilatés.

ㅇ Le $6^{\circ}$ arceau ventral simple à son bord apical. Tarses antérieurs à 3 premiers articles légèrement dilatés.

Philonthus gratiosus, ERIsaut, Ann. Soc. Ant. Fr. 1866, 359.

Philonthus suavis, Brisout, Col. Heft. II, 1867, 116.- FaUver, Faun. Gallo-Rhén,

III, 449, note,

Long., $0^{\mathrm{m}}, 00500$ (2 1/3 l.); - larg., 0m,0008 (1/3 l.), 
Patrie. Les environs de Madrid. Elle nous a élé donnée par M. Puton, de Remiremont (Vosges).

OBs. Elle est moindre que le rufimanus. Les élytres sont un peu plus fortement ponctuées. Les cuisses et hanches intermédiaires sont concolores, les antérieures, seules, sont d'un roux testacé.

Comme il y avail déjà un gratiosus. Erichson $(461,55)$, M. Brisout a dù changer son premier nom.

\section{Plilonthus quisquiliariug, GrLENhAL.}

Allongé, subdéprimé, finement pubescent, d'un noir brillant, avec les élytres d'un noir un peu verdâtre, les palpes d'un roux de poix, la base des antennes et les pieds testacés, les cuisses postérieures rembrunies. Tête et prothorax lisses, luisants : celui-ci à peine oblong, subrétréci en avant. Elytres finement et densement, abdomen finement et assez densement, ponctués.

$\sigma^{7}$ Le $6^{c}$ arceau ventral médiocrement et angulairement sinuć dans le milieu de son bord apical, avec un espace lisse, allongé, triangulaire, au

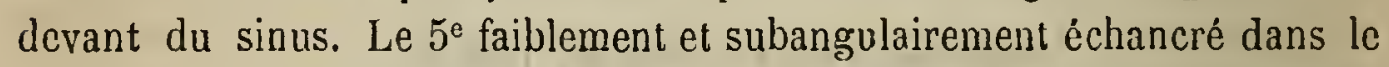
milieu de son bord postérieur. Tarses antérieurs à $1^{\text {cr }}$ et $2^{\theta}$ arlicles fortement, le $3^{\mathrm{e}}$ un peu plus fortement, dilatés.

+ Le $6^{\mathrm{e}}$ arceau ventral subarrondi, le $5^{\mathrm{e}}$ simple, à leur bord apical. Tarses antérieurs presque simples.

Staphylinus quisquiliarius, Gylennal, Ins. Silec. II, 33̈̈, 50. - ManNerneim, Brach. 29, 64. - Eorsduval et Lacordaire, Faun. Ent. Par. I, 406, 39.

Philonthus quisquiliarius, Nordnanv, Symb. 93, 61. - ERicison, Col. March. I, 469, 31 ; - Gen. et Spec. Staph. 473, 78. - Redtendacier, Faun. Austr. 703 , 24. - Hefr, Faun. Col. IIelv. I, 267, 35. - Fairandine et Labouldène, Faun. Ent. Fr. I, 5223, 34. - Krastz, Ins. Deut. II, 607, 42. - Thlonson, Skand. Col. II, 160, 20. - Facvel, Faim. Gallo-hihén. III, 463, 30.

Variélé $a$. Elytres rouges, à base noire.

Staphylimus dimidiatus, Borsdurat. et Lacordaine, Faun. Ent, Par. I, 402, 31. Philonthus dimidialus, Enicnson, Col. Mar'ch. I, 407, 30. - IIEer, Faun. CoI. IIdr. I, 206, 31 .

Philonthus rubidus, Ericnson, Gen. et Spec. Staph, 475, 77. - Redtenbacirer, Faun. Austr. 704, 26. 
Long., $0^{\mathrm{m}}, 0060$ (2 3/4 l.); - larg., 0m,0010 (1/2 1. à peine).

Corps allongé, assez étroit, subdéprimé, d'un noir brillant, avec les élytres un peu verdâtres; revêtu sur celles-ci et l'abdomen d'une fine pubescence grise, assez longue, subéparse ou modérément serrée.

Tête suborbiculaire, un peu moins large que le prothorax; fortement sétosellée; d'un noir luisant; lisse, avec quelques points assez forts, épar's, en arrière sur les côtés. Front large, à peine convexe, marqué de chaque côté, entre les yeux, de 2 pores sétifères rapprochés et subtransversalement disposés, dont l'interne souvent moindre et un peu plus en arrière. Cou glabre, presque lisse, d'un noir luisant. Labre noir, brillant, assez fortement sétosellé en avant. Mandibules et palpes d'un roux de poix plus ou moins foncé.

Yeux assez grands, subovales, plus ou moins obscurs.

Antennes suballongées, environ de la longueur de la tête et du prothorax réunis; subfiliformes ou à peine épaissies; légèrement pubescentes et éparsement pilosellées vers leur base; noires, avec le $1^{{ }^{\mathrm{e}} \mathrm{r}}$ article testacé ainsi que souvent la base du $2^{\mathrm{e}}$ et les pédicelies des suivants; le $1^{\mathrm{er}}$ allongé, en massue à peine arquée : les $2^{\mathrm{e}}$ et $3^{\mathrm{e}}$ obconiques, suballongés, subégaux ou avec le $3^{\mathrm{e}} \mathrm{à} \mathrm{peine} \mathrm{plus} \mathrm{long:} \mathrm{les} 4^{\mathrm{e}}$ à $10^{\mathrm{e}}$ graduellement un peu plus courts, subobconiques : les $4^{\mathrm{e}}$ à $7^{\mathrm{e}}$ oblongs ou suboblongs : les pénultièmes a peine plus longs que larges, vus de côté : le dernier ovalaire, subéchancré au bout et subacuminé inférieurement.

Prothorax à peine oblong, subrétréci en avant; un peu moins large que les élytres; tronqué au sommet, avec les angles antérieurs infléchis et subarrondis; presque droit sur les côtés, vu de dessus ; subarrondi à sa base ainsi qu'aux angles postérieurs; peu convexe; distinctement sétosellé, avec la longue soie latérale située contre lc rebord même; d'un noir luisant; lisse, avec 2 séries dorsales composées de 5 points assez profonds et assez gros, dont les 2 antérieurs et parfois les $3^{\mathrm{e}}$ et $4^{\mathrm{e}}$ un peu plus écartés entre eux; marqué de plus, de chaque côté, outre ceux de la inarge, de 5 autres points semblables el épars. Repli d'un noir ou d'un brun de poix, glabre, lisse.

Écusson densement pointillé, pubescent, noir.

Élytres subcarrées, un peu plus longues que le prothorax; subdéprimées; finement mais assez profondément, densement et subaspèrenent poncluées; d'un noir brillant et souvent un peu verdâtre; subéparscment 
ou modérément pubescentes; à peine sétosellées, avec 1 très-longue soie vers l'écusson et 1 autre derrière les épaules. Celles-ci étroitement arrondies.

Abdomen allongé, moins large que les élytres; subparallèle ou à peine arque sur les cólés; assez convexe sur le dos ; subimpressionné en travers sur la base des 3 premiers segments; éparsement sétosellé; finement et assez densement ponctué, souvent un peu moins densement en arrière; d'un noir brillant; à pubescence à peine plus serrée que celle des élytres. Le $6^{\mathrm{e}}$ segment moins ponctué, moins pubescent, à peine arrondi au sommet.

Dessous du corps subaspèrement pointillé, finement pubescent, d'un noir brillant. Dessous de la tête glabre, lisse, avec le côté des tempes pubescent. Lame mésosternale presque lissie; à arête transversale saillante, faiblement arquée, à peine descendue jusqu'au $1^{\text {er }}$ tiers; à pointe assez prolongée, étroite, mais souvent subémoussée au bout. Métasternum subdéprimé sur son milieu, à peine et très-finement canaliculé sur sa ligne médiane. Ventre convexe, éparsement sélosellé, longuement en arrière.

Pieds médiocres, subaspèrement ponctués, finement pubescents, testacés, avec les hanches antérieures et intermédiaires d'un brun ou d'un roux de poix, les hanches et les cuisses postérieures plus ou moins rembrunies. Cuisses antérieures finement épineuses en dessous vers leur sommet: les postérieures plus grêles. Tibias antérieurs plus ( $q$ ) ou moins $\left(\sigma^{*}\right)$ épineux en dehors. Hanches intermédiaires plus ou moins rapprochées. Tarses postérieurs à $1^{\mathrm{er}}$ article subégal au dernier, moins long que les 3 suivants réunis.

Patrie. Celte espèce se rencontre assez communément dans presque toute la France, courant sur la vase, ou parmi les détritus du bord des ruisseaux. Elle est plus répandue dans le Midi que dans le Nord.

OBs. Elle a la forme allongée du rufimanus. Elle ressemble beaucoup au concinnus, surtout à la variété ochropus; mais les antennes sont un peu plus grêles, avec leurs pénultièmes articles un peu moins courts; les élytres, moins transverses, sont un peu plus densement ponctuées; surtout, le $1^{\mathrm{er}}$ article des tarses postérieurs est moins long relativement au dernier, etc.

Rarement, les séries dorsales du prothorax sont de 4 points.

La variété a (rubidus, Er.), longtemps regardée comme une espèce distincte, est remarquable par ses élytres rouges, parfois étroitement, 
d'autres fois assez largement noires à leur base. Les pieds sont d'un roux testacé, avec les hanches postérieures souvent seules, rembrunies.

Peut-être doit-on rapporter au quisquiliarius type le phaeopus de Stcphens (Man. Brit. Col. 397), et à la variété rubidus l'inquinatus du même auteur (Ill. Brit. V, 223)?

Le linearis, Hochh. (Bull. Mosc. 1849, I, 140) appartiendrait aussi à la même espèce.

\section{V· SECTION. - Séries dor'sales du prothorax de è points.}

OBS. Nous faisons entrer dans cette section un petit nombre d'espèces de taille médiócre. Le dernier árticle d's palpes maxillaires est plus long que le pénultième, soit assez grêle et exactement fusiforme, soit en cône allongé, assez brusquement rétréci à sa base et graduellement atténué vers son extrémité, dès environ le tiers basilaire. Le dernier des labiaux suit à peu près les mêmes modifications, mais il est généralement aus:i èpais que le précédent. La lame mésosternale assez constante quant à son arête transversale, qui est plus ou moins, mais jamais fortement arquie, rarement subangulée, assez accusée, et qui s'arrête vers le tiers antérieur, offre sa pointe. terminale assez prolongée, plus ou moins aiguë et parfois subémoussée au bout. Les hanches intermédiaires sont légèrement distantes ou rapprocbées dans leur milieu. Les 3 premiers articles des tarses antérieurs sont plus ou moins fortement dilatés chez les $\sigma$, à peine ou légèrement chez les $\$$. Le $1^{\mathrm{e}^{\mathrm{r}}}$ article des tarses postérieurs est sensiblement ou beaucoup plus long que le dernier. La tête est ovale, moins large que le prothorax.

a Prothorax à peine oblong, subarqué sur les côtés, presque aussi large ou un peu moins large en arrière que les élytres. Téte ovalaire.

b Abdomen assez finement et assez densement ponctué, assez brillant. Taille moyenne.

c Elytres noires. Pieds obscurs, avec les tarses d'un roux de poix - NIGRITA.

cc Élytres d'un noir bronzé. Pieds fauves, avec les hanches remhrunies. . . . . . . . . . . . . . . . Fumanlus.

hb Abdomen très-finement et densement pointillé. Taille petite.

d Élytres d'un noir submétallique et peu brillant.

e Elytres et abdomen à peine grisâtres : celui-ci assez brillant, densement pointillé à sabase, moins densement sur les 3 derniers segments. Pieds d'un brun ferrugineux. Antennes et palpes obscurs. . . . . . . VIRGo 
ee Élytres et abdomen évidemment grisatres : celui-ci peu brillant, densement pointille, éparsement sur le dernicr segment seul. Pieds, base des antennes et palpes d'un roux testacé. - . . . . . . . . . Micans.

dd Élytres d'un rouge clair assez brillant. Pieds d'un roux testacé.

f Antenines subaliongées, avec les $4^{\mathrm{e}}$ à $7^{\mathrm{e}}$ articles oblongs, les pénultièrnes à peine plus longs que larges : les

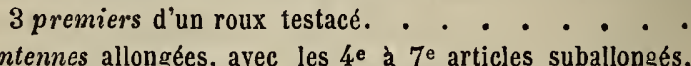

ff Antennes allongées, avec les $4 \mathrm{e}$ à $7^{\mathrm{e}}$ articles suballongés,
les pénultièmes oblongs : le 1 er seul d'un roux testacé. salinus.
horax oblong, presque droit sur les côtés, sensiblement moins
ge que les élytres. Téte suboblongue. Elytres rouges. 1er article

ff Antennes allongées, avec les $4 \mathrm{e}$ à $7^{\mathrm{e}}$ articles suballongés,
les pénultièmes oblongs : le 1 er seul d'un roux testacé.
aa Prothorax oblong, presque droit sur les côtés, sensiblement moins
large que les élytres. Téte suboblongue. Elytres rouges. 1er article FULVIPES. des antennes et pieds testacés. . . . . . . . . RubripenNis.

\section{Philonthus nigrita, Gravenhorst.}

Allongé, subfusiforme, peu convexe, très-finement pubescent, d'un noir brillant, avec les tarses d'un roux de poix. Tête et prothorax lisses, luisants : celui-ci à peine oblong, subrétréci en avant. Élytres finement et densement, abdomen assez finement et assez densement, ponctués : celui-ci un peu moins densement en arrière.

$\sigma^{*}$ Le $6^{\circ}$ arceau ventral profondément et aigument entaillé dans le milieu de son bord apical, avec le fond de l'entaille rempli par une membrane subpellucide. Tarses antérieurs à 3 premiers articles assez fortement dilatés.

ㅇ Le $6^{\mathrm{e}}$ arceau ventral simplement arrondi à son bord apical. Tarses antérieur's à 3 premiers articles légèrement dilatés.

Staphylinus nigrita, Gravenhorst, Mon. 68, 44.

Philonthus nigrita, Norduann, Symb. 101, 86. - Erichson, Col. March. I, 471, 37 ; - Gen. et Spec. Staph. 481, 89. - Redtenbacher, Faun. Austr. 825. Heer, Faun. Col. Helv. I, 269, 42. - Falrmaire et Laboulbène, Faun. Ent. Fr. I, 526, 47. - KraAtz, Ins. Deut. II, 611, 47. - Thonson, Skand. Col. II, 165, 33. - Fauvel, Faun. Gallo-Rhén. III, 484, 57.

$$
\text { Long., } 0^{\mathrm{m}}, 0066 \text { (3 1.); - larg., } 0^{\mathrm{m}}, 0015 \text { (2/3 l.). }
$$

Corps allongé, subfusitorme, peu convexe, d'un noir brillant; revêtu 
sur les élytres et l'abdomen d'une très-fine pubescence d'un gris obscur et modérément serrée.

Tête ovale, moins large que le prothorax; fortement sétosellée; d'un noir luisant; lisse, avec quelques points assez forts, épars, en arrière sur les côtés. Front large, subconvexe, marqué de chaque côté, entre les yeux, de 2 pores sétifères assez gros et subobliquement disposés, dont l'interne un peu plus en arrière. Cou glabre, presque lisse, d'un noir luisant. Labre d'un noir brillant, fortement sétosellé en avant. Mandibules et palpes d'un noir de poix, avec celles-là et la base de ceux-ci parfois moins foncées.

Yeux assez grands, subovales, plus ou moins obscurs.

Antennes suballongées, un peu plus longues que la tête et le prothorax réunis; assez grêles, subfiliformes ou à peine épaissies ; légèrement pubescentes et éparsement pilosellées, surtout vers leur base; obscures, avec le dernier article un peu moins foncé; le $1^{\mathrm{e}}$ allongé, en massue à peine arquée : les $2^{\mathrm{e}}$ et $3^{\mathrm{c}}$ assez allongés, obconiques : le $3^{\mathrm{e}}$ un peu plus long que le $2^{\circ}$ : les suivants graduellement un peu moins longs, subobconiques : les $4^{\mathrm{e}}$ à $7^{\mathrm{e}}$ oblongs, les pénultièmes suboblongs : le dernier ovale-oblong, tronqué au bout, brusquement subacuminé inférieurement.

Prothorax à peine oblong, subrétréci en avant; presque aussi large à sa base que les élytres; tronqué au sommet, avec les angles antérieurs infléchis et subarrondis; à peine arqué sur les côtés; vu de dessus; subarrondi à sa base ainsi qu'aux angles postérieurs ; médiocrement convexe; parfois à peine soyeux; très-éparsement sétosellé, avec la longue soie latérale située contre le rebord même; d'un noir luisant ; lisse, avec 2 séries dorsales composées de 6 points médiocres, dont l'antérieur parfois un peu plus écarté; marqué de plus, de chaque côté, outre ceux de la marge, de 5 points semblables et épars. Repli noir, glabre, lisse.

Écusson finement pointillé, finement pubescent, noir.

Élytres subcarrées ou à peine transverses, un peu plus larges en avant qu'en arrière; à peine plus longues que le prothorax; subdéprimées; finement, densement et aspèrement ponctuées; d'un noir brillant; trèsfinement et modérément pubescentes; à peine sétosellées, avec une soie plus longue vers l'écusson et une autre derrière les épaules. Celles-ci étroitement arrondies.

Abdomen allongé, moins large que les élytres; graduellement et subarcuément atténué en arrière; convexe sur le dos; subimpressionné en travers sur le milieu de la base des 3 premiers segments; éparsement et assez fortement sétosellé; assez finement et assez densement ponctué, un

BR. 
peu plus lâchement en arrière; d'un noir brillant; à pubescence plus longue et un peu moins serrée que celle des élytres. Le $6^{\circ}$ segment à peine arrondi au sommet.

Dessous du corps aspèrement ponctué, finement pubescent, d'un noir brillant. Dessous de la tête presque glabre et presque lisse, avec le còté des tempes pubescent. Lame mésosternale à arête transversale saillante, arquée, descendue jusqu'au $1^{\text {er }}$ tiers; à pointe aiguë, parfois subémoussée au bout. Métasternum à peine convexe sur son milieu, finement canaliculé en arrière sur sa ligne médiane. Ventre convexe, éparsement sétosellé.

Pieds médiocres, aspèrement pointillés, noirs, avec les tarses et parfois les genoux d'un roux de poix. Cuisses antérieures finement épineuses en dessous vers leur sommet; les postérieures suballongées, plus grêles. Tibias antérieurs plus ou moins épineux en dehors. Hanches intermédiaires rapprochées. Tarses postérieurs à $1^{\mathrm{e}}$ article beaucoup plus long que le dernier, presque égal aux 3 suivants réunis.

Patrie. Cette espèce est peu commune. Elle se prend parmi les mousses des forêts humides, dans la Normandie, le Berry, le Beaujolais, les Alpes, les Pyrénées, etc.

OBs. Elle a la taille et la tournure des grands individus du varians. Mais les antennes sont plus longues; les tarses antérieurs des $\sigma$ sont moins fortement dilatés; les hanches antérieures sont concolores; le prothorax présente sur le dos 2 séries composées de 6 points, par exception de 5 .

Le dernier artịcle des palpes maxillaires est allongé, assez grêle, fusiforme.

\section{Philonthus fumarius, GravenHoRst.}

Allongé, subfusiforme, peu convexe, finement pubescent, d'un noir brillant, avec les élytres un peu bronzées, les palpes d'un roux de poix et les pieds fauves. Tête et prothorax lisses, luisants : celui-ci presque aussi large que long, subrétréci en avant. Élytres finement et densement, abdomen finement et assez densement, ponctués : celui-ci moins densement en arrière.

$\sigma$ Le $6^{\circ}$ arceau ventral assez profondément et angulairement sinué dans le milieu de son bord apical, avec un espace triangulaire-lisse, 
allongé, au dévant du sinus. Tarses antérieurs à 3 premiers articles assez fortement dilatés, le $2^{\mathrm{e}}$ un peu plus fortement.

ㅇ Le $6^{\circ}$ arceau ventral arrondi à son bord apical. Tarses anterieurs à peine dilatés.

Staphylinus fumarius, Gravenhorst, Mon. 67, 43.

Philonthus fumarius, Nordmann, Symb. 100, 84.- Erichson, Col. March. I, 472, 38 ; - Gen. et Spec. Staph. 482, 91 - Redtenbacher, Faun. Austr. 706, 36.

- Heer; Faun. Col. Helv. 1, 270, 44. - Fairmatre et Laboulbène, Faun. Ent, Fir. I, 527, 50. - Kratтz, Ins. Deut. II, 610, 46. - Thомson, Skand. Col. IX, 154, 39, 1867. - FAUvel, Faun. Gallo-Rhén. III, $483,56$.

Long., $0^{\mathrm{m}}, 0066$ (3 l.) ; - larg., $0^{\mathrm{m}}, 0015$ (2/3 l.).

Cor'ps allongé, subfusiforme, peu convese, d'un noir brillant ; revêtu sur les élytres et l'abdomen d'une fine pubescence grisâtre et modérément serrée.

Tête ovale, moins large que le prothorax; fortement sétosellée; d'un noir luisant; lisse, avec quelques gros points épars en arrière sur les côtés. Front large, subconvexe, marqué de chaque côté entre les yeux de 2 pores sétifères assez gros et subtransversalement disposés, l'interné parfois un peu plus en arrière. Cou glabre, presque lisse, d'un noir luisant. Labre brillant, noir, fortement sétosellé en avant. Mandibules brunâtres, parfois un peu ferrugineuses. Palpes d'un roux de poix.

Yeux assez grands, subovales, obscurs ou lavés de gris.

Antennes suballongées, un peu plus courtes que la tête et le prothorax réunis ; faiblement épaissies ; légèrement pubescentes et éparsement pilosellées, surtout vers leur base ; noires, avec les $1^{\text {er }}$ et dernier articles d'un brun parfois un peu roussâtre; le $1^{\text {er }}$ allongé, en massue subarquée: les $2^{\mathrm{e}}$ et $3^{\mathrm{e}}$ assez allongés, obconiques : le $3^{\mathrm{e}}$ plus long que le $2^{\mathrm{e}}$ : les suivants graduellement moins longs : le $4^{e}$ assez long, subcylindrique : les $5^{\mathrm{e}}$ à $6^{\mathrm{e}}$ oblongs, subcylindrico-coniques: les pénultièmes suboblongs; obconiques : le dernier oblong, tronqué au bout et subacuminé inférieurement.

Prothorax presque aussi large à sa base que long dans son milieu; subrétréci ell avant, presque aussi large en arrière que les élytres; tronqué au sommet, avec les angles antérieurs infléchis et subarrondis; faiblement arqué sur les côtés, vu de dessus; subarrondi à sa base ainsi qu'aux 
angles postérieurs ; médiocrement convexe; éparsement sétosellé, avec la longue soie latérale située sur le rebord même; d'un noir luisant ; lisse, avec 2 séries dorsales composées de 6 points médiocres et subégalement distants ; marqué de plus, de chaque côté, de 5 points semblables et épars, outre ceux de la marge. Repli noir, glabre, lisse.

Ėcusson finement pointillé, finement pubescent, noir.

Élytres subtransverses, de la longueur du prothorax ou a peine plus longues; subdéprimées; finement, densement et aspèrement ponctuées ; d'un noir brillant, un peu bronzé et parfois légèrement verdâtre ; finement et modérément pubescentes; à peine sétosellées, avec 1 soie, notamment plus longue, vers l'écusson, et 1 autre vers les épaules. Celles-ci étroitement arrondies. Ailes blanchâtres.

Abdomen suballongé, moins large que les élytres, subarcuément subatténué en arrière; convexe sur le dos, avec les 3 premiers segments subimpressionnés en travers sur le milieu de leur base; éparsement sétosellé; plus longuement sur les côtés ; finement et assez densement ponctué sur les premiers segments, plus lâchement sur l'extrémité du $3^{\mathrm{e}}$ et sur les 3 derniers; d'un noir brillant; à pubescence plus longue et moins serrée que celle des élytres. Le $6^{\mathrm{e}}$ segment à peine arrondi au sommet.

Dessous du corps aspèrenıent pointillé, finement pribescent, d'un noir brillant, avec le sommet de chaque arceau ventral souvent d'un roux de poix. Dessous de la tête presque lisse, presque glabre, avec les côtés des tempes pubescents. Lame mésosternale presque lisse; à arête transversale saillante, à peine arquée, située vers le $1^{\text {er }}$ tiers ; à pointe aiguë, parfois émoussée au bout. Métasternum à peine convexe sur son milieu, subsillonné en arrière sur sa ligne médiane, à lobe postérieur souvent d'un roux de poix ou au moins sur les côtés de sa base. Ventre convexe, plus éparsement ponctué en arrière, éparsement sétosellé, plus longuement vers son extrémité.

Pieds médiocres, aspèrement pointillés, finement pubescents, d'un roux fauve, avec les hanches rembrunies. Cuisses antérieures finement épineuses en dessous vers leur sommet; les postérieures plus grêles, suballongées. Tibias antérieurs plus ou moins épineux en dehors. Hanches intermédiaires assez rapprochées. Tarses postérieurs à $1^{\mathrm{er}}$ article beaucoup plus long que le dernier, presque égal aux 3 suivants réunis.

Patrie. On prend cette espèce assez communément, parmi les mousses des lieux humides ou marécageux, au printemps, dans diverses localités : 
les environs de Paris et de Lyon, la Normandie, l'Alsace, la Lorraine, le Bugey, les Alpes, les Pyrénées, etc.

OBs. Elle a tout à fait la taille et la forme de la précédente, dont elle se distingue par ses élytres un peu métalliques, et par la couleur des pieds.

Nous avons vu un exemplaire, sans doute immature, dont les élytres et le dos de l'abdomen sont d'un brun roussâtre, et tout le desseus du corps d'un roux ferrugineux.

\section{Philonthus virgo, Gravenhorst.}

Allongè, subfusiforme, peu convexe, très-finement pubescent, d'un noir brillant, avec les pieds d'un brun ferrugineux et les hanches obscures. Tête et prothorax lisses, luisants : celui-ci presque aussi large que long, subrétréci en avant. Élytres et abdomen finement et densement ponctués : celui-ci moins densement en arrière.

$\sigma^{*}$ Le $6^{\circ}$ arceau ventral sensiblement et subangulairement sinué dans le milieu de son bord apical, avec un espace lisse triangulaire, oblong, au-devant du sinus. Tarses antérieurs à 3 premiers articles dilatés, le $1^{\text {er }}$ assez fortement, le $2^{\mathrm{e}}$ très-fortement, le $3^{\mathrm{e}}$ fortement.

\& Le $6^{\mathrm{e}}$ arceau ventral simplement subarrondi à son bord apical. Tarses antérieurs à 3 premiers articles à peine dilatés.

Staphylinus virgo, Gravenhorst, Micr. 169, 19; - Mon. 69, 45. - Latreille, Hist. Nat. Crust. et Ins. IX, 323, 63. - Grulenhal, Ins. Suec. II, 31 5, 61. Mannerheim, Brach. 31, 77. - Boisduval et Lacordaire, Faun. Ent. Par. I, 4.04, 35.

Philonthus virgo, Nordyand, Symb. 101, 85. - Ericason, Gen. et Spec. Staph. 483, 93. - Heer, Faun. Col. Helv. I, 293, 43. - Fatrimaire et Laroulbène, Faun. Ent. Fr. I, 527, 48. - KRAATZ, Ins. Deut. II, 611, 48. - FaUvel, Faun. GalloRihén. III, 486, 61 .

Philonthus palustris, Brisout, Ann. Soc. Ent. Fr. 1859, Bull. 232.

$$
\text { Long., } 0^{\mathrm{m}}, 0060 \text { (2 3/4 l.); - larg., } 0^{\mathrm{m}}, 0012 \text { (1/2 l.). }
$$

Corps allongé, subfusiforme, peu convexe, d'un noir brillant ; revêtu sur les éiytres et l'abdomen d'une très-fine pubescence d'un gris obscur et modérément serrée. 
Téte ovale, mọins large que le prothorax; assez fortement sétosellée ; d'un noir luisant ; lisse, éparsement et ạsșez fortement ponctıée en arrière. sur les côtés. Front large, subconvexe, marqué de chaque côté, entre les yeux, de 2 pores sétifères médiocres, assez rapprochés et subobliquement disposés, dont l'interne un peu plus en arrière. Cou glabre, presque lissc,' d'un noir brillant. Labre noir, fortement sétosellé en avant. Mandibules et palpes d'un brun de poix.

Yeux assez grands, subovales, plus ou moins obscurs.

Antennes suballongées, à peine plus longues que la tête et le prothorax réunis ; subfiliformes ou à peine épaissies ; finement pubescentes et éparsement pilosellées, surtout vers leur base; noires, avec l'insertion des premiers articles souvent d'un roux de poix; le $1^{\mathrm{er}}$ allongé, en massue subarquée : les $2^{\mathrm{e}}$ et $3^{\mathrm{e}}$ suballongés, obconiques : le $3^{\mathrm{e}}$ un peu plus long que le $2^{\circ}$ : les suivants graduellement moins longs, subcylindrico-coniques : les $4^{\mathrm{e}} \mathrm{a} 7^{\mathrm{e}}$ oblongs, les pénultièmes suboblongs ou à peine oblongs : le dernier oblong, subéchancré au bout et obtusément acuminé inférieurement.

- Prothorax presque aussi large à sa base que long dans son milieu; subrétréci en avant; un peu mais visiblement moins large en arrière que les élytres; tronqué au sommet, avec les angles antérieurs infléchis et subarrondis; à peine arqué sur les côtés, vu de dessus; subarrondi à sa base ainsi qu'aux angles postérieurs ; légèrement convexe; éparsement sétosellé, avec la longue soie latérale située sur le rebord même; d'un noir luisant; lisse, avec 2 séries dorsales composées de 6 points médiocres ou assez fins, dont le $1^{\text {er }}$ et le dernier parfois un peu plus écartés des autres; marqué, de plus, de chaque côté, outre ceux de la marge, de 5 autres points semblables et épars. Repli noir, glabre, lisse.

Écusson finement pointillé, finement pubescent, noir.

Élytres à peine transyerses, un peu plus longues que le prothorax; un peu plus larges en arrière qu'en avant; subdéprimées ; finement, densement et subrâpeusement pointillées ; d'un noir assez peu brillant et à peine métallique ; recouvertes d'une très-fine pubescence, modérément serrée et qui les rend à peine grisâtres; à peine sétosellées, avec 1 longue soie vers l'écusson et 1 autre derrière les épaules. Celles-ci étroitement arrondies.

Abdomen suballongé, moins large que les élytres; subarcuément subalténué en arrière; assez convexe sur le dos, avec les 3 premiers segments légèrement impressionnés en travers à leur base; distinctement sćtosellé; finement et densement ponctué, avec la ponctuation moins serrée sur leș 
$4^{\circ}$ et $5^{\circ}$ segments, éparse sur le $6^{\circ}$; d'un noir ássez brillant; a pubescence. plus longue et à peine moins serrée que celle des élytres. Le $6^{0}$ segment subarrondi au sommet.

Dessous $d u$ corps aspèrement pointillé, finement pubescent, d'un noir brillant. Dessous de la tête presque lisse, presque glabre, pubescent sur les côtés des tempes. Pointe mésosternale presque lisse ; à arête transversale assez saillante, subarquée, descendue jusqu'au tiers antérieur ; à pointe terminale aiguë. Métasternum subdéprimé sur son milieu. Ventre convexe, un peu moins densement pointillé en arrière, éparsement sétosellé, avec quelques soies plus longues vers son extrémité : celle-ci parfois moins sombre.

Pieds médiocres; aspèrement pointillés, finement pubescents, d'un brun ferrugineux, avec les genoux et les tarses parfois un peu plus clairs et les hanches plus ou moins rembrunies. Cuisses antérieures finement épineuses en dessous vers leur sommet; les postérieures plus grêles. Tibias antérieurs assez fortement épineux en dehors. Hanches intermédiaires rapprochées. Tarses postérieurs à $1^{\text {er }}$ article beaucoup plus long que le dernier, subégal aux 3 suivants réunis.

Patrie. On prend cette espèce, mais peu communément, parmi les détritus mouillés des marais saumâtres, dans la Provence et autres provinces méridionales.

OBs. Elle est un peu moindre que le $P h$. fumarius. Les élytres sont moins métalliques et moins brillantes, un peuplus firement pointillées. La ponctuation de l'abdomen est plus fine et plus serrée, a vec la pubescence de celui-ci à peine moins dense que celle des élytres.

Parfois le sommet du ventre est d'un roux de poix. Les hanches antérieures et intermédiaires sont quelquefois de la même coulcur que le reste des pieds. Rarement, les cuisses postérieures sontrun peu rembrunies.

\section{Philonthus micans, Gravenhorst.}

Allongé, subfusiforme, peu convexe, finement pubescent, noir, avec la bonche, la base des antennes, le sommet de l'abdomen et les pieds d'un roux testacé. Tête et prothorax lisses, luisants : celui-ci à peine aussi large que long, rétréci en avant. Élytres et abdomen peu brillants, plus ou moins grisâtres, finement et densement pointillés. 
$\sigma^{*}$ Le $6^{\circ}$ arceau ventral sensiblement et angulairement sinué dans le milieu de son bord apical, avec un espace lisse au devant du sinus. Tarses antérieurs à 3 premiers articles assez fortement dilatés.

† Le $6^{\ominus}$ arceau ventral subarrondi à son bord apical. Tarses antérieurs presque simples.

Staphylinus micans, Gravenhorst, Micr. 25, 34; - Mon. 76, 69. - LATREIlle, Hist. Nat. Crust. et Ins. IX, 314, 39. - GrLlendal, Ins. Suec. II, 344, 60. Manneraeim, Brach. 31, 76. - Boisduval et LaCordaire, Faun. Ent. Par. I, 406, 40. Philonthus micans, Norduan, Symb. 102, 88.- Erichson, Col.March. I, 473, 40; - Gen. et Spec. Staph. 484, 95. - Redtenbacuer, Faun. Austr. 706, 38. - HeER, Faun. Col. Helv. I, 270, 45. - FairMaire et Labourbène, Faun. Ent. Fr. I, 528, 51. - Kraatz, Ins. Deut. II, 612, 49. - Thouson, Skand. Col. II, 165, 37.- Fauvel, Faun. Gallo-Rhén. III, 484, 58.

$$
\text { Long., } 0^{\mathrm{m}}, 0056 \text { (2 1/2 l.); - larg., } 0^{\mathrm{m}}, 0011 \text { (1/2 l.). }
$$

Corps allongé, subfusiforme, peu convexe, d'un noir luisant sur la tête et le prothorax, peu brillant et paré sur les élytres et l'abdomen d'une fine pubescence cendrée, assez longue et assez serrée, qui les rend plus ou moins grisâtres.

Tête ovale, moins large que le prothorax, fortement sétosellée; d'un noir luisant; lisse, avec des points assez forts, épars, en arrière sur les côtés. Front large, un peu convexe, marqué de chaque côté, entre les yeux, de 2 pores sétifères assez gros et très-rapprochés, subtransversalement disposés, avec l'interne souvent un peu plus en arrière. Cou glabre, presque lisse, d'un noir luisant. Labre d'un brun de poix, sétosellé en avant. Parties de la bouche d'un roux testacé, avec l'extrême pointe des mandibules parfois plus foncée.

Yeux assez grands, evales-oblongs, plus ou moins obscurs, souvent à reflets micacés.

Antennes suballongées, un peu plus longues que la tête et le prothorax réunis; à peine épaissies; légèrement pubescentes, éparsement pilosellées, surtout vers leur base; obscures, avec le $1^{{ }^{e_{r}}}$ article et l'articulation des suivants d'un roux testacé et le dernier souvent d'un brun ferrugineux : le $1^{\mathrm{er}}$ allongé, en massue à peine arquée : les $2^{\mathrm{e}}$ et $3^{\mathrm{e}}$ obconiques : le $2^{\mathrm{e}}$ suballongé, le $3^{\mathrm{e}}$ un peu plus long : les $4^{\mathrm{e}}$ à $10^{\mathrm{e}}$ graduellement moins longs, non contigus, parfois brièvement pédicellés : les $4^{\mathrm{e}} \mathrm{a} 6^{\mathrm{e}}$ oblongs, subcylindrico-coniques : les $7^{\mathrm{e}} \mathrm{a} 10^{\mathrm{e}}$ suboblongs, subobconiques : le der- 
nier ovalaire-oblong, obliquement tronqué au bout, à peine acuminé inférieurement.

Prothorax à peine aussi large à sa base que long dans son milieu, plus ou moịns rétréci en avant; un peu moins large en arrière que les élytres ; tronqué au sommet, avec les angles antérieurs infléchis et subarrondis; à peine arqué sur les côtés, vu de dessus; subarrondi à sa base ainsi qu'aux angles postérieurs; faiblement convexe; distinctement sétosellé, avec la

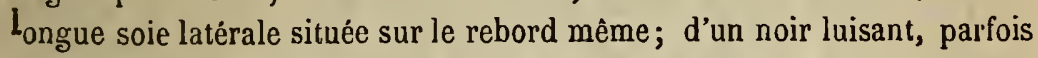
submétallique; lisse, avec 2 séries dorsales composées de 6 points médiocres, dont l'antérieur un peu plus écarté; marqué de plus, de chaque côté, outre ceux de la marge, de 5 autres points semblables et épars. Repli d'un noir de poix, glabre, lisse.

Écusson finement pointillé, finement pubescent, noir.

Élytres subcarrées, un peu plus longues que le prothorax ; un peu plus larges en arrière qu'en avant; subdéprimées ; à peine chagrinées; finement, densement et subrâpeusement pointillées ; d'un noir peu brillant et submétallique, avec une fine pubescence cendrée, assez longue, assez serrée et qui les rend visiblement grisâtres; à peine sétosellées, avec 1 longue soie redressée vers l'écusson et 1 autre derrière les épaules. Celles-ci étroitement arrondies.

Abdomen suballongé, un peu moins large que les élytres, à peine arqué sur les côtés et un peu rétréci en arrière; assez convexe sur le dos, avec les 3 premiers segments subimpressionnés en travers à leur base; distinctement sétosellé; finement et densement ponctué; d'un noir peu brillant, avec l'extrémité du $5^{\text {e }}$ segment et le $6^{\mathrm{e}}$ en entier d'un roux de poix testacé; revêtu d'une fine pubescence cendrée, assez longue et assez serrée, qui le rend un peu grisâtre. Le $6^{\mathrm{e}}$ segment moins ponctué, moins pubescent, subtronqué ou à peine arrondi au sommet.

Dessous du corps densement et subaspèrement pointillé, finement pubescent, d'un noir peu brillant, avec l'extrémité du ventre et le sommet de chaque arceau plus ou moins largement d'un roux testacé. Dessous de la tête presque glabre, presque lisse. Lame mésosternale presque lisse, à arête transversale subarquée, assez saillante, située vers le tiers antérieur; à pointe terminale plus ou moins aiguë, parfois subémoussée au bout. Métasternum subdéprimé sur son milieu. Ventre convexe, un peu grisâtre par l'effet de la pubescence, éparsement sétosellé, avec quelques soies plus longues vers l'extrémité.

Pieds médiocres, finement pointillés, finement pubescents, d'un roux 
testacé, avec les' hanches postérieures plus foncées. Cuisses antérieures finement épineuses en dessous vers leur sommet; les postérieures un peu plus allongées. Tibias antérieurs éparsement épineux en dehors vers leur base. Hanches intermédiaires plus ou moins rapprochées. Tarses.postérieurs à $1^{\text {er }}$ article sensiblement plus long que le dernier, subégal aux 3 suivants réunis.

Patris. Cette espèce est médiocrement commune parmi les moussę lıumides, dans les forêts et sur le bord des ruisseaux, aux environs de Paris et de Lyon, dans l'Alsace, le Beaujolais, les Alpes, les Pyrénées, etc.

OBs. Elle diffère du Ph. virgo par la couleur plus grisâtre des élytres et de l'abdomen; par les pieds, les palpes et la base des antennes d'une couleur plus claire; par son abdomen plus densement et plus uniformément pointillé, d'un roux de poix testacé à son extrémité, et par la couleur rousse des derniers arceaux du ventre. Sa taille est moindre; l'abdomen est un peu moins brillant, etc.

Nous avons vu une variété prise en Suisse et dont l'espace lisse de devant l'échancrure du ơ' est beaucoup plus net et plus allongé. En même temps, les palpes, la base des antennes, le sommet de l'abdomen, les hanches antérieures et intermédiaires et même les pieds postérieurs sont d'une couleur plus obscure (Helveticus, nobis).

Nous avons également examiné une variété remarquable, un peu plus allongée, un peu moins grise et á peine moins mate sur les élytres et l'abdomen et chez laquelle les pieds sont d'un ferrugineux sombre et la marye postérieure des 2 derniers arceaux du ventre assez largement d'un roux subtestacé tranché. Les mâchoires et le menton sont testacés, les palpes et la base des antennes d'un noir ou d'un brun de poix. Les élytres sont plus visiblement chagrinées entre les points.

Cette variété. dont nous n'avons vu qu'un seul exemplaire et qui a tout l'air d'une espèce distincte(toenianus, nobis), a été capturée en novembre, aux environs de Lyon, en tamisant les feuilles mortes des forêts.

On doit rapporter all micans le Truquii de Peyron (Ann. Soc. Ent. Fr. 1858,427 ) et peut-être l'obscuripennis de Stephens (Ill. Brit. V, 236).

\section{Phillonthus fulvipes, Fabricius.}

Allonge, subfusiforme, peu convexe, finement pubescent, noir, avec les élytres d'un rouge clair, la bouche, la base des antcnnes et les picds d'un 
roux testacé. Tète et prothorax lisses; luisants : celui-ci à peine aussi large que long, rétréci en avant. Elytres et abdomen finement et assez densement ponctués. Pénultièmes articles des anternes à peine oblongs.

$\sigma^{7}$ Le $6^{\circ}$ arceau ventral sensiblement et angulairement sinué dans le milieu de son bord apical, avec un grand espace triangulaire lisse, oblong, au devant du sinus. Le $5^{\text {e }}$ souvent subangulairement subéchancré dans le milieu de son bord postérieur, avec l'espace au devant de l'échancrure plus lissé. Tarses antérieurs à 3 premiers articles fortement dilatés, le $2^{\mathrm{e}}$ un peu plus fortement.

ㅇ Le $6^{\circ}$ arceau ventral à peine arrondi, le $5^{e}$ entier, à leur bord apical. Tarses antérieurs à 3 premiers articles très-faiblement dilatés.

Staphylinus fulvipes, Fabricius, Ent. Syst. I, II, 526, 31; - Syst. El. II, 597, 40. - - Gravenhoast, Mier. 24, 33; - Mon. 75, 66. - Latreille, Hist. Nat. Crust. et Ins. IX, 314, 38. - Gyllenhal, Ins. Suec. II, 343, 59. - Mannerheim, Brach. 30, 73. - Boisduval et Lacordaire, Faun. Ent. Par. I, 402, 30. Le Staphylin noir à étuis fauves, Grofrroy, Hist. Nat. I, 365. Philonthus fulvipes, NordmanN, Symb. 102, 89.-ERICHson, Col. March. I, 473, 4 ; - Gen. et Spec. Staph. 485, 96.- Pedtenb.ıcher, Faun. Austr. 706, 37. - Heer, Faun. Col. Helv. I, 270, 46. - Fairmaire et Laboulbène, Faun. Ent. Fr. I, 528, 55. - Kraatz, Ins. Deut. II, 614, 52.- Thomson, Skand. Col. II, 166, 38. - Fauvel, Faun. Gallo-Rhên. III, 485, 60.

Variété $a$. Base des antennes et palpes d'un roux brunâtre. Pieds, surtout les postérieurs, plus ou moins rembrunis.

Philonthus varipes, NIULSANT et Rey, Ann. Soc. Linn. Lyon, 1861, viII, $120 ;-0 \Gamma$. Ent. XII, 1861, 142.

Philonthus obscuripes, Brisout, Cat. Grenier, 1863, 34, 43.

$$
\text { Long., } 0^{\mathrm{m}}, 0056 \text { (2 1/2 l.); - larg., } 0^{\mathrm{m}}, 0011 \text { (1/2 l.). }
$$

Corps allongé, subfusiforme, peu convexe, d'un noir brillant, avec les élytres d'un rouge clair; revêtu sur celles-ci €̂́ sur l'abdomen d'une fine pubescence grise et modérément serrée.

Tête ovale, moins large que le prothorax; assez fortement sétoselléc; d'un noir luisant; lisse, avec dess points épars, parfois assez nombreux, en arrière sur les côtés. Front large, subconvexe, marqué de chaque côté, cntre les yeux, de 2 pores sétifères assez forts, très-rapprochés, dont l'interne un peu plus en arrière. Cou glabre, presque lisse, d'un noir lui- 
sant. Labre d'un brun de poix, sétosellé en avant. Parties de la bouche d'un roux testacé, avec le dernier article des palpes souvent plus foncé.

Yeux assez grands, ovales-oblongs, plus ou moins obscurs.

Antennes suballongées, à peine plus longues que la tête et le prothorax réunis; à peine épaissies; légèrement pubescentes et éparsement pilosellées surtout vers leur base; obscures, avec les 3 premiers articles d'un roux testacé plus ou moins clair ; le $1^{\text {er }}$ allongé, en massue à peine arquée : les $2^{\mathrm{e}}$ el $3^{\mathrm{e}}$ obconiques : le $2^{\mathrm{e}}$ suballongé : le $3^{\mathrm{e}}$ un peu plus long : les $4^{\mathrm{e}} \mathrm{a}$ $10^{\circ}$ graduellement moins longs, subobconiques : les $4^{\circ} \dot{a} 6^{\circ}$ oblongs : les suivants suboblongs, avec les pénultièmes à peine plus longs que larges : le dernier ovale-suboblong, à peine échancré au bout et subacuminé inférieurement.

Prothorax à peine aussi large que long; plus ou moins rétréci en avant; un peu moins large en arrière que les élytres; tronqué au sommet, avec les angles antérieurs infléchis et subarrondis ; à peine arqué sur les côtés, vu de dessus; arrondi à la base ainsi qu'aux angles postérieurs; faiblement convexe ; distinctement sétosellé, avec la longue soie latérale située sur le rcbord même ; d'un noir luisant; lisse, avec 2 séries dorsales composées de 4 points médiocres, dont l'antérieur un peu plus écarté; marqué de plus, de chaque côté, outre ceux de la marge, de 4 ou 5 autres points semblables et épars. Repli d'un noir de poix, glabre, lisse.

Écusson finement ponctué, finement pubescent, noir.

Élytres subcarrées ou à peine transverses, un peu plus longues que le prothorax; un peu plus larges en arrière qu'en avant; subdéprimées; finement, assez densement et subaspèrement ponctuées ; d'un rouge vermillon assez brillant, avec une fine pubescence grise et modérément serrée ; à peine sétosellées, avec 1 soie plus longue vers l'écusson et 1 autre derrière les épaules. Celles-ci subarrondies. Ailes blanches.

Abdomen suballongé, moins large que les élytres; faiblement arqué sur les cótés et subatténué en arrière ; assez convexe sur le dos, avec les 3 premiers segments subimpressionnés en travers à leur base; assez fortement sétosellé ; finement et assez densement ponctué; d'un noir assez brillant, avec une fine pubescence grise, assez longue et modérément serrée. Le $6^{e}$ segment moins ponctué, moins pubescent, à peine arrondi au sommet.

Dessous du corps subaspèrement ponctué, finement pubescent, d'un noir brillant. Dessous de la tête presque glabre et presque lisse, avec les côtés des tempes légèrement pubescents. Lame mésosternale à arête transver-

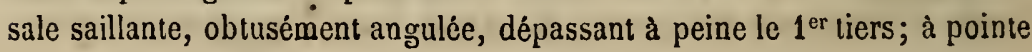


terminale aiguë, parfois subémoussée au bout. Métasternum à peine convexe sur son milieu, parfois finement et obsolètement canaliculé sur sa ligne médiane. Ventre convexe, un peu moins densement ponctué en arrière, éparsement sétosellé, avec quelques soies plus longues vers l'extrémité.

Pieds médiocres, subaspèrement pointillés, finement pubescents ; d'un roux testacé parfois assez clair, avec les hanches un peu plus obscures. Cuisses antérieures finement épineuses en dessous vers leur sommet; les postérieures un peu plus longues. Tibias antérieurs assez fortement épineux en dehors. Hanches intermédiaires plus ou moins rapprochées. Tarses postérieurs à $1^{\mathrm{er}}$ article beaucoup plus long que le dernier, subégal aux 3 suivants réunis.

Patrie. Cette espèce est assez commune, sous les pierres et les feuilles tombées, au bord des rivières, dans presque toute la France.

OBs. Elle a tout a fait la forme du micans, dont on la croirait une variété à élytres rouges. Mais les pénultièmes articles des antennes sont un peu moins oblongs, avec la base de celles-ci plus largement testacée. La ponctuation des élytres et de l'abdomen est un peu moins fine et un peu moins serrée, et le sommet de ce dernier est généralement concolore, etc.

La variété a (varipes, nobis) offre les palpes, la base des antennes et les pieds plus obscurs, ceux-ci parfois seulement en partie. Elle est particulière aux provinces méridionales et elle se rencontre aussi sur les collines de l'Auvergne et du Bourbonnais.

Peut-être doit-on appliquer au fulvipes le rubripennis de Stephens (Ill. Brit. V, 239)?

\section{5\%. Philonthus ตalinug, KiesenWeTter.}

Allongé, subfusiforme, peu convexe, finement pubescent, d'un noir brillant, avec les élytres d'un rouge clair, la bouche, le $1^{\mathrm{er}}$ article des antennes et les pieds testacés. Tête et prothorax lisses, luisants : celui-ci à peine aussi large que long, rétréci en avant. Élytres et abdomen finement et densement ponctués. Pénultièmes articles des antennes oblongs.

$\sigma$ Le $6^{\circ}$ arceau ventral sensiblement et angulairement sinué dans le milieu de son bord apical, avec un espace triangulaire lisse au devant 
du sinus. Le $5^{\circ}$ à peine et subangulairement échancré dans le milieu de son bord postérieur. Tarses antérieurs à 3 premiers articles fortement dilatés, le $2^{\mathrm{c}}$ à peine plus fortement.

o Le $6^{6}$ arceau ventral subarrondi, le $5^{\mathrm{e}}$ simple, à leur bord apical: Tarses antérieurs à 3 premiers articles presque simples ou à peine dilatés.

Philonthus sàlinus, Kiesenwetter, Stett. Ent. Zeit. 1844, 347. - RedtendaCaer, Faun. Austr. 825. - Faipmaire et Labouldène, Faun. Ent. Fr. I, 529, 56. - Kraatz, Ins. Deut. If, 613, 51.- FAUVEL, Faun. Gallo-Rhén. III, 485, 39.

$$
\text { Long., 0m,0060 (2 3/4 1.); - larg., } 0^{\mathrm{m}}, 0012 \text { (1/2 1.). }
$$

Corps allongé, subfusiforme, peu convexe, d'un. noir brillant, avec les élytres d'un rouge clair ; revêtu sur celles-ci et sur l'abdomen d'une fine pubescence grise et modérément serrée.

Tête ovale, moins large que le prothorax, distinctement sétosellée; d'un noir luisant; lisse, avec des points épars et assez nombreux en arrière et sur les côtés. Front large, subconvexe, marqué de chaque côté, entre les yeux, de 2 pores sétifères assez gros, rapprochés et transversalement disposés. Cou glabre, presque lisse, d'un noir luisant. Labre d'un noir de poix, fortement sétosellé en avant. Parties de la bouche d'un roux testacé, avec le dernier article des palpes concolore.

Yeux assez grands, ovales-oblongs, obscurs, parfois grisâtres.

Antennes allongées, grêles, un peu plus longues que la tête et le prothorax réunis; à peine épaissies; légèrement pubescentes ; éparsement pilosellées, surtout vers leur base; obscures, avec le $1^{\mathrm{er}}$ articlé- et là base du suivant d'un roux testacé : le $1^{\mathrm{er}}$ allongé, en massue à peine arquée : les $2^{\mathrm{e}}$ et $3^{\mathrm{e}}$ assez allongés, obconiques : le $3^{\mathrm{e}}$ à peine plus long que le $2^{\mathrm{e}}$ : les $4^{\mathrm{c}}$ à $10^{\mathrm{e}}$ graduellement moins longs, subobconiques : les $4^{\mathrm{e}}$ à $7^{\mathrm{e}}$ suballongés, les suivants oblongs : le dernier ovale-oblong, obliquement subtronqué au bout, obtusément.acuminé inférieurement.

Prothorax à peine aussi large que long; rétréci en avant; un peu moins. large en arrière que les élytres; tronqué au sommet, avec les angles antérieurs infléchis et subarrondis; à peine arqué sur les côtés, vu de dessus; subarrondi à la base ainsi qu'aux angles postérieurs; faiblement convexe; éparsement sétosellé, avec la longue soie latérale située sur le rebord même; d'un noir luisant, lisse, avec 2 séries dorsales composées de 6 points assez fins, dont l'antérieur un peu plus écarté ; marqué 
de plus, de chaque côté, outre ceux de la marge, de 4 ou 5 autres points semblables et épars. Repli noir, glabre, lisse.

Écusson finement pointillé, finement pubescent, noir.

Élytres subcarrées, un peu plus longues que le prothorax, un peu plus larges en arrière qu'en avant; subdéprimées ; finement, densement et subaspèrement ponctuées ; d'un rouge vermillon assez brillant, avec une fine pubescence grise et modérément serrée ; légèrement sétosellées, avcc 1 soie plus longue vers l'écusson et 1 autre derrière les épaules. Celles-ci subarrondies. Ailes blanches.

Abdomen assez allongé, moins large que les élytres, subarcuément atténué en arrière; subconvexe sur le dos, avec les 3 premiers segments subimpressionnés en travers à leur base ; fortement sétosellé; finement et densement ponctué; d'un noir assez brillant, avec le sommét souvent moins foncé, et une fine pubescence grise et modérément serrée. Le $6^{\circ} \mathrm{seg}-$ ment moins ponctué, moins pubescent, à pẹne arrondi au sommet.

Dessous du corps subàspèrement pointillé, finement pubescent, d'un noir assez brillant, avec le sommet du ventre souvent d'un brun roussâtre: Dessous de la tête presque glabre et presque lisse. Lame mésosternale à arête transversale saillante, obtusément angulée, dépassant à peine le premier tiers ; à pointe terminale plus ou moins aiguë. Métasternum à peini convexe sur son milieu, finement et obsolètement canaliculé sur sa ligne médiane. Ventre convexe, moins densement ponctué en arrière; éparsement sétosellé, avec les soies de l'extrémité plus longues.

Pieds médiocres, subaspèrement pointillés, légèrement pubescents, d'un roux testacé, avec les hanches postérieures seules, rembrunies. Cuisses antérieures finement épineuses en dessous vers leur sommet; les postérieures un peu plus allongées. Tibias antérieurs fortement épineux en dehors. Hanches intermédiaires rapprochées. Tarses postérieurs à $1^{\text {er }}$ article beaucoup plus long que le dernier, subégal aux 3 suivants réunis.

Patrie. Cette espèce, peu commune, se rencontre au bord des eaux salées, dans le Languedoc et la Provence.

OBs. Elle est facile à confondre avec le $P h$. fulvipes. Elle en est distincte par une taille un peu plus grande et par son abdomen un peu plus attérné en arrière. Les antennes, plus longues, ont leurs articles plus allongés; avec le $1^{\text {er }}$ seul, entièrement testacé. Le dernier article des palpes n'est jamais obscurci, et les hanches antérieures et intérmédiäires ne sont pas. 
plus foncées que le reste des pieds. Les élytres et l'abdomen sont un peu plus densement ponctués, etc.

\section{Philonthus rubripennis, KIESENwetTER.}

Allongé, subfusiforme, subdéprimé, finement pubescent, d'un noir brillant, avec les élytres rouges, la bouche, la base des antennes et les pieds d'un roux testacé. Tête et prothorax lisses, luisants : celui-ci oblong, subrétréci en avant, moins large que les élytres. Celles-ci finement et assez densement, abdomen très-finement et densement, ponctués.

$\sigma^{7}$ Le $6^{\circ}$ arceau ventral angulairement échancré au sommet, avec un espace triangulaire lisse au devant de l'échancrure.

ㅇ Le $6^{\circ}$ arceau ventral subarrondi au sommet.

Philonthus rubripennis, KIESENWETTER, Stett. Ent. Zeit. 1844, 846. - REDTENBACher, Faun. Austr. 825. - Fairmaire et Laboulbène, Faun. Ent. Fr. I. 529, 57. Krastz, Ins. Deut. II, 612, 50. - Fauvel, Faun. Gallo-Rhén. III, 468, 36. Philonthus lividipes, Baudi, Stud. Ent. 1, 129.

$$
\text { Long., } 0^{\mathrm{m}}, 0056 \text { (2 1/2 l.); - larg., } 0^{\mathrm{m}}, 0013 \text { (1/2 1. fort). }
$$

Corps allongé, subfusiforme, subdéprimé, d'un noir brillant, avec les élytres rouges; revêtu sur celles-ci et sur l'abdomen d'une fine pubescence grise, assez longue, et assez serrée.

Tête ovale-suboblongue, moins large que le prothorax, sétosellée; d'un noir luisant; lisse, avec des points épars sur les tempes. Front large, subconvexe, subfovéolé en avant, marqué de chaque côté, entre les yeux, de 2 pores sétifères très-rapprochés et obliquement disposès, dontl'interne beaucoup moindre et situé plus en avant. Cou glabre, presque lisse, d'un noir luisant. Labre roux, fortement sétosellé en avant. Parties de la bouche d'un roux testacé, avec la base des mandibules plus foncée.

Yeux assez grands, ovales-oblongs, obscurs, parfois micacés.

Antennes suballongées, assez grêles, environ de la longueur de la tête et du prothorax réunis ; a peine épaissies ; finement duveteuses, éparsement pilosellées vers leur base; d'un roux brunâtre, avec le $1^{\text {er }}$ article d'un roux testacé; celui-ci en massue allongée : les $2^{\circ}$ et $3^{\mathrm{e}}$ assez allon- 
gés, obconiques : le $3^{\circ}$ à peine plus long que le $2^{\circ}$ : les suivants graduellement moins longs, obconiques, avec les pénultièmes non ou à peine transverses : le dernier ovalaire, obliquement subéchancré au bout et acuminé infé rieurerrent.

Prothorax oblong, graduellement rétréci en avant; sensiblement moins large en arrière que les élytres; subtronqué au sommet, avec les angles antérieurs infléchis et largement arrondis ; presque droit sur les côtés ; subarrondi à sa base ainsi qu'aux angles postérieurs; subconvexe ; éparsement sétosellé ; à longue soie latérale située tout près du rebord; d'un noir luisant, parfois à peine métallique; lisse, avec 2 séries dorsales composées de 6 points assez fins, dont les extrêmes un peu plus écartés des autres ; marqué de plus, de chaque côté, $d: 4$ points semblables et épars. Repli roux, glabre, lisse.

Écusson finement poinlillć, finement pubescent, obscur.

Élytres subcarrées, de la longueur du prothorax; graduellement sub élargies en arrière ; subdéprimées; finemınt, assez densement et subrâpeusement ponctuées; d'un rouge assez brillant ; tinement pubescentes, avec 1 soie redressée sur le còté des épaules et 1 autre vers l'écusson. Epaules subarrondies.

Abdomen peu allongé, un peu moins large à sa base que les élytres; subarcuément atténué en arrière ; subconvexe sur le dos, avec les 3 premiers segments à peine impressionnés en travers à leur base; éparsement sélosellé; très-finement et densement ponctué; d'un noir peu brillant, avec le sommet noins foncé; assez longuement et assez densament pubescent. Le $6^{\mathrm{e}}$ segment moins pubescent, plus lisse, subarrondi au sommet.

Dessous du corps aspèrement pointillé, finement pubescent, d'un noir assez brillant, avec le sommet du ventre roux. Dessous de la tête lisse, presque glabre. Ventre convexe, épar'sement sétosellé.

Pieds médiocres, aspèrement pointillés, finement pubescents, d'un roux testacé. Cuisses postérieures assez grêles. Tibias antérieurs épineux en dehors. Tarses postérieur's a $1^{\text {er }}$ article sensiblement plus long que le dernier, un peu moins long que les 3 suivants réunis.

Patrie. Celle rare espèce, particulière à l'Allemagne, se retrouve en Provence et dans la Guienne, au bord des ruisseaux, sous les détritus.

Ons. Elle diffère du micans par sa couleur, des fulvipes et salinus par son prothorax plus oblong, plus droit sur les cótés, plus étroit relativeBR. 
ment aux élytres; celles-ci sont plus courtes, plus élargies en arrière, etc. Les élytres et les pieds sont parfois d'un roux plus ou moins foncé.

Nous plaçons ici une espèce non encore signalée en France :

\section{Philonthus luxuriang, ERIChson.}

Allongé, subfusiforme, peu convexe, légèrement pubescent, d'un noir brillant, avec les élytres bleues et le dernier article des antennes testacé. Tête et prothorax lisses, luisants, submétalliques : celui-ci suboblong, subrétréci en avant, un peu moins large que les élytres. Celles-ci et l'abdomen assez finement et moderément ponctués.

$\sigma^{7}$ Le $6^{e}$ arcean ventral sensiblement sinué au sommet, avec un espace lisse au devant du sinus. Tarses antérieurs à 3 premiers articles assez fortement dilatés.

q Le $6^{\mathrm{e}}$ arceau ventral subarrondi au sommet. Tarses antérieurs à 3 premiers articles légèrement dilatés.

Philonthus luxurians, Erichson, Gen. et Spec. Staph. 491, 106.

$$
\text { Long., } 0^{\mathrm{m}}, 0066 \text { (3 l.) ; - larg., } 0^{\mathrm{m}}, 0011 \text { (1/2 l.). }
$$

Patrie. La Corse. (Collection Revelière).

OBs. Cette jolie espèce ressemble aux rufimanus, alcyoneus et suavis, dont elle se distingue par la couleur testacée du dernier article des antennes et par les séries dorsales du prothorax composées de 6 points.

VI SECTION. - Séries dorsales du prothorax de plus de 6 points.

OBs. Dans cetle section, le derrier article des palpes est variable, tantôt allongé et fusiforme, lanıôt suballongé et conico-fusiforme, néanmoins toujours plus long que le précédent. Le dernier des labiaux suit les mèmes modifications que celui des maxillaires. La lame mésosternale offre son arête transversale plus ou moins saillante; arquée ou subangulée, descendue jusqu'au tiers seulement; sı pointe est plus ou moins prolongée, parfois mousse, d'autres fois plus ou moins aciculée. Les hanches intermédiaires sont légèrement distantes, Les tarses antérieurs, plus for- 
tement dilatés chez les $\sigma^{\prime}$ que chez les $q$, sont rarement simples dans les 2 sexes. Les postérieurs ont leur $1^{\text {er }}$ article subégal au dernier, un peu moins long que les 3 suivants réunis, qui sont oblongs et subnoueux. La tête est variable, le prothorax peu ou à peine rétréci en avant.

Cette section est restreinte à un très-petit nombre d'espèces, trèsdisparates et dont voici les différences :

a Elytres noires ou d'un noir submétallique. Antennes obscures, concolores. Tarses brunatres. Taille assez grande.

b Tibias antérieurs droits. Tête à peine moins large en arrière. Antennes à peine épaissies. Prothorax assez fortement et modérément ponctué sur les côtés. Élytres noires. Tar'ses antérieurs plus ou moins dilatés. . . . . . . . . . Punctus.

bb Tibias antérieurs subarqués. Tête sensiblement rétrécie en arrière. Antennes visiblement épaissies. Prothorax fortement et éparsement ponctué sur les côtés. Élytres submétalliques. Tarses antérieurs simples. . . . . . . . . . . . pUElla (1).

aa Etytres d'un rouge vermillon, à base noire. Base des antentes et pieds d'un rouge testacé. Tibias antérieur's droits. Taille petite. . . . . . . . . . . . . . . . dimidiatipensis.

\section{Philonthus punctug, Gravenhorst.}

Allongé, péu convexe, subéparsement pubescent, d'un noir brillant, avec la bouche et les tarses brunâtres. Tête et prothorax luisants : celui-ci subcarré, subrétréci en avant, assez fortement et modéríment ponctué sur les côtés. Élytres et abdomen assez fortentent ponctués, ce dernier moins densement. Antennes à peine épaissies, à pénultièmes articles non transverses. Tibias antérieurs droits.

$\sigma^{*}$ Le $6^{\mathrm{e}}$ arceau ventral sensiblement et subangulairement sinué dans le milieu de son bord apical, avec un léger espace lisse au devant du sinus. Le $5^{\mathrm{e}}$ souvent à peine échancré dans le milieu de son bord postérieur. Tarses antérieurs à $1^{\mathrm{er}}$ article assez fortement, les $2^{\mathrm{e}}$ et $3^{\mathrm{e}}$ fortement, le $4^{\mathrm{e}}$ faiblement, dilatés. Tête à peine moins large que le prothorax.

․ Le $6^{\mathrm{e}}$ arceau ventral subarrondi, le $5^{\mathrm{e}}$ simple, à leur bord apical

(1) Le $P$. puclla parait ici paradoxal. Il a un peu le port de l'Hesperus rufipennis, mais les caractères génériques sont ceux des Philonthus. 
Tarses antérieurs à 3 premiers articles légèrement dilatés. Tèle un pcu moins large que le prothorax.

Staphylinus punctus, Gravenhorst, Micr. 20, 22; - Mon. 85, 75. - Boisduvid et Lacordaire, Faun. Ent. Par. I, 393, 14.

Staphylinus punctatus, Latreille, Hist. Nat. Crust. et Ins. IX, 309, 29.

Staphylinus multipunctatus. MaNNERHEIM, Brach. 31, 79.

Philonthus multipunctatus, NoRdmanN, Symb. 106, 95.

Philonthus punctus, Erichson, Cot. March. I, 477, 47; - Gen. et Spec. Staph. 498, 120. - Redtenbacher, Faun. Austr. 707, 40. - HeEr, Faun. Col. IIelv. I, ¿71, 51. - Fairmaire et Labouldève, Faun. Ent. Fr. I, 529, 58. - Kratu, Ins. Deut. II, 618, 59. - Tномео , Skand. Col. II, 161, 23.

Philonthus punctatus, Fauvel, Faun. Gallo-Rhén. III, 445, 10.

$$
\text { Long., } 0^{\mathrm{m}}, 0087 \text { (4l.); - larg., } 0^{\mathrm{m}}, 0011 \text { (1l.). }
$$

Corps allongé, peu convexe, d’un noir bri lant ; revêtu sur les élyıtres et l'abdomen d'une fine pubescence grise ei peu serrée.

Tête en carré subarrondi, non ou à peine moins large en arrière; dislinctement sétosellée; éparsement pubescente postérieurement, sur le vertex et sur les tempes; assez fortement et modérément ponctuée sur les côtés; d'un noir assez luisant. Front très-large, subconvexe, creusé entre les yeux, de 4 pores un peu plus gros que les points, subtransversalemenı disposés : les externes situés contre le bord interne des yeux, à soie très-longue : les intermédiaires unn peu plus écartés, à soie courte ; offrant en outre, en avant, quelques autres soies assez longues. Vertex paré, de chaque côté, d'une très-longue soie. Cou glabre, presque lisse, noir, brillant. Labre d'un noir brillant, fortement sétosellé en avant. Parties de la bouche brunâtres.

Yeux grands, ovales-oblongs, obscurs ou parfois grisâtres.

Antennes suballongées, à peine aussi longues que la lête et le prothorax réunis; subfiliformes ou à peine épaissies; légèrement pubescentes et éparsement pilosellées; obscures, avec l'articulation des premiers articles parfois roussâtre; le $1^{\text {er }}$ allongé, ell massue subarquée : les $2^{\mathrm{e}}$ et $3^{\mathrm{e}}$ obconiques : le $2^{\mathrm{e}}$ suballongé : le $3^{\mathrm{e}}$ allongé, plus long que le $2^{\circ}$ : les suivants graduellement plus courts, non contigus : les $4^{\mathrm{e}}$ à $7^{\mathrm{e}}$ suballongés ou oblongs, subcylindrico-coniques : les pénultièmes suboblongs, avec les $9^{\mathrm{e}}$ et $10^{\circ}$ cependant à peine plus longs que larges : le dernier ovaleoblong, obliquement tronqué au bout et acuminé inférieurement.

Prothorax subcarré, subrétréci en avan!; moins large en arrière que 
les élytres; tronqué au sommet, avec les angles antériours inflíchis et subarrondis; faiblement ou à peine arqué sur les côtés, vn de dessıs, avec ceux-ci, vus latéralement, largement sinués au devant des angles postérieurs, qui sont très-obtus; subarrondi à sa base; légèrement convexe; distinctement sétosellé, avec la longue soie la'érale située contre le rebord nême; d'un noir assez luisant; presque lisse ou très-finement chagriné (1), avec 2 séries dorsales un peu irrégulières, composées de 10 a 12 points assez forts, parfois géminés, avec les parties latérales couvertes de points semblables, sans ordre et modérément serrés. Repli noir, glabre, lisse.

Écusson finement chagriné, ponctué, pubescent, noir.

Élytres subtransverses, à peine plus longues que le prothorax; subdéprimées ou à peine convexes; assez fortement et densement ponctuées ; d'un noir brillant et parfois submétallique, avec une pubescence grise, bien distincte et peu serrée; à peine sétosellées, avec 1 soie plus Inngue vers l'écusson, et 1 autre sur le côté des épaules. Celles-ci étroitement arrondies. Ailes enfumées.

Abdomen suballongé, un peu moins large que les élytres; à peine arqué sur les côtés; un peıı alténué tout à fail en arrière; assez convexe sur le dos, avec les 3 premiers segments subimpressionnés en travers à leur base ; éparsement sétosellé, a vec des soies plus longues sur les côtés ; assez fortement et peu densement ponclué ; d'un noir brillant, avec une pubescence un peu plus longue et encore moins serrée que celle des élytres. Le $6^{\text {e }}$ segment à peine arrondi au sommet.

Dessous du corps subaspèrement ponctué, finement ;ubescent, d'un noir brillant. Dessous de la téte presque gìabre, très-éparsement ponctué. Lame mésosternale à arête transversale saillante, arquée, atteignant à peine le premier tiers; à pointe terminale plus ou moins prolongée, très aiguë. Métasternum à peine convexe sur son milieu, parfois obsolètement canaliculé sur sa ligne médiane. Ventre convexe, éparsement sétosellé, avec les soies de l'extrémité plus longues.

Pieds médiocres, aspèrement ponctıés; finement pubescents: noirs, avec les tarses d'un brun parfois roussâtre. Cuisses antérieures finement épineuses en dessous vers leur sommet; les postérieures plus allongées. Tioias antérieurs assez fortement épineux en dehors. Hanches intermé-

(1) La tête, le cou et le prothorax paraissent très-finement chagrinés, quand on les examine avec une forte loupe. 
diaires un peu écartées. Tarses postérieurs à $1^{\mathrm{e}^{\mathrm{r}}}$ article subégal au dernier, presque égal aux 3 suivants réunis.

Patrie. Cette espèce est assez commune, sous les détritus, dans les lieux marécageux, dans les environs de Paris et de Lyon, la Flandre, le Languedoc, la Provence, etc.

OBs. Elle est de la taille des plus grands exemplaires du Ph. ebeninus, dont elle a la tournure, mais elle est plus noire, et surtout la ponctuation du prothorax est bien différente, ainsi que celle de la tête.

\section{Philontluus puella, Nordmann.}

Allongé, peu convexe, subéparsement pubescent, d'un noir brillant, avec les élytres submétalliques, la bouche et les tarses brunâtres. Tête et prothorax luisants : celui-ci subcarré, à peine rétréci en avant, fortement et éparsement ponctué sur les côtés. Élytres et abdomen assez fortement ponctués, ce dernier un peu moins densement. Antennes sensiblement épaissies, à pénultièmes articles transverses. Tarses antérieurs simples. Tibias antérieurs subarqués.

$\sigma^{7}$ Le 6e arceau ventral sensiblement el angulairement sinué dans le milieu de son bord apical. Tête transverse, plus large que le prothorax.

ㄴ Le $6^{\ominus}$ arceau ventral subarrondi à son bord apical. Tête suborbiculaire, à peine aussi large que le prothorax.

Staphylinus punctus, Gyllenaal, Ins. Suec. II, 346, 62.- MANnERaeia, Brach. 31, 78.

Philonthus punctus, Noromann, Symb. 106, $\Omega 4$.

Philonthus puella, Nordman, Symb. 101, 87. - Erichson, Col. March. I, 472, 89;

- Gen. et Spec. Staph. 493, 10. - KraAtz, Ihs. Deut. II, 620, 60. - Thomson,

Skand. Col. II, 162, 24. - Fauver, Faun. Gallo-Iítén. III, 446, 11.

Philonthus parumpunctatus, Eurchson, Gen. et Spec. Staph. 499, 121.- Farmalre et Labourbène, Faun. Ent. Fr. I, 529, 59.

$$
\text { Long., } 0^{\mathrm{m}}, 0075 \text { (3 1/2 1.); - larg., } 0^{\mathrm{m}}, 0019 \text { (4/5 l.). }
$$

Corps allongé, peu convexe, d'un noir brillant, avec les élytres submétalliques; revêtu sur celles-ci et sur l'abdomen d'une finepubescence grise et peu serrée. 
Tête plus ou moins grande, sensiblement rétrécie en arrière, distinctement sétasellée; pubescente sur les tempes; fortement et grossièrernent ponctuée (1) sur les côtés; d'un noir luisant. Front très-large, subconvexe, creusé entre les yeux de 4 pores à peine plus gros que les points : les externes un peu écartés du bord interne des yeux, à soie très-longue : les internes non ou à peine plus distants, situés plus en arrière, à soie plus courte (2). Vertex paré de chaque côté d'une très-longue soie: Cou glabre, obsolètement pointillé sur les côtés, d'un noir brillant. Labre d'un noir brillant, fortement sétosellé en avant. Parties de la bouche brunâ

Yeux assez grands, subovales, obscurs, lavés de gris, séparés du prothorax par un intervalle très-grand.

Antennes peu allongées, plus courtes que la tête et le prothorax réunis ; sensiblement épaissies ; légèrement pubescentes et éparsement pilosellées, surtout vers leur base; noires; à ${ }^{\mathrm{er}}$ article allongé, en inassue subarquée : les $2^{\mathrm{e}}$ el $3^{\mathrm{e}}$ suballongés, obconiques : le $3^{\mathrm{e}}$ à peine plus long que le $2^{\mathrm{e}}$ : les suivants graduellement plus courts, subobconiques : lé $4^{\mathrm{e}}$ suboblong :

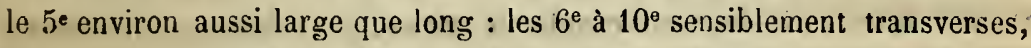
avec les pénultièmes un peu plus fortement : le dernier ovalaire, subéchancré au bout, obtusément acuminé inférieurement.

Prothorax subcarré, à peine rétréci en avant; un peu moins targe en arrière que les élytres; tronqué au sommet, avec les angles antérieurs infléchis et arrondis; à peine arqué sur les côtés, vu de dessus, avec cenx-ci, vus latéralement, subsinués au devant des angles postérieurs, qui sont-très-obius; subarrondi à sa bıse; faiblement convexe; éparsement sétosellé, avec la longue soie latérale située sur le rebord même; d'un noir luisant; presque lisse, avec 2 séries dorsales un peu irrégulières, composées de 8 forts points, les antérieurs et postérieurs souvent géminés, et les parties latérales couvertes de points semblables, épars ou disposés par groupes. Repli d'un brun roussâtre, glabre, lisse.

Écusson pointillé, pubescent, noir.

Élytres transverses, de la longneur du prothorax ou à peine plus longues; subdéprimées; assez fortement, densement et subrâpeusement poncluécs ; d'un noir brillant et submétallique, avec une pubescence grise, peu ou modérément serrée; éparsement sétosellées, avec 1 soie plus

(1) Cette ponctuation est éparse et parfois $\left(\sigma^{*}\right)$ disposée par groupes.

(2) Le devant du front est quelquefois faiblement impressionné sur son milieu, avec quelques petits points obsolètes. 
longue vers l'écusson et 1 autre derrière les épaules. Celles-ci étroitement arrondies.

Abdomen peu allongé, moins large que les élytres; à peine arqué sur les côtés et un peu atténué tout à fait en arrière; subconvexe sur le dos, avec les 3 premiers segments subimpressionnés en travers à leur base ; éparsement sétosellé, avec les soies des côtés beaucoup plus longues; un peu moins fortement ponctué que les élytres, avec la ponctuation un peu moins serrée en arrière; d'un noir assez brillant; à pubescence assez longue et peu serrée. Le $6^{\mathrm{e}}$ segment subtronqué ou à peine arrondi au sommet.

Dessous $d u$ corps aspèrement ponctué, finement pubescent, d'un noir brillant, avec le $6^{\mathrm{e}}$ arceau ventral et le sommet du précédent souvent d'un roux de poix. Dessous de la téte presque glabre, éparsement pointillé à sa base, avec les tempes pubescentes sur les côtés. Lame mésosternale à arête transversale saillante, fortement arquée, située vers le tiers antérieur; à pointe terminale plus ou moins prolongée, souvent subaciculée, relevée, rugueuse et pubescente vers son sommet. Métasternum à peine convexe sur son milieu, très-finement canaliculé sur sa ligne médiane. Ventre convexe, éparsement sétosellé, à soies de l'extrémité plus longues.

Pieds médiocres, aspèrement ponctués, finement pubescents, noirs, avec les tarses souvent brunâtres. Cuisses antérieures assez fortement épineuses en dessous vers leur sommet; les postérieures suballongées. Tibias antérieurs subarqués, fortement épineux en dehors. Hanches intermédiaires légèrement écartées. Tarses postérieur's à $1^{\text {er }}$ article aussi long ou à peine plus long que le dernier, un peu plus court que les 3 suivants réunis; les antérieurs simples dans les 2 sexes.

Patrie. Cette espèce se trouve, en automne, dans les bouses, au mont Pilat et dans les Hautes-Pyrénées.

Oss. Elle est un peu moins allongée que le Ph. punctus, avec les élytres plus courtes et plus métalliques. La tête est plus grosse, plus rétrécie en arrière. La ponctuation des côtés de celle-ci et du prothorax est plus forte et moins serrée. Les antennes, moins allongées, sont plus épaissies, avec leurs pénultièmes articles transverses. Les tibias antérieurs sont plus $\left(\sigma^{\circ}\right)$ ou moins ( $q$ ) arqués, avec leurs tarses simples dans les 2 sexes, etc.

Les Watsoni et minax de Stephens (Ill. Brit. 240 et 241) sont peut-être synonymes du puella? 
61. Philonthus dimidiatipennis, ERICHSON.

Allongé, sublinéaire, peu convexe, légèrement pubescent, d'un noir luisant, avec les deux tiers postérieur's des elytres d'un rouge vermillon, la bouche, la base des antennes et les pieds d'un roux testacé. T'éte et prothorax luisants : celui-ci suboblong, à peine rétréci en avant, très-éparsement ponctué sur les côtés. Elytres assez fortement et assez densement, abdomen finement et densement, ponctués. Tibias antirieurs droits.

$\sigma^{7}$ Le $6^{\mathrm{e}}$ arceau ventral sensiblem $\div$ nt et subangulairement échancré dans le milieu de son bord apical, avec l'échancrure bordée d'une légère membrane pellucide. Tarses antérieurs à 3 preniers articles fortement dilatés, le $2^{e}$ un peu plus fortement.

으 $6^{\mathrm{e}}$ arceau ventral subarrondi à son hord apical. Tar'ses antérieurs à 3 premiers articles assez fortement dilatés.

Philonthus dimidiatipennis, Erichson, Gen. et Spec. Staph. 500, 123. - Fairmaire et Laboulbène, Faun. Ent. Fr. I, 530, 60.- KraAtz, Ins. Deut. II, 621, 60-61.JacQuelin Dis Val, Gen. Col. Eur. Staph. pl. 14, fig. 69.- Fauver, Faun. GalloRhén. III, 464, 31.

$$
\text { Long., } 0^{\mathrm{m}}, 0060 \text { (2 2/3 1.); - larg., } 0^{\mathrm{m}}, 0010 \text { (1/2 l.). }
$$

Corps allongé, sublinéaire, peu convexe, d'un noir brillant, avec les élytres parées d'une grande tache d'un rouge vermillon, occupant environ leurs deux tiers. postérieurs; revêtı sur celles-là et sur l'abdomen d'une fine pubescence grise et peu serrée.

Tête subovale, à peine moins large que le prothorax ; éparsement sétosellée ; pubescente sur les tempes; assez fortement et modérément ponctuée sur les côlés; d'un noir luisant. Front large, faiblement convexe, marqué entre les yeux de 4 pores sétifères à peine plus gros que les points : les externes situés contre le bord interne des yeux, à soie très-longue : les intermédiaires plus écartés entre eux, à peine plus en arrière, à soie plus courte. Vertex paré de chaque côté d'un pore à soie très-Iongue. Cou glabre, obsolètement pointillé sur les côtés, d'un noir brillant. Labre d'un noir brillant, sétosellé en avant. Parties de la bouche d'un roux testacé, avec le sommet des mandibules et des palpes souvent plus foncé. 
Yeux médiocres, subovales, obscurs ou grisâtres.

Antennes peu allongées, à peine anssi longues que la tête et le prothorax réunis; faiblement épaissies ; légèrement pubescentes et éparsement pilosellées vers leur base; obscures, avec les 2 ou 3 premiers articles d'un roux testacé; le $1^{\mathrm{er}}$ allongé, en massue subarquée : les $2^{\mathrm{e}}$ et $3^{\mathrm{c}}$ suballongés, obconiques : le $3^{\mathrm{e}}$ à peine plus long que le $2^{\mathrm{e}}$ : les suivants graduellement un peu plus courts, subobconiques : les $4^{\mathrm{e}}$ à $6^{\mathrm{e}}$ suboblongs : les $7^{\mathrm{e}} \mathrm{a} 10^{\circ}$ à peine aussi larges que longs, avec les pénultièmes $(q)$ paraissant parfois subtransverses, vus de côté : le dernier ovalaire, subéchancré au bout, subacuminé inférieurement.

Prothorax suboblong, à peine rétréci en avant; un peu moins large en arrière que les élytres; tronqué au sommet, avec les angles antérieurs infléchis et subarrondis; subparallèle ou à peine arqué sur les côtés, vu de dessus; subarrondi à sa base ainsi qu'aux angles postérieurs ; faiblement convexe; éparsement sétosellé, avec la longue soie latérale située contre le rebord même; d'un noir luisant; presque lisse, avec 2 séries dorsales un peu irrégulières, composées de 6 à 8 points assez fins, dont l'antérieur plus écarté et les postérieurs souvent géminés, et les parties latérales couvertes de 6 ou 7 points semblables ét épars. Repli brunâtre, glabre, lissé.

Écusson pointillé, pubescent, noir.

Élytres en carré à peine oblong; un peu plus longues que le prothorax; subdéprimées; assez fortement et assez densement ponctuées; d'un rouge vermillon brillant, avec le tiers basilaire noir, cette dernière couleur descendant un peu sur les côtés et souvent prolongée sur la suture jusque près du sommet; parsemées d'une fine pubescence grise; ćpar=ement ciliées à leur bord apical; à peine sétosellées, avec 1 longue soie vers l'écusson et 1 autre derrière les épaules. Celles-ci arrondies. Ailes blanches.

Abdomen suballongé: moins large que les élytres; subparallèle ou a peine arqué sur les côtés; subconvexe sur le dos, avec les 3 premiers segments étroitement impressionnés en travers à leur base; éparsement sétosellé, avec les soies des côtés plus longues; plus finement et plus densement ponctué que les élytres; d'un noir assez brillant, avec une fine pubescence grise et modérément serrée. Le $6^{\mathrm{e}}$ segment moins ponctué, moins pubescent, subarrondi au sommet.

Dessous $d u$ corps aspèrement pointillé, finement pubescent, d'un noir assez brillant, avec le sommet du ventri souvent brunâtre. Dessous de la 
têle presure glabre, éparsement ponctué. Lame mésosternale presque lisse, à arête transversale assez fine, subangulée, ne dépassant pas le $1^{\text {er }}$ tiers; à pointe terminale tès-aiguë, assez, prolongée, acérée. Métasternum à peine convexe sur son milieu, finement canaliculé sur sa ligne médiane. Ventre convexe, éparsement sétosellé, avec quelques soies plus longues ver's le sommet.

Pieds suballongés, pointillés, finement pubescents, d'un roux testacé, avec les hanches postérieures plus foncées. Cuisses antérieures finement épineuses en dessous vers leur sommet; les postérieures un peu plus longues. Tibias antérieurs droits, peu ou éparsement épineux en dehors. Hanches intermédiaires plus ou moins rapprochées. Tarses postérieurs à $1^{\text {er }}$ article subégal au dernier, un pen moins long que les 3 suivants réunis.

Patrie. Cette espèce se prend sur tout le littoral de la, Méditerranée, sous les détritus et sous les pierres.

OBs. Sa taille et sa couleur la distinguent suffisamment des espèces précédentes, auxquelles elle ressemble peu. Elle a plutôt la tournure du fulvipes.

La tache basilaire noire des élytres, rarement très-restreinte, s'étend au moins jusqu'au premier liers, quelquefois jusqu'à la moitiè et même, dans ce dernier cas, la partie rouge est parfois nébuleuse.

\section{Genre Rabigus, Rabige, Mulsant et Rey. \\ Étymologie : anagramme de Gabrius.}

Caractères. Corps allongé, subatténué en avant, subconvexe, ailé, finement pubescent.

Tête assez grande, saillante, subovale, un peu moins large que le prothorax, portée sur un col court et assez étroit. Tempes non rebordées sur les côtés. Existome subtronqué au sommet. Labre court, subbilobé. Mandibules assez saillantes, subfalciformes, acérées, dentées vers le milieu de leur côté interne, croisées au repos. Palpes maxillaires assez développés, a $1^{\text {er }}$ article court : les $2^{\mathrm{e}}$ et $3^{\mathrm{e}}$ assez épais, obconiques, subégaux : le dernier exactement conique, à peine aussi long que le précédent. Palpes labiıux petits, à $1^{\mathrm{er}}$ article assez court : le $2^{\mathrm{e}}$ épais, obconique : le dernier presque conique, à peine plus long el presque aussi épais que le 
2e. Menton grand, trapéziforme, rétréci et submembraneux en avant, Ironqué au sommet.

Yeux petits ou médiocres, subarrondis ou subovales, séparés du cou par un intervalle un peu plus grand que leur diamètre.

Antennes suballongées, un peu épaissies, à $1^{\text {er }}$ article allongé, en massue : les $2^{e}$ et $3^{\circ}$ suballongés, obconiques, subégaux : les suivants graduellement un peu plus courts, subcontigus, avec les pénultièmes subtransverses ou transverses : le dernier courtement ovalaire, subéchancré au bout.

Prothorax suboblong, subparallèle, moins large que les élytres; paré sur le dos de 2 séries de 6 points ; tronqué au sommet; à angles antérieurs non saillants; arrondi à sa base; très-finement rebordé sur celle-ci et sụr les côtés (1); à rebord latéral subsinueusement infléchi d'arrière en avant. Repli assez étroit, incliné, visible vu de côté, sans opercule prothoracique.

Écusson grand, triangulaire.

Elytres subtransverses, environ de la longueur du prothorax; à peine et simultanément échancrées à leur bord apical; subarrondies à leur angle postéro-externe; ̀̀ peine rebordées sur la suture. Repli étroit, médiocrement infléchi. Épaules peu saillatites.

Prosternum peu développé au devant des hanches antérieures, offrant entre celles-ci un angle à disque gibleux, à sommet très-ouvert, obtus et émoussé. Mésosternum à lame médiane triangulaire, traversée vers son $\mathbf{1}^{\text {er }}$ tiers par une arête subarquée, saillante; à sommet aigu, à peine prolongé jusqu'à la moitié des hanches intermédiaires. Médiépisternums grands, séparés du mésosternum par une très-fine suture transversale et subarquée. Médiépimères allongées, assez étroites. Métasternum court, fortement échancré au devant de; hanches postéricures ; prolongé entre celles-ci en un lobe assez saillant, corné, explané, incisé dans son milieu ; avancé entre les intermédiaires en angle très-ouvert, à peine prononcé et subarrondi. Postépisternums étroits, divergeant un peu en arrière du repli des élytres. Postépimères médiocres on assez grandes, triangulaires.

Abdomen assezez allongé, subatténué tout à fait en arrière; fortement rebordé sur les côtés; à 4 premiers se rements subégaux ou graduellement à peine plus longs, et le $5^{\mathrm{e}}$ un peu plus grand : le $6^{\mathrm{e}}$ assez saillant, rétractile : celui de l'armure enfuui, émetlant souvent 2 lanières étroites. Ventre

(1) La longue soie des côtés est placée contre le rebord latéral même. 
à arceaux subégaux, le $5^{\mathrm{e}}$ parfois à princ plus grand : le $6^{\mathrm{e}}$ assez saillant, rélractile.

Hanches antérieures grandes, environ de la longuear des cuisses, trèssaillantes, contiguës au sommet. Les intermédiaires un peu moindres, conico subovales, peu saillantes, rapprochées. Les postérieures médiocres, peu saillantes, faiblement écarlées à leur base, divergentes au sommet, en cône court et mousse; à lame supérienre étranglée vers son $1^{\mathrm{e} r}$ tiers; à lame inférieure nulle ou enfouic.

Pieds médiocres, peí robustes. Trochanters antérieurs petits, cunéiformes; les intermédiaires et postérieurs un peu plus grands, subcunéiformes. Cuisses subcomprimées, atténuées vers leur extrémité; les postérientes plus longues, plus grêles, sublinéaires; les antérieures à peine ou non spinosules en dessous vers leur sommet. Tibias subélargis de la base à l'extrérnité, éparsement épineux, munis au bout de leur tranche inférieure de 2 éperons grêles, l'interne un peu plus long; les antéricurs plus courts, à peine épineux en dehors. Tarses antérieurs courts, à 3 premiers articles subdéprimés, fortement $(\sigma)$ ou légèrement ( $q$ ), mais subgraduellement un peu moins dilatés, et le $4^{\mathrm{e}}$ simplement triangulaire. Les intermédiaires et postérieurs plus ou moins allongés, subatténués vers leur extrénité, à $1^{\text {er }}$ article allongé, presque 2 fois aussi long que le dernier, subégal aux 3 suivants réunis : ceux-ci oblongs, graduellement moins longs : le dernier assez grêle, sublinéaire ou à peine on massue, un peu moins long que les 2 précédents réunis. Ongles petits, très-grèles, à peine arqués.

Oвs. I.cs espèces de ce genre, assez agiles, vivent dans les lieux humides, parmi les détritus.

Cetle coupe générique, que nons avons cru devoir créer aux dépens du genre Philonthus, se distingue aisément de celui-ci par la structure des palpes, surtout des maxillaires, dont le dernier article, exactement conique, est à peine aussi long que le précédent. Le dernier article des palpes labiaux est à peine plus long que le 2 e.

La présence des ailes sous les élytres, qui sont bien moins courtes, sépare suffisanment les Rabigus du genre Gefyrobius.

Deux espèces, à forme homogène mais à couleur différente, rentrent dans notre genre Rabigus. En voici les distinctions :

a Corps noir, avec le prothorax et les élytres rouges : cclles-ci rembrunies à leur base. Yeux petits, subarrondis. . . . . . . . . . . Tenuis. ad Corps noir, avec les élylres submétailiques. Ycux médiocres, subovales. rullcts. 


\section{Rabigus tennis, Fabriclus.}

Allongé, subconvexe, finement pubescent, d'un noir brillant, avec la base des antennes et les pieds roux, le prothorax et les élytres d'un rouge clair, et celles-ci rembrunies à leur base. Élytres finement et assez densement pointillées, $\dot{a}$ peine aussi longues que le prothorax: celui-ci suboblong, subparallèle. Abdomen finement et densement pointillé.

$\sigma$ Le 6 e arceau ventral sensiblement et angulairement sinué dans le milieu de son bord apical, avec un espace Iriangulaire, allongé, lisse, au devant du sinus. Les 3 premiers articles des tarses antérieurs fortement dilatés.

ㄴ Le $6^{\mathbf{e}}$ arceau ventral simple. Les 3 premiers articles des tarses antérieurs très-légèrement dilatés.

Staphylinus tenuis, Fabricius, Ent. Syst. I, II, 528, 43 ; - Syst. El. II, 599, 53.

- Gravenhorst, Micr. 59,58 ; - Mon. 72, 59. - Latreille, Hist. Nat. Crust. et Ins. IX, 322, 63.- Bolsduval et Lacordaire, Faun. Ent. Par. I, 403, 32. Paederus, dinidiatus, Panzer, Faun. Germ. 27, 24; - Ent. Germ. 362, 3. Philonthus tenuis, Nordmann, Symb. 103, 91.- Ericuson, Col. Narch. I, 474, 42 ; - Gen. et Spec. Staph. 488, 101. - Redtenbacher, Faun. Austr. 706, 36. Heer, Faun. Col. Helv. I, 270, 46. - Fairmaire et Laboulbève, Faun. Ent. Fr. I, 528, 54. - KraAtz, Ins. Deut. II, 617, 58. - Faurel, Faun. Gallo-Rhén. III, $477,48$.

Philonthus gracilis, Letzner, Arb. Ver. Ges. 1846, 78.

Variété $a$. Élytres presque entièrement enfumées.

$$
\text { Long., } 0^{\mathrm{m}}, 0052 \text { (2 1/3 l.); - larg., } 0^{\mathrm{m}}, 0007 \text { (1/3 l.). }
$$

Corps allongé, subconvexe, d'un noir brillant, avec le prothorax et les élytres d'un rouge clair et celles-ci plus ou moins rembrunies à la base, recouvert sur ces dernières et sur l'abdomen d'une fine pubescence grise et assez serrée.

Tête subovale, subrétrécie en arrière, un peu moins large que le prothorax ; éparsement sélosellée; d'un noir brillant; lisse sur son disque, mais finement et subéparsemคnt ponctuée en arrière sur le vertex et sur les tempes. Front très-large, subconvexe, marqué en avant de 4 pores subtransversalement disposés : les externes sétifères, situés contre le 
bord interne des yelı : les intermédiaires beaucoup plus écartés entre eux, beaucoup plus tins, à soie plus courte et souvent caduque. Cou lisse, glabre, d'un noir brillant. Labre noir. Mandibules et palpes d'un brun de poix, parfois un peu roussâtres à leur base.

Yeux petits, subarrondis, obscurs ou grisâtres.

Antennes suballengées, un peu plus courtes que la tête et le prothorax réunis ; visiblement subépaissies ; éparミement pilosellées vers leur base; noires, avec le $1^{\text {er }}$ article roux, et le $2^{e}$ parfois d'un roux de poix à sa base; le $1^{\text {er }}$ allongé, épaissi en massue : les $2^{\mathrm{e}}$ et $3^{\mathrm{c}}$ suballongés, obconiques, subégaux: les suivauts graduellement un peu plus courts et un peu plus épais : le $4^{\mathrm{e}}$ subcarré : le $5^{\mathrm{e}}$ à peine, les $6^{\mathrm{e}}$ à $10^{\mathrm{e}}$ légèrement transverses, vus de cóté, avec les pénultièmés plus sensiblement : le dernier courtement ovalaire, subtronqué ou subéchancré au bout et acuminé inférieurement.

Prothorax suboblong, subparallèle, plus étroit que les élytres; tronqué au sommet, avec les angles antérieurs infléchis et subarrondis; presque droit sur les cótés; arrondi à la base ainsi qu'aux angles postérieurs; convexe; éparsement sétosellé, avec la longue soie des côtés située sur la marge même; d'un rouge clair et très-brillant; lisse, avec 2 séries dorsales compiosées de 6 points assez fins, dont celui du sommet un peu plus écarté ; marqué de plus, sur les côtés, outre ceux de la marge (1), de 5 autres points semblables, épars et distants. Repli roux, lisse, glabre.

Écusson pointillé, pubescent, d'un noir de poix brillant.

Élytres subtransverses, à peine aussi longues que le prothorax; subdéprimées ou à peine convexes; finement, subaspèrement et assez densement pointillées; d'un rouge clair et assez brillant, avec la base plus ou moins largement rembrunie; finement et modérément pubescentes, avec 1 longue soie obscure et redressée sur les épaules et 1 autre semblable de chaque côté de l'écusson. Épaules étroitement arrondies.

Abdomen suballongé, à peine moins large à sa base que les élytres; subarqué sur les côtés et subatténué tout à fait en arrière; assez fortement convexe sur le dos ; éparsement sétosellé; finement et densement pointillé; d'un noir assez brillant; à pubescence un peu plus longue et un peu plus serréc que celle des élytres. Le $6^{\text {e }}$ segment nooins pubescent, moins ponctué, à peine arrondi au sommet.

Dessous du corps densement pointillé, finement pubescent, d'un noir

(1) Les points de la marge ne sont point situés sur le rebord latéral mème. 
assı $\mathrm{z}$ brillant, a vec l'antépecius et le médipectus d'un roux testacé. Dessous de la tête glabre, presque lisse ou à peine ponctué. Métasternum subdéprimé sur son milieu. Ventre convexe, à peine sétosellé.

Pieds médiocres, finement pointillés, très-finement pubescents, d'un roux parfois assez obscur, avec les hanches, cuisses el trochanters antérieurs et intermédiaires toujours plus pâles. Cuisses postérieures allongées, sublinéaires. Tar'ses postérieur's à peine moins longs que les tibins, à $1^{\text {er }}$ article notablement plus long que le dernier.

Patrie. Cette espèce se prend sous le: piarres el sous les détritus, en Alsace, dans le Dauphiné, dans la Gaienne, les Pyrénées, etc. Elle n'est pas rare aux environ; de Lyon, dans les îles du Rhône.

OBs. Quelquefois la base du $2^{c}$ ar.icle des antennes est plus ou moins rons:âtre, mais très-rarement l'article entier est de celle couleur. La partic rembrunie des élytres, sonvent élendue jusqu'à la moitié de leur longu'ur, envahit parfois presque toute leur surface, moins 1; bord apical qui reste un peu roussâtre.

\section{Rbabigus pullus, Nordiann.}

Allongi, subconvexi, finement pubescent, d'un noir brillant, avec les élytres subinétalliques. Celles-ci assez finement et assez densement ponctuées, de la longueur du prothorax: celui-ci suboblong, subparallèle. Abdomein finement el assez densement pointillé.

6" Le $6^{\circ}$ arceau ventral sensiblement et angulairement sinué dans le milieu de son bord apical, avec un espace triangulaire, assez allongé, lisse, au devant du sinus. Les 3 premiers articles des tarses antérieurs fortement dilalés.

\& Le $6^{\mathrm{e}}$ arceau ventral simple. Les 3 premiers articles des tarses antérieurs lègèrement dilatés.

Philouthus pullus, Nordyann, Symb. 104, 92.- Erichson, Col. March, I, 475, 43; - Gen. et Spec. Staph., 488, 102. - Redrenbacher, Faun. Austr. 705, 35. Ileer, Faun. Col. Helv. I, 583, 48. - Fairahike et Laboulbène, Faun. Ent. Fr. I, 527, 49. - KradTz, Ins. Deut. II, 617, 57. - Fauvel, Faun. Gallo-Rhén. III, $477,47$.

$$
\text { Long., } 0^{\mathrm{m}}, 0052 \text { (2. 1/3 l.); - lnrg., } 0^{\mathrm{m}}, 0007 \text { (1/3 l.). }
$$


Corps allongé, subconvexe, d'un noir brillant, avec les élytres un peu métalliques; recouvert sur celles-ci et sur l'abdomen d'une fine pubescence grise et médiocrement serrée.

Téte subovale, 'rétrécie en arrière, un peu moins large que le prothorax; éparsement et longuement sélosellée, d'un noir brillant; lisse sur son disque mais finement et modérément ponctuee en arrière et sur les tempes. Front très-large, subconvexe, paré en avant de 4 pores sétiferes transversalement disposés : les externes situés tout près du bord interne des yeux. les intermédiaires beaucoup plus écartés entre eux, beaucoup plus fins Cou lisse, glabre, d'un noir brillant. Labre noir. Ilandibules et palpes d'un noir de poix.

Yeux médiocres, subovales, plus ou moins obscurs.

Antennes suballongées, à peine plus courtes que la tête et le prothorax réunis; subépaissies; légèrement pilosellées vers leur base; entièrement noires; à $1^{\text {er }}$ aricle allongé, épaissi en massue : les $2^{\mathrm{e}}$ et $3^{\mathrm{e}}$ suballongés, obconiques, subégaux : les suivants graduellement un pen plus courts et un peu plus épais : les $4^{\mathrm{e}}$ et $5^{\mathrm{c}}$ presque carrís : les $6^{\circ}$ et $7^{\mathrm{e}}$ à peine, les $8^{\mathrm{e}}$ à $10^{\mathrm{e}}$ plus sensiblement transverses: le dernier courtentent ovalaire, subéchancré au bout et subacuminé inférieurement.

Prothorax suboblong, subparallèle, plus étroit que les élytres; tronqué au sommet, avec les angles antérieurs infléchis et arrondis; presque droit sur les côtés; arrondi à sa base, ainsi qu'aux angles postérieurs; convexe; éparsement sétosellé, avec la longue soie des côtés située sur le rebord latéral même; d'un noir brillant; lisse, avec 2 séries dorsales composées de 6 points assez fins, celui du sommet un peu plus écarté; marqué de plus, vers les côtés, outre ceux de la marge, de $\mathbf{5}$ autres points semblables, épars et distants. Repli noir, lisse, glabre.

Écusson finement pointillé, finement pubescent, d'un noir brillant.

Élytres subtransverses, de la longueur du prothorax; subdéprimées ou à peine convexes; assez finement et assez densement ponctuées; d'un noir assez brillant et un peu bronzé; finement et modérément pubescentes, avec 1 longue soie obscure et redressée sur les épaules et 1 autre scublable de chaque côté de la base de l'écusson. Épaules subarrondie s.

Abdomen asscz allongê, un peu moins large à sa base que les élytres; à peine arqué sur les côtés et subatténué tout à fait en arrière; assez fortement convexe sur 1 : dos; fortenent et longuement sétosellé ; finement et assez denscment pointillé; d'un soir brillant, avic une fine pubescence 
assez longue et médiocrement serrée. Le $6^{\text {e }}$ segment moins pubescent, moins ponctué, subarrondi au sommet.

Dessous du corps finement ponctué, finement pubescent, d'un noir brillant. Dessous de la tête presque glabre, presque lisse ơ avec quelques rares points épars. IIétasternum subdéprimé sur son milieu. Ventre convexe, non sétosellé ou avec 1 seule soie de chaque côté des derniers arceaux.

Pieds médiocres, densement pointillés, finement pubescents; noirs ou d'un noir de poix. Cuisses postérieures allongées, sublinéaires. Tarses postérieurs à peine moins longs que les tibias, à $1^{\mathrm{er}}$ article notablement plus long que le dernier.

Patrie. Cette espèce est assez commune, sous les détritus, dans les environs de Lyon. Elle se prend aussi dans ceux de Paris, la Normandie, le Maine, l'Alsace, la Lorraine, le Beaujolais, les Alpes, la Guienne, etc.

OBs. On la prendrait pour une variété noire de l'espèce précédeute, tant elle en a la tournure. Mais outre la coloration, les yeux sont un peu plus grands et moins arrondis; les élytres, un peu moins courtes, sont un peu moins finement ponctuées. La ponctuation de l'abdomen est un peu moins serrée, et ce dernier, surtout, est beaucoup plus fortement sétosellé sur le dos, etc.

Quelquefois les pieds sont brunâtres.

Il est à noter que les 2 espèces de ce genre ont la tête subrétrécie en arrière, et les élytres parées sur les côtés d'une seule soie située sur les épaules (1).

Le pullus de Runde (Brach. Hal. 9) semble plutôt se rapporter au micans.

Genre Gefyrobius, GÉFrrobie, Thomson.

Tномson, Skand. Col. II, 166, 1860.

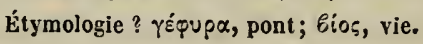

Caractéres. Corps allongé, subatténué en avant, subconvexe, aptère, à peine pubescent.

(1) Quant à celle des côtés de l'écusson, ello se remarque aussi, quoique moins visiblement, dans d'autres genres. 
Tête assez grande, saillante, subovale, moins large que le prothorax, portée sur un col court et assez étroit. Tempes non rebordées sur les côtés. Épistome tronqué au sommet. Labre court, bilobé. Mandibules assez saillantes, subfalciformes, acérées, dentées vers le milieu de leur côté interne, croisées au repos. Palpes maxillaires assez développés, à $1^{\text {er }}$ article court : les $2^{\mathrm{e}}$ et $3^{\mathrm{e}}$ obconiques : le $3^{\mathrm{e}}$ un peu plus court que le $2^{\mathrm{e}}$ : le dernier à peine plus long que le précédent, elliptico-conique. Palpes labiaux courts, à $1^{\text {er }}$ article grêle, le $2^{\mathrm{e}}$ court, assez épais : le $3^{\mathrm{e}}$ plus long mais non plus grêle que le $2 \mathrm{e}$, elliptico-r:onique. Menton grand, trapéziforme, rétréci et submembraneux en avant, subtronqué au sommet.

Yeux petits, subovales, subdéprimés, séparés du cou par un intervalle plus long que leur plus grand diamètre.

Antennes assez courtes, subépaissies; à $1^{\mathrm{er}}$ article allongé en massue : les $2^{\circ}$ et $3^{\circ}$ oblongs, obconiques : les $4^{\mathrm{e}}$ à $10^{\mathrm{e}}$ graduellement un peu plus épais, plus ou moins transverses, subcontigus : le dernier courtement ovalaire, subtronqué au bout.

Prothorax suboblong, subrétréci en avant, presque aussi large en arrière que les élytres ; paré sur le dos de 2 séries de 4 points ; tronqué au sommet; à angles antérieurs non saillants; arrondi à sa base; à peine rebordé sur celle-ci, plus visiblement sur les côtés (1) ; à rebord latéral subsinueusement infléchi d'arrière en avant. Repli assez étroit, incliné, visible en avant vu de côté, sans opercule prothoracique.

Écusson médiocre, triangulaire.

Élytres transverses, beaucoup plus courtes que-le prothorax; sensiblement et simultanément échancrées à leur bord apical; arrondies à leur angle postéro-externe; à peine rebordées sur la suture. Repli étroit, médiocrement infléchi. Épaules effacées.

Prosternum un peu développé au devant des hanches antérieures; offrant entre celles-ci un angle à disque relevé en forme de fatte, à sommet obtus et émoussé. Mésosternum à lame médiane triangulaire, traversée après son premier tiers par une arête arquée, saillante; à sommet rétréci en pointe subémoussée et prolongée environ jusqu'à la moitié des hanches intermédiaires. Médiépisternums grands, séparés du mésosternum par une fine suture transversale. Médiépimères étroites, sublinéaires. Métasternum très-court, échancré au devant des hanches postérieures, prolongées entre celles-ci en un petit lobe, explané et incisé; avancé entre les intermé-

(1) La longue soie des côtés est située sur le rebord latéral même. 
diaires en angle très-ouvert ou à peine senti. Postépisternums étroits, divergeant en arrière du repli des élytres. Postépimères assez grandes, triangulaires.

Abdomen peu allongé, assez large, subarqué sur les côtés ; fortement rebordé latéralement; à $2^{\mathrm{e}}$ segment basilaire découvert: les suivants subégaux, le $5^{\mathrm{e}}$ plus grand : le $6^{\mathrm{e}}$ saillant, rétractile : celui de l'armure enfoui. Ventre à 4 premiers arceaux subégaux, le $5^{\mathrm{c}}$ plus grand : le $6^{\mathrm{e}}$ assez saillant, rétractile.

Hanches antérieures très-grandes, de la longueur des cuisses, trèssaillantes, coniques, contiguës au sommet. Les intermédiaires grandes, subovales, peu saillantes, rapprochées dans leur milieu. Les postérieures peu développées, peu saillantes, rapprochées à leur base, divergentes au sommet, en cône court et mousse; à lame supérieure subétranglée vels son premier tiers et gibbeuse sur celui-ci; à lame inférieure nulle ou enfouie.

Pieds assez courts, peu robustes. Trochanter's antérieurs petits, cunéiformes; les intermédiaires et postérieurs un peu plus grands, subcunéiformes. Cuisses subcomprimées, atténuées vers lcur extrémité ; les antérieures finementspinosules en dessous vers celle-ci. Tibias subélargis de la base au sommet, plus ou moins épineux, munis au bout de leur tranche inférieure de 2 éperons grêles, dont l'interne plus long; les antérieurs plus courts et un peu plus robustes. Tu'ses antérieurs assez courts, simples dans les 2 sexes; les intermédiaires et postérieurs un peu plus longs, à peine atténués vers leur extrénité, à $1^{\mathrm{er}}$ article allongé, un peu plus long que le dernier, un peu moins long que les 3 suivants réunis : ceux-ci oblongs, graduellement plus courts : le dernier en massue grêle, subégal aux 3 précédents réunis. Ongles très-petits, grêles, arqués.

OBs. La petite espèce qui sert de base à ce genre est médiocrement agile. Elle vit dans les lieux humides.

Cette coupe générique est remarquable par l'absence d'ailes sous les élytres, avec celles-ci proportionnellement beaucoup plus courtes que dans la plupart des Philonthates. Le métasternum est très-peu développé, les antennes et les pieds sont peu allongés, l'abdomen est assez large, etc.

Les tarses postérieurs sont moins longs que dans le genre Rabigus, avec leur $1^{\text {er }}$ article moins allongé et seulement un peu plus long que le dernier. Les tarses antérieurs sont simples dans les 2 sexes. Les élytres sont plus courtes, sans ailes en dessous, etc. 


\section{Gefyrobins mitidulus, Gravenhorst.}

Allongé, subconvexe, aptère, éparsement pubescent, d'un noir trèsbrillant, avec la bouche et les antennes d'un roux de poix, et les pieds d'un roux testacé. Élytres fortement et subéparsement ponctuées, beaucoup plus courtes que le prothorax: celui-ci suboblong, subrétréci en avant. Abdomen assez large, finement et subéparsement pointillé.

$\sigma^{*}$ Le $6^{\circ}$ arceau ventral subsinueusement et subangułairement échancré au sommet.

ㅇ Le $6^{\mathrm{e}}$ arceau ventral subarrondi au sommet.

Staphylinus nitidulus, Gravenhorst. Micr. 27, 37; - Mon. 69, 31. - Latrellue, Hist. Nat. Crust. et Ins. IX, 315, 42. - Gyllenhal, Ins. Suec. II, 330, 46. MaNnerheim, Brach. 29, 60.

Staphylinus denigrator, Gravenhorst, Mon. 92, 88.

Philonthus denigrator, Nordsans, Symb. 85, 44 .

Philonthus nitidulus, Nordmann, Symb. 85, 43.- Ericuson, Col. March. I, 458, 18;

- Gen. et Spec. Staph. 450, 36. - Redtrngacher, Faun. Austr. 702, 20. - Heer,

Faun. Col. Helv. 262, 19. - Fairmaire et LaboulbÈne, Faun. Ent. Fr. I, 520, 25.

- KraAtz, Irs. Deut. II, 589, 23. -Fauvel, Faun. Gallo-Rhén. III, 475, 45.

Gefyrobius nitidulus, Thомson, Skand. Col. II, 167, 1.- Rye, Ent. Ann. 1864, 83.

$$
\text { Long., } 0^{\mathrm{m}}, 0044 \text { (2 l.); - larg., } 0^{\mathrm{m}}, 0006 \text { (1/4 l. fort). }
$$

Corps allongé, subconvexe, aptère, d'un noir très-brillant; revêtu sur les élytres d'une fine pubescence grisâtre et peu serrée.

Tète subovale, $\mathbf{s}$ nsiblement moins large que le prothor:x ; éparsement sćtosellée; d'un noir très-brillant, lisse, avec quelques rares points derrière les yeux. Front très-large, subconvexe, offiant en avant 4 pores sétifères assez forts, transversalement disposés, les intermédiaires un peu plus écartés, les externes situés contre le bord interne même des yeux. Cou lisse, glabre, d'un noir très-brillant. Labre noir, avec les autres parties de la bouche d'un roux de poix parfois assez foncé.

Yeux subovales, noirs.

Antennes assez courtes, moins longues que la tête et le prothorax réunis; subépaissies; légèrement pilosellées vers leur base; d'un roux plus ou moins foncé; à $1^{\mathrm{e}_{\mathrm{r}}}$ article allongé, renflé en massue $:$ les $2^{\mathrm{e}}$ et 
$3^{\circ}$ oblongs, obconiques : le $3^{\text {e }}$ a peine aussi long que le $2^{\circ}$ : les suivants graduellement à peine plus épais : le $4^{\mathrm{e}}$ presque carré, le $5^{\mathrm{e}}$ à peine transverse : les $6^{\circ}$ à $10^{\circ}$ subobconiques, sensiblement transverses : le dernier courtement ovalaire, subtronqué au bout et subacuminé inférieurement.

Prothorax suboblong, subrétréci en avant; presque aussi large en arrière que les élytres; tronqué au sommet, avec les angles antérieur's infléchis et arrondis; faiblement arqué sur les côtés ; arrondi à sa base ainsi qu'aux angles postérieurs ; assez fortement convexe; légèrement sétosellé, avec la longue soie des côtés située sur le rebord latéral même; d'un noir très-brillant; lisse, avec 2 séries dorsales composées de 4 points médiocres et assez distants ; marqué de plus, outre ceux de la marge, de 5 points semblables, épars dans l'ouverture des angles antérieurs. Repli noir, lisse, glabre.

Écusson obsolètement pointillé, légèrement pubescent, d'un noir brillanit.

$\dot{E} l y t r e s$ transverses, beaucoup plus courtes que le prothorax ; subélargies en arrière ; légèr ement convexes ; fortement et subéparsement poncruées; d'un noir de poix très-brillant; éparsement pubescentes, avec quelques légères soies redressées sur les côtés, dont 1 plus longue près des'épaules. Celles-ci effacées.

Abdomen peu allongé, aussi large à sa base que les élytres ; arcuément subélargi dans son milieu; convexe sur le dos; éparsement sétosellé; finement et subéparsement pointillé; d'un noir brillant, avec une très-fine pubescence grisâtre, un peu plus scrrée que celle des élytres. Le $6^{\mathrm{e}} \mathrm{seg}$ ment à peine pubescent, plus lisse, subarrondi au sommet.

Dessous du corps légèrement pointillé; finement et légèrement pubescent; d'un noir brillant, avec le sommet du ventre souvent d'un roux de poix. Dessous de la tête lisse, presque glabre. Métasternum très-court, à peine convexe ou subdéprimé. Ventre convexe, éparsement sétosellé.

Pieds assez courts, légèrement pointillés, légèrement pubescents, d'un roux testacé, avec les hanches postérieures un $\eta^{\wedge}$ u plus foncées; celles-ci gibbeuses et lisses à leur base. Tarses antérieurs simples.

Patrie. Celte espèce est rare en France : l'Alsace, les montagnes lyonnaises, les Alpes, etc. Elle se prend sous les pierres, au bord des ruisseaux.

OBs. Elle ressemble à un peti Quedius. Elle est remarquable par la brièveté et la forte ponctuation de ses élytres, et par l'absence d'ailes 
dessous celles-ci, ce que nous n'avons observé dans aucun autre Philonthate.

Bien que Leach ait considéré cette espèce comme le type de son genre Gabris, Thomson a cru devoir l'en détacher pour ea créer son genre Gefyrobius.

\section{Genre Gabrius. GABRIE, Leach. \\ LaAch in Stephens, III. Brit. Ent. V, p. 249. \\ Étymologie : nom propre.}

Caractères. Corps allongé, subdéprimé ou peu convexe, ailé, peu pubescent.

Tête assez grande, saillante, subovale ou. oblongue, portée sur un col court et assez étroit. Tempes non rebordées sur les cotés. Épistome tronqué au sommet, à marge antérieure subcornée. Labre très-court, subincisé dans son milieu, subbilobé. Mandibules saillantes, subfalciformes, acérées, angulairement dilatées ou dentées vers le milieu de leur côté interne, croisées au repos. Palpes maxillaires assez développés, à $1^{\mathrm{er}}$ article bien distinct, assez court: le $2^{\mathrm{c}}$ oblong, subarqué, assez fortement épaissi : le $3^{\mathrm{e}}$ plus court, obconique : le dernier presque 2 fois aussi long que le $3^{\mathrm{e}}$, en cône subfusiforme (1) et plus ou moins aminci ou acuminé vers son extrémité. Palpes labianx courts, a $1^{\text {er }}$ article oblong, grêle : le $2^{\mathrm{e}}$ aussi long mais plus épais, obconique : le $3^{\mathrm{e}}$ un peu plus long, mais sensiblement plus grêle que le $2^{\mathrm{e}}$, plus ou moins subulé. Menton grand, transverse, rétréci et submembraneux en avant, subtronqué : au sommet.

Yeux médiocres ou assez petits, subovalts ou subarrondis, peu saillants, séparés du cou par un intervalle plus long que leur plus grand diamètre.

Antennes suballongées, parfois assez courtes; subépaissies, à $1^{\text {or }}$ article allongé, en massue : les $2^{\circ}$ et $3^{\circ}$ obconiques : le $3^{\circ}$ souvent plus long : les $4^{\mathrm{e}} \mathrm{a} 10^{\mathrm{e}}$ graduellement un peu plus courts, non ou peu contigus, avec les pénultièmes non ou rarement transverses : le dernier subovalaire, tronqué ou subéchancré au bout.

(1) C'est-à-dire en cône plus ou moins brusquement rétréci à sa base, où il es moins large que le sommet du précédent. 
Prothorax oblong ou suboblong, subparallèle, parfois subrétréci en avant, moins large que les élytres, tronqué au sommet, à angles antérieurs non saillants ; arrondi à sa base ; très-finement rebordé sur celle-ci et sur les côtés; à rebord llatéral subsinueusement infléchi d'arrière en avant. Repli assez étroit, incliné, visible vu de côté, sans opercule prothoracique.

Écusson grand, triangulaire ou subogival.

Élytres subcarrées, à peine simultanément échancrées à leur bord apical ; à peine arrondies à leur angle postéro-externe; finement rebordées sur la suture. Repli assez étroit, médiocrement infléchi. Épaules peu saillantes.

Prosternum peu développé au devant des hanches antérieures, offrant entre celles-ci un triangle à disque gibbeux ou en forme de faîte, à sommet droit ou subobtus, parfois subémoussé. Mésosternum à lame médiane triangulaire, à sommet aigu, parfois subémoussé, à peine prolongé jusqu'au milieu des hanches intermédiaires; à arête transversale assez saillante, arquée uu à peine angulée, située après le premier tiers. Médiépisternums grands, séparés du mésosternum par une suture suboblique et subarquée. Médiépimères étroites, allongées, parfois sublinéaires. Métasternum assez court, assez fortement échancré au devant des hanches postérieures ; prolongé entre celles-ci en un lobe plus ou moins saillant, explané, incisé, corné ou subcorné; non ou à peine avancé entre les intermédiaires, et séparé de l'intermède par une sulure droite ou subarquée en avant. Postépisternums étroits ou très-étroits, parfois sublinéaires. Postépimères petites, triangulaires ou en onglet.

Abdomen suballongé, subatténué en arrière, fortement rebordé sur les cóiés; à 4 premiers segments subégaux, le $5^{\ominus}$ un peu plus grand : les 2 premiers parfois subimpressionnés en travers sur le milieu de leur base: le $6^{\circ}$ plus ou moins saillant, rétractile : celui de l'armure caché, émettant 2 ou 3 lanières. Ventre à 4 premiers arceaux subégaux, le $5^{\circ}$ parfois un peu plus grand : le $6^{\ominus}$ plus ou moins saillant, rétractile.

Hanches antérieures très-grandes, de la longueur des cuisses, trèssaillantes, coniques, contiguës au sommet. Les intermédiaires moindres, peu saillantes, conico-subovales, rapprochées ou légèrement distantes. Les postérieures assez petites, peu saillantes, rapprochées à leur base, divergentes au sommet, en cône court et mousse; à lame supérieure subétranglée vers son premier tiers; à lame inférieure nulle ou enfouie.

Pieds médiocres, peu robustes. Trochanters antérieurs petits. Cuisses 
plus ou moins comprimées, subatténuées vers leur extrémité, parfois élargies vers leur milien; distinctement épineuses en dessous vers leur sommet interne, au moins les artérieures. Tibias subélargis de la base au sommet, plus ou moins fortement épineux, munis au bout de leur tranche inférieure de 2 éperons grêles, dont l'interne plus long; les antérieurs plus courts. Tarses antérieurs courts, simples dans les 2 sexes ; les intermédiaires et postérieurssuballongés subatténués vers leur extrémité, à $1^{\text {er }}$ article subégal au dernier, subégal aux 2 suivants réunis : les $2^{\circ}$ à $4^{\circ}$ oblongs ou suboblongs, graduellement plus courts : le dernier grêle, en massue. Ongles petits, grêles, arqués.

OBs. Les espèces de ce genre sont petites ou assez petites et agiles. Elles vivent parmi les détritus, les mousses, les champignons desséchés et les feuilles mortes.

Les pores sétifères, situés entre les yeux, sont rapprochés, deux ensemble, sur les cótés du front. Le prothorax offre sur le dos 2 séries composées de 5 ou 6 points enfoncès, avec la longue soie latérale placée tout orès du rebord ou conıre le rebord lui même.

Cette coupe générique se remarque par la structure des palpes labiaux, dont le dernicr article est sensiblement plus grêle que le précédent et subsubulé. L'angle postéro-externe des élytres, vues de dessus, paraît à peire arrondi ou presque droil (1).

Elle répond à un assez pelit nombre d'espêces, dont voici l'analyse :

a Séries dorsales du prothorax de 5 points.

b Antennes assez longues, à $3 \mathrm{e}$ article suballongé, un peu plus long que le $2 \mathrm{e}$, les penultièmes à peine transverses. Prothorax subrétréci en avant. Antennes obscures, à base testacée. Taille moyenne.

c Elytres d'un noir de poix, un peu plus courtes que le prothorax: celui-ci suboblong. Ventre à extrémité seule d'un roux de poix. vernalis. cc Élytres bronzées, de la longueur du prothorax : celui-ci oblong.

Ventre à intersections largement testacées.

d Tête subovalaire. . . . . . . . . . . . . . tibralss.

dd Tête oblongue. . . . . . . . . . . . . . . Pisciformis.

bb Antennes assez courtes, à $3^{\ominus}$ article oblong, subégal au 2e, les pénultièmes visiblement transverses.

e Prothorax oblong, à peine rétréci en arrière. Antennes assez

(1) Cet effet provient de ce que les cotés du bord apical sont obliquement ou méme subsinueusement coupés vers les angles postéro-externes. 
épaisses, rousses, à base testacée. Prothorax et élytres d'un noir de poix. Taille petite. . . . . . . . . . .

ee Prothorax suboblong, rétréci en arrière. Antennes assez grèles, d'un roux brunâtre, à base testacée. Prothorax brun, élytres d'un testacé de poix. Taille très-petite. . . . . . . aa Séries dorsales du prothorax de 6 points. Antennes assez longues, à $2^{\mathrm{e}}$ et $3^{\mathrm{e}}$ articles suballongés.

f Pruthorax suboblong, subrétréci en avant. Le dernier article des palpes maxillaires peu acuminé. Taille assez petite. . . .

ff Prothorax oblong, subparallèle ou à peine rétréci en arrière. Le dernier article des palpes maxillaires fortement acuminé.

g Tête subovale, non ou à peine moins large que le prothorax : celui-ci un peu plus court que les élytres.

h Le $3^{\circ}$ article des antennes visiblement plus long que le $2^{\mathrm{e}}$, le $4^{\mathrm{e}}$ oblong, les $5^{\mathrm{e}}$ et $6^{\mathrm{e}}$ suboblongs. Elytres densement ponctuées. Taille assez petite. . . . . . . . . Asturus.

hh Le $3^{\mathrm{e}}$ article des antennes subégal au $2^{\mathrm{e}}$, le $4 \mathrm{e}$ suboblong, le 5e subcarré, le $6^{\text {e }}$ subtransverse. Elytres peu densement ponctuées. Taille petite. . . . . . . . . . Nigritulus.

gg Tete suboblongue, sensiblement moins large que le protharax : celui-ci un peu plus long que les élytres. Le $3 \mathrm{e}$ article des antennes à peine plus long que le $2 \mathrm{e}$, le $4^{\mathrm{e}}$ suboblong, les $5^{\mathrm{e}}$ et $6^{\text {e }}$ subcarrés. Elytres assez fortement et peu densement ponctuées. Taille assez petite. . . . . . . . . . LATicollis.

a. Séries dorsales du prothorax de 5 points.

\section{Crabrius vernalis, Gravenhorst.}

Allongé, peu convexe, finement pubescent, d'un noir de poix brillant, avec la bouche, la base des antennes et les pieds testacés. Élytres assex fortement et densement ponctuées, un peu plus courtes que le prothorax : celui-ci suboblong, subrétreici en avant. Abdomen finement pointillé.

$\sigma$ Le $6^{\text {e }}$ arceau ventral profondément et aigument entaillé au sommet, avec les lobes latéraux prolongés et subnembraneux.

ㅇ Le $6^{\circ}$ arceau ventral arrondi au sommet.

Staphylinus vernalis, Gravenhorst, Mon. 75, 67.- Gyllenhal, Ins. Suec. II, 332, 48. - Mannerieim, Brach. 29, 62.- Boisduval et Lacordaire, Faun. Ent. Par. I, $404,36$.

Philonthus vernalis, Nordmans, Symb. 93, 59. Erichson, Col. March. I, 470, 35;

- Gen. et Spec. Staph. 478, 83. - Redtenbacher, Faun. Austr. 705, 33. - 
Heer, Faun. Col. Helv. I, 263, 37. - Faramare et Laboulbène, Faun. Ent. Fr. I, 523, 33. - Kratiz, Ins. Deut. II, 606, 41. - Fauver, Faun. Gallo-Rhén. III, 487,62 .

Gubrius vernalis, Thomson, Skand. Col. II, 170, 1, 1860.

$$
\text { Long., } 0^{\mathrm{m}}, 0058 \text { (2 2/3 l.); - larg., } 0^{\mathrm{m}}, 00075 \text { (1/3 l.). }
$$

Corps allongé, peu convexe, d'un noir de poix brillant; revêtu sur les élytres et l'abdomen d'une fine pubescence grise.

Tête ovale-oblongue, un peu moins large que le prothorax ; éparsement sétosellée; d'un noir très-brillant; lisse, avec quelques points enfoncés, épars, derrière les yeux. Front très-large, à peine convexe, offirant de chaque côté, entre les yeux, 2 pores sétifères rapprochés et obliquement disposés. Cou glabre, lisse, d'un noir très-brillant. Parties de la bouche testacées.

Yeux obscurs, à facettes micacées.

Antennes plus courtes que la tête et le prothorax réunis; subépaissies; pilosellées vers leur base; noires, avec leur $1^{\text {er }}$ article testacé : le $1^{\text {er }}$ allongé, en massue : les $2^{\mathrm{e}}$ et $3^{\mathrm{e}}$ oblongs, obconiques : le $3^{\mathrm{e}}$ un pèu plus long que le $2^{\mathrm{e}}$ : les suivants graduellement un peu plus courts et plus épais, avec lez pénultièmes a peine transverses : le dernier subovalaire, subéchancré au bout et subacuminé inférieurement.

Prothorax suboblong, presque aussi large que les élytres; subrétréci en avant; tronqué au sommet, avec les angles antérieurs infléchis et subarrondis ; faiblement arqué sur les côtés; médiocrement arrondi à sa base, avec les angles postérieurs obtus et subarrondis ; modérément convexe; éparsement sétosellé ; d'un noir de poix très-brillant; lisse, avec 2 séries dorsales composées de 5 points assez fins et assez distants, les 2 postérieurs plus rapprochés ; marqué de plus, sur les côtés, outre les points du rebord latéral, de $\mathbf{5}$ autres points semblables. Repli noir, glabre, lisse.

Écusson pointillé, pubescent, d'un noir de poix brillant.

Élytres un peu plus courtes que le prothorax; subdéprimées ou peu convexrs; assez densement et assez fortement ponctuées; d'un noir de poix brillant, avec une assez fine pubescence grise, 1 fine soie redressée sur le côté des épaules, et 1 autre vers l'écusson. Épaules subarrondies.

Abdomen suballongé, un peu moins large à sa base que les élytres; subatténué en arrière; subconvexe sur le dos ; éparsement sétosellé ; assez densement et finement pointillé; d'un noir assez brillant et subirisé, avec 
une fine pubescence grise et assez serrée. Le $6^{\mathbf{e}}$ segment moins pubescent, moins ponctué, subarrondi au sommet.

Dessous du corps finement ponclué, finement pubescent; d'un noir brillant. Dessous de la tête presque lisse. Métasternum subconvexe. Ventre convexe, éparsement sétosellé, souvent d'un roux de poix à son extrémité.

Pieds médiocres, légèrement ponctués, finement pubescents, testacés, ainsi que les hanches antérieures et intermédiaires, et les postérieures à peine plus foncées. Tarses antérieur's simples dans les 2 sexes.

Patrie. Cette espèce se trouve sous les pierres et les feuilles mortes. Elle est assez rare, et elle se rencontre sur divers points de la France: les environs de Paris, la Normandie, l'Alsace, li Savoie, etc.

On lui rapporte le suaveolens Steph. (Ill. Brit. V, 429), le femoralis Kochh (Bull. Mosc. 1851, III, 19), et le flavipes Motsch (Bull. Mosc. 1860, II, 567).

OBs. Le plus souvent, les élytres sont moins foncées que la tête et le prothorax. La ponctuation de l'abdomen est généralement plus fine et plus serrée à la base et sur les côtés des segments, surtout des preiniers.

Quelquefois les antennes sont ferrugineuses vers leur sommet.

\section{Gabrius tibialis, Mulsant et Rey.}

Allonge, peu convexe, éparsement pubescent, d'un noir brillant avec les élytres bronzées, la bouche, la base des antennes, le sommet de l'abdomen et la marge postérieure de chaque arceau ventral d'un roux testacé, et les pieds d'un roux ferrugineux, avec les cuisses pâles. Élytres àssez fortement et densement ponctuées, de la longueur du prothorax : celui-ci oblony, a peine rétréci en avant. Abdomen finement et modérément ponctué.

$\sigma^{*}$ Le $6^{\mathrm{e}}$ arcenu ventral légèrement et angulairement échancré à son sommet, avec l'échancrure bordée d'une membrane très-étroite. Le $5^{\mathrm{e}}$ à peine sinué dans le milieu de son bord apical.

q Le $6^{\mathrm{e}}$ arceau ventral arrondi au sommet. Le $5^{\mathrm{e}}$ simple.

$$
\text { Long., } 0^{\mathrm{m}}, 00 \dot{0}\left(2 \mathrm{2} / 4 \mathrm{l} \text { ) ; - lars., } 0^{\mathrm{m}}, 00075\right. \text { (1/3 l.). }
$$

Corps allongé, peu convexe, d'un noir brillant, avec les élytres bronzées; 
revêtu sur celles-ci et sur l'abdomen d'une fine pubescence grise et peu serrée.

Têle subovale, subrétrécie en arrière; un peu ou à peine moins large que le prothorax ; distinctement sétosellée; d'un noir brillant et submétallique ; lisse, avec quelques points épars derrière les yeux. Front trèslarge, à peine convexe, avec les 4 pores sétifères, situés entre les yeux, rapprochés 2 à 2 sur les côtés, l'interne plus petit et plus en avant. Cou glabre, lisse, d'un noir brillant. Labre et autres parties de la bouche d'un roux testacé.

Yeux obscurs oul grisâtres.

Antennes suballongées, un peu plus courtes que la iête et le prothor ax réunis ; subépaissies; légèrement pilosellées vers leur base; obscures, avec le $1^{\text {er }}$ article d'un roux testacé, ainsi que la base des deux suivants; le $1^{\mathrm{er}}$ allongé, en massue subarquée : les $2^{\mathrm{e}}$ et $3^{\mathrm{e}}$ obconiques : le $3^{\mathrm{e}}$ un peu ou à peine plus long que le $2^{\mathrm{e}}$ : les $4^{\mathrm{e}}$ à $10^{\mathrm{e}}$ graduellement un peu plus courts : les $4^{\mathrm{e}} \grave{a} 6^{\mathrm{e}}$ suboblongs : le $7^{\mathrm{e}}$ non, les $8^{\mathrm{e}} \grave{\mathrm{a}} 10^{\mathrm{e}}$ à peine transver'ses, vus de côté : le dernier courtement ovalaire, tronqué au bout . et acuminé inférieuremenı.

Prothorax obiong, un peu moins large que les élytres; à peine atténué en avant, tronqué au sommet, avec les angles antérieurs subinfléchis et arrondis ; subparallèle ou à peine arqué sur les côtés ; arrondi à sa base, avec les angles postérieurs obtus et subarrondis; subconvexe; distinctement sétosellé ; d'un noir brillant et submétallique; lisse, avec 2 séries dorsales composées de 5 points assez fins, dont les 3 postérieurs un peu moins écartés ; marqué de plus, en avant, sur les côtés, de 4 autres points semblables (1), outre ceux du rebord latéral, avec la longue soie situéc tout près dudit rebord. Repli brunâtre, presque lisse, glabre.

Écusson pointillé, pubescent, d'un noir bronzé.

Élytres subcarrées, un peı plus larges en arrière, de la longueur du prothorax; subdéprimées; assez fortement et denscment ponctuées; d'un bronzé assez clair et brillant, avec une fine pubescence grise, assez longue et peu serrée, et quelque soies redressées sur les côtés, dont 1 notamment plus longue, vers les épaules. Celles-ci subarrondies.

Abdomen suballongé, un peu moins large à sa base que les élytres; subatténué en arrière; subconvexe sur le dos; distinctement sétosellé; finement et modérément ponctué; d'un noir brillant, avec le sommet

(1) Ces 4 points sont disposés en losange. 
d'un roux testacé, et le bord apical de chaque segment d'un roux de poix ; recouvert d'une fine pubescence grise, assez longue, un peu plus serrée que celle des élytres. Le $6^{\mathrm{e}}$ segment moins ponctué, moins pubescent, obtusément tronqué au sommet.

Dessous du corps finement et subaspèrement ponctué, finement pubescent, avec l'antépectus et le médipectus d'un roux de poix, le dessous des angles antérieurs du prothorax et la marge postérieure de chaque arceau ventral d'un roux testacé, celle des deux derniers plus largement. Dessous de la tête glabre, lisse. Métasternum à peine convexe. Ventre assez convexe, éparsement sétosellé.

Pieds médiocres, finement ponctués, finement pubescents ; d'un roux ferrugineux, avec les hanches postérieures plus foncées et les cuisses pâles. Tarses antérieurs simples.

Patrie. Cette espèce est très-rare. Elle a été trouvée, au premier printemps, aux environs de Fréjus et dans le Languedoc, parmi les détritus marécageux.

OBs. Elle diffère du G. vernalis par la teinte bronzée des élytres qui sont moins courtes, par la bordure testacée des segments de l'abdomen et des arceaux du ventre, par son prothorax plus oblong, par ses cuisses d'une couleur plus pâle, par la forme de l'incision du $6^{\mathrm{e}}$ segment de l'abdomen des $\sigma$, etc.

On la prendrait pour une variété immature du Philonthus fimetarius ; mais les palpes sont autrement conformés, les pénultièmes articles des antelınes à peine plus courts; le prothorax est plus oblong, avec les points des séries plus petits et au nombre de 5 , etc.

Les articles intermédiaires des antennes sont moins courts que chez le Philonthus ventralis, avec la tête et le prothorax plus oblongs, etc.

Les tarses postérieurs sont assez grêles, avec les $2^{\mathrm{e}}$ à $4^{\mathrm{e}}$ articles suballongés ou oblongs.

Nous plaçons ici, avec doute, l'espèce suivante que nous n'avons pas vue en nature.

3. Gabrius pisciformis, Fauvel.

Philonthus pisciformis, FAUVEL, Faun. Gallo-Rhén. III, 468, 37.

Long., 5 1/2 millim. 
PAtrie. Entraigues (Var).

OBs. Cette espèce, qui nous semble une variété immature de notre tibialis, en différerait par sa tête plus oblongue, par ses antennes un peu plus courtes et à pénultièmes articles plus transverses.

Près de là vient une espèce qui n’a point été rencontrée dans la France continentale :

\section{Gabriug badius, Kiesenwetter.}

Allongé, peu convexe, éparsement pubescent, d'un noir très-brillant, avec les élytres à peine bronzées, la bouche et les pieds d'un roux de poix. Élytres fortement et éparsement ponctuées, un peu plus longues que le prothorax : celui-ci oblong. subparallèle. Abdomen assez finement et éparsement ponctué.

$\sigma^{\circ}$ Le $6^{\circ}$ arceau ventral assez largement et angulairement échancré, avec les lobes latéraux finement pointillés et densement ciliés (1).

$\subsetneq$ Le $6^{\mathrm{e}}$ arceau ventral un peu prolongé, arrondi et finement cilié au sommet.

Philonthus badius, Kiesenwwetter, Berl. Ent. Zeit. 1858, 61. - Fauver, Faun. Gallo-Rhén. III, 468 (note).

Philonthus insularis, GaUtier, Mitth. Schw. Ent. Ges. 1868, II, 326. - Marseul, l'Abeille, 1869-1870, VII, 205.

$$
\text { Long., } 0^{\mathrm{m}}, 0055 \text { (2 1/2 l.); - larg., } 0^{\mathrm{m}}, 0007 \text { (1/3 l.). }
$$

Patrie. Porto-Vecchio, Omessa, Caporalino, en Corse (collection Revelière).

OBs. Cette espèce se distingue des précédentes par la ponctuation de ses élytres plus forte et plus éparse. La teinte générale est plus brillante, submétallique sur la tête, le prothorax et les élytres. Les distinctions du $\sigma^{\star}$ sont remarquables par la ciliation des lobes latéraux de l'échancrure.

Le sommet du ventre est souvent d'un roux testacé.

(1) Parfois le $6^{\circ}$ arceau est lisse et subimpressionné au devant de l'échancrure: 


\section{Gabrius splendidulus, Gravenhorst.}

Allongé, sublinéaire, subdéprimé, éparsement pubescent, d'un noir de poix brillant, avec les intersections de l'abdomen et les antennes rousses, la base de celles-ci, la bouche et les pieds testacés. Élytres assez finement et peu densement ponctuées, de la longueur du prothorax: celui-ci oblong, subrétréci en arrière. Abdomen finement et modérément ponctué.

$\sigma^{*}$ Le $6^{\text {e }}$ arceau ventral largement sinué au sommet.

q Le $6^{\mathrm{e}}$ arceau ventral subarrondi au sommet.

Staphylinus splendidulus, Gravennorst, Micr. 41,60 ; - Mon. 93, 89. - Latreille, Hist. Nat. Crust. et Ins. IX, 327, 73. - Gyleenhal, I:Is. Suec. II, 343, 64. Cafus splendidulus, ManNerireim, Brach. 32, 3.

Gyrohypnus splendidulus, Norduann. Symb. 126, 30.

Staphylinus nanus, Gravenhorst, Mon. 96, 93.-Gyllenilıl, Ins. Suec. II, 347, 63. Cafius nanus, ManNerheim, Brach. 32, 2.

Gyrophypnus nanus, Nordman,, Symb. 126, 29.

Staphylinus parvulus, Graveniorst, Jicr. 42, 63 ; - IIon. 95, 91.

Philonthus splendidulus, Enichson, Col. March. I, 470, 36 ; - Gen. et Spec.

Staph. 478, 84.- Redtenbacher, Faun. Austr. 70j, 3. - Heer, Faun. Col. Helv. I, 269, 41. - Fairmaire, et Laboulbène, Faun. Ent. Fr. I, 522, 30. - Kradtz, Ins. Deut. II, 608, 43.- Fauvel, Faun. Gallo-Rhén. III, 465, 33.

Gabrius splendidulus, Thомson, Skand. Col. II, 170, 2.

Variété $a$ (immature). Prothorax et élytres d'un roux de poix. Sommet de l'abdomen largenent testacé, avec la marge postérieure de chaque segment largement d'un roux testacé.

Philonthus analis, HeEr, Faun. Col. Helv. I, 268, 38.

$$
\text { Long., } 0^{\mathrm{m}}, 0052 \text { (2 1/3 l.); - larg., } 0^{\mathrm{m}}, 0005 \text { (1/4 1.). }
$$

Corps allongé, sublinéaire, subdéprimé, d'un noir de poix brillant; revêtu sur les élytres et l'abdomen d'une fine pubescence grise et peu serrée.

Tête subovale, à peine moins large que le prothorax ; éparsement sétosellée; d'un noir de poix bri.lant; lisse, avec quelques puints épars sur les còtés, vers les tempes. Front très-lurge, à peine convexe, subimpressionné ou subsillonnẻ sur son milıeil entre lés yeux, avec les pores séti- 
fères, situés entre ceux-ci, transversalement disposés, les externes plus rapprochés entre eux. Cou en bourrelet, glabre, lisse, d'un noir brillant. Labre et autres parties de la bouche testacés.

Yeux obscurs.

Antennes assez courtes, beaucoup moins longues que la tête et le prothorax réunis; assez épaisses presque dès leur base; légèrement pirosellées vers celle-ci ; rousses, avec les 3 premiers articles plus clairs, le $1^{\text {er }}$ allongé, en massue subarquée : les $2^{\mathrm{e}}$ et $3^{\mathrm{e}}$ oblongs, obconiques, subégaux : les suivants graduellement un peu plus courts et à peine plus épais : les $4^{\mathrm{e}}$ et $5^{\mathrm{e}}$ presque carrés ou à peine plus larges que longs : les $6^{\mathrm{e}}$ a $10^{\mathrm{e}}$ subobconiques, sensiblement transverses : le dernier courtement subovalaire, à peine échancré au bout et subacuminé inférieurement.

Prothorax oblong, subrétréci en arrière où il est un peu moins large que les élytres; tronqué au sommet., avec les angles antérieurs infléchis et arrondis; presque droit ou à peine arqué sur les côtés; arrondi à sa base ainsi qu'aux angles postérieurs; légèrement convexe; éparsement sétosellé, avec la longue soie des côtés située contre le rebord même; d'un noir de poix brillant; lisse, avec 2 séries dorsales composées de 5 points assez fins, assez distants ; marqué de plus, en avant sur les côtés, dé 5 autres points semblables et épars, outre ceux du rebord latéral. Repli d'un roux de poix, lisse, glabre.

Écusson à peine pointillé, à peine pubescent, d'un noir de poix brillant.

Élytres subcarrées ou à peine oblongnes, de la longueur du prothorax; subdéprimées; asstz finement et pell deı.scment ponctuées; d'un noir ou d'un brun de poix brillant; éparsement pubescentes, avec des soies redressées sur les côtés, dont, 1 notamment plus longue, vers les épaules. Celles-ci étroitement arrondies.

Abdomen assez allongé, un peu moins large à sa base que les élytres; à peine arqué sur les côtés et à peine atiénué en arrière; assez convexé sur le dos; fortement sétosellé; finement et modérément ponctué ; d'un noir brillant, avec le sommet d'un roux subtestacé ainsi que le bord apical de chaque segment; recouvert d'une fine pubescence grise et peu serrée. Le $6^{\text {e }}$ segment subarrondi et finement granulé-cilié(1) à son bord postérieur.

Dessous du corps finement ponctué, légèrement pubescent, d'un noir de poix brillant, avec le sommet du ventre largement, les intersections ventrales plus étroitement, testacés. Dessous de la tête lisse, glabre. Méta-

(1) Cela se remarque dans beaucoup de Philonthates, mais ici c'est très-apparent. $\mathrm{BR}$. 
sternum subdéprinié, finement canaliculé en arrière sur sa ligne u.édiane. Ventre convexe, éparsement sétosellé, plus longuement vers son extrémité.

Pieds médiocres, légèrement ponctués, légèrement pubescents, testacés, avec les hanches postérieures et souvent les intermédiaires plus foncées. Tarses antérieurs simples.

Patrie. Cette espèce se prend parmi les mousses et les feuilles mortes, dans le bois carié et les troncs caverneux, et souvent en compagnie de fourmis, dans les localités hoisées et dans les montagnes : les environs de Paris et de Lyon, la Normandie, la Lorraine, la Bourgogne, l'Auvergne, le Jura, les Alpes, la Savoie, les Pyrénées, etc.

OBs. Elle est remarquable, entre ses congénères, par sa forme sublinéaire et par ses antennes assez courtes et assez épaisses.

Elle varie pour la couleur. Le prothorax et les élytres sont parfois d'un brun roussâtre, avec l'abdomen presque entièrement testacé ou faiblement rembruni à la base de chaque segment. Ces inodifications se rapportent aux sujets immatures et c'est sans doute à un de ceux-ci que doit s'appliquer le Philonthus analis de Heer. Toutefois, ce dernier est un peu plus grand, avec les élytres un peu plus fortement ponctuées.

\section{Gabritus thermarum, AuBÉ.}

Allongé, subdéprimé, éparsement-pubescent, d'un noir brillant, avec le prothorax d'un brun de poix et les élytres d'un testacé obscur, la base des antennes et les pieds testacés. Elytres assez fortement et éparsement ponctuées, un peu plus longues que le prothorax: celui-ci suboblong, non rétréci en arrière. Abdomen finement et peu densement pointillé.

$\sigma^{7}$ Le $6^{\text {e }}$ arceau ventral assez largement et assez profondément sinué au sonimet.

ㄴ Le $6^{\circ}$ arceau ventral subarrondi et parfois obtusément tronqué au sommet.

Philonthus thermarum, AubÉ, Ann. Soc. Ent. Fr. 1850, VIII, 316.- FaInMaIRe et Laboulbène, Faun. Ent. Fr. I, 5222, 31. - Krintz, Ins. Deut. II, 608, 44. Fauver, Faun. Gallo-Rhén. III, 470, 39.

Philonthus exilis, Kraitz, Stett. Ent. Zeit. XII, 293.

Gabrius pumilus, Motschulsky. Enum. Nouv. Esp. 1859, 5ళ, 112. 


$$
\text { Long., } 0^{\mathrm{m}}, 0032 \text { (2 1/2 l.); - larg., } 0^{\mathrm{m}}, 0004 \text { (1/5 l.). }
$$

Corps allongé, subdéprimé, d'un noir de poix, avec le prothoray et surtout les élytres plus claires; revêtu sur celles-ci ct sur l'ablomen d'une fine pubescence grise et peu serrée.

Tête ovale-oblongue, presque droite sur les cỏtés, un peu moins large quc le prothorax; distinctement sélosellée; d'un noir de poix brillant; lisse, avec quelques rares points derrière les yeux. Front large, subdéprimé en avant, ou il offre parfois une faible impression fovéiforme, située entre les pores sétifères : ceux-ci assez petits, transversalement disposés, les externes rapprochés. Cou subglobuleux, glabre, lisse, d'un noir de poix brillant. Parties de la bouche d'un roux de poix.

Yeux assez petits, subovalairement arrondis, obscurs ou grisâtres, parfois micacés.

Antennes asscz courtes, sensiblement moins longues que la tête et le prothorax réunis; à peine épaissies; distinctement pilosellées vers leur base; d'un roux brunátre, avec les 3 premiers articles testacés; le $1^{\mathrm{er}}$ allongé, en massue subarquée : les $2^{\mathrm{e}}$ et $3^{\mathrm{e}}$ oblongs, obconiques, subégaux : les suivants graduellement à peine plus courts, subobconiques : les $4^{\circ}$ et $5^{\mathrm{e}}$ à peine ou non, les $6^{\mathrm{e}}$ à $10^{\mathrm{e}}$ légèrement transverses : le dernier subovalaire, à peine tronqué au bout et à peine acuminé inférieurement.

Prothorax suboblong, plutôt subrétréci en avant qu'en arrière, où il est un peu moins large que les élytres; obtusément tronıqué au sommet, avec les angles antérieurs infléchis et arrondis; presque droit ou à peine arqué sur les côtés; subarrondi à sa base ainsi qu'aux angles postérieurs; faiblement convexe; fortement sétosellé, avec la longue soie des côtés située assez près du rebord; d'un brun ou d'un roux de poix brillant; lisse, avec 2 séries dorsales composées de 5 points fins, dont les 3 postérieurs un peu plus rapprochés; marqué de plus, sur les côtés, de 4 autres points semblables, écartés et disposés en losange, outre ceux du rebord latéral. Repli roussâtre, lisse, glabre.

Écusson à peine ponctué, à peine pubescent, d'un brun de poix brillant.

Élylres subcarrées, un peu plus larges en arrière qu'en avant, un peu plus longues que le prothorax; subdéprimées; assez fortement et éparsement poncluées; d'un testacé de poix brillant; éparsement pubescentes; distinctement sétosellées sur les côtés, avec 1 soie notamment plus longue sur les épaulcs. Celles-ci subarrondies. 
Abdomen peu allongé, un peu moins large à sa base que les élytres ; peine arqué sur les còtés, parfois subatténué tout à fait en arrière; assez convexe sur le dos; éparsement sétosellé; plus finement et un peu moins lâchement ponctué que les élytres; d'un noir de poix assez brillant, avec le sonmet parfois roussâtre; recouvert d'une fine pubescence grise et peu serrée. Le $6^{\mathrm{e}}$ segment moins ponctué, moins pubescent, subarrondi au sommet.

Dessous du corps finement pointillé, finement pubescent, d'un noir de poix brillant, avec l'antépectus et le sommet du ventre souvent d'un roux testacé. Dessous de la tête glabre, lisse. Métasternum subconvexe, presque lisse sur son milieu, finement canaliculé cn arrière sur sa ligne médiane. Ventre convexe, éparsemenl sétosellé, surtout vers son sommet.

Pieds médiocres ou assez courts, à peine ponctués, légèrement pubescents, d'un testacé assez pâle. Cuisses passablement élargies avant leur milieu. Tarses antérieurs simples.

Patriz. Celte petite espèce est rar'e. Fille a été prise dans les environs de Paris dans la tannée des serres chaudes. Nous l'avons capturée nousmemes dans le Beaujolais et dans les cnvirons de Lyon, dans les bassescours, sous les pirres ou les planches placées sur les tas de fumiers. Elle habite aussi plusieurs autres régions de la France.

OBs. Elle diffère du splendidulus par sa taille moindre; par sa forme moins linéaire, plus atténuée en avant; par ses antennes moins épaisses et à pénultièmes articles moins transverses; par son prothorax moins long, plutôt subrétréci en avant qu'en arrière; par ses élytres d'une couleur plus claire, etc.

On la prendrait pour une variété immature et de petite taille du G. nijritulus; mais.les séries dorsales du prothorax sont de 5 points au lieu de 6 , la tête est plus oblongue et les antennes paraissent à peine plus courtes, elc.

Les élytres sont constamment d'une couleur de poix plus ou moins testacée; mais, suivant que les sujets sont plus ou moiris immatures, le prothorax prend une teinte roussatre ainsi que le sommet de l'abdomen et les intersections ventrales. Alors les antennes deviennent entitrement teslacées.

Les maritimus, Motsch. (Bull. Mlosc. 1858, II, 661), Libanicus, Saulc. (Ann. Ent. Fr. 1864, 639), mimulus, Rott. (Berl. Ent. Zeit. 1870, 30), angustatus, Kr. (Wiegm. Arch. 1859, I, 92), pygmeus, Kr. (id. 93), ct breviventer, $\mathrm{S}_{\mid} \cdot \mathrm{erk}$. (Bull. Jlosc. 1835, 1503), ne paraisscut pas distinc:s du thermarum. 
aa. Sérles dorsales du prothorax de 6 points.

6. Gabrius exiguus, Nurdmann.

Allongé, peu convexe, finement pubescent, d'un noir brillant, avec les élytres bronzées, la bouche et la base des antennes d'un roux de poix, et les pieds testacés. Élytres assez finement et subéparsement ponctuies, de la longueur du prothorax : celui-ci suboblong, subreitréci en avant. Abdomen finement et assez densement pointillé.

$\sigma^{\circ}$ Le $6^{\circ}$ arceau ventral subtronqué ou à peine échancré au sommet; longitudinalement relevè sur son disque en dos d'àne, lisse. Tibias postérieurs densement ciliés en dedans de longs poils mous et pâles.

\& Le $6^{\circ}$ arceau ventral subarrondi au sommet. Tibias postérieurs simples.

Philonthus exiguus, Nordyann, Symb. 105, 93.-EkIGason, Col. March. I, 475, 44;

- Gen. et Spec. Staph. 491, 107. - Redrenbacher, Faun. Austr. 706, 36. -

HeEr, Faun. Col. Helv. 1, 271, 48. - Kradtz, Ins. Deut. II, 615, 54. - Fauvet,

Faun. Gallo-Rhén. III, 488, 63.

Gabrius exiguus, Tromson, Skand. Col. IX, 156, 5, 1867.

$$
\text { Long., } 0^{\mathrm{m}}, 0044 \text { (2 l.); - larg., } 0^{\mathrm{m}}, 0007 \text { (1/3 l.). }
$$

Corps allongé, peu convexe, d'un noir brillant, avec les élytres bronzées; recouvert sur celles-ci et sur l'abdomen d'une fine pubescence grisâtre et peu serrée.

Tête ovale-oblongue, un peu moins large que le prothorax; éparsement sétosellèe sur les côtés ; d'un noir brillant; lisse, avec quelques points en arrière vers les tempes. Front très-large, à peine convexe, parfois à peine fovéolé en avant entre les pores sétifères : ceux-ci très-rapprochẻs 2 à 2 , situés près des yeux et disposés obliquement, avec l'interne beaucoup moindre et plus en avant. Cou en bourrelet, noir, lisse, glabre. Labre d'un noir de poix, avec les autres parties de la bouche roussâtres.

Yeux subovales, obscurs, lavés de gris.

Antennes suballongées, sensiblement plus courtes que la tête et le prothorax réunis; légèrement épaissies; distinctement pilosellées vers leur base; obscures, avec les 2 ou 3 premiers articles d'un roux de poix assez foncé; le $1^{\text {er }}$ allongé, en massue à peine arqriée : les $2^{\text {e }}$ et $3^{\text {e }}$ suballongés, 
obconiques, subégaux : les suivants graduellement un peu plus courts et à peine plus épais, subobconiques : les $4^{\mathrm{e}}$ et $5^{\mathrm{e}}$ suboblongs, le $6^{\mathrm{e}}$ à peine aussi long que large : le $7^{\mathrm{e}}$ à peine, les $8^{\circ}$ a $10^{\circ}$ plus sensiblement transverses : le dernier courtement ovalaire, à peine échancré au bout et à peine acuminé infërieurement.

Prothorax suboblong, subrétréci en avant, un peu moins large en arrière que les élytres; subtronqué au sommet, avec les angles antérieurs infléchis et subarrondis ; presque droit sur les côtés; arrondi à sa base ainsi quaux angles postérieurs ; assez convexe; éparsement sétosellé, avec la longue soic des côtés située tout près du rebord latéral ; d'un noir brillant; lisse, avec 2 séries dorsales composées de 6 points assez fins et subégalement distants ; marqué de plus, sur less côtés, de: 6 points (1) semblables, ..dont les 4 internes disposés en série longitudinale irrégılière. Repli noir, lisse, glabre.

Écusson pointillé, pubescent, d'un noir brillant.

Élytres subcarrées, subélargies en arrière, de la longueur du prothorax; subdéprimées; assez finement et subéparsement ponctuées; d'un noir bronzé brillant et parfois un peu verdâtre; légèrement et éparsement pubescentes; érarsement sétosellées sur les côtés, avec 1 soie plus longue sur les épaules: Celles-ci étroitement ärondies."

Abdomen peu allongé, à peine moins large à sa base que les élytres; subarqué sur les côtés et subatténué tout à fait en arrière; subconvexe sur le dos ; éparsement sétosellé; finement, modérément et subécailleusement pointillé; d'un noir assez brillant; un peu plus densement pubescent que les élytres. Le $6^{e}$ segment à peine pubescent, presque lisse ainsi que le sommet du $5^{\mathrm{e}}$, subarrondi à son bord postérieur.

Dessous 'du corps légèrement ponctué, finement pubescent, d'un noir brillant, avec le sommet du ventre souvent d'un roux de poix. Dessous de la tête glabre, presque lisse. Métasternum à peine ponctué, à peine canaliculé en arrière sur sa ligne médiane. Ventre convexe, três-éparsement sétosellé.

Pieds nédiocres, pointillés, finement pubescenls, testacés, avec les hanches postérieures rembrunies et les antérieures d'un roux de poix. Tarses antéricurs simples.

Patrac. Cette espèce est rare en France. Elle se prend sous les feuilles

(1) En exceptant toujours ceux de la marge. 
mortes et sous les pierres, en Normandie, en Auvergne, dans les montagnes du Lyonnais, les Alpes, les Pyrénées, etc.

OBs. Elle est presque de la taille de l'astutus, mais la tête est un peu moins large, le prothorax moins long et moins parallèle; le dernier article des palpes maxillaires est moins acuminé; les antennes, plus obscures, sont un peu moins épaissies, les parties de la bouche d'une couleur plus sombre, etc.

Nous avons vu un exemplaire des environs de Lyon à taille un peu plus grande, dont les élytres sont un peu moins bronzées et les antennes presque concolores, c'est-à-dire non plus claires à leur base (nigricornis, nobis).

Nous avons vu deux exemplaires mâles, identiques quant à la ciliation des tibias postérieurs, mais un peu différents quant au $6^{\text {e }}$ arceau ventral, qui était, dans l'un, subtronqué ou même subarrondi, et, dans l'autre, visiblement subéchancré au sommet.

Le pusillus de Heer $(271,49)$ serait d'une taille moindre, il aurait les élytres plus fortement ponctuées et le sommet de l'abdomen d'une couleur plus claire.

Quant au melanocephalus du même auteur $(269,40)$, il nous a paru, d'après un type communiqué, n'être encore autre chose qu'une varièté de l'exiguus?

\section{Gabrius astutus, Erichson.}

Allongé, subdéprimé, finement pubescent, d'un noir brillant, avec la base des antennes d'un brun de poix, la bouche et les pieds testacés. Élytres assez finement et densement ponctuees, un peu plus longues que le prothorax: celui-ci oblong, subparallèle. Abdomen finement et densement pointillé.

$\sigma^{*}$ Le $6^{e}$ arceau ventral faiblement et étroitement sinué dans le milieu de son bord apical, avec un espace allongé, triangulaire, lisse, au devant du sinus.

q Le $6^{\mathrm{e}}$ arceau veniral subarrondi à son bord apical.

Philonthus astutus, Erichson, Gen. et Spec. Staph. 492, 108. - Fairmaire et LABoulò̀ne, Faun. Ent. Fr. I, 528, 52.- Redtenbicher, Faun. Austr. 706, 39.KraAtz, Ins. Deut. II, 614, 33.- Fauvel, Faun. Gallo-Rhén. III, 467, 35. 
Long., $0^{\mathrm{m}}, 0060$ (2 3/4 l.); - larg., $0^{\mathrm{m}}, 0008$ (1/3 l.).

Corps allongé, subdéprimé, d'un noir brillant, revêtu sur les élytres et l'abdomen d'une fine pubescence grise, plus serrée sur ce dernier.

Tête subovale, aussi large ou presque aussi large que le prothorax; distinctement sétosellée; d'un noir brillant; lisse, avec quelques points assez gros et épars, en arrière, vers les côtés. Front très-large, faiblement convexe, obsolètement sillonné en avant entre les pores sétifères : ceux-ci très-rapprochés 2 à 2 , situés près des yeux et obliquement disposés, l'interne moindre et plus en avant. Cou en bourrelet, noir, lisse, glabre. Labre d'un noir de poix, avec les autres parties de la bouche plus ou moins testacées.

Yeux obscurs, parfois un peu grisâtres.

Antennes suballongées, un peu plus courtes que la tête et le prothorax réunis; visiblement épaissies; distinctement pilosellées vers leur base ; obscures, avec le $1^{\text {er }}$ article d'un brun de poix parfois un peu roussâtre; celui-ci en massue allongée : les $2^{\mathrm{e}}$ et $3^{\mathrm{e}}$ suballongés, obconiques : Je $3^{\mathrm{e}}$ évidemment plis long que le $2^{\mathrm{e}}$ : les suivants graduellement un peu plus courts et plus épais, subobconiques : le $4^{\mathrm{e}}$ oblong, les $5^{\mathrm{e}}$ et $6^{\mathrm{e}}$ suboblongs : les $7^{\mathrm{e}}$ et $8^{\mathrm{e}}$ non, les $9^{\mathrm{e}}$ et $10^{\mathrm{e}}$ à peine transverses, vus de côté : le dernier subovale, à peine échancré au bout et subacuminé inférieurement.

Prothorax oblong, subparallèle ou à peine rétréci en arrière, où il est sensiblement moins large que les élytres; obtusément tronqué au sommet, avec les angles antérieurs infléchis e! arrondis; presque droit sur les côtés ; subarrondi à sa base ainsi qu'aux angles postérieurs ; faiblement convexe ; distinctement sétosellé, avec la longue soie des cótés située tout près du rebord latéral; d'un noir brillant ; lisse, avec 2 séries dorsales comp̣osées de 6 points assez forts et subégalement distants; marqué de plus, outre ceux de la marge, de 5 points semblables, épars, dans l'ouverture des angles antérieurs. Repli noir, lisse, glabre.

Écusson ponctué, pubescent, d'un noir brillant.

Élytres subcarrées, un peu plus larges en arrière qu'en avant, un peu plus longues que le prothor.ux ; subdéprimées; assez finement et densement ponctuées; d'un noir brillant; finement et subéparsement ou modérément pubescentes; distinctement sétosellées sur les côtés, avic 1 soie plus longue vers les épaules. Celle's-ci subarrondies. 
Abdomen suballongé, un peu moins large à sa base que les élytres; subarqué sur less côtés et subalténué tout à fait en arrière; assez convexe sur le dos ; assez fortement sétosellé ; finement, densement et subécailleusement pointillé, à peine moins densement dans sa partie postérieure ; d'un noir assez. brillant, avec une fine pubescence grise, plus longue et évidemment plus serrée que celle des élytres. Le $6^{\mathrm{e}}$ segment à peine pubescent, presque lisse, à peine arrondi au sommet.

Dessous du corps finement pointillé, finement pubescent, d'un noir brillant, inec le sommet du ventre pariois moins foncé. Dessous de la tête lisse et glabre. Métasternum subdéprimé sur son milieu. Ventre convexe, éparsement sétosellé.

Pieds médiocres, finement ponctués, finement pubescents, d'un roux testacé, avec les cuisses postérieures parfois un peu rembrunies, assez étroites. Tarses antérieur's simples.

Patrie. Celte espèce est mėdiocrement commurie dans les lieux humides, sous les pierres, les mousses et les détritus, dans plusieurs parties de la France : le Bourbonnais, le Beaujolais, les environs de Lyon, le Bugey, les Alpes, la Savoie, les Pyrénées, etc.

OBs. Elle a tout à fait la tournure du G. nigritulus, mais avec une taille plus avantageuse.

Elle diffère des nigricornis et exiguus par le prothorax plus oblong et plus parallèle et p.r le dernier article des palpes maxillaires à pointe plus prolongée. Elle est aussi grande que le premier, plus grande que lc deuxième. La tète est un peu plus large et moins oblongue que dans l'un et l'autre.

Nous avons vu des exemplaires immatures entièrement d'un roux de poix, avec la tête seule rembrunie.

On peut rapporter à l'astutus l'erythrostomus, Hocch.(Bull. Hosc, 1851, III, 22).

Nous colloquons ici une petite espèce de Cor'se assez intiressante :

Gabriug piliger, Mulsant el Rey.

Allongé, subparallèle, peu convexe, iparsement poilu, d'un noir brillant, avec la bouche et les pieds d'un roux de poix. Elytres fortement et 
peu densement ponctuées, de la longueur du prothorax: celui-ci suboblong, subparallèle. Abdomen finement et assez densement pointillè.

$$
\text { Long., } 0^{\mathrm{m}}, 0042 \text { (1 3/4 l.); - larg., } 0^{\mathrm{m}}, 0005 \text { (1/4 l.). }
$$

Patrie. Corte Saint-François, en Corse (collection Revelière).

OBs. Cette petite espèce est remarquable par sa forme subparallèle. Elle est de la taille des plus grands exemplaires du nigritulus. La tête, plus grosse, en carré suborbiculaire, est plus large que le prothorax. Celui-ci moins oblong, moins étroit, a les points des séries plus fo:ts et plus profonds. Les élytres sont plus courtes, plus fortement ponctuées; elles sont parées, ainsi que l'abdomen, d'une pubescence assez longue, peu serrée et blanchâtre.

De prime abord, elle est plus large, plus parallèle que le nigritulus, non atténuée en avant.

\section{Gabrius nigritulus, Gravenhorst.}

Allongé, subdéprimé, éparsement pubescent, d'un noir brillant, avec la bouche, la base des antennes et le sommet de l'abdomen d'un roux de poix, et les pieds testacés. Élytres assez fortement et peu densement ponctuées, un peu plus longues que le prothorax: celui-ci oblong, subparallèle, Abdomen finement et assez densement pointillé.

$\sigma$ Le $6^{\text {e }}$ arceau ventral à peine sinué dans le milieu de son bord apical, avec un espace triangulaire, lisse et subpellucide, au devant du sinus. Tête un peu plus large que le prothorax.

† Le $6^{\mathrm{e}}$ arceau ventral subarrondi à son bord apical. Tête à peine moins large que le prothorax.

Staphylinus nigritulus, Gravenhorst, Micr. 41, 61; - Mon. 94, 90.- Latreille, Hist. Nat. Crust. et Ins. IX, 328, 79.

Staphylinus aterrimus, Gravenhorst, Micr. 41, 62.- Latreille, Hist. Nat. Crust. et Ins. IX, 328, 80. - Gyllenhal, Ins. Suec. II, 349, 63.- Boisduval et LaCorDAIRE, Faun. Ent. Par. I, 408, 43.

Cafius aterrimus. MANNERHEIM, Brach. 32 , 5.

Gyrohypnus aterrimus, NoRdmanN, Symb. 126, 32.

Cafius pumilus, NaNNERHEIM, Brach. $32,4$. 
Philonthus aterrimus, Ericrson, Col. Narch. I, 476, 45;-Gen. et Spec. Staph. 492, 109. - Redtenbacher, Faun. Austr. 706, 39. - Heer, Faun. Col. Helv. I, 271, 50. - Falraalre et Laboulbène, Faun. Ent. Fr. I, 528, 53.

Philonthus nigritulus. KraAtz, Ins. Deut. II, 616, 56. - Fauvel, Faun. Gallo-Rhén. III, 469, 38.

Gabrius aterrimus, ThомsoN, Skand. Col. II, 170, 3, 1860.

$$
\text { Long., } 0^{\mathrm{m}}, 0040 \text { (1 3/4 l.); - larg., } 0^{\mathrm{m}}, 0004 \text { (1/5 l.). }
$$

Corps allongé, subdéprimé, d'un noir brillant; recouvert sur les élytres et l'abdomen d'une fine pubescence grise, plus serrée sur ce dernier.

Tête subovale, distinctement sétosellée; d'un noir très-luisant; lisse, a vec plusieurs points épars en arrière, vers les côtés. Front très-large, subdéprizné ou à peine convexe, subimpressionné ou obsolètement fovéolé en avant, entre les pores sétifères : ceux-ci rapprochés 2 à 2 , situés près des yeux et à peine obliquement disposés, l'interne moindre, un peu ou parfois à peine plus en avant. Cou en bourrelet, lisse, glabre, d'un noir brillant. Parties de la bouche d'un roux de poix.

Yeux obscurs.

Antennes suballongées, un peu plus courtes que la tête et le prothorax réunis; faiblement épaissies; légèrement pilosellées vers leur bașe; obscures, avec les deux premiers articles souvent d'un roux de poix; le $1^{\text {er }}$ a!longé, en massue subarquée : les $2^{\mathrm{e}}$ et $3^{\mathrm{e}}$ suballongés, obconiques, subégaux : les suivants graduellement un peu plus courts et à peine plus épais, subobconiques : le $4^{\mathrm{e}}$ suboblong, le $5^{\mathrm{e}}$ subcarré : les $6^{\mathrm{e}}$ et $\mathbf{7}^{\mathrm{e}}$ à peine, les $8^{\mathrm{c}}$ à $10^{\mathrm{e}}$ légèrement transverses, vus de côté : le dernier subovalaire, subtronqué au bout et subacuminé inférieurement.

Plothorax oblong, subparallèle, sensiblement moins large que les élytres; tronqué au sommet, avec les angles antérieurs infléchis, obtus et subarrolldis ; presque droit sur les côtés; arrondi à sa base ainsi qu'aux angles postérieurs; faiblement convexe; distinctement sétosellé, avec la longue soie des côtés située tout près du rebord latéral; d'un noir très-brillant ; lisse, avec 2 séries dorsales composées de 6 points assez fins, l'antérieur un peu plus distant; marqué de plus, outre ceux de la marge, de 5 points semblables, en avant vers les côtés. Repli noir ou brun, lisse, glabre.

Écusson pointillé, à peine pubescent, d'un noir brillant.

Elytres subcarrées, à peine plus larges en arrière; un peu plus longues que le prothorax; subdéprimées; assez fortement et peu densement ou modérément ponctuées; d'un noir de poix brillant et partois un peu bru- 
nâtre; éparsement pubescentes; distinctement sétosellées sur les côtés, avec 1 soie plus longue vers les épaules. Celles-ci étroitement arrondies.

Abdomen suballongé, un peu moins large à sa base que les élytres; à peine arqué sur les côtés et subatténué tout à fait en arrière; subconvexe sur le dos; distinctement séiosellé; finem et un $\mathrm{p}^{\wedge} \mathrm{u}$ plus densement pointillé que les élytres ; d'un noir assez brillant, avec le sommet souvent d'un roux de poix ; recouvert d'une fine pubescence grise, assez longue et modérément serrée. Le $6^{e}$ segment plus gliabre, plus lisse, subarrondi au sommet.

Dessous $d u$ corps finement pointillé, finement pubescent, d'un noir brillant, avec le sommet du ventre et souvent les intersections ventrales d'un roux de poix. Dessous de la têle lisse et glabre. Métasternum à peine convexe, très-finement canaliculé sur sa ligne médiane. Ventre convexe, éparsement sétosellé.

Pieds médiocres, finement ponctués, finement pubescents, testacés, avec les hanches postérieures plus 'oncées. Tarses antérieurs simples.

Patrie. Celte espèce eit très-commune, dans presque toule la France, sous les détritus, les feuilles tombées, les fumiers, les champignons, etc.

OBs. Outre la taille, elle diffère du G. astutus par ses antennes moins épaissies, à $3^{\ominus}$ article subégal au $2^{\ominus}$, a vec les $4^{\ominus}$ à $6^{\circ}$ moins oblongs et les pénultièmes un peu plus courts, Les élytres et l'abdomen sont un peu moins densement pointillés. Les pores sétifères, situés entre les yeux, sont moins obliquement disposés, parfois même subtransversalement.

Les sujets immatures sont d'un brun de poix, avec les côtés du prothorax et les élytres un peu roussatres, et les intersectious abdominales et ventrales d'un roux testacé. Quelquefois tout le corps, moins la tête, est de cette dernière couleur.

Chez les $\sigma^{\prime \prime}$ de petite taille, la tête n'est pas plus large que le prothorax.

On rapporte au nigritulus les pygmaeus, attenuatus et basalis de Stephens (Ill. Brit. V, 250 et 251), ainsi que le phoeopus du même auteur (Man. Brit. Col. 400), le pygmaeus Snell. (Faun. Ned. II. 70), et le picipennis Maekl. (Bull. Mosc. 1852, Il, 313).

La larve du nigritulus a été décrite par H. Kroyer in Schiödte (Nat. Tidss. 1864, p. 200).

Près du nigritulus vient une cspc̀ce étrangère à la France, et dont voici la description sommaire : 
Gabrius trossultes, Nordann.

Allongé, subdéprimé, éparsement pubescent, d'un noir de poix brillant, avec les élytres d'un brun fauve, la bouche, la base des antennes et les intersections ventrales testacees. Elytres fortement et peu densement ponctuées, de la longueur du prothorax: celui-ci oblong, subparallèle. Abdomen finement et assez densement pointillé.

Philonthus trossulus, Nordmann, Symb. 102, 90.-- KraAtz, Ins.' Deut. II, 616, b̈3. Gabrius trossulus, Thomson, Skand. Col. II, 171, 4. 1860.

$$
\text { Long., } 0^{\mathrm{m}}, 0050 \text { (2 1/3 l.); - larg., } 0^{\mathrm{m}}, 0004 \text { (1/5 l.). }
$$

Patrie. Cette espèce est particulière à la Suède et au nord de l'Allemagne.

OBs. Elle ressemble beaucoup au nigritulus. Elle est un peu plus grande, plus allongée, avec les élytres plus fortement ponctuées, un peu plus courtes relativement au prothorax, etc.

Les élytres sont tantôt d'un brun de poix; tantôt un peu roussâtres.

\section{Gabrius laticollis, Fauvel.}

Allongé, subdéprimé, finement pubescent, d'un noir de poix brillant et submétallique, avec la bouche, la base des antennes et les pieds testacés. Elytres assez fortement et peu densement ponctuées, un peu plus courtes que le prothorax: celui-ci oblong, subparallèle. Abdomen finement et assez densement pointillé.

$\sigma$ Le $6^{e}$ arceau ventral assez profondément et angulairement entaillé au sommet. Tibias postérieurs ciliés-frangés en dedans.

ㅇ Le $6^{\mathrm{e}}$ arceau ventral arrondi au sommet. Tibias postéricurs simples.

Philonthus laticollis, Fauvel, Faun. Gallo-Rhén. III, 488, 64, pl. V, fig. 19.

$$
\text { Long., } 0^{\mathrm{m}}, 0049 \text { (2 1/4 l.); - larg., } 0^{\mathrm{m}}, 0007 \text { (1/3 l.). }
$$


Corps allongé, subdéprimé, d'un noir de poix brillant, submétallique sur la tête, le prothorax et les élytres; recouvert sur celles-ci et l'abdomen d'une fine pubescence grisâtre.

Téte suboblongue, sensiblement moins large que le prothorax; éparsement sétosellée; d’un noir luisant, à peine métallique; lisse, avec quelques points assez forts, épars sur les tempes. Front très-large, subconvexe, obsolètement fovéolé en avant entre les pores sétifères : ceux-ci très-rapprochés 2 à 2 , situés près des yeux, l'interne moindre, parfois plus en avant. Cou glabre, presque lisse, d'un noir brillant. Labre brunâtre. Mandibules et palpes testacés.

Yeux obscurs, souvent micacés.

Antennes assez courtes, moins longues que la tête et le prothorax réunis; faiblement épaissies; distinctement sétosellées, surtout vers leur base; d'un roux obscur, avec leur ex (rémité souvent moins foncée et le $1^{\mathrm{er}}$ article testacé : celui-ci en massue allongée et subarquée : les $2^{\mathrm{e}}$ et $3^{\mathrm{e}}$ suballongés, obconiques : le $3^{\mathrm{e}}$ à peine plus long que le $2^{\mathrm{e}}$ : les suivants graduellement un peu plus courts et à peine plus épais : le $4^{\mathrm{e}}$ suboblong : les $5^{\mathrm{e}}$ et $6^{\mathrm{e}}$ subcarrés ou à peine oblongs: les $8^{\mathrm{e}}$ à $10^{\mathrm{e}}$ légèrement tranverses, avec les pénultièmes néanmoins plus fortement : le dernier courtement ovalaire, obliquement tronqué au bout et subacuminé inférieurement.

Prothorax oblong, subparallèle, un peu moins large que les élytres; tronqué au sommet, avec les angles antérieurs infléchis et arrondis; presque droit sur les côtés; arrondi à la base ainsi qu'aux angles postérieurs; faiblement convexe; éparsement sétosellé, à longue soie des côtés situéc près du rebord latéral; d'un noir de poix luisant, à peine métallique; lisse, avec 2 séries dorsales composées de 6 points médiocres dont les extrêmes souvent plus écartés de leưrs voisins; marqué de plus, sur les côtés, outre ceux de la marge, de 5 ou 6 autres points semblables, mais épars. Repli d'un brun de poix, lisse, glabre.

Écusson à peine pubescent, à peine pointillé, noir, brillant.

Élytres subtransverses, à peine plus larges en arrière; un peu plus courtes que le prothorax ; subdéprimées ou déprimées ; subimpressionnées le long de la suture; assez fortement et peu densement ponctuées; d'un noir de poix brillant et submétallique; éparsement pubescentes, avec 1 longue soie redressée sur le côté des épaules. Celles-ci subarrondies. Abdomen peu allongé, à peine roins large à sa base que les élytres, à peine arqué sur les côtés el subatténué en arrière; assez convexe sur le dos; à peine sétosellé; finement et assez densement pointillé, un peu moins 
en arrière; d'un noil assez brillant et subazuré, avec le sommet souvent moins foncé; à pubescence plus fine et un peu plus serrée que celle des élytres. Le $6^{\mathrm{c}}$ segment subarrondi au sommet.

Dessous du corps aspèrement pointillé, finement pubescnt, 'd'un noir de poix brillant, avec le sommet du ventre moins foncé. Dessous de la tête presque lisse et presque glabre. Métasternum peu convexe, éparsement ponctué. Ventre convexe, subirisé, éparsement sétosellé vers son sommet.

Pieds médiocres, légèrement ponctués, légèrement pubescents, testacés, arec les hanches intermédiaires et postérieures un peu plus foncées. Tarses antericur's simples.

Patrie. Celte espèce, qui nous a été communiquée par M. Pandellé, se trouve, à la fin de l'été, parmi les mousses et les feuilles mortes, dans les environs de Tarbes où elle est rare.

OBs. Elle diffère des précédentes par sa tête plus oblongue et moins large et par ses élytres plus courles. Elle est moins grande que l'astutus, plus grande que le nigritulus dont elle a le faciès. La tête est plus étroite que chez le trossulus.

Les tibias postérieurs des $\sigma$ sont ciliés intérieurement, comme chez le G. exiguus, ce qui rend ces 2 espèces remarquables parmi leurs congénères.

\author{
Genre Hesperus, Hespère, Fauvel. \\ FAuvec, Faun. Gallo-Rhẻn. 11. 426, pl. V, fig. 15.

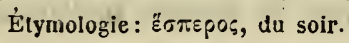

CARACTÈRes. Corps allongé, subparallèle, peu convexe, ailé, à peine pubescent, un peu à forme de Xantholin.

Tête grande, saillante, subcarrée on suborbiculaire, portée sur un col court, assez étroit, beaucoup moins large que le vertex. Tempes obsolètement rebordées en avant sur les côtés. Épistome offrant en avant une marge submembrancuse assez étroite, subsinuée dans le miliea de son bord antri:eur. Labre très-court, bilobé. Mandibules saillantes, falciformes, acérécs, dentées vers le milien de leur côté interne, croisécs au repos. Palpes maxillaires très-développés, à $1^{\mathrm{cr}}$ article court : le $2^{\mathrm{e}}$ en massue oblongue, arquée et subdéprimée : le $3^{e}$ suballongé, obconique, 'plus 
étroit mais aussi long que le $2^{\mathrm{e}}$ : le dernier allongé, grêle, beaucoup plus long que le précédent, subcylindrico-fusiforme. Palpes labiaux courts, avec les 2 premiers articles subégaux : le dernier plus long, fusiforme. Jenton fortement transverse, largemeni tronqué en avant, corné.

Yeux assez grands, subuvales, peu saillants, séparés du cou par un intervalle à peine plus long que son plus grand diamètre.

Anteinnes peu allongées, sensiblement épaissies; à $1^{\text {or }}$ article allongé, en massue subarquée : les $2^{\mathrm{e}}$ et $2^{\mathrm{e}}$ obconiques, suballongés : le $3^{\mathrm{e}}$ un pen plus long que le $2^{\mathrm{e}}$ : les $4^{\mathrm{e}}$ à $10^{\mathrm{e}}$ graduellement un peu plus courts, non contigus, avec les pénultièmes subtransverses : le dernier ovalaire, subéchancré au bout.

Prothorax en carré suboblong, moins large que les élytres; tronqué au sommet, à angles antérieurs non saillants ; subarrondi à sa base; finement rebordé sur celle-ci et sur les côtés; à rebord latéral sinueusement infléchi d'arrière en avant. Repli assez étroit, subexcavé, incliné, visible vu de côté, sans opercule prothoracique.

Écusson grand, ogival.

Èlytres subcarrées; à peine simultanément échancrées à leur bord apical; à peine arrondies à leur bord postéro-externe; distinctement rebordécs sur la suture. Repli médiocre, assez fortement infléchi. Épaules peu saillantes.

Prosternum peu développé au devant des hanches antérieures, offrant entre celles-ci un triangle large, subconvexe, à sommet subaigu mais subémoussé. Mésosternum à lame médiane triangulaire, distinctement ribordée sur les còtés, fortement arrondie au sommet, prolongée jusqu'au milieu environ des hanches intermédiaires; à arête transversale arquée, à peine sensible et festonnée en arrière. Médiépisternums grands, séparés du méso:ternum par une suture transversale. Médiépimères médiocres, cblongues, trapéziformes, avec un espace triangulaire notable, situé en dedans et séf aré du reste de la surface par une arête oblique (1). Métasternum court assez fortement échancré au devant des hanches postérieures; prolongé entre celles-ci en en lobe enfoncé, incisé, brièvement explané ; avancé entre les intermédiaires en angle arrondi, séparé de la lame mésosternale par un in!crmède court, assez large, à peine voûté.

(1) Birn que nous n’en ayons pas toujours parlé, cette arête existe dans les geures précédents, et mêne chez les Staphylinates; mais elle est ici plus accusée, et elle retranche en dedans une plus grande partie de la surface. 
Postépisternums étroits, en languette obtuse à leur sommet. Postépimères petites, iriangulaires.

Abdomen allongé, subatténué en arrière, fortement rebordé sur les côtés; à 4 premiers segments subégaux, le $5^{\mathrm{e}}$ plus grand : le $6^{\mathrm{e}}$ plus ou moins saillant, rétractile : celui de l'armure caché, sétosellé-fasciculé. Ventre à $2^{\circ}$ arceau basilaire un peu apparent, subangulé dans le milieu de son bord postérieur : le $1^{\text {er }}$ plus long sur les côtés que les suivants : le $5^{\ominus}$ un peu plus long que les précédents : le $6^{\circ}$ plus ou moins saillant, rétractile.

Hanches antérieures grandes, de la longueur des cuisses, très-saillan tes coniques, contiguës au sommet. Les intermédiaires moindres, peu saillantes, conico-subovales, assez fortement distantes. Les postérieures assez petites, assez saillantes, rapprochées à leur base, divergentes au sommet, en cône court et-mousse; à lame supérieure sillonnée en travers dans son premier tiers; à lame inférieure nulle ou enfouie.

Pieds médiocres, peu robustes. Trochanters antérieurs petits, cunéiformes; les autres un peu plus grands; les intermédiaires subcunéiformes, les postérieurs ovales-oblongs. Guisses subcomprimées, subatténuées vers leur extrémité, à peine épineuses en dessous vers celle-ci. Tibias subélargis de la base au sommet, plus ou moins épineux, munis au bout de leur tranche inférieure de 2 éperons grêles, dont l'interne un peu plus long; les anterieurs plus courts et un peu plus robustes. Tarses antérieurs courts, à 4 premiers articles légèrement dilatés, chez les $\sigma$ seulemen:; les intermédiaires et postérieur's allongés, à peine alténués vers leur extrémité, à $1^{\text {er }}$ article allongé, subégal aux 3 suivants réunis, ccux-ci suboblong:, graduellement à peine plus courts : le dernier allongé, grèle, presque aussi. Iong que le $1^{\mathrm{er}}$. Ongles petits, grêles, subarqués, souvent tendus.

Oвs. La scule espèce de ce genre, de taille moyenne et à démarche agile, vit parni les champignons.

La lame mésosternale fortement arronảie au sommet, ce qui force les hanches intermédiaires à s écarter davantage, tel est le caractère saillant de cette coupe générique. Les palpes maxillaires sont encore plus développés et autrement conformés que dans le genre Philonthus. L'arète transversale arquée du mésosternum est à peine sentie, au point de ne pas mériter le nom d'arête, et les côtés de la lame méscsternale sont pius fortement rebordés que dans les autres genres, etc. 
Tout le corps est longuement et éparsement sétosellé sur les cỏtés. Le prothorax est éparsement ponctué, avec un espace médian lisse, et la longue soic latérale assez distante du rebord.

Ce genre se borne à une seules espèce française.

\section{- 1. Hesperung mufpenaig, Gravenhorst.}

Allongé, subparallèle, peu convexe, d'un noir brillant, avec la bouche, le sommet des antennes, les élytres, les tibias et les tarses roux. Téte et prothorax éparsement ponctués sur les côtés. Élytres et abdomen subéparsement ponctués, peu pubescents.

$\sigma^{7}$ Le $6^{e}$ arceau ventral légèrement et subangulairement cilié dans le milieu de`son bord apical. Tarses antérieurs légèrement dilatés.

q Le $6^{\mathrm{e}}$ arceau ventral arrondi au sommet. T'arses antérieurs à peine dilatés ou presque simples.

Staphylinus rufipennis, Gravenhorst, Nicr. 41), 59; - Mon. 104, 105. - Latrellele, Hist. Nat. Crust. et Ins. IX, 327,' 77.

Philonthus rufipennis, Nordmans, Symb. 110, 100. - ERichson, Col. March. I, 477, 46 ; - Gen. et Spec. Staph. 504, 131. - Red renbacuer, Faun. Austr. 825.

- Falrmaire et L.bouldènz:, Faun. Ent. Fr. I, 530, 61. - KraAtz, Ins. Deut. II $621,61$.

Hesperus rufpennis, FaUveL, Faun, Gallo-Rhén. III, 426, 1.

$$
\text { Long., } 0^{\mathrm{m}}, 009 \text { (4 l.); - larg., } 0^{\mathrm{m}}, 0015 \text { (2/3 l.). }
$$

Corps allongé, subparallèle, peu convexe, d'un noir brillant, avec les élytres rouges ; revêtu sur celles-ci et sur l'abdomen d'une fine pubescence d'un gris obscur et très-peu serrée.

Tête en carré subtransverse et arrondi aux angles, aussi large ( $q$ ) ou à prine plus large $\left(\sigma^{*}\right)$ que le prothorax ; longuement et éparsement séto sellée dans son pourtour; à peine pubescente; fortement et éparsement ponctuée, avec un espace longitudinal lisse, sur son milieu; d'un noir très-brillant. Front très-large, faiblement convexe. Cou noir, glabre, lisse ou avec 2 ou 3 petits points sur les côtés. Épistome à marge submembraneuse pâle; subsinué dans son milieu. Labre d'un roux de poix, finement cilié et fortement sétoselté en avant. Parties de la bouche rousses, arec les mandibules ferrugincuses. 
Yeux assez grands, obscurs, lavés de gris.

Antennes peu allongées, sensiblement plus longues que la têle; visiblement épaissies; distinctement pilosellées; noires, avec le dernier ou les deux derniers arlicles d'un roux ferrugineux parfois assez clair (1); le $1^{\text {er }}$ allongé, en massue assez grêle et subarquée : les $2^{\text {e }}$ et $3^{\text {e }}$ obconiques, suballongés : le $3^{\mathrm{e}}$ un peu plus long que le $2^{\mathrm{e}}$ : les suivants graduellement un peu plus courts et plus épais, subobconiques, avec les pénultièmes subtransverses, vus de côté : le dernier ovalaire, obliquement subéchancré au bout et subacuminé inférieurement.

Prothorax subcarré, un peu plus long que large; évidemment moins large que les élytres; tronqué au sommet; à angles antérieurs fortement infléchis et arrondis; subparallèle sur ses côtés, vu de dessus, a vec ceux-ci, vus latéralement, subsiuués en arrière, et les angles postérieurs obtus; subarrondi à sa base; assez convexe; à peine pubescent; légèrement sétosellẻ vers les angles antérieurs, à pore sétifère bien marqué et légèrement distant du rébord latéral ; assez finement et éparsement ponctué, avec un espace longitudinal lisse, médian, assez étroit ; d'un noir très-brillant. Repli brunâtre, glabre, lisse.

Écusson finement pointillé, légèrement pubescent, d'un noir assez brillant.

Élytres subcarrées, à peine plus longues que le prothorax; subdéprimées ou à peine convexes; subaspèrement ponctuées ; d'un rouge brillant; éparsement pubescentes, avec 3 longues soics obscures sur les côtés, et quelques autres, beaucoup plus courtes, sur toute la surface. Épaules subarrondies.

Abdomen allongé, moins large à sa base que les élytres; graduellement subatténué en arrière ; assez convexe sur le dos; éparsement et longuement sétosellé; paré en outre de soies beaucoup plus courtes et un peu plus nombreuses ; subéparsement et assez fortement ponctué; d'un noir trèsbrillant; éparsement pubescent. Le $6^{\mathrm{e}}$ segment peu ponclué, subsinueusement tronqué au sommet.

Dessous du corps modérément et subaspèrement ponctué, légèrement pubescent, dun noir brillant. Dessous de la tête presque lisse et presque glabre. Lame mésosternale finement rugueuse en avant, plus fortement en arrière; à arĉle transversale à peine sentie, arquée el testonnée. $M \dot{e}$. tasternum subconvexe, très-finement canaliculé sur sa lignc médiane.

(1) Souvent le $2^{\circ}$ article et parfois le $1^{\text {er }}$ sont d'un roux de poix à leur insertion. 
Ventre convexe, éparsement sétosellé, avec quelques soies plus longues.

Pieds médiocres, finement pubescents, subaspèrement ponctués, d'un noir de poix, avec les tibias et les tarses plus clairs ou rougeâtres. Cuisses postérieures assez grêles. Tibias intermédiaires plus fortement épineux que les autres.

Patrie. Cette espèce est rare. Elle se trouve dans les champignons qui poussent au pied des arbres des forêts, dans les environs de Paris, dans le Beaujolais et autres lieux boisés, tels que la Bourgogne, les Landes, les Pyrénées, etc.

OBs. Elle a la forme du Philonthus puella, mais avec une ponctuation et une couleur différentes. Elle appartient à la section 8 d'Erichson:

\section{Genre Cafius, Cafie, Leach.}

LzAch in Stepnens, Ill. Brit. Ent. V, 245. - Cuntes, Brit. Ent. VII, 322.

Ėtymologie : $x \alpha \varphi \varepsilon ́ \omega$, je respire.

Caractères. Corps allongé, linéaire, déprimé, ailé, pubescent sur les élytres et l'abdomen, à forme de Xantholin.

Tête grande, saillante, subcarrée ou en carré suboblong, au moins aussi large que le prothorax, portée sur un col court et étroit. Tempes nullement rebordées sur les côtés. Épistome subsinueusement tronqué au sommet, sans rebord submembraneux sensible. Labre très-court, bilobé. Mandibules saillantes, falciformes, acérées, dentées vers le milieu de leur côté interne, croisées au repos. Palpes maxillaires médiocrement développés, à $1^{\text {er }}$ article court : le $2^{\mathrm{e}}$ suballongé, en massue arquée : le $3^{\mathrm{e}}$ plus court, obconique : le dernier fusiforme, un peu plus grêle et un peu plus long que le précédent. Palpes labiaux courts, à $1^{\mathrm{er}}$ article oblong : le $2^{\mathrm{e}}$ à peine plus court, mais un peu plus épais : le dernier à peine plus étroit ct un peu plus long que le précédent, subfusiforme. Mlenton grand, trapéziforme, plus étroit en avant, tronqué au sommet, parfois submembraneux dans sa partie antérieure.

Yeux plus ou moins grands, subovales, peu saillants, séparés du cou par un intervalle plus ou moins long.

Antennes peu allongées, subfiliformes; à $1^{\text {er }}$ article allongé, en massue subarquée : les $2^{\mathrm{e}}$ et $3^{\mathrm{e}}$ obconiques : le $3^{\mathrm{e}}$ un peu plus long que le $2^{\mathrm{e}}$ : les 
$4^{\circ}$ a $10^{\circ}$ graduellement un peu plus courts, non contigus, avec les pénullièmes subtransverses : le dernier subovale, subtronqué au bout.

Prothorax en carré suboblong, plus ou moins rétréci en arrière, moins large que les élytres; paré sur le dos de 2 séries de 3 ou 4 gros points enfoncés, sétifères ; tronqué au sommet ; à angles antérieurs non saillants ; subarrondi à sa base; très-finement rebordé sur celle-ci et sur les côtés ; à rebord latéral brusquement et sinueusement infléchi d'arrière en avant, dès son tiers postérieur (1). Repli assez large, incliné, visible vu de côté, sans opercule prothoracique.

Écusson grand, triangulaire ou subogival.

Elytres suboblongues, à peine simultanément échancrées à leur bord apical; subarrondies à leur angle postéro-externe; finement rebordées sur la suture. Repli médiocre, fortement infléchi, subparallèle. Epaules peu saillantes.

Prosternum un peu développé au devant des hanches antérieures, offrant entre celles-ci un angle subaigu, à disque convexe, à sommet subcarinulé ou submucroné. Mésostermum à lame médiane triangulaire, à pointe trèsaiguë, parfois subémoussée au bout, prolongée un peu au delà du milieu des hanches intermédiaires; à disque traversé avant son milieu par une arête arquée, sensible. Médiépisternums grands, séparés du mésosternum par une fine suture oblique. Médiépinières étroites, parfois sublinéaires. Métasternum assez développé, fortement échancré au devant des hanches postérieures ; prolongé entre celles-ci en un lobe explané, subcorné, parfois très-court, incisé ou entaillé dans son milieu; avancé entre les intermédiaires en angle plus ou moins prolongé. Postépisternums très-étroits, sublinéaires. Postépimères très-petites, en onglet (2).

Abdomen allongé, subparallèle, fortement rebordé sur les côtés; à $2^{{ }^{\theta}}$ segment basilaire parfois distinct : les suivants subégaux ou graduellement un peu plus grands : le $6^{\circ}$ saillant, rétractile : celui de l'armure caché, émettant 2 longs fascicules de soies. Ventre à $2^{\mathrm{e}}$ arceau basilaire souvent visible : les suivants subégaux : le $5^{\mathrm{e}}$ un peu plus grand : le $6^{\circ}$ plus ou moins saillant, rétractile.

Hanches antérieures grandes, environ aussi longues que les cuisses, saillantes, coniques, contiguës au sommet. Les intermédiaires assez

( 1 ; Le pore sétifere des côtés est assez distant du bord latéral.

(2) Poùr juger du véritable développement des médiépimères, dıs postépisternums et des postépimères, il faut que les élytires soient normalement fermées. 
grandes, peu saillantes, subovales, très-légèremınt distantes. Les postérieures petites, plus ou moins saillantes, rapprochées à leur base, divergentes au sommet, en cône court et mousse ; à lame supérieure subétranglée vers son premier tiers ; à lame inféricure nulle ou enfouie.

Pieds peu allongés. Trochanters antèrieurs petits, cunéiformes; les inlermédiair'es et postérieurs un peu plus grands, subcunéiformes. Cuisses subcomprimées, subatlénuées vers leur extrémitẻ ; les antérieures à peine spinosules en dessous vers leur sommet. Tibias subélargis dès leur base, plus ou moins épineux, munis au bout de leur tranche inférieure de 2 éperons grêles, dont l'interne plus long; les antérieurs plus courts et moins épineux. Tarses antérieurs courts, à 4 premiers articles subdéprimés, dilatés dans les 2 sexes; les intermédiaires et postérieurs assez allongés, à $1^{\mathrm{er}}$ article allongé, subégal aux 3 suivants réunis : ceux-ci triangulaires, graduellement plus courts : le dernier assez grêle, en massue, beaucoup moins long que le $\mathbf{1}^{\mathrm{er}}$. Ongles petits, grêles, arqués.

Ons. Les espèces de ce genre, peu agiles, fréquentent le littorál de la mer.

Cette coupe générique diffère du genre Philonthus par sa forme linéaire, semblable à celle des Xantholins; par son prothorax plus oblong, plus ou moins rétréci en arrière, à longue soie plus distante du rebord latéral. Le métasternum est plos développé que dans tous les autres Philonthates. La structure des palpes et des tarses antérieurs et postérieurs la distingue suffisamment du genre Gabrius. La lame mésosternale n'est pas fortement arrondie au sommet comme dans le genre Hesperus, avec les hanches intermédiaires beaucoup moins écarlées.

Trois espèces françaises entrent dans le genre Cafius; En voici les signes distinctifs.

a Élytres grossièrement et assez densement ponctuées, assez brillantes, à peine plus longues que le prothorax. Corps d'un noir de poix, avec les palpes, la majeure partie des antennes, le dessus de l'abdomen, le dessous du prothorax, le ventre, les tibias et les tarses plus ou moins ferrugineux Yeux médiocres. . . . cicarricusus

aa Elytres plus ou moins finement et densement pointillées, mates.

b $\dot{E} l y l v e s$ concolores, un peu plus longues que le prothorax, assez

finement et densement ponctıées. Abdomen assez brillant, concolore, assez furtement ponctué. Yeux médiocres, séparés du cou par un intervalle grand. Le dernier article des antennes ferrugineux. . . . . . . . . . . . Fucicola. 


$$
\text { STAPHYLINIENS. - Cafius }
$$

bb Elytres a marge latérale testacée, sensiblement plus longues que le prothorax, très-finement et très-densement pointillées. Abdomen mat, linéé de cendré, très-finement ponctué. Yeux assez grands, séparés du co:t par un intervalle moins grand. Le dernier article des antennes concolore. . . . . . халтносома.

\section{Cafiug cleatricosug, ERICHSON..}

Allongé, linéaire, déprimé, d'un noir de poix, avec les palpes, les antennes (moins leur base), le dessus de l'abdomen, le dessous du prothorax, le ventre, les tibias et les tarses ferrnginenx. Tête et prothorax luisants, à cicatrices. Élytres à peine plus longnes que le prothorax, assez brillantes, grossièrement et assez densement ponctuées. Abdomen pubescent, finement et densement pointille.

$\sigma^{*}$ Le $6^{\text {e }}$ arceau ventral assez fortement, le $5^{\mathrm{e}}$ faiblement sinués dans le milieu de leur bord apical.

ㄴ Les $5^{\mathrm{e}}$ et $6^{\mathrm{c}}$ arceaux du ventre simples.

Philonthus cicatricosus, Ericuson, Gen. et Spec. Staph. 454, 43. - Falrmaire et

LABOULbène, Faun. Ent. F. I, 521, 29.

Cafus cicatricosus, Fauvel, Faun. Gallo.Rhén. III, 423, 2.

$$
\text { Long., } 0^{\mathrm{m}}, 0110 \text { (5 1.); - larg., } 0^{\mathrm{m}}, 0015 \text { (2/3 l.). }
$$

Corps allongé, linéaire, déprimé, d'un noir de poix, avec l'abdomen errugineux : celui-ci et les élytres à pubescence grise, plus éparse sur ces dernières.

Tête grande, en carré à peine oblong, plus large que le prothorax, éparsement sétosellée, grossièrement ponctuée derrière les yeux, d'un noir de poix luisant. Front très-large, subdéprimé, marqué sur son milieu d'une petite fossette oblongue et, de chaque côté, en arrière, de 2 cicatrices à fond grossièrement ponctué, avec les pores sétifères, situés entre les yeux. placés eux-mêmes au fond d'une impression ou large fossette arrondie. Saillie antennaire assez sensible. Cou lisse, d'un noir de poix luisant. Labre fortement sétosellé ell avant. Mlandibules d'un noir de poix. Palpes d'un roux ferrugineux.

Yeux médiocres, grisâtres, micacés, séparés du cou par un espace plus long que leur plus grand diamètre. 
Antennes peu allongée:, plus longues que la tète, subfiliformes; légèr cment pubescrntes et pilosellées vers leur base; ferrugineuses, avec le $1^{\mathrm{er}}$ article renıbruni; celui-ci allongé, en massne assez grèle $\mathrm{c} t \mathrm{à} \mathrm{peine}$ arquée : les $2^{\mathrm{e}}$ et $3^{\mathrm{e}}$ obconiques : le $2^{\mathrm{e}}$ oblong : le $3^{\mathrm{e}}$ un peu plus long, suballongé : les suivants graduellement un peu plus courts: les $4^{\mathrm{e}} \mathrm{à} 6^{\mathrm{e}}$ suboblongs : les $7^{\mathrm{e}}$ et $8^{\mathrm{e}}$ non, les $9^{\mathrm{e}}$ et $10^{\mathrm{e}} \mathrm{a}$ peine transverses, vus de côté : le dernier subovale, à peine tronqué ou subéchancré au bout.

Prothorax en carré suboblong et visiblement rétréci en arrière, où il est sensiblement moins large que les élytres; obtusément tronqué au sommet; à angles antérieurs fortement infléclis et arrondis; subarqué au avant sur les côtés, avec ceux-ci, vus latéralement, largement sinués en arrière et les angles postérieurs obtus et arrondis; à peine arrondi à sa base; peu convexe; lisse, avec la longue soie des côtés as:ez distante du rebord latéral; paré sur le dos de 2 séries de 2 ou 3 gros points enfoncés, sétifères, l'antérieur écarté, dans une fosselte arrondie, les 2 postérieurs rapprochés au fond d'une impression ou cicatrice oblongue; offrant en outre, dans l'ouverture des angles antérieurs et en arrière vers la marge latérale, quelques autres gros points enfoncés, sétifères; d'un noir de poix luisant, avec la partie infléchie des angles antérieurs finement chagrinée et moins foncée. Repli finement chagriné, glabre, d'un ferrugineux obscur.

Écussun chagriné, ponctué, légèrement pubescent, obscur.

Elytres suboblongues, à peine plus longues que le prothorax; déprimées; grossièrement et assez densement ponctuées; d'un noir de poix assez brillant; éparsement pubescentes, ciliées de pâle à leur sommet, avec 2 ou 3 longues soies sur les côtés. Épaules étroitement arrondies.

Abdomen allongé, un peu moins large à sa base que les élytres; subparallèle ou subatténué tout à fait en arrière; subconvexe sur le dos; trèséparsement sétosellé, à pores sétifères bien marqués ; finement et densement pointillé ; d'un ferrugineux peu brillant et parfois assez obscur ; finement et modérément pubescent. Le $6^{\mathrm{e}}$ segment un peu moins ponctué, subarrondi au sommet.

Dessous du corps assez densement et aspèrement ponctué, finement pubescent, d'un noir de poix assez brillant, avec l'antépectus et le ventre ferrugineux. Dessous de la tête presque lisse ou très-éparsement et légèrement ponctué. Pointe mésosternale subacérée. Métasternum subdéprimé. Ventre assez convexe, finement chagriné entre les points, à pores sétifères fortement accusés mais peu nombreux, parfois rapprochés plusieurs ensemble sur les $5^{\circ}$ et $6^{\ominus}$ arceaux. 
Pieds peu allongés, légèrement pubescents, subaspèrement ponctués, noirs on bruuâtres, avec les tibias et les tarses plus ou moins ferrugineux. Cuisses postérieures assez grêles. Tibias antérieurs à pubescence brillanțc, s'étendant aussi sous les cuisses. Tarses antérieurs médiocrement ou même assez fortement dilatés dans les 2 sexes.

Patrie. Cette espèce, remarquable par les cicatrices ou impressions de sa tête et de son prothorax, se prend dans les environs de Toulon, d'Hyères et de Cette, et dans d'autres localités du littoral méditerranéen. Elle se tient cachée sous les fucus et autres dèbris marins, et souvent elle se creuse un trou dans la vase humide.

OBs. Les pieds sont parfois presque entièrement d'un roux ferrugineux. Rarement, les élytres sont d'un roux de poix.

Le plus souvent, les séries dorsales du prothorax ne présentent que 3 points. Quelquefois même, les 2 postérieurs sont rédıits à un seul.

\section{ə. Cafius fuclcola, Curtis.}

Allongé, linéaire, déprimé, d'un noir brunâtre, avec la bouche, le dernier article des antennes et les pieds plus ou moins ferrugineux. Tête et prothorax assez brillants. Elytres mates, brièvement pubescentes, un peu plus longues que le prothorax, densement et râpeusement ponctuées. Abdomen assez brillant, assez longuement pubescent, plus fortement et moins densement ponctué, concolore.

$\sigma^{*}$ Le $6^{\circ}$ arceau ventral échancré au sonmet en triangle assez profond, le $5^{\text {e }}$ plus largement et moins profondément.

$q$ Les $5^{\circ}$ et $6^{\ominus}$ arceaux du ventre entiers.

Cafius fucicola, Curtis, Brit. Ent. VII, 323. - Fauvel, Faun. Gallo-Rhén. III, $423,3$.

Philonthus fucicola, Nordmann, Symb. 84, 42. - Erictison, Gen. et Spec. Staph. $454,42$.

$$
\text { Long., } 0^{\mathrm{m}}, 0098 \text { ( } 4 \text { 1/2 l.); - larg., } 0^{\mathrm{m}}, 0015 \text { (2/3 l.). }
$$

Corps allongé, linéaire, déprimé, d'un noir brunâtre, mat sur les ély!res; recouvert sur celles-ci et l'abdomen d'une fine pubescence grise ct brillante. 
Téte graude, subcarrée, plus large que le prothorax, distinctementsétosellée, finement chagrinée; grossièrement ponctuée derriére les yeux ; d'ụn noir assez brillant. Front très-large, peu convexe, assez grossièrement et rugueusement ponctué le long du bord interne des yeux ; creusé, de chaque côté, entre ceux-ci, d'un pore sétifère plus fort et fovéiforme, avec une impression médiane obsolète. Cou lisse, d'un noir luisant. Labre brillant, noir, fortement sétosellé en avant. Mandibules obscures. Palpes d'un ferrugineux foncé, avec le dernier article, moins le sommet, plus clair.

Yeux médiocres, obscurs, séparés du cou par un espace plus long que leur plus grand diamètre.

Antennes plus courtes que la tête et le prothorax réunis; subfiliformes ou à peine épaissies; finement duveteuses ; légèrement pilosellées, surtout vers leur base ; obscures, avec l'insertion des premiers articles et souvent le dernier plus ou moins ferrugineux; le $1^{\text {er }}$ allongé, en massue assez longue et subarquée : les $2^{\mathrm{e}}$ et $3^{\mathrm{e}}$ obconiques : le $3^{\mathrm{e}}$ un peu plus long que le $2^{\mathrm{e}}$ : les suivants graduellement un peu plus courts: les $4^{\mathrm{e}}$ et $5^{\mathrm{e}}$ subcarrés : les $6^{\circ}$ à $10^{\circ}$ légèrement transverses, les pénultièmes néanmoinj un peu plus fortement : le dernier ovalaire, obliquement tronqué au bout et subacuminé inférieurement.

Prothorax un peu plus long que large; subsinueusement rétréci en arrière, où il est moins large que les élytres; obtusément tronqué au sommet; à angles antérieurs infléchis et arrondis ; tronqué sur le milieu de sa base; obliquement et arcuément coupé sur les côtés de celle-ci, avec les angles postérieurs très-obtus ; peu convexe ; très-finement chagriné ; creusé sur le dos de 2 séries de 4 gros points sétifères, dont l'antérieur plus écarté et situé presque sur la marge même, avec 3 ou 4 points semblables dans l'ouverture des angles antérieurs ; fortement sétosellé sur les côtés, avec la longue soie latérale assez distante du rebord; d'un noir assez brillant et parfois brunâtre. Repli lisse, glabre, brun.

Écusson pointillé, pubescent, d'un noir peu brillant.

Élytres à peine oblongues, un peu plus longues que le prothorax; déprimées; assez finement, densement et râpeusement ponctuées; d'un noir brunâtre et mat ; brièvement et assez densement pubescentes ; ciliées de gris pâle à leur sommet; très-éparsement sétosellées, avec 1 soie plus longue vers l'écusson, 1 autre après le milieu des côtés et 2 autres sur les épaules, dont le postérieur naissant d'un pore plus gros. Épaules arrondies. 
Abdomen suballongé, moins large que les èlytres; subparallèle ou à peine arqué sur les còtés, puis allénué tout à fait en arrière; subconvexe sur le dos; à pores sétifères bien marqués et subfovéolés; un pell plus fortement mais moins densement ponctué que les élytres; d'un noir assez brillant, avec le rebord latéral moins foncé; finement et assez longuement pubescent; éparsement sétosellé. Le $6^{\circ}$ segment moins ponctué, subarrondi au sommet.

Dessous du corps aspèrement ponctué, finement pubescent, d'un noir assez brillant, avec l'antépectus et le ventre souvent moins foncés. Ventre convexe, éparsement sélosellé.

Pieds peu allongés, légèrement pubescents, aspèrenient ponctués, fer rugineux, avec le sommet des cuisses et des tibias parfois rembruni. Cuisses postérieures plus grêles. Tarses antérieurs plus ( $\left.\sigma^{*}\right)$ ou moins ( $q$ ) dilatés.

Patrie. Celte espèce, propre à l'Angleterre, a été trouvée à Morlaix el à la Rochelle.

Oss. Elle diffère du cicatricosus par sa taille moindre et par sa couleur plus obscure; par ses élytres plus mates et plus longues; par son abdomen moins allongé, plus noir, plus brillant, plus fortement et moins densement ponctué. Les points de la tête et dú prothorax sont moins gros et moins en fossette, etc.

Le repli des élytres n'est pas testacé comme chez le Xantholoma. La ponctuation de l'abdomen est plus forte et moins serrée, celle des élytres un peu moins fine, un peu moins dense el plus râpeuse. L'abdomen est plus brillant; les élytres sont un peu moins longues, etc.

\section{Cafius xantholoma, Gravenhorst.}

Allongé, linéaire, déprimé, noir, avec la marge inférieure du repli des élytres testacé, les tibias et les tarses d'un roux de poix, et l'abdomen linéé de cendré. Tête et prothorax brillants. Elytres et abdomen mats, finement pubescents, très-finement et très-densement pointillés. Élytres sensiblement plus longues que le prothorax.

$\sigma^{7}$ Le $6^{\mathrm{e}}$ arcean ventral assez fortement, le $5^{\mathrm{e}}$ sensiblement sinués dans le milieu de leur bord apical. Le $6^{\mathrm{e}}$ offrant au devant du sinus une étroite 
ligne longitudinale lisse (1). Le $5^{e}$ parfois faiblement et longitudinalement impressionné au devant de son sinus.

q Les $5^{\mathrm{e}}$ et $6^{\mathrm{e}}$ arceaux du ventre simples.

Slaphylinus xantholoma, Gratenhonst, Mon. 41, 3. - Gyll.f.NHat, Ins. Suec. II, $323,39$.

Cafius xantholoma, CURtis, Brit. Ent. VII, 322. - MaNNERHEim, Brach. 31, 1. - Thouson, Skand. Col. II, 152, 1, 1860. - Fauvel, Faun. Gallo-Rhén. III, $424,4$.

Gyrohypnus xantholoma, NoRdmans, Symb. 126, 28.

Philonthus xantholoma, Ericuson, Gen. et Spec. Staph. 452, 40, - FaIrmaire et

LABoulbène, Faun. Ent. Fr. I, 521, 28. - JaCQCELin du VAL, Gen. Col. Eur. Staph. pl. 14, fig. 68. - KraATz, Ins. Deut. II, 594, 29.

Variété a. Pieds, pourtour du prothorax, écusson et abdomen roux, celui-ci varié de noir et de cendré.

Philonthus variegatus, Erichson, Gen. et Spec. Staph. 453, 41.

$$
\text { Long., } 0^{\mathrm{m}}, 009 \text { (3 1/2 1.); - larg., } 0^{\mathrm{m}}, 0015 \text { (2/3 l.). }
$$

Corps allongé, linéaire, déprimé, noir, avec la marge inférieure du repli des élytres testacée : celles-ci et l'abdomen mats, revêtus d'une fine pubescence grise et assez serrée, ce dernier avec des lignes de taches soyeuses et cendrées.

Tête grande, presque carrée, aussi large ( $q$ ) ou un peu plus large $\left(\sigma^{\circ}\right)$ que le prothorax, éparsement sétosellée, finement chagrinée et grossièrement ponctuée derrière les yeux; d'un noir brillant et parfois submétallique. Front très-large, subdéprimé, creusé entre les yeux de 2 points enfoncés, grossiers, fovéiformes et sétifères, écartés, entre lesquels se trouve une légère fossette oblongue. Cou lisse, d'un noir brillan. Labre cilié et fortement sétosellé en avant. Mandibules et palpes couleur de poix, avec le dernier article des maxillaires souvent roussâtre.

Yeux assez grands, obscurs ou grisâtres, séparés du cou par un espace à peine aussi long que leur plus grand diamètre.

Antennes peu allongées, plus courtes que la tête et le prothorax réunis ; subfiliformes ou à peine épaissies; légèrement pubescertes et pilosellées vers leur base; obscures, avec l'insertion des premiers articles souvent

(1) Ce $6^{\mathrm{e}}$ arceau est parfois obscurément subélevé en faite sur sa ligne médiane. 
d'un roux de poix; le $1^{\text {er }}$ allongé, en massue subarquée : les $2^{\circ}$ et $3^{\circ}$ obconiques : le $2^{\mathrm{e}}$ oblong : le $3^{\mathrm{e}}$ un peu plus long, suballongé : les suivants graduellement un peu plus courts, avec les pénultièmes non ou à peine transverses, vus de côté : le dernier subovalaire, obtusément acuminé au bout.

Prothorax en carré suboblong ct subrétréci en arrière, où il est beaucoup moins large que les élytres ; tronqué au sommet; à angles antérieurs fortement infléchis et arrondis; à peine arqué en avant sur les côtés, avec ceux-ci, vus latéralement, largement sinués en arrière et les angles postérieurs obtus; subarrondi à sa base; peu convexe; lisse, avec la longue soie des côtés assez distante du rebord latéral ; paré sur le dos de 2 séries de 4 gros points sétifères, l'antérieur souvent plus écarté, parfois un peu moindre, avec 3 ou 4 gros points, également sétifères, dans l'ouverture des angles antérieurs; distinctement sétosellé sur les côtés (1); d'un noir très-brillant et submétallique, avec la partie infléchie des angles antéricurs finement chagrinée et souvent moins foncée. Repli presque lisse, glabre, brunâtre.

Écusson pointillé, pubescent, obscur et mat.

Élytres oblongues, sensiblement plus longues que le prothorax; déprimées ; très-finement et très-densement pointillées ; d'un noir mat, avec le repli pilus ou moins largement testacé ; finement et assez densement pubescentes, ciliées de pâle à leur sommet, avèc 2 soies redressées sur le côté des épaules. Celles-ci arrondies.

Abdomen allongé, un peu moins large à sa base que les élytres; subparallèle ou subatténué tout à fait en arrière; subconvexe sur le dos; à pores sétifères bien marqués; très-finement et très-densement pointillé; d'un noir mat; finement et assez densement pubescent, avec 2 séries dorsales de taches oblongues, composées de poils soyeux et cendrés, et des traits de même couleur sur les $3^{\mathrm{e}}$ et $5^{\mathrm{e}}$ segments, le long du rebord latéral (2). Le 6e taché de cendré, subpellucide et subarrondi au sommet, a vec celui-ci parfois à peine sinué dans son milieu.

Dessous du corps finement et densement pointillé, densement pubescent, d'un noir peu brillant. Dessous de la tète finement chagriné, éparsement

(1) Les soies s'étendent mème le long du bord postérieur, et cela aussi chez les autres espèces.

(2) Dans les échantiltons bien frais, on aperçoit une $3^{\text {s }}$ tache cendríe sur le milieu de la base des $4^{e}$ et $5^{e}$ segments. 
ponctué. Pointe mésosternale émoussée. Métasternum subdéprimé. Ventre assez convexe, à pores sétifères bien marqués et épars.

Pieds peu allongés, finement pubescents, aspèrement pointillés, obscurs, avec les tibias et les tarses d'un roux de poix. Cuisses postérieures assez grêles. Tarses antérieurs plus $\left(\sigma^{*}\right)$ ou moins ( ( ) fortement dilatés.

Patrir. Cette espèce est très-répandue, soụs les fucus et autres débris marins, sur tout le littoral de la Manche, de l'Océan et de la Méditerranée.

OBs. Elle diffère des espèces précédentes par sa couleur plus obscure, pär ses élytres plus long!nes, par son abdomen varié de taches cendrées. La taille est moindre, etc.

Elle varie beaucoup pour la taille (de 6 a 9 millimètres) et pour la couleur. Chez les sujets immatures, les pieds sont entièrement d'un roux testacé, et le ventre est d'un roux ferrugineux ou au moins sur le bord postérieur de chaque arceau. La variété $a$ est remarquable par son prothorax bordé de roux et par son abdomen ferrugineux, varié de noir et de cendré.

Les $5^{\mathrm{e}}$ et $6^{\circ}$ arceaux du ventre sont parfois plus densement pointillés que les précédents.

\section{Genre Pseudidus, Pseudide, Mulsant et Rey.}

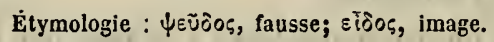

CaRaCtères. Corps allongé, linéaire, déprimé, ailé, pubescent, à forme de Xantholin.

Tête grande, saillante, en carré suboblong, de la largeur du prothorax, portée sur un col court et très-étroit. Tempes nullement rebordées sur les côtés. Épistome subsinueusement tronqué au sommet. Labre très-court, bilobé. Mlandibules saillantes, falciformes, acérées, angulairement dentées vers le milieu de leur côté interne, croisées au repos. Palpes maxillaires assez développés, à $1^{\mathrm{er}}$ article bien distinct, assez court : les $2^{\mathrm{e}}$ et $3^{\mathrm{e}}$ obconiques : le $3^{\mathrm{e}}$ aussi long, mais un peu moins épais que le $2^{\mathrm{c}}$ : le dernier fusiforme ou en cône atténué, un peu ou à peine plus long que le précédent. Palpes labiaux courts, à 2 premiers articles assez courts, subégaux, et le dernier plus long, subelliptique ou en fuseau peu allongé. Menton grand, trapéziforme, plus étroit en avant, tronqué au sommet, submembraneux dans sa partie antérieure. 
Yeux assez petits, subovalairement arrondis, peu saillants, séparés du cou par un intervalle plus long que leur plus grand diamètre.

Antennes suballongées, à peine épaissies, à $1^{\mathrm{er}}$ article en massue allongée : les $2^{\circ}$ et $3^{\mathrm{e}}$ obconiques : le $3^{\mathrm{e}}$ un pcu plus long que le $2^{\mathrm{c}}$ : les $4^{\mathrm{c}} \mathrm{a}$ $10^{\mathrm{e}}$ graduellement un peu plus courts, avec les pénultièmes non transverses : le dernier ovalaire-oblong, subtronqué au bout.

Prothorax en carré oblong, moins large que les élytres; densement pointillè, avec une ligne médiane lisse; subtronqué au sommet; à angles antérieurs non saillants; arrondi à sa base; très-finement ou à peine rebordé sur celle-ci et sur les côtés; à rebord latéral sinueusement infléchi d'arrière en avant (1). Repli assez large, incliné, très-visible vu de côté, sans opercule prothoracique.

Écusson grand, triangulaire.

Élytres oblongues, à peine simultanément échancrées à leur bord apical ; arrondies à leur angle postéro-externe; finement rebordées sur la suture. Repli étroit, médiocrement infléchi, subparallèle. Épaules peu saillantes.

Prosternum un peu développé au devant des hanches antérieures, offrant eritre celles-ci un angle aigu, à disque convexe, à sommet carinulé et submucroné. Mésosternum à lame médiane triangulaire, à pointe trèsaiguë, subaciculée et prolongée un peu au delà du milieu des hanches intermédiaires; à disque plan, traversé vers ou après son premier tiers par une arête très-fine et bissinuée. Médiépisternums grands, séparés du mésosternum par une fine suture suboblique. Médiépimères très-étroites, sublinéaires. Métasternum assez développé, échancré au devant des hanches postérieures; prolongé entre celles-ci en un lobe explané, subcorné, court, finement incisé dans son milieu; avancé entre les intermédiaires en angle court, obtus et subarrondi. Postépisternums très-étroits, sublinéaires. Postépimères peu distincles ou très-petites, en onglet.

Abdomen allongé, subparallèle, fortement rebordé sur les côtés; à 4 premiers segments subėgaux, le $5^{\mathrm{c}}$ un peu plus grand : le $6^{\mathrm{e}}$ saillant, rétractile : celui de l'armure caché, émettant 2 lanières étroites. Ventre à $1^{\text {er }}$ et $5^{\mathrm{e}}$ arceaux, et parfois $2^{\mathrm{e}}$, un peu plus grands que les autres : le $6^{\mathrm{e}}$ firis ou moins saillant, rétractile.

IJ.c.c.l s antérieures grandes, presque aussi longues que les cuisses, saillantes, coniques, contiguës au somm t. Les intermédiaires assez

(1) Le pore à longue soie est assez distant du rebord tatéral. 
grandes, peu saillantes, ovales-oblongues, rapprochées dans leur milieu. Les postérieures petites, un peu saillantes, rapprochées à leur base, divergentes au sommet, en cône court et mousse; à lame supérieure subétranglée vers son premier tiers; à lame inférieure nulle ou enfouie.

Pieds peu allongés. Trochanters antérieurs et intermédiaires petits, cunéiformes; les postérieurs un peu plus grands, subcunéiformes. Cuissę subcomprimées, subatténuées vers leur extrémité. Tibias subélargis de la base au sommet, plus on moins épineux, munis au bout de leur tranche inférieure de 2 éperons grêles, dont l'interne plus long; les antérieurs plus courts, moins épineux ainsi que les postérieurs. Tarses antérieurs courts, à 4 premiers articles subdéprimés, médiocrement dilatés dans les 2 sexes; les intermédiaires et postérieurs suballongés, à $1^{\text {er }}$ article allongé, subégal aux 3 suivants réunis : ceux-ci suboblongs, gradueltement plus cour's : le dernier grêle, moins long que le $1^{\mathrm{er}}$. Ongles petits, très-grêles, arqués.

Oвs. Les espèces de ce genre fréquentent le bord des eaux. Elles sont peu agiles.

Celte coupe générique lie la précédente aux Bisnius. Elle ne diffère du genre Cafius que par son prothorax densement pointillé et moins rétréci en arrière, par ses tibias antérieurs et postérieurs moins épineux, et surtout par l'arête transversale du mésosternum, qui est beaucoup plus fine, non arquée, mais bissinuée (1). Du resıe, la fine pubescence du corps, la ponctuation serrée de la têle et du prothorax impriment à ces insectes un aspect particulier, avec une teinte presque entièrement mate, qu'on ne retrouve nulle part.

Nous ferons rentrer 3 espèces dans notre genre Pseudidus. En voici les caractères :

a Le dernier article des palpes maxillaires conico-fusiforme, visiblement plus long que le pénultième. Les $2^{\mathrm{e}}$ et $3^{\mathrm{e}}$ articles des antennes inégaux. Les 3 premiers segments de l'abdomen peu visiblement impressionnés à leur base.

b Téte non ou à peine plus large que le prothorax : celui-ci subparallèle ou à peine rétréci en arrière, mat, à angles antévieurs obtus. Abdomen très-densement pointillé et densement pubescent. Antenus et picds plus ou moins obscurs. . . . . . . . SERICEUs.

(1) Parfuis d'une manièrc tiès-obsolèle. 


\section{staphyliniens. - Pseudidits}

bb Tête un peu plus large que le prothorax : celui-ci subrétréci en arrière, un peu brillant, à angles antciricurs subrcctangulaires. Abdomen densement pointillé et peu densement pubescent. Bouche, antennes et pieds plus ou moins testacés. . .'. . . Pruinosus.

aa Le dervier article des palpes maxillaires conique, non ou à peine plus long que le pénultième. Les $2^{\circ}$ et $3^{\mathrm{e}}$ articles des antennes subégaux. Les 3 premiers segments de l'abdomen faiblement impressionnés à leur base (1).

\section{Pendidus sericens, HoLne.}

Allongé, linéaire, déprimé, très-finement pubescent, d'un noir mat, avec le sommet des antennes, les genoux et les tarses roussâtres. Élytres visiblement plus longues que le prothorax. Tete et prothorax densement ponctués, avec une ligne médiane lisse : celui-ci subparallèle. Élytres et abdomen très-finement et très-densenent pointillés.

$\sigma^{*}$ Le $6^{\mathrm{e}}$ arceau ventral angulairement entaillé, le $5^{\mathrm{e}}$ à peine sinué, dans le milieu de leur bord apical.

q Les $5^{\mathrm{e}}$ et $6^{\mathrm{e}}$ arceaux du ventre simples.

Remus sericeus, HoLMe, Trans. Ent. Soc. Lond. II, 64, 1837.

Plilonthus sericeus, Erichson, Gen. et Spec. Staph. 509, 141. - FairmalRe et Laboulbène, Faun. Ent. Fr. I, 532, 69.

Cafius sericeus, Thonson, Skand. Col. II, 153, 2, 1860. - Fauvec, Faun. GalloRhén. III, 425, 8.

Varièté $a$. Tibias d'un roux testacé, avec les tarses plus clairs.

$$
\text { Long., 0"m,0052 (2 1/3 l.); - larg., } 0^{\mathrm{m}}, 0008 \text { (1/3 l.). }
$$

Cor ps allongé, linéaire, déprimé, d'un noir mat ; revêtu d'une très-fine pubescence crndréc, plus serrée sur les élytres et l'abdomen.

Téte grande, en carré suboblong, de la largeur du prothorax ou à peine plus large, éparsement sétoselléc sur les côtés, légèrement pubescente, finement chagrinée et en outre distinctement et densement ponctuée, excepté

(1) Dans la seclion aa, non-seulement les 3 premiers segments de l'abdomen sont un peu plus visiblement imprussionnés à leur base que dans la section opposée, mais encore le $4^{\mathrm{e}}$ parait l'être à peine.

Bri. 
en avant; d'un noir mat. Front très-large, peu convexe ; offrant sur son milieu un espace longitudinal lisse, assez brillant et parfois finement $\mathrm{et}$ obsolètement canaliculé antérieurement. Col finement chagriné, glabre, d'un noir mat. Labre éparsement sétosellé vers son sommet. Mandibules et palpes d'un roux de poix plus ou moins foncé.

\section{Yeux obscurs.}

Antennes un peu plus courtes que la tête et le prothorax r'éunis; à peine épaissies ; légèrement pubescentes et éparsement pilosellées vers leur base; obscures ou d'un roux brunâtre, avec le dernier article parfois moins foncé, et l'insertion des premiers articles d'un roux de poix ; le $1^{\text {er }}$ allongé, en massue à peine arquée : les $2^{\mathrm{e}}$ et $3^{\mathrm{e}}$ obconiques : le $2^{\mathrm{e}}$ oblong, le $3^{\mathrm{e}}$ un peu plus long : les $4^{\mathrm{e}}$ à $10^{\mathrm{e}}$ graduellement un peu plus courts, subobconiques : les $4^{\mathrm{e}}$ à $6^{\mathrm{e}}$ suboblongs : les $7^{\mathrm{C}}$ à $10^{\mathrm{e}}$ à peine ou non plus longs que larges : le dernier ovalaire-oblong, obliquement subtronqué au bout et subacuminé inférieurement.

Prothorax en carré oblong, subparallèle ou à peine rétréci en arrière, où il est sensiblement moins large que les élytres; oblusément tronqué au sommet; à angles antérieurs arrondis; arqué à sa base, avec les angles postérieurs obtus; peu convexe; légèrement pubescent et éparsement sétosellé, avec la longue soie des côtés assez distante du rebord latéral; très-finement chagriné et en outre assez finement et densement ponctué, avec une ligne médiane longitudinale, lisse, subélevée en arrière; d'un noir mat, avec ladite ligne assez brillante. Repli très-finement chagriné, noir: glabre.

Écusson densement pointillé, pubescent, d'un noir mat.

Élytres oblongues, visiblement plus longues que le prothorax; déprimées ; très-finement et très-densement pointillées; d'un noir mat et un peu grisâtre ; très-finement el densement pubescentes; brièvement ciliées de pâle à leur bord apical; parées sur les côtés de quelques légères soies redressées, dont 1, beaucoup plus lon jue, vers les épaules. C'elles-ci subarrondies.

Abdomen allongé, un peu moins large à sa base que les élytres; subparallèle sur ses côtés ou à peine atténué tont à fait en arrière; légèrement convexe sur le dos; éparsement et longuement sétosellé, surtout latéralement; très-finement et très-densement pointıllé ; d’un noir mat, avec une très-fine et dense pubescence cendrée, qui lui donne un aspect grisâtre. Le $6^{\circ}$ segment moins ponctué, un peu plus brillant, obtusément tronqué ou à peine arrondi au sommet. 
Dessous du corps très-densement et très-finement pointillé, finement et densement pubescent, d'un noir peu brillant. Dessous de la tête plus fortement ponctué. Métasternum subdéprimé. Ventre assez convexe, éparsement sétosellé, à $5^{\mathrm{e}}$ arceau marqué à sa base de 2 pores sétifères plus gros et plus profonds.

Pieds peu allongés, très-finement pointillés, très-finement pubescents, obscurs, avec les genoux et les tarses d'un roux de poix subtestacé, les trochanters et le sommet des hanches parfois un peu roussâtres. Cuisses ostérieures assez grêles, presque sublinéaires. Tarses antérieurs médiocrement dilatés.

Patrie. Cette espèce, remarquable par la ponctuation serrée de la tête et du prothorax, par sa fine pubescence cendrée et sa teinte mate, est indiquée quelquefois des environs de Paris et de Toulouse. Quant à nous, tous les exemplaires que nous avons vus provenaient des bords de la mer, des côtes de la Bretagne, de la Gironde, du Languedoc et de la Provence. Elle est assez rare sous les fucus et autres plantes marines.

OBs. La variété $a$ se distingue par ses pieds d'un roux testacé, avec les tarses plus clairs et les cuisses plus ou moins rembrunies.

Les exemplaires des côtes de l'Océan sont souvent d'une taille à peine plus grande que le filum.

\section{Pgeudidus pruinosus, ERICHSON.}

Allongè, linéaire, déprimé, très-finement pubescent, d'un noir presque mat, avec la bouche, les antennes (moins leur base) et les pieds d'un roux testacé. Élytres un peu plus longues que le prothorax. Tête et prothorax un peu brillants, densement ponctués, avec une ligne médiane lisse : celui-ci subrétréci en arrière. Elytres très-finement et très-densemient, abdomen finement et densement pointillés.

$\sigma^{*}$ Le $6^{e}$ arceau ventral angulairement entaillé dans le milieu de son bor'd apical.

\& Le 6 arceau ventral subarrondi au sommet.

Philonthus pruinosus, Erichson, Gen. et Spec. Staph. 510, 142. - Fairaraire e

Laboulbène, Faun. Ent. Fr. I, 532, 68. 


$$
\text { Long., } 0^{\mathrm{m}}, 0052 \text { (2 1/3 l.); - larg., } 0^{\mathrm{m}}, 0008 \text { (1/3 l.). }
$$

Corps allongé, linéaire, déprimé, d'un noir presque mat; revêtu d'une très-fine pubescence cendrée, un peu plus serrée sur les élytres et l'abdomen.

Tète grande, en carré à peine oblong, un peu plus large que le prothorax ; éparsement sétosellée sur les côtés, à peine pubescente, très-obsolètement chagrinée et, en outre, assez fortement et densement ponctuée; d'un noir un peu brillant. Front très-large, à peine convexe, offrant sur son milieu un espace longitudinal lisse, assez brillant, prolongé jusque sur l'épistome où il s'élargit. Cou à peine chagriné, glàbre, d'un noir assez brillant. Labre, mandibules et palpes d'un roux têstacé, avec la pointe de celles-là plus foncée.

Yeux obscurs. :

Antennes un peu plus courtes que la tête et le prothorax réunis ; à peine épaișsies ; légèrement pubescentes et éparsement sétosellées vers leur base ; d'un roux testacé, avec leurs 3 premiers articles un peu plus sombres; le $1^{\mathrm{er}}$ allongé, en massue à peine arquée : les $2^{\mathrm{e}}$ et $3^{\mathrm{e}}$ obconiques : le $2^{\mathrm{e}}$ oblong : le $3^{\mathrm{e}}$ à peine plus long : les $4^{\mathrm{e}}$ à $10^{\mathrm{e}}$ graduellement un peu plus courts, subobconiques ${ }^{\prime}$ les $4^{\mathrm{e}}$ à $7^{\mathrm{e}}$ suboblongs : les $8^{\circ}$ à $10^{\circ}$ environ aussi larges quélongs : le dernier ovâluire-oblong, obliquement subtronqué au bout et subacuminé inférieurement.

Prothorax en carré long, subrétréci en arrière, où il est sensiblement moins large que les élytres; obtusément tronqué au sommet; à angles antérieurs presque droits et non arrondis; "subarqué à sa base, avec les angles postérieurs subobtus; peu convexe ou même subdéprimé sur son milieu; éparsement pubescent ; éparsement sétosellé, avec la longue soie dès côtés assez distante du rebord latéral; obsolètement chagriné et, en outre, assez finement et densement ponctué, avec une ligné médiane longitudinale, lisse, subélevée en àrrière; entièrement d'un noir un peu brillant. Repti presque lisse, noir, glabre.

Ecícson très-densement pointillé, pubescent, obścur.

Élytres oblongues, à peine plus longues que le prothorax; déprimées; très-finement et très-densement pointillées; d'un noir mat ou presque mat et un peu grisâtre ; très-finement et assez densement pubescentes ; brì̀vement ciliées de pâle à leur, bord apical; parées, sur les côlés, de quelques légères soies redressées, dont 1, beaucoup plus longue, ver's les épaulés. Celles-ci subarrondies. 
Abdomen allorigé, à peiné moins large à sa base que les ćlytres; subparallèle; faiblement convexe sur le dos; a peine sétosellé, plus distinctement vers son extrémité ; moins finement et moins densement pointillé que les'élytres; d'un noir peu brillant, avec une très-fine pubescence cendrée, assez longue et peu serrée. Le $6^{\circ}$ segment presque lisse ou à peine ponctué, couleur:de poix, subarrondi au sommet.

Dessous du corps densement et finement pointillé, finement pubescent, d'un noir assez brillant.' Dessous de la tête plus fortement ponctué. Métasternum subdéprimé. Ventre' assez convexe, à peine sétosellé; plus distinctement eis arrière.

Pieds peu allongés, finement pointillés, finenıent pubescents; d'un roux de poix testacé, avec les genoux, les tibias et les tarses plus clairs. Cuisses postérieures assëz grêles. Tarses antérieurs 'médiocrement dilatés.

Patrie. Cette espèce est rare. Elle se prend sur le bord de la mer, dans les Pyrénées-Orientales.

OBS. Elle ressemble infiniment à la précédente. Elle est un peu moins mate, avec la pubescence de l'abdomen plu; longue et moins serrée. La tête est plus large relativement au prothorax, avec celui-ci un peu plus long, plus visiblement rétréci en arrière, et ses angles antérieurs un peu plus droits et moins arrondis. La ponctuation de l'abdomen est moins fine et moins serrée. Les parties de la bouche, les antennes et les pieds sont constamment d'une couleur plus claire, etc.

\section{Poendidus filum; KiESEnWETTER.}

Allongé, linéaire, déprimé, très-finement pubescent, d'un noir mat, avec la bouche, les antennes et les pieds d'un roux ferrugineux. Tête et prothorax très-fnèment ch zgrinés, densement ponctués, avec un espace longitudinal lisse. Elytres finement et tiès-densement, abdomen très-finement et très-densement pointillés : celui-ci faiblement impressionné sur la base des 3 premiers segments, à peine sur celle du $4^{\mathrm{e}}$.

$\sigma$ Le $6^{e}$ arceau ventral angulairement sinué dans le milieu de son bord apical.

ㄴ Le $6^{\mathrm{e}}$ arceau ventral simple. 
Philonthus filum, Kiesenwetter in Kuster, Kaef. Eur. XVII, 19. - Fairmatre et Laboulbène, Faun. Ent. Fr. I, 532, 70.

$$
\text { Long., } 0^{\mathrm{m}}, 0044 \text { (2 l.); - larg., } 0^{\mathrm{m}}, 0004 \text { (115 l.). }
$$

Corps allongé, linéaire, déprimé, d'un noir mat ; recouvert d'une trèsfine pubescence cendrée, serrée sur les élytres et l'abdomen.

Tête en carré suboblong, de la largeur du prothorax; très-éparsement sétosellée; légèrement pubescente; très-finement chagrinée ; densement ponctuée, avec un espace médian lisse, ne touchant pas au cou mais prolongé jusqu'à l'épistome; entièrement d'un noir peu brillant. Front trèslarge, subdéprimé. Cou à peine chagriné, d'un noir peu brillant. Labre, mandibules et palpes d'un roux plus ou moins ferrugineux.

Yeux obscurs.

Antennes assez courtes, moins longues que la tête et le prothorax réunis ; subfiliformes ou à peine épaissies; légèrement pubescentes et éparsement pilosellées vers leur base; d'un roux ferrugineux, avec les 3 premiers articles souvent un peu rembrunis; le $1^{\text {er }}$ allongé, en massue subarquée; les $2^{\mathrm{e}}$ et $3^{\mathrm{e}}$ oblongs, obconiques, subégaux : les suivants graduellement à peine pius courts, subobconiques : les $4^{\mathrm{e}}$ et $5^{\mathrm{e}}$ non, les pénultièmes à peine transverses, vus de côté : le dernier ovalaire, subtronqué au bout et subacuminé inférieurement.

Prothorax en carré long et subrétréci en arrière, où il est sensiblement moins large que les élytres; arcuément tronqué au sommet; à angles antérieurs subobtus et subarrondis; presque rectiligne sur ses côtés, vu de dessus; faiblement arqué à sa base, avec les angles postérieurs subobtus ; peu convexe ou même subdéprimé sur son disque; éparsement pubescent ; éparsement sétosellé, avec la longue soie des côtés assez disante du rebord latéral ; très-finement chagriné; assez finement et dense ment ponctué, avec un espace médian longitudinal, lisse, assez étroit, subélevé tout à fait en arrière; d'un noirpresque mat. Repli noir, lisse, glabre. Ecusson très-densement pointillé, pubescent, obscur.

Élytres oblongues, un peu plus longues que le prothorax ; déprimées ; finement, très-densement et subrugueusemeñt pointillées; d'un noir mat et à peine grisâtre ; très-finement et densement pubescentes; brièvement ciliées de pâle à leur bord apical; parées, sur les côtés, de quelques légères soies redressées, dont 1 , beaucoup plus longue, sur les épaules. Celles-ci étroitement arrondies. 
Abdomen allongé, à peine moins large à sa base que les élytres; subparallèle ; peu convexe sur le dos; faiblement impressionné en travers sur la base des 3 premiers segments, à peine sur celle du $4^{\circ}$; légèrement sétosellé; très-finement et très-densement pointillé ; d'un noir mat et un peu grisătre par l'effet de la très-fine et dense pubescence cendrée. Le $6^{\circ}$ segment assez large, moins pubescent et moins ponctué, plus brillant ct parfois couleur de poix, à peine arrondi au sommet.

Dessous du corps très-densement et finement pointillé, très-finement pubescent, d'un noir peu brillant et un peu grisâtre. Dessous de la tête moins finement ponctué. Hétasternum subdéprimé ou peu convexe. Ventre assez convexe, à peine sétosellé.

Pieds assez courts, très-finement pointillés, finement pubescents, d'un roux ferrugineux, avec les hanches et parfois la base des cuisses rembrunies, les trochanters restant roussâtres. Cuisses postérieures assez grêles. Tarses antérieurs médiocrement dilatés, le $1^{\mathrm{er}}$ article moins que les 3 suivants.

Patrie. Cette espèce, peu commune, se trouve dans le sable humide, au bord des eaux saumâtres, sur tout le littoral de la Méditerranée.

Obs. Par son aspect mat, cette espèce ressemblerait à un petit sericeus. Mais la structure des palpes maxillaires n'est pas tout à fait la même, et leur dernier article est un peu moins long, plus conique. Les $2^{\mathrm{e}}$ et $3^{\mathrm{e}}$ articles des antennes sont plus courts, obconiques, subégaux. Les 3 premiers segments de l'abdomen sont faiblement mais visiblement impressionnés à leur base. Le prothorax, à peine plus étroit, est moins parallèle, un peu rétréci en arrière, etc.

Genre Bisnius, Bisnie, Thomson.

Tromsov, Skand. Col. II, 168, 1860. Étymologie incertaine.

CARActères. Corps aliongé, linéaire, subdéprimé, ailé, légèrement pubescrni, à forme de Xantholin.

Tête grande, saillante, subcarrẻe ou oblongue, portée sur un col court et très-étroit. Tempes nullement rebordées sur les côtés. Épistome bissinueusement tronqué au sommet, à marge antérieure étroite, submembra- 
neuse ou cornée. Labre irès-court, à peine bilobذ. Mandibules saillantes, falciformes, acérées, angulairement diłatées vers le milieu de leur côté interne, croisées au repos. Palpes maxillaires médiocres, $\dot{a} 1^{\mathrm{er}}$ article rudimentaire : le $2^{\mathrm{e}}$ oblong, en massue subarquée : le $3^{\mathrm{e}}$ un peu plus court, plus épais, obconique : le dernier conique, plus long que le $3^{\mathrm{e}}$, souvent subaminci vers le bout. Palpes labiaux courts, à $2^{\mathrm{e}}$ article assez court, un peu plus épais que le $\mathbf{1}^{\text {er }}$ : le dernier à peine plus long, coirique: Menton fortement transverse, plus étroit en avant, tronqué au sommet.

Yeux petits, subarrondis, peu saillants, séparés du cou par un intervalle plus long que leur plus grand diamètre (1).

Antennes assez courtes, subépaissies, à $1^{\text {er }}$ article allongé, en massue subarquée : les $2^{\mathrm{e}}$ et $3^{\mathrm{e}}$ obconiques, suballongés, subégaux : les $4^{\mathrm{e}} \mathrm{a} 10^{\mathrm{e}}$ graduellement un peu plus courts, subcontigus', avec les pénultièmes subtransverses ou transverses : le dernier ovalaire, tronqué olı à peine échancré au bout.

Prothorax oblong, subrétréci en arrière, moins large que les élytres; plus ọ moins ponctué sur les côtés ; tronqué au sommet, à angles antérieurs non saillants ; subarrondi à sa base; très-finement rebordé sur celle-ci et sur les côtés; à rebord latéral subsinueusement infléchi d'arrière en avant (2). Repli étroit, incliné, visible vu de côté, sans opercule prothoracique.

Écusson grand, triangulaire.

Élytrés oblongues ou suboblongues, à peine simultanément échancrées à leur bord apical; subarrondies à leur angle postéro-externe; finement rebordées sur ila suture: Repli médiocre, assez fortement infléchi, subparallèle. Épaules peu saillantes.

Prosternum un peu développé au devant des hanches antérieures, offrant entre celles-ci un angle à somnet subaigu, à disque voûté. Mésosternum à lame médiane triangulaire, à sommet rétréci en pointe trèsaiguë et prolongée au moịns jusqu'au milieu des hąnches intermédiaires; à disque traversé dans son milieu par une arête transversale arquée, saillante. Médiépisternums grands, séparés du mésosternum par une fine suture transversalement oblique. Médiépimères très-réduite:, allongées ou sublinéaires. Métasternum assez grand, échancré au devant des hanches postérieures; prolongé entre celles-ci en un petit lobé, explané, subcorné.

(1) Les facettes des yeux sont relativement assez grossières.

(2) Dans ce genre, la tongue soie latćrale est assez distante du rebord. 
incisé dans son milieu; avancé entre les intermédiaires en une saillie obtuse: parfois confondue avec l'üternède qui est étroit. Postépisternums très-étroits, linéaires. Postépimères très-petites, en onglet.

Abdomen allongé, subparallèle ou subarqué sur lés côlés; fortement rebordé latéralement ; à 4 premier's segments subégaux, le $5^{\mathrm{e}}$ un peu plus grand: les 3 ou 4 premiers plus ou moins impressionnés en travers sur le milieu de leur base : le $6^{\prime \prime}$ plus ou noins saillant, rétracile : celui de l'armure celcé. Ventre à $2^{\mathrm{e}}$ arceau basilaire souvent distinct: les suivants subégaux : le $5^{\mathrm{e}}$ un peu plıs grand : le $6^{\mathrm{e}}$ plus ou moins saillant, rétractile.

IIanches antérieures grande:, de la longueur des cuisses, très-saillantes, coniques, contiguës au sommet. Les intermédiaires un peu moindres, peu saillantes, conico-subovales; rapprochées dans leur milieu. Les postérieures assez petites, à̃sez saillanies, 'faiblement écartéè à leur base, divergentes au sommet, coniques; à lame supérieute subétranglée dans son premier tiers; à lame inférieure nulle ou enfouie.

Pieds peu allongés, peu, robuptes. Trochanters antérieurs petits, les intermédiaircs moins petits, subcunéiformes; les postérieurs un peu plus grands, ovales-oblongs. Cuissés subcomprimées, atténuées vers leur extrémité ; Yes antérieures très-finement spinosules en dessous vers le sommet de leur côté interne. Tibias subélargis de la base au sommet, finement épineux, munis au bout de leur tranche inférieure de 2 petits éperons grêles, dont l'interne plus long; les antérieur's plus courts; les intermédiaires plus fortement épineux! Tarses"antérieurs 'courts, subdéprimés, plus $\left(\sigma^{*}\right.$ ) ou moins ( $ᄋ$ ) dilatés; lës interniédiaires et posterieurs peu allongés, à peine atténués vếs leur extrémita a a $1^{\text {er }}$ article moins long que les 3 suivants réunis, subégal a dernier ( 1$)$ : l s $2 \mathrm{e}$ à $4^{\mathrm{e}}$ assez couris, subégaux ou graduellement à peine plus courts: le dernier légèrement en massue, subégal aux 2 précẻdents réunis. Ongles très-petits, très-grêles, subarqués.

Oвs. Les petites espècés de cé genre-sont peu agileš et riveraines.

Leach (in Stephens, Ill. Brit. Ent. V, 247, 1833) donne pour type de son genre Bisnius le St. cephalotes, et lui assigne pour caraclères : le dernier article des palpes acuminé, les tarses antérieurs simples dans les

(1) Thomson dit: Tarsi postici articulo to 50 multo breviori. Quant à nous, nous arons toujour's vu le $1^{\text {er }}$ alticle au moins aussi long que le dernier. 
2 sexes, caractères fugitifs et non exclusifs, qu'on remarque dans d'autres genres ou sous-genres détachés des Philonthus.

Dans le genre ci-dessus décrit, les tarses antérieurs sont plus ou moins fortement dilatés chez les $\sigma^{\star}$. Thomson doit avoir eu des raisons pour appliquer le nom de Bisnius à des espèces qui ne présentent pas les caractères signalés par Leach pour sa coupe générique. Nous adopterons sa manière de voir, en excluant toutefois la synonymie de l'auteur anglais.

Les tarses postérieurs sont moins allongés, et le dernier article des palpes est autrement conformé que dans les genres Cafius et Pseudidus.

Le genre Bisnius renferme un petit nombre d'espèces, dont voici les différences :

a Antennes obscures, à base plus ou moins testacée, à pénultièmes articles à peine ou faiblement transverses.

b Tête non rétrécie en arrière. Les 3 premiers segments de l'abdomen légèrement impressionnés à leur base, a vec le fond des impressions à peine pointillé. Élytres d'un noir de poix, à sommet plus ou moins roussâtre. Pieds d'un testacé obscur.

bb Tête subrétrécie en arrière. Les 3 premiers segments de l'abdomen sensiblement impressionnés à leur base, avec le fond des impressions assez fortement ponctué. Élytres d'ın rouge de brique, à base plus ou moins rembrunie.

PROCERULLS.

a Antennes obscures, à base à peine moins foncée, à pénultièmes articles sensiblement transverses. Les 3 premiers segments de l'abdomen fortement impressionnés à leur base, avec le fond des impressions fortement et rugueusement ponctué. Corps d'un noir brillant. Pieds plus ou moins obscurs. . aaa Antennes entièrement testacées, à pénultièmes articles sensib!ement transverses. Les 3 premiers segments de l'abdomen sensiblement impressionnés à leur base, avec le fond des impressions presque lisse. Corps d'un noir brillant, avec les élytres d'un brun de poix. Pieds testacés. . . . . E Elongatulos.

1. Bismiug procerullus, Gravenhorst.

Allongé, linéaire, subdéprimé, légèrement pubescent, d'un noir brillant, avec la bouche, la base des antennes et les pieds d'un testacé obscur, et le. sommet des élytres d'un roux de poix. Tête el prothorax assez fortement et modérément ponctués, avec un espace longitudinal lisse. Élytres et abdomen finement et assez densement pointillès : celui-ci légèrement 
impressionné à la base des 3 premier's segments. Tête nullement rétrécie en arrière.

$\sigma^{\circ}$ Le $6^{\circ}$ arceau ventral légèrement sinué dans le milieu de son bord apical, avec un espace triangulaire lisse et subpellucide, au devant du sinus.

ㄴ. Le 6 e arceau ventral obtusément arrondi au sommet.

Slaphylimus procerulus, Gravenhorst, Mon. 95, 92. - Boisduval et LaCordaire, Faun. Ent. Par. 1, 409, 45.

Gyrohypnus procerulus, ManNerheIM, brach. 34, 16.

Plitonthus procerulus, Enichson, Col. March. I, 479, 49; - Gen. et Spec. Staph.

511, 144. - Redtenbacher, Faun. Austr. 707, 43. - Heer, Faun. Col. Helv. I, 272, 53. - Fairmaire et Laboulbène, Faun. Ent. Fr. I, 530,63. - Kraatz,

Ins. Deut. II, 624, 6 5.

Bisnius procerulus, Тномsоn, Sk2nd. Col. II. 169, 2, 1860.

Erichsonius procerulus, Fauvel, Faun. Gallo-Rhén. III, 431, 5.

$$
\text { Long., } 0^{\mathrm{m}}, 0038 \text { (1 3/4 1.); - larg., } 0^{\mathrm{m}}, 0004 \text { (1/5 l.). }
$$

C'orps allongé, linéaire, subdéprimé, d'un noir brillant, avec le sommet des élytres à peine roussâtre ; revêtu sur celles-ci et sur l'abdomen d'une fine pubescence gi isâtre.

Tète suncarrée ou à peine oblongue, de la largeur du proihorax ; éparsement sétosellée; à peine pubescente ; assez fortement et assez dense$m^{\circ} n t$ ponctuée sur les côtés, plus éparsement en dedans, avec un espace médian lisse, assez étroit; entièrement d'un noir brillant. Front trèslarge, peu convexe, triangulairement subimpressionne en avant vers l'épistome. Cou presque lisse, glabre, d'un noir brillant. Labre, mandibules et palpes d'un roux de poix, ces derniers souvent subtestacés.

Yeux obscurs, parfois lavés de gris.

Antennes assez courtes, un peu moins longues que la tête et le prothorax réunis; subépaissies; légèrement pubescentes et éparsement pilosellées vers leur base; obscures, avec les 3 premiers articles d'un roux de poix; le $1^{\text {cr }}$ allongé, en massue subarquée : les $2^{\mathrm{e}}$ et $3^{\mathrm{e}}$ suballongés, obconiques, subégaux : les suivants graduellement à peine plus courts : les $4^{\mathrm{e}}$ et $5^{\mathrm{e}}$ presque carrés : le $6^{\mathrm{e}}$ à peine, les $8^{\mathrm{e}}$ à $10^{\mathrm{e}}$ légèrement trarısverses : le dernier subovalaire, subtronqué au bout et à peine acuminé inférieure,ment. 
Prothorax oblong, à peine rétréci en arrière, où il est sensiblement moins large que les élytres; tronqué au sommet, avec les angles anté. rieurs à peine obtus el subémoussés ; presque droit suriles côtés ; subarqué à sa base, avec les angles postérieurs obtus et arrondis ; pen convexe; à peine pubescent; légèrement sétosellé, avec la longue soie des côtés as:ez distante du rebord latéral : assez fortement et peu densement ou modérément ponctué, avec un espace longitudinal médian lisșe, assez étroit; entièrement d'un noir brillant. Repli noir, lisse, glabre.

Écusson épärsement pointillé, à peine pubescent, d'un noir brillant.

Élytres oblongues, sensiblement plus longues que le prothorax; subdéprimées; finement et assez densement ponctuées ; d'un noir de poix brillant, avec le bord apical souvenț un peu roussâtre ; éparsement pubescentes, avec 2 ou 3 soies redressées, dont 1 notamment plus longue, sur

- le côté des épaules. Celles-ci étroitement arrondies.

Abdomen allongé, un peu moins large à sa base que les élytres; a peine arqué en arrière sur les côtés; subconvexe sur le dos, avec les 3 premiers segments légèrement impressionnés en travers à leur base; éparsement sétosellé ; un peu plus finement et un peu plus densement pointillé que les élytres, avec le fond des impressions à peine moins pointillé ; d'un noir assez brillant, avec uné fine pubescence grise, ass $\mathrm{z}$ serrée. Le $6^{\circ}$ segment moins' ponctué, moins pubescent, subtronqué ou à peine arrondi au sommet.

Dessous du corps finement pointillé, finement pubescent, d'un noir brillant, avec le $6^{\mathrm{e}}$ arceau ventral et le bord apical des précédents souvent d'un roux de poix. Dessous de la tête éparsement et fortement ponctué. Métasternum subconvexe, très-finement canaliculé sur sa ligne médiane. Ventre convexe, éparsement sétosellé, à premiers arceaux à peine resserrés à leur base.

Pieds assez courts; finement ponclués, finement pubescents; d'un testacé plus ou moins obscur, avec les harıches et parfois les-cuisses plus foncées. Tarses antérieurs à 3 premiers articles plus $\left(\sigma^{\circ}\right)$ ou moins $(q)$, le $4^{\mathrm{e}}$ à peine, dilatés.

Patrie. Celte espèce vit sur le bord des ruisseaux ou des marais. Elle est assez commune dans presque toute la France.

Obs. La couleur rousse du sommet des élytres s'avance parfois, en se fondant, jusque près du milieu. Les antennes et les pieds deviennent alors d'une teinte plus claire. 


\section{Staphyliniens. - Bisnius}

Quelques auleurs lui rapportent le planatus de Gravenhorst(Han. 108, 112)? le cinerascens de Stephens (Ill. Brit. V, 252), el le Lathrobioides de Baudi (Stud. Ent. I, 130).

\section{Bisning prolixus, Ericuson.}

Allongé, linéaire, subdéprimé, peu pubescent, d'un noir brillant, avec la bouche, la buse des antennes, les pieds et les deux tiers postérieurs des élytres d'un roux testacé. Tête et prothorax assez fortement et assez densement ponctués, avec un étroit espace longitudinal lisse. Elytres et abdomen finement et assez densement pointillés : célui-ci sensiblement impressionné à la base dès 3 premier's segments. Tête subrétrécie ën arrière.

○" Le $6^{c}$ arceau ventral légèrement et subangulairement sinué dans le milieu de son bord apical, avec un espace triangulaire, lisse, au devant du sinus.

q Le $6^{\mathrm{e}}$ arceau ventral subarrondi au sommet.

Philonthus prolixus, Erichson, Gen. et Spec. Staph. 510, 143. - Redtendacier,

Faun. Austr. 707, 43. - Fairaaine et Laboul.bène, Faun. Ent. Fr. I. \$30, 62. -

KraAtz, Ins. Deut. II, 625, 66 .

Leplacimus pubipennis, Kolen.sti, Melet, Ént. III, 16, 53.

Erichsonius prolixus, Fauvel, Faun. Gallo-Rhén. III, 432, 7.

Variété $a$. Elytres presque entièriment cnfumées: Pieds d'un testacé obscur:

Erichsonius scmipunctatus, Fainadre et Germar, Ann. Soc. Elit. Fr. 1861, 434.-

Fauvel, Bull. Soc. Linn. Norm. 186!, 10, 316.

$$
\text { Long., } 0^{\mathrm{m}}, 0042 \text { (2 l.); - larg., } 0^{\mathrm{m}}, 0004(1 / 51 .) \text {. }
$$

Corps allongé, linéaire, subdéprimé, d'un noir brillant, avec les élytres (moins leur base) d'un ronx testice; prevêtu sur celles-ci et sur l'abdomen d'une fine pubescence grise et peu snrrée.

Tête suboblongue, un p̣eu rélrécie en arriere, ıı peu plus large antérieurement que le prothorax ; éparsement sétosellée ; légèrement pubes- 
cente ; assez fortement et assez densement ponctuée, avec un étroit espace longitudinal, médian, lisse; entièrement d'un noir brillant. Front trèslarge, à peine convexe, offrant vers l'épistome une large el faible impression triangulaire, lisse mais parfois finement pointillée dans son milieu. Cou lisse, glabre, d'un noir brillant. Parties de la bouche d'un roux testacé, avec le labre et la pointe des mandibules souvent plus foncés.

Ycux obscurs, parfois un peu grisâtres.

Antennes assez courtes, moins longues que la tête et le prothorax réunis; faiblement épaissies; légèrement pubescentes et éparsement pilosellées vers leur base; obscures, avec les 2 premiers articles d'un roux testacé et le $3^{\mathrm{e}}$ d'un roux de poix ; le $1^{\mathrm{er}}$ allongé, en massue subarquée : les $2^{\mathrm{e}}$ et $3^{\mathrm{e}}$ suballongés, obconiques, subégaux : les suivants graduellement à peine plus courts : les $4^{\mathrm{e}}$ et $5^{\mathrm{e}}$ suboblongs : le $6^{\mathrm{e}}$ subcarré, les $7^{\mathrm{e}}$ à $10^{\mathrm{e}}$ à peine transverses : le dernier subovalaire, subtronqué au bout et subacuminé inférieurement.

Prothorax en carré long et subrétréci en arrière, où il est beaucoup moins large que les élytres ; tronqué au sommet, avec les angles antérieurs infléchis, subobtus el subarrondis; presque droit sur les côtés; légèrement arqué à sa base, avec les angles postérieurs obtus et arrondis; peu convexe; à peine pubescent; légèrenent sétosellé, avec la longue soie des côtés assez distante du rebord latéral ; assez fortement et assez densement ponctué, avec un étroit espace longitudinal médian, lisse; entièrement d'un noir brillant. Repli noir, lisse, glabre.

Écusson à peine pointillé, à peine pubescent, d'un noir brillant.

Élytres oblongues, sensiblement plus longues que le prothorax; subdéprimées ou mème déprimées; assez finement et assez densement ponctuées; d'un rouge testacé, avec la base plus ou moins largement rembrunie, au moins dans son tiers antérieur; éparsement pubescentes, avec une longue soie sur le côté des épaules. Celles-ci étroitement arrondies.

Abdomen allongé, un peu moins large à sa base que les élytres; à peine arqué en arrière sur les côtés; subconvexe sur le dos, avec les 3 preniers segments sensiblement, et parfois le $4^{\mathrm{e}}$ faiblement, impressionnés eu travers à leur base; éparsement sétosellé; finement et assez densement ponctué, avec le fond des impressions plus fortement; d'un noir bristant, avec une fine pubescence grise, un peu plus serrée que celle des élytres. Le $6^{\circ}$ segment moins ponctué, moins pubescent, obtusément tronqué ou à veine arrondi au sommet.

Dessous du cor'ps tinement ponctué, finement pubescent, d'un noir 
brillant, avec le sommet du ventre et parfois le bord apical d s derniers arceaux couleur de poix. Dessous de la tête éparsement et un peu plus fortement ponctué. Métasternum subconvexe, finement canaliculé sur sa ligne médiane. Ventre assez convexe, moins finement ponctué que la poitrine, éparsement sétosellé, à premiers arceaux un peu russerrés à leur base.

Pieds peu allongés, finement ponctués, finement pubescents, d'un roux testacé, avec les hanches rembrunies. Tarses antérieurs à 3 premiers articles sensiblernent, le $4^{\mathrm{e}}$ à peine, dilatés.

Patrie. Cette espèce se trouve sous les pierres, dans les endroits vaseux. On la rencontre assez souvent courant au soleil dans le lit desséché des ruisseaux. Son habitat ne s'étend pas au nord autant que les espèces précédentes : le Bourbonnais, le Beaujolais, les environs de Lyon, la Savoie, les Alpes, les Pyrénées, ete.

OBs. La forme est un peu plus grêle et la couleur des élytres plus claire que chez le B. procerulus. La tête est subrétrécie en arrière, un peu plus large en avant que le prothorax. Celui-ci, un peu plus étroit, paraît un peu plus long. Les $4^{\mathrm{e}}$ et $5^{\mathrm{e}}$ articles des antennes sont plus oblongs. L'impression basilaire des premiers segments de l'abdomen est plus sensiblement et surtout plus fortement ponctuée.

Les élytres sont parfois entièrement rembrunies ou avec l'extrémité un peu plus claire. Les cuisses postérieures et quelquefois tous les pieds prennent alors une teinte plus sombre.

L'Erichsonius semipunctatus de FAureL (p. 431) ne serait qu'une variété du prolixus, ainsi qu'il semble l'indiquer lui-même dans son sup-

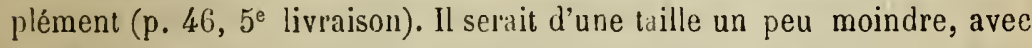
les élytres unicolores, brunes ou d'un brun de poix, un peuplus courtes. L'abdomen serait plus mat, et les pieds seraient d'un roux testacé. Du reste, comme le dit l'auteur précité, les procerulus el prolixus sont d'une étude difficile à cause de leurs variations. Les orbus et elongatulus, au contraire, se distinguent nettement.

On doit sans doute rapporter au prolixus le dissimilis de Baudi (Berl. Eut. Zeit. 1866, 387). 


\section{IBisnitus ordbatg, KIESENWETTER.}

Allongé, linéaire, peu convexe, peu pubescent, d'un noir brillant, avec les antennes et les pieds obscur's, les genoux et les tarses testacés. Tête et prothorax assez fortement et assez densement ponctués, avec un espace longitudinal lisse. Élytres et abdomen finement et assez densement pointilles : celui-ci fortement impressionné sur la base des 3 premiers segments, moins fortement sur celle du $4^{\mathrm{e}}$.

$\sigma$ Le $6^{\ominus}$ arceau ventral sensiblement et subangulairement sirué dans - le milieu de son bord apical, avec un léger espace lisse sur les bords du sinus.

\& Le $6^{\circ}$ arceau ventral simple.

Philonthus orbus, Kinsenwetter, Stett. Ent. Zeit. 1850, z20; - Ann. Soc. Ent. Fr. $1851,418$.

Erichsonius orbus, Fauves, Faun. Gallo-Rhén. III, 430, 4.

$$
\text { Long., } 0^{\mathrm{m}}: 0036 \text { (1 2/3 l.); - larg., } 0^{\mathrm{m}}, 0004 \text { (1/5 l.). }
$$

Corps allongé, linéaire, pru convexe, d'un noir brillant, revêtu d'une très-fine pubescence cendrée et peu serrée.

Tête suboblongue, de la largeur du prothorax; éparsement sétosellée; à peine pubescente ; assez fortement et assez densement ponctuée, avec un espace médian lisse, élar ri vers l'épistome; entièrement d'un noil trèsbrillant. Front très-large, subconvexe. Cou lisse, glabre, d'un noir trèsbrillant. Labre et mandibules d'un brun de poix, avec les palpes plus clairs.

Yeux noirs.

Antennes assez courtes, moins longues que la tête et lè prothorax réunis; subépaissies; légèrement pubescentes et éparsement pilosellées vers leur base; obscures, avec les premiers artieles à peine moins foncés ou parfois d'un roux de poix; le $1^{\text {er }}$ allongé, en missue subarquée $:$ les $2^{\circ}$ et $3^{c}$ ublongs, obconiques, subégaux : les suivants griduellement ì peine plus courts subobconiques : le $4^{\mathrm{e}}$ à peine, le $5^{\mathrm{c}}$ lígèrement, les $6^{\mathrm{e}}$ à $10^{\mathrm{e}}$ sensi- 
blement transverses : le dernier ovalaire, subtronqué au bout et subacuminé inférieurement.

Prothorax oblong, subparallèle sur ses côtés, sensiblement moins large que les élytres; arcuément tronqué au sommet; à angles antérieurs subobtus et subarrondis; subarqué à sa base, avec les angles postérieurs obtus; peu convexe; à peine pubescent; éparsement sétosellé, avec la longue soie des côtés assez distante du rebord latéral; assez fortement et assez densement, mais irrégulièrement ponctué, avec un espace longitudinal, médian, lisse, assez large; d'un noir très-brillant. Repli noir, lisse, glabre.

Écusson à peine pointillé, presque glabre, d'un noir brillant.

Élytres oblongues, sensiblement plus longues que le prothorax; subdéprimées oll à peine convexes; finement et assez densement ponctuées ; d'un noir brillant; éparsement pubescentes, avec quelques rares soies sur les côtés, dont 1, notamment plus longue, sur les épaules. Celles-ci étroitement arrondies.

Abdomen allongé, subrétréci vers sa base où il est sensiblement moins large que les élytres; subarqué en arrière sur les côtés; assez fortement convexe sur le dos, avec les 3 premiers segments fortement, le $4^{\mathrm{e}}$ assez fortement, impressionnés en travers à leur base; légèrement sẻtosellé; finement et assez dens-ment pointillé, avec la ponctuation plus forte, plus serrée et rugueuse dans le fond des impressions, plus légère ou effacée sur le dos des 3 premiers segments, qui sont presque lisses en arrière sur leur milieu; d'un noir brillant, avec une fine pubescence cendrée, un peu plus serrée que celle des élytres. Le $6^{\text {e }}$ segment subtronqué ou à peine arrondi au sommet.

Dessous du corps modérément ponctué, éparsement pubescent, d'un noir brillant. Dessous de la tête à peine moins ponctué. Métasternum à peine convexe, très-finement canaliculé sur sa ligne médiane. Ventre assez convexe, sétosellé en arrière, à 3 premiers arceaux resserrés et plus fortement ponctués à leur base, le $6^{\mathrm{c}}$ et le bord apical des précédents souvent d'un roux de poix.

Pieds assez courts, légèrement ponctués, finement pubescents, d'un brun de poix plus ou moins foncé, avec les genoux et les tarses testacés. Tarses antérieurs à 3 premiers articles médiocrement et subégalement, le $4^{\circ}$ à peine ou non, dilatés.

Patrie. Celle espèce est rare. Elle se trouve dans la vase, au bord des BR. 
eaux douces ou saumâtres, aux environs de Perpignan, de Cette et de Nîmes, etc.

OBs. Elle est remarquable par sa couleur d'uil noir brillant, et surtout par son abdomen plus convexe et plus fortement imprussionné à la base des premiers segments que dans aucun autre de ses congénères.

Les pénultièmes articles des antennes (6-10) sont plus sensiblement transverses que chez les procerulus et prolixus. Elles sont un peu plus obscures à leur base. Les pieds sont ordinairement d'ıne teinte plus foncée, etc.

\section{Bisming elongatulus, Erichson.}

Allongé, linéaire, subdéprimé, légèrement pubescent, d'un noir brillunt. avec les palpes, les antennes et les pieds testacés, et les élytres d'un brur de poix. Tête et prothorax assez fortement et modérément ponctués, avec un espace longitudinal lisse. Elytres et abdomen finement et assez densement pointillés : celui-ci sensiblement impressionné à la base des 3 premiers segments.

$\sigma$ Le $6^{e}$ arceau ventral légèrenınt sinué dans le milieu de son bord apical, avec un espace triangulaire lisse et subpellucide, au devant du sinus.

q Le $6^{\mathrm{e}}$ arceau ventral subarrondi au sommet.

Philonthus elongatulus, Ehichson, Col. March. I, 479, 50;-Gen. et Spe.c. Staph. 511, 145. - Redtenbacher, Faun. Austr. 707, 42. - Heek, Faun. Col. Helv. I, 270, 54. - Fairmaire et Laboulbène, Faun. Ent. Fr. I, 531, 65. - Kraatz, Ins. Deut. II, 623, 64 .

Bisnius elongatulus, Tномsоn, Skand. Col. II, 168, 1, 1860.

Erichsonius villosulus, FAUvel, Faun. Gallo-Phén. III, 430, 3.

Variété $a$. Élytres entièrement d'un roux de poix.

$$
\text { Long., } 0^{\mathrm{m}}, 0038 \text { (1 3/4 1.); - larg., } 0^{\mathrm{m}}, 0004 \text { (1/5 l.). }
$$

Corps allongé, linéaire, subdéprimé, d'un noir brillant, arec les élytres brunâtres; revêtu sur celles-ci et sur l'abdomen d'une fine pubescence grise et peu serrée. 
Téte subcarrée, un peu plus large que le prothorax; éparsement sétosellée ; à peine pubescente ; assez fortement et assez densement ponctuée sur les côtés, plus éparsement en dedans, avec un assez large espace médian lisse, encore plus élargi en avant; entièrement d'un noir brillant. Front très-large, subdéprimé, subimpressionné sur son milieu entre les yeux. Cou presque lisse, glabre, d'un noir brillant. Labre et mandibules d'un roux de poix, avec la pointe de celles-ci plus foncée. Palpes testacés.

Yeux obscurs.

Antennes assez courtes, moins longues que la tête et le prothorax réunis'; sensiblement épaissies; légèrement pubescentes et éparsement sétosellées vers leur base; entièrement testacées; à $1^{\mathrm{er}}$ article allongé, en massue subarquée; les $2^{\mathrm{e}}$ et $3^{\mathrm{e}}$ oblongs, obconiques : le $3^{\mathrm{e}}$ aussi long et à peine plus grêle que le $2^{\circ}$ : les suivants graduellement un peu plus courts et plus épais, subobconiques : le $4^{\mathrm{e}}$ non, le $5^{\mathrm{e}}$ légèrement, les $6^{\mathrm{e}}$ à $10^{\mathrm{e}}$ sensiblement transverses : le dernier subovalaire, subtronqué au bout et subacuminé inférieurement.

Prothorax oblong, à peine rétréci en arrière où il est sensiblement moins large que les élytres; tronqué au sommet, avec les angles antérieurs arrondis ; presque droit sur les côtés ; subarqué à sa base, avec les angles postéricurs très-obtus et arrondis; peu convexe ; à peine pubescent; légèrement sétosellé, avec la longue soie des côtés assez distante du rebord latéral; assez fortement et assez peu densement ponctué, avec les points souvent confusément disposés en séries, et un espace longitudinal médian, lisse et médiocrement large; entièrement d'un noir brillant. Repli brunâtre, lisse, glábre.

Écusson légèrement pouctué, légèrement pubescent, d’un noir de poix assez brillant.

Élytres oblongues, un peu plus longues que le prothorax; subdéprimées; finement et assez densement poiutillées; d'un noir ou d'un brun de poix brillant, passant souvent au roussâtre, surtout en arrière; éparsement pubescentes; à peine et éparsement ciliées à leur sommet, avec ordinairement 2 soies redressées, dont 1 plus longue, sur le côté des épaules. Celles-ci étroitement arrondies.

Abdomen allongé, un peu moins large à sa base que les élytres; à peine arqué en arrière sur les côtés; légèrement convexe sur le dos, avec les 3 premiers segments sensiblement impressionnés en travers à leur base; éparsement et longuement sétosellé; finement et assez densement pointillé, 
avec le fond des impressions presque lisse; d'un noir assez brillant, a vec une fine pubescence grise, un peu plus longue et un peu plus serrée que celle des élytres. Le $6^{\text {e }}$ segment souvent moins foncé, toujours plus lisse et moins pubescent, subsinué dans le milieu de son bord apical.

Dessous du corps légèrement ponctué, finement pubescent, d'un noir de poix brillant, avec l'extrémité du ventre et le bord apical des arceaux d'un roux ferrugineux. Dessous de la tête obsolètement chagriné, glabre, presque lisse ou avec quelques points clair-semés. Métasternım à peine convexe, très-finement canaliculé sur sa ligne médiane. Ventre assez convexe, éparsement sétosellé, à premiers arceaux à peine resserrés à leur base.

Pieds assez courts, légèrement pointillés, finement pubescents, testacés ainsi que les hanches antérieures et intermédiaires, les postérieures rousses. Tarses antérieurs à 3 premiers articles médiocrement et subégalement, le $4^{\mathrm{e}}$ à peine, dilatés.

Patrie. Cette espèce se trouve assez communément, dans toute la France, au bord des eaux ou dans les lieux marécageux.

OBs. Elle se distingue des autres par la couleur plus claire des antennes et des pieds; de l'orbus par son abdomen moins convexe, avec les impressions basilaires des premiers segments moins profondes, presque lisses au lieu d'être rugueusement ponctuées. De plus, le $4^{\mathrm{e}}$ segment n'est pas sensiblement impressionné, et le $6^{\mathbf{e}}$ est subsinué au somımet. Les antennes sont plus épaissies, etc.

Les élytres passent parfois du brun ou roux de poix plus ou moins testacé. En même temps, le sommet de l'abdomen se montre d'une couleur moins foncée.

L'elongatulus répond peut-être au villosulus de Stephens (Ins. Brit. V, 251)?

T,ROISIÈME RAMEAU

\section{RÉMATES}

Caractìres. Corps plus ou moins ponctué et pubescent.

Tête grosse, en carré suboblong, à pores sétifères, situés entre les yeux, peu distincts et confondus avec la ponctuation. Labre très-court, à peine 
ou légèrement entaillé dans son milieu, non visiblement bilobé. Le $2^{\mathrm{c}}$ article des antennes triangulairement renflé, sensiblement ou même beaucoup plus épais qne le suivant. Prothorax oblong. Mésosternum triangulaire, presque plan, sans arête transversale arquée ou angulée. Iétasternum offrant entre les hanches postérieures un lobe peu saillant, infléchi, entaillé ou échancré : celles-ci rapprochées à leur base. Opercules prothoraciques très-développés, subtriangulaires, membraneux.

OBs. Ce rameau, dont les espèces sont petites, rappelle celui des Staphylinates par la conformation du lobe postéro-médian du métasternum. Il s'en distingue, ainsi que des Philonthates, par la singulière structure du $2^{e}$ article des antennes. Il diffère de ce dernier rameau notamment par le repli du prothorax muni d'un opercule très-apparent.

Les yeux sont petits ou assez petits, séparés du cou par un intervalle plus long que leur plus grand diamètre. Le labre, à peine entaillé, n'•șt pas visiblement bilobé. La lame mésosternale est sans arête transversale arquée ou angulée.

Un seul genre (1) européen répond au rameau des Rémates.

Genre Remus, RÈme, Thomson.

Tromson, Skand. Col., II, 1860, p. 167; - IX, 1867, p. 142.

Étymologie : nom propre.

Caractères. Corps allongé, sublinéaire, subdépriné, ailé, pubescent.

Tête grande, saillante, en carré suboblong, portée sur un col court, moins large que le vertex. Tempes très-finement rebordées en avant sur les côtés, à peine ou obsolètement en arrière. Epistome obtusément tronqué au sommet, à inarge antérieure submembraneuse et subverticale. Labre

(1) Holme (Trans. Ent. Soc. Lond. 1837, II, I, p. 64) avait créé son genre Remus sur l'espèce sericeus, dont Thomson et Fauvel ont fait un Cafius et pour laquelle nous avous cru devoir établir notre genre Pseudidus. Comme les caractères signalés par l'auteur anglais sont insignifiants et qu'ils peuveut conveni: aux trois genres à la fois, nous avons dù suivre la manière de voir de Thomson qui, plutôt que de créer un nom nouveau, a regardé celui de IIolme comme non avenu et l'a appliqué à une autre espece (cinerascens) dont il donne, en deux lignes (Skund. Col. IX, p. 142), les caractères génériques réels et exclusifs. 
très-court, non visiblement bilobé, simplement subentnillé dans son milieu. Mandibule; sail'antes, falciformes, acérées, dentées en dedans vers leur milieu, croisées au repos. Palpes maxillaires peu allongés, à $1^{\text {er }}$ article très-court: le $2^{\mathrm{e}}$ oblıng, on massue : le $3^{\mathrm{e}}$ plus court, assez épais : le dernier en cône atténué, plus long que le précédent. Palpes labiaux courts, à $2^{\mathrm{e}}$ article épais, assez court : le dernier subsubulé, un peu plus long que le 2 . Menton fortement transverse, plus étroit en avant, tronqué au sommet, submembraneux.

Yeux petits ou assez petits, peu saillants, subovales, obliques, séparés du cou par un intervalle sensiblement ou mệme beaucoup plus long que leur plus grand diamètre.

Antennes peu allongées, subépaissies; à $1^{\text {er }}$ article allongé, en massue : le $2^{\mathrm{e}}$ dilaté en triangle isocèle et renversé : le $3^{\mathrm{e}}$ aussi long, mais beaucoup plus grêle que le $2^{\mathrm{e}}$ : les suivants graduellement un peu plus courts, subcontigus, avec le pénultième non ou à peine transverse : le dernier subovalaire, obliquement tronqué au sommet.

Prothorax oblong, subparallèle, moins large que les élytres; plus on moins tronqué au sommet; ponctué sur les côtés; à angles hntérieurs non saillants ; subarrondi à sa base; très-finement rebordé sur celle-ci et sur les côtés; à rebord latéral subsinueusement infléchi d'arrière en avant (1). Repli assez étroit, incliné, visible vu de côté, muni d'un opercule prothoracique très-développé, membraneux, subtriangulaire, à sommet arrondi.

Écusson grand, triangulaire.

Elytres oblongues ou suboblongues, tronquées ou à peine échancrées à leur bord apical; arrondies à leur angle postéro-externe; finement rebordées sur la suture. Repli médiocre, assez fortement infléchi. Épaules pen saillantes.

Prosternum légèrement développé au devant des hanches antérieures, offrant entre celles-ci un triangle large, à sommet droit ou subaigu, à disquè gibbeux ou obtusément caréné. Mésosternum à lame médiane triangulaire, presque plane, sans arête transversale ; à sommet aigu, prolongé jusqı'au tiers des hanches intermédiaires ou à peine au delà. Médiépisternums grands, séparés du mésosternum par une fine suture transversale. Médiépimères très-étroites, en forme d'ongleí. Métasternum court, assez fortement échancré au devant des hanches postérieures, prolongé entre

(1) Dans ce genre, la longue soie latérale est légèrement distante du rebord. 
celles-ci en un lobe court, angulairement entaillé au sommet; non avancé mais largement el obtusément tronqué ver's l'intermède des h ınches intermédiaires. Postépisternums étroits, sublinéaires. Postépimères petites, triangulaires.

Abdomen assez allongé, subparallèle ou un peu atténué en arrière, fortement rebordé sur les côtés; à 4 premiers segments subégaux, le $5^{\mathrm{e}}$ à peine plus grand : les 3 premiers subimpressionnés en travers sur le milieu de leur base : le $6^{\mathrm{e}}$ plus ou moins saillant, rétractile : celui de l'armur caché, rilié-fasciculé. Ventre à $2^{\mathrm{e}}$ arceau basilaire distinct, angulé dans le milieu de son bord postérieur : le $1^{\text {er }}$ plus long sur les côtés que les suivants : le $5^{\mathrm{e}}$ non ou à peine plus long que les précédents : le $6^{\mathrm{e}}$ plus ou moins saillant, rétractile.

Hanches antérieurés grandes, de la longueur des cuisses, très-saillantes, coniques, contiguës au sommet. Les intermédiaires moindres, peu saillantes, conico-subovales, rapprochées dans leur milieu. Les postérieures petites, assez saillantes, rapprochées à leur base, divergentes au sommet; à lame supérieure en cône court et mousse, subétranglée vers son premier tiers; à lame inférieure nulle ou enfouie.

Pieds assez courts, peu robustes. Trochanters antérieurs et intermédiaires assez petits, cunéiformes; les postérieurs un peu plus grands, ovales-oblongs. Cuisses subcomprimées, subatténuées vers leur éxtrémité, très-finement épineuses en dessous vers leur sommet interne. Tibias subélargis de la base au sommet, plus ou moins épineux, munis au bout de leur Iranche iuférieure de 2 éperons grêles dont l'interne plus long; les antérieurs plus courts, moins épineux. Tarses antérieurs courts, subdéprimés, à 4 premiers articles plus ( $\sigma^{\circ}$ ) ou moins ( $\$$ ) dilatés ; les inter-' médiaires el postérieurs peu allongés, à peine atténués vers leur extrémité, à $1^{\text {er }}$ arlicle oblong, plus court que le derniér, moins long que les 2 suivants rẻunis : les $2^{\mathrm{e}} \mathrm{a} 4^{\mathrm{e}}$ assez courts, triangulaires, graduellement un peu plus courts : le dernier à peine aussi long que les 2 précédents réunis. Ongles petits, grêles, à peine arqués.

Obs. Les petites espèces de ce genré sont assez promptes. Elles fréqụentent les lieux marécageux.

Cette coupe générique, jadis créée par Holme, rejetée depuis, a été rétablie avec raison par Thomson. Le développement des opercules prothoraciques, l'absence d'arête transversale sur le mésosternum, et surtout la structure dn $2^{\mathrm{e}}$ article des antennes, sont des caractères qui militent avan- 
tageusement en faveur de ce genre, sans compter les modifications accessoires qui viennent les corroborer.

Nous n'en mentionnerons que 3 espèces dont 2 françaises. En voici les différences :

a Tête fortement et peu densement ponctuèe sur les côtés. Antennes obscures, avec l'extrémité d'un testacé pâle. Ėlytres suboblongues. . . . . . . . . . . . . . . . . signaticornis.

aa Tête finement et très-densement pointillée sur les cơtés. Antennes obscures, avec le 1 er article d'un roux testacé. Élytres oblongues. Cinerascens.

1. Remus aignaticornis, Mulsañt et Rey.

Allongé, sublinéaire, subdéprimé, finement pubescent, d'un noir de poix assez brillant, avec les pieds, la bouche et les antennes d'un testacé obscur' et l'extrémité de celles-ci plus pâle. Tête fortement et peu densement, prothorax fortement et éparsement, ponctués sur les côtés. Élytres densement, abdomen très-densement pointilles.

$\sigma^{\circ}$ Le $6^{\circ}$ arceau ventral sensiblement sinué dans le milieu de son bord apical. Tarses antérieurs fortement dilatés.

ㅇ Le $6^{\mathrm{e}}$ arceau ventral subarrondi au sommet. Tarses antérieurs médiocrement dilatés.

Philonthus signaticornis, Mulsant et Rey, Ann. Soc. Lin. Lyon, 1863, 62, pl. 2, fig. $6 a$; - 0p. Ent. II, 75, 3, 1853. - Fairmaire et Laboulbène, Faun. Ent, Fr. I, 331, 66. - KraATz, Ins. Deut. II, 623, 63.

Erichsonius signaticornis, FAUVEL, Faun. Gallo-Rhén. III, 429, 2.

Variété $a$. Élytres rousses.

Variété $b$ (immature). Corps d'un roux testacé, avec la tête noire.

$$
\text { Long., } 0^{\mathrm{m}}, 0044 \text { (2 l.); - larg., } 0^{\mathrm{m}}, 0005 \text { (1/4 l.). }
$$

Corps allongé, sublinéaire, subdéprimé, d'un noir brillant sur la tête et le prothorax, moins brillant sur les élytres, presque mat sur l'abdomen; revêtu sur celles-là et sur ce dernier, d'une finc pubescence cendrée et asse\% serrée. 
Tête en carré suboblong, de la largeur du prothorax ; éparsement sétosellée dans son pourtour ; légèrement pubescente sur les tempes; fortement et subéparsement ou modérémeut ponctuée, avec un large espace longitudinal lisse, non prolongé jusqu'au cou ; d'un noir brillant. Front très-large, peu convexe. Cou noir, brillant, lisse. Épistome à marge antérieure d'un roux de poix. Labre d'un roux brillant, éparsement sétosellé en avant. Mandibules ferrugineuses. Palpes d'un roux testacé.

Yeux petits, noirs, lavés de gris.

Antennes peu allongées, un peu plus longues que la tête; sub ${ }^{3}$ paissies; légèrement pilosellées; d'un roux obscur, avec l'extrémité devenant graduellement d'un teslacé pâle, et le $1^{\text {er }}$ article souvent d'un roux testacé : celui-ci allongé, en massue : le $2^{2}$ dilaté en triangle renversé : le $3^{\mathrm{e}}$ aussi long mais beaucoup plus grêle que le $2^{\mathrm{e}}$ : les suivants graduellement un peu plus courts : les $4^{\mathrm{e}}$ et $5^{\mathrm{e}}$ un peu plus longs que larges : les $6^{e}$ à $9^{e}$ non, le $10^{e}$ à peine transverses, vus de côté : le dernier subovalaire, obliquement tronqué au bout et subacuminé inférieurement.

Prothorax en carré oblong; un peu moins large que les élytres ; tronqué au sommet; à angles antérieurs arrondis ; subparallèle sur ses côtés, vu de dessus, avec ceux-ci, vus latéralement, à peine sinués en arrière ; subarrondi à sa base, avec les angles postérieurs obtus; légèrement convexe; paré d'une légère pubescence redressée et peu serrée, avec un pore sétifère bien prononcé et légèrement distant du rebord latéral; fortement et éparsement ponctué, avec un large espace longitudinal lisse; d'un noir de poix brillant. Repli noir ou brunâtre, glabre, lisse.

Écusson éparsement ponctué, à peine pubescent, d'un noir de poix assez. brillant.

Elytres suboblongues, un peu plus longues que le prothorax, subdéprimées; finement et densement ponciuées; d'un noir de poix assez brillant; finement pubescentes, avec 1 ou 2 longues soies redressées sur le côté des épaules. Celles-ci étroitement arrondies.

Abdomen suballongé, à peine moins large à sa base que les élytres; subparallèle ou à peine arqué sur les côtés et souvent subatténué en arrière; assez convexe sur le dos ; visiblement impressionné en travers sur le milieu de la base des 3 premiers segments ; cparsenent sélosellé; beaucoup plus finement et plus densement pointillé que les élytres; d'un noir peu brillant, aree une fine pubesconce cendrée, plus serrẻe que celle des élytres, et qui lui imprime une teinte un peu grisâtre. Le $6^{\text {e }}$ segment 
étroit, souvent d'un roux de poix à son extrúmité, à peine arrondi au sommet, moins ponctué que les précédents.

Dessous du corps finement et densement pointillé, d'un noir assez brillant, finement pubescent. Dessous de la tête très-finement chagriné, moins pubescent, plus forternent mais peu densement ponctué. Lame mésosternale presque lisse. Métasternum subdéprimé. Ventre convexe, éparsement sétosellé, souvent d'un roux de poix à son sommet.

Pieds assez courts, finement et densement pointillés, finement pubescents, d'un roux testacé plus ou moins obscur, avec les genoux, le sommet des tibias et les tarses ordinairement plus clairs. Cuisses antérieures trèsfinement ciliées-spinosulées en dessous, surtout vers leur extrémité. Tibias antérieurs un peu moins épineux que les autres.

Patrie. Cette espèce, médiocremeni commune, 'se prend sous les détritus et parmi les mousses, au bord des ruisseaux, des fossés et des marécages, dans uiverses parties de la Fránce : la Flandre, la Normandie, le Beaujolais, le Bugey, les environs de Lyon, la Bresse, les Alpes, la Guienne, etc.

OBS. Suivant qu'elle est plus ou moins adulte, cette espèce varie beaucoup pour la couleur. Dans l'état le plus complet, les antennes sont obscures, avec leur extrémité seule plus claire. D'antres fois, elles sont d'un roux sombre, avec le $1^{\mathrm{e}_{\mathrm{r}}}$ article testacé et les derniers encore plus pâles. Rarement, elles sont entièrement testacées. Quelquefois les pieds sont d'un roux testacé, avec les cuisses et même les tibias postérieurs plus ou moins rembrunis. Chez les sujets immatures, tantôt les élytres sont rousses avec le prothorax d'un roux de poix, tantôt le corps est d'un roux testacé, avec la tête seule rembrunie, et dans ce dernier cas les antennes et les pieds sont entièrement testacés.

Parfois les intersections ventrales, plus rarenent les abdominales, sont d'un brun roussâtre.

Nous signalerons ici, pour mémoire, une espèce étrangère à la France, et qui valide le genre Remus.

Renus rivularis, Kiesenwetter.

Allongé, sublinéaire, subdéprimé, finement pubescent, d'un noir de poix assez brillant, avec les pieds, la bouche, la base et l'extrémité des antennes 
d'un roux testacé. Tête fortement et modérément, prothorax assez fortement è subéparsement ponctués sur les côtés. Elytres et abdomen finement et très-densement pointiliés. Tête très-grande.

Philonthus rivularis, KiesewwetTer, Berl. Zeit. 61, 1858.

Erichsonius rivularis, Fauvel, Faun. Gallo-Rhén. III, 428 (note).

$$
\text { Long., } 0^{\mathrm{m}}, 0055 \text { (2 1/2 l.); - larg. ., 0m,0007 (1/3 l.). }
$$

Patrie. Étolie (Grèce).

OBs. Celtu espèca est plus grande que le signaticornis. La tête, plus grosse, est à peine plus densement ponctuće sur les côtés. La ponctuation du prolhorax, à peine moins tỉne, ëst un peu moins clair-semée. Les ilylres sont plus densement pointillées. La base des antennes et les pieds sont d'une couleur plus claire, dı moins chez les adultes.

Le prothorax est plus étroit relativement aux élytres, ce qui donne à l'insecte une forme moins linéaire, elc.

\section{Heszag cinérascens, Gravenhorst.}

Allongé, sublinéaire, subdéprimé, d'un noir de poix, avec les pieds, la bouche et la base des antennes d'un roux testacé. Tête assez brillante, finement et très-densement pointillée, avec uno ligne longitudinale lisse. Prothorax brillant, assez fortement et modérément ponctué sur les côtés. Elylres et abdomen obscurs, mats, très-finement et très-densement pointillés, finement et densement pubescents.

$\sigma^{7}$ Le $6^{\text {e }}$ arceau ventral sensiblement et subangulairement sinué dans le milię de son bord apical. Tarses antérieurs assez fortement dilatés.

ㅇ Le $6^{\text {e }}$ arceau ventral faiblement sinué dans le milieu de son bord apical. Tarses antérieurs médiocrement dilatís.

Staphylinus cinerascens, Gravenhorst, Micr. 49, 74; - Mon. 117, 137. - LATREIlle, Hist. Nat. Crust. et Ins. IX, 334, 94. - Gyllenhal, Ins. Suec. II, 361, 7 วั.

Philonthus cinerascens, NoRdann, Symb. 108, 97.- Erichson, Col. March. I, 478, 
48; - Gen. et Spec. Staph. 509, 140.- Redtenbacher, Faun. Austr. 707, 41.HeEr, Faun. Col. Helv. I, 272, 52. - Fairaaire et Laboulbène, Faun. Ent. Fr. I, 531, 67. - KraAtz, Ins. Deut. II, 622, 62.

Remus cinerascens, Thomson, Skand. Col. II, 167, 1, 1860.

Erichsonius cinerascens, Fauved, Faun. Gallo-Rhén. III, 428, 1.

$$
\text { Long., } 0^{\mathrm{m}}, 0044 \text { (2 1.); - larg., } 0^{\mathrm{m}}, 0005 \text { (1/4 1.). }
$$

Corps allongé, sublinéaire, subdéprimé, d'un noir assez brillant sur la tête et le prothorax, mat sur les élytres et l'abdomen; revêtu sur celles-là et sur ce dernier d'une fine pubescence cendrée, serrée et qui lui imprime une teinte grise.

Tête en carré suboblong, de la largeur du prothorax; éparsement sétosellée dans son pourtour ; légèrement pubescente ; finement et très-densement pointillée, avec une assez étroite ligne longitudinale lisse, raccourcie en avant et en arrière; d'un noir assez brillant. Front très-large, légèrement convexe. Cou noir, lisse, brillant. Épistome à marge antérieure d'un roux de poix. Labre roux, éparsement sétosellé en avant. Parties de la bouche d'un roux plus ou moins testacé.

Yeux assez petits, obscurs, lavés de gris.

Antennes peu allongées, un peu plus longues que la tête ; subépaissies ; légèrement pilosellées; obscures, avec le $1^{\text {er }}$ article et parfois le sommet d'un roux testacé; le $1^{\text {er }}$ allongé, en massue : le $2^{\mathrm{e}}$ épaissi en triangle renversé : le $3^{\mathrm{e}}$ aussi long mais plus grêle que le $2^{\mathrm{e}}$ : les suivants graduellement un peu plus courts : les $4^{\mathrm{e}}$ et $5^{\mathrm{e}}$ un peu plus longs que larges : les $6^{\mathrm{e}}$ à $9^{\mathrm{e}}$ non, le $10^{\mathrm{e}}$ à peine ou non transverses, vus de côté : le dernier subovalaire, obliquement tronqué au bout et subacuminé inférieurement.

Prothorax en carréoblong, moins large que les élytres ; tronqué au sommet; à angles antérieurs largement arrondis; subparallèle sur ses côtés, vu de dessus, avec ceux-ci, vus latéralement, subsinués en arrière ; subarrondi à sa base, avec les angles postẻrieurs obtus ; légèrement convexe; paré d'une légère pubescence redressée, courte et peu serrée, avec un pore sétifère bien prononcé et légèrement distant du rébord latéral; assez fortement et modérément ponctué, avec un espace longitudinal lisse, assez étroit, et les interstices des points souvent obsolètement chagrinés; d'un noir de poix brillant. Repli noir, glabre, lisse.

Écusson densement pointillé, finement pubescent, obscur. 
Elytres oblongues, sensiblement plus longues que le prothorax, subdíprimées, très-finement et très-densement pointillées ; obscures, mates ou presque mates; fincment et densement pubescentes, avec 2 soies redressées sur le côté des épaules. Celles-ci étroitement arrondies.

Abdomen suballongé, un peu ou à peine moins large à sa base que les élytres; subparallèle ou parfois un peu atténué en arrière; assez convexe sur lo dos, subimpressionné en travers sur le milieu de la base des 3 premiers segments; éparsement sétosellé; très-finement et très-densement pointillé ; d'un noir mat, plus ou moins gris par l'effet de la dense pubes-

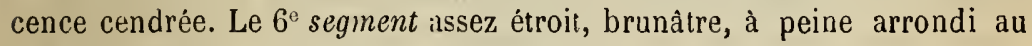
sommet, moins ponctué que les précédents.

Dessous du corps très-finement et densement pointillé, très-finement pubescent, d'ur noir assez brillant, avec le sommet dı ventre et les iatersections ventrales d'un roux ferrugineux. Dessous de la tête à peine moins densement pointillé. Lame mésosternale rugueuse. Métasternum à peine convexe, à peine ou très-finement canaliculé en arrière sur sa ligne médiane. Vintre convexe, éparsement sétosellé.

Pieds assez courts, finement et densement pointillés, finement pubescents, d'un roux ferrugineux on testacé, avec les hanches postérieures rembrunies. Cuisses antérieures très-finement ciliées-spinosulées en dessons, surtout vers lnur extrémité. Tibias antérienr's légèrement épineux.

Patrie. Cette espèce est assez commune parmi les herbes, les mousses et les détritus des marais. Elle se rencontre dans presque toute la France.

OBs. Avec le facies du signaticornis, elle est cependant bien distincte par sa teinte plus grise, par sa tête beauconp plus tinement et plus densement ponctuée, avec l'espace liss: moin; large; pul son prothorax a ponctuation un peu moins forte et un peu plus serrée; par son écusson et ses élytres plus finement et plus densement pointillés, et celles-ci surtout plus longues et moins brillantes. Les antennes sont moins pâles à leur extrémité, etc.

Les antenn:s sont parfois entièrement rousses ou d'un roux ferrugineux.

Nous avons trnuvé, dans les dunes de la plage de Saint-Raphaël, une varićté plus noire, moins cendrée et d'une taille constamment plus grandc. Elle semblerait devoir constituer une espèce distincte, que nous appellerons provisoirement subniger. 


\title{
DEUXIĖME BRANCHE
}

\author{
QUÉDIAIRES
}

Caractères. Corps allongé ou suballongé, rarement oblong ; généralement fusiforme ou subfusiforme. Tête saillante, de grosseur variable; portée sur un col très-court, ordinairement très-épais et un peu ou à peine moins large que le vertex, rarement sensiblement plus étroit que celui-ci. Tempes rebordées sur les côtés. Antennes plus ou moins développées, quelquefois courtes ou assez courtes. Prothorax subtransverse ou aussi large que long, parfois á peine plus long que large, plus ou moins rétréci en avant; aussi larye ou un peu plus large que les élytres ; rarement à peine moins large que celles-ci ; à rebord latéral subhorizontal ou à peine infléchi d'arrière en avant et d'une manière assez régulièrement arquée ou subarquée, ou rarement à peine subsinuée; à repli plus ou moins enfoui ou refoulé en dessons, nullement visible vu de còté. Élytres de longueur variable, mousses latéralement. Abdomen généralement atténué en arrière. Pieds médiocres. Tarses antérieurs plus ou moins dilatés.

OBs. Les deux véritables caractères qui distinguent les Quédiaires des Staphylinaires, sont: $1^{\circ}$ celui des tempes rebordées, signalé par Thomson; $2^{\circ}$ celui du repli du prothorax enfoui et non visible vu de côté. En outre, le col est plus large et la tête moins étranglée à sa base, et l'abdomen est généralement plus atténué en arrière.

Ajoutez à ces caractères :

Labre transverse, parfois entier ou subentier, le plus souvent bilobé, à lobes arrondis, quelquefois divergents ; tantôt entièrement corné, tantôt corné, avec les côtés membraneux.

Menton transverse, corné, avec l'inturvalle, qui le sépare de la languetle, membraneux.

Antennes insérées au devant du front, écartées à leur naissance, à 3 premiers articles plus ou moins allongés.

Prothorax plus ou moins arrondi à sa base, plus ou moins arqué et finement rebordé sur les côtés.

Hanches intermédiaires le plus souvent rapprochées. 
Nous allons faire ressortir, dans le tableau suivant, les principaux caractères des différentes coupes génériques de la branche des Quédicires.

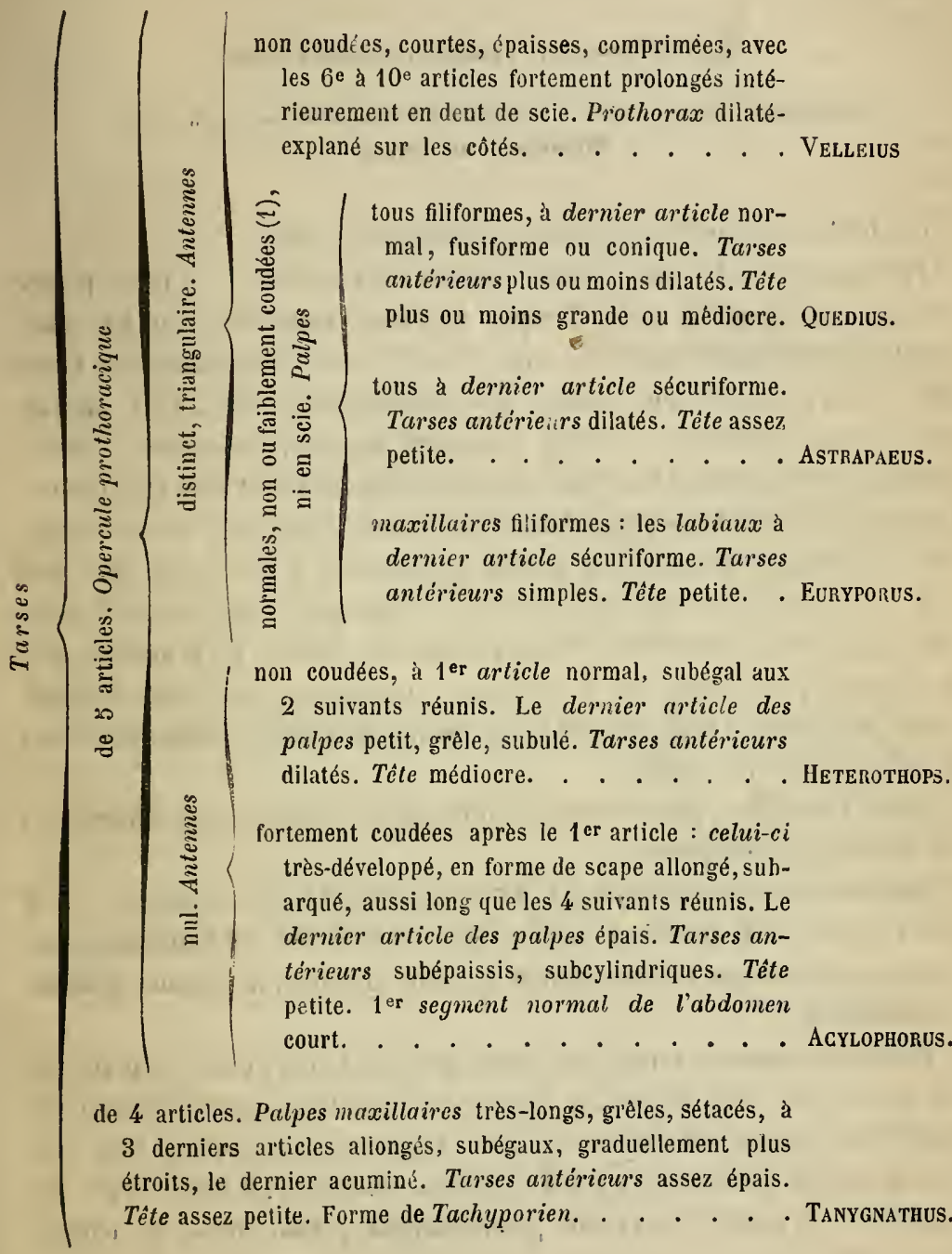

(1) Dans le genre Euryporus, les antennes sont faiblemeut coudées, mais leur $1^{\text {or }}$ article est seulement égal aux 2 suivants réunis. 


\section{Genre Velleius, Velleye, Manmerheim.}

Mannerheim, Brach., p. 19. - Jacqublin Du Vad, Gen. Col. Staph., p. 36.

Étymologie : nom propre.

CARACtÈnes. Corps large, oblong, subdéprimé, ailé.

Tête assez grande, subarroudie, faiblement resserrée à sa base, portée sur un cou large et court. Tempes fortement rebordées sur les côtés. Épistome submembraneux et à peine échancré à son bord antérieur. Labre très-court, profondément bilobé, très-densement cilié en avant. Mandibules assez saillantes, robustes, fortement arquées, très-aiguës, subsillonnées en dehors vers leur base, dentées intérieurement vers leur milieu, croisées au repos. Palpes maxillaires assez développés, à $1^{\mathrm{er}}$ article court : les $2^{\text {e }}$ et $3^{\mathrm{e}}$ assez allongés, en massue subarquée : le $3^{\mathrm{e}}$ à peine plus long que le $2^{\mathrm{e}}$ : le dernier subfusiforme, un peu plus grêle mais non ou à peine plus long que le précédent. Palpes labiaux médiocres, de 3 articles graduellement plus longs : les 2 premiers obconiques : le dernier subfusiforme, émoussé au bout. Menton transverse, trapéziforme, submembraneux dans sa partie antérieure.

Yeux assez gros, peu saillants, subovalaires, séparés du prothorax par un intervalle assez grand.

Antennes courtes, épaisses; à $1^{\mathrm{er}}$ article suballongé, en massue : le $2^{\mathrm{e}}$ court : le $3^{\mathrm{e}}$ deux fois aussi long, obconique : les $4^{\mathrm{e}} \mathrm{a} 10^{\mathrm{e}}$ subcomprimés, fortement prolongés intérieurement en dent de scie : le dernier subovalaire, oblong.

Prothorax subtransverse, plus large que les élytres; dilaté-explané sur les côtés, qui sont arrondis; largement échancré au sommet, avec les angles antérieurs infléchis et saillants ; largement arrondi à la base ainsi qu'aux angles postérieurs ; à rebord latéral tranchant; à repli large, non visible vu de côté, à opercule prothoracique grand, corné,'en triangle allongé.

Écusson grand, subogival.

Élytres simples, en carré transverse, dépassant un peu la poitrine; obliquement coupées au soramet, de manière à former un angle rentraut sensible à la suture; subparallèles sur les côtés; arrondies à leur angle 
postéro-externe. Repli assez prononcé, subrétréci en arrière. Épaules cachées.

Prosternum peu développé au devant des hanches antérieures, formant entre celles-ci un angle court, assez ouvert, fortement relevé dans la partie postérieure de sa ligne médiane en forme de carène tranchante et voûtée. Mésosternum à lame médianie triangulaire ; à sommet très-aig u ou acumiré, prolongé environ jusqu'au milieu des hanches intermédiaires. Médiépisternums issez grands, séparés du mésosternum par une arête saillante. Médiépimères suballongées, subparallèles. Métasternum assez court, fortement échancré au devant des hanches postérieures; prolongé entre celles-ci en un lobe court, échancré ou enfoui; à peine avancé, entre les intermédiaires, en saillie très-obtuse. Postépisternums assez étroits, subrétrécis et subarrondis au sommet, divergeant à peine du repli des élytres. Postépimères médiocres, oblongues, triangulaires.

Abdomen peu allongé, subrétréci en arrière, fortement rebordé sur les côtés ; à $1^{\text {er }}$ segment plus ou moins recouvert, les 3 suivants subégaux, le $5^{\mathrm{e}}$ plus grand : le $6^{\mathrm{e}}$ plus ou moins saillant, subsemi-circulaire, rétractile : celui de l'armure enfoui, émettant parfois 2 lanières assez larges. Ventre a $5^{\mathrm{e}}$ arceau un peu plus grand que les précédents : le $6^{\mathrm{e}}$ plus ou moins saillant, rétractile.

Hanches antérieures grandes, presque de la longueur des cuisses, saillantes, conico-ovalaires, plus ou moins contiguës. Les intermédiaires aussi grandes, subdéprimées, subovales, contiguës. Les postérieures médiocres, très-légèrement écartées à leur base, divergentes au sommet, épineuses intérieurement à celui-ci en dessous ; à lame supérieure en cône court et mousse, subétranglé vers son milieu; à lame inférieure nulle ou enfouie.

Pieds médiocrement allongés, robustes. Trochanters antérieur's et intermédiaires petits, subcunéiformes; les postérieur's un peu plus grands, oviltrs-oblongs. Cuisses subcomprimées, atténuées vers leur extrémité, subépitieuses en dessous ; les postérieures plus longues et moins élargies. Tibias subépaissis de la base au sommet, armés au bout de leur tranche inferieure de 2 forts èper ons acérés, subdivergents; les intermédiaires et postérieurs épineux : les antérieurs plus courts, seulement épineux à leur Iranche inférieure et vers le sommet de celle-ci. Tarses antérieurs courts, à 3 premiers asticles fortement dilatés, le $4^{\mathrm{e}}$ moins fortement; les intermédiuires el postérieurs phus allongés, subatténués vers leur extrémité, à $1^{\text {er }}$ article oblong ou suballongé, obconique, un peu moins long que BR. 
les 3 suivants réunis : ceux-ci triangulaires, graduellement un peu plus courts : le dernier allongé, en massue subdéprimée, un peu plus long que le $1^{\mathrm{er}}$. Ongles assez grands, arqués, acérés, subdentés ou angulés en dessous vers leur base.

Obs. L'unique espèce de ce genre vit ordinairement dans̆ les nids de frelons (Vespa crabro), auxquels elle fait la guerre.

Cef'e coupe générique est bien caractérisće par la structure particulière des antennes et par sa forme large et robuste.

Elle se réduit à une seule espèce française :

\section{Velleîns dilatatus, Fabricius.}

Large, oblong, subdéprimé, finement pubescent, d'un noir brillant, avec les élytres un peu plus mates. Tête et prothorax assez luisants, très-finement chagrinés et pointillés, presque glabres : celui-ci subtransverse, arrondi et dilaté-explané sur les côtés, plus large que les élytres :celles-ci finement et densement, abdomen un peu moins densement, ponctués.

$\sigma$ Le $6^{\text {e }}$ arceau ventral largement et faiblement sinué dans le milieu de son bord apical, avec un léger espace triangulaire, lisse, au devant du sinus. Tête assez large.

o Le $6^{\mathrm{e}}$ arceau ventral simplement subarrondi à son bord apical. Téte un peu moins large (1).

Staphylinus dilatatus, Fabricius, Mant. Ins. I, 220, 7. - Paykull, Faun. Suec. III, 389, 29. - Latrellle, Hist. Nat. Crust. et Ins. IX, 326, 74.- Gravenhorst, Mon. 89, 85. - Gyllenhal, Ins. Suec. II 299, 18.

Staphylinus serraticornis, SHRank. Faun, Boic. I, 641, 866.

Staphylinus concolor, MarshaM, Ent. Brit. 498, 4.

Velleius dilatatus, ManverHeim, Brach. 19, 1. - Bolsduval et LaCoRdarke, Faun. - Ent. Par. I, 357. - Nordanan, Symb. 16, 1. - Runde, Brach. Hal. I, 1. - HeER, Faun. Col. Helv. I, 282, 1. - Falrailie et Laboulbène, Faun. Fnt. Fr. I, 534. 1. - Thouson, Skand. Col. II, 172. - JacQuelin du Vac, Gen. Cal. Staph. pl. 15, fig. 71. - Fauvel, Faun. Gallo-Khén. IlI, 491, 1.

(1) Les tarses antérieurs des $q$ sont à peine moins dilatés. Dans Fauvel, pour les dislinctions sexuelles, au lieu de : derrière l'écusson, il faut lire : derrière l'échlocincrure. 
Quedius dilatatus, Ericnson, Col. March. I, 484, 1; - Gen. et Spec. Staph. 524,1.

- Khastz, Ins. Deut. 490, 1.

Philonthus dilatatus, Redtenbacker, Faun. Austr. 707, 44.

$$
\text { Long., } 0^{\mathrm{m}}, 017 \text { (7 2/3 1.); - larg., } 0^{\mathrm{m}}, 0049 \text { (2 1/4 l.). }
$$

Cor'ps large, oblong, subdéprimé, d'un noir brillant, plus mat sur les élytres; revêtu sur celles-ci d'une fine pubescence d'un gris obscur et assc'z serrée.

Tête subarrondie, moins large que le prothorax; d'un noir brillant; presque lisse ou très-finement chagrinée et très-finement et éparsement pointillée; presque glabre sur son disque; marqué de chaque côté de quelques pores sétifères, dont notamment 3 plus gros : 1 juxta-oculaire et 2 postoculaires, et 2 rapprochés, moindres, plus en dedans, sur le vertex. Front très-large, faiblement convexe, plus ou moins impressionné de chaque joôté, entre les antennes. Cou d'un noir luisant, à peine chagriné et pointillé. Épistome pâle et à peine échancré en avant. Labre d'un noir de poix, fortement sétosellé à son bord antérieur. Mandibules noires. Palpes bruns, avec l'extrémité parfois roussâtre.

Yeux obscurs, tachés de livide.

Antennes courtes, robustes, à peine plus longues que la tête; trèsfinement duveteuses et brièvement pilosellées; obscures, avec le dernier article d'un roux ferrugineux; le $1^{\text {er }}$ suballongé, en massue obconique : le $2^{\mathrm{e}}$ court, obconique : le $3^{\mathrm{e}}$ deux fois aussi long que le $2^{\mathrm{e}}$, obconique : les $4^{\mathrm{e}} \mathrm{a} 10^{\mathrm{c}}$ fortement prolongés intérieurement en dents de scie transverses, graduellement un peu moins épaisses : le dernier plus long, plus itroit, subovalaire-oblong, subrétréci mais subémoussé au sommet.

Prothorax subtransverse, subsemi-circulaire, subrétréci en avant, sensiblement plus large que les élytres; largement échancré au sommet, avec les angles antérieurs infléchis, saillants mais arrondis; fortement arqué sur les côtés; largement arrondi à sa base ainsi qu'aux angles postérieurs; assez convexe sur le dos; plus ou moins explané latéralement; encore plus finement chagriné et pointillé que la tête; presque glabre; offrant en avant, sur le dos, de 1 à 3 pores sétifères plus ou moins en série, et, dans son pourtour, une série de pores semblables, excepté dans le milieu du bord antérieur entre les 2 séries dorsales; d'un noir assez luisant, souvent un peu soyeux et subirisé.

Ecusson subarrondi au somwet, ponctué, pubescent, noir. 
Elytres subtransverses, environ de la longueur du prothorax; subdéprimées; finement, densement et subrâlıeusement ponctuées sur un fond Irès-finement chagriné; d’un noir peu brıllaut, avec une pubescence assez serrée, quelques soies assez raides et redressées, plus nombreuses sur les côtés, et une série de longs cils au bord apical. Épaules cacheses.

Abdomen peu allongé, moi ıs large que les élyıres, graduellement sub. atténué vers son extrémité; longitudinalement subconvexe sur le dos, avec les 3 premicrs segments subimpressionnés en travers à leur base; éparsement et longuement sétosellé (1), plus fortement sur les côtés; assez finement et assez densement ponctué; d'un noir brillant et irisé; à pubescence un $p: u$ plus longue que celle des élytres. Le $6^{\text {e }}$ segment à peine arrondi au sommet.

Dessous du corps subaspèrement ponctué, finement pubescent, d'un noir lirillant, avec le repli du prothorax, le prosternum et la pointe mésosternale souvent roussâtres. Dessous de la tête plus lisse, éparsement ponctué et pubescent en arrière sur les côtés. Métasternum subdéprimé, obsolètement canaliçulé sur sa ligne médiane. Ventre assez convexe, fortement sétosellé (1), jlus ou moins irisé.

Pieds robustes, aspèrement ponctués, pubescents, noirs, avec les hanches antérieures souvent roussâtres en dedans. Cuisses subépineuses en dessous: surtout vers leur extrémité; les antérieures et intermédiaires élargies vers leur base, les postérieures plus grêles et plus longues. Tibias robustes, épincux seulement en dessous, à pubescence interne d'un fauve doré. Tarses garnis en dessous d'une brosse de poils d'un fauve plus ou moins brillant; les antérieurs à 3 premiers articles plus ou moins fortement dilatés et le $4^{\mathrm{\theta}}$ moins fortmment; les intermédiaires et postérieurs à $f^{\text {er }}$ article un pell moins long que le dernier, les $2^{\mathrm{e}}$ à $4^{\mathrm{e}}$ graduellement plus courts.

Patrie. Celte : spè: e se prend daus les guêpiters du frelon (Vespa crabro) it quelquefois sous les cada res et les pierres, dans les environs de Paris et de Lyon, la Picardie, l'Alsace, la Bourgogne, la Sirvoie, la Guienne, etc.

OBs. M. Rouget, dans ses Coléoptères parasites des Vespides (Mém. Ac. Dijon, 1873, 3e série, I, 161), a fait connâtue l'histoire des métamorphose:

(1) Les soies du dos de l'abdomen et du ventre, disposées en séries transversales, surtout sur les derniers segments, sont insérées dans un gros pore ou point enfoncé, très-distinct. 
de cet insecte, ses mœurs et la manière de le chasser. Sa larve avait d'abord été signalée par Newmann (Zool. 2585), et puis décrite et figurée par Schiödte (Nat. Tidss. 1864, 203, pl. X, fig. 9-16).

Dans cette espèce, les élytres et les pieds sont parfois d'un brun ro!ıssâtr،

Genre Quedius. Qứdie, Stephens.

Stephens, Ill. Brit. Enl. v, p. 215 - Jacqublin do Val, Gen. Col. Staph. 37.

Étymologie : inconnue.

Caractères. Corps plus ou moins allongé, rarement oblong, souvent fusiforme ou subfusiforme, légèrement pubescent, avec la tête et le prothorax glabres et lisses.

Tête plıs ou moins grande, subtransverse, suborbiculaire ou ovalaire, portée sur un col très-court, épais, généralement un peu ou à peine moius large que le vertex. Tempes visiblement, rarement obsolètement rebordées sur les côtés. Épistome corné ou subcorné, souvent subvertical, tronqué à son bord antérieur, parfois subimpressionné oll subéchancré en avanı. Labre transverse, tantôt bilobé, tantôt simplement fendu dans son milieı, quelquefois entier ou presque entier. Mandibules assez saillantes, assez robustes, subfalciformes, acérées, sillonnées en dehors surtout à leur base, grossièrement dentées intérieurement vers leur milieu. Palpes maxillaires médiocres, subfiliformes, à $1^{\mathrm{er}}$ article petit : les $2^{\mathrm{e}}$ et $3^{\mathrm{e}}$ suballongís, obconiques : le $3^{\mathrm{e}}$ souvent plus court que le $2^{\mathrm{e}}$ qui est subarqué : le dernier fusiforme, conico-fusiforme ou conique, souvent plus grêle que le précédent, aussi long, plus long ou à peine moins long que celui-ci. Palpes labiaux courts, à $1^{\mathrm{er}}$ article ob!ong : le $2^{\mathrm{e}}$ ordinairement plus épais, obconique, parfois plus long: le dernier fusiforme ou conıqu", généralement plus long que le $2^{\mathrm{e}}$. Menton grand, trapéziforme, plus étroit et submembraneux en avant, subtronqué au sommet.

Yeux de grosseur variable, subovales, rarement subarrondis, séparés du prothorax par un intervalle également variable.

Antennes plus ou moins altongées, généralement subfiliformes ou peu épaissies, à $1^{\text {er }}$ article en massue plus ou moins allongée : le $3^{\text {e }}$ généralement plus long que le $2^{\mathrm{e}}$ : les suivants graduellement un peu plus courts, non ou peu coñtigus : le dernier ovalaire ou oblong, subacuminé au bout.

Prothorax parfois transverse, souvent aussi large que long, rarement 
suboblong, plus ou moins rétréci en avant, tronqué ou subéchancré au sommet, à angles antérieurs plus ou moins infléchis et les postérieurs arrondis ou obtus; plus ou moins arrondi à sa base; finement rebordé sur celle-ci et sur les côtés ; à rebord latéral subhorizontal ou à peine infléchi d'arrière en avant, d'une manière plus ou moins régulièrement arquée ou très-rarement à peine sinuée postérieurement. Repli plus ou moins enfoui ou refoulé en dessous, nullement visible vu de côté.

Écusson grand ou assez grand, triangulaire ou subogival.

Élytres de longueur variable, simultanément subéchancrées au sommet, subarrondies à leur angle postéro-externe; finement et parfois obsolètement rebordées sur la suture. Repli assez étroit, subvertical. Épaules effacées ou peu saillantes, le plus souvent subépineuses en dessous.

Prosternum peu développé au devant des hanches antérieures, formant entre celles-ci un angle large plus ou moins ouvert, à disque longitudinalement relevé en faîte ou en carène, à sommet parfois un peu recourbé en dessous. Mésosternum à lame médiane triangulaire, généralement prolongée jusqu'au milieu des hanches, à sommet très-aigu ou acéré. Médiépisternums très-grands, séparés du mésosternum par une arête subtransverse, parfuis très-fine. Médiépimères médiocres, allongées ou oblongues. Métasternum assez court, échancré au devant des hanches postérieures; prolongé entre celles-ci en un lobe court, angulairement échancré ; tronqué ou subarrondi dans le milieu de son bord antérieur. Postépisternums assez grands, rétrécis postérieurement en languette émoussée, divergeant plus ou moins du repli des élytres. Postépimères grandes ou assez grandes, en onglet allongé.

Abdomen plus ou moins allongé, parfois oblong, souvent atténué en arrière, fortement rebordé sur les côtés; à ̀e segment basilaire parfois découvert, d'autres fois caché, ainsi que, rarement et en partie, le $1^{\text {cr }}$ normal: les suivants quelquefois graduellement plus longs, souvent subégaux, avec le $5^{\circ}$ plus grand, ordinairement largement sinué ou subéchancré à son bord postérieur : le $6^{\mathrm{e}}$ plus ou moins sallant, rétractile : celui de l'armure enfoui, émettant souvent 4 lanières ciliées. Ventre à arceaux subégaux, le $5^{\mathrm{e}}$ quelquefois plus grand : le $6^{\mathrm{e}}$ plus oumoins saillant, rétraclile.

Hanches antérieures très-grandes, de la.Iongueur des cuisses, saillantes, coniques, contiguës au sommet (1). Les intermédiaires grandes,

(1) Dans les Quédiaires, comme dans les Staphylinaires, les hanches antérieures offrent, au devant de leur insertion externe, une pièce rudimentaire, isolée, que nous appellerons pièce axillaire, cela dit une fois pour toutes. 
parfois assez saillantes en dedans, subovales, obliquement disposées, contiguës au sommet. Les postérieures médiocres, légèrement écartées à leur base, divergentes au sommet, qui est muni en dessous d'une série d'épines; à lame supérieure en cône court et mousse, subétranglé vers son milieu; à lame inférieure nulle ou enfouie.

Pieds médiocres, généralement peu robustes. Trochanters antérieurs petits, cunéiformes, les autres plus grands; les intermédiaires subcunéiformes, les postérieurs en ovale oblong et souvent acuminé. Cuisses plus ou moins comprimées, plus ou moins atténuées vers leur extrémité; plus ou moins spinosules en dessous, au moins les antérie'ıres ; les postérieures plus grêles et un peu plus longues. Tibias généralement subélargis de la base au sommet, plus ou moins épineux, munis au bout de leur tranche inférieure de 2 longs éperons assez grêles, dont l'interne plus long; les antérieur's plus courts et parfois plus robustes, à peine épineux ou simplement pubescents. Tarses antérieurs courts, à 4 premiers articles transverses, subcordiformes, subégaux, plus ou moins dilatés, le $4^{\mathrm{e}}$ moins fortement; les intermédiaires et postérieurs plus ou moins développés, subatténués vers leur extrénité, à $1^{\mathrm{er}}$ article plus ou moins allongé, aussi long ou plus long que le dernier ( 1 ) : les $2^{\mathrm{e}}$ à $4^{\mathrm{e}}$ ordinairement oblongs ou suboblongs, graduellement plus courts : le dernier en massue plus ou moins allongée. Ongles longs, grêles, arqués.

OBs. Les espèces de ce genre sont nombreuses et de tailles diverses. Leurs mœurs sont variées, et pourtant un peu moins fimicoles que chez les Philonthus.

Cette coupe générique diffère de ce dernier genre non-seulement par ses tempes rebordées sur les côtés et par le repli du prothorax plus enfoui, mais encore par sa tête généralement moins étranglée en arrière et portée sur un cou plus épais et par ses postépisternums divergeant en arrière du repli des élytres, etc.

Les espèces du genre Quedius, étant fort nombreuses, nous les ripartirons en 4 sections répondant à 5 sous-genres, dont voici le tableau :

I. Yux petits, occupant environ le tiers des cơtés de la tête. Labre bilobé. . . . . . . . . . . . . S.-genre Edrquus.

II. Yeux médiocres, occupant environ la moitié des cotés de la tête. Labre bilobé. . . . . . . . . . . S.-genre Quedius.

(1) Ce $i^{\text {er }}$ article est, rarement, moins long que le dernier. 
III. Yeux grands, occupant les deux tiers des cotés de la tète.

a. Labre entier ou presque entier. Corps subparallèle. Abdomen

à peine atténué en arrière. . . . . . . . . S.-genre Microsaurus.

aa. Labre plus ou moins bilobé, ou aı inoins fendu ou sillonné en avant dans son milieu. Corps plus ou moins fusiforme. Abdomen plus ou moins atténué en arrière. . . . . S.-genre Sauridus.

IV. Yeux très-grands, occupant presque entièrement les cótés de la tête. Labre bilobé ou parfois presque entier. Corps fusiforme ou subfusiforme. Abdomen atténué en arrière. . . S.-genre RapHinus (1).

SOUS-GENRE EDIQUUS, MuLSANT ET REY.

Ėtymologie : anagramme de Quedius.

CaRaCTÈRES. Yeux petits, subarrondis ou brièvement ovales, occupant environ le tiers des côtés de la tête, à facettes assez grossières. Labre bilobé. Le dernier article des palpes maxillaires tout à fait conique, un peu plus long que le précédent. Cuisses, toutes, spinosules en dessous, ou au moins vers leur extiémilé. Tibias antérieurs assez forts. Le $1^{\text {er }}$ article des tarses postérieurs parfois à peine moins long que le dernier. Abdomen peu atténué er arrière. Prosternum relevé en carène sensible.

Le sous-genre Ediquus se réduit à 2 espèces, dont voici les caractères principaux :

a. Antennes longues, à articles tous plus longs que larges. Prothorax déprimé latéralement. Tête ovale-allongée. Taille assez grande. Longrconnis.

aa. Antennes courtes, aे articles 7-10 fortement transverses. Prothorax non déprimé latéralement. Tête ovale suboblongue. Taille trèspetite. . . . . . . . . . . . . . MICROPS.

\section{Quedius (Ediquus) longicornis, Kraatz.}

D'un roux brun, avec la tête noire, le disque du prothorax et la base de chaque segment de l'abdomen largement couleur de poix; antennes grêles; élytres densement ponctuées.

(1) Nous reprendrons en particulier les caracteres de chaque sous-genre, en y ajoutant quelques autres considérations. 
$\sigma$ Li: $6^{\mathrm{e}}$ arceau ventral largement et à peine échancré au sommet, avec une impression en forme de sillon obsolète au devant de l'échancrure. Taries antérieurs fortement dilatés.

q Le 6 arceau ventral subarrondi au sommet. Tarses antérieurs un peu moins fortement dilatés.

Quedius fulgidus, var. '̈, ËIchson, Gen. et Spec. Staph. 526.

Quedius longicornis, KraAtz, Ins. Deut. II, 494, 4. - Fauvel, Faun. Gallo-Rhén. III, 499, 3.

Microsaurus longicornis, Tromson, Skand. Col. IX, 168̈, 8, b.

$$
\text { Long., } 0^{\mathrm{m}}, 0088 \text { (4 l.); - larg., } 0^{\mathrm{m}}, 0016 \text { (3/4 l.). }
$$

Tête brièvement ovalaire, très-finement chagrinée, presque mate, d'un noir de poix ; à tempes densement pointillées, pubescentes en arrière, avec la soie frontale située loin de l'orbite postérieure de l'œil. Palpes ferrugineux.

Yeux petit;, plus courts que les tempes.

Antennes grêles, assez longues, ferrigineuses, à $3^{\mathrm{e}}$ article d'une moitić plus long que le $2^{\mathrm{e}}$ : le $4^{\mathrm{e}}$ un peu, le $10^{\mathrm{e}}$ peu plus longs que larges.

Prothorax à peine transverse, d'un noir de poix, très-obsolètemenı chagriné, presque mał, plus clair sur les bords ; subrétréci sur les côtés vers sou sommet et arrondi à la base; à points ordinairement petits.

Écusson lisse.

Élytres non plus longues que le prothorax, rousses, densement, finement et subrugueusement ponctuées.

Abdomen presque parallèle, couleur de poix, avec les segments testacés à leur marge postérieure, sans soies apicales sur le dos.

Pieds d'un testacé ferrugineux, avec les tibias postérieurs rembrunis, assez éparsement et assez finement épineux.Tarses postérieurs à $1^{\mathrm{er}}$ article à peine plus court que le $5^{\mathrm{e}}$.

Patrie. Saint-Germain, Fontainebleau, dans les forêts, sous les pierres, les vieux troncs d'arbres. Très-rare.

OBs. Les antennes sont plus allongées et les yeux plus petits que dans les variétés claires des mesomelinus et xanthopus décrits plus loin. L'écussoll est lisse. 
Nous n'avons pas eu sous les yeux cette espèce, dont nous donnons la description d'après Kraatz, Thomson et Fauvel (1).

\section{Quedius (Gdiquus) mierops, Gravenhorst.}

Assez allongé, peu convexe, éparsement pubescent, d'un brun de poix brillant, avec la tête noire, les antennes d'un roux brunâtre, leur base, les palpes, les pieds et la marge des segments abdominaux testacés. Tête et prothorax lisses, luisants : celui-ci aussi large que long, subrétréci en avant. Écusson éparsement ponctué. Élytres assez finement et subéparsement ponctués, de la longueur du prothorax. Abdomen un peu plus fincment mais plus densement ponctué, subirisé.

$\sigma^{7}$ Le $6^{e}$ arceau ventral largement sinué dans le milieu de son bord apical, ave un léger espace triangulaire lisse au devant du sinus. Le $5^{\mathrm{e}}$ ə̀ peine sinué dans le milieu de son bord posiérieur.

ᄋ Le $6^{e}$ arceau ventral à peine arrondi au sommet. Le $5^{\mathrm{e}}$ simple.

Staphylinus microps, Gravenhorst, Stettin, Ent. Zeit. 1847, 213.

Quedius chrysurus, Kiesenwetter, in Küster, Käf. Eur. XII, 55, 1848. — KraAtZ,

Ins. Deut. II, : $220,35$.

Philonthus chrysurus, Redtenbacher, Faun. Austr. édit. 3, 202.

Microsaurus microps, THowson, Skand. Col. IX, 166, 8, $c$. Quedius microps, FaUvel, Faun. Gallo-Rhén. III, 500,

$$
\text { Long., } 0^{\mathrm{m}}, 0045 \text { (2 1.); - larg., } 0^{\mathrm{m}}, 0007 \text { (1/3 l.). }
$$

Corps assez allongé, peu convexe, d'un brun de poix brillant, avec la tête noire; revêtu sur les élytres et l'abdomen d'une fine pubescence d'un gris blond et peu serrée.

Tête ovale-suboblongue, subparallèle, moins large que le prothorax, éparsement et longuement sétosellée, sur les côtés; d'un noir luisant;

(1) Nous ferons remarquer, en passant, une contradiction qui existe entre les atlteurs à propos de cette espèce. Thomson (p. 166) dit: Capmt breviter ovale, et M. Fauvel : Tête élroite, trés-allongée, subparallèle, ovalaire, c'est-à-dire tout à fait le contraire. 
lisse; à pores temporal et postoculaires gros, écartés chacun de l'œil d'un espace au moins aussi grand que le diamètre antéro-postérieur de celui-ci, avec 1 seul ou rarement 2 petits points rapprochés de chaque côté du vertex. Front large, subdéprimé, à point juxta-oculaire médiocre, joignant l'œil. Cou glabre, presque lisse, luisant. Épistome corné, roussâtre. Labre d'un brun roux, sétosellé en avant. Mandibules d'un brun ferrugineux. Palpes testacés, les maxillaires à dernier article tout à fait conique.

Yeux petits, peu saillants, courtement ovales, obscurs, souvent lavés de gris micacé.

Antennes courtes, sensiblement plus longues que la tête ; à peine épais sies; finement duveteuses et éparsement pilosellées; ferrugineuses ou d'un roux brunâtre, avec la base plus claire; à $1^{\mathrm{er}}$ article en massue suballongée : le $2 \mathrm{e}$ oblong, obconique : le "3e à peine plus long, un peu plus grêle, obconique : les suivants graduellement à peine plus épais, non contigus : le $4^{\mathrm{e}}$ presque carrè : le $5^{\mathrm{e}}$ à pein`, les $6^{\mathrm{e}}$ à $10^{\mathrm{e}}$ fortement trans verses : le dernier subovalaire, subitement acuminé au bout.

Prothorax aussi large que long; subrétréci en avant; à peine plus large que les élytres; largement tronqué au sommet, avec celui-ci subsinué de chaque côté près des angles antérieurs, qui sont subinfléchis et arrondis ; subarqué sur les côtés ; largement arrondi à sa base, avec les angles postérieurs obtus et subarrondis; assez convexe sur son disque; éparsement el sérialement sétosellé sur les côtés; à pore sétıfère latéral médiocre, situé assez près de la marge; d'un brun de poix luisant; lisse; offrant en avant 2 séries dorsales composées de 3 points assez fins, dont l'antérieur submarginal et beaucoup plus écarté; paré, en outre, sur les côtés, à égale distance entre les 2 points postérieurs du dos el les angles antérieurs, de 2 points semblables, rapprochés transversalement, sans compter les marginaux.

Écusson éparsement ponctué, à peine pubescent, d'un brun de poix brillant.

Élytres subcarrées, subparallèles, de la longueur du prothorax ; subdéprimées ou à peine convexes; assez finement et subrâpeusement ponctuées; d'un brun de poix brillant; légèrement et éparsement pubescentes sur leur disque ; ciliées-subspinosulées à leur bord apical ; éparsement sétosellées sur les còtés, a vec 1 soie beaucoup plus longue près des épaules, et 1 autre un peu plus en armère. Epaules à calus distinct, épineuses en dessous. 
Abdomen suballongé, moins large que les élytres, subatténué postérieurement; subconvexe sur le dos, avec les 3 premiers segments à peine impressionnés en travers à leur base; éparsement et longuement sétosellé; un peu plus finement mais plus densement ponctué que les élytres, plus éparsement vers son sommet; d'un brun de poix brillant et subirisé, avec le $6^{\ominus}$ segment entièrement, la marge apicale du $5^{\text {e }}$ largement, celle des précédents étroitement, testacés; à pubescence longue et modérément serrée. Le $6^{\mathrm{e}}$ segment subtronqué.ou à peine arrondi au sommet.

Dessous $d u$ corps aspèrement ponctué, pubescent, d'un brun de poix brillant, avec le repli du prothorax, l'antépectus, le médipectus, le sommet du ventre et la marge apicale des arceaux plus ou moins testacés. Dessous de la tête presque glabre, presque lisse. Prosternum subcaréné. Mésosternum offrant après son milieu un espace subrelevé, lisseet éparsement sétosellé. Métasternum subdéprimé. Ventre convexe, éparsement sétosellé, plus ou moins irisé, à $2 \mathrm{e}$ arceau basilaire prolongé sur le $\mathbf{1}^{\mathrm{er}}$ normal en angle sensible.

Pieds aspèrement pointillés, légèrement pubescents, d'un roux testacé, avec les cuisses et les tibias postérieurs parfois un peu plus sombres dans leur milieu. Cuisses spinosules en dessous, surtout vers leur extrémité ; les postérieures un peu moins épaisses. Tibias antérieurs assez forts, simplement pubescents. Tarses antérieurs à 3 premiers articles très-fortement, le $4^{\mathrm{e}}$ moins fortement, dilatés; les postérieurs à $1^{\text {er }}$ article suballongé, à peine moins long que le dernier, subégal aux 2 suivants réunis : les $2^{\mathrm{e}}$ à $4^{\mathrm{e}}$ graduellement plus courts.

Patrie. Cette rare espèce se rencontre dans la Picardie, aux environs de Fontainebleau et à la Grande-Chartreuse, en juillet, dans le tan des vieux arbres, parfois en compagnie de la Formica fuliginosa.

OBs. Elle est remarquable par la petitesse de sa taille, sa tête suboblongue et subparallèle, par ses yeux petits et occupant seulement le tiers des côtés de la tête, par son écusson ponctué, etc.

Chez les immatures, le corps est d'un roux ferrugineux, avec la tête plus obscure, les antennes entièrement testacées, et les intersections abdominales et venırales plus pâles.

Les adultes sont parfois presque entièrement d'un noir de poix. 
SOUS-GENRE QUEDIUS VERUS

Microsaurus, Tnomson, Skand. Col. II, 174.

Caractères. Yeux médiocres, occupant environ la moitié des côtés de lit tête. Labre bilobé. Le dernier article des palpes maxillaires fusiforme oll conico-fusiforme, très-rarement conique (1). Cuisses ordinairement (1)!tes, spinosules en dessous; les postérieures parfois même épineuses. Tibias antérieurs généralement assez robustes, sensiblement élargis de la base au sommel. Le $1^{\text {er }}$ article des tarses postérieurs subégal ou à peine fin 1 au dernier, rarement visiblement moins long que celui-ci. Abdomen ordinairement peu atténué en arrière. Prosternum plus ou moins relevé Iongitudinalement en faîte ou en carène.

Le sous-genre Quedius renferme un assez grand nombre d'espèces, dont nous allons essayer d'indiquer les différences, dans le tableau suivant :

a. Prothorax impressionné sur les côtés, avec 1 ou 2 points dorsaux en série. Élytres rouges. Corps assez large.

b. Elytres lisses, ponctuées sur les côtés seulement. Tempes rapprochées ou suhcontiguës en arrière en dessous. Taille assez grande.

bb. Élylres uniformément et éparsentent ponctuées. Tempes curtus. sêparées en dessous par un espace sensible et subparallèle. Taille assez petite. . . . . . . . . • . . .

:la. Prothorax à séries dorsales de 3 points, en comptant le juxtamarginal.

c. Élytres à ponctuation uniforme, normale.

d. Le dernier article des palpes maxillaires fusiforme ou subfusiforme. Taille grande ou moyenne.

e. Écusson ponctué. Abdomen ferrugineux. . . . . . ventralis.

ee. Écusson lisse.

f. Antennes subfiliformes, à pénultièmes articles non ou à peine transverses.

g. Élytres assez densement ponctuées, noires, à repli testacé. Taille grande. . . . . . . . . LATERALIS.

gg. Elytres éparsement ponctuées, rouges. Taille assez grande.

BREVIS.

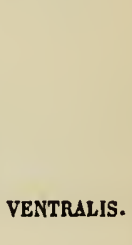


h. Prothorax plus ou moins impressionné sur les cotés, au moins chez les $\sigma$.

i. Prothorax sans points sur les cotés du disque.

k. Élytres rouges, fortement et éparsement ponctuées. Taille grande. . . . . . . . • •

kk. Elytres d'un noir submétallique, fortement et subéparsement ponctuées. Taille moyenne. . . . BREVICORNIS.

kk. Elytres d'un noir de poix, assez fortement et assez densement ponctuées. 1 point isolé, situé assez loin du bord postéro-interne des yeux. Taille un peu plus grande. • . . . . . . .

ii. Prothorax avec 2 ou plusieurs points sur les côtés du disque.

1. Élytres d'un noir bleuatre. Prothorax à 3 ou 4 points latéraux en série arquée. Le $1 \mathrm{er}^{\mathrm{r}}$ article des tarses postéricurs subégal au dernier. . . . .

1l. Élytres noires, sans reflet bleuâtre. Prothorax à 2 points latéraux obliquement disposés. Le $1^{\mathrm{er}} \mathrm{ar}$ ticle des tarses postérieurs un peu moins long que le dernier.

MESOMELINUS

FAGETI.

NIGROCAERULEU:.

11l. Elytres rouges, ou en partie.

m. Antennes brunes ou brunâtres, à base noire. Pieds plus ou moins obscurs.

n. Prothorax avec 2 points obliques sur les côtés du disque. Abdomen subconcolore. Antennes avec les $6^{\mathrm{e}} \grave{a} 10^{\mathrm{e}}$ articles fortement transverses.

0. Élytres à peine plus longues que le prothorax, fortement ponctuées. Points postoculaires subégaux. Pore sétifère latéral $d u$ prothorax situé assez loin de la marge. .

00. Elytres de la longueur du prothorax, assez finement ponctuées. Points postoculaires très-inégaux. Pore sétifère latéral du prothorax situé tout près de la marge. . .

nn. Prothorax avec 3 ou 4 points en série arquée ASSECLA. sur les côtés du disque. Abdomen et marge des segments roux au sommet. Antennes avec les $6^{\mathrm{e}}$ à $10^{\mathrm{e}}$ articles moins transverses. 1 seul point postoculaire isolé. . . . . .

VARIABILIS.

OCHRIPENNIS.

FULGIDUS.

mm. Antennes brunes, leur base, les pieds, le sommet de l'abdomen et la marge des segments d'un roux testacé. . . . . . . . CRUENTUS.

hh. Prothorax non impressionné sur les côtés, d'un roux de poix sur ceux-ci. Abdomen éparsement ponctué. p. Élytres d'un noir ou d'un brun de poix. Taille 
moyenne. Ventre à $2^{\mathrm{e}}$ arcean basilaire prolongé sur le $1^{\text {cr }}$ normal en angle aigiı. . . . . . xanthopus.

pp. Elytres rouges, rembrunies à l'angle postéro-externe, Taille moindre. Ventre à $2^{\mathrm{c}}$ arceau basilaire prolongé sur le $1^{\text {er }}$ normal en pointe brusque, fine, aciculée. . . . . . . . . . . scitus.

dd. Le dernier article des palpes maxillaires conique. Taille. très-petite. Écusson éparsement ponctué. . . . . . infuscatus cc. Elytres offrant sur leur disque, outrs la sculpture foncière, des points en série. Écusson lisse.

q. Tempes obsolètement rebordées en avant. Élytres presque mates, avec une série de 4 points légers sur les cótés du disque. • . • • • • • • • • • • • • LAEVigatus.

qq. Tempes distinctement rebordées jusqu'en avant des joues. Elytres brillantes, avec 3 séries de 5 à 8 points enfoncès (1).

r. Elytres à fond éparsement pointillé. Abdomen èparsement ponctué. Antennes à pénnltièmes articles légèrement transverses. Taille moyenne. . . . . . cinctus.

rr. Élytres à fond obsolètement ruguleux. Abdomen modérément ponctué. Antennes à pónultic̀mes articles plus transverses. Taille assez petite. . . . . PEDICulus.

\section{Duedius curtus, Erichson.}

Suballongé, peu convexe, légèrement pubescent, d'un noir brillant, avec les élytres rousses, la bouche, les antennes et les pieds d'un roux de poix. T'ite et prolhorax lisses, luisants : celui-ci fortement transverse, subrétréci en avant. Écusson lisse. Élytres lisses intérieurement, ponctuées sur les côtés. Abdomen finement et modérément ponctué.

$\sigma^{7}$ Le $6^{e}$ arcean ventral échancré au sommet, avec une légère impre: siun triangulaire, au devant de l'échancrure.

\& Le $6^{\mathrm{e}}$ arceau ventral subarrondi au sommet.

Quedius curtus, Ericrson, Gen. et Spec. Staph. 534, 16. - Fairmaire et Labortbène,

Faun. Ent. Fr. I, 535, 2.- Redtendacher, Faun. Austr. édit. 3, 197. - Faciel, Faun. Gallo-Rhén. III, 500, 5 .

(1) Parfois les points de la série intermédiaire sont moins nombreux. 


$$
\text { Long., } 0^{\mathrm{m}}, 0082 \text { (3 3/4 l.); - larg., } 0^{\mathrm{m}}, 0023 \text { (1 l.). }
$$

Corps suballọngé, épais, assez large, peu convexe, d'un noir brillant, avec les élytres rouges ; revêtu sur celles-ci et l'abdomen d'une fine pubescence grisâtre et peu serrée.

Tête subtransverse, un peu moins large que le prothorax; d'un noir assez luisant; presque lisse, obsolètement pointillé sur les côtés ; éparsement sétosellée latéralement; marquée sur le vertex de 2 petits points obsolètes ou peu distincts, très-écartés, et, derrière le bord postéro-interne des yeux, d'un très-gros point sétifère, et d'un autre, moindre, sur les tempes. Front très-large, peu convexe, à pore juxta-oculaire gros. Cou à peine distinct du vertex. Épistome subcorné, d'un rouge brun, subimpressionné en avant. Labre rougeâtre, fortement sétosellé en avant. Mandibules obscures. Palpes roux.

Yeux subovales, très-peu saillants, brunâtres.

Antennes assez courtes, un peu plus longues que la tête; grêles, subfiliformes ou à peine épaissies; finement duveteuses et légèrement pilosellées; d'un roux parfois assez foncé; à $1^{{ }^{\mathrm{e}} \mathrm{r}}$ article en massue allongée : le $2^{\mathrm{e}}$ oblong; obconique : le $3^{\circ}$ assez allongé, plus long que le $2^{\mathrm{e}}$ : les suivants graduellement à peine plus épais, non contigus : le $4^{\mathrm{e}}$ presque carré : les $5^{\mathrm{e}} \mathrm{a} 10^{\mathrm{e}}$ obconiques, peu ou à peine transverses: le dernier $\mathrm{s}$ ubovalaire, obliquement tronqué au sommet.

Prothorax court, fortement transverse, subrétréci en avant; de la largeur des élytres ou à peine plus large ; subéchancré au sommet, avec les angles antérieurs infléchis et subarrondis; à peine arqué sur les côtés ; arrondi à la base ainsi qu'aux angles postérieurs; subconvexe sur le dos, subimpressionné de chaque côté ; d'un noir luisant; sérialement sétosellè sur sa marge latérale; lisse sur son disque, distinctement pointillé vers les angles postérieurs ; sans point dorsal ; à pore sétifère latéral gros, situé tout près de la marge, à soie courte.

Écusson lisse, luisant, glabre, d'un noir de poix, à reflets rouges sur ses bords.

Élytres transverses, un peu plus longues que le prothorax; à peine plus larges en arrière qu'en avant; subdéprimées ou très-faiblement convexes ; lisses ou presque lisses intérieurement, graduellement et distinctement ponctuées sur les côtés ; d'un rouge brillant; ciliées-spinosulées à leur bord apical; finement et subéparsement pubescentes sur leur 
disque, avec 2 longues soies redressées sur les côtés, près des épaules. Celles-ci cachées, épineuses en dessous.

Abdomen peu allongé, moins large que les élytres, subatténué en arrière; assez convexe sur le dos; non distinctement sétosellé ; finement et modérément ponctué; plus lisse sur le dos du $1^{\text {er }}$ segment; d'un noir brillant et à peine irisé, avec l'extrémité rougeâtre; à pubescence assez courte, déprimée, à peine plus serrée que celle des élytres. Le $6^{\ominus}$ segment à peine arrondi au sommet.

Dessous du corps aspèrement ponctué, pubescent, d'un noir brillant, avec le sommet du ventre roussâtre. Dessous de la tête éparsement ponctué-pileux en arrière. Métasternum subdéprimé. Ventre convexe.

Pieds aspèrement ponctués, légèrement pubescents, d'un roux de poix assez foncé, avec les tarses plus clairs. Guisses antérieures et intermédiaires spinosules en dessous, surtout. vers leur extrémité; les postérieures plus grêles. Tibias antérieurs assez forts, plus courts que les cuisses, à peine épineux. Tarses antérieurs à 3 premiers articles fortement dilatés, le $4^{\mathrm{e}}$ moins fortement; les postérieurs à $1^{\mathrm{er}}$ article suballongé, subégal aux 2 suivants réunis, à peine aussi long que le dernier: celui-ci allongé, assez grêle : les $2^{\mathrm{e}}$ à $4^{\mathrm{e}}$ oblongs, graduellement moins longs.

Patrie. Cette espèce, très-rare, se prend dans la Bourgogne, le Périgord, le Dauphiné, la Provence, etc. Elle paraît au printemps et à l'antomne.

OBs. Elle est remarquable par sa forme épaisse et large, par son prothor.x sans points dorsaux et surtout par ses élytres lisses intérieurement.

Erichson nous paraît aroir eu sous les yeux, à la fois, le véritable curtus et le crassus de Fairmaire; car il place son insecte dans la section des prothorax sans séries dorsales de points, et, d'un autre côté, il lui donne des élytres ponctuées.

\section{Quedius brevis, Erichson.}

'Oblong, subparallèle, peu convexe, éparsement pubescent, d'un noir de poix brillant, avec les côtés du prothorax rougeâtres, la bouche, les antennes, les élytres, la poitrine, l'extrémité de l'abdomen et la marge des segments abdominaux et ventraux, d'un roux testacé. Tête et prothorax luisants: celui-ci transverse, subrétréci en avant. Écusson presque lisse, BR. 
Elytres fortement et éparsement, abdomen finement et plus densement, ponctués.

$\sigma^{*}$ Le $6^{\text {e }}$ arceau ventral largement et angulairement échancré dans le milieu de son bord apical, avec un espace triangulaire, lisse, au devant de l'échancrure. Le $5^{\mathrm{e}}$ à peine et subangulairement sinué au milieu de son bord postérieur.

ㄴ Le $6^{\mathrm{e}}$ arceau ventral subarrondi au sommet. Le $5^{\mathrm{e}}$ simple.

Quedius brevis, Ericason, Gen. et Spec. Staph. 535, 17. - Fatrmatre et Laboulbène,

Faun. Ent. Fr. I, 535, 1. - KraATZ, Ins. Deut. II, 500, 11. - JacQUeuin du VAL,

Gen. Col. Staph. pl. 15, fig. 72. - Ryẹ, Ent. Ann. 1857, 76. - Fauver, Faun.

Gallo-Rhén. III, 502, 6 .

Microsaurus brevis, Thouson, Skand. Col. II, 177, 9.

Philonthus brevis, Redtenbacaer, Fain. Austr. 708, 46.

$$
\text { Long., } 0^{\mathrm{m}}, 006 \text { (2 2/3 l.); - larg., } 0^{\mathrm{m}}, 0017 \text { (3/4 l.). }
$$

Corps oblong, assez large, subparallèle, d'un noir de poix brillant, avec les élytres, l'extrémité de l'abdomen et la marge des segments d'un roux testacé; recouvert sur les élytres et l'abdomen d'une fine pubescence blonde et peu serrée.

Tête transverse, subarrondie, moins large que le prothorax; d'un noir luisant; éparsement et très-longuement sétosellée sur les côtés; presque lisse ou très-obsolètement chagrinée et pointillée, surtout en avant; parée, derrière les yeux, de 2 gros pores sétifères. Front très-large, subconvexe, marqué de chaque cóté d'un gros pore juxta-oculaire. Cou presque lisse, glabre, luisant. Épistome submembraneux et pâle antérieurıment. Labre d'un roux brillant, sétosellé en avant. Parties de la bouche d'un roux testacé, avec les mandibules obscures.

Yeux ovales, yeu saillants, noirs, parfois à taches livides.

Antennes courtes, un peu plus longues que la tête, à peine épaissies; finement duveteuses et obsolètement pilosellées; entièrement rouss' $\mathrm{s}$; à $1^{\text {er }}$ article en massue oblongue : les $2^{\mathrm{e}}$ et $3^{\mathrm{e}}$ obconiques :. le $3^{\mathrm{e}}$ plus long que le $2^{\mathrm{e}}$ : le $4^{\mathrm{e}}$ subcarré : les suivants graduellement à peine plus épais, subcontigus : les $5^{\mathrm{e}}$ et $6_{-}^{\mathrm{e}}$ à peine, les $7^{\mathrm{e}}$ à $10^{\mathrm{e}}$ légèrement transverses, le $10^{\mathrm{e}}$ néanmoins paraissant un peu moins court que les précédents : le dernier ovalaire-oblong, obliquement tronqué au bout.

Prothorax transverse, subrétréci en avant, un peu on à peine plus larg 
que les élytres; largenıent tronqué au sommet, avec les angles antérieur $\mathrm{S}$ subinfléchis, droits mais subarrondis; subarqué sur les côtés, qui sont brièvement et sérialement sétosellés; largement arrondi à sa base, avec les angles postérieurs obtus; assez convexe; subimpressionné en arrière sur les côtés; d'un noir de poix luisant, passant au rougeâtre latéralement: surtout vers les angles antérieurs; presque lisse; marqué en avant, sur le dos, de 1 ou de 2 points longiludinalement disposés de chaque côté de la ligne médiane; creusé en outre d'1 gros pore sétifère, près de la marge latérale et vers son tiers antérieur, et d'1 autre moindre, de chaque côté, sur la base (1).

Écusson presque lisse, glabre, d'un brun de poix parfois un „peu roussâtre.

Élytres transverses, environ de la longueur du prothorax; subparalèles; subdéprimées ou faiblement convexes; fortement et éparsement ponctuées; d'un rouge testacé brillant; éparsement pubescentes, avec une série de cils spinosules au bord apical, et 2 longues soies sur les côtés, vers les épaules. Celles-ci cachćes.

Abdomen peu allongé, un peu moins large que les élytres; subatténué en arrière; subconvexe sur le dos, avec les 3 premiers segments à peine impressionnés en travers à leur base; éparsement et très-longuement sétosellé ; finement et modérément ponctué ; éparsement pubescent; d'un noir brillant et subirisé, avic la marge apicale des segments et le $G^{\mathrm{e}}$ entièrement d'un roux testacé. Celui-ci subtronqué au sommet.

Dessous du corps aspèrement ponctué, finement pubescent, d'un noir de poix brillant, avec l: repli du prothorax, l'antépectus, le médipectus, le $6^{\mathrm{e}}$ arceau ventral et la marge apicale des précédents, d'un roux testacé. Dessous de la tête presque lisse, très-éparsement ponctué, à peine pubescent, a vec l'intervalle des tempes sensible et subparallèle. Dlétasternum à peine convexe, avec 2 longues soies en arrière. Ventre convexe, sübirisé, éparsement et longuement sétosellé; à $2^{\mathrm{e}}$ arceau basilaire prolongé sur le $1^{\text {er }}$ normal en pointe courte, peu aiguë et presque lisse.

Pieds subrâpeusement ponctués, légèrement pubescents; d'un rouge tesıacé. Cuisses très-finement spinosules en dessous, surtout vers leur extrémité; les postérieures plus allongćes et plus grêles. Tibias antérieurs

(1) Ces pores sont à soie très-Jongue, ainsi que ceux de la tête, et les points susmentionnés existent indépendamment d'autres petits points qu'on remarque sur les marges. 
assez robustes, plus courts que les cuisses, simplement pubescents en dehors. Tarses antérieurs à 4 premiers articles fortement mais graduellement moins dilatés; les postérieurs à $1^{\mathrm{er}}$ article suballongé, à peine aussi long que le dernier : les $2^{\mathrm{e}}$ à $4^{\mathrm{e}}$ graduellement à peine moins longs.

Patrie. Cette espèce, peu commune, se trouve sous les pierres, sous les écorces et sous les feuilles mortes, dans les forêts et souvent dans les nids des Formica rufa et fuliginosa. Son habitat est très-étendu : les environs de Paris, la Nornandie, l'Alsace, la Lorraine, le Bourbonnais, les montagnes du Lyonnais, les Alpes, les Pyrénées, etc.

OBs. Cette espèce diffère du curtus par sa laille moindre, par sa forme plus parallèle et moins trapue, par la ponctuation plus forte et plus uniforme des élytres, par son abdomen moins noir et surtout moins rétréci en arrière, par l'ıntervalle des tempes, en dessous, :plus large et plus parallèle, etc.

\section{Quedius ventralis, ARagona.}

Allongé, peu convexe, éparsement pubescent, d'un noir brillant, avec l'abdomen ferrugineux, les palpes et le sommet des tarses d'un roux de poix. Téte légèrement pointillée. Prothorax luisant, subtransverse, subrétréci en avant. Écusson ponctué. Élytres fortement et modérément, abdomen plus finement, ponctués.

$\sigma$ Le $6^{e}$ arceau ventral largement et circulairement sinué à son sommet. Tête en carré subtransverse, presque aussi large que le prothorax. Ėpistome fortement impressionné-subéchancré en avant.

o Le $6^{\text {e }}$ arceau ventral subarrondi au sommet. Tèle subovalaire, sensiblement moins large que le prothorax. Epistome faiblement impressionné-subéchancré en avant (1).

Staphylinus ventralis, Aragona, De Quib. Col. It. 1830, 12.

Emus nitidus, Borsduval et LaCordajre, Faun. Ent. Par. I, 378, var. A.

Quedius fulgidus, Erichson, Gen. et Spec. Staph. 526, var. 3.

(1) Les tarses antérieurs des $q$ paraissent un peu moins dilatés. 
Quedius truncicola, Falrmarre et Laboulbè̀ne, Faun: Ent: Fr. I, 338, 14. - Rye, Ent. Ann. 1861, 63; 1863, 112. Quedius ventralis, FaUvel, Faun. Gallo-Rhén. III, 507, 14.

$$
\text { Long., } 0^{\mathrm{m}}, 010 \text { (4 1/2 l.); - larg., } 0^{\mathrm{m}}, 0011 \text { (1/5 l.). }
$$

Corps allongé, peu convexe, d'un noir brillant, avec l'abdomen plus ou moins ferrugineux; revêtu sur celui-ci et les élytres d'une fine pubescence grisâtre et peu serrée.

Tête éparsenent sétosellée sur les côtés; d'un noir brillant; à peine chagrinée et légèrement mais visiblement pointillée, surtout cliez les $\sigma^{\prime \prime}$; marquée en outre, derrière les yeux de quelques points plus forts et épars, dont 3 plus gros et sétifères : 1 sur les tempes, les 2 autres obliquement disposés derrière le bord postéro-interne des yeux. Front très-large, peu convexe, plus ( $\left.\sigma^{*}\right)$ ou moins ( $\$$ ) impressionné en avant, a point juxta-oculaire gros. C'ou presque lisse, glabre, luisant. Épistome livide et plus ou moins impressionné en avant. Labre d'un noir ou d'un brun de poix, fortement sétosellé à son bord antérieur. Mandibules noires. Palpes d'un roux de poix.

Yeux ovales, peu saillants, obscurs, lavés de gris sombre.

Antennes assez courtes, un peu plus longues que la tête; subẻpaissies; finement duveteuses et légèrement pilosellées ; obscures, avec l'extrémité graduellement moins foncée; à $1^{\text {er }}$ article en massue allongée et subarquée : les $2^{\mathrm{e}}$ et $3^{\mathrm{e}}$ obconiques : le $2^{\mathrm{e}}$ oblong: le $3^{\mathrm{e}}$ plus long, suballongé : les suivants graduellement un peu plus épais, peu contigus : le $4^{e}$.presque carré : le $5^{\mathrm{e}}$ à peine, les $6^{\mathrm{e}}$ à $10^{\mathrm{e}}$ plus visiblement transverses, subégaux: le dernier subovalaire, obliquement subacuminé au sommet.

Prothorax subtransverse, subrétréci en avant; un peu on à peine plus large que les élytres; très-largement ou à peine échancré all sommet, avec les angles antérieurs subinfléchis, presque droits mais émous és; sensiblement arqué sur' les côtév; subarrondı à sa base ainsi qu'aux angles postéricurs; assez convexe sur le do;; plus ou moins impressionnẻ de chaque côté, vers les angles postérieurs ; sérialement sélosellé en avant sur les côtés, avec le pore sétifère latéral plus ou moins distant de la marge; d'un noir luisant ; presque lisse(1); offrant antérieurement 2 séries

(1). On aperçoit parfois une ponctuation obsolcte dans l'ouverture des angles antérieurs. 
dorsales composées de 3 points médiocres, dont l'antérieur, submargina et un peu plus écarté, et, en outre, 3 ou 4 autres points semblables, disposés en série arquée, sur les côtés du disque (1).

Écusson distinctement ponctué et pubescent, surtout en arrière, d'un noir brillant.

Élytres subcarrées, subparallèles, à peine plus longues que le prothorax ; subdéprimées, subsillonnées en arrière le long de la suture ; plus ou moins impressionnées au sommet vers leur angle postéro-externe ; fortement et modérément ponctuées; d'un noir d'ébène brillant; éparsement pubescentes, avec la pubescence parfois semi-redressée; parées à leur bord apical d'une série de cils subspinosules, et sur les côtés d'une série de soies légères, avec 3 beaucoup plus longues et plus obscures. Épaules cachées, subépineuses.

Abdomen suballongé, moins large que les élytres; sensiblement atténué en arrière; subconvexe sur le dos, avec les 3 premiers segments subimpressionnés en travers à leur base ; très-éparsement et longuement sétosellé ; assez finement et modérément ponctué ; d'un ferrugineux assez brillant et subirisé, avec la base souvent un peu rembrunie; à pubescence assez longne. Le $6^{\mathrm{e}}$ segment subtronqué au sommet.

Dessous du corps subaspèrement ponctué, pubescent, d'un noir brillant, avec le ventre plus ou moins ferrugineux, et le repli du prothorax souvent d'un roux de poix. Dessous de la tête presque lisse, presque glabre. Prosternum subcaréné. Mésosternum inégal, sétosellé. Métasternum subdéprimé sur son milieu. Ventre convexe, longuement et très-éparsement sétosellé; à $2^{\mathrm{e}}$ arceau basilaire prolongé sur le $1^{\mathrm{er}}$ normal en pointe assez aiguë.

Pieds aspèrement ponctués, pubescents ; obscurs, avec le dernier article des tarses roux ou ferrugineux. Cuisses spinosules en dessous; les postérieures plus grêles. Tibias antérieur's assez, robustes, à peine arıués, peu épineux. Tarses antérieurs à 4 preniers articles fortement dilatés, les $1^{\text {or }}$ ct surtout $4^{\mathrm{e}}$ moins fortement; les postérienrs à $1^{\mathrm{er}}$ article suballongé, à peine égal au dernier, subégal aux 2 suivants réinis : les $2^{e}$ à $4^{\mathrm{e}}$ graduellement plus courts.

Patrie. Cette rare espèce se trouve dans lis tronis caverneux des arbres, tilleuls, chênes, noyers, etc., de juin à octobre, dans les environs de Paris

(1) Nous faisons abstraction des points marginanx ou submarginaux qui existent presque toujours, et céla dit pour toutes les espèces. 
et de Lyon, la Flandre, la Normandie, la Champagne, l'Alsace, la Lorraine, le Bourbonnais, le Beaujolais, la Guienne, les Pyrénées, etc.

OBs. Elle se distingue de toutes ses voisines par son écusson ponctué et son abdomen ferrugineux.

Dans les sujets immatures, l'abdomen est testacé, les antennes et les palpes sont d'un brun ferrugineux.

\section{Quedius Iateralis, Gravenhorst.}

Suballongé, subdéprimé, légèrement pubescent, d'un noir brillant, avec le repli des élytres blond, la bouche et la base des antennes d'un roux testacé, les intersections ventrales et les pieds couleur de poix, et les tarses plus clairs. Tête et prothorax luisants : celui-ci subtransverse, subrétréci en avant. Écusson lisse. Elytres et abdomen assez fortement et assez densement ponctués.

$\sigma^{*}$ Le $6^{e}$ arceau ventral fortement et angulairement sinué dans le milieu de son bord apical, avec une large impression longitudinale lisse au devant du sinus. Le $5^{\mathrm{e}}$ légèrement sinué dans le milieu de son bord postérieur, avec une dépression lisse au devant du sinus.

오 Le $5^{\mathrm{e}}$ arceau ventral simple, le $6^{\mathrm{e}}$ subarrondi, à leur bord apical.

Staphylinus lateralis, Gravenhorst, Micr. 3̋, 50; - Mon. 42, 4. - Latreille, Hist. Nat. Crust. et Ins. IX, 319, 55. - Gyllenhal, Ins. Suec. IV, 477, 20-21. Philonthus lateralis, Nordm.nn, Symb. 76, 7. - Redtenbacuer, Faun. Austr. 708, 50), - HeEr, Faun. Helv. I, 279, 55.

Enius lateralis, BoIsduval et Lacordaire, Fain. Ent. Par. I, 375, 26.

Quedius lateralis, Curtis, Brit. Ent. XIV, pl. 638. - Erichson, Col. March. J, 485̈, $2 ;-$ Gen. et Spec. Staph. 520̈, 2. - Fairmaire et Laboulbėne, Faun. Ent. Fr. I, 539, 15.- Kratz, Ins. Deul. II, 491, 2.- Fauvel, Faun. Gallo-Rhén. III, 502, 8. Microsaurus lateralis, Thomson, Skand. Col. II, 174, 2.

$$
\text { Long., } 0^{\mathrm{m}} .011 \text { (5 l.); - larg., } 0^{\mathrm{m}} .0030 \text { (1 } 1 / 3 \text { l.). }
$$

Corps allongè, subdépi iné, d'un noir brillanı, avec le repli des élytres blond; revètu sur celles-ci et l'abdomen d'une légère pubescence d'un gris obscur et peu serrée. 
Tête subtransverse, un peu ou sensiblement moins large que le prothorax; d'un noir luisant, lisse ; éparsement et assez finement ponctuée et légèrement pubescente derrière les yeux; parée de chaque côté, vers le bord interne de ceux-ci, de 2 gros pores sétifères, de 4 autres, plus faibles, écartés et transversalement disposés sur le vertex, et de 2 autres sur les tempes. Front large, à peine convexe. Cou presque lisse, glabre. Epistome avec une bordure membraneuse pâle. Labre d'un noir depoix, fortement sétosellé en avant. Parties de la bouche d'un roux testacé, avec les mandibules ferrugineuses.

Yeux assez grands, ovales, obscurs, lavés de livide.

Antennes assez courtes, moins longues que la tête et le prothorax réunis ; à peine épaissies ; finement duveteuses et distinctement pilosellées; brunâtres, graduellement moins foncées vers la base, avec le $1^{\mathrm{er}}$ article d'un roux testacé : celui-ci en massue allongée : les $2^{\circ}$ et $3^{\circ}$ obconiques : le $2^{\mathrm{e}}$ oblong : le $3^{\mathrm{e}}$ suballongé, d'un tiers plus long que le précédent : les suivants graduellement plus courts, brièvement pédicellés; subcylindrico-coniques : les $4^{\mathrm{e}}$ à $6^{\mathrm{e}}$ oblongs ou suboblongs : les pénultùmes non ou à peine plus longs que larges : le dernier ovalaire-oblong, acuminé au sommet.

Prothorax subtransverse, subrétréci en avant; aussi large ou même un peu plus large en arrière que les élytres; largement subéchancré au sommet, avec les angles antérieurs subinfléchis et subarrondis; subarqué sur les côtés, qui sont sérialement sétosellés; largement arrondi à la base ainsi qu'anx angles postérieurs ; entièrement d'un noir lisse et brillant; marqué sur la parije antérieure du dos de 2 séries longitudinales composées de 3 pores sétifères assez forts, et de quelques autres entre ceux-ci et les côtés, sans compter ceux du rebord.

Écusson glabre, lisse, d'un noir brillant.

Élytres transverses, environ de la longueur du prothorax ; subdéprimées ; assez fortement, râpeusement et assez densement ponctuées ; d'uı noir brillant, avec le repli d'un blond testacé ; légèrement et subépaisement pubescentes, avec les cils du bord apical subspinosules et une sérit: de soies redressées sur les côtẻs, dont 2 notamment plus longues, l'une vers les épaules, l'autre vers le premier tirrs. Épaules cachées, épineuses en dessous.

Abdomen suballongé, un peu moins large à sa base que les élytres; subarcuément et sensiblement atténué en arrière; subconvexe sur le dos, avec les 3 premiers segments faiblement impressiounés en traver's à léur 
base ; éparsement et longuement sétosellé sur les côtés; assez fortement et presque aussi densement ponctué que les élytres, un peu moins en arrière; d'un noir brillant et irisé ; à pubescence fine, assez longue et peu serrée. Le $6^{\text {e }}$ segment arrondi au sommet.

Dessous du corps assez fortement ponctué, pubescent; d'un noir brillanı, avec le repli du prothorax brunâıe, les intersections ventrales souvent moins foncées et le sommet dn ventre quelquefois roussâtre. Dessous de la tête presque glabre et presque lisse. Prosternum presque lisse, subcaréni, avec 2 longues soies rapprochées. Mésosternum presque lisse, éparsenınt sétosellé. Métasternum subdéprimé, avec 2 longues soies en arrière, à lobe postérieur d'un roux de poix. Ventre convexe, irisé, épalsement et longnement sétosellé, à $2^{\mathrm{e}}$ arceau basilaire obtusément prolongé sur le $1^{\text {er normal. }}$

Pieds râpeusement ponctués, pubescents, couleur de poix, avfc les genoux, le sommet des tibias et les tarses ordinairement roussâtres (1). Cuisses finement spinosules (2) en dessous, surtout vers leur extrémité ; es postérieures plus allongées, plus grêles. Tibias antérieur's simplement pubescents en dehors. Tarses antérieurs à 4 premiers articles fortemen: mais graducllem•nt un peu moins dilatés $d u 2^{\mathrm{e}}$ an $4^{\mathrm{e}}$; les postérieurs à $1^{\text {er }}$ article allongé, subégal aux 2 suivants réunis : les $2^{\mathrm{e}}$ à $4^{\mathrm{e}}$ graduellement plus courts, et le dernier subégal au $1^{\mathrm{C}_{\mathbf{r}}}$.

Patrie. On renconire cette espèce assez communément, dans les forêts et les montagnes, parmi les champignons, les feuilles mortes et les vieux fagots, dans diverses parties de lia France : les environs de Paris et de Lyon, la Normandie, le Bourbonnais, le Beaujolais, les Alpes, lit Provence, les Pyrénées, etc.

OBS. Sa taille avantageuse et la couleur blonde du repli des élytres font de cette espèce une des plus ficiles à distinguer.

Chez les adultes, le ventre est presque entièrement noir ; chez les sujets plus iminatures, le sommet et les intersections de ce segment sont plus ou moins largement roux. D'autres fois, les pieds tendent à affecter cette dernière couleur, ou an moins les tibias. Parfois les antennes sont d'un roux obscur, avec la base toujours plus claire.

(1) Même dans les exemplaires les plus adultes.

(2) Thomson (II, 174) dit : femora postica mutica. Nous avons vu toutes cuisses épiueuses ou spinosules. 


\section{Quedius erassus, Fairmaire.}

Suballongé ou oblong, subdéprimé, éparsement pubescent, d'un noir brillant, avec les élytres rouges, les antennes et les pieds d'un brun rou geâtre, et les palpes plus clairs. Tête et prothorax luisants : celui-ci transverse, à peine rétréci en avant. Écusson presque lisse. Ėlytres assez fortement et éparsement, abdomen plus finement, ponctués.

$\sigma^{*}$ Le $6^{\text {e }}$ arceau ventral faiblement et subangulairement sinué dans le

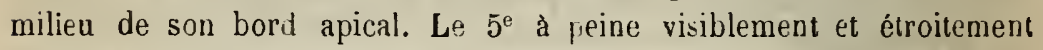
sinué dans le milieu de son bord postérieur.

으 Le $6^{\mathrm{e}}$ arceau ventral à peine arrondi, le $5^{\mathrm{e}}$ presque simple, à leur bord apical.

Quedius crassus, Fairmaire, Ann. Soc. Ent. Fr. 1860, 153. - Fauvel, Faun. GalloRhén. III, 502, 7.

Quedius amplicollis, Scriba, Berl. Ent. Zeit. 186\$; 15\%. - MARSEUL, l'Abeille, 1871, VIII, 277.

$$
\text { Long., 0m,008 (3 2/3 l.); - lars., 0 0 }, 0022 \text { (1 l.). }
$$

Cor'ps suballongé ou oblong, assez large, subdéprimé, d'un noir brillant, avec les élytres rouges; revêtu sur celles-ci et sur l'abdomen d'une fine pubescence grisâtre tt peu serrée.

Tête sublransverse, subarrondie, un pell moins large que le prothorax, d'un noir assez luisant ; presque lisse ou obsulètemrnt chagrinée et pointillée, subpubescente et éparsement et finement ponchée sur les tempe:; éparsement sétosellée sur les côtés; marquée sur le vertex de 2 perirs points enfoncés, distants, et derrière les yeux de 2 autres points beaucoup plus gros, assez écartés, obliquement disposés, dont l'interne plns en avant. Front très-large, peu convexe, à pores juxta-oculaires assez. gros. Cou presque lisse, glabr", luisant. Epistome plus ou moins impressionné en avant, ce qui le fait paraitre comme échancré. Labre fortement sétosellé antérieurement, d'un noir brillant. Mandibules obscures. Palpes roux.

Yeux ovales, peu saillar.ts, brunâtres. 
Antennes assez courtes, un peu plus longues que la tête; faiblement épaissies; finement duveteuses et légèrement pilosellées ; d'un blond rougeâtre; à $1^{\mathrm{er}}$ article en massue allongée : les $2^{\mathrm{e}}$ et $3^{\mathrm{e}}$ obconiques : le $2^{\circ}$ oblong : le $3^{\mathrm{e}}$ suballongé, plus long que le $2^{\mathrm{e}}$ : les suivants graduellement un peu plus épais, peu ou non contigus : le $4^{\mathrm{e}}$ presque carré : les $5^{\mathrm{e}}$ à $10^{\circ}$ obconiques, légèrement transverses, avec les pénultièmes un peu plus sensiblement : le dernier ovalaire, obliquement subacuminé au summet.

Prothorax transverse, à peine rétréci eu avant; à peine plus large que les élytres; largement tronqué au sommet; à angles antérieurs infléchis et subémoussés; subarqué sur les côtés; arrondi à sa base ainsi qu'aux angles postérieurs, qui sont très -obtus; subconvexe sur le dos; subimpressionné de chaque côté près des angles postérieurs ; d'un noir luisant ; sérialement sétosellé sur les côtés, exce 'té en arrière; presque lisse (1); offrant 2 séries dorsales composées de 3 petits points, dont l'antérieur, submarginal et plus écarté, et, en outre, 2 ou 3 autres points semblables, sur les côtés du disque, entre ceux du dos et la marge latérale, près de laquelle 1 gros pore à soie nulle ou caduque.

Écusson presque lisse ou à peine chagriné, glabre, d'un noir ou d'un brun de poix brillant.

Elytres subtransverses, plıs longues que le prothorax, à peine plus larges en arrière qu'en avant; subdéprimées; assez forlement et éparsemont ponctuées; d'uu rouge brillant; éparsement pubescentes, avec une série de cils spinosules au bord apical et 2 longues soies sur les côtés, 1 vers le tiers antérieur, l'autre vers les épaules. Celles-ci cachées, à angle huméral souvent muni d'un faisceau de 4 ou 5 ćpines.

Abdomen peu allongé, un pen moins large que les élytres ; sensiblement et arcuénıent alténué en arrière; assez convexe sur le dos, avec les 3 preıniers segments à peine innpressionnés en travers à leur base; éparsement et longuement sétosellé; plus tinement et moins làchement ponctué que les élytres; d'un noir brillant; à pubescence assez longue. Le $6^{\mathrm{e}}$ segment obtusèment et subsinueusement tronqué au sommet.

Dessous du corps aspèrement ponclué, pubescent, d'un noir brillant, ivec le repli du prothorax et parfois la pointe mésosternale d'un roux de poix. Dessous de la téte presque lisse, presque glabre, sérialement pouctué et pubesceut en arrère et sur les côiés. Prosternum subcarré, à pointe recourbée. Mésosternum traver:é par une série arqute de longues soies.

(1) On aperçoit souvent une ponctuation obsolète vers tes angles antérieurs. 
Métasternum subdéfrimé, obsolèlement canaliculé sur sa ligne médiane. Ventre convexe, éparsement sétosellé, à soies longues, entremêlées de soies plus courtes et plus légères.

Pieds aspèrement ponctués, pubescents, d'un brın rougeâire, avec le sommet des tarses plus clair. Cuisses distinctement spinosules en dessous; surtout vers leur extrémité ; les postéricures plus grêles. Tibias antérieurs assez forts, plus courts que les cuisses, simplement pubescents ou avec 1 ou 2 épines en dessous. Tarses antérieur's à 3 premiers articles fortement dilatés, le $4^{\mathrm{e}}$ un peu moins fortement; les postérieurs à $1^{\mathrm{er}}$ article suballongé, à peine égal au dernier, subégal aux 2 suivants réunis; les $2^{\mathrm{e}}$ à $4^{\mathrm{e}}$ graduellement plus courts.

Patrie. Cette espèce est rare. On la prend sous les pierres et au pied des arbres, en juin, dans la Provence, le Languedoc, etc.

OBs. Elle a été longtemps assimilée au curtus, dont elle se distingue par sa tête plus lurge; par son épistone impressionné ; par ses antennes ınoins grèles et à pénultièmes articles uu peu plus courts; par son cou séparé du vertex par une ligne plus prononcée; par son prothorax un peu moins transverse; par ses élytres plus longues, à ponctuation plus forte et plus uniforme; par son abdoman moins acuininé, plus fort.ment et moius densement ponctué. La lête est aussi moin, lisse, moins brillante, plis visiblement pointillée, etc.

\section{Quedius breviconis, Thomson.}

Suballongé, peu convexe, éparsement pubescent, d'un noir brillant, uvec les élytres rouges, le sommet des antennes ferrugineux, les palpes et les tarses d'un roux de poix. Tite et prothorax luisants : celui-ci trarsverse. rétréci en avant. Elytres assez fortement et subéparsement ponctuées. Abdomen assez finement et assez densement ponctú.

$\sigma^{7}$ Le $6^{\mathrm{e}}$ arcenu ventral médiocrement échancré au sommet. Tarses antérieurs dilatés.

$q$ Nous est inconnue.

Microsaurus brcvicornis, THomson, Skand. Col. II, 175, 5; - IX, 163, 5.

Quedius brevicomis, Fauvel, Faun. Gallo-Rhén. III, s03, 9. 


$$
\text { Long., } 0^{\mathrm{m}}, 010 \text { (4 1/2 l.); - larg., } 0^{\mathrm{m}}, 0027 \text { (1 1/4 l.). }
$$

Corps suballongé, peu convexe, d'un noir brillant, avec les élyires rouges; revêtụ sur celles-ci et l'abdomen d'une fine pubescence griłâtre et peu serrée.

Tête grande, transverse, un peu moins large que la base du prothorax, d'un noir assez luisanı, presque lisse ou à peine pointillée; très-éparsement et longuement sétosellée sur les côtés; marqué, outre le pore sétifère des tempes, de 2 petits points transversalement rapprochés, de chaque côté du vertex, et d'un $3^{e}$ très-gros, situé à égale distance de ceux-ci et du bord postéro-interne de l'œil. Front très-large, faiblement convexe, à pores juxta-oculaires gros, ne touchaı, pas au bord interne des yeux. Col très-court, presque lisse, glabre, luisant. Épistome impressionné en avant sur son milieu, à marge antérieure livide. Labre d'un noir de poix, fortement sétosellé au sommet. Mandibules noires. Palpes d'un roux de poix assez clair.

Yeux ovales, peu saillants, obscurs.

Antennes assez courtes, un peu plus longues que la tête; assez épaissies; finement duveteuses et légèrement pilosellées; obscures, a vec leur sommet un peu ferrugineux; à $1^{\text {er }}$ article en massue allongée : le $2^{\circ}$ oblong, obconique : le $3^{\mathrm{e}}$ un peu plus long, obconique : les silivants graduellement un peu plus épais, subcontigus, obconiques : les $4^{\mathrm{e}}$ et $5^{\mathrm{e}}$ non ou à peine, les $6^{\text {e }}$ a $10^{\circ}$ fortenient transverses : le dernier ovalaire, obliquement subacuminé au sommet.

Prothorax assez fortement transverse, sensiblement rétréci en avant, un peu plus large à sa base que les élytres; largement tronqué ou à peine échancré au sommet; à angles antérieurs infléchis et subarrondis; arqué sur les côtés; largement arrondi à sa base ainsi qu'aux angles postérieurs ; subconvexe sur le dos; subimpressionné de chaque côté; d'un noir luisant ; sérialement sétosellé sur les côtés, avec la longue soie latérale située assez loin de la marge ; presque lisse; offrant 2 séries dorsales composées de 3 points médiocres, dont l'antérieur submarginal, plus rapproché du $2^{\circ}$ et plus en dehors, avec une fine ponctuation obsolète dans l'ouverture des angles antérieurs; șans points sur les côtés du dịsque, à part le gros pore sétifère.

Écusson lisse, glabre, d'un noir brillant.

Elytres transverses, un peu plus longues que le prothorax, subpa- 
rallèles; subdéprimées ou à peine convexes; assez fortement et peu densement ponctuées; d'un rouge brillant; éparsement pubescentes, avec 2 longues soies obscures et redressées, sur les côtés, derrière les épaules. Celles-ci à calus assez saillant, presque lisse.

Abdomen suballongé, muins large que les élytres; sensiblement et subarcuément alténué en arrière; convexe sur le dos, avec les 3 premiers segments légèrement impressionnés en travers à leur base : éparsement t't longuement sétosel!é; assez finement et assez densement ponctué; d'un noir assez brillant, avec la marge apicale des 2 derniers segments coulen: de poix ; à pubescence un peu plus longue et un peu plus serrée que celle des élytres. Le $6^{\mathrm{e}}$ segment subarrondi au sommet.

Dessous du corps aspèrement ponctué, finement pubescent, d'un noir brillant. Ventre convexe, éparsement sétosellé.

Pieds aspèrement ponctués, finement pubescents, avec les tibias un peu moins foncés et les tarses d'un roux de poix au moins à leur extrémité.

Patrie. La Flandre, les environs de Paris, dans les forêts, sous les écorces. Très-rare. Cette espèce nous a été généreusement communiquée par M. Lethierry, de Lille. Elle a été capturée dans un hêtre carié, dans la forêt de Mormal, entre le Quesnoy et Landrecies (Nord).

OBs. Elle est sensiblement plus grande et un peu moins trapue que le Q. crassus. La tête est plus grosse et plus large. Les antennes sont plus obscures, plus épaisses, avec leurs pénulièmes articles plus transverses. Les pieds sont d'une couleur plus foncée, etc.

Bien que Thomson dise : Caput ovato-orbiculare, notre insecte semble convenir, pour le reste, à sa description. Peut-être l'auteur suédois n'a-t-il $\epsilon u$ sous les yeux que des mâles efféminés.

\section{Duedius fageti, Thomson.}

Allongé, peu convexe, très-éparsement pubescent, d'un noir brillant, auec les élytres submétalliques, la bouche et les tarses roussâtres. Tête à peine pointillée. Prothorax luisant, subtransverse, subrétréci en avant. Ecusson lisse. Élytres fortement et subéparsement, abdomen plus finement et plus densement, ponctués. Le $1^{\mathrm{er}}$ article des tarses postérieurs moins long que le dernier. 
ơ Le 6e arceau ventral légèrement, le $5^{\text {e }}$ encore plus faibleuteni it subangulairement sinués dans le milieu de leur bord apical, avec un espace triangulaire allongé, lisse, au devant des sinus.

ㄴ Les $6^{\mathrm{e}}$ et $5^{\mathrm{e}}$ arceaux du ventre simples.

Microsaurus fageti, Tномson, Skand. Col. IX, 161, 3. с.

Quedius fageti, RYE, Ent. Ann. 1869, 27. - MARSEul, l'Abeille, 1871, VIII, 287, 249. - Fauvel, Faun. Gallo-Rhén. III, 503, 10.

$$
\text { Long., 0m,007 (3 1/5 1.); - larg., } 0^{\mathrm{m}}, 0015 \text { (2/3 l.). }
$$

Corps allongé, peu convexe, d'un noir brillant, avec les élytres submétalliques; revêtu sur celles-ci et l'abdomen d'une fine pubescence d'un gris obscur et très-peu serrée.

Tête subovalaire, sensiblement moins large que le prothorax; d'un noir brillant; éparsement sétosellée sur les côtés; à peine chagrinée et trèsobsolètement pointillée; offrant, derrière les yeux 2 gros points enfoncés, très-écartés et obliquement disposés, et 2 autres, de chaque côté du vertex, très-rapprochés, l'interne moindre et peu distinct. Front large, subconvexe, obsolètement biimpressionné entre les antennes, à pore juxta-oculaire très-gros. Cou subconvexe, presque lisse, glabre, luisant. Épistome subcorné, obscur. Labre d'un noir de poix, sétosellé en avant. Parties de la bouche roussâtres, avec Ja base des mandibules plus foncée.

Yeux ovales, peu saillants, obscurs, à reflets micacés.

Antennes assez courtes, un peu plus longues que la tête ; subépaissies ; finement duveteuses et légèrement pilosellées; entièrement obscures; à $1^{\text {er }}$ article allongé, en massue : les $2^{\text {e }}$ et $3^{\mathrm{e}}$ obconiques : le $3^{\mathrm{e}}$ un peu plus long que le $2^{\mathrm{e}}$, suballongé : les suivants graduellement un peu plus épais, peu contigus : le $4^{\mathrm{e}}$ subcarré : le $5^{\mathrm{e}}$ à peine, les $6^{\mathrm{e}} \mathrm{à} 10^{\mathrm{e}}$ légèrement transverses : le dernier subovalaire, obliquement subacuminé au sommet.

Prothorax subtransverse, suborbiculaire, subrétréci en avant; de la largeur des élytres ou à peine plus large; largement tronqué au sommet, avec les angles antérieurs infléchis, presque droits, mais subémoussés; sensiblement arqué sur les côtés; arrondi à sa base ainsi qu'aux angles postérieurs; assez convexe sur le dos; impressionné-subexplané sur les côtés, qui sont sérialement et légèrement sétosellés, avec le pore sétifìre latéral assez distant de la marge; d'un noir luisant; presque lisse; offr.ut en avant, sur le dos, 2 séries de 3 points médiocres, dont l'antérieur submarginal et plus écarté. 
Ecusson lisse, glabre, d'un noir brillant.

Élytres subcarrées, à peine plus larges en arrière qu'en avant; un peu plus longues que le prothorax; subdéprimées ou faiblement convexes; subsillonnées le long de la suture; fortement et assez lâchement ponctuées; d'un noir brillant et à peine métallique; légèrement ciliées au bord apical; très-éparsement pubescentes sur le disque, avec les côtés parés d'une série de soies légères, très-écartées, dont 2 beaucoup plus longues et plus obscures, près des épaules. Celles-ci cachées.

Abdomen suballongé, moins large que les élytres; à peine atténué en arrière; assez convexe sur le dos, avec les 3 premiers segments sensiblement impressionnés en travers à leur base; fortement sétosellé, surtou: vers l'extrémité; un peu plus finement et plus densement ponctné que les élytres, avec le $1^{\text {er }}$ segment presque lisse sur son milieu; d'un noir brillant; à pubescence assez longue et peu serrée. Le $6^{\mathrm{e}}$ segment subtronqué au sommet.

Dessous du corps aspèrement ponctué, légèrement pubescent, d'un noir brillant, avee le repli du prothorax et le devant du prosternum moins foncés. Dessous de la tête presque lisse, presque glabre. Prosternum subcaréné. Mésosternum rugueux. Métasternum subdéprimé sur son milieu. Ventre convexe, éparsement sétosellé ; à $2^{\mathrm{e}}$ arceau basilaire aigument prolongé sur le $1^{\text {er }}$ normal.

Pieds aspèrement ponctués, finement pubescents, d'un noir de poix, avec les tarses roussâtres. Cuisses obsolètement spinosules ell dessous ver's leur extrémité; les postérieures plus grêles. Tibias antérieurs assez forts, peu épineux. Tarses antérieurs à 4 premiers articles fortement dilatés, les $1^{\mathrm{er}}$ et $4^{\mathrm{e}}$ toutefois moins fortement ; les postérieurs à $1^{\mathrm{er}}$ article suballongé, sensiblement moins long que le dernier, subégal aux 2 suivants réunis : les $2^{\mathrm{e}}$ à $4^{\mathrm{e}}$ graduellement plus courts.

Patrie. Cette espèce est très-rare en France. Elle a été capturée, en août, sous les écorces, à la Grande-Chartreuse.

Obs. Elle est remarquable par sa taille moyenne; par son prothorax sans points sur les côtés du disque; par ses élytres à reflet submétallique, fortement et subéparsement ponctuées, subsillonnées le long de la sulure depuis l'écusson jusqu'au sommet. L'espace triangulaire lisse qui précède l'échancrure des $5^{\mathrm{e}}$ et $6^{\mathrm{e}}$ arceaux du ventre chez les $\sigma^{\prime}$ est plus allongé que dans toute autre espèce voisine et il est presque prolongé jusqu'à la marge de l'arceau précédent. 
Peut être doit-on rapporter au fageti le maurus de Sahlberg (Ins. Fenn. I, 317)?

\section{Quediug mesomelinus, Marsham.}

Allongé, subdéprimé, éparsement pubescent, d'un noir de poix brillant, avec l'extrémité des antennes, le sommet du ventre et les pieds d'un roux brunâtre, les tarses et les palpes plus clairs. Tête à peine pointillée. Prothorax luisant, subtransverse, rétréci en avant. Écusson lisse. Élytres assez fortement et assez densement ponctuées; abdomen plus finement ponctue, irise. Le $1^{\mathrm{er}}$ article des tarses postérieur's un peu moins long que le dernier.

$\sigma^{7}$ Le $6^{\ominus}$ arceau ventral très-faiblement, le $5^{\circ}$ à peine, sinués dans le milieu de leur bord apical, arec un léger espace lisse au devant du sinus. Les $4^{\theta}$ et $5^{\theta}$ offrant sur leur milieu une petise touffe de poils obscurs, peu nombreux, souvent peu distincte. Tête courtement ovalaire, un peu moins large que le prothorax.

१ Le $6^{\mathrm{e}}$ arceau ventral subarrondi, les $4^{\ominus}$ et $5^{\ominus}$ simples. Tête subovalaire, sensiblement moins large que le prothorax (1).

Staphylinus mesomelinus, Marsham, Ent. Brit. 310. - Fauvel, Faun. Gallo-Rhén. III, 506, 13.

Staphylinus nitidus, var. Gravenhorst, Micr. 31,46 ; - Mon. var. 1, 42, 5 .

Staphylinus variabilis, var. $a, b$, c, Gyllenhal, Ins. Suec. II, 3103 (2). - HeER, Faun. Col. Helv., var. $b, 273$.

Quedius fulgidus, var. 2, Erichson, Gen. et Spec. Staph. 326. - Krattz, Ins. Deut. II, 492.

Microsaurus temporalis, Thomson, Skand. Col. IX, 161, 3, 6 .

Quedius temporalis, Rye, Ent. Ann. 1869, 27. - Marsevi, l'Abeille, 1871, VIII, $286,248$.

Variété $a$. Antennes et pieds d'un roux ferrugineux.

Variété $b$. Corps d'un brun de poix, à prothorax rouge.

$$
\text { Long., } 0^{\mathrm{m}}, 009 \text { (4l.); - larg., } 0^{\mathrm{m}}, 0017 \text { (3/4 l.). }
$$

(1) Les tarses antérieurs des - + paraissent un peu moins dilatés.

(2) Dans Fauvel, au lieu de 503, lisez 303.

BR. 
Corps allongé, subdéprimé, d'un noir de poix brillant; recouvert sur les élytres et l'abdomen d'une fine pubescence grisâtre et peu serrée.

Tête plus ou moins ovale, moins large que le prothorax; éparsement sétosellée sur les côtés; d'un noir brillan!; à peine chagrinẻe et à peine pointillée; offrant sur les tempes 1 gros point sétifère, 1 autre assez loin du bord postéro-interne des yeux et 2 autres plus pelits, rupprochés, de chaque côté du vertex. Front large, subconvexe, à pore juxta-oculaire gros. Cou presque lisse, glabre, luisant. Épistome subcorné, d'un brun de poix. Labre d'un noir de poix, fortement sétosellé en avant. Mandibules obscures. Palpes roussâtres.

Yeux ovales, peu saillants, noirâtres, parfois lavés de gris.

Antennes assez courtes, un peu plus longues que la tête; à peine épaissies ; finement duveteuses et légèrement pilosellées; d'un roux brunâtre, avec les 3 premiers articles généralement plus foncés; le $1^{{ }^{\mathrm{r}}}$ en massue allongée : les $2^{\mathrm{e}}$ et $3^{\mathrm{e}}$ obconiques : le $2^{\mathrm{e}}$ oblong : le $3^{\mathrm{e}}$ suballongé, plus long que le précédent : les suivants graduellement un peu plus épais, non ou peu contigus : le $4^{\mathrm{e}}$ subisolé, presque carré : les $5^{\mathrm{e}}$ à $10^{\mathrm{e}}$ légèrement transverses, avec les pénultièmes plus sensiblement : le dernier subovalaire, obliquement tronqué et subacuminé au sommet.

Prothorax subtransverse, suborbiculaire, subcomprimé et rétréci en avant; à peine plus large que les élytres; tronqué au sommet, avec les angles antérieurs infléchis, presque droits mais émoussés; arqué sur les côtés ; largement arrondi à sa base ainsi qu'aux angles postérieurs; assez convexe sur le dos; plus ou moins impressionné sur les côtés, qui sont sérialement sétosellés, avec le pore sétifère latéral distant de la marge; d'un noir luisant; presque lisse ; offrant en avant 2 séries dorsales composées de 3 points médiocres, dont l'antérieur submarginal et plus écarté; sans points sur le disque entre les séries et la marge (1).

Écusson lisse, glabre, d'un noir brillant.

Élytres subcarrées, à peine plus larges en arrière qu'en avant; visiblement plus longues que le prothorax; subdéprimées; plus ou moins sillonnées en arrière le long de la suture; assez fortement et assez densement ponctuées; d'un noir de poix brillant, avec le bord apical ct la suture parlois un peu roussâtres; ciliées-spinosules au sommet; éparsement

(1) Il y a seulement le gros point sétifère latéral, qui existe toujours, et de plus, 2 petits points formant quadrille avec 2 autres points de la marge antérieure. 
pubescentes, avec quelques soies redressées sur les côtés, dont 2 notamment plus longues près des épaules. Celles-ci cachées, épineuses en dessous.

Abdomen suballongé, un peu moins large que les élytres; faiblement atténué en arrière; subconvexe sur le dos, avec les 3 premiers segments subimpressionnés en travers à leur base; éparsement et longuement sétosellé; plus finement et à peine plus densement ponctıé que les élytres ; d'un noir brillant et plus ou moins irisé; à pubescence assez longue et peu serrée. Le $6^{\text {e }}$ segment subsinueusement tronqué au sommet.

Dessous du corps aspèrement ponctué, légèrement pubescent, d'un ıoir brillant, avec le sommet du ventre et la marge des arceaux souvent un pen roussâtres, ainsi que le repli du prothorax, le prosternum et le mésosternum. Dessous de la tête presque lisse, presque glabre. Prosternum carinulé. Mésosternum rugueux, à pointe noire, subcarénéc. Métasternum subdéprimé, finement canaliculé sur sa ligne médiane. Ventre assez convexe, éparsement sétosellé, subirisé, à pores sétifères bien marqués et comme fovéolés; à $2^{\mathrm{e}}$ arceau basilaire aigument prolongé sur le $1^{\mathrm{er}}$ normal.

Pieds aspèrement ponctıés, légèrement pubescents, d'un roux brunâtre, avec les tarses plus clairs. Cuisses plus ou moins spinosules en dessous, surtout vers leur extrémité; les postérieures plus grêles. Tibias antérieur's assez robustes, simplenent pubesceuts en dehors. Tarses antérieurs à $2^{\circ} \mathrm{et}$ $4^{\mathrm{e}}$ articles fortement, les $1^{\mathrm{er}}$ et $4^{\mathrm{e}}$ moins fortement dilatés; les postérieurs à $1^{\text {er }}$ article suballongé, un peu moins long que le dernier, subégal aux 2 suivants réunis : les $2^{\mathrm{e}}$ à $4^{\mathrm{e}}$ graduellement moins longs.

Patrie. Cette espèce, médiocrement commune, vit parmi les mousses, les champignons, dans les troncs cariés et les plaies des arbres. Elle pré-fère les forêts et les montagues : les environs de Lyon, l'Auvergne, la Grande-Chartreuse, la Savoie, la Guienne, les Pyrénées, etc.

OBs. Elle est un peu plus grande que le fageti. Les élytres, sans reflet inétallique, sont un peu plus longues, moins fortement, mais plus densement ponctuées. La tète des $\sigma^{*}$ est plus grande et plus large, etc.

Certains exemplaires inmatures ont le prothorax rouge (rufithorax nobis), d'autres, les élytres et l'abdomen d'un brun roussâtre.

Nous avons vu, du Mont-Dore, 2 échantillons à forme plus étroite, à élytres un peu plus courtes, moins déprimées et un peu plus fortement ponctuées, à antennes et pieds d'une couleur plus claire et qu'on prendrait pour une espèce distincte (arvernicus, nobis). Celte variét a été auss 
capturée dans la grotte de Crémieux (lsère), près Lyon, par le docteur Octave Mayet.

L'Emus occultus de Lacordaire (Faun. Ent. Par. I, 379, 31) se rapporte probablement à un petit mesomelinus.

Peut-être aussi doit-on lui appliquer les nigricornis, skrimshiranus et atripennis de Stephens (Ill. Br. V, 222, 225, 436)?

1. Quedius migrocoeruleus, Mulsant et Rey.

Allongé, subdéprimé, subéparsement pubescent, d'un noir brillant, avec les élytres à léger reflet bleuâtre, les palpes, les tibias antérieurs et les tarses roussâtres. Tête très-finement chagrinée et poiniillée. Prothorax luisant, suborbiculaire, subrétréci en avant. Écusson lisse. Élytres assez fortement et densement, abdomen beaucoup plus finement, ponctués. Le $1^{\mathrm{er}}$ article des tarses postérieurs subégal au dernier.

$\sigma$ Le $6^{e}$ arceau ventral faiblement et subangulairement sinué dans le milieu de son bord apical, a vec un léger espace lisse au devant du sinus. Le $5^{\ominus}$ à peine sinué au milieu de son bord postérieur, à espace lisse à peine sensible, paré près de sa base d'une large touffe de poils courts et d'un noir velouté, voilée elle-même par une épaisse pubescence, couchée et d'un blond fauve. Le $4^{\mathrm{e}}$ paré, près de son extrémité, d'une touffe semblable plus grande et également voilée par une pubescence d'un blond fauve. Le $3^{\ominus}$ plus finement et plus densement ponctué dans le milieu de sa partie postérieure. Téte subtransverse, presque aussi large que le prothorax.

$\sigma^{\circ}$ Le $6^{\mathrm{e}}$ arceau ventral subarrondi à son bord apical. Les $3^{\mathrm{e}}, 4^{\mathrm{e}}$ et $5^{\mathrm{e}}$ simples. Tête courtement subovalaire, sensiblement moins large que le prothorax.

$$
\text { Long., } 0^{\mathrm{m}}, 0093 \text { (4 1/4 l.); - larg., } 0^{\mathrm{m}}, 0019 \text { (4/5 1.). }
$$

Corps allongé, subdéprimé, d'un noir brillant, avec les élytres à peine bleuâtres ; recouvert sur celles-ci et l'abdomen d'une fine pubescence grisâtre et peu serrée.

Tête subrétrécie en arrière ; éparsement sétosellée sur les côtés; d'un noir brillant ; très-finement chagrinée et 'en outre très-finement et éparse- 
ment pointillée; distinctement pubescente et assez densement ponctuée vers la base des tempes; offrant, de chaque côté, sur celles-ci, un gros point sétifère, plus 2 autres subobliquement (1) disposés vers le hord postéro-interne des yeux, dont l'externe beaucoup moindre, et 2 autres plus en arrière et plus en dedans sur le vertex, subobliquement (1) disposés, dont l'interne plus ptlit. Front très-large, subconvexe, parfois subimpressionné en avant, à pore juxta-oculaire gros. Cou glabre, éparsement pointillé, luisant. Existome subcorné, parfois subéchancré, d'un brun de poix un peu roussâtre. Labre d'un brun de poix, fortement sétosellé vers son bord antérieur. Mandibules obscures. Palpes plus ou moins roussatres.

Yeux ovales, peu saillants, obscırs, à reflets gris et micacés.

Antennes assez courtes, un peu plus longues que la tête; assez sensiblement épaissies; finement duveteuses et légèrement pilosellées; d'un roux plus ou moins brunâtre, avee les 3 premiers articles noirs : le $1^{\mathrm{e}}$ en massue allongée et à peine arquée : le $2^{\mathrm{e}}$ suboblong, obconique : lẹ $3^{\mathrm{a}}$ assez allongé, obconique, beancoup plus long que le $2^{\mathrm{e}}$ : les suivants graduellement un peu plus épais, non contigus : le $4^{\circ}$ en carré à peine

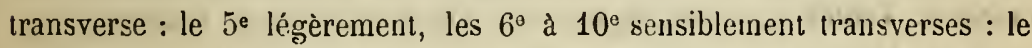
dernier courtement ovalaire, obliquement subéchancré en dessus vers son sommet, subacuminé inférieurement.

Prothorax suborbiculaire ou à peine transverse; subrétréci en avant ; un peu ou à peine plus large que les élytres; largement tronqué à son bord antérieur, a vec celui-ci parfois faiblement sinué de chaque côté ávant les angles, qui sont subinfléchis, presque droits mais subarrondis; plus ou moins arqué sur les côtés; arrondi à sa base ainsi qu'aux angles postérieurs; assez convexe sur le dos; subexplané $\left(c^{*}\right)$ ou subimpressionné (q ) vers les côtẻs, qui sont sérialement sétosellés, avec le gros pore sétifère latéral médiocrement distant de la marge; d'un noir luisant; presque lisse sur son milieu; plus ou moins obsolètement et éparsement pointillé en avant, surtout vers les angles antérieurs; offrant sur le dos 2 séries dorsales composées de 3 points médiocres, dont l'antéricur souvent plus écarté, siué assez loin de la marge antérieure; paré en ontre, sur les côtés lu disque, d'une série arquée de 3 ou 4 points, au devant de laquelle on apesçoit un groupe de 4 à 6 points, dont au moins 2 marginaux.

Écusson presque lisse, glabre, d'un nuir brillant.

(1) Cette obliquité est peu sensib!e et tend souvent à la disposition transversale. 
Élytres subcarrées, à peine plus larges en arrière qu'en avant; un peu plus longues que le prothorax; subdéprimées, subsillonnées en arrière le long de la suture; assez fortement et densement ponctuées; d'un noir brillant, à léger reflet bleuâtre ; subspinosulées à leur bord apical ; éparsement pubescentes, avec une série de soies légères, redressées sur les côtés, dont 2 notamment plus longues et plus obscures près des épaules. Celles-ci à calus assez saillant, épineuses en dessous.

Abdomen suballongé, moins large que les élytres; subatténué en arrière dès son milieu; subconvexe sur le dos, avec les 3 premiers segments à peine impressionnés en travers à leur base; éparsement sétosellé; assez finement et densement ponctué; d'un noir brillant et à peine irisé; à pubescence plus longue et un peu plus serrée que celle des élytres. Le $6^{\text {e }}$ segment subtronqué ou à peine arrondi au sommet.

Dessous du corps subaspèrement ponctué, finement pubescent, d'un noir brillant. Dessous de la tête presque lisse, presque glabre. Prosternum subcaréné, à pointe plus ou moins recourbée en dessous. Mésosternum rugueux, sétosellé. Métasternum subdéprimé, à lobe postérieur un peu roussâtre. Ventre convexe, éparsement sétosellé, à pores sétifères bien marqués; à $2^{\mathrm{e}}$ arceau basilaire prolongé sur le $1^{\mathrm{er}}$ normal en angle plus ou moins aigu et plus ou moins ponctué.

Pieds aspèrement ponctués, finement pubescents, d'un noir ou d'un brun de poix, avec les tibias antérieurs et tous les tarses plus ou moins roussâtres. Cuisses épinenses en dessous, les postérieures plus grêles. Tibias antérieurs assez forıs, peu épineux. Tarses antérieurs à 3 premiers articles fortement dilatés, le $4^{\mathrm{e}}$ moins fortement; les postérieurs à $1^{\mathrm{er}}$ arlicle assez allongé, presque égal au dernier, subégal aux 2 suivants réunis : les $2^{\mathrm{e}}$ à $4^{\mathrm{e}}$ graduellement moins longs.

Patrie. Celte espèce habite dans le sable et sous les pierres, dans les caves humides, dans les environs de Lyon, le Bcaujolais, la Provence, etc. Elle est rare.

Obs. Elle est de la taille des plus graıds exemplaires du mesomelinus, proportionnellement un peu plus large, d'une couleur plus foncée dans toutes ses parties. Les antennes sont un peu plus épaisses. La tête, plus grande $\epsilon t$ plus visiblement pointillée, offre 2 points au lieu de 1 vers le bord postéro-interne des yeux. Le prothorax présente sur les côtés du disq̣ıe 2 à 4 points en série arquée, avec le pore latéral un pen moins éloigné du bord. Les élytres, plus densement ponctuées, ont un lége 
reflet bleuâtre. L'abdomen est moins irisé, les tarses postérieurs ont leur $1^{\text {er }}$ article plus long, et les distinctions des $\sigma^{*}$ sont bien différentes, etc.

Chez les exemplaires immatures, les pieds sont entièrement roux, ainsi que les antennnes moins les 3 premiers articles, et les élytres sont violacées.

\section{LARVE}

Nous allons donner ici la description de la larve du Quedius nigrocoerileus.

Corps suballongé, subconvexe, d'un roux testacé brillant plus ou moins livide et maculé de taches plus sombres, avec l'abdomen mat et d'un gris obscur.

Tête grande, suborbiculairement transverse, rétrécie en arrière, beaucoup plus large (1) que le prothorax, à peine convexe, éparsement sétosellée; presque lisse en arrière, plus ou moins ridée en avant, où elle offre 2 larges impressions chagrinées; parcourue sur son disque par 3 fines lignes longitudinales écartées, prolongées jusqu'à la partie ridée, dont la médiane plus fine el les latérales divergeant un peu en avant; d'un testacé brillant, pâle et livide, avec une grande tache obtriangulaire, basilaire et médiane, brunâtre, flanquée de chaque côté d'une autre plus grande, plus confuse et plus ou moins fondue avec la couleur foncière. Épistome fortement denté en avant, avec les deux dents du milieu comme soudées sur un prolongement conique. Mandibules très-longues, grêles, f.lciformes, brunes à base testacée. Palpes grêles, pâles, à dernier article étroit, allongé, subcylindrique, terminé par un petit lobe conique ou subsubulé.

Yeux rẻduits à 4 ocelles lisses, pariois confluents et rembrunis.

Antennes testacées, pâles vers leur extrémité ; à $1^{\mathrm{er}}$ article assez épais et assez court, subobconique : le $2^{e}$ plus grêle, très-allongé, subcylirdrique, subépaissi au bout : le $3^{\mathrm{e}}$ moins long, plus grêle, subépaissi vers son dernier tiers où il offre 3 soies divergentes; lobé à son sommet interne : le dernier encore plus grêle, à peine aussi long que la moitié du précédent, fusiforme, trisẻtosellé a vant son extrémité, tricilié au bout.

(1) Cénéralement, surtout chez les premières espèces, les larves des Quedius ont la lète plus grosse que celle des larves des Philonthus. 
Prothorax en carré rétréci en avant, tronqué au sommet et à la base, assez largement rebordé sur celle-ci ; assez convexe ; éparsement et longuement sétosellé ; presque lisse ou obsolètement ridé en travers; plus ou moins impressionné sur les côtés ; parcouru sur sa ligne médiane par un canal très-fin et à peine visible; d'un testacé brillant et plus ou moins livide.

Mésothorax et métathorax courls, subégaux; moins longs, pris ensemble, que le prothorax; un peu plus larges que celui-ci ; subconvexes et plus ou moins inégaux sur leur disque; plus ou moins ridés et impressionnés sur leurs côtés, qui sont plus ou moins angulairement dilatés en avant et puis subrétrécis en arrière; longuement et éparsement sétosellés; d'un testacé brillant, avec des transparences nébuleuses.

Abdomen assez allongé, graduellement et assez fortement rétréci en arrière ; très-peu convexe ou subdéprimé ; finement chagriné en travers ; très-inégal ou scabreux, parcouru sur sa ligne médiane par un silloncanaliculé profónd, non prolongé sur le dernier sègment; fortement et longuement sétosellé; d'un gris obscur et mat; à $1^{\text {er }}$ segment plus court, plus brillant et plus lisse: les suivants subégaux, fortement impressionnés et cicatrisés sur les côlés : le dernier transverse, subrétréci en arrière, à peine échancré au sommet, où il offre 2 lanières, deux fois aussi longues que lui, assez écartées, subatténuées vers leur extrémité, à peine recourbées en dedans, éparsement et longuement sétosellées en dehors et en dessus, terminées par un article grêle, cylindrique, une fois moins long, déjeté en bas et un peu en dehors et portant au bout une longue soie.

Dessous du corps d'un testacé livide. Dessous de la tète et prosternum presque lisses et à peine chagrinés. Ventre inégal, finement chagriné, creusé ou sillonné sur son milieu ; fortement sétosellé ; à tube terminal cylindrique, infléchi, plus long que les lanières supérieures, annelé de brun, foriement sétosellé en dessous.

Pieds assez courts, testacés. Hanches très-grandes, éparsement épineuses. Cuisses assez grêles, sublinéaires, fortement épineuses en dessous. Tibias beaucoup plus courts, subcylindriques, fortement épineux dans tout leur pourtour, terminés par un crochet solide, assez long, épineux eu dessus, acéré et à peine arqué au bout.

OBs. Cette larve se trouve dans les caves, avec l'insecte parfait. Elle est remarquable par la grosseur de sa tête et par son abdomen assez fortement alténué en arrière. 


\section{Queding variabilis, HeER.}

Allongé, peu convexe, éparsement pubescent, d'un noir brillant, avec le sommet des patpes et les tarses plus ou moins roussâtres. Tête à peine chagrinée et à peine pointillée. Prothorax luisant, suborbiculaire, subrétréci en avant. Écusson lisse. Élytres assez fortement et densement, abdomen un peu plus finement, ponc:ués. Le $1^{\text {or }}$ article des tarses postén rieurs un peu moins long que le dernier.

$\sigma^{*}$ Le $6^{\text {e }}$ arceau ventral à peine sinué dans le milieu de son bord apical, avec un léger espace lisse au devant du sinus. Le $5^{\circ}$ presque entier à son bord postérieur, paré à sa base d'une touffe transversale de poils d'un noir velouté. Le $4^{\mathrm{e}}$ paré sur son milieu d'une touffe semblable mais plus grande : l'une et l'autre sans mélange de poils fauves.

\& Le $6^{\mathrm{e}}$ arceau ventral subarrondi à son bord apical. Les $4^{\circ}$ et $5^{\mathrm{e}}$ simples (1):

Philonthus variabilis, HeER Faun. Col. Ifelv. I, 273, 56 (2).

$$
\text { Long., } 0^{\mathrm{m}}, 0082 \text { (3 3/4 1.); - larg., } 0^{\mathrm{m}}, 0016 \text { (3/41.). }
$$

Corps allongé, peu convexe, d'un noir brillant; revêtu sur les élytr'es et l'abdomn d'une fine pubescence grisâtre et peu serrée.

Tête subovalaire, sensiblement moins large que les élytres; éparsement sétosellée sur les côtés; d'un noir brillant; à peine chagrinée et à peine poinlillée; légèrement pubescente et assez densement ponctuée à la base des tempes; offrant de chaque côté, sur celles-ci. 1 gros point sétifère, plus 2 autres subobliquement disposés (3) vers le bor'd postérointerne des yeux, dont l'ex'erne bien moindre, et 2 autres plus en delans, sur le vertex, subobliquement disposés, dont l'intrine plus petit. Front large, subconvexe, souvent subfovéolé en avant, à pores juxta-oculaires gros. Cou glabre, à peine pointillé, luisant. Épistome subcorné, brunâtre.

(1) Les tarses antérieurs des $\$$ sont un peu moins dilatés.

(2) En excluant la synonymie de Gyllenhal.

(3) Comme dans l'espèce précédente, cette obliquité. peu sensible, tend à la disposition transversale. 
Labre d'un noir de poix, fortement sétosellé en avant. Mandibules obscures. Palpes brunâtres, à dernier article plus ou moins roussâtre.

Yeux ovales, peu saillants, plus ou moins obscurs.

Antennes assez courtes, un peu plus longues que la tête ; subépaissies ; finement duveteuses et légèrement pilosellées; noirâtres, avec l'extrémité rarement moins foncée; à $1^{\text {er }}$ article en massue allongée : le $2^{\mathrm{e}}$ oblong, obconique : le $3^{e}$ suballongé, obconique, sensiblement plus long que le $2^{\mathrm{e}}$ : les suivants graduellement un peu plus épais, non contigus : le $4^{\mathrm{e}}$ en carré à peine transverse : le $5^{\mathrm{e}}$ sensiblement, les $6^{\mathrm{e}}$ à $10^{\mathrm{c}}$ plus fortement transverses : le dernier courtement ovalaire, obliquement subéchancré rll dessus vers son sommet et obtusément acuminé inférieurerrient.

Prothorax suborbiculaire ou à peine transverse; subcomprimé et subrétréci en avant; à peine plus large que les élytres; largement tronqué au sommet, avec les angles antérieurs infléchis, presque droits mais ćmoussés; plus ou moins arqué sur les côtés; arrondi à sa base ainsi qu'aux angles postérieurs; subconvexe sur le dos; plus ou moins impressionné, surtout en arrière, vers les côtés, qui sont sérialement sétosellés, avec le gros point sétifère latéral situé tont près de la marge; d'un noir luisant; presque lisse ou à peine pointillé vers les angles antérieurs; offrant en avant 2 séries dorsales composées de 3 points médiocres, dont l'antérieur subınarginal et un peu plus écarté; paré en outre, sur les cótés dı disque, de 2 autres points obliquenent disposés, au devant desquels on aperçoil, vers le bord antérieur, un groupe de 2 à 5 points.

Écusson lisse, glabre, d'un noir brillant.

Élytres subcarrées, subparallèles, à peine plus longues que le prothorax; à peine convexes; à peine subsillonnées en arrière le long de la suture ; assez fortement et densement ponctuées; d'un noir brillant; ciliéesspinosulées à leur bord apical; éparsement pubescentrs, avec quelques légères soies redressées sur les côtés, dont 2 notamment plus longues et plus obscures, près des épaules. Celles-ci à calus assez saillant, subépineuses en dessons.

Abdomen suballongé, moins large que les élytres ; subattérué en arrière après son milieu; assez convexe sur le dos, avec les 3 premiers segments à peine ou non visiblement impressionnés en travers à leur base; éparsement sétosellé; densement mais un peu ou à peine plus finenent ponctuí que les élytres; d'un noir brillant, non ou peu irisé; à pubescence peu serrée. Le $6^{\mathrm{c}}$ segment à peine arrondi au sommet.

Dessous du corps aspèrement ponctué, tinement pubescent, d'un noir' 
brillant. Dessous de la tête presque glabre et presque lisse, ou avec quelques points pilifères très-écartés. Prosternum subcaréné, à pointe non ou à peine recourbée. Mésosternum très-rugueux, sétosellé. Métasternum à peine convexe sur son milieı. Ventre convexe, éparsement sétosellé, à pores sétifères bien marqués; à $2^{\circ}$ arceau basilaire prolongé, dans son

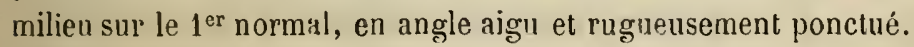

Pieds aspèrement ponctućs, aspèrement pubescents, obscurs, avec les tarses plus ou moins roussâtres, les intermédiaires et postérieurs souvent avec leur dernier article, senl de celte dernière couleur. Cuisses épinenses en dessous; les postérieures plus grêles. Tibias antérieurs assez forts, peu ćpineux. Tarses antérieurs ì 4 premiers articles graduellement moins dilatés ; les postérieurs à $1^{\mathrm{e}}$ article suballongé, moins long que le dernier, subégal aux 2 suivants réunis : les 2 à $4^{\mathrm{e}}$ graduellement plus courts.

Patrie. Cette espèce est assez commune, sous les immondices, les fumiers secs, autour des habitations, dans les celliers, dans les environs de Lyon et le Beaujolais, etc.

OBs. Elle est de la forme du mesomelinus, dont elle diffère par ses palpes, ses ant nnes, ses pieds et son ventre plus obsemr's, avec le dos de l'abdomen moins irisé, et surtout par son prothorax paré de 2 points sur les côtés du disque, et ses tempes ponctuées à leur base.

Elle est moindre que le nigrocoeruleus, avec la tête moins grande, les palpes, les antenries et les pieds d'une couleur plus foncée. Le prothorax, moins dilaté, offre sur les cótés du disque des points moins nombreux. Les élytres, un peu moins longues et moins déprimées, sont sans reflet bleuâtre. L'abdomen est un peu plus fortement ponctué. Les tarses postérieurs sont moins grêles, à $1^{\mathrm{er}}$ article moins long comparativement an dernier, etc.

La dénomination de variabilis des auteurs devant être considérée comne non avenue, plutôt que le créer un nom nouveau, nous l'avons appliquée à l'insecte qui nous occupe, el qui répond assez bien au variabilis de Heer, cn excluant la synonymie et la variété $b$.

\section{Guedius ochripennis, MÉnÉtriés.}

Allongé, peu convexe, éparsement pubescent, d'un noir brillant, avec les élytres rouges, les palpes, les antennes et les pieds obscurs, les tibias 
antérieurs et les tarses plus on moins roussâtres. Téte à peine chagrinée et sparsement pointillée, avec 2 points subégaux ver's le bord postéro-interne des yeux. Prothorax luisant, siborbiculaire, subrétréci en avant, paré de 2 points obliques sur les côtés du disque. Écusson lisse. Élytres à peine plus longues que le prothorax, fortement et assezdensement, abdomen plus finement, ponctués. Le $1^{\mathrm{er}}$ article des tarses postérieurs à peine aussi long que le dernier.

б Le $6^{\mathrm{e}}$ arceau ventral légèrement et largement sinué dans le milieu de son bord apical, avec un espace lisse à peine distinct ou très-réduit au (evant du sinus. Le $5^{\mathrm{e}}$ paré vers sa base, le $4^{\mathrm{e}}$ sur son milieu, d'une large brosse de poils d'un noir velouté, voilée par une longue pubescence grisâtre. Téte subtransverse, un peu ou à peine moins large que le prothorax. Tarses antérieurs très-fortement dilatés. Les postérienrs à 4 preniers arti-

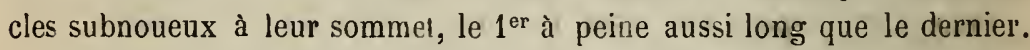

$\uparrow$ Le $6^{\circ}$ arcean ventral subarrondi au sommet. Les $4^{\mathrm{e}}$ et $5^{\mathrm{e}}$ simples. Tête très-brièvement subovalaire ou aussi large que longue, sensiblement moins large que le prothorax. Tarses antérieurs un peu moins fortement dilatés. Les postérieurs plus grêles, à 5 premiers articles moins noueux, le $1^{\text {er }}$ subégal au dernier (1).

Staphylinus ochripennis, MÉNÉTRIÉs, Cat. Rais. 145, Staphylinus nitidus, Gravenhosst, Micr. 31 (partim). Staphylinus variabilis, Gyllenial, Ins. Suec. II, 304, var. $f$.

Emus floralis. Boisduval et Lacondale, Faun. Ent. Par. I, 380, 33.

Philonthus fulgidus, HEьR, Faun. Col. Helv. I, 273, 57

Quedius ochripenuis, Fauvel, Gallo-Rhén. III, 504, 11.

$$
\text { Long., } 0^{\mathrm{m}}, 0088 \text { (4 l.); - larg., } 0^{\mathrm{m}}, 0010 \text { (1 l.). }
$$

Corps allongé, peu convexe, d'un noir brillant, avec les élytres l'oug't: ; revêtı sur celles-ci d'une fine pubescence grise et peu serrée.

Tête plus ou moins large, éparsemı nt sétosellée sur les côtés; d'un noir brillant; à peine chagrinée et éparsement pointillée ; plus fortement ponctuée et légèrement pubescente sur les tempes; offrant de chaque côté sur celles-ci un gros pore sétifère, plus 2 autres de force subégale, subtrans-

(1) En général, chez les espèces voisines, les tarses postérieurs des $\$$ sont un peu plus grêles, moins noueux, à $1^{\text {er }}$ article paraissant un peu plus long. 
versalement disposés vers le bord postéro-interne des yeux, et 2 autres un peu moindres, disposés de même, plus en dedans sur le vertex. Front très-large, subconvexe, à point juxta-oculaire assez gros. Cou glabre, éparsement pointillé, luisant. Épistome subcorné, brunâtre, plus ou moins impressionné-subéchancré en avant. Labre d'un noir de poix, fortemnt sétosellé au sommel. Mandibules obscures. Palpes d'un brun parfois roussâtre.

Yeux brièvement ovales, peu saillants, plus ou moins obscurs.

Antennes assez courtes, un peu plus longues que la tête; sensiblement épaissies; finement duveteuses et légèrement pilosellées; plus ou moins obscures, avec les 3 premiers article noirs ; le $1^{\mathrm{er}}$ en massue allongée : le $2^{\mathrm{e}}$ oblong, obconique : le $3^{\mathrm{e}}$ suballongé, obconique, plus long quele $2^{\circ}$ : les suivants graduellement un peu plus épais, peu contigus : le $4^{\mathrm{e}}$ presque carré : le $5^{\mathrm{e}}$ sensiblement, les $6^{\mathrm{e}}$ à $10^{\mathrm{e}}$ fortement transverses : le dernier subovalaire, obliquement subéchancré en dessus au sommet et obtusément acuminé inférieurement.

Prothorax suborbiculaire ou à peine transverse; subcomprimé et plus ou moins subrétréci en avant; à peine ou non plus large que les élytres, largement tronqué ou à peine bissinué au sommet, avec les angles antérieurs infléchis, presque droits mais subémoussés; plus ou moins arqué sur.les côtés; subarrondi à sa base ainsi qu'aux angles postérieurs; subconvexe sur le dos; plus ou moins impressionné vers les côtés, qui sont sérialement sétosellés, avec la longue søie latérale située assez loin de la marge; d'un noir luisaut ; presque lisse, souvent éparsement pointillé sur sa partie antérieure; offrant en avant 2 séries dorsales composées de 3 points médiocres, dont l'antérieur submarginal et un peu plus écarté; paré en outre, sur les côtés du disque, de 2 autres points obliquement disposés, au devant desquels on aperçoit, vers la marge antérieure, un groupe de 3 ou 4 autres points.

Écusson presque lisse, glabre, d'un noir brillant.

Élytres subcarrées, subparallèles, à peine plus longues que le prothorax; subdéprimées ; subsillonnées, surtout en arrière, le long de la suture, plus ou moins fortement et assez densement ponctuées; d'un rouge brillant, parfois ochracé; ciliées-spinosulées à leur bord apical; éparsement pubescentes, avec quelques légères soies redressées sur lés côtés, dont 2 notamment plus longues et souvent caduques, près des épaules. Celles-ci à calus assez saillant, subépineuses en dessous.

Abdomen peu allongé, un peu moins large que les élytres; subatténué 
après son milieu; subconvexe sur le dos, avec les 3 premiers segments subimpressionnés en travers à leur base; éparsement et longuement sétosellé; assez densement et assez finement ponctué, plus lâchement sur le $1^{\text {er }}$ segment; d'un noir brillant peu irisé; à pubescence assez longue et peu serrée. Le $6^{\circ}$ segment à peine arrondi au sommet.

Dessous du corps aspèrement ponctué, pubescent, d'un noir brillant, avec l'extrémité du ventre parfois moins foncée. Dessous de la tête presque lisse et presque glabre ou très-éparsement ponctué. Prosternum subcarré, à pointe à peine recourbée en dessous. Mésosternum rugueux, sétosellé $\mathrm{n} n$ arrière. Métasternum subdéprimé sur son milieu, à lobe postérieur un peu roussâtre. Ventre convexe, éparsement et longuement sétosellé, à peine irisé; à $2^{\mathrm{e}}$ arceau basilaire prolongé sur le $1^{\text {er }}$ normal en angle assez aigu.

Pieds aspèrement pointillés, pubescents, noirs, avec les tibias antérieur's et les tarses plus ou moins roussâtres. Cuisses plus ou moins épineuses en dessous, surtout vers leur extrémité; les postérieures plus grêles. Tibias antérieurs assez forts, très-peu épineux. Tarses antérieurs à 3 premiers articles plus ou moins fortement dilatés, le $4^{\mathrm{e}}$ moins fortement ; les postérieur's à $1^{\text {er }}$ article suballongé, non ou à peine moins long que le derniei, subégal aux 2 suivants réunis : les $2^{\mathrm{e}}$ à $4^{\mathrm{e}}$ graduellement plus courts.

Patrie. Cette espèce est commune dans presque toute la France, tout l'été, sous les pierres, les détritus, dans les troncs caverneux des arbres, et parfois sur les rameaux de ceux-ci, etc.

Ons. Outre la couleur des élytres, elle se distingue des nigrocoeruleus et variabilis par les points postoculaires subégaux en grosseur et plus transversalement disposés. Il en est de même des 2 points du vertex. Les distinctions des $\sigma^{7}$ ne sont pas tout à fait les mêmes, etc.

Quelquefois les antennes et les pieds sont d'un brun plus ou moins roussâtre.

Rarement, les points du vertex sont subobliquement disposés.

Nous rapportons avec doute à l'ochripennis le Microsaurus fulgidus de Thomson, var. $b$ (Skand. Col. II, 175). Près de la viendrait aussi le Micr. puncticollis du même auteur (Skand. Col. IX, 164, 5 b), espèce encore bien voisine. 


\section{Quediug assecla, Mulsant et Rey.}

Allongé, assez étroit, peu convexe, éparsement pubescent, d'un noir brillant, avec les élytres rouges, les palpes, l'extrémité des anternes, les tibias et les tarses plus ou moins roussâtres. Tête finement chagrinée et ì peine pointillée, avec 2 points vers le bord postéro-interne des yeux, l'externe très-petit. Prothorax luisant, subtransverse, subrétréci en avant, paré de 2 points obliques sur les côtés du disque. Ecusson lisse. Élytres de la longueur du prothorax, assez finement et assez densement ponctuées ainsi que l'abdomen. Le $1^{\mathrm{er}}$ article des tarses postérieurs subégal au dernier.

$\sigma^{7}$ Le $6^{\text {e }}$ arceau ventral très-faiblement et largement sinué dans le milieu de son bord apical, avec un espace lisse à peine sensible au devant du sinus. Les $4^{\mathrm{e}}$ et $5^{\mathrm{e}}$ avec une brosse de poils noirs très-réduite et à peine distincte.

ㄴ Le $6^{\mathrm{e}}$ arceau ventral subarrondi au sommet, les $4^{\mathrm{e}}$ et $5^{\mathrm{e}}$ simples.

$$
\text { Long., } 0^{\mathrm{m}}, 0082 \text { (3 3/4 l.); - larg., } 0^{\mathrm{m}}, 0017 \text { (3/4 l.). }
$$

Corps allongé, assez étroit, peu convexe, d'un noir brillant, avec les élytres rouges et le sommet du ventre plus ou moins roussâtre; revêtu sur les élytres et l'abdomen d'une fine pubescence grisâtre et peu serrée.

Tête courtement subovalaire, moins large que le prothorax ; éparsement et longuement sétosellée sur les côtés ; d'un noir brillant; finement chagrinée et à peine ou éparsement pointillée ; distinctement et assez densement ponctuée et pubescente sur les tempes; offrant de chaque côté, sur celles-ci, 1 fort point sétifère, plus 2 autres postoculaires, subtransversalement disposés, dont l'externe très-petit et l'interne gros, plus 2 autres de grosseur médiocre et subégale, transversalement disposés, plus elı dedans sur le vertex. Front large, subconvexe, parfois à peine fovéolé antérieurement, à point juxta-oculaire assez gros el touchant au bord interne de l'œil. Cou glabre, à peine pointillé, luisant. Épistome subcorné, brunâtre, plus ou moins impressionné. Labre d'un noir de poix, fortement sétosellé en avant. Mandibules obscures. Palpes plus ou mọins roussâtres. 
Yeux subovales, peu saillants, plus ou moins obscurs.

Antennes assez courtes, visiblement plus longues que la tête; légèrement épaissies; finement duveteuses et légèrement pilosellées; d'un roux parfois brunâtre, avec les 3 premiers articles plus foncés : le $1^{\text {er }}$ en massue allongée : le $2^{\ominus}$ oblong, obconique : le $3^{\mathrm{e}}$ suballongé, obconique, plus long que le $2^{e}$ : les suivants graduellement un peu plus épais, non contigus : le $4^{\mathrm{e}}$ presque carré : le $5^{\mathrm{e}}$ à peine, le $6^{\circ}$ légèrement, les $7^{\mathrm{e}}$ à $10^{\circ}$ assez fortement transverses, avec les pénultièmes un peu plus fortement : le dernier subovalaire, subéchancré en dessus vers son sommet et obtusément acuminé inférieurement.

Prothorax suborbiculaire, subtransvirse, subcomprimé et subrétréci en avant; de la largeur des élytres ou à peine plus large ; largement tronqué ou à peine bissinué au sommet, avec les angles antérieurs infléchis, presque droits mais subémoussés; plus ou moins arqué sur les côtés ; subarrondi à sa base ainsi qu'aux angles postérieurs; subconvexe sur le dos; plus ou moins impressionné en arrière vers les côtés, qui sont sérialement sétosellés, avec le gros point sétifère latéral situé tout près de la marge ; d'un noir luisant; presque lisse ou à peine pointillé vers les angles antérieurs; offrant en avant 2 séries dorsales composées de 3 points assez fins, subégalement distants, dont l'antérieur parfois assez éloigné de la marge ; paré en outre, sur les côtés du disque, de 2 autres points fins et obliquement disposés, au devant desquels on aperçoit, vers le bord antérieur, un groupe de 2 ou 3 autres points.

- Écusson presque lisse, glabre, d'un noir brillant.

Élytres en carré subtransverse, subparallèles, de la longueur du porthorax; subdéprimées ou à peine convexes; à peine sillonnèes le long de la suture; assez finement, assez densement et subéparsement ponctuées ; d'un rouge brillant ; ciliées -spinosulées à leur bord apical; éparsement pubescentes, avec quelques légères soies redressées sur les côtés, dont 2 notamment plus longues près des épaules. Celles-ci cachées, à calus assez saillant, subépineuses en dessous.

Abdomen suballongé, un peu moins large que les élytres; plus ou moins atténué en arrière; subconvexe sur le dos, avec les 3 premiers segments à peine impressionnés en travers à leur base ; éparsement et longuement sétosellé; assez finement et assez densement ponctué; d'un noir brillant et non irisé; à pubescence un peu plus longue et un peu plus serrée que celle des élytres. Le $6^{\circ}$ segment à peine arrondi au sornmet.

Dessous du corps aspèrement ponctué, finement pubescent, d'un noir 
brillant, avec le sommet du ventre partois à peine moins foncé. Dessous de la tête presque glabre, éparsement ponctué à la base. Prosternum subcaréné. Mésosternum rugueux, sétosellé en arrière. Métasternum à peine convexe sur son milieu. Ventre convexe, éparsement et longuement sétosellé ; à $2^{\mathrm{e}}$ arceau basilaire prolongé sur le $1^{\text {er }}$ normal en angle subaigu.

Pieds aspèrement pointillés, finement pubescents, d'un noir olı d'un brun de poix, avec les tibias et les tarses roux. Cuisses subépineuses en dessous, surtout ver's leur extrémité ; les postérieures plus grêles. Tibias antérieurs assez forts, peu épineux. Tarses antérieurs à $2^{\mathrm{e}}$ et $3^{\mathrm{e}}$ articles très-fortement, le $1^{\text {er }}$ un peu moins, le $4^{\mathrm{e}}$ sensiblement moins, dilatés ; les postérieur's assez grêles, à $1^{\text {er }}$ article allongé, subégal au dernier et aux 2 suivants réunis : les $2^{\mathrm{e}}$ à $4^{\mathrm{e}}$ graduellement plus courts.

Patrie. Cette espèce, peu commune, se prend sous les écorces et dans les plaies des arbres, en juin, dans les environs de Lyon et dans la Provence.

OBs. A peine moindre que l'ochripennis, elle est sensıblement plus étroite, avec les antennes, les palpes et les pieds d'une couleur moins obscure. Les antennes sont un peu moins épaisses vers leur extrémité. La tête, moins grande, a les points postoculaires de grosseur inégale, el le juxtaoculaire frontal joignant le bord même de l'œil. Le prothorax, moins sensiblement impressionné vers les côtés, a les points dı disque un peu plus fins, avec le gros pore latéral situé plus près de la marge. Les élytres sont plus courtes; l'abdomen est plus atténué en arrière. Les tarses postérieurs ont leur $1^{\mathrm{er}}$ article plus allongé, subégal au dernier. La tête est plus étroite que le prothorax dans les 2 sexes, etc:

Parfois le sommet de l'abdomen et du ventre est d'un roux foncé.

Rarement, le prothorax présente 1 seul point, au lieu de 2 , sur les côtés du disque.

\section{Quedius fulgidus, FABRICIUS.}

Assez allongé, subdéprimé, éparsement pubescent, d'un noir brillant, avec les élytres rouges, les antennes et les pieds brunâtres, les palpes, les tarses, le soinmet de l'abdomen et la marge apicale des segments plus ou moins roux. Téte finement chagrinée et éparsement pointillée, avec 3points 
en série arquée entre les yeux et le cou. Prothorax luisant, subtransverse, rétréci en avant, paré sur les côtés du disque de 3 ou 4 points en série arquée. Écusson lisse. Élytres à peine plus longues que le prothorax, assez fortement et assez densement, abdomen plus finement et plus densement ponctués. Le $1^{\mathrm{er}}$ article des tarses postérieurs à peine ou un peu moins long que le dernier.

$\sigma^{7}$ Le $6^{\text {e }}$ arceau ventral très-faiblement sinué dans le milieu de son bord apical, avec un espace lisse sensible ai devant du sinus. Le $5^{\mathrm{e}}$ à peine sinué dans le milieu de son bord postérieur, paré vers sa base, le $4^{\mathrm{e}}$ après son milieu, d'une large brosse de poils obscurs, voilée par une épaisse pubescence blonde. Tête subtransverse, presque aussi large que le prothorax. Tarses postérieurs à $1^{\mathrm{er}}$ article un peu moins long que le dernier.

\& Le $6^{\mathrm{e}}$ arceau ventral subarrondi au sommet, les $4^{\mathrm{e}}$ et $5^{\mathrm{e}}$ simples. Tête courtement ovalaire, sensiblement moins large que le prothorax. Tarses postérieurs plus grêles, moins noueux, à $1^{\mathrm{er}}$ article allongé, subégal au dernier.

Staphylinus fulgidus, Fabricius, Mant. Ins. I, 220, 14; - Syst. El. II, 596.

Staphylinus variabilis, Gyllenhal, Ins. Suec. II, 303, 21 (partim.).

Emus nitidus, Bolsduval et Lacordaire, Faun. Ent. Par. I, 277, 29.

Quedius fulgidus, Erichson, Gen. et Spec Staph. 525, 3 (partim). - Kratiz, Ins.

Deut. II, 492, 3 (partim). - Fauvel, Faun. Gallo-Rhén. III, 505, 12.

Philonthus fulgidus, HeEr, Fann. Col. Helv. I, 273, 57.

$$
\text { Long., } 0^{\mathrm{m}}, 0095 \text { ( } 4 \text { 1/3 l.); - larg., } 0^{\mathrm{m}}, 0011 \text { (1 l.). }
$$

Corps assez allongé, subdéprimé, d'un noir brillant avec les élytres rouges et le sommet de l'abdomen roussâtre; recouvert sur les élytres et l'abdomen d'une fine pubescence grise et peu serrée.

Tête plus ou moins grande, éparsement sétosellée sur les côtés; d'un noir brillant; finement chagrinée et éparsement pointillée sur son disque; assez densement ponctuée et pubescente sur les tempes; offrant de chaque côté, sur celles-ci, 1 assez gros point sétifère, plus 1 seul gros point postoculaire, assez écarté du bord postéro-interne des yeux et formant comme une série arquée avec les 2 autres points moindres et situés plus en dedans, entre lui et le cou. Front très-large, à peine convexe, parfois subimpressionné en avaut, à pore juxtaoculaire assez gros. Cou glabre 
éparsement pointillé, brillanı. Épistome subcorné, d'un brun rousssâtre, plus ou moins impressionné sur son milieu. Labre d'un brun de poix, parfois roussâtre, fortement sétosellé en avant. Mandibules obscures. Palpes roux, quelquefois un peu rembrunis dans leur milieu.

Yeux subovales, peu saillants, plus ou moins obscurs.

Antennes assez courtes, un peu plus longues que la tête ; faiblement épaissies; finement duveteuses et légèrement pilosellées ; d'un brun parfois à peine roussâtre, a vec les 3 premiers articles noirs; le $1^{\text {er }}$ en massue allongée : le $2^{\mathrm{e}}$ oblong, obconique : le $4^{\mathrm{e}}$ sụballongé, obconique, plus long que le $2^{\mathrm{e}}$ : les suivants graduellement à peịne plus épais, non contigus : le $4^{\mathrm{e}}$ presque carré : le $5^{\mathrm{e}}$ à peine, les $6^{\mathrm{e}}$ à $10^{\circ}$ médiocrement transverses, subégaux : le dẹrnier subovalaire, obliquement subẹchancré en dessus vers son sommet et subacuminé inférieurement.

Prothorax subtransverse, plus ou moins comprimé et rétréci en avant; un peu $\left(\sigma^{\circ}\right)$ ou à peine ( $q$ ) plus large que les élytres; largement tronqué ou à peine bissinué au sommet, avec les angles antérieurs infléchis, presque droits mais subarrondis ; plus ou moins fortement arqué sur les côtés; subarrondi à sa base ainsi qu'aux angles postérieurs ; subconvexe sur le disque; plus ou imoins impressionné, surtout en arrière, vers lẹs côtés qui sont sérialement sétosellés, avec le gros point sétifère latéral situé assez près de la marge; d'un noir luisant; presque lisse ou à peine pointillé vers les angles antérieurs ; offrant en avant 2 séries dorsales composées de 3 points médiocres, subégalement distants, dont l'antérieur parfois assez écarté de la marge; paré en outre, sur les côtés du disque, de 3 ou 4 points semblables mais disposés en série arquée, au devant desquels on aperçuit, vers le bord antérieur, un groupe de 3 à 5 autres points.

Écusson presque lisse, glabre, d'un noir brillant

Élytres subcarrées, subparallèles, un peu ou à peine plus longues que le prothorax ; subdéprimées; à peine subsillonnées le long de la suture; assez fortement, assez densement et subaspèrement ponctuées; d'un rouge brillant; ciliées-spinosulées à leur bord apical ; éparsement pubescentes, avec quelques soies redressées sur les côtés, dont 2 notamment plus longues près des épaules. Celles-ci à calus distinct, subépineuses en dessous.

Abdomen suballongé, moins large que les élytres ; plus ou moins atténué en arrière après son milieu; subconvexe sur le dos, avec les 3 premiers segments à peine impressionnés en travers à leur base; éparseınent et longuement sétosellé ; finement et densement ponctué ; d'un noir brillant et non ou à peine irisé, avec le $6^{\mathbf{e}}$ segment et la marge apicale des précé- 
dents plus ou moins roussâtres; à pubescence assez longue et plus serrée que celle des élytres. Le $6^{\text {e }}$ segment subtronqué ou à peine arrondi au sommet.

Dessous du corps aspèrement ponctué, finement pubescent, d'un noir brillant, avec le $6^{\circ}$ arceau ventral et la marge apicale de tous les précédents plus ou moins largement, d'un roux subtestacé. Dessous de la tête très-éparsement ponctué et pubescent en arrière. Prosternum subcaréné, à pointe souvent un peu recourbée en dessous. Mésosternum rugueux, sétosellé postérieurement. Métasternum à peine convexe sur son milieu, à lobe postérieur un peu roussâtre. Ventre convexe, éparsement et longuement sétosellé (1); à $2^{\circ}$ arceau basilaire prolongé sur le $1^{\text {er }}$ normal en angle obtus.

Pieds aspèrement ponctués, finement pubescents, d'un brun de poix, avec les tarses et parfois les tibias d'un roux ferrugineux. Cuisses plus ou moins épineuses en dessous vers leur extrémité, surtout les postérieures : celles-ci plus grêles. Tibias antérieurs assez forts, à peine épineux. Tarses antérieurs à 3 premiers articles fortenent, le $4^{\mathrm{e}}$ moins fortement, dilatés ; les postérieurs à $1^{\text {er }}$ article plus ou moins allongé, un peu moins long ou presque aussi long que le dernier, subégal aux 2 suivants réunis : les $2^{\mathrm{e}} \mathrm{a}$ $4^{\mathrm{e}}$ graduellement plus courts.

Patric. Cette espèce se prend sous es pierres, sous les mousses et les détritus, pendant l'été, dans presque toute la France. Elle est moins commune à Lyon que l'ochripennis.

OBs. Elle est plus grande et plus large que l'assecla. Elle s'en distingue, ainsi que de l'ochripennis, par son point postoculaire unique, formant une série arquée avec ceux du vertex, qui sont très-obliquement disposés ; par les points des côtés dı disque du prothorax plus nombreux, 3 ou 4 en série arquée; par ses antennes moins épaisses vers leur extrémité; par sun abdomen plus densement ponctué, ttc.

Chez les exemplaires immatures, les élytres et l'extrémité de l'abdomen sont d'un roux testacé, ainsi que les tibias et les tarses, et parfois le $\mathbf{1}^{\text {er }}$ article des antennes.

M. Pandellé nous a communiqué un exemplaire $\sigma^{*}$, dont les antennes, presque entièrement rousses, ont leur $4^{\mathrm{e}}$ article un peu plus étroit et plus

(1) Le 5 e arceau ventral présente, de chaque côté, à son sommet, 3 à 5 points sétiferes. 
oblong, et dont les élytres, d'un rouge vif, sont un peu moins densement ponctuées, avec leur bord apical un peu plus arrondi. Ce n'est là qu'une variété singulière.

Elle varie aussi beancoup pour la taille, et quelques exemplaires atteignent à peine 7 nillimètres.

Une variété, as:ez commune, a le sommet de l'abdomen, tant en dessus qu'en dessous, d'un roux beaucoup plus foncé ou brunåtre; le bord postérieur du $5^{\mathrm{e}}$ arceau ventral paré, de chaque côté, de 3 points sétifères au lieu de 4 (1). De plus, le prothorax n'offre parfois que 2 points sur les côtés du disque. les élytres paraissent à peine plus courtes, et la taille est un peu moindre (peranxius, nobis).

Nous avons vu deux exemplaires à forme plus étroite et plus parallèle, à élytres plus courtes, à abdomen largement d'un roux testacé à son extrémité et à ponctuation moins serrée sur la partie dorsale, et chez lesquels le prothorax ne présente également que 2 points sur les côtés du disque. C'est sans doute à cette race qu'on doit rapporter le Microsaurus 4-punctatus de Thomson (Skand. Col. IX, 159, 3, a), qui semble lui convenir pour la forme générale et la structure des antennes, à part la couleur plus obscure du sommet de l'abdomen.

On doit probablement aussi appliquer au fulgidus de Fabricius le fulgidus de Fairmaire (Faun. Franc. I, 539, 16), moins la synonymie et la variété B, et les haemopterus et rufitarsis de Stephens(IIl. Brit. V, 217 et 220 (2).

\section{Quedius eruentus, OLIVIER.}

Allongé, subdéprimé, légèrement pubescent, d'un noirbrillant, avec les élytres, la bouche, la base des antennes, les pieds et l'extrémité de l'abdomen lurgement, d'un roux subtestace, les intersections abdominales et ventrales diun roux de poix. Tete et prothorax luisants : celui-ci transverse, subrétréci en avant, ussez fortement arqué sur les côtés. Écusson li.se. Elytres assez fortement et subéparsement, abdomen plu: finement et plus densement, ponctués.

(1) Le caractère de présenter 3 ou 4 soies de chaque cóté de l'avant-dernier arceau du ventre n'est absolı ni dans cette espece, ni dans les voisines, car souvent une des soips fait défut et laisse alors à sa place un vide plus grand.

$(-2)$ La synonymie de cetle espèce est inextricable, les auteurs l'ayant confondue arec les précédentes. 
$\sigma^{7}$ Le $6^{\text {e }}$ 'arceau ventral sensiblement, le $5^{\text {e }}$ à peine, sinués dans le milieu de leur bord apical : celui-ci avec un léger espace lisse au devant du sinus. Tête transverse ou suborbiculaire, un peu moins large que le prothorax : celui-ci un peu plus large que les élytrés.

q Le $6^{\mathrm{e}}$ arceau ventral subarrondi au sommet, le $5^{\mathrm{e}}$ à peine sinué dans le milieu de son bord apical. Tête subovale, sensiblement moins large que le prothorax.

Staphylinus cryentus, Olivier, Ent. III, nos 42, 27, 34, pl. 5, fig. 49.

Quedius cruentus, Ericrson, Gen. et Spec. Staph. 527, 4. - Fairmaire et Labouldène,

Faun. Ent. Fr. I, 340, 20. - Kraatz, Ins. Deut. II, 495, 5. - Fauvel, Faun. Gallo-Rhén. III, 508, 15.

Philonthus cruentus, Redtenbacher, Faun. Austr. 708, 48.

Quedius nivicola, Kiesenwerter, Berl. Ent. Zeit. 1858, 58.

Variété a. Ėlytres noires, à suture plus ou moins roussâtre.

Quedius cruentus, ERICHSON, Gen. et Spec. Staph. 527, var. 1 et 2.

$$
\text { Long., } 0^{\mathrm{m}}, 008 \text { (3 2/3 l.); - larg., } 0^{\mathrm{m}}, 0020 \text { (7/8 l.). }
$$

Corps allongé, subdéprimé, d'un noir brillant, avec les élytres et l'extrémité de l'abdomen d'un roux subtestacé; revêtu sur celles-là et celui-ci d'une légère pubescence grisâtre et peu serrée.

Tête suborbiculaire ou subovale, un peu ou sensiblement moins large que le prothorax ; d'un noir luisant ; presque imperceptiblement chagrinée et obsolètement pointillée sur son disque; légèrement pubescente, plus fortement sur les tempes ; éparsement ponctuée sur celles-ci ; éparsesement sétosellée sur les côtés. Front large, à peine convexe, paré de chaque côté de 2 pores sétifères, dont le postérieur plus gros, et de 2 autres plus petits, rapprochés, près du cou. Cou presque lisse, glabre. Épistome à bordure submer braneuse, souvent parlagée $\left(\sigma^{\prime}\right)$ en 2 bourrelets. Labre d'un noir de poix, fortement sétosellé en avant. Parties de la bouche d'un roux subtestacé, avec les mandibules plus foncées.

Yeux assez grands, ovales, obscurs, parfois livides.

Antennes courtes, sensiblement moins longues que lá lête et le prothorax réunis, visiblement épaissies, finement duveteuses ft distinctement pilo ellées; brunâtres ou d'un roux obseur, avec les 2 ou 3 premiers articles subtestacés; le $1^{\mathrm{cr}}$ en massue suballongée et assez épaisse : les $2^{\circ}$ 
et $3^{\circ}$ obconiques : le $2^{e}$ oblong : le $3^{e}$ suballongé, sensiblement plus long que le précédent : les suivants gradnellement un peu plus épais, brièvement pédicellés : le $4^{\mathrm{e}}$ subcarré, le $5^{\mathrm{e}}$ légèrement, les autres fortement transverses, avec le $10^{\mathrm{e}}$ néanmoinș un peu moins fortement : le dernier ovalaire, obliquement acuminé au sommet.

Prothorax transverse, subrétréci en avant; un peu ou à peine plus large en arrière que les élytres; à peine ou très-largement échancré au sommet, avec les angles antérieurs infléchis, presque droits et subémoussés ; assez fortement arqué sur les côtés; subimpressionné $(q)$ ou subexplané $\left(\sigma^{*}\right)$ en arrière vers ceux-ci, qui sont sérialement sétosellés antérieurement avec la longue soie sétifère située près de la marge ; largement arrondi à sa base ainsi qu'aux angles postérieurs; d'un noir lisse et luisant; souvent à peine pointillé vers les angles antérieurs ; marqué sur la partie àntérieure du dos de 2 séries formées de 3 pores sétifères médincres et de quelques autres épars sur les côtés, dont les 2 latéraux assez écartés et à peine obliquement disposés.

Écusson lisse ou presque lisse, d'un noir brillant.

Élytres transverses ou subtransverses, de la longueur environ du prothorax; subdéprimées; parfois subimpressionnées le long de la suture; assez fortement et assez lâchement ponctuées; d'un roux subtestacé brillant, avec une fine pubescence très-peu serrée, les cils du bord apical subspinosules, et quelques soics redressées sur les côtés, dont l'humérale set la suivante notamment plus longues. Épaules plus ou moins cachées subépineuses en dessous.

Abdomen suballongé, moins large que les élytres ; subatténué en arrière après son milieu; subconvexe sur le dos, avec les 3 premiers segments subimpressionnés en travers à leur base ; éparsement et longuement sétosellé; un peu plus finement et plus densement ponctué que les élytres, avec la ponctuation néanmoins un peu moins serrée en arrière ainsi que sur le $1^{\text {er }}$ segment; d'un noir assez brillant, avec l'extrémité du $5^{\mathrm{e}}$ segment Jargement et le $6^{\circ}$ entièrement d'un roux subtestacé, et les intersęctions des précédents d'un roux de poix plus ou moins foncé ; à pubescence plus longue et un peu plus serrée que celle des élytres. Le $6^{\text {e }}$ segment subironqué ou subarrondi au sommet.

Dessous du corps aspèrement ponctué, pubescent, dun noir brillant, avec l'extrémité du ventre largement d'un roux subtestacé, et les intersecti ns d'un roux de poix. Dessous de la tête presque glabre et presque lisse. Prosternum presque lisse, caréné, avee 2 soi.s raplrochées. Mléta- 
sternum subdéprimé, paré en arrière de 2 soies écartées. Ventre convexe, fortement sétosellé; à $2^{\mathrm{e}}$ arceau basilaire prolongé sur le $1^{\mathrm{er}}$ normal en angle subaigu.

Pieds râpeusement ponctués, pubescents, d'un roux subtestacé, avec les hanches postérieures souvent rembrunies. Cuisses finenient spinosules en dessous, surtout dans leur dernière moitié; les postérieures moins épaisses. Tibias antérieur's presque droits, avec 1 ou 2 épines en dehors. Tarses antérieurs à 4 premiers articles fortement dilatés, graduellement moins du $2^{\mathrm{e}}$ an $4^{\mathrm{e}}$; les postérieurs à $1^{\mathrm{er}}$ article suballongé, subégal aux 2 suivants réunis, à peine moins long que le dernier : les $2^{\circ}$ à $4^{\mathrm{e}}$ graduellement plus courts.

Patrie. Cette espèce est médiocrement commune. Elle se prend de diverses manières, sous les pierres, dans le tronc carié ou le tan des vieux arbres, sous les feuilles mortes, et parfois en battant, dans plusieurs parties de la France: les environs de Paris et de Lyon, la Normandie, l'Alsace, la Lorraine, la Bourgogne, le Beaujolais, la Guienne, les Pyrénées, elc.

La variété $a$, à élytres plus on moins rembrunies, excepté sur la surture, est particulière au Piémont et à la Corse.

Cette espèce n'a pas besoin de commentaire. La coulenr testacée dẹs 3 premiers articles des antennes la distingue suffisamment.

Chez les sujets immatures, les élytres sont d'un roux plus clair, les antennes et les pieds entièrement d'un roux testacé, ainsi que les $5^{\mathrm{e}}$ et $6^{\text {e }}$ segments de l'abdomen, tant en dessus qu'en dessous, et ses intersections. La taille est aussi très-variable.

On doit peul-être regarder comme synonymes du cruentus, les hoemorrhous, erythropterus et analis de Stephens (Ill. Brit. V, 217, 226 et 435) (1)?

(1) Ici se placerait le Quedius abietum de Kiesenwetter (Berl. Ent. Zeit. 1858, 57), qui commencerait la série des espèces à prothorax non impressionné sur les côlés.

Il est plus allongé, plus jarallèle que le $Q$. ochripcnnis. La tête est relativement plus grosse, avec 1 très-gros point isolé, situć assez loin du bord postéro-interne des yeux; les antennes paraissent plus robustes; le prothorax, moins rétréci en avant, ne présente pas de points sur les côtés du disque; la ponctuation des élytres est un peu plus forte, le $6^{\mathrm{e}}$ arceau ventral est largement, le $5^{\mathrm{e}}$ à peine, échancrés au sommet, avec un espace triangulaire lisse au devant de l'échancrure, etc.

Long., $0^{\mathrm{m}}, 011$ (5 1.).

Patrie. La Grèce, sur le Pinus abies. 


\section{Quedius xanthopus, ERICHSON.}

Allongé, peu convexe. éparsement pubescent, d'un noir ou d'un brun de poix brillant, avec les côtés du prothorax et les antennes d'un roux brunâtre, la base de celles-ci, les palpe; les pieds, le sommet de l'abdomen ct la marge apicale des segments d'un roux testacé. Tête et prothorax lisses, luisants : celui-ci à peine transverse, subrétréci en avant. Écusson lisse. Élytres assez fortement et peu densement, abdomen plus finement, ponctués.

$\sigma^{7}$ Le $6^{\text {e }}$ arceau ventral largement et très-faiblement sinué dans le milieu de son bord apical, avec un grand espace triangulaire lisse au devart de l'échancrure. Tarses antérieurs très-fortement dilatés.

\& Le $6^{\mathrm{e}}$ arceau ventral subarrondi ou subsinueusement arrondi au sommet. Tarses antérieurs fortement dilatés.

Staphylinus variabilis. var. $c$, Gyllenhal, Ins. Suec. II, 303.

Quedius xanthopus, Erichson, CoI. March, I, 487, 4; - Gen. et Spec. Staph.527, 5. Fairmatke et Laboulbène, Faun. Ènt. Fr. I, 542, 25. - Kraatz, Ins. Deut. II, 495, 6. - Rye, Ent. Ann. 1859, 131.-Fauved, Faun. Gallo-Rhén. III, 310, 16. Philonthus xanthopus, Redtenbacher, Faun. Austr. 709. - Heer, Faun. Col. Helv. I, $273,58$.

Microsaurus xanthopus, Thomson, Skand. Col. II, 175, 4 .

$$
\text { Long., } 0^{\mathrm{m}}, 0076 \text { (3 1/2 l.); - larg., } 0^{\mathrm{m}}, 0015 \text { (2/3 l.). }
$$

Corps allongé, peu convexe, d'un noir ou d'un brun de poix brillant, avec l'extrémité de l'abdomen testacée; paré sur celui-ci et les élytres d'ine fine pubescence grise et très-peu serrée.

Tête brièvement subovale, moins large que le prothorax; éparsement et longuement sétosellée sur les côtés; d'un noir luisaut; presque lisse; non ou à peine ponctuée à la base des tempes; offrant de chaque côté, sur celles-ci, un assez gros pore sétifère: plus 3 autres poirts graduellement moins gros, disposés en série arquée, entre le cou et les yeux, l'antérieur assez écarté du bord postéro-interne de ceux-ci. Front large, subconvexe, à point juxtaoculaire assez gros. Cou glabre, lisse, luisant. Epistome corné, brun. Labre d'un noir de poix, furtement sétosel!é en avant. Mandibules obscures. Palpes d'un roux testacé. 
Yeux brièvement subovalaires, peu saillants, obscurs.

Antennes médiocres, sensiblement plus longues que la tête; à peine épaissies ; finement duveteuses et légèrement pilosellées; d'un roux un peu brunâtre, avec les 3 ou 4 premiers articles plus clairs; le $1^{\mathrm{er}}$ en massue a llongée : le $2^{\mathrm{e}}$ oblong, obconique : le $3^{\mathrm{e}}$ assez allongé, obconique, plus long que le $2^{\mathrm{c}}$ : les suivants graduellemeut un peu plus épais, peu ou non contigus : le $4^{\mathrm{e}}$ subişolé, ả peine plus long que large : le $5^{\mathrm{e}}$ subcarré : les $6^{\mathrm{e}}$ à $10^{\mathrm{e}}$ subobconiques, légèrement transverses, avec le $10^{\mathrm{e}}$ paraissant parfois à peine moins court : le dernier ovalaire, acuminé au sommet.

Prothorax suborbiculaire, à peine transverse, subcomprimé et subrétréci en avant; non ou à peine plus large que les élytres; largement tronqué au sommet ou à peine sinué de chaque côté de celui-ci, vers les angles antérieurs, qui sont infléchis, presque droits mais subarrondis; plus ou mooins arqué sur les côtés ; subarrondi à sa base ainsi qu'aux angles postérieurs; légèrement convexe sur son disque; sérialement sétosellé en avant sur les côtés, avec le gros point sétifère latéral distant de la marge; d'un noir de poix luisant, avec les côtés graduellement moins foncés ou même un peu roussâtres ; presque lisse; offrant en avant 2 séries dorsales composées de 3 points assez forts et subégalement distants, et de chaque côté du disque, 2 autres points semblables, transversalement rapprochés, sans compter les marginaux ou submarginaux.

Ecusson lisse, slabre, d'un noir luisant.

Élytres subcarrées, à peine plus larges en arrière qu'en avant, un peu plus longues que le prothorax; subdéprimées ou à peine convexes; subsillonnées, surtout en arrière, le long de la suture; assez fortement el peu densement ponctuées; d'uu noir de poix brillant et comme vernissé; ciliées-subspinosulées à leur bord apical ; très-éparsement pubescentes, avec la pubescence semi-conchée et quelques légères soies sur les côtés, dont l'humérale et celle du $1^{\text {er }}$ tiers notamment plus longues. Epaules à calus assez saillant, subépineuses en dessous.

Abdomen suballongé, moins large que les élytres, atténué en arrière après son milieu; assez convexe sur le dos, avec les 3 premiers se aments non ou à peine impressionnés en travers à leur base ; iparsement et longuement sétosellé; plus finement et à peinı plus densentent ponctué que les élytres, avec le $1^{\text {er }}$ segment pr'esyue lisse sur son unilieu; d'un noir de poix brillant, avec la marge apicale des segments d'un roux testacé, celle deș durnier's plus largement; à pubescence ássez longue et peu serrée. Le $6^{\text {e }}$ segment à peine arıondi ou même subsinueusement trondué au sontimet. 


\section{STAPHYLINIENS. - Quedius}

Dessous $d u$ corps aspèrement ponctué, légèrement pubescent, d'ún noir de poix brillant, avec le repli du prothorax, l'antépectus et le médipectus roux, et la marge apicale des arceaux da ventre d'un roux testicé, celle des derniers largement. Dessous de la tête prisque lisse: presque glabre. Prosternum subcaréné, à pointe un peu recourbée en dessous. Mésosternum subconvexe, presque lisse, à pointe subcarinulée, rembrunie. Métastermum subdéprimé sur son milieu. Ventre convexe, éparsement et longuement sétosellé, à $2^{\mathrm{e}}$ arceau basilaire prolongé sur le $1^{\mathrm{er}}$ normal en angle aigu ou très-aigu.

Pieds aspèrement ponctnés, légèrement pubescents, d'un roux testacé, avec les épines des tibias intermédiaires et postérieurs plus obscures. Cuisses spinosulrs en dessous, surtout vers leur extrémité; les postérieures plus grêles. Tibias antérieurs assez forts, à peine ou non é,yineux. Tarses antérieurs à 3 premiers articles plus ou moins fortement dilatés, le $4^{\mathrm{e}}$ moins fortement; les postérieurs à $1^{\mathrm{er}}$ article suballongé, un peu moins long que le dernier, subégal aux 2 suivants réunis : les $2^{\mathrm{e}}$ \ $4^{\mathrm{e}}$ graduellement plus courts.

Patrie. Celte espèce, exclusive aux régions boisses et thoutagneuses; se trouve dans les lichens et les troncs cariés des sapins, sous les mousses e! les feuilles mortes, dàns les champignons et parmi les vieux fagots, sur divers points de la France : la Flandre, l'Alsace, la Lorraine, le Bugey, l'Auvergne, le mont Pilit, la Savoie, les Alpes, les Pyrénées, ètc.

OBs. Cette espèce diffère du mesomeiinus par sa forme plus étroite, par son prothorax non impressionné vers les côtés, et par ses antennes et ses pieds d'une couleur plus claire, etc.

Chez les immatures, parfois le prothorax est rougeâtre, d'autres fois tout le corps est d'un brun roussâtre.

\section{Quedius seitus, Gravenhorst.}

Suballongé, peu convexe, éparsement pubescent, d'un roux testacé brillant, avec la tête noire, le disque du prothorax, l'angle postéroexterne des élytres, le postpectus et la base des segments abdominnux plus ou moins rembrunis. Tête et prothorax presque lisses, luisants : relui-ci subtransverse, subrétréci en avant. Écusson lisse. Élytres assez fortemer. et modérément, abdomen plus finement, ponctués. 
$\sigma^{\circ}$ Le $6^{\text {e }}$ arceau ventral largement et faiblement sinué dans le milieu de son bord apical, avec un assez grand espace triangulaire lisse au devant $d u$ sinus. Le $5^{\mathrm{e}}$ parfois à peine sinué dans le milieu de son bord postérieur.

Les $5^{\mathrm{e}}$ et $6^{\mathrm{e}}$ arceaux du ventre simples.

Staphylinus scitus, Gravenhonst, Mon. 50, 13. - Gyllenhal, Ins. Suec. II. 306, 22. - Mannerheim, Brach. 26, 30. - Runde, Brach. Hal. 6, 23.

Qucdius scitus, Enıchson, Col. March I, 487, 5; - Gen. et Spec. Staph. 528, 6.

- Farrmaire et Laboulbène, Faun. Ent. Fr. I, 540, 18. - Kraatz, Ins. Deut. II, 496, 7. - Rye, Ent. Ann. 1859, 131.-F Fuvel, Faun. Gallo-Rhén. III, 510, 17. Philonthus scitus, Nordmann, Symb. 79, 18.- Redtenbacher, Paun. Austr. 708, 49.

- Heer, Faun. Col. Helv. I, 274, 60.

Variété $a$. Élytres d'un roux testacé, sans taches.

Staphylinus analis, Fabricius, Mant. Ins. I, 221, 19. - PANZeR, Ent. Germ. 355, 25.

Variété $b$. Corps d'un roux testacé clair, avec la tête rembrunie.

Staphylinus atricillus et pygmaeus, Gravengorst, Mon. 53 et 57.

$$
\text { Long., } 0^{\mathrm{m}}, 0066 \text { (3 l.); - larg., } 0^{\mathrm{m}}, 0014(2 / 3 \text { ।.). }
$$

Corps suballongé, peu convexe, d'un roux testacé brillant, avec la tête noire, le disque du prothorax, l'angle postéro-externe des élytres et la base des segments abdominaux plus ou moins rembrunis; revêtu sur les élytres et l'abdomen d'une fine pubescence grisâtre et peu serrée.

Tête subovale, moins large que le prothorax; éparsement et longuement sétosellée sur les côtés; d'un noir luisant; presque lisse ou à peine chagrinée ; offrant de chaque côté, sur les tempes, 1 point sétifère médiocre, et plus en dedans, 1 gros point sétifère, situé loin du bord postérointerne des yeux, avec 2 autres points plus petits et transversalement disposés près du cou. Front large, subconvexe, à point juxtaoculaire assez gros. Cou glabre, presque lisse, luisa!t. Epistome subcorné, roussâ!re. Labre roux, fortement sétosellé en avant. Mandibules d'un roux brunâtre. Palpes d'un roux testacé.

Yeux courtement ovalaires, peu saillants, plus on muins obscurs.

Antennes médiocres, sensiblement plus longues que la tête; à peine épaissies; finement duveteuses et légèrement pilosellées; entièremcrıt d'un 
roux testacé; à $1^{\text {er }}$ article en massue allongée : les $2^{\mathrm{e}}$ et $3^{\mathrm{e}}$ obconiques : le $2^{\mathrm{e}}$ oblong : le $3^{\mathrm{e}}$ suballongé, un peu plus long que le $2^{\mathrm{e}}$ : les suivants graduellement un peu plus courts et un peu pius épais, non contigus : le $4^{\mathrm{e}}$ subisolé, à peine plus long que large : le $5^{\mathrm{e}}$ non, les $6^{\mathrm{e}}$ à $10^{\circ}$ légèrrment transverses, avec les pénultièmes un peu plus sensiblement : le dernier subovalaire, brusquement et obliquement acuminé all sommet.

Prothorax subtransverse, subrétréci (n avant; un peu plus large que, les élytres; tronqué au sommet, avec les côtés de celui-ci subsinuís près des angles antérieurs, qui sont infléchis, presque droits mais subarrondis; médiocrement arqué sur les côtés; subarrondi à sa base ainsi qu'aux angles postérieurs; subconvexe sur le disque; légèrement sétosellé sur les côtés, avec le gros point sétifère latéral assez distant de la marge ; d'un nōir ou d'un brun de poix luisant, avrc le pourtour pius clair ou roussâtre ; presque lisse ou à peine pointillé vers les angles antérieurs; offrant en aviut 2 séries dorsales composées de å points médiocres, dont l'antérieur parfois un peu plus écarté, et 1 autre, de chaque côté du disque, entre le pore sétifère et le point antérieur de la série dorsale.

Écusson lisse, glabre, d'un brun de poix luisant et sonvent roussâtre.

Élytres subcarrées, subparallèles, évidemment plus longues que le prothorax; subdéprimées ou à peine convexes; à peine subsillonnées en arrière le long de la suture ; assez fortement et modérément ponctuées ; d'un rouge testacé brillanı, avec l'angle postéro-externe couvert par une grande tache tringulaire, obscure; ciliées-spinosulées à leur bord apical; très-éparsement pubescentes, avec quelques légères soies sur les côtés, dont 1 humérale et 1 posthumérale beaucoup plus longues. Épaules à calus assez prononcé et presque lisse, subépineuses en dessous.

Abdomen suballongé, moins large que les élytres ; sensiblement altínué en arrière; subconvexe sur le dos, avec les 3 preniers segments à peine impressionnés en travers à leur base; épar'sement et très-longuement sétosellé ; plus finement, mais à peine plus densement ponctué que les élytres, avec le $1^{\text {er }}$ segment plus lisse sur son milieu; d'un brun de poix, avec la marge apicale des segments plus ou moins largement d'un roux testacé; à pubescence assez longue et peu serrée. Le $6^{\mathrm{e}}$ segment subarrondi au sommet.

Dessous du corps aspèrement ponctué, légèrement pubescent, d'un roux brillant, avec le postpectus et la base des arceaux du ventre plus ou moins rembrunis. Dessous de la tête presque glabre, presque lisse, d'un noir de poix. Prosternum caréné, à pointe un peu recourbée. Mésosternum un pu 
rugueux, à pointe carinuléc. Métasternum subdéprimé sur son milieu. Ventre convexe, éparsement et longuement sétosellé, à $2^{\mathrm{e}}$ arceau basilaire prolongé sur le $1^{\text {er }}$ normal en pointe fine, aciculée.

Pieds aspèrement pointillés, ligèrement pubescents, d'un roux testacé. Cuisses finement spinosules en dessous vers leur extrémité; les postérieures presque mutiques, plus grêles. Tibias antérieurs médiocres, non ou à peine épineux. Tarses antérieurs à 3 premiers articles fortement, le $4^{\mathrm{e}}$ moins fortement, dilatés; les postérieurs à ${ }^{\text {er }}$ article allongé, subégal au dernier, subégal aux 2 suivants réunis : les $2^{\mathrm{e}}$ à $4^{\mathrm{e}}$ graduellement moins longs.

Patrie. Cette espèce, peu commune, se prend, au printemps et à l'automne, dans les plaies et le tan des vieux arbres, dans les régions boisées : les environs de Paris et de Lyon, l.t Flandre, la Picardie, la Normandie, le Limousin, l'Alsace, la Lorraine, la Bourgogne, le Jura, le Bugey, le Beaujolais, la Savoie, les Alpes, la Provence, les Landes, les Pyrénées, etc.

OBs. Elle est remarquable par sa taille assez petite et par sa couleur général s plus claire que chez les précédentes. Les élytres ont leur angle postéro-externe plus ou moins rembruni. Le prolongement du $2^{\ominus}$ arceau basilaire est aciculé, etc.

Quelquefois, les élytres sont immaculées, d'autres fois tout le corps est testacé, avec la tête seule plus obscure. Rarement, le prothorax est presque entièrement d'un brun ou d'un noir de poix.

Peut-être doit-on rapporter à la vạiété $b$ l'atriceps de Stephens ( $\mathrm{Ill}$. $\mathrm{Br}$. $\mathrm{V}, 218$ ).

Quant au scitus de Lacordaire $(378,30)$, nous ne savons à quelle espèce l'attribuer.

\section{Quedius infuscatus, ERICHSON.}

Suballongé, subfusiforme, subdéprimé, à peine pubescent, d'un noir de poix brillant, avec la tête noire, les élytres d'un testacé ferrugineux à disque enfume, la base des antennes, les palpes, les pieds et la marge des segments abdominaux d'un testacé de poix. Tète et prothorax lisses, luisants : celui-ci aussi long que large, rétréci en avant. Ėcusson ponctué. Élytres assez finement et subéparsement ponctuées, plus longues que le prothorax. Abdomen finement ponctué, plus éparsement en arrière. 
$\sigma^{7}$ Le $6^{\text {e }}$ arceau ventral angulairement et aigument entaillé au sommet

ㄴ. Le $6^{\mathrm{e}}$ arceau ventral subarrondi au sommet.

Quedius infuscatus, Erichson, Gen. et Spec. Staph. 543, 29.- Fairmaire el Laboul. BÈNE, Faun. Ent. Fr. I, 537, 9. - FaUvel, Faun. Gallo-Rhén. III, 511, 1 s.

$$
\text { Long., } 0^{\mathrm{m}}, 0045 \text { (2 1.); - larg., } 0^{\mathrm{m}}, 0008 \text { (1/3 1. fort). }
$$

Corps suballongé, subfusiforme, subdéprimé, d'un noir de pois brillant, avec les élytres d'un testacé ferrugineux à disque rembruni ; revêtu sur celles-ci et l'abdomen d'une fine pubescence grise et très-peu ser.'s $\cdot$

Tête subovalo-orbiculaire, moins large que le prothorax; éparsement et longuement sétosellée sur les côtés; 'un noir luisant ; presque liss:? offrant de chaque côté, sur les tempes, 1 point sétifère assez gros, 1 aulre plus en dedans, écarté du bord postéro-interne des yeux, et 2 autres moindres, encore plus en dedans, subtransversalement disposés, rapprochés sur le vertex. Front très-large, à peine convexe, à point juxtaoculaire assez gros, touchant à l'œil. Cou glabre, presque lisse ou avec 2 petịts points sur les côtés, luisant. Épistome corné, obscur. Labre brun, sétosellé en avant. Mandibules ferrugineuses. Palpes d'un testacé de poix, à dernier article conico-fusiforme.

Yeux médiocres, assez saillants, subovales, obscurs.

Antennes peu allongés, sensiblement pliss longues que la tête; subépaissies; finement luveteuses el légèrement pilosellées; d'un roux brunâtre, avec la balse plus claire; à $1^{\text {er }}$ article en massue suballongée : les $2^{\mathrm{e}}$ et $3^{\mathrm{e}}$ oblongs, obconiques : le $3^{\circ}$ non ou à peine plus long que le $2^{\mathrm{e}}$ : les suivants graduellement in peu plus épais, peu ou non contigus: le $4^{\mathrm{e}}$ presque carré : le $5^{\mathrm{e}}$ à peine, les $6^{\mathrm{e}}$ à $10^{\mathrm{e}}$ sensiblement transverses, a vec les pénultièmes plus fortement : le dernier brièvement ovalaire, brusquement acuminé au sommet.

Prothorax aussi large que long; sensiblement rétréci en avant; à peine moius large à sa base que les élytres; tronqué au somnet, avec les angles antérieurs infléchis et subarrondis; médiocremment arqué sur les côtés subarrondi à sa base, avec les angles postrieurs obtus; assez convexe sur son disque ; éparsement et sérialement sétosellé sur les côtés; à longue soie latérale située assez près de lą marge: d'un noir de poix luisant; lisse; offrant en avant 2 séries dorsales composées de 3 points médiocres, assez rapprochés et subégalement distants, et 2 autres semblables entre le $2^{e}$ dorsal et les angles anterieurs, sans compler les marginaux. 
Écusson éparsement ponctué, à peine pubescent, d'un brun de poix.

Élytres suboblongues, un peu plus longues en arrière qu'en avani, sensiblement plus longues que le prothorax; subdéprimées; à peine sillonnées en arrière le long de la suture; assez finement et subéparsement ponctuées; d'un testacé ferrugineux brillant, avec le disque plus ou moin; enfumé intérieurement ; à pubescence légère et très-éparse, avec quelques soies sur les côtés, dont l'buinérale et la posthumérale beaucoup plus longues, et des cils subspiniformes le long du bord apical. Épaules à calus assez distinct.

Abdomen peu allongé, moins large que les élytres; graduellement atténué en arrière; convexe sur le dos, avec les 3 premiers segments non ou à peine impressionnés en travers à leur base; éparsement et trèslonguement sétosellé; finement et modérément ponctué, plus lâchement vers son extrémité; d'un noir de poix brillant, avec le sommet roussâtre, ainsi que la marge apicale des segments; à pubescence longue et peu serrée. Le $6^{\mathrm{e}}$ segment subarrondi à son bord postérieur.

Dessous $d u$ corps aspèrement ponctué, finement pubescent, d'un noir ou d'un brun de poix brillant, avec le repli du prothorax, le prosternum et le mésosternum moins foncés, le sommet du ventre et la marge apicale des arceaux encore plus clairs. Dessous de la tête presque glabre, presque lisse ou avec quelques assez gros points en arrière vers les côtf́s. Prosternum subcaréné. Mésosternum rugueux. Métasternum subdéprimé, finement canaliculé postérieurement sur sa ligne médiane. Ventre convexe, éparsement sétosellé, à $2^{\circ}$ arceau basilaire prolongé sur le $1^{\text {er }}$ normal en angle subaigu.

Pieds légèrement ponctués et pubescents, d'un roux de poix testacé, avec les hanches postérieures plus foncées. Cuisses spinosules en dessous, surtout vers leur extrémité; les postérieures un peu moins épaisses. Tibias antérieurs médiocres, presque mutiques. Tarses antérieurs à 4 premiers articles graduellement moins fortement dilatés; les postérieurs à $1^{\text {er }}$ article allongé, subégal au dernier, aussi long que les 2 suivants réunis : les $2^{2}$ à $4^{\text {e }}$ graduellement plus courts.

Patrie. Cette espèce est très-rare. Elle se prend sous les détritus et les fumiers secs, dans les vieux nids et les vieux fagots, près des étables et des habitations, en juillet et août, dans les environs de Paris, la Flandre, la Normandie, l'Auvergne, à la Grande-Chartreuse, etc.

OBs. Elle se distingue de toutes celles du même sous-genre par la peti- 
tesse de sa taille, par son écusson ponctué et pär la structure da dernier article des palpes. Le prothorax est plus rétréci en avant, les élytres sont plus longues, et l'abdomen est plus atténué en arrière, etc.

Elle ressemble au microps à s'y tromper. Mais sa forme est plus large ; sa tête est moins oblongue; les angles postérieurs du prothorax sont moins arrondis, avec celui-ci plus rétréci en avant; les élytres sont plus longues, et leur ponctuation est à peine plus forte, celle de l'abdomen un peu moins fine et moins serrée. Enfin, le dernier article des palpes est un peu moins conique, et le $1^{\text {er }}$ article des tarses postérieurs un peu plus loing; surtout, les yeux sont beaucoup plus gros, etc.

\section{Quedius Inevigatus, Gyllenhal.}

Suballongé, subparallèle, subdéprimé, d'un noir brillant, avec les palpes, la base des antennes, les élytres les pieds et la marge apicale des segments abdominaux, rougeâtres. Tề!e et prothorax lisses, liiisants : celui-ci subtransverse, non ou à peine rétréci en avant. Écusson lisse. Elytres très-finement chagrinées, presque mates, glabres, obsolètement et bissérialement ponctuées. Abdomen légèrement pubescent, finement et modérément ou subéparsement ponctué.

$\sigma^{*}$ Le $6^{\mathrm{e}}$ arceau ventral légèrement et subangulairement sinué dans le milieu de son bord apical, avec un espace triangulaire lisse au devant du

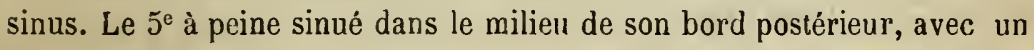
léger espace lisse au devant du sinus. Tarses antérieurs très-fortement dilatés.

\& Le $6^{\mathrm{e}}$ arceau ventral subarrondi au sommet. Le $5^{\mathrm{e}}$ simple. Tarses antérieurs fortement dilatés.

Staphylinus laevigatus, Gyllenhal, Ins. Suec. II, 306, 23. - MinNerheim, Brach. $26,31$.

Emus lacvigatus, Boisduval et LaCGRdare, Faun. Ent. Par. I, 380, 32.

Philonthus laevigatus, Nordinan, Symb. 79, 19. - Redtenbacher, Faun. Austr. 709, 52. - HeEr, Faun. Col. IIelv. I, 274, 61.

Quedius laevigatus, ERICHson, Col. March. I, 488, 6 ; - Gen. et Spec. Staph. 529, 7. -

Fairmaire et Laboulbène, Faun. Ent. Fr. I, 536, 5.- Kraatz, Ins. Deut. II, 497, 8.

- Faviel, Faun. Gallo-Rhén. III, 512, 19.

Microsaurus laevigatus, Tномson, Skand. Col. II, 176, 7.

BR. 
Variété a. Élytres à disque largement enfumé.

Microsaurus resplendens, Thomson, Skand. Col. II, 176, 6.

$$
\text { Long., } 0^{\mathrm{m}}, 0077 \text { (3 1/2 l.); - larg., } 0^{\mathrm{m}}, 0018 \text { (4/5 l.). }
$$

Corps suballongé, subparallèle, subdéprimé, d'un noir brillant, avec les élytres rouges; revêtu sur l'abdomen d'une fine pubescence grisâtre et peu serrée.

Tête subtransversalement orbiculaire, à peine moins large que le prothorax ; très-éparsement sétosellée sur les côtés ; d'un noir luisant, parfois à peine métallique; lis e; parée de chaque côté, sur les tempes, de 1 pore sélifère, situé tout près des yeux, et, plus en dedans, entre le bord postéro-interne de ceux-ci et le cou, de 2 autres pores, dont l'antérieur beaucoup plus gros et distant des yeux. Front très-large, à peine convexe, plus ou moins impressionné en avant, à pore juxta-oculaire gros, joignant l'œil. Cou subconvexe, glabre, presque lisse, brillant. Epistome subcorné, brunâtre. Labre d'un brun roux ou ferrngineux, longuement sétosellé en avant. Handibules ferrugineuses. Palpes roux.

Yeux assez grands, assez saillants, subarrondis, noirs, parfois grisâtres.

Antennes assez courtes, plus longues que la tête ; sensiblement épaissies ; finement duveteuses et distinctement pilosellées; brunâtres, avec les 3 premiers articles roux; le $1^{\text {er }}$ en massue suballongée: les $2^{\mathrm{e}}$ et $3^{\mathrm{e}}$ obconiques : le $2^{e}$ oblong : le $3^{\mathrm{e}}$ suballongé, plus long que le $2^{\mathrm{e}}$ : les suivants gradnellement plus courts et plus épais, non ou peu contigus : le $4^{\mathrm{e}}$ à peine, le $5^{\mathrm{e}}$ sensiblement, les $5^{\mathrm{e}} \mathrm{à} 10^{\mathrm{e}}$ très-fortement transverses : le dernier ovale, obtusément acuminé au sommet.

Prothorax subtransverse, non ou à peine rétréci en avant; de la largeur des élytres; largement tronqué au sommet, avec les angles antérieurs subinflèchis et presque droits; modérément arqué sur les côtés; subarrondi à sa base ainsi qu'aux angles postérieurs; peu convexe sur son disque; à peine sétosellé sur les côtés, avec le pore sétifère latéral'situé tout près de la marge ; d'un noir luisant, parfois submétallique et faiblement soyeux ; lisse; offrant antérieurement 2 séries dorsales divergeant d'arrière en avant et composées de 3 points assez gros, dont l'antérieur submarginal plus écarté, souvent nul ou obsolète ; marqué en outre, entre le $2^{\circ}$ dorsal et le pore sétifère latéral, d'un autre point, tantôt plus fin, tantôt plus gros, sans compter les marginaux.

Ecusson lisse, glabre, d'un noir de poix brillaut. 
Élytres en carré à peine oblong, subparallèles, évidemment plus longues que le prothorax; subdéprimées ou même déprimées; subsillonnées le long de la suture; plus ou moins impressionnées au sommet près de leur angle postéro-externe ; très-finement chagrinées; rouges ou rongeâtres ; peu brillantes; ciliées-spinosulées à leur bord apical; glabres, ou parées seulement de 2 séries longitudinales de 4 petits points sétifères, souvent obsolètes, l'un vers la suture, l'autre vers le milieu du disque, et, sur les côtés, de quelques légères soies redressées, a vec 1 beaucoup plus longue près des épaules et 1 autre semblable plus en arrière. Épaules à calus assez saillant, épineuses en dessous.

Abdomen peu allongé, moins large que les élytres; subparallèle, subconvexe sur le dos, avec les 3 premiers segments subimpressionnés en travers à leur base; éparsement et longuement sétosellé; finement et modérément ou subéparsement ponctué, plus lâchement en arrière; d'un noir brillant parfois subazuré, avec le $6^{\text {e }}$ segment et la marge apicale des pré-

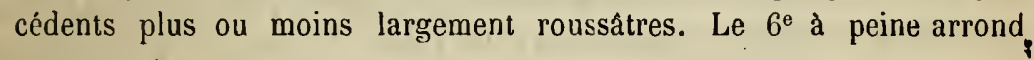
au sommet.

Dessous du corps aspèrement ponctué, finement pubescent, d'un noir brillant, avec le repli du prothorax, l'antépectus et le médipectus d'un roux de poix, le sommet du ventre et la marge apicale des arceaux d'un roux subtestacé. Dessous de la tête presque lisse ou peu ponctué et pubescent en arrière. Prosternum subcorné, à pointe parfois un peu recourbée. Mésosternum subruguleux, sétosellé postérieurement. Métasternum subdéprimé, finement canaliculé en arrière sur sa ligne médiane. Ventre convexe, éparsement sétosellé, à $2^{\mathrm{e}}$ arceau basilaire prolongé sur le $1^{\mathrm{er}}$ normal en angle obtus.

Pieds aspèrement ponctués, légèrement pubescents, roux. Cuisses antérieures et intermédiaires spinosules; les postérieures fortement épineuses en dessous, surtout vers leur extrémité ; celles-ci plus grêles. Tibias antérieurs assez forts, jeu épineux. Tarses antérieurs à 4 preniers articles graduellement moins fortement dilatés ; les postérieurs à $1^{\text {er }}$ article suballongé, subégal aux 2 suivants réunis, sensiblement moins long que le dernier : celui-ci allongé, grêle : les $2^{\mathrm{e}} \mathrm{a} 4^{\mathrm{e}}$ graduellement plus courts.

Patrie. Cette espèce est assez commune dans la carie et sous les écorces des vieux sapins, en été, dans l'Alsace, la Lorraine, l'Auvergne, la Savoie, au mont Pilat, dans les Alpes, les Pyrénées, etc.

OBs. Elle est très-distincte de toutes les précédentes par la sculpture des 
élytres non ponctuées, mais simplement chagrinées. La forme est plus parallele et plus déprimée. Les tempes, contrairement à toutes les espèces, sont obsolètement rebordées en avant.

La variété $a$, dont les élytres sont enfumées, avec la base, la suture et la marge apicale d'un roux testacé, a les hanches et la base des cuisses postérieures un peu rembrunies, et les intersections abdominales et ventrales d'un testacé pâle.

On doit sans doute rapporter au laevigatus les laevipennis, Dufour (Bull. Soc. Sc. Pau, 1843, 110) et longipennis, Mannerheim (Bull. Mosc. 1846, II, 509).

\section{Queding cinetus, Paykull.}

Asse allongé, subdéprimé, à peine pubescent, d'un noir brillant, avec la suture, les marges apicale et latérale des élylres d'un roux testacé, le sommet de l'abdomen, les genoux et les tarses d'un brun de poix. Tête et prothorax presque lisses, luisants ; celui-ci subtransverse, subrétréci en avant. Ecusson lisse. Elytres légèrement pointillées, presque glabres, trisérialement ponctuées. Abdomen éparsement pubescent, assez finement et éparsement ponctué, irisé.

$\sigma^{7}$ Le $6^{\text {e }}$ arceau ventral beaucoup plus densement ponctué que le précédent, largement, subangulairement et sensiblement sinué dans le milieu de son bord apical, avec un léger espace au devant du sinus. Le $5^{\mathrm{e}} \mathrm{à}$ peine sinué dans le milieu de son bord postérieur, avec un étroit espace longitudinal lisse, au devant du sinus, prolongé jusqu'à l'arceau précédent.

Le $6^{\mathrm{e}}$ arceau ventral à peine plus densement ponctué que le précédent, à peine ou subsinueusement arrondi au sommet. Le $5^{\mathrm{e}}$ simple (1).

Staphylinus cinctus, PAYкuLL, Mon. Car. App. 137, 34-33 ; - Faun. Suec. III, 395,36 .

Staphylinus impressus, Panzer, Faun. Germ. 36, 21.-Gravenhorst, Miir. 35, 51 ;

- Mon. 39, 1. - Latreille, Hist. Nat. Crust. et Ins. IX, 320, 50. - Gyllenhal, Ins. Suec. II, 307, 24. - Mannerneim, Brach. 26, 32. - Redtendacher, Faun. Austr. 709, 32. - Heer, Faun. Col. Helv. 1, 274, 62.

Staphylinus marginellus, MarShaM, Ent. Brit. 505, 21.

(1) Les tarses antérieurs des $\sigma^{n}$ sont à peine moins fortement dilatés. 
Emus impressus, Borsduval et Lacordarre, Faun. Ent. Par. I, 381, 35.

Quedius impressus, Erichson, Col. March, I, 489, 7 ; - Gen. et Spec. Staph. 530, 8.- Fairmaire et Laboulbène; Faun. Ent. Fr. I, 535, 3.- Kraatz, Ins. Deut. II; $499,10$.

Microsaurus impressus, Tionson, Skand. Col. II, 174, 1.

Quedius cinctus, Fauvel, Faun. Gallo-Rhén. III, 514, 21.

Variété $a$. Élytres entièrement d'un roux testacé.

Staphylinus flavescens, Fabricius, Syst. Ent. 266, 9; - Spec. Ins. I, 336, 10 :

$$
\text { Long., } 0^{\mathrm{m}}, 008 \text { (3 2/3 1.); - larg., } 0^{\mathrm{m}}, 0019 \text { (4/5 1.). }
$$

Corps assez allongé, subdéprimé, d'un noir brillant, avec la suture, la marge apicale et le repli des élytres d'un roux testacé; revêtu sur l'abdomen d'une fine pubescence blonde et peu serrée.

Tète subarrondie, un peu moins large que le prothorax; éparsement sétosellée sur les côtés; d’ın noir luisant ; presque lisse; marquée de chaque côté, derrière les yeux, de 3 points assez rapprochés et disposés ell triangle dont le juxta-oculaire un peu moindre, et, sur le vertex, de 2 autres petits points, transversalement situés. Front large, subconvexe, à pore juxta-oculaire gros. Cou subconvexe, glabre, presque lisse, luisant. Épistome corné, noir. Labre d'un noir de poix, sétosellé en avant. Mandibules brunâtres. Palpes d'un brun de poix. avec les articulations et parfois le dernier article plus clairs.

Yeux assez grands, subovales, peu saillants, obscurs, lavés de gris.

Antennes médiocres, sensiblement plus longues que la tête; faiblement épaissies; finement duveteuses et légìrement pilosellées; ubscures; à $1^{\mathrm{er}}$ aricle en massue allongée : le $2^{\mathrm{e}}$ oblong, obconique: le $3^{\mathrm{e}}$ suballongé, obconique, plus long que le $2^{e}$ : les suivants graduellenent un peu plus courts et un peu plus épais, non contigns : les $4^{\mathrm{e}}$ à $6^{\mathrm{e}}$ subcylindriques, les $7^{\mathrm{e}}$ à $10^{\mathrm{e}}$ subobconiques: les $4^{\mathrm{e}}$ et $5^{\mathrm{e}}$ à peine oblongs, le $6^{\mathrm{e}}$ presque carré : le $7^{\text {e }}$ légìrement, les pénultièmes sensiblement tranverses : le dernier subovale, obliquement tronqué au bout et subacuminé inférieurement.

Prothorax sub'ransverse, subrétréci en avant, aussi large ou à peine moins large que lus élytr.s; largement uronqué au sommet, avec celui-ci subsinué, de chaque côté, près dés angles antérieurs, qui sont infléchis, presułue droits mais émoussés; subarquré sur lrs côtés; subarrondi à sa base ainsi qu'aux angles postérieurs; subconvexe sur le disque; sériale- 
ment sétosellé sur les cô:és, arec lu grus pure latéral situé assez près de la marge; d'un noir luisant; presque lisse, ou parfois à peine pointillé vers les angles antérieurs; offrant en avant 2 séries dorsales subdivergentes antérieurement et composées de 3 points médiocres, dont l'antérieur parfois plus écarté, el, sur les côtés, 3 ou 4 autres points épars et distants, sans compter les marginaux.

Écusson lisse, glabre, d'un noir luisant.

Élytres subcarrées, à peine plus larges en arrière qu'en avant, un peu ou à peine plus longues que le prothorax; subdéprimées; subsillonnées en arrière le long de la suture; subimpressionnées au sommet près de leur angle postéro-externe ; très-finement et légèrement pointillées; d'un noir luisant et parfois submétallique, avec la suture, la marge apicale et le repli latéral plus ou moins d'un roux testacé; ciliées-subspinosulées à leur bord postérieur ; glabres sur leur disque; à peine pubescentes sur leurs côtés et vers le sommet, avec ceux-là parés de quelques soies redressées, dont 2, derrière les épaules, notamment plus longues ; ınarquées en outre, sur le disque, de 3 séries de points sétifères assez gros, et au nombre de 7 ou 8 : la $1^{\text {re }}$ juxta-suturale, l'intermédiaire à points antérieurs souvent oblitérés, la $3^{\mathrm{e}}$ près des còtés. Epaules à calus assez saillant, subépineuses en dessors.

Abdomen peu allongé, moins large queles élytres; subatténué en arrière; subconvexe sur le dos; non ou à peine impressionné en travers à la base des 3 premiers segments ; éparsement et longuement sétosellé; assez finement et éparsement ponctué; d'un noir brillant et plus ou moins irisé, avec le sommet couleur de poix, ainsi que parfois la marge apicale des segments; à pubescence assez longue et peu serrée. Le $6^{\text {e }}$ segment à peine arrondi au sommet.

Dessous $d u$ corps aspèrement ponctué, légèrement pubescent, d'un unir brillant, avec le sommet du ventre et la marge apicale des arceaux d'un roux de poix, ainsi que souvent le repli du prothorax et le bord antérieur du prosternum. Dessous de la tête presque lisse, presque glabre. Prosternum relevé en faîte. Hésosternum subanğ uleux, sétosellé et subciurinulé à sa pointe. Métasternum subdèprimé, à peme canaliculé en arrièr: sur sa ligne médiane. Ventre convexe, éparsement tot longuement sèlosellé, à ponctuation moins serrée en arrière; plus ou moius irisé ; à $2^{e}$ arceau basilaire prolongé sur le $1^{\text {er }}$ normal en angle très-ouvert et arrondi.

Pieds aspèrement ponctués, finement pubescents, dun noir de poix, avec les tarses, les genoux, les trochanter's antér'eur's et intermédiair's et 
l'insertion des postérieurs moins foncés ou d'un roux de poix. Cuisses spiriosules en dessous; les postérieures plus fortement; celles-ci un peu moins épaisses. Tibias antérieurs assez robustes, peu épineux. Tarses antérieurs à $2^{\mathrm{e}} \mathrm{tt} 3^{\mathrm{e}}$ articles plus ou moins fortement dilatés, les $1^{\mathrm{er}}$ et $4^{\mathrm{e}}$ moins fortement ; les postérieurs à $1^{\mathrm{er}}$ article allongé, subégal au dernier, au moins égal aux 2 suivants réunis : les $2^{\mathrm{e}}$ à $4^{\mathrm{e}}$ graduellement moins longs.

Patrie. Celte espèce est très-commune, dans presque toute la France, dans les bouses, les champignons décomposés, et sous les détritus en voie de putréfaction.

OBs. La couleur et la sculpture des élytres la distinguent suffisamment du laeviyatus. De plus, les tempes sont distinctement rebordées dans toute leur longueur.

La variété $a$, à élytres entièrement rousses, est peu commune. Elle a en même temps la marge des segments abdominaux et les pieds d'une couleur plus claire. Les exemplaires de la Provence et de la Corse sont souvent d'une taille plus forte, avec la couleur générale plus noire.

\section{LARVE}

Voici la description de la larve du Quedius cinctus :

Corps allongé, subconvexe, d'un roux testacé brillant, avec l'abdomen plus mat.

Tête grande, suborbiculaire mais presque droite sur le milieu de ses côtés, beaucoup plus large que le prothorax ; subconvexe, éparsement sétosellėe; presque lisse ou obsolétement ridée; biimpressionnée en avant; d'un roux testacé brillant. Epistome armé en avant de 7 ou 9 dents fortes et aiguës, la médiane beaucoup plus petite et moins saillınte. Mandibules longues, arquées, falciformes, acérée:, testacés. Palpes grêles, pâles, à dernier article suballongé, altéuué vers son extrémité et trrminé par un lobe de moitié moindre, très-grêle, subulé.

Yeux réduits à 3 ou 4 ocelles lisses, confluents, plus ou moins rembrunis.

Antennes testacées, à $1^{\text {er }}$ article très-court: le $2^{\mathrm{e}}$ allongé, subdilaté vers son sommet : le $3^{\text {e }}$ presque aussi épais, moins long, subcylindrique, lobé au bout de son côté interne, offrant avant son extrémité 3 soies 
divergentes : le dernier un peu moins long, beaucoup plus grêle, subcylindrique, trisétosellé vers son sommet, brièvement tricilié au bout.

Prothorax en carré suboblong ou semi-cylindrique, tronqué an sommet et à la base, assez largement rebordé sur celle-ci ; longitudinalement convexe; lisse ou presque lisse ; éparsement sétosellé et biimpressionné sur les côtés; d'un roux testacé brillant.

Mésothorax et métathorax courts, subégaux, moins longs, pris ensemble, que le prothorax, un peu plus larges que celui-ci; subconvexes sur leur disque; longuement et éparsement sétosellés et impressionnés sur les côtés, qui sont angulairement dilatés, le $1^{\text {er }}$ en avant et en arrière, le $2^{\circ}$ dans son milieu; d'un roux testacé brillant, presque lisse.

Abdomen à peine aussi long que le thorax, fortement rétréci en arrière, surıout après son milieu; subdéprimé ; finement chagriné, un peu inégal ; creusé sur sa ligne médiane d'un large sillon, s'effaçant vers le tiers postérieur ; fortement et longuement suhispido-sétosellé; d'un testacé livide et peu brillant; à $1^{\text {er }}$ segment plus court, plus brillant et presque lisse : les suivants subégaux, impressionnés et cicatrisés sur leurs côtés, qui sunt subarqués : le dernier asșez court, fortement transverse, à peine plus long que le précédent, largement tronqué au sommet, où il offre 2 lanières 3 fois aussi longues que lui, écartécs d'un espace égal à la largeur de leur base, à peine alténuées vers leur extrémité, à peine recourbées en dedans, subhispido-sétosellées en dehors inférieurement, longuement et plus éparsement sétosellées dans leur dernière moitié, terminées par un article très-grêle, filiforme, d'un tiers moins long, un peu déjeté en dehors et portant au bout 1 longue soie qui lui fait suite et 1 autre courte et divergente.

Dessous du corps d'un testacé un peu roussâtre. Dessous de la tête et prosternum presque liss:s, brillants, Ventre subinégal, finement chagriné, sillonné sur son milieu, fortement sétosellé, à tube terminal subcylindrique, subinfléchi, sensiblement moins long que les lanières supérieures, fortement sétosellé en dessous.

Pieds assez courts, testacés. Hanches très-grandes, épineuses. Cuisses a peine épaissies au sommet, mutiques. Trochanters avec 3 ou 4 soies spinosules. Tibias un peu plus courı que les cuisses, subitement atténués dans leur dernier tiers, plus ou moins fortement épineux dans leur pourtour, termivés par un crochet solide, assez long, acéré, subarqué, muni vers son milieu de 2 ou 3 petites épines. 
Obs. Cette larve, qui se prend dans les bouses et les fumiers mi-desséchés, a la tête un peu moins parallèle que celle de la larve du nigrocoeruleus. Les dents de l'épistome sont différentes, et les mandibules moins. grêles. La structure des palpes et des antennes n'est plus la mème. Le prothol'ax est un peu plus long et plus parallèle. Le dernier segment de l'abdomen est plus court, avec ses lanières beaucoup plus longues, et le tube terminal plus court que celles-ci. Les hanches et les cuisses sont mutiques, etc.

\section{Quedius pediculus, Nordmann.}

Assez allongé, subdéprimé, à peine pubescent, d'un noir brillant, avec la bouche, la suture, la marge apicale et le repli des élytres, la marge apicale des segments abdominaux, et les tarses, d'un roux de poix. Tête et prothorax lisses, luisants : celui-ciaussi large que long, à peine rétréci en avant. Écusson lisse. Élytres à peine ruguleuses, presque glabres, trisérialement ponctuées. Abdomen légèrement pubescent, finement et assez densement ponctué, subazuré.

$\sigma^{7}$ Le $6^{\mathrm{e}}$ arceau ventral plus densement ponctué que le $5^{\mathrm{e}}$, légènement et subangulairement sinué dans le milieu de son bord apical.

ㅇ Le $6^{\mathrm{e}}$ arceau ventral ponctué comme le $5^{\mathrm{e}}$, subarrondi au sommet.

Philonthus pediculus, Nordmann, Symb. 79, 24.

Quedius pediculus, Erichson, Gen. et Spec. Staph. 531, 9. - Fauvel, Faun. GalloKhén. III, 513, 20.

Philonthus punctatellus, Heer, Faun. Helv. I, 275, 63. - Redtenbacher, Faun. Austr. 826.

Quedius punctatellus, Fairmaire et Laboulbène, Faun. Ent. Fr. I, 536, 4.-Kratatz, Ins Deut. II, 498, 9.

$$
\text { Long., } 0^{\mathrm{m}}, 0055 \text { (2 1/2 l.); - larg., } 0^{\mathrm{m}}, 0014 \text { (2/3 1.). }
$$

Corps assez allongé, subdéprimé, d'un noir brillant, avec la marge des élytres moins foncée; revêtu sur l'abdomen d'une fine pubescence grisâtre et peu serrée.

Tête subarrondie, moins large que le prothorax; éparsement sétosellée sur les côtés ; d’un noir luisant; lisse ; parée de chaque côté, derrière les yeux, de 3 points disposés en triangle, dont l'interue plus gros, l'antérieur 
moindre et touchant au bord postérieur de l'œil; marquée, plus en dedans, vers le cou, de 2 autres petits points, très-rapprochés transversalement. Front large, subconvexe, à pore juxla-oculaire gros. Cou subconvexe, glabre, presque lisse, luisant. Épistome corné, brun. Labre d'un noir de poix, sétosellé en avant Mandibules brunâtres. Palpes d'un roux de poix.

Yeux assez grands, subovales, peu saillants, obscurs, lavés de gris.

Antennes médiocres, plus longues que la têle; subépaissies; finement duveteuses et légèrenent pilosellées; noirâtres, avec l'extrême base des premiers arlicles, et surtout du $2^{\mathrm{e}}$, rousse ; le $1^{\mathrm{er}}$ en massue assez, allongée : le $2^{\mathrm{e}}$ oblong, obconique : le $3^{\mathrm{e}}$ suballongé, obconique, un peu plus long que le $2^{\mathrm{e}}$ : les suivants graduellement un peu plus longs et un peu plus épais, subobconiques, non contigus : le $4^{\mathrm{e}}$ presque carré : le $5^{\mathrm{e}}$ à peine, les $6^{\mathrm{e}}$ et $7^{\mathrm{e}}$ sensiblement, les $8^{\mathrm{e}}$ à $10^{\mathrm{e}}$ assez fortement transverses (1) : le dernier subovale, obliquement tronqué au sommet et subacuminé infèrieurement.

Prothorax aussi large que long, à peine rétréci en avant, de la largeur des élytres; largenent tronqué au sommet, a vec celui-ci à peine sinué, de chaque côté, près des angles antérieurs, qui sont infléchis, presque droits mais subarrondis; subarqué sur les côtés; subarrondi à sa base ainsi qu'aux angles postérieurs ; légèrement convexe sur son disque; distinctemeut et sérialement sétosellé sur les côtés, avec le gros pore sétifère latéral situé assez près de la marge ; d'un noir luisant; lisse; offrant en avant 2 séries dorsales subdivergentes antérieurement et composées de 3 points médiocres, dont l'antérieur plus distant, et, entre celles-ci et la marge latérale, 3 points semblables, écartés et disposés en triangle, sans compter les marginaux.

Écusson lisse, glabre, d'un noir luisant.

Elytres subcarrées, à peine plus larges en arrière qu'en avant, à peine plus longues que le prothorax; subdéprimées ou à peine convexes; plus ou moins impressionnées au sommet près des angles postérieurs; presque lisses, ou à points confluents et formant des rides ou strioles obsolètes; d'un noir luisant, avec la suture à peine, la marge apicale étroitement, et le repli latéral largement d'un roux de poix, quelquefois subteslacé; ciliées-spinosulées à leur bord apical; glabres sur leur disque; légèrement

(1) Il faut examiner ces articles de côté. En les voyant de dessus, comme sans doute l'a fait Erichson, ils paraissent moins courts. 
pubescentes sur leurs côtés el vers leur sommet, avec ceux-là parés de quelques soies redressées, dont 2 notamment plus longues derrière les épaules; marquées en outre, sur leur disque, de 3 séries longitudinales de 7 ou 8 petits points sétifères, à soie courte, la $1^{\text {re }}$ juxta-suturale, l'intermédiaire à point souve:t moins nombreux, la $3^{\mathrm{e}}$ près des côtés. Epaules à calus assez saillant, spinos!lles eì dessous.

Abdomen peu allongé, moins large que les élytres; subatténué vers son extrémité; subconvexe sur le dos, avec les 3 premiers segments non ou à peine impressionnés en travers à leur base; très-éparsement sétosellé; finement, et assez denseınent ponctué ; d'un noir brillant, subazuré ou parfois subirisé, avec le sommet et parfois la marge apicale des segments d'un roux de poix plus ou moins foncé; à pubescence assez. longue et peu serrée. Le $6^{\mathrm{e}}$ segment un peu moins ponctué, subtronqué au sommet.

Dessous du corps aspèrement ponctué, finement pubescent, d'un noir brillant, avec le repli du prothorax, le prosternum et le mésosternum souvent moins foncés, le sommet du ventre et souvent la marge apicale des arceaux d'un roux de poix plus ou moins obscur. Dessous de la tête presque lisse ou à peine chagriné, parfois subponctué et subpileux en arrière. Prosternum simplement relevé en faîte. Mésosternım presque lisse, à pointe subcarinulée. Métasternum subdéprimé. Ventre convexe, éparsement sétosellé, à $2^{\mathrm{e}}$ arceau basilaire arrondi dans le milieu de son bord postérieur.

Pieds aspèrement pointillés, finement pubescents, noirs, avec les tarses, les trochanters antérieurs et intermédiaires, l'in *ertion des postérieurs et souvent les genoux d'un rolux de poix. Cuisses faiblement spinosules en dessous; les postérieures un peu moins épaisses. Tibias antérieurs assez robustes, à peine épineux. Tarses antérieurs à 3 premiers articles fortement, le $4^{\mathrm{e}}$ moiis fur allongé, à peine moins long que le dernier, subégal aux 2 suivants réunis : les $2^{\mathrm{e}}$ à $4^{\mathrm{e}}$ graduellement plus courts.

Patrie. Cette espèce, assez rare, habite près des neiges, sous les pierres, les moltes de terre, les crottins secs, dans les bautes montagnes, en juillet et août : les Vosges, la Savoie, les Alpes, les Pyréuées, etc.

Obs. Elle est plus petite que le cinctus, généralement plus noire. La ponctuation des élytres est plus confuse, avec les points en série un peu moins gros.et à soie plus courte, et celle de l'abdomen est plus serrée. La 
tête est un peu moins grosse, et les pénultièmes articles des antennes un peu plus transverses, etc.

- Chez les immatures, les élytres sout ou largement bordées de roux testacé, ou entièrement d'un brun roussâtre, a vec les pieds plus clairs que dans le type.

Parfois le vertex n'offre qu'un seul point de chaque côté. Soluvent, le point antérieur des séries dorsales du prothorax manque tout à fait.

Nous mentionnerons ici, comme mémoire, uile espèce étrangère à la France, remarquable par les séries dorsales du prothorax composées de 4 points :

\section{Quedius polystigma, WaNkow.}

Assez allongé, subdéprimé, éparsement pubescent, d'un noir brillant, avec la bouche, la base des antennes, les tarses, les cuisses antérieures et intermédiaires, et le sommet de l'abdomen roussâtres, le reste des pieds brunâtre, et la suture des élytres d'un roux obscur. Tête et prothorax presque lisses, luisants : celui-ci aussi long que large, rétréci en avant, ’̀ séries dorsales 4-ponctuées. Écusson lisse. Elytres de la longueur du prothorax, assez fortement et assez densement ponctuées; abdomen moins densement.

$\sigma^{*}$ Le $6^{\mathrm{e}}$ arceau ventral sensiblement et largement sinué à son sommet.

\& Le $6^{\mathrm{e}}$ arceau ventral subarrondi au sommet.

Quedius polystigma, Wankow, Ann. Soc. Ent. Fr. 1867, 233, 3. - M MarSeul, l'Abeille, 1871, viII, 284, 245. - Fauvel, Faun. Gallo-Rhén. III, 511, note.

$$
\text { Long., } 0^{\mathrm{m}}, 0066 \text { (3 l.); - larg., } 0^{\mathrm{m}}, 0014 \text { (2/3 l.). }
$$

Patrie. La Lithuanie (collection Pandellé).

OBs. Cette espèce, que nous plaçons ici, se distingue de toute autre par son prothorax à séries dorsales 4-ponctuées. en comptant le point submarginal antérieur. Le postćrieur est plus écarté, et ces séries sont flanquée.s, de chaque côté, d'une autre série triponctuée. Ces caractères doivent en faire l'objet d'une section à part. Quant au reste; elle ressemble beaucoup au $Q$. mesomelinus. 


\section{STAPHYLINIENS. - Quedius}

Le Quedius tenellus d'Erichson (Gen. et Spec. Staph. 551, 42) est s a-1 doute une variété immature de cette espèce.

\section{SOUS-GENRE MICROSAURUS, STEPIIENS,}

Stepuens, III. Brit. V, 433̈. - Quedius, Thouson, Skand. Col, II, 173.

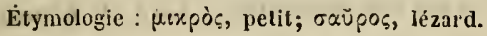

Caractères. Yeux grands, occupant les deux tiers des côtés de lı tête. Labre entier ou presque entier, subarrondi à son bord antérieur. Le dernier article des palpes maxillaires à peine plus long que le précédent, fusiforme ou conico-fusiforme. Cuisses antérieures finement, les intermédiaires faiblement spinosules en dessous ; les postérieures simplement pubescentes ou ciliées. Tibias antérieurs courts, assez robustes. Le $1^{\mathrm{er}}$ article des tarses postérieur's subégal ou à peine égal au dernier. Abdomen à peine atténué tout à fait en arrière. Prosternum relevé en faitte ou en carène obtuse. Corps subparallèle.

OBs. Dans ce sous-genre, le corps, de grande taille, est plus paraillèle, plus allongé, un peu moins déprimé que dans les autres.

Il renferme un petit nombre d'espèces, dont nous esquisserons les caractères ainsi qu'il suit :

a. Ecusson lisse. Front 4-ponctué entre les yeux, sans compter les points juxta-oculaires. Antennes à premiers articles maculés d'obscur en dessus. Abdomen subirisé. . . . . . . . poliginosus.

aa. Écusson ponctué.

b. Front 6-ponctué entre les yeux, sans compter les points juxtaoculaires. Antennes immaculées. Abdomen fortement irisé. :

bb. Front imponctué sur son milieu, offrant seulement les 2 points juxta-oculaires.

c. Antennes immaculées. Élytres sensiblement plús courtes que le prothorax, noires ou souvent d'un rouge brun. $A b$ domen fortement irisé. . . . . . . . . . . .

TRISTIS.

cc. Antennes ou entièrement noires, ou rousses avec les premiers articles un peu rembrunis. Abdomen à peine irisé.

d. Elytres beaucoup plus courtes que le prothorax. Palpcs, extrémité des antennes, tibias et tarses d'un roux de poix.

MOLOCHINUS

dd. Elytrcs environ de la longueur du prothorax. Palpes, antennes et pieds obscurs ou noirâtres.

MACULICORNIS.

UNICOLOR. 


\section{Quedius (mierosaurus) fuliginosus, Gravenhorst.}

Allongé, subconvexe, finement pubescent, d'un noir assez brillant, avec les antennes d'un roux ferrugineux et les palpes plus clairs, les pieds d'un noir de poix et les tarses roussâtres. Tête et prothorax presque lisses, luisants : celui-ci aussi long que large, subrétréci en avant. Front 4-ponctué entre les yeux. Écusson lisse. Élytres et abdomen assez finement it densement ponctués : ce dernier un peu moins densement en arrière, subirisé.

$\sigma^{7}$ Le $6^{\text {e }}$ arceau ventral fortement sinué dans le milieu de son bord apical, avec une forte impression triangulaire, lisse, au devant du sinus. Le $5^{\mathrm{e}}$ à peine sinué dans le milieu de son bord postérieur, avec une large impression lisse au devant du sinus.

Le $6^{\mathrm{e}}$ arceau ventral subogivalement arrondi à son bord postérieur. Le $5^{\text {e }}$ simple.

Staphylinus fuliginosus, Gravenhorst, Micr. 34, $49 ;$ - Mon. 48, 10.-Latreille.

Hist. Nat. Crust. et Ins. IX, 319, 56 .

Staphylinus tristis, Gyllenhal, Ins. Suec. II, 301, 19. - Mannerheim, Brach.

25, 26. - RUNDE, Brach. Hall. 5, 20.

Philonthus tristis, Nordmann, Symb. 75, 4 .

Quedius fuliginosus, Erichson, Col. March. I, 490, 9; - Gen. et Spec. Staph. 537,

20. - Fairmaire et Laboulbène, Faun. Ent. Fr. I, 339, 17. - KraAtz, Ins. Deut.

II, 503, 14. - Thomson, Skand. Col. II, 173, 2. - Fauvel, Faun. Gallo-Rhén. III, $515,23$.

Philonthus fuliginosus, Redtenbacher, Faun. Austr. 710, 59. - Heer, Faun. Col. Helv. I, 276, 66 .

$$
\text { Long., } 0^{\mathrm{m}}, 0102 \text { (4 2/3 l.); - larg., } 0^{\mathrm{m}}, 0027 \text { (1 } 1 / 4 \text { l.). }
$$

Corps allongé, peu convexe, d'un noir assez brillant; revêtu sur les élytres et l'abdomen d'une fine pubescence grisâtre et modérément serrée.

Tète suborbiculaire ou brièvement ovalaire, un peu moins large que le prothorax; d'un noir luisant; presque lisse; avec une série de petits points râpeux, sur les tempes ; parée, de chaque côté, de 7 ou 8 gros pores sétifères, le $1{ }^{\text {er }}$ situé au dessus de l'insertion des antennes, les autres disposés tout autour des yeux. Front large, à peine convexe, inarqué de 
chaque côté, entre les yeux, outre ceux sus-indiqués, de 2 petits pores, à soie courte, transversalement rapprochés 2 à 2 , et, sur le vertex, de 2 autres pores semblables, à peine plus gros, subobliquement rapprochés 2 à 2, parfois confondus, rarement nuls. Cou presque lisse, glabre. Épistome à bordure nembraneuse pâle. Labre noir, fortement sétosıllé en avant. Parties de la bouche d'un roux testacé, avec les mandibul's d'un noir de poix.

Yeux grands, ovales, obscurs, parfois livides.

Antennes moins longues que la tête et le prothorax réunis; à peine épaissies; finement duveteuses et distinctement pilosellées; d'un roux ferrugineux, avec le $1^{\mathrm{er}}$ article parfois moins foncé, souvent taché d'obscur sur le dos, ainsi que les 2 suivants; le $1^{\mathrm{er}}$ en massue allongée : les $2^{\mathrm{e}}$ et $3^{\mathrm{e}}$ obconiques : le $2^{\mathrm{e}}$ oblong : le $3^{\mathrm{e}}$ suballongé, d'un tiers plus long que le précédent : les suivants graduellement un peu plus courts, brièvement pédicellés, subcylindrico-coniques : les $4^{\mathrm{e}}$ à $8^{\mathrm{e}}$ oblongs ou suboblongs : les $9^{\text {e }}$ et $10^{\text {e }}$ à peine oblongs : le dernier ovale-oblong, obliquement acuminé au sommet.

Prothorax environ aussi long que large; subrétréci en avant, aussi large ou même un peu plus large en arrière que les élytres; largement Ironqué ou à peine échancré an sommet, avec les angles antérieurs subinfléchis, presque droits mais subémoussés; subarqué sur les côtés, larrgement arrondi à la base ainsi qu'anx angles postérieurs ; assez convexe ; légèrement el sérialement sétosellé sur les côtés; entièrement d'un noir presque lisse et luisant ; marqué sur la parie antérieure du dos de 2 séries composées de 3 pores médiocres et subégalement distants, et de 3 autres semblables, situés en dehors de ceux-ci, vers le $1^{\text {er }}$ quart, le $1^{\text {er }}$ ordinairement solitaire, les 2 autres rapprochés, placés près du rebord latéral, et dont le plus en arrière, plus gros, porte la longue soie latérale.

Écusson glabre, lisse, d'un noir brillant.

Élytres Iransverses, à peine aussi longues que le prothorax, subdéprimies ou à peine convexes; à suture un peu relevée; assez finement, râpeusement et densement ponctuées; ciliées-spinosulées à leur bord apical; d'un noir assez brillant, avec une fine pubescence grisâtre et modérément serrée, et quelques soies redressées sur les côtés, celle des épaules et la suivante beaucoup plus longues. Épaules cachées.

Abdomen allongé, à peine moins large à sa base que les élytres; faiblement atténué en alrière, après son milieu; assez convexe sur le dos, avec les 3 premiers segments à peine impressionnés en travers ì leur 
base; éparsement et assez longucurnt sétosellé; assez finement et presque aussi densement ponctué que les ėlytres, néanmoins un peu moins densement en arrière ; d'un noir assez brillant et subirisé; à pubescence fine et modérément serrée. Le $6^{\circ}$ segment à peine arrondi au sommet.

Dessous du corps subaspèrement ponctué, pubescent, d'un noir brillant, avec le ventre subirisé. Dessous de la tête presque lisse, éparsement pubescent. Prosternum presque lisse, longitudinalement relevé en faîte. Mésosternum presque lisse, sétosellé vers sa pointe. Métasternum subdéprimé, avec 2 longues soies écartées en arrière, à lobe postérieur d'un roux de poix. Ventre convexe, éparsement sétosellé, à $2^{\circ}$ arceau basilaire prolongé sur le $1^{\text {er }}$ normal en angle obtus et arrondi.

Pieds râpeusement pointillés, pubescents, d'un noir de poix, avec les tarses, souvent les genoux, parfois les tibias antérieurs, roussâtres. Cuissës antérieures finement et densement spinosules en dessous de leur dernière moitié ; les postérieures plus allongées, moins élargies. Tibias antérieurs assez forts, à peine épineux. Tarses antérieurs à 4 premiers articles fortement dilatés, graduellement moins $d u 2^{\mathrm{e}}$ au $4^{\mathrm{e}}$; les postérieurs à $1^{\mathrm{er}}$ article allongé, subégal aux 2 suivants réunis, presque égal au dernier : les $2^{\mathrm{e}}$ à $4^{\mathrm{e}}$ graduellement plus courts.

Patrie. Cette espèce habite parmi les mousses, les détritus, les feuilles mortes et les vieux fagots, dans diverses localités de la France : la Normandie, l'Auvergne, le Beaujolais, les environs de Lyon, les Alpes, la Provence, les Landes, les Pyrénées, etc. Elle est peu commune.

OBs. Cette espèce et les 4 suivantes forment comme un groupe à part, distinct par le labre subarrondi en avant, presque entier ou avec une légère striole sur le milieu de son bord antérieur.

Chéz les exemplaires non complétement adultes, les pieds antérieurs sont entièrement roux, et les intersections ventrales d'un roux de poix foncé. Quelquefois mẻme, les élytres sont brunâtres avec la suture plus claire, et tous les pieds roux.

Cette espèce répond peut-être aux dilatatus Marsham (Ent. Brit. 504), gracilis et picicornis Stephens (Ill. Brit. V, 215), et granulipennis Iotschusky (Bul. Mosc. 1858, II, 656).

24. Quedius (MLicrosanrus) tristis, GravenhoRst.

Allongé, subconvexe, finement pubescent, d'un noir assez brillant, 


\section{STAPHYLINIENS. - Quedius}

avec les antennes et les palpes roux, les pieds d'un noir de poix et les tarses moins foncés. Tête et prothorax presque lisses, luisants : celui-ci aussi long que large, rétréci en avant. Front 6-ponctué entre les yeux. Écusson ponctué. Élytres et abdomen assez finement et densement poncués: celui-ci fortement irisé.

$\sigma^{7}$ Le $6^{\mathrm{e}}$ arcean ventral assez fortement et angulairement sinué dans le milieu de son bord apical, avec une large impression subogivale lisse

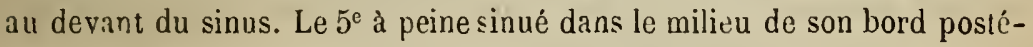
rieur, avec une large et faible dépression lisse au devant du sinus.

으 $6^{\mathrm{e}}$ arceau ventral subogivalement arrondi à son bord postérieur. Le $5^{\mathrm{e}}$ simple.

Staphylinus tristis, Gravenhonst, Micr. 34, 48; - Mon. 48, 11.-Latreille, Hist. Nat. Crust. et Ins. IX, 319, $\mathbf{5}$.

Philonthus frontalis, Nordmann, Symb. 76, 5 .

Emus tristis, Boisduyal et Lacordaire, Faun. Ent. Par. I, 376, 27.

Quedius frontalis, Ericuson, Gen. et Spec. Staph. 536, 19. - Fairmaire et LaboulBÈNe, Faun. Ent. Fr. I, 536, 7.

Philonthus tristis, Redtenbacher, Faun. Austr. 709, 5.

Quedius tristis, KraATz, Ins. Deut. II, 502, 13. - JaCQUelin du VAL, Glan, Ent. I, 5:), note 5. - Fauvel, Faun. Galio-Rhén. III, 315, 22.

Variétć $a$. Pieds entièrement d'un roux ferrugineux. Élytres brunâtres.

$$
\text { Long., 0m,011 (5 l.); - larg., 0n,0028 (1 1/3 l.). }
$$

Corps allongé, subconvexe, d'un noir assez brillant; revêtu sur les élytres et l'abdomen d'une fine pubescence grisâtre et assez serrée.

Tête brièvement ovalaire, un peu ou même sensiblement moins large que le prothorax; d'un noir luisant; presque lisse, avec une série de petits points rápeux et confluents, sur les tempes; parée de chaque côté de 7 gros pores sétifères, le $1^{\text {er }}$ situé au dessus de l'insertion des antennes, les autres tout autour des yeux. Front large, marqué de chaque côté, entre ceux-ci, outre ceux sus-indiqués, d'un groupe composé de 3 petits pores à soie courte, dont l'interne plus en arrière; d'un autre semblable nais isolé, parfois nul, au niveau du bord postérieur de l'oeil; de 2 autres, subobliquement rapprochés, de chaque côté du vertex. Cou presque lisse, glabre. Épistome à bordure submembraneuse souvent obscure. Labre noir, fortement sétosellé en avant. Parties de la bùche rousses, avec les mandibules d'un noir de poix.

BR. 
Yeux grands, ovales, obscurs, souvent livides.

Antennes moins longues que la lête et le prothorax réunis; subfiliformes ou à peine épaissies ; finement duveteuses et éparsement pilosellées ; rousses, avec l'extrémité un peu rembrunie; à $1^{\text {er }}$ article en massue allongée : les $2^{\mathrm{e}}$ et $3^{\mathrm{e}}$ obconiques : le $2^{\mathrm{e}}$ oblong $:$ le $3^{\mathrm{e}}$ suballongé, d'un tiers plus long que le $2^{\mathrm{e}}$ : les suivants graduellement un peu plus courts, brièvement pédicellés : les $4^{\mathrm{e}}$ à $7^{\mathrm{e}}$ oblongs, subcylindrico-coniques : les pénultièmes suboblongs : le dernier subovale, obliquement subéchancré au bout et subacuminé inférieurement.

Prothorax environ aussi long que large (1), plus ou moins rétréci en avant; aussi large ou même un peu plus large en arrière que les élytres; très-largement ou à peine échancré au sommet, avec les angles antérieurs subinfléchis, presque droils mais subarrondis; subarqué sur les côtés; arrondi à la base ainsi qu'aux angles postérieurs; assez convexe sur son disque; sérialement sétosellé sur les côtés; d'un noir presqué lisse et luisant; marqué sur la partie antérieure du dos de 2 séries composées de 3 pores médiocres et subégalement distants, plus, de 2 ou 3 autres pores semblables en dehors de ceux-ci, et disposés sur une ligne transversale ou arquée, et de 2 autres, obliquement rapprochés, près des angles antérieurs, et dont le plus en arrière, plus gros, porte la longue soie latérale.

Ecusson pubescent, finement chagriné, épariement ponctué, d'un noir assez brillant.

Élytres transverses, de la longueur du prothorax ou à peine plus longues; subdéprimées ou à peine convexes; assez fỉnement, râpeusement, densement ou même très-densement ponctuées ; ciliées-spinosulées à leur bord apical ; d'un noir assez brillant, avec une fine pubescence grisâtre et assez serrée, et quelques légères soies redressées sur les côtés, dont 1 notamment plus longue, vers le tiers antérieur. Épaules plus ou moins cachées.

Abdomen allongé, un peu moins large à sa base que les élytres; faiblement atténué en arrière après son milieu; convexe sur le dos, avec les 3 premiers segments non ou à peine impressionnés en travers à leur base ; éparsement et assez longuement sétosellé; assez finement, subrâpeusement et densement ponctué ; d'un noir assez brillant et irisé ; à pubes-

(1) Le prothorax, étant rétréci en avant, paraît parfois un peu plus long que large, mais, en réalité, it n'est pas plus long dans son milieu que large à sa base. 
cence fine et serrée, un peu moins évidente que celle des élytres. Le $6^{\mathrm{e}}$ segment subtronqué ou à peine arrondi au sommet.

Dessous du corps aspèrement ponctué, pubescent, d'un noir brillant. avec le ventre plus ou moins irisé. Dessous de la tête presque glabre, presque lisse ou avec quelques rares points à la base et sur les côtés. Prosternum presque lisse, parfois brunâtre, relevé en faîte sur sa ligne inédiane. Mésosternum presque lisse, sétosellé vers son sommet. Métasternum subdéprimé, offrant en arrière 2 soies écartées, à lobe postérieur d'un roux de poix. Ventre convexe, assez fortement sétosellé, à $2^{\mathrm{e}}$ arceau basilaire prolongé sur le $1^{\text {er }}$ normal en forme d'arc.

Pieds râpeusement pointillés, pubescents, d'un noir de poix, avec les tarses, souvent les genoux et parfois les tibias antérieurs moins foncés ou roussâtres. Cuisses antérieures finement spinosules $r$ dessous vers leur extrémité ; les postérieures plus allongées, moins épaisses. Tibias antérieurs assez forts, simplement pubescents. Tarses antérieurs à 4 premiers articles fortement dilatés, graduellement moins du $2^{\mathrm{e}}$ au $4^{\mathrm{e}}$; les postérieurs à $1^{\text {er }}$ article allongé, subégal aux 2 suivants réunis, presque égal au dernier : les $2^{\mathrm{e}} \mathrm{à} 4^{\mathrm{e}}$ graduellement moins longs.

Patrie. Celte espèce est commune dans presque toute la France, parmi les détritus végétaux et les matières animales à moitié desséchées. Elle est très-répandue dans les environs des Lyon.

Oвs. Elle est distincte du fuliginosus par son écusson ponctué ; par son front paré entre les yeux de 6 points au lieu de 4 , sans compter le pore juxta-oculaire; par.ses élytres un peu moins courtes; par son abdomen plus irisé, plus densement ponctué en arrière, etc.

Quelquefois les antennes sont entièrement d'un roux testacé ainsi que les palpes, et les pieds antérieurs sont roux avec leurs tarses plus clairs. Rarement, le sommet de l'abdomen, tant en dessus qu'en dessous, est d'un roux brunâtre.

Celte espèce varie aussi beaucoup pour la taille. Nous avons vu un exemplaire moindre, dont tous les pieds sont d'un roux ferrugineux et uniforme.

On doit sans doute rapporter au tristis le laevicollis de Brullé (Exp. Sc. Mor. III, 131). 


\section{Quedius (Microsaurus) molochinus, Gravenhorst.}

Allongé, subconvexe, finement pubescent, d'un noir brillant, avec les palpes roux, les antennes et les pieds d'un roux de poix. Tête et prothorax presque lisses, luisants : celui-ci aussi long que large, subrétréci en avant. Écusson pointille. Elytres plus courtes que le prothorax, finement et densement ponctuées ainsi que l'abdomen : celui-ci fortement irisé.

$\sigma$ Le $6^{\text {e }}$ arceau ventral largement, fortement et subangulairement sinué dans le milieu de sun bord apical, avec une impression triangulaire, suboblongue, lisse, au devant du sinus. Le $5^{\mathrm{e}}$ plus étroitement et moins fortement sinué dans le milieu de son bord postérieur, avec une impression lisse, au devant du sinus, prolongée parfois en un espace allongé lisse jusque près de sa moitié. Le $4^{\mathrm{e}}$ avec un espace lisse vers son sommet (1).

\& Le $6^{\mathrm{e}}$ arceau ventral subarrondi au sommet. Les $4^{\mathrm{e}}$ et $5^{\mathrm{e}}$ simples.

Staphylinus molochinus, Gravenhorst, Mon. 46, 6. - Grllenhad, Ins. Suec. II, 302, 20. - ManNerheim, Brach. 25, 28. - Runde, Brach. Hal. 5, 21. Staphylinus laticollis, Gravenhorst, Micr. 173, 28 ;-Mon. 47, 8.

Staphylinus picipennis, Paykull, Faun. Suec. III, 373, 8.

Staphylinus laevicollis, hunde, Brach. Hal. 6, 24.

Philouthus molochinus, Nordmann, Symb. 76, 6. - Redtenbacher. Faun. Austr. 709, 53. - HEER, Faun. Col. Helv. I, 276, 63.

Emus molochinus, Borsduval et LacordarRe, Faun. Ent. Par. I, 377, 28.

Quedius molochinus, Ericason, Col. March. I, 489, 8 ; - Gen. et Spec. Staph. 535, 18. - Fairmaire et Larollbène, Faun. Ent. Fr. I, 537, 8. - Kraatz, Ins. Deut. II, 500, 12. - Thomson, Skand. Col. II, 173, 1. - Fauvec, Faun. GalloRhén. III, $516,24$.

Quedius simplicifrons, Fatruaire, Ann. Soc. Ent. Fr. 1861. 580.

Variété $a$. Élytres châtaines ou d'un rouge brun.

$$
\text { Long., } 0^{\mathrm{m}}, 0099 \text { (4 1/2 l.); - larg., } 0^{\mathrm{m}}, 0012 \text { (1 l.). }
$$

Corps allongé, subconvexe, d'un noir brillant; revêtu sur les élytres et l'abdomen d'une fine pubescence cendrée et serrée.

(1) Le $3^{e}$ offre, mais rarement, un espace lisse à peine scnsible vers le milieu de son bord postérieur. 
Tête subovalaire, moins large que le prothorax; très-éparsement et longuement sétosellée sur les côtés; d'un noir luisant; presque lisse ; marquée de chaque côté d'un gros point sur les tempes, et de $\mathbf{3}$ autres, plus en dedans, disposés en série longitudinale arquée et dont l'intermédiaire plus gros. Front large, subconvexe, avec 1 seul point juxtaoculaire, gros. Cou presque lisse, glabre, luisant. Épistome à bord antérieur subcorné, d'un brun souvent roussâtre. Labre entier, d'un noir de poix, fortement sétosellé en avant. Mandibules obscures. Palpes roux.

Yeux grands, subovales, peu saillants, obscurs, lavés de livide.

Antennes médiocres, un peu plus longues que la tête; assez grêles, subfiliformes; finement duveteuses et légèrement pilosellées; entièrement rousses; à $1^{\text {er }}$ article en massue allongée : les $2^{\mathrm{e}}$ et $3^{\mathrm{e}}$ obconiques : le $3^{\mathrm{e}}$ suballongé, plus long que le $2^{\mathrm{e}}$ : les suivants graduellement un peu plus courts, nullement contigus : les $4^{\mathrm{e}} \mathrm{a} 6^{\mathrm{e}}$ oblongs, cylindriques : les pénultièmes suboblongs, subobconiques : le dernier subovalaire, obliquement tronqué au sommet et acuminé inférinurement.

Prothorax aussi long que large, subrétréci en avant; aussi large ou même un peu plus large que les élytres; largement et à peine subéchancré au sommet, avec les angles antérieurs infléchis, presque droits mais subarrondis; subarqué sur les côtés ; arrondi à sa base ainsi qu'aux angles postérieurs; assez convexe sur son disque; légèrement sétosellé sur les côtés, avec le gros pore sétifère latéral situé loin de la marge ; d'un noir luisant; presque lisse ; marqué en avant de 2 séries dorsales composées de 3 points médiocres, dont l'intérieur submarginal, parfois plus écarté, et, de chaque côté, de 2 points semblables, sans compter les marginaux et le gros pore sétifère.

Écusson pubescent, pointillé, d'un noir brillant.

Elytres transverses, subparallèles, plus courtes que le prothorax; subdéprimées ou à peine convexes; finement, densement et râpeusement ponetuécs; d'un noir ou d'un brun châtain assez brillant; ciliées-spinosulées à leur bord apical; densement pulsescentes sur leur disque, avec quelques soies redressées sur les côlés, dont 1 notamment plus longue, vers le tiers antérieur. Épaules cachées.

Abdomen allongé, à peine moins large que les élytres, à peine atténué vers son sommet; convexe sur le dos, avec les 3 premiers segments à peine impressionnés en ıravers à leur base ; éparsement sétosellé; finement, des.sement et subrâpensement ponctué, avec le $2^{\mathrm{e}}$ segment basilaire parfois découvert, presque lisse; d'un noir assez brillant et fortement irisé; à pu- 
besceuce tine, assez longue et strrée. Le $6^{\text {e }}$ segment subarrondi au sommet. : Dessous du corps assez densement et aspèrement ponctué, assez densement pubescent, d'un noir brillant, avec le repli du prothorax et le prosternum plus ou moins roux. Dessous de la tête presque lisse, presque glabre. Prosternum presque lisse, subcaréné. Mésosternum rugueux et sétosellé vers son sommet. Métasternum subdéprimé, finement canaliculè en arrière sur sa ligne médiane. Ventre convexe, égarsement sétosellé, fortement irisé, avec la marge apicale des premiers arceaux parfois d'un roux châtain ; à $2^{\mathrm{e}}$ arceau basilaire prolongé sur le $1^{\mathrm{er}}$ normal en angle obtus et subarrondi.

Pieds aspèrement ponctués, pubescents, d'un roux de. poix, avec les hanches intermédiaires et postérieures plus foncées, ainsi que parfois les cuisses postérieures. Cuisses antérieures spinosules en dessous, les postérieures moins épaisses, plus allongées. Tibias antérieurs assez forts, simplement pubescents. Tarses antérieurs à 4 premiers articles très-fortement dilatés, graduellement moins du $2^{\mathrm{e}}$ au $4^{\mathrm{e}}$; les postérieurs à $1^{\mathrm{er}}$ article allongè, subégal au dernier, au moins égal aux 2 suivants réunis : les $2^{\mathrm{e}}$ à $4^{\mathrm{e}}$ oblongs, graduellement moins longs.

Patrie. Cette espèce se trouve assez communément, dès le premier printemps, sous les détritus dans les prés humides et les lieux marécageux, dans presque toute la France.

Obs. Elle se distingue du fuliginosus par son écusson ponctué, du tristis par son front pourvu seulement du point juxta-oculaire normal, de l'un et l'autre par ses élytres plus courtes, par sa forme un peu plus étroite.

Les élytres passent du noir au brun châtain, au rouge brun et mème, chez les immatures, au roux testacé, avec les antennes et les pieds d'une couleur plus claire.

Les variétés à élytres tout à fait noires sont plutôt méridionales.

On peut rapporter au molochinus les denudatus et Lathburi de Stephens (Ill. Brit. V, 216 et 218).

26. Quedius (Microsanrus) macnlicornis, Mulsant el ReY.

Allongé, subconvexe, finement pubescent, d'un noir brillant, avec les antennes ferrugineuses, à premier's articles maculés de noir, les palpes, les tibias et les tarses d'un roux de poix. Tête et prothorax lisses, luisants : 
celui-ci aussi long que large, subrétréci en avant. Écusson pointillé. Elytres beaucoup plus courtes que le prothorax, assez finement et densement ponctuées; abdomen plus finement ponctué, moins densement en arrière, à peine irisé.

$\sigma^{*}$ Le $6^{e}$ arcean ventral profondément sinué à son bord apical en angle parfois subarrondi au sommet, avec une impression subogivale lisse au devant du sinus. Le $5^{\mathrm{e}}$ sensiblement, assez largement et subangulairement sinué dans le milieu de son bord postérieur, avec une courte impression au devant du sinus, précédée d'un espace triangulaire allongé, lisse, prolongé jusque près de la base. Le $4^{\mathrm{e}}$ avec un assez large espace lisse, prolongé jusque près de la base. Le $3^{\mathrm{e}}$ avec un étroit espace lisse, étendu jusque près de la base. Le bord des sinus des $5^{\text {e }}$ et $6^{\text {e }}$ subpellucide, avec toutes les impressions et espaces lisses bordés de chaque côté de soies assez raides et subredressées.

오 Le $6^{\mathrm{e}}$ arceau ventral subarrondi au sommet. Les $3^{\mathrm{e}}$ à $5^{\mathrm{e}}$ simples.

$$
\text { Long., } 0^{\mathrm{m}}, 0098 \text { (4 1/2 l.); - larg., } 0^{\mathrm{m}}, 0022 \text { (1 l.). }
$$

Corps allongé, subconvexe, d'un noir brillant; revêtu sur les élytres et l'abdomen d'une fine pubescence d'un gris obscur et assez serrée.

Tête brièvement ovalaire, un peu moins large que le prothorax; très-éparsement et longuement sétosellée sur les côtés; d'un noir luisant; lisse; marquée de chaque côté d'un gros point sur les tempes, et de 3 autres, plus en dedans, disposés en série longitudinale arquée, et dont celui du veriex un peu moindre. Front large, subconvexe, avec 1 seul point juxta-oculaire assez gros. Cou subconvexe, glabre, lisse, luisart. Epistome subcorné, d'un brun parfois livide. Labre entier, d'un noir de poix, fortement sétosellé en avant. Mandibules obscures. Palpes d'un roux de poix, souvent assez clair.

Yeux grands, subovales, peu saillants, noirs, lavés de gris.

Antennes médiocr @s, sensiblement plus longues que la tête; grêles, subfiliformes; finement duveteuses et distinctement pilosellées; d'un roux ferrugineux, avec les dernier et $1^{\mathrm{er}}$ articles un peu plus clairs, celui-ci et surtout les 3 suivants plus ou moins maculés d'obscur en dessous: le $1^{\text {er }}$ en mascue allongée : les $2^{\text {e }}$ et $3^{\mathrm{e}}$ obconiques : le $3^{\mathrm{e}}$ assez allongé, plus long que le $2^{\text {e }}$ : les suivants graduellement un peu plus courts, non contigus 
et brièvement pédicelıés : les $4^{\mathrm{e}}$ à $6^{\mathrm{e}}$ oblongs, cylindriques : les pénultièmes un peu moins longs, obconico-subcylindriques : le dernier ovaleoblong, obliquement tronqué au sommet et acuminé inférieurement.

Prothorax aussi long que large, subrétréci en avant; un peu plus large que les élytres; largement subéchancré au sommet, avec les angles antérieurs infléchis, presque droits mais arrondis ; subarqué sur les côtés; subarrondi à sa base ainsi qu'aux angles postérieurs ; médiocrement convexe sur le disque; légèrement sétosellé sur les côtés, avec le gros pore sétifère latéral situé assez loin de la marge; d'un noir luisant; lisse; marqué en avant de 2 séries dorsales composées de 3 points assez forts et subégalement distants, et, de chaque côté, de 2 points plus petits, l'un près de la marge antérieure et faisant parfois défaut, l'autre près de la marge latérale, un peu en avant du gros pore sétifère, sans compter les marginaux.

Écusson pubescent et pointillé en arrière, d'un noir brillant.

Élytres fortement transverses, d'un tiers plus courtes que le prothorax; subdéprimées ou à peine convexes; assez finement, densement et râpeusement ponctuées; d'un noir brillant; ciliées-spinosulées à leur bord apical; assez densement pubescentes sur leur disque, avec 1 longue soie redressée vers le tiers antérieur des côtés. Épaules cachées.

Abdomen allongé, à peine moins large que les élytres, à peine atténué tout à fait vers son sommet; convexe sur le dos, avec les 3 premiers segments non ou à peine impressionnés en travers à leur base; trèséparsement sétosellé; finement et densement pointillé, moins densement sur les $5^{\mathrm{e}}$ et $6^{\mathrm{e}}$ segments, presque lisse sur le $2^{\mathrm{e}}$ basilaire qui est souvent découvert; d'un noir assez brillant, non ou à peine irisé; à pubescence fine et assez serrée. Le $6^{\mathrm{e}}$ segment subarrondi au sommet.

Dessous du corps aspèrement ponctué, finement pubescent, d'un noir brillant. Dessous de la tête presque lisse, presque glabre. Prosternum souvent d'un roux de poix, simplement et obtusément relevé en faite. Mésosternum ruguenx et sétosellé vers son sommet. Métasternum subdéprimé, à lobe postérieur d'un brun de poix. Ventre convexe, éparsement sétosellé, non irisé, à $2^{\text {e }}$ arceau basilaire prolongé sur le $1^{\text {er }}$ normal en angle très-obtus et largement arrondi.

Pieds aspèrement pointillés, finement pubescents, brunâtres, avec les tibias et les tarses et souvent les trochanters antérieurs et intermédiaires d'un roux de poix. Cuisses antérieures finement spinosules en dessous; les postérieures moins épaisses, plus allongées. Tibias antérieurs assez ro- 
bustes, simplement pubescents. Tarses antérieurs à 4 premiers articles très-fortement dilatés, graduellement un peu moins $d u 2^{e}$ au $4^{\mathrm{e}}$; les postérieurs à $1^{\text {er }}$ article allongé, subégal au dernier, au moins égal aux 2 suivants réunis : les $2^{\mathrm{e}} \mathrm{à} 4^{\mathrm{e}}$ graduellement moins longs.

Patrie. Cette espèce, qui est rare, se trouve, en juillet et août, parmi les mousses humides et les feuilles tombées, dans les montagnes du Lyonnais, à la Grande-Chartreuse, dans les Pyrénées, etc.

OBs. Cette espèce a, comme le fuliginosus, les premiers articles des antennes plus ou moins tachés d'obscur sur le dos ; mais elle est moindre, plus étroite; l'écusson est visiblement pointillé, et le front n'est pourvu, entre les yeux, que des seuls points juxta-oculaires.

Elle est aussi étroite mais un peu moins allongée que le molochinus auquel elle ressemble beaucoup. Elle est plus noire, plus brillante, avec la base des antennes et surtout les cuisses plus obscures. La tête est un peu plus grosse; le point interne des côtés du disque du prothorax est plus petit, parfois nul, situé plus près de la marge antérieure; les élytres sont encore plus courtes et un peu moins finement ponctuées; l'abdomen, à peine plus finement et à peine plus densement pointillé, n'est pas visiblement irisé, et il semble un peu plus parallèle, etc.

Du reste, elle diffère des 3 précédentes espèces par ses distinctions masculines.

\section{2\%. Quedius (Ficroaurus) anieolor, KIESENIVETTER}

Allongé, subconvexe, finement pubescent, d'un noir brillant, avec les palpes et les tarses brunâtres. Tête et prothorax lisses, luisants : celui-ci subtransverse, rétréci en avant. Écusson éparsement pointillé. Élytres de la longueur du prothorax, assez finement, assez densement et rugueusement ponctuées. Abdomen assez finement, densement et subuniformément ponctué, à peine irisé.

$\sigma^{7}$ Le $6^{\text {e }}$ arceau ventral profondément échancré en hémicycle ou en angle à son sommet, avec une impression tringulaire, oblongue, lisse

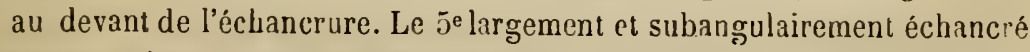
dans le milieu de son bord postérieur, avec un espace triangulaire, sub- 
déprimé, lisse, au devant de l'échancrure. Le $4^{\mathrm{e}}$ avec un espace triangulaire, oblong, subdéprimé, lisse, au milieu de sa partie postérieure.

q Le $6^{\mathrm{e}}$ arceau ventral subarrondi au somme!, les $4^{\mathrm{e}}$ et $5^{\mathrm{e}}$ simples.

Quedius unicolor, Kiesenwetrer, Stett. Ent. Zeit. 1847, 75.- FaIRMarRe et Laboulbène, Faun. Ent. Fr. I, 536, 6. - KraAtz, Ins. Deut. II, 504, 15. - FadveL, Faun. Gallo-Rhén. III, 517, 25.

Philonthus unicolor, Redtenbacher, Faun. Austr. 825.

$$
\text { Long., } 0^{\mathrm{m}}, 0096 \text { (4 1/3 l.); - larg., } 0^{\mathrm{m}}, 0021 \text { (1 l.). }
$$

Corps allongé, subconvexe, d'un noir brillant; revêtu sur les élytres et l'abdomen d'une fine pubescence d'un gris obscur et peu serrée.

Tête subarrondie, moins large que le prothorax; très-éparsement et longuement sétosellée sur les côtés ; d'un noir luisant ; lisse ; marquée de chaque côté, d'un gros point sétifère sur les tempes, et, entre le bord postéro-interne de l'œil et le cou, de 2 autres points, subobliquement disposés, et dont l'antérieur beaucoup plus gros. Front large, subconvexe, à point juxta-oculaire assez fort (1). Cou glabre, lisse, luisant. Épistome vertical, subcorné, brunâtre. Labre entier, d'un noir brillant, fortement sétosellé en avant. Mandibules noires. Palpes brunâtres ou d'un noir de poix, avec leur base moins foncée.

Yeux grands, subovales, peu saillants, obscurs.

Antennes assez courtes, un peu plus longues que la tête; subfiliformes, finement duveteuses et légèrement pilosellées; noires, avec l'intersection des premiers articles d'un roux de poix; le $1^{\text {er }}$ en massue allongée : le $2^{\mathrm{e}}$ oblong, obconique : le $3^{\mathrm{e}}$ suballongé, obconique, plus long que le $2^{\mathrm{e}}$ : les suivants graduellement un peu plus courts, non contigus, subobconiques : les $4^{\mathrm{e}} \mathrm{à} 7^{\mathrm{e}} \mathrm{à} \mathrm{peine} \mathrm{oblongs} \mathrm{:} \mathrm{les} \mathrm{pénultièmes} \mathrm{à} \mathrm{peine} \mathrm{aussi} \mathrm{larges}$ que longs : le dernier subovale, tronqué au bout et acuminé inférieurement.

Prothorax subtransverse, rétréci en avant, un peu plus large que les élytres; largement subéchancré au sommet, avec les angles antérieurs infléchis, presque droits mais arrondis ; subarqué sur les côtés; subarrondi à sa base ainsi qu'aux angles postérieurs; subconvexe sur son disque; sub-

(1) On aperçoit en arrière, près du bord postéro-interne de chaque œil, au moins un petit point, accidentellement 2 ou 3 petits points. 
déprimé latéralement; sérialement sétosellé sur les côtés, avec le pore sétifère latéral situé loin de la marge, accompagné parfois, en devant, d'un autre point bien moindre; d'un noir luisant, lisse; offrant en avant 2 séries dorsales composées de 3 points médiocres, dont l'antérieur un peu plus distant, et, de chaque côté, un autre point semblable, outre le $1^{\text {er }}$ dorsal et le gros pore sétifère latéral.

Écusson légèrement pubescent, éparsement ponctué, d un noir brillant. Élytres transverses, environ de la longueur du prothorax; subdéprimées ou à peine convexes; subsillonnées le long de li suture; assez finement, assez densement et rugueusement ponctuées ; d'un noir brillant; ciliées-spinosulées à leur bord apical; subéparsement pubescentes sur leur disque, avec quelques ı ares et courtes soies redressées sur les cỏtés et 1 très-longue, vers le tiers antérieur de ceix-ci. Épaules cachées.

Abdomen allongé, un peu moins large que les élytres; à yeine atténué tout à fait vers son sommet; subconvexe sur le dos, avec les 3 premicrs segments à peine impressionnés en travers à leur base; très-éparsement sétosellé ; assez finement et densement ponctué, à peine moins densement en arrière ; presque lisse sur le $2^{\mathrm{e}}$ segment basilaire qui est souvent découvert; d'un noir brillant et à peine irisé ; à pubescence à peine plus serrée que celle des élytres. Le $6^{\text {e }}$ segment à peine arrondi au sommet.

Dessous du corps aspèrement ponctué, pubescent, d'un noir brillant. Dessous de la tête presque glabre, lisse. Prosternum obtusément relevé en faîte. Mésosternum rugueux et cilié vers son sommet. Métasternum subdéprimé. Ventre convexe, éparsement sétosellé, non irisé.

Pieds aspèrement ponctués, pubescents, noirs, avec les tarses d'un brun roussâtre. Cuisses artérieures finement spinosules en dessous; les pastérieures plus grêles, plus allongées. Tibias antérieurs assez robustes, à peine épineux. Tarses antérieurs à 4 premiers articles fortement dilatés, graduellement moins du $2^{\mathrm{e}}$ au $4^{\mathrm{e}}$; les postérieurs à $L^{\mathrm{er}}$ article suballongé, subégal aux 2 suivants réunis, à peine égal au dernier : les $2^{e}$ à $4^{e}$ graduellement plus courts.

Patrie. Cette rare espèce se rencontre en juillet el août, parni les mousses des montagnes, au mont Pilat, dans les Alpes, les Pyrénées, etc.

OBs. Les différences sexuelles de cette espèce sont à peu près les mémes que celles du $Q$. maculicornis. Elle se distingue de celui-ci et du précédent par la couleur foncée des palpes, des antennes et des pieds. 
Les antennes sont un peu moins longues et un peu moins grêles, avec leurs pénultièmes articles plus courts. Le prothorax est un peu plus transverse, plus rétréci en avant. Les élytres, un peu moins courtes, ont leur ponctuation à peine plus forte, à peine moins serrée, etc.

SOUS-GENRE SAURIDUS, MULSANT ET REY.

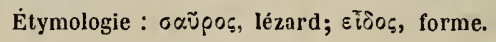

Caractères. Yeux grands, occupant les deux tiers des côtés de la tête. Labre plus ou moins bilobé, ou au moins fendu ou sillonné en avant dans son milieu. Le dernier article des palpes maxillaires fusiforme, conicousiforme ou conique. Cuisses antérieures et souvent les intermédiaires plus ou moins spinosules en dessous; les postérieures généralement mutiques ou simplement ciliées. Tibias antérieurs ordinairement assez grêles ou peu robustes. Le $1^{\text {er }}$ article des tarses postérieurs tantôt plus long, tantôt aussi long, parfois un peu moins long que le dernier. Abdo men plus ou moins atténué en arrière. Prosternum relevé en faite ou plus ou moins caréné sur sa ligne médiane. Corps subfusiforme ou fusiforme.

Le sous-genre Sauridus est assez nombreux en espèces : ce qui nous oblige à en donner deux tableaux :

a. Le 1er article des tarses postérieur's allongé, évidemment plus long que le dernier. Antennes à articles, tous, plus longs que larges. Tête grande ou assez grande, un peu moins large que le prothorax.

b. Tempes assez densement pointillees. Abdomen irisé.

c. Taille grande. Prothorax noir. Elytres rouges.

d. Tarses antérieurs plus $\left(\sigma^{\prime \prime}\right)$ ou moins $(q)$ fortement dilatés. Têle subtransverse. Prothorax subimpressionné sur les côtés. Élytres assez finement ponctuées. Hanches et cuisses postérieures plus ou moins rembrunies. . . . . .

dd. Tarses antéricurs médiocrement $\left(\sigma^{\circ}\right)$ ou légèrement (í) dilatés. Tète subarrondie ou courtement ovalaire. Prothorax non impressionné sur les côtés. Élytres assez finement ponctuées. Hanches et cuissés postérieures non rembrunies. . . . . . . . . . . . . . .

cc. Taille médiocre. Prothorax rembruni sur le disque, roussâtre sur les cotés. Elytres rousses ou rarement brunes, finement

bb Tempes presque lisses ou avec une fine série de petits points. Prothorax et élytres d'un noir de poix : celles-ci médiocrement et assez densement ponctuées. Abdomen à peine irisé. . .

OCHROPTERUS.

FICIPES.

NIGRICEPS. ROBUSTUS. 


\section{Quedius (Sauridus) ochropterus, Erichson.}

Assez allongé, subdéprimé, finement pubescent, d'un noir brillant, avec les palpes, les antennes, les élytres, la marge apicale des segments abdominaux et les pieds roux, les cuisses postérieures un peu rembrunies et le sommet des antennes testacé. Tête et prothorax lisses, luisants: celui-ci à peine transverse, subrétréci en avant, subimpressionné vers les côtés. Écusson lisse. Élytres à peine plus longues que le prothorax, assez fortement et assez densement ponctuées. Abdomen moins densement ponctué en arrière, irisé. Le $1^{\mathrm{er}}$ article des tarses postérieurs évidemment plus long que le dernier.

$\sigma^{7}$ Le $6^{e}$ arceau ventral sensiblement et angulairement sinué dans le milieu de son bord apical, avec une impression triangulaire, lisse, au

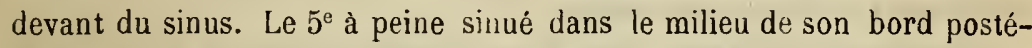
rieur, avec un léger espace lisse au devant du sinus. Tarses antérieurs fortement dilatés.

오 Le $6^{\mathrm{e}}$ arceau ventral arrondi au sommet. Le $5^{\mathrm{e}}$ simple. Tarses antérieur's assez fortement dilatés.

Quedius ochroplerus, Erichson, Gen. et Spec. Staph. 538, 23.- Fairmaire et LA-

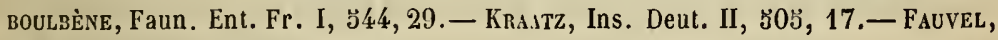
Faun. Gallo-Rhén. III, 517, 26.

Variété a. Élytres plus ou moins rembrunies sur leur disque.

Quedius fimbriatus, var. Kıesenwetter in Kuster, Käf. Ent. XII, 28.

$$
\text { Long., 0m,0094 (4 1/4 1.); - larg., 0 } 0^{\mathrm{m}}, 0014 \text { (1 } 1 / 5 \text { l.). }
$$

Corps assez allongé, subdéprīmé, d'un noir brillant, avec les élytres rougeâtres; revêtu sur celles-ci et l'abdomen d'une fine pubescence grisâlre et peu serrée.

Tête grande, suborbiculairement transverse, un peu moins large que le proihorax; très-éparsement et largement sétosellée sur les côtés; d'un noir luisant et submétallique; lisse ; marquée du chaque côtó, derrièr., les 
yeux, de 3 points sétifères, assez écartés et disposés en triangle : l'externe gros, sur les tempes (1): l'antérieur gros, situé près du bord postérointerne des yeux : l'interıe moindre, sur le vertex. Front très-large, à peine convexe, à point juxta-oculaiı gros, touchant à l'œil. Cou glabre, presque lisse, luisant. Épistome corné, brunâtre. Labre noir, fortement sétosellé en avant. Mandibules obscures. Palpes roux, à dernier article souvent plus foncé, surtout au sommet.

Yeux grands, subovales, médiocrement saillants, noirs, lavés de gris micacé.

Antennes médiocres, plus longues que la tête; grêles, subfiliformes; finement duveteuses et assez fortement pilosellées ; rousses, avec le sommet devenant testacé; à $1^{\mathrm{er}}$ article en massue allongée et à peine arquée : les $2^{\mathrm{e}}$ et $3^{\mathrm{e}}$ obconiques : le $2^{\mathrm{e}}$ suballongé : le $3^{\mathrm{e}}$ allongé, plus long que le $2^{\mathrm{e}}$ : les suivants graduellement un peu plus courts, non contigus, subcylindriques ou subcylindrico-coniques : les $4^{\mathrm{e}}$ à $7^{\mathrm{e}}$ assez longs : les $8^{\mathrm{e}}$ à $10^{\mathrm{e}}$ un peu plus longs que larges ou suboblongs : le dernier ovale-oblong, obliquement acuminé au sommet.

Prothorax à peine transverse, plus ou moins rétréci en avant, largement tronqué au sommet, avec les angles antérieurs subinfléchis, presque droits mais subarrondis; subarqué sur les côtés ; largement arrondi à sa base, à angles postérieurs très-obtus ; légèrement convexe sur son disque; subimpressionné vers les côtés, qui sont éparsement sétosellés, avec le gros pore sétifère latéral situé loin de la marge; d'un noir luisant et submétallique; lisse ; marqué en avant de 2 séries dorsâles composcees de 3 points assez forts et subégalement distants ; et, de chaque côté, de 2 autres points écartés et disposés sur une ligne longitudinale à peine oblique, dont le postérieur moindre el faisant parfois défaut, sans compter les marginaux et le gros pore sétifère latéral.

Écusson glabre, lisse, d'un noir de poix luisant.

'Élytres subtransverses, à peine plus larges en arrière qu'en avant; à peine ou non plus longues que le prothorax; subdéprimées; assez fortement, assez densement et rugueusement ponctuées; d'un rouge acajou, assez brillant, avec la partie intérieure du disque souvent rembrunie; ciliées-spinosulées à leur bord apical ; éparsement pubescentes sur leur

(1) Les tempes, examinées latéralement, offrent une série subgéminée transversalement oblique et irréguliere de petits points pileux et subconfluents, nombreux et bien apparents. 
disque, avec quelques légères soies redressées sur les còtés, dont 2 beaucoup plus longues, derrière les épaules. Celles-ci cachées.

Abdomen peu allongé, moins large que les élytres; fortement atténué en arrière; subconvexe sur le dos, avec les 3 premiers segments faiblement impressionnés en travers à leur base, le $2^{\mathrm{e}}$ basilaire parfois découvert et presque lisse ; éparsement sétosellé ; assez fortement et assez densement ponctué vers sa base, moins densement en arrière; d'un noir brillant et plus ou moins irisé, avec la marge apicale d'un brun de puix parfois roussâtre; à pubescence assez longue et peu serrée. Le $6^{\mathrm{e}}$ segment subtronqué au sommet.

Dessous du corps aspèrement ponctué, finement pubescent, d'un noir brillant, avecla marge apicale des arceaux du ventre plus ou moins roussâtre. Dessous de la tête presque lisse, presque glabre, excepté à la base. Prosternum relevé en faîte. Mésosternum rugueux et sétosellé vers son sommet. Métasternum déprimé, à lobe postérieur d'un roux de poix. Ventre con . vexe, éparsement sétosellé, irisé ; à $2^{\mathrm{e}}$ arceau basilaire arrondi en arrière.

Pieds aspèrement ponctués, finement pubescents, roux ou rougeâtres, avec toutes les hanches et les cuisses postérieures rembrunies, moins leur sommet. Cuisses antérieures et intermédiaires finement spinosules en dessous ; les postérieures mutiques, plus grêles et plus allongées. Tibias antérieurs peu robustes, simplement pubescents. Tarses antérieurs plus ou moins fortement dilatés, mais graduellement moins du $1^{\text {er }}$ au $4^{\mathrm{e}}$ article; les postérieurs grêles, à $1^{\text {er }}$ article allongé, à peine plus long que les 2 suivants réunis, évideminent plus long que le dernier : les $2^{\mathrm{e}} \mathrm{à} 4^{\mathrm{e}}$ graduellement moins longs.

Patrie. Cette espèce se prend, assez rarement, en juillet el août, sous les écorces et dans la carie des vieux arbres, dans les Vosges, les Alpes, les Pyrénées, etc.

OBs. Comparée aux précédentes, elle ne souffre aucun commentaire. Elle est plus déprimée, moins parallèle, plus fusiforme, avec l'abdomen plus fortement atténué en arrière. Le labre est distinctement bilobé, etc.

Les individus les plus adultes õnt les élytres enfumées sur leur' disque ; les immatures ont la bouche, les antennes et les pieds testacés, les côtés du prothorax roussâtres, les élytres d'un roux clair et la marge des segments abdominaux d'un roux testacé.

Les exemplaires de la Corse, bien qu'adultes, ont généralement les élytres non rembrunies. 


\section{Quedius (Sauridus) picipes, ManNERHeIM.}

Assez allongé, subdéprimé, finement pubescent, d'un noir brillant, avec les élytres, les palpes, les antennes et les pieds roux. Tête et prothorax lisses, luisants : celui-ci à peine transverse, subrétréci en avant. Écusson lisse. Elytres à peine aussi longues que le prothorax, assez finement et densement ponctuées. Abdomen finement et densement ponctué, fortement irisé. Le $1^{\mathrm{er}}$ article des tarses postérieurs sensiblement plus long que le dernier.

$\sigma^{7}$ Le $6^{\circ}$ arceau ventral très-faiblement et subangulairement sinué dans le milieu de son bord apical, avec une impression longitudinale lisse

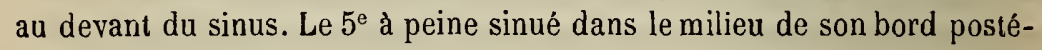
rieur, avec un léger espace lisse au devant du sinus.

ㅇ Le $6^{\mathrm{e}}$ arceau ventral subarrondi au sommet, le $5^{\mathrm{e}}$ lisse.

Staphylinus picipes, MaNNERHEIM, Brach. 26, 34.

Philonthus variicolor, NoRdmanN, Symb. 76, 9.

Philonthus picipes, Nordmann, Symb. 77, 11.- Redtenbacher, Faun. Austr. 710, 62.

Quedius picipes, Ericrson, Col. March. I, 491, 10;-Gen. et Spec. Staph. 537,

21.-Fairmaire et Laboul.bène, Faun. Ent. Fr. I, 543, 28.- KraAtZ, Ins. Deut.

II, J05, 16. - Fauvel, Faun. Gallo-Rhén. III, 318, 27.

Philonthus gracilicornis, HeER, Faun. Col. Helv. I, 274, 59.

Raphirus picipes, Thosson, Skand. Col. IX, 172, 2, e.

$$
\text { Long., } 0^{\mathrm{m}}, 0089 \text { (4 l.); - larg., } 0^{\mathrm{m}}, 0012 \text { (1 l.). }
$$

Corps assez allongé, subdéprimé, d'un noir brillant, avec les élytres rousses; revêtu sur celles-ci et l'abdomen d'une fine pubescence grisâtre et peu serrée.

Tête assez grande, subarrondie ou courtement ovale, un peu moins large que le prothorax ; très-éparsement et longuement sétosellée sur les côtés ; d'un noir luisant ; lisse ; finement pointillé sur les tempes ; marqué, de chaque côté, sur celles-ci, d'un gros point sétifère, et de 2 autres semblables situés plus en dedans, dont l'un près du bord postéro-interne des yeux, et l'autre sur le vertex. Front très-large, à peine cunvexr, à 
pore juxta-oculaire gros et joignant l'œil. Cou glabre, presque lisse, luisant. Epistome corné, obscur. Labre d'un noir de poix, fortement sétosellé en avant. Mandibules brunes. Palpes d'un roux parfois subtestacé.

Yeux grands, subovales, peu saillants, noirs, parfois lavés de gris.

Antennes médiocres, beaucoup plus longues que la tête ; grêles, subfiliformes; finement duveteuses et assez fortement pilosellées; entièrement rousses; à $1^{\text {er }}$ article en massue allongée el subarquée : le $2^{\text {e }}$ allongé, obconique : le $3^{\mathrm{e}}$ allongé, obconique, plus long que le $2^{\mathrm{e}}$ : les suivants graduellement un peu plus courts, mais à peine plus épais, non contigus : les $4^{\mathrm{e}}$ à $6^{\mathrm{e}}$ oblongs, subcylindriques : les $7^{\mathrm{e}}$ à $10^{\mathrm{e}}$ suboblongs, subobconi ques, arec les pénultièmes paraissant parfois, vus de côté, à peine plus longs que larges : le dernier oblong, obliquement tronqué au sommet en dessus et obtusément acuminé inférieurement.

Prothorax à peine transverse, subrétréci en avant; de lial largeur des élytres ; largement tronqué ou à peine échancré au sommet, avec les angles antérieurs inflèchis, presque droits mais subarrondis; subarqué sur les côtés ; largement arrondi à sa base ainsi qu'aux angles postérieurs ; assez convexe sur son disque; éparsement sétosellé sur les côtés; à pore sétifère latéral situé assez loin de la marge; d'un noir luisant ; lisse; marqué en avant de 2 séries dorsales composées de 3 points assez forts et subégalement distants, et, de chaque còté, de 1 ou 2 points assez écariés et disposés sur une ligne longitudinale, sans compter les marginaux et le gros pore sétifère latéral.

Écusson glabre, lisse, d'un noir luisaut.'

Elytres transverses, à peine pius larges en arrière qu'en avant, à peine aussi longues que le prothorax, subdéprimées ; assez finement, densement et à peine rugueusement ponctuées; d'un rouge acajou brillant ; ciliéessubspinosulées à leur bord apical; subéparsement pubescentes sur leur disque, avec quelques légères et rares soies redressées sur les côtés, dont 1 beaucoup p!us longue, vers le tiers antérieur de ceux-ci. Epaules cachées.

Abdomen suballongi, un peu moins large que les élytres; assez fortement atténué en arrièré ; subconvexe sur le dos, avec les 3 premiers segments non visiblement impressionnés en travers à leur base, le $2^{\mathrm{e}}$ basilairc souvent découvert tt presque lisse ; éparsement sétosellè ; assez fiuement et densement ponctué vers sa base, un peu moins densement en arrière; d'un noir brillant, fortement irisé ou azuré ; à pubescence assez longue et peu serrée. Le 6 e segment subtronqué ou à peine arrondi au sommet.

BR. 
Dessous du corps aspèrement ponctué, finement pubescent, d'un noir brillant, avec le repli du prothorax, le prosternum et le mésosternum parfois moins foncés. Dessous de la tête presque glabre et presque lisse. ou avec quelques rares points pileux, surtout en arrière. Prosternum subcaréné, à pointe parfois recourbée. Mésosternum subdéprimé, rugueux et cilié vers son sommet. Métasternum subdéprimé, à lobe postérieur un peu roussâtre. Ventre convexe, éparsement sétosellé, plus ou moins fortement irisé ou azuré, à sommel parfois d'un roux de poix ; à $2^{\mathrm{e}}$ arceau basilaire arrondi dans le milieu de son bord postérieur.

Pieds aspèrement pointillés, finement pubescents, d'un roux subtestacé, avec les hanches postérieures non ou à peine plus foncées. Cuisses antérieures et intermédiaires finement spinosules en dessous; les postérieures mutiques, plus grêles et plıs allongées. Tibias antérieurs peu robustes, à peine épineux. Tarses antérieurs à 4 premiers articles légèrement dilatés (.o ), un peu plus fortement chez les $\sigma$; les postérieurs grêles, à $1^{\text {er }}$ article allongé, à peine plus long q'xe les 2 suivants réunis, sensiblement plus long que le dernier : les $2^{\mathrm{e}} \mathrm{à} 4^{\mathrm{e}}$ graduellement moins longs.

Patrie. Cette espèce se trouve, en été et en automne, sous les mousses, les feuilles tombées, les détritus et autres matières végétales décomposées, et parfois sur les rameaux des arbres, du nord au midi de la France. Elle est assez commune.

OBs. Elle est bien disliucte de l'ochropterus par sa tête moins transverse, moins grosse et moins brusquement rétrécie en arrière; par son prothorax un peu moins large et un peu plus convexe, non subimpressionné vers les côtés; par ses élytres à peine plus courtes, plus finement, un peu moins densement et moins rugueusement ponctuées; par ses hanches et ses cuisses postérieures non rembrunies; par ses tarses antérieurs ınoins dilatés; par le $6^{\mathrm{e}}$ arceau ventral des $\sigma$ plus faiblement échancré, etc.

Les exemplaires des montagnes, parfois moindres, ont l'abdomen sensiblement moins densement ponctué en arrière, et à reflets dorés plus ou ınoins éclatants ; ceux de la Provence, plus noirs, ont l'abdomen, au contraire, beaucoup moins ou à peine irisé.

Les immatures ont le prothorax d'un roux de poix, la bouche, les antennes, les pieds et la marge apicale des segments abdominaux, teslacés.

On peut rapporter au picipes le pyrrhopus de Stephens (Ill. Brit. V, 216). 
Nous avons vu quelques exemplaires de la Provence, à forme un peu plus trapue; à abdomen plus atténué et comme acuminé en arrière $e_{t}$ d'une couleur presque uniformément bleuâtre; à tarses antérieurs plus fortement dilatés que dans le picipes, mais un peu moins que dans l'ochropterus, dont ils se distinguent par la tête plus arrondie et moins transverse, par leur prothorax moins impressionné sur les côtés; par leurs élytres un peu moins finement ponctuées, et par leurs pieds postérieurs concolores, c'est-à-dire entièrement roux. Elle est donc comme intermédiaire entre les 2 espèces précitées. Nous nommerons provisoirement cette race Quedius provincialis, nobis.

\section{Quedius (Sauridus) nigriceps, Kratz.}

Allongé, subfusiforme, subdéprimé, légèrement pubescent, d'un brun de poix brillant, avec la tête noire, les antennes d'un roux obscur et leur base plus claire, les palpes, les pieds et la marge des segments abdominaux roux, ainsi que les côtés du prothorax. Tête et prothorax lisses, luisants : celui-ci à peine plus long que large, rétréci en avant. Écusson lisse. Élytres de la longueur du prothorax, finement et densement ponctuées. Abdomen finement et densement ponctué vers sa base, plus éparsement en arrière, irisé. Le $1^{\mathrm{er}}$ article des tarses postérieur's sensiblement plus long que le dernier.

$\sigma$ Le $6^{\text {e }}$ arceau ventral sensiblement et subangulairement sinué dans le milieu de son bord apical, avec une légère impression lisse au devant du sinus. Tarses antérieurs fortement dilatés.

\& Le $6^{\text {e }}$ arceau ventral subarrondi au sommet. Tarses antérieur's un peu moins dilatés

Quedius maurorufus, Fairuatre et Laboulbènč, Faun. int. Fr. I, 541, 21. JacQueun dU V.al, Gen. Col. Eur. Staph. pl. 15, fig. 73. Quedius praecox, Fauvel, Faun. Gallo-Rhén. III, 321, 31.

Variété a. Élytres et prothorax rongeâtres, avec celui-ci parfois rembruni sur son milieu.

Quedius maurorufus, var. ERichson, Col. March. I, 493 ; - Gen. et Spec. Staph. $542,28$. 
Qnedius nigrieeps, KraAtz, Ins. Deut. II, 510, 23.

Raphirus nigriceps, Thouson, Skand. Col. IX, 169, 2, b.

Quedius pineti, Ch. Brisout, Ann. Soc. Ent. Fr. 1866, 359. - Maliseul, l'A beille, 1871, VIII, 283.

$$
\text { Long., } 0^{\mathrm{m}}, 0076 \text { (3 1/2 l.); - larg., } 0^{\mathrm{m}}, 0015 \text { (2/3 l.). }
$$

Corps allongé, subfusiforme, subdéprimé ; revêtu sur les élytres et l'abdomen d'une légère pubescence grisâtre et peu serrée.

Tête assez grosse, brièvement subovale, un peu moins large que le prothorax; très-éparsement sétosellée sur les côtés ; d'un noir luisant; lisse; finement et assez densement ponctuée derrière les yeux, où se trouvent 3 points sétifères formant le triangle : l'externe, sur les tempes, contre le bord postérieur de l'œil : l'intermédiaire, assez près du bord postéro-interne du mème organe : l'interne, plus petit, plus en dedans, sur le vertex. Front large, subconvexe, à pore juxta-oculaire assez gros. Cou glabre, lisse, luisant. Épistome submembraneux, brunâtre, parfois, livide. Labre d'un noir brillant, fortement sétosellé en avant. Mandibules d'un brun de poix. Palpes d'un roux testacé.

Antennes médiocres, presque 2 fois aussi longues que la tête ; assez grêles ou à peine épaissies; finement duveteuses et distinctement pilosellées; d'un roux obscur, a vec la base plus claire; à $1^{\text {er }}$ article en massue allongée : les' $2^{\mathrm{e}}$ et $3^{\mathrm{e}}$ obconiques : le $2^{\mathrm{e}}$ oblong : le $3^{\mathrm{e}}$ assez allongé, plus long que le $2^{\mathrm{e}}$ : les suivants graduellement un peu plus courts, obconico-subcylindriques, peu contigus : les $4^{\mathrm{e}}$ et $5^{\mathrm{e}}$ oblongs : les $6^{\mathrm{e}} \mathrm{a}$ $10^{\mathrm{e}}$ suboblongs : le dernier oblong, obliquement acuminé au sommet.

Prothorax à peine plus long que large, plus ou moins rétréci en avant; presque aussi large à sa base que les élytres; largement tronqué ou à peine échancré au sommet, avec les angles antérieurs infléchis, presque droits mais émoussés ; subarqué sur les côtés; arrondi à sa base ainsi qu'aux angles postérieurs; assez convexe sur son disque; épar'sement sétosellé sur les côtés; à pore sétifère latéral situé assez loin de la marge ; d'un noir luisant, avec les côtés devenant graduellement roussátres ; lisse; marqué en avant de 2 séries dorsales composées de 3 points médiocres, dont l'antérieur un peu plus écarté, et, de chaque côté, de 2 autres points moindres, assez distants, obliquement disposés, situés entre le $1^{\mathrm{er}}$ dorsal et le gros pore latéral, l'antérieur plus en dehors, près de la marge.

Ecusson glabre, lisse, d'un noir de poix luisant. 
Elytres transverses, environ de la longueur du prothorax ; subdéprimées; finement, densement tet subrâpeusement ponctuées; d'un brun de poix assez brillant, avec les côtés souvent plus clairs ou roussâlres ; ciliéessubspinosulées à leur bord apical; légèrement pubescentes sur leur disque, avec quelques légères soies redressées sur les côtés, dont 1 , beaucoup plus longue, vers le tiers antérieur de ceux-ci. Épaules cachées, subépineuses en dessous.

Abdomen à peine moins large à sa base que les élytres; assez fortement et graduellement atténué en arrière; subconvexe sur le dos, avec les 3 premiers segments à peine impressionnés en travers à leur base ; éparsement et longuement sétosellé ; finement et densement ponctué vers sa base', plus éparsement en arrière; d'un noir ou d'un brun de poix brillant et irisé, avec la marge apicale des segments d'un roux souvent subtestacé ; à pubescence plus longue et un peu plus serrée que celle des élytres. Le $6^{\mathrm{e}}$ segment subtronqué ou à peine arrondi au sommet.

Dessous $d u$ corps aspèrement ponctué, finement pubescent, d'un noir brillant, avec le repli du prothorax, l'antépectus, le médipectus et la marge apicale des arceaux du ventre plus ou moins roux. Dessous de la tête presque lisse ou avec quelques points épars et pileux. Prosternum caréné. Mésosternum cilié ver's son sommet. Métasternum subdéprimé, à lobe postérieur parfois roussátre. Ventre convexe, très-éparsement sétosellé, fortement irisé; à $2^{\mathrm{e}}$ arceau basilaire prolongé sur le $1^{\mathrm{er}}$ normal en angle obtus et arrondi.

Pieds aspèrement pointillés, finement pubescents, roux, avec les hanches postérieures plus foncées. Cuisses antérieures finement spinosules en dessous; les postérieures plus longues et plus grêles. Tibias antérieurs peu robustes, peu épineux. Tarses antérieur's à 3 premiers articles plus $\left(\sigma^{\circ}\right)$ ou moins $(q)$ fortement dilatés, le $4^{\mathrm{e}}$ moins fortement; les postérieur's grêles, à $1^{\text {er }}$ article allongé, à peine plus long que les 2 suivants réunis, sensiblement plus long que le dernier: les $2^{\mathrm{e}}$ à $4^{\mathrm{e}}$ graduellement plus courts.

Patrie. Cette espèce, peu commune, se trouve au printemps et à l'automne, sous les feuilles mortes et principalement parmi les aiguilles des pins, et parfois en battant ces mêmes arbres, dans les environs de Paris, dans la Normandie, les montagnes du Lyonnais, au mont Pilat, dans les Alpes, le Languedoc, elc. On la preıld aussi dıns les fourmilières.

Ors. Elle est bien distincte des ochropterus et picipes, par sa taille 
moindre ; par sa tête moins grande, par son prothorax moins court, plus ou moins roux sur les côtés ; par ses élytres plus finement et plus densement ponctuées ; par son abdomen plus fortement atténué en arrière, etc.

Le prothorax et les élytres sont parfois entièrement roux, avec les antennes et les pieds d'un roux testacé. Les variétés foncées sont plus rares.

On doit sans doute rapporter à la variété $a$ le ruficollis de Stephens (Ill. Brit., V, 244).

Quant au Quedius praecox d'Erichson $(540,26)$, que cite Gravenhorșt, il nous semble douteux qu'il puisse convenir au nigriceps de Kraatz, car le premier de ces auteurs donne à son insecte la forme du peltatus et des antennes couleur de poix à base testacée, ce qui n'a pas précisément lieu chez le nigriceps. Dans le doute, nous avons dù, de préférence, adopter cette dernière dénomination,

M. Tournier, de Genève, a eu l'obligeance de nous communiquer deux cxemplaires, provenant de Cette, et dont la taille est un peu moindre, la couleur d'un roux ferrugineux, avec la tête noire, et le prothorax rembruni et à ceinture bien nette et asscz large, d'un roux testacé, embrassant la base et les côtés. Les élytres, à peine plus déprimées, paraissant un peu plus densement ponctuées. Les antennes et les pieds sont à peine plus robustes. Malgré ces différences, nous regardons ces échantillons comme une variété locale du nigriceps, qui varie beaucoup, suivant les altitudes, pour la taille, la couleur et même la ponctuation.

\section{Quedius (Sauridus) robustus, SCRIBA.}

Assez allongé, subfusiforme, peu convexe, légèrement pubescent, d'un noir de poix brillant, avec la bouche, les antennes, les pieds et la marge des segments abdominaux roux, le milieu des antennes, les hanches et la base des cuisses postérieures rembrunis. Tête et prothorax lisses, luisants : celui-ci aussi long que large, subrétréci en avant. Écusson lisse. Élytres un peu plus courtes que le prothorax. médiocrement et assez densement ponctuées. Abdomen assez finement et assez densement ponctue, à peine irisé. Le $1^{\mathrm{er}}$ article des tarses postérieurs sensiblement plus long que le dernier. 
$\sigma^{7}$ Le $6^{\text {e }}$ arceau ventral faiblement et subangulairement sinué dans le milieu de son bord apical, avec un espace triangulaire lisse au devant du sinus. Le $5^{\mathrm{e}}$ avec un léger espace lisse vers le milieu de son bord postérieur.

ㅇ Le $6^{\mathrm{e}}$ arceau ventral subarrondi au sommet. Le $5^{\mathrm{e}}$ simple.

Quedius robustus, Scriba, Heyd. Reis: Span. 1870, 81 - Fauvel, Faun. Gallo-Rhén. III, 518, 28.

Quedius parviceps, Fauvel, Cat. Stierl. 359.

$$
\text { Long., } 0^{\mathrm{m}}, 0077 \text { (3 1/2 l.); - larg., } 0^{\mathrm{m}}, 0015 \text { (2/3 l.) }
$$

Corps assez allongé, subfusiforme, peu convexe, d'un noir de poix brillant; revêtu sur les élytres et l'abdomen d'une légère pubescence grisâtre et peu serrée.

Téte assez grande, subarrondie, un peu moins large que le prothorax; très-éparsement sétosellée sur les côtés; d'un noir luisant et à peine métallique; lisse ; offrant sur les tempes une seule rangèe subtransversale de petits points pileux ; marquée, de chaque côté, sur celles-ci, d'1 gros point sétifère, formant le triangle avec 1 autre point semblable situé près du bord postéro-interne des yeux et un $3^{\circ}$ moindre et placé plus en dedans, sur le vertex. Front très-large, subconvexe, à pore juxtaoculaire assez gros. Cou glabre, lisse, luisant. Épistome corné, obscur. Labre noir, fortement sétosellé en avant. Mandibules d'un brun de poix. Palpes roux, à sommet un peu rembruni.

Yeux grands, ovales, peu saillants, obscurs, lavés de gris.

Antennes médiocres, beaucoup plus longues que la tête ; à peine épaissies; finement duveteuses et assez fortement pilosellèes; rousses, avec le milieu un peu rembruni et le dernier article subtestacé; le $1^{\text {er }}$ en massue allongée : le $2^{\ominus}$ suballongé, obconique : le $3^{\ominus}$ allongé, obconique, plus long que le $2^{\circ}$ : les suivants graduellement un peu plus courts et un peu plus épais, non contigus : les $4^{\mathrm{e}}$ et $5^{\mathrm{e}}$ oblongs, subcylindriques : les $6^{\mathrm{e}} \mathrm{a}$ $10^{\mathrm{e}}$ subobconiques, suboblongs, avec les pénultièmes paraissant parfois à peine plus longs que larges : le dernier oblong, obliquement acuminé au sommet.

Prothorax aussi long que iarge, subrétréci en avant, de la largeur des élytres; largement tronqué ou à peine échancré au sommet, avec les 
angles antérieurs infléchis, presque droits mais subarrondis; subarqué sur les côlés ; subarrondi à sa base ainsi qu'aux angles postérieurs; subconvexe sur son disque, sérialement sétosellé sur les côtés ; à pore sétifère latéral situé loin de la marge; d'un noir luisant et à peine métallique; lisse; marqué en avant de 2 séries dorsales composées de 3 points médiocres, dont l'antérieur un peu plus écarté, et, de chaque côté, d'1 autre point, un peu moindre, situé entre celui-là et le gros pore sétifère latéral, sans coinpter les marginaux.

Ecusson glabre, lisse, d'un noir luisant.

Élytres fortement transverses, subparalièles, un peu plus courtes que le prothorax; subdéprimées ou à peine convexes ; médiocrement, assez densement et subrugueusement ponctuées; d'un noir de poix brillant, avec la marge apicale rarement moins foncée ; ciliées-spinosulées le long de celles-ci; brièvement et éparsement pubescentes sur le disque, avec quelques rares soies redressées sur les côtés, dont 1 notamment plus longue, vers le tiers antérieur de ceux-ci. Épaules cachées.

Abdomen suballongé, un peu moins large que les élytres; assez fortement et graduellemeut atténué en arrière; subconvexe sur le dos, avec les 3 premiers segments à peine impressionnés en travers à leur base; éparsement sétosellé; assez finement et assiez densement ponctué, à peine moins densement en arrière; d'un noir de poix brillant et à peine irisé, avec la marge apicale des segments, súrtout des derniers, moins foncée ou même roussâtre, à pubescence longue et peu serrée. Le $6^{e}$ segment subtronqué ou même subsinueusement tronqué au sommet.

Dessous du corps aspèrement ponctué, finement pubescent, d'un noir de poix brillant, avec le repli du prothorax, le prosternum, le mésosternum et la marge postérieure des arceaux du ventre plus ou moins roux. Dessous de la tête presque glabre et presque lisse. Prosternum subcaréné, à pointe un peu recourbée. Mésosternum cilié vers son sommet. Métastérnum subdéprimé, à lobe postérieur roux. Ventre convexe, très-éparsemen ${ }^{t}$ sétosellé; à peine irisé; à $2^{\mathrm{e}}$ arceau basilaire arqué sur le milieu de son bord postérieur.

Pieds aspèrement pointillés, finement pubescents, roux, avec les hanches et souvent la base des cuisses postérieures plus ou moins rembrunies. Cuisses antérieures finement spinosules en dessous, les postérieures mutiques, plus grêles et plus allongées. Tibias antérieurs peu robustes, peu épineux. Tarses antérieurs à 3 premiers articles fortement, le $4^{\mathrm{e}}$ moins fortemént, dilatés; les postérieurs grêles, à lar article allongé, à peine plus 
long que les 2 suivants réunis, sensiblement plus long que le dernier : les $2^{\mathrm{e}}$ à $4^{\mathrm{e}}$ graduellement moins longs.

Patrie. Celte espèce se prend, en août, à Chamouni, sous les pierres, près des neiges. Elle est très-rare.

Ons. Elle est à peu près de la taille du nigriceps; avec le prothorax et les élytres d'une couleur toujours plus foncée, celles-ci moins finement et moins densement ponctuées, et l'abdomen moins irisé. Les tempes sont moins densement pointillées, les antennes plus rembrunies dans leur milieu, etc.

La marge des segments abdominaux est, en dessus, parfois à peine moins foncée, d'autres fois d'un roux assez clair.

aa. Le $1^{\text {er }}$ article des tarses postérieurs suballongé, à peine plus long, aussi long, parfois un peu moins long que le dernier.

e. Front pourvu seulement des 2 points juxia-oculaires. Antennes plus ou moins allongées, à pénultièmes articles non ou à peine transverses.

f. Elytres peu brillantes, à intervalle des points finement chagriné. Antennes à pénultièmes articles suboblongs. Labre bilobé. Forme trapue, postérieurement subacuminée. . " PEltatus.

ff. Elytres brillantes, à intervalles de points lisses.

g. Abdomen sans plaques d'un gris cendré.

h. Élytres plus ou moins fortement ponctuées. Labre assez fortement bilobé.

i. Tempes non ou à peine pointillées. Téte assez grosse, subtransverse ou suborbiculaire. Le dernier article des palpes maxillaires fusiforme. Élytres asséz densement ponctuées.

k. Tuille assez grande. Antennes à péuultièmes articles au moins aussi longs que larges.

I. Élytres fortement ponctuées, d'un noir submétallique, liserées de roux testacé dans leur pourtour. .

II. Elytres assez fortement ponctuées, rougeâtres, a disque intérieurement rembruni. $\cdot \cdot \cdot \cdot \cdot \dot{ }$

kk. Taille moyenne. Antennes à pénultièmes articles
peine aussì longs que larges. Élytres à disque intérieurement rembruni.

DUBius.

MONTANUS.

ii. Tempes assez densement pointillées.

m. Prothorax noir ou 'd'un noir de poix, subconcolore.

Le dernier article des palpes maxillaires subfusi-

forme. Tête assez grande, subarrondie.

n. Antennes à peinultièmes arlicles au moins aussi longs que larges. $\dot{E}$ lytres assez densement ponctuées, d'un roux brunâtre. Ventrc assez densement ponctué. '. 
nn. Antennes à pénultièmes articles à peine aussi longs que larges. Élytres modérément ponctuées, brunátres. Ventre éparsement ponctué. .

mm. Prothorax plus ou moins roux, au moins sur les côtés. Le dernier article des palpes maxillaires conico-fusiforme. Tête médiocre, subarrondie ou brièvement ovale.

0. Elytres marginées de roux, avec 1 bande humérale testacée ; de la longueur du prothorax. . . .

00. Elytres brunătres ou marginées de roux, sans bande humérale testacée.

p. Elytres plus larges en arrière, un peu plus courtes que le prothorax, assez densement ponctuées, plus ou moins marginées de roux. Couleur genérale assez claire. . . . .

UMBRINUS.

SUTURALIS.

pp. Élytres subparalleles, de la longueur du prothorax, éparsement ponctuées, subconcolores. Couleur générale assez obscure. . . . .

hb. Elytres finement et plus ou moins densement pointillées. Labre légèrement bilobé. Tète assez petite. Le dernier article des palpes maxillaires conique.

q. Elytres marginées de testacé, avec 1 bande humérale de même couleur. Téte ovale. Le 3 e article des an-

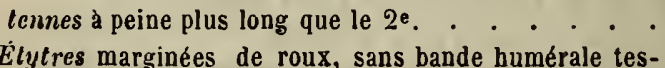

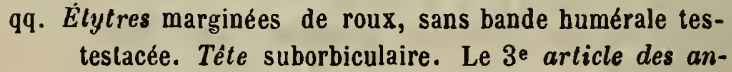
tennes sensiblement plus long que le $2 \mathrm{e}$. . . .
men paré sur les côtés de plaques formées par une puobltTteratus. que le prothorax. Tête sensiblement étranglée à sa base.

LIMBATUS.

BICOLOR.

MAURORUPUS. RIPARIUS.

ee. Front ponrvu, sur le milieu, outre les 2 points juxta-oculaires, de 2 autres points sétiferes transversalement disposés.

r. Antennes suballongées, à pénultièmes articles nullement transverses. Labre sensiblement bilobé. Prothorax à séries dorsales parfois biponctuées. Ėlytres d'un tiers plus longues que celui-ci. Abdomen maculé de gris sur les côtés. Taille médiocre. . . . . . . . . . . . .

rr. Antennes courtes, à pénultièmes articles transverses ou Kraatzi. subtransverses. Labre légèrement fendu, à peine bllobé. Prothorax à séries dorsales 3-ponctuées. Élytres un peu plus longues que celui-ci. Taille petite.

s. Tête et prothorax d'un bronzé assez clair. Élytres d'un roux bronzé, à ponctuation serrée. . . . . .

ss. Tête et prothorax d'un bronzé obscur. Élytres d'un brun de poix bronzé, à ponctuation modérément serrée. . LUCIDULUS. SCINTILLANS. 


\section{Quedius (Snuridus) peltatus, Erichson.}

Peu allongé, fusiforme, subdéprimé, finement pubescent, d'un noir brillant, avec les élytres brunâtres et presque mates, la bouche, les antennes et les pieds d'un roux de poix, les hanches et les cuisses postérieures rembrunies. Téle et prothorax lisses, luisants : celui-ci suborbiculaire, subrétréci en avant. Écusson lisse. Élytres à peine plus longues que le prothorax, finement chagrinées, assez finement et assez densement ponctués. Abdomen assez finement et éparsement ponctué, plus ou inoins irisé. Le $1^{\mathrm{wr}}$ article des tarses postérieurs subégal au dernier.

$\sigma$ Le $6^{\circ}$ arceau veritral assez profondément échancré en angle subaigu, avec une impression oblongue, triargulaire, lisse, au devant de l'échancrure. Le $5^{\text {e }}$ à peine sinué dans le milieu de son bord postérieur. avec un léger espace lisse au devant du sinus. Tarses antérieurs fortement dilatés,

† Le $6^{\text {e }}$ arceau ventral subarrondi au sommet. Le $5^{e}$ simple. Tarses antérieurs assez fortement dilatés.

Quedius praecox, EnICHson, Col. March. I, 492, 12,

Quedius peltatus, Ericuson, Gen. et Spec. Staph. 540, 25. - Falrmaire et LaboulBÈNe, Faun. Ent. Fr. I, 543, 27. - KraATz, Ins. Deut, II, 507, 19.

Philonthus peltatus, Redtenbacher, Faun. Austr. 825,

Philonthus praecox, HeEr, Faun. Col. Helv. I, 278, 70.

Quedius irideus, MILler, Verh. Zool. Bot. ver. in Wien, I, 110.

Raphirus peltatus, Тномson, Skand. Col. IX. 169, 1, b.

Quedius fumatus, FAUVEL, Faun. Gallo-Rhén. III, 522, 32.

$$
\text { Long., } 0^{\mathrm{m}}, 0067 \text { (3 l.); -- larg., } 0^{\mathrm{m}}, 0017 \text { (3/4_..). }
$$

Corps peu allongé, fusiforme, subdéprimé, d'un noir brillant, avec les élytres brunâtres et presque mates; revêtu sur celles-ci et sur l'abdomen d'une fine pubescence grisâtre et peu serrée.

Tète assez petite, subarrondie, beaucoup moins large que le prothorax; 
très-éparsement sétosellèe sur les côtés ; d'un noir luisant et submétallique ; lisse ; finement pointillée sur les tempes ; marquée de chaque côté, sur celles-ci, d' 1 gros point sètifère joignant le bord postérieur de l'œil, formant le triangle avec 1 autre point plus gros, sitné tout près du bord postéro-interne du même organe, et un $3^{\mathrm{e}}$, un peu moindre et placé plus en dedans, sur le vertex. Front très-large, à peine convexe, à pore juxtaoculaire assez petit. Cou glabre, lisse, brillant. Épistome subcorné, brunâtre. Labre noir, fortement sétosellè en avant. Mandibules obscures. Palpes d'un roux de poix.

Yeux grands, subovales, un peu saillants, obscurs.

Antennes médiocres, plus longues que la tête; assez grêles; faiblement épaissies; finement duveteuses et sensiblement pilosellées; d'un roux de poix, avec les articles $2^{\mathrm{e}}$ et $3^{\mathrm{e}}$ parfois tachés d'obscur; le $1^{\mathrm{er}}$ en massue allongée : le $2^{\mathrm{e}}$ oblong, obconique : le $3^{\mathrm{e}}$ suballongé, obconique, plus long que le $2^{\mathrm{e}}$ : les suivants graduellement un peu plus courts et à peine plus épais, peu contigus, subobconiques : les $4^{\mathrm{e}}$ à $6^{\mathrm{e}}$ oblongs, les $7^{\mathrm{e}}$ à $10^{\mathrm{e}}$ suboblongs : le dernier oblong, obliquement acuminé au sommet.

Prothorax suborbiculaire, subrétréci en avant; aussi large à sa base que les élytres ; largement tronqué ou à peine échancré au sommet, avec les angles antérieurs infléchis, presque droits mais subémoussés; sensiblement arqué sur les côtés; arrondi à sa base ainsi qu'aux angles postérieurs; légèrement convexe; sérialement sétosellé sur les côtés, avec le pore sétifère latéral situé assez loin de la marge; d'un noir luisant et à peine métallique; lisse; marqué elı avant de 2 séries dorsales composées de 3 points médiocres, dont l'antérieur souvent plus écarté, situé assez loin de la marge; offrant en outre, de chaque côté, 1 ou 2 autres points rapprochés sur une ligne longitudinale, sans compter le gros pore sétifère et les marginaux.

Écusson glabre, lisse, d'un noir luisant.

Élytres transverses, à peine plus longues que le prothorax ; subdéprimées; assez finement et assez densement ponctuées, et en outre finement chagrinées dans les intervalles des points; brunâtres, peu brillantes ou presque mates, avec la marge apicale parfois un peu plus claire ; ciliées-subspinosulées le long de celle-ci; finement et subéparsement pubescentes sur leur disque, avec quelques rares soies redressées sur les côtés, dont 1 notamment plus longue, vers le tiers antérieur de ceux-ci, et 1 semblable vers les épaules. Celles-ci cachées.

Abdomen peu allongé, moins large que les élytres; fortement et gra- 
duellement atténué en arrière; assez convexe sur le dos, avec les 3 premiers segments á peine impressionnés en travers à leur base ; éparsement et longuement sétosellé; assez finement et éparsement pouclué; d'un noir brillant et plus ou moins irisé ; à pubescence peu serrée. Le $6^{\mathrm{e}}$ segment subtronqué ou à peine arrondi au sommet.

Dessous du corps aspèrement ponctué, légèrement pubescent, d'un noir brillant, avec le repli du prothorax, le prosternum et le mésosternum souvent d'un roux de poix. Dessous de la tête presque glabre et presque lisse, ou avec quelques points pileux, épars. Prosternum relevé en faite. Mésosternum cilié vers son sommet. Métasternum subdéprimé. Ventre convexe, éparsement sétosellé, fortement irisé.

Pieds aspèrement pointillés, finement pubescents, d'un roux de poix, avec les hanches et les cuisses postérieures plus ou moins rembrunies, celles-ci parfois subirisées. Cuisses antérieures et intermédiaires finement spinosules en dessous, surtout vers leur extrémité; les postérieures plus grèles et plus longues. Tibias antérieurs peu robustes, à peine épineux. Tarses antérieurs à 4 premiers articles plus $\left(\sigma^{\circ}\right)$ ou moins $(q)$ fortement dilatés, le $4^{\mathrm{e}}$ moins fortement; les postérieurs à $1^{\mathrm{er}}$ article suballongé, subégal aux 2 suivants réunis, subégal au dernier : les $2^{\mathrm{e}}$ à $4^{\mathrm{e}}$ graduellement moins courts.

Patrie. Cette espèce, assez l'are, se prend, en été, sous les écorces, les feuilles mortes et dans le tronc des vieux arbres, surtout dans les forêls, dans les environs de Paris et de Lyon, la Flandre, la Normandie, la Bo'rrgogne, la Bresse', les Alpes, etc.

OBs. Elle est remarquable par sa forme trapue et postérieurement acuminée; par ses élytres peu brillantes et a intervalles de points. finement chagrinés. Les tarses postérieurs sont moins grêles que chez les robustus et nigriceps, avec leur $\perp^{\text {er }}$ article non plus long que le dernier.

Dans les immatures, les élytres sont d'un roux brunâtre, avec les antennes et les pieds postérieurs entièrement roux.

Nous avons vu un exemplaire des Apennins (collection Abeille de Perrin), chez lequelles élytres sont plus brillantes mais toujours finement chagrinées. Les $2^{e}$ et $3^{e}$ articles des antennes rembrunis ne permettent pas de la séparer du peltatus.

Peut-ètre doit-ón rapporter à cette espece le fumatus de Stephens (IU. Brit., V, 245). 
Près du peltutus marcherait le cincticollis de Kraatz, dont nous donnerons une courte description :

\section{Quedius cincticolifm, Kratz.}

Suballongé, fusiforme, subdéprimé, finement pubescent, d'un brun de poix brillant, avec la tête noire, le pròthorax d'un roux de poix, rembruni sur son disque, la marge apicale des élytres et des segments abdominaux, la bouche, les antennes et les pieds d'un roux plus ou moins testacé. Téte et prothorax presque lisses, luisants : celui-ci à peine transverse, rétréci en avant. Écusson lisse. Élytres presque plus courtes que le prothorax, moins brillantes, à peine chagrinées, assez finement et peu densement ponctuées. Abdomen finement et modérément ponctué, plus éparsement en arrière. Le $1^{\mathrm{er}}$ article des tarses postérieurs subégal au dernier.

Quedius cincticollis, KraAтZ, Ins. Deut. II, 508, 20.

$$
\text { Long., } 0^{\mathrm{m}}, 0055 \text { (2 1/2 l.); - larg., } 0^{\mathrm{m}}, 0011 \text { (1/2 l.). }
$$

Patrie. L'Autriche, la Hongrie.

Ors. Cette espèce nous a été donnée par M. Tournier, de Genève. Elle a un peu le port trapu du peltatus. Mais elle est moindre, et les élytres, moins distinctement chagrinées, sont par là un peu plus brillantes. La couleur générale est moins noire, etc.

Elle varie du brun foncè au brun plus clair(1).

(1) M. Revelière nous a communiqué un insecte d'Espagne qui est peut-être une variété immature du cincticollis, et qui semblerait se rapporter au praecox d'Erichson, a part la coloration des antennes. Il est de la forme d'un petit picipes; la tête et le prothorax sont d'un noir de poix, avec le pourtour de ce dernier et tout le reste du corps d'un roux testacé, les pieds un peu plus clairs et les antennes rousses. Nous le nommerous provisoirement Quedius circumductus, nobis.

Pour la forme générale, il se placerait entre le picipes et le peltatus. Comme chez celui-ci, le $1^{\text {er }}$ article des tarses postérieurs nous a semblé subégal au dernier. 
33. Quedius (Sauridus) dubius, HeER.

Peu allongé, subfusiforme, subdéprime, finement pubescent, d'un noir brillant et submétallique, avec la bouche, les antennes, le pourtour des élytres, la marge apicale des segments abdominanx et les pieds d'un roux testacé, les cuisses postérieures plus ou moins rembrunies. Tète et prothorax lisses, luisants: celui-ci subtransverse, subrétréci en avant. Ėcusson lisse. Elytres un peu plus longues que le prothorax, fortement et asse: densement ponctuées. Abdomen finement et assez densement ponctué, irisé. Le $1^{\mathrm{er}}$ article des tarses postérieurs à peine égal au dernier.

$\sigma$ Le $6^{e}$ arcean ventral sensiblement et angulairement. échancré dans le milieu de son bord apical, avec un espace triangulaire lisse au devant de l'ćchancrure. Le $5^{\text {e }}$ à peine sinué dans le milieu de son bord postérieur, avec un espace lisse à peine sensible au devant du sinus.

오 Le $6^{\mathrm{e}}$ arceau ventral subarrondi au sommet. Le $5^{\mathrm{e}}$ siniple.

Staphylinus dubius, HeER, Mitth. I, 156.

Quedius fimbriatus, Erichson, Gen. et Spec. Staph. כ̈39, 24.- Krastz, Ins. Deut.

II, 506, 18.

Philonthus fimbriatus, Redtenbacher, Faun. Austr. 710, 58.

Quedius dubius, Fauvel, Faun. Gallo-Rhen. III, 519, 29.

$$
\text { Long., } 0^{\mathrm{m}}, 0076 \text { (3 1/2 l.); - larg., } 0^{\mathrm{m}}, 0019 \text { (5/6 l). }
$$

Corps peu allongé, subfusiforme, subdéprimé, d'un noir brillant et submétallique, avec les élytres liserées de roux testacé ; revêtu sur celles-ci et l'abdomen d'une fine pubescence blonde, plus longue et plus serrée sul' ce dernier.

Tête assez grande, subarrondie, un peu moins large que le prothorax; éparsement sétosellée sur les côtés; d'un noir luisant et submétallique; lisse ; à peine pointillée ou avec une seule rangée de petits points sur les tempes; marquée, de chaque côté, derrière les yeux, de 2 gros points sétifères, obliquement disposés, et d'1 autre moindre, plus en dedans, sur le vertex. Front très-large, à peine convexe, à point juxta-oculaire médiocre. Cou glabre, lisse, luisant. Epistome submembraneux, livide. Labr'e noir, 
iortement sélosellé en avant. Mandibules ferrugineuses. Palpes d'un roux testacé, à sommet largement rembruni.

Yeux grands, subovales, peu saillants, obscurs, lavés de gris.

Antennes médiocres, sensiblement plus longues :que la tête; assez grêles ; à peine épaissies ; finement duveteuses et légèrement pilosellées ; entièrement $d^{\prime} u n$ roux testacé; à $1^{\text {er }}$ article en massue allongée : le $2^{\circ}$ oblong, obconique : le $3^{\mathrm{e}}$ suballongé, obconique, plus long que le $2^{\mathrm{e}}$ : les suivants graduellement un peu plus courts et à peine plus épais, nan contigus : les $4^{\mathrm{e}}$ à $6^{\mathrm{e}}$ oblongs, subcylindrico-obconiques : les $7^{\mathrm{e}}$ à $10^{\mathrm{e}}$, suboblongs, subobconiques : le dernier subovalaire, acuminé au sommet.

Prothorax subtransverse, subrétréci en avant, de la largeur des élytres ; tronqué au sommet et à peine sinué de chaque côté de celui-ci, près des angles antérieurs, qui sont infléchis, presque droits mais subarrondis; modérément arqué sur les côtés ; subarrondi à sa base ainsi qu'aux angles postérieurs; subconvexe; sérialement sétosellé sur les côtés, avec le pore sétifère latéral situé assez près de la marge ; d'un noir luisant et submétallique; lisse; marqué en avant de 2 séries dorsales composées de 3 points, dont l'antérieur un peu moindre et plus écarté; offrant en outre, de chaque côté, un point assez petit, situé assez près du point dorsal antérieur et tout près de la marge, sans compter les marginaux et le gros pore latéral.

Écusson glabre, lisse, d'un noir brillant.

Élytres à peine transverses, à peine plus longues en arriëre qu'en avant, un peu plus longues que le prothorax; subdéprimées; fortement et assez densement ponctuées; d'un noir brillant et submétallique, avec los côtés, le calus huméral, la marge apicale et parfois la suture d'un roux testacé, mais d'une manière assez étroite; ciliées-subspinosulées à leur sommet; brièvement et éparsement pubescentes sur leur disque, avec quelques légères soies redressées sur les côtés, dont 1, beaucoup plus longue, vers le tiers antérieur de ceux-ci. Épaules cachées, à calus assez marqué.

Abdomen suballongé, un peu moins large que les élytres; assez fortement el graduellement alténué en arrière; subconvexe sur le dos; avec les 3 premiers segments à p. ine impressionnés en travers à leur base; éparsement sétosellé sur les côtés et vers le sommet; finement et assez den* sement ponctué, plus éparsement vers l'extrémité ; d'un noir brillant et plus ou moins irisé, avec le $2^{\mathrm{e}}$ segment basilaire parfois découvert, presque lisse et d'un roux testacé, et la marge apicale de tous les suivants 
plus ou nooins roussàtre; à pubescence plus fine, plus longue et plus serrée que celle des élytres. Le $6^{\mathrm{e}}$ segment subtronqué ou à peine arrondi au sommel.

Dessous du corps aspèrement ponctué, finement pubescent, d'un noir brillant, ávec le repli du prothorax brunâtre, ef la marge a picale des arceaux du vèntre rousse. Dessous de la téte presque glabre,'presque lisse. Prosternum sulcarré, à pöinte parfois un peu recourbée. Mésosternum rugueux et cilié vers son sommet. Métasternum subdéprimé. Ventre convexe, éparsement sétosellé, subirisé, à $2^{e}$ arceau basilaire prolongè sur le $1^{\text {er }}$ normal en angle très-obtus et subarrondi.

Pieds aspèrement pointillés, finement pubescents, d'un roux testacé, avec les hanches et parfois les cuisses postérieures rembrunies. Cuisses antérieures finement spinosules en dessous; les postérieures plus grêles et plus longues. Tibiàs antérieurs peu robustes, à peinể êpineux. Tarses antérieur's à 3 premiers articles fortement dilatés, le $4^{\mathrm{e}}$ moins fortement; les

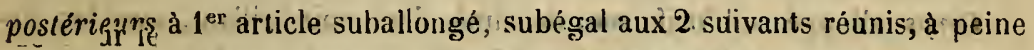

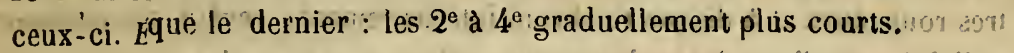

Abdome Cette, rare espèce se prend sous les pierres el les détritus, en été, dans lus forêts et les montagnes : dans les environs de Paris, la Normandie, l’Alsace, les Vosges, les Alpes, etc.

Elle a été capturée au mont Pilat, par feu M. Siméan, de Lyon.

OBs. Elle a la forme trapue du peltatıs, mais elle est plus brillante, avec ses élytres non chagrinées dans l'intervalle des points:

Les exemplaires les plus adultes ont les élytres presque entièrement d'un noir submétallique, avec le'calus huméral seul un peu roussátrè: Les hariches et cuisses intermédiaires, les hanches, cuisses et mẻne parfois tibias postérieurs sont plus ou moins rembrunis.

\section{Quedius (Sauridus) montanus, HEER.}

Suballong', subfusiforme, subdéprimé, finement pubescent, d'un noir brillant, avec la bouche, les antennes, la marge apicale des segments abdominaux et les pieds roux, les élytres rọıgeâtres, à disque rembruni intér ieurement. Téte et prothorax lisses, luisants : celui-ci aussi large que long, subrétréci en avant. Ecusson lisse. Elytres de la iongueur dil 
prothorax, assez fortement et assex densement ponctuées. Abdomen finemenit ${ }^{\top}$ et subéparsement ponctué, subirisé. Le $1^{\mathrm{er}}$ article des tarses postérieurs égal au dernier.

$\sigma^{\prime}$ Le $6^{\circ}$ arceau ventral assez sensiblement et subangulairement sinué dans le: milieu de son bord apical, avec un espace triangulaire lisse et subimpressionné, au devant du sinus. Tarses antérieurs fortement dilatés.

Le $6^{\circ}$ arceau ventral subarrondi au sommet. Tarses antérieurs assez fortement dilatés.

Philonthus montanus, HeER, Faun. Col. Helv. 1, 277, 68.

$$
\text { Long., } 0^{\mathrm{m}}, 0073\left(3 \mathrm{1} / 3 \mathrm{l} \text {.); - larg., } 0^{\mathrm{m}}, 0016(3 / 4 \mathrm{l} \text {.). }\right.
$$

Corps allongé, subfusiforme, déprimé, d'un noir brillant, aves: les élytres rougeâtres et à disque rembruni intérieurement; revêtu sen otitre, et l'abdomen d'une fine pubescence grisâtre et peu serrée. nt dorsal

Tête assez grande, suborbiculaire; un peu moins large que lest leumorax, éparsement sétosellée sur les côtés; d'un noir luisant et à peine métallique ; lisse ou à peine chagrinée; :presque imponctuée ou avec une seule rangée de petits points sur les tempes; marquée, de chaque côtć, derrière les yeux, de 2 très-gros points. sétifères rapprochés et subobliquement disposés, et d'un $3^{\mathrm{e}}$ moindre, plus en dedans, sur le vertex. Front très-large, subconvexe, à pore juxla-oculaire assez. gros. Cou glabre, lisse, luisant. Épistome subcorné, brunâtre. Labre noir, fortement sétosellé en avant. Mandibules ferrugineuses. Palpes d'un roux subtestacé, à sommet à peine rembruni.

Yeux grands, subovales, peu saillants, obscurs, lavés de gris.

Antennes médiocres, sensiblement plus longues que la tête; assez grêles, à peine épaissies; finement duveteuses et distinctement pilosellées; entièrement rousses; a $^{\mathrm{er}}$ article en massue allongée le $3^{\mathrm{e}}$ suballongé, obconique, plus long que le $2^{\mathrm{e}}$ : les suivants graduellement un peu plus courts et à peine plus épais, peu ou non contigus : les $4^{\mathrm{e}}$ à $6^{\circ}$ oblongs, subcylindriques : les $7^{\mathrm{e}}$ aे $10^{\circ}$ aे peine oblongs, subobconiques : le dernier ovalaire, subacuminé au sommet.

Prothorax aussi long que large, subrétréci en avant, à peine plus large que les élytres; largement tronqué ou à peine échancré au sommet, avec 
les angles antérieurs infléchis, presquue droits mais émoussés ; modérément arqué sur les côtés; subarrondi à sa base ainsi qu'aux angles postérieurs ; subconvexe sur son disque; sérialement sétosellé sur les côtés, avec le pore sétifère latéral situé assez loin de la marge; d'un noir luisant êt à peine métallique; lisse; marqué en avant de 2 séries dorsales composées de 3 points médiocres et subégalement distants ; offrant en outre; de chaque côté, 1 oı 2 points: situés sur une ligne longitudinale, entre lo point dorsal antérieur et le pore latéral.

Écusson glabre, lisse, d'un noir luisant.

Elytres subtransverses, à peine plus larges en arrière qu'en avant; de la longueur du prothorax ; subdéprimées, parfois subimpressionnées vers l'angle postéro-externe, ‘̀ suture plus ou moins relevée; assez fortement et assez densement ponctuées; d'un rougeâtre brillant, avec la partic intérieure du disque plus ou moins rembrunie; ciliées-subspinosulées à leur bord apical; éparsement pubescentes, avec quelques légères soies redressées sur les côtés, dont 1 beaucoup plus longue; vers le tiers antérieur de ceux-ci. Épaules cachées.

Abdomen suballongé. un peu moins large que les élytres ; assez fortement et subarcuément atténué en arrière; subconvexe sur le dos, avec les 3 premiers segments non ou à peine impressionnés en travers à leur base ; éparsement sélosellé sur les côtés et vers le sommet; finement et subéparsement ponctué, avec le $2^{\mathrm{e}}$ segment basilaire parfois découvert et presque lisse; d'un noir brillant et subirisé, avec la marge apicale des segments rouss ; à pubescence un peu plus longue et un peu plus serrée que celle des élytres. Le $6^{\text {e }}$ segment à peine arrondi au sommet.

Dessous du corps aspèrement ponctué, finement pubescent, d'un noir brillant, avec le repli ủu prothorax brunâtre, et la marge apicale des arceaux plıs ou moins rousse. Dessous de la tête presque glabre et presque lisse, ou seulement ponctué à sa base. Prosternum subcaréné. Mésosternum cilié vers son sommet. Métasternum subdéprimé, à lobe postérieur un peu roussâtre. Ventre convexe, très-éparsenent sétosellé, plus ou moins irisé ; à $2^{\mathrm{e}}$ arceau basilaire subarrondi dans le milieu de son bord postérieur.

Pieds aspèrement ponctués, finement pubescents, roux, avec toutes les hanches rembrunie:; ainsi que parfois la base des cuisses postérieures. Cuisses antérieures tinement spinosules en dessous; les postérieures plus grêles et plus longues. Tibias antérieur's peu robustes, à peine épineux. Tarses antérieurs à 3 premiers articles plus ou moins fortement dilatés, le $4^{\mathrm{e}}$ moins fortement; les postérieurs à $1^{\mathrm{er}}$ article suballongé, aussi long que 
les 2 suivants réunis, égal au dernier : les $2^{e}$ aे $4^{e}$ graduellewent plu courts.

Patrie. Cêtte espèce est rare. Elle a été capiurée, parmi les mousses, à la Grande-Chartreuse.

Oss: On la prendrait pour une varièté du dubius, à élytres plus largement rousses sur les côtés et au sommet. Mais les palpes sont moins rembrunis à leur extrémité ; le pore sétifère latéral du prothorax est situé plus loin de la marge, et celui-ci est un peu moins court, à peine plus large à sa base que, les élytres; celles-ci, un peu moins longues, sont un:peu moins fortement ponctuées; la ponctuation de l'abdomen est un peu moins serrée vers sa base; les hanches intermédiaires, et surtout les antérieures, sont plus obscures; la pubescence est moins blonde, et celle des élytres plus fine et un peu moins courte, etc.

- Parfois les antennes, les palpes et les pieds sont d'un teștacé pâle, et alors la couleur rouge des élytres se montre, plus claire. C'est à cette variété qu'appartient un type de Heer, qui nous a été généreusement communiqué par. M. Henri 'Tournier, de Genève.

Le Quedius fumbriatus de Fairmaire et Laboulbène (Faun. Ent. Fr. 544, 30) semble appartenir au montanus plutôt qu'au dubius? Il en est peutètre ainsi du speculator de Kiesenwetter (in Küster, Káf. Eur., XII, 57).

\section{Quedius (Sauridus) anceps, Fatrmaire et Labouldéne.}

Suballongé, subfusiforme; subdéprimé, finement pubescent, d' $\imath$ noir brillant, avec la bouche, les antennes, la marge apicale des segments "äbdominaux et les pieds roux, ainsi que les cótés et le sommet des élytres, le disque de celles-ci et les hanches plus ou moins rembrunis. Tête et prothorax lisses, luisants, celui-ci aussi large que long, subrètréci ('n avant. Écusson lisse. Élytres un peu plus courtes que le prothorax, assez fortement et assez densement ponctuées. Abdomen finement et modériinent pónctué vers sa base, plus éparsement en arrière, subirisé. Le. 1 er article des tarses posterieurs subégál au dernier.

$\sigma$ Le $b^{\circ}$ arceau ventral sensiblement et subangulairement sinué daus le milieu de son bord apical, avec un espace triangulaire lisse au devant 
Ju sinus Le $5^{\ominus}$ à peine sinué dans le milicu de son bord postérieur, avec un I léger espace lisse el prolongé jusqu'à la base, au dévant du sinuśs. Tarses antérieurs fortement dilatés.

ㅇ Le 6 arceau ventral subarrondi au sommet. Le 5 es simple. Tarses antérieurs assez fortement dilatés.

Quedius anceps, Fatraalre et Laboulbène; Faun. Ent. Fr. I. 543, 26 .

Variété a. Élytres plus déprimées, presqque entièrement noires;

Long., $0^{\mathrm{m}}, 0067$ (3 l.); - larg., $0^{\mathrm{m}}, 0014$ (2/3 l.).

Corps suballonge, fusiforme, subdéprimé, d'un noir brillant, avec les marges latérale et apicale des élytrés rougeâtres ; revêtu sur celles-ci et l'abdomen d'une fine pubescence grisâtre et peu serrée.

Tête assez grande, subtransverse ou subarrondie; un peu moins large que le prothorax ; éparsement sétosellée sur les côtés ; d'un noir luisant ; lisse ; marquée de chaque côté, dérrière les yeux, de 2 gros points sétifères et subobliquement disposés, 'et d'un $3^{e}$ moindre, plus en dedans. sur le vertex. Front très-large,' subconvexe, à pore juxta-oculaire! gros. Cou glabre, lisse, luisant. Épistome subcorné, d'un roux livide. Labre d'un noir de poix, fortement sétosellé en avant. Mandibules d'un brun ferrugineux. Palpes d'un roux subtestacé.

Yeux grands, subovales, peu saillants, obscurs, pariois lavés de gris. Antennes médiocres, plus longues que la tête, faiblement épaissies; faiblement duveteuses et distinctement pilosellées ; rousses, avec les premiers articles parfois lachés de nébuleux; le $1^{\text {er }}$ en massue allongée : Ie $2^{\mathrm{e}}$ oblong, obconique : le $3^{\mathrm{e}}$ suballongé, obconique, plus long que le $2^{\mathrm{e}}$ : les 'suivants graduellement un peu plus courts et un peu plus épais, non ou peu contigus, subobconiques : les $4^{\mathrm{e}}$ à $7^{\mathrm{e}}$ suboblongs : le $8^{\mathrm{e}}$ aussi long que large : les $9^{\mathrm{e}}$ et $10^{\circ} \grave{a}$ peine aussi longs que larges ou subtransverses : lé dernier ovalaire, acuminé au sommet.

Prothnrax aussi long que large, subrétréci en avant; de la largeur des élytres ou à peine plus large; à peine échancré au sommet; avec les angles antérieurs infléchis,. presque droits mais émoussés ; subarqué sur les côtés, qui, vus latéralement, sont subsinués en arrière; subarrondi à sa base ainsi qu'aux angles postérienrs; subconvexe sur son disque ; légèrement sétosellé sur les côlés, avec le pore sétifère latéral situé așsèz 
loin de la marge; d'un noir luisant et à peine métallique; lisse; marqué en avant de 2 séries dorsales composées de 3 points, dont l'antérieur parfois un peu moindre et un peu plus écarté ; offrant en outre, de chaque côté, 1 autre point situé entre le point dorsal antérieur et le gros pore latéral, mais plus près du premier.

Écusson glabre, lisse, d'un noir luisant.

Elytres transverses, subparallèles ou à peine plus larges en arrière qu'en avant ; un peu plus courtes que le prothorax; subdéprimées ou déprimées; assez fortement, assez densement et subrugueusement pónctuées; d'un noir brillant, avec la suture à peine roussâtre, la marge apicale assez étroitement et les côtés plus largement roussâtres ; ciliéessubspinosulées à leur bord apical ; éparsement pubescentes sur leur disque ; légèrement sétosellées sur leurs côtés, avec $\mid$ soie beaucoup plus longue vers le tiers antérieur de celıx-ci. Épaules cachées.

Abdomen suballongé, un peu moins large que les élytres ; assez fortement et subarcuément atténué en arrièrè subconvexe sur le dos, avec les 3 premiers segments à peine visiblement impressionnés en travers à leur base ; éparsement sétosellé sur les côtés et vers le sommet; finement et modérément ponctué vers sa base, plus éparsement vers son extrémité, avec le $2^{\theta}$ segment basilaire parfois découvert et presque lisse; d'un noir assez brillant et subirisé, avec la marge apicale des segments rousse ; d pubescence assez longue et peu serrée. Le $6^{\text {e }}$ segment à peine arrondi au sommet.

Dessous du corps aspèrement ponctué; finement pubescent, d'un noir brillant, avec le repli du prothorax brunâtre et la marge apicale des arceaux du ventre rousse. Dessous de la tête presque glabre et presque lisse. Prosternum subcaréné, parfois d'un roux obscur. Mésosternum cilié vers son sommet. Métasternum subdéprimé. Ventre convexe, éparsement sétosellé; plus ou moins irisé; à $2^{\mathrm{e}}$ arceau basilaire subarrondi dans le milieu de son bord postérieur.

Pieds aspèrement ponctués, tinement pubescents; roux, avec les hanches plus ou moins rembrunies, ainsi que parfois la base des cuisses postérieures. Cuisses antérieures finement spinosules en dessous; les postérieures plus grêles et plus longues. Tibias antérieurs peu robustes, à peine épineux. Tarse; antérieurs a 3 premiers articles plus ou moins fortement dilatés, le $4^{\mathrm{e}}$ moins fortement ; les postérieurs a $1^{\mathrm{er}}$ article suballongé, aussi long que les 2 suivants réunis, subégal au dernier : les $2^{\mathrm{e}}$ à $4^{\mathrm{e}}$ graduellement plus courts. 
Patrie. Cette espèce se trouve, en juillet et août, parmi les mousses et les feuilles mortes, dans la Savoie, les Alpes, les Pyrénées, elc.

OBs. Elle est un peu moindre que le montanus. Les antennes, un peu moins longues, ont leurs pénultièmes articles un peu plus courts. Le prothorax est un peu plus visiblement subsinué en arrière, vu de côté. L'abdomen est un peu plus densement ponctué sur sá base. Le dessous de la tête n'est pas ponctué én arrière, etc.

E!le varie pour la taille et la couleur. Quelquefois les élytres, plus déprimées, son presque entièrement noires. Purfois les antennes sont d'un testacé pâle.

Nous avons "vu une monstruosité, chez laquelle les 3 premiers segments de l'abdomen sont échancrés et pectinés à leur bord postérie ur.

\section{Quedius (Sauriduø) cyanescens, Mulsant et REY.}

Suballongé, subfusiforme, subdéprimé, finement pubescent, d'un noir brillant, avec les élytres d'un roux brunâtre, la bouche, les antennes, la marge des segments abdominaux et les pieds roux. Tête et prothorax lisses, luisants : celui-ci aussi large que long, subrétréci, en avant. Écusson lisse. Élytres de la longueur du prothorax, assez fortement et assez densement ponctuées. Abdomen assez finement et assez densement ponctué ver's sa base, plus éparsement en arrière, fortement azuré. Ventre assez densement ponctué. Le $1^{\mathrm{er}}$ article des tarses postérieurs subégal au dernier.

$\sigma^{7}$ Le $6^{\text {e }}$ arceau ventral sensiblement et subangulairement sinué dans lo milieu de son bord apical, avec un espace triangulaire, lisse et subimpressionné, au devant du sinus. Le $5^{\circ}$ a peine sinué dans le milieu de son bord postérieur, offrant au devant du sinus un large espace lisse prolongé jusqu'à la base. Le $4^{\mathrm{e}}$ avec un espace lisse aussi large mais non prolongé jusqu'à la base. Tarses antérieurs fortement dilatés.

\& Le $6^{\mathrm{e}}$ arceau ventral subarrondi au sommet. Le $5^{\text {e }}$ simple. Tarses antérieurs médiocrement dilatés.

Long., $0^{\mathrm{m}}, 0066$ (31.); - larg., $0^{\mathrm{m}}, 0014(2 / 31$.$) .$ 
Corps suballongé, subfusiforme, subdéprimé, d'un noir britlant, avec les élytres d'un roux brunâtre; revêtu sur celles-ci et l'abdomen d'une fine pubescence d'un gris blond et modérément serrée.

Tête assez grande, subarrondie, un peu moins large que le prothorax; éparsement, sétosellée sur les côtés; d'un noir lưisant et à peine métallique; lisse ; finement el assez densement pointillée sur les tempes; marquée, de chaque côté derrière les yeux, de 2 gros points sétifères, dont le temporal un peu moindre, et d'un $3^{\mathrm{e}}$ encore plus petit, plus en dedans, sur le vertex. Front large, subconvexe, à pore juxia-oculaire ovale, médiocre. Cou glabre, presque lisse, Iuisant. Epistome corné, brunâtre. Labre noir sétosellé en avant. Mandibules et palpes plus ou moins roux.

Yeux grands, subovales, peu saillants, obscurs, lavés de gris.

Antennes médiocres, beaucoup plus longues que la tête; assez grêles, à peine épaissies ; finement duveteuses et médiocrement pilosellées ; d'un roux parfois assez foncé, avec les $2^{\mathrm{e}}$ et $3^{\mathrm{e}}$ articles souvent tactiés d'obscur; le $1^{\text {er }}$ en massue allongée : le $2^{\mathrm{e}}$ oblong, obconique : le $3^{\mathrm{e}}$ assez allongé, obconique, beaucoup plus long que le $2^{\mathrm{e}}$ : les suivants grâduellement un peu plus courts et un peu plus épais, non contigus, subcylindrico-obconiques : les $4^{\mathrm{e}}$ et $5^{\mathrm{e}}$ oblongs : les $6^{\mathrm{e}}$ a $10^{\mathrm{e}}$ a peine oblongs, au moins aussi longs que larges : le dernier subovalaire, acuminè au sommet.

IT Prothórax aussi long que large, subrétrèci en avant; de la lägeur des élytres ; lärgement tronqué el à peine échancré au sommet, avec les angles antérieurs infléchis, presque droits mais émoussés ; plus ou moins arqué sur leś côtẻs quï, vus latéralement, sont a peine subsinués en arrière; subarrondi à sa base áinsi qu'aux angles postérieurs; subconvexe sur son disque; légèrement sétosillé sur les côtés, avec le pore sétifère latéral situé non bieu loin de la marge; d'un noir luisant et à peine métallique; lisse; marqué en avant de 2 séries dorsales composées de 3 points assez gros et subégalement distants; offrant en outre, de chaque cólé, 1 point semblable, situé non loin du point dorsal antérieur, entre celui-ci et le pore latéral.

Ecusson glabre, lisse, d'un noir luisant.

Elytres subtransverses, subparallèles, aussi longues ou a peine aussi longues que le prothorax ; subdéprimées; assez fortement, assez densement et subrugueusement ponctuées; d'un roux brunâtre et brillant; ciliéesspinosulées à leur bord apical; subéparseinent ou modérément pubescentes sur leur disque avec quelques légères soies redressées sur les côtés, dont 1 , beaucoup plus longue, vers le tiers antérieur de ceux-ci, et 1 
autre semblable vers les épaules. Celles-ci cachces, subépineuses en dessous.

Abdomen suballongé, un peu moins large que les élytres; assez fortement et graduellement atténué en arrière; assez convexe sur le dos, avec les 3 premiers segments non ou à peine impressionnés en travers à leur base ; éparsement sétosellé ; assez finemient et assez densement ponctué vers sa base, plus éparsement en arrière; d'un noir brillant et fortemeni azuré, avec la marge apicale des segments plus ou moins roussâtre; a pubescence assez longue et modérément serrée. Le $G^{\mathrm{e}}$ segment à peine arrondi au sommet.

Dessous du corps aspèrement ponctué, finement pubescent, dun noir brillant, avec le repli du prothorax, l'antépectus, le médipectus et la marge apicale des arceaux du ventre d'un roux de poix. Dessous de la tête presque glabre, presque lisş. Prosternum subcaréné, à pointe parfois subrecourbée. Mésosternum carinulé et ciliè à sa pointe. Métasternum subdẹ́primẹ́, à lobe postérieur un peu roussâtre. Ventre convcxe, éparsemeut sétosellé; fortement azuré et irisé, assez delısement ponclué, un peu moins denșement en arrière; à $2^{\text {e }}$ arceau basilaire prolongé sur le $1^{\text {er }}$ normal en angle prononcé.

Pieds rảpeusement ponctués, firiement pubescents; roux aínsique les hanches. Cuisses antérieures finement spinosules en dessous ; les postérieures plus grê!es el plus longues: Tibias antérieurs assez étroits, à peine épineux. Tarses antérieurs à 3 premiers articles fortement $\left(\sigma^{\prime}\right)$ ou nédiocrement ( ? ) dilatés, le $4^{\mathrm{e}}$ moins sensiblenent ; les postérieurs à $1^{\text {er }}$ article allongé, subégal aux 2 suivants réunis, subégal au dernier : les 2 a $4^{\circ}$ oblongs, graduellement moins longs.

Patrie. Cetie espece, exclusivement méridionale, se trouve, assez rarement, parmi les débris marécageux, dans les environs d'Hyères, depuis le premier printemps.

OBs. Très-voisine de l'anceps, elle s'en distingue par la ponctuation fine et assez serrée des tempes; par ses antennes un peu plus longues et à pénultièmes articles ün ṕeu moins courts. Lés élýtrés, d'ùn róux plus obscur, sont concolores ou sans tache rembrunie, un peu moins iransverses. Les hanchès ne sont pas rembrunies, ni la base des cuisses postérieures. Les tarses postérieurs, plus développés, ont leurs articles proportionnellement plus longs. Le prolongement du $2^{\mathrm{e}}$ arceau ventral sur le suivant est plus sensible et plus angulè. Les tarses antérieurs des $\$$ s sont moins dila tés, letc. 


\section{Quedius (Sauridus) umbrinus, ERICHSON.}

Suballongé, subfusiforme, subdéprimé, finement pubescent; d'un noir de poix brillant, avec les élytres brunâtres et leur marge apicale plus claire, la bouche, les antennes, la marge apicale des derniers arceaux du ventre et les pieds d'un roux de poix. Tête et prothorax lisses, luisants : celui-ciaussi large que long, subrétréci en avant. Écusson lisse. Élytres un peu plus courtes que le prothorax, fortement et modérément ponctuées. Abdomen assez finement et eparsement ponctue. Le $1^{\mathrm{er}}$ article des tarses postérieurs à peine égal au derniér.

- $\sigma$ Le $6^{\circ}$ arceau ventral sensiblement et subangulairement sinué dans le milieu de son bord apical, avec un espace triangulaire lisse áu devant du sinus. Le $5^{e}$ à peine sinué dans le milieu de son bord postérieur, avec un léger espace lisse au devant du sinus. Tarses antérieurs fortement dilatés:

ㅇ Le $6^{\mathrm{e}}$ arceau ventral subarrondi au sommet, le $5^{\mathrm{e}}$ simple. Tarses antérieurs médiocrement dilatés.

Staphylinus maurorufus, Gyllenhal; Ins. Suec. II, 309, 25. - Manneraein, Brach. $26,36$.

Philonthus maurorufus, Nondane, Symb. 77, 10.

Quedius umbrinus, ERICHSon, Col. March. I, 491, 11;-Gen. et Spec. Staph. 541,

- Fatrmaire el Laboulbène, Faun. Ent. Fr. I, 542, 24: - KraAtz, Ins. Deut. II, 509, 21. - Fauvel, Faun. Gallo-Rhén. III,' '520, 30.

Philonthus umbrinus, RedtenbaGher, Faun. Austr. 711. - HeEr, Faun. Col. Helv, I, 277, 67 .

Raphirus umbrinus, Thosison, Skand. Col, II, 178.

Variété a. Prothorax d'un brun de poix. Élytres d'un roux brunatre. - Long., $0^{\mathrm{m}}, 0061$ (2 3/4 l.); - lars., $0^{\mathrm{m}}, 0013$ (3/5 1.).

Corps suballongé subfusiforme, subdéprimé, d'un noir de poix brillant, avec les élytres brunâtres; revêtu sur celles-ci d'une fine pubescence grisâtre et peu serrée.

Téte assez grande, subarrondie, un peu moins large que le prothorax; 
éparsement sétosellée sur les côtés; d'un noir luisant ; lisse ; finement et assez densement pointillée sur les tempes; marquée de chaque côté, derrière les yeux, de 2 gros points sétifères, et d'un $3^{\circ}$ un peu moindre, plus en dedans, sur le vertex. Front très-large, subconvexe, à pore juxta-oculaire ovale, assez gros. Cou glabre, presque lisse, luisant. Epistome corné, brunatre. Labre noir, sétosellé en avant. Mandibules et palpes d'un roux de poix.

Yeux grands, subovales, peu saillar.ts, obscurs, lavés de gris.

Antennes assez courtes, sensiblement plus. longues que la tête; à peine épaissies ; finement duveteuses et distinctement pilosellées; d'un roux de poix, avec les $2^{\circ}$ et $3^{\mathrm{e}}$ articles souvent tachés $d^{\prime}$ obscur : le $1^{\mathrm{er}}$ en massue allongée : le $2^{\mathrm{e}}$ oblong, obconique: le $3^{\mathrm{e}}$ suballongé, obconique, sensiblement plus long que le $2^{\mathrm{e}}$ : les suivants graduellement un peu plus courts et a peine plus épais, peu contigus, subobconiques : les $4^{\mathrm{e}}$ et $5^{\mathrm{e}}$ suboblongs : les $6^{\text {e }}$ el 7 e aussi longs que larges :i les pénultièmes à peine aussi longs que larges ou subtransverses : le derniel subovalaire, obliquement tronqué au sommet.

Prothorax aussi long que large, subrétréci en avant; à peine plus large que les élytres; largement échancré au sommet, avec les angles antérieur's inflèchis, presque droits mais émoussés; subarqué sur les côtés, qui, vus latéralement, sont à peine subsinués en arrière ; subarrondi à la base ainsi qu'aux angles postérieurs; médiocrement convexe sur le dos; ; épar'sement et légèrement sétosellé sur les côtés, avec le pore sétifère lątéral situé non très-loin de la marge ; d'un noir de poix luisant, avec les côtés parfois moins foncés; lisse; marqué en avant de 2 séries dórsales composées de 3 points, dont l'antérieur un peu moindre et un peu plus écarté ; offrant en outre, de chaqu côté, 1 point semblable, situé entre le $1^{\text {er }}$ dorsal et le pore latéral.

Écusson glabre, lisse, d'un noir ou d'un brun de poix brillant.

Elytres transverses, subparalleles, un peu plus covirtés que le protho. rax ; subdéprimées; fortemént et modérément poncluéês; d'un brun do poix assez brillant, avec la marge apicale souvent un peu plas claire; ciliées-spinosulées à leur bord apical ; éparsement pubescentes sur leur disque, avec quelques légères soies redressées sur les côtés, dont 1 be ıucoup plus. longue, vers le tiers antérieur de ceux-ci, et 1 -autre semblable vers les épaules. Celles-ci cachées.

Abdomen peu allongé, un peu moins large que les élytres; graduellement atténué en ạrière ; subconvexe sưr le dos, avęc les/3 premiers 
segments à peine inpressionnés en travers à leur base; éparsement $\in t$ longiuement sélosellé ; assez finęment et éparsement ponctué; d'un noir brillant et irisé on azuré, avec la marge apicale des 2 derniers segments d'un roux de poix; à pubescence peu serrée. Le $6^{\ominus}$ segment à peine arrondi au sommet.

1. Dessouis du corps aspèrevient ponctué, finement pubescent, d'un noir brillant, avec le repli du prothorax, l'antépectus, le médipectus et souvent la marge apicale des derniers arceaux du ventre d'un roux' de poix. Dessouis de la tête presque glabre, presque lisse. Prosternum subcaréné, a pointe un peu recourbée. Mésosternum cilié vers son sommet. Métasternum subdéprimé, à lobe postérieur un peu roussâtre. Ventre convexe, éparsement sétosellé, éparsement ponctué; plus ou moins irisé et azuré; à $2^{\mathrm{e}}$ arceau basilaire prolongé sur le $1^{\mathrm{er}}$ nornal en angle obtus et arrondi. Pieds aspèrement ponctués, légèrement pubescents, d un roux de poix, ainsi que les hanches! Cuisses antérieures finement / subspinosules en dessous; les postérieures plus grêles et plus longues. Tibias antérieurs peu robustes, à peine épineux. Tarses antérieurs à 3 premierș articles fortement $\left(\sigma^{*}\right)$ ou médiocrement $(q)$ dilatés, le $4^{\mathrm{e}}$ moins fortement; les postérieurs a 1 er article suballongé, subégal aux 2 suivants réunis, à peine égal au dernier : les $2^{\mathrm{e}}$ à $4^{\mathrm{e}}$ graduellement plus courts.

PAtrie. Cette espèce est assez commune, en été, sous les pierres, parmi les mousses, dans les tróncs cariès des arbres, dans les forêts ét les montagnes : dans l'Alsace, la Lorraine, les Vosges, al mont Pilat, dans l'Auvergne, les Alpes, la Savoie, les Pyrénées, les collines du Gard, etc.

OBs. Elle diffère du cyanescens par sa taille un peu moindre, par ses antennes moins longues, à pénultièmes articles un peu plus courts; par ses élytres plus courtes, un peu plus fortement et un peu moins densement ponctuées : par son abdomen plus éparsement ponctué, tant en dessus qu'en dessous ; par ses tarses postérieurs un peu moins allongés, etc.

Le prothorax est parfois d'un brun de poix, avec les élytres d'un roux brunàtre. Celles-ci soni quelquefois obscures et sans liseré plus clair.

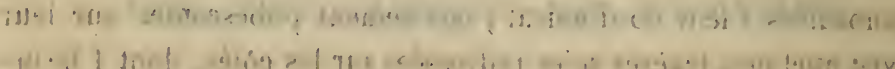

38. Quedius (Sauridus) suturalis, KIESENWETtER.

Allongé, fusiforme, subdéprimé, finement pubescent, d'un brịn de poix brillant et un peu roussätre, avec la, tête noire, la bouche, la base des 
anterries, les pieds; la marge apicale des segments abdominaux, la suture, le bord postérieur des élytres et une tache huméralé, d'un roux testacé. Téte et prothorax lisses, luisants : celui-ci aussi long que large, rétréci en avant.' Ecusson lisse. Elytres de la longueur. du prothorax, assez fortement et assez densement ponctuées. Abdomen assez finement et subejparsement ponctué, irisé. Le $1^{\mathrm{er}}$ article des tarses postérieurs subégal au dernier.

$\sigma$ Le $6^{e}$ arceau ventral largement et subangulairement échancré dan's le milieu de son bord apical, avec une impression lisse, subsillonnée, au devant de l'échancrure. Tarses antérieurs fortement dilatés.

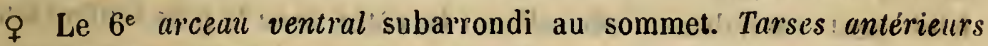
assez légèrènent dilatés.

Quedius suluralis, Kirsenwetter, stett. Ent. Zeit. VI, 225. - KrAatz, Ins. Deul. II, 511,2 .

Quedius muscorum, Ch. Brisout, Cat. Grenier, 1863; 32, 40. - Marseul, l'Abeille, 1871, VIII, 282, 243.

Raphirus marginalis, Tномsом. Skand. Col. IX, 171, 2, d.

$$
\text { Long., } 0^{\mathrm{m}}, 0067 \text { (3.1.); - larg., } 0^{\mathrm{m}}, 0013 \text { (3/5 l.). }
$$

Corps allongé, fusiforme, subdéprimé, d'un brun de poix brillant et un peu roussâtre, avec la lête noire, la suture, la marge postérieure et une tache subhumérale des élytres d'un roux testacé; revètu sur celles-ci et l'abdomen d'une très-fine pubescence grise et peu serrée.

Tête médiocre, subarrondie, moins large que le prothorax; éparsement et longuement sétosellée sur les côtés; d'un noir luisant; lisse; finement et assez densement pointillée sur les tempes; marquée de chaque côté, derrière les yeux, de 2 points sétifères, et d'un $3^{\circ}$, plus en dedans, sur le vertex, l'inturmédiaire beancoup plas gros. Front large, à peine convexe, parfois subdéprimé ou subimpressionné en avant, à pore juxta-oculaire médiocre. Cou glabre, presque lisse, luisaut, Existome submembraneux, livide. Labre roux, sétosellé en avant. Mandibules rousses. Palpes d'un roux testacé.

Yeux grands, subovales, un peu saillanț, obscurs, parfois grisâtres.

Antennes médiocres, sensiblement plus longues que la lête; à peine épaissies; finement duveteuses et asse\% fortement pilosellées; d'un roux parfois assez foncé, avec la base plus claire; à $1^{\text {er }}$ article en massue allongèe : le $2^{\circ}$ oblong, ubconique : le $3^{\circ}$ suballongé, obconique, un peu 
plus long que le $2^{\mathrm{e}}$ : les suivants graduellement un peu plus courts et à peine plus épais, non ou peu contigus, subobconiques : lc $4^{\mathrm{c}}$ oblong : les $5^{\mathrm{e}}$ à $7^{\mathrm{a}}$ à peine oblongs, les pénultièmes aussi longs que larges : le dernier ovalaire, obliquement tronqué en dessus vers son sommet et acuminć inférieurement.

Prothorax aussi long que large, sensiblement rétréci en avant; environ de la longueur des élytres; à peine échancré au sommet, avec les angles antérieurs infléchis, presque droits mais émoussés ; subarqué sur les côtés, qui, vus latéralemeni, sont subsinués en arrière; subarrondi à sa base ainsi qu'aux angles postérieurs; faiblement convexe sur son disque; assez faiblement et sérialement sétosellé sur les côtés, avec le pore sétifère latéral situé assez près de la marge; d'un brun de poix luisant, souvent un pelı roussâtre; lisse; marqué en avant de 2 séries dorsales composées de 3 points médiocres ou assez petits, dont l'antérieur parfois un peu plus écarté ; offrant en outre, de chaque côté, 2 petits points subobliquement disposés, entre le $1^{\text {er }}$ dorsal et le pore latéral.

Écussın glabre, lisse, d'un brun de poix luisant.

Elytres subcarrées, à peine plus larges en arrière qu'en avant; de la longueur du prothorax ; subdéprimées ; assez fortement, assez densement et subrugueuement ponctuées; d'un brun de poix assez brillant et plus ou moins roussâtre, avec la suture étróitcment, la marge apicalc un peu plus largement et une grande tache ou bande humérale d'un roux testacé; ciliées-spinosulées à leur bord postérieur; subéparsement pubescentes sur leur disque, avec quelques légères soies redressées sur les côtés, dont 2 beaucoup plus longues, l'une vers le tiers antérieur, l'autre vers les épaules. Celles-ci cachées.

Abdomen suballongé, un peu moins large que les élytres; graduellement et fortemunt alténué en arrière; subconvexe sur le dos, avec les 3 premiers segments à peine impressionnés en travers à leur base: éparsement el longuement sétosel'é; assez finement et subéparsement ponctué, avec la ponctuation un peu plus serrée sur la base des premiers segments; d'un brun de poix brillant et plus ou moins irisé, avec la marge apicale des segments d'un roux testacé; à pubescence fine et peu serrée. Le $6^{\text {e }}$ segment à peine arrondi au sommet.

Dessous du corps aspèrement ponctué, finement pubescent, d'un brun de poix brillant, avec le repli du proihorax, l'antépectus, le médipectus et la marge apicale dis arceaux du ventre d'un roux testacé. Dessous de la tête presque lisse, presque glabre. Prosternum caréné. Mésosternum 
cilić vers son sommet. Métasternum subdéprimé, à lobe postérieur roussâtre. Ventre convexe, éparsement sétosellé, subirisé.

Pieds aspèrement pointillés, finement pubescen's, d'ụn roux sublestacé, avec les cuisses parfois plus pâles et les hanches postérieures un peu obscurcies. Cuisses antérieures finement spinosules en dessous; les postérieures plus étroiles et plus longues. Tibias antérieurs assez grêles, à peine épineux. Tarses antérieurs a 3 premiers arlicles fortement $\left(\sigma^{*}\right)$ ou assez légèrement ( $\$$ ) dilatés, le $4 \mathrm{e}$ moins scnsiblement; les postérieurs à $1^{\text {er }}$ article allongé, à peine plus long que les 2 suivants réunis, subégal au dernier : celui-ci allongć : les $2^{\mathrm{e}}$ à $4^{\mathrm{e}}$ oblongs, graduellement plus courts.

Patrie. Cette espèce, qui est rare, se trouve en juillet et aoûi, parmi les feuilles mortes, au mont Pilat, à la Grande-Chartreuse, dans les Pyrénées, etc.

OBs. Elle differe de l'umbrinus par son corps plus étroit, plus fusiforme: par sa tète moins grosse et moins convexe, par son prothorax plus comprimé et plus rétréci antérieurement, avec 2 points, au lieu d' 1 , sur les côtés du disque; par ses élytres moins courtes, un peu plus finement ct plus densement poncluées, et autrement colorées, eic.

La couleur varie du roux foncé au brun de poix, avec la bande humérale des élytres plus ou moins réduite. C'est peut-être à cetle dernière rariéić qu'on doil appliquer le Quediuis muscorum de M. Brisout, bien que les antennes nous aient paru, dans cet insecte, un peu plus grêles que dans le suturalis type, avec la ponctuation des élytres ct de la base de l'abdomen à peine plus lâche. Il semblerait faire passage à notre bicolor, décrit ci-après.

Nous avons vu, sous le nom de pulchellus Muller, un exemplaire encore plús foncé en couleur.

L'humeralis de Stephens (Ill. Brit. V, 220), est peut-être synonyme du Q. suturalis.

\section{Quedius (Sauridus) limbrtus, HeER.}

Assez allongé, subfusiforme, subdéprimé, légèrement pubescent, d'un roux de poix brillant, avec la tête noire, l'abdoinen obscur a marge apicale des segments plus claire, la bouche, la base des antennes et les pieds d'in 
roux testacé. Tête et prothorax lisses, luisants : celui-ci aussi long que large, subrétréci en avant. Écusson lisse. Elytres un peu plus courtẹ que le prothorax, assez fortement et assez densement ponctuées. Abdomen assez finement et densement ponctué vers sa base, plus éparsement en arrière, fortement irisé. Le $1^{\text {er }}$ article des tarses postérieurs égal au dernier.

$\sigma$ Le 6 e arceau ventral sensiblement sinue au sommet, avec un espace oblong, triangulaire, lisse, au devant du sinus. Le $5^{\mathrm{e}}$ avec un lêger espace lisse au devant du milieu de son bord apical, Tarsés antérieurs fortement dilatés.

$\subsetneq$ Le $6^{e}$ arceau ventral subarrondi au sommet. Le $5^{\mathrm{e}}$ simple.

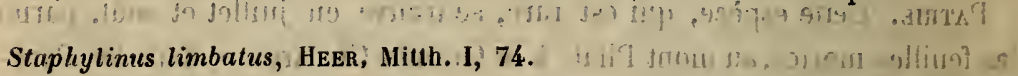
Quedius maurorufus, Ericuson, Gen. et Spec. Staph. 542, 28 (partim). TR Kratz,

Ins. Deut. II, 514, 26 (partim).

Heterothops limbatus, HeER, Faun. Col.: Helv. I, 281, 4 .

Raphirus maurorufus, Thomson, Skand, Col, II, 178, 2.

Quedius limbatus, Fauver, Faun, Gallo-Rhén. III, 525, 35.

$$
\text { Long., } 0^{\mathrm{m}}, 0045 \text { (2 l.); - larg., } 0^{\mathrm{m}}, 0012 \text { (1/2 l.). }
$$

Corps assez allongé, subfusiforme, subdéprimé, d'un roux de poix brillant, avec la tête noire et l'abdomen rembruni; recouvert sur celui-ci et les élytres d'une fine pubescence blonde et peu serrée.

Tête médiocre, brièvement ovale, moins large que le prothorax; éparsement et longuement sétosellée sur les côtés; d'un noir luisant; éparsement pointillée sur les tempes; marquee, de chaque cốté, derrière les yeux, de 2 points obliquement disposés, dont l'antérieur plus gros, et d'un $3^{\mathrm{e}}$ joignant le bord postérieur de l'œil. Front large, subconvexe, à point juxta-oculaire assez gros. Cou glabre, lisse, luisant. Épistome subvertical, subcorné, brunâtre. Labre d'un brun de poix, sétosellé en avant. Parties de la bouche d'un roux testacé.

Yeux grands, subovales, assez saillants, noirátres ou d'un gris obscur.

Antennes médiocres, moins longues que la tête et le prothorax réunis ; faiblement épaissies; finement duveteuses et distinctement pilosellées: d'un roux brunâtre, avec la bașe graduellement plus claire ; à 1 er aricle en massue allongée : les $2^{\mathrm{e}}$ et $3^{\mathrm{e}}$ oblongs, obconiques : le $3^{\mathrm{e}}$ un peu plus long que le $2^{\circ}$ los suivants graduellement un peu plus courts et un $\mu$ eu 
plus épais, peu contigus, subobconiques : les $4^{\mathrm{e}}$ à $6^{\circ}$ suíoblongs, les pénultièmes non ou à peine transverses : le dernier subovalaire, obliquement tronqué au bout et acuminé inférieurement.

Prothorax aussi long que large, subrétréci en avant, aussi large environ que les élytres ; largement tronqué au sommet, avec les angles antérieurs subinfléchis et subarrondis ; médiocrement arqué sur les côtés ; arrondi à la base ainsi qu'aux angles postérieurs; subconvexe sur son disque; sérialement sétosellé sur les côtés, avec le pore sétifêre latéral situé assez loin de la marge; d'un roux de poix luisant, parfois assez clair, avec le disque le plus souvent rembruni ; lisse ; marqué en avant 2 séries dorsales composées de 3 points assez fins, dont l'antérieur ou submarginal parfois plus distant, avec 1 autre point semblable, de chaque côté, entre le $2^{\circ}$ de la série dorsale et le pore sétifère latéral.

Écusson glabre, lisse, luisant, d'un brun de poix.

Élytres transverses, un peu plus larges en arrière qu'en avant, un peu ou à peine plus courtes que le prothorax; subdéprimées; assez fortement et assez densement poncluées; d'un roux de poix brillant, quelquefois obscur, avec la suture, la marge apicale et les côtés plus pâles ; ciliéessubspinosulées à leur bord postérieur ; subéparsement pubescentes sur leur disque, avec quelques très-rares soies sur les côtés, dont 2 notamment plus longues, l'une vers le quart antérieur, l'autre sur les épaules. Celles-ci non saillantes, à calus presque lisse.

Abdomen suballongé, environ de la largeur des élytres à sa base, assez fortement atténué en arrière, subconvexe sur le dos, avec les 3 premiers segments à peine impressionnés en travers antérieurement ; éparsement et longuement sétosellé; assez finement et densement ponctué à sa base, graduellement plus fortement et plus éparsement en arrière; d'un noir de poix brillant et fortement irisé, avec la marge apicale des segments plus ou moins d'un roux de poix; à pubescence assez longue, à peine plus serrée que celle des élytres. Le $6^{\mathrm{e}}$ segment subtronqué ou subarrondi au sommet.

Dessous du corps aspèrement ponctué, légèrement pubescent, d'un brun ou d'un roux de poix brillant, avec le ventre plus foncé, mais à marge apicale des arceaux roussâtre. Dessous de la tête presque lisse ou éparsement ponctlé à la base. Prosternum relevé en faite ou carène obtuse. Mésosternum rugueux et cilié-sétosellé vers son sommet. Métasternum subdéprimé sur son milieu. Ventre convexe, éparsement sétosellé, subirisé.

Piels aspìrement ponctués, finement pubescents, d'un roux testacé, BR. 
avec la base des hanches postérieures parfois un peu rembrunie. Cuisses antérieures finement spinosules en dessous vers leur extrémité; les postérieures plus grêles et plus longues que les autres. Tibias antérieur's assez étroits, à peine épineux. Tarses antérieurs à 3 premiers articles plus $\left(\sigma^{*}\right)$ ou moins $(q)$ dilatés, le $4^{\mathrm{e}}$ moins sensiblement; les postérieurs à $1^{\mathrm{er}}$ article allongé, subégal aux 2 suivants réunis, égal au dernier : les $2^{\mathrm{e}} \mathrm{à}^{\mathrm{e}}$ graduellement moins longs.

Patrie. Cette espèce est rare. Elle se prend, en été et en automne, parmi les mousses, dans les Vosges, les Alpes, la Savoie, les Pyrénées, etc.

Oвs. Elle ressemble beaucoup au Q. suturalis, dont elle diffère par sa taille moindre; par sa tête un peu moins grosse; par ses élytres un peu plus courtes, sans bande humérale plus pâle, à ponctuation à peine moins forte mais plus serrée; par son abdomen plus finement et plus densement ponctué sur sa base. La couleur générale est moins foncée, etc.

Les adultes ont le prothorax et les élytres plus ou muins rembrunis sur leur disque ; les immatures ont ces mêmes parties d'un roux testacé concolore, et même l'abdomen, ou au moins sa base, participe de la même couleur. Le dessous du corps varie aussi du noir de poix au roux plus ou moins clair.

D'après Erichson, notre limbatus, qui est son mauror'ufus, serait le Staphyl. praecox de Gyllenhal (Ins. Suec. II, 310, 26).

\section{Quedius (Sauridus) bicolor, Mulsant et Rey.}

Aliongé, subfusiforme, peu convexe, éparsement pubescent, d'un brun de poix brillant, avec la tête et l'abdomen noir's, le sommet de celui-ci et les anternes roussätres, la base de celles-ci, la bouche et les pieds d'un roux testacé. Tète et prothorax lisses, luisants : celui-ci aussi long que large, subrétréci en avant. Ecusson lisse. Elytres de la longueur du prothorax ou à peine plus longues, assez fortenent et éparsement ponctuées, a pubescence assez longue. Abdomen assez fortement et éparsement poncıué, à peine irisé. Lè $1^{\mathrm{er}}$ article des tarses postérieur's subégal au dernier.

$\sigma$ Le $6^{\text {e }}$ arcean ventral profondément et subaigument échancré au sommet, avec un espace triangulaire allongé, lisse et subimpressionné au 
devant de l'échancrure. Le 5 e faiblement sinué dans le milieu de son bord postérieur, avec un espace lisse, au devant du sinus. Tarses antérienr's fortement dilatés.

i Nous est inconnue.

$$
\text { Long., } 0^{\mathrm{m}}, 0058 \text { (2 2/3 l.); - larg., } 0^{\mathrm{m}}, 0012 \text { (1/2 l.). }
$$

Corps allongé, subfusiforme, peu convexe, d'un brun de poix brillant, avec la tête et l'abdomen plus foncés; revêtu sur celui-ci et les élytres d'une fine pubescence grisâtre, assez longue et peu serrée.

Tète médiocre, subarrondie, sensiblement moins large que le prothorax; éparsement et longuement sétosellée sur les côtés; d'un noir luisant; presque lisse; éparsement pointillée sur les tempes; marquée sur celles-ci d'un gros point sétifère postoculaire, et de 2 autres semblables, obliqquement disposés, derrière le bord postéro-externe des yeux. Front large, à peine convexe, à pore juxta-oculaire assez gros. Cou glabre, presque lisse, luisant. Épistome subcorné, brunâtre. Labre d'un brun de poix, sétosellé en avant. Mandibules d'un brun roussâtre. Palpes d'un roux testacé.

Yeux grands, subovales, peu saillants, obscurs, lavés de gris.

Antennes médiocres, beaucoup plus longues que la tête; à peine épaissies; finement duveteuses et assez fortement pilosellées; d'un roux assez foncé, avec la base un peu plus claire; à ${ }^{\text {er }}$ article en massue allongée :

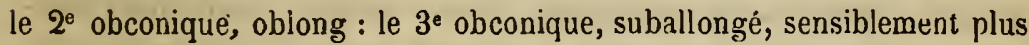
long que le $2^{\mathrm{e}}$ : les suivants graduellement un peu plus courts et à peine plus épais, non contigus, obconico-subcylindriques : les $4^{\mathrm{e}} \mathrm{à} 7^{\mathrm{e}}$ oblongs, les pénultièmes à peine aussi larges que longs : le dernier ovalaire-oblong, graduellement acuminé au sommet.

Prothorax aussi large que long, un peu rétréci en avant, à peine moins large que les élytres; largement tronqué ou à peine échancré au sommet, avec les angles antérieurs infléchis, presque droits mais émoussés; à peine arqué sur les côtés, vu de dessus, avec ceux-ci, vus latéralement, subsinués en arrière; subarrondi à sa base ainsi qu'aux angles postérieurs; médiocrement convexe sur son disque; sérialement sétosellé sur les côtés, avec le pore sétifêre latéral situé assez loin de la marge; d'un brun de poix luisant, avec les cô tés à peine rougeâtres ; lisse ; marqué en avant de 2 séries dorsales composées de 3 points assez forts et subégalement distants; offrant en outre, de chaque côté, 1 point sem- 
blable, situé non loin du dorsal antérieur, entre celui-ci et le pore sćtifère latéral.

Écusson glabre, lisse, luisant, d'un brun de poix.

Elytres subcarrées, subparallèles, de la longueur du prothorax ou à peine plus longues ; subdéprimées, à suture assez relevée; assez fortement et éparsement ponctuées; d'un brun de poix brillant et à peine rougeâtre, uniforme, avec le repli moins foncé ; ciliées-spinosulées à leur borå apical ; assez longuement et éparsement pubescentes sur leur disque, avec la pubescence non tout à fait couchée, et quelques légères soies redressées sur les côtés, dont 2 beaucoup plus longues, l'une vers le quart antérieur, l'autre sur les épaules. Celles-ci à peine saillantes.

Abdomen suballongé, un peu moins large que les élytres; graduellement et assez fortement atténué en arrière; subconvexe sur le dos, avec les 3 premiers segments à peine impressionnés en travers à leur base ; éparsement et longuement sétosellé ; assez fortement et éparsement ponctué; d'un noir de poix brillant et à peine irisé, avec l'extrémité assez largement roussâtre, et la marge apicale des segments brunâtre; à pubescence assez longne et très-peu serrée. Le $6^{\mathrm{e}}$ segment à peine arrondi au sommet.

Dessous du corps aspèrement et éparsement ponctué, éparsement pubescent, d'un noir de poix brillant, avec le dessous du prothorax, le mésosternum et le sommet du ventre d'un roux testacé. Dessous de la tête presque glabre, presque lisse. Prosternum caréné. Mésosternum cilie vers sa pointe. Métasternum subdéprimé. Ventre convexe, éparsement sétosellé, à marge apicale des arceaux d'un rouge cuivreux; à $2^{e}$ arceau basilaire prolongé sur le $1^{\mathrm{er}}$ normal en angle arrondi.

Pieds aspèrement ponctués, légèrement pubescents, entièrement d'un roux testacé. Cuisses antérieures Irès-finement spinosules en dessous; les postérieures grèles, plıs longues. Tibias antérieurs peu robustes, à peine épineux. Tarses antérieurs à 3 premiers articles fortement $\left(\sigma^{*}\right)$ dilatés, le $4^{\mathrm{e}}$ moins fortement ; les postérieurs à $1^{\mathrm{er}}$ article allongé, subégal aux 2 suivants réunis, subégal au dernier : les $2^{\mathrm{e}} \mathrm{a} 4^{\mathrm{e}}$ oblongs, graduellement plus courts.

Patrie. Celte espèce, qui est très-rare, a étć trouvée, en août; à la Grande-Chartreuse, parmi les mousses humides.

OBs. Elle ressemble au Q. umbrinus, mais la tète est sensiblement moins grosse, le prothorax plus étroit et moins arqué sur les côtés; les 
élytres, un peit moins courtes, sont un peu moins déprimées et moins ponctuées, etc.

On la prendrait pour une variété obscurè du suturalis. La ponctuation des élytres et de l'abdomen est moins serrée, et ce caractère la sépare aussi du limbatus. Elle se distingue, en outre, de ce dernier, par une taille un peu plus forte, par une couleur plus sombre, par ses élytres moins courtes et plus parallèles, etc.

\section{Quedius (Sauridus) oblitteratus, Erichson.}

Allongé, fusiforme, subdéprimé, finement pubescent, d'un noir brillant, avec les palpes, la base des antennes, les pieds, la marge apicale des segments abdominaux, la suture, les côtès et le bord postérieur des élytres, et une tache humérale d'un roux plus ou moins lestacé. Tête et prothorax lisses, luisants; celui-ci à peine plus lorg que large, rétréci en ausant. Écusson lisse. Elytres à peine plus longues que le prothorax, finement et densement ponctuées. Abdomen finement et densement ponctué, un peu moins en arrière, irisé. Le $1^{\text {er }}$ article des tarses postérieur's à peine plus long que le dernier.

$\sigma$ Le 6e arceau ventral distinctement, assez largement et subangulairement sinué dans le milieu de son bord apical, a vec un espace triangulaire lisse, au devant du sinus. Le $5^{\mathrm{e}}$ à peine sinué dans le milieu de son bord postérieur, avec un très-léger espace lisse au devant du sinus. Tarses antérieurs fortement dilatés.

q Le $6^{\mathrm{e}}$ arceau ventral arrondi au somnet, ir $5^{\mathrm{e}}$ simple. Tarses antérieurs légèrement dilatés.

Quedius oblitteratus, Erichson, Gen. et Spec. Staph. 549, 38. - Falrmalre et

L.dBoulbèn: , Faun. Ent. Fr. I, 544, 32. - Fauvel, Faun. Gallo-Rhén. III, 523, 33. Quedius nemoralis, Baudi, Stud. Ent. I, 131.

Raphirus suturalis, TвuMso.v, Skand. Col. IX, 170, 2, c.

$$
\text { Long , } 0^{\mathrm{m}}, 006 \text { (2 3/4 l.); - larg., } 0^{\mathrm{m}}, 0012 \text { (1/2 1.). }
$$

Corps allongé, fusiforme, subdép:iné, d'un noir brillant, avec la suture, les côtés et le bord postéricur des élytres et une tache humérale 
d'un roux plus ou moins testacé ; revêtu sur celles - ci et l'abdomen d'une fine pubescence grise et modérément serrée.

Tête assez petite; ovale, sensiblement moins large que le prothorax; éparsement sétosellée sur les côtés; d'un noir luisant ; lisse ; finement et assez densement pointillée sur les tempes; marquée derrière les yeux de 3 points sétifères disposés en triangle, dont l'externe assez petit, l'intermédiaire gros, l'interne petit, situé sur le vertex. Front large, à peine convexe, à pore juxta-oculaire médiocre. Cou glabre, presque lisse, luisant. Épistome subcorné, brunâtre. Labre légèrement bilobé, noir, for tement sétosellè en avant. Mandibules ferrugineuses. Palpes testacés ou d'un roux testacé, à dernier article conique.

Antennes médiocres, un peu plus courtes que la tête et le prothorax réunis ; subfiliformes ou à peine épaissies; finement duveteuses et assez fortement pilosellées ; d'un roux de poix, avec le $1^{\mathrm{er}}$ article testacé ; celui-ci en massue suballongée : le $2^{\circ}$ oblong, obconique : le $3^{\circ}$ suballongé, obconique, plus long que le $2^{\mathrm{e}}$ : les suivants graduellement un peu plus courts et à peine plus épais, non contigus, subobconiques: les $4^{\mathrm{e}}$ à $6^{\mathrm{e}}$ oblongs, les pénultièmes non ou à peine plus longs que larges : le dernier oblong: obliquement subéchancré au sommet et acuminé inférieurement.

Prothorax un peu ou à peine plus long que large; rétréci en avant; un peu moins large que les élytres ; tronqué ou à peine échancré au sommet, avec les angles antérieurs infléchis, presque droits mais émoussés; faiblement arqué sur les côtés; arrondi à la base ainsi qu'aux angles postérieurs ; subconvexe sur son disque; légèrement sétosellé sur les côtés, avec le pore sétifère latéral situé loin de là ınarge; d'un noir luisant et à peine métallique; lisse; marqué en avant de 2 séries dorsales composées de 3 points médiocres, dont l'antérieur un peu plus écarté; offrant en outre, de chaque côté, 1 autre point, situé entre le $1^{\text {er }}$ dorsal et le pore latéral, mais plus près de celui-là (1).

Écusson glabre, lisse, d'uu noir ou d'un brun de poix brillant.

Élytres subcarrées, un peu ou à peine plus longues que le prothorax; un peu plus larges en arrière qu'en avant: subdéprimées; tìnement et densement ponctuées, un peu plus densement vers la suture; d'un noir assez brillant, avec la suture étroitement, la marge apicale et les côtés plus largement et une tache humérale plus ou möins grande, d'un roux

(1) Toujours sans compter les marginaux, bien que nous omettions souvent de le àire. 
plus ou moins testacé; finement ciliées-spinosulées à leur bord postérieur ; finement et modérément pubescentes, avec quelques légères soies redressées sur les côtés, dont 2 beaucoup plus longues, l'une vers le liers antérieur, l'autre vers les épaules. Celles-ci peu saillantes.

Abdomen suballongé, un peu moins large à sa base que les élytres; graduellement et fortement atténué en arrière; subconvexe sur le dos, avec les 3 premiers segments non ou à peine impressionnés en travers à leur base ; éparsement sétosellé ; finement et densement ponctué antérieurement, un peu ou à peine moins densement en arrière; d'un noir brillant et plus ou moins irisé, avec la marge apicale des segments, surtout des derniers, d'un roux plus ou moins testacé ; à pubescence longue et modérément serrée. Le $6^{\mathrm{e}}$ segment à peine arrondi au sommet.

Dessous $d u$ corps aspèrement pointillé, finement pubescent, d'un noir brillant, avec le repli du prothorax et le prosternum brunâtres, el la marge apicalc des arceaux du ventre d'un roux plus ou moins testacé. Dessous de la tête presque lisse ou éparsement ponctué et pubescent à la base. Prosternum subcaréné. Mésosternum cilié vers son somıet. Métasternum subdéprimé, Ventre convexe, éparsement sélosellé, plus ou moins irisé ou azuré; à $2^{\mathrm{e}}$ arceau basilaire prolongé sur le $1^{\mathrm{er}}$ normal en angle prononcé, mais à sommet arrondi.

Pieds finement et aspèrement ponctués, finement pubescents, d'un roux plus ou moins testacé, avec les hanches postérieures rembrunies, moins leur sommet. Cuisses antérieures très-finement spinosules en dessous; les postérieures plus grêles, allongées. Tibias antérieur's peu robustes, à peine épineux. Tarses antérieurs à 3 premiers articles plus $\left(\sigma^{*}\right)$ ou moins $(q)$ dilatés, le $4^{\mathrm{e}}$ à peine moins; les postérieurs à $1^{\mathrm{er}}$ article allongé, à peine plus long que les 2 suivants réunis, un peu ou à peine plus long que le dernier : celui-ci allongé, grêle : les $2^{\ominus}$ à $4^{\circ}$ oblongs, graduellement plus courts.

Patrie. Cette espèce est assez commune, sous les feuilles mortes, dans les forets, sur divers points de la France : la Picardie, la Normandie, la Bretagne, la Champagne, l'Alsace, les environs de Paris et de Lyon, les Landes, la Guienne, les Pyrénées. la Provence, etc.

OBs. Elle est distincte des précédentes par sa forme un peu plus étroite; par sa tête moindre et plus ovale; par son labre moins bilobé; par le dernier article des palpes maxillaires plus court et plus conique. 
Les élytres sont tachées, à peu près comne chez le suturalis; mais la taille est moindre, la tête plus putite, le corps plus fusiforme.

Elle varie beaucoup pour la taille et surtout pour la couleur. Le prothorax esı parfois roussâtre sur les côtés. Les élytres, parfois brunâtres et sans tache humérale pronioncée, sont rarement entièrement rousses. Quelquefois, surtout chez les immatures, les antennes et les autres parties rousses se montrent d'un testacé pâle, et c'est sur de semblables exemplaires qu'a dû être faite la description d'Erichson.

Quelquefois, le prothorax présente 2 points, au lieu de 1, sur les côtés de son disque.

Rarement, les antennes sont presque entièrement obscures.

Les exemplaires des dunes de la mer ont les élytres un peu plus finement ponctuées, avec leurs taches plus pâles.

Dans cette espèce, il est vrai, le $1^{\text {er }}$ article des tarses postérieurs, plus allongé, parait parfois visiblement un peu plus long que le dernier, ce qui la rapprocherait du groupe $a$. Mais I a tête est plus petite, le labre esı plus légèrement bilobé, les élytres sont plus finement et plus densement pointillées, et, surtout, le dernier article des palpes maxillaires est conique. Ce concours de caractères nous a forcés de transporter le Quedius oblitteratus à côté du maurorufus, qui les présente également (1).

Nous avons eu sous les yeux quelques exemplaires, chez lesquels cette particularité du $1^{\text {er }}$ article des tarses postérieurs parait encore plus sensible, et qui sont, en même temps, d'une taille un peu plus grande. Leurs palpes, leurs antennes et parfois leurs pieds sont plus obscurs, et les élytres sont presque concolores ou au moins sans tache humérale. Nous nommerons cette variété Quedius ovaliceps, nobis.

\section{Quedius (Sauridus) maurorufus, Gravenhorst.}

Allongé, fusiforme, peu convexe, finement pubescent, d'un brun de poix brillant, avec la tête et les élytres noires : celles-ci moins brillantes, finement liserées de testacé obscur à leur bord apical, le sommet de l'abdomen

(1) Le Q. coxalis de Kraatz (Berl. Ent. Zeit. 1858, 59) différerait de l'oblilteratus par sa taille un peu moindre, par sa tete plus grande, par ses yeux plus saillants, par ses élytres à pubescence plus rare et plus longue et à ponctuation plus forte et moins serrée, par sor abdomen plus lachement ponctué, par le $6^{\mathrm{e}}$ arceall ventral des $\sigma^{7} \mathrm{a}$ échancrure plus large et plus profonde, etc. -- Lon⿺尢丶, $0^{n}, 005 \mathrm{i}$. - Italie, Grèce. 
d'un ronx de poix, les palpe:, la base des antennes et les pieds d'un roux testacé. Tête et prothorax lisses, luisants : celui-ci suborbiculaire, rétréci en avant. Ecusson lisse. Elytres de la longueur du prothorax, finement, très-densement et râpeusement ponctuées. Abdomen assez densement et finement ponctué vers sa base, un peu moins densement en arrière, subirisé. Le $1^{\mathrm{er}}$ article des tarses postérieur's subégal au dernier.

$\sigma$ Le $6^{\mathrm{e}}$ arceau ventral largement et subangulairement sinué dans le milieu de son bord apical, avec un espace triangulaire, subdéprimé,

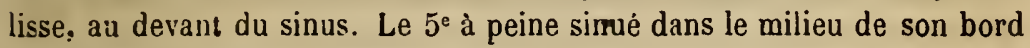
postérieur. Tarses antérieurs fortement dilatés.

$\uparrow$ Le $6^{\mathrm{e}}$ arceau ventral subarrondi au sommet, le $5^{\mathrm{e}}$ simple. Tarses antérieur's légèrement dilatés.

Staphylinus maurorufus, Gravenaonst, Mon. 56, 20.

Emus praecox, Boisduval et Lacordaire, Faun. Ent. Par. I, 382, 37.

Philonthus praecox, Nondmann, Symb. 78, 12.

Quedius praccox, FaIRMaIRe et Laboulbène, Faun. Ent. F. I, 542, 23.

Quedius modestus, Krastz, Ins. Deut. II, 509.

Quedius acuminatus, Fairmaire, Ann. Soc. Ent. Fr. 1860, 155.

Raphirus modestus, Tномson, Skand. Col. X, 316 .

Quedius maurorufus, FAUVEL, Faun. Gallo-Rhén. III, 526, 36.

Variété $a$. Corps d'un roux de poix, avec la tête noire.

Variété $b$. Corps d'un roux testacé, avec la tête noire et le disque du prothorax rembruni.

$$
\text { Long., } 0^{\mathrm{m}}, 0066 \text { (3 L.); - larg., } 0^{\mathrm{m}}, 0015 \text { (2/3 l.). }
$$

Corps allongé, peu convexe, d'un brun de poix brillant avec la tête et les élytres plus foncées; recouvert sur celles-ci et l'abdomen d'une trèsfine pubescence grise et modérément serrée.

Téle assez petite, suborbiculaire, sensiblement moins large que le prothorax; éparseınent et longuement sétosellée sur les côtés; d'un noir luisant; lisse ; médiocrement pointilée derrière les yeux, où elle présente 3 points sétifères disposès en triangle, dont l'intermédiaire plus gros, le I€mporal et celui du vertex beaucoup moindres. Front large, subconvexe, a pore juxta-oculaire assez gros. Cou glabre, presque lisse. Épislome subcorné, d'un brun livide. Labre d'un brun ou d'un roux de poix, 
légèrement bilobé, fortement sétosellé en avant. Mandibules d'un roux ferrıgineux. Palpes d'un roux testacé, à dernier article conique.

Antennes assez courtes, plus longues que la tête; subfiliformes ou à peine épaissies ; finement duveteuses et assez fortement pilosellées ; brunatres ou d'un roux obscur, avec le $1^{\text {er }}$ article d'un roux testacé : celui-ci en massue allongée : le $2^{\mathrm{e}}$ oblong, obconique : le $3^{\mathrm{e}}$ suballongé, obconique, plus long que le $2 \mathrm{e}$ : les suivants graduellement un peu plus courts et à peine plus épais, non contigus, subcylindrico-obconiques : les $4^{\mathrm{e}} \mathrm{a} 6^{\mathrm{e}}$ oblongs ou suboblongs : les pénultièmes environ aussi larges que longs: le dernier ovalaire, obliquemént acuminé au sommet.

Prothorax aussi large que long, suborbiculaire, plus ou moins rétréci en avant, de la largeur des élytres ; largement tronqué au sommet, avec les angles antérieurs infléchis, presque droits mais subarrondis ; sensiblement arqué sur les côtés qui, vus latéralement, sont presque droits ou à peine sinués en arrière ; arrondi à sa base ainsi qu'aux angles postérieurs; assez convexe sur son disque; éparsement sétosellé sur les côtés, avec le pore sétifère latéral situé loin de la marge; d'un brun de poix luisant, avec les côtés graduellement plus clairs ou rougeâtres; lisse; marqué en avant de 2 séries dorsales composées de 3 points médiocres, dont l'antérieur ordinairement plus distant; offrant en outre, de chaque côté, 1 petit point, situé entre le dorsal antérieur et le pore latéral.

Écusson glabre, lisse, d'un brun de poix luisant.

Elytres subtransverses, subparallèles, aussi longues ou à peine plus longues que le prothorax; subdéprimées; souvent subrelevées à la suture et parfois subimpressionnées vers les angles postéro-externes; finement, très-densement et râpeusement ponctuées ; d'un noir de poix généralement peu brillant, avec la marge apicale finement liserée de testacé plus ou moins obscur, et la suture parfois un peu roussâtre; ciliées-spinosulées à leur bord postérieur; finement et subéparsement ou modérément pubescentes, avec quelques légères soies redressées sur les côtés, dont 2 notamment plus longues, l'une vers le tiers antérieur, l'autre vers les épaules. Celles-ci cachées.

Abdomen assez allongé; un peu moins large que les élytres; subgraduellement et assez fortement atténué en arrière; convexe sur le dos, avec les 3 premiers segments à peine impressionnés en travers à leur base; éparsement et longuement sélosellé; assez finement et densement ponctué vers sa base, un peu moins densement vers l'extrémité; à $2^{e}$ segment basilaire parfois découvert et lisse; d'un noir de poix brillant, avec le 


\section{STAPHYLINIENS. - Quedius}

sommet subirisé et d'un roux obscur; à pubescence assez longue et un peu plus serrée que celle des élytres. Le $6^{\circ}$ segment à peine arrondi au sommet.

Dessous du corps aspèrement pointillé, finement pubescent, d'un noir brillant, avec le repli du prothorax, l'antépectus et le médipectus roux, et l'extrémité du venıre d'un roux de poix irisé. Dessous de la tête à fond lisse, avec quelques points pileux. Prosternum subcaréné. Mésosternum cilié vers son sommet. Métasternum subdéprimé, parfois obsolètement et finement canaliculé en arrière, sur sa ligne médiane. Ventre convexe, éparsement sétosellé, irisé-rosé; à $2^{2}$ arceau basilaire prolongé sur le

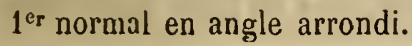

Pieds aspèrement pointillés, finement pubescents, d'un roux testacé, avec la base des hanches postérieures rembrunie. Cuisses antérieures à peine spinosules en dessous; les postérieures plus grêles, allongées. Tibias antérieurs assez étroits, à peine épineux. Tarses antérieurs à 3 premiers articles plus $\left(\sigma^{*}\right)$ ou moins ( $q$ ) dilatés, le $4^{\mathrm{e}}$ moins sensiblement; les posterieurs à $1^{\text {er }}$ article assez allongé, subégal aux 2 suivants réunis, subégal au dernier : les $2^{\mathrm{e}}$ à $4^{\mathrm{e}}$ graduellement plus courts.

Patrie. On prend celle espèce, peu communément, toul l'été, parmi les détritus et les mousses humides des forèts et lieux marécageux, dans les environs de Paris et de Lyon, la Normandie, les Alpes, les Pyrénées, etc.

OBs. Elle est remarquable par ses élytres peu brillantes, à ponctuation très-scrrée et râpeuse, finement liserées de roux à leur sommet et sans tache humérale. Le $3^{\mathrm{e}}$ article des antennes est peu allongé, et le per $^{\text {erticle }}$ des tarses postérieurs est moins long que dans l'oblitteratus.

Chez les immatures, le corps est d'un roux de poix, avec la tête noire ou obscure, et la marge abdominale des segments abdominaux d'un roux leslacé.

Nous avons vu un exemplaire beaucoup moindre ( 4 millim.) et presque entièrement noir, à éiytres sans liscré apparent.

Du reste, cette espèce est très-variable, et sa synonymie difficile à établir.

\section{Quedius (Sauridus) riparius, KeLLNER.}

Assez allongé, subfusiforme, subdéprimé, finement pubescent, d'un noir brillant, avec les élytres à peine bronzées, les genoux et les tarses roux. 
Tète et prothorax lisses, luisants : celui-ci subtransver'se, rétréci en avant. Écusson lisse. Élytres d'un tier's plus longues que le prothorax, assez densement ponctuées. Abdomen assez finement et assez densement ponctué, à peine irisé, paré sur les côtés de plaques d'une pubescence d'un gris cendré. Le $1^{\mathrm{er}}$ article des tarses postérieurs un peu moins long que le dernier.

$\sigma^{*}$ Le $6^{e}$ arceau ventral sensiblement et angulairement échancré à son sommet, avcc un espace oblong, lisse au devant de l'échancrure. Le $5^{\mathrm{e}}$ à peine sinué dans le milieu de son bord apical, avec un léger espace lisse, au devant du sinus.

우 Le $6^{\mathrm{c}}$ arceau ventral subarrondi au sommet, le $5^{\mathrm{e}}$ simple.

Quedius riparius, Kellner, Stett. Ent. Zeit. 1843, IV, 31.- Krattz, Ins. Deut. II, ว̈18, 32. - Fauvel, Faun. Gallo-Rhén. III, 498, 1.

$$
\text { Long., } 0^{\mathrm{m}}: 0059 \text { (2 2/3 l.); - larg., } 0^{\mathrm{m}}: 0014 \text { (2/3 l.). }
$$

Corps assez allongé, subfusiforme, subdéprimé, d'un noir brillant, avec les élytres à peine bronzées ; revêtu sur celles-ci et l'abdomen d'une fine pubescence grisâtre et modérément serrée, condensée en plaques sur les côtés de ce dernier.

Tête suborbiculaire, étranglée à sa base, un peu moins large que le prothorax ; éparsemeut sétosellée sur les côtés ; d'un noir luisant; lisse ; distinctement ponctuée sur les tempes; parée de chaque côté, en dedans de celles-ci, d'une série oblique de 3 gros points enfoncés, dont l'intermédiaire parfois moindre. Front large, subconvexe, à pore juxta-oculaire gros. Cou glabre, lisse, à peine plus large que la moitié du diamètre de la tête, les yeux compris. Épistome subvertical, corné, brunâtre. Labre d'un noir brillant, fortement sétosellé en avant. Parties de la bouche brunâtres, avec les mardibules souvent moins foncées.

Yeux grands, assez saillants, subovales, obscurs.

Antennes suballongées, de la longueur de la lête et du prothorax réunis, à peine épaissies, finement duveteuses et légèrement pilosellées; noirătres; à $1^{\mathrm{er}}$ article en massue allongée : le $2^{\mathrm{e}}$ obconique, oblong : le $3^{\mathrm{e}}$ obcoıique, allongé, beaucoup plus long que le $2^{\mathrm{e}}$ : les suivants graduellement à peine plus épais et un peu plus courts, peu contigus, obconiques, tous plus longs que larges, avec les $4^{\mathrm{e}}$ à $6^{\mathrm{e}}$ suballongés ou oblongs et les pé- 
nultièmes suboblongs : le dernicr ovale-oblong, obliquement tronquć au bout et acuminé inférieurement.

Prothorax subtransverse, plus ou moins létréci en avant; à peine moins large que les élytres ; tronqué ou à peine échancré au sommet, avec les angles antérieurs infléchis ei subarrondis; subarqué sur les côtés, vu de dessus, avec ceux-ci, vus latéralement, subrectilignes en arrière ; subarrondi à sa base ainsi qu'aux angles postérieurs; subconvexe sur son disque; éparsement et sérialement sétosellé sur les côtés; à gros pore sétifère latéral situé assez près de la marge; d'un noir luisant; lisse ; offrant en avant 2 séries dorsales, divergentes antérieurement et composées de 3 points médiccres et, de chaque côté, d'l autre point semblable, situé près du dorsal antérieur.

Écusson lisse, glabre, d'un noir luisant.

Élytres en carré suboblong, un peu plus larges en arrière qu'en avant, d'un liers plus longues que le prothorax; subdéprimées ou à peine convexes, avec la suture un peu relevée; assez finement, nettement et assez densement ponctuées; d'un noir brillant, à peine bronzé et rarement un peu bleuâtre; ciliées-subspinosulées à leur bord apical ; finement et modérément pubescentes sur leur disque, avec des poils subredressés et subconvergents sur la suture, plus pâles et d'un blond brillant, et quelques légères soies redressées sur les côtés, dont 2 plus obscures et plus longues, l'une vers le quart antérieur, l'autre sur les épaules. Celles-ci trèspeu saillantes, subépineuses en dessous.

Abdomen peu allongé, un peu moins large que les élytres; sensiblement atténué en arrière; subconvexe sur le dos, avec les $2^{\mathrm{e}}$ et $3^{\mathrm{e}}$ segments sensiblement impressionnés en travers à leur base et le $1^{\text {er }}$ presque enlièrement caché ; éparsement et très-longuement sétosellé, avec les soies à reflets pâles ; assez finement et assez densement ponctué, très-éparsement sur le $6^{\mathrm{e}}$ segment, lisse sur la marge postérieure du $5^{\mathrm{e}}$; d'un noir brillant, souvent un peu irisé, surtout en arrière; revêtu d'une fine pubescence modérément serrée, condensée en plaques triangulaires d'un gris cendré, sur les côtés des $2^{\mathrm{e}}$ à $5^{\mathrm{e}}$ segments. Le $6^{\mathrm{e}}$ étroit, arrondi au sommet.

Dessous du corps aspèrement ponctué, finement pubescent, d'un noir brillant. Dessous de la tête presque lisse ou très-éparsement ponctué en arrière. Prosternum relevé en faîte sur sa ligne médiane. Métasternum subconvexe. Ventre convexe, éparsement et longuement sétosellé, à $1^{\mathrm{er}}$ arceau normal caché ou enfoui.

Pieds aspèrement pointillés, finement pubescents, obscurs ou brund- 
tres, avec les trochanter's couleur de poix, les genoux et les tarses roux, Cuisses postérieures plus grêles et un peu plus longues que les autres. Tibias antérieurs assez forts, non ou à peine épineux. Tarses antérieurs à 4 premiers articles plus ou moins fortement dilatés; les postérieurs à $1^{\text {er }}$ article suballongé, à peine égal aux 2 suivants réunis, un peu moins long que le dernier : les $2^{\mathrm{e}}$ à $4^{\mathrm{e}}$ oblongs, graduellement plus courts.

Patrie. Cette espèce se prend, en août, sous les mousses et les détritus, au bord des ruisseaux, dans les Alpes et les Pyrénées. Elle est rare.

OBs. Elle ressemble un peu au $Q$. mesomelinus, mais les yeux sont plus grands et la taille est moindre. Indépendamment de la couleur, elle diffère des précédents par son abdomen paré sur les côtés de plaques d'un gris cendré, et par ses élytres plus longues. La tête est plus étranglée en arrière, avec les 3 points postoculaires en série oblique assez régulière. Le cou, un peu plus étroit, est à peine plus large que la moitié du plus grand diamètre de la tête, les yeux compris.

Parfois on aperçoil 2 petits points accidentels, disposés transversalement, en arrière de l'épistome.

\section{Quedius (Sauridus) Kraatzi, C. Brasout.}

Suballongé, subfusiforme, subdéprimé, finement pubescent, d'un noir de poix un peu bronzé, avec la bouche, la base des antennes, l'extrémité de l'abdomen, la marge des segments, les cuisses et le sommet des tarses d'un roux subtestacé, les tibias et les élytres d'un roux de poix obscur, celles-ci un peu bronzées, à marge apicale plus pâle. Tèle et prothorax lisses, luisants : celui-ci subtransverse, rétréci en avant, Front 4-ponctué. Écusson lisse. Élytres d'un tiers plus longues que le prothorax, assez finement et densement ponctuées, à pubescence brillante. Abdomen finement et densement ponctué, fortement irisé, à pubescence condensée sur les côtés en plaques cendrées. Le $1^{\mathrm{er}}$ article des tarses postérieurs un peu moins long que le dernier.

or Nous est inconnu.

Q Le $6^{\text {e }}$ arceau ventral arrondi au sommet. 
Quedius Kraatzi, Ch. Brisout, Ann. Soc. Ant. Fr. 1859, Bull. 231. - Fauvel, Faun, Gallo-Rhén. III, 498, 2.

$$
\text { Long., } 0^{\mathrm{m}}, 006 \text { (2 3/4 l.); - larg., 0 } 0^{\mathrm{m}}, 0015 \text { (2/3 l.). }
$$

Corps suballongé, subfusiforme, subdéprimé, d'un noir de poix un peu bronzé, avec les élytres d'un roux de poix obscur'; revêtu sur celles-ci et l'abdomen d'une pubescence blonde, plus ou moins serrée, condensée en plaques sur les côtés de ce dernier.

Tête suborbiculaire, subétranglée à sa base, moins large que le prothorax; éparsement sétosellée sur les côtés ; d'un noir de poix luisant et un peu bronzé; lisse ou très-finement chagrinée ; distinctement ponctuée sur les tempes; marquée de chaque côté, en dedans de celles-ci, d'une série oblique et subarquée de 3 gros points enfoncés, dont l'antérieur encore plus gros. Front large, subconvexe, creusé sur son milieu de 2 gros points transversalement rapprochés, outre les juxta-oculaires. Cou glabre, lisse, un peu plus large que la moitié du diamètre de la tête, les yeux compris. Épistome subvertical, corné, brunâtre. Labre d'un noir de poix, sétosellé en avant. Parties de la bouche rousses.

Yeux grands, assez saillants, subovales, obscurs ou livides.

Antennes médiocres, un peu moins longues que la tête et le prothorax réunis ; à peine épaissies; très-finement duveteuses et légèrement pilosellées; deun roux brunâtre, avec le $1^{\text {er }}$ article plus clair; celui-ci en massue allongée : le $2^{\mathrm{e}}$ oblong, obconique : le $3^{\mathrm{e}}$ suballongé, obconique, plus long que le $2^{\mathrm{e}}$ : les suivants graduellement à peine plus épais et un pea plus courts, non contigus, obconico-subcylindriques : les $4^{\circ}$ à $6^{\circ}$ oblongs, les pénultièmes subcarrés : le dernier ovalaire, acuminé inférieurement au sommet.

Prothorax subtransverse, rétréci en avant, de la longueur des élytres; à peine échancré au sommet, avec les angles antérieurs infléchis et subarrondis ; arcuément subdilaté sur le milieu de ses côtés; arrondi à sa base ainsi qu'aux angles postérieurs; subconvexe sur son disque; distinctement sétosellé sur les côtés; à gros pore sétifère latéral situé assez près de la marge; d'un noir de poix luisant et un peu bronzé, avec les côtés moins foncés; lisse; offrant en avant 2 séries dorsales composées de 3 ou parfois seulement de 2 points assez forts, et flanqués de chaque côté de 2 points semblables.

Écusson glabre, lisse ou finement chagriné, d'un noir de poix un peu bronzé. 
Elytres en carré suboblong, un peu plus larges en arrière qu'en avant, d'un tiers plus longues que le prothorax; subdéprimées; subsillorincees, surtout en arrière, le long de la suture; assez finement, densement et râpeusement ponctuées ; d'un roux de poix obscur et un peu bronzé, avec un liseré plus pâle au bord apical; ciliées-spinosulées le long de celui-ci; recouvertes sur leur disque d'une pubescence assez serrée, blonde, brillante sous cerlain jour, avec 2 séries dorsales de soies obscures, redressées mais un peu inclinées en arrière, l'une près de la suture, l'autre près des côtés ; ceux-ci éparsement et finement sétosellés, avec 2 soies plus longues, plus fortes et plus obscures, près des épaules. Cielles-ci effacées, épineuses en dessous.

Abdomen suballongé, un peu moins large que les élytres, fortement atténué en arrière ; subconvexe sur le dos, avec les $2^{\mathrm{e}}$ et $3^{\mathrm{e}}$ segments légèrement impressionnés en travers à leur base et le $1^{\text {er }}$ presque entièrement caché; éparsement et longuement sétosellé; finement, densement et subrâpeusement ponciué, plus éparsement sur la partie postérieure du dos de chaque segment ; d'un noir de poix assez brillant et fortement irisé, avec la marge apicale des segments d'un roux subtestacé, celle des 2 derniers plus largement; revêtu d'une fine pubescence serrée et couchée, condensée en plaques triangulaires et cendrées, sur les côtés des $2^{\mathrm{e}}$ ì $5^{\mathrm{e}}$ segments. Le $6^{\mathrm{e}}$ moins ponctué, subarrondi au sommet.

Dessous du corps aspèrement ponctué, finement pubescent, d'un brun de poix assez brillant, avec l'antépectus, le sommet du ventre et la marge apicale des arceaux d'un roux testacé. Dessous de la tête presque lisse, un peu ponctué à la base. Prosternum relevé en faite ou en dos d'âne. Métasternum peu convexe. Ventre convexe, éparsement et longuement sétosellé, plus ou moins irisé.

Pieds aspèrement pointillés, finement pubescents, d'un roux plus ou moins testacé, avec les tibias et la base des tarses plus obscurs. Cuisses postérieures plus étroites et un peu plus longues que les autres. Tibias antérieurs peu robustes, simplement pubescents. Tarses antérieurs à 3 premiers articles fortement dilatés, le $4^{\ominus}$ moins fortement; les postérieurs à $1^{\text {er }}$ article suballongé, à peine égal aux 2 suivants réunis, un peu moins long que le dernier : les $2^{\mathrm{e}}$ à $4^{\mathrm{e}}$ oblongs, graduellement plus courts.

Patrie. Gette espèce est très-rare. Elle se prend au bord des ruisseaux, dans la chaine des Pyrénćes. M. Valćry Mayet l'a prise à la Massane (Pyrenées-Orientales). 
OBs. Elle a la forme du riparius. Outre la coloration, elle s'en distingue par son front 4 -ponctué.

Cette espèce et la précédente répondent au groupe 1 de $\mathbf{M}$. Fauvel, qui lui donne, entre autres caractères, une tête rétrécie en avant des antennes, très-étranglée à la base; - un cou petit, étroit; - des yeux médiocres. Nous n'avons pas vu la tête plus rétrécie en avant des antennes que dans les autres groupes. Elle est effectivement sensiblement étranglée à sa base chez le $Q$. riparius, un peu moins chez le Kraatzi ; mais les $Q$. peltatus, suturalis, alpestris, auricomus, boops, etc., présentent aussi une semblable conformation, quoique plus faiblement. On peut en dire autant du cou, qui est plus ou moins large, mais jamais absolument étroit, car il est toujours plus large que la moitié du plus grand diamètre de la tête. Quant aux yeux, nous les avons vus grands, occupant environ les deux tiers des côtés de la tête.

\section{Quedius (Sauridus) Iueidulus, ERICHSON.}

Allongé, fusiforme, peu convexe, finement pubescent, d'un bronzé brillant et assez clair, avec les élytres d'un roux bronzé, l'abdomen brunâtre, la bouche, la base des antennes et les pieds d'un roux plus ou moins testacé. Tête et prothorax lisses, luisants : celni-ci aussi long que large, rétréci en avant. Front 4-ponctué. Écusson presque lisse. Ėlytres un peu plus longues que le prothorax, assez finement et assez densement ponctuées. Abdomen finement et très-densement pointillé vers sa base, à peine moins densement en arrière, irisé. Le $1^{\text {er }}$ article des tarses postérieurs suballongé, à peine égal au dernier.

$\sigma^{*}$ Le $6^{\mathrm{e}}$ arceau ventral très-faiblement, largement et subangulairement sinué dans le milieu de son bord apical, a vec un large espace triangulaire, subimpressionné, lisse, au devant du sinus.

\& Le $6^{\mathrm{e}}$ arceau ventral subarrondi au sommet.

Quedius lucidulus, Erichson, Col. March. I, 495, 17; - Gen. et Spec. Staph. : 550 , 40. - Fatrmaire et laboulbène, Faun. Ent. Fr. I, 541, 22, obs. 2e. - Kraatz, Ins. Deut. II, 520, 34. - SEIDLITz, Faun. Balt. 264. - Fauvel, Faun. Gallo-Rhén. III, $527,38$.

BR. 


$$
\text { Long., } 0^{\mathrm{m}}, 0054 \text { (2 1/2 1.); - larg., } 0^{\mathrm{m}}, 0011 \text { (1/2 l.). }
$$

Corps allongé, fusiforme, peu convexe, d'un bronzé brillant et assez clair, avec les élytres rousses et l'abdomen d'un roux brunâtre; revêtu sur celles-là et sur celui-ci d'une pubescence blonde et assez longue, plus serrée sur ce dernier.

Tête médiocre, subarrondie, plus étroite que le prothorax ; éparsement et longuement sétosellée sur les côtés ; d'un bronzé luisant et assez clair; lisse; marquée derrière les yeux de 2 points sétifères dont l'interne beaucoup plus gros, et, de chaque côté, sur le vertex, de 2 aut res points assez petits et transversalement rapprochés. Front large, à peine convexe, noté entre les yeux de 2 petits points écartés, outre les juxta-oculaires qui sont plus gros. Cou glabre, lisse. Épistome submembraneux, d'un roux livide. Labre roux, à peine bilobé ou simplement fendu en avant. Mandibules et palpes roux : ceux-ci à dernier article conique.

Yeux grands, ovales, peu saillants, obscurs, lavés de gris.

Antennes courtes, assez robustes, un peu plus longues que la tête; visiblement épaissies; finement duveteuses et légèrement pilosellées; d'un roux brunátre, avec le $1^{\mathrm{er}}$ article plus clair : celui-ci en massue allongée ; les $2^{\mathrm{e}}$ et $3^{\mathrm{e}}$ oblongs, obconiques, assez épais : le $3^{\mathrm{e}}$ à peine plus long que le $2^{\mathrm{e}}$ : les suivants graduellement un peu plus courts et plus épais, subcontigus, subobconiques : le $4^{\mathrm{e}}$ à peine oblong : les $5^{\mathrm{e}}$ et $6^{\mathrm{e}}$ presque carrès : les $7^{\mathrm{e}} \mathrm{a} 10^{\mathrm{e}}$ subtransverses ou transverses : le dernier ovalaire, inférieurement acuminé au sommet.

Prothorax aussi long que large, plus ou moins rétréci en avant, de la largeur des élytres; largement tronqué ou à peine échancré au sommet. avec les angles antérieurs infléchis, presque droits mais èmoussés; subarqué sur les côtés; arrondi à sa base ainsi qu'aux angles postérieurs ; assez convexe sur son disque; légèrement sétosellé sur les côtés, avec le pore sétifère latéral situé assez loin de la marge; d'un bronzé luisant et assez clair ; lisse; marqué en avant de 2 séries dorsales, divergentes antérieurement et composées de 3 points médiocres et subégalement distants; offrant en outre, de chaque côté, 3 autres points écartés, disposés en triangle, situés entre le gros pore latéral et les $1^{\text {er }}$ et $2^{\mathrm{e}}$ des séries dorsales.

Écusson glabre, presque lisse, d'un bronzé luisant.

Élytres subcarrées, un peu plus larges en arrière qu'en avant ; évidem- 
ment un peu plus longues que le prothorax ; subdéprimées on à peine convexes ; assez finement et assez densement ponctuées ; d'un roux assez brillant et plus ou moins bronzé ; ciliées-subspinosulées à leur bord postérieur ; finement et modérément pubescentes, avec quelques légères soies redressées, sur les côtés, dont 2 notamment plus longues, l'une vers le tiers antérieur, l'autre vers les épaules. Celles-ci cachées.

Abdomen peu allongé, moins large que les élytres; graduellement et assez fortement atténué en arrière; convexe sur le dos, avec les 3 premiers segments à peine impressionnés en travers à leur base; fortement sétosellé ; finement et très-densement pointillé vers sa base, à peine moins densement en arrière; d'un brun plus ou moins roussâtre et peu brillant, avec la partie dorsale plus foncée et plus ou moins irisée; à pubescence fauve ou blonde et assez serrée, condensée, de chaque côté, en une large bande longitudinale. Le 6 e segment roux, subarrondi au sommet.

Dessous du corps aspèrement pointillé, pubescent, d'un brun de poix brillant, avec le repli du prothorax, le prosternum, le mésosternum et l'extrémité du ventre plus ou moins roux. Dessous de la tête presque lisse ou avec quelques rares points pileux. Prosternum relevé en faite. JIésosternum court, cilié vers son sommet. Métasternum subdéprimé. Ventre convexe, éparsement sétosellé, plus ou moins irisé; à $2^{\mathrm{e}}$ arceau basilaire arrondi à son bord postérieur.

Pieds aspèrement pointillés, finement pubescents, d'un roux testacé plus ou moins pâle, avec les tibias plus foncés et les hanches postérieures rembrunies. Cuisses antérieures élargies, à peine spinosules en dessous; les postérieures un peu plus longues, moins épaisses. Tibias antérieurs subélargis de la base au sommet, peu épineux. Tarses antérieurs à 4 premiers articles fortement, mais graduellement un peu moins élargis; les postérieurs à $1^{\text {er }}$ article suballongć, subégal aux 2 suivants réunis, à peine égal au dernier : les $2^{\mathrm{e}} \mathrm{à} 4^{\mathrm{e}}$ graduellement plus courts.

Patrie. Cette espèce, médiocrement commune, se prend dans lẹs crottins et les champignons, en juillet et aoul, dans les régions montagneuses ou boisées : la Normandie, les Vosges, l'Auvergne, le mont Pilat, les Alpes de la Sэvoie et du Dauphiné, les Landes, les Pyrénées, etc.

OBs. Elle est d'une taille beaucoup moindre que le Krautzi. La tête est moins étranglée en arrière, avec le cou relativement plus large. Le labre est à peine bilobé. Le dernier article des palpes est un peu moins long, plus exactement conique. Les antennes, plus courtes, ont leurs pénul- 
tièmes articles visiblement transverses ou subtransverses. Les séries dorsales du prothorax sont composées de 3 points au lieu de 2 , en comptant le submarginal. Les élytres sont moins longues, elles ne recouvrent pas tout à fait autant le $1^{\text {er }}$ segment abdominal. L'abdomen, un peu moins acuminé en arrière, a sa pubescence un peu plus serrée sur les cótés, mais moins distinctement condensée en taches sur ceux-ci, etc.

L'abdomen est parfois entièrement roux, tant en dessus qu'en dessous.

\section{Quedius (Sauridus) seintillans, Gravenhorst.}

Allongé, fusiforme, subconvexe, finement pubescent, d'un noir bronzé brillant, avec les élytres moins foncées, la base des antennes, les palpes et les pieds d'un roux subtestacé. Tête et prothorax lisses, luisants : celui-ci aussi long que large, subrétréci en avant. Front 4-ponctué. Écusson presque lisse. Élytres un peu plus longues que le prothorax, assez finement et moderément ponctuées. Abdomen finement et densement ponctué vers sa base, un peu moins en arrière, fortement irisé, garni sur les côtés d'une longue pubescence serrée et à reflets dorés. Le $1^{\mathrm{er}}$ article des tarses postérieurs subégal au dernier.

$\sigma^{*}$ Le $6^{\text {e }}$ arceau ventral faiblement et angulairement sinué dans le milieu de son bord apical, avec un espace oblong, assez étroit, parfois subsulciforme, lisse, au devant du sinus.

\& Le 6e arceau ventral subarrondi au sommel.

Staphylinus scintillans, Gravenhorst, Mon. 70, 53.

Quedius scintillans, Erichson, Col. March. I. 494, 16 ; - Gen. et Spec. Staph. 549 39. - Perris, Ann. Soc. Ent. Fr. 1853, 572. - Fairmaire et Labouldène, Faun. Ent. Fr. I, 541, 22. - KraATz, Ins. Deut. If, 519, 33. - FavveL, Faun. GalloRhén. III, 527, 37.

Quedius monspeliensis, FaIRMaire, Ann. Soc. Ent. Fr. I, 1857, 636. Raphirus scintillans, Тномsом, Skand. Col. II, 178, 3.

Variété a. Élytres d'un roux testacé.

Emus vicinus, Boisduval et Lacordare, Faun. Ent, Par. I, 383, 39. Quedius vicinus, ErIcuson, Gen. et Spec. Staph. 552, 45.

Long., $0^{\mathrm{m}}, 0054$ (2 1/2 l.); - larg., $0^{\mathrm{m}}, 0011$ (1/2 l.). 
Corps allongé, fusiforme, subconvexe, d'un noir bronzé, avec les élytres brunâtres; revêtu sur celles-ci d'une fine pubescence d'un gris foncé, plus longue, plus serrée et d'un blond doré sur l'abdomen.

Tète médiocre, subarrondie, moins large que le prothorax; éparsement sétosellée sur les còtés; d'un noir bronzé luisant; lisse ou à peine chagrinée; offrant derrière les yeux 2 points sétifères dont l'interne plus gros, et, de cbaque côté, sur le vertex, 2 autres petits points, transversalement rapprochés. Front large, subconvexe, marqué sur son milieu, outre les 2 points juxta-oculaires qui sont assez forts, de 2 petits points écartés. Cou glabre, lisse. Existome subcorné, brunâtre. Labre d'un brun de poix, parfois roussâtre, à peine bilobé, sétosellé en avant. Mandibules d'un roux de poix. Palpes d'un roux parfois assez obscur, à dernier article conique.

Yeux grands, ovales, peu saillants, obscurs, souvent micacés.

Antennes courtes, un peu plus longues que la tête; subépaissies; finement duveteuses et légèrement pilosellées; d'un roux de poix ou brunâtres, avec le $1^{\text {er }}$ article plus clair; celui-ci en massue allongée: les $2^{\mathrm{e}}$ el $3^{\mathrm{e}}$ suballongés, obconiques, le $3^{\mathrm{e}}$ un peu plus grêle et à peine plus long que le $2^{\mathrm{e}}$ : les suivants graduellement un peu plus courts et un peu plus épais, peu contigus, subobccniques : les $4^{\mathrm{e}}$ et $5^{\mathrm{e}}$ suboblongs : le $6^{\mathrm{e}}$ aussi long que large : les pénultièmes subtransverses ou transverses : le dernier subovalaire, acıminé inférieurement.

Prothorax aussi long que large, plus ou moins rétréci en avant; de la largeur des élytres; largement tronqué au sommel, avec les angles antérieurs infléchis, presque droits mais subarrondis ; subarqué sur les côtés; subarrondi à sa base ainsi qu'aux angles postérieurs; subconvexe sur son disque; éparsement sétosellé sur les côtés, avec le pore sétifère latéral gros et situé assez loin de la marge; d'un noir bronzé luisant; lisse; marqué en avant de 2 séries dorsales sensiblement divergentes antérieurement et composées do 3 points médiocres el subégalement distants; offrant en outre, de chaque côté, 3 petits points écartés et disposés en triangle, sans compter le gros pore latéral, et situés entre celui-ci et les $1^{\text {er }}$ et $2^{\circ}$ des séries dorsales.

Ecusson glabre, presque lisse, d'un noir de poix brillanı.

Elytres subcarrées, un peu plus larges en arrière qu'en avant; un peu plus longues que le prothorax; subdéprimées ou faiblement convexes; parf is subsillonnées en arrière le long de la suture; assez finement et modérément ou peu densement poncluées; d'un brun de poix bronzé et m 
brillant, avec la tranche apicale même parfois subtranslucide; ciliéessubspinosulées à leur bord postérieur; subéparsement et assez longuement pubescentes, avec quelques légères soies redressées sur les côtés, dont 2 beaucoup plus longues, l'une vers le tiers antérieur, l'autre vers les épaules. Celles-ci cachées.

Abdomen peu allongé, un peu moins large que les élytres ;"assez fortement et subarcuément atténué en arrière; convexe sur le dos, avec les 3 premiers segments à peine impressionnés en travers à leur base; éparsement et longuement sétosellé ; finement et densement ponctué vers sa base, un peu moins densement en arrière ; à $2^{\mathrm{e}}$ segment basilaire parfois découvert et lisse; d'un noir de poix brillant et fortement irisé, avec le sommet d'un brun de poix souvent un peu roussatre; à pubescence longue, d'un gris blond ou doré, plus apparente ou bord apical des 4 premiers segments et condensée de chaque côté, où elle forme comme une large bande longitudinale. Le $6^{\mathrm{e}}$ segment plus ou moins arrondi au sommet.

Dessous du corps aspèrement ponctué, pubescent, d'un noir de poix brillant, avec le repli du prothorax et le prosternum brunâtres, et l'extrémité du ventre souvent d'un roux obscur. Dessous de la tête lisse, avec quelques points pileux, vers la base. Prosternum gibbeux ou relevé en faite mousse. Mésosternum court, cilié vers son sommet. Métasternum peu convexe, subcanaliculé en arrière sur sa ligne médiane. Ventre convexe, éparsement sétosellé, fortement irisé; à $2^{\mathrm{e}}$ arceau basilaire arrondi à son bord postérieur.

Pieds aspèrement pointillés, finement pubescents, d'un roux testacé, avec les hanches, au moins les intermédiaires et postérieures, rembrunies. Cuisses antérieures épaissies, à peine spinosules en dessous; les postérieures à peine plus longues, moins épaisses. Tibias antérieurs subélargis de la base au sommet, peu épineux. Tarses antérieurs à 4 premiers articles fortement, mais graduellement un peu moins élargis; les postéricurs à $1^{\text {er }}$ article suballongé, subégal aux 2 suivants réunis, subégal au dernier : les $2^{\mathrm{e}} \mathrm{à} 4^{\mathrm{e}}$ graduellement plus courts.

Patrie. Cette espèce se prend dès le premier printemps, sous les écorces, les détritus végétaux et les feuilles mortes des lieux humides, principalement dans les contrées méridionales : la Provence, le Languedoc, les Landes, etc. Elle est peu commune. Nous ne l'avons jamais capturèe daus les environs de Lyon.

OBs. Elle est d'une couleur plus obscure que le lucidulus. Les élytres 
sont un peu moins longues, plus foncées, moins densement ponctuées. Les antennes sont un peu moins robustes, avec la tête un peu moins courte, etc.

Chez les plns adultes, toutes les hanches sont rembrunies, ainsi que souvent la base des antennes, le milieu des cuisses et des tibias intermé diaires et postérieurs. Chez les immatures, les côtés du prothorax se montrent d'un roux de poix, et ceux des élytres sont roux, ou bien celles-ci deviennent quelquefois entièrement d'un roux testacé, et c'est sans doute à cette variété qu'il faut attribuer le vicinus de Boisduval et Lacordaire.

Les exemplaires des Apennins ont la taille généralement un peu plus forte et la couleur d'un bronzé moins obscur. Les élytres paraissent un peu moins parallèles et à peine plus fortement ponctuées, et les pénultièmes articles des antennes à peine plus transverses (1).

Le fuscipes de Stephens (Ill. Brit. V, 243) s'applique peut-être aux variétés à pieds rembrunis.

M. Perris, dans son admirable travail sur les insectes du pin maritime, a fait connaitre les métamorphoses du Quedius scintillans. Sa larve, remarquable par les poils spatuliforines de son abdomen, vit, suivant cet habile observateur, sous les écorces d'arbres, au milieu des excréments des insectes xylophages, dont elle attaque probablement aussi les larves (Ann. Soc. Ent. Fr. 1853, 570, pl. 17, fig. 37-43).

Le $Q$. scintillans et les 2 espèces précédentes forment comme un petit groupe à part, à front 4-ponctué.

\author{
SOUS-GENRE RAPHIRUS, STEPIENS (2). \\ StBpilevs, III. Brit. v, p. 2 't1. \\ Ėtymologie : incertaine.
}

Caractỉies. Yeux très-garands, occupant presque entièrement les côtés de la lête. Labre bilobé ou subbilobr, qu' lquefois presque enticr. Le

(1) Nous avons vu un exemplaire de la Toscane, communiqué par MI. Revelière, et dont les élytres, d'un bronzé roussâtre, paraissent un peu plus finement et à peine, plus densement ponctuées. Cette variété semble faire passage au lucidulus, mais la pubescence de l'abdomen est celle du scintillans. Nous l'appellerons Quedius etruscus, nobis.

(2) Ce mème sous-genre ne répond qu'en partie à celui de Thomson (Skand. Col. II, p. 177). 
dernier article des palpes maxillaires conico-fusiforme ou conique. Cuisses antérieures et souvent les intermédiaires spinosules en dessous ; les postérieures gėnéralement mutiques ou simplement ciliées. Tibias antérieurs ordinairement peu robustes, ou même assez grêles. Le $1^{\text {er }}$ article des tarses postérieurs subégal au dernier, rarement plus long que celui-ci. Abdomen plus ou moins fortement atténué en arrière. Prosternum relevé en carène ou en faîte arqué. Corps subfusiforme ou fusiforme.

Nons donnerons également, en 2 tableaux, les caractères des diffërentes espèces du sous-genre Raphirus.

a. Écusson lisse. Le $1^{\text {er }}$ article des tarses postériewrs à peine égal au dernier.

b. Labre distinctement bilobé. Le dernier article des palpes maxillaires allongé, grèle, conico-fusiforme. Antennes suballongées. abdomen irisé, à pubescence normale. . . . . . . . pyrenaeus.

bb. Labre entier ou presque entier. Le dernier article des palpes maxillaires oblong, tout à fait conique. Antennes courtes, $\dot{a}$ p $\dot{c}-$ nultièmes articles subtransverses.

c. Abdomen peu irisé, subconcolore, à pubescence normale. Taille très-petite. . . . . . . . . . . . . . . .

cc. Abdomen irisé, paré, de chaque côté, d'une série de 5 taches triangulaires, bien tranchées et formées de poils d'un doré brillant. Taille petite. . . . . . . . . . Auricomus.

\section{4r. Quediug (Raphirus) pyrenaeus, Сн. BRIsour.}

Suballongé, subfusiforme, subdéprimé, légèrement pubescent, d'un noir brillant, avec la bouche, les antennes et les pieds roux, et un très-faible liseré d'un roux de poix au bord apical des élytres. Tête et prothorax lisses, luisants : celui-ci subtransverse, "réiréci en avant. Écusson lisse. Élytres de la longueur du prothorax, assez fortement et assez densement ponctuées. Abdomen assez fortement et peu densement ponctué, irisé. Le $1^{\mathrm{er}}$ article des tarses postérieurs à peine égal au dernier.

$\sigma^{*}$ Le $6^{\text {e }}$ arceau ventral assez profondément, largement et angulairement échancrè au sommet, avec une impression subsillonnée, lisse, au devant de l'échancrure. Le $5^{\mathrm{e}}$ à peine sinué dans le milieu de son bord postérieur.Tarses anterieurs très-fortement dilatés. 
오 Le $6^{\mathrm{e}}$ arceau ventral subarrondi au sommet, le $5^{\mathrm{e}}$ simple. Tarses antérieurs médiocrement dilatés.

Quedius pyrenaeus, Cr. Brisout, Cat. Grenier, 1863, 33, 42.- Marseul, l'Abeille, 1871, VIII, 284, 246. - FaUved, Faun. Gallo-Rhén. III, 528, 39.

Variété $a$. Élytres d'un roux testacé.

$$
\text { Long., 0m,0051 (2 1/3 l.); - larg., } 0^{\mathrm{m}}, 0014 \text { (2/3 l.). }
$$

Corps suballongé, subfusiforme, subdéprimé, d'un noir brillant, avec les élytres moins brillantes; recouvert sur celles-ci et l'abdomen d'une fine pubescence grisâtre et peu serrée.

Tête assez grande, subtransversalement subarrondie, un peu moins large que le prothorax, éparsement sétosellée sur les côtés; d'un noir luisant; lisse; finement pointillée à la base des tempes ; marquée, de chaque côté, derrière les yeux, de 3 points sétifères disposés en triangle, dont l'intermédiaire gros, l'externe et l'interne très-petits ou petits. Front assez resscrré, peu convexe, à pore juxta-oculaire ovale, assez petit. Cou glabre, lisse. Epistome corné, brunâtre. Labre bilobé, d'un noir de poix, sétosellé en avant. Mandibules d'un roux de poix. Palpes roux : le dernier article des maxillaires allongé, conico-fusiforme.

Yeux très-grands, subovales, assez saillants, obscurs ou grisâtres.

Antennes suballongées, beaucoup plus longues que la tête; à peine épaissies ; finement duveleuses et distinctement pilosellées ; d'un roux ferruçineux, avec le $1^{\mathrm{er}}$ article à peine plus clair : celui-ci en massue allongée: le $2^{\mathrm{e}}$ oblong, obconique : le $3^{\mathrm{e}}$ suballongé, un peu plus long que le $2^{\mathrm{e}}$ : les suivants graduellement un peu plus courts et à peine plus épais, subobconiques, peu contigus : les $4^{\mathrm{e}}$ et $5^{\mathrm{e}}$ oblongs, les $6^{\mathrm{e}}$ à $10^{\mathrm{e}}$ un peu plus longs $\left(\sigma^{\prime}\right)$ ou all moins aussi longs ( $q$ ) que larges : le dernier suboblong, obliquement subéchancré au somnet et subacuminé inférieurement.

Prothorax subtrausverse, plus ou moins rétréci en avant; à peine plus large que les élytres; largement tronqué ou à peine échancré au sommet. avec les angles antérieurs infléchis, presque droits mais subarrondis ; plus ou moins arłuee sur les côtés, qui, vus latéralement, sont à peine subsinués en arrière ; largement arrondi à sa base, avec les angles postérieurs sensibles mais obtus; subconvexe sur le dos; légèrement sétosellé sur les côtés, avec le pore sétifère latéral situé à une distance médiocre 
de la marge; d'un noir luisant; lisse ; marqué en avant de 2 séries dorsales composées de 3 points assez forts et subégalement distants ; offrant, en outre, de chaque côté, 1 autre point semblable, situé entre le $1^{\text {er }}$ dorsal, dont il est peu éloigné, et le gros pore latéral.

Écusson glabre, lisse, d'un noir luisant.

Élytres transverses ou subtransverses, visiblement plus larges en arrière qu'en avant; aussi longues ou à peine plus courtes que le prothorax; subdéprimées; assez fortement, assez densement et râpeusement ponctuées ; d'un noir peu ou médiocrement brillant, avec parfois un liseré d'un roux obscur et à peine sensible, au bord apical et sur la suture; ciliées-subspinosulées à leur bord postérieur; finement et peu densement pubescentes, avec quelques soies redressées, sur les côtés, dont 1 beaucoup plus longue, vers les épaules. Celles-ci à calus assez saillant.

Abdomen peu allongé, un peu moins large que les élytres; subarcuément et assez fortement atténué en arrière; subdéprimé vers sa base; assez convexe postérieurement ; éparsement et longuement sétosellé; assez fortement et peu densement ponctué; d'un noir brillant et plus ou moins irisé, avec l'extrémité souvent couleur de poix ; à pubescence fine et peu serrée, uniforme et assez longue. Le $6^{e}$ segment étroit, à peine arrondi au sommet.

Dessous du corps aspèrement ponctué, finement pubescent, d'un noir brillant, avec le repli du prothorax brunâtre. Dessous de la tête glabre, presque lisse. Prosternum subcaréné. Mésosternum subconvexe, légèrement cilié vers son sommet. Métasternum à peine convexe, très-finement canaliculé sur son milieu. Ventre convexe, éparsement sétosellé, plus ou moins irisé.

Pieds éparsement pointillés, légèrement pubescents, d'un r'oux plus ou moins foncé, avec toutes les hanches et parfois la base des cuisses postérieures rembrunies. Guisses antérieures renflées, éparsement subspinosules en dessous; les postérieures assez grêles, plus longues. Tibias antérieurs assez élargis vers leur sommet, à peine épineux. Tarses antérieurs à 3 premiers articles plus $\left(\sigma^{\circ}\right)$ ou moins $(q)$ fortement dilatés, le $4^{\mathrm{e}}$ moins sensiblement; les postérieurs à $1^{\mathrm{er}}$ article suballongé, subégal aux 2 suivants réunis, à peine égal au dernier: les $2^{\mathfrak{e}}$ à $4^{\mathrm{e}}$ graduellement plus courts.

PAtrie. Cette espèce est rare. Elle se trouve, en été, sous les mousses et les écorces, dans la chaîne des Pyrénées. 
OBs. Elle a un peu la forme du peltatus, mais elle est bien moindre. Elle est un peu plus petite que l'anceps, dont elle se distingue par ses yeux plus grands, par sa couleur plus noire, par son abdomen un peu plus fortement ponctué. Le prothorax paraît un peu plus court, etc.

La variétė $a$ est remarquable par ses élytres, ses antennes et ses pieds d'un roux testacé assez clair. Elle se trouve aux Eaux-Bonnes, et elle nous a èté cơmmuniquée par M. Pandellé.

\section{Quedius (Faphirus) alpestris, HeER.}

Suballongé, subfusiforme, subdéprimué, légèrement pubescent, d'un noir bronze brillant, avec les antennes, les hanches et cuisses anterieures et intermédiaires, les genoux et les tarses roussâtres. Tête et prothorax lisses, luisants : celui-ci aussi long que large, à peine rétréci en avant. Écusson lisse. Elytres un peu plus longues que le prothorax, assez fortement et peu densement ponctuees. Abdomen finement et densement pointillé, à peine irisé. Le $\mathbf{1}^{\mathrm{er}}$ article des tarses postérieurs à peine égal au dernier.

$\sigma^{*}$ Le 6e arceau ventral légèrement et subangulairement échancré au sommet, avec un espace lisse, au devant de l'échancrure, Tarses antérieur's fortement dilatés.

․ Le $6^{\mathrm{e}}$ arceau ventral subarrondi au sommet. Tarses antérieur's médiocrement dilatés.

Staphylinus aeneipennis, HEER, Mitth. I, 75.

Philonthus alpestris, HeER. Faun. Col. Helv. I, 280, 76.

Quedius alpestris, Kraatz, Ins. Deut. II, 517, 31.-FaUvel, Faun. Gallo-Rhén. III, 529,41 .

Quedius salyrus, Kilsenwetter, Stett. Ent. Zeit. VIII, 75, - Redtenbachen, Faun. Austr. 825.

$$
\text { Long., } 0^{\mathrm{m}}, 0044 \text { (2 l.); - larg., } 0^{\mathrm{m}}, 0007 \text { (1/3 1.). }
$$

Corps suballongé, subfusiforme, subdéprimé, d'un noir dı onzé brillant; revêtu sur Ies élytres et l'abdomen d'une fine pubescence d'un gris obscur et peu serrée. 
Tête assez grande, subtransverse, à peine moins large que le prothorax; très-éparsement sétosellée sur les côtés; d'un noir bronzé luisant ; lisse , avec 3 points sétifères derrière les yeux, assez rapprochés êl disposés en triangle, dont l'intermédiaire gros, le temporal et celui du vertex petits. Front assez large, à peine convexe, à point juxta-oculaire médiocre. Cou glabre, lisse. Épistome corné, noir. Labre presque entier, noir, sétosellé en avant. Mandibules et palpes brunâtres : le dernier article des maxillaires oblong, conique.

Yeux très-grands, subovales, assez saillants, obscurs, lavés de gris.

Antennes courtes, un peu plus longues que la tête ; à peine épaissies; finement duveteuses et légèrement pilosellées; d'un roux tantôt subtestacé, tantôt assez obscur; à $1^{\text {er }}$ article en massue allongée : le $2^{\mathrm{e}}$ à peine moins épais, oblong, obconique : le $3^{\mathrm{e}}$ oblong, obconico-subeliptique, à peine plus étroit et à peine aussi long que le $2^{\mathrm{e}}$ : les suivants graduellement un peu plus courts et à peine plus épais, subobconiques, peu contigus : les $4^{\mathrm{e}}$ et $5^{\mathrm{e}}$ à peine oblongs, les pénultièmes subtransverses : le dernier ovalaire, obliquement tronqué au bout et acuminé inférieurement.

Prothorax environ aussi large que long, à peine rétréci en avant; de la largeur des élytres ; largement tronqué au sommel, avec les angles antérieurs infléchis, presque droits mais subarrondis ; subarqué sur les côtés ; arrondi à sa base ainsi qu'aux angles postérieurs ; subconvexe sur le dos ; à peine sétosellé sur les côtés, avec le pore sétifère latéral situé non loin de la marge; d'un noir bronzé luisant ; lisse; marqué en avant de 2 séries dorsales composées de 3 points médiocres et subégalement distants; offrant, en outre, de chaque côté, 1 ou 2 points moindres, situés entre le $1^{\text {er }}$ dorsal et le pore sétifère latéral.

Écusson glabre, lisse, d'un noir luisant.

Élytres subtransverses, subparallèles, un peu ou à peine p'us longues que le prothorax, subdéprimées ou faiblement convexes, avec la suture parfois un peu relevée en arrière ; assez fortement, peu densement et subrâpeusement ponctuées; d'un noir bronzé brillant; ciliées-spinosulées à leur bord apical, surtout près des angles postéro-externes; à pubescence légère et éparse sur le disque, avec quelques rares soies redressées sur les côtés, dont 1 ou 2 plus longues, près des épaules. Celles-ci cachées. Abdomen peu allongé, à peine moins large que les élytres; subatténué en arrière après son milieu ; subconvexe sur le dos, avec les 3 premiers segments à pcine impressionnés en travers à lcur base; éparsēment sétosellé ; finement et densement pointillé, à peine móins densement vers son 
extrémité; d'un noir peu brillant; à pubescence fine, un peu plus serrée que celle des élytres. Le $6^{\text {e }}$ segment plus fortement et moins densement ponctué, plus brillant, souvent couleur de poix, arrondi au sommet.

Dessous $d u$ corps aspèrement ponctué, pubescent, d'un noir brillant. Dessous de la tête presque lisse, presque glabre. Prosternum relevé en faite. Métasternum subdéprimé. Ventre convexe, éparsement sétosellé, non ou à peine irisé.

Pieds assez courts, pointillés, légèrement pubescents, d'un noir ou d'un brun de poix, avec les hanches et cuisses antérieures et intermédiaires, les genoux et tous les tarses plus ou moins roussâtres. Cuisses antérieures à peine spinosules ou simplement ciliées en dessous, assez renflées; les postérieures plus grêles, un peu plus longues. Tibias antérieuirs subélargis de la base au sommet, à peine épineux. Tarses antérieur's à 3 premiers articles plus $\left(\sigma^{*}\right)$ ou moins $(q)$ dilatés, le $4^{\mathrm{e}}$ moins sensiblement; les postérieur's à $1^{\text {er }}$ article suballongé, subégal aux 2 suivants réunis, à peine égal au dernier : les $2^{\mathrm{e}}$ à $4^{\mathrm{e}}$ graduellement plus courts.

Patrie. Cette espèce, qui est très-rare, se trouve, en juillet et août, en Savoie, à la Grande-Chartreuse, dans les Alpes-Maritimes, etc.

OBs. Elle est à peu près de la taille du microps, dónt elle se distingue par sa couleur d'un noir bronzé, par son écusson lisse, et surtout par ses yeux beaucoup plus grands, etc.

La taille est moindre que chez le pyrenaeus; le labre est moins bilobé ou presque entier; le dernier article des palpes maxillaires est moins allongé, il est tout à fait conique; les antennes sont plus courtes, avec leurs pénultièmes articles subtransverses, etc.

Souvent les élytres sont d'un bronzé verdâtre ou bleuâtre.

\section{Quedius (Raphirus) auricomus, KIESENWETTER.}

Allongé, subfusiforme, peu convexe, pubescent, d'un noir bronzé brillant, avec la bouche, les antennes et les pieds testacés, et l'abdomen par's de chaque côté de taches de poils dorés. Tête et prothorax lisses, luisants : celui-ci à peine aussi long que large, rétréci en avant. Écusson lisse. $\dot{E} l y t r e s \dot{a}$ peine plus longues que le prothorax, assez fortement et peu densement ponctuées. Abdomen finement et assez densement pointillé, 
éparsement au sommet, à peine irisé. Le $1^{\mathrm{er}}$ article des tarses postéricurs à peine égal au dernier.

$\sigma^{*}$ Le $6^{\mathrm{e}}$ arceau ventral assez profondément et subrectangulairement échancré au sommet, avec un espace triangulaire, lisse, au devant de l'échancrure. Le $5^{\mathrm{e}}$ à peine sinué dans le milieu de son bord poștérieur. Tarses antéricurs fortement dilatés.

ㄴ Le $6^{\mathrm{e}}$ arceau ventral subarrondi au sommet, le $5^{\mathrm{e}}$ simple. Tarses antérieurs assez fortement dilatés.

Quedius auricomus, Kiesenwetter, Stett. Ent. Zeit. 1850, 220; - Ann. Soc. Ent.

Fr. 1851, 420. - Fairmaire et Laboulbène, Faun. Ent. Fr, I, 540, 19. - KraAtz. Ins. Deut. II, 501, note. - Fauvec, Faun. Galio-Rhén. III, 529, 40.

$$
\text { Long., } 0^{\mathrm{m}}, 0047 \text { (2 1/5 l.); - larg., } 0^{\mathrm{m}}, 0007 \text { (1/3 I.). }
$$

Corps allongé, subfusiforme, peu convexe, d'un noir bronzé brillant; à pubescence assez grossière et dorée, éparse sur les élytres, condensée en taches sur les côtés de l'abdomen.

Tête grande, subtransverse, presque aussi large ou à peine moins large que le prothorax; très-éparsement sétosellée sur les côtés; d'un noir bronzé luisant; lisse, avec 3 points sétifères derrière les yeux, disposés en triangle et dont le temporal très-petit, l'intermédiaire, assez gros, celui du vertex médiocre et souvent accompagné, plus en dedans, d'un autre point un peu moindre. Front assez large, à peine convexe, à pore juxta-oculaire médiocre. Cou glabre, lisse. Épistome étroit, subcorné, brunâtre. Labre presque entier, noir, sétosellé en avant. Mandibules rousses ou d'un roux testacé. Palpes testacés : le dernier article des maxillaires oblong, conique.

Yeux très-grands, subovales, assez saillants, plus ou moins obscurs.

Antennes courtes, un peu plus longues que la tête; à peine épaissies; finement duveteuses et légèrement pilosellées; entièrement testacées; a $1^{\text {er }}$ article en massue allongée : les $2^{\mathrm{e}}$ et $3^{\mathrm{e}}$ oblongs, obconiques : le $2^{\mathrm{e}}$ à peine moins épais que le $1^{\text {er }}$ : le $3^{\mathrm{e}}$. un peu plus grêle et à peine aussi long que le $2^{\mathrm{e}}$ : les suivants graduellement un peu plus courts et à peine plus épais, subobconiques, non ou peu contigus : les $4^{\mathrm{e}}$ et $5^{\mathrm{e}}$ à peine, les $6^{\mathrm{e}}$ et $7^{\mathrm{e}}$ non plus longs que larges : les pénultièmes subtransverses : le dernier subovalaire, obliquement tronqué au sommet et subacuminé inférieurement. 
Prothorax à peine aussi long que large, rétréci en avant; au moins aussi large à sa base que les élytres; largement tronqué au sommet, avec les angles antérieurs infléchis et arrondis ; plus ou moins arqué sur les còtés ; arrondi à sa base ainsi qu'aux angles postérieurs; légèrement convexe sur le dos ; sérialement sétosellé sur les côtés, avec le pore sétifère latéral situé non loin de lạ marge; d'un noir bronzé luisant; lisse; marqué en avant de 2 séries dorsales composées de 3 points médiocres ou assez gros et subégalement distants; offrant en outre, de chaque côté, 1 point semblable, situé assez près du $1^{\text {er }}$ dorsal, entre celui-ci et le gros pore latéral.

Écusson glabre, lisse, d'un noir bronzé luisant.

Élytres subcarrées ou à peine transverses, à peine plus larges en arrière qu'en avant ; à peine ou non plus longues que le prothorax; subdéprimées ou très-faiblement convexes ; à suture subrelevée, surtout en arrière ; asjez fortement, peu densement et subrâpeusement ponctuées ; d'un noir bronzé brillant, souvent plus clair que le prothorax; ciliées-spinosulées à leur bord apical ; à pubescence assez grossière, éparse et d'un doré brillant, avec quelques légères soies redressées sur les côtés, dont 2 beaucoup plus longues, l'une vers le tiers antérieur, l'autre vers les épaules. Celles-ci cachées.

Abdomen assez allongé, un peu moins large que les élytres; graduellement et subarcuément subatténué en arrière; convexe sur le dos, avec les 3 premiers segments à peine impressionnés en travers à leur base; éparsement et lorguement sétosellé ; finement et assez densement pointillé ; d'un noir brillant, à peine ou non irisé ; à pubescence longue, condensée sur les côtés des 5 premiers segments en forme de taches triangulaires, obliques et d'un doré brillant. Le $6^{\text {e }}$ assez étroit, moins ponctué, à pıbescence obscure, à sommet souvent couleur de poix, subarrondi.

Dessous $d u$ corps aspèrement pointillé, finement pubescent, d'un noir de poix brillant, avec le repli du prothorax, l'antépectus, le médipectus et la marge apicale des. derniers arceaux du ventre d'un roux de poix parfois subtestacé. Dessous de la tête presque glabre, avec quelques rares points. Prosternum caréné. Mesosternum cilié vers sa pointe. Métasternum subdéprimé. Ventre convexe, éparsement sétosellé, azuré ou subirisé; à $2^{\circ}$ arceau basilaire prolongé sur le $1^{\text {er }}$ normal en angle obtus.

Pieds assez courts, aspèrement pointillés, légèrement pubescents, tes-tacés, avec la base des hanches postérieures souvent un peu rembrunir. Cuisses antérieures assez renflées, très-finement spinosules en dessous; 
les postérieures plus grêles, plus allongées. Tibias antérieurs peu robustes, à peine épineux. Tarses antérieurs à 3 premiers articles plus $\left(\sigma^{\circ}\right)$ ou moins ( $q$ ) fortement dilatés, le $4^{\mathrm{e}}$ un peu ou à peine moins fortement; les postérieurs à $1^{\text {er }}$ article suballongé, subégal aux 2 suivants réunis, à peine égal au dernier: les $2^{\mathrm{e}}$ à $4^{\mathrm{e}}$ graduellement un peu plus courts.

Patrie. Cette espèce est assez rare. Elle se prend, en été, parmi les mousses humides, dans les régions froides : la Normandie, la Savoie, la Grande-Chartreuse, les Pyrénées, etc.

OBs. Elle est distincte de toutes les autres par les taches de poils d'un doré brillant qui parent les côtés de l'abdomen. Cette espèce et la précédente ont le $3^{\mathrm{e}}$ article des antennes plus court relativement au $2^{e}$.

Parfois, le point postérieur des séries dorsales est géminé ou accompagné d'un point accidentel.

aa. Écusson ponctué et pubescent.

b. Téte subovalaire. Labre subbilobé ou visiblement fendu. Le dernier article des palpes maxillaires conicu-fusiforme.

c. Abdomen non trilinéé de cendré fauve. Le 1er article des tarses postérieurs sensiblement plus long que le dernier. d. Élytres obscures. Abdomen à pubescence normale. Taille assez grande. . . . . . . . . . . . dd. Élytres d'un bronzé assez clair. Abdomen à pubescence

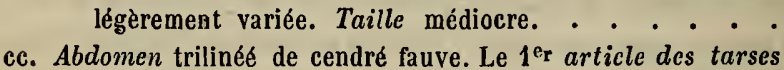
postérieurs non ou à peine plus long que le dernier. Elytres

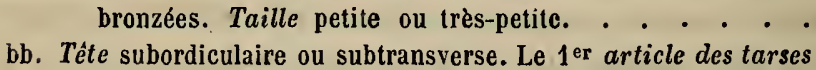
postérieurs subégal ou à peine égal au dernier.

e. Taille assez grande. Labre subbilobé. Le dernier article des palpes maxillaires allongé, conico-fusiforme. Le $3^{\circ}$ article des antennes un peu plus long que le $2 \mathrm{e}$. Pieds

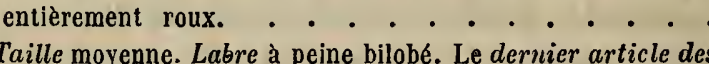
palpes maxillaires assez allongé, conico-fusiforme. Le $3^{\mathrm{e}}$ article des antennes à peine plus long que le $2 \mathrm{e}$. Pieds roux, à cuisses et tibias postérieurs rembrunis. . . - .

cee. Taille petite ou très-petite. Labre entier ou presque entier. Le dernier article des palpes maxillaires peu allongé, conique. Le $3^{\mathrm{e}}$ article des antennes subégal au $2^{\mathrm{e}}$ ou à peine plus long.

RUPIPES.

SEMIOBSCURUS.

VIRGULATUS.

MONTICOLA.

ACUMINATUS. 
f. Tête suborbiculaire, un peu ou sensiblement moins large que le prothorax. Yeux médiocrement saillants. Élytres d'un noir bronzé. Abdomen presque mat, concolore. Taille petite. . . . . . . . . . . . . . .

f. Tête subtransverse, aussi large ou à peine moins large que le prothorax. Yeux saillants.

g. Abdonien mat ou presque mat, à pelne irisé, uniformément pointillé, légèrement atténué en arrière. Hanchés postéricures non rembrunies. Élytres un peu moins longues que le prothorax. Taille petite. . . . . .

ATTENUATUS.

Abdomen brillant, graduellement moins densement pointillé vers son sommet, plus ou moins fortement atténué en arrière. Hanches postérieures plus ou moins rembrunies.

h. Elytres d'un noir de poix, à peine moins longues que le prothorax. Abdomen plus ou moins irisé. Ventre densement ponctué. Taille petite. . . hh. Elytres noires, environ de la longueur du prothorax. Abdomen peu irisé. Ventre éparsement ponctué. Taille très-petite. . .".'. . . . . . Boops.

hhh. Élytres brunâtres ou rousses, beaucoup plus courtes que le prothorax. Taille très-petite. . . . . Brevipenns.

\section{Quedius (Raphirus) rufipes, Gravenhorst.}

Allongé, fusiforme, peu convexe, finement pubescent, noir, avec les palpes, les antennes et les pieds d'un roux testacé. Tête et prothorax lisses, luisants : celui-ci aussi long que large, rétréci en avant. Écusson pointillé. Elytres de la longueur du prothorax, très-finement et trèsdensement pointillées-chagrinées. Abdomen très-finement et densement pointillé, irisé, à pubescence normale. Le $1^{\mathrm{er}}$ article des tarses postérieurs d'un tier's plus long que le dernier.

$\sigma$ Le $6^{\circ}$ arceau ventral largement, angulairement et assez profondément échancré au sommet, avec une impression oblongue, triangulaire, parfois subsulciforme, lisse, au devant de l'échancrure. Tarses antérieurs forlement et arcuément dilatés.

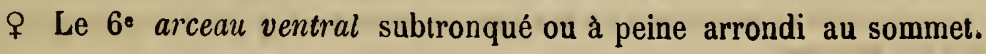
Tarses antérieurs graduellement et à peine dilatés. 
Slaphylinus rufipes, Gravenuorst, Micr. 171, 24. - Latreille, Hist. Nat. Crust. et Ins. IX, 324, 67 .

Staphylinus ruficornis, Gravenhorst, Mon. 50,12. - Latreille, Hist. Nat. Crust. et Ins. IX, 326, 76 .

Emus attenuatus,, Boisduval et Lacordaire, Faun. Ent. Par. I, 483, 38.

Quedius rufipes, Ericason, Gen. et Spec. Staph. 543, 30. - Fairmaire et LaboulBèNe, Faun. Ent. Fr. I, 537, 10.- Fauvel, Faun. Gallo-Rhén, III, 531), 43.

Philonthus rufipes, HEER, Faun. Col. Helv. I, 583.

$$
\text { Long., } 0^{\mathrm{m}}, 0077 \text { (3 1/3 l.); - larg., } 0^{\mathrm{m}}, 0014 \text { (2/3 l.). }
$$

Corps allongé, fusiforme, peu convexe, d'un noir luisant sur la tête et le prothorax, moins brillant sur les élytres et l'abdomen; recouvert sur ces dernières et ce dernier d'une fine pubescence d'un gris obscur et serrée.

Tête subovale, beaucoup moins large que le prothorax; longuement et éparsement sétosellée sur les côtés; d'un noir luisant et à peine métallique; lisse ou presque lisse ; finement pointillée sur les tempes, avec 3 points sétifères, derrière les yeux, disposés en ligne transversale arquée, et dont l'intermédiaire gros, le temporal et celui du vertex petits, celui-ci aussi loin du cou que du point du milieu. Front assez large, à peine convexe, à pore juxta-oculaire médiocre, oblong. Cou glabre, lisse, luisant. Epistome submembraneux, d'un livide obscur. Labre subbilobé ou visiblement. fendu, d'un noir luisant, fortement sétosellé en avant. Mandibules d'un roux de poix. Palpes d'un roux testacé, avec le dernier article souvent un peu plus foncé, conico-fusiforme.

Yeux très-grands, subovales, médiocrement saillants, obscurs, lavés de gris.

Antennes médiocres, sensiblement plus longues que la tête; asséz grêles ; à peine épaissies ; finement duveteuses et légèrement pilosellées ; entièrement testacées ou d'un roux testacé; à $1^{\text {er }}$ article en massue allongée et assez grêle : le $2^{e}$ suballongé, obconique : le $3^{e}$ allongé, plus long que le $2^{\mathrm{e}}$ : les suivants graduellement un peu plus courts et à peine plus épais, non ou peu contigus, subobconiques : les $4^{\mathrm{e}}$ à $6^{\mathrm{c}}$ suballongés $\left(\sigma^{\star}\right)$ ou oblongs ( $q)(1)$, les pénultièmes aussi longs $(q)$ ou à peine plus

(1) Quelquefois, surtout chez les espèces suivantes, les antennes ont leurs articles intermédiaires et pénultièmes un peu plus courts chez les $\$$, et ces derniers parfois un peu plus épais. 
longs $\left(\sigma^{*}\right)$ que larges, vus de còté : le dernier subovalaire, obliquement tronqué au sommet et acuminé inférieurement.

Prothorax aussi long ou à peine plus long que large, assez fortement rétréci en avant, de la largeur des élytres ; largement tronqué ou à peine échancré au sommet, avec les angles antérieurs infléchis et subarrondis ; subarqué sur les côtés; arrondi à sa base ainsi qu'aux angles postérieurs; assez convexe sur son disque; sérialement sétosellé sur les côtés, avec le gros pore sétifère latéral situé loin de la marge; d'un noir luisant et à peine métallique; lisse ; marqué en avant de 2 séries dorsales composées de 3 points médiocres et subégalement distants; offrant en outre, de chaque côté, un autre point semblable, situé presque à égale distauce entre le $1^{\text {er }}$ dorsal et le pore latéral.

Écusson pubescent, finement et densement pointillé, obscur.

Elytres subtransverses, à peine plus larges en arrière qu'en avant; de la longueur du prothorax ou à peine plus courtes; subdéprimées ou faiblement convexes, souvent subsillonnées le long de la suture; trèsfinement et très-densement pointillées-chagrinées ; d'un noir souvent assez peu brillant; ciliées-subspinosulées à leur bord apical; à pubescence fine et serrée, avec quelques légères et courtes soies redressées sur les côtés, et 1 très-longue, vers le tiers antérieur de ceux-ci. Épaules cachèes, épineuses en dessous.

Abdomen plus ou moins allongé, un peu moins large à sa base que les élytres ; fortement et graduellemeut allénué en arrière ; longitudinalement convexe sur le dos; éparsement et longuement sétosellé, plus fortement vers l'extrémité; très-finement et densement pointillé, encore plus densement sur la base des premiers segments; d'un noir peu brillant et plus ou moins irisé ; à pubescence fine et serrée. Le $6^{\mathrm{e}}$ segment un peu moins ponctué et couleur' de poix vers son sommet, qui est subarrondi.

Dessous du corps densement et aspèrement pointillé, finement et densement pubescent, d'un noir assez brillant, avec la marge apicale des derniers arceaux du ventre souvent d'un roux cuivreux. Dessous de la tète presque glabre, presque lisse. Prosternum subcaréné, parfois roussátre. Mésosternum à pointe acérée et légèrement ciliée, à rudiment de carène basilaire. Métasternum subdéprimé, obsolètement canaliculé sur sa ligne médiane, à lobe postérieur un peu roussâtre. Ventre convexe, éparsement et longuement sétosellé, plus ou moins irisé; à $2^{\circ}$ arceau basilaire prolongé sur le $1^{\text {cr }}$ normal en angle obtus mais prononcé.

Pieds densement et aspèrement pointillés, finemelt pubescenıs, d'uu 
roux testacé, avec les hanches postérieures rembrunies, Cuisses antéricures et intermédiaires distinctement spinosules en dessous; les postírieures plus grêles, plus allongées. Tibias antérieurs peu robustes, à peine épineux. Tarses antérieurs des $\sigma^{\mathrm{a}} 2^{\mathrm{e}}$ et $3^{\mathrm{e}}$ articles fortement dilatés, les $1^{\mathrm{er}}$ et $4^{\mathrm{e}}$ un peu moins fortement: ceux des $q$ à 4 premiers articles à peine et graduellement moins dilatés ; les postérieurs à $1^{\mathrm{e}}$ article allongé, un peu plus long que les 2 suivants réunis, d'un tiers plus long que le dernier : les $2^{\mathrm{e}} \mathrm{a} 4^{\mathrm{e}}$ graduellement plus courts.

Patrie. Cette espèce est assez commune dans presque toule la France, sous les pierres. les mousses et les feuilles mortes.

OBs. Son écusson ponctué et pubescent la distingue des précédentes.

Suivant M. Fauvel, on doit lui assimiler le semiobscurus de Marsham (Ent. Brit. 512, 41) et de Stephens (Ill. Brit., V, 241).

\section{LAR V E}

Nous donnons ici la description de la larve du Quedius rufipes :

Corps allongé, subconvexe, plus ou moins rétréci antérieurement, d'un roux testacé brillant, avec l'abdomen mat.

Tête grande, presque carrée, un peu plus large en avant, arrondie aux angles postérieurs, rectiligne sur les côtés, plus large que le prothorax ; légèrement convexe; éparsement sétosellée, avec des soies assez courtes et d'autres beaucoup plus longues; lisse sur le vertex; très-finement chiagrinée dans sa partie antérieure, qui présente un large espace enclos par une espèce de losange transversal et irrégulier ; entièrement d'un roux testacé brillant. Epistome fortement et aigument quadridenté en avant, à dents obscures, les intermédiaires plus saillantes. Mandibules !ongues, falciformes, d'un roux testacé, à peine rembrunies à leur pointe. Palpes maxillaires grêles, pâles, à $1^{\mathrm{er}}$ article rudimentaire, le $2^{\mathrm{c}}$ oblong, le $3^{\mathrm{e}}$ allongé : le dernier plus étroit, terminé par un petit lobe subulé. Palpes labiaux petits, grêles.

Yeux réduits à 3 ocelles lisses, souvent noirs, rapprochés, dont les 2 antérieurs parfois confluents.

Antennes pâles, grêles, à $1^{\mathrm{er}}$ article rudimentaire et peu distinct (1) : le $2^{\mathrm{e}}$ allongé, subcylindrique, subépaissi au bout : le $3^{\mathrm{e}}$ un peu plus étroit,

(1) Généralement, dans les larves des Brévipennes, le $1^{\text {ei }}$ article des antennes est peu distinct et peut être considéré comme un tubercule antennifêre. 
à peine en massue, presque aussi long que le $2^{\mathrm{e}}$, tricilié vers son dernier tiers, lobé à son sommet interne : le dernier un peu plus grêle, subcylindrique, moins long que le précédent, tricilié au bout.

Prothorax suboblong, fortement rétréci en avant, subarrondi au sommet, largement tronquè à la base, rebordé sur celle-ci ; subarqué sur les côtés ; assez convexe ; parsemé de soies assez courtes, mélangées de soies plus longues; presque lisse, avec quelques rides ou impressions sulciformes de chaque côté du disque ; d'un roux testacé brillant.

Mésothorax et métathorax courts, subégaux; à peine aussi longs, pris ensemble, que le prothorax; un peu moins larges que celui-ci; largement rebordés à leur base; subconvexes sur leur disque; impressionnés sur leurs côtés, qui sont subdilatés en avant ;.mélangés de soies assez courtes et de longues; d'un roux testacé brillant.

Abdomen allongé, environ aussi long que le reste du corps; sensiblement et arcuément ċlargi sur les côtés ; subdéprimé; sillonné-canaliculé sur sa ligne médiane; fortement sétosellé, à soies assez grossières; à $1^{\text {er }}$ segment d'un roux testacé, lisse et brillant, impressionné sur les côtés : es autres, très finement chagrinés, d'un testacé livide et mat, plus ou moins bossués, impressionnés ou cicatrisés sur les côtés, subégaux : le dernier étroit, transverse, rétréci en arrière, tronqué au sommet, où il présente 2 lanières 2 fois aussi longues que lui, écartées à leur base, presque droites, subcylindriques, fortement sétosellées, surtout en dehors, brusquement et brièvement rétrécies vers le bout et terminées par un long appendice grêle, un peu moins long, sétifère, déjeté en dehors.

Dessous du corps d'un roux testacé. Dessous de la tête et proslernum presque lisses, brillants. Ventre excavé, inégal, finement chagriné, fortement sétosellé; à tube terminal d'un tiers plus long que les lanières supérieures, tendu, subcylindrique jusqu'à son dernier liers, après lequel il est subétranglè, puis subélargi au bout; cilié-sétosellé, surtout sur les côtès et en dessus.

Pieds assez courts, grêles, translucides, testacés. Hanches grandes, subépineuses. Cuisses sublinéaires, mais un peu plus épaisses vers le sommet, épineuses en dessous. Tibias plus courts, plus étroits, linéaires, épineux dans leur pourtour, terminés par un crochet solide, assez grêle, subarqué, très-acéré.

OBs. Cette larve, remarquable par son corps subétranglé derrière la tête et par son abdomen arcuément subélargi, se rencontre dans les bois, parmi les feuilles mortes, où elle fait la guerre aux petits insectes ou aux 
autres petites larves qui viennent se nourrir des substances cryptogamiques dont ces feuilles sont inicctées.

La nymphe est plus épaisse, d'un roux ferrugincux assez brillant. Elle laisse facilement deviner l'insecte parfait. La tête est repliẻe en dessous, le prothorax subverticalement infléchi. L'écusson est très-développé, et les élytres sont rejetées sur les côtés. Tous les segments de l'abdomen sont découverts et pourvus, sur les côtés, d'une soie raide, courte et émoussée; les 3 premiers sont munis, de chaque côté, à leur base, d'un ombilic relevé eı forme de pointe saillante, et le dernier est armé, au soinmet, de 2 fortes épines acérées, qui forment comme une espèce de croissant. Les antennes et les pieds, repliés en dessous, sont voilés d'une légère pellicule. Le dernier arceau du ventre offre, à son sommet, 2 épines disposées comme dans le segment supérieur correspondant, mais beaucoup moins fortes et moins saillantes.

\section{Quediug (Raphirus) gemiobseurus, ErrCHSON.}

Allongé, fusiforme, peu convexe, finement pubescent, d'un noir submétallique, avec les élytres bronzées, les palpes, les antennes et les pieds testacés, les cuisses postérieures un peu rembrunies. Tête et prothorax lisses, luisants : celui-ci à peine plus long que large, rétréci en avant. Écusson pointillé. Élytres un peu plus longues que le prothorax, trèsfinement et densement pointillées-chagrinées. Abdomen très-finement et densement pointillé, subirisé, à pubescence variée de roux et de taches obscures et subfovéiformes. Le $1^{\mathrm{er}}$ article des tarses postírieurs sensiblement plus long que le dernier.

$\sigma^{7}$ Le $6^{\circ}$ arceau vertral subangulairement échancré au sommet, avec un espace triargulaire oblong, à peine impressionné, lisse, au devant de l'échancrure. Tarses antérieur's assez fortement et subarcuément dilatés.

\& Le $6^{\text {e }}$ arceau ventral à peine arrondi au sommet. Tarses antérieurs graduellement et légèrement dilatés.

Quedius semiobscurus, Erichson, Gen. et Spec. Staph. 544, 32. - Fairmaire et LAboulbène, Faun. Ent. Fr. I, 538, 11. - KradTz, Ins. Deut, II, 501. Philonthus attenuatus, HeER, Faun. Col. Helv. I, 279, 72. 
Quedius proximus, Krastz, Berl. Ent. Zeit. 1858, 60.

Quedius semiaeneus, Fauvel, Faun. Gallo-Rhén. III, 531, 44.

Variété $a$. Élytres rousses.

$$
\text { Long., } 0^{\mathrm{m}}, 0067 \text { (3 l.); -- larg., } 0^{\mathrm{m}}, 0012 \text { (1/2 l.). }
$$

Corps allongé, fusiforme, peu convexe, d'un noir submétallique, avec les élytres bronzées; revêtu sur celles-ci et l'abdomen d'une fine pubescence plus ou moins obscure et serrée.

Tète assez courtement ovale, sensiblement moins large que le prothorax; longuement et éparsement sétosellée sur les côtés; d'un noir luisant et submétallique; lisse; à peine pointillée sur les tempes, avec 3 points sétifères disposés en ligne transversale arquée, derrière les yeux, le temporal et celui du vertex petits, l'intermédiaire gros et joignant presque le bord postéro-interne de l'œil. Front assez large, à peine convexe, à pore juxta-oculaire médiocre, ovale. Cou glabre, lisse, luisant. Épistome subcorné, obscuŕ. Labre subbilobé ou visiblement fendu, d'un noir luisant, fortement sétosellé en avant. Mandibules d'un brun ou d'un roux de poix. Palpes testacés, à dernier article un peu rembruni, conico-fusiforme.

Yeux très-grands, subovales, médiocrement saillants, obscurs, lavés de gris.

Antennes assez courtes, un peu plus longues que la tête ; à peine épaissies ; finement duveteuses et brièvement pilosellées; entièrement testacées; à $1^{\text {er }}$ article en massue très-allongée et assez grêle : les $2^{\circ}$ et $3^{\text {e }}$ obconiques : le $3^{\mathrm{e}}$ suballongé, à peine plus long que le $2^{\circ}$ : les suivants graduellement un peu plus courts et à peine plus épais, non contigus : les $4^{\mathrm{e}}$ à $6^{\mathrm{e}}$ oblongs, subcylindriques : les $7^{\mathrm{e}}$ à 10 subobconiques, avec les pénultièmes aussi longs que larges $\left(\sigma^{*}\right)$ ou sublransverses $(q)$, vus de côté : le dernier subovalaire, obliquement tronqué au sommet et acuminé inférieurement.

Prothorax à peine plus long que large, plus ou moins rétréci en avant; à peine moins large à sa base que les élytres; largement tronqué au sommet, avec les angles antérieurs infléchis et subarrondis; subarqué sur les côtés; arrondi à sa base ainsi qu'aux angles postérieurs; assez convexe sur son disque; sérialement sétosellé sur les côtés, avec le pore sétifère latéral situé loin de la marge; d'un noir luisant et submétallique; lisse; 
marqué en avant de 2 séries dorsales composées de 3 points médiocres et subégalement distants ; offrant en outre, de chaque côté, 1 autre point moindre, situé entre le pore sétifère latéral et le $1^{\text {er }}$ dorsal, mais plus près de celui-ci.

Écusson pubescent, finement et densement pointillé, d'un noir bronzé. Ellytres subtransverses, à peine plus larges en arrière qu'en avant; un peu ou à peine plus longues que le prothorax ; subdéprimées ou faiblement convexes ; plus ou moins sillonnées le long de la suture ; très-finement et densement pointillées-chagrinées; d'un bronzé assez brillant et plus ou moins clair, avec la marge apicale souvent finement liserée de roux testacé; ciliées-spinosulées à leur bord postérieur ; à fine pubescence d'un gris ubscur, assez longue et assez serrée, avec quelques courtes soies redressées et obsolètes, sur les côtés, et 1 beaucoup plus longue, vers le tiers antérieur de ceux-ci. Épaules très-peu saillantes, épineuses en dessous.

Abdomen plus ou moins allongé, un peu moins large que les élytres; fortement et graduellement atténué en arrière; assez convexe sur le dos; éparsement sétosellé; très-finement et densement pointillé, encore plus densement sur la base des premiers segments ; d'un noir peu brillant et subirisé ; à pubescence fine, serrée, obscure, avec une ciliation d'un roux plus ou moins doré au bord apical des segments, et de larges plaques subimpressionnées (1) ou subfovéolées plus condensées et d'un noir velouté, vers la base des 3 premiers. Le $6^{\mathrm{e}}$ souvent inoins ponctué, couleur de poix et subarrondi à son sommet.

Dessous du corps densement et aspèrement pointillé, finement et densement pubescent, d'un noir assez peu brillant, avec le prosternum parfois moins foncé, le sommet du ventre et la marge apicale des arceaux d'un roux ferrugineux. Dessous de la tête presque glabre, presque lisse. Prosternum relevé en faite. Mésosternum subdéprimé. Ventre convexe, longuement et éparsement sétosellé, fortement irisé ; à $2^{\circ}$ arceau basilaire en angle très-obtus à son bord postérieur.

Pieds finement pointillés, finement pubescents, testacés, avec les hanches intermédiaires couleur de poix, les postérieures noires et les cuisses postérieures souvent un peu rembrunies. Cuisses antérieures et intermédiaires spinosules en dessous vers leur extrémité; les postérieures plus grêles, un peu plus longues. Tibias antérieurs peu robustes, à peine

(1) Ces plaques sont ordinairement au nombre de 3 , mais celle du milieu fait parfois défaut. 
épineux. Tarses antérieurs des $\sigma^{\circ}$ à $2^{\circ}$ et $3^{\text {e }}$ articles assez fortement dilatés, les $1^{\text {er }}$ et $4^{\circ}$ un peu moins ; ceux des $q$ à 4 premiers articles légère- ment et graduellement moius dilatés; les postérieurs à $1^{\text {or }}$ article allongé, à peine plus long que les 2 suivants réunis, sensiblernent plus long que le dernier : les $2^{\ominus}$ à $4^{\circ}$ graduellement plus courts.

Patrie. Cette espèce se trouve un peu moins communément que le rufipes, dans presque toute la France et de la même manière,

OBs. Elle est un peu moindre que cette dernière. Les élytres, moins obscures, sont d'un bronzé plus ou moins clair. La pubescence de l'abdomen, moins uniforme, est variée de poils ou cils roux et de plaques d'un noir velouté. Les antennes sont un peu plus courtes, avec leurs pénultièmes articles un peu plus transverses $(q)$. Les hanches intermédiaires et les cuisses postérieures sont ordinairement d'une couleur plus obscure. La marge apicale des arceaux du ventre est plus généralement d'un roux ferrugineux, etc.

Quelquefois les élytres sont d'un roux légèrement bronzé. La taille varie aussi beaucoup, et parfois, elle dépasse à peine $0^{\mathrm{m}}, 0041 / 2$.

On doit peut-être rapporter au semiobscurus d'Erichson les nitipennis. semiaeneus et rufipennis de Stephens (Ill. Brit. V, 242 et 243).

Il est douteux que le velutinus de Motschulsky doive appartenir a l'espèce ci-dessus décrite.

\section{J.ARVE}

La larve du Quedius semiobscurus ressemble beaucoup à celle du rufipes. Elle est un peu moindre. La tête, un peu moins grande, est plus parallèle sur ses côtés. Les palpes maxillaires sont moins grêles et moins développés. Les antennes, moins longues, ont leurs articles proportionnellement moins allongés et plus épais. Le prothorax est moins rétréci en avant, et l'abdomen moins élargi sur les côtés. Le dernier segment de celui-ci est plus court, à lanières plus épaisses et moins longues. Le tube terminal du ventre est un peu plus court, subatténué toui à fait au bout, mais non étranglé avant son sommet.

La nymphe est d'une couleur plus grêle et plus brillante, avec: les soies des côtés de l'abdomen plus longues et moins grossières, et les épines terminales du dernier segment de celui-ci et du dernier arceau ventral plus grêles et plus acérées. 


\section{Quedius (Raphirus) virgulatus, ERICHSON.}

Allongé, fusiforme, peu convexe, finement pubescent, d'un noir bronzé brillant, avec les élytres d'un bronzé un peu plus clair, les palpes, les antennes et les pieds testacés. Tête et prothorax lisses, luisants : celui-ci à peine plus long que large, rétréci en avant. Écusson pointillé. Élytres $\grave{a}$ peine plus longues que le prothorax, finement, densement et subrugueusement pointillées, à pubescence grise, mélée de poils d'un fauve doré. Abdomen finement et densement ponctué, à peine irisé, à pubescence formant 3 lignes cendrées. Le $1^{\mathrm{er}}$ article des tarses postérieurs égal au dernier.

$\sigma$ Le $6^{\text {e }}$ arceau ventral largement et subangulairement échancré au sommet, avec un espace triangulaire oblong, subimpressionaé, lisse, au devant de l'échancrure. Tarses antérieurs fortement dilatés.

ㅇ Le $6^{\mathrm{e}}$ arceau ventral subarrondi au sommet. Tarses antérieurs légèrement dilatés.

Quedius virgulatus, Erichson, Gen. et Spec. Staph. 547, 36. - FaUvel, Faun. Galto-Rhén. III, 532, 42.

$$
\text { Long., } 0^{\mathrm{m}}, 0048 \text { (2 1/5 l.); - larg., } 0^{\mathrm{m}}, 0007 \text { (1/3 l.). }
$$

Corps allongé, fusiforme, peu convexe, d'un noir bronzé brillant, un peu moins foncé sur les élytres; revêtu sur celles-ci et l'abdomen d'une fine pubescence grisâtre, assez longue, mélangée de poils d'un fauve doré, condensée sur ce dernier suivant 3 lignes cendrées.

Tête subovalaire, sensiblement moins large que le prothorax; longuement et éparsement sétosellée sur lles côtés; d'un noir bronzé luisanı; lisse; finement pointillée a la base des tempes, avec 3 points sétifères derrière les yeux, le temporal et celui du vertex très-petits, le juxtapostoculaire assez gros. Front assez large, à peine convexe, à pore juxtaoculaire médiocre. Cou glabre, presque lisse,:Iuisant. Épistome étroit, subcorné, brunâtre. Labre légèrement bilobé, d'un noir brillant, sétosellé $r n$ avant. Mandibules d'un roux obscur. Palpes testacés, à dernier article souvent rembruni, suballongé, conico-fusiforme. 
Yeux très-grands, subovales, médiocrement saillants, obscurs ou grisàtres.

Antennes assez courtes, sensiblement plus longues que le prothorax; faiblemenı épaissies; très-finement duveteuses et brièvement pilosellées; testacées ou d'un roux testacé; à $1^{\text {er }}$ article en massue allongée et assez étroite : le $2^{\circ}$ oblong, obconique : le $3^{\mathrm{e}}$ un peu plus allongé, obconique, un peu plus grêle et à peine plus long que le $2^{\mathrm{e}}$ : les suivants graduellement un peu plus courts et un peu plus épais, non contigus, subobconiques : le $4^{\mathrm{e}}$ oblong : les $5^{\mathrm{e}}$ et $6^{\mathrm{e}}$ presque aussi larges que longs, les pénultièmes subtransverses : le dernier subovalaire, obliquement tronqué au sommet et acuminé inférieurement.

Prothorax à peine plus long que large, rétréci en avant; à peine moins large à sa base que les élytres; tronqué au sommet, avec les angles antérieurs infléchis, presque droits mais émoussés ou subarrondis; subarqué sur les côtés; arrondi à sa base ainsi qu'anx angles postérieurs ; assez convexe sur son disque; sérialement sétosellé sur les côtés, avec le pore sétifère latéral situé à une distance médiocre de la marge ; d'un noir bronzé luisant; lisse; marqué en avant de 2 séries dorsales composées de 3 points médiocres ou assez petits et subégalement distants ; offrant en outre, de chaque côté, 1 point semblable, situé entre le $1^{\text {er }}$ dorsal et le pore sétifère latéral.

Écusson finement pubescent, finement pointillé, d'un bronzé brillant. Élytres presque carrées, à peine plus longues que le prothorax; subdéprimées ou à peine convexes, subsillonnées le long de la suture ; finement, densement et subrugueusement pointillées; d'un bronzé assez brillant, moins foncé que le prothorax; ciliées de poils d'un fauve doré à leur marge apicale ; à pubescence grise et assez longue, couchée et mélangée de quelques poils plus courı, plus grossiers et d'un fauve doré, avec quelques légères soies redressées sur les ê̂tẻs, dont 1 be ucoup plus longue, vers le tiers antérieur de ceux-ci. Épaules très-pen saillantes.

Abdomen suballongé, moins large que les élytres; fortement et gradıellement atténué en arrière; longitudinalement convexe sur le dos; fortement sétosellé ; finement et densement pointillé, un peu plus densement sur le $1^{\text {er }}$ segment, un peu moins sur le dos des autres; d'un noir assez brillant, non ou à peine irisé ; à pubescence assez longue, couchée, grisâtre, condensée suivant 3 lignes longitudinales cendrées sous un certain jour, !auves et soyeuses sous un autre, et dont la médiane est plus étroite. Le $6^{\circ}$ segment subarrondi au sommet. 
Dessous du corps finement pointillé, pubescent, d'un noir assez brillant, avec le repli du prothorax et le prosternum moins foncés, le sonımet du ventre et la marge apicale des arceaux d'un roux de poix. Dessous de la tête glabre, presque lisse. Prosternum relevé en faîte. Mésosternum cilié vers son sommet. Mélasternum subdéprimé. Ventre convexe, fortement sétosellé, peu irisé.

Pieds légèrement pointillés, légèrement pubescents, testacés, avec la base des hanches postérieures rembrunie, ainsi que parfois le milieu des cuisses et tibias postérieurs. Cuisses antérieures et intermédiaires à peine spinosules en dessous vers leur extrémité ; les postérieures plus grêles, un peu plus longues. Tibias antérieurs assez étroits, peu épineux. Tarses antérieurs à 3 premiers articles plus $\left(\sigma^{\circ}\right)$ ou moins $(q)$ dilatés, le $4^{\mathrm{e}}$ moins sensiblement; les postérieurs à $1^{\text {er }}$ article allongé, subégal aux 2 suivants réunis, égal au dernier ou à peine plus long : les $2^{\mathrm{e}} \mathrm{a} 4^{\circ}$ oblongs, graduellement moins longs.

Patrie. Celte espèce, qui estrare, se rencontre dans les Alpes maritimes. Elle est commune en Corse.

OBs. Elle est bien moindre que le semiobscurus, avec les élytres d'un bronzé moins clair et le $1^{\text {er }}$ article des tarses postérieurs moins long comparativement au dernier. Ce qui la distingue d'entre toutes les autres espèces voisines, c'est son abdomen trilinéé de cendré fauve.

Nous avons vu des exemplaires de Corse, dont la taille atteignait à peine 4 millimètres. Parfois les élytres sont d'un bronzé roussâtre, et peut-être doit-on rapporter cette variété au flavipennis de Baudi (Stud. Ent. I, 132).

\section{Quedius (Ruphirus) monticola, ERICHSON.}

Allongé, subfusiforme, peu convexe, finement pubescent, d'un noir brillant, avec les palpes, les antennes et les pieds un peu rembrunis. Tète et prothorax lisses, luisants : celui-ci aussi long que lärge, subrétréci en (uvant. Écusson pointillé. Élytres de la longueur du prothorax, finement, densement et subrugueusement pointillées. Abdomen finement et densement pointillé, un peu moins densement en arrière, subirisé. Le $1^{\text {er }}$ article des turses postérieurs subégal au dernier. 
ơ Le $6^{\circ}$ urceu ventral sensiblement et angulairement échancré au sommet, avec un espace triangulaire, oblong, subdéprimé, lisse, au devant de l'échancrure. Tarses antérieut's fortement et arcuément dilatés.

\& Le $6^{\mathrm{e}}$ arceau ventral subarrondi au sommet. Tarses antérientrs légèrement et subgraduellement dilatés.

Quedius monticola, Erichson, Gen. et Spec. Staph. 341, 31. - Fairmatre et LaboulBène, Faun Ent. Fr. I, 544, 31. - Krata, Ins. Deut. II, 513, 27. Philonthus paradisianus, HEeR, Faun. Col. Helv. 278, 69. Qucdius paradisianus, Fauvel, Faun. Gallo-Rhén. III, 333, 47.

$$
\text { Long., } 0^{\mathrm{m}}, 0073 \text { (3 1/3 1.); - larg., } 0^{\mathrm{m}}, 0014(2 / 3 \mathrm{l} \text {.). }
$$

Corps allongé subfusiforme, peu convexe, d'un noir brillant, recouvert sur les élytres et l'abdomen d'une fine pubescence d'un gris obscur et assez serrée.

Tête suborbiculaire ou à peine transverse, un peu moins large que le prothorax ; longuement et éparsement sétosellée sur les côtés; d'un noir luisant et à peine métallique; lisse ; distinctement pointillée à la base des tempes, avec 3 points sétifères disposés en arc transversal derrière les yeux, le temporal et celui du vertex petits, celui du milieu plus gros, joignant presque le bord postéro-interne de l'œil. Front assez large, à peine convexe, à pore juxta-oculaire oblong, médiocre. Cou glabre, lisse, luisant. Épistome subcorné, brunatre. Labre subbilobé ou visiblement fendu, d'un noir brillant, fortement sétosellé en avant. Mandibules d'un ronx ferrugineux. Palpes d'un roux testacé, à dernier article des maxillaires allongé, conico-fusiforme.

Yeux très-grands, subovales, médiocrement saillants, obscurs, lavés de gris.

Antennes peu allongées, sensiblement plus longues que la tête; faiblement épaissies (1); finement duveteuses et légèrement pilosellées; entièrement d'un roux testacé ; à $1^{\mathrm{er}}$ article en massue allongée et peu épaisse : le $2^{\circ}$ oblong, obconique : le $3^{\mathrm{e}}$ suballongé, obconique, plus long que le $2^{\mathrm{c}}$ : les survants graduellement plus courts et un peu plus épais, non ou peu contigus, subobconiques : les $4^{\mathrm{e}}$ à $6^{\mathrm{e}}$ oblongs $\left(\sigma^{\circ}\right)$ ou suboblongs $(q)$ :

(1) Les antennes des $\subsetneq$ sont ici visiblement plus courtes et plus épaisses que celles des $\sigma$. 
le $\boldsymbol{7}^{\mathrm{e}}$ suboblong $\left(\sigma^{*}\right)$ ou subcarré $(q)$ : les pénultièmes à peine plus longs que larges $\left(\sigma^{*}\right)$ ou subtransverses $(q)$, vus de côté : le dernier subovale, obliquement tronqué au sommet et acuminé inférieurement.

Prothorax environ aussi large que long, subrétréci en avant, de la largeur des élytres; largement tronqué ou à peine échancré au sommct, avec les angles antérieurs infléchis, presque droits mais subarrondis; légèrement arqué sur les côtés; subarrondi à sa base ainsi qu'aux angles postérieurs ; assez convexe sur son disque; éparsement sétosellé sur les côtés, avec le pore sétifêre latéral situé assez loin de la marge; d'un noir luisant et à peine métallique; lisse ; marqué en avant de 3 séries dorsales composées de 3 poinls médiocres, dont l'antérieur parfois plus écarté ; offrant en outre, de chaque côté, 1 autre point semblable, situé entre le pore latéral et le $1^{\text {er }}$ dorsal, mais un peu plus près de celui-ci.

Écusson légèr'ement pubescent, finement et assez densement pointillé, surtout en arrière, d'un noir assez brillant.

Élytres plus ou moins transverses, subparallèles, aussi longues ou à peine moins longues que le prothorax; subdéprirnées ou à peine convexes et obsolètement sillonnées le long de la suture; finement, densement et subrugueusement pointillées ; d'un noir assez brillant et parfois brunâtre ; ciliées-spinosulées à leur bord apical; à pubescence assez serrée, avec quelques courtes soies redressées, sur les côtés, et \ beaucoup plus longue, vers le tiers antérieur de ceux-ci. Épaules cachées.

Abdomen suballongé, un peu moins large que les élytres; assez fortement et graduellement atténué en arrière ; assez convexe sur le dos, avec les 2 premiers segments à peine impressionnés en travers à leur base; éparsement sétosellé; finement et densement pointillé ; un peu moins densement en arrière; d'un noir assez brillant et subirisé ; à pubescence asssez longue, uniforme et atsez serrée. Le $6^{\text {e }}$ segment subarrondi alı summel, qui est souvent couleur de poix.

Dessous du corps aspèrement ponctué, finement pubescent, d'un noir brillant, avec le repli du prothorax, le prosternum et le mésosternum souvent bıunatres, le sommet du ventre et la marge apicale des arceaux d'un roux de poix. Dessous de la tête glabre, presque lisse. Prosternum subcaré.é. Mésosternum subrugueux et ciliẻ vers sa pointe. Métasternum subdéprimé. Ventre convexe, éparsement sétosellé, fortement irisé ; a $2^{\mathrm{e}}$ arceau basilaire en angle très-obtus à son bord postérieur.

Pieds aspèrement pointillés, finement pubescents, d'un roux testacé, avec les hanches postérieures souvent rembrunies. Cuisses antérieures et 
intermédiaires subspinosules en dessous vers leur extrémité rieures plus grêles, un peu plus longues. Tibias anterieurs assez étroits, à peine épineux. Tarses antérieurs des $\sigma^{\circ}$ à $2^{\circ}$ et $3^{\mathrm{e}}$ articles fortement dilatés, le $1^{\text {er }}$ et $4^{\mathrm{e}}$ moins fortement; ceux des $q$ à 4 premiers articles légèrement et graduellement moins dilatés; les postérieurs à $1^{\text {er }}$ article allongé, à peine plus long que les 2 suivants réunis, subégal au dernier : celui-ci allongé, grêle : les $2^{\mathrm{e}}$ à $4^{\mathrm{e}}$ oblongs, graduellement un peu moins longs.

Patrie. Cette espèce, peu commune, habite les mousses des forèts des régions montagneuses. On la trouve, en juillet et août, dans l'Alsace, les Vosges, l'Auvergne, le mont Pilat, la Savoie, les Alpes du Dauphiné, les Alpes maritimes, etc.

OBs. Sa tête plus grosse et moins ovale, ses élytres moins finement et moins densement pointillées, son abdomen moins atténué en arrière, les $1^{\text {er }}$ et dernier articles des tarses postérieurs moins inégaux, une coulcur plus brillante, tels sont les caractères qui différencient cette espèce du Q. rufipes.

Quelquefois les élytres paraissent sensiblement plus courtes que le prothorax. Rarement, les cuisses postérieures sont un peu bronzées daus leur milieu.

Près du monticola viendrait l'espèce suivante :

\section{Quedius collaria, Erichson.}

Allongé, subfusiforme, subdéprimé, finement pubescent, d'un noir brillant, avec la bouche, les antennes, les pieds et le prothorax d'un roux testacé, celui-ci largement rembruni sur son disque. Tête et prothorax lisses, luisants : celui-ci aussi long que large, rétréci en avant. Écusson pointillé. Elytres à peine aussi longues que le prothorax, finement, densement et rubrâpeusement ponctuées. Abdomen finement et très-densement pointillé, plus éparsement en arrière, subirisé. Le $1^{\mathrm{er}}$ arlicle des tarses postérieurs subégal au dernier.

Quedius collaris, Erichson, Gen. et Spec. Staph. 545, 33. - KaAatz, Ins. Deut. II, 515, 28. 


$$
\text { Long., } 0^{\mathrm{m}}, 0070 \text { (3 1/4 l.) ; - larg., } 0^{\mathrm{m}}, 0014 \text { (/23 l.). }
$$

Patrie. Les monts Carpathes, la Volhynie.

OBs. Cette espèce diffère du monticola par la couleur du prothorax, de l'attenuatus par sa taille plus grande, etc. (1).

\section{Quedius (Raphirus) acuminatus, Hосннuтн.}

Suballongé, fusiforme, peu convexe, finement pubescent, d'un noir bronzé brillant, avec les palpes, les antennes et les pieds d'un roux testacé, les cuisses et les tibias postérieurs, moins les genoux, rembrunis. Tête et prothorax lisses, luisants : celui-ci aussi long que large, subrélréci en avant. Écusson pointillé. Elytres de la lonyueur du prothorax, finement, densement et subrugueusement pointillées. Abdomen finement et densement pointillé, un peu plus densement vers la base, à peine irisé. Le $1^{\mathrm{er}}$ article des tarses postérieurs subégal au dernier.

$\sigma^{*}$ Le $6^{\circ}$ arceau ventral légèrement et angulairement échancré au sommet, avec un espace triangulaire subimpressionné, lisse, au devant de l'échancrure. Tarses antérieurs fortement dilatés.

우 $6^{\circ}$ arceau ventral subarrondi au sommet. Tarses antérieurs légèrement dilatés.

Quedius acuminatus, HockeUtn, Bull. Mosc. 1849, I, 151. - FAUVrL, Faun. GalloRhén. III, 533, 46.

Quedius Bonvouloiri, Сн. Brisout, Cat. Grenier, 1863, 31, 40.

$$
\text { Long., } 0^{\mathrm{m}}, 006\left(23 / 4 \text { l.); - larg., } 0^{\mathrm{m}}, 0012\right. \text { (1/2 l.). }
$$

Corps suballongé, fusiforme, peu convexe, d'un noir bronzé brillant, revêlu sur les élytres et l'abdomen d'une fine pubescence d'un gris obscur et modérément serrée.

Tête subarrondie, un peu moins large que le prothorax; longuement

(1) Là viendrait se placer le fulvicollis de Stephens (Ill. Brit. V, 244), espece à tête presque aussi large que le prothorax; à élytres bronzées, à peine plus courtes que celui-ci qui est plus ou moins rougeâtre; à cuisses et tibias postérieurs rembrunis. Long., $0^{\mathrm{m}}, 00030$. Écosse. 
et éparsemeut sétosellée sur les côtés ; d'un noir bronzé luisant; lisse; à peine pointillée sur les tempes, avec 3 points sétifères disposés en arc transversal, derrière les yeux, le temporal très-petit, l'intermédiaire gros, celui du vertex petit. Front assez large, à peine convexe, à pore juxtaoculaire oblong. Cou glabre, lisse, luisant. Épistome subcorné, brunâtre. Labre à peine bilobé, à peine fendu, d'un noir brillant, sétosellé en avant. Mardibules d'un roux ferrugineux. Palpes d'un roux testacé : le dernier article des maxillaires suballongé, conico-fusiforme.

Yeux très-grands, subovales, médiocrement saillants, obscurs, à reflets gris et micacés.

Antennes peu allongées, sensiblement plus longues que la tête; à peine épaissies, finement duveteuses et légèrement pilosellées; entièrement d'un roux testacé ; à $1^{\mathrm{er}}$ article en massue allongée : le $2^{\mathrm{e}}$ oblong, obconique : le $3^{\circ}$ suballongé, obconique, à peine plus long que le $2^{\circ}$ : les suivants graduellement un peu plus courts et à peine plus épais, non contigus, subnbconiques : les $4^{\mathrm{e}}$ et $5^{\mathrm{e}}$ oblongs $\left(\sigma^{*}\right)$ ou à peine oblongs $(q)$ : les

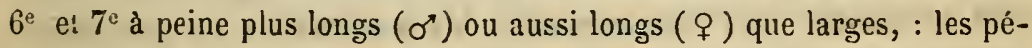
pénultièmes subcarrés $\left(\sigma^{\circ}\right)$ ou à peine transverses ( $q$ ), vus de côté : le dernier subovalaire, obliquement tronqué au sommet et subacuminé inférieurement.

Prothorax environ aussi large que long, subrétréci en avant, de la largeur des élytres ; largement tronqué ou à peine échancré au sommet, avec les angles antérieurs infléchis, presque droits naais émoussés ; subarqué sur les côtés; arrondi à sa base ainsi qu'aux angles postérieurs ; subconvexe sur son disque; éparsement sétosellé sur les côtés, avec le pore sétifêre latéral situé assez loin de la marge; d'un noir bronzé luisant; lisse; marqué en avant de 2 séries dorsales composées de 3 points assez petits et subégalement distants, avec 1 autre point semblable, de chaque côté, entre le pore sétifère latéral et le $1^{\text {er }}$ dorsal, mais un peu plus près de celui-ci.

Écusson légèrement pubescent, finement et peu densement pointillé, d'un noir assez brillant et submétallique.

Élytres subtransverses, à peine plus larges en arrière qu'en avant, de la longueur du prothorax ou à peine plus longues; subdéprimées ou à peine convexes; finement, densement et subrugueusement pointillées; d'un noir bronzé assez brillant, parfois plus clair que le prothorax; à pubescence assez serrée, avec quelques rares soies obsolètes sur les côtés, dont 1 très-longue, vers le tiers antérieur. Épaules cachées.

BR. 
Abdomen suballongé, un peu moins large que les élytres; fortement et graduellement atténué en arrière, longitudinalement convexe sur le dos; éparsement sétosellé; finement et densement pointillé, un pelu plus densement vers sa base ; d'un noir assez brillant et à peine irisé ; à pubescence longue et modérément serrée. Le $6^{\text {e }}$ segment à peine arrondi au sommet, d'un brun de poix à son bord postérieur, ainsi que parfois le précédent.

Dessous $d u$ corps aspèrement pointillé, finement pubescent, d'un noir brillant, avec la marge apicalc des derniers arceaux du ventre moins foncée. Dessous de la tête presque lisse, glabre. Prosternum relevé el faite. Mésosternum cilié vers sa pointe. Métastermum subdéprimé, Ventre convexe, éparsement sétosellé, plus ou moins irisé; à $2^{\mathrm{e}}$ arceau basilaire en angle très-obtus à son bord postérieur.

Pieds aspèrement pointillés, finement pubescents, d'un roux testacé, avec les hanches rembrunies, ainsi que les cuisses et tibias postérieurs, moins les genoux. Cuisses antérieures et intermédiaires finement spinosules en dessous vers leur extrémité; les postérieures un peu moins épaịsses, un peu plus longues. Tibias antérieurs peu robustes, peu épineux. Tarses antérieurs à 3 premiers articles plus $\left(\sigma^{\prime}\right)$ ou moins $(q)$ dilatés, le $4^{\mathrm{e}}$ moins sensiblement; les postérieur's à $1^{\mathrm{er}}$ article allongé, subégal aux 2 suivants réunis, subégal au dernier : celui-ci allongé, grêle : les $2^{\mathrm{e}}$ à $4^{\mathrm{e}}$ suboblongs, graduellement plus courts.

Patrie. Cette espèce, assez rare, se prend sous les mousses, dans les Pyrénées, à une grande altitude.

OBs. Sa forme est plus raccourcie et plus acuminée en arrière que le monticola, avec la taille moindre et la couleur un peu plus bronzée. Le dernier article des palpes maxillaires est un peu moins allongé, et le labra moins bilobé. Les tarses postérieurs sont un peu moins allongés, etc.

Les antennes des $q$ sont un plus plus courtes que celles des $\sigma^{\circ}$, un peu plus épaissies, avec leurs pénultiemes articles un peu moins longs.

\section{Quedius (Raphirus) attenuatus, Gyllenhal.}

Allongé, fusiforme, peu convexe, finement pubescent, d'un noir brillani et submétallique, avec les élytres un peu bronzées, les palpes moins leur sommet, les antennes et les pieds testacés. Téte et prothorax lisses, 
luisants : celui-ci aussi long que large, rétréci en avant : celle-là subarrondie, sénsiblement moins large que le prothorax. Écusson pointillé. Elytres de la longueur du prothorax, finement, densement et stibrigueusement pointillees. Abdomen très-finement et très-densemènt pointillé, un peu moins densement vers son sommet, plus ou moins irisé, piesque mat. Le $1^{\mathrm{er}}$ article des tarses postérieurs à peine égal au dernier.

$\sigma^{*}$ Le $6^{\mathrm{e}}$ arceau ventral sensiblement et subrectangulairement échancré au sommet, avec un espace triangulaire, subdéprimé ou à peine impressionné, lisse, au devant de l'échancrure. Le $5^{\text {e }}$ souvent avec un léger espace lisse vers le milieu de son bord postérieur. Tarses antérieurs trèsfortement et arcuément dilatés.

으 Le $6^{\mathrm{e}}$ arcean ventral subtronque ou à peine arrondi au sommet, le $5^{\mathrm{e}}$ simple. Tarses antérieurs médiocrement et subgraduellement dilatés.

Staphylinus altenuatus, Gylennal, Ins. Suec. II, 311, 27. - MaNNerheim. Brach. 27, 38. - Runde, Brach. Hal. 6, 13.

Staphylinus maurorufus, Ruvde, Brach. Hal. 6, 26.

Philonthus attenuatus, Nordyan, Symb. 78, 13. - Redtendicher, Faun. Austr. 710, 57. - HeER, Faun. Col. Helv. 1, 279, 72.

Emus scintillans, Boisduval el Lacordatre, Faun: Ent. Par. I, 384, 40 ..

Quedius attenuatus, Ericuson, Col. March. I, 493, 14; - Gen. et Spec. Staph, 516,

34. - Fairiaire et Laboulbène, Faun. Fnt. Fr. I, 538, 12. - KraAtz, Ins. Deut.

பl $13,29$. - Fauvel, Faun. Gallo-Rhén. 1II, 532, 45.

Raphirus attenuatus, Thowson, Skand. Col. II, 179. 4.

Quedius fallaciosus, Kra.rz, Berl. Ent. Zeit. 1852, 268.

Variété $a$. Téte un peu plus grosse. Élytres sensiblement plus courtes que le prothorax, d'un roux brunâtre. Abdomen subparallèle.

Variété $b$. Elytres rousses.

Long., $0^{\mathrm{m}}, 0054$ (2 1/2 l.); - larg., $0^{\mathrm{m}}, 0008$ (1/3 l. fort.).

Corps allongé, fusiforme: peu convexe, d'un noir submétallique, avec les élytres un peu bronzées; revêtu sur celles-ci et l'abdomen d'une très-. fine pubescence grisâtre et plus ou moins serrée.

:Tête suborbiculaire, sensiblement moins large que le prothorax;longuement ęt éparsement sétosellée sur les côtés; d'un noir luisant et : submétallique; lisse ; à peine pointillée à la bạsę des tempes, aveo 3 poịnts sétifères disposés en triangle derrière les yeux, le temporal et celui du 
vertex petits, l'intermédiaire gros, joignant le bord postéro-interne de l'œil. Front assez large, à peine convexe, à pore juxta-oculaire ovale, assez fort. Cou glabre, presque lisse, luisant. Épistome étroit, subcorné, obscur. Labre à peine bilobé, légèrement fendu, d'un noir brillant, sétoșellé en avant. Mandibules d'un roux de poix plus ou moins foncé. Palpes testacés, à dernier article plus ou moins rembruni, oblong, conique.

Yeux très-grands, subovales, assez saillants, obscurs, lavés de gris micacé.

Antennes peu allongées, évidemment plus longues que la tête; faiblement épaissies; très-finement duveteuses et brièvement pilosellées ; testacées; à $1^{\text {er }}$ article en massue très-allongée : les $2^{\mathrm{e}}$ et $3^{\mathrm{e}}$ suballongés, obconiques : le $3^{\mathrm{e}}$ à peine plus grêle, mais non plus long que le $2^{\circ}:$ les suivants gradıellement un peu plus courts et à peine plus épais, non contigus, subobconiques : les $4^{\mathrm{e}}$ et $5^{\mathrm{e}}$ suboblongs : les $6^{\mathrm{e}}$ et $7^{\mathrm{e}}$ subcarrés : les pénultièmes subtransverses: le dernier subovale, obliquement tronqué au sommet et acuminé inférieurement.

Prothorax environ aussi large que long, plus ou moins rétréci en avant; aussi large ou presque aussi large que les élytres; tronqué au sommet, avec les angles antérieurs infléchis et subarrondis ; subarqué sur les côtés ; arrondi à sa base ainsi qu'aux angles postéricurs; assez convexe sur son disque ; éparsement sétosellé sur les côtés, avec le pore sétifère latéral situé loin de la marge ; d'un noir luisant et submétallique; lisse ; marqué en avant de 2 séries dorsales composées de 3 points médiocres, dont l'antérieur souvent plus écarté, avec 1 autre point moindre, de chaque côté, entre le $1^{\text {er }}$ dorsal et le pore sétifère latéral.

Écusson légèrement pubescent, plus ou moins pointillé, surtout en arrière, d'un noir submétallique et assez brillant.

Élytres subtransverses, à peine plus larges en arrière qu'en avant; environ de la longueur du prothorax; subdéprimées ou à peine convexes, souvent subsillonnées le long de la suture; finement, densement et subrugueusement pointillées; d'un noir assez brillant et un peu bronzé, souvent brunâtre; à pubescence assez courte et assez serrée, avec quelques soies obsolètes, sur les côtés, et 1 très-longue, vers le tiers antérieur de ceux-ci. Épaules cachées.

Abdomen suballongé, un peu moins large que les élytres; plus ou moins fortement atténué en arrière; longitudinalement convexe sur le dos ; éparsement sétosellé; très-finement et très-densement pointillé, un peu moins densement sur le $6^{\text {e }}$ segment; d'un noir presque mat et plus 
ou moins irisé ; à pubescence très-fine, assez courte et serrée. Le $6^{\circ} \mathrm{seg}$ ment un peu plus brillant, à peine arrondi au sommet.

Dessous $d u$ corps finement pointillé, finement pubescent, d'un noir brillant, avec le repli du prothorax, le prosternum et le mésosternum souvent moins foncés. Dessous de la tête glabre, presque lisse. Prosternum subcaréné. Mésosternum légèrement cilié vers sa pointe. Métasternum subdéprimé, parfois obsolètement canaliculé sur sa ligne médiane. Véntre convexe, éparsement sétosellé, très-fortement irisé-cuivré; à $2^{\mathfrak{e}}$ arceau basilaire en angle très-obtus et subarrondi à son bord postérieur.

Pieds finement pointillés, finement pubescents, tesłacés, avec les hanches postérieures rembrunies. Cuisses antérieures et intermédiaires à peine spinosules en dessous vers leur extrémité ; les postérieures un peu moins épaisses, un peu plus longues. Tibias antérieurs peu robustes, à peine épineux. Tarses antérieurs des $\sigma^{\circ} \grave{a}^{\circ}$ et $3^{e}$ articles très-fortement dilatés, le $1^{\mathrm{er}}$ un peu, le $4^{\mathrm{e}}$ sensiblement moins; ceux des $q$ médiocrement et subgraduellement moins dilatés; les postérieurs à $1^{\mathrm{e}_{\mathrm{r}}}$ article suballongé, subégal aux 2 suivants réunis, à peine égal au dernier : les $2^{\mathrm{e}}$ à $4^{\mathrm{e}}$ graducllement plus courts.

Patrie. Cette espèce, peu commune, vit sous les mousses et les feuilles mortes. On la trouve tout l'été, à diverses altitudes, dans les environs de Paris et de Lyon, la Normandie, la Champagne, l'Alsace, la Lorraine, l'Auvergne, la Bourgogne, le Beaujulais, les Alpes de la Savoie et du Daupbiné, les Pyrénées, etc.

OBs. Elle est moindre et plus étroite que le $Q$. acuminatus. La couleur est moins sombre; le dernier article des palpes maxillaires moins allongé, obconique ; le $3^{\mathrm{e}}$ article des antennes moins long relativement au $2^{\mathrm{e}}$; les pieds postérieurs sont généralement moins rembrunis ; te $1^{\text {er }}$ article des larses postérieurs est un peu moins allongé, à peine égal au dernier; l'abdomen est plus finement et plus densement pointillé, presque mat, si ce n'est vers son sommet ; la tête est un peu moins grosse, etc.

Quant à la forme générale, elle ressemble aux rufipes et semiobscurus, à part la taille qui est bien plus petite. La tête est moins grosse et plus arrondie, le labre moins bilobé, le dernier article des palpes maxillaires plus court et plus conique, et le $1^{\text {er }}$ article des tarses postérieurs moins long relativement au dernier, etc.

Les élytres varient quant à leur longueur et leur couleur. Celle-ci passe du noir un peu bronzé au brun de poix $\mathrm{cl}$ au roux submétallique. 
Quelquefois, le sommet du ventre et la marge apicale des arceaux est d'un roux ferrugineux,.et, il est à remarquer que, dans ce cas, le ventre es! moins brillant et moins fortement irisé.

- Les tibias postérieurs, et parfois les intermédiaires et le milieu des cuisses postérieures, sont souvent plus ou moins enfumés, tant dans les variétés que dạns l'espèce typique:

56. Quedius (Eaphirus) pieipennis, HeEr.

Allongé, subfusiforme, peu convexe, finement pubescent, d'un noir brillant et submétallique, avec les angles antérieurs du prothorax un peu roussâtres, les élytres d'un brun de poix un peu bronzé, les palpes; . les antennes et lés pieds d'un roux.testacé, et les tibias postérieurs à peine rembrunis. Tète et prothorax lisses, luisants : celui-ci aussi long que large, subrétréci. en avant : celle-là subtransverse, à peine moins large que le prothorax. Écusson pointillé. Élytres un peu ou évidemment moins longues que le prothorax, finement, densement et subrugueusement pointillées. Abdomen très-finement, très-densement et uniformément pointillé, à peine irisé, mat. Le $1^{\mathrm{er}}$ arlicle des tarses postérieurs à peine aussi long que le dernier.

$\sigma^{*}$ Le $6^{\mathrm{e}}$ arceau ventral largement et angulairement échancré au sommet, avec un espace triangulaire oblong, subimpressionné, lisse au devant de l'échancrure. Le $5^{\mathrm{e}}$ avec un léger espace lisse vers le milieu de son bord postérieur. Tarses antérieurs très-fortement dilatés.

† Le $6^{c}$ arceau ventral à peine arrondi au sommet, le $5^{\mathrm{e}}$ siniple. Tarses antérieurs médiocrement dilatés.

Phitonthus picipennis, HeER, Faun. Col. Helv. I, 279, 75.

$$
\text { Ĺng., } 0^{\mathrm{m}}, 0051 \text { (2 1/3 1.); - larg., } 0^{\mathrm{m}}, 0008 \text { (1/3 1. fort). }
$$

Patrie. Cette espèce, qui est très-rare, se trouve, en juillet, sous les mousses, au mont Pilat et dans les Alpes.

OBs. Elle ressemble infiniment à l'attenuatus, et nous ne la décrirons pas plus amplement. Cependant. nous la croyons une espèce distincte. 
En effet, elle est moins fusiforme, parfois même, presque subparallèle, sa tète étant plus grosse et son abdomen moins atténué en arrière. La tête, plus transverse est à peine moins large que le prothorax, et celui-ci, un peu moins attẻnué en avant, a ses angles antėrieurs ordinairement d'un roux de poix, un peu plus prononcés et moins arrondis. Les élytres sont plus courtes et un peu moins finement pointillées. L'abdomen, moins rétréci en arrière, est encore plus mat, et surtout moins irisé, et sa ponctuation est uniformément serrée sur les 5 premiers segments, plus éparsement sur le $6^{\circ}$. Les tarses postérieurs nous ont paru un peu moins grèles et un peu moins allongés. Les lobes $d u 6^{\circ}$ arceau ventral, de chaque côté de l'échancrure du $\sigma^{\circ}$, sont moins arrondis, ou même faiblement angulés, etc.

Le prothorax est rarement entièrement noir. Les élytres sont parfois d'un roux brunâtre. Les hanches et les cuisses postérieures ne sont nullement rembrunies, au lieu qu'elles le sont souvent ou presque toujours, du moins les premières, dans l'attenuatus et le persimilis.

\section{ธ. Quedius (Raphirus) persimilis, Mulsant et Rey.}

Allongé, fusiforme, peu convexe, finement pubescent, d'un noir brillant, avec les elytres d'un noir de poix, les palpes moins leur sommet, les antennes et les pieds testacés, les hanchos et tibias postérieurs rembrunis. Tête et prothorax lisses, luisants : celui-ci à peine plus long que large, non rétréci en avant : celle-là subtransverse, a peine moins large que le prothorax. Écusson pointillé. Elytres a peine moins longues que le prothorax, très-finement, densement et subrugueuscment pointillées. Abdomen très-finement et très-densement pointillé ver's sa base, moins densement en arrière, irisé. Le $1^{\mathrm{er}}$ article des tarses postérieurs allongé, ègal au dernier.

$\sigma$ Le $6^{\text {e }}$ urcean ventral légèremønt et angulairement entaillé, avec un léger espace lisse, au devant de i'entaille. Tarses antérieur's très-for- . tement dilatés.

Q Le $6^{\text {e }}$ arceau ventral subarrondi au sommet. Tarses antérieurs légè1 cunent dilatés. 


$$
\text { Long., } 0^{m}, 0048 \text { (2 1/4 1.); - larg., } 0^{m}, 0007 \text { (1/3 1.). }
$$

Corps allongé, fusiforme, peu convexe, d'un noir brillant ; revêtu sur les élytres el l'abdomen d'une fine pubescence grise et asscz serrée.

Tête subtransversalement arrondie, à peine moins large que le prothorax; longuemont et éparsement sétosellée sur les côtés; d'un noir luisant; lisse; finement pointillée à la base des tempes, avec 3 points sétifères disdosés en triangle transversal derrière les yeux, le temporal et celui du vertex très-petits, l'intermédiaire assez gros, joignant le bord postéruinterne de l'œil. Cou glabre, presque lisse, luisant. Épistome submembraneux, livide. Labre entier ou presque entier, d'un noir brillant, sétosellé en avant. Mandibules d'un roux foncé. Palpes testacés, à dernier article plus ou moins rembruni, oblong, tout à fait conique.

Yeux très-grands, subovales, saillants, obscurs, mêlés de gris micacé.

Antennes peu allongées, sensiblement plus longues que la tête, assez grêles, subfiliformes ou à peine épaissies; très-finement duveteuses et légèrement pilosellées; entièrement lestacées; à $1^{\text {er }}$ article en massue allongée et assez grêle : les $2^{\mathrm{e}}$ el $3^{\mathrm{e}}$ suballongés, obconiques : le $3^{\mathrm{e}}$ à peine plus étroit, non ou à peine plus long que le $2^{\circ}$ : les suivants graduellement un peu plus cuurts et à peine plus épais, non ou peu contigus, subobconiques: les $4^{\mathrm{e}}$ à $7^{\mathrm{e}}$ oblongs ou suboblongs : les pénultièmes à peine $\left(\sigma^{\circ}\right)$ ou non ( $q$ ) plus longs que larges : le dernier subovale, obliquement tronqué au bout et acuminé inférieurement.

Prothorax à peine plus long que large, non ou à peine rétréci en avant; de la largeur des élytres; tronqué au sommet, avec les angles antérieurs infléchis et subarrondis; subarqué sur les côtés qui, vus latéralement, sont presque droits ou à peine sinués; arrondi a sa base ainsi qu'aux angles postérieurs; légèrement convexe sur son disque ; sérialement sélosellé sur les côtés, avec le pore sétifère latéral situé à une distance médiocre de-la marge; d'un noir luisant; lisse; offrant en avant 2 séries dorsales composées de 3 points assez petits, dont l'antérieur souvent plus écarté, et, de chaque cóté, 1 point semblable, situé entre le pore sétifère latéral et le $1^{\text {er }}$ dorsal, mais plus près de ce dernier.

Écusson finement pubescent, lisse à sa base, firement et subéparsement pointillé en arrière, d'un noir brillant.

Élytres subcarrées ou -subtransverses, à peine plus larges en arrière qu'en avant; un peu ou à peine moins longues que le prothorax ; subdé- 
primées oll à peine convexes, souvent subsillonnées le long de la suture ; très-finement, densement et subrugueusement pointillées; d'un noir de poix brillant, à peine métallique et parfois brunâtre; à pubescence assez longue et assez serrée, avec quelques légères soies redressées sur les côtés, et 1 très-longue, vers le tiers antérieur de ceux-ci. Épaules cachées.

Abdomen suballongé, un peu moins large que les élytres; fortement atténué en arrière; longitudinalement convexe sur le dos; assez fortement sétosellé ; très-finement et très-densement pointillé à sa base, graduellement moins densement en arrière, dès le sommet du $3^{\text {e }}$ segment ; d'un noir brillant et plus ou moins irisé; à pubescence assez longue et assez serrée. Le $6^{\text {e }}$ segment souvent couleur de poix, subarrondi au sommet.

Dessous du corps aspèrement pointillé, finement pubescent, d'un noir brillant, avec le repli du prothorax et le prosternum moins foncés, le sommet du ventre et la marge apicale des arceaux souvent d'un roux de poix cuivreux. Dessons de la tête glabre, presque lisse. Prosternum relevé en faile arqué. Mlésosternum légèrement cilié sur ses côtés et vers sa pointe. Métasternum subdéprimé, finement canaliculé en arrière sur sa liq̣ne médiane. Ventre convexe, assez densement pointillé, éparsement sétosellé, fortement irisé; à $2^{\mathrm{e}}$ arceau basilaire prolongé sur le $1^{\mathrm{er}}$ normal en angle très-ouvert.

Pieds finement pointillés, finement pubescents, testacés, avec les tibias postćrieurs plus ou moins rembrunis, ainsi que la base des hanches postéricures. Cuisses antéricures et intermédiaires très-finement spinosules cn dessous vers leur extrémité ; les postérieures moins épaisses, un peu plus longues. Tibias antérieurs assez grêles, peu épineux. Tarses antérieur's à 3 preniers articles plus $\left(\sigma^{\prime}\right)$ ou moins $(\$)$ dilatés, le $4^{\mathrm{e}}$ moins scnsiblement; les posterrieurs assez grêles, à $1^{\text {er }}$ article allongé, subégal aux 2 suivants réunis, égal au dernier ou à peine plus long: celui-ci allongé : les $2^{\mathrm{e}}$ à $4^{\mathrm{e}}$ oblongs, graduellement moins longs.

Patrie. Cette espèce est peu commune. Elle se trouve, en automne, dans les environs de Lyon cl dans les Alpes, sous les détritus accumulés sur le sable des rivières. Nous l'avons capturée, en décembre, dans les dunes de Frẻjus, tout près de la mer.

OBs. Elle est comme intermédiaire entre l'attenuatus et le boops. Elle est un pou moindre que le premier. La tête, un peu plus grosse, est plus 
transverse. Les antemnes, un peu plus grêles, ont les articles intermédiaires un peu plus longs et les pénultièmes un peu moins courts. Le prothorax, un peu plus oblong, est moins rétréci en avant. L'écusson paraît moins densement pointillé. Les élytres, généralement un peu plus courtes relativement au prothorax, sont à peine moins finement pointillées. L'abdomen est un peu plus brillant, moins ponctué sur le dos des $4^{\mathrm{e}}$ et $5^{\circ}$ segments. Les tarses antérieurs des $q$ sont plus légèrement dilatés. Les tarses postérieurs sont à peine plus grêles, avec leur $1^{\text {er }}$ article un peu plus allongé, etc.

A part la forme et la ponctuation de l'abdomen, le persinilis, par la grosseur de sa tête, pourrait être assimilé au picipennis, mais la taille est moindre; les antennes sont moins fortes et un peu plus grêles, avec leurs pénultièmes articles à peine moins transverses; les élytres, un peu moins courtes, sont un peu plus finement pointillées; l'abdomen est plus rétréci et moins densement pointillé en arrière, plus irisé. Le $1^{\text {er }}$ article des tarses postérieurs est un peu plus allongé comparativement au dernier, etc.

Rarement, les côtés du prothorax sont d'un roux de poix. Chez les exemplaires les plus adultes, non-seulement les tibias postérieurs sont rembrunis, mais encore les cuisses postérieures et les tibias intermé-diaires.

Quand l'écusson est épilé, il paraî̀ à peine pointillé.

\section{Queding (Raphirus) boops, Gravenhorst.}

Allongé, fusiforme, peu convexe, finement pubescent, d'un noir brillant, avec les palpes, les antennes et les pieds testacés. Títe et prothora.x lisses, luisants: celui-ci à peine plus long que large, peu rétréci en avant : celle-là subtransverse, à peine moins large que le prothorax. Ecusson pointillé. Élytres de la longueur du prothorax, finement, densement et subrugueusernent pointillées. Abdomen finement et densement pointillé, moins densement en arrière, non ou peu irisé. Le $1^{\text {er }}$ article des tarses postérieurs subégal au dernier.

$\sigma^{*}$ Le 6e arceau ventral sensiblement et angulairement échancré au sommet, avec un léger espace lisse, au devant de l'échancrure, Tarses antérieurs fortement dilatés. 
I Le $6^{\circ}$ arceau ventral a peine arrondi ou parfois subsinueusement tronqué au sommet. Tarses antérieurs médiocrement dilatés.

Staphylinus boops, Graveniorst, Micr. 21, 26 ; - Mon. 71, 54.- Latreille, Hist. Nat. Crust et Ins. IX 311,31.— Gyllenhal, Ins. Suec. II, 312, 28.—Manserheim, Brach. 27, 39.

Emus boops, Boisduval et Licordatre, Faun. Ent. Par. I, 385, 41.

Philonthus boops, Nordmann, Symb. 78, 14. - Redtenbacher, Faun. Austr. 709, 56. - HeEr, Faun. Col. Helv. I, 280, 74 .

Quedius boops, Ericrson, Col. March. I, 494, 15 ; - Gen. et Spec. Staph. 548, 37.

- Fairmaire el laboulbène, Faun. Ent. Fr. I, 538, 13. - Kratiz, Ins. Deut. II, 516, 30.-Fauvel, Faun. Gallo-Rhén. III, 534, 48.

Raphirus boops, TномsоN, Skand. Col. II, 179, 5.

$$
\text { Long., } 0^{\mathrm{m}}, 0043 \text { (2 l.); - larg., } 0^{\mathrm{m}}, 0007 \text { (1/3 l.). }
$$

Corps allongé, fusiforme, peu convexe, d'un noir brillant; revêtu sur les élytres et l'abdomen d'une fine pubescence grisâtre, peu ou modérément serrée.

Tête assez grosse, subtransverse, à peine moins large que le prothorax ; longu^ment et éparsement sétosellée sur les côtés ; d'un noir luisant; lisse (1); à peine pointillée sur les tempes, avec 3 points sétifères, disposés en triangle derrière les yeux : le temporal et celui du vertex très-petits : l'intermédiarile assez gros, touchant à l'angle postéro-interne de l'œil. Front assez large, à peine convexe, à pore juxla-oculaira assez fort. Cou glabre, presque lisse, luisant. Épistome étroit, corné, obscur. Labre entier ou presque entier, d'un noir brillant, sétosellé en avant. Mandibules d'un roux de poix, quelquefois brunâtres. Palpes testacés, à dernier article oblong, conique, rarement plus foncé.

Yeux très-grands, subovales, saillants, obscurs et lavés de gris.

Antennes courtes, un peu plus longues que la tête; à peine épaissies; tinemeut duveteuses et brièvement pilosellées; entièrement testacées; à $1^{\text {er }}$ arlicle en massue allongće et assez grêle : les $2^{\mathrm{e}}$ et $3^{\mathrm{e}}$ suballongés, obconiques: le $3^{\circ}$ un peu plus étroit et à peine aussi long que le $2^{\mathrm{e}}$ : les suivants graduellement un peu plus courts et à peine plus épais, non contigus, subobconiques : les $4^{\mathrm{e}}$ à $6^{\mathrm{e}}$ oblongs : les pénultièmes à peine $\left(\sigma^{\mathrm{N}}\right)$

(1) A un fort grossissement, la tête parait plus visiblement chagrinée que dans les espèces vơisines. 
ou non ( $q$ ) plus longs que larges : le dernier subovalaire, obliquement tronqué au sommet et acuminé inférieurement.

Prothorax à peine plus long que large, peu rétréci en avant, à peine moins large que les élytres; tronqué au sommet, avec les angles antérieurs infléchis, presque droits mais émoussés; subarqué sur les côtés, qui, vus latéralement, sont presque rectilignes en arrière; arrondi à sa base ainsi qu'aux angles postérieurs ; légèrement convexe sur son disque; éparsement sétosellé sur les côtés, avec le pore sétifère latéral situé assez loin de la marge; d'un noir luisant; lisse ; marqué en avant de 2 séries dorsales composées de 3 points assez petits, dont l'antérieur plus écarté, et, de chaque côté, de 1 autre point semblable, situé entre le pore latéral et le $1^{\text {er }}$ dorsal, mais ún peu plus près de ce dernier.

Écusson légèrement pubescent, subéparsement pointillé, d'un noir brillant.

Elytres subtransverses, un peu plus larges en arrière qu'en avant; environ de la longueur du prothorax; subdéprimées ou à peine convexes, parfois obsolètement subsillonnées en arrière le long de la suture; finement, densement et subrugueusement pointillées ; d'un noir plus ou moins brillant, à peine métallique et parfois un peu brunâtre; à pubescence fine et peu serrée, avec quelques légères soies redressées, sur les côtés, dont 2 beaucoup plus longues, l'une vers le tiers antérieur de ceux-ci, l'autre vers les épaules. Celles-ci très-peu saillantes ou cachées.

Abdomen suballongé, à peine moins large à sa base que les élytres; plus ou moins fortement atténué en arrière; longitudinalement convexe sur le dos ; éparsement sétosellé, plus fortement vers son extrémité ; finement et densement pointillé, plus éparsement sur le dos de chaque segment ct vers le sommet; d'un noir brillant, non ou à peine irisé; à pubescence un peu plus serrée, surtout sur les côtés, que celle des élytres. Le $6^{\mathrm{e}}$ segment subarrondi au sommet, qui est souvent couleur de poix.

Dessous du corps éparsement pointillé, assez longuement pubescent, d'un noir brillant, avec le repli du prothorax, le prosternum et le mésosternum souvent moins foncés, et la marge apicale des arceaux du ventrc généralement d'un roux de poix. Dessous de la tête glabre, presque lisse. Prosternum relevé en faite arqué. Mésosternum cilié vers son sommet. Mélasternum subdéprimé, obsolètement canaliculé en arrière sur sa ligne médiane. Ventre convexe, éparsement sétosellé, subirisé, à $2^{\text {e }}$ arccall bssilaire en angle très-ouvert et subarrondi, dans le milieu de son bord postérieur. 
Pieds finement pointillés, finement pubescents, testacés, avec les hanches postérieures rembrunies. Cuisses antérieures et intermédiaires finement spinosules en dessous vers leur extrémité ; les postérieures moins épaisses, un peu plus longues. Tibias antérieurs assez grêles, à peine ćpineux. Tarses antérieurs à 3 premiers articles plus $\left(\sigma^{\prime \prime}\right)$ ou moins $(q)$ dilatés, le $4^{\mathrm{e}}$ moins sensiblement; les postérieurs à $1^{\mathrm{er}}$ article suballongé, subégal aux 2 suivants réunis, subégal au dernier : celui-ci grêle : les $2^{\circ}$ à $4^{\circ}$ graduellement plus courts.

Patrie. Cetle espèce est commune, toute l'année, sous les pierres, les mousses, les feuilles mortes et les détritus, dans presque toute la France.

OBs. C'est, avec le virgulatus, la plus petite du genre. Outre la taille, elle diffère du persimilis par ses antennes plus courtes, un peu moins grêles et à pénultièmes articles à peine moins longs. Les élytres, un peu plus noires, sont un peu moins finement pointillées. La ponctuation du dos de l'abdomen, et surtout du ventre, est moins serrée. Les tarses antérieurs des $q$ paraissent un peu moins légèrement dilatés, etc.

Les cuisses postérieures et les tibias intermédiaires et postérieurs sont parfois enfumés.

Chiz les immatures, le prothorax et les élytres sont d'un roux de poix plus ou moins foncé.

\section{Quediug (Raphirus) brevipennis, FalRmaire.}

Allongé, subfusiforme, peu convexe, finement pubescent, d'un noir de poix brillant, avec la tête et l'abdomen noirs, les palpes, les antennes et les pieds testacés. Tête et prothorax lisses, luisants : celui-ci à peine plus long que large, peu rétréci en avant. Écusson pointillé. Élytres beaucoup plus courtes que le prothorax, finement, assez densement et subécailleusement pointillées. Abdomen finement et densement pointillé, moins densement en arrière, non ou à peine irisé. Le $1^{\mathrm{er}}$ article des tarses postérieur's subégal au dernier.

$\sigma^{*}$ Le $6^{\mathrm{e}}$ arceau ventral angulairement échancré au sommet, avec un léger espace lisse, au devant de l'échancrure. Tarses antérieurs fortement dilatés. 
ㄴ Le $6^{6}$ arceau ventral subarróndi au sommet. Tarses antérieurs médiocrement dilatés.

Quedius brevipennis, Farmaire, Ann. Soc. Ent. Fr. 18:9, 41. Quedius boops, var. $\beta$, Fauver, Faun. Gallo-Rhén. III, 535.

Variété a. Prothorax et élytres d'un brun de poix.

Variëté $b$. Prothorax d'un roux testacé. Élytres brunâtres.

Variété $c$. Prothorax, élytres et sommet de l'abdomen d'un roux testacé.

$$
\text { Long., 0m,004 (1 4/5 l.); - larg., } 0^{\mathrm{m}}, 0007 \text { (1/3 I.). }
$$

Patrie. Les Pyrénées, les Alpes maritimes.

OBs. C'est peut-être avec raison que M. Fauvel réunit le brevipennis au boops, dont il est probablement une variété brachyptère, ainsi que nous en avons vu des exemples chez quelques autres espècès.

Toutefois, nous ferons observer que la tête est encore plus grosse, environ de la largeur du prothorax ; que celui-ci est d'un roux de poix à ses angles postérieurs, même chez les exemplaires les plus foncés; que les élytres paraissent un peu moins densement pointillées; qu'au contraire, la ponctuation de l'abdomen est plus serrée, surtout vers sa base; que la couleur générale est moins noire et plus instable; que le dernier article des palpes nous a semblé un peu grêle et souvent rembruni.

Genre Astrapaeus, AstrapéE, Gravenhorst.

Gravenhorst, Mon. Micr., 199. - Jacouelin du VaL, Gen. Slapl., 40 pl. 16. fig. 77. Étymologie : $\alpha \sigma \tau \rho \alpha \pi \alpha i \varsigma \varsigma$, fulgurant.

Caractéres. Corps allongé, subparallèle, subconvexe, ailé, à peine pubescent, avec la tête et le prothorax glabres et luisants.

Téte médiocre, subovalaire, portée sur un cou très-large et court, un peu moins large que le vertex. Tempes fortement rebordées sur les côtẻs : à rebord subinterrompu dans, son milieu. Épistome étroit, submembra- : neux, largement tronqué en avant. Labre court, bilobé. Mandibules sail- 
lantes, robustes, arquées, finement sillonnées eǹ dehors, mutiques en dedans, médiocrement croisées au repos. Palpes maxillaires médiocrement développés mais assez épais, à $1^{\text {er }}$ article petit: les $2^{\mathrm{e}}$ et $3^{\mathrm{e}}$ assez grands, obconiques: le $3^{\mathrm{e}}$ plus court que le $2^{\mathrm{e}}$ : le dernier grand, plus $\left(\sigma^{*}\right)$ oll moins ( $q$ ) sécuriforme. Palpes labiaux robustes, courts, à $1^{\mathrm{e}^{\mathrm{r}}}$ article subcylindrique : le $2^{\mathrm{e}}$ plus court, obconique : le dernier grand, fortement sécuriforme. Menton transverse, trapéziforme, plus étroit en avant, tronqué ou à peine échancré au sommet.

Yeux assez grands, subovales, peu saillants, séparés du prothorax par un intervalle assez court.

Antennes suballongées, subfiliformes; à $1^{\text {er }}$ article en massue allongée : le $3^{\mathrm{e}}$ plus long que le $2^{\mathrm{e}}$ : les suivants graduellement un peu plus courts, peu contigus : le dernier brièvement ovalaire, obliquement tronqué au bout.

Prothorax transverse, un peu plus large que les élytres, subrétréci en avant; subsinué de chaque côté de son bord antérieur, plus faiblement sur les côtés de sa base, avec tous les angles arrondis; très-finemen। rebordé à la base et sur les côtés; à rebord latẻral rẻgulièrement arqué, à peine abaissé d'arrière en avant. Repli large, fortement retourné en dessous, non visible vu de côté; à opercule prothoracique grand, triangulaire, submembraneux.

Ecusson grand, subogival.

Élytres transverses, individuellement et subobliquement coupées à leur bord apical, largement arrondies à leur angle postéro-externe; rebordées sur la suture. Repli assez étroit, subvertical. Épaules peu saillantes, épineuses en dessous.

Prosternum faiblement développé au devant des hanches antérieures; offrant entre celles-ci un triangle relevé ou gibbeux à sa base, rebordẻ postérieurement en forme de gouttière, à sommet droit ou subaigu. Mésosternum à lame médiane triangulaire, aiguë, prolongée environ jusqu'au milieu des hanchos intermédiaires. Médiépisternums grands, séparés du mésosternum par une arête saillante et arqiiée. Médiépimères longitudinales, oblongues, à angle antéro-interne lisse, séparé du reste de la surface par une arête fine et subarquée. Métasternum assez court, échancré pour recevoir les hanches postérieures; prolongé entre celles-ci en un lobe court, échancré ; arrondi et à peine avancé entre les hanches postérieures. Postépisternums assez. étroits, terminés en languette, à bord interne subparallèle au repli des élytres. Postépimères assez petites, triangulaires. 
Abdomen allongé, atténué seulement vers le sommet; fortement rebordé sur les côtés; à 4 premiers segments subégaux : le $5^{\mathrm{e}}$ plus grand, à peine ct largement sinué dans le milieu de son bord postérieur : le $6^{\mathrm{e}}$ plus ou moins saillant, rétractile : celui de l'armure enfoui, émeltant parfois 2 lanières ciliées. Ventre à $2^{\mathrm{e}}$ arceau basilaire prolongé sur le $1^{\text {er }}$ normal en pointe mousse : les suivants subégaux : le $5^{\mathrm{e}}$ un peu plus grand : le $6^{\mathrm{e}}$ plus ou moins saillant, rétractile.

Hanches antérieures grandes, de la longueur des cuisses, saillantes, coniques, contiguës au sommet. Les intermédiaires grandes, peu saillantes, subovales, obliquement disposées, contiguës en arrière. Les po.stérieures médiocres, légèrement écartées à leur base, divergentes au sommet, épineuses en dessous à celui-ci; à lame supérieure en cône court et mousse, subétranglé dans son premier liers; à lame inférieure nulle ou enfouie.

Pieds peu allongés, assez robustes ; les antérienrs plus courts et plus épais. Trochanters cunéiformes; les antérieurs petits, les intermédiaires (t) postérieurs plus grands. Cuisses subcomprimées, plus ou moins atténuées vers leur extrémité ; les antérieures et intermédiaires spinosules en dessous, au moins vers leur extrémité. Tibias subélargis de la base au sommet, plus courts que les cuisses, plus ou moins épineux, armés au bout de leur tranche inférieure de 2 forts éperons, dont linterne plus long; les antérieur's encore plus courts, simplement pubescents sur leur tranche externe. Tarses antérieurs courts, à \& premiers articlés trèscourts, subégaux, tomenteux en dessous, foriement mais graduellement moins dilatés; les intermédiaires et postérieurs suballongés, à peine atténués vers leur extrémité, à $1^{\text {er }}$ article suballongé, subégal au dernier : celui-ci en massue assez grêle : les $2^{\mathrm{e}}$ à $4^{\mathrm{e}}$ subtriangulaires, graduellement plus courts. Ongles assez forts, subarqués.

OBs. La seule espèce de ce genre, de taille grande, vit au pied et dans les plaies des arbres.

Avec la forme des Quedius, cette coupe générique s'en distingue facilement par la structure des palpes.

Elle se réduit à une seule espèce. 


\section{Astrapaeus ulmi, Rossl.}

Allongé, subparallèle, subconvexe, à peine pubescent, d'un noir brillant, avec les élytres rouges, ainsi qu'une bande avant le sommet de l'abdomen, la bouche et la base des antennes d'un roux testacé, les tibias et les tarses d'un roux de poix. Tête et prothorax éparsement pointillés, très-luisants : celui-ci transverse, subrétréci en avant. Élytres un peu plus longues que le prothorax, finement pointillées, avec une série de gros points sur le milieu du disque. Abdomen assez fortement et assez densement ponctué, subirisé.

$\sigma^{*}$ Le $6^{\mathrm{e}}$ arceau ventral faiblement sinué dans le milieu de son bord apical, avec un léger espace lisse, au devant du sinus. Le dernier article des palpes maxillaires fortement sécuriforme, celui des labiaux très-fortement.

\& Le $6^{\mathrm{e}}$ arceau ventral subarrondi à son bord apical. Le dernier article des palpes maxillaires légèrement sécuriformn, celui des labiaux fortement.

Staphylinus ulmi, Rossı, Faun. Etr. I, 248 (Ed. Helw. 307), 611, pl. 5, fig. 6. Olivier, Ent. III, no $42,17,17$, pl. IV, fig. 17.-Gravenhorst, Mon. 47, 7. Staphylinus ulmineus, Fabricius, Syst. El. II, 595, 28.

Astrapaeus ulmi, Gravenhorst, Micr. 199, 1. - Litreille, Hist. Nat. Crust. ct Ins. IX, p. 288, pl. 79, fig. 3 ; - Gen. Ins. I, 284, 1.- MaNNERHEIM, Brach.19, 1. - Nordyans, Symb. 16, 1. - Erichson, Gen. et Spec. Staph. 553, 1. - Fairmaire et Laboulbèse, Faun. Ent. Fr. I, 545, 1. - KraAtz, Ins. Deut. II, 523, 1. JAGQUELIN DU VAL, Gen. Staph. pl. 16, fig. 77. - FAuveL, Faun. Gallo-Rhén. III, 540,1 .

Astrapxeus ulmineus, Boisduval et LaCoRdate, Faun. Ent. Par. I, 3̋6, 1.

$$
\text { Long., } 0^{\mathrm{m}}, 012 \text { (5 1/2 l.); - larg., } 0^{\mathrm{m}}, 0028 \text { (1 1/4 l.). }
$$

Corps allongé, subparallèle, subconvexe, d'un noir brillant, avec les élytres et un anneau avant le sommet de l'abdomen rouges; revêtu sur ce dernier d'une fine pubescence grisâtre et peu serrée.

Téte médiocre, subovale, moins large que le prothorax; éparsement sétosellée sur les còtés; d'un noir très-luisant; éparsement et obsolètc- 
ment pointillée, avec 3 points sétifères derrière les yeux, dont le temporal et l'intermédiaire assez gros, et celui du vertex petit. Front large, assez convexe, à pore juxta-oculaire assez gros, placé en avant, près du superantennaire. Con glabre, presque lisse, luisant. Épistome livide. Labre d'un roux testacé, fortement sétosellé en avant. Mandibules obscures. Palpes roux.

Yeux assez grands, obscurs, lavés de gris.

Antennes suballongées, bien plus longues que la tête; subfiliformes; très-finement duveteuses et faiblement pilosellées; obscures, avec la base d'un roux testacé, et le sommet ferruyineux; $1^{\mathrm{er}}$ article en massue allongée : le $2^{\mathrm{e}}$ oblong, obconique : le $3^{\mathrm{e}}$ suballongé, obconique, plus long que le $2^{\mathrm{e}}$ : les suivants graduellement un peu plus courts, subobconiques : les $4^{\mathrm{e}}$ à $7^{\mathrm{e}}$ suboblongs : les $8^{\mathrm{e}}$ et $9^{\mathrm{e}}$ à peine aussi larges que longs : le $10^{\mathrm{e}}$ subtransverse, vu de côté : le dernier courtement ovalaire, obliquement tronqué et mousse all bout.

Prothorax transverse, subrétréci en avant; un peu plus large que les élytres; subsinué de chaque côté de son bord apical, avec les angles antérieurs infléchis et arrondis ; subarqué sur les côtés; arrondi à sa base, avec celle-ci à peine subsinuée près des angles postérieurś, qui sont très-obtus et arrondis; assez convexe sur son disque; d'un noir trèsluisant ; éparsement et très-finement pointillé; offrant en avant, de chaque côté du disque, 2 points distants, en série longitudinale, dont l'antérieur submarginal, à soie longue, et le postérieur moindre, nu, souvent obsolète ou nul ; à pore sétifère latéral situé presque contre la marge, avec les marginaux très-rares.

Écusson glabre, lisse, luisant, d'un noir de poix à transparence rousse. Elytres carrées, un peu ou à peine plus longues que le prothorax; subdéprimées ou faiblement convexes; sillonnées le long de la suture; finement el éparsement pointillées, avec 3 à 5 gros points disposés en sćrie longitudinale irrégulière sur le milieu du disque, une série de points semblables sur les côtés eux-mêmes, et une troisième, composcee de points un peu moindres, plús nombreux et plus rapprochés, le long du bord inférieur du repli; presque glabres; à peine pubescentes sur leurs côtés, qui offrent en outre 2 ou 3 longues soies obscures; finement cilićes-subspinosulées à leur bord apical; entièrement d'un rouge éclatant. Epaules peu saillantes, épineuses en dessous.

Abdomen allongé, à peine moins large que les élytres; subparallèle ou un peu atténué tout à fait vers le sommel; longitudinalement convexe s'Ir 
le dos; éparsement sétosellé; assez fortement et assez densement ponctué, à peine moins densement en arrière; d'un noir brillant et subirisé, avec un large anneau rouge, embrassant la partie postérieure du $5^{e}$ segment et la base du $6^{\mathrm{e}}$; à pubescence couchée et peu serrée. Le $6^{\mathrm{e}}$ segment subarrondi au sommet.

Dessous du corps fortement ponctué, finement pubescent, d'un noir brillant, avec l'extrémité du $5^{\mathrm{C}}$ arceau, la base et le sommet du $6^{\circ}$ rouges. Dessous de la téte éparsement ponctué et pileux en arrière, sur les côtés. Prosternum avec 2 longues soies rapprochées au devant de sa bosse. Mésosternum rugueux, cilié vers son sommet. Métasternum subdéprimé, subfovéolé en arrière sur son milieu. Ventre convexe, éparsement sétosellé, subirisé.

Pieds aspèrement ponctués, finement pubescents, noirs, avec les tibias et les tarses d'un roux foncé. Cuisses antéricures sinuées et ciliées en dessous de poils d'un fauve doré. Tibias antérieur's garnis à leur tranche inférieure de cils de couleur semblable. Tarses antérieurs à 4 premiers articles fortement mais graduellement moins dilatés; les postérieurs à $1^{\text {er }}$ article suballongé, subégal aux 2 suivants réunis, subégal au dernier : les $2^{\mathrm{e}} \mathrm{a}^{\mathrm{e}}$ graduellement plas courts.

Patrie. Cette espèce se plait dans les expositions chaudes, principalement dans nos contrées méridionales. On la rencritre dès la fin de l'hiver, sous les écorces et les plaies, au pied et dans le tan des vieux arbres. Pendant les grands froids, elle se tient enterrée à la base des touffes d'herbes. Elle est assez rare.

\section{Genre Euryporus, Eurypone, Erichson.}

Erichson, Col. March., I, p. 496. - Jagqueuin du VaL, Gen. Staph., 39, pl. 16, ng. 76.

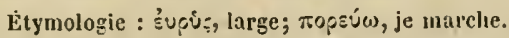

Caractères. Corps médiocrement allongé, assez large, subdéprimé, ailé, finement pubescent, avec la tête et le prothorax glabres et lisses.

Tête petite, ovalaire, oblongue; portée sur un cou large et court, à peine moins large que le vertex. Tempes fortement rebordées sur les côtés. Epistome submembraneux et largement tronqué en avant. Labre transverse, entièrement corné, profondément fendu dans son milieu. Mandibules saillantes, acérées, fortement arquées, unidentées en dedans prìs 
de leur base, croisées au repos. Palpes maxillaires médiocres, à $1^{\mathrm{er}}$ article petit : le $2^{e}$ allongé, un peu en massue : le $3^{\text {e }}$ beaucoup plus court, obconique : le dernier allongé, subégal au $2^{\circ}$ (1). Palpes labiaux assez robustes, à $1^{\mathrm{er}}$ et $2^{\mathrm{e}}$ articles courts, obconiques, subégaux ou avec le $2^{\mathrm{e}}$ à peine plus court : le $3^{\mathrm{e}}$ grand, sécuriforme. Menton grand, transverse, plus étroit en avant, tronqué ou à peine échancré au sommet.

Yeux assez grands, subovales, peu saillants, séparés du prothorax par un intervalle assez court.

Antennes suballongécs, subfiliformes, faiblement coudées après le $1^{\mathrm{er}} \mathrm{ar}-$ ticle : celui-ci en massue allongée, égal aux 2 suivants réunis : ceux-ci suballongés : les $4^{\mathrm{e}}$ à $10^{\mathrm{e}}$ graduellement à peine plus couris : le dernier en ovale acuminé.

Prothorax subtransverse, rétréci en avant; un peu plus large que les élytres ; tronqué ou à peine échancré au sommet, arrondi à sa base ; finement rebordé sur celle-ci et sur les côtés; à rebord latéral régulièrement arqué, à peine abaissé d'arrière en avant. Repli large, refoulé en dessous jusqu'au tégument supérieur, nullement visible, vu de côté, à opercule prothoracique assez grand, triangulaire, membraneux.

Ecusson assez grand, subogival.

Élytres fortement transverses, simultanément subéchancrées à leur bord apical, arrondies à leur angle postéro-externe, rebordées sur la suture. Repli étroit, subvertical. Épaules peu saillantes, épineuses en dessous.

Prosternum peu développé au devant des hanches antérieures; formant entre celles-ci un angle obtus et mousse, fortement relevé sur sa ligne médiane en carène voûtée. Mésosternum à lame médiane triangulaire (2), très-aiguë, prolongée jusqu'au milieu des hanches intermédiaires. Médiépisternums grands, séparés du mésosternum par une arête assez saillante et subarquée. Médiépimères assez étroites, allongées, longitudinales. Métasternum court, fortement échancré pour recevoir les hanches postérieures; prolongé entre celles-ci en un lobe court, échancré, enfoui ou subvertical, parfois subincliné et fendu; avancé entre les intermédiaires en angle peu senti, très-ouvert et mousse. Postépisternums étroits, subdivergents en arrière, terminés en languette. Postépimères petites, triangulaires.

Abdomen peu allongé, subatténué seulement vers son sommet ; forte-

(1) Le dernier article des palpes maxillaires varie un peu de forme suivant le sexé.

(2) Comme chez certains Philonthes, elle est traversée par une arète angulée. 
ment rebordé sur les còtés; à $2^{\circ}$ segment basilaire souvent découvert : les 4 premiers normaux subégaux; le $5^{\ominus}$ plus grand, à peine sinué à son bord postérieur : le $6^{\mathrm{c}}$ plus ou moins saillant, rétractile : celui de l'armure caché. Ventre à $2^{\mathrm{e}}$ arceau basilaire prolongé sur le $1^{\text {or }}$ normal en angle Irès-obtus: les suivants subégaux, le $5^{\mathrm{e}}$ à peine plus grand : le $6^{\mathrm{e}}$ plus ou moins saillant, rétractile.

Hanches anterieures grandes, de la longueur des cuisses, saillantes, coniques, subcontiguës au sommet. Les intermédiaires grandes, peu saillantes, subovales, obliquement disposées, contiguës en arrière. Les postérieures assez grandes, légèrement écartées à leur base, divergentes au sommet, qui offre en dessous 2 ou 3 petites épines; à lame supérieure en cỏne court, large, subdéprimé, mousse, à peine étranglé dans son premier tiers sur son côté externe; à lame inférieure nulle ou enfouie.

Pieds médiocres, assez grêles. Trochanters antérieurs petits; subcunéiformes; les intermédiaires el postérieurs plus grands : ccux-là oblongs, mousses au bout : ceux-ci en ovale subacıminé. Cuisses subcomprimées, subatténuées vers leur extrémité; les antérieures et intermédiaires spinosules en dessous, surtout vers leur extrémité. Tibias peu élargis de la base au sommet, armés au bout de leur tranche inférieure de 2 éperons assez forts, dont l'interne un peu plus long; les antérieurs beaucoup plus courts que la cuisse, simplement pubescents sur leur tranche externe; les intermédiaires et postérieurs plus ou moins épineux. Tarses antérieur's courts, simples dans les 2 sexes, à 4 premiers articles graduellement moins longs; les intermédiaires et postérieurs plus développés, à peine atténués vers leur extrémité, à $1^{\mathrm{er}}$ article allongé, sensiblement plus long que le dernier : celui-ci en massue grêle : les $2^{\mathrm{e}}$ à $4^{\mathrm{e}}$ suballongés ou oblongs. graduellement moins longs. Ongles médiocres, assez grêles, arqués.

OBs. L'espèce typique de ce genre vit parmi les mousses et les feuilles mortes des forêts.

Cetle coupe générique se distingue du genre Quedius par la petitesse de sa tête, par la structure des palpes labiaux et par ses tarses antérieurs simples dans les 2 sexes. Ce dernier caractère la sépare des Astrapaeus. Les antennes sont faiblement coudées après le $1^{\text {er }}$ article, mais celui-ci est bien moins long que dans le genre Acylophorus.

.Nous ne connaissons qu'une espèce française du genre Euryporus. 


\section{Euryporus picipes, Paykull.}

Suballongé, assez large, subdéprimé, légèrement pubescent, d'un noir brillant, avec la bouche, la base et le sommet des antennes d'un roux testacé, les intersections ventrales et les pieds d'un roux de poix, et les tarses plus clairs. Tête et prothorax lisses, luisants : celui-ci subtransverse, rétreci en avant. Elytres fortement et asse\% densement, abdomen moins densement ponctués.

$\sigma^{*}$ Le $6^{\text {e }}$ arceau ventral légèrement mais distinctement sinué dans le milieu de son bord apical. Le dernier article des palpes maxillaires subépaissi vers son sommet, obliquement tronqué au bout.

Le $6^{\text {e }}$ arceau ventral subarrondi à son bord apical. Le dernier article des palpes maxillaires subfusiforme, subalténué vers son sommet.

Oxyporus picipes, Paykull, Faun. Suec. III, 426, 2. - Gyllenhal, Ins. Suec. II, $413,2$.

Pelecyphorus picipes, Nordmans, Symb. 14, 1.

Euryporus picipes, ERichson, Col. March. I, 496, 1; - Gen. et Spec. Staph. 554, 1.

- Redtenbacher, Faun. Austr. 712, 710. - Heer, Faun. Col. Helv. I, 283, 1.

- Fairmaire et Laboulbène, Faun. Ent. Fr. I, 545, 1. - KraAtz, Ins. Deut. II, 482, 1.- Thomson, Skand. Col. II, 180, 1. - Fauvel, Faun. Gallo Rhén. III, 341, 1.

$$
\text { Long., } 0^{\mathrm{m}}, 0089 \text { (4 l.); - larg., } 0^{\mathrm{m}}, 0025 \text { (1 1/4 l.). }
$$

Corps suballongé, àssez large, subdéprimé, d'un noir brillant; revêtu sur les élyıres et l'abdomen d'une fine pubescence d'un gris obscur et peu serrée.

Tête ovalaire-oblongue, environ de la largeur du tiers du prothorax; lisse ; d'un noir luisant ; parée, de chaque côté, en avant de 2 gros pores sétifères et de 3 autres derrière les yeux, les 2 intérieurs plus rapprochés. front assez large, subconvexe. Cou lisse, glabre. Épistome offrant en avant une membrane pâle, plus ou moins étroite. Labre d'un roux testacé, dislinctement sétosellé vers son sommet. Mandibules et palpes d'un roux plus ou moins lestacé.

Yeux grands, subovales, obscurs, souvent grisâtres.

Antinnes environ de la longueur de la tête et du prothorax réunis; 
subfiliformes ou à peine épaissies; finement duveteuses et assez densement pilosellées, avec le $\boldsymbol{~}^{\text {er }}$ arlicle plus éparsement; noires, avec celui-ci, la base $d u 2^{\mathfrak{c}}$, l'insertion des suivants et le sommet du dernier d'un, roux testacé ; le $1^{\text {er }}$ en massue allongée, presque aussi long que les 2 suivants réunis : ceux-ci suballongés, obconiques : le $3^{\mathrm{c}}$ plus'long que le $2^{\mathrm{e}}$ : les $4^{\mathrm{e}}$ à $10^{\mathrm{e}}$ graduellement un peu plus courts, subobconiques, brièvement pédicellés: les $4^{\mathrm{C}}$ à $8^{\mathrm{e}}$ suboblongs, les pénultièmes non ou à peine oblongs : le dernier ovalaire, subacuminé au bout.

Prothorax subtransverse, rétréci en avant, un peu plus large en arrière que les élytres; à peine échancré au sommet, avec les angles antérieurs subinfléchis et subarrondis ; assez fortement arqué sur les côtés, vu de dessus; largement arrondi à la base ainsi qu'aux angles postérieurs; cntièrtment d'un noir' lisse et luisant; marqué, sur la partie antérieure du dos, de 3 pores sétifères assez forts, disposés en 2 séries longitudinales, ct de quelques autres, sans ordre, vers les angles antérieurs et le long du bord postérieur, ávec le gros pore latéral situé assez loin de la marge. Écusson glabre, lisse, d'un noir brillant.

Élytres fortement transverses, évidemment plus courtes que le prothorax; subdéprimées; un peu relevées sur la suture; fortement, râpeusement et assez densement ponctuées; d'un noir brillant, parfois subazuré; recouvertes d'une légère pubescence d'un gris obscur, déprimée et peu serrée, avec 2 ou 3 soies redressées sur les côtés, la postérieure ordinairement plus courte. Epaules cachées ou peu saillantes.

Abdomen peu allongé, aussi large que les élytres; subarcuément subalténué en arrière, après son milieu; subconvexe sur le dos, avec les 3 premiers segments très-faiblement impressionnés en travers à leur base; éparsement sétosellé sur les côtés; presque aussi fortement mais moins densement ponctué que les élytres; d'un noir brillant, parfois subazuré; à pubescence fine et peu serrée. Le $6^{\mathrm{c}}$ segment subarrondi au sommet.

Dessous du corps assez fortement ponctué, pubescent, d'un noir brillant, avec le repli du prothorax, le prosternum et la marge apicale des arceaux du ventre d'un roux de poix plus ou moins obscur. Dessous de la tête pubescent, éparsement et assez fortement ponctué. Mésosternum parfois à pointe rousse. Métasternum subdéprimé, subexcavé ou subsillonné sur son milieu, à lobe postérieur roussâtre. Ventre convexe, éparsement sétosellé, plus ou moins irisé.

Pieds ràpeusement ponctués, pubescents, d'un roux de poix plus ou u.oins foncé, avec les tarses, surtoutles antérieurs, plus clairs. Cuisses 
antérieures et intermédiaires spinosules, surtout en dessous, dans leur dernière moitié; les postérieures allongẻes, assez grêles. Tibias antérieur's presque droits, éparsement épineux en dehors. Tarses antérieurs simples; les postérieur's assez grêles, à $1^{\mathrm{er}}$ article allongé, plus long que les 2 suivants réunis, sensiblement plus long que le dernier.

Patrie. Cette espèce, médiocrement cornmune, scmble préférer les forêts et les montagnes : les Alpes, le Bugey, le mont Pilat, la Bourgogne le Beaujolais, les Pyrénées, etc.

Elle se rencontre généralement parmi les mousses humides, au printemps et à l'automne.

OBs. La couleur des pieds est variable. Ils sont tantôt d'un brun de poix assez foncé, tantôt d'un roux obscur, avec les tarses, en tous cas, toujours plus clairs. Souvent les pieds antérieurs sont presque entièrement roux. Les intersections ventrales sont parfois d'un roux de poix, plus rarement concolores, ete.

Genre Heterothops, HÉTÉRothops, Stephens.

Stephens, Ill. Brit. V, 256. - Jacouelin du Val, Gen. Staplı. 38, „1. 15, fig. 74.

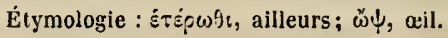

Caractères. Corps plus ou moins allongé et fusiforme, subconvexe, ailé, finement pubescent, avec la tête et le prothorax glabres et lisses.

Tête médiocre, brièvement ovale ou ovale-oblongue ; portée sur un cou large et court, un peu moins large que le vertex. Tempes finement rebol'dées sur les côtés. Épistome plus ou moins corné, tronqué ou à peine échancré en avant. Labre transverse, corné, entier ou presque entier. Mandibules peu saillantes, acérées, arquées, dentées en dedans, un peu croisées au repos. Palpes maxillaires médiocres, ì $1^{\text {er }}$ article petit : le $2^{\mathrm{e}}$ suballongé, obconique : le $3^{\mathrm{e}}$ subégal au $2^{\mathrm{e}}$ mais plus renflé : le dernier pelit, étroit, subulé. Palpes labiaux courts, à $1^{\text {er }}$ artiele petit: le $2^{\text {e }}$ beaucoup plus long plus ou moins épaissi, obconico-subcylindrique : le dernier petit, étroit, subulé. Menton court, trapéziforme, transverse, tronqué au sommet. 
Yeux médiocres, plus ou moius ovales, peu saillants, séparés du protho rax par un intervalle grand.

Antennes de longueur variable, subfiliformes; à $1^{\mathrm{er}}$ article renflé en massue plus ou moins allongée : les $2^{\mathrm{e}}$ et $3^{\mathrm{e}}$ suballongés ou oblongs : les suivants graduellement à peine plus courts ou avec les intermédiaires et pénultièmes parfois subégaux: le dernier oblong ou ovalaire-oblong, subéchancré ou tronqué au sommet et subacuminé inférieurement.

Prothorax tan!ôt subtransverse, tantôt aussi long ou rarement à peine plus long que large, plus ou moins rétréci en avant;non ou à peine moins large que les élytres ; tronqué au sommet, arrondi à sa base; très-finement rebordé sur celle-ci et sur les côtés; à rebord latéral faiblement arqué ou presque droit, légèrement abaissé d'arrière en avant. Repli large, refoulé en dessous jusqu'au tégument supérieur, nullement visible vu de côté, à opercule prothoracique nul.

Ecusson grand, ogival.

Elytres subcarrées ou subtransverses, un peu plus larges en arrière ; individuellement et subobliquement coupées, surtout en dedans, à leur bord apical ; largement arrondies à leur bord postéro-externe; finement et obsolètement rebordées sur la suture. Repli étroit, à peine retourné en dessous. Épanles peu saillantes ou cachées, subépineuses en dussous.

Prosternum assez peu développé au devant des hanches antérieures; formant entre celles-ci un angle plus ou moins obtus et mousse, à côtés souvent brisés, à disque gibbeux à sa base. Mésosternum à lame médiane triangulaire, à peine prolongée jusqu'au milieu des hanches intermédiaires, à sommet subaigu mais émoussé ou subarrondi, à disque convexe, rugueux et cilié. Médiépisternums grands, séparés du mésosternum par une très-fine arête transversale subarquée. Jédiépimères étroites, sublinéaires ou un peu élargies à leur base. Métasternum médiocre, largement échancré pour recevoir les hanches postérieures; prolongé entre celles-ci en un lobe large, subtronqué ou à peine entaillé; a vancé entre les intermédiaires en angle plus ou moins prononcé. Postépisternums très-ètroits, linéaires. Postépimères assez petites, triangulaires.

Abdomen plus ou moins allongé, atténué en arrière; fortement rebordé sur les côtés; à $2^{\mathrm{e}}$ segment basilaire parfois découvert : les suivants subégaux, le $5^{\text {e }}$ souvent plus grand : le $6^{\text {e }}$ saillant, rétractile : celui de l'armure caché, émettant 2 appendices fortement et longuement ciliés. Ventre à $2^{\mathrm{e}}$ arceau basilaire prolongé sur le $1^{\mathrm{er}}$ normal en angle plus ou 
moins arrondi : les suivants subigaux, le $5^{\mathrm{e}}$ parfois un peu plus grand : le $6^{\mathrm{e}}$ plus ou moins saillant, rétractile.

Hanches antérieures très-grandes, épaisses, un peu plus longues que les cuisses, saillantes, coniques, contiguës au sommet. Les intermédiaires grandes, subdéprimées, subovales, obliquement disposées, contiguës en arrière. Les postérieures assez, grandes, subcontiguës à leur base, assez divergentes au sommet, qui offre en dessous quelques petités épines; à lame supérieure subdéprimée, en cône court, large et arrondi, à peine étranglé dans son premier tiers; à lame inférieure nulle ou enfouie.

Pieds courts ou assez courts. Trochanters antérieurs petits, subcunéiformes; les intermédiaires et postérieur's plus grands, oblongs ou subelliptiques. Cuisses comprimées, plus ou moins élargies vers leur base et fortement atténuées vers leur cxtrémité; les antérieures et intermédiaires Irès-finement et obsolètement spinosules en dessous, au moins vers leur sommet ; les antérieures, de plus, souvent largement cintrées ou sinuées, avant celui-ci, sur leur tranche inférieure. Tibias subélargis de la base au sommet, armés au bout de leur tranche de dessous de 2 éperons trèsgrêles, dont l'interne un peu plus long; les antérieurs plus courts et plus robustes, noll ou à peine épineux; les intermédiaires et postérieurs plus ou moins épineux. Tarses antérieur's courts, à 3 premiers articles fortement dilatés, le $4^{\mathrm{e}}$ moins fortement; les intermédiaires et postérieurs plus développés, subfiliformes, à $1^{\text {er }}$ article plus ou moins allongé, subégal au dernier ou un peu plus long : celui-ci en massue très-grèle : les $2^{\mathrm{e}}$ à $4^{\mathrm{e}}$ suballongés ou oblongs, graduellement moins longs. Ongles petits, grêles, subarqués.

OBs. Les Heterothops vivent sous les détritus, les feuilles mortes, les mousses, etc. Ils rappellent la forme des petits Quedins, et se distinguent aisément de ce dernier genre par la structure de l'article terminal des palpes et par l'absence des opercules prothoraciques.

Les espèces du genre Heterothops sont petites et pen nombreuses. En voici les différences principales :

a. Téte subcarrée ou brièvement ovalaire, à angles postérieurs assez marqués. Abdomien peu brillant, à pubescence assez courte et serrée.

b. Antennes allongées, à pénultièmes articles suboblongss. Élytres assez densement pubescentes, assez finement et assez densement pointillées.

Binotatus. 
bb. Antennes assez courtes, à pinultièmes arlicles subtransverses ou transverses. Elytres densement pubescentes, finement et densement pointillees.

c. Le $3^{\circ}$ article des antenncs à peine plus court que le $2^{\mathrm{e}}$. Base des antennes, sommet des élytres et de l'abdomen d'un roux de poix. . . . . . . . . .

cc. Le $3^{\mathrm{e}}$ arlicle des antennes subégal au $2 \mathrm{e}$. Antennes, ély-

tres ét abdomen noirs, subconcolores. - . . . . NIGER.

aa. Téte ovale-oblongue, à angles postéricurs effacés.

d. Antennes obscures, plus claires à leur base. Elytres et abdomen plus ou moins densement ponctués, roux à leur sommet.

e. Abdomon peu brillant, à pubescence assez courte et serrée. Antennes avec les $7^{\text {e }}$ à $9^{e}$ articles subtransverses, le $10^{\mathrm{e}}$ aussi long que large. . . . . .

ee. Abdomen assez brillant, à pubescence longue et assez serrée.

f. Antcnnes à pinultièmes articles tous au moins aussi longs que larges. Épaules et marge apicale des élytres d'un roux de poix. . . . . . . .

ff. Antennes avec les $7^{\text {e }}$ et $9 \mathrm{e}$ articles subtransverses, le 11) presque curré. Elytres largement bordées de roux, sur les côtés et à leur marge apicale. . . .

du. Autennes noires, subconcolores. Élytres éparsement ponctuées. Abdomen concolore, assez densement pointillé. Pieds brunåtres.

PRAEVIUS.

SERICANS.

DISSIMILIS.

FLATOLIMBatus.

QUADRIPUNCTULUS.

\section{Heterothops binotatus, ERICHson.}

Allongé, subfusiforme, peu convexe, finement pubescent, d'un noir de poix brillant, avec les élytres brunâtres et leur marge apicale d'un roux testacé, le sommet de l'abdomen d'un roux de poix, la base des antennes et les pieds testacés. Antennes allongées, $\dot{a}$ arlicles tous plus longs que larges. Têle et prolhorax lisses, luisants: celıi-là brièvement ovalaire : celui-ci aussi large que long: rétréci en avant. Écusson pointillé. Élytres un peu plus longues que le prothorax, assez finement et assez densement pointillées. Abdomen peu brillant, finement et densement pointillé, iparsement sur le dernier segment.

$\sigma$ Le $6^{e}$ arceau ventral entaillé à son sommet en angle assez étroit et subaigu. 
\& Le $6^{\text {e }}$ arceau ventral subogivalement arrondi à son sommet.

Heterothops binotatus, Enicison, Gen. et Spec. Staph. 516, 2. - Farrmaire et LAboulbène, Faun. Ent. Fr. I, 533, 2. - KhaAtz, Ins. Deut. II, 485, 2. - Fauvel, Faun. Gallo-Rhén. III, 536, 1.

$$
\text { Long., } 0^{\mathrm{m}}, 0048 \text { (2 1/4 l.); - larg., } 0^{\mathrm{m}}, 0007 \text { (1/3 l.). }
$$

Corps allongé, fusiforme, peu convexe, d'un noir de poix plus ou moins brillant, avec les élytres brunâtres ; revêtu sur celles-ci et l'abdomen d'une fine pubescence d'un gris obscur, assez courte et plus ou moins serrée.

Tête brièvement ovalaire, un peu moins large que le prothorax; d'un noir luisant ; lisse ; marquée sur le vertex de 2 petits points transversalement disposés, et, de chaque côté, entre les yeux, de 3 petits points sétifères rangés en série longitudinale; plus, d'1 autre, beaucoup plus gros, faisant suite aux précédents et situé près du cou; plus, d'1 autre moindre, sur les tempes. Front large, subdéprimé ou à peine convexe. Cou convexe, glabre, lisse. Épistome subcorné, brunâtre. Labre d'un noir de poix, sétosellé en avant. Mandibules d'un brun ferrugineux, avec leur pointe rembrunie. Palpes brunâtres, à article terminal pâle.

Yeux subovales, peu saillants, obscurs.

Antennes allongées, un peu moins longues que la tête et le prothorax réunis ; grêles, subfiliformes; finement duveteuses ; légèrement pilosellées vers leur base; obscures, avec lrs 2 ou 3 premiers articles testacés; le $1^{\mathrm{e}}$ en massue allongée : les $2^{\mathrm{e}}$ et $3^{\mathrm{e}}$ suballongés ou oblongs, obconiques : le $3^{\mathrm{e}}$ non ou à peine plus long que le $2^{\mathrm{e}}$ : les suivants graduellement un peu plus courts, subcylindrico-obconiques: le $4^{\mathrm{e}}$ à $7 \mathrm{e}$ oblongs ou suboblongs : les pénultièmes un peu ou à peine plus longs que larges : le dernier oblong, subéchancré au bout et subacuminé inférieurement.

Prothorax anssi large que long, rétréci en avant; presque aussi large que les élytres; tronqué au sommet, avec les angles antérieurs médiocremient infléchis et arrondis; légèrement arqué sur les côtés ; arrondi à la base ainsi qu'aux angles postérieurs ; subconvexe sur son disque; d'un noir de poix luisant; lisse ; éparsement sétosellé; à pore sétifère latéral situé assez près de la marge ; offrant en avant, sur le dos, 2 séries composées de 2 points sétifères, écartés, dont les antérieurs submarginaux et situés plus en dehors.

Écusson pubescent, densement pointillé, brunâtre. 


\section{STAPHYLINIENS, - Heterothops}

Elytres carrées ou suboblongues, à peine plus larges en arrière qu'en avant; un peu plus longues que le prothorax; subdéprimées; assez finement et assez densement pointillées; d'un noir brunatre et assez brillant, avec leur marge apicale plus ou moins étroitement d'un roux testacé; nement ciliées-spinosulées à leur bord postérieur; finement et asscz densement pubescentes, avec quelques légères soies redressées sur les côtés, et 1, très-longue, vcrs les épaules. Celles-ci cachées.

Abdomen allongé, un peu moins large que les élytres; subatténué en arrière; subconvexe sur le dos, avec les 3 premiers segments subimpressionnés en travers sur le milieu de leur base; éparsement et longuement sétosellé; finement et densement pointillé sur les 5 premiers segments, éparsement sur le dernier; d'un noir généralement peu brillant, avec le sommet d'un roux de poix; à pubescence assez courte (1), un peu plus serrée que celle des élytres. Le $6^{\text {e }}$ segment arrondi à son bord postérieur.

Dessous du corps aspèrement pointillé, finement pubescent, d'un noir brillant, avec la marge apicale des arceaux du ventre d'un roux de poix. Dessous de la tête à fond lisse, très-éparsement ponctué et pileux. Ventre convexe, parfois un peu en dos d'àue à sa base et à son sommet, éparsement sétosellé, à $6^{\mathrm{e}}$ arceau inoins ponctué.

Pieds finement pointillés, finement pubescents, testacés, avec les hanches postérieures rembrunies. Cuisses antérieures et intermédiaires finement spinosules en dessous, au moins vers leur extrémité; les postérieures plus grêles et plus longues. Tibias antérieurs courts, assez robustes, à peine épineux. Tarses antérieurs à $2^{\mathrm{e}}$ et $3^{\mathrm{e}}$ articles fortcment, les $1^{\mathrm{er}}$ et $4^{\mathrm{e}}$ moins fortement dilatés ; les postérieur's à $1^{\mathrm{er}}$ article suballongé, subégal aux 2 suivants réunis, à peine égal au dernier : celui-ci allongé, grêle : les $2^{\mathrm{e}}$ à $4^{\mathrm{e}}$ oblongs, graduellement moins longs.

Patrie. Cette espèce, assez rare, se trouve sous les détritus et au pied des plantes dans les dunes des côtes de l'Océan et de la Méditerranée.

OBs. Quelquefois les élytres sont d'un brun un peu roussâtre, avec la marge apicale de tous les segments de l'abdomen rousse. Souvent les cuisses et tibias postérieurs sont un peu rembrunis, surtout dans leur milieu

On doit peut-ètre appliquer au binotatus les holmensis et kirbyellus de Stephens (Ill. Brit. V, 257).

(1) Les cils du bord apical des segments sont plus longs. 
2. Heterothops praevius, Erichson.

Suballongé, subfusiforme, subconvexe, finement pubescent, d'un noir brillant, avec les élytres brunâtres et leur marge apicale rousse, la base des aniennes, la marge apicale des segments ventraux et les pieds dun roux de poix. Antennes assez courtes, à pénultièmes articles subtransverses. Tête et prothorax lisses, luisants : celle-là brièvement ovalaire: celui-ci à peine, plus large que long, rétréci en avant. Écusson pointillé. Elytres un peu plus longues que le prothorax, finement et densement pointillées. Abdomen peu brillant, finement et densement pointillé, un peu moins sur le dernier segment.

$\sigma$ Le $6^{\text {e }}$ arceau ventral entaillé à son sommet en angle subaigu. Tarses antérieurs fortement dilatés.

$\uparrow$ Le $6^{e}$ arceau ventral subogivalement arrondi à son sommet. Tar'ses antérieurs assez fortement dilatés.

Trichopygus dissimilis, NoRdnans, Symb. 137, 2.

Emus subuliformis, BoIsDUval et LaCORDaiRe, Faun. Ent. Par. 1, 385, 42.

Heterothops praevius, Ericason, Col. Narch. I, 480,1; - Gen. et Spec. Staph 516, 1. - Redtenbacier, Faun. Austr. 711. - Heer, Faun. Col. Helv. I, 281, 1, - Fatrasire et Laboul.bène, Faun. Ent. Fr. I, 533, 1. - Krati, Ins. Deut. II, 484, 1. - Thomson, Skand. Col. II, t80, 1. - Fauver, Faun. Gallo-Rhén. III, $537,2$.

Variété $a$. Élytres entièrement ou presque entièrement rousses.

$$
\text { Long., } 0^{\mathrm{m}}, 0044 \text { (2 l.); - larg., } 0^{\mathrm{m}}, 0007 \text { (1/3 l.). }
$$

Corps suballongé, subfusiforme, subconvexe, d'un noir plus ou moins brillant, ave la marge apicale des élytres rousse; revêtu sur celles-ci et l'abdomen d'ine fine pubescence grise, assez courte et serrée.

Tête courtement ovalaire, moins large que le prothorax; d'un noir luisant; lisse; marquée sur le vertex de 2 pelits points transversalement disposés, et, de chaque côté, entre les yeux, de 3 points sétifères, un peu plus gros et rangés en série longitudinale, dont l'antérieur juxla-oculaire, et le postérieur suivi en arrière d'l autre point plus gros et situé près du 
cou; avec 1 autre point sétifère sur chacune des tempes, qui sont, en outre, légèrement pointillées après celui-ci. Front large, à peine convexe. Cou convexe, glabre, presque lisse. Epistome subcorné, brunâtre. Labre d'un brun ou d'un roux de poix, sétosellé en avant. Mandibules d'un brun ferrugineux, avec leur pointe plus obscure. Palpes d'un brun de poix, à article terminal plus pâle.

Yeux subovales, peu saillants, obscurs.

Antennes assez courtes, sensiblement plus longues que la tête; assez grêles; subfiliformes; très finement duveteuses; légèrement piloscllées inférieurement; obscurss, avec. leur base d'un roux de poix plus ou moins foncé; à $1^{\text {er }}$ árticle en massue allongée : les $2^{\circ}$ et $3^{\circ}$ oblongs, obconiques : le $3^{\mathrm{e}}$ un peu plus grêle et à peine plus court que le $2^{\mathrm{e}}$ : les suivants subobconiques, subtransverses, avec les $4^{\mathrm{c}}, 5^{\mathrm{c}}$ et $10^{\mathrm{c}}$ lléanmoins paraissant à peine moins courts : le dernier oblong, subéchancré au bout et subacuminé inférieurement.

Prothorax à peine plus large que long, rétréci en avant, presque aussi large que les élytres; tronqué au sommet, avec les angles antérieurs subinfléchis et subarrondis; à peine arqué sur les côtés; arrondi à sa base ainsi qu'aux angles postérieurs; assez convexe sur son disque; d'un noir luisant ; lissé; éparsement sétosellé, à pore sétifère latéral joignant presque la marge; offrant avant le milieu du dos 2 points écartés, et, vers la marge antérieure, 2 autres encore plus distants.

Écusson finement pubescenl, tinement et densement pointillé, brunâtre.

Élytres subcarrées, non ou à peine plus larges en arrière qu'en avant: un peu ou à peine plus longues que le prothorax; subdéprimées ou faiblement convexes; finement et densement pointillées; d'un noir plus ou moins brunâtre et assez brillant, avec leur marge apicale rousse; ciliéc'sspinosulées \& leur bord postérieur ; finement et densement pubescentes, avec quelques rares soies obsolètes, redressées, sur les côtés, et 1, trèslongue, vers les épaules. Celles-ci cachées.

Abdomen assez allongé, un peu moins làrge que les élytres; graduellement suhalténué en arrièrc; assez convexe sur le dos, avec les 2 premier's segments subimpressionnés en travers sur le milieu de leur base; éparsenıent et longuement sétosellé ; tinement et densement pointillé ; un peu moins densement sur le $6^{\mathrm{e}}$ segment; d'un noir généralement péu brillant ; à pubescence asssez courte et serréc. Le $6^{\circ}$ segment subarrondi au summel.

Dessous du corps finement pointillé, finement pubescent, d'un noir de poix assez brillant, avec le repli du prothorax souvent moins foncé et la 
marge apicale des arceaux du ventre d'un roux de poix. Dessous de la tête éparsement ponctué-pileux. Métasternum subconvexe. Ventre convexe, en dos d'âne ou en faîte à sa base, moins sensiblement vers son sommet, éparsement sétosellé, à peine moins pointillé en arrière.

Pieds finement pointillés, légèrement pubescents, d'un roux parfois assez foncé, avec les hanches postérieures subconcolores. Cuisses antérieures et intermédiaires finement spinosules en dessous, au moins vers leur extrémité;les postérieures moins élargies et plus longues. Tibias antérieurs courts, assez robustes, à peine épineux. Tarses antérieurs à 3 premiers articles plus $\left(\sigma^{*}\right)$ ou moins ( $q$ ) dilatés, le $4^{\mathrm{e}}$ moins sensiblement; les postérieur's à $1^{\text {er }}$ article assez allongé, subégal aux 2 suivants réunis, subégal au dernier : celui-ci allongé, grêle : les $2^{\mathrm{e}}$ à $4^{\mathrm{e}}$ oblongs, graduellement moins longs.

Patrie. Cette espèce est assez commune, en été, sous les détritus, les feuilles mortes et les fumiers desséchés, dans presque toute la France. On la rencontre souvent dans les granges, les celliers et les étables.

Obs. Elle est un peu moindre que l'H. binotatus. Les antennes, plus courtes, ont leurs articles intermédiaires et pénultièmes moins longs que larges. Le prothorax paraît plus rétréci en avant, avec le pore sétifère latéral situé encore plus près de la marge. Les élytres, un peu moins longues, sont un peu moins élargies en arrière, et leur ponctuation et leur pubescence sont peut-être à peine plus fines et plus serrées. Les tarses antérieurs des $q$ sont un peu moins dilatés, etc.

Les élytres sont parfois rousses avec la région scutellaire rembrunie, ou bien entièrement rousses.

Nous avons trouvé, avec l'Heterothops praevius, une larve qui paraît lui appartenir et dont voici la description :

\section{LARVE}

Corps très-allongé, sublinéaire, subconvexe, éparsement sétosellé, d'un testacé clair, avec l'abdomen pâle.

Tète à peine oblongue, subrétrécie en avant, un peu plus large que le prothorax ; sillonnée de chaque côté en avant, vers l'insertion des antennes ; subarrondie et éparsement sétosellée en arrière, sur les côtés; à peine convexe d'un testacé clair, lisse et luisant. Épistome quadridenté en 
staPHYLiNiens. - Heterothops

avant, avec les 2 dents intermédiaires plus saillantes et plus aiguës. Mandibules assez grêles, falciformes. Palpes maxillaires courts, d'un testacé pâle, à dernier article atténué, moins long que le pénultième.

Yeux lisses, indistincls.

Antennes courtes, pâles, èparsement ciliées vers leur extrémité; à $1^{\text {er }}$ article rudimentaire : le $2^{\circ}$ suballongé, assez épais, subcylindrique ou à peine plus étroit vers sa base : le $3^{\circ}$ plus étroit, très-court : le dernier très-petit, subulé.

Prothorax subcarré ou à peine oblong, un peu plus large en arrière; tronqué au sommet et à la base; assez convexe; éparsement sétosellé; presque lisse; d'un testacé clair et luisant.

Mésothorax et métathorax courts, subégaux, à peine aussi longs ou un peu moins longs, pris ensemble, que le prothorax ; graduellement subćlargis en arrière, où le $1^{\text {er }}$ est un peu plus large et le $2^{\text {e }}$ sensiblement plus large que la base du prothorax; subangulés et cicatrisés postérieurement sur les côtés, avec les stigmates assez distincts; subconvexes ; éparsement sétosellés; d'un testacé clair, lisse et luisant.

Abdomen allongé, sublinéaire oll assez brusquement atténué tout à fait en arrière; à peine convexe ; obsolètement sillonné sur le dos; éparsement sétosel!é; pâle, mou, assez brillant ; à segments subégaux, mamelonnés et cicatrisés sur les côtés; à stigmates distincts : le dernier beaucoup plus étroil, presque carré, subtronqué au sommet, où il offre 2 lanières assez épaisses, écartées à leur base, aussi longues que lui, sétosellées en dehors, subcylindriques, émettant de leur sommet un appendice sétifère, plus grêle, d'une moitié moins long, atténué, fortement déjeté en dehors.

Dessous du corps pâle, éparsement sétosellé. Dessous de la tête et prosternum presque lisses, luisants. Ventre très-inégal, à tube terminal subcylindrique, plus long que les lanières supérieures, à peine cilié sur le dos, plus densement en dessous ( 1 ).

Pieds courts. Hanches grandes. Ciuisses sublinéaires, épineuses en dessous. Tibias plus courts, subatténués vers leur extrémité, éparsement épineux dans lcur pourtour, terminés par un crochet très -acéré et presque droit.

(1) Pendant la marche, cette larve se sert puissamment de ce lube terminal comme de point d'appui pour progresser.

BR. 
OBs. Cette larve se trouve au pied des murs, dans les remises et les celliers, souvent en compagnie de l'Aglenus brunneus et de quelques espèces de Cryptophagus.

\section{Heterothops niger, Kratitz.}

Suballongé, fusiforme, subconvexe, finement pubescent, d'un noir brillant, avec le sommet du ventre et les pieds d'un roux brunâtre. Antennes assez courtes, à pénultièmes articles transverses. Tête et prothorax lisses, luisants : celle-là subcarrée : celui-ci subtransverse, fortement rétréci en avant. Ecusson pointillé. Élytres un peu plus longues que le prothorax. finement et assez densement pointillées. Abdomen assez peu brillant, finement et densement pointillé, éparsement sur le dernier segment.

$\sigma^{7}$ Le $6^{\circ}$ arceau ventral légèrement et angulairement entaillé à son sommet. Tarses antérieurs fortement dilatés.

ㅇ Le $6^{\mathrm{e}}$ arceau ventral subarrondi au sommet. Tarses antérieurs assez fortement dilatés.

Heterothops niger, Kratiz, Berl. Ent. Zeit. 1868, p. 332. - Marjeul, Ab. Vili, $276,230$.

$$
\text { Long., } 0^{\mathrm{m}}, 0038 \text { (1 3/4 l.);- larg., } 0^{\mathrm{m}}, 0007 \text { (1/3 l.). }
$$

Corps suballongé, fusiforme, subconvexe, d'un noir brillant, revêtu sur les élytres et l'abdomen d'une fine pubescence d'un gris obscur, assez courte et plus ou moins serrée.

Tête en carré arrondi aux angles, sensiblement moins large que le prothorax ; d'un noir luisant; presque lisse ; marquée sur le vertex de 2 trèspetits points, très-éc:artés el transversalement disposés, et, de chaque côté, entre les yeux, de 3 points sétifères plus gros et en série longitudinale, dont l'antérieur juxta-oculaire et le postérieur suivi en arrière d'1 autre point plus gros, avec 1 autre point sétifère sur chacune des tempes. Front large, à peine convexe. Cou subconvexe, glabre, presque lisse. Épistome submembraneux, d'un livide assez obscur. Labre d'un roux de poix, sétosellé en avant. Mandibules d'un roux obscur. Palpes brunâtres, à article termiual plus pâle. 
Yeux brièvement ovales, peu saillants, plus ou moins obscurs.

Antennes assez courtes, sensiblement plus longues que la tête; assez grêles, subfiliformes ou à peine épaissies; très-finement duveteuses ; légèrement pilosellées vers leur base; noirâtres, avec la base moins foncée ; à $1^{\mathrm{er}}$ article visiblement épaissi en massue suballongée : les $2^{\mathrm{e}}$ et $3^{\circ}$ oblongs, obconiques, subégaux : les suivants obconiques : le $4^{\mathrm{e}}$ environ aussi large que long: les $5^{\mathrm{e}}$ à $10^{\mathrm{e}}$ visiblement transverses, avec le $10^{\circ}$ néanmoins paraissant à peine moins court : le dernier suboblong, subéchancré au bout et subacuminé postérieurement.

Prothorax subtransverse, plus ou moins fortement rétréci en avant; aussi large à sa base que les élytres; tronqué au sommet, avec les angles antérieurs subinflèchis et subarrondis; faiblement arqué sur les côtés; arrondi à sa base ainsi qu'aux angles postérieurs ; assez convexe sur son disque; d'un noir luisant; presque lisse; éparsement sétosellé ; à pore sétifère latéral situé contre la marge; offrant, avant le milieu du dos, 2 points assez écartés, et vers la marge antérieure, 2 autres beaucoup plus distants.

Écusson finement pubescent, finement pointillé, noir.

Elytres subcarrées, un peu plus larges en arrière qu'en avant; un pen plus longues que le prothorax; subdéprimées ou à peine convexes ; finement et assez densement pointillécs; d'un noir assez brillant, avec le sommet non ou à peine moins foncé; ciliẻes-spinosulées à leur bord apical ; finement et assez densement pubescentes, avec quelques légères soies redressées sur les côtés, dont 1 beaucoup plus longue près des épaules. Celles-ci cachées.

Abdomen assez allongé, un peu moins large que les élytres; assez fortement atténué en arrière; assez convexe sur le dos, avec les 2 premiers segments subimpressionnés el travers à leur base; éparsement et longuement sétosellé; finement et densement pointillé sur les 5 premiers segments, éparsement sur le $6^{\circ}$; d'un noir souvent peu brillant, avec le sommet à peine moins foncé; à pubescence assez courte, plus serrée que celle des élytres. Le 6 e segment subarrondi au sommet.

Dessous du corps finement pointillé, tinement pubescent, d'un noir assez brillant, avec l'extrémité du ventre moins foncée. Dessous de la tête presque lisse, éparsement ponctué et pileux en arrière. Métasternum à peine convexe, souvent finement canaliculé sur sa ligne médiane. Ventre convexe, en dos d'âne à sa base, éparsement sétosellé, à peine moins pointillé en arrière. 
Pieds finement pointillés, finement pubescents, d'un roux brunâtre, avec les hanches postérienres encore plus foncées. Cuisses antérieures et intermédiaires finement spinosules en dessous, au moins vers leur extrèmité ; les postérieures moins élargies. Tibias antérieur's courts, assez robustes, à peine épineux. Tarses antérieurs à 3 premiers articles plus ( $\sigma$ ou moins $(q)$ dilatés, le $4^{\mathrm{e}}$ moins fortement; les postérieurs à $1^{\mathrm{er}}$ article assez allongé, subégal aux 2 suivants réunis, subégal au dernier : celui-ci allongé, grêle : les $2^{\mathrm{e}}$ à $4^{\mathrm{e}}$ oblongs, graduellement moins longs.

Patrie. Cette espèce est rare. Elle se prend, en été, dans les troncs cariés des arbres, aux environs de Lyon, dans les Alpes, les Pyrénées, etc.

OBs. Elle est un peu moindre, à peine plus fusiforme que l'H. praevins. Surtout, elle est plus noire dans toutes ses parties. Le prothorax est un peu plus court, un peu plus convexe, plus rétréci en avant. Les élytres sont un peu inoins densement ponctuées. Le $3^{e}$ article des antennes paraît un peu moins court et un peu moins grêle relaivement au $2^{\mathrm{e}}$, avec les oénuliièmes plus visiblement transverses. L'entaille du $6^{e}$ arceau ventral des $\sigma$ est moins profonde et moins aiguë, etc.

Parfois, outre les points ordinaires, le prothorax présente un point accessoire sur les côtés du disque, dans l'ouverture des angles postérieurs, mais loin de ceux-ci.

Quelquefois; les cuisses postérieures sont rembrunies, ou au moins à leur base.

L'Heterothops niger figurait, à tort, dans quelques collections, sous le nom de 4-punctulus.

4. Heterothops sericnng, Mulsant et Rey.

Allongé, fusiforme, subconvexe, très-finement pubescent, d'un noir brillant, avec la marge apicale des élytres étroitement et le sommet de l'abdomen roussâtres, la base des antennes et les pieds d'un roux testacé. Antennes allongées, avec les $7^{\mathrm{e}} \dot{a} 10^{\circ}$ articles subtransverses et le $10^{\mathrm{c}}$ au moins aussi long que large. Tête et prothorax lisses, luisants : celle-là ovale-oblongue : celui-ci aussi large que long, rétréci en avant. Écusson pointillé. Élytres un per plus longues que le prothorax, finement et densement pointillées. Abdomen peu brillant, très-finement el.très-densement pointillé, à pubescence assez courte et soyeuse. 
$\sigma^{*}$ Le $6^{\circ}$ arceau ventral angulairement entaillé à son sommet. Tarses antérieurs fortement dilatés.

\& Le $6^{\circ}$ arceau ventral subarrondi au sommet. Tarses antérieurs médiocrement dilatés.

Variété a. Elytres rousses ou d'un roux lestacé.

$$
\text { Long., } 0^{\mathrm{m}}, 0044\left(2 \text { l.); - larg., } 0^{\mathrm{m}}, 0007\right. \text { (1/3 l.). }
$$

Corps allongé, fusiforme, subconvexe, d'un noir plus ou moins brillant, avec le sommet de l'abdomen ei la marge apicale des élytres roussâtres ; revêtu sur celles -ci d'une très-fine pubescence grise et assez. courte, plus serrée et soyeuse sur l'abdomen.

Tête ovale-oblongue, beaucoup moins large que le prothorax; d'un noir luisant; lisse; marquée sur le vertex de 2 petits points très-écartés ; sur le front, d'uı point juxta-oculaire; derrière les yeux, de 3 points sétifères disposés en série longitudinale et dont le postérieur plus gros; et, sur les tempes, d'un autre point sétifère, entouré d'une fine ponctuation pileuse, obsolète. Front large, subconvexe. Cou glabre, presque lisse. Epistome subcorné, livide. Labre d'un roux de poix, sétosellé len avant. Mandibules rousses. Palpes d'un roux de poix, avec le pénultième article rembruni, au moins à sa base.

Yeux subovales, peu saillants, obscurs.

Antennes allongées, un peu moins longues que la tête el le prothorax réunis; assez grêles, subfiliformes; très-finement duveteuses et à peine pilosellées ; plus ou moins obscuris ou d'un roux brunâtre, avec les 2 on

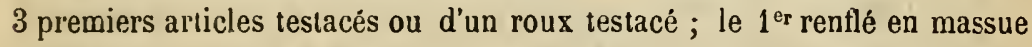
suballongée : les $2^{\mathrm{e}}$ et $3^{\mathrm{e}}$ suballongés ou oblongs, obconiques, subégaux : les suivants obconiques : les $4^{\mathrm{e}}$ et $5^{\mathrm{e}}$ à peine plus longs que larges : le $6^{\mathrm{e}}$ aussi long que large : les $7^{\mathrm{e}} \grave{a} 9^{\mathrm{e}}$ subtransverses et le $10^{\mathrm{e}}$ un peu moins cuurt : le dernier ovalaire-oblong, subacuminé au sommet.

Prothorax aussi large que long, plus ou moins rétréci en avant; presque aussi large à sa base que les élytres; tronqué au 'sommet, avec les angles antérieurs subinfléchis, presque droits mais émoussés; à peine arqué sur les côtés qui sont presque rectilignes, vus latéralement; subarrondi à sa base ainsi qu'aux angles postérieurs; subconvexe sur son disque; d'un noir de poix luisant, avec les angles antérieurs souvent moins foncés ou uême un peu roussâtres; lisse ; éparsement sétosellé; à pore sétifère 
latéral gros et situé près de la marge; offrant avant le milieu du dos à petits points assez rapprochés, et, vers la marge antérieure, 2 autres beaucoup plus écartés.

Écusson finement pubescent, finement pointillé, d'un noir assez brillant. Ėlytres subcarrées, un peu plus larges en arrière qu'en avant; un peu plus longues que le prothorax; subdéprimées ou à peine convexes; finement, densement et subrugueusement pointillées ; d'un noir assez brillant, avec leur marge apicale et parfois le calus huméral étroitement roussâtres ; ciliées-spinosulées à leur bord postérieur ; très-finement et assez densement pubescentes, avec la pubescence assez courte ou médiocrement longue; parées, sur les côtés, de quelques rares et légères soies redressées, dont 1 très-longue vers les épaules. Celles-ci cachées.

Abdomen allongé, à peine moins large que les élytres; fortement et subgraduellement atténué en arrière; subconvexe sur le dos, avec les 2 premiers segments à peine impressionnés en travers sur le milieu de leur base ; éparsement et longuement sétosellé ; très-finement et trèsdensement pointillé ; d'un noir généralement peu brillant, avec le sommet plus ou moins roussâtre, ainsi que souvent la marge postérieure des derniers segmen!s; à pubescence très-fine, grise, déprimée, assez courte, serrée et soyeuse. Le $6^{\text {e }}$ segment un peu moins ponctué, subarrondi au sommet.

Dessous du corps densement pointillé, finement pubescent, d'un noir brillant, avec le repli du prothorax moins foncé, et la marge apicale des arceaux du ventre plus ou moins roussâtre. Dessous de la tête presque glabre, presque lisse ou à peine ponctué. Métasternum à peine convexe. Ventre convexe, éparsement sétosellé, un peu en dos d'âne à sa base.

Pieds finement pointillés, finement pubescents, d'un roux testacé, avec les hanches postérieures rembrunies, au moins à leur base. Cuisses antéricures et intermédiaires très-finement spinosules en dessous vers leur sommet; les postérieures un peu moins t́largies. Tibias antérieurs assez courts, assez forts, à peine épineux. Tarses antérieurs à 3 premiers articles plus $\left(\sigma^{\circ}\right)$ ou moins ( $q$ ) dilatés, le $4^{\theta}$ moins fortement: les postérieurs à $1^{\text {er }}$ article allongé, à peine peu lorig que les 2 suivanıs réunis, un peu plus long que le dernier : celui-ci allongé, grêle : les $2^{e}$ à $4^{e}$ suballongés ou oblongs, graduellement moins longs.

Patrie. Cette espèce, peu commune, se prend en Provence, sous les détritus marins. 
OBs. Contrairement aux espèces à tête oblongue, l'H. sericans a son abdomen peu brillant et revêtu d'une pubescence assez courte comme chez les précédentes. Les tarses postérienrs sont un peu plus grêles, avec leur $1^{\text {er }}$ article un peu plus allongé relativement au dernier, que chez l'H. praevius. Les antennes sont plus allongées; la tête est plus oblongue, le prothorax un peu moins court et à pore sétifère latéral situé un peu moins près de la base, etc.

Dans les immatures, le prothorax devient d'un brun rougeâtre et les élytres passent au roux plus ou moins testacé. Le fulvipennis de Motschulsky (Bull. IIosc. 1860, II, 572) semble plutôt se rapporter à cette variété qu'aux praevius à élytres rousses, car l'auteur précité dit : capite oblongo-ovato. Quant à son minutus (p.572), il différerait de notre sericans par ses aniennes presque entièrement noires.

Souvert les tibias, surtout les intermédiaires et les postérieurs, sont un peu rembrunis dans leur milieu.

Accidentellement, un ou deux des points de la marge postérieure du prothorax sont beaucoup plus gros et plus profonds, et simulent comme 1 ou 2 fossettes au devant de l'écusson.

Nous avons vu un exemplaire paradoxal, intermédiaire entre le praevius et le sericans, et qui a la tête ovale-oblongue, l'abdomen à pubescence courte, les antennes moins longues et à articles 7 à 10 sensiblement et subégalement transverses. Nous l'appellerons provisoirement paradoxus.

\section{Heterothops dissimilig, Gravenhorst.}

Allongé, fusiforme, subconvexe, finement pubescent, d'un noir de poix brillant, avec les élytres brunâtres et leur marge apicale ronsse, la bouche, la base des antennes et les pieds testacés, et la marge postérieure des segments de l'abdomen d'un roux de poix. Antennes allongées, à penultièmes articles lous au moins aussi longs que larges. Tête et prothorax lisses, luisants : celle-là ovale-oblongue: celui-ci aussi large que long, rétréci en avant. Écusson pointillé. Elytres de la longueur du prothorax, assez finement et assez densement pointillées. Abdomen finement et densement pointillé, un peu moins densement en arrière.

$\sigma$ Le $6^{\text {e }}$ arceau ventral sensiblement et angulairement entaillé à son sommet. Tar'ses antérieurs fortement dilatés. 
f Le $6^{\mathrm{e}}$ arceau ventral subarrondi au sommet. Tarses antérieurs assez fortement dilatés.

Tachyporus dissimilis, Gravenhorst, Micr. 125, 1. - Latreille, Hist. Nat. Crust. et Ins. X. 5, 1.

Tachinus dissimilis, Gravenhorst, Mon. 23, 1.

Staphylinus subuliformis, Gyllenhal, Ins. Suec. II, 312, 29. - Manneraeim, Brach. 27,40 .

Heterothops dissimilis, Erichson, Col. March. I, 480, 2; - Gell. et Spec. Staph. 517, 3.- Redtenbacher, Faun. Austr. 712. - Heer, Faun. Col. Helv: I, 281, 2. Fairmaire et Laboulbène, Faun. Ent. Fr. I, 533, 3. - Kraatz, Ins. Deut. II, 485, 3.- Jacquedin du Val, Gen. Staph. pl. 15, fig. 74. - Thomson, Skand. Col. II, 181, 2. - Fauvel, Faun. Gallo-Khén. III, 538, 4.

$$
\text { Long., } 0^{\mathrm{m}}, 0040 \text { (1 4/5 l.); - larg., } 0^{\mathrm{m}}, 0007 \text { (1/3 l.). }
$$

Corps allongé, fusiforme, subconvexe, d'un noir brillant, avec le sommet des élytres un peu roussâtre; revêtu sur celles-ci et l'abdomen d'une fine et longue pubescence grisâtre et assez serrée.

Tête ovale-oblongue, beaucoup moins large que le prothorax; d'un noir luisant; presque lisse; marquée sur le front d'un fort point juxtaoculaire; sur le vertex, de 2 petits points écartés ; derrière les yeux, de 3 points sétifères en série longitudinale, et dont le postérieur plus gros; et, sur les tempes, d'l autre petit point sétifère, accompagné en arrière d'une fine ponctuation pileuse. Front large, à peine convexe. Cou glabre, presque lisse. Épistome submembraneux, livide. Labre d'un brun ou d'un . roux de poix, sétosellé en avant. Mardibules ferrugineuses ou rousses. Palpes testacés, avec le pénultième arlicle des maxillaires plus foncé, au moins à sa base.

Yeux subovales, peu saillants, obscurs.

Antennes suballongées, à peine moins longues que la tête et le prothorax réunis ; grêles, subfiliformes, très-finement duveteuses ; légèrement pilosellées vers leur base; obscures, avec le $1^{\text {er }}$ article testacé; celui-ci épaissi en massue suballongée : les $2^{\circ}$ et $3^{\mathrm{e}}$ oblongs, obconiques, subégaux : le $3^{\mathrm{e}}$ paraissant un peu plus grêle que le $2^{\mathrm{e}}$ : les suivants graduellement à peine plus courts, obconico-subcylindriques : les $4^{\mathrm{e}} \grave{a} 6^{\mathrm{e}}$ oblongs : les pénultièmes à peine oblongs ou au moins aussi longs que larges : le dernier oblong, subtronqué au bout et subacuminé inférieurement.

Prothorax aussi large que long, plus ou moins rétréci en avant, presque aussi large à sa base que les élytres ; tronqué au sommet, avec les angles 
antérieurs infléchis et subarrondis; à peine arqué sur les côtés, qui, vus la:éralement, sont subrectilignes; arrondi à sa base ainsi qu'aux angles postérieurs; assez convexe sur son disque ; d'un noir de poix luisant, avec les angles antérieurs nıoins foncés; lisse; éparsement sétosellé; à pore sétifère latéral situé près de la marge; offrant avant le milieu du dos 2 petits points assez rapprochés, et, vers la marge antérieure, 2 autres beaucoup plus écartés.

Écusson finement pubescent, finement pointillé, d'un noir ou d'un brun de poix assez brillant.

Elytres subtransverses, un peu plus larges en arrière qu'en avant, environ de la longueur du prothorax; subdéprimées ou à peine convexes; assez finement, assez densement et subrugueusement pointillées; d'un noir ou d'un brun de poix assez brillant, avec la marge apicale un peu roussâtre, ainsi que souvent le calus huméral ; ciliées-spinosulées à leur bord postérieur; à pubescence assez longue et assez serrée, avec quelques légères soies redressées sur les côtés, dont 1 , très-longue, vers les épaules. Celles-ci cachées.

Abdomen allongé, à peine moins large que les élytres; plus ou moins fortement atténué en arrière; assez convexe sur le dos, avec les 2 premiers segments à peine impressionnés en travers sur le milieu de leur base; éparsement tet longuement sétosellè ; finement et densement pointillé, graduellement moins densement en arrière; d'un noir assez brillant, avec la marge apicale des segments plus ou moins d'un roux de poix; à pubescénce longue et modérément serrée. Le $6^{6}$ segment souvent entièrement roux, subarrondi au sommet.

Dessous $d u$ corps aspèrement pointillé, finement pubescent, d'un noir brillant, avec la marge apicale des arceaux du ventre roussâtre. Dessous de la tête presque lisse, très-éparsement ponctué et pileux. MIétasternum à peine convexe. Ventre convexe, éparsement sétosellé, un peu en dos d'âne à sa base.

Pieds finement pointillés, finement pubescents, testacés, avec les hanches postérieures plus ou moins rembrunies. Cuisses antérieures et intermédiaires légèrement spinosules en dessous vers leur extrémité; les postérieures moins élargies. Tibias antérieurs assez courts, assez forts, à peine épineux. Tarses untérieurs à 3 premiers articles plus ( $\sigma^{*}$ ) ou moins ( 9 ) dilatés, le $4^{\mathrm{e}}$ moins fortement; les posterieurs à $1^{\mathrm{er}}$ article allongé, subégal aux 2 suivants réunis, subégal au dernier : celui-ci allongé, grêle : les $2^{\mathrm{e}}$ à $4^{\mathrm{e}}$ oblongs, graduellement moins longs. 
Patrie. Celte espèce, qui est assez rare, se rencontre sous les détritus végétaux, dans plusieurs localités de la France : la Flandre, la Normandie, le Languedoc, la Guienne, la Provence, etc. Elle paratt exclusivement marine, ou s'éloigner peu de l'influence de la mer.

Ors. Elle se distingue du sericans par la structure des antennes, qui ont tous leurs articles plus longs que larges, et surtout par son abdomen, dont la pubescence est plus longue et moins serrée.

Parfois le prothorax est d'un brun rougeâtre, et les élytres sont d'un brun de poix un peu roussâtre.

Comme chez l'espèce précédente, les points de la marge postérieure du prothorax, au dessus de l'écusson, sont convertis en 2 fossettes profondes.

Le brunnipennis de Kiesenwetter (Berl. Ent. Zeit. 1858, 56) parait Irès-voisin du dissimilis. Il aurait le prothorax plus étroit que les élytres, avec celles-ci un peu plus longues et d'une teinte un peu moins foncée. Le seul exemplaire que nous ayons reçu sous le nom susdit a les pénultièmes articles des antennes à peine moins longs que dans le dissimilis type.

M. Pandel!é nous a envoyẻ 2 individus $\sigma^{\circ}$, provenant des environs de Lille, et qui nous paraissent une variété remarquable. Les antennes sont un peu plus courtes, avec leurs pénultièmes articles proportionnellement moins longs, mais toutefois au moins aussi longs que larges. Les élytres, un peu plus courtes, sont à la fois un peu plus convexes, moins élargies en arrière, un peu moins densement pointillées. La taille est plus petite. Cette variété semble faire le passage du dissimilis au quadripunctulus. Nous la nommerons parvicornis, nobis,

\section{Heterothops tiavolimbatu, MoTSChuLSKY.}

Suballongé, fusiforme, peu convexe, finement pubescent, d'un brun de poix brillant, avec la tête noire, les côtés des élytres, la marge apicale de celles-ci et des segments abdominaux roux, la bouche, ln base des antennes et les pieds testacés. Antennes suballongées, avec les $7^{\mathrm{e}}$ a $9^{\mathrm{e}}$ articles subtransverses et le $10^{\circ}$ presque carré. Tête et prothorax lisses, luisants : celle-là ovale-oblongue : celui-ci à peine moins long que large, fortement rétréci en avant. Elytres un peu plus longues que le prothorax, 
assez finement et assez densement pointillées. Abdomen tres-finement et densement pointille, un peu moins densement en arrière.

$\sigma^{*}$ Le $6^{\circ}$ arceau ventral en dos d'àne, entaillé au sommet en angle assez. étroit, profond et aigu. Tarses antérieurs très-fortement dilatés.

Le $6^{\text {e }}$ arceau ventral simplement subconvexe, subarrondi au sommet. Tarses antérieur's assez fortement dilatés. .

Staphylinus subuliformis, var. b. GrLlenhal, Ins. Suec. II, 312, 29.

Heterothops praevius, Tromsar, Skand. Col. II, 180, 1. - Morschucsxy, Bull. Mosc. 1860, II, 577I ; - Enum. Nouv. Esp. 1860, 33, 61,

Variété $a$. Prothorax d'un roux de poix. Élytres d'un roux testacé.

$$
\text { Long., } 0^{\mathrm{n}}, 0044 \text { (2l.); - larg., } 0^{\mathrm{m}}, 0008 \text { (1/3 l. fort.). }
$$

Corps suballongé, fusiforme, peu convexe, d'un brun de poix brillant, avec la tête plus foncée, les côtés et la marge apicale des élytres plus ou moins largement roux ; revêtu sur celles-ci et l'abdomen d'une fine pubescence blonde, plus ou moins longue et plus ou moins serrée.

Tête ovale-oblongue, subparallèle dans le milieu de ses côtés, beaucoup moins large que le prothorax; d'un noir luisant; presque lisse; offrant sur le vertex 2 petits points sétifères écartés, et, de chaque côté, 1 point juxta-oculaire interne, 3 points postoculaires, dont le postérieur plus gros, 1 autre sur les tempes : celıi-ci entouré d'une très-fine ponctuation pileuse. Front large, subconvexe. Cou glabre, lisse. Épistome subcorné, brunâtre. Labre d'un brun de poix souvent roussâtre, sétosellé en avant. Handibules d'un roux de poix. Palpes testacés, avec le pénultième article souvent rembruni.

Yeux subovales, peu saillants, obscurs.

Antennes suballongées, moins longues que la tête et le prothorax réunis ; assez grêles; à peine épaissies ; très-finement duveteuses; légòrement pilosellées vers leur base; obscures ou d'un roux brunatre, avec le $1^{\text {er }}$ article testacé et les 2 suivants souvent d'un roux de poix; le $1^{\text {er }}$ épaissi en massue suballongée : les $2^{\mathrm{e}}$ et $3^{\mathrm{e}}$ oblongs, obconiques, subégaux : les suivants graduellement à peine plus courts et à peine plus épais, obconiques : les $4^{\mathrm{e}} \mathrm{a} 6^{\mathrm{e}}$ suboblongs : les $7^{\mathrm{e}}$ à $9^{\mathrm{e}}$ subtransverses : le $10^{\circ}$ presque aussi large que long $\left(\sigma^{\circ}\right)$ ou à peine transverse $(\uparrow)$ : le dernier oblong, subtronqué au bout et subacuminé inférieurement. 
Prothorax à peine moins long que large, fortement rétréci en avant; aussi large à sa base que les élytres; tronqué au sommet, avec les angles antérieurs infléchis et subarrondis; à peine arqué sur les côtés; arrondi a sa base ainsi qu'aux angles postérieurs ; subconvexe sur son disque; d'un brun de poix luisant, souvent plus clair ou roussâtre dans son pourtour; lisse; éparsement sétosellé ; à pore sétifère latéral situé près de la marge; offrant avant lo milieu du dos 2 petits points sétifères assez rapprochés, et, vers la marge antérieure, 2 autres plus écartés.

Écusson finement pubescent, très-finement pointillé, d'un brun de poix assez brillant.

Élytres subcarrées, évidemment plus larges en arrière qu'en avant; un peu plus longues que le prothorax; subdéprimées ; assez finement, assez densement et à peine rugueusement pointillées; d'un brun de poix assez brillant, avec les côtés largement, la marge apicale un peu moins largement d'un roux subtestacé; ciliées-spinosulées à leur bord postérieur; à pubescence assez longue et modérément serrée, avec quelques légères soies redressées, sur les côtés, dont 1 , très-longue, vers les épaules. Celles-ci cachées.

Abdomen suballongé, un peu moins large que les élytres; plus ou moins fortement atténué en arrière; assez convexe sur le dos, avec les 2 premiers segments à peine impressionnés en travers sur le milieu de leur base ; éparsement et longuement sétosellé ; très-finement et densement pointillé, moins densement ou même subéparsement en arrière, surtout sur le dos des derniers segments; d'un noir ou d'un brun de poix assez brillant, avec la marge postérieure de tous les segments plus ou moins rousse; à pubescence longue et assez serrée. Le $6^{\mathrm{e}}$ segment entièrement roux, subarrondi au sommet.

Dessous du corps aspèrement pointillè, finement pubescent, d'un noir assez brillant, avec le repli du prothorax moins foncé et la marge apicale des arceaux du ventre largement rousse. Dessous de la tète presque lisse, ou à peine ponctué et pileux. Métasternum à peine convexe. Ventre convexe, éparsement sétosellé, parfois presque entièrement roux.

Pieds finement pointillés, finement pubescents, testacés, avec les hanches postérieures souvent rembrunies, au moins à leur base. Cuisses antérieures et intermédiaires légèrement spinosules en dessous vers leur sommet; les postérieures moins élargies. Tibias antérieurs courts, assez robustes, à peine épineux. Tarses antérieurs à 3 premiers articles plus $\left(\sigma^{\circ}\right)$ ou moins ( $q$ ) fortement dilatés, le $4^{\mathrm{e}}$ moins fortement; les postérieurs à 
$1^{\text {cr }}$ article allongè, subégal aux 2 suivants réunis, subégal au dernier : celui-ci allongé, grêle : les $2^{\mathrm{e}}$ à $4^{\mathrm{e}}$ suballongés ou oblongs, graduellement moins longs.

Patrie. Cette espèce, médiocrement commune, se prend, tout l'été, sous les mousses, les feuilles mortes et autres détritus des forêts et des montagnes : les environs de Paris, le Forez, les montagnes du Lyonnais, les Alpes, eic.

OBS. Outre sa coloration moins foncée, elle diffère du dissimilis par sa forme un peu moins allongée et moins étroite; par ses antennes un peu plus robustes et à pénultièmes articles (7-9) subtransverses; par son prothorax un peu plus court, plus fortement rétréci en avant; par ses élytres plus longues, plus élargies en arrière et toujours largement bordées de roux sur les côtés.

Chez les immatures le prothorax est d'un rouge brun et les élytres sont d'un roux testacé.

\section{ซ. Heterothops quadripunctulus, Gravenhorst.}

Suballongé, subfusiforme, subconvexe, légèrement pubescent, d'un noir brillant, avec les pieds brunätres. Antennes assez courtes, avec les $8^{\mathrm{e}} \dot{a}$ $10^{\mathrm{e}}$ articles aussi longs que larges. Tête et prothorax lisses, luisants : celle-lì ovale-oblongue : celui-ci un peu plus long que large, subrétréci en avant. Elytres de la longueur du prothorax, assez finement et éparsement ponctuees. Abdomen finement et assez densement pointille: plus éparsement en arrière.

$\sigma$ Le $6^{\mathrm{e}}$ arceau ventral profondément et aigument entaillé à son sommet. Tarses antérieurs assez fortement dilatés.

i Le $6^{\circ}$ arceau ventral subarrondi à son sommet. Tarses antérieurs lègèrement dilatés.

Tachinus 4-punclulus, Gravenhorst, Mon. 24, 2.

Staphylinus subuliformis, ZetTERs1edt, Faun. Lapp. I, 72, $14 ;$ - Ins. Lapp. 62, 20.

Trichopygus pumilio, Nordmans, Symb. 138, 4.

Heterothops 4-punctulus, Enichson, Col. MIarch. I, 481, 3; - Gen. et Spec. Staph. 517, 4. - Redrensicher, Faun. Austr. 712.- Heen, Faun. Col. Helv. I, 281, 3. 
- Fairu.ine et Laboulbène, Faun. Ent. Fr. I, 533, 4. - Krattz, Ins. Deut. II. 486, 4.-Thomson, Skand.Col. II, 181, 3.-Fauvel, Faun. Gallo-Rhén. III, 538, 3.

$$
\text { Long., } 0^{\mathrm{m}}, 0036 \text { (1 2/3 l.); - larg., 0m,0005 (1/4 1.) }
$$

Corps suballongé, fusiforme, subconvexe, d'un noir brillant; revêtu sur les élytres et l'abdomen d'une fine pubescence grisâtre, plus éparse sur les premières.

Tête ovale-oblongue, moins large que le prothorax; d'un noir luisant ; lisse; marquée de chaque côté, entre les yeux, d'un point juxta-oculaire ; derrière le bord postéro-interne de ceux-ci, de 3 points longitudinalement disposés ; offrant en outre, sur le vertex, 2 autres petits points, situés sur une ligne transversale. Front large, faiblement convexe. Cou glabre: lisse. Épistome corné, brunâtre. Labre noir, brillant, sétosellé en avant. Mandibules d'un roux de poix. Palpes obscurs.

Yeux subovales, très-peu saillantś, noirâtres.

Antennes assez courtes, sensiblement moins longues que la tête et le prothorax réunis ; assez grêles, subfiliformes; très-finement duveteuses; légèrement pilosellées vers leur base; noires, avec leur $1^{\text {er }}$ article rarement un peu moins foncé ; celui-ci en massue assez allongée : les $2^{\mathrm{e}}$ et $3^{\mathrm{e}}$ obconiques, suboblongs, subégaux : les $4^{\mathrm{e}}$ à $10^{\mathrm{e}}$ subobconiques, aussi longs que larges, avec les $4^{\mathrm{e}}$ à $6^{\mathrm{e}}$ néanmoins un peu plus longs:le dernier oblong, obliquement tronqué au bout et subacuminé inférieurement.

Prothorax un peu plus long que large, subrétréci en avant; à peine aussi large à sa base que les élytres; tronqué au sommet, avec les angles antérieurs infléchis et arrondis; à peine arqué sur les côtés ; arrondi à sa base ainsi qu'aux angles postérieurs ; médiocrement convexe sur son disque; d'un noir luisant; lisse ; à pore sétifère latéral situé contre la marge ; offrant avant le milieu du dos et vers le sommet 2 petits points sétifères, ces derniers plus écartés.

Écusson légèrement pubescent, légèrement ponctué, d'un noir brillant.

Élytres presque carrées, un peu plus larges en arrière qu'en avant; environ de la longueur du prothorax; subdéprimées; assez finement, éparsement et subrâpeusement ponctuées; d'un noir brillant ; légèrement et éparsement pubescentes, avec une longue soie redressée sur les côtés, près des épaules. Celles-ci effacées.

Abdomen suballongé, à peine nuoins large que les élytres; sensiblement atténué en arrière ; subconvexe sur le dos, avec les 2 premiers seg- 
ments subimpressionnès en travers sur le milieu de leur base; éparsement sétosellé; finement et assez densement pointillé, plus éparsement en arrière, surtout sur la partie postérieure du dos des segments; d'un noir assez brillant; à pubescence plus serrée et plus déprimée que celle des élytres. Le $6^{\text {e }}$ segment peu ponctué, subtronqué $\left(\sigma^{\prime \prime}\right)$ ou à peine arrondi ( $q$ ) au sommet.

Dessous du corps aspèrement pointillé, finement pubescent, d'un noir assez brillañt. Dessous de la tête avec quelques points pileux et assez forts, vers la base. Métasternum faiblement convexe. Ventre convexe, éparsement et longuement sétosellé.

Pieds finement pointillés, finement pubescents, obscurs ou brunâtres, avec les genoux, les tarses et parfois les hanches antérieures moins foncés. Cuisses postérieures moins élargies à leur base que les autres. Tibias anté. rieurs assez forts, à peine épineux. Tarses antérieur's à 3 premiers articles plus ( $\left.\sigma^{\prime}\right)$ ou moins ( + ) dilatés, le $4^{\mathrm{e}}$ moins sensiblement; les postérieurs à $1^{\text {er }}$ article allongé, subégal aux 2 suivants réunis, subégal au dernier : celui-ci allongé, assez grêle : les $2^{\mathrm{e}}$ à $4^{\mathrm{e}}$ suballongés ou oblongs, graduellement moins longs.

Patrie. Cette espèce est très-rare en France. Elle préfère les contrées froides : la Flandre, l'Alsace, les Alpes, etc.

Elle habite les mousses humides.

OBs. Elle est très-dintincte de toutes les précédentes par sa taille moindre, ses antennes plus obscures et surtout par ses élytres plus éparsement ponctuées. Cette ponctuation, bien que assez fine, ainsi que l'indique Erichson, est relativement assez forte, quand on la compare à celle des autres espèces.

Genre Acylophorus, Acylophore, Nordmann.

Nordyanx, Symb. ad. Mon. Staph., 1837, 127, pl. J, fig. 19.

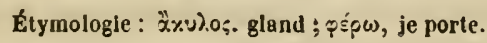

Caractères. Corps allongé, fusiforme, peu convexe, ailé.

Téte petite, inclinée ou subverticale, ovale, séparée du prothorax par an col court et épais. Tempes. contiguês en dessous, rebordées sur les 
côtés. Epistome très-court, corné, subtronqué en avant. Labre fortement transverse, subarrondi à son bord antérieur, obsolètement fendu dans son milieu. Mandibules saillantes, falciformes, fortement dentées intérieurement vers leur milieu, croisées au repos, à pointe acérée. Palpes maxillaires médiocres, à $1^{\text {er }}$ article petit : les $2^{\mathrm{e}}$ et $3^{\mathrm{e}}$ obconiques : le $3^{\mathrm{e}}$ plus renflé et un peu plus court que le $2^{\mathrm{e}}$ : le dernier épais, en ovale acuminé. Palpes labiaux courts, de 3 articles : le $1^{\text {er }}$ subcylindrique, étroit : les 2 derniers épais, formant ensemble une massue ovalaire. Menton transverse, tronqué au sommet.

Yeux grards, ovales-oblongs, très-peu saillants, séparés du prothorax par un intervalle assez grand.

Antennes assez longues, grêles à leur base, épaissies vers leur sommet, fortement coudées après le $1^{\text {er }}$ article : celui-ci très-développé, en forme de scape allongé, subarqué, aussi long environ que les 4 suivants réunis : les $4^{\mathrm{e}}$ à $10^{\mathrm{e}}$ graduellement plus courts : le dernier subglobuleux, subcomprimé vers le bout.

Prothorax de la largeur des élytres à sa base; fortement rétréci en avant; subéchancré au sommet, arrondi à sa base, à peine rebordẻ sur celle-ci, plus dịstinctement sur les côtés ; à rebord latéral régulièrement arqué ; à peine abaisséd'arrière en avant. Repli large, refoulé en dessous, non visible vu de côté, à opercule prothoracique nul.

Écusson assez grand, subogival.

Elytres transverses, simultanément échancrées à leur bord apical ; subarrondies à leur angle postéro-externe; finement et obsolètement rebordées sur la suture. Repli étroit, un peu infléchi. Epanles cachées, épineuses en dessous.

Prosternum peu développé au devant des nanches antérieures, formant entre celles-ci un triangle transverse, à partie antérieure du disque plane et inclinée, la postérieure relevée en bosse ou en faìte, à sommet peu aigu. Mésosternum à lame médiane triangulaire, rebordée en gouttière sur les côtés, prolongée en poin'e acéré ou subaciculée au moins jusqu'au milieu des hanches intermédiaires. Médiépisternums grands, séparés du mésosternum par une arête fine et subtransverse. Jédiépimères assez grandes, en carré long et assez étroit. Métasternum assez développé, échancré pour recevoir les hanches postéricures; prolongé entre celles-ci en un lobe saillant, corné, légèrement fendu dans son milieu (1). Postépister-

(1) Ce lobe rappclle un peu celui des Philonthus. 
nums graduellement rétrécis en arrière en angle al'ongé, divergcant fortement du repli des élytres. Postépimères très-grandes, triangulaires.

Abdomin allongé, atténué pos'érieurement; épaissement rebordé sur les côtés; à $1^{\text {er }}$ et $2^{\mathrm{e}}$ segments basilaires parfois découverts el lisses: le $1^{\text {er }}$ normal sensiblement plıs courtque le $2^{\mathrm{e}}$ : celui-ci et les $3^{\mathrm{e}}$ et $4^{\mathrm{e}}$ subégaux ou graduellement à peine plus longs : le $5^{\circ}$ p'us grand, le $6^{\text {e }}$ saillant, rétractile : celui de l'armure caché, émettant souvent 2 styles étroits ét ciliés. Ventre à arceaux subégaux : le $5^{\mathrm{e}}$ un peu plus grand : le $6^{\mathrm{e}}$ sail-. lani, rétractile, arrondi au sommet.

Hanches antérieures grandes, de la longueur des cuisses, saillantes, coniques, subcontiguës au sommet. Les intermédiaires grandes, peu saillantes, subovales, obliquement disposées, contiguës en arrière. Les postéricures médiocres, légèrement écartées à leur base, divergentes au sommet, qui offre en dessous 2 ou 3 épines (1); à lame supérieure subdéprimér, en cône courı, large, arrondi, stibétranglé vers la base de son côté externe; à lame inférieure nulle ou enfonie.

Pieds assez courts. Trochanters antérieur's petits, subcunéiformes; les intermédiaires et postéricur's un peu plus grands : ceux-là cunéiformes, ceux-ci en ovale subacuniné. Cnisses antérieures et intermédiaires subcomprimées, élargies vers leur base, atténuées vers leur extrémité; les antérieures à peine spinosules en dessous, vers leur sommet; les postéricures allongćes, sublinéaires. Tibias assez grêles, un peu rétrécis vers leur base, armés au bout de leur tranche inférieure de 2 petits éperons grêles, obsolètes dans les antérieurs, plus longs dans les intermédiaires : ceux-ci à peine fléchis en dedans avant leur sommet; les antérieurs courts, à peine épineux, les antres plus ou moins épineux : les postérieurs plus grêles, ail moins aussi longs que les cuisses. Tarses antérieurs subépaissis, subcylindriques, à 4 premiers articles très-coults, fortement contigus : le dernier subégal à eux tous réunis, à ongles longs, assez robustes, presque droits, à peine arqués; les intermédiaires et postérieurs grêles, subfiliformes ou à peine allénués vers leur extrémité, à $1^{\text {er }}$ article trèsallongé, presque égal̃ aux 3 suivants réunis : ceux-ci plus ou moins oblongs, graduellement à peine plus courts : le dernier suballongé, à ongles petits, très-grêles, arqués.

(1) Les antérieures, quand on las soulève, présentent aussi quelques épines a leur sommet, épines transformécs sourent en cils raides, surtout dans les autres genres.

BR. 
OBs. Les Acylophorus, insectes de taille moyenne, vivent parmi les mousses humides ou au pied des plantes aquatiques

Ce genre est remarquable par ses antennes coudées et à scape trèsdéveloppé; par sa tête petite; par le développement des postépimères; par son abdomen dont le $1^{\mathrm{er}}$ segment normal, contrairement aux autres Quédiaires, est sensiblement plus court que le $2^{\circ}$; par la structure de ses tarses antérieurs et surtout de leurs ongles; par la longueur du $1^{\text {er }}$ article des tarses intermédiaires et postérieurs, etc.

Une seule espèce française rentre dans le genre Acylophor'us.

\section{Acylophorus glabricollis, BorsDUVAL et LaCORDAIRE.}

Allongé, fusiforme, peu convexe, subéparsement pubescent, d'un noir brillant, avec un anneau d'un roux orangé à la base du 6 e segment abdominal, les mandibules, la base des palpes, les genoux et les tarses rous. sâtres. Tête et prothorax luisants: celui-ci transverse, rétréci en avant. Elytres fortement et asse\% densement ponctuées. Abdomen fortement ponctué ver's sa base, plus légèrement en arrière.

Staphylinus glabricollis, Boisduval et LaCordare, Faun. Ent. Par. I, 396, 20. Staphylinus rufilabris, ZetTeRstedt, Ins. Lapp. 65, 42. Acylophorus Ahrensi, NoRDManN, Symb. 127, 1. Acylophorus gabricoltis, Ericison, Col. March. I, 482, 1; - Gen. et Spec. Staph. 519, 1.- Redtenbacher, Faun. Austr. 826, 708-709.- Heer, Faun. Col. Helv. I, 584, 1.- Fatrmatre et Laboulbène, Faun. Ent. Fr. I, 534, 1. - Kraitz, Ins. Deut. II, 480, 1. - JACQUELIN DU V.L, Gen. Col. Eur. Staph. pl. 15, fig. 75. Fauvel, Faun. Galto-Rhén. III, 542, 1.

$$
\text { Long., } 0^{\mathrm{m}}, 0060 \text { (2 2/3 1.); - larg., } 0^{\mathrm{m}}, 0016 \text { (2/3 l.). }
$$

Corps allongé, fusiforme, peu convexe, d'un noir brillant, avec un anneau roux à la base du $6^{\mathrm{e}}$ segnient abdominal ; revêtu sur les élytres et l'abdomen d'une fine pubescence grise, assez longue et peu serrée.

Tète de la largeur de la moitié de la base du prothorax; lisse; d'un noir luisant; brièvement pubescente et densement pointilléc derrièr ? les yeux, marquée entre ceux-ci de 2 pores sétifères écartés et transversalement disposés, et de quelques autres sur les côtés dı vertex. Front sub.convexc. Cou lisse, glabre. Epistome lisse, souvent d'un roux de poix 
obscur. Labre d'un noir brillant, densement cilié et éparsement sétosellé en avant. Mandibules et base des palpes rousses.

Yeux grands, ovales-oblongs, noirs.

Antennes environ de la longueur de la tête et du prothorax réunis; sensiblement épaissies; finement duveteuses et éparsement pilosellées; noires, avec la base du $1^{\text {er }}$ article et l'insertion du $2^{\circ}$ souvent roussâtres; à scape aussi long que les 4 articles suivants réunis, en massue trèsallongée et subarquée : les $2^{\circ}$ à $10^{\circ}$ subobconiques, graduellement plus courts et plus épais : les $2^{\text {c }}$ et $3^{\text {e }}$ suballongés : les intermédiaires oblongs ou suboblongs: les pénultièmes subtransverses: le derniel court, subcomprimé et presque mousse au bout.

Prothorax transverse, fortement rétréci en avant; aussi large en arrière que les élytres; subéchancré au sommet, avec les angles antérieurs infléchis et arrondis; subarqué sur les côtés ; largement arrondi à la base ainsi qu'aux angles postérieurs; subconvexe; entièrement d'un noir lisse et luisant; éparsement sétosellé sur les côtés et vers le bord antérieur; paré sur le disque de 4. pores sétifères subtransversalement disposés un peu au devant du milieu, les extérieurs situés plus en avant, plus rapprochés du rebord latéral que des intermédiaires.

Écusson pubescent, ponctué, d'un noir brillant, plan ou parfois subexcavé.

Elytres Iransverses, à peu près de la longueur du prothorax, à peine convexes; parfois un peu relevées sur la suture; fortement, râpeusement et assez deusement ponctuées; d'un noir brillant; ciliées-spinosulées à leur bord apical; recouvertes sur leur disque d'une pubescence grise, assez longue, peu ou modérément serrée; parées en outre, sur les côtés, de quelques soies obscures et redressées, dont celle des épaules et surtout la suivante beaucoup plus longues. Épaules effacées.

Abdomen suballongé, moins large que les élytres; graduellement et assez fortement atténué en arrière; assez convexe sur le dos, avec les 3 premiers segments faiblement impressionnés en travers à leur base; éparsement sétosellé sur les côtés et au sommet; assez fortement, subrugueusement et assez densement ponctué sur la base des premiers segments, plus làchement et plus légèrement sur l'extrémité de ceux-ci et sur les derviers; d'un noir brillanı, avecla base du $6^{e}$ segment d'un roux orangé (1);

(1) Quand ce segment est retiré søus le précédent, ce caractèrc de cotoration.ne s'aperçoit pas, et, par la dessication, cettc couleur devient d'un jaune orangé. 
à pubescence plus obscure, plus longue et plus redressée que celle des élytres. Le $6^{\text {e }}$ segment subarrondi au sommet; celui de l'armure également teslacé à sa base.

Dessous du corps aspèrement et fortement ponctué, pubescent, dun noir brillant, avec la base du $6^{\mathrm{e}}$ arceau ventral rousse. Dessous de la tête à peine pubescent, éparsement ponctué. Métasternum peu convexe, à lobe postérieur lisse. Ventre convexe, éparsement sétosellé; à pubescence assez longue et semi-redressée.

Pieds ponctués, pubescents, d'un noir brillant, avec les tarses plus ou moins roussâtres ainsi que souvent les genoux. Cuisses antérieures et intermédiaires plus ou moins èlargies vers leur base; les postérieures allongées, assez grêles. Tibias antérieurs droits, simplement pubescents, à pubescence courte ct soyeuse. Tarses postérieur's grêles, à $1^{\text {er }}$ article très-allongé, environ de la longueur des 3 suivants réunis.

Patrie. Cette espèce, peu cornmune, se prend pour ainsi dire dans l'eau, où elle se tient cachée dans le milieu des touffes de joncs ou autres plantes aquatiques.

Nous donnerons de ce genre une autre espèce, jusqu'ici étrangère à la France.

\section{Acylophorus Wagenschieberi, KIEsenivetTEr.}

Allongé, fusiforme, peu convexe, modérément pubescent, d'un noir brillant, avec la bouche, la base des antennes, et les pieds roux. Tête et prothorax lisses, luisants : celui ci presque aussi lon! que large, rétréci en avant. Elytres assez fortement et densement, abdomen moins densement ponctués : celui-ci subirisé.

Acylophorus Wagenschieberi, KIesenwetter, Stett. Ent. Zeit. 1850, XI, 220. Kratiz, Ins. Deut. II, 481, 2. - Redtenbacher, Faun. Austr. Ed. 3, 195.

Thouson, Skand. Col. II, 182, 1. - Fauvel, Faun. Gallo-Rhén. III, 542, note. .

$$
\text { Long., } 0^{\mathrm{m}}, 0067 \text { (3 l.); - larg., } 0^{\mathrm{m}}, 0017 \text { (3/4 l.). }
$$

Patrie. La Prusse, l'Allemagne septentrionale.

Oвs. C.tte espèce, un peu plus grande que la précédente, s'en distingue suffisamment par la couleur plus claire de la bouche et des pieds, ainsi 
que de la base des antennes. La pubescence et la ponctuation des élytres sont un peu plus serrées, et cette dernière est un peu moins forte. L'abdomen, plus également ponctué, est subirisé et sans anneau roux. Le prothorax est plus long, etc.

Quelquefois le dernier aricle des antennes est un peu roussătre. Chez les exemplaires immatures, le prothorax et les élytres se montrent d'un roux de poix, ainsi que l'extrémité de l'abdomen.

(ienre Tanygnathus, TAnygnatne, Erichson.

Ericusov, Col. March., I, 417; - Gen.et spec. Staph., 288, pl. 1, fig.4. - JacqurLuy du Vat, Gen. Col. Staph. 29, pl. 11, fig. 53 s.

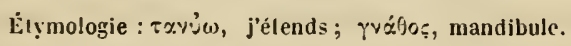

Caractères. Corps oblong, asser. large, fusiforme, à forme de Tachypore, subconvexe, ailé.

Téte petite, suboblongue, infléchie, engagée dans le prothorax. Tempes très-finement rebordées sur les củtés. Expistome subcorné, tronqué en avant. Labre membraneux, très-court, entier ou presque entier. Mandibules grêles, très-saillantes, falciformes, fortement croisées au repos. Palpes maxillaires très-allongés, à $1^{\mathrm{er}}$ article petit : les 3 autres allongés, subégaux, mais graduellement plus étroits: le dernier acumine. Palpes labiaux allongés, de 3 articles : le 3 suballongé, plus long que le $2^{\mathrm{e}}$, un

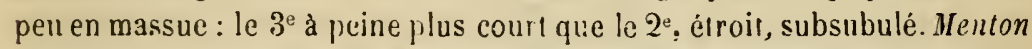
assez grand, trapéziforme, rétıcíci en avant, avec la pièce prébasilaire trèsdéveloppée, oblongue, subconvexe.

Yeux assez petits, subarrondis, peu saillants, à facettes assez grossières, séparés du prothorax par un intervalle très-court.

Antennes allongées, grêles, subfiliformes, légìrement coudées après le $1^{\text {cr }}$ article : celui-ci assez, allongé : les suivants tous sensiblement plus longs que larges : le dernier oblong, subacuminé au sommel.

Prothorax transverse, de la largeur des élytres ; fortement rétréci en avant; tronqué au sommet, subarrondi à sa base; non visiblement rcbordé sur celle-ci, très-finement sur les côtés qui sont ar.jués t't à peine abaissés d'arrière en avant. Repli large, refoulé en dessous presque jusqu'au tégument supérieur, nullenont visible vu de cô'é, à opercull' prothoracique nul. 
Ecusson assez grand, subogival.

Élytres transverses, simultanément subéchancrées à leur bord apical et distinctement et individuellement sinuées vers leur angle postéro-externe, non visiblement rebordées sur la suture. Repli étroit, peu retourné en dessous. Épaules embrassées par le prothorax.

Prosternum peu développé au devant des hanches antérieures, entre lesquelles il forme un angle subobtus, à sommet subémoussé, à disque relevé en bosse ou en faîte. Mésosternum à lame médiane triangulaire, à sommet subaigu et à peine prolongé jusqu’à la moitié des hanches intermédiaires. Médiépisternums grands, séparés du mésosternum par une fine arête oblique. Médiépimères médiocres, oblongues, lisses, avec leur angle antéro-interne pointillé et prolongé en dedans. Métasternum assez court, échancré pour recevoir les hanches postérieures ; prolongé entre celles-ci en un lobe corné, saillant, triangulaire, horizontal, légèrement fendu en son milieu; tronqué ou non avancé dans le milieu de son bord antérieur. Postépisternums assez étroits, létrécis en arrière en onglet très-allongé et acéré, divergeant à peine du repli des élytres. Postépimères très-grandes, en triangle oblong.

Abdomen suballongé, atténué en arrière; assez fortement rebordé sur les côtés; à $2^{\mathrm{e}}$ segment basilaire parfois découvert: le $1^{\mathrm{er}}$ normal et les suivants graduellement plus longs, ou bien subégaux, avec le $5^{\mathrm{e}}$ plus long (1): le $6^{\text {e }}$ plus ou moins saillant, étroit rétractile : celui de l'armure caché, émettant parfois 3 styles assez grêles et poilus. Ventre à 4 premiers segments graduellement un peu plus courts, le $5^{\mathrm{e}}$ un peu plus grand : le $6^{\mathrm{e}}$ plus ou moins saillant, étroit, rétractile.

Hanches antérieures très-grandes, assez épaisses, au moins aussi longues que les cuisses, saillantes, coniques, contiguës au sommet. Les intermédiaires grandes, subdéprimées, subovales, obliquement disposées, fortement contiguës en arrière. Les postérieures grandes, très-faiblenent distantes à leur base, médiocrement divergentes à leur sommet; à lame supérieure en forme de disque subdéprimé, légèrement conique, arrondi au sommet et recouvrant un peu la base des cuisses; à lame inférieure nulle ou enfouie.

Pieds assez courts. Trochanters antérieurs el intermédiaires médiocros,

(1) Quand les seyments sont étendus, ils paraissent graduellement plus longs; quand ils sont contractés, le $1^{\text {er }}$ parait court, les $2^{e}$ à $4^{e}$ un peu plus longs et subégaux, avec le be plus grand, mais subrétractile. 
subcunéiformes; les postérieurs à peine plus grands, subelliptiques ou ovales-oblongs, subacuminés et subdétachés à leur sommet. Cuisses comprimées, plus ou moins élargies à leur base et atténuées vers leur extrémité; les postérieures plus étroites. Tibias assez grêles, sublinéaires, éparsement épineux, armés au bout de leur tranche inférieure de 2 petits éperons grêles, plus longs dans les intermédiaires ; les antérieurs courts, moins épineux. Tarses atténués vers leur extrémité, de 4 articles; les anterieur's courts, à 3 premiers articles assez courts et assez épais, le dernier grêle, linéaire, subégal aux 2 précédents réunis ; les intermédiaires et postérieurs plus développés, grêles, à $1^{\mathrm{er}}$ article allongé, au moins égal aux 2 suivants réunis : ceux-ci oblongs : le dernier très-grêle, linéaire, à peine aussi long que les 2 précédents réunis. Ongles petits, grêles, subar'qués.

OBs. La seule espèce française du genre Tanygnathus vit parmi les mousses mouillées et rappelle la forme de certains Tachyporus et de l'Habrocerus. Mais la structure des banches postérieures la range forcément parmi les Staphyliniens. Cette coupe diffère des autres Quédiaires par ses tarses composés de 4 articles seulement, et par la conformation des palpes. Elle a plus de rapports avec les Acylophorus qu'avec les Heterothops.

\section{Tanggnathus termimalis, ERICHSON.}

Oblong, assez large, fusiforme, subconvexe, très-finement pubescent, d'un noir brillant, avec le pourtour du prothorax et la marge apicale des ílytres roux, la bouche, la base des antennes et les pieds d'un roux testacé. Tête et prothorax lisses, luisants : celui-ci transverse, fortement rétréci en avant. Élytres un peu plus longues que le prothorax, finement. et densement pointillées. Abdomen finement et densement pointillé, moins densement en arrière, fortement sétosellé.

$\sigma$ Le $6^{\circ}$ arceau ventral largement, faiblement et subangulairement échaneré au sommet. Tarses antérieurs à 3 premiers articles garnis sur leur côté interne d'une longue ciliation subhorizontale, påle, brillante, argentée, serrie et glanduleuse ou granuleuse.

ㅇ Le $6^{\text {e }}$ arceau ventral étroitement arrondi ạu sommet, Tarses antévieurs simples, 
Tanygnathus terminalis, ERICHSon, Col. March. I, 418, 1; - Gen. et Spec. Staph. 288, 1, pl. 1, fig. 4. - Piedtenbacner, Faun. Austr. 689. 701. - Falrdaire et Laboclbène, Faun Ent. Fr. I, 496, 1.- Kratz, Ins. Deut. II, 478, 1.- JacQuelis Du Val, Gen. Col. Eur. Staph. pl. 11, fig. 53. - Thousos, Skand. Col. li, 183, 1. - Fauvel, Faun. Gallo-Rhén. III, 544, 1 .

$$
\text { Long., 0 }{ }^{\mathrm{m}}, 004\left(13 / 4 \text { l.); - larg., } 0^{\mathrm{m}}, 0012(1 / 21:)\right. \text {. }
$$

Corps oblong, assez large, fusiforme, subconvexe, d'un noir brillant, avec le pourtour du prothorax et la marge apicale des élytres roux ; revêtu sur celles-ci et l'abdomen d'une très-fine pubescence grisâtre et plus ou moins serrée.

Tète petite, suboblongue, beaucoup moins large que prothorax; d'un noir luisant; lisse, a vec 3 petits points sétifères, à soie longue, de chaqtie côté, près des yeux. Front large, subconvexe. Epistome subcorné, brınâtre. Labre membraneux, testacé ou pâle, sétosellé en avant. Parties le la bouche testacées ou d'un roux testacé.

Yeux subarrondis, peu saillants, obscurs, souvent micacés.

Antennes allongées, faiblement coudées, un peu plus longues que !a tête et le prothorax réunis; grêles; subfiliformes; très-finement duveteuses et à peine pilosellées; obscures, avẹc le sommet plus foncé et le $1^{\text {er }}$ article testacé ou d'un roux testacé : celui-ci en massue assez allongée. et assez grêle : les suivants obconico-subcylindriques, tous plus long; que larges: les $2^{\mathrm{e}}$ à $6^{\mathrm{e}}$ assez allongés, les pénulièmes oblongs : le dernier oblong, subcylindrique, subacuminé au sommet.

Prothorax transverse, fortement acuminé en avant; de la largeur des élytres à sa base; tronqué au sommet, a vec les angles antérieurs infléchis, très-oblus et arrondis; médiocrement arqué sur les côtés; subarrondi à sa base; à angles postérieurs obtus et arrondis; assez convexe sur son disque ; d'un rouge brun luisant, avec le milieu plus ou moins rembruni ; lisse ; légèrement et sérialement sétosellé sur les côtés; marqué, un peu avant le milieu du dos, de 2 points sétifères assez ćcartés et transversalement disposés.

Écusson très-finement pubescent et pointillé, d'un noir assez brillant.

Élytres transverses, un peu ou à peine plus longues que le prothorax; à peine plus larges en arrière qu'ell avant ; légèrement convexes; finement, densement et subrugueusement pointillées; d'un noir assez brillant, avec la marge apicale étroitement d'un roux souvent peu tranché; très finement et densement pubescentes, avec quelques soies re.lressées 
sur les côtés, dont 1, plus longue et plus raide, vers le quart antérieur de ceux-ci. Épauies cachées.

Abdomen suballongé, à peine moins lar à à sa base que les élytres; plus ou moins atténué en arrière; longitudinalement convexe sur le dos; fortement sétosellé; funement et densement pointilié, plus éparsement vers son extrémité, surtout sur la partie postérieure des 3 ou 4 derniers segments; d'un noir assez brillant, avec le sommet d'un roux de poix ainsi que parfois la marge apicale des segments, surtout des derniers; à pubescence un peu p!us longue et moins serrée que celle des élytres. Le $6^{\mathrm{e}}$ segment arrondi au sommet.

Dessous du corps finement pointillé, finement pubescent; d'un noir assez brillant, avec le dessous du prothorax, l'extrémité du ventre et souvent la marge apicale des arceaux d'un roux de poix. Métasternum à peine convexe. Ventre convexe, longuement et éparsement sétosellé en arrière.

Pieds très-finement pointillés, très-finement pubescents, d'un roux testacé, avec les hanches postérieures rembrunies. Cuisses mutiques, les postérieures plus étroites. Tibias antérieurs brièvement et peu épineux. Tarses antérieurs à 3 premiers articles subépaissis ; les intermídiaires et postérieurs à $1^{\text {er }}$ article allongé : les $2^{\text {e }}$ et $3^{\mathrm{e}}$ oblongs, graduellement plus courts.

Patrie. Celte espèce se prend, en mai, parmi les mousses et les herbes des marais. Elle est très-rare. La Bretagne, le Bugey, la Guienne, etc.

OBS. Quelquefois le prothorax et les élytres sont presque entièrement noirs. D'autres fois, la marge apicale de ces dernières est d'un roux testacẻ bien tranché. Souvent les pieds antérieurs sont d'une couleur plus claire que les autres ; rarement, les cuisšes et tibias postérieurs sont d'un roux obscur.

Nous avons un exemplaire, de Prusse, à élytres un peu moins finement pointillées, un peu plus convexes, dont la suture est très-finement roussâtre (Tanygnathus borealis, nobis). 


\section{ERRRATA ET ADDENDA}

Page 64, ligne 20, ajoutez après pubescents : ou rarement épinenx.

Page 195, ligne 1, au lieu de Othide, lisez Orthide.

Page 252, ligne 26, au lieu de Philonthus, lisez Staphylinus.

Page 309, ligne 3, -- se rapporter au, lisez : se rapprocher $\mathrm{du}$.

Page 391, ligne 4. - Gabris, lisez Gabrius.

Page 445, ligne 22. - Erichsonius, lisez Philonthus.

Page 445, ligne 23, avant le mot Fauvec, mettez : Evichsonius semipunctatus.

Page 447. ligne 24, supprimez tout cet alinéa jusqu’à la ligne 31 inclusivement, le semipunctatus étant, parait-il, une espèce distincte, d'après $\mathbf{M}$. Fauvel qui la maintient.

Page 471, ligne 32, au lieu de $y u x$, lisez yeux.

Page 553, ligne 22, - microaturus, lisez microsaurus.

Page 129. - Le Platydracus fulvipes, var. cingulus, Villa, dont il est fait mention en note, a été trouvé aux environs de Seillans (Var), par M. l'abbé Michalet, chasseur zélé et jntelligent.

Page 448. - Avant le Bisnius orb̉us, placez l'espèce suivante, dont nous rapportons la description de M. Fauvel :

1-2. Bisnius semipunetatus, Fairmaire et Germar.

Philonthus semipunctatus, Fatrmalre et Germar, Ann. Soc. Ent. Fr. 1861, 434,Fauvec, Bull. Soc. Linn, Norm. 1866, X, 346. - Erichsonius semipunctatus, Fauver, Faun. Gallo-Rhén. III, 431, 6.- Actobius semipunctatus, Fauvel, Faun. Gallo-Rhèn. III, 6e livr. Suppl. 72.

Très-voisin du procerulus; distinct seulement par sa taille d'un tiers plus petite, les antennes plus courtes, à premiers articles transversaux, les pattes plus claires, les élytres plus étroites, plus courtes, à pubescence plus longue et poncluation plus fine, plus serrée, unicolores, d'un brun de poix ou brunes, l'abdomen plus 'mat, plus pubescent ; $\sigma$ ' 7e segment à incision plus profonde, moins triangulaire. - Long., 3 1/2-4 millim.

Sous les pierres, les détritus, les écorces ; surtout dans les dunes ; Mars à mai (R.).

Lille (Cussac); Sainte-Marie-aux-Mines (Bourgeois); Aube (Garnier); Elbeuf (Levoiturier); Calvados, Merville! Limoges ! Bordeaux! Grignols (Cabarrus); Carcassonne! Allier (Desbrochers des Loges); Nice (Tappes); Saint-Sever (Coutures).

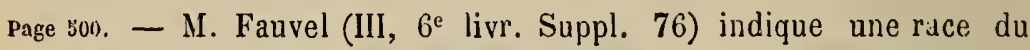
Querius ochripennis à élytres verdàtres-métalliques, sous le nom de niyrocaeruleus, et qui pourrait bien être le même insecte que nous avons décrit sous la même dénomination. 


\title{
TABLEAU MÉTHODIQUE
}

\section{ES \\ COLÉOPTERES BRÉVIPENNES}

\author{
FANILLE DES STAPHYLINIEAS
}

1or Groupe. STA PHYLINIDES

$1^{\text {re }}$ famille. STAPHILINIEIS

$1^{\text {re }}$ BRANCHE. STAPHYLINAIRES

t"rameau. STAPH YLINATES

Genre Emus, Curtis.

hirtus. LINNÉ.

Genre Creophilus, Mansernein. maxillosus, LINNÉ.

Genre Leistotrophus, Perty.

nebulosus, Fabricius.

marginalis, GÉNÉ.

murinus, Liswé.

Genre Trichoderima, Thousox. chrysocephalum, Fourcroy. pubescens, De GeER.

Genre Abemus, Mulsant et Rigy. chloropterus, Panzer. fossor, Scopol.

Genre Staphylinus, LinxÉ. caesareus, Crderhielm. medioximus, fairmaire. erythropterus, LinNÉ.

Genre Platydracus, Tuomsov.

S. genre Bemasus, Mulsant et Rey. lutarius, Gravenhorst. meridionalis, Rosenaater.

S.-genre Plalydracus verus. chalcocephalus, Fabricius. stercorarius, OLjvier. latebricola, Gravenhorst. fulvipes. ScopoLt.

Genre Ocypus, Stephens.

S -genre Goerius, Leacu.

Baudii, Fauvec.

olens. Mueller. brachypterus, Fains. et Laboctb. italicus, Aragona. megacephalus, Nordmann. cyaneus, Paykull. similis, FabriciUs. decurtatus, Mulsant et Rey.

S. genre Ocypus verus. alpestris, ERichson. macrocephalus. Gravenhorst. brunnipes, Fabricius. 
aethiops, WaLtL.

8.-genre Pseudocypus, yulcant el Rey. mus, Bruli.é.

fuscatis, Gravenhonst. picipennis, Fabricius. aenocephalus, De GeEr. confusus, Triqu. obscuroaeneus, Fairmalke. fulvipennis, ERICHSON.

Genre Tasgius, LEacil.

pedator, Gravenhonst. ater. Grdvennorst.

\section{Genre Anodus, Nordann.}

morio, Gr.ive.Nionst. compressus, Mabsian. minax, Mulcant et Rey. falcifer, NondM.nN.

\section{2' rameau. PHILON'THATES}

\section{Genre Orthidus, Julsant et ReY.}

cribratus, Enicnson.

Genre Philonthus, Cuntis.

Premiere section

splendens, Fabricius. intermedius, BoIsDuval et Lacord. laminatus, Cheutzer.

\section{Deuxième seclion}

laevicollis, Borsduval et Laco?d. montivagus, JJEER. nimbicula, Fauver.

\section{Troisième secticn}

nitidus, Fabricics.

cyanipennis, Fabricius. aeneus, Rossi.

carbonarius, ERICIIson. addendus, Silık. temporalis, liulsant et REY. tenuicornis, MULs.ñ et ReY. atratus, Gravenhonst. Ghilianii, Kratz. scutatus, Ericison. decorus, Gianenhorst. politus, Fabricius. lucens, ERICHSON. varius, Gyllenlial. melanarius, Mulsant et Rey. pyrenaeus, Kiesenwetter. frigidus, KiesenwetTer. marginatus, FAbRicius. lepidus, Gravenrorst. albipes, Gravennonst. heterodosus, MULS.NT et I:EY. umbratilis, Gravenhorst. anguinus, Favver. subrigosus, MUlsant et Rey. cephalotes, Gravenionst. megacephalus, HeEr. fimetarius, Gravenhonst. sordidus, Gravenhohst. sparsus, Lucas. fuscus, Gravenhonst.

\section{Quatrième section}

ebeninus, Cravennonst. corruscus, Giavenionst. dimidiatus. Sallberg. concinnus, Grarenuonst. gagates, NUL'ANT et Riey. iumigatus, Ericasox. debilis, Gravenhorst. sanguinolentus, GRarenhors r. stragulatus, Eiricison. fenestratus, FaUvel. cruentatus, GMEI.IN. scybalarius, Nordnax. varians, Paykull. agilis, Gravenhorst. ventralis, Gravenhorst. discoideus, Gravenhorsi. rufimanus, ERicusison. 
alcyoneus, Ericlison.

suaris, Brisout.

quisquilarius, Gruexhal.

\section{Cinquième section}

nigrita, Graveniorst.

fumarius, Gravengonst.

virgo, Graveniorst.

micans, Graveinorst.

fulvipes, Fabricius.

salinus, Kiesenwetter.

rubripennis, KIEsENWETTER.

luxurians, Ericuson.

\section{Sixième section}

punctus, Graveniorst.

puella, Nordans.

dimidiatipennis, Ericusox.

Genre Rabigues, Mulsant et Rey.

tenuis, Fabricius.

pullus, Nordyan.s.

Genre Gefyrobius, Tnomson.

nitidulus, Gravenhorst.

Genre Gabrizs, Lеach.

vernalis, Gravenuorst.

tibialis, Mlusant et Rer.

pisciformis, Fautel.

badius, KiesenwetTER.

splendidulus, Graveniorst.

thermarum, $\Lambda$ UBÉ.

exiguus, Nordvan.

astutus, Erichson.

piliger, Muls.nNt et REY.

nigritulus, GraVENHORST.

trossulus, Nordvans.

laticollis, FAUYeL.

Genre Hesperis, Fauvel.

rufipennis, Graveniorst.

Genre Cafius, Leach.

cicatricosus, Ekichson. fucicola, Curtis.

xantholoma, Gravenuorst.

Genre Pseudidus, Mulsant et Rey. sericeus, HoL.ME. pruinosus, ERICIISON. filum, Kiest:NWETER.

Genre Bisnizs, ТномsоN,

procerulus, Gravenitorst.

semipunctatus, Falrmatre el Germar. prolixus. ER'Cuson. orbus, Kiesenwettek. e'ongatus, Ericasor.

\section{3· rameau. RÉMATES}

Genre Remus, Thomson.

signaticornis, Mclsant et RE. rivularis, KIESENWETTER. cinerascens, GravenhoRst.

\section{2e BRANCHE. QUÉDIAIRES}

Genre Velleius. Mannerheim.

dilatatus, Fabricius,

Genre Quedius, Stepnens.

S.-genre Ediquus, HoL-AYT et ReY.

longicornis, Kraatz.

microps, GnavenhoRst.

S.-genre Quedius verus.

curtus, Erichson.

brevis, ERICIISON.

ventralis, AR.IGONA,

lateralis, Gravenhorst.

crassus, Fairmaire.

brevicornis, THomson,

fageti, Tuouson.

mesomelinus, Marshay. 
nigrocoeruleus, MUisant et REY. variabilis, HeEr.

ochripennis, MÉNÉTrIÈs. assecla, Mulsant et REY. fulgidus, FABricius. cruentus, OLivizr. abietum, KIESENWETTER. xanthopus, Ericuson. scitus, Gravenhorst. infuscatus, ERIChSON. laevigatus, Gyli.enHal. cinctus, PAYkULL. pediculus, Nordmann. polystigma, Wankow.

S.-genre Microsaurus, StepHens.

fuliginosus, Gravenhorst. tristis, Gravenhorst. molochinus, Gravenhorst. maculicornis, MULSANT et REY. unicolor, KIESENWETTER.

S.-genre Sauridus, HoLsant el kEY. ochropterus, Erichson. picipes, Mannerheim. provincialis, Muls.nT et REY. nigriceps, Кratzz. robustus, Scriba. peltatus, Erichson. cincticollis, KraATz. dubius, HeER. montanus, HeEr. anceps, Fairmajre et Laboul.bène. cyanescens, Mulsant et REY. umbrinus, ERICHSON. suturalis, KiESENWETTER. limbatus, HeEr. bicolor, Mulsant et Rey. oblitteratus, ERIctson. olaliceps, Mulsant et Rey. coxalis, Krantz. maurorufus, Gravenhorst. ripariUS, KELLNER.
Kraatzi, C. Brisout. lucidulus. Erichson. scintillans, Gravenhorst. etruscus, Mulsant et REY.

S.-genre Raphirus, Tномsох. pyrenaeus, C. Brisout. alpestris, HEER. auricomus, Kiesenwetter. rufipes, Gravenhorst. semiobscurus, Erichson. virgulatus, Erichson. monticola, ErichSON. collaris, ERICHSON. fulvicollis, Stephens. acuminatus. Носннитн. attenuatus, Gyllendal. picipennis, HEER. persimilis, Mulsant et Rey. boops, Grayenhorst. brevipennis, Falratike.

Genre Astrapaeus, Gravenhorst. ulmi, Rossi.

Genre Euryporus, ERICHSON. picipes, Paykull.

Genre Heterothops, Stapnens.

binotatus, Ericason. praevius, Enichson. niger, KraAtz. sericans, Mul:aNt et Rey. dissimilis, Gravenhonst. flavolimbatus, MotscruLsky. quadripunctulus, Gravenhorst.

Genre Acylophor'us, Nordmans. glabricollis, Bolduval et LaCordaire. Wagenschieberi, hiesenwetter.

Genre Tanygnathus, Erichson terminalis, ERICHson. 


\section{TABLE ALPHABÉTTQQUE}

DE LA

\section{FAMILLE DES STAPHYLINIENS}

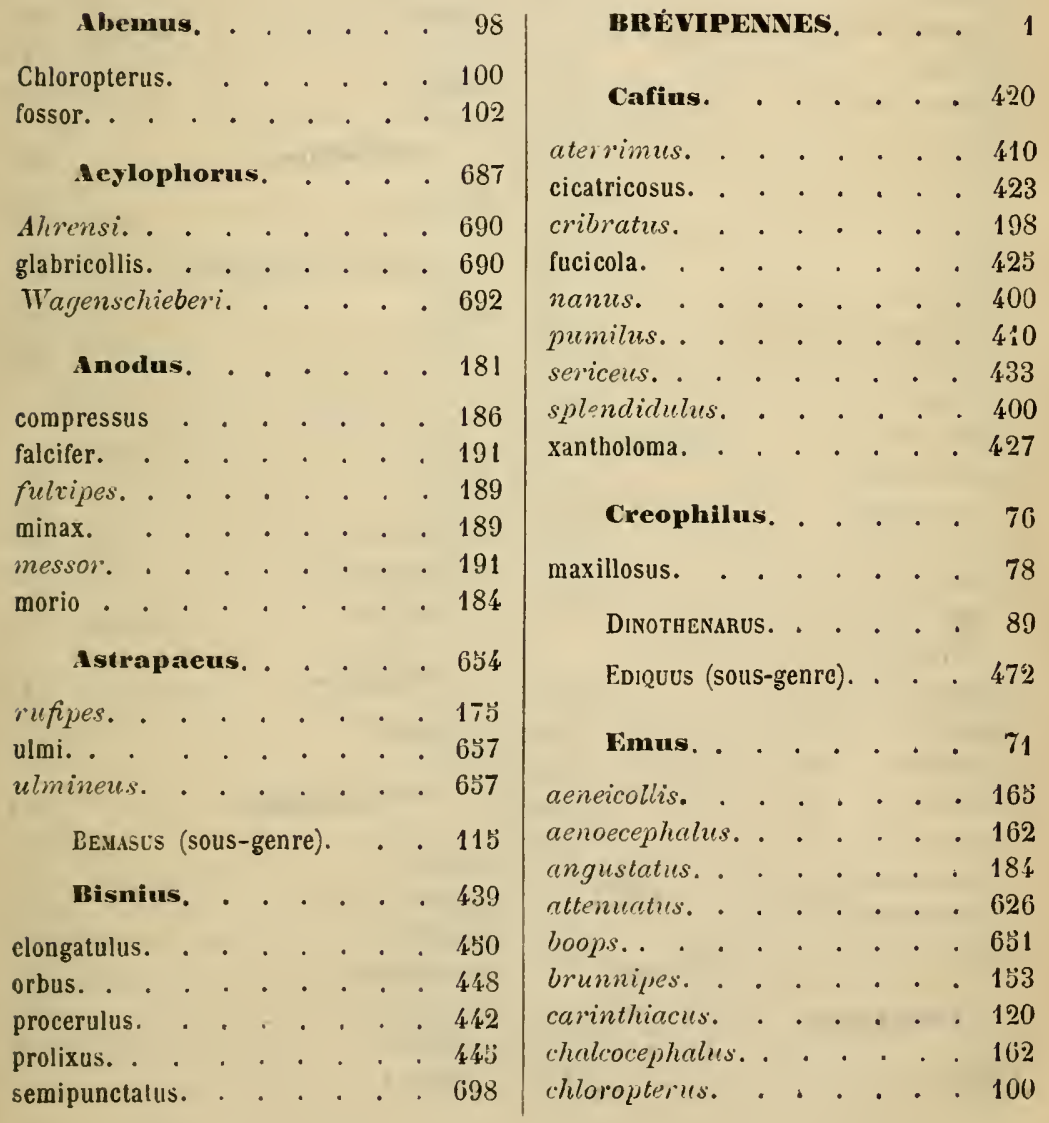


chrysocephaless. . . . . . 92

cyantus. . . . . . . . 139

erythopterus . . . . . 108

Alavicornis. . . . . . 109

floralis. . . . . . . 308

fossor. . . . . . . 103

fuscatus. . . . . . 184

hirtus. . . . . . . . 73

impressus. . . . . . . . 533

laevigatus. . . . . . . 529

lateralis. . . . . . . . 487

marginalis... . . . . . $81 ;$

maxillosus. . . . . . . 78

molochinus. . . . . . . 348

morio. . . . . . . 184

murinus. . . . . . . 87

nebulosus. . . . . . . 8 k

nigripes.. . . . . . . . 179

nitidus. . . . . . 484, 314

occultus. . . . . . . . 500

olens. . . . . . . . . 134

picifcnmis. . . . . . . 171

praecox. . . . . . . . 601

pubescens. . . . . . . . 94

rufipalpis. . . . . . . 187

rufipes. . . . . . . 175

scintillans. . . . . . 643

similis. . . . . . . . 143

stercorarius. . . . . . 123

subuliformis. . . . . . 670

tristis. . . . . . . . 563̆

nicinus. . . . . . . . 612

ERichsonius.

cinerascens. . . . . . . 460

orbus... . . . . . . . 448

procerulus. . . . . . . . 443

prolixus. . . . . . . . 443

rivularis. . . . . . . . 4009

semipunclatus. . . . 445, 447

signaticornis. . . . . . . 450

villosulus. . . . . . . . 450

Euryporus. . . . . 659

picipes .
Gabrius.

astulus. . . . . . . . 407

aterrimus. . . . . . . . 411

badius. . . . . . . . 399

exiguus. . . . . . . . 40 3

flavipes. . . . . . . . 396

laticollis. . . . . . . 413

maritimus. . . . . . . 404

nigricornis. . . . . . . . 407

nigritulus. . . . . . . . 410

piliger. . . . . . . . . 400

pisciformis. . . . . . : 398

pumilus. . . . . . . 402

splendidulus. . . . . . . . 400

thermarım. . . . . . . 402

tibialis. . . . . . . . . 396

trossulus. . . . . . . . 413

vernalis. . . . . . . 394

Gefyrobius. . . . . . 386

nilidulıs. . . . . . . . 389

Gokrius (sous-genre). . . . 132

olens. . . . . . . . . 134

cyaneıts. . . . . . . 139

Gy oltypnus. . . . . .

aterrimus. . . . . . . 410

nanus, . . . . . . . 401)

procerulus. . . . . . . 443

spl-ndidulus. . . . . . . 400

xantholoma. . . . . . . 428

Hesperus. . . . . . 415

rufifennis. . . . . . . 418

Heterothops. . . . . 604

binotatus. . . . . . . : 667

brunnipennis. . . . . . 682

dissimilis. . . . . . . . 679

fluvolimbatus. . . . . . 082

fulvipennis. . . . . . 679

limbatus. . . . . . . . $\$ 92$

minutes. . . . . . . . 070 
niger.

paradoxus.

particornis.

praevius.

praerius.

quadripunctulus.

sericans.

Leistotrophus.

marginalis.

murinus.

nebulosus.

\section{LEPTACINCS}

pubipennis.

4 佔

Microsiurles (sous-genre). . 341

brevicornis.

482

brexis.

432

fageti.

$495^{\circ}$

วั10

533

329

487

473

474

310

puncticollis.

อั17

530

497

521

santhopus.

Beypus.

130,146

abbreviatipennis. . . . . 145

aeneocephalus. . . . . 164

aethiops. . . . . . . . 135

alpestris. . . . . . . 148

alpicola. . . . . . . 153

ater. . . . . . . . . . 179

Baudii. . . . . . . . . 133

brachypterus. . . . . . . 136

brunnipes. . . . . . . 152

cerdo. . . . . . . . . 187

Chevrolati. . . . . . 150

compressus. . coilfusus. . . . . . . 167

cupreus. . . . . . . . . 165

curtipennis.. . . . . . 136

cyaneus. . . . . . . . 138

decurtatus. . . . . . $14 j$

erosicollis. . . . . . . 186

falcifer. . . . . . . . 191

fulvipennis. . . . . . . 170

fuscatus. . . . . . . . 159

hesperus. . . • • . . . 157

Italicus. . . . . . . $130^{\circ}$

macrocephalus. . . . . . 150

masculus. . . . . . . 155

megacephalus. . . . . . . 138

micropterus. . . . . . . 136

$\min a x . .9 .4 .9189$

morio. . . . . . . . 184

mus. . . . . . . . 157

obscuroaeneus. . . . . . 168

olens. . . . . . . . 134

peda'or. . . . . . . . 175

picipes. . . . . . . . 157

picipennis. . . . . . . 162

Saulcyi. . . . . . . . 186

siculus. . . . . . . 177, 186

similis. . . . . . . 142

Orthidus. . . . . . 193

cribratus. . . . . . . . . 197

\section{OXYPonCS}

picipes. . . . . . . 662

PAl:DERUS

dimidistus. . . . . . . 382

PELECYPHORLS

picip's. . . . . . . 662

PHilonthates. . . . 193

Philonthus. . . . . 200

addendus. . . . . . . . 232

adscitus. . . . . . . . 213

aeneus. . . . . . . 226

BR. 
agilis. 334

albipes 271

alcyoneus. 346 alpestris.

alpigradus. 337 analis. 400,402 anguinus. . . . . . . . 278 angulicollis . . . . . . . 229 angustatus . . . . . . . 404 anthrax. . . . . . . . 337 astutus. . . . . . . . . 407 aterrimus. . . . . . . . 411 atratus. . . . . . . . . 241 attenuatus. . . . . . 630,643 badius. . . . . . . . . 399 bimaculatus. . . . . . . 255 bipustulatus. . . . . . . 320 boops. . . . . . . . . . 651 brevicomis.. . . . . . . 301 brevis. . . . . . . . . 482 breviventer. . . . . . . . 404 carbonarius. . . . . . 229, 237 caucasicus. . . . . . . . $30 \mathrm{5}$ celer. . . . . . . . . . 319 cephalotes. . . . . . . . 283 chrysurus. . . . . . . . 474 cicatricosus. . . . . . . . 423 cinerascens. . . . . . . . 439 coeruleipennis. . . . . . . 224 concinnus. 305 consputus. . . . . . . . 204 corruscus. 303 costalus. . . . . . . . . 334 corvinus. . . . . . . . . 312 cribratus. cruentatus. $32: 3$ cruentus. 518 cyanipennis. . . . . . . . 223 debilis. 317 decorus. . . . . . . . . 247 denigrator. . . . . . . . 389 dilatatus. . . . . . . . 467 dimidiatipennis. 377 dimidiatus. . . . . . 303, 348 discoideus.

dissimilis. 447

duplopunctatus. 247 ebeninus. $30 \mathrm{I}, 304,306$ elongatulus . 450 erythrostomus. . . . . . . 40! exilis. . . . . . . . . 402 exiguus. . . . . . . . . 405 femoralis. . . . . . 396 fenestratus. . . . . . . 325 filum. . . . . . . . . 437 fimbriatus. . . . . . . 573 fimetarius. . . . . . . . 286 favopterus. . . . . . . . 260 frigidus. . . . . 202, 264 frontalis . . . . . . 543 fucicola. . . . . . . . 425 fulgidus. . . . . : 308,514 fuliginosus. . . . . . . . 542 fulvipes. . . . . . . . . 362 fumarius. . . . . . . . 330 k fumigatus. . . . . . . 313 fuscicurnis. . . . . . . 328 fuscus. . . . . . . . 296 gagates . . . . . . . 310 Ghilianii . . . . . . . . 244 gilvipes. . . . . . . . . 269 gracilicornis. . . . . . . $\$ 60$ gracilis. . . . . . . . . 382 gratiosıs. . . . . . . . 347 helveticus. . . . . . . . 362 heterodoxus. . . . . . . 273 immundus. . . . . . . . 329 insularis. . . . . . . . 399 intermedius. . . . . . . . 207 janthinipennis. . . . 24.2, 263 laetus. . . . . . . . . 244 laevicollis. . . . . 212, $21: 5$ laevigatus. . . . . . . . 529 laminatus. . . . . . 2017,200 lateralis. . . . . . . . : 487 lathrobioides. . . . . . . 44! laticollis. . . . . . . . 413 lepidus. . . . . . . . 209 lhesgicus. . . . . . . . 303 Libanicus. . . . . . . . 404 
lividipes. . . . . . . . . 368

longicornis. . . . . . . . 329

lucens. . . . . . . . 252

luxurians. . . . . . . 370

Mannerheimi. . . . . . 253

marginatus. . . . . . . 266

mucrorufus. . . . . . . 586

megacephalus. . . . . . . 286

melanarius. . . . . . . 259

melanocephalus. . . . . 407

micans. . . . . . . 359

mimulus. . . . . . . . 404

molochinus. . . . . . . 348

montanus. . . . . . . 578

montivagus. . . . . . , 215

multipunctalus.. . . . . . 372

nigrita . . . . . . . . 352

nigritulus. . . . . . . . 411

nimbicola. . . . . . . 217

nitidulus. . . . . . . . 389

nitidus. . . . . . . 220

obscuripes. . . . . . . . 363

ochropus, . . . . . . 306

opacus. . . . . . 311,33k

orbus. . . . . . . . 448

pachycuphalus.. . . . . . 291

palustris. . . . . . . 35:

paradisianus. . . . . . . 637

partuilpunctaties. . . . . 374

pediculus. . . . . . . . $\$ 37$

peltatus. . . . . . . . 371

peregrinus. . . . . . . 331

perplexus. . . . . . . . 331

picipennis. . . . . . 412,646

picipes. . . . . . . . . $\$ 60$

pisciformis. . . . . . . 398

placidus. . . . . . . . 290

politus. . . . . . . . 250

pracess. . . . . . $\$ 31,601$

procerulus. . . . . . . 443

prolixus. . . . . . . . 445

proximus. . . . . . 23)

pruinosus. . . . . . . . 435

puella. . . . . . . . 374

pullius. punclatellus. . . . . . . 537

punctalus. . . . . . . . 372

punctiventris. . . . . . . 237

punctus. . . . . . 371, 374

pusillus. . . . . . . . . 407

pygmaeus. . . . . . 401, 412

pyrenaeus . . . . . . 261

quisquiliariıs. . . . . . 348

rigiticonnis. . . . . . . 287

rivularis. . . . . . . . 459

rotundicollis. . . . . . 245

rubidus. . . . . . . 348

rubripennis. . . . . . . 368

ruficornis. . . . . . . . $32 \mathrm{~s}$

rufimanus. . . . . . . 34 4

rufipennis. . . . . . 418

rufipes. . . . . . . . 626

salinus. . . . . . . . . 365

sanguinolentus. . . . . . . 320

scutatus. . . . . . . . $24 \%$

scitus. . . . . . . . . 524

scybalarius. . . . . . 328

semipunctatus. . . . . . 445

sericeus. . . . . . . . 433

signaticonis. . . . . . . 450

siuuatocollis. . . . . . . 247

sordidus. . . . . . . . . 290

sparsus. . . . . . . . 295

splendens.. . . . . . . . 203

splendidulus. . . . . . . 400

stenoderus, . . . . . . . 289

strogulatus. . . . . . . 322

suluis. . . . . . . , 347

subfuscus. . . . . . . . 276

subrugosus. . . . . . . 280

succicolı. . . . . . . 230

temporalis. . . . . . . 233

tenuicornis. . . . . . . 237

tenuis. . . . . . . . . 382

thrinavuil. . . . . . 402

toenianus. . . . . . . 362

tristis... . . . . . 342,543

trossulus. . . . . . 413

Truquii. . . . . . . . 362

umbratilis. . . . . . . . 276 


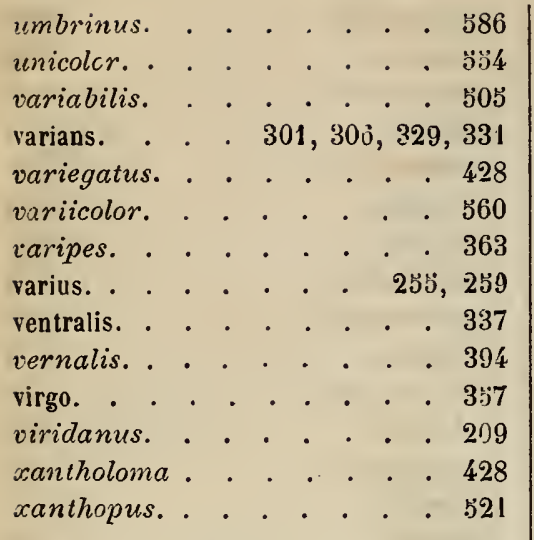

Platydracus. . . . . 113

chalcecophalus. . . . . . . 120

fulvipes. . . . . . . 127

latebricola . . . . . . . 125

lutarius. . . . . . . . 116

meridionalis. . . . . . 118

stercorarius. . . . , . . . 122

Pseudidus. . . . . . 430

filum. . . . . . . . 437

pruinosus. . . . . . . . 435

ericeus. . . . . . . . $\$ 33$

FSEUdocypus (sous-geure). 147

QUÉDIAIRES. . . . . 462

Quedius. . . . . 469,477

abietum. . . . . . . 520

acuminatus. . . . . 601, 640

alpestris. . . . . . . . . 619

amplicollis. . . . . . 490

anceps. . . . . . . . . 580

arvernicus. . . . . . . 499

assecla. . . . . . . . . 511

auricomus. . . . . . 621

attenuatus. . . . . . 642

bicolor. . . . . . . . . 594

Bonvoultiri. . . . . . 640 boops. . . . . . . 650,654

brevicornis. . . . . . . 492

brevipennis. . . . . . . 653

brevis. . . . . . . . . 481

chrysurus. . . . . . . . 474

cincticollis. . . . . . . . 574

cinctus. . . . . . . . . 532

circumductus. . . . . . . 574

collaris. . . . . . . . . 639

coxalis. . . . . . . 600

crassus. . . . . . . . . 490

cruentus. . . . . . . 517

curtus. . . . . . . . . . 479

cyanescens. . . . . . . 583

dilatatus. . . . . . . . 467

dubius. . . . . . . 575

etruscus. . . . . . . . 615

fageti. . . . . . . . 494

fallaciosus. . . . . . . 643

fimbriatus. . . . . . $\$ 57,575$

flavipennis. . . . . . . . 636

frontalis. . . . . . . 545

fulgidus. . . 473, 484, 497, 517

fulgidus. . . . . . . . 513

fuliginosus . . . . . . . 342

fumatus. . . . . . . . 571

Kraatzi.. . . . . . . . 606

impressus. . . . . . . . 533

infuscatus. . . . . . . . 526

irideus. . . . . . . . . 571

laevigatus. . . . . . . . $\$ 29$

lateralis. . . . . . . 487

limbatus. . . . . . . . 591

longicornis. . . . . . 472

lucidulus. . . . . . . . . 609

maculicornis. . . . . . .

maurorufus. . . . . 563,502

maurorufus. . . . . . . 600

mesomelinus. . . . . . . 497

microps. . . . . . . . 474

modestus. . . . . . . . 601

molochinus. . . . . . . 548

monspeliensis. . . . . . 612

monticola. . . . . . . 636

montanus. . . . . . . 577 
muscorum. . . . . . . 589 nemoralis... . . . . 597

nigriceps. . . . . . . 563

nigrocoeruleus. . . . . . 500

nivicola. . . . . . . . 518

oblitteratus. . . . . . . 597

ochripennis. . . . . . . 507

ochropterus. . . . . . . 557

oraliceps . . . . . . . 600

paradisia.uis. . . . . . 637

parviceps. . . . . . . 567

pediculus. . . . . . . . 537

peltatus. . . . . . . 571

peranxius. . . . . . 517

persimilis. : . . . . . 647

picipennis. . . . . . . 646

picipes. . . . . . . 560

pineti. . . . . . . . . 64

polystigma. . . . . . . . 540

praccox. . . . . 563, 571, 601

provineialis . . . . . 563

proximus. . . . . . . 631

punctatellus. . . . . . . 537

pulchellus. . . . . . . . 591

pyrenaeus. . . . . . . 616

riparius. . . . . . . 603

robustus. . . . . . . 566

rufipes. . . . . . . 625

rufithorax. . . . . . . 499

satyrus. . . . . . . 619

scintillans. . . . . . . 612

scitus. . . . . . . . . 523

semiaeneus. . . . . . 631

semiobscurus. . . . . . 630

simplicifrons. . . . . . 548

speculator. . . . . . . 580

suturalis. . . . . . . . 588

temporalis.. . . . . . . 497

tenellus. . . . . . . . 541

tristis. . . . . . . . . . 544

truncicola. . . . . . . 485

umbrinus. . . . . . . . 586

unicolor. . . . . . . . 353

variabilis. . . . . . . 305

ventralis. , , : : : , , 484 virgulatus. . . . . . . 63 k

vicinus. . . . . . . . 612

xanthopus. . . . . . . 521

Rabigus. . . . . . . 379

pullus. . . . . . . . $38 \mathbf{i}$

tenuis. . . . . . . . 382

RAPHIRUS (sous-genre). . . 615

attenuatus. . . . . . . 6,3

boops. . . . . . . . 651

marginalis. . . . . . . 589

maurorufus. . . . . . . 592

modestus. . . . . . 601

nigriceps. . . . . . . . 561

peltatus. . . . . . . . 571

picipes. . . . . . . . . 560

scintillans. . . . . . . 012

suturalis. . . . . . . 597

umbrinus. . . . . . 586

RËMATES. . . . . . 452

Remns. . . . . 453

cinerascens. . . . . . . 459

rivularis. . . . . . . . 458

sericeus. . . . . . . . 433

signaticornis. . . . . . . 450

subniger. . . . . . . 101

Sauridus (sous-genre), . . 550

STAPHX XINIDES.

STAPHYLINIEIS. . . . . 67

STAPHYLINAIRES. . . 68

STA PII YLINATES . . . . 69

Staphylinus. . . . . 103

aeneicollis. . . . . . : 185

aéneipennis, . , . :" , : 619 
aeneocephalus.

aeneus.

aethiops.

agilis.

albipes.

alpestris.

alpicola.

amoenus.

analis.

anthras.

ater.

aterrimus.

atralus.

atricillus.

atrocyaneess.

atteruatus.

aureofasciatus.

asuresceris.

azureus.

Boudii.

bicinctus.

bimaculatus.

bipunclatus.

bipustulatus.

bombylius.

boops.

brachypterus.

brevicornis.

brevipennis.

brunnipes.

caerulescens.

caesareus.

carbonarizs.

castanopterus.

celer.

cephalotes.

cerdo.

chalcocephalus.

chloropterus.

chrysocephalus.

cinctus.

cinerascens. . . . . . . . 439

cingulus.

caenosus.

coeruleipennis.
127,129

221

$120,162,165$

209,227

317,334

148

153

$22\}$

324

337

179 .

332,410

227,2 i , 313 524

139

643

129

139

127

133

127

255, 331

. 160

336,331

74

651

136

301

148

153

242

107

239, 259

111

339

283

187

$120,162,171$

100

92

32

21

224 coerulescens.

compressus.

139, 1 '2

concinnus.

187

31) 6

concolor.

466

conformi:

341

confusus.

167

contaminatus. . . . . . . 320

corruscus.

304

crassicollis.

161)

crebrepunctaties.

125

cruentatus.

326

cruentus.

518

cupreus.

165

cyaneus. .

139

cyanicornis.

227

cyanipenriv.

224

debilis.

317

decorus.

248

denigrator. .

389

dilatatus.

466,544

dimidiatus.

305,348

discoideus.

341

dubizis.

236,573

ebeninus.

301

edentulus.

184

erythropterus.

110

erythropus :

$103,197,110$

falcifer.

fimetarius.

127,153

flavescens.

191

flavescens.

287, 317

flavopteris.

333

flavopunctatus.

269

fodiens. . .

116

fossor.

103

fragilis.

102

296

fulgidus.

314

fuliginosus.

542

fulvicollis.

646

fulvipennis.

171

fulvipes.

, 3 3'3

fumarius.

355

fuscatus.

159,179

fuscipes. . . . . . . . . 137

fuscus. . . . . . . . . 296

glabricollis. . . . . . 690 
globulifer.

143

hirtus.

impressus.

immundus.

interinedius.

italirus.

laericollis.

lacvigatus.

laminatus.

latebricola.

luteralis.

laticeps.

laticollis.

lepidus.

limbatus.

lucidus.

luganensis.

lutarius.

macrocephalus.

marginalis.

marginatus.

marginellus.

masculus.

inaurorufus.

maxillosus.

medioximus.

melanarius.

meridionalis.

mesomelinus.

metallicus.

micans.

microcephalus.

microps.

minax.

molochinus. . . . . . . . 548

morio.

morsitans.

Mulsanti.

multipunctatus.

murinus.

mus.

nainzes.

nebulosus.

nigrita.

nigritulus.

$329, .337$

207

137

213,548

วั29

209

125

487

227

548

26 ?

วิ2

317

187

116

150

80

266

532

155

$586,601,643$

78

110

184

118

497

227,241

360

274

474

189

160,154

193

118

$37 \%$

213,352

410 nigritus.

nitens.

143

nitidicolli... . . . . . . 256 nitidulus. . . . . . . . 389

nitidus. . . 221, 304, 497, 5118

obscuroneneus. . . . . . . 168

ochripennis. . . . : . . 508

achropterus. . . . . . . 120

ochropus. . . . . . . . 306

olens. . . . . . . . . . 134

opacus. . . . . . 331, 332

ophthalmicus. . . . . . . 139

particomis. . . . . . 334

parvulus. . . . . . . 400

pedator. . . . . . . . 175

picipennis. . . . . . 102, 848

picipes. . . . . . 157, 56

planatus. . . . . . . 1 1

planus. . . . . . . . . 304

politus. . . . . . 204, 250

praecos. . . . . . . . 594

procerulus. . . . . . . . 443

prebescens. . . . . . . 92, 04

punctutus. . . . . . . . 372

punctus. . . . . . 372, 374

pygmaents. . . . . . . . \$24

quisquiliarius. . . . . . . 348

rigidicornis. . . . . . . 287

ruficornis. . . . . . . 626

rufilabris. . . . . . . . 090

mefipennis. . . . . . 418

rufipes. . . . . . . 026

rupicola. . . . . . . 125

sanguinolentus. . . . . 32

scintillans. . . . . . . 012

scitus. . . . . . . . . \$24

serraticornis. . . . . . . $\$ 56$

sexlus. . . . . . . . 201

similis. . . . . 113, 227

simplex. . . . . . . . . 274

sordidus. . . . . . . . 201

splendens. . . . . . . . 204

splendidulus. . . . . . . 40"

stercorarius. . . . . . . 123

subfuscus. . , . . , , 276 
subuliformis. . $29 \mathbf{t}^{\circ}, 680,683,685$ tenuis. . . . . . . . . 382 terminatus. . . . . . . . 296 tessellatus. . . . . . . . 84 testaceus. . . . . . . . 342 tricolor. . . . . . . . . 127 tristis. . . . . . 102, 542, 545 ulmi. . . . . . : . 657 ulmineus. . . . . . . 657 umbratilis. . . . . . . 276 vagans. . . . . . . 171 variabilis. . . 497, 503, 514, 521 varians. . . . 2!5, ริ06, 331, 332 varius. . . . . . . . $255^{\circ}$ ventralis. . . . . . 337,484 vernalis. . . . . . . 394 virgo. . . . . . . . . . 357 xantholoma. . . . . . 428

TACIINUS

dissimilis. . . . . . 680 quadripunctulus. . . . . . 685

TACHYPORUS

dissimilis. 693
Tanygnathus. 693

borealis. 697 terminalis. 695

Tasgius. 173

abbrevialus. . . . . . . 153

ater. . . . . . . . 179

confinis. . . . . . . 179

pedator. . . . . . . 175

rufipes. . . . . . . . 175

Trichoderma. . . . . $\delta 9$

chrysocephalum. . . . . . . 91

pubescens. . . . . . . . 94

TRICHOPYGCS

dissimitis. . . . . . . 670

pumilio. . . . . . . . 685

Velleius. . . . . $41 j$ '

dilatatus. . . . . . . . 4600

\section{A R V ES}

Creophilus maxillosus. . . . 80 Philonthus sordidus. . . . 293 Trichoderma pubescens. . . . $96 \sqrt{ }-$ concinnus. . . . 3199

Platydracus chalcocephalus. . . $122+315$ Ocypus cyaneus. . . . . . 141 - ventralis. . . . . 340 Tasgius pedator. . . . . . 177 Quedius cinctus. . . . . . 533

Philonthus aeneus. . . . . $229 \sqrt{ }-$ nigrocaeruleus. . . . 503

- - tenuicornis. . . . 240 f - rufipes. . . . . 628

$\lambda_{j}$ - varius. . . . . $258 \sqrt{ }-$ semiobscurus. . . . 633

$\checkmark$ - fimetarius. . . . 289 Heterothops pracvius. . . . 6i2 
EXPLICATION DES PLANCHES 


\section{Plamelue I}

1. Hanche postérieure de l'Ocypus olens et à peu près aussi de la plupart des Staphyliniens.

2. Narge latérale du prothorax de la plupart des Staphylinaires.

3. Marge latérale du prothorax de la plupart des Quédixires.

4. Pointe mésosternale postérieure de la plupart des Staphylinates.

5. Pointe mésosternale postérieure de la plupart des Philonthates.

6. Les trois premiers articles des antennes des Staphylinates et Phi'onthates.

7. Les trois premiers articles des antennes des Rémates.

8. Tarse postérieur du genre Emus.

9. Tarse postérieur du genre Creophilus.

10. Lame mésosternale du genre Emus et à peu près aussi du genre Creophilus.

11. Lame mésosternale du genre Leistotrophus.

12. Lame mésosternale du genre Tirichoderma.

13. Les deux derniers articles des palpes maxillaires des genres Abemus et Platydracus.

14. Les deux derniers articles des palpes maxillaires du genre Staphylinus.

15. Tête du Staphylinus caesareus.

16. Tête du Platydracus chalcocephalus et à peu près aussi des lutarius et meridionalis.

17. Tete des Platydracus stercorarius et latebricola.

18. Les deux derniers articles des palpes maxillaires de plusieurs Ocypus.

19. Les deux derniers articles des palpes labiaux de plusieurs Ocypus.

20. Lame mésosternale des Ocypus, Tasgius et Anodus.

21. Mandibule de la plupart des Ocypus et Tasgius.

22. Mandibule de la plupart des Anodus.

23. Les deux derniers articles des palpes labiaux des Tasgius.

24. Les deux derniers articles des palpes labiaux des Anodus.

25. Lame mésosternale du genre Orthidus.

26. Sommet des cuisses antérieures du genre Orthidus.

27. Sommet des cuisses antérieures du genre Philonthus.

28. Tarse postérieur du genre Orthidus.

29. Tarse postérieur d'un grand nombre de Philonthus.

30. Tarse postérieur de plusieurs Philonthus.

31. Lame mésosternale du Philonthus nitidus et de plusieurs autres Philonthus.

32. Tarse postérieur du genre Gefyrobizs et à peu près aussi du genre Gabrius.

33. Lame mésosternale du genre Hesperus.

34. Lame mésosternale du Cafius xantholoma. 
BREVIPENNES

Staphylnaires

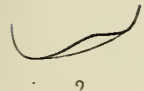

2
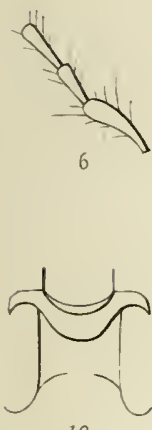

1
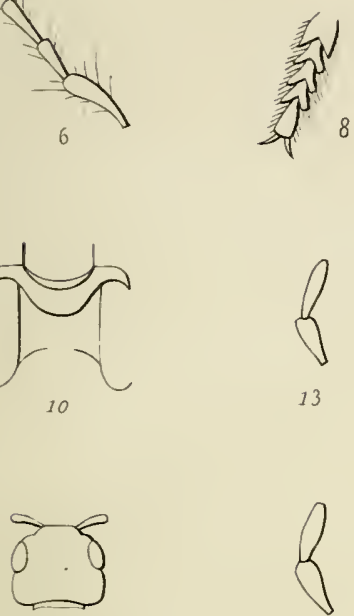

15

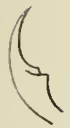

21
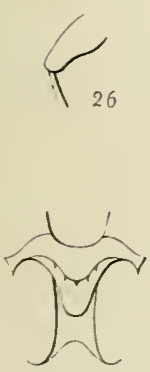

33
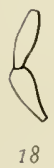

Q
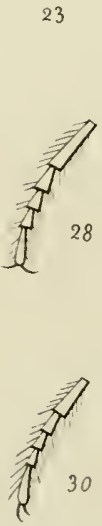
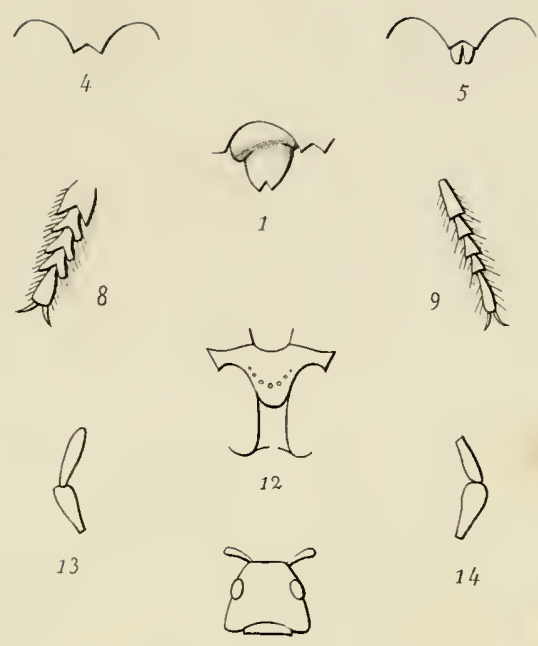

Q

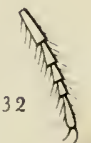

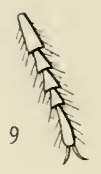

8

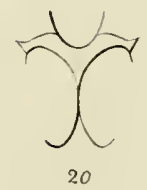

8
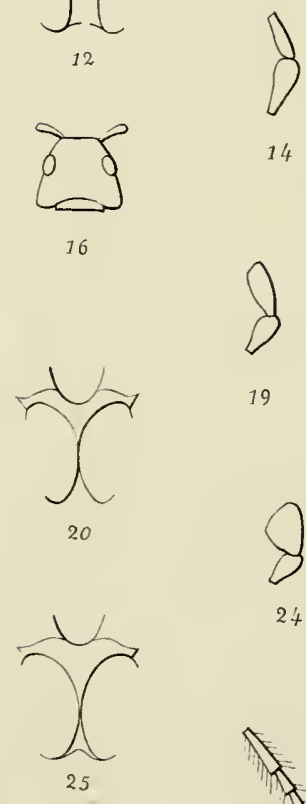

19
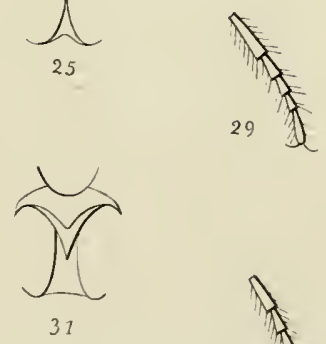
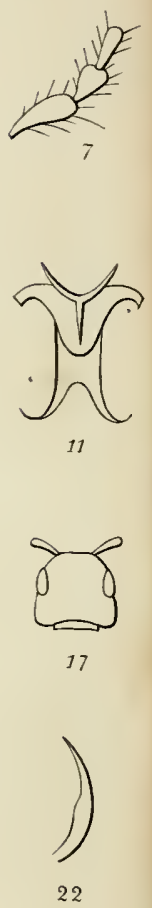

22
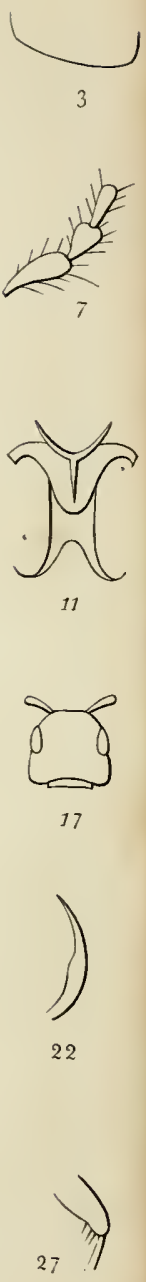

2

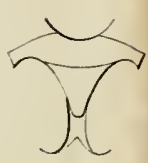

34 



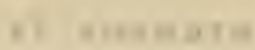

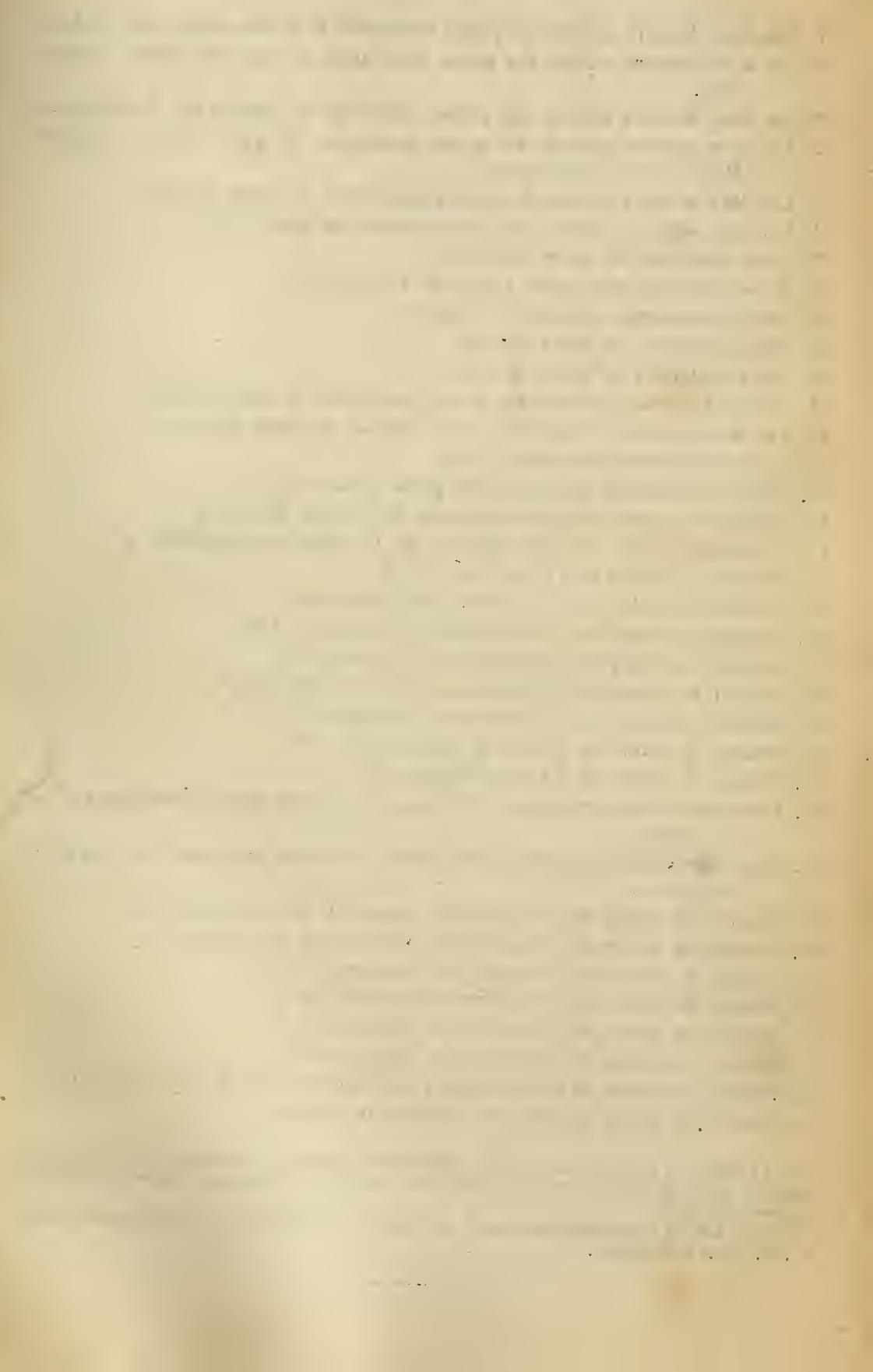




\section{Planche II}

1. Les deux derniers articles des palpes maxillaires de la plupart des Philonthus.

2. Les deux derniers articles des palpes maxillaires de plusieurs autres Philonthus.

3. Les deux derniers articles des palpes labiaux de la plupart des Philonthus.

4. Les deux derniers artic'es des palpes maxillaires du genre Hesperus et du Philonthus cyanipennis.

5. Les deux derniers articles des palpes maxillaires du genre Rabigıs.

6. Les deux dernieis articles des palpes labiaux du genre Grabrius.

7. Tarse postérieur du genre Hesperus.

8. Tarse postérieur des genres Cafus et Pseudidus.

9. Lame mésosternale du genre Pseudidus.

10. Tarse postérieur du genre Bisnizs.

11. Tarse postérieur du genre Remus.

12. Les deux derniers articles des palpes maxiliaires du genre Remus.

13. Les deux derniers articles des palpes labiaux du genre Remus.

14. Lame mésosternaie du genre Remus.

15. Pointe mésosternale postérieure du genre Remus (1).

10. Trochanter, cuisse et tibia postérieurs de l'Emus hir'tus o".

17. Trochanter, cuisse et tibia antérieurs du Creophilus maxillosus $\sigma$.

18. Sommet du ventre de l'Emus hirtus o'.

19. Sommet du ventre du Creophilus naxillosus $\sigma^{\circ}$.

20. Sommet du ventre du Leistotrophus nebulosus o' (2).

21. Sommet du ventre du Leistotrophus murinus $\sigma$.

22. Sommet du ventre du Trichoderma chrysocephalum $\sigma$

23. Sommet du ventre du Trichoderma pubescens $\sigma$.

24. Sommet du ventre de l'Abemus chloropterus $\sigma$.

25. Sommet du ventre de l'Abemus fossor $\sigma$.

26. Lame mésosternale du genre $A b z m u s$ et à peu près aussi du sous-genre Platydracus.

27. Lame mésosternale du genre Staphylinus et à peu près aussi du sous-genre Bemasus.

28. Sommet du ventre des Staphylinus caesareus et Erythropterus $\sigma^{\circ}$.

29. Sommet du ventre des Platydracus lutarius et meridionalis $\sigma$.

30. Sommet du ventre du Platydracus chalcocephalus ơ.

31. Sommet du ventre du Platydracus stercorarius $\sigma$ ".

32. Sommet du ventre du Platydracus latebricolı $\sigma$ ".

33. Sommet du ventre du Platydracus fiulvipes $\sigma$.

34. Sommet du ventre de l'Ucypus olens et à peu près aussi du brachypterus ơ".

35. Sommet du ventre des Ocypus italicus et cyaneus $\sigma$.

(1) La planclıe I et les quiuse premières figur's de la planche II coneernent la classification; toules les autres figures ont trait à des,difrérences sexuelles ou spécifques, rarement générıques ou sous-génériques.

(2) Nous faisons abstraction du segment de l'arinure, qui, du tresle, esıle plus souvent caclié ou l'eliré sous le précédent. 
BREVIPENNES

Staphylinaires

1

1

\{

5
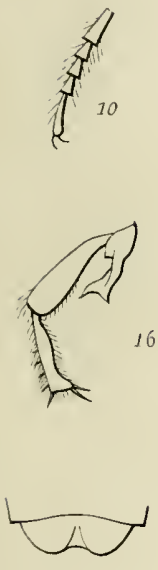

2]

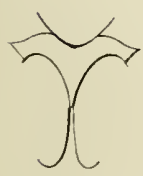

26

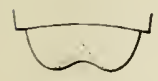

31

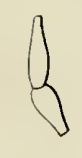

2
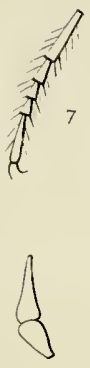

12
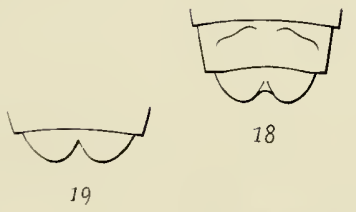

18

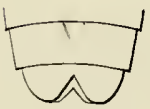

25
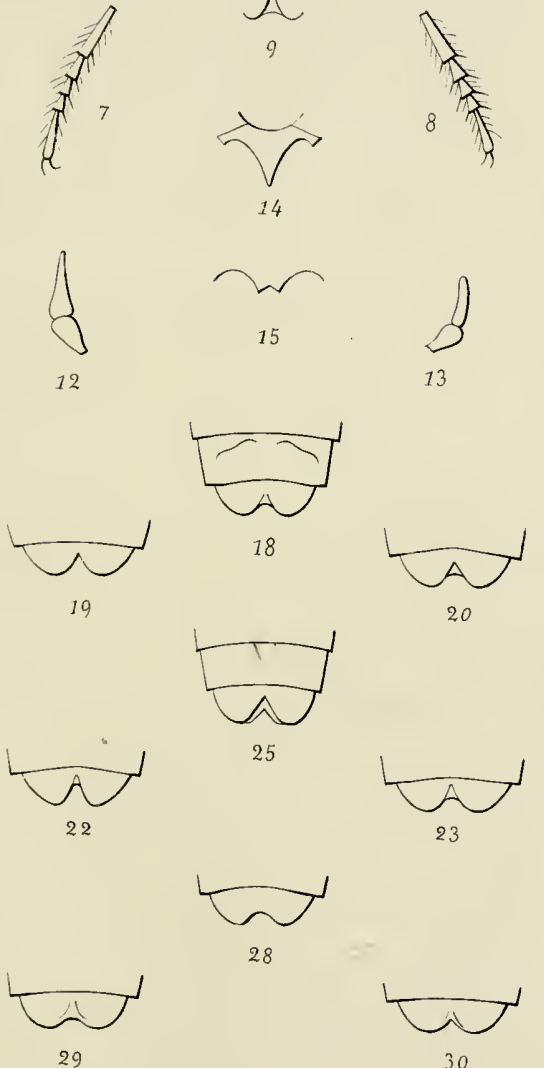

28

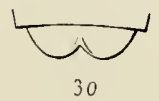

$\square$

33

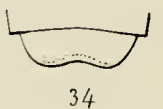

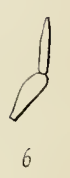
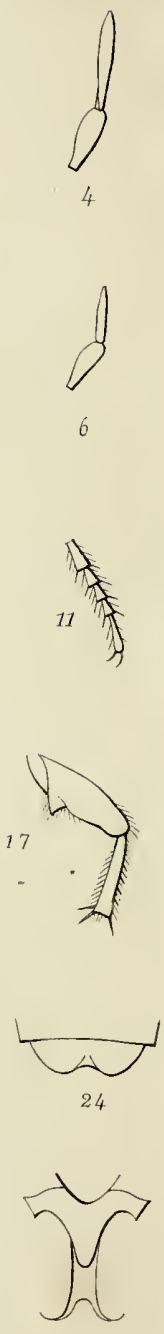

27

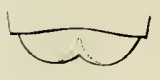

35 



$$
\text { r }
$$




\section{Planehe III}

1. Sommet du ventre des Ocypus similis et decurtatus $\sigma$.

2. Sommet du ventre de l'Ocypus alpestris $\sigma^{\prime}$.

3. Sommet du ventre des Ocypus macrocephalus et brunnipes $\sigma$.

4. Sommet du ventre de l'Ocypus cethiops o'.

5. Sommet du ventre de l'Ocypus mus $\sigma^{*}$ (1).

b. Les deux derniers articles des palpes maxillaires de l'Ocypus brunnipes $\sigma^{*}$.

7. Les deux derniers articles des palpes maxillaires de l'Ocypus brunnipes $\$$.

8. Sommet du ventre des Ocypus fuscatus, picipennis et aeneocephalus $\sigma$.

9. Sommet du ventre de l'Ocypus obscuroaeneus $\sigma$.

10. Sommet du ventre de l'Ocypus fulvipennis $\sigma$.

11. Sommet du ventre du Tasgius podator $\sigma^{7}$.

12. Sommet du ventre du Tasgius ater $\sigma^{7}$.

$1 \therefore$ Sommet du ventre des Anodus morio et compressus $\sigma$.

14. Sommet du ventre de l'Anodus minax o".

13. Les deux derniers articles des palpes maxillaires du Tasgius pedator $\sigma^{\star}$.

16. Les deux derniers articles des palpes maxillaires du Tasgius pedator $\$$.

17. Les deux dernicrs articles des palpes maxillaires du Tasgius ater $\sigma$.

18. Les deux derniers articles des palpes maxillaires du Tasgius ater

19. Sommet du ventre de l'Orthidus cribratus $\sigma$.

20. Sommet du ventre du Philonthus splendens $\sigma$.

21. Tibia antérieur du Philonthus splendens.

22. Tibia antérieur du Philonthus intermedius.

23. Sommet du ventre du Philonthus intermedius ct à peu près aussi des laminatus et scutatus or.

24. Sommet du ventre des Philonthus laevicollis et monticagus o".

25. Sommet du ventre du Philonthus nitidus $\sigma$.

26. Sornmet du ventre du Philonthus cyanipennis $\sigma$.

27. Sommet du ventre du Philonthus aeneus $\sigma$.

28. Sommet du ventre du Philonthus carbonarius $\sigma$.

29. Sommet du ventre du Philonthus addendus $\sigma$.

39. Sommet du ventre du Philonthis temporul s or.

31. Sommet du ventre du Philonthus tenuicomis $\sigma$.

32. Sommet du ventre du Philonthus atratus o.

33. Tepli basilaire des $2^{\mathrm{e}}$ et $3^{\mathrm{e}}$ segments abdominaux des Philonthus aeneus; carbonarius et addendus.

34. Repli basilaire des $2^{\mathrm{e}}$ et $3^{\mathrm{e}}$ segments abdominaux des Philonthus temporalis et tenuiconis.

(1) Bien que ees distinctions sexutelles n'oftrent souvent qua des nuances presque insensibles; nous avons cru devoir les figurer presque toulcs, afln de falre saisir les differences de l'espèce à cello qui précède. 
BREVIPENNES

Staphylinaires

$\mho_{1}$

\}

6

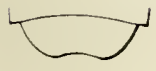

11

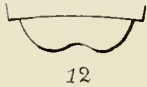

\&

16

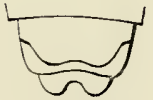

23

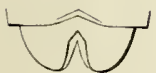

20

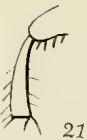

21

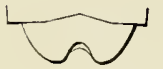

19
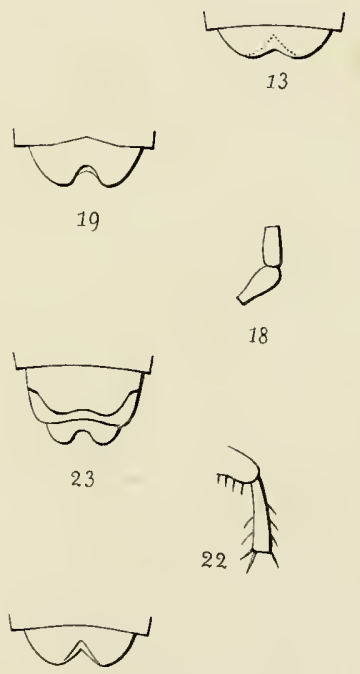

25

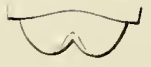

27

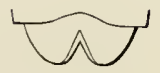

28
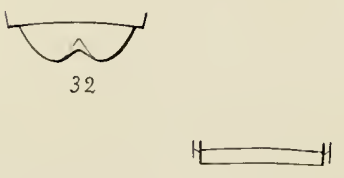

34
8

17

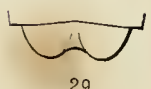

g

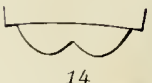

14

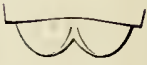

24

29

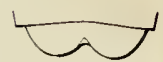

31 




\section{Planehe Iy}

1. Sommet du ventre du Philonthus decorus $\sigma$.

2. Sommet du ventre du Philonthus politus $\sigma$.

3. Sommet du ventre du Philcrithus lucens $\sigma$.

4. Sommet du ventre du Philonthus varius $\sigma$.

j. Sommet du ventre des Philonthus melanarius et pyrenaeus $\sigma$.

6. Sonımet du ventre du Philonthus frigidus $\sigma^{*}$.

7. Sommet du ventre du Philonthus marginatus et à peu près aussi du lepidus or.

8. Sommet du ventre du Philonthus albipes $\sigma^{\prime}$.

9. Sommet du ventre du Philonthus umbratilis $\sigma$.

10. Sommet du ventre du Philonthus cephalotes $\sigma$.

11. Sommet du ventre du Philonthus fimetarius $\sigma$.

12. Sommet du ventre des Philonthus scrdidus et sparsus $\sigma^{7}$.

13. Sommet du ventre des Philonthus ebeninus, corruscus et consinnus $\sigma$.

14. Sommet du ventre du Philonthus gagates $\sigma$.

15. Sommet du ventre du Philonthus funigatus $\sigma$.

16. Sommet du ventre du Philonthus debilis et à peu près aussi du sanguinolentus $\sigma$.

17. Sommet du ventre des Philonthus cruentutus et scybalarius $\sigma$.

18. Sommet du ventre du Philonthus varians $\sigma$.

19. Sommet du ventre du Philonthus agilis $\sigma^{\prime \prime}$.

20. Sommet du ventre du Philonthus ventralis et à peu près aussi du discoideus $\sigma$.

21. Sommet du ventre du Philonthus vufimanus $\sigma$.

22. Sommet du ventre du Philonthus quisquiliarius $\sigma$.

23. Sommet du ventre des Philonthus nigrita et fumarius $\sigma$.

24. Sommet du ventre des Philonthus virgo et micans $\sigma$.

2:. Sommet du ventre des Philonthus fulvipes et salinus $\sigma$.

26. Sommet du ventre du Philonthus punctus $\sigma$.

27. Sommet du ventre du Philonthus puella $\sigma$.

28. Sommet du ventre du Philonthus dimidiatipennis $\sigma$.

29. Sommet du ventre du Rabigus tenuis $\sigma$.

30. Sommet du ventre du Rabigus pullus $\sigma$.

31. Sommet du ventre du Gefyrobius nitidulus $\sigma$.

32. Sommet du ventre du Gabrius vernalis $\sigma$.

33. Sommet du ventre du Gabrius tibialis ơ'.

34. Sommet du ventre du Gabrius splendidulus $\sigma$. 
BREVIPENNES

Staphylinaires

\section{U \\ 1}
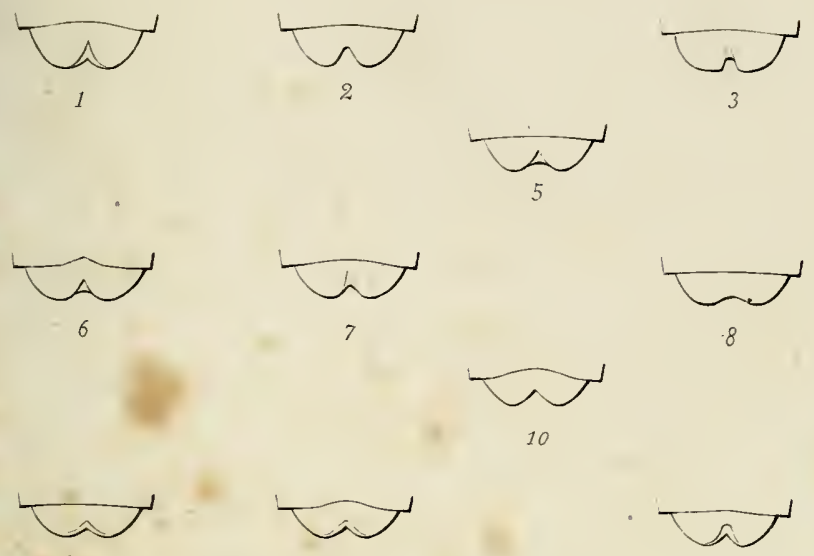

11
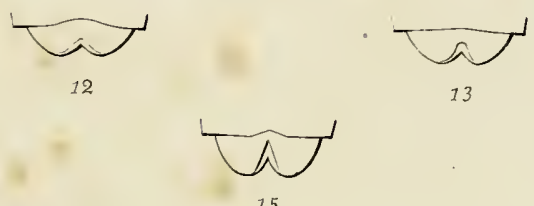

15
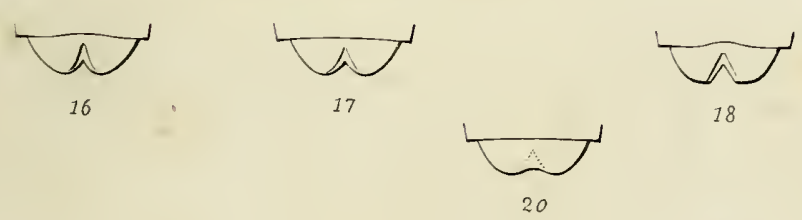

18

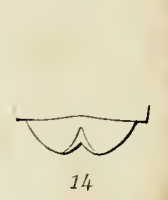

14
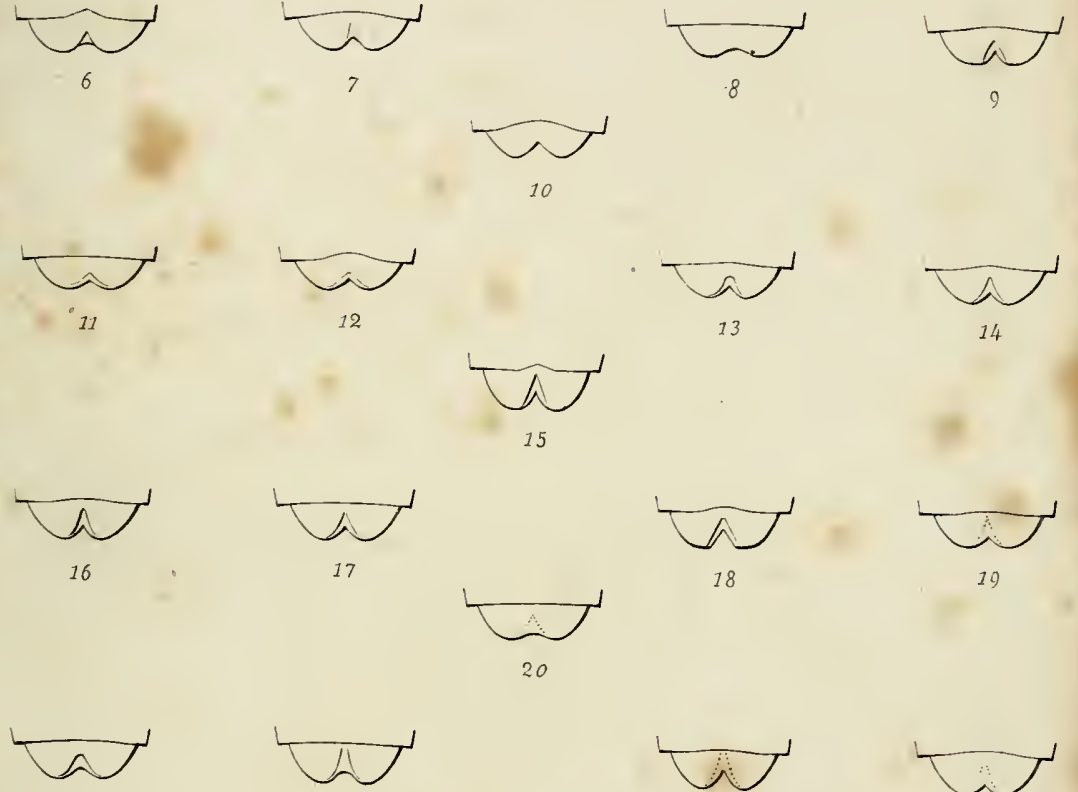

21

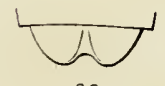

22

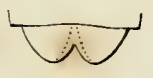

23
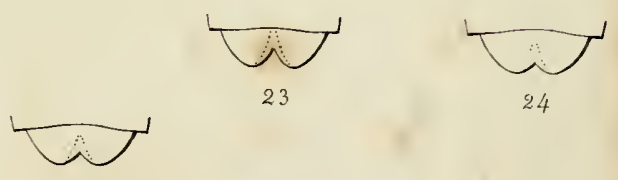

25

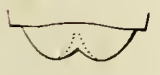

26

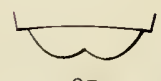

27
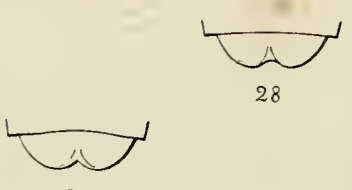

28

30
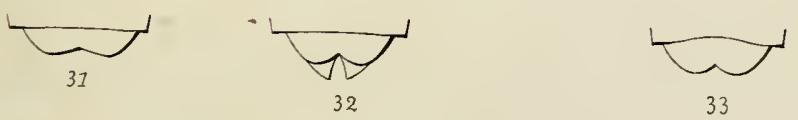

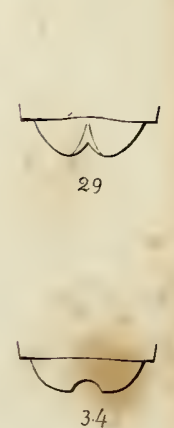

29

24 
. 


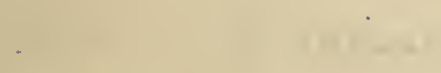

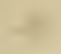




\section{PIanelhe V}

4. Sommet du ventre du Gabrius exiguus o*.

2. Somnel du ventre du Gıbrius nitidulus et à peu près aussi de l'astutus $\sigma$.

3. Tibra postérieur des Gabrius exiguus et laticollis o7.

4. Tibia postérieur des autres Gabrius $\sigma^{\nearrow}$.

5. Sommet dı ventre des autres Gabrizs $\sigma$.

6. Sommet du ventre de l'Hesperus rufipennis $\sigma$.

7. Sommet du ventre du Cafius cicatricosus $\sigma^{7}$.

8. Sommet du ventre du Cafius xantholoma $\sigma$.

9. Sommet du ventre des Pseudidus sericeus, pruinosus et filum $\sigma$.

10. Sommet du ventre des Bisinius procerulus et prolixus $\sigma$.

11. Sommet du ventre du Bisnius orbus $\sigma$.

12. Sommet du ventre du Bisuius elongatus $\sigma$.

13. Sommet du ventre du Remus signaticornis $\sigma$.

14. Sommet du ventre du Remus cinerascens $\sigma$.

15. Sommet de l'abdomen de la larve du Creophil.us maxillosus.

16. Sommet de l'abdomen de la larve du Trichoderma pubescens.

17. Sommet de l'abdomen de la larve du Platydracus chalcocephalus.

18. Sommet de l'abdomen de la larve de l'Ocypus cyaneus.

19. Sommet de l'abdomen de la larve du Tasgius pedator.

20. Sommet de l'abdomen de la larve du Philonthus aeneus.

21. Sommet de l'abdomen de la larve du Philonthus tenuicornis ?

22. Sommet de l'abdomen de la larve d" Philonthus varius.

23. Sommet de l'abdomen de la larve du Plitonthus fimeturius?

24. Sominet de l'abuomen de la lurve du Philonthus sordidus?

23. Sommet de l'abJomen de la larve du Philonthus concinnus.

26. Sommet de l'abdomen de la larve du Philonthus fumigatus?

27. Somnet de l'ablomen de la larve du Philonthus ventralis. 
BREVIPENNES

Staphylinaires

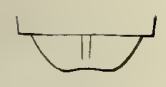

1
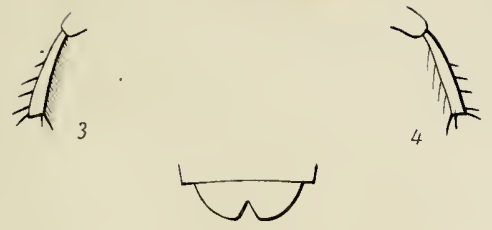

5

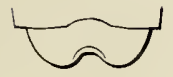

7
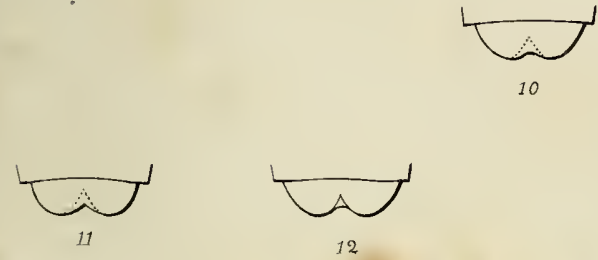

12
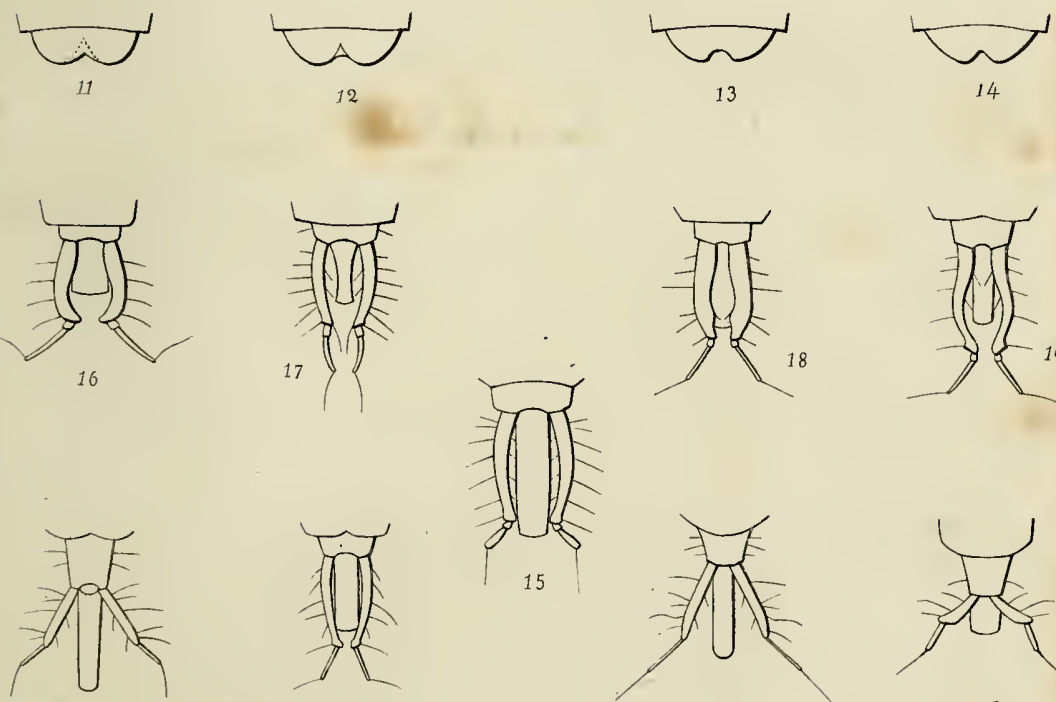

20

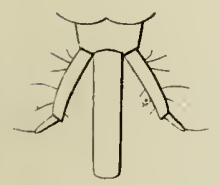

24
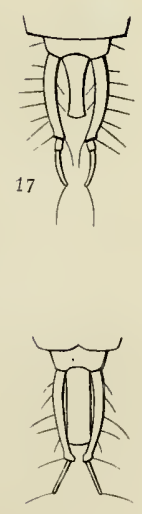

21

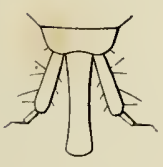

25
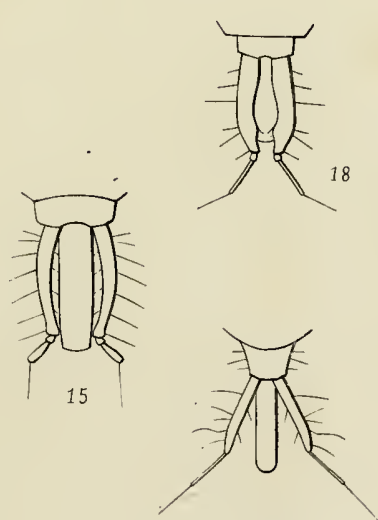

22
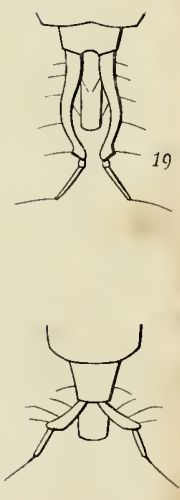

23

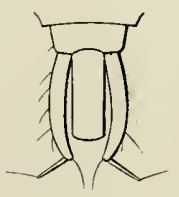

26
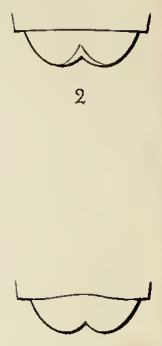

9

14 



\section{Planehe VI}

1. Base des antennes du genre Euryporus.

2. Base des antennes du genre Acylophorus.

3. Sommet des palpes maxillaires du Quedius lateralis et de beaucoup dautres Quectius.

4. Sommet des palpes maxillaires des Quedius sciutillans, luciutulus et de quelques autres Quedius.

5. Sommet des palpes labiaux du genre Astrapaeus $\sigma^{7}$.

6. Sommet des palpes labiaux du genre Eurypoirus o".

7. Sommet des palpes maxillaires du genre Heterothops.

8. Sominet des palpes maxillaires dı genre Acylophorus.

9. Sommet des palpes maxillaires du genre Tanygnathus.

10. Intervalle des tempes, en dessnus, des Quedius curtus, crassus ef de presque tous les Quedius.

11. Intervalle des tempes, en dessous, du Quedius brevis.

12. Prolongement du $2^{\mathrm{e}}$ arceau basilaire du ventre sur le $1^{\text {er }}$ normal du Quedius lateralis et de quelques autres Quedius.

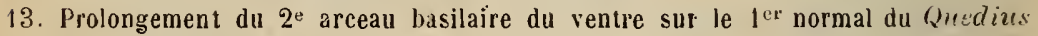
xcintlopus.

14. Prolongement du $2^{\mathrm{C}}$ arceau basilaire du ventre sur le 1 er normal du Quectiuss sritus.

15. Prolongement du 2 arceau basilaire du ventre sur le $\mathbf{i}^{\mathrm{er}}$ normal de plusieurs Quedius (1).

16. Sommet du ventre du Quedius nigrocuerulus et de quelques autres especes voisines. $\sigma^{x}$

17. Sommet du venıre du Quedius cruentuis $\sigma$ et de la plupart des Quedurs $\sigma^{\star}$.

18. Sommet du veritre du Queclius pediculus $\sigma$.

19. Sommet du ventre du Quedius tristis $\sigma^{\prime}$ et à peu prìs anssi du fuluginosus o".

2(1. Sommet du ventre du Queclius molochinus $\sigma^{*}$.

21. Sommet du ventre du Quedius maculicornis $\sigma^{7}$.

22. Sommet dı ventre du Quedius anicolor $\sigma$.

23. Sommet du ventre du Quedius anceps $\sigma^{\circ}$.

24. Sommet du ventre du Quedias cyanescens $\sigma$.

2\%. Sommet du ventre du Qucedius bicolor $\sigma^{7}$.

26. Summet du ventre du Quedius scintillans $\sigma$.

27. Sommet du rentre du Quedius rufipe; $\sigma^{\star}$ et de la plupart des Quedius (solis-geure Raphirus).

23. Sommet du ventre de la plupart des Hcterothous $\sigma^{7}$.

29. Sommet du ventre de l'Hetorothops niger $\sigma$.

30. Sommet du veutre du Tanyynatus terminalis $\sigma$.

31. Sommet de l'abdomen de la larve du Quedius nigrocceruleus.

32. Sommet de l'abdumen de la larve du Quecdius cinctus.

33. Sommet de l'abdomen de la larve dı Quedius rufipes.

(1) On lruave plusicurs intermédiaires entre les forme, 12 el lij el 15 el 13 


\section{BREVIPENNES}

Quédiaires
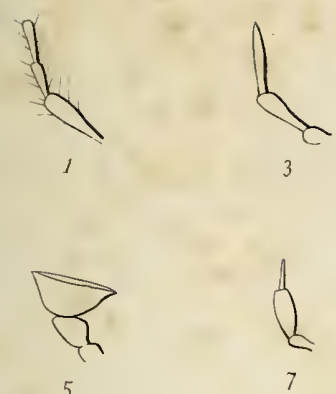

.
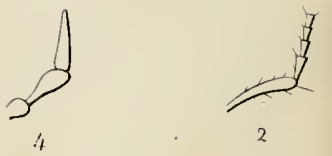

5

(1)
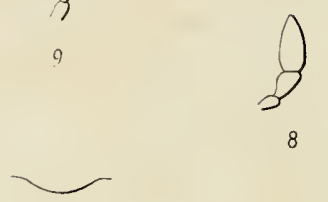

12
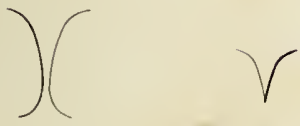

10

13

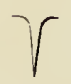

14
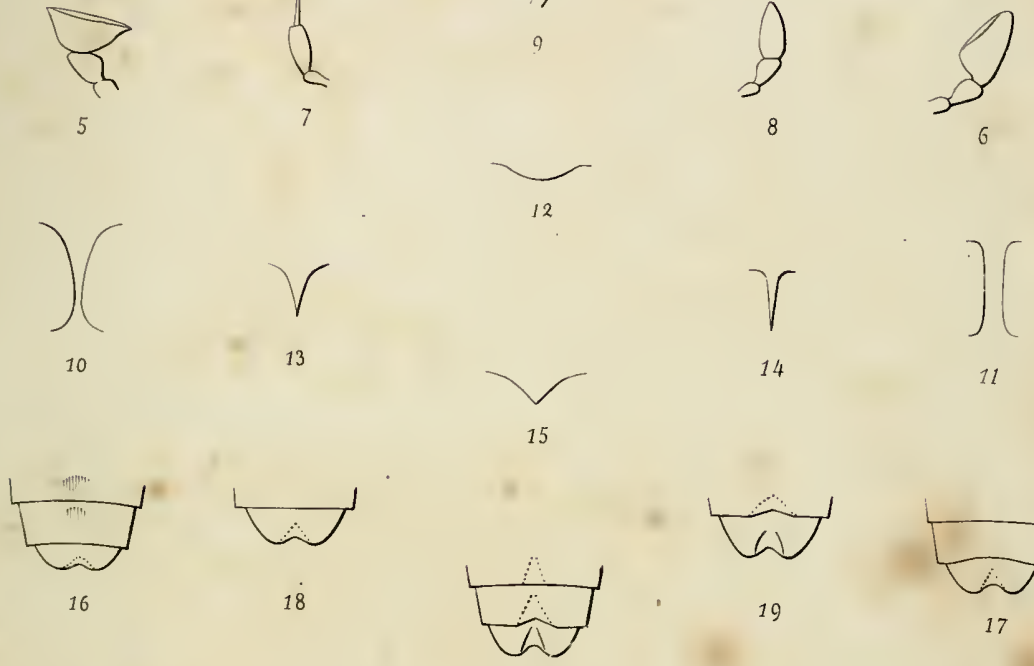

10
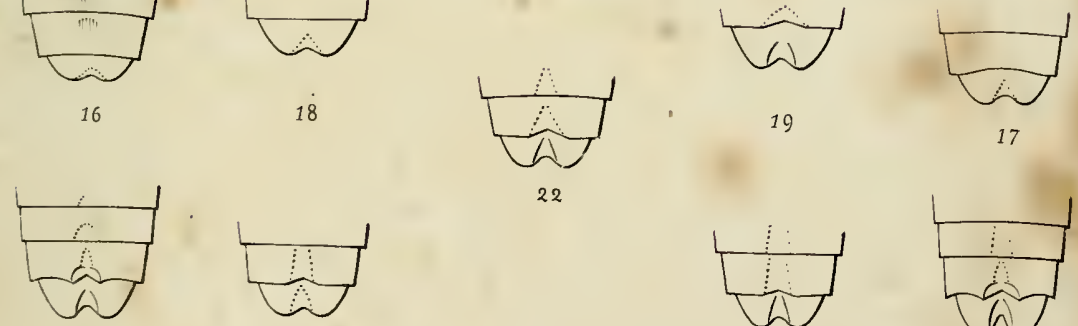

20

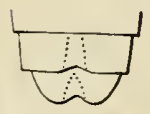

23

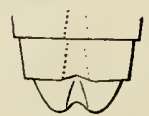

24
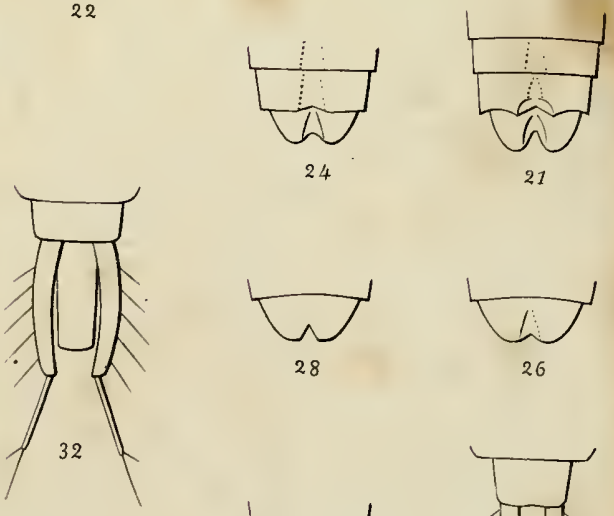

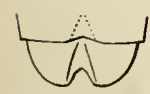

25

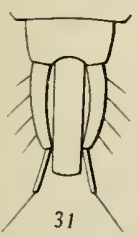

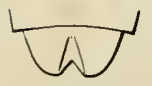

27

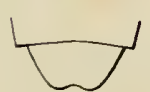

29
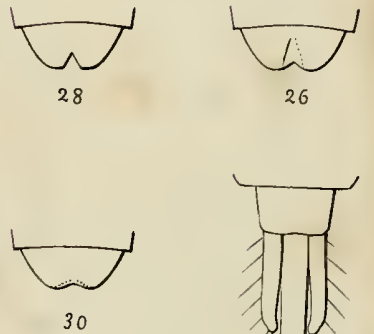

\section{Rey del.}




\section{!}

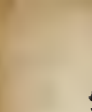

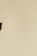

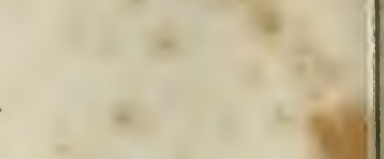


. 






\section{if $x+2=$

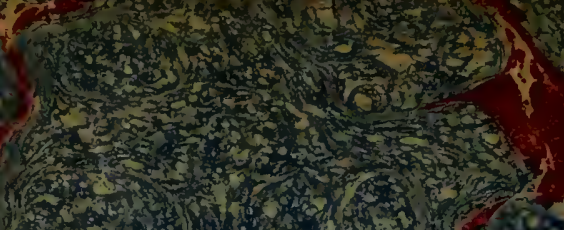

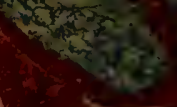

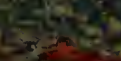

क्षित्र

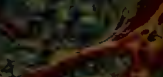

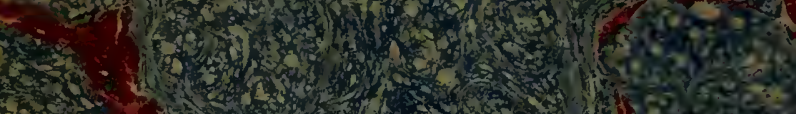

(2)

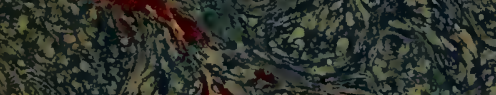

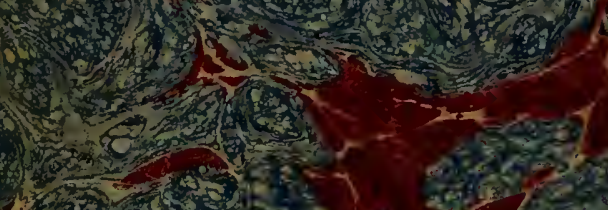

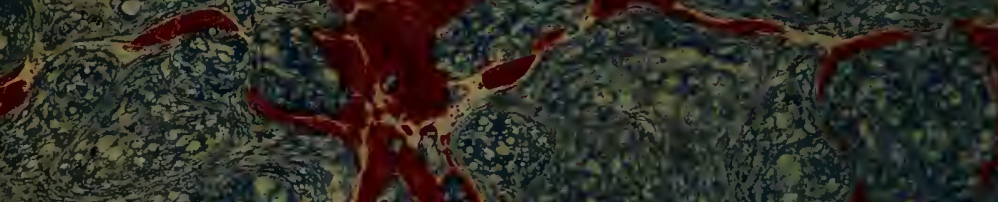

26.

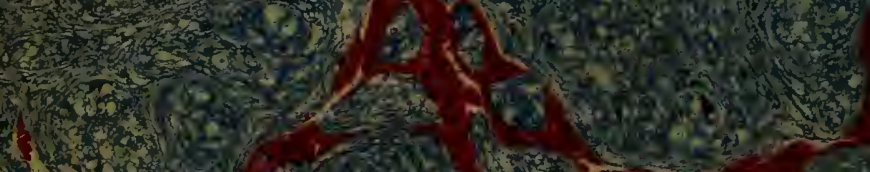

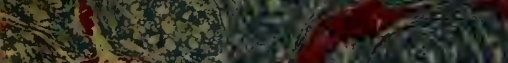

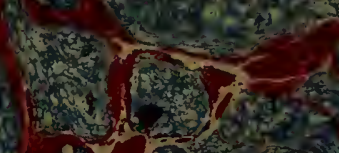

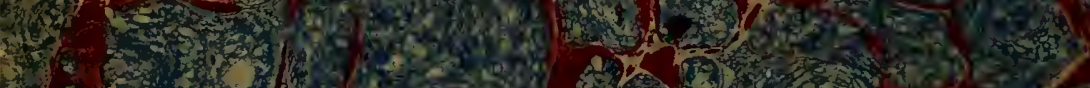

sers

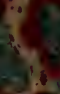

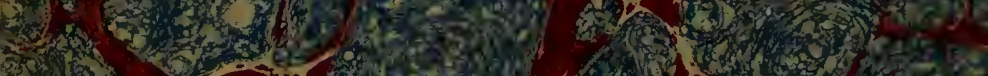
(6) 303

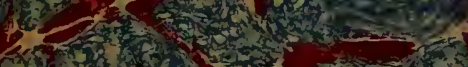

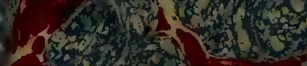

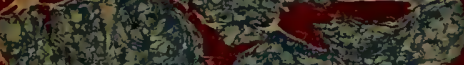

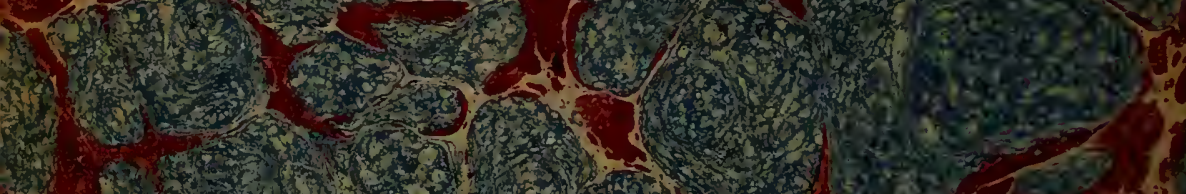

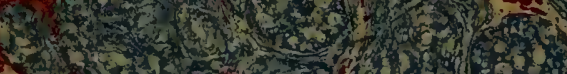

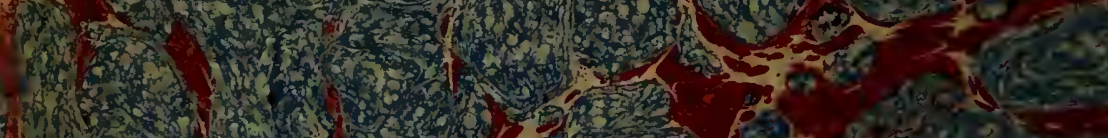

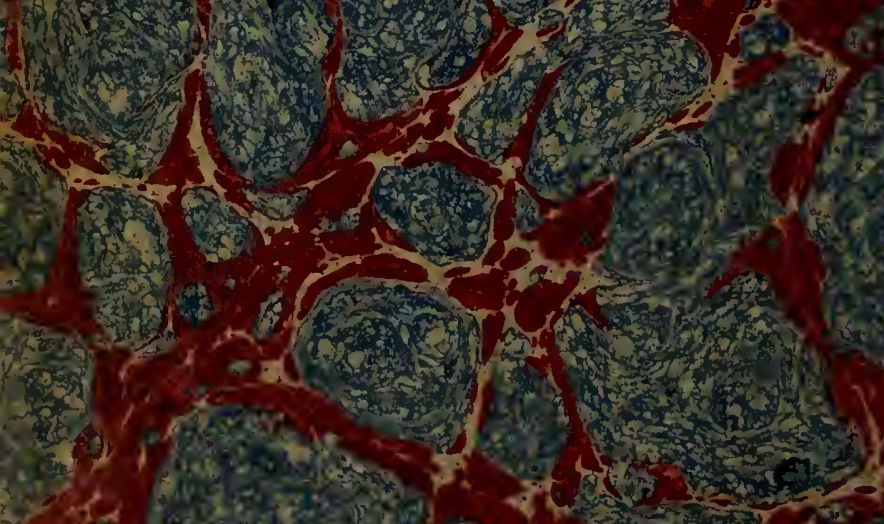

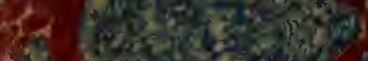

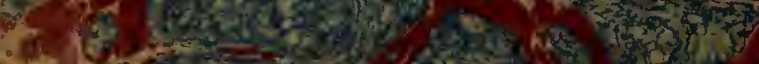




\section{or s \\ 20. $2+2$ \\ (ach \\ (1) 25

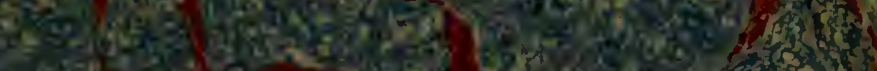 $+7$ 1950 -

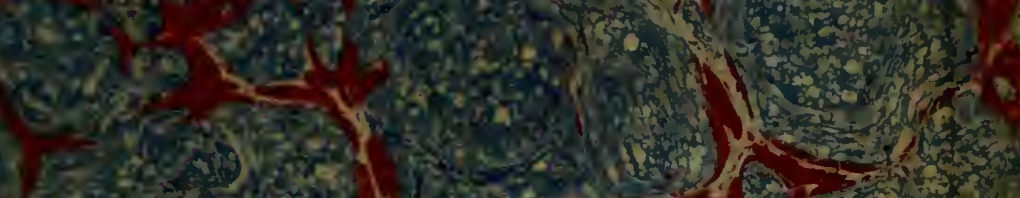

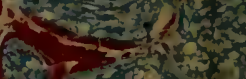

tor

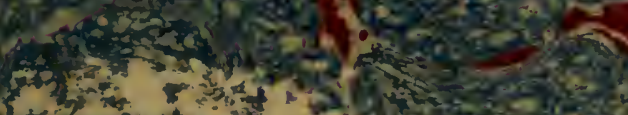

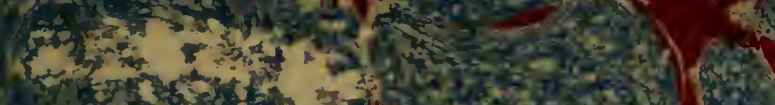

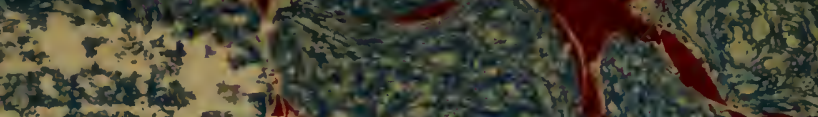

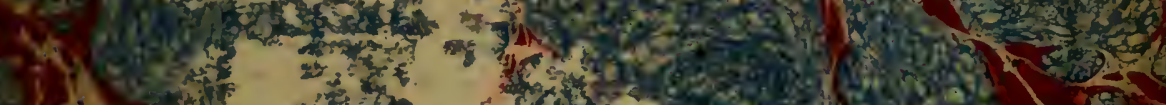

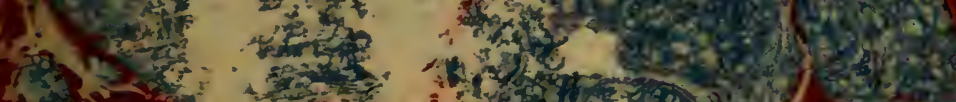

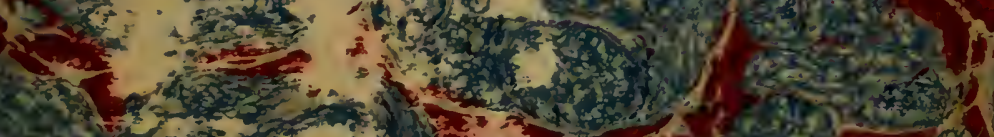

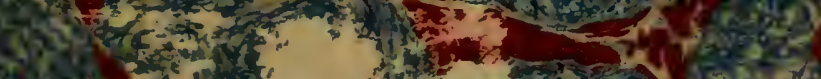

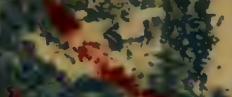

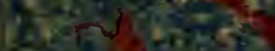

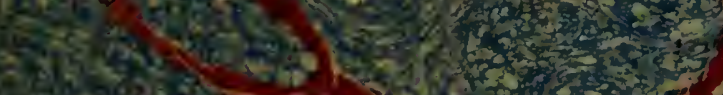
it: if 
30112062199952 